
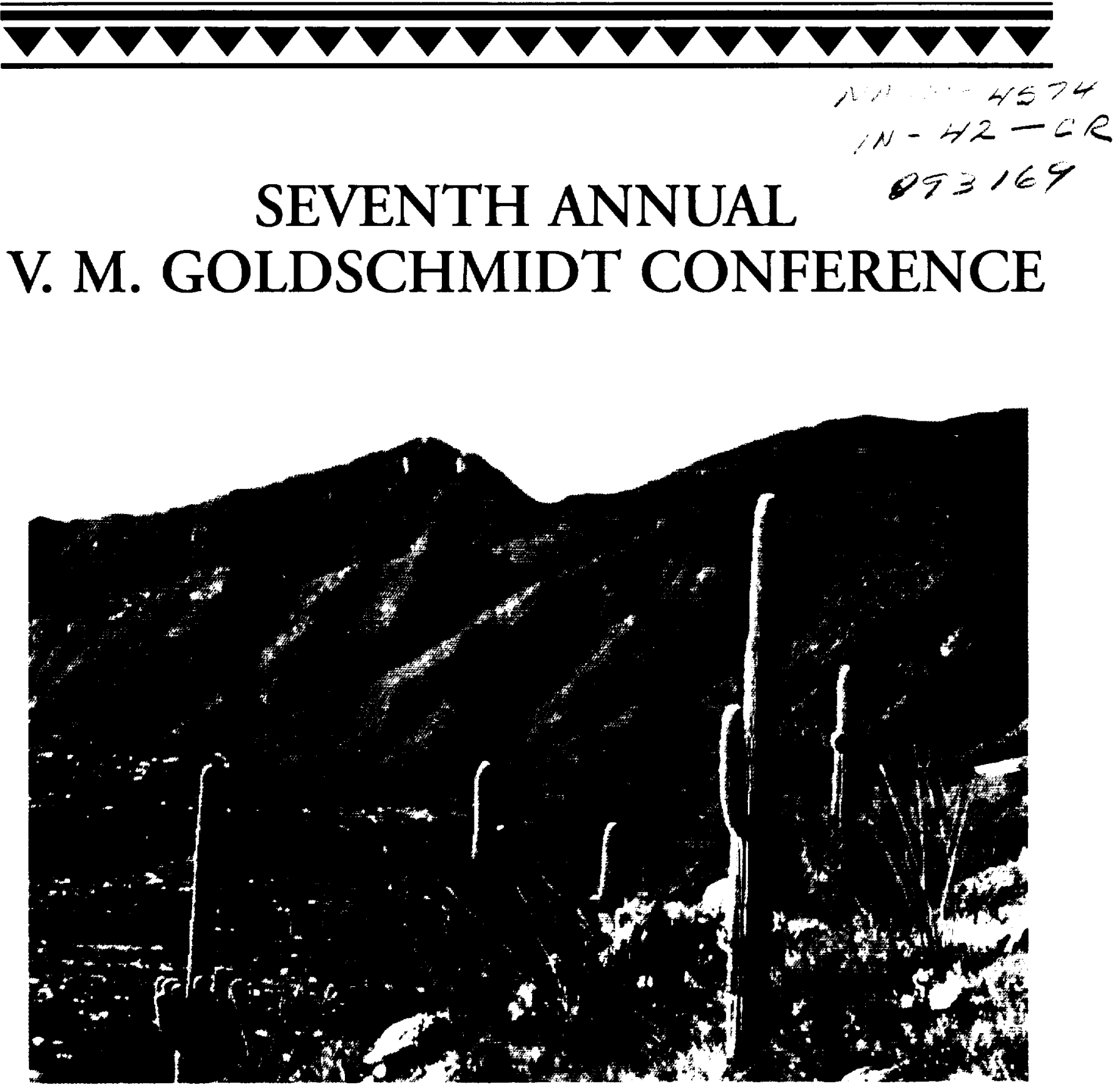

June 2-6, 1997
Tucson, Arizona 



\section{Compiled in 1997 by \\ LUNAR AND PLANETARY INSTITUTE}

The Institute is operated by the Universities Space Research Association under Contract No. NASW-4574 with the National Aeronautics and Space Administration.

Material in this volume may be copied without restraint for library, abstract service, education, or personal research purposes; however, republication of any paper or portion thereof requires the written permission of the authors as well as the appropriate acknowledgment of this publication.

Abstracts in this volume may be cited as

Author A. B. (1997) Title of abstract. In Seventh Annual V.M. Goldschmidt Conference, p. XX, LPIContribution No. 921, Lunar and Planetary Institute, Houston.

This report is distributed by

ORDER DEPARTMENT

Lunar and Planetary Institute

3600 Bay Area Boulevard

Houston TX 77058-1113

Mail order requestors will be invoiced for the cost of shipping and handling. 


\title{
SEVENTH ANNUAL V. M. GOLDSCHMIDT CONFERENCE
}

\author{
Hosted by \\ Department of Planetary Sciences/Lunar and Planetary Laboratory \\ and Department of Geosciences, The University of Arizona
}

\section{Sponsored by}

Geochemical society

European Association of Geochemistry

Lunar and Planetary Institute

The University of Arizona

National Aeronautics and Space Administration

\author{
Organizers \\ Michael J. Drake, Conference Chair \\ Joaquin Ruiz, Program Chair
}

\section{Program Committee}

J. Ruiz Chair

J. Patchett General and Isotope Geochemistry

J. Quade and M. Zreda Surficial Processes and Hydrology

G. Gehrels and S. Baldwin Geochronology

T. Swindle Planetary

J. Ganguly Experimental

M. Barton Hydrothermal

LPI Contribution No. 921 


\section{Contents}

Subduction of the Aseismic Cocos Ridge Displaced Magma Sources Beneath the Cordillera de Talamanca, Costa Rica

M. Abratis and G. Wörner 1

Topography of Transition Zone Discontinuities: A Measure of "Olivine" Content and Evidence for Deep Cratonic Roots

C. B. Agee, Y. Gu, and A. M. Dziewonski

Uranium Enrichment in Lithospheric Mantle: Case Studies from French Massif Central

O. Alard, J.-L. Bodinier, and J.-M. Dautria

Rare-Earth-Element Anomalies in the Décollement Zone of the Nankai Accretionary Prism, Japan: Evidence of Fluid Flow?

J. L. Alexander, K. T. Pickering, and E. H. Bailey.

Rare Earth Elements in Japanese Mudrocks: The Influence of Provenance

J. L. Alexander, K. T. Pickering, and E. H. Bailey.

The Evolution of Seawater Strontium Isotopes in the Last Hundred Million Years: Reinterpretation and Consequences for Erosion and Climate Models

C. J. Allègre, J. Gaillardet, S. Levasseur, L. Meynadier, and P. Louvat

From Pat to Tats: The Lead Isotope Legacy in the Studies of the Continental Crust-Upper Mantle System

C. J. Allègre, G. Manhès, B. Dupré, B. Hamelin, O. Brevard, C. Gariepy, C. Göpel, R. Doucelance, and S. Alves 4

Geochronology of the Jack Hills Detrital Zircons by Precise Uranium-Lead Isotope-Dilution Analysis of Crystal Fragments

Yu. V. Amelin

Iridium in the Oceans

A. D. Anbar and G. J. Wasserburg

The Helium-Heat-Lead Paradox

D. L. Anderson

Control of Distribution Patterns of Heavy Metals in Ganga Plain Around Kanpur Region, India, by Fluvial Geomorphic Domains

A. A. Ansari, I. B. Singh, and H. J. Tobschall

Geochemical and Isotopic Features of Ferrar Magmatic Province (Victoria Land, Antarctica)

P. Antonini, G. Demarchi, R. Petrini, E. M. Piccirillo, L. Civetta, M. D'Antonio, and G. Orsi

Rare Earth Elements in Marine Fine-Grained Sediments from the Northwestern Portuguese Shelf (Atlantic)

M. F. Araújo, A. Gouveia, and J.-M. Jouanneau

Aspects of Arc Fluxes

R. J. Arculus .7

General Kinetic Model for Dolomite Precipitation Rate with Application to the Secular History of Seawater Composition 
High-Precision Uranium-series Chronology from Speleothems

Y. Asmerom, J. L. Banner, J. A. Hoff, E. Ito, and R. L. Edwards

Trace-Element Modeling of Aqueous Fluid-Peridotite Interaction in the Mantle Wedge of Subduction Zones

J. C. Ayers

Rainfall Variations in Southeastern Australia over the Last 500,000 Years from Speleothem Deposition

L. K. Ayliffe, P. C. Marianelli, K. C. Moriarty, R. T. Wells, M. T. McCulloch, G. E. Mortimer, and J. C. Hellstrom.

The Role of Water in High-Pressure Fluids

P. Azimov

The Kinetic Conditions of Metamorphic Mineralogenesis: Evidence from Minerals and Assemblages

$P$. Azimov and A. Shtukenberg

Carbon-14 in Carbon Dioxide Used to Determine the Residence Time of Labile Organic Carbon in the Vadose Zone

D. H. Bacon and C. K. Keller

Kinetics of Perlite Glass Degassing: TG and DSC Analysis

N. S. Bagdassarov, F. Ritter, and Y. Yanev

Isotopic and Elemental Compositions of Early Diagenetic Carbonates in Modem Mississippi and Mahakam Deltaic Sediments

A. M. Bailey and H. H. Roberts

Gold Complexation by Chloride-bearing Fluids: An EXAFS Study

E. H. Bailey, P. F. Schofield, and J. F. W. Mosselmans

Estimating Soil Organic Carbon Storage: State Factor vs. Mechanistic Approaches

W. T. Baisden and R. Amundson

Whole-Mantle vs. Layered Mantle Convection and the Role of a High-Viscosity Lower Mantle in Terrestrial Volatile Evolution

C. J. Ballentine and P. van Keken

Spatial Platinum-Group-Element Distribution in Magmatic Sulfides: Implications for Platinum-Group-Element Behavior

During Mantle Melting

C. Ballhaus and P. Sylvester

Atomic-Resolution Thermal Emission Microscopy Data for the Role of Structural Inheritance in the Weathering of Chlorite

J. F. Banfield and T. Murakami

Geochemical and Geophysical Implications of the Radiocarbon Calibration

E. Bard

Helium Isotopes of the Cameroon Line Volcanic Chain

D. N. Barfod, C. J. Ballentine, A. N. Halliday, M. D. Kurz, and J. G. Fitton

The Heard Island Continental Component: Osmium-Isotopic Evidence for Mantle vs. Magma Contamination

J. Barling, J. S. McBride, D. D. Lambert, and I. A. Nicholls 
Experimental Trace-Element Partitioning in Tonalitic Systems

The Boron Isotope Systematics of Groundwater from Crystalline Basement and Sedimentary Aquifers (Southwestern Germany-Northern Switzerland)

S. Barth

Gold in Hydrothermal Solutions: Thermodynamic Properties of $\mathrm{Au}(\mathrm{HS})_{2}-(\mathrm{aq})$ and Solubility of Gold at High Pressures and Temperatures

E. N. Bastrakov, V. A. Pokrovskii, and C. A. Heinrich

A Tale of Two Plumes and the Case of the Lead-Paradox

A. R. Basu

Documenting and Modeling Heterogeneous Fluid-Rock Interaction in Contact Aureoles with Stable Isotopes

L. P. Baumgartner, G. T. Roselle, M. L. Gerdes, M. Person, and J. W. Valley

Rare Earth Elements, Yttrium, Thorium, and Uranium in Crustal Melting-The Behavior of Accessories During

Metamorphism and Anatexis of Metapelites: The Kinzigite Formation (Ivrea-Verbano, Northern Italy)

F. Bea and P. G. Montero

Radiocarbon Variations in Modem Corals

J. W. Beck, G. S. Burr, L. Calsoyas, and D. J. Donahue

Assessing Trace-Element Fluxes in Island Arc Systems Using Ratios of Highly Incompatible Elements in Eclogites

H. Becker and R. W. Carlson

Constraints from Uranium-Thorium-Lead-Neodymium-Strontium Systematics of Paleozoic Gamet Pyroxenites on Sedimentaltered Mid-Ocean-Ridge-Basalt-Mantle Mixing in Arc Magma Petrogenesis

H. Becker and R. W. Carlson

The Atomic and Electronic Structure of the (001) Surface of Monoclinic Pyrrhotite $\left(\mathrm{Fe}_{7} \mathrm{~S}_{8}\right)$ Studied by Using Scanning

Tunneling Microscopy Low Energy Electron Diffraction, and Quantum-Mechanical Calculations

U. Becker, A. R. Lennie, D. J. Vaughan, A. W. Munz, and G. Thornton

Ultradepleted Mantle Beneath the Baltic Shield

B. V. Belyatsky, A. Arzamastsev, and L. K. Levsky

Microbial Metabolism, Iron Reduction, and Silicate Dissolution: Coupled Processes in Mineral Weathering

P. C. Bennett, W. J. Choi, J. A. Roberts, F. K. Hiebert, and W. J. Ullman

Hafnium Isotopic Compositions Do Not Constrain Early Archean Neodymium Evolution

V. C. Bennett and A. P. Nutman

The Osmium Mantle Evolution Curve and Limits on Accretion and Differentiation of the Earth from Archean (2.9-3.8 Ga)

Ultramafic Rocks

V. C. Bennett, T. M. Esat, and A. P. Nutman. 
The Solubility of Calcium- and Magnesium-Exchanged Clinoptilolite

L. G. Benning, R. T. Wilkin, and H. L. Barnes

Age and Origin of HIMU Volcanism in the Balleny Islands: Melting of Plume-delivered Deep Mantle or Shallow Asthenospheric Mantle?

J. H. Berg, D. Weis, W. C. McIntosh, and B. I. Cameron

Depth Profiling of Mineral Hydration Reactions by Elastic Recoil Detection Analysis (ERDA)

A. J. Berry, R. A. Wogelius, D. G. Fraser, and G. W. Grime

The Particle-Specific Nature of Mica Weathering: Real-Time Observation of K+Exchange in Clay-sized Mica Particles Using Fluid Cell TMAFMTM

B. R. Bickmore and M. F. Hochella Jr.

Surface Chemistry of Minerals and Tektites as Constrained by X-Ray Photoelectron Spectroscopy

G. G. Biino.

Soil Microbes as Indicators of Ecosystem Pollution by Heavy Metals

S. B. Bintrim, J. S. Ireland, D. Joseph, J. Handelsman, and R. M. Goodman ..

Chondritic Lutetium/Hafnium Source Composition of the Isua Supracrustal Sequence

J. Blichert-Tofi, M. T. Rosing, F. Albarède, and D. Bridgwater

Silicate Weathering Rates Along a Stream Channel Draining into Lake Fryxell, Taylor Valley, Antarctica

A. E. Blum, D. M. McKnight, and W. B. Lyons

The Effect of Late Cenozoic Glaciation on Silicate Weathering Rates and the Marine Strontium Isotope Record

J. D. Blum

Modeling Mantle Melting with Variable Partition Coefficients

J. D. Blundy and J. A. Brodie

Trace-Element Partitioning Between Clinopyroxene, Silicate Melt, and Carbonate Melt in the System Diopside-Albite-Dolomite

J. D. Blundy and J. A. Dalton

Rhenium-Osmium Systematics of the Lower Oceanic Crust

J. Blusztajn, S. R. Hart, H. J. B. Dick, and G. Ravizza

Model for the Origin and Distribution of Metals in Porphyry Copper Systems with Applications to Exploration

R. J. Bodnar

Solubilities of Highly Siderophile Elements in Silicate Melts: Experimental Results and Geochemical Implications

A. Borisov and H. Palme

Surface Nucleation on Isostructural Sulfate Minerals: Implications for Modeling Crystal Growth Rates

D. Bosbach and A. Putnis . 
Controls on Bacterial Sulfate Reduction in a Dual-Porosity Aquifer

Peridotite Xenoliths from the Slave Craton, Northwest Territories

F. R. Boyd and D. Canil

Rhenium-187/Osmium-187 Isotopic Constraints on the Chemical Evolution of the Martian Mantle

A. D. Brandon, R. J. Walker, J. W. Morgan, and G. G. Goles

Isotopic Ratios and Release Rates of Strontium from Weathering Feldspars

S. L. Brantley, J. Chesley, and L. L. Stillings.

Experimental Constraints on the Role of Aqueous Fluids in the Origin of Boron/Beryllium Variations in Arc Magmas

J. M. Brenan, H. F. Shaw, and F.J. Ryerson

Isotope Stratigraphy for the Late Paleozoic Greenhouse/Icehouse Transition: Proxy Signals for Links Between

Ocean Chemistry, Climate, and Tectonics

$P$. Bruckschen and J. Veizer .36

Variation of Barium/Calcium in Planktonic Foraminifera as an Indicator of Glacial Melt-Water Discharge in the Gulf of Mexico

T. P. Buerkert and L. H. Chan

Argon-40/Argon-39 Laser-Probe Dating of Diamonds

R. Burgess, G. Turner, and J. W. Harris

Geochemistry and Mineralogy of a Granitic Soil Chronosequence in the Sierra Nevada, California

D. L. Burkins, J. D. Blum, K. Brown, and R. C. Reynolds .38

Argon in the Mantle: Resolving Atmospheric Contaminants by Laser Probe

P. G. Burnard, D. W. Graham, and G. Turner

Coral-based Radiocarbon Calibration Results to 20 k.y. BP Based on Thorium-230 Ages of Corals from the South Pacific

G. S. Burr, K. A. Banks, S. C. Gray, R. L. Edwards, J. Récy, G. Cabioch, F. W. Taylor, and J. M. O'Malley.

Samarium-Neodymium Isotopic Modeling of the Evolution of the Earth's Depleted Mantleand Crust: 1. The Time of Crust-Mantle Differentiation and the Mass of the Depleted Mantle

A. R. Calderwood

Samarium-Neodymium Isotopic Modeling of the Evolution of the Earth's Depleted Mantle and Crust: 2. The Age of Crust-Mantle Differentiation and the Mean Samarium-147/Neodymium-144 and Neodymium-143/Neodymium-144 Ratios of the Depleted Mantle-The Whole Mantle has a Mid-Ocean Ridge Basalt Isotopic Composition

A. R. Calderwood

Samarium-Neodymium Isotopic Modeling of the Evolution of the Earth's Depleted Mantle and Crust: 3. Testing Crustal Growth Models With and Without Recycling Against a Hadean to Recent $\varepsilon_{N d}(t)$ Database 
Systematic Declines in Slab Fluxes Registered Across the Central American Arc at Older Behind-the-Front Central Volcanos in Southeastem Guatemala

Silicate Weathering Rates and Atmospheric Strontium Fluxes: A Comparison of Arid Sites in Hawai'i and New Mexico

R. C. Capo, B. W. Stewart, and O. A. Chadwick

Ruthenium Solubility in Hematite

C. J. Capobianco

The Geochemical Evolution of a Late Palaeozoic Convergent Margin: The New England Fold Belt Case

G. Caprarelli and E. C. Leitch

Rhenium-Osmium Systematics of Kimberlite Megacryst Inclusions: Implications for the Source of Kimberlitic Magmas

R. W. Carlson and D. R. Bell

$\delta^{13} \mathrm{C}-\delta^{15} \mathrm{~N}$ Diamond Systematics and the Origin of the Large $\delta^{13} \mathrm{C}$ Range in Eclogitic Diamonds: Evidence for a High-

Temperature Fractionation Process

P. Cartigny, J. W. Harris, and M. Javoy

The Mantle Nitrogen Isotopic Composition and Evolution: The Diamond Record

P. Cartigny, J. W. Harris, S. R. Boyd, and M. Javoy.

Mineralogic and Uranium Isotopic Data of Fracture Infillings from the Potential Underground Laboratory Site in the

Vienne Granitoids (France)

J. Casanova, M. Cuney, P. Négrel, M. Cathelineau, Y. Coulibaly, A. Bourguignon,

and J.F. Aranyossy

Tectonic and Geochemical Consequences of Cretaceous LIP Formation in the Pacific

P. R. Castillo, P. E. Janney, and R. L. Larson

Equilibrium and Kinetic Studies of Hydrogen Isotope Fractionation Between Hydrous Minerals and Water Using the lon Microprobe

T. Chacko, D. Cole, L. Riciputi, J. Horita, and R. Ripperdan

Lithium Isotope Composition of Rivers

L. H. Chan, Y. Huh, and J. M. Edmond

How Does the Oceanic Lithosphere Contribute to Ocean-Island-Basalt Volcanism?

C. Chauvel, G. Guille, S. Blais, and R. Maury

Chemical and Isotopic Characteristics of Xenoliths from Hannuoba, China: Implications for the Composition and Evolution of the Upper Mantle

D. Chen, B. Li, and X. Zhi

Three-Stage Evolution of Fluid During Continental Collision with Special Reference to Study of the Ore-forming Fluid of Gold Deposits in the Eastern Qinling Mountains, China

$Y$. Chen 
Rhenium-Osmium Studies of Evolved Continental Basalts: Present Knowledge and Future Studies

Lead-Isotopic Records of Two Central Pacific Iron Manganese Crusts: A Possible Connection with Cenozoic

Changes in Continental Weathering

J. N. Christensen, A. N. Halliday, J. R. Hein, D. K. Rea, and L. V. Godfrey

Source, Transport, and Partitioning of Metals Between Water, Colloids, and Bed Sediments of the Animas River, Colorado

S. E. Church, B. A. Kimball, D. L. Fey, D. A. Ferderer, T. J. Yager, and R. B. Vaughn

Strontium-Thorium-Radium Systematics in Ocean Island Basalts: Evidence for Plume Contamination and Rapid

Magma Extraction

C. Claude-Ivanaj, C. J. Allègre, and B. Bourdon

New Methods for Chlorine and Rubidium Isotopic Analysis: Killing Two Isotopic Birds with One Molecular Stone

R. A. Cliff and M. H. Dodson.

How Monazite Records Geological Events: Evidence from Uranium-Thorium-Lead ${ }_{\text {tor }}$ Determination with the Electron Microprobe

A. Cocherie, O. Legendre, J. J. Peucat, and A. Kouamelan.

Probing the Stability and Reactions of Biomolecules Under High-Pressure Hydrothermal Conditions

G. D. Cody, J. G. Blank, R. Hazen, H. Yoder Jr., and S. Chang

Precise Determination of Seasonal Temperature Variation from the Prepubescent Stage of an Exceptionally Preserved Female Jurassic Ammonite

M. L. Coleman, M. Gruszczynski, J. D. Hudson, C. Kulicki, and M. C. Isaacs

Melting Conditions and Mantle Enrichment Ages Beneath the Northwestem Tibetan Plateau Inferred from Uranium-238/

Thorium-230 Disequilibria

K. M. Cooper, M. R. Reid, N. W. Dunbar, W. C. McIntosh, and F. M. Phillips

Flexure of the Main Central Thrust in the Kathmandu Area Due to Ramping on the Main Boundary Thrust

P. Copeland, P. Le Fort, B. N. Upreti, and S. Rai

Single-Phase Lead-Lead Dating of Coexisting Gamet and Staurolite in the Black Hills Collisional Orogen (South Dakota), with Implications for Early Proterozoic Tectonism

P. S. Dahl and R. Frei

A Comparison of the Adsorption of 2,4,6-Trichlorophenol onto $\alpha-\mathrm{Al}_{2} \mathrm{O}_{3}$ and Bacillus Subtilis

C. J. Daughney and J. B. Fein

Reconciling Geophysical and Geochemical Constraints on Mantle Reservoirs and Mass Fluxes

G. F. Davies

Proterozoic Gabbroic Intrusions from Southeastem Norway: Evidence for Interaction Between Asthenosphere and Metasomatized Lithospheric Mantle

G. J. L. M. de Haas 
Trace-Element Distributions in Hawai'ian Soils: Quantifying Dust Input and Weathering Losses

L. A. Derry, M. J. Alfano, A. C. Kurtz, and O. A. Chadwick

The Potentiometric Determination of Stability Constants for Lanthanum Acetate Complexes in Aqueous Solutions to $85^{\circ} \mathrm{C}$

R. Ding and S. A. Wood.

Noble-Gas Isotopes in Tertiary Basalts of the Southwestem United States

A. Dodson, D. J. DePaolo, and B. M. Kennedy.

Plumbotectonics of Rocks in the Minnesota River Valley

B. R. Doe

Dating of Multiple Proterozoic Thermal Events by SHRIMP Uranium/Lead Geochronology at Broken Hill, New South Wales, Australia

A. G. Donaghy, K. Ehlers, G. M. Gibson, D. W. Maidment, A. P. Nutman,

and C.J. Venn.

Modeling Wetland Chemistry Using Endmember Mixing Analysis Constrained by Isotopic Data

R. J. Donahoe

Reexamination of Mantle Topology in Isotopic Multispace

$R$. Doucelance, C. J. Allègre, and E. Lewin

Unraveling the Physical Basis of Biomineralization

P. M. Dove, H. H. Teng, and Y.J. Zhao

Neodymium, Strontium, and Lead Isotopic Composition of the Lowland Creek Volcanics, West-Central Montana

F. Ö. Dudás and V. O. Ispolatov

Stratification of $\delta^{37} \mathrm{Cl}$ in Miocene Halite, Carpathian Mounjains: Implications for Source of Chloride

C. J. Eastoe and T. Peryt.

Fixation Rates of Carbon Dioxide by Chemical Weathering in the Continental Arc of the Western Americas, $15^{\circ} \mathrm{S}$ to $70^{\circ} \mathrm{N}$

J. M. Edmond and Y. Huh

Microbial Dissolution of Pyrite: Surprising Insights from Studies Using Organisms in Enrichment Cultures from an Acid

Mine Drainage Environment

K. J. Edwards, M. O. Schrenk, J. F. Banfield, and R. M. Goodman

Comparison of Chlorine and Bromine Isotope Fractionation in Diffusion: Geochemical Consequences

H. G. M. Eggenkamp and M. L. Coleman

Uranium- and Thorium-Series Disequilibrium Dating of Young Mediterranean Volcanic Rocks

J. Eikenberg, S. Bajo, and I. Zumsteg

Slab-derived Fluids in the Mantle: Oxygen-Isotope Evidence from Melt Inclusions

J. M. Eiler, B. I. A. McInnes, J. W. Valley, C. M. Graham, and E. M. Stolper 
Strontium-Isotope Geochemistry of Laptev Sea-Surface Sediments, Ice-rafted Detritus, and Suspended Particulate Material of East Siberian Rivers: Implications for Sediment Distribution Patterns in the Arctic Ocean

A. Eisenhauer, V. Rachold, H. Meyer, H. Kassens, F. Lindemann, R. F. Spielhagen, and B. Wiegand

Low-Temperature Reactions Between Seawater and Oceanic Crust at Ridge Flanks

H. Elderfield, E. Suess, M. J. Monl, G. Wheat, and ODP Leg 168 Scientific Party .66

Subduction Zone Processing of Oceanic Crust

T. Elliott and T. Plank

Earliest Evidence for Chirality in the Solar System: Implications for the Origin of Life

M. H. Engel and S. A. Macko...

Modem Peculiarities of Free Radical Formation Mechanisms of Sediment Structure and Quility in Terrestrial Aquatic Systems

L. S. Ernestova

Experimentally Determined Solubilities of Platinum and Rhodium in a Haplobasaltic Silicate Melt at $1300^{\circ} \mathrm{C}$, and Calculated Metal/Silicate Partition Coefficients

W. Ertel, H. St. C. O'Neill, D. B. Dingwell, and P. J. Sylvester

Helium-3 Evidence for a Comet Shower in the Late Eocene

K. A. Farley, E. M. Shoemaker, A. Montanari, and D. B. Patterson

In Situ and Whole-Grain Laser Fluorination of Subarc Mantle Minerals Using Excimer and Carbon Dioxide Lasers:

Potential Insights into Oxygen Mobility and Metasomatism in the Mantle Wedge

J. Farquhar, A. D. Brandon, and D. Rumble III

Ion Microprobe Measurements of Carbon-13/Carbon-12 in Graphite: Evidence for Multiple Fluid Influx Events in the Deep Crust of South India

J. Farquhar, E. Hauri, C. Alexander, and J. Wang

Experimental Study of Adsorption/Desorption Kinetics and Thermodynamics of EDTA-Bacteria Interactions

J. B. Fein

Monsoonal Circulation and Chemical Weathering in the Late Miocene

G. M. Filippelli

Molecular Models of Calcite: Structure, Defects, and Diffusion

D. K. Fisler and R. T. Cygan

Rheology and Kinetics of Replacement

R. C. Fletcher and E. Merino

Elemental Flux Rates and Residence Times in Subduction-influenced Mantle

J. D. Foden and M. Elburg

The Shiant Isles Main Sill: Neodymium and Strontium Isotopes Tell the Tale of Two Magmas and Subsolidus Alteration

K. A. Foland, F. G. F. Gibb, and C. M. B. Henderson 
Xenotime: Its Compositional Diversity and Bearing on the HREE Evolution in Peraluminous Granites

H.-J. Förster

An Archean Alkaline Picrite Suite and the Temporal Evolution of the Mantle Sources of Terrestrial Magmas

D. Francis and R. Johnstone

The Dissolution Mechanisms of Periclase and Forsterite: A Mechanism for the Incorporation of Water in the Deep Mantle

D. G. Fraser, A. J. Berry, K. Refson, J. A. Mejias, and R. A. Wogelius .

Rhenium-Osmium Isotope Systematics of Base-Metal Porphyry and Manto-Type Copper Deposits in Chile: Evidence

for a Different Source for Copper

C. Freydier, J. Ruiz, and F. Munizaga

Homblende Dissolution Kinetics at $25^{\circ} \mathrm{C}$

P. Frogner and P. Schweda

Experimental Determination of the Partial Molar Volume and Compressibility of Silicon Dioxide in Silicate Liquids at Pressures up to $35 \mathrm{kbar}$

G. A. Gaetani, P. D. Asimow, and E. M. Stolper.

Coupling Modern Chemical and Mechanical Weathering Rates of Silicates Using Rivers

J. Gaillardet, P. Louvat, B. Dupré, and C. J. Allègre

Tracer Diffusion of Samarium and Neodymium in Garnet: Experimental Determination and Implications for Geochronology

J. Ganguly, M. Tirone, and R. Hervig 77

Distribution of Trace Elements in Anhydrous Spinel Peridotites from Ronda Ultramafic Massif: Implications for the Nature of Large-Ion-Lithophile-Element, Rare-Earth-Element, and High-Field-Strength-Element Reservoirs and Mantle Fluids in the Subcontinental Lithospheric Mantle

C. J. Garrido and J.-L. Bodinier.

Icelandic Low $\delta^{18} \mathrm{O}:$ Ocean-Crust Contamination or Mantle Source?

M. A. M Gee, M. F. Thirlwall. D. Lowry, R. N. Taylor, and B. J. Murton

Stable-Isotope Evidence for Limited Fluid Flow in the Adamello Contact Aureole, Northern Italy

M. L. Gerdes, L. P. Baumgartner, and J. W. Valley

Geochemistry and Mineralogy of the Lemhi Pass Rare-Earth-Element/Thorium Deposits: An Example of Rare-Earth-

Element/Thorium Mobility

P. E. Gibson, S. A. Wood, and L. Lang

Effects of Vegetative and Glacial Cover on the Chemical Weathering of Basalt in Southwest Iceland

S. R. Gislason

Divergent Mantle Evolution on Earh and Mars and the Origin of Depleted Planetary Mantles

J. D. Gleason, D. A. Kring, and W. V. Boynton 
Phosphorus Scavenging at the Mixing of Acidic Volcanic Water and Seawater

S. V. Golubev, E. A. Erofeeva, A. V. Savenko, and V. S. Savenko

Experimental Growth and Behavior of Monazite with Implications for Natural Metamorphic Rocks

E. B. Gorisch and J. C. Ayers

Secular Variation in the Composition of the Subcontinental Lithospheric Mantle

W. L. Griffin, S. Y. O'Reilly, C. G. Ryan, O. Gaul, and D. A. Ionov

Seasonal and Spatial Iron Cycling in a Shallow Alluvial Aquifer Adjacent to an Alpine Stream

A. R. Groffman and L. J. Crossey

Partitioning of Minor Elements Between Olivine and Wadsleyite and Their Effects on the 410-km Discontinuity

G. H. Gudfinnsson and B. J. Wood

Bioaccumulation of Aqueous Uranium by Lichens: The Influence of Surface Phosphate Groups on Short-Term Uptake and Release?

J. R. Haas, E. H. Bailey, and O. W. Purvis

Transport Behavior of Zinc and Arsenic (Vanadium) as Influenced by $\mathrm{pH}$ and Sulfate: Column Experiments and Modeling

A. Hadeler, M. Isenbeck-Schröter, and M. Kofod

Plasmas, the Early Solar System, and Climate Dynamics

A. N. Halliday, D.-C. Lee, J. N. Christensen, M. Rehkämper, W. Yi, and X. Luo

Microscopic Investigation of Dissolution and Alteration of Metal Sulfide Minerals

R. J. Hamers, S. R. Higgins, B. Hu, M. Cardona, J. Banfield, K. Rodgers, and H. Henkel 86

The Behavior of Rhenium and Osmium During Melt Extraction and Metasomatism in the Mantle: Tightening Age

Constraints on Lithospheric Mantle Evolution

M. Handler, V. C. Bennett, and T. M. Esat

Amino Acids on the Moon? NASA's Apollo Program and the Search for Extraterrestrial Organic Matter

P. E. Hare

Systematic Changes in Lead Isotopic Composition with Soil Age in Glacial Granitic Terrains

Y. Harlavan, Y. Erel, and J. D. Blum

Evidence for Potassium-rich Fluids During the Genesis of Granulites from the Ivrea-Verbano Zone, Northem Italy

D. E. Harlov and L. Franz

Experimental Calibration of the Equilibrium: 6 Buddingtonite $+3 \mathrm{O}_{2}=2$ Tobelite +12 Quarz $+2 \mathrm{~N}_{2}+6 \mathrm{H}_{2} \mathrm{O}$ at $2 \mathrm{kbar}$

D. E. Harlov, W. Heinrich, and M. Gottschalk

The Origin of Himalayan Inverted Metamorphism and Anatexis Inferred from Thorium-Lead Ion-Microprobe Dating

T. M. Harrison, O. M. Lovera, M. Grove, E. J. Catlos, A. Yin, and F. J. Ryerson 
Deep-Sea Corals and Clams: Chemical Monitors of Hydrothermal Vent Field Activity

S. R. Hart and J. Blusztajn

Stability Relations of an Aluminous Phase in the Uppermost Lower Mantle

B. Harte, J. W. Harris, and M. T. Hutchison

Decompression Melting Models for Lithosphere-derived Continental Flood Basalts in the Paraná-Etendeka Province

C. J. Hawkesworth, K. Gallagher, L. Kirstein, D. W. Peate, S. P. Turner, and M. S. M. Mantovani

High-Pressure Hydrothermal Organic Synthesis: Experimental Constraints on the Origin of Life

R. M. Hazen, J. G. Blank, G. D. Cody, R. J. Hemley, H. K. Mao, H. S. Yoder Jr., H. J. Morowitz, and S. Chang

Hydrogen Penetration of Minerals and Glasses During Hydrolysis at Hydrothermal Conditions

R. Hellmann

Constraints on Desert Vamish Provenance Using Radiogenic Isotope Signatures

N. G. Hemming, T. Liu, and W. S. Broecker

Argon-40/Argon-39 Geochronology of Fine-grained Sediments from Heinrich Layer 2: Further Evidence for a Dominant

Labrador Sea Source for the Heinrich Layers

S. R. Hemming, C. M. Hall, W. S. Broecker, P. E. Biscaye, and G. C. Bond

Understanding Natural Lead-Isotope Distributions in the Ocean: A General-Circulation-Model Approach

G. M. Henderson and E. Maier-Reimer

Large Boron Isotope Fractionation Between Hydrous Vapor and Silicate Melt at Igneous Temperatures

R. L. Hervig, D. London, G. B. Morgan, and M. B. Wolf

High-Pressure Reactions Between Iron Metal and Mantle Silicates

$V . J$. Hillgren and R. Boehler

Coupled Volatile (Helium, Argon, Water) Behavior in the Southem Mariana Trough

D. R. Hilton, C. G. Macpherson, and K. Hammerschmidt

Minettes of the Schirmacher Oasis, East Antarctica: Implications for the Involvement of an Ancient Subduction Zone

in Lamprophyre Genesis.

M. Hoch and H. J. Tobschall

Variation in Soil Surface Area in a Chronosequence of Soils from Glen Feshie, Scotland, and Its Implications for Mineral Weathering Rate Calculations

M. E. Hodson, S. J. Langan, F. M. Kennedy, and D. C. Bain

Geochemistry of 3-Ga Terrains of the Superior Province, Canada: Generation of Felsic Melts in Archean Oceanic Plateau?

P. Hollings and D. Wyman

Subduction at the Margins of an Active Oceanic Plateau: Geochemical Evidence from the 2.7-Ga Confederation Assemblage, Uchi Subprovince, Northem Superior Province, Canada

P. Hollings, D. Wyman, R. Kerrich, and A. Polat 
Generation of Subduction Zone Magmas: Experimental Constraints.

Differences Between Measured and Modeled Mineralogy and the Effect on the Weathering Rate

J. Holmqvist, H. Sverdrup, and D. Kurz

The Pressure Dependence of Metal/Silicate Partition Coefficients of Highly Siderophile Elements

A. Holzheid, P. Sylvester, H. Palme, H. St. C. O' Neill, and D. C. Rubie

Primordial Helium and Neon in the Earth: A Speculation on Early Degassing

M. Honda and I. McDougall

Meteoritic Nanofossils and Microfossils

R. B. Hoover

Bimodal Distribution of Soil Organic Carbon Pools and Their Significance

Y.-P. Hsieh

Radiocarbon Calibration and $\Delta^{14} \mathrm{C}$ During Deglaciation from Varved Sediments of the Cariaco Basin

K. A. Hughen, J. T. Overpeck, S. J. Lehman, M. Kashgarian, L. C. Peterson, R. Alley, and D. Sigman.

Chemical Weathering Yields and Strontium Isotope Systematics from Major Siberian Rivers

Y. Huh and J. M. Edmond

Iridium/Osmium Constraints on Terrestrial Accretion and Core Formation

M. Humayun, A. D. Brandon, H. J. B. Dick, and S. B. Shirey.

Nitrogen Solubility in Silicate Melt Under Oxidized and Reduced Conditions Using Laser Extraction/Static Mass

Spectrometry Analysis

F. Humbert, G. Libourel, B. Marty, and C. France-Lanord

A New Type of Mantle Metasomatism? Trace-Element Composition of Feldspar-bearing Peridotite Xenoliths in Basalts from Southern Siberia

D. A. Ionov, W. L. Griffin, V. S. Prikhodko, and S. Y. O'Reilly

Mantle Domains and Crust-Mantle Coupling in Southeastern Siberia (Russia) and Mongolia

D. A. Ionov, S. Y. O'Reilly, and W. L. Griffin.....

Moraine Formation in the European Alps Mirrors North Atlantic Heinrich Events

S. Ivy-Ochs, H. Kerschner, P. W. Kubik, H.-A. Synal, G. Patzelt, and C. Schlüchter

Seawater Isotope Records, Crustal Evolution, Tectonics, Glaciation and Atmospheric Evolution

S. B. Jacobsen, J. Wills, and Q. Yin

Isotopic Constraints on the Accretion and Early Differentiation History of the Earth

S. B. Jacobsen, Q. Yin, W. F. McDonough, and C. L. Harper 
Solubilities of Tungsten and Cobalt in Silicate Melts as a Function of Melt Composition

W. L. Jaeger, M. J. Drake, and C. J. Capobianco.

Equilibrium Between Garnet and Clinopyroxene in Eclogitic Rocks

E. Jagoutz, E. Zinner, and D. Jacob

A Terrestrial Record of Changing Carbon Dioxide Levels in the Cretaceous

A. H. Jahren and N. C. Arens

Geochemical Consequences of Core Formation in the Presence of Some Volatiles

D. Jana and D. Walker

The Influence of Silicate Melt Composition on Distribution of Siderophile Elements Among Metal and Silicate Liquids

D. Jana and D. Walker

Basaltic Magma Degassing in Various Tectonic Environments: Chemical and Isotopic Behavior of Carbon Dioxide, Nitrogen, and Water

M. Javoy, F. Pineau, and N. Jendrzejewski

The Origin of Middle Rare-Earth-Element Enrichments in Acidic Natural Waters

K. H. Johannesson, X. Zhou, and C. Guo

Mass-Balance Relationships in Jurassic Iron-Oxide-(Copper-Rare-Earth-Element) Deposits in the Great Basin

D. A. Johnson and M. D. Barton.

Contrasting Styles of Differentiation for the Earth, Moon, and Mars

J. H. Jones, L. E. Borg, and L. E. Nyquist

Trace-Element Systematics in Basalt Structure and Evolution of the Earth's Mantle

J. L. Joron, M. Treuil, E. Lewin, and C. J. Allègre

Electrolyte Effects on the Dissolution Kinetics of Biotite and Phlogopite at Room Temperature

B. E. Kalinowski

Deposition of Banded-Iron Formation by Isolation of Continental Basins

B. S. Kamber, M. Bau, N. J. Beukes, R. K. O'Nions, and R. M. Corfield

Trace-Element Thermobarometry Using Titanium in Gamet

S. D. Keane, E. J. Essene, and C. E. Manning

The Importance of Atmospheric Additions in Maintaining Ecosystem Nutrient Status in Hawai' ian Rainforests

M. J. Kennedy, O. A. Chadwick, L. A. Derry, and P. Vitousek

High Water Contents of Glasses and Melt Inclusions from the Loihi Seamount: Evidence for Assimilation of a Modified Seawater Component

A. J. R. Kent, M. D. Norman, I. D. Hutcheon, and E. M. Stolper. 
Identifying the Nature, Degree, and Timing of Isotopic Exchange in a Developing Pyrenean Thrust System

J. G. Kirby and A. M. McCaig .

The Reaction $\mathrm{MgCr}_{2} \mathrm{O}_{4}+\mathrm{SiO}_{2}=\mathrm{Cr}_{2} \mathrm{O}_{3}+\mathrm{MgSiO}_{3}$ and the Free Energy of Formation of Magnesiochromite $\left(\mathrm{MgCr}_{2} \mathrm{O}_{4}\right)$

S. Klemme and H. St. C. O'Neill

Strontium Isotope Systematics During Basalt-Crust Interaction

K. M. Knesel and J. P. Davidson

Carbonados from Central Africa and Brazil: Are They Related to Impact Events? A Geochemical, Spectroscopic, and X-Ray Study

C. Koeberl, M. Schrauder, M. A. G. Andreoli, F. Brandstätter, C. Lengauer, and I. Gilmour

Surface Charge of Hydrous Ferric Oxides in Sediments and Aquifer Solids

M. Kofod, A. Hadeler, and M. Isenbeck-Schröter

Bacterial Clay Authigenesis: Implications for River Chemistry

K. O. Konhauser

Structure of Surface Sites Predicted from Crystal Chemistry: Implications for Interpretation of Infrared and X-Ray Absorption Fine-Structure Spectroscopy Data

C. M. Koretsky and D. A. Sverjensky

Using the Geochemistry of Regolith Materials to Do Planetary Geology

R. L. Korotev, L. A. Haskin, and B. L. Jolliff

Strontium, Oxygen, and Carbon Isotope Evolution of Triassic Seawater

C. Korte and J. Veizer

Composition of Earth's Continental Crust as Inferred from Impact Melts in the Maya Block and Kaapvaal Craton

D. A. Kring, E. Pierazzo, and E. P. Turtle

Kinetics of Xenon Release and $\mathrm{Xe}_{\mathrm{s}}-\mathrm{Xe}_{\mathrm{n}}$ Age-Spectrum Dates of Zircons from Polymetamorphic High-Grade Terrains:

A Case Study of Samples from the Rayner Complex (East Antarctica)

D. P. Krylov

Age and Genesis of Vostok-2 Scheelite Deposit (Russia) as a Result of Crust-Mantle Interaction (Samarium-Neodymium and Rubidium-Strontium Isotope Data)

R. Sh. Krymsky, B. V. Belyatsky, and M. G. Rub

Differences in Geochemical Features Between Permian and Triassic Cherts from the Southem Chichibu Terrane, Southwest Japan: Rare-Earth-Element Abundances, Major-Element Compositions, and Strontium Isotope Ratios

T. Kunimaru, H. Shimizu, K. Takahashi, and S. Yabuki

Mantle Xenology: Constraints on the Degassing History of the Earth

J. Kunz, M. Moreira, Th. Staudacher, and C. J. Allègre 
Germanium/Silicon Fractionation During Weathering of Hawai'ian Basalts

A. C. Kurtz, L. A. Derry, O. A. Chadwick, and M. J. Alfano

Radiocarbon Dating of Climatic and Cultural Changes on the Russian Far East During the Late Glacial and Holocene

Y. V. Kuzmin, G. S. Burr, J. M. O'Malley, and A. J. T. Jull

Proxy Records of Long-lived Cosmogenic Nuclides: Implications to Temporal Variations in Cosmic-Ray Flux and Climate

D. Lal

Lead, Strontium, and Neodymium Isotopic Variations Along the New Hebrides Arc: Evidence for Mantle Source

Mixing and

Crust Contamination Related to the Collision of D'Entrecasteaux Ridge

C. Laporte and L. Briqueu.

Coupled Plagioclase Exchange Reactions in a Natural Hydrothermal System

P. B. Larson

Monte Carlo Investigation of the Complex Growth/Dissolution Mechanism of Aluminosilicates: Kaolinite

A. C. Lasaga and V. W. Sletten

Measurement of Lead Isotope Ratios in Plagioclase Using the Cameca IMS 1270 Ion Microprobe

G. D. Layne, N. Shimizu, and S. A. Morse.

Carbon Isotopes and Soil Organic Carbon in 1995-1996 Wheat Free-Air Carbon Dioxide Enrichment Experiments

at Maricopa, Arizona

S. W. Leavitt, E. Pendall, T. Brooks, E. A. Paul, B. Kimball, and H. Johnson

Tungsten Isotopic Constraints on the Differentiation of Mars and the Eucrite Parent Body

D.-C. Lee and A. N. Halliday

Tungsten Isotopic Evidence for the Accretion of the Moon

D.-C. Lee, A. N. Halliday, G. A. Snyder, and L. A. Taylor

The Role of Microtexture in Weathering Rates: Direct Comparisons of Experimentally and Naturally Weathered Feldspars

M. R. Lee, M. E. Hodson, and I. Parsons

Partitioning of Volatile Elements During Core Formation

J. Li and C. B. Agee.

Mineral Reaction Mechanisms and Kinetics in the Matrix During Metamorphism

I. I. Likhanov, V. V. Reverdatto, and A. A. Ten.

Basin Fluids Connected with Sediment-hosted Microdisseminated Gold

J. Liu and J. Liu

In Situ Measurement of Mineral (Silicate) Dissolution Kinetics Under Hydrothermal Conditions Using Scanning White Light Interferometry

A. Lüttge, I. N. Maclnnis, and A. C. Lasaga 
Pathways of Organic Remineralization in Holocene and Latest Pleistocene Sediments of the Anoxic Cariaco Basin

T. W. Lyons, R. W. Murray, D. G. Pearson, L. C. Peterson, D. J. Hollander, J. P. Werne, and ODP Leg 165

Shipboard Scientific Party

In Situ Measurement of Calcite Dissolution Rates Using Real-Time Phase Shift Interferometry

I. N. MacInnis, K. Onuma, and K. Tsukamoto

Tracing Plume, Mid-Ocean-Ridge-Basalt, and Atmosphere Contributions to Kolbeinsey Ridge Basalts: Helium, Neon, and Argon Isotope Evidence

C. G. Macpherson, D. R. Hilton, D. F. Mertz, and T. Dunai

Chlorine Contamination of Mid-Ocean Ridge Lavas: New Insight from Chlorine Stable Isotope Ratios

A. J. Magenheim, B. B. Hanan, and M. R. Perfit

Argon-Argon Dating of Basanites from Volcanic Pipes of North Minusa Depression, Khakassia, Russia

V. G. Malkovets, A. V. Travin, Yu. D. Litasov, and K. D. Litasov

Uranium-Lead Chronology of Meteorites: A Review of the Investigations During the Last 25 Years

G. Manhès, C. Göpel, and C.J. Allègre

Natural Variations of Copper and Zinc Isotopic Compositions

C. Maréchal, F. Albarède, and E. Nicolas

Strontium Isotopes in Pore Water from the Unsaturated Zone at Yucca Mountain, Nevada

B. D. Marshall, K. Futa, and Z. E. Peterman

Petrogenesis of Oversaturated Trachytes Associated with Alkaline Basalts in the Continental Cameroon Volcanic Line

(West Africa): Constraints from Argon-40/Argon-39 Dating and from Strontium, Neodymium and Oxygen Isotopes

A. Marzoli, P. Renne, and E. M. Piccirillo.

$\xi$

Characterization of Carbon in Rocks by Time-of-Flight Secondary Mass Spectrometry

E. A. Mathez and D. Mogk

Pressure and Temperature Dependence of Sulfide Solubility in Mafic Magmas

J. A. Movrogenes and H. St. C. O'Neill

Magma and Platinum-Group-Element Sources in the Bushveld Complex Inferred from Rhenium-Osmium, Rubidium-

Strontium, and Platinum-Group-Element Systematics

T. E. McCandless, J. Ruiz, and B. I. Adair

Experimental Tests of Abiotic Organic Synthesis in Hydrothermal Systems

T. McCollom, B. Simoneit, and G. Ritter.

Trace-Element Systematics in Porites Coral: High-Resolution Proxies of Sea-Surface Temperature

M. T. McCulloch, C. Alibert, D. Sinclair, G. Mortimer, and L. Kinsley.

A Comparison of Provenance Information Obtained from Detrital Zircon and Feldspar Grains in a Sandstone from the

Devonian Catskill Clastic Wedge

D. K. McDaniel and S. M. McLennan 
Regional Gradients in European Holocene Climate: New Evidence from Speleothem Calcite

F. McDermott, S. Frisia, I. J. Fairchild, Y. Huang, A. Longinelli, B. Spiro, C. J. Hawkesworth, E. Keppens, and $K$. van der Borg

The Compositions of Archean Komatiites

W. F. McDonough, S. M. Eggins, S. S. Sun, and I. H. Campbell

Lead-Neodymium Isotopic Evidence for Provenance and Post-Depositional Lead Transport in the Early Proterozoic

Huronian Supergroup, Canada

S. M. McLennan, A. Simonetti, and S. L. Goldstein

Oxide Phases in Mid-Cayman-Rise Gabbros

J. K. Meen and D. Elthon

Strontium Isotopic Exchange on a Submillimeter Scale and the Implications for Rubidium-Strontium Dating of Basement Gneisses

S. Meffan-Main and R. A. Cliff.

2.0-Billion-Year-Old Isotopically Heavy Carbonate Carbon: Comparison of Distal and Proximal Carbonate Sequences from the Onega Palaeobasin, Karelia, Russia

V. A. Melezhik, A. E. Fallick, P. V. Medvedev, and V. V. Makarikhin

Carbonate Formations of Neoproterozoic Age in the North-Central Norwegian Caledonides as Revealed by Carbon,

Strontium, Uranium, and Lead Isotopes

V. A. Melezhik, B. G. Pokrovsky, I. M. Gorokhov, G. V. Ovchinnikova, and D. Roberts

Preservation of Oceanic Island Basalts and Arclike Rare-Earth-Element Patterns in Eclogites: A Case Study of the Acatlan Complex, Southern Mexico

D. Meza-Figueroa and J. Ruiz

Aluminosilicate Mineral Formation in Amazon Delta Sediments During Early Diagenesis: Results from Substrate Incubation Experiments and Studies of Natural Particles

P. Michalopoulos and R. C. Aller

Early Mars Evolution: Clues from Martian Meteorites

D. W. Mittlefehldt and M. M. Lindstrom

Nondetrital Origins of Uranium-bearing Minerals and Pyrites in Early Proterozoic Quartz-Pebble Conglomerates of the Elliot Lake District, Ontario

R. L. Mock and H. Ohmoto

Modification of Bioorganic Carbon in Early Archean Sediments

S. J. Mojzsis, A. Lepland, J. Fessenden, and G. Arrhenius

Rare-Gas Systematics in the Upper Mantle: A Complete Study of a Popping Rock

M. Moreira, J. Kunz, and C. J. Allègre

An Appraisal of Endmember Energy and Mixing Properties of Rare-Earth Garnets

R. Moretti and G. Ottonello 
Mass and Element Recycling at Convergent Margins

J. D. Morris and F. Tera 144

Constraints on Fluids Involved in Detachment Faulting: A Laser Microprobe Study in the Whipple Mountains Metamorphic Core Complex

J. Morrison

Hydrosulfide Complexes of Copper at $22^{\circ} \mathrm{C}$ : A Novel Approach to the Measurement of Stability Constants by the Solubility Method

B. W. Mountain and T.M. Seward

Melting Experiments on Subcontinental Mantle Vein Assemblages

D. S. Musselwhite and S. F. Foley

Amphibole Inclusions in SNC Meteorites: Evidence for a Dry Martian Interior?

B. O. Mysen, D. Virgo, R. K. Popp, and C. M. Bertka

Evidence for Subcontinental Mantle in Magmatism Within the Zimbabwe Craton and Rhenium-Osmium Mantle Modeling

Th. F. Nagler, J. D. Kramers, B. S. Kamber, R. Frei, and M. D. A. Prendergast

Growth of Gibbsite on Muscovite: The Importance of Basal-Plane Reactive Surface Area

K. L. Nagy

The Whole Enchilada: Consistency, Correctness, and Physical Insight in High Pressure-Temperature Mineral

Physics Data for Hydrous Mantle Phases

A. Navrotsky, K. Bose, P. J. Schields, Y. Wang, and D. J. Weidner

Strontium Isotopic Characterization of Groundwater and Calcite from the Potential Underground Laboratory Site in the Vienne Granitoids (France)

P. Négrel, J. Casanova, and J. F. Aranyossy

Origin of Hercynian Leucogranites from Central Kazakhstan: Crustal Affinity vs. Primitive Isotopic Composition

E. V. Negrey and K. N. Shatagin 150

Temperature and Compositional Controls on the Mineral-Melt Partitioning of the High Field Strength and Rare Earth Elements for Amphibole and Magnetite

R. L. Nielsen, J. S. Beard, and M. L. Hilyard 150

Carbon and Helium Isotope Systematics of North Fiji Basin Basalt Glasses

Y. Nishio, S. Sasaki, T. Gamo, H. Hiyagon, and Y. Sano

Compositions of Primitive Magmas and Source Characteristics of the Hawai'ian Plume: Constraints from Picritic Lavas

M. D. Norman and M. O. Garcia

Temporal Evolution of Feldspar Surfaces During the Initial Stages of In Situ Weathering

M. A. Nugent, S. L. Brantley, C. Pantano, and P. Maurice 
Kinetics of the Intersite Cation Exchange in $\mathrm{MgAl}_{2} \mathrm{O}_{4}$ Spinel: The Influence of Nonstoichiometry

H. St. C. O'Neill

Secular Changes in Neodymium and Lead Isotopes in Atlantic, Indian, and Pacific Ferromanganese Crusts and Deepwater Circulation

R. K. O'Nions, H. F. Ling, M. Frank, and F. von Blanckenburg.

Mantle Apatite Revisited: Major Reservoir for Uranium and Thorium in the Mantle and Reflector of Mantle-Fluid Sources

S. Y. O'Reilly, W. L. Griffin, P. Morgan, D. A. Ionov, and M. D. Norman

The Importance of Aridity as a Control on Chemical Weathering: Evidence from the Marine Osmium Record

R. Oxburgh

Input and Removal Fluxes of Osmium in the Oceans: Constraints from Residence-Time Estimates

R. Oxburgh

Origin of Carbonado Diamond and Nanodiamond in Primitive Meteorites: Radiation-induced Diamond Crystallization

M. Ozima and M. Tatsumoto

A Molecular Record of Organic Burial and Carbon Dioxide Variability in the Middle Miocene

M. Pagani, M. A. Arthur, and K. H. Freeman

Late Cretaceous-Neogene Basalts from Chatham Island: Implications for HIMU Mantle Beneath Continental Borderlands of the Southwest Pacific

K. Panter, J. Blusztajin, S. Hart, and P. Kyle.

Replacement Reactions in Alkali Feldspars at Near-Surface Temperatures

I. Parsons and M. R. Lee

Neodymium Isotopes and the Origin of Phanerozoic Sediments at a Continental Scale in North America

P. J. Patchett, N. D. Boghossian, B. S. Canale, C. N. Garzione, J. D. Gleason, and M. A. Roth.

Constraints on Sediment Recycling from Western Nicaragua

L. C. Patino and M. J. Carr

Helium-4 as a Tracer of Eolian Dust: A Two-Million-Year Record from ODP Site 806, Ontong Java Plateau

D. B. Patterson and K. A. Farley

Strontium/Calcium Ratios in Marine Barite over the Past 35 Million Years

A. Paytan and M. Kastner

Total Barium vs. Amount of Barite in Sediments as Indicators of Productivity

A. Paytan, R. W. Murray, M. Kastner, and M. Leinen

Single-Crystal Rhenium-Osmium Isotopic Dating of Sulfide Inclusions Within a Zoned Siberian Diamond

D. G. Pearson, S. B. Shirey, G. P. Bulanova, R. W. Carlson, and H. J. Milledge 
A Description of the Paleoclimate in the South China Sea by Means of Molecular Biomarkers in Deep-Sea Sediments

C. Pelejero, J. O. Grimalt, M. Sarnthein, and L. Wang

El Niño's Winter Precipitation Recorded in Pine Cellulose Deuterium/Hydrogen Ratios

E. Pendall and S. W. Leavitt.

Enhanced Soil Respiration and Decomposition Under Elevated Carbon Dioxide

E. Pendall, S. W. Leavitt, T. Brooks, and B. Kimball

Geochemical and Isotope Evolution of Hydrothermal-Magmatic Systems of the Uksichan Volcano (Kamchatka Island Arc System)

A. B. Perepelov, V. Yu. Prokofiev, and S. I. Dril'

Mantle Heterogeneities at the Asian Continental Margin Induced by Cenozoic Subduction Components

T. V. Petrova, S. V. Esin, and V. A. Kutolin

Neodymium, Strontium, and Lead Isotopic Signatures and Eolian Mass-Accumulate-Rate Variations of Central North Pacific

Dust Characterize the Paleoclimate of Central and Eastern Asia for the Past 11 Million Years

T. Pettke, D. K. Rea, and A. N. Halliday

Experimental Study of Trace-Element Partitioning in Fluids and Melts Generated During Sediment Subduction

T. Plank and M. Johnson

Archean Aluminum-depleted Komatiites and Komatiitic Basalts with Majorite-Gamet and Ocean-Island-Basalt-like

Trace-Element Characteristics: Recycling of Oceanic Lithosphere into Deep Mantle

A. Polat and R. Kerrich

Geochemical Diversity of Ultramafic and Mafic Volcanic Rocks in the Late Archean Greenstone Belts, Superior Province, Canada

A. Polat, R. Kerrich, P. Hollings, and D. Wyman

Rubidium and Strontium Isotopes in Hydrothermal Minerals from Iron Ore Deposits of the Siberian Platform and Some Applications for an Internal Isochron

A. G. Polozov, G. P. Sandimirova, and Yu. A. Pakhol' chenko

Speciation of Iron in Suspended Sediments from World Rivers

S. W. Poulton and R. Raiswell. 166

Generation of Hawai'ian Tholeiites at About $5 \mathrm{GPa}$ from a Carbonated Gamet Lherzolite Mantle

D. C. Presnall, Y.-H. Weng, and J. A. Dalton 166

Trace Elements in Residual and Sedimentary Deposits of Kaolins from Minho (Northwestem Portugal)

M. I. Prudêncio, M. A. Gouveia, and M. A. Sequeira Braga

Laser Probe Oxygen Isotope Studies of Metagabbroic Minerals: Tracers of Fluid-Rock Exchange in Orogenesis

B. Putlitz, A. Matthews, J.W. Valley, and Y. Katzir 
The Thermodynamics and Kinetics of the Crystallization of Solid Solutions from Aqueous Solutions: Implications for Trace-Element Sorption

A. Putnis, M. Prieto, A. Fernández-González, and L. Fernández-Díaz

Carbon Sequestration Under Chaparral and Pine After Four Decades of Soil Development

S. A. Quideau, O. A. Chadwick, R. C. Graham, and M. A. Anderson

A New Model Invoking Soret Effect for the Origin of Iron-Titanium Oxide Deposits Associated with the Proterozoic Anorthosites

A. S. P. Rao and K. Srinivas

A New Tectonic and Petrologic Model for the Origin of the Proterozoic Anorthosites

A. S. P. Rao and K. Srinivas

Trace-Element Characteristics of Pristine and Mantle-Hybridized Slab Melts: Implications for the Petrogenesis of Adakiteand High-Magnesium Andesite

R. P. Rapp and N. Shimizu

Variations in Niobium/Tantalum Ratios Between Calcalkaline and High-Niobium Basalts from Costa Rica: Implications for the Presence of Rutile in Arc Magma Sources

M. K. Reagan and T. A. Plank

Surface-Symmetry Constraints on the Selective Incorporation of Trace Elements at Growthsteps: Example of Calcite R. J. Reeder

Fractionation of Platinum-Group-Element Abundances in the Lithospheric Mantle

M. Rehkämper, A. N. Halliday, and J. G. Fitton

Ion Microprobe Thorium-230/Uranium-238 Dating of Zircon Delimits the Thermal Evolution of Rhyolitic Magmas Beneath Long Valley Caldera

M. R. Reid, C. D. Coath, T. M. Harrison, and K. D. McKeegan

Uranium-series Disequilibria in Speleothems from the Bahamas: Sea Levels, Carbonate Deposition, and Diagenesis

D. A. Richards, C. J. Borton, P. L. Smart, R. L. Edwards, and M. S. Roberts

Chemical Changes in Soil Pore Water During Recharge: Implications for Water Movement

P. L. Richards

Core Formation in Earth and Mars

$K$. Righter and $M$. J. Drake

Rhenium is Compatible in Garnet During Mantle Melting and Magma Genesis

K. Righter and E. H. Hauri

Effect of Water on Nickel, Cobalt, and Tungsten Metal/Silicate Partitioning at $10 \mathrm{kbar}, 1300^{\circ} \mathrm{C}$

K. Righter, M. J. Drake, and R. L. Hervig 
The Leached Layer on Dissolving Wollastonite

J. D. Rimstidt, E. J. Weissbart, and J. J. Rosso 176

Geochemistry and Trace-Element Variations in Muntele Mic Granitoid, Southern Carpathians, Romania

I. N. Robu, L. Robu, and M. Stoian.

Rare-Earth-Element Content and Variations in Some Volcanic Rocks from Metaliferi Mountains, Brad-Sacarimb

Zone (Romania)

L. Robu, I. N. Robu, and I. Tiepac

Strontium-Neodymium Isotope Systematics of the Platinum-bearing Belt of the Urals, Russia

Y. L. Ronkin, K. S. Ivanov, V. R. Shmelev, and O. P. Lepikhina

Estimation of Mantle and Crustal Material Participation in Evolution of the Huge Kachar Ore-Geochemical System of the Urals, Russia: Strontium-Neodymium-Lead Isotope Limitations

Y. L. Ronkin, Y. A. Poltavets, O. P. Lepikhina, and Z. I. Poltavets

Isotope Geochemistry of Quartz-Carbonate Veins Associated with the Coeur d'Alene Mineralization

P. E. Rosenberg and P. B. Larson

Linked Dissolution/Precipitation Reactions at Silicate Surfaces

J. J. Rosso and J. D. Rimstidt

The Role of Secondary Iron Minerals on the Mobility of Arsenic During the Flooding of Lignite Mines

T. R. Rüde, S. Wohnlich, and A. Vogelgsang

Thermal Structure of Archean Cratons: A New Look at Conductive Geotherms and Xenolith Pressure-Temperature Arrays

R. L. Rudnick

Chemical Transfer Events in Subduction Zones as a Function of Slab Depth

J. G. Ryan

Osmium Isotope Systematics in the Horoman Peridotite

A. Saal, E. Takazawa, F. Frey, N. Shimizu, and S. Hart.....

Response of $\alpha-\mathrm{Fe}_{2} \mathrm{O}_{3}$ Dissolution Rates to $\mathrm{pH}$ Jumps

S. D. Samson and C. M. Eggleston

Uranium-Lead Geochronological Investigation of Exposed Basement Within the Cadomia Terrane, Channel Islands:

A Test of Indirect Methods of Basement Characterization

S. D. Samson, B. V. Miller, and R. D'Lemos

Noble Gas and Carbon Isotopes in Mariana Trough Basalt Glasses

Y. Sano, Y. Nishio, T. Gamo, A. Jambon, and B. Marty

Influence of $\mathrm{pH}$ and Dissolved Phosphate on the Sorption of Uranium onto Calcium Carbonate

A. V. Savenko 
Deposition of Heavy Metals in the Flood Plain Sediments of the Yamnua River (Tributary of Ganga), India

D. P. Saxena and V. Subramanian

Palaeoproterozoic Crustal Evolution of the Southem Eyre Peninsula, Gawler Craton, Australia

B. F. Schaefer, J. Foden, and M. Sandiford

Mantle Flow and Partial Melting: Evidence from Ultramafic Nodules in Alkali Basalts from Intraplate Volcanos

$P$. Schiano and $Y$. Bottinga

Carbon Isotope Record and Antiquity of Terrestrial Life: A Status Report

M. Schidlowski

Transport of Lead in Natural Gas

A. P. Schmidt and Th. W. De Loos

Platinum Group Elements (PGE) in Abyssal Peridotites from the Oceanic Upper Mantle

G. Schmidt and J. E. Snow

Distribution and Identification of Microorganisms in Acidic Mine Drainage as Determined by Fluorescence In Situ

Hybridization for Environmental Samples

M. O. Schrenk, K. J. Edwards, J. F. Banfield, and R. M. Goodman

Synthesis of Organic Compounds During Aqueous Alteration of the Murchison Meteorite Parent Body

M. Schulte and E. Shock

Rate of Quartz Dissolution in a Tropical Weathering Environment

M. S. Schulz, A. F. White, and D. V. Vivit

Lichen Weathering at Cone Pond, New Hampshire

D. W. Schwartzman, R. Aghamiri, and S. C. Bailey

Fixation and Mobilization of Fluorine in Two Neighboring Geochemical Provinces in Sri Lanka

A. Senaratne

Ion Pairing and Cluster Formation in Hydrothermal Solutions

T. M. Seward, C. M. B. Henderson, J. M. Charnock, and T. Driesner

Problem of Heterogenic Accumulation of the Earth and the Moon: Evidence from Titaniferous Magmatism

E. V. Sharkov

Paleoproterozoic Large Baltic Igneous Province of Siliceous High-Magnesium (Boninite-like) Series Rocks as a Result of Ancient Plume Activity: Geological and Petrological Evidences

E. V. Sharkov, I. S. Krassivskaya, and V. F. Smol'kin.

Modification of Sanidine Rubidium-Strontium and Oxygen Isotopic Systems During Structure Ordering

K. N. Shatagin, V. N. Volkov, and B. G. Pokrovsky 
Trace-Element Partitioning in Pigeonite-Garnet-Melt Assemblages in Natural Peridotite Composition at High Pressures

High-Pressure Phase Equilibrium in the System MORB- $\mathrm{H}_{2} \mathrm{O}-\mathrm{CaCO}_{3}$ : The Role of Carbon

Dioxide in Subduction Zones

Initial Osmium Isotopic Compositions for Munro Township, Ontario, Komatiites Revisited: Additional Evidence for Near-Chondritic, Late-Archean Convecting Mantle Beneath the Superior Province

$$
\text { S. B. Shirey. }
$$

Crustal Growth and Paleogeography in Hercynian and Appalachian Belts by Samarium-Neodymium Isotopic Study of Shales

F. Simien, M. Mattauer, and C. J. Allègre

Spatial and Temporal Variations in Mid-Ocean-Ridge Basalt Geochemistry Along the East Pacific Rise Crest:

Uranium-series Disequilibria, Radiogenic Isotopes, and Elemental Variability in a Closely Spaced, Two-dimensional

Grid of Samples from $9^{\circ} 48^{\prime}-52 ' \mathrm{~N}$

K. W. W. Sims, S. J. Goldstein, M. R. Perfit, D. J. Fornari, S. R. Hart, M. C. Smith, and M. T. Murrell

Microbially. Induced Corrosion and Precipitation of Iron Phosphates by Deep Subsurface Bacteria Grown as

Biofilms on 1020 Carbon Steel

G. Southam, R. Donald, P. Castro, B. Pitonzo, and P. Amy

Petrographic and Geochemical Evidence for Evolution of Siberian Lithosphere in Xenoliths from Kimberlites of Yakutia

Z. V. Spetsius

Rhenium-Osmium Isotopic Constraints on the Genesis of Magmatic Nickel-Copper-Cobalt-Platinum-Group-

Element Ores, East Kimberley, Westem Australia

R. A. Sproule, D. D. Lambert, and D. M. Hoatson

Experimental Mineral-Aqueous Fluid Partitioning of Trace Elements at $1000^{\circ}-1200^{\circ} \mathrm{C}$ and $3.0-5.5 \mathrm{GPa}$ :

Implications for the Generation of Island Arc Basalts

R. Stalder, S. F. Foley, G. P. Brey, and I. Horn

Biologically Mediated Alteration of Volcanic Ash in Seawater: Litho-, Bio-, and Hydrosphere Interaction

H. Staudigel, E. Verdurmen, G. Davies, R. A. Chastain, A. Yayanos, H. DeBaar, and W. B. Bourcier

A Large, Mantle-derived Igneous Province Dominated by Felsic Magmatic Rocks

K.P. Stewart

Lead and Neodymium Isotopic Equilibrium and Closed Systems in Bituminous Clastic Sediments?

$P$. Stille and F. Gauthier-Lafaye

The Surface of Dissolving Conundum $\left(\alpha-\mathrm{Al}_{2} \mathrm{O}_{3}\right.$ ) Under Variable pH Conditions

L. L. Stillings, S. D. Samson, and C. M. Eggleston.

Timing and Duration of the Last Interglacial: Constraints from Westem Australia

C. H. Stirling, T. M. Esat, M. T. McCulloch, and K. Lambeck 
Quantum Chemical Studies on Dissolution of Silicate Minerals

H. Strandh and L. G. M. Pettersson

Enstatite Chondrite Earth: Implications for Global Argon Isotope Systematics

F. M. Stuart

Carbonate Growth Studied by Synchrotron X-Ray Scattering

N. C. Sturchio and R. P. Chiarello

Exposure Ages from Contrasting Geomorphic Settings in the Dry Valleys, South Victoria Land, Antarctica, from

Cosmogenic Neon-21 Isotope Analysis

M. A. Summerfield, F. M. Stuart, T. Dunai, D. E. Sugden, H. A. P. Cockburn, and G. H. Denton

Rhenium-Osmium Systematics of the Rottenstone Nickel-Copper-Platnium-Group-Element Deposit, Canada

K. Suzuki, L. Hulbert, Y. Miyata, H. Amakawa, and Y. Nozaki

Detection of Molybdenite Alteration and Resulting Rhenium-Osmium Fractionation Through Near-Infrared Microspectroscopy and Micro-X-Ray Diffraction

K. Suzuki, H. Kagi, M. Nara, B. Takano, and Y. Nozaki

Boron Isotopic Mass Balance in Boron-affected Agricultural Soil

G. H. Swihart, Y. Xiao, D. L. Suarez, E. H. McBay, and D. H. Smith

Noble Gases on Mars and Earth: Key Similarities and Differences

T. D. Swindle

The Interaction of $\mathrm{Mn}^{2+}$ and $\mathrm{Zn}^{2+}$ Ions with (1014) Surfaces of Calcite During Growth as a Function of Chlorinity:

From Isomorphous Substitution to Two-Phase Coprecipitation?

M. Temmam, J. Paquette, and H. Vali

Microscopic Characterization of Mechanisms and Fundamental Parameters Governing Calcite Mineralization

H. H. Teng, P. M. Dove, C. Orme, and J. J. DeYoreo

Magma Interactions at Chaos Crags, Lassen Volcanic National Park, California

F. J. Tepley III, J. P. Davidson, and M. A. Clynne

The Effect of Climate on Mass Transport of Minor and Trace Elements in Soils Developed on Basaltic Bedrock

N. Teutsch, Y. Erel, L. Halicz, and O. A. Chadwick

Some Isotopic Thoughts on Crust-Mantle Evolution

G. R. Tilton

Boron Isotopic and Light-Element Variations in Aeolian Volcanic Arc Lavas

S. Tonarini, W. P. Leeman, M. Pennisi, and G. Ferrara

Chromatographic Determination of the Stability of Aluminum-Organic Complexes: Ligands Produced and Excreted by Environmental Microorganisms

K. A. Traexler, S. A. Welch, and W. J. Ullman 
Early Silicate Differentiation in Mars

A. H. Treiman

Radiocarbon in Soil Organic Matter and Soil Respiration: A Comparison of Boreal, Temperate, and Tropical Forests

S. E. Trumbore

Uranium-238/Thorium-230 Disequilibria, Magma Petrogenesis, and Flux Rates Beneath the Depleted Tonga-

Kermadec Island Arc

S. P. Turner, C. J. Hawkesworth, N. W. Rogers, J. Bartlett, I. Smith, and T. Worthington.

Microbially Mediated, Proton-promoted Feldspar Dissolution by Organic Acid Excretion Under Unbuffered

and Nutrient-limited Conditions in Oxic Aquifers

W. J. Ullman, S. A. Welch, and P. C. Bennett

Experimental Study of Anorthite Dissolution and Its Secondary Minerals Under High Partial Pressure of Carbon

Dioxide: Weathering in the Archean

S. Utsunomiya, T. Murakami, H. Kadohara, and K. Tsukimura

Assessment of Weathering Rates in Sand, Loess, and Clay Soils for Regional Applications

C. Van der Salm

Geochemical Fluxes at Convergent Margins and the Composition of West Sunda Magmatism

R. Varne and $M$. Gasparon

Could Ferrar Magmatism Have Been Produced by Fluxing of Mid-Ocean Ridge Basalt Asthenosphere by Crustal Melts?

$R$. Varne and $R$. Sweeney

Rare-Earth-Element Geochemistry of Natural and Mining-related Acid Waters, Upper Animas River Basin, Colorado

P. L. Verplanck, D. K. Nordstrom, M.-J. Gimeno, and W. G. Wright

Hafnium-Neodymium Isotopic Composition of the Crust and Mantle Through Time: New Directions with

Hafnium Whole-Rock Studies

J. D. Vervoort, J. Blichert-Toft, P. J. Patchett, and F. Albarede

Argon-Xenon Fractionation and the Mechanisms of Rare Gas Diffusion in Potassium Feldspar

I. M. Villa

Stable Chlorine Isotope Composition of Volcanic Gas Condensates

C. Wahrenberger, C. J. Eastoe, T. M. Seward, and V. Dietrich

The Impact of Land Use Change on Soil Carbon Dynamics

Y. Wang, R. Amundson, and S. Trumbore

Silicon in the Earth's Core, Sulfur in the Core of Mars

H. Wänke and G. Dreibus 
Prediction of Thermodynamic Properties in the System Salt- $\mathrm{CO}_{2}-\mathrm{CH}_{4}-\mathrm{H}_{2} \mathrm{O}$ : First Principle Simulations and Equation-of-State Approaches

J. H. Weare

Magmatic and Metamorphic Evolution of the Grenville-Age Guichicovi Complex in Southern Mexico

B. Weber, D. J. Morán-Zenteno, F. Söllner, and H. Köhler.

Kerguelen Plateau-Broken Ridge: A Major Large Igneous Province Related to the Kerguelen Plume

D. Weis and F. A. Frey

A Complete Postglacial Record of Atmospheric Lead Deposition in a Peat Bog Profile, Jura Mountains, Switzerland

D. Weiss, W. Shotyk, R. Frei, and J. D. Kramers

Factors Controlling Arsenic and Uranium in Shallow Groundwater, Southem Carson Desert, Nevada

A. H. Welch and M. S. Lico

Experimental Observations of the Effect of Microorganisms on Silicate Weathering

S. A. Welch, W. W. Barker, and J. F. Banfield

Experimental Weathering of Granitoids: Importance of Relative Mineral Reaction Rates

A. F. White, T. D. Bullen, D. V. Vivit, and M. S. Schulz

The Deep Mantle Subduction: Flux in the Lesser Antilles

W. M. White, D. R. Gravatt, and J. D. Devine

In Situ Determination of the Heat of Solution of $\mathrm{La}_{2} \mathrm{O}_{3}$ in Silicate Melts at $1760 \mathrm{~K}$

M. C. Wilding and A. Navrotsky

Temperature- and Free-Energy-Dependence of Zeolite Precipitation and Dissolution Rates

R. T. Wilkin and H. L. Barnes

A Predictive Model for Rare-Earth-Element Partitioning Between Clinopyroxene and Anhydrous Silicate Melt

B. J. Wood and J. D. Blundy

Calculation of the Distribution of Cobalt Chloride Complexes and the Solubility of Cobalt Sulfides in Hydrothermal Solutions to $350^{\circ} \mathrm{C}$

S. A. Wood

Calculation of the Volatility of Copper Chlorides at Elevated Temperatures and Pressures: Why is Copper Enriched in the Vapor Phases of Fluid Inclusions?

S. A. Wood

Crustal History and Processes as Reflected in Lead Isotopic Signatures: Some Examples from North America 
Intra-Annual Measurements of $\delta^{18} \mathrm{O}$ Compared with $8^{13} \mathrm{C}$ in Tree Cellulose: A Unique Record Reflecting Either

Physiological Responses or Challenging Fundamental Assumptions

W. E. Wright, S. W. Leavitt, and A. Long

Carbonate-rich Liquids and Critical Fluids in Mantle Plumes

P. J. Wyllie and I. D. Ryabchikov

An Oceanic Crustal Origin for Young Continental Crust Along the West Antarctica-Australia Sector of the Paleozoic Gondwana Seaboard

R. J. Wysoczanski, T. R. Ireland, J. H. Berg, and J. A. Gamble

Surface Microtopograph of an Alkali Feldspar: Transmission Electron Microscopy and Scanning Force Microscopy Studies H. Xu. P. R. Buseck, D. R. Veblen, and B. L. Ramakrishna

Biogenic Evaporites from Secretion of Populus Diversifolia Around Desert Area, Xinjiang, Northwestem China

S. Yabuki, A. Okada, Z. Fan, and Q. Chang

Ferric and Ferrous Contents of Marine Sediments: Indicator of the Atmospheric $\mathrm{P}_{\mathrm{O} 2}$ Level and of Paleotectonic Setting

$K$. Yamaguchi and H. Ohmoto

Experimental Study of the Effect on Intraplate Magmatism of Eclogite Entrained in Mantle Plumes

G. M. Yaxley and D. H. Green

Lead-Lead Age and Source of Sediments of the Proterozoic Intracratonic Cuddapah Basin, India

J. K. Zachariah, K. Gopalan, and R. Srinivasan.

First Laser Ablation Microprobe Measurements of Trace-Element Partitioning Between Hydrous Phases in

High-Pressure Metamorphic Rocks

T. Zack and S. F. Foley

Rare-Earth-Element Concentration of the Giant Clam from Off Hatsushima Cold Seepage, Sagami Trough

J. Zhang and T. Ishii

Xenology and Young Age of Earth

Y. Zhang .

Calcium Isotopes in Seawater and the Calcium Cycle

P. Zhu and J. D. Macdougall

Effect of Melting Time on the Uranium -series Disequilibria in Young Lavas

$H$. Zou and A. Zindler

Infracambrian-sourced Crude Oils: Occurrence and Chemistry

J. E. Zumberge, C. F. Schiefelbein, and S. W. Brown

Author Index 



\section{Abstracts}

SUBDUCTION OF THE ASEISMIC COCOS RIDGE DISPLACED MAGMA SOURCES BENEATH THE CORDILLERA DE TALAMANCA, COSTA RICA. M. Abratis and G. Wömer, Geochemisches Institut, Universität Göttingen, D-37077 Göttingen, Germany (mabratil@gwdg.de).

The majority of volcanic and intrusive rocks (>5 Ma) of the Cordillera de Talamanca exhibit normal island-arc characteristics with mainly calc-alkaline pattems.

Based on age relations, geochemical, and isotopic data, we subdivide three groups of rocks that occur in a typical island-arc environment prior to the Cocos Ridge arrival at this subduction zone: Precollisional Miocene arc volcanics and intrusives (type 1) are mainly middle- to high-K-calc-alkaline, characterized by intermediate concentrations of $\mathrm{LREE}, \mathrm{Ce} / \mathrm{Yb}_{\mathrm{n}}: 3-6$. Type 2 rocks, also precollisional, in the Fila Costeña are basalts or gabbros, showing larger ranges in LREEs, $\mathrm{Ce} / \mathrm{Yb}_{\mathrm{n}}: 2-12$. A third type of rocks was not yet dated; they represent primitive low-K island-arc tholeiites (type 3) with distinctly flat REE pattems (Ce/Yb $: 1-4)$.

When the aseismic Cocos Ridge collided with the Costa Rican subduction zone about $5 \mathrm{~m}$.y. ago, the subduction angle was reduced and the uplift of the Cordillera de Talamanca was enhanced. Coincidently, volcanism waned in this region. Syncollisional alkaline magmatism occurred in the back-arc region. These rocks (type 4) have a steep $\mathrm{REE}$ pattem $\left(\mathrm{Ce} / \mathrm{Yb}_{\mathrm{d}}\right.$ : 15-33). The latest igneous products after collision (type 5 ) document a fundamental change in the location of melt generation: These volcanics (adakites) were derived from partial melting of the subducted slab itself or hydrated basaltic rocks at the base of the Talamanca crust. Characteristic garnet in the residuum is proven by a HREE depletion $\left(\mathrm{Ce} / \mathrm{Yb}_{n}: 12\right.$ $30)$.

Strontium vs. Nd isotopes show a slightly positive correlation and an unusual trend crossing the mantle array. Variations in ${ }^{87} \mathrm{~S} /$ ${ }^{86} \mathrm{Sr}(0.70332-0.70415)$ are larger than those of ${ }^{143} \mathrm{Nd}^{144} \mathrm{Nd}$ (0.512953-0.513036). A clear distinction exists between the younger series (types 4,5) on the mantle array and the older series (types 13 ) with higher $\mathrm{Sr}$ isotope ratios off the array to the right. Isotopes indicate an initially homogeneous magma source, slightly enriched in comparison to MORB compositions.

We interpret the displacement down the mantle array as the admixture of sediments in the source. The horizontal trend off the array (from adakites to calc-alkaline Talamanca rocks) could reflect the effect of Sr-rich slab fluids (low in Nd).

Lead isotope ratios show only little contribution of sedimentderived lead. However, a distinct difference in the ${ }^{206} \mathrm{~Pb} / 204 \mathrm{~Pb}$ ratio of the series is obvious. The older groups (types $1-3$ ) have lower $\mathrm{Pb}$ isotopic ratios and lie within the field of the Galapagos Spreading Center and that of the East Pacific Rise MORBs. The younger groups (types 4,5 ) tend to higher $\mathrm{Pb}$ isotopic ratios that correspond to the field of the Galapagos Island hot spot (GI). This Gl signature in the adakites is thus in contrast to the normal wedge signature (types 1-3) and supports the hypothesis of direct melting of the Galapagos hot-spot trace (i.e., Cocos Ridge). Nevertheless, generation within the lower crust of the upper Caribbean plate cannot be ruled out since it may produce a similar isotopic signature. Fragments of a hot-spot-derived late Cretaceous igneous province [1] with comparable ${ }^{206} \mathrm{~Pb} / 204 \mathrm{~Pb}$-enriched signature are found all over the Caribbean and could also make up the lower crust of southern Costa Rica.

Thermal arguments favor melting of the $\sim 10-\mathrm{m} . \mathrm{y}$-old Cocos Ridge crust over Cretaceous sub-Talamanca basaltic oceanic material.

References: [1] Donnelly T. W. et al. (1990) in The Geology of North America: H. The Caribbean Region (G. Dengo and J. E. Case, eds.), pp. 339-374, Geol. Soc. Am., Boulder.

TOPOGRAPHY OF TRANSITION ZONE DISCONTINUITIES: A MEASURE OF "OLIVINE" CONTENT AND EVIDENCE FOR DEEP CRATONIC ROOTS. C. B. Agee, Y. Gu, and A. M. Dziewonski, Department of Earth and Planetary Sciences, Harvard University, 20 Oxford Street, Cambridge MA 02138,USA (agee@eps.harvard.edu).

Examination of travel times and amplitudes of underside reflections from upper-mantle discontinuities (SS precursors) using more than 13,000 high-quality broad-band and long-period transverse component seismograms shows the $410-\mathrm{km}$ discontinuity to be depressed under oceans but elevated under continents. The $520-\mathrm{km}$ discontinuity is observed when the mid-path reflections are under mid-age oceanic crust, but is absent when they are under cratons. Preliminary amplitude analysis shows that the peak-to-peak amplitude ratio between $S 410$ S and S660S is 0.90 beneath oceans and 0.75 beneath continents.

Our observations indicate that the large-scale features of 410 topography are correlated with the continent-ocean function, and 660 topography with the presence of subduction zones. In other words, there is very low correlation between 410 and 660 topography. This is inconsistent with simple models of adiabatic upwelling and downwelling through the upper mantle transition zone and the opposite signs of the Clapeyron slopes in the "olivine" P-T phase diagram. Hence, the global-scale topographies of the 410 and the 660 may result from different physical processes, complex mantle flow patterns, or compositional differences between the upper and lower mantle.

The amplitude analysis discussed above suggests that the shear wave velocity jump at 410 is $20 \%$ greater beneath oceans than beneath cratons. The size of the velocity jump has been widely used as an indicator of the olivine content at the 410 . In forsteritic olivines, such as those present in peridotite xenoliths, the increase in velocity of the olivine to $\beta$-phase transformation is approximately $12 \%$ for shear waves. Therefore, as examples, a 410 with $60 \%$ olivine should show an S-wave velocity jump of $7.2 \%$, and a 410 with only $48 \%$ olivine should show a $5.8 \%$ change. This assumes that the other minerals present, such as pyroxenes and garnet, do not have abrupt changes in elastic properties nor do they change abruptly in modal abundance at the 410 . One interpretation of the sharp, pronounced 410 beneath oceans and the muted, more modest 410 beneath cratons, is that the former is richer in olivine component than the latter. This is consistent with low "olivine" content causing the 520 to "disappear" in the subcratonic transition zone as we discuss below. 
With regard to the presence of 520 beneath the oceans and its absence under cratons, it is well established that the $\beta$-phase to $\gamma$ spinel transformation, corresponding to 520 , is associated with a very modest increase in density and elastic moduli. This increase translates into a seismic velocity increase of only about $1 \%$ or an order of magnitude less than is associated with the olivine to $\beta$ phase and $\gamma$-spinel to perovskite + magnesiowüstite transformations. In the various pyrolite models the olivine content of the mantle is $\sim 60 \%$, therefore the actual velocity increase one might expect for this composition is $-0.6 \%$. Such an increase may just be resolvable with our reflection data and is represented in the feature at -3.25 that we see in our slowness profile of the suboceanic mantle. If the olivine content decreases with depth in the subcratonic transition zone and drops below the pyrolite level to $30 \%$ of the mantle mineralogy by 520 , then it is conceivable that our seismic-imaging techniques would fail to detect the corresponding $0.3 \%$ increase in $S$-wave velocity.

In summary, SdS observations of the 410 and the 520 , combined with phase equilibria and mineral physics constraints, argue for a compositional difference between the suboceanic and subcratonic upper mantle transition zones. We propose that the subcratonic transition zone is both olivine-depleted and $60^{\circ}-70^{\circ} \mathrm{C}$ cooler relative to the suboceanic transition zone. It is unlikely that this olivinedepleted zone reaches up into the shallow ( $<200 \mathrm{~km}$ depth) subcratonic mantle since the xenolith source region there is thought to be, on average, rich in both olivine and pyroxene. Thus we envisage a subcratonic mantle root that forms with two compositionally distinct zones: the shallow harzburgite, xenolith source region, and a deeper olivine-depleted zone that may begin at a level of $200-$ $400-\mathrm{km}$ depth and extend below the 520 . Such compositional stratification or zonation is predicted by magma-ocean solidification scenarios. In these models the shallow mantle is enriched in olivine and pyroxene by crystal flotation and upward accumulation and, as a consequence, the prototransition zone is left enriched in gamet. It is conceivable that this type of primordial stratification survives to some extent beneath ancient cratons, thus explaining the modest $S$ wave velocity jump at 410 and absence of the 520 .

\section{$=$}

URANIUM ENRICHMENT IN LITHOSPHERIC MANTLE: CASE STUDIES FROM FRENCH MASSIF CENTRAL. O. Alard, J.-L. Bodinier, and J.-M. Dautria, UMR 5569, GéofluidesBassins-Eau, ISTEEM, cc 057, Université de Montpellier II, Place E. Bataillon, 34095 Montpellier Cedex 05, France (alard@dstu. univmontp2.fr).

Mantle xenoliths are often enriched in LILE relative to heavy REE. This feature is classically attributed to enrichment by melts/ fluids infiltrated in the lithosphere. Moreover, several recent papers have reported peridotite from worldwide continental occurrences characterized by selective $\mathrm{U}$ and $\mathrm{Pb}$ enrichment [e.g., 1,2]. However, current interpretations of selective $U$ enrichment in mantle xenoliths call upon posteruption alteration involving $\mathrm{U}$ - and $\mathrm{Pb}$-rich fluids.

Our ICP-MS study of a wide number of mantle xenoliths collected in various localities from French Massif Central confirms the widespread distribution of U-rich peridotites at the scale of this region [e.g., 3]. Virtually all the analyzed samples are selectively enriched in $U$ with $U_{N} / T_{N}$ ratios as high as 60 in several samples.
It is worth noting that $\mathrm{U}$ - and $\mathrm{Pb}$-rich xenoliths include peridotites that are otherwise depleted in highly incompatible elements, with compositions typical of unmetasomatized "depleted MORB mantle." The only noticeable exceptions are xenoliths characterized by overall enrichment of LILE and negative anomaly of HFSE, a signature that is commonly ascribed to mantle metasomatism by carbonaterich melts. The U/Th ratio tends to be roughly correlated with $\mathrm{Pb}$ / Ce. In individual xenolith suites this ratio is well correlated with $\mathrm{Sr}$ / $\mathrm{Ce}$ and LREE/MREE.

In contrast with the conclusions of previous studies, our data indicate that the selective enrichment of $U$ in mantle xenoliths is of primary origin. This is shown by (1) the absence of detectable alteration products in the studied samples, (2) the low $U / T h$ values of the host lavas ( $\approx$ primitive mantle values), (3) the fact that the elevated U/Th values of bulk rocks are also observed in separated minerals (olivine, cpx) analyzed after extensive acid leaching, and (4) the absence of a marked $U$ anomaly in the samples affected by "carbonate-melt" metasomatism. Our data suggest that the U anomaly is not just overwhelmed by overall LILE but more likely erased.

On the basis of our results, we suggest that a considerable proportion of the subcontinental lithospheric mantle is characterized by a U/Th ratio much higher than the primitive mantle value. Our data for acid-leached olivine separates indicate that fluid inclusions trapped in minerals have elevated $U / T h$ value. Together with experimental evidence [4], this observation is consistent with $U$ enrichment by water-rich small melt fractions ( $\pm \mathrm{Sr}$ and LREE). These fluids might be either derived from subduction processes [e.g., 5], or they may represent evolved liquids resulting from meltrock reactions in the lower lithosphere, above a mantle plume [6]. The latter hypothesis is supported by OD numerical simulation [7] of reacting porous flow involving partition coefficient of water-rich small volume melts. This results (for the most soluble elements) from coupled chromatographic effect and source effects of reactions at decreasing melt mass. If time-integrated, this U enrichment could represent an efficient way to generate enriched isotopic reservoirs.

References: [1] Jochum K. P. et al. (1989) Nature, 340, 548550. [2] lonov et al. (1995) Chem. Geol., 120, 275-294. [3] Alard et al. (1996) C. R. Acad. Sci. Paris, 323, 763-770. [4] Brenan et al. (1995) GCA, 59, 3331-3350. [5] Rosenbaum et al. (1997) Geology, 25, 77-80. [6] Bedini et al. (1997) EPSL, submitted. [7] Vernieres et al. (1997) JGR, submitted.

RARE-EARTH-ELEMENT ANOMALIES IN THE DÉCOILEMENT ZONE OF THE NANKAI ACCRETIONARY PRISM, JAPAN: EVIDENCE OF FLUID FLOW? J. L. Alexander ${ }^{1.2}$, K. T. Pickering1, and E. H. Bailey ${ }^{3}$, 'Department of Geological Sciences, University College London, Gower Street, London, WC IE 6BT, UK, '2Department of Mineralogy, The Natural History Museum, Cromwell Road, London, SW7 5BD, UK, ${ }^{3}$ Department of Physiology and Environmental Science, The University of Nottingham, Sutton Bonington Campus, Leicestershire, LE12 SRD, UK.

Rare-earth-element (REE) pattems play a key role in understanding the provenance of mudrocks. However, there is uncertainty about the extent to which REE are mobile in sediments, and the effect this has on the provenance signal. This study focuses on Miocene to Pliocene hemipelagic muds from Ocean Drilling Pro- 


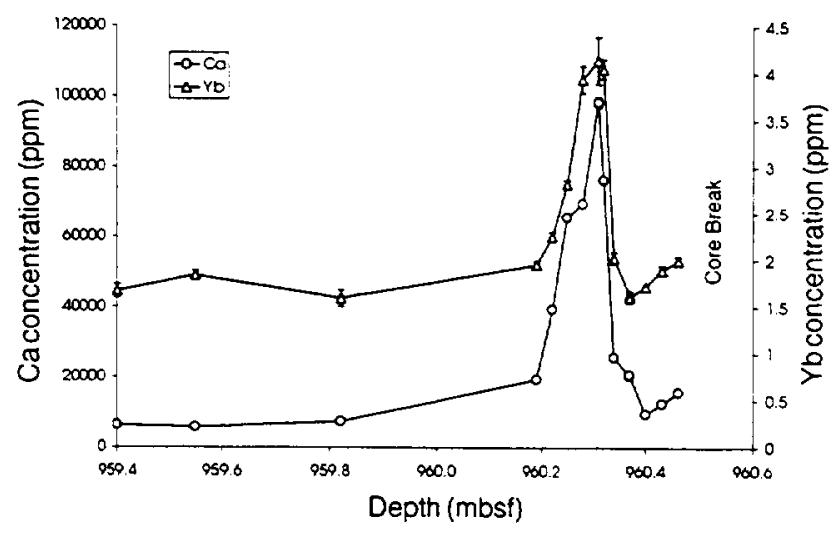

Fig. 1. Graph of $\mathrm{Ca}$ and $\mathrm{Yb}$ concentrations vs. depth. showing the HREE anomaly near one of the core breaks.

gram (ODP) Site 808 , drilled in the toe of the Nankai accretionary prism, southeastern Japan [1].

The hemipelagic muds are composed mainly of quartz, feldspar, and mixed-layer clays. Most have a typical shale REE composition, but several samples are enriched in REE. Four of these, found at depths between $1025 \mathrm{mbsf}$ and $1100 \mathrm{mbsf}$, are associated with hydrothermal deposits, rich in $\mathrm{Mn}$ (up to $18 \% \mathrm{MnO}$ ).

The décollement is located between $945.0 \mathrm{mbsf}$ and $964.3 \mathrm{mbsf}$. Most samples have REE, trace-, and major-element concentrations similar to the other hemipelagic muds, despite being brecciated. However, there is a heavy REE enrichment in some samples from the décollement that are close to breaks in core recovery (Figs. 1 and 2). These anomalies are not the result of contamination, changes in lithology, or heavy minerals. They are associated with an enrichment in $\mathrm{Ca}$, which is present as calcite, and to a lesser extent with Mn. During selective leaching, a large proportion of HREE in the anomalous samples was extracted at the same time as calcite.

The enrichment of HREE in otherwise typical mudrocks suggests that they have been transported to the décollement in fluids, where they were co-precipitated with calcite. A potential source for these REE is the series of umbers and hydrothermal deposits, from

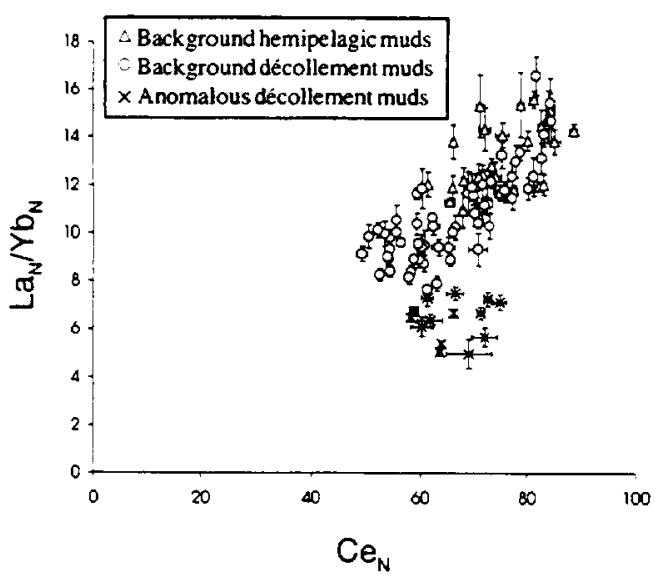

Fig. 2. Graph of $\mathrm{La}_{N} / \mathrm{Yb}_{\mathrm{N}}$ vs. Ce $\mathrm{Ce}_{\mathrm{N}}$, showing the different fractionation trends of anomalous décollement mudrocks. where HREE may be preferentially leached. Thermodynamic modeling indicates that such a fractionation in pore fluids is probable.

The location of the anomalies at discrete levels near core breaks suggests that these breaks may have been conduits for fluid flow, but the shape of the anomalies implies that they are not in equilibrium with present-day fluids (Fig. 1). It is possible that carbonate-rich fluids are pulsed along the décollement, as suggested by [2].

References: [1] Shipboard Scientific Party (1991) in Proc. Ocean Drilling Program, Initial Repts., 131 (A. Taira et al., eds.), pp. 71-269. [2] Sample J. C. (1996) Geology, 10, 897-900.

RARE EARTH ELEMENTS IN JAPANESE MUDROCKS: THE INFLUENCE OF PROVENANCE. J. L. Alexander ${ }^{1.2}$, K. T. Pickering ${ }^{1}$, and E. H. Bailey ${ }^{3},{ }^{1}$ Department of Geological Sciences, University College London, Gower Street, London, WCIE 6BT, UK, 'Department of Mineralogy, The Natural History Museum, Cromwell Road, London, SW7 5BD, UK, '3 Department of Physiology and Environmental Science, The University of Nottingham, Sutton Bonington Campus, Leicestershire, LE12 5RD, UK.

The Boso Peninsula lies to the east of Tokyo Bay, Japan. It comprises a thick sequence of Miocene to Pliocene sediments, deposited during the development of the Japanese Island Arc, while the Pacific and Philippine Sea plates were being subducted. This study focuses on samples from the Amatsu Formation, a sequence of middle- to upper-Miocene hemipelagic mudrocks. These sediments are sandy in places, particularly toward the top of the sequence, and are intercalated with thin layers of tuff.

Samples from different locations within the sequence were analyzed for major elements using ICP.AES and for rare earth elements (REE) using ICP-MS. The provenance of the sediments was determined using major elements, plotted on the discriminant diagrams of Roser and Korsch [1]. In general, mudrocks from locations low in the sequence plot in the "intermediate provenance" field (dominantly andesitic detritus), whereas those from higher in the sequence plot in the "mafic provenance" field (basaltic and andesitic detritus). This trend is also discemable at the smaller scale of a 120-m transect, and across major faults in the sequence. Within the faults themselves, the patterns are mixed.

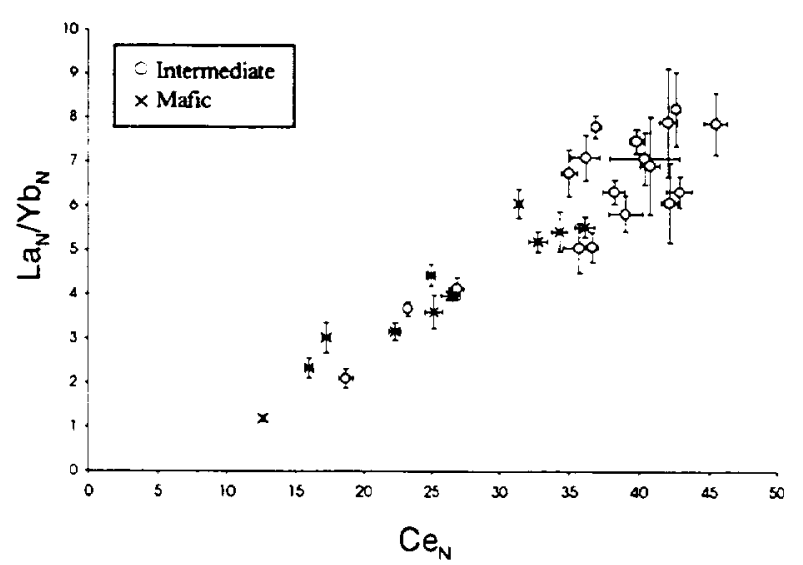

Fig. 1. Graph of $\mathrm{La}_{N} / \mathrm{Yb}_{N}$ vs. Ce $\mathrm{e}_{N}$. showing the relationship between provenance and $R E E$ fractionation. 
REE patterns for the same series of samples show a strong relationship with provenance (Fig. 1). Most of the samples plotting in the "intermediate provenance" field have chondrite-normalized $\mathrm{La}_{\mathrm{N}} / \mathrm{Yb}_{\mathrm{N}}$ ratios of $>5$ and $\mathrm{Ce} \mathrm{N}_{\mathrm{N}}$ values of $>35$, while those plotting in the "mafic provenance" field have $\mathrm{La}_{\mathrm{N}} / \mathrm{Yb}_{\mathrm{N}}$ ratios of $<5$ and $\mathrm{C} \mathrm{e}_{\mathrm{N}}$ values of $<35$. A few samples do not conform to this trend, but most can be explained by other factors. There is also some overlap of samples close to the borders between fields on the discriminant diagrams. However, there does not appear to be any redistribution of REE by fluids, e.g., along fault planes.

The trends in REE fractionation with provenance seen here are in agreement with those discussed by Bhatia [2]. However, there are very few similar studies with which to compare this work. Although the relationship between provenance and REE fractionation appears to be strong, it should be remembered that the study area is small and the results may not be generally applicable. Similar studies have been criticized due to uncertainties in provenance and the small datasets used [3]. Further work on a large selection of different mudrock suites of known provenance is necessary.

References: [1] Roser B. P. and Korsch R. J. (1988) Chem. Geol., 67, 119-139. [2] Bhatia M. R. (1985) Sedimentary Geol.,45, 97-113. [3] McLennan S. M. (1989) in Geochemistry and Mineralogy of Rare Earth Elements (B. R. Lipin and G. A. McKay, eds.), pp. 169-200, Rev. Mineral., 21, 169-200.

THE EVOLUTION OF SEAWATER STRONTIUM ISOTOPES IN THE LAST HUNDRED MILLION YEARS: REINTERPRETATION AND CONSEQUENCES FOR EROSION AND CLIMATE MODELS. C. J. Allègre, J. Gaillardet, S. Levasseur, L. Meynadier, and P. Louvat, Institut de Physique du Globe-CNRS, URA 1758, UFR Sciences de la Terre, Université Paris VII Denis Diderot, 4 Place Jussieu, 75252 Paris Cedex 05, France (allegre@ipgp.jussieu.fr).

The current popular interpretation of the ${ }^{87} \mathrm{Sr} /{ }^{86} \mathrm{Sr}$ evolution curve of the Tertiary period is to correlate the increase of Sr isotopes with the Himalayan Orogeny. This interpretation seems wrong because it completely ignores (1) carbonate recycling, (2) modern data on rivers on $\mathrm{Ca}, \mathrm{Sr}$, and $\mathrm{Sr}$ isotopes, and (3) the constraints given by ${ }^{187} \mathrm{Os} /{ }^{186} \mathrm{Os}$.

Using geochemical results on modern rivers and the decomposition of the different sources obtained by inversion of the budget equations on multielements $[1,2]$, we have computed the contribution of the different sources on the ${ }^{87} \mathrm{Sr} /{ }^{86} \mathrm{Sr}$ budget on seawater as well as the isotopic composition of each of them.

We find that the silicate component in rivers has a $\mathrm{Sr}$ isotopic composition of 0.720 and that the carbonate weathering over silicate weathering ratio is 1.9 for $\mathrm{Sr}$ and 9 for $\mathrm{Ca}$. However, a major ambiguity exists about the source of the mantle component between erosion of volcanics and hydrothermal circulation at ridge crest. This ambiguity can be solved by the use of Os isotopes. Using the Sr-Os correlation, we can complete the different evolutions that cause the Sr-isotope evolution curve.

Most of the ${ }^{87} \mathrm{Sr} /{ }^{86} \mathrm{Sr}$ evolution is created by the slowing of the spreading rate from $100 \mathrm{Ma}$ to the present. The effect of the Himalaya (if any) is only visible for the last $12 \mathrm{~m} . \mathrm{y}$.

Tuming to climate, we confirm the idea that chemical erosion does not depend on climate but mostly on altitude and lithology.
This is supported by the studies on basalt in islands [3] as well as granitic and sedimentary areas [2].

All these studies have important consequences for the regulation of $\mathrm{CO}_{2}$ in the geological timescale. Most of the regulation can be done through aerial volcanism, which, on one hand, releases $\mathrm{CO}_{2}$ into the atmosphere and, on the other hand, extracts $\mathrm{CO}_{2}$ by erosion of $\mathrm{Ca}, \mathrm{Mg}$ silicates and increases the $\mathrm{CO}_{2}$ content of the rain.

References: [1] Negrel et al. (1993). [2] Gaillardet et al. (1996). [3] Louvant et al. (1996).

FROM PAT TO TATS: THE LEAD ISOTOPE LEGACY IN THE STUDIES OF THE CONTINENTAL CRUST-UPPER MANTLE SYSTEM. C. J. Allègre, G. Manhès, B. Dupré, B. Hamelin, O. Brevard, C. Gariepy, C. Göpel, R. Doucelance, and S. Alves, Institut de Physique du Globe-CNRS, URA 1758, UFR Sciences de la Terre, Université Paris VII Denis Diderot, 4 Place Jussieu, 75252 Paris Cedex 05, France (allegre@ipgp.jussieu.fr).

The work done by Patterson and Tatsumoto on $\mathrm{Pb}$-isotope analysis of seven $\mathrm{K}$ feldspars of granites of various ages and the effect of increasing J-type granites with time was the starting point for modeling the growth of the continental crust.

When Gast et al. discovered the $\mathrm{Pb}$-isotope heterogeneity in the mantle, Tatsumoto's group immediately demonstrated an important complement there: they discovered that MORBs were completely different from OIBs in $\mathrm{Pb}$-isotope signatures. At the same time, they defined a mantle isochron with an age of around $2 \mathrm{Ga}$. These studies gave the starting signal for all the work done since in the geochemical exploration of the crust mantle system.

Passing through time and the various contributions of many people, including Armstrong, Wasserburg, Dole and Zartman, Hart, Tilton, O'Nions, Tera, and others, we want to concentrate on the present situation with two specific points of view.

First, we have studied the evolution of the continental crust through time. To do that we use the $(I, S)$ terminology of Manhès and

$$
\left(\frac{208^{*}}{206^{*}}, \frac{207^{*}}{206^{*}}\right)
$$

the diagram of Dupré. We then describe the kinetics of continental growth as well as the decay of the recycling proportions through time.

The second approach is to analyze the OIBs. The study using the $\mathrm{Pb}$ information from one archipelago permits us to extract the source signal from the local mixing.

The treatment of the source signal allows us to determine the systematics of the origin of OIBs and the way they contribute to the signature of the upper mantle. In fact, the comparison of the information within the $\mathrm{Pb}$ isotope system itself is almost the same as the high isotopic systems $\mathrm{Hf}, \mathrm{Os}, \mathrm{Sr}, \mathrm{Nd}, \mathrm{He}$, and $\mathrm{Pb}$.

With the continued improvement in the accuracy and precision

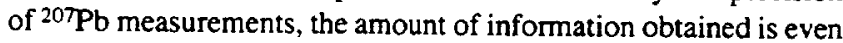
higher.

GEOCHRONOLOGY OF THE JACK HILLS DETRITAL ZIRCONS BY PRECISE URANIUM-LEAD ISOTOPEDILUTION ANALYSIS OF CRYSTAL FRAGMENTS. 
Yu. V. Amelin, Jack Satterly Geochronology Laboratory, Royal Ontario Museum, 100 Queen's Park, Toronto, Ontario M5S 2C6, Canada (yuria@rom.on.ca).

Uranium-lead ages were determined for 12 whole grains and 45 fragments from another 14 grains of detrital ircon from the Jack Hills metaconglomerate, Western Australia, using isotope-dilution thermal ionization mass spectrometry in combination with air abrasion and HF leaching. The results of this study demonstrate that the grain fragmentation method can be used to determine precise crystallization ages of detrital zircons, despite the variable degree of discordance between grain domains, and to study complex internal zircon structures. Air-abrasion treatment of crystal fragments removes internal zones affected by metamictization and $\mathrm{Pb}$ loss, and is more efficient when applied to grain fragments rather than whole grains.

The data indicate the presence of two groups of detrital zircons with ages of 3.31-3.52 Ga ("young group") and 3.82-4.11 Ga ("old group"), in agreernent with earlier SHRIMP and direct $\mathrm{Pb}$ evaporation data for zircon from the same sample. The zircons of the "old group" show more complex internal age distributions, but still provides clear evidence for extensive zircon growth during two discrete periods of $3.96-4.00 \mathrm{Ga}$ and $4.02-4.03 \mathrm{Ga}$, in addition to older ( $>4.1-\mathrm{Ga}$ ) episodes. This evidence is substantiated by analyses of two fragments with concordant U-Pb systems at $4026 \pm 3 \mathrm{Ma}$ and $3982 \pm 6 \mathrm{Ma}$. Precise crystallization ages of detrital zircons in the "young group," determined by multiple fragment analyses, are compared with published ages of Archean rocks in the Narryer Gneiss Complex. This comparison shows that the sources of sediments are distinct from the rocks presently exposed in the area.

IRIDIUM IN THE OCEANS. A. D. Anbar ${ }^{1}$ and G. J. Wasserburg2, 'Department of Earth and Environmental Sciences, University of Rochester, Hutchison Hall 227, Rochester NY 14627, USA (anbar@earth.rochester.edu), 2Division of Geological and Planetary Sciences, Mail Stop 170-25, California Institute of Technology, Pasadena CA 91125, USA (isotopes@gps.caltech.edu).

Iridium has been measured in a vertical profile in the open Atlantic Ocean by negative thermal ionization mass spectrometry (NTIMS), following the clean chemical separation of Ir from 4-kg samples. We have previously used NTIMS to study Ir in the Baltic Sea, the Baltic rivers, and the Pacific Ocean [1]. The methods are described in detail elsewhere [2]. The data presented here include the first determinations of Ir in seawater below $1000 \mathrm{~m}$, and allow a comparison of the behavior of Ir in different ocean basins.

The Atlantic Ocean was sampled in May 1996 at the BATS site $\left(31^{\circ} 50^{\prime} \mathrm{N}, 64^{\circ} 10^{\prime} \mathrm{W}\right)$. Samples were collected during a single cast using PVC Niskin bottles with a Teflon-coated inner spring, lowered on a steel cable. After recovery, all samples were acidified by adding $2 \mathrm{ml}$ of $12 \mathrm{~N} \mathrm{HCl}$ to each liter of seawater and storing in acidwashed polyethylene bottles.

Data from the Atlantic and Pacific Oceans are presented in Fig. 1. In the open ocean, the concentration of Ir is essentially depthindependent below the mixed layer. The concentrations in the deep sea are much more uniform than in shallower waters, brackish waters, or rivers (Fig. 2). The $2 \sigma$ deviation of the data below $500 \mathrm{~m}$ is within the analytical uncertainty from counting statistics and

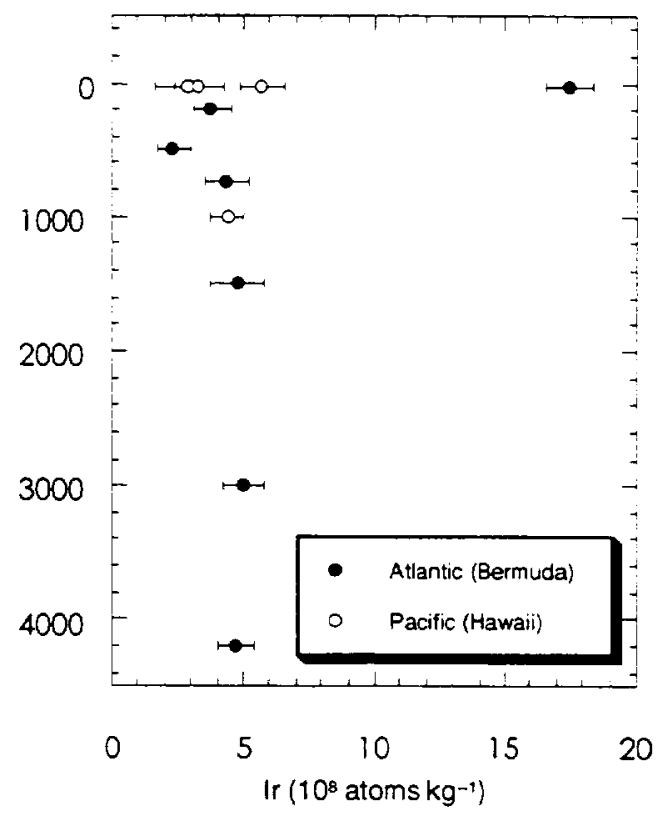

Fig. 1. Iridium in the open ocean.

uncertainties in the chemical blank [2]. The average Ir concentration in the Atlantic Ocean at these depths is $4.9 \pm 0.5 \times 10^{8}$ atoms kg-1, identical to the concentration determined at $1000 \mathrm{~m}$ in the Pacific $\left(4.4 \pm 0.6 \times 10^{8}\right.$ atoms $\left.\mathrm{kg}^{-1}\right)$.

The small but significant variations in shallower water may be evidence of minor redistribution resulting from adsorption of Ir to particles, or uptake of Ir in the marine biological cycle. The PGEs have a high affinity for organisms and organic compounds in natural waters [3-5]. The enrichment in the Atlantic mixed layer could result from dissolution of eolian dust or micrometeorites, both of

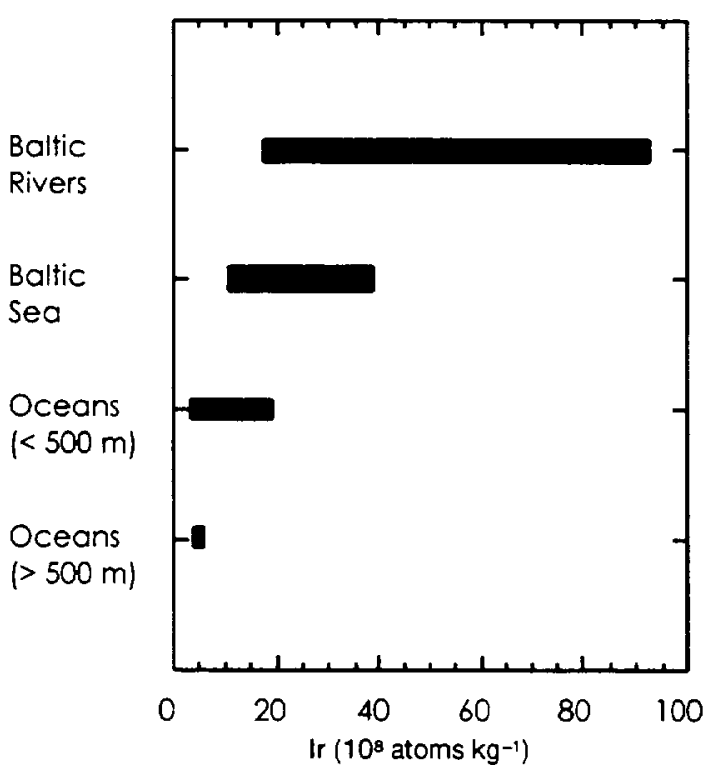

Fig. 2. Iridium concentration ranges. 
which are significant sources of Ir to the oceans. The difference between the concentrations in the Pacific and Atlantic mixed layers suggests that eolian inputs are the cause.

Previously we found that the dominant dissolved Ir source may be riverine rather than extraterrestrial infall, and estimated an ocean residence time of $2 \times 10^{3}-2 \times 10^{4}$ yr based on the Ir concentration in the Pacific Ocean, the burial flux of Ir in deep-sea sediments, and the riverine Ir flux [1]. Therefore, Ir is expected to be fairly uniformly distributed with depth in the oceans, and between ocean basins. The data from the Atlantic Ocean confirm this prediction.

Acknowledgments: Division Contribution No. 5814 (964).

References: [1] Anbar A. D. et al. (1996) Science, 273, 1524. [2] Anbar A. D. et al. (1997) Anal. Chem., in press. [3] Wells M. C. et al. (1988) GCA, 52, 1737. [4] Wood S. A. et al. (1994) GCA, 58, 625. [5] Li J. et al. (1990) Environ. Sci. Tech., 24, 1038.

THE HELIUM-HEAT-LEAD PARADOX. D. L. Anderson, Seismological Laboratory, California Institute of Technology, Pasadena CA 91125 , USA.

The isotope ratio ${ }^{3} \mathrm{He} /{ }^{4} \mathrm{He}(\mathrm{R})$ plays a central role in geochemical models of mantle evolution that involve an undegassed lower mantle, rich in the primordial isotope ${ }^{3} \mathrm{He}$. A large primordial volatile-rich reservoir is inconsistent with high-temperature accretion and with recent estimates of crustal and bulk Earth chemistry and cooling rates. High $\mathrm{R}$ can altematively reflect high integrated ${ }^{3} \mathrm{He} /(\mathrm{U}, \mathrm{Th})$ ratios, or low ${ }^{4} \mathrm{He}$ abundances, as expected in refractory portions of the upper mantle. I show that high $\mathbf{R}$ materials are deficient in radiogenic ${ }^{4} \mathrm{He}$ and are not enriched in ${ }^{3} \mathrm{He}$. The seemingly primitive noble gases in "hotspot" magmas are apparently derived from $\mathrm{CO}_{2}$ rich gases formed by degassing of MORB and stored in fluid inclusions in refractory (low-U) mantle. The low $R$ in MORB compared to some midplate volcanos is related to the " $\mathrm{Pb}$ paradox," which is actually the "U paradox," and the He-heat flow paradox. High- $R$ basalts are associated with recent midplate magmatism, or the earliest products of such magmatism. They are related to new lithospheric cracks, not an undegassed primordial lower mantle. High $\mathbf{R}$ are consistent with an extensively degassed volatile-poor planet and therefore with accretional models and other geochemical data. There is no evidence that the Earth is a gas-rich body or has a primordial reservoir.

MORBs have high ${ }^{3} \mathrm{He}^{22} \mathrm{Ne}$ and ${ }^{4} \mathrm{He} / 21 \mathrm{Ne}$ ratios compared to OIBs and compared to solar or production ratios, indicating that MORBs are degassed and that the degassed volatiles are tapped by OIBs. Carbon isotopes suggest a common source of MORBs and OIBs prior to degassing. Cerium/lead, U/Nb, and ${ }^{206} \mathrm{~Pb} / 204 \mathrm{~Pb}$ also suggest a common source.

The ${ }^{238} \mathrm{U} / 4 \mathrm{He}$ age of MORB is $\sim 1-2 \mathrm{Ga}$ and, allowing for degassing, the age may be much older. The ${ }^{238} \mathrm{U} /{ }^{206} \mathrm{~Pb}$ age of the MORB mantle is $4.5 \mathrm{Ga}$. The ratio of the $\mathrm{He}$ and $\mathrm{Pb}$ ages is about the same as implied by MORB degassing and the He-heat paradox. Carbon isotopes and "popping rock" indicate about $85 \%$ degassing of average MORBs. $\mathrm{CO}_{2}$-rich fluid cannot wet grain boundaries and they are therefore trapped in the upper mantle, while degassed melts can escape. Trapping of $\mathrm{CO}_{2}$ and $\mathrm{He}$ in the shallow mantle explains various paradoxes: the He-heat-flow paradox and the missing $C$ paradox. $\mathrm{A} \mathrm{CO}_{2}$-rich shallow mantle is predicted, explaining widespread carbonatitic metasomatism in continental rifts and oceanic islands.
Most of the mantle is extensively degassed. The gas that is trapped in the shallow mantle evolves along a different $R$ track than MORBs, and is tapped by tectonic fracturing and magma fracturing at midplate locations.

\section{CONTROL OF DISTRIBUTION PATTERNS OF HEAVY} METALS IN GANGA PLAIN AROUND KANPUR REGION, INDIA, BY FLUVIAL GEOMORPHIC DOMAINS. A. A. Ansari' ${ }^{1}$ I. B. Singh ${ }^{2}$, and H. J. Tobschall ${ }^{3}$, 'Institute of Geology and Mineralogy, Chair of Applied Geology, Schlossgarten 5, D-91054 Erlangen, Germany (aansari@geol.uni-erlangen.de), 2Department of Geology, University of Lucknow, Lucknow-226007, India, 3Institute of Geology and Mineralogy, Chair of Applied Geology, Schlossgarten 5, D-91054 Erlangen,Germany (htobscha@geol.unierlangen.de).

Ganga Plain is a large alluvial tract formed in response to the development of Himalaya. Because of its setting in front of the rising Himalayan chain, a huge sediment load is brought into the plain that is redistributed by fluvial processes. Heavy metal loads from various industrial and urban activities are disposed of into the streams and surfaces of this plain, and are remobilized and redistributed by sedimentological and hydrological processes operating therein. These processes regulate the extent of heavy metal pollution. This plain is one of the most densely populated regions of the world, and the main resources are agriculture, which depends heavily on water.

The plain shows a majority of characteristic fluvial landforms, i.e., fluvial channels of various types and dimensions, terraces, fans, ponds, and lakes.

The area under study is located in the southern part of the Central Gangetic Plain and shows three main regional geomorphic surfaces: active flood plain surface $\left(T_{0}\right)$, river valley terrace $\left(T_{1}\right)$, and upland terrace surface $\left(\mathrm{T}_{2}\right)$. These surfaces have their own characteristic features and control the distribution patterns of heavy metal pollutants in the plain.

Incorporating the heavy metal contents in sediments and soils into the geomorphological settings, hydrological characteristics (monsoon rains) of Ganga Plain around Kanpur region, five distinctive geomorphic-geochemical domains are identified: (1) Loni River domain, (2) Ganda Nala domain, (3) Ganga River domain, (4) sewage network domain, and (5) Pandu River domain.

These domains are independent operating systems that have their own characteristic channel and hydraulic systems that control the mobilization and distribution of heavy metal pollutants in the area.

As an example, in streams of the sewage network domain, there are increased concentrations of heavy metals in the sediments in

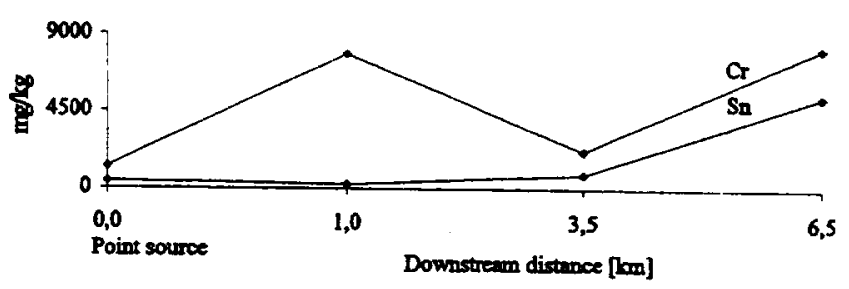

Fig. 1. Increasing concentrations of $\mathrm{C}_{\mathrm{r}}$ and $\mathrm{Sn}$ downstream from the point sources in the sewage network domain. 
parts far downstream, at a considerable distance from the point sources (Fig. 1). This is due to the presence of several channel sinks within the streams that cause heavy metals to accumulate in these geomorphic sinks.

Delineation and identification of these geomorphic-geochemical terrains help in understanding the geochemical behavior and pathways of pollutants in sediments and soils including the extent and nature of anthropogenic impact. This model of geomorphic-geochemical terrains can be applied to other fluvial systems of the world with some modifications.

GEOCHEMICAL AND ISOTOPIC FEATURES OF FERRAR MAGMATIC PROVINCE (VICTORIA LAND, ANTARCTICA). P. Antonini ${ }^{1}$, G. Demarchi ${ }^{1}$, R. Petrini ${ }^{1}$, E. M. Piccirillo ${ }^{1}$, L. Civetta ${ }^{2}$, M. D'Antonio ${ }^{3}$, and G. Orsi ${ }^{3}$, 'Dipartimento di Scienze della Terra, Università di Trieste, Italy, ${ }^{2}$ Osservatorio Vesuviano, Napoli, Italia, ${ }^{2}$ Dipartimento di Geofisica e Vulcanologia, Università Federico II, Naples, Italy.

The Ferrar Magmatic Province (FMP) is part of the Mesozoic Gondwana low-Ti province. The FMP extends along the protoPacific margin of Gondwana from Antarctica to Tasmania, Australia, and New Zealand. The tholeiitic magmatism of FMP differs from that of the other Mesozoic CFB provinces by some affinity with calk-alkaline rocks (occurrence of orthopyroxene, high $\mathrm{SiO}_{2}$ content, high LILE/HFSE ratios, high initial Sr isotopic composition).

Lavas and sills of the southem Prince Albert Mountains (Victoria Land, Antarctica) have been analyzed for major, trace, and rare earth elements and for $\mathrm{Sr}, \mathrm{Nd}$, and $\mathrm{Pb}$ isotopes.

The studied rocks are two pyroxenes, tholeiitic-andesitic basalts and andesites (mg\# 66-13), characterized by the occurrence of orthopyroxene in the least-evolved rocks ( $\mathrm{mg} \#>50$ ).

The investigated rocks show parallel steep LREE/MREE ( $\mathrm{La}_{\mathrm{N}}$ $\mathrm{Gd}_{\mathrm{N}}=2.8-3.5$ ) and flat MREE/HREE chondrite-normalized patterns $\left(\mathrm{Gd}_{N} / \mathrm{Yb}_{\mathrm{N}}=1.0-1.2\right)$ with $\mathrm{HREE}$ contents lower than MORBs in the least-evolved rocks.

Initial $\mathrm{Sr}, \mathrm{Nd}$, and $\mathrm{Pb}$ isotopic compositions show the typical "crustal signature" of the FMP: ${ }^{87} \mathrm{Sr} /{ }^{86} \mathrm{Sr}=0.7097-0.7125 ;{ }^{143} \mathrm{Nd}$ ${ }^{144} \mathrm{Nd}=0.51230-0.51240 ;{ }^{206} \mathrm{~Pb} /{ }^{204} \mathrm{~Pb}=18.580-18.643 ; \quad 207 \mathrm{~Pb}$ ${ }^{204} \mathrm{~Pb}=15.606-15.620 ;{ }^{208} \mathrm{~Pb} / 204 \mathrm{~Pb}=38.238-38.285$. Initial ${ }^{87} \mathrm{~S} \mathrm{I} /$ ${ }^{86} \mathrm{Sr}$ ratios are positively correlated with the degree of evolution, $\mathrm{SiO}_{2}$ content, and LREE/MREE ratios, supporting the hypothesis of interactions with crustal materials during magma differentiation. AFC modeling indicates that the compositions of lower crustal enderbites of Victoria Land basement can represent a possible contaminant.

The high initial ${ }^{207} \mathrm{~Pb} /{ }^{204} \mathrm{~Pb}$ of FMP rocks are similar to those of the uncontaminated (initial ${ }^{87} \mathrm{Sr} /{ }^{86} \mathrm{Sr}<0.705$ ), low-Ti basalts of the Gondwana province (e.g., Paranà), suggesting that the $\mathrm{Pb}$-isotopic feature of FMP rocks was not significantly affected by crustal contamination.

An old ${ }^{235} \mathrm{U}$-enriched component in the mantle source explains the high initial ${ }^{207} \mathrm{~Pb} /{ }^{204} \mathrm{~Pb}$ ratios of FMP, and a depleted mantle component is required to justify their low HFSE and HREE contents.

The present data indicate for FMP a dominant lithospheric mantle source in which depleted components underwent old "metasomatic" enrichment event(s).
RARE EARTH ELEMENTS IN MARINE FINE-GRAINED SEDIMENTS FROM THE NORTHWESTERN PORTU. GUESE SHELF (ATLANTIC). M. F. Araújo', A. Gouveia'. and J.-M. Jouanneau' ${ }^{2}$ ' 'Departamento de Química, ITN, Estrada Nacional 10, 2695 Sacavém, Portugal, '2Département de Géologie et Océanographie, URA, CNRS, Univ. Bordeaux I, Avenue des Facultés, 33405 Talence Cedex, France.

The northwestem Portuguese shelf is characterized by a strong fluvial input and by the presence of two important fine-grained deposits (at the midshelf), with the largest situated near the heads of the Porto submarine canyon. Recently published works involving chemical, mineralogical, and sedimentological studies, together with accumulation rates $\left({ }^{210} \mathrm{~Pb}\right)$ and radiocarbon dating $\left({ }^{14} \mathrm{C}\right)$, have pointed out its recent origin. These publications suggest that it is an active formation still receiving material with a terrigeneous origin, probably from the discharges of the river basins.

In an attempt to understand the origin of the fine-grain-sized formation and the dispersal pathways of the riverbome material, we discuss the REE distribution in surficial sediments collected all over the deposit, in selected fragments of a core ( $3 \mathrm{~m}$ depth) collected at the sedimentary formation and in fine-grained sediments collected at the main river course draining this area. Analyses were carried out by instrumental neutron activation analysis (INAA) at the RPI in Sacavém.

Previously, some authors have pointed out the imporance of the REE distribution in estuarine and marine sediments. Piper (1974) stated that they enable us to ascertain the source of elements present in sedimentary phases, while Sholkovitz (1990) discussed the shalenormalized REE patterns of shelf and slope sediments in light REE (LREE) relative to heavy REE (HREE).

In this work we estimate the shale-normalized REE pattern of the shelf sediments from the drainage basin of the major Iberian River, which has been taken to be the major source of the sedimentary formation. Flat REE patterns suggest that the relative abundances are similar in the sediments and continental shale, pointing to a continental origin. In addition, the relative distributions of the LREE and HREE from sediments of the drainage basin and the finegrained marine sediments are calculated and compared in order to ascertain the origin of the sedimentary material.

ASPECTS OF ARC FLUXES. R. J. Arculus, Department of Geology, Australian National University, Canberra, ACT 0200 , Australia (Richard.Arculus@anu.edu.au).

The global arc magmatic mass flux is of first-order imponance. Results from the most comprehensive seismic study of an intraoceanic arc (Izu-Bonin, IB) [1] indicate a crustal growth rate (CGR) for $\sim 50 \mathrm{~m} . y$. of $100-200 \mathrm{~km}^{3} \mathrm{~km}^{-1}$ (strike length) m.y.-1, comparable to the crustal growth rate (episodic) for the neighboring backarc basin, equivalent to a global CGR of $\sim 8 \mathrm{~km}^{3} \mathrm{yr}^{-1}$ and significantly higher than the commonly cited but poorly constrained global average of $30 \mathrm{~km}^{3} \mathrm{~km}^{-1} \mathrm{~m} . \mathrm{y}^{-1}$ [2] that gives a global CGR of $1.65 \mathrm{~km}^{3} \mathrm{yr}^{-1}$. Taking the global subducted sediment flux to the mantle of $1.6 \mathrm{~km}^{3}$ $\mathrm{yr}^{-1}$ [3] allows significant to trivial continental CG to possible absolute crustal loss. Further important conclusions from the crustal velocity structure determined for the IB arc follow from the thickness $(\sim 7 \mathrm{~km})$ determined of "tonalitic" crust $\left(\mathrm{Vp} \sim 6 \mathrm{~km} \mathrm{~s}^{-1}\right)$ out of 
a total $20 \mathrm{~km}$. There is evidence that erupted felsic rocks of the IB arc are derived predominantly by fractional crystallization of mafic parent magmas. However, the expected proportions of felsic to mafic/ultramafic cumulates resulting from this process are not observed in the crustal column established by $\mathrm{Vp}<7.8 \mathrm{~km} \mathrm{~s}^{-1}$. It is likely that (1) a significant fraction of the uppermost mantle of the IB arc is ultramafic (olivine-pyroxene) cumulative rock and (2) the total magmatic flux is $>200 \mathrm{~km}^{3} \mathrm{~km}^{-1} \mathrm{~m} . \mathrm{y} .^{-1}$. Although the primary flux of magma from the mantle beneath the arc is basaltic, the overall composition of the arc crust is probably closer to andesitic as a result of subcrustal sequestration of mafic/ultramafic cumulates, and a considerable fraction of the mafic/ultramafic cumulates may be entrained (delaminated) in the advective (asthenospheric) wedge flow.

Temporally extensive studies of arc magmatism are best ascertained from ashes recovered by marine drilling. Notable results concerning the evolution of the IB-Mariana (M) systems over $\sim 48 \mathrm{~m}$.y. of history since arc inception are (1) absence of a consistent and monotonic increase in alkalinity overall; (2) an apparent steady increase in the minimum $\mathbf{K}$ content of the Mariana magmas; (3) a change in comparative fertility of mantle wedge sources in the IB arc from relatively fertile to refractory subsequent to backarc (Shikoku Basin) formation; (4) absence of such an effect in the M arc, where more extensive backarc spreading has occurred; $(5)$ the appearance of alkaline compositions in the $\mathrm{M}$ arc, related to one or more of (a) arc renaissance subsequent to initial stages of backarc rifting, (b) tapping of a long-lived wedge heterogeneity along the arc strike, or (c) first subduction of distinctive high- $\mu$ sediments; and (6) the overwhelming predominance of tholeiitic magmas in the IBM systems, based on analyses of glass shards only.

References: [1] Suyehiro et al. (1996). [2] Reymer and Schubert (1984). [3] von Huene and Scholl (1991).

\section{GENERAL KINETIC MODEL FOR DOLOMITE PRECIPI- TATION RATE WITH APPLICATION TO THE SECULAR HISTORY OF SEAWATER COMPOSITION. R. S. Arvidson and F. T. Mackenzie, Department of Oceanography, University of Hawai'i, Honolulu HI 96822, USA (arvidson@soest.hawaii.edu).}

Despite much evidence of the importance of kinetics in controlling the formation of sedimentary dolomite, there is also a general perception that the study of dolomite reactions at lower temperatures is not feasible in the laboratory. This notion rightly derives from the observed difficulty in forming dolomite in experiments of reasonable duration through batch reaction of $\mathrm{CaCO}_{3}$ at temperatures less than $\sim 200^{\circ} \mathrm{C}$. The slow rate that attends experiments at lower temperatures renders detection of product phases (typically through powder XRD) difficult at a low extent of reaction. Additional problems arise from the difficulty in measuring in situ solution properties, the lack of aqueous models appropriate to the high solute concentrations of these experiments, the difficulty in estimation of surface area terms in epitaxial crystal growth, the necessity of performing multiple experiments under identical conditions to achieve a single rate measurement, and the resolution of the relationship of phases observed under experimental conditions with those that appear in sediments and the rock record. Most importantly, there is a poor understanding of the relationship between reaction rate and solution composition, compared with that available for minerals such as quartz and calcite.

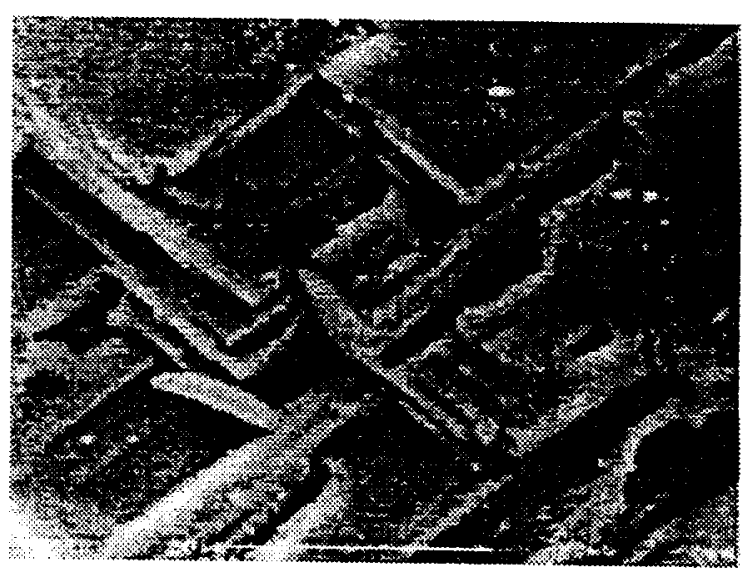

Fig. 1. Stepwise growth of synthetic dolomite in syntaxial continuity with original seed material. SEM at $2000 \times$ magnification, total horizontal field of view $-60 \mu \mathrm{m}$.

We present new data from a series of experiments that measure the steady-state rate of dolomite precipitation as a function of temperature and solution composition. These measurements were conducted over a range of moderate temperatures using a seeded flow reactor designed to measure slow rates by analysis of reacted fluid chemistry. The advantages of this experimental approach include the ability to vary experimental conditions within a single reactor run and to measure syntaxial crystal growth in dilute solutions having relatively low supersaturations (Fig. 1). Solution analyses are used to calculate rates and to estimate in situ saturation state through an aqueous model that permits extrapolation to higher temperature. Rate measurements and saturation state estimates are then used to calculate Arrhenius rate constants for the overall precipitation reaction. By alternately fixing and varying chemical composition and temperature respectively we were able to solve for the free parameters (activation energy, reaction order, and frequence) in a simple expression that relates the measured rate to the distance from equilibrium:

$$
\log r=-\frac{\varepsilon_{A}}{2.3 R T}+\log A+n \log (\Omega-1)
$$

- Although nonmechanistic in form, similar relations have been used with success to model both precipitation and dissolution rates for other carbonate minerals.

The combination of high activation energy $\left(\varepsilon_{A}\right)$ and order $(n)$ implies a strong sensitivity to environmental shifts in temperature and saturation state $(\Omega)$. We explore this sensitivity through several scenarios for the past $1 \varepsilon_{\wedge}$ m.y. This effort is constrained by the variations in the flux of sedimentary dolomite implied by mass-age relations in the rock record, the range of potential temperature and $\mathrm{pCO}_{2}$ variations over this interval, and the phase boundaries of carbonate minerals. We employ a general mass-balance model in concert with the parameters from our rate equation to estimate apparent changes in seawater chemistry.

HIGH-PRECISION URANIUM-SERIES CHRONOLOGY FROM SPELEOTHEMS. Y. Asmerom 1 , J. L. Banner ${ }^{2}$, J. A. Hoff $^{3}$, E. Ito ${ }^{3}$, and R. L. Edwards ${ }^{3}$, 'Department of Earth and 
Planetary Sciences, University of New Mexico, Albuquerque NM 87131, USA (Asmerom@unm.edu), 2Department of Geological Sciences, University of Texas, Austin TX 78712, USA, ${ }^{3}$ Department of Geology and Geophysics, University of Minnesota, Minneapolis MN 55455, USA.

Uranium-series chronology of corals, using thermal ionization mass spectrometry of $\mathrm{Th}$ and $\mathrm{U}$, has made possible an unprecedented precision in ages of climatic events, coral-terrace-based neotectonics, and the independent calibration of the ${ }^{14} \mathrm{C}$ timescale $[1,2]$. In contrast to the marine coral-based chronologic work, many short timescale continental processes lack materials suitable for precise chronology. Speleothems are one of the few exceptions that may provide fine chronology comparable to that of corals. In many cases they may have better preservation history than corals because they are more dense and remain isolated in caves without extensive exchange with water. They occur widely in very diverse climatic and tectonic settings. Stable isotope, radiogenic isotope, elemental, luminescence, and growth data have been used to constrain a variety of tectonic, climatic, and hydrologic processes.

Unlike marine carbonates, speleothems may contain a substantial amount of detrital $\mathrm{Th}$. Understanding the ${ }^{230} \mathrm{Th} /{ }^{232} \mathrm{Th}$ ratio variation of detrital Th is a crucial consideration in chronology based on continental carbonates. Recently, we reported a highresolution $\mathrm{Sr}$ isotope proxy record for Holocene paleohydrology possibly linked to major changes in tropical climate based on $U$ series dated speleothem from Barbados [3]. Here we describe the UTh data of the spaleothem in order to discuss the potential and limitations in U-series chronology of speleothems. Uranium-238 concentrations in the spaleothem varied from 0.326 to $0.836 \mathrm{ppm}$, while ${ }^{232}$ Th concentrations varied generally from $\sim 32.33$ to $0.012 \mathrm{ppb}$, with most of the samples having less than $10 \mathrm{ppb}$. The high ${ }^{232} \mathrm{Th}$ samples come from sections immediately below growth hiatuses. As expected, the spaleothem had excess ${ }^{234} U$ (measured $\delta^{234} U \sim 40$ ).

The tip of the spaleothem gave an age of $356 \pm 47(2 \sigma) \mathrm{yr}$, while a sample from the bottom, with a large amount of detrital ${ }^{232} \mathrm{Th}$ (4.39 ppb), gave an age of $5412 \pm 168$ yr. A cleaner chip from the bottom ( ${ }^{232} \mathrm{Th}=0.013 \mathrm{ppb}$ ) gave an age of $5298 \pm 67 \mathrm{yr}$. Typical age precision is in the range of \pm 50 yr $(2 \sigma)$. The precision in age primarily reflects (1) analytical uncertainties associated mostly with the measurement of ${ }^{230} \mathrm{Th}$ and (2) uncertainties due to initial ${ }^{230} \mathrm{Th}$ correction, in particular of samples with a large amount of detrital Th. Analytical precision may be improved by using larger sample sizes than we did $(-300 \mathrm{mg})$. However, the gain in precision is at the cost of age accuracy due to sampling age averaging, unless sampling can be done with a computer-controlled microdrill. We constrained initial ${ }^{230} \mathrm{Th} /{ }^{232} \mathrm{Th}$ by obtaining two isochrons, one from a layer with low detrital Th and another with high detrital Th. In addition, we dated growth layers on both sides of two growth hiatuses. The initial ${ }^{230} \mathrm{Th} /{ }^{232} \mathrm{Th}$ correction value for the dirty (older) side that results in age crossover to the age of the younger, cleaner side is a maximum ${ }^{230} \mathrm{Th} / 232 \mathrm{Th}$ value. Our data showed that the samples have at least two detrital Th components, one associated with the dirty layers having a low initial ${ }^{230} \mathrm{Th} / 232 \mathrm{Th}$ atomic ratio $\sim 2.5 \mathrm{ppm}$, and a second component associated with clean layers having a ${ }^{230} \mathrm{Th} /{ }^{232} \mathrm{Th}$ ratio $\sim 20 \mathrm{ppm}$. The low ${ }^{230} \mathrm{Th} / 232 \mathrm{Th}$ ratio of the high-Th component is consistent with Th derived from dust that has a high ${ }^{232} \mathrm{Th} / 238 \mathrm{U}$ ratio ( $\kappa$-value) as a result of long-term depletion of $U$ due to weathering [4]. The second component, with a ${ }^{230} \mathrm{Th}$
${ }^{232} \mathrm{Th}$ ratio $\sim 20 \mathrm{ppm}$ corresponding to an equilibrium $\kappa$-value of 0.84 -much lower than the average upper crustal $\kappa$-value of 3.8 4.2 [4]-most likely reflects the Th contribution from detrital carbonate.

The problem associated with initial correction of detrital Th improves markedly with age, especially for samples with ages greater than the half-life of $230 \mathrm{Th}(\sim 75 \mathrm{k} . \mathrm{y}$.), even for samples with large amounts of detrital Th. Given a closed system, continental carbonates and in particular speleothems may provide highly precise chronologic control to a variety of geologic processes.

References: [1] Bard et al. (1990) Nature, 345, 405-410. [2] Edwards et al. (1993) Science, 260, 962-968. [3] Banner et al. (1996) Geology, 1049-1053. [4] Asmerom and Jacobsen (1993) EPSL, 115, 245-256.

TRACE-ELEMENT MODELING OF AQUEOUS FLUIDPERIDOTITE INTERACTION IN THE MANTLE WEDGE OF SUBDUCTION ZONES. J. C. Ayers, Vanderbilt University, P.O. Box 105B, Nashville TN 37235, USA (Ayersj@ctrvax. vanderbilt.edu).

Recent measurements of partition coefficients for $\mathrm{Rb}, \mathrm{Th}, \mathrm{U}, \mathrm{Nb}$, $\mathrm{La}(\mathrm{Ce}), \mathrm{Pb}, \mathrm{Sr}, \mathrm{Sm}, \mathrm{Zr}$, and $\mathrm{Y}$ between peridotite assemblage minerals and $\mathrm{H}_{2} \mathrm{O}$-rich fluid $[1,2]$ enabled us to refine models of aqueous fluid transport in the deep mantle wedge of subduction zones and identify processes responsible for the unique chemical signatures of island arc basalts (IAB). Fluid released from the subducted slab may hydrate peridotite at the base of the mantle wedge and be transported to the IAB source through alternating cycles of hydration and dehydration of wedge peridotite with inter-

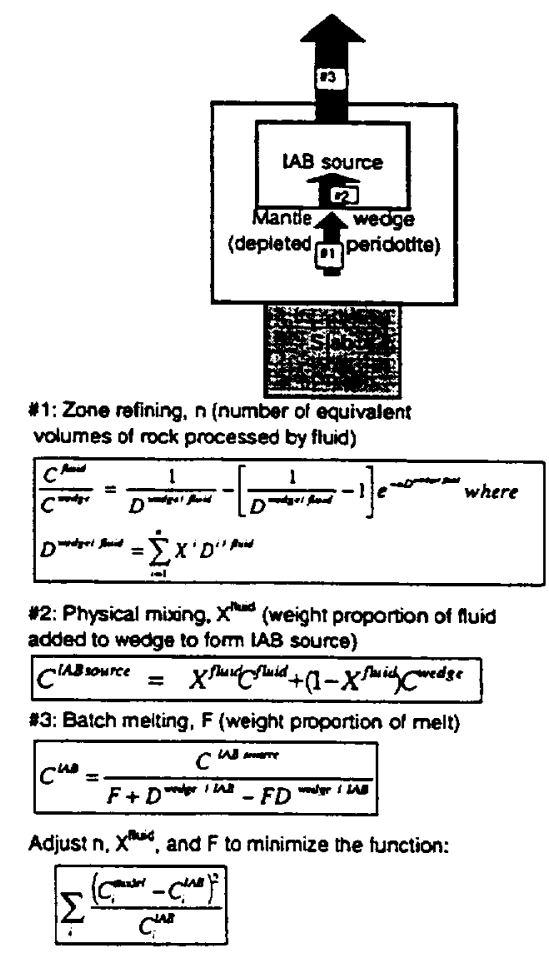

Fig. 1. 


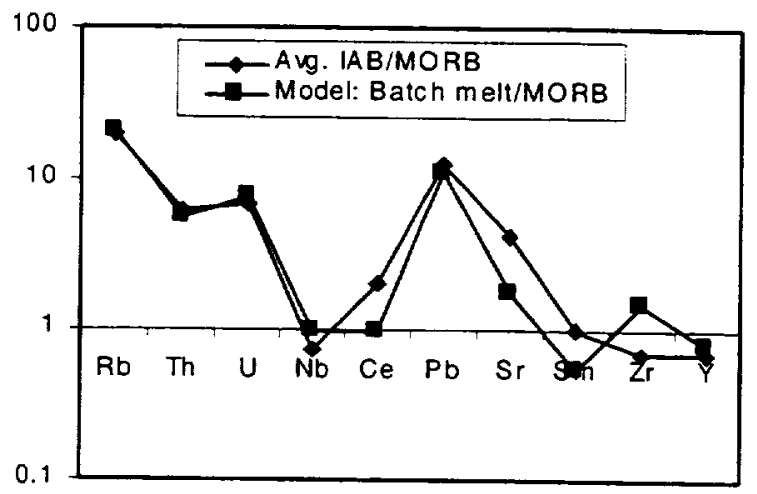

Fig. 2.

vening vertical and lateral transport. Alternatively, if hydrous minerals are not stable, fluid may flow porously through the peridotite wedge. In either case, partitioning equilibrium between peridotite and $\mathrm{H}_{2} \mathrm{O}$-rich fluid is likely to prevail. Zone refining was used to model the chemical effects of peridotite/ $\mathrm{H}_{2} \mathrm{O}$ interaction during porous fluid flow or successive dehydration/hydration reactions. Fluid composition evolves during zone refining according the parameter $n$, the number of equivalent volumes of rock processed by the fluid. As fluid moves from the slab into the wedge, equilibrium concentrations of trace elements decrease precipitously, such that trace elements become effectively immobilized at the base of the mantle wedge. Smaller fluxes of trace elements persist from the base of the wedge to the IAB source. The composition of the IAB source depends on the weight proportion of fluid added $\mathrm{X}_{\text {fluid }}$, and the composition of IAB depends on the weight proportion of melt generated during batch melting $F$. Assuming an average depleted lherzolite mineralogy of $70 \%$ olivine, $25 \%$ orthopyroxene, and $5 \%$ clinopyroxene, initial trace-element concentrations in the fluid $=0$ (no slab input other than $\mathrm{H}_{2} \mathrm{O}$ ) and in the depleted wedge from McCulloch and Gamble [3], we adjusted parameters to provide an optimal fit to the average composition of IAB, obtaining values of $\mathrm{n}=21, \mathrm{X}_{\text {fluid }}=0.072$, and $\mathrm{F}=0.032$. The average error in the fit to average IAB was $35 \%$ relative. Thus, the trace-element composition of $\mathrm{IAB}$ can be modeled with no significant input from the slab other than $\mathrm{H}_{2} \mathrm{O}$, which scavenges trace elements from the peridotite wedge before reaching the IAB source and inducing melting. The slab signature may be retained for elements such as $\mathrm{B}$ and $\mathrm{Be}$ that are highly incompatible and that have very low concentrations in the depleted mantle wedge. That $\mathrm{H}_{2} \mathrm{O}$ contents of IAB are generally $<6 \mathrm{wt} \%$ suggests that not all of the $7.2 \mathrm{wt} \% \mathrm{H}_{2} \mathrm{O}$ required to metasomatize the IAB source remains in the source to dissolve in the subsequently formed melt.

References: [1] Ayers et al. (1997) in press. [2] Brenan et al. (1995) GCA, 59, 3331-3350. [3] McCulloch and Gamble (1991) EPSL, 102, 358-374.

RAINFALL VARIATIONS IN SOUTHEASTERN AUST. RALIA OVER THE LAST 500,000 YEARS FROM SPELEOTHEM DEPOSITION. L. K. Ayliffe ${ }^{l}$, P. C. Marianelli ${ }^{1}$, K. C. Moriarty ${ }^{2}$, R. T. Wells ${ }^{3}$, M. T. McCulloch 1 , G. E. Mortimer', and J. C. Hellstrom ${ }^{1}$, 'Research School of Earth Sciences, The Australian National University, Canberra, ACT 0200, Australia (Linda.
Ayliffe@ anu.edu.au; Pyramo.Marianelli@anu.edu.au),2School of Earth Sciences, The Flinders University of South Australia, Bedford Park SA 5042, Australia, ${ }^{3}$ School of Biological Sciences, The Flinders University of South Australia, Bedford Park, SA 5042, Australia.

Australia is an arid continent and relatively minor changes in the quantity and/or distribution of rainfall can have a dramatic effect on the environment. Large-scale changes in effective precipitation in Australia over the last few hundred thousand years have been observed in the geological record. Most of what we know of past rainfall changes, however, is restricted to the last $40 \mathrm{k} . \mathrm{y}$.; comparatively little is known about the period beyond this.

Secondary cave calcite deposits (speleothems) are formed by chemical interactions between rainwater, biogenic soil $\mathrm{CO}_{2}$, and the limestone bedrock, so their formation is sensitive to changes in regional hydrological regimes. Speleothems can be accurately dated back to 500 k.y. using the TIMS (Thermal Ionization Mass Spectrometry) ${ }^{230} \mathrm{Th} /{ }^{234} \mathrm{U}$ dating method [ 1 ] and can therefore provide an extended paleoprecipitation record. The present study applies U/Th dating to 44 speleothems samples from 4 caves in the Naracoorte region of South Australia (Fig. 1) in order to document periods of speleothem growth, and hence deduce timing and likely magnitude of past precipitation events in Australia over the last 500 k.y. The dataset comprises 36 new TIMS dates and 8 previously published $\alpha$ counting dates [2].

High-precision TIMS ${ }^{230} \mathrm{Th} /{ }^{234} \mathrm{U}$ dating has enabled a temporal resolution of past rainfall events not previously attainable. Results show that the highest effective precipitation for southeastem Australia occurred during stadials and interstadials of the last four glacial-interglacial cycles. Interglacials and glacial maxima are comparatively arid. Lower regional temperatures over the continent, as well as a stronger Walker circulation, may account for the observed periods of increased effective precipitation. The results suggest that the present climatic regime of interior Australia may be suboptimum in terms of effective precipitation.

References: [1] Edwards L. R. et al. (1986) EPSL, 81, 175-

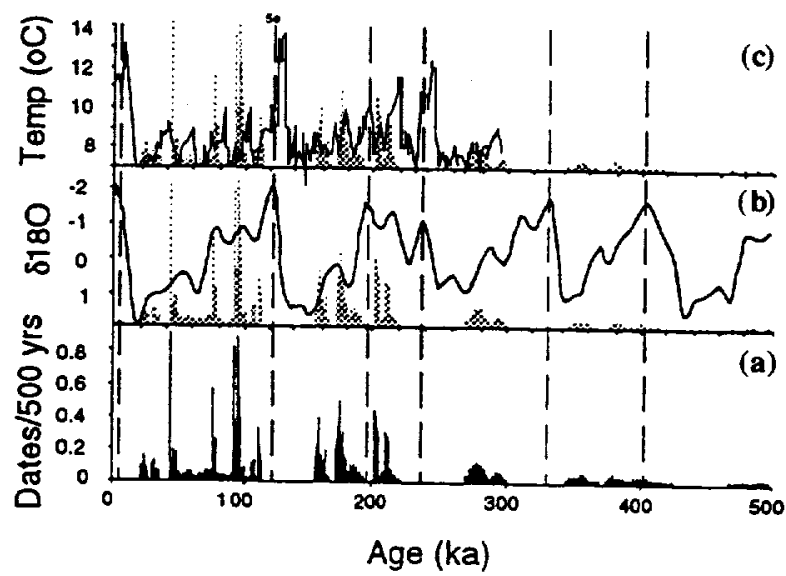

Fig. 1. (a) Cumulative frequency distribution of speleothem deposition at Naracoorte; (b) SPECMAP and speleothem record; (c) RC11-120 radiolarian temperatures [3] and speleothem record. Dashed lines indicate approximate positions of high sea-level stands. 
192. [2] Ayliffe L. K. and Veeh H. H. (1988) Chem. Geol., Isotop. Geosci. Sect., 72, 11-234. [3] Martinson D. G. et al. (1987) Quatern. Res., 27, 1-29.

THE ROLE OF WATER IN HIGH-PRESSURE FLUIDS. P. Azimov, Institute of Precambrian Geology and Geochronology, Russian Academy of Sciences, ${ }^{2}$ Makarov Emb., St. Petersburg, 199034, Russia (az@Inpi.spb.su).

Fluid composition in subduction zones is now debatable. Some researchers suggest, based on results of fluid-inclusion investigations in high-pressure rocks, that the fluids consist primarily of $\mathrm{N}_{2}$, $\mathrm{CO}_{2}$, and, in some cases, light hydrocarbons such as $\mathrm{CH}_{4}$. Other researchers believe that $\mathrm{H}_{2} \mathrm{O}$ is the main component of the fluid in subduction zones.

To ascertain the role of $\mathrm{H}_{2} \mathrm{O}$ in the eclogitic fluids, eclogites from the Marun-Keu high-pressure complex (Polar Ural, Russia) have been examined. Special attention has been paid to the mechanisms that form minerals and mineral assemblages.

Most of the assemblages, even formed under HT-HP metamorphism $\left(700^{\circ}-900^{\circ} \mathrm{C}, 13-24 \mathrm{kbar}[1]\right)$, contain hydrous minerals, so the breaking of primary magmatic plagioclase from troctolites during earlier stages of eclogitization happened according to the reaction

$$
\mathrm{An}+\mathrm{H}_{2} \mathrm{O}=\mathrm{Zo}+\mathrm{Ky}+\mathrm{SiO}_{2}(\mathrm{aq})
$$

experimentally investigated by Mattews and Goldsmith [2]. The absence of quartz among reaction products confirms the removal of silica through aqueous solution.

Numerous small $(\sim 0.010 .1 \mathrm{~mm})$ gamet grains in bimineral eclogites are located along cleavage cracks in the large $(2-6 \mathrm{~cm})$ omphacite crystals (see Fig. 1). The gamet forms "bands" along fluid-flow pathways. Such a location of garnet grains cannot be explained by simultaneous crystallization of gamet and omphacite, because garnet crystallized later than pyroxene. Hypothesis of the intergranular silicate melt cannot be applied either, since the melt at $800^{\circ} \mathrm{C}$ is $\sim 107-108 \times$ more viscous than fluid. The melt could not penetrate through cleavage cracks in omphacite grains. Hence this garnet should be crystallized from fluid.

However, nonaqueous fluids have very low solvency. The trans-

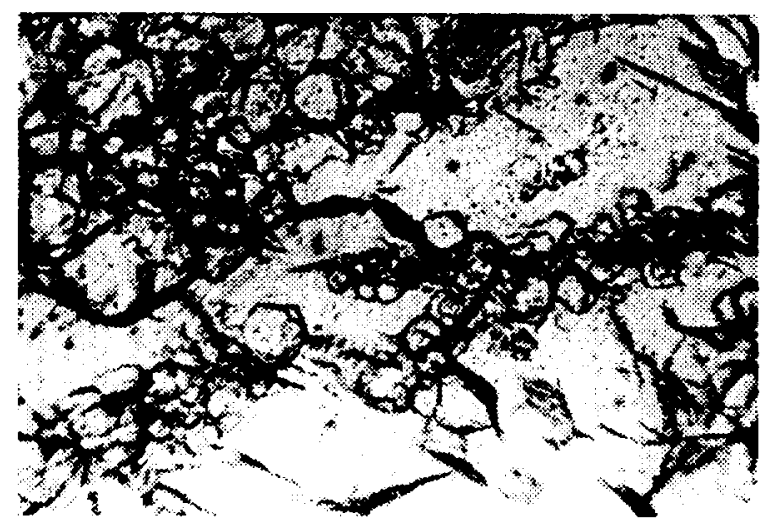

Fig. 1. Numerous gamet grains in the cleavage cracks of the large omphacite crystal. portation of large amounts of solute by $\mathrm{CO}_{2}, \mathrm{~N}_{2}$, or $\mathrm{CH}_{4}$ fluid seems doubtful.

Other processes of breaking up unsteady assemblages and forming new ones, both HT and LT (zoisitization, kyanitization. silicification, and so on), also proceeded in the presence of $\mathrm{H}_{2} \mathrm{O}$. During the latest, low-temperature stages of the eclogitic metamorphism, mass transfer was on a much larger scale than earlier. At that time numerous quartz veins and zones of silica enrichment formed. It is difficult to explain such a mass transfer by transportation with nonaqueous fluids, in which solvency is negligible.

Thus the character of mineral reactions demonstrates that both high- and low-temperature eclogitic metamorphism of the MarunKeu complex was accompanied by fluid fluxes. Transporting fluids were mainly aqueous, and intergranular silicate melt was lacking at that time.

References: [1] Udovkina (1985). [2] Mattews and Goldsmith (1984).

THE KINETIC CONDITIONS OF METAMORPHIC MINERALOGENESIS: EVIDENCE FROM MINERALS AND ASSEMBLAGES. P. Azimov ${ }^{1}$ and A. Shtukenberg ${ }^{2}$, 'Institute of Precambrian Geology and Geochronology, Russian Academy of Sciences, 2Makarov Emb., St. Petersburg, 199034. Russia (az@Inpi.spb.su), 2Department of Crystallography, Geological Faculty, St. Petersburg State University, 7-9, Universitetskaya Emb., St. Petersburg, 199034, Russia (sasha@shd.tepkom.spb.su).

The present work is aimed at the investigation of kinetic conditions of mineral growth as well as dissolution. Knowledge of those conditions (such as reaction kinetic limiting process, temporal evolution of intensive thermodynamic variables, disequilibrium degree of the system, fluid flow regime, rock deformations, nonstationarity, etc.) allows observation of regional metamorphism dynamics. That is why studies of natural mineral kinetic features are important for understanding metamorphic rock history.

The following peculiarities of mineral crystals and grains have been examined: (1) morphological: habit, euhedrity, striation, growth hillocks and steps, splitting, grain deformation; (2) anatomical: inclusions of other minerals (their composition, orientation, disposition), simple and sector zoning, twinning, mosaic fabric, optical anomalies, and deformation patterns; (3) populational: population density and grain-size distribution, grain location in host grains (aggregate).

Both experimental and computer modeling of crystal growth have been carried out. A computer model describing primary zoning for different crystal growth conditions is constructed. The formationof primary (growth) zoning, optical anomalies, and growth twinning are researched experimentally. Our interpretation of mineral crystal peculiarities is based on the results of mineral crystallization and reaction modeling (ours and that taken from the literature).

The minerals from Riphean eclogites of the Marun-Keu highpressure complex (Polar Ural, Russia) and from Late Archean kyanite-staurolite-muscovite schists of the Keivy complex (Kola Peninsula, Russia) have been investigated using the approaches mentioned above. This research has allowed reconstruction of the evolution of the fluid regime during rock formation.

The minerals studied provide evidence for the essential fluid 
flow during metamorphism. They also show tremendous differences between flow velocities for fluids of various composition (such as siliceous, ferromagnesium, calciferous). Stages limiting growth from those solutions were different as well; most of the mineral assemblages show appreciable disequilibrium at their formation.

\section{CARBON-14 IN CARBON DIOXIDE USED TO DETERMINE THE RESIDENCE TIME OF LABILE ORGANIC CARBON IN THE VADOSE ZONE. D. H. Bacon' ${ }^{1}$ and C. K. Keller ${ }^{2}$, 'Pacific Northwest National Laboratory, P.O. Box 999, Richland WA 99352, USA (dh_bacon@pnl.gov), 2Department of Geology, Washington State University, Pullman WA 99164-2812, USA (ckkeller@wsu.edu).}

The global stock of $\mathrm{C}$ in vadose zones is large and its tumover rate is of interest to those studying the global $\mathrm{C}$ cycle. However, the techniques used to fractionate soil organic matter into components with different mean residence times are difficult to apply to the vadose zone because of the low organic matter content in subsoil sediments. Alternatively, the gas phase is readily sampled in the vadose zone, facilitating direct measurements of the isotopic content of $\mathrm{CO}_{2}$. A determination of the ${ }^{14} \mathrm{C}$ content and, hence, the mean residence time, of respired $\mathrm{CO}_{2}$ would provide the basis for an estimate of the mean residence time of labile organic $\mathrm{C}$. However, the isotopic content of respired $\mathrm{CO}_{2}$ cannot be measured in situ. It has been shown that at steady state, vadose $\mathrm{CO}_{2}$ will be enriched in ${ }^{14} \mathrm{C}$ by at least $8.7 \%$ relative to respired $\mathrm{CO}_{2}$ because of the difference between rates of diffusion for ${ }^{12} \mathrm{CO}_{2}$ and ${ }^{14} \mathrm{CO}_{2}$. Mixing with atmospheric $\mathrm{CO}_{2}$ can further complicate the relationship between respired and vadose $\mathrm{CO}_{2}$.

The effects of transport processes other than steady-state diffusion on the fractionation between vadose $\mathrm{CO}_{2}$ and respired $\mathrm{CO}_{2}$ have not been investigated. To this end, a finite-element model was developed to simulate the net respiration and transport of $\mathrm{CO}_{2}$, ${ }^{13} \mathrm{CO}_{2}$, and ${ }^{14} \mathrm{CO}_{2}$ in the vadose zone beneath a grassland site near Pullman, Washington (WSU site). Calibrated to the concentrations and $\mathrm{C}$ isotope content of $\mathrm{CO}_{2}$ collected by a gas sampling device at various depths in the vadose zone over a period of one year, the model was used to calculate the ${ }^{13} \mathrm{C}$ and ${ }^{14} \mathrm{C}$ content of respired $\mathrm{CO}_{2}$ (Fig. 1). Spatial and temporal variations in $\mathrm{H}_{2} \mathrm{O}$ content control the amount of mixing between $\mathrm{CO}_{2}$ produced in the vadose zone and $\mathrm{CO}_{2}$ in the atmosphere. When this mixing was accounted for in transient simulations, the results suggest that ${ }^{13} \mathrm{C}$ and ${ }^{14} \mathrm{C}$ content of respired $\mathrm{CO}_{2}$ vary considerably less with time than do the $\mathrm{C}$ isotopic contents of vadose $\mathrm{CO}_{2}$.

Respired $\mathrm{CO}_{2}$ is produced by some combination of organic matter degradation (bacterial respiration) and root respiration. The radiocarbon content of respired $\mathrm{CO}_{2}$ is observed to be more like that of dissolved organic C (DOC) than that of soil organic matter (SOM) (Fig. 1). It seems clear that respired $\mathrm{CO}_{2}$ at the WSU site is distinctly modem, and that the oldest fractions of SOM cannot be a significant component of the organic matter being decomposed. Notably, the radiocarbon content of respired $\mathrm{CO}_{2}$ is intermediate between that of DOC and the 1994 atmosphere. The $\mathrm{CO}_{2}$ produced by root respiration would have $\mathrm{a}^{14} \mathrm{C}$ content similar to that of the 1994 atmosphere. Assuming that the organic matter undergoing decomposition has the same ${ }^{14} \mathrm{C}$ signature as DOC, a linear mixing model can be used to determine the fraction of $\mathrm{CO}_{2}$ produced by organic matter degrada-

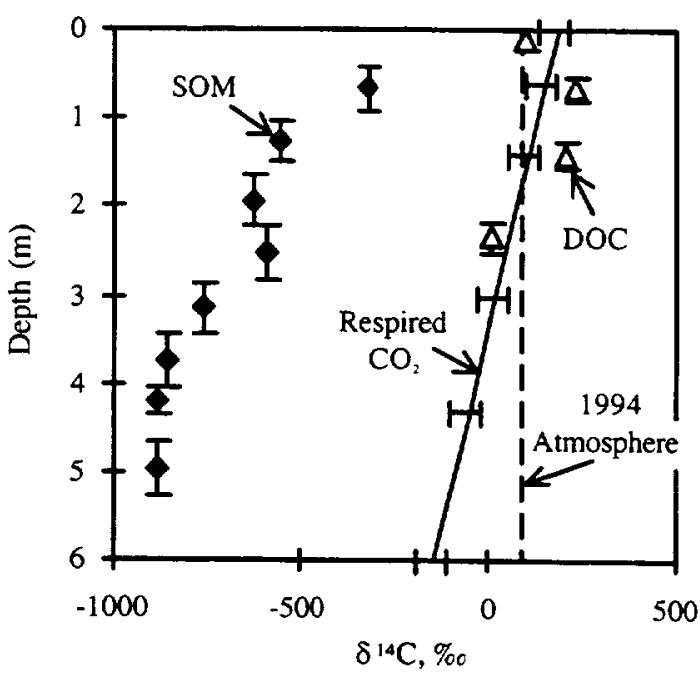

Fig. 1. Comparison of the carbon- 14 contents of soil organic matter (SOM), dissolved organic carbon (DOC) and respired $\mathrm{CO}_{2}$ from the WSU site. Vertical error bars show sample interval. Horizontal error bars show range of predicted values.

tion (F). This gives values for $F$ of $42 \%$ at a depth of $0.6 \mathrm{~m}, 17 \%$ at $1.4 \mathrm{~m}$, and $42 \%$ at $2.3 \mathrm{~m}$.

KINETICS OF PERLITE GLASS DEGASSING: TG AND DSC ANALYSIS. N. S. Bagdassarov', F. Ritter ${ }^{2}$, and Y. Yanev ${ }^{3}$, 'Institut für Meteorologie und Geophysik, Universität Frankfurt, Feldbergstrasse 47,60323 Frankfurt, Germany (nickbagd@geophysik.uni-frankfurt.de), ${ }^{2}$ Physikalisches Institut, Universität Frankfurt, Robert-Mayer-Strasse 10, 60323 Frankfurt, Germany, ${ }^{3}$ Geological Institute, Academy of Sciences, Acad. G. Bonchev Street 24, Sofia 1113, Bulgaria (yotzo@geology.acad.bg).

Studies of water degassing and water interaction in solid rocks and melts shed light on the genesis of lithospheric fluids, contamination, and alteration processes in rocks. Kinetics of dehydration of natural volcanic glasses has a particular interest. Possessing "memory" on thermal and degassing prehistory, water-bearing glasses have been under the scope of geochemists for a long time. The importance of studies on the kinetics of water degassing stems from the wide potential industrial use of perlites-natural water-beaing glass. This experimental study deals with the kinetics of water degassing from perlites and pitchstones. Temperature-time profiles of natural perlite samples from Eastern Rhodopes (Bulgaria) and pitchstones from Trans-Baikal Region (Russia) have been obtained by the use of the thermal balance STA 409 Netzsch. The initial water content in samples varied between 4.5 and $6.5 \mathrm{wt} \% \mathrm{H}_{2} \mathrm{O}$. One sample of pitchstone and 7 samples of perlite glasses from Eastern Rhodopes were chosen for TG/DSC experiments. Perlite samples from the Eastem Rhodopes paleogene volcanic area (age 37-30 m.y.) contained several percent of $\mathrm{H}_{2} \mathrm{O}$. The cooling rate during the formation of perlites can be subdivided into fast and slow regimes estimated from the geological environment. Water composition and content of phenocrysts correlate with the cooling rate of samples. Volcanic bodies intruded in sediments at different conditions: (1) 
submarine intrusion or intrusion in water-bearing sediments, and (2) subareal intrusion (as usual in calderas). This fact determines an effective cooling rate and thermal conditions of glass formation at peripheries of domes and lava flows. Cylinders of glassy samples were drilled from cobbles of rock and dried in a vacuum furnace at $105^{\circ} \mathrm{C}$ for $36 \mathrm{~h}$.

The water losses and the thermal effect of dehydration have been monitored in the temperature interval $100^{\circ}-1400^{\circ} \mathrm{C}$ in $\mathrm{Ar}$ atmosphere. Before temperature-time profiling the furnace has been evacuated up to $10^{-4}$ tor and filled with Ar gas. The fumace has been specially calibrated using a set of standard substances $(\mathrm{Zn}, \mathrm{Sn}, \mathrm{Qz}$, $\mathrm{Ag}$, and $\mathrm{Au}$ ) in order to determine a reliable differential scanning calorimetry sensitivity. During the experiment the flow of Ar in the furnace was maintained at pressure 1.05-1.1 bar.

The results of temperature scanning of pitchstone and perlite glasses indicate an identical shape of DTG and DSC peaks. Weight and thermal losses due to degassing are simultaneous.

Pitchstone: The TG and DTG signals indicate two maximum degassing temperatures $225^{\circ}$ and $290^{\circ} \mathrm{C}$. These peaks in TG signal relate to similar peaks in DSC. Perlitic water is driven out smoothly under heating by a wide range of temperature $140^{\circ}-600^{\circ} \mathrm{C}$ up to softening temperature range, which has been determined by viscosity measurements of glasses using a parallel plate method.

Slow-cooled Perlite: DTG and DSC signal have one distinct peak that extends from $140^{\circ}$ to $800^{\circ}-850^{\circ} \mathrm{C}$.

Fast-cooled Perlite: DTG and DSC signals exhibit two distinct peaks at $210^{\circ}$ and $610^{\circ} \mathrm{C}$. The temperature range of TG and DSC peaks are wider than in slow-cooled perlites and extend smoothly up to $1000^{\circ} \mathrm{C}$.

Comparison of the thermal effect of dehydration from perlite glasses with table values of water evaporation indicate the signifi-

TABLE 1.

\begin{tabular}{|c|c|c|}
\hline Sample/Water Content & $\begin{array}{c}\text { TG/DSC } \\
\text { Temperatures }{ }^{\circ} \mathrm{C}\end{array}$ & $\begin{array}{l}\text { Peak DH }(\mathbf{k J} / \mathrm{mol}) \\
\text { from DSC Peak } \\
\text { Integration }\end{array}$ \\
\hline Perlite $4.47 \%$ & 300,640 & 76 \\
\hline Perlite $6.10 \%$ & 210,610 & 61 \\
\hline Perlite $5.28 \%$ & 285 & 57 \\
\hline Perlite $6.54 \%$ & 270 & 65 \\
\hline Perlite $5.52 \%$ & 320 & 71 \\
\hline Perlite $4.70 \%$ & 310 & 75 \\
\hline Perlite $4.90 \%$ & 290 & 75.5 \\
\hline Pitchstone $6.01 \%$ & 210,300 & 74 \\
\hline Pitchstone $5.95 \%$ & 225.290 & 73 \\
\hline Sample/Water Content & $\begin{array}{c}\mathrm{DH}_{\text {degassing }}(\mathrm{kJ} / \mathrm{mol})- \\
\mathrm{DH}_{\text {evsporation }}(\mathrm{kJ} / \mathrm{mol}) \\
\text { from TG \& DSC Scanning }\end{array}$ & $\begin{array}{l}\text { Cooling Rate Estimated } \\
\text { from Geological } \\
\text { Setting }\end{array}$ \\
\hline Perlite $4.47 \%$ & $70-75$ & fast \\
\hline Perlite $6.10 \%$ & $65-70$ & fast \\
\hline Perlite $5.28 \%$ & $105-110$ & fast \\
\hline Perlite $6.54 \%$ & $65-70$ & slow \\
\hline Perlite $5.52 \%$ & $80-85$ & slow \\
\hline Perlite $4.70 \%$ & $65-70$ & fast \\
\hline Perlite $4.90 \%$ & $68-70$ & fast \\
\hline Pitchstone $6.01 \%$ & $75-80$ & $?$ \\
\hline Pitchstone $5.95 \%$ & $100-110$ & $?$ \\
\hline
\end{tabular}

cant effect of pressure at which water has been incorporated in the cracks of perlite. At $300^{\circ} \mathrm{C}$ the difference between the thermal effect of dehydration and enthalpy of evaporation is about $80-100 \mathrm{~kJ} / \mathrm{mol}$ for pitchstone, $60-75 \mathrm{~kJ} / \mathrm{mol}$ for perlite. The difference is attributed to the large effect of water expansion during dehydration (PV). This means that perlite water is located in small capillaries where it has been captured under significant pressure. In order to escape from capillaries and zeolites the pressure of vapor should exceed the Laplace pressure $-2 s / R$, where $s$ is the surface tension, $R$ stands for the effective capillary radius.

ISOTOPIC AND ELEMENTAL COMPOSITIONS OF EARLY DIAGENETIC CARBONATES IN MODERN MISSISSIPPI AND MAHAKAM DELTAIC SEDIMENTS. A. M. Bailey' and H. H. Roberts' ${ }^{2}$ ' Department of Geology, University of Southem Louisiana, Lafayette LA 70504, USA, ${ }^{2}$ Coastal Studies Institute, Louisiana State University, Baton Rouge LA 70803, USA.

Early [1] and later studies [2] describe numerous carbonate concretions in fine-grained siliciclastic sediments of the Mississippi Delta. Recent research [3] shows significant diagenetic carbonates in fine-grained siliciclastic sediments of the Mahakam Delta. In the river-dominated Mississippi Delta, sideritic lenses are the common diagenetic carbonate. Dolomite and calcite occur as accessory minerals and as occasional concretions. In the tide-dominated Mahakam Delta, equidimensional Mg-calcite concretions and microfossil replacements appear to be the most frequent diagenetic carbonate bodies. Siderite occurs in Mahakam sediments and is similar to that of the Mississippi Delta, though it appears to be less common in Holocene sediments. To better understand the microbially mediated reactions resulting in these early diagenetic carbonates, isotopic data have been collected for characterized samples from suites of structurally intact, $\mathrm{X}$-radiographed cores from both deltas. Previous data include $X$-ray diffraction examinations for concretions and electron microprobe analyses collected from polished thin sections. Data for the present study consist of $\delta^{13} \mathrm{C}$ and $\delta^{18} \mathrm{O}$ determinations, by outside laboratories, for characterized samples from the previous studies.

For Mississippi Delta siderite in these suites, $\delta^{13} \mathrm{C}(\mathrm{PDB})$ values range from around $O \% \circ$ to $>+10$, with an overall mean around +7 . $\delta^{18} \mathrm{O}(\mathrm{PDB})$ values for siderite range from $<-9$ to $>0$, with an overall mean around -3 . In general, there appears to be a negative relation between $\delta^{13} \mathrm{C}$ and $\delta^{18} \mathrm{O}$. Pleistocene siderite concretions from the Mahakam Delta (with significant calcite) display light $\mathrm{C}$ and $\delta^{18} \mathrm{O}$ values similar to those for the Mississippi Delta siderites.

For calcite concretions from the Mississippi Delta, $8^{13} \mathrm{C}$ and $\delta^{18} \mathrm{O}$ values are slightly negative. However, Mahakam calcite $\delta^{13} \mathrm{C}$ values are much more negative, reaching values of $<-24$, while associated $\delta^{18} \mathrm{O}$ values are around 0. Only limited data are available for dolomite from the Mississippi Delta, but $\delta^{13} \mathrm{C}$ values appear to be around 0 .

Generally positive $\delta^{13} \mathrm{C}$ values and low $\mathrm{Mn} / \mathrm{Fe}$ ratios indicate that the Mississippi Delta siderite of these studies formed in the zone of methanogenesis through precipitation in interstitial spaces during burial diagenesis. The inverse relationship between $\delta^{13} \mathrm{C}$ and $\delta^{18} \mathrm{O}$ in these samples has also been noted for ancient siderites [4]. In the present study, this relationship may point to concomitant diagenetic reactions that produced bicarbonate with lighter $O$ dur- 
ing burial. Negative values of $8^{13} \mathrm{C}$ for Pleistocene siderite of the Mahakam Delta indicate formation at a different stage of burial diagenesis.

In general, lighter $C$ in calcite concretions and associated pyrite in the tide-dominated Mahakam Delta suggest that an enhanced sulfide-reduction zone may have limited early siderite production, resulting in $\mathrm{Mg}$-calcite as the predominant carbonate phase. Slightly negative values of $\delta^{13} \mathrm{C}$ and $\delta^{18} \mathrm{O}$ for calcite (and dolomite) concretions of the Mississippi Delta may reflect a very shallow origin in the river-dominated Mississippi Delta.

References: [1] Ho C. and Coleman J. M. (1969) Bull. Geol. Soc. Amer., 80, 183-191. [2] Bailey A. M. and Roberts H. H. J. Sed. Res., in review. [3] Bailey A. M. and Roberts H. H. (1996) J. Conf. Abstracts, 1, 35. [4] Mozley P. S. and Burns S. J. (1993) J. Sed. Pet., 63, 73-83.

GOLD COMPLEXATION BY CHLORIDE-BEARING FLUIDS: AN EXAFS STUDY. E. H. Bailey ${ }^{1}$, P. F. Schofield ${ }^{2}$, and J.F. W. Mosselmans, ${ }^{3}$ Department of Physiology and Environmental Science, University of Nottingham, Sutton Bonington Campus, Loughborough, Leicestershire LE12 5RD,UK(Liz.Bailey@nottingham.ac.uk), '2Department of Mineralogy, The Natural History Museum, Cromwell Road, London SW7 5BD, UK, '3Daresbury Laboratories, Daresbury, Warrington, Cheshire WA4 4AD, UK.

Gold chloride complexation has been studied for a variety of technological and geochemical reasons for over 100 years. While it is generally thought that $\mathrm{Au}$ is transported in sulphidic solutions under hydrothermal conditions, the dominant species being [Au(HS) $\left.]_{2}\right]^{-}[1]$, this has not been spectroscopically proven within realistic $\mathrm{Au}$ [2]. Indeed, many other species have been suggested including organic complexes. The importance of chloride or mixed chlorohydroxy complexes is likely to be important during weathering processes

The dominant chloride species under oxidized meteoric conditions has been proposed to be $\left[\mathrm{AuOH}\left(\mathrm{H}_{2} \mathrm{O}\right)\right]^{0}$ by Vlasopoulos and Wood [3] but Mann [4] predicts $\left[\mathrm{AuCl}_{4}\right]^{-}$. From Raman and UV/vis spectroscopic data, Peck et al. [5] suggested that a mixed chlorohydroxy ligand species predominates over a wide $\mathrm{pH}$ range with hydroxide ligands replacing chloride as $\mathrm{pH}$ increases, such that at low $\mathrm{pH}\left[\mathrm{AuCl}_{4}\right]^{-}$is the dominant complex while at high $\mathrm{pH}$ it is $\left[\mathrm{AuCl}(\mathrm{OH})_{3}\right]^{-}$. These results were confirmed by the recent EXAFS study, at ambient conditions, of Farges [2]. They found that $\mathrm{pH} 2$ $\left[\mathrm{AuCl}_{4}\right]^{-}$was the dominant complex, whereas at $\mathrm{pH} 7.5$ and 9.2 $\left[\mathrm{AuCl}_{3}(\mathrm{OH})\right]^{-}$and $\left[\mathrm{AuCl}_{2}(\mathrm{OH})_{2}\right]^{-}$respectively were the major species. Significant changes with increasing temperature have also been predicted, e.g., with the transformation of the $\left[\mathrm{Au}(\mathrm{III}) \mathrm{Cl}_{4}{ }^{-}\right.$

TABLE 1

\begin{tabular}{lccc}
\hline$[\mathrm{Au}](\mathrm{m})$ & {$[\mathrm{Cl}](\mathrm{m})$} & $\mathrm{pH}$ & Temperature Range $\left({ }^{\circ} \mathrm{C}\right)$ \\
\hline 0.1 & 0.4 & 1.97 & $25-150$ \\
0.1 & 0.4 & 5.92 & $25-125$ \\
0.1 & 0.4 & 8.59 & $25-150$ \\
0.1 & 3.0 & 0.4 & $25-175$ \\
0.1 & 3.0 & 4.4 & $25-125$ \\
0.01 & 0.04 & 2.0 & $25-100$ \\
\hline
\end{tabular}

square-planar species into the linear $\left[\mathrm{Au}(\mathrm{I}) \mathrm{Cl}_{2}\right]^{-}$complex above $100^{\circ} \mathrm{C}[6]$.

We have monitored gold-chloride complexation up $10175^{\circ} \mathrm{C}$ from in situ EXAFS measurements using the method of Mosselmans et al. [7]. Solutions of $0.1 \mathrm{~m}$ and $0.01 \mathrm{~m} \mathrm{Au}$ were prepared from $\mathrm{KAuCl}_{4}$ at a range of $\mathrm{pHs}$ (Table 1). $\mathrm{pH}$ adjustment was carried out by addition of $\mathrm{NaOH}$ and $\mathrm{HCl}$.

EXAFS spectra were collected in transmission mode at $25^{\circ} \mathrm{C}$ temperature intervals between $25^{\circ}$ and $175^{\circ} \mathrm{C}$. Analysis of the absorption-edge position and the XANES structures indicates no reduction in oxidation state from $\mathrm{Au}(\mathrm{III})$ to $\mathrm{Au}(\mathrm{I})$ with increasing temperature.

Speciation changes were observed with increasing $\mathrm{pH}$ and temperature. At low $\mathrm{pH}(<4)$ and high chloride concentrations the $\left[\mathrm{AuCl}_{4}\right]^{-}$complex predominates with a bond length of $\sim 2.28 \AA$. A second shell is also present at $4 \AA$ indicating two further chloride ligands are present possibly axially above and below the plane of the complex. No variation is observed as a function of temperature. At $\mathrm{pH} 6 \mathrm{OH}^{-}$enters the first coordination sphere and by $\mathrm{pH} 8.6$ the first co-ordination sphere appears to be mainly dominated by $\mathrm{OH}^{-}$at $1.98 \AA$. Increasing the temperature for the solution at pH 6 causes the removal of the $\mathrm{OH}^{-}$-bearing species and the predominance of the $\left[\mathrm{AuCl}_{4}\right]^{-}$complex. At the higher $\mathrm{pH}$ however, increased temperature induces the replacement of the $\mathrm{Cl}^{-}$ligand by $\mathrm{OH}^{-}$ligands.

References: [1] Renders P. J. and Seward T. M. (1989) GCA, 53, 245-253. [2] Farges F. et al. (1993) GCA, 57, 1243-1252. [3] Vlassalopoulos D. and Wood S. (1990) GCA, 54, 3-12. [4] Mann A. W. (1984) Econ. Geol., 79, 38-49. [5] Peck J. A. et al. (1991) GCA, 55, 671-676. [6] Pan P. and Wood S. (1991) GCA, 55, 23652371. [7] Mosselmans J. F. W. et al. (1996) Chem. Geol., 127, 339350.

ESTIMATING SOIL ORGANIC CARBON STORAGE: STATEFACTOR VS. MECHANISTIC APPROACHES. W. T. Baisden and R. Amundson, Ecosystem Sciences, 151 Hilgard Hall, University of Califomia, Berkeley CA 94720-3110, USA.

The potential release of soil organic $\mathrm{C}$ (SOC) to the atmosphere during global change has led to considerable interest in the independent variables that control SOC storage. Hans Jenny conceptualized these variables with his state factor theory of soil formation:

$S O C=f($ climate, biota, relief parent material, time. . .)

Most published studies of SOC storage vs. independent variables (including the best estimates of global SOC storage) rely on the relationship between $S O C$ and a single state factor (climate). Rather than attempting to understand the role of other state factors in controlling SOC storage, most recent work has focused on including other soil properties assumed to be mechanistically linked to SOC dynamics in multivariate regressions. While this focus produces good predictions of SOC storage and has considerable merit in understanding the mechanistic basis for SOC storage, it is not as satisfying for estimating SOC storage based on entirely independent parameters. Yet the estimation of SOC storage based on independent variables is preferable for regional and global analysis, and critical for estimating SOC storage over geologic timescales.

Unfortunately, Jenny's state factors have proven difficult for 
scientists to quantify. Using a regional database of soil survey data from throughout Califomia, we provide a novel application of statistical methods to quantify the relationship between independent variables and SOC storage. First, we used a multivariate regression of independent variables combined with soil properties (dependent) to achieve a high $R^{2}$ value $(-0.7)$ in predicting SOC. In presenting these results, we display the attraction and utility of this sort of analysis. Then we use factor analysis on a large dataset of soil properties (excluding SOC) to estimate the best quantitative indexes for use in representing state factors (independent variables). When the dataset is restricted to conform to the linear model inherent in factor analysis, we find that a regression based on these independent variables can equal or exceed the predictive ability (i.e., adjusted $\mathrm{R}^{2}$ ) of the more mechanistic approaches.

WHOLE-MANTLE VS. LAYERED MANTLE CONVECTION AND THE ROLE OF A HIGH-VISCOSITY LOWER MANTLE IN TERRESTRIAL VOLATILE EVOLUTION. C. J. Ballentine and P. van Keken, Department of Geological Sciences, University of Michigan, Ann Arbor MI 48109-1063,USA (chrisjb@umich.edu).

A two-layer steady-state mantle model readily accounts, in particular, for the He and $\mathrm{Ne}$ isotopic composition of the upper mantle and plumes assumed to be representative of the lower mantle system. In these models, a degassed and lithophile-depleted upper mantle is assumed to be almost completely decoupled from a more volatile-rich and lithophile-rich lower mantle. Weight is added to the relevance of this model by simple mass balance considerations. The volume of the depleted upper mantle (assumed to be above the 670-km discontinuity) complements the lithophile-enriched continental crust, while the $\mathrm{K}$ content of the degassed upper mantle, together with the continental crust alone, can readily account for most of the ${ }^{40}$ Ar now in the atmosphere. Assuming steady state and a Loihi-like composition of the lower mantle, layered mantle models requires a flux of $\leq 1 \%$ of the lower mantle mass per billion years to account for the ${ }^{3} \mathrm{He} /{ }^{4} \mathrm{He}$ and ${ }^{21} \mathrm{Ne} /{ }^{22} \mathrm{Ne}$ in the degassed upper mantle. A similar flux from the lower mantle is required to account for the upper-mantle $\mathrm{Pb}$ isotopic composition.

Although elegant, the steady-state model is not without its problems. For example, estimates from hotspot geoid anomalies suggest that the flux from the lower mantle is an order of magnitude higher than the geochemical steady-state estimate. As tomographic imaging becomes more refined, there is now strong evidence for longterm structure $(>100 \mathrm{Ma}$ ) within the mantle system that traverses the $670-\mathrm{km}$ discontinuity, including evidence that some subducting slabs penetrate the $670-\mathrm{km}$ discontinuity. Although it is possible that these images may result from thermally coupled circulation in the lower mantle, any oceanic crust input into the lower mantle would result in a retum flux to the upper mantle far greater than the geochemical models would suggest.

Another approach to the problem of mantle convection or isolation has been the generation of numerical fluid dynamical models. It is certainly possible within the constraints imposed by mantle rheology to construct models that create either stable layered convection or whole-mantle convection. Nevertheless, stable layer models do not easily enable plume penetration from the lower mantle without "cascading" and causing massive mantle overtum, while whole-mantle convection models similarly result in a flux from the lower mantle into the upper mantle that is larger than even the geophysical constraints would imply. More recently it has been proposed that these observations could be reconciled by a highviscosity lower mantle.

We have conducted numerical experiments to study the influence of a higher viscosity lower mantle on the mixing efficiency of mantle convection. Models have been considered where the lower mantle viscosity was increased to up to two orders of magnitude higher than that of the upper mantle, while maintaining the overall vigor of convection as measured by the total surface heat production rate. The models show consistently that, although the efficiency of mixing is retarded in the lower mantle, the entire mantle is efficiently homogenized within $0.5-1 \mathrm{Ga}$ due to an increased mixing rate in the upper mantle.

An additional set of model calculations is performed that explicitly incorporates passive "volatile" tracers to investigate degassing at mid-ocean ridges. The mantle is considered to have initially uniform high volatile content. Tracers are used to track the amount of mantle that has moved through the degassing zone under a ridge. A surprising conclusion is that models with a higher-viscosity lower mantle degas more rapidly than models with uniform viscosity. This is because in order to match the surface heat flow with the presentday heat flow, models with a higher-viscosity lower mantle need higher velocities in the upper mantle, leading to more rapid cycling of mantle material through the ridges.

It is concluded that these models with a simple stepwise increase of viscosity in the lower mantle do not seem to satisfy the noble gas constraints. We propose that additional mechanisms of mantle isolation have to be established. These may be caused by strongly temperature- and pressure-dependent theology and phase transitions.

SPATIAL PLATINUM-GROUP-ELEMENT DISTRIBUTION IN MAGMATIC SULFIDES: IMPLICATIONS FOR PLATINUM-GROUP-ELEMENT BEHAVIOR DURING MANTLE MELTING. C. Ballhaus ${ }^{1,3}$ and P. Sylvester ${ }^{2},{ }^{1}$ Geology Department, Australian National University, Canberra. ACT 0200, Australia, ${ }^{2}$ Research School of Earth Sciences, Australian National University, Canberra, ACT 0200, Australia, ${ }^{3}$ Institut für Mineralogie, Universität Tübingen, 72074 Tübingen, Germany.

Concentrations and solubility limits of precious metals (PGE, $\mathrm{Re}, \mathrm{Au}$ ) in high-temperature sulfides are poorly known, yet important to understand the behavior of PGE during mantle melting. Microanalysis using PIXE at best detects $\mathrm{Ru}, \mathrm{Rh}$, and Pd, whereas $\mathrm{Pt}, \mathrm{Os}$, and Ir remain undetected. We report new $\mathrm{PGE}$ microanalyses with Laser ICP-MS, performed on PGE-saturated magmatic sulfides (pyrrhotite, pentlandite, chalcopyrite) of the Merensky reef (Bushveld Complex). Laser ablation has a higher sensitivity than PIXE and also gives three-dimensional information. Because ablation rates are known, one can distinguish with laser ablation PGEs in solid solution from those that occur as micro-inclusions.

Standards used were synthetic $\mathrm{Fe}_{1-\mathrm{x}} \mathrm{S}$ minerals doped with 3$11 \mathrm{ppm}$ of a single PGE and tempered at $800^{\circ} \mathrm{C}$ and $1 \mathrm{GPa}$ for 3 days in a piston cylinder press. Aliquots of the nun products were analyzed with conventional solution ICP-MS, and polished equivalents were checked for homogeneity with the laser probe. Subsequent analysis of the natural Merensky sulfides showed that most PGE 
occur as polymetallic micro-inclusions rather than in solid solution, notably $\mathrm{Os}$, Ir, $\mathrm{Re}$, and $\mathrm{Pt}$. Inclusion volumes range from $<0.001$ to $\sim 0.008 \mu \mathrm{m}^{3}$, and there is no correlation between inclusion composition and the nature of the host sulfide. We suggest that the PGE inclusions have formed before the magmatic mass exsolved upon cooling to pyrrhotite, pentlandite, and chalcopyrite. They may indeed be magmatic in origin; if the latter speculation proves true, PGE in magmatic liquids (both sulfide and silicate) may occur as polymetallic clusters rather than as binary metal-S or metal-O complexes. Consequently, available metal-sulfide and metal-silicate PGE partition coefficients may be of limited value for modeling noble metal fractionation during mantle melting.

\section{ATOMIC-RESOLUTION THERMAL EMISSION MICROS- COPY DATA FOR THE ROLE OF STRUCTURAL INHERI-} TANCE IN THE WEATHERING OF CHLORITE. J. F. Banfield and T. Murakami, Mineralogical Institute, The University of Tokyo, Tokyo, Japan.

Naturally weathered surfaces are frequently in intimate contact with their weathering products. In many cases, surface energy is minimized by development of clays in topotactic orientations, with the consequence that some degree of structural continuity exists between the primary and secondary phase. This has given rise to the suggestion that structural polymers may be inherited by weathering products. This is of some importance because the mechanisms of such transformations are different from dissolution-reprecipitation and thus require different kinetic models. This paper details the structural and chemical changes that occur when vermiculite is formed by weathering of chlorite.

Il $\underline{b b}$ and Ibb Mg, Al, Fe-chlorite from Koongarra, Australia, is transformed to vermiculite via a range of intermediate structural and chemical states. Initial loss of interlayer cations is accompanied by shifts involving the 2:1 layers, causing extensive streaking of 201 reflections. This is somewhat analogous to shifts that accompany cation exchange in vermiculite. Shifts, which are required to change the relative positions of layers to those found in vermiculite, occur early, as expected based on vermiculite cation exchange experiments that show displacements are inhibited by low interlayer charge. Displacements may be driven by interactions between cations in the interlayer and the 2:1 layer, possibly by stabilization of "a"-type interactions as vacancies appear in sites above tetrahedral cations. Semiquantitative analysis of reduction of intensity in atomicresolution images of interlayers indicate they range from brucitelike to having $\mathrm{M} 3$ and $\mathrm{M} 4$ occupancies approaching $\sim 0.2$ (interlayer charge of $\sim 0.75^{+}-1.5^{+}$per formula unit). Further loss is accompanied by partial to complete interlayer collapse in the vacuum. Octahedral cations (predominantly $\mathrm{Mg}$ and $\mathrm{Fe}$ ) tend to be removed from every second interlayer, leading to semiregular interstratifications of chlorite-vermiculite. Resulting intergrowths of chlorite, chlorite-vermiculite, and vermiculite retain the primary chlorite orientation and morphology and sense of octahedral tilt in 2:1 layers. These results indicate vermiculitization is a continuous process that occurs by an essentially solid-state mechanism. Layer displacement may occur by an elastic process (no rupture of bonds within the $2: 1$ layer) at the tip of the growing vermiculite portion of the intergrowth. Removal of cations from the chlorite-vermiculite junction is probably facilitated by rapid diffusion along the vacancy-rich interlayer.
Magnesium is removed in solution, $\mathrm{Fe}$ in precipitated locally in aggregates of nanocrystalline $\mathrm{Al}-, \mathrm{Si}-$, and $\mathrm{P}$-bearing goethite.

\section{GEOCHEMICAL AND GEOPHYSICAL IMPLICATIONS} OF THE RADIOCARBON CALIBRATION. E. Bard, Institut Universitaire de France and CEREGE, Université d'Aix-Marseille III, CNRS UMR132-FU17, Europe de l'Arbois, BP 80, 13545 Aixen-Provence Cedex 4, France (ebard@arbois.cerege.fr).

A precise and accurate chronological framework is crucial to study the dynamics of a variety of phenomena that occurred during the last $40,000 \mathrm{yr}$. The radiocarbon dating method has been widely applied since the fifties but it is recognized that ${ }^{14} \mathrm{C}$ ages are not strictly accurate. This problem justifies the construction of a calibration to calculate true calendar ages.

For example, the ${ }^{14} \mathrm{C}$ calibration is needed in prehistoric archeology to study the spread and evolution of populations during the upper paleolithic period. In geophysics it is important in order to obtain recurrence rates of seisms or volcanic eruptions. The field of paleoclimatology clearly illustrates the importance of the ${ }^{14} \mathrm{C}$ calibration because rapid climatic change are studied in different types of archives spread at different latitudes and in different comparments of the ocean-atmosphere-biosphere system. Accuracy is also crucial to evaluate the phasing between climatic events and variations of Earth's orbit parameters.

Two decades of precise $\beta$-counting measurements on wood have resulted in the calibration for most of the Holocene period for which fossil trees are abundant. By contrast, suitable samples are very rare and/or small beyond the Holocene-Pleistocene boundary. Fortunately, the construction of the calibration has been fostered by the development of mass spectrometric techniques that can be applied to small samples.

Carbon-14 measured by accelerator mass spectrometry (AMS) on fossils from lacustrine and marine varved sediments compared dating by $A M S-{ }^{14} \mathrm{C}$ and $\mathrm{U}$ series analyzed by thermal ionization mass spectrometry (TIMS) on marine or lacustrine carbonates.

The calibration curve obtained so far is characterized by a longterm trend with ${ }^{14} \mathrm{C}$ ages being significantly younger than calendar ages during most of the last $40,000 \mathrm{yr}$. Superimposed on this long trend of decreasing atmospheric $\Delta^{14} \mathrm{C}$ are abrupt ${ }^{14} \mathrm{C}$ shifts that occurred over centuries to millennia. To a certain extent it is possible to delineate the different causes of atmospheric ${ }^{14} \mathrm{C}$ variations by considering complementary information obtained for other cosmogenic nuclides studied at different latitudes.

It appears that the long-trend shift of ${ }^{14} \mathrm{C}$ ages is due to several periods of lowered shielding effect of the geomagnetic dipole field that occurred during the last $50,000 \mathrm{yr}$. This interpretation is supported by paleomagnetic measurements performed on volcanic and sedimentary rocks.

Most of the high-frequency component is linked to magnetic fluctuations of solar origin as revealed by studying the last three centuries for which direct observations of the Sun are available. A similar conclusion is derived by comparing ${ }^{14} \mathrm{C}$ events with cosmogenic isotope concentration maxima in polar ice cores $\left({ }^{10} \mathrm{Be}\right.$ and ${ }^{36} \mathrm{Cl}$ ).

Several unusually large and rapid ${ }^{14} \mathrm{C}$ shifts occurred between 16,000 and $8000 \mathrm{yr}$. BP, which corresponds to a period of major climatic changes. By contrast with the ${ }^{14} \mathrm{C}$ variability mentioned 
previously, which is linked to fluctuation of production by cosmic rays, these so-called ${ }^{14} \mathrm{C}$ "age plateaux" are probably due to abrupt variations in the rates of exchanges and/or in reservoir sizes within the global $\mathrm{C}$ cycle. This interpretation is supported by independent geochemical proxies and by numerical modeling of the $\mathrm{C}$ cycle.

HELIUM ISOTOPES OF THE CAMEROON LINE VOLCANIC CHAIN. D. Barfod ', C. J. Ballentine', A. N. Halliday', M. D. Kurz ${ }^{2}$, and J. G. Fitton ${ }^{3}$, 'Department of Geological Sciences, University of Michigan, Ann ArborMl 48 109-1063,USA (dbarfod@ umich.edu ), 2Woods Hole Oceanographic Institution, Woods Hole MA 02543, USA, ' ${ }^{3}$ Department of Geology and Geophysics, University of Edinburgh, Edinburgh EH9 3JW, UK.

We report here the preliminary results of a He isotopic study of basaltic lavas and mantle xenoliths from the Cameroon line. Combined observations of $\mathrm{He}$ isotopes with $\mathrm{Pb}$ and $\mathrm{Nd}$ isotopes and trace elements are used to investigate source enrichment effects and to characterize processes that give rise to the HIMU component in the mantle.

The Cameroon line is an intraplate, alkaline volcanic province extending $1600 \mathrm{~km}$ from the African continental interior into the Gulf of Guinea to the island of Pagalu. At the continent-ocean boundary $(\mathrm{COB})$ young $(<10-\mathrm{Ma})$ lavas have extremely radiogenic $\mathrm{Pb}\left({ }^{206} \mathrm{~Pb} / 204 \mathrm{~Pb}=20.5\right)$ and become progressively less radiogenic with distance from the $\mathrm{COB}\left({ }^{206} \mathrm{~Pb} /{ }^{204} \mathrm{~Pb}=19.0\right)$. This trend is also seen in Nd-Sr space. Lavas from Mt. Cameroon and the ocean islands show systematic temporal progressions to more radiogenic $\mathrm{Pb}$ and $\mathrm{Sr}$ and less radiogenic $\mathrm{Nd}$ with decreasing age. In contrast to the $\mathrm{Pb}, \mathrm{Sr}$, and $\mathrm{Nd}$ isotopic trends, the lavas of the Cameroon line have relatively uniform trace-element and $\mathrm{Hf}$ isotopic compositions.

Helium isotopic compositions of continental and oceanic lavas, determined by in vacuo crushing of olivine separates, range from 5.4 to $8.0 \mathrm{R} / \mathrm{R}_{\mathrm{a}}$, overlapping values observed in the HIMU ocean island St. Helena and in MORB. Low ${ }^{3} \mathrm{He}^{/ 4} \mathrm{He}$ in these lavas correlates with radiogenic $\mathrm{Pb}$ and unradiogenic $\mathrm{Nd}$, and high $\mathrm{Ce} / \mathrm{Pb}$ and $\mathrm{Th} / \mathrm{Pb}$.

In the continental sector, young lavas ( $\leq 1 \mathrm{Ma}$ ) range from 5.4 to $7.0 \mathrm{R} / \mathrm{R}_{\mathrm{a}}$, similar to the upper limits observed in free gases from volcanic lakes. Helium isotopes in mantle xenoliths ( 6.6 to $5.4 \mathrm{R}$ $R_{a}$ ) show isotopic equilibrium between phases, but are uncorrelated with calculated $\mathrm{U}+\mathrm{Th} / \mathrm{He}$ ratios. The mantle xenoliths phases show evidence of textural and chemical equilibrium; a systematic partitioning of He suggests

$$
\mathrm{D}_{\mathrm{cpx}}^{\mathrm{He}}>\mathrm{D}_{\mathrm{cpx}}^{\mathrm{He}}>\mathrm{D}_{\mathrm{olv}}^{\mathrm{He}}
$$

Relative homogeneity of He isotopes in magmatic gases between three distinct sample types (young lavas, xenoliths, free gases) along $1200 \mathrm{~km}$ of the volcanic chain (both oceanic and continental portions) indicates a single, dominant noble-gas source that is pervasive throughout the Cameroon line magmatic system today. High ${ }^{206} \mathrm{~Pb} / 204 \mathrm{~Pb}$ and fractionated $\mathrm{Th} / \mathrm{Pb}$ and $\mathrm{Ce} / \mathrm{Pb}$ correlated with low ${ }^{3} \mathrm{He} /{ }^{4} \mathrm{He}$ is consistent with $\sim 125-\mathrm{Ma}$ metasomatism of the lithosphere. Lack of correlation between $\mathrm{U} / \mathrm{He}$ and ${ }^{3} \mathrm{He} /{ }^{4} \mathrm{He}$ in the xenoliths suggests recent overprinting of the He isotopic compositions in these samples. Bulk MORB-source addition cannot explain the data because unradiogenic $\mathrm{Nd}$ is correlated with MORB-like
${ }^{3} \mathrm{He} /{ }^{4} \mathrm{He}\left(\mathrm{e} . \mathrm{g} ., \varepsilon_{\mathrm{Nd}}=3.90\right.$ and $8.0 \mathrm{R} / \mathrm{R}_{\mathrm{a}}$ ). These results are consistent with a HIMU source generated by pervasive metasomatism of the lithosphere and characterized by ${ }^{3} \mathrm{He} /{ }^{4} \mathrm{He}$ between 5 and $7 \mathrm{R} / \mathrm{R}_{\mathrm{a}}$.

Recycled oceanic crust might be expected to have very low ${ }^{3} \mathrm{He} /$ ${ }^{4} \mathrm{He}$ due to ${ }^{4} \mathrm{He}$ produced over $>1.0$ b.y. of storage time. The high ${ }^{3} \mathrm{He} /{ }^{4} \mathrm{He}$ values observed in this study suggest that the Cameroon HIMU end member cannot be simply related to plate recycling.

THE HEARD ISLAND CONTINENTAL COMPONENT: OSMIUM-ISOTOPIC EVIDENCE FOR MANTLE VS. MAGMA CONTAMINATION. J. Barling ${ }^{1.2}$, J. S. McBride ${ }^{2}$, D. D. Lambert ${ }^{2}$, and I. A. Nicholls ${ }^{2},{ }^{1}$ Geological Institute, Copenhagen University, Øster Voldgade, 10, DK-1350Copenhagen K, Denmark, 2VIEPS Department of Earth Sciences, Monash University, Clayton VIC 3168, Australia.

Lavas from Heard Island (southern Indian Ocean) exhibit extremely well-correlated $\mathrm{Sr}, \mathrm{Nd}$, and $\mathrm{Pb}$ isotope compositions. These variations have been interpreted as resulting from the presence of up to $2-4 \%$ continent-derived sediment in the plume source [1]. However, Heard Island is located on the Kerguelen Plateau (KP), a large igneous province formed by the Kerguelen plume during the breakup of Gondwana. Although the plateau is believed to be largely oceanic in origin, the presence of small continental fragments within the plateau cannot be ruled out. In addition, trace-element and $\mathrm{Sr}$, $\mathrm{Nd}$, and $\mathrm{Pb}$ isotopic data from the southem sector of the KP indicate the involvement of continental lithosphere in the early history of the Kerguelen plume [2]. The possibility therefore remains that the continental characteristics seen in Heard lavas reflect interaction with continental material at shallow levels. If this is the case, a minimum of $20 \%$ continental material must have been assimilated to produce the maximum isotopic enrichment observed in Heard lavas [1].

Owing to the high Os concentration in mantle peridotite ( $\sim 3 \mathrm{ppb})$, the Os isotopic composition of the mantle is much less sensitive to lithospheric contamination than are mantle-derived basalts $(<0.01-$ $0.8 \mathrm{ppb} O \mathrm{Os}$ ). We therefore undertook a pilot study of Os isotope systematics of Heard Island lavas and ultramafic xenoliths in order to investigate further the origin of the enriched "continental" contaminant.

Heard Island lavas fall into two isotopically distinct series: the heterogeneous Big Ben Series (BBS) which has ${ }^{87} \mathrm{Sr} /{ }^{86} \mathrm{Sr}=0.7051-$ $0.7079, \varepsilon_{\mathrm{Nd}}-0.2$ to $-4.6,{ }^{206} \mathrm{~Pb} /{ }^{204} \mathrm{~Pb}=17.79-18.21$, and ${ }^{3} \mathrm{He} /{ }^{4} \mathrm{He}$ $R / R_{a}=7.4-8.4$; and the relatively homogeneous Laurens Peninsula Series (LPS), which has ${ }^{87} \mathrm{Sr} /{ }^{86} \mathrm{Sr}=0.7047-0.7049, \varepsilon_{\mathrm{Nd}}=+0.6$ to $+2.0,{ }^{206 \mathrm{~Pb}} / 204 \mathrm{~Pb}=18.53$ to 18.83 , and ${ }^{3} \mathrm{He} /{ }^{4} \mathrm{He} \mathrm{R} / \mathrm{R}_{\mathrm{a}}=16-18$. The Re-Os dataset includes one LPS sample $\left({ }^{87} \mathrm{Sr} /{ }^{86} \mathrm{Sr}=0.7049\right)$, four BBS samples $\left({ }^{87} \mathrm{Sr} /{ }^{86} \mathrm{Sr}=0.7051-0.7060\right)$, and two ultramafic xenoliths (cumulates). ${ }^{187} \mathrm{Os} /{ }^{188} \mathrm{Os}$ ratios for the $\mathrm{BBS}$ range from $0.1340-0.1754$ but, in contrast to $\mathrm{Sr}, \mathrm{Nd}, \mathrm{Pb}$, and $\mathrm{He}$ isotope systematics, the ${ }^{187} \mathrm{Os} /{ }^{188} \mathrm{Os}$ ratio for the LPS sample $(0.1341)$ is identical within uncenainty to the ${ }^{187} \mathrm{Os} /{ }^{188} \mathrm{Os}$ ratio of a BBS sample with ${ }^{87} \mathrm{Sr} /{ }^{86} \mathrm{Sr}=0.7053$.

The Heard $\mathrm{Os}-\mathrm{Pb}$ data array falls along the EMl trend of Hauri et al. [3], which they interpret to be generated by addition of $1.8-\mathrm{Ga}$ oceanic crust $+10 \%$ pelagic sediment to a "FOZO" mantle. Assuming that $20-40 \%$ of this contaminant approximates the $2-4 \%$ pelagic sediment in previous Heard mixing models, a range of ex- 
pected ${ }^{187} \mathrm{Os} / 188 \mathrm{Os}$ can be calculated $(0.171-0.231)$. This brackets the measured ${ }^{187} \mathrm{Os} /{ }^{188} \mathrm{Os}$ of the most radiogenic lava $(0.1754)$ and provides strong suppor for the mantle contamination hypothesis. In contrast, addition of $20 \%$ average continental crust [4] to the LPS plume-derived magma results in a lava with a ${ }^{187} \mathrm{Os} /{ }^{188} \mathrm{Os}$ ratio of 4.88. In addition, while old, refractory subcontinental lithospheric mantle $\left({ }^{187} \mathrm{Os} /{ }^{188} \mathrm{Os}<0.128\right)$ can be ruled out as a major source of Heard lavas, ancient pyroxenite veins from refertilized portions of the lithospheric mantle can contain highly radiogenic Os [5] and could contribute to the enriched Os isotope geochemistry of plumederived basalts.

References: [1] Barling et al. (1994). [2] Mahoney et al. (1993). [3] Hauri et al. (1996). [4] Esser and Turekian (1993). [5] McBride et al. (1996).

EXPERIMENTAL TRACE-ELEMENT PARTITIONING IN TONALITIC SYSTEMS. M. G. Barth', S. F. Foley ${ }^{2}$, and I. Hom $^{3}$, 'Department of Earth and Planetary Sciences, Harvard University, 20 Oxford Street, Cambridge MA 02138, USA (barth@ eps.harvard.edu), ${ }^{2}$ Mineralogisch-Petrologisches Institut, Universität Göttingen, Goldschmidtstrasse 1, 37077 Göttingen, Germany, ${ }^{3} \mathrm{De}-$ partment of Earth Sciences, Memorial University of Newfoundland, St. John's NF AIB 3X5, Canada.

The partitioning of an extensive suite of trace elements between garnet, clinopyroxene, orthopyroxene, rutile, sphene, and tonalitic melts has been studied experimentally under upper-mantle conditions. Our experiments were performed on a natural tonalite doped with two different trace-element mixtures and with $\mathrm{TiO}_{2}$ to stabilize titanates. Reversal runs were done to ensure attainment of equilibrium. Trace-element concentrations of crystals and coexisting melt were measured by laser ablation microprobe. The partition coefficients (Ds) are independent of the trace-element concentration over the concentration ranges used.

The Ds were determined at seven different pressure-temperature conditions $\left(1.8-2.5 \mathrm{GPa}, 900^{\circ}-1100^{\circ} \mathrm{C}\right.$ and $\left.2-5 \mathrm{wt} \% \mathrm{H}_{2} \mathrm{O}\right)$. The Ds repored in this study are a considerable extension of the few available datasets in intermediate to silicic systems. The Ds mostly agree well with previously published data [1], but show lower values for highly incompatible elements (e.g., Nb, La). Rutile is the only one of the investigated phases that can fractionate $\mathrm{Nb}$ from $\mathrm{La}$.

The garnet partition coefficients show steeper patterns with higher Ds for heavy rare earth elements (REE), lower Ds for highly incompatible elements, and lower $\mathrm{La} / \mathrm{Yb}$ ratios than published data from basaltic systems. The Ds of the compatible increase significantly with decreasing temperature (e.g., $D_{E r}=9.4$ at $1040^{\circ} \mathrm{C}, 26.3$ at $900^{\circ} \mathrm{C}$ ); the $\mathrm{La} / \mathrm{Yb}$ ratio decreases with decreasing temperature $\left(0.00046\right.$ at $1040^{\circ} \mathrm{C}, 0.00007$ at $\left.900^{\circ} \mathrm{C}\right)$.

It is well known that plots of $\log D_{i}$ vs. the ionic radius $\left(r_{i}\right)$ for series of isovalent cations describe parabolas with maxima corresponding to the size of the crystal lattice site(s) on which substitution occurs. By fitting the parabola to the experimentally determined $D_{i}$ we can calculate the strain-free partition coefficient $D_{0}$ for defined $P, T$, and $X$, the optimum radius $r_{0}$ of the lattice site and the Young's Modulus $E$ of the lattice site [2]. We applied this method to the trivalent cations because $S c$ and the REE cover a wide range of ionic radii, and because particularly the REE can be measured well by laser ablation microprobe.
$D_{0}$ and $E$ of gamet increase nearly linearly with decreasing temperature and are independent of the water content of the melt. $D_{0}$ does not change with increasing water content despite the decreasing degree of polymerization of the melt. This observation contradicts the opinion that the partition coefficients are strongly influenced by the melt structure.

In order to constrain the dependence of $\mathrm{D}_{0}$ on the solid-solution composition we calculated the lattice constant a of garnet [3]. $\mathrm{D}_{0}$ and a show a rough positive correlation. We infer that $D_{0}$ depends on the crystal structure. Not all variations of the Ds, however, can be explained by changes of the lattice constant because the correlation between temperature and $D_{0}$ is much better than between a and $D_{0}$.

We showed that the solid-solution composition and consequently the crystal structure has an important influence on the partition coefficients. The composition of garnet depends on the melt composition. Therefore, the Ds are influenced strongly but indirectly by the composition of the melt. However, there is no causative relationship between the degree of polymerization of the melt and trace-element behavior. Besides the crystal structure, there must be other factors that cause the temperature dependence of the partition coefficients.

References: [1] Green T. H. (1994) Chem. Geol., 117, 1-36. [2] Blundy J. and Wood B. (1994) Nature, 372, 452-454. [3] Novak G. A. and Gibbs G. V. (1971) Am. Mineral., 56, 791-825.

THE BORON ISOTOPE SYSTEMATICS OF GROUNDWATER FROM CRYSTALLINE BASEMENT AND SEDIMENTARY AQUIFERS (SOUTHWESTERN GERMANYNORTHERN SWITZERLAND). S. Barth, Department of Earth and Space Sciences, State University of New York at Stony Brook, Stony Brook NY 11794-2100, USA, and Institute of Geology and Paleontology, University of Tübingen, D-72076 Tübingen, Germany.

Introduction: The relatively large mass difference between the two stable isotopes of $\mathrm{B},{ }^{10} \mathrm{~B}$ and ${ }^{11} \mathrm{~B}$, leads to a wide range of $B$ isotope variations in nature $\left(\delta^{11} \mathrm{~B} \approx 90 \% 0[1] ; \delta^{11} \mathrm{~B}=\left\{\left[{ }^{11} \mathrm{~B} /\right.\right.\right.$ $\left.\left.\left.\left.{ }^{10} B_{\text {Sample }}\right) /\left({ }^{11} \mathrm{~B} /{ }^{10} B_{\text {Standard }}\right)\right]-1\right\} \times 10^{3}\right)$. Natural waters (e.g., seawater, river water, groundwater, brines, geothermal water) encompass a range in $\delta^{11} \mathrm{~B}$ of $\approx 75 \%$ (from -16 to $+59 \%$ [2]). In order to investigate the potential of $B$ isotopes for constraining the hydrochemical evolution of groundwater and their reactivity with aquifer rocks, I have analyzed groundwater from a variety of lithologically distinct crystalline basement and sedimentary (Permian to Triassic) aquifers in southwestem Germany and northem Switzerland.

Experimental: The ${ }^{11} \mathrm{~B} /{ }^{10} \mathrm{~B}$ isotopic ratios of groundwater (37) samples) were measured by NTIMS (Negative Thermal Ionization Mass Spectrometry) using an NBS-design, $15-\mathrm{cm}$ radius of curvature, $60^{\circ}$ sector, solid-source mass spectrometer at the State University of New York at Stony Brook. Boron samples containing around $1-10 \mathrm{ng} B$ were analyzed by a direct loading procedure [3] with an analytical uncertainty $\left(2 \sigma_{\text {mean }}\right)$ of $\pm 0.5 \%$ determined on replicate analyses $(n=3-4)$. Boron concentrations were determined by NTIMS isotope dilution and ICP-OES with analytical uncertainties

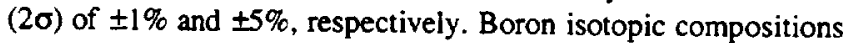
are reported in conventional $\delta$ notation relative to a mean ${ }^{1} \mathrm{~B} /{ }^{10} \mathrm{~B}$ ratio of $4.00125(n=5)$ measured for the NIST SRM-95! boric acid standard.

Results and Discussion: Groundwater from aquifers within 


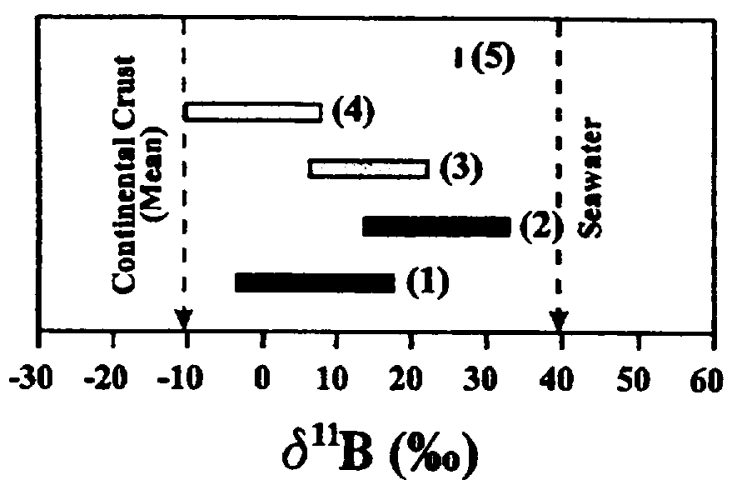

Fig. 1. Distribution of $\delta^{\prime \prime} \mathrm{B}$ values in groundwater from crystalline basement and sedimentary aquifers (SW Germany-N Switzerland). The $\delta^{\prime \prime} B$ values of mean continental crust $(-10.5 \%)$ and seawater $(+39.5 \%)$ are from [ 4$]$ and [5] respectively.

the crystalline basement and (Permian to Triassic) sedimentary cover show a wide range in $\delta^{11} \mathrm{~B}$ of $\approx 43 \%$, from $-10.2 \%$ to $+33.0 \%$, and variable B concentrations of 0.05 to $13.4 \mathrm{mg} / \mathrm{l}$. The existence of distinct groups is suggested (see Fig. 1): (1) groundwater from the crystalline basement (gneisses with granitic intrusives) is characterized by a $\delta^{11} \mathrm{~B}$ range of -3.5 to $+17.6 \%$ ( $\mathrm{B}=0.2-13.4$ $\mathrm{mg} / \mathrm{l}$ ), (2) groundwater from Permian (Rotliegend) sediments (mainly siltstones with interbedded nonmarine evaporites) tends to higher $\delta^{\prime \prime}$ B values of +13.7 to $+33.0 \%$ ( $\left.B=8.0-11.0 \mathrm{mg} / \mathrm{l}\right)$, (3) groundwater from Lower Triassic (Buntsandstein) sediments (sandstones) has $\delta^{11} \mathrm{~B}$ values of +6.4 to $+22.2 \%$ ( $\left.\mathrm{B}=1.8-7.3 \mathrm{mg} / \mathrm{l}\right)$, (4) groundwaters from Middle Triassic (Muschelkalk) sediments (mainly carbonates, i.e., dolomites and limestones, with interbedded shales and marine evaporites) has comparatively low $\delta^{\prime \prime} \mathrm{B}$ values of -10.2 to $+7.7 \% \circ$ ( $B=0.05-7.1 \mathrm{mg} / \mathrm{l})$, and (5) a groundwater sample from Upper Triassic (Keuper) sediments (mainly carbonates with some shales and marine evaporites) is set apart by a high $\delta^{11} \mathrm{~B}$ value of $+26.3 \%$ o $(B=9.6 \mathrm{mg} / \mathrm{l})$.

The observed $\delta^{11} \mathrm{~B}$ variations suggest that the B isotopic compositions of groundwater are controlled by several factors among which the nature of the $B$ source and isotope fractionalion processes related to adsorption and desorption and/or mineral precipitation and dissolution are relevant.

References: [1] Barth S. (1993) Geol. Rundsch., 82, 640651. [2] Vengosh A. et al. (1991) GCA, 55, 2591-2606. [3] Hemming N. G. and Hanson G. N. (1994) Chem. Geol., (Isot. Geosci. Sect. 114, 147-156. [4] Chaussidon $M$. and Albarède F. (1992) EPSL, 108, 229-241. [5] Spivack A. J. and Edmond J. M. (1987) $G C A, 51,1033-1043$.

GOLDIN HYDROTHERMALSOLUTIONS: THERMODYNAMIC PROPERTIES OF Au(HS) ${ }_{2}$ (aq) AND SOLUBILITY OF GOLD AT HIGH PRESSURES AND TEMPERATURES. E. N. Bastrakov', V. A. Pokrovskii'2, and C. A. Heinrich'2, 'Department of Geology, Australian National University, ACT 0200, Australia (enb 653@anu.edu.au), 2Departement Erdwissenschaften NO, ETH Zentrum, Zürich CH-8092, Switzerland.

Seward [1] has demonstrated that $\mathrm{Au}(\mathrm{HS})_{2}$ - is the dominant $\mathrm{Au}$ species in near-neutral reduced $\mathrm{S}$-bearing aqueous solutions. The

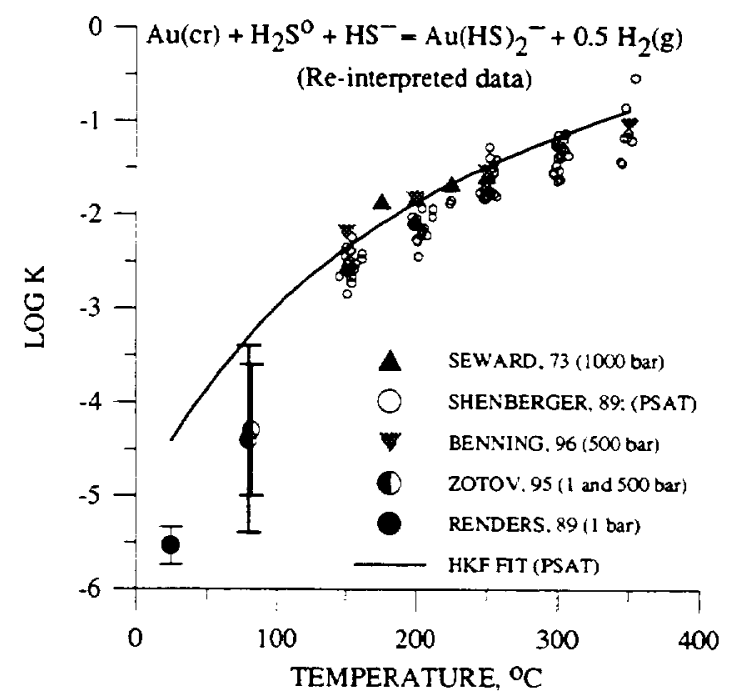

Fig. 1. Logarithm of the equilibrium constant for reaction (1) plotted as a function of temperature.

stability of this species has been extensively studied from $25^{\circ}$ to $400^{\circ} \mathrm{C}[1-5]$. However, the reported $\log \mathrm{K}$ values for the reaction

$$
\mathrm{Au}(\mathrm{cr})+\mathrm{H}_{2} \mathrm{~S}^{\mathrm{O}}+\mathrm{HS}^{-}=\mathrm{Au}(\mathrm{HS})_{2}{ }^{-}+0.5 \mathrm{H}_{2}(\mathrm{~g})
$$

are only fairly consistent (see review in [5]). To date no quantitative comparison of data obtained by different investigators has been conducted in a satisfactory systematic manner. The purpose of this paper is to present the results of a comprehensive analysis of the literature data on the solubility of Au in near-neutral solutions.

The $\log \mathrm{K}$ values for reaction (1) were calculated on the basis of the individual Au solubility measurements reported in the literature. Chemical equilibria in the experimental systems were modeled by a Gibbs free-energy minimization technique [6] using a selfconsistent set of thermodynamic data.

The calculated distribution of aqueous species at experimental temperatures and pressures resulted in values of $\log \mathrm{K}$ for reaction (1) shown in Fig. 1. It can be seen that the $\log \mathrm{K}_{1}$ values derived from different experimental studies are reasonably consistent despite very different experimental techniques employed [1-4]. The standard partial molal volume of $\mathrm{Au}(\mathrm{HS})_{2}{ }^{-}$at $25^{\circ} \mathrm{C}$ and 1 bar calculated from the experimental data of Benning and Seward [5] $\left(\sim 60 \mathrm{~cm}^{3}\right.$ $\mathrm{mol}^{-1}$ ) agrees reasonably well with a value reported by Zotov et al. [4], $83 \pm 15 \mathrm{~cm}^{3} \mathrm{~mol}^{-1}$.

The values of $\log \mathrm{K}_{1}$ were regressed to obtain a tentative set of

TABLE 1. Standard partial molal properties of $\mathrm{Au}(\mathrm{HS})_{2}^{-}$ derived in the current study.

\begin{tabular}{|c|c|c|c|}
\hline$\Delta \mathrm{G}^{\mathrm{o}}$ & 2275 & $a_{3} s$ & -3.0715 \\
\hline $\mathbf{S}^{\circ+}$ & 56.126 & $a_{4}{ }^{f} \times 10^{-4}$ & -3.7068 \\
\hline $\mathrm{CP}_{\mathrm{p}^{+}}^{+}$ & 11.818 & $c_{1}^{+}$ & 20.9083 \\
\hline$V^{o} ;$ & 75.390 & $c_{2}{ }^{* *} \times 10^{-4}$ & -0.9380 \\
\hline a. $1 \times 10$ & 12.3789 & $\omega \cdot \times 10^{-5}$ & 0.7875 \\
\hline$a_{2} \times 10^{-2}$ & 22.4437 & & \\
\hline
\end{tabular}

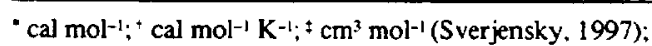

$1 \mathrm{cal} \mathrm{mol}^{-1} \mathrm{bar}^{-1}$; $\mathrm{cal} \mathrm{K} \mathrm{mol}^{-1} \mathrm{bar}^{-1}$ :** $\mathrm{cal} \mathrm{K} \mathrm{mol}^{-1}$. 
standard partial molal thermodynamic properties and HKF equation of state [7] for $\mathrm{Au}(\mathrm{HS})_{2}{ }^{-}$(see Table 1) that are consistent with the solid curve depicted in Fig. 1.

The results of this study indicate that the discrepancies in the previously reported $\log \mathrm{K}_{1}$ values result from the interpretation of the experimental observations rather than from the experimental observations themselves. It is possible to reconcile the results of different experimental studies and to predict Au solubility in nearneutral solutions at temperatures and pressures of geologic interest (up to $1000^{\circ} \mathrm{C}$ and $5 \mathrm{kbar}$ ). However, additional experimental studies seem to be necessary to confirm the temperature dependence of $\log \mathrm{K}_{1}$ and to refine estimates for stability of the neutral complex, AuHS $^{0}$ that predominates at low $\mathrm{pH}$ conditions.

References: [1] Seward (1973). [2] Shenberger and Barnes (1989). [3] Renders and Seward (1989). [4] Zotov et al. (1995). [5] Benning and Seward (1996). [6] Shvarov (1992). [7] Shock and Helgeson (1988).

\section{A TALE OF TWO PLUMES AND THE CASE OF THE LEAD} PARADOX. A. R. Basu, Department of Earth and Environmental Sciences, University of Rochester, Rochester NY 14627, USA.

There are remarkable parallelisms in major-element, trace-element, and $\mathrm{Nd}, \mathrm{Sr}, \mathrm{Pb}$, and $\mathrm{He}$ isotopic compositions of the Hawai' 'ian tholeiites and the 250-Ma-old continental flood basalt province in Siberia. It is generally believed that both the volcanic provinces are due to partial melting of lower-mantle-derived plumes, the principal evidence being that ${ }^{3} \mathrm{He} /{ }^{4} \mathrm{He}$ ratios much greater than the depleted mantle ratio of $8 \times$ the atmospheric ratio $\left(R_{a}\right)$ are found in these basaltic provinces. In the case of Hawai' $i$, the He isotopic ratio of $32 R_{a}$ and for the Siberian flood basalts, a value of at least $13 R_{a}$ have been established, which are diagnostic of lower-mantle origin. In addition, rapid eruption rates, homogeneous bulk compositions of the lavas, and systematic temporal and spatial evolution of the erupted lavas can all be explained by partial melting in a relatively stationary plume model. In the case of the Hawai'ian plume, the pristine basalts erupted through the thick oceanic lithosphere, whereas in the Siberian flood basalt province the lithospheric lid with an aged continental crust had to be encountered by the erupting magma. Once the contamination effects of these two different types of lithospheres are accounted for in the plume-derived magma, significant insights into the $\mathrm{Pb}, \mathrm{Nd}, \mathrm{Sr}$ isotopic and trace-element ratio signatures of the relatively uncontaminated plume source can be obtained. The results obtained in the case of these two plumes show remarkable convergence, with implications for the observed shift in the isotopic composition of mantle-derived $\mathrm{Pb}$ to the right of the

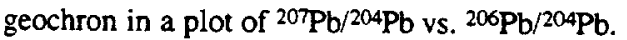

In the case of the Hawai'ian tholeiites from Lanai, Koolau, and Kahoolawe, all show extreme variation in $\mathrm{Sr}, \mathrm{Nd}$, and $\mathrm{Pb}$ isotopic ratios. In a plot of ${ }^{207 \mathrm{~Pb} / 204} \mathrm{~Pb}$ vs. ${ }^{206} \mathrm{~Pb} /{ }^{204} \mathrm{~Pb}$, Hawai' ian basalts plot to the right side of the geochron; however, the above three volcanos plot closest to the geochron with ${ }^{206} \mathrm{~Pb} / 204 \mathrm{~Pb}$ values ranging from a high of 18.4 to a low of almost 17.7. These three volcanos show the greatest influence of a supposedly primitive mantle plume component of all the Hawai' ian Islands. This conclusion can be supported by their REE patterns, Nd, Sr isotopic ratios, as well as in the nearchondritic $\mathrm{Ce} / \mathrm{Pb}$ ratio of near 10 in some of the basalts. In the case of the Siberian tholeiites, the least contaminated Putorana and
Norils'k tholeiites demonstrate essentially the same characteristics as in Hawai' $\mathrm{i}$ in their $\mathrm{Nd}, \mathrm{Sr}, \mathrm{Pb}$ isotopic ratios and a near-chondritic $\mathrm{REE}$ pattern and $\mathrm{Ce} / \mathrm{Pb}$ ratios of 10 to 14 . This comparison allows the least contaminated tholeiites from these two provinces to be very near the geochron, eliminating the $\mathrm{Pb}$ paradox. The positive correlation in $\mathrm{Pb}$-isotopic diagrams observed in most Hawai' ian basalts, and also in Siberian basalts, are results of mixing, principally between a bulk silicate earth component and a depleted uppermantle component. This result suggests that there is essentially no $\mathrm{Pb}$ depletion in bulk silicate earth and that $\mathrm{U} / \mathrm{Pb}$ fractionation does not need to be associated with core formation.

\section{DOCUMENTING AND MODELING HETEROGENEOUS FLUID-ROCK INTERACTION IN CONTACT AUREOLES WITH STABLE ISOTOPES. L. P. Baumgartner ${ }^{1}$, G. T. Ro-} selle $^{1}$, M. L. Gerdes ${ }^{2}$, M. Person ${ }^{3}$, and J. W. Valley', 'Department of Geology and Geophysics, University of Wisconsin, 1215 West Dayton, Madison WI 53706, USA, 'Earth and Planetary Sciences, Johns Hopkins University, Baltimore MD, USA ${ }^{3}$ Department of Geology and Geophysics, University of Minnesota, Minneapolis MN 55455, USA.

Heterogeneous fluid-rock interaction is ubiquitous in contact aureoles. It is readily documented by the spatial distribution of geochemical and petrologic alteration of contact metamorphic rocks. We have studied the Ubehebe Peak contact aureole (Death Valley National Park, CA) to develop adequate techniques to quantitatively describe and model $C$ and $O$ isotope exchange in carbonates by hydrothermal fluids. A large dataset ( $>400$ samples) was assembled using systematic sampling techniques (on grids) to avoid bias. A representative coverage of the contact aureole was attained. Samples were analyzed for bulk carbonate $O$ and $C$ isotope ratios and phase petrology

Bulk carbonate values of $\delta^{18} \mathrm{O}$ and $\delta^{13} \mathrm{C}$ for most of the aureolewide sample show a relatively narrow range in $\delta^{18} \mathrm{O}$ from 25.0 to $28.0 \%$ VSMOW and $\delta^{13} \mathrm{C}$ from -0.5 to $0.5 \%$ PDB, even close to the contact. However, some samples have been shifted to values as low as $\delta^{18} \mathrm{O} 11.1 \%$ and $\delta^{13} \mathrm{C}-9.1 \%$.

Interpretation of the isotope data reveals that both low $\delta^{13} \mathrm{C}$ and $\delta^{18} \mathrm{O}$ values are limited to $\sim 800 \mathrm{~m}$ of the contact, and that fluids were magmatic. The amount of $\mathrm{C}$ and $\mathrm{O}$ necessary to produce the observed alteration can be estimated using the average isotopic composition of the infiltrated samples. These calculations yield an estimate of $\mathrm{X}_{\mathrm{CO}_{2}}=0.26$ (assuming a binary, magmatic $\mathrm{H}_{2} \mathrm{O}-\mathrm{CO}_{2}$ fluid) and an overall volumetric fluid-rock ratio of 0.20 for the 800 $m$ isotopically altered zone. These results would also require that most of the magmatic fluid was expelled radially and not preferentially through the top of the intrusion. While it is possible that magmatic fluids may actually contain significant amounts of $\mathrm{CO}_{2}$, this is typically not considered likely based on $\mathrm{CO}_{2}$ melt solubility experiments. Possible sources of additional $\mathrm{CO}_{2}$ are rapidly progressing decarbonation reactions, which provide $\mathrm{CO}_{2}$ from the host rock, with an appropriate low $\delta^{13} \mathrm{C}$ signature. Rapid, near-complete reaction during skam formation at the contact is proposed to follow a diffusion-limited Rayleigh distillation (DLRD) mechanism [1]. The DLRD mechanism results in $\mathrm{CO}_{2}$ with $\delta^{13} \mathrm{C}$ similar to magmatic C. Based on the proposed DLRD model, 10-15 $\mathrm{m}$ of skarn along the contact is necessary to produce the required amount of 
$\mathrm{CO}_{2}$. Although not quite enough skarn is exposed at Ubehebe Peak, it seems nevertheless likely that metamorphic $\mathrm{CO}_{2}$ production has contributed significantly.

Heterogeneity, as documented by the isotopic data, ranges from the centimeter to decameter scale. Detailed geostatistical analysis of the stable isotope data made use of semivariograms, in which the variance of all possible pairs of data located in bins at defined distances from each other is plotted against the bin separation distance. From these plots the range-a measure of the distance over which samples are significantly correlated-and the sill-a measure for the variance of noncorrelated samples-were extracted. For data from the most intensely infiltrated zone, the innermost $100 \mathrm{~m}$ of the contact aureole, the semivariogram, has a range of $28 \mathrm{~m}$, while the data obtained from samples collected more than $800 \mathrm{~m}$ from the contact (no isotope shift due to infiltration) have a distinct smaller range of $13 \mathrm{~m}$. Simultaneously, the sill of the semi variogram decreases from 7.8 to 0.6 . These stable isotope variograms are used as input to forced convection models in an attempt to constrain statistical properties of the permeability distribution during the hydrothermal alteration of the Ubehebe contact aureole.

References: [1] Baumgartner et al. (1992) 29th IGC.

RARE EARTH ELEMENTS, YTTRIUM, THORIUM, AND URANIUM IN CRUSTAL MELTING - THE BEHAVIOR OF ACCESSORIES DURING METAMORPHISM AND ANATEXIS OF METAPELITES: THE KINZIGITE FORMATION (IVREA-VERBANO, NORTHERN ITALY). F. Bea ${ }^{1}$ and P. G. Montero' ${ }^{2}$ ' Department of Mineralogy and Petrology, Campus Fuentenueva, Universidad Granada, 18002 Spain (fbea@ goliat.ugr.es), ${ }^{2}$ Centro de Instrumentación Científica, Campus Fuentenueva, Universidad Granada, 18002 Spain (pmontero@goliat. ugr.es).

The Kinzigite Formation in Ivrea-Verbano (N. Italy) ranges from middle amphibolite to granulite facies and shows evidence of intense partial melting. Metapelites have a primary REEYThU-rich accessory assemblage composed of Zircon, monazite, and lessabundant xenotime whose modal abundance, average grain size, and textural position change as the metamorphic grade increases. Zircon is significantly more abundant in granulite-grade metapelites due to the extraction of $\mathrm{Zr}$-poor partial melts. The abundance of monazite is almost the same, but the modal monazite/Zircon ratio decreases with increasing metamorphic grade as monazite was more soluble into the melt than Zircon. The abundance and grain size of xenotime decrease rapidly with increasing metamorphic grade because xenotime was consumed in garnet-forming reactions. This process decoupled $Y$ from HREE and $U$ from $T h$, and caused the $U$ depletion in granulite-grade rocks. Monazite is also involved in gamet-forming reactions and shows progressively lower concentrations of $U, Y$, and HREE as the metamorphic grade increases. The proportion of accessory grains included in major minerals (hardly available for the melt at low melt fractions) decreases with increasing metamorphism, whereas the proportion of accessories placed in grain boundaries and triple junctions (easily available for the melt) increases concomitantly. This effect is more intense for monazite than for Zircon, though most monazite grains placed at triple junctions were crystallized directly from the partial melt instead of being restitic. Monazite grains included in gamet are often partially or totally replaced by a fine mixture of LREE-rich apatite and cheralite. This reaction involves the change of LREE (from monazite) by $\mathrm{Ca}$ (from garnet) and, though not entirely clear, it might be prograde. Occasionally, monazite is extensively retrograded, producing secondary allanite. The direct crystallization of monazite from the anatectic melt, as well as its involvement in both prograde and retrograde reactions, indicate that this mineral behaves as an open system during high-grade metamorphism and anatexis and is therefore capable of recording the age of those events more sensitively than Zircon. But this behavior also produces the coexistence of several generations of monazite crystals, each recording (and on many occasions mixing) different events. To get reliable monazite $\mathrm{U}-\mathrm{Pb}$ ages therefore requires carefully performed textural studies for selecting the right monazite grains.

Leucosomes segregated from granulite-grade metapelites have a small Eu anomaly (either positive or negative) and their $\mathrm{Zr}$ and LREE concentrations indicate they were saturated with Zircon and monazite at a temperature of $750^{\circ}-800^{\circ} \mathrm{C}$, the same range obtained with gamet thermometry on mesosomes. Leucosomes segregated from amphibolite-grade metapelites have a large positive Eu anomaly and have lower-than-saturation concentrations of REE and, especially, $\mathrm{Zr}$. This effect is not related to the kinetics of melt segregation but to the poor accessories availability for the melt at the lowest degree of partial melting, which, according to textural observations, is worse for Zircon than for monazite.

RADIOCARBON VARIATIONS INMODERN CORALS.J. W. Beck, G. S. Burr, L. Calsoyas, and D. J. Donahue, NSF AMS, Arizona Facility, Department of Physics, University of Arizona, Tucson AZ 85721, USA (Wbeck@physics.arizona.edu).

AMS radiocarbon measurements on modem corals reveal that ocean surface waters experience significant seasonal variability in radiocarbon concentration. These variations are associated with seasonal changes in the $\mathrm{C}$ cycle. These seasonal variations are principally related to changes in the proportion of ${ }^{14} \mathrm{C}$-rich $\mathrm{CO}_{2}$ entering the surface ocean across the ocean/atmosphere interface relative to the amount of ${ }^{14} \mathrm{C}$-depleted $\mathrm{C}$ entering the mixed layes from the deep ocean. Such variations may be produced locally, but also may be laterally advected from other regions of the ocean basin. We present several high-frequency radiocarbon records derived from corals collected from the tropical Pacific Ocean. Some of these show features that suggest strong modulation of mixed-layer ${ }^{14} \mathrm{C}$ concentration by ENSO.

ASSESSING TRACE-ELEMENT FLUXES IN ISLAND ARC SYSTEMS USING RATIOS OF HIGHLY INCOMPATIBLE ELEMENTS IN ECLOGITES. H. Becker and R. W. Carlson, Department of Terrestrial Magnetism, Carnegie Institution of Washington, 5241 Broad Branch Road, Northwest, Washington DC 20015, USA (becker@dtm.ciw.edu).

Eclogites from high-pressure terranes show temperature-dependent differential fractionation of highly incompatible elements [1]. Here, a set of trace-element ratios is used as a model for the composition of subducted altered and unaltered oceanic crust at temperatures of $900^{\circ}-1000^{\circ} \mathrm{C}$. We calculate the annual arc magma 
fluxes per kilometer arc length for $\mathrm{K}, \mathrm{Ba}, \mathrm{Pb}, \mathrm{Th}, \mathrm{U}, \mathrm{Nd}$, and $\mathrm{Sr}$, and compare the results with the element inventory of average basaltic oceanic crust ( $0.5 \mathrm{~km}$ altered N-MORB, $6.4 \mathrm{~km} \mathrm{N-MORB),} \mathrm{sub-}$ ducted annually per kilometer arc length. A simple first-order model for the Mariana arc system shows that the nearly complete transfer of $\mathrm{K}$ from average basaltic oceanic crust to arc magmas would result in much higher $\mathrm{K}$ abundances in Mariana arc magmas than actually observed. Consequently, only $<30-50 \%$ of $\mathrm{K}$ lost during devolatilization appears to be transferred to the arc magmas. The rest may reside in the cool parts of the mantle wedge or escape through hydrothermal transport at shallow depths. In a more detailed model, average fractionation factors obtained from eclogites equilibrated at $500^{\circ}-600^{\circ} \mathrm{C}$ and from high-pressure veins formed at $600^{\circ}-650^{\circ} \mathrm{C}$ are used to calculate the element loss from average subducted basaltic oceanic crust between these temperatures and $900^{\circ}-1000^{\circ} \mathrm{C}$. The results show that subducted basaltic crust can provide as much as $98 \%$ of the $\mathrm{K}$ in arc magmas. For $\mathrm{Ba}, \mathrm{Th}, \mathrm{U}, \mathrm{Pb}, \mathrm{Nd}$, and $\mathrm{Sr}$, the fractions from average subducted basaltic crust in the Mariana arc magma budget would be $23,14,18,26,6$, and $10 \%$ respectively. These are maximum values, since the sediment column in subducted oceanic crust may provide a substantial fraction of $K$ in the arc magma budget. These results indicate that a minimum of 75$95 \%$ of the $\mathrm{Ba}, \mathrm{Th}, \mathrm{U}, \mathrm{Pb}, \mathrm{Nd}$, and $\mathrm{Sr}$ in Mariana arc magmas is derived from sources other than average subducted basaltic crust. The results for $\mathrm{Ba}$ and $\mathrm{Th}$ are consistent with the good correlations of ${ }^{6} \mathrm{Ba}^{6} \mathrm{Na}$ and ${ }^{6} \mathrm{Th} / 6 \mathrm{Na}$ with the $\mathrm{Ba}$ and $\mathrm{Th}$ sediment flux for different arc systems [2] and imply that the $\mathrm{Ba}$ and $\mathrm{Th}$ budgets in arc magmas are largely controlled by fluids or melts derived from subducted sediments (the same may be true for $U$ ). Our results for $\mathrm{Sr}$ and $\mathrm{Nd}$ and the poor correlation of ${ }^{6} \mathrm{Sr} /{ }^{6} \mathrm{Na}$ with the Sr sediment flux [2] indicate that the mantle wedge provides a large contribution to the $\mathrm{Sr}$ and $\mathrm{Nd}$ budget in arc magmas.

References: [1] Becker et al. (1996) EOS Trans. AGU, 77, F784. [2] Plank and Langmuir (1993) Nature, 362, 739-743.

CONSTRAINTS FROM URANIUM-THORIUM-LEADNEODYIUM-STRONTIUMSYSTEMATICSOFPALEO-ZOIC GARNET PYROXENITES ON SEDIMENT-ALTERED MIDOCEAN-RIDGE-BASALT-MANTLE MIXING IN ARC MAGMA PETROGENESIS. H. Becker and R. W. Carlson, Department of Terrestrial Magnetism, Camegie Institution of Washington, 5241 Broad Branch Road, Northwest, Washington DC 20015, USA (becker@dtm.ciw.edu).

New U-Th-Pb data in conjunction with $\mathrm{Sr}-\mathrm{Nd}$ isotope data [1] on gamet pyroxenite layers in garnet-bearing peridotite massifs from lower Austria provide unique constraints on the nature of sources that contribute to magmas produced at convergent plate margins. The pyroxenites investigated represent high-pressure cumulates that crystallized in the deep lithosphere $(P=3-3.5 \mathrm{GPa})$ from incompatible-element-enriched melts derived from sublithospheric sources. These samples have not been affected by the shallow crustal contamination processes that tend to obscure slab-derived signatures in arc lavas. Lead abundances in the pyroxenites are very high (typically $\sim 5 \mathrm{ppm}$ ) and correlate with $\mathrm{Na}$ abundances and modal abundances of cpx. Compared with other mantle rocks, Th and $U$ abundances are high, and Th/U low (0.7-2.7). Uranium/lead, $\mathrm{Th} / \mathrm{Pb}, \mathrm{Th} / \mathrm{U}$, and $\mathrm{Nd} / \mathrm{Pb}$ show no conclusive correlations with modal mineralogy, but vary systematically with initial $\mathrm{Sr}$ isotopic compositions. This indicates that possible variations in $\mathrm{Th} / \mathrm{U}$ and $\mathrm{Nd} / \mathrm{Pb}$ caused by high-P fractionation or melting in the sub-arc mantle are likely being obscured by parental magma heterogeneity resulting from fractionation processes in the slab. Initial $\mathrm{Pb}$ isotopic compositions of the pyroxenites at $335 \mathrm{Ma}$ form a cluster close to the composition of typical upper crustal $\mathrm{Pb}$ at this time. In $207 \mathrm{~Pb} / 204 \mathrm{~Pb}$ ${ }^{87} \mathrm{Sr} /{ }^{86} \mathrm{Sr}, \mathrm{Nd} / \mathrm{Pb}-{ }^{87} \mathrm{Sr} /{ }^{86} \mathrm{Sr}$, and $\mathrm{Nd} / \mathrm{Pb}-\mathrm{Th} / \mathrm{U}$ diagrams, the spread of the data requires at least three components: (1) a component derived from sediment (high ${ }^{87} \mathrm{Sr} /{ }^{86} \mathrm{Sr},{ }^{207 \mathrm{~Pb}} /{ }^{204} \mathrm{~Pb}, \mathrm{Nd} / \mathrm{Pb}<0.6, \mathrm{Th} / \mathrm{U}=2-$ 3); (2) a component from altered MORB (moderate ${ }^{87} \mathrm{Sr} /{ }^{86} \mathrm{Sr},{ }^{207} \mathrm{~Pb}$ / ${ }^{204} \mathrm{~Pb}, \mathrm{Nd} / \mathrm{Pb}<1-2, \mathrm{Th} / \mathrm{U}<0.7-1$ ); and (3) a depleted mantle-like component (low ${ }^{87} \mathrm{Sr} /{ }^{86} \mathrm{Sr},{ }^{207 \mathrm{~Pb} / 204} \mathrm{~Pb}, \mathrm{Nd} / \mathrm{Pb}>10, \mathrm{Th} / \mathrm{U}=2-2.5$ ). Neodymium/lead and Th/U of those pyroxenites that show the strongest sediment signature lie outside the field for pelagic and terrigenous sediments indicating (1) that incorporation of bulk sediment from the slab can not explain this endmember composition, and (2) significant fractionation of $\mathrm{Nd} / \mathrm{Pb}$ (factor 3-4) and $\mathrm{Th}$ $\mathrm{U}$ (factor 1.5-2) during devolatilization or partial melting of metasediments in the slab. The depleted mantle-like component may have been acquired by interaction of the melts with the peridotitic wallrocks in the mantle wedge. Mixing models show that if the fluid or melt component was derived from pelagic or terrigenous sediment, it may have provided up to $30 \%$ of the $\mathrm{Pb}$ in the pyroxenites. Comparison of the results with data from intraoceanic island arcs indicates that those lavas with coupled high $T h / U(>3)$ and moderately low $\mathrm{Nd} / \mathrm{Pb}(>1-2)$ may have been strongly affected by shallow-level crustal contamination.

References: [1] Becker (1996) J. Petrol., 37, 785-810.

THE ATOMIC AND ELECTRONIC STRUCTURE OF THE (001) SURFACE OF MONOCLINIC PYRRHOTITE ( $\mathrm{Fe}_{7} \mathrm{~S}_{8}$ ) STUDIED BY USING SCANNING TUNNELING MICROSCOPY, LOW-ENERGY ELECTRON DIFFRACTION, AND QUANTUM-MECHANICAL CALCULATIONS. U. Becker', A. R. Lennie ${ }^{2}$, D. J. Vaughan ${ }^{2}$, A. W. Munz ${ }^{3}$, and G. Thomton ${ }^{3}$, 'Institut für Mineralogie, Universität Münster, Corrensstrasse 24, D-48149 Münster, Germany (udo@pmin37.unimuenster.de), 2Department of Earth Sciences, University of Manchester, Oxford Road, Manchester M13 9PL, UK, 'Interdisciplinary Research Center in Surface Science, Liverpool University, Liverpool L69 3BX, UK.

The surface atomic structure and reactivity at the atomic level of monoclinic pyrrhotite $(001)$ has been examined using low-energy electron diffraction (LEED) and scanning tunneling microscopy (STM) following sputtering and annealing the surface at $=300^{\circ} \mathrm{C}$.

A phase transition is observed in LEED pattems taken at elevated temperatures. At temperatures above $\approx 300^{\circ} \mathrm{C}$, the LEED patterns show only the periodicity of the roughly hexagonal closestpacked $\mathrm{S}$ atoms, whereas at lower temperatures, additional LEED spots appear that reflect the ordering of Fe vacancies. This transition is reversible.

STM images taken at negative-bias voltages exhibit triangular terraces separated by steps. Measured step heights are integer multiples of $2.9 \AA$, which is one quarter of the $4 C \mathrm{Fe}_{7} \mathrm{~S}_{8}$ unit cell size in the $c$ direction, and corresponds to the distance between two consecutive Fe or $S$ layers. Although the STM images of single terraces appear to have an atomic arrangement corresponding to the ordering within those Fe layers that contain vacancies, bright spots 
in the images are most likely to represent $S$ atoms, with a vacancy ordering that is induced by the Fe vacancies. This conclusion is supported by experimental STM images, which show a reversed orientation of the surface geometry on successive terraces when separated by steps of $2.9 \AA$, and by quantum mechanical calculations of STM images that show S 3p-like states at the top of the valence band.

Pymhotite (001) surfaces contain triangular pits with dimensions ranging from the atomic scale to more than $100 \AA$ across. These are formed by the successive removal of $\mathrm{Fe}_{3} \mathrm{~S}_{3}$ units from the surface. Images taken following exposure of the surface to $6000 \mathrm{~L} \mathrm{O}_{2}$ did not alter the flat terraces but formation of adsorptive structures near steps, especially at comers, was observed. The reaction mechanism of the surface with $O$ at the atomic scale can be explained by the nature of the bond with the surface atoms. The formation of the $S$ $\mathrm{O}$ bond is inhibited by the spin transformation of $\mathrm{O}_{2}$, and $\mathrm{Fe}-\mathrm{O}$ bonds can only be formed at comers of terraces where Fe from interlayers is exposed to the surface.

\section{ULTRADEPLETED MANTLE BENEATH THE BALTIC} SHUELD. B. V. Belyatsky ${ }^{1}$, A. Arzamastsev ${ }^{2}$, and L. K. Levsky ${ }^{1}$, ${ }^{1}$ Institute of Precambrian Geology and Geochronology, Russian Academy of Sciences, Makarova Emb. 2, 199034 St. Petersburg, Russia (boris@ger.ras.spb.ru; lev@ad.iggp.ras.spb.ru), 2'Geological Institute, Kola Sciences Center, Russian Academy of Sciences, Fersman Street 14, 184200 Apatity, Russia (arzamas@ kscgi.murmansk.su).

In xenoliths from the Siberian kimberlites, unusual isotopic $\mathrm{Nd}$ signatures were measured: $\varepsilon_{N d}=20, T=2000 \mathrm{~m} . \mathrm{y}$. [1-3]. These signatures bear witness to the existence of an ultradepleted mantle reservoir beneath the Siberian craton. How widely is the mantle distributed with such anomalous parameters?

In response to this question we studied $\mathrm{Rb}-\mathrm{Sr}$ and $\mathrm{Sm}-\mathrm{Nd}$ mineral isotopic systems of spinel peridotite xenolith from host Olmelanephelinite (Khibina massif, Kola Peninsula). The Rb-Sr isotopic system ( $T=427 \pm 6 \mathrm{~m}$.y. and $\mathrm{I}_{\mathrm{Sr}}=0.70358 \pm 6$ based on

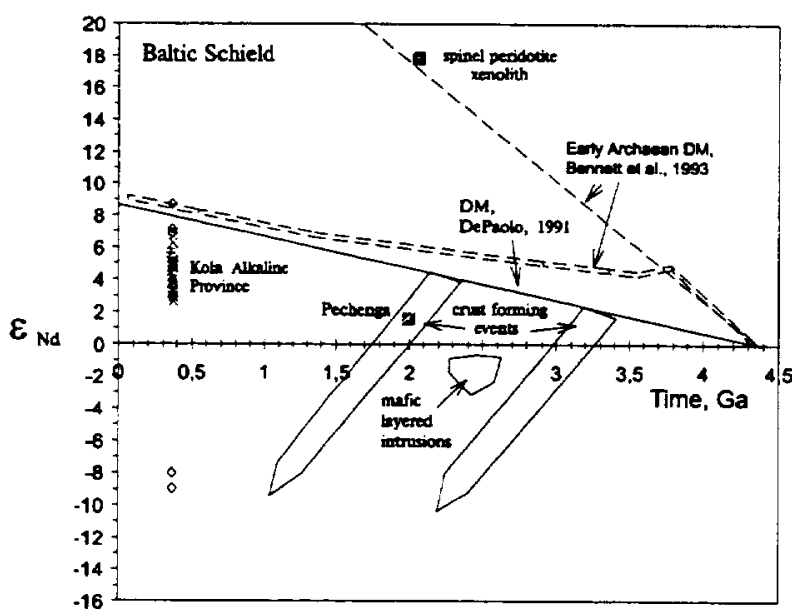

Fig. 1. Evolution diagram $\varepsilon_{\mathrm{Nd}^{-}} \mathrm{T}$ for different mantle reservoirs beneath the Baltic Shield. Data from $[5,6]$. orthopyroxene, amphibole, olivine, and whole rock) was equilibrated nearly completely before or/and at the time of melanephelinite extrusion. The melanephelinite, if it corresponds to its origin to the Khibina carbonatite, has $\mathrm{T}=365 \mathrm{~m} . \mathrm{y}$. and $\mathrm{I}_{\mathrm{sr}}=0.70392 \pm 6$ [4].

The Sm-Nd mineral isotopic system is disequilibrated: $\mathrm{T}=$ $2054 \pm 79 \mathrm{~m} . y$. and $\varepsilon_{\mathrm{Nd}}=17.9$. These figures taken at face value demonstrate the similarity of Siberian xenoliths to the existence of ultradepleted domain beneath the Baltic Shield also. The anomalous Archean reservoir could be formed as a result of primordial depletion $\sim 4500 \mathrm{~m} . y$. ago or at the expense of repeated depletion accompanied by crust-forming events in this region. If such a depletion really existed, its influence on the $T_{D M}$ situation will be unpredictable.

However, a model of recent mantle-crust metasomatic processes could suggest another explanation for the obtained results. In this case, the measured Sm-Nd age is younger than the "real" mantle age, which corresponds to the primary closing of the isotopic system in the mantle, and the measured $\varepsilon_{\mathrm{Nd}}$ value is higher than the actual value, which corresponds to the evolution curve of a normal depleted reservoir (MORB-like).

References: [1] McCulloch M. T. (1989) Geol. Soc. Austr. Spec. Publ., 14, 864-876. [2] Snyder et al. (1993). [3] Zhuravlev A. et al. (1991) Geokhimya, 7, 982-993. [4] Kramm U. (1993) Eur. J. Mineral., 5, 985-989. [5] Bennett V. et al. (1993) EPSL, 119, 299 317. [6] DePaolo (1991).

MICROBIAL METABOLISM, IRON REDUCTION, AND SILICATE DISSOLUTION: COUPLED PROCESSES IN MANERAL WEATHERING. P. C. Bennett ${ }^{1}$, W. J. Choi ${ }^{1}$, J. A. Roberts', F. K. Hiebert', and W. J. Ullman'2, 'Department of Geological Sciences, The University of Texas at Austin, Austin TX 78712, USA, ${ }^{2}$ College of Marine Studies, University of Delaware, Lewes DE 19958, USA.

At the U.S. Geological Survey's Bemidji research site, microbes efficiently degrade spilled petroleum in a shallow sand and gravel outwash aquifer. Microbial oxidation of hydrocarbon in the anaerobic plume-core is coupled in part to the reductive dissolution of iron oxide minerals, with ferric iron acting as the terminal electron acceptor [e.g., 1]

$$
\mathrm{CH}+5 \mathrm{FeOOH}+2 \mathrm{H}_{2} \mathrm{O} \rightarrow \mathrm{HCO}_{3}^{-}+5 \mathrm{Fe}^{2+}+9 \mathrm{OH}^{-}
$$

Coincident with the mobilization of ferrous iron, however, dissolved silica increases from 0.3 to $\sim 1.1 \mathrm{mmol} / \mathrm{l}$ as silicate minerals dissolve at circum neutral $\mathrm{pH}$. Dissolved organic $\mathrm{C}$ concentration is very high, and is principally composed of simple and complex organic acids [2].

To investigate the relationship between microbial metabolism and silicate weathering, pristine mineral specimens were placed in the Fe-reducing part of the aquifer and allowed to colonize and react for periods up to one year. Post reaction surface examination shows that some relatively resistant minerals such as microcline, quartz, and anorthoclase support microbial colonies, with extensive weathering near the areas of microbial attachment (Fig. 1). Some relatively less-resistant minerals, such as albite and olivine are uncolonized, and unweathered. In control experiments, silicates in acidic, non-Fe-reducing regions do not weather. 


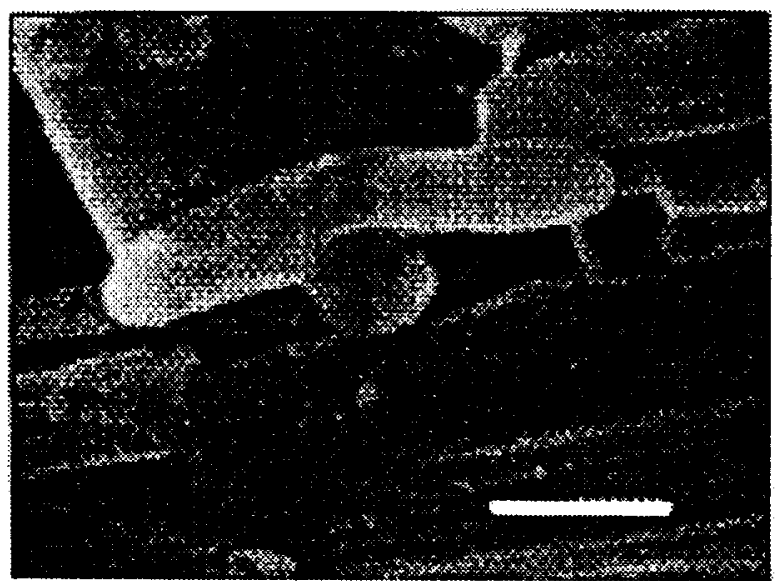

Fig. 1. SEM micrograph of a microbe attached to a microcline surface reacted for one year in the aquifer. Scale bar is $0.5 \mu \mathrm{m}$.

There are several mechanisms that can explain the observed relationship between microbial colonization, $\mathrm{Fe}$ reduction, and silicate weathering. One possibility is that microbes produce regions of locally low $\mathrm{pH}$, with silicate dissolution enhanced via proton-promoted hydrolysis. While this is probably a contributing factor, it does not explain the dissolution of quartz, which is insensitive to low $\mathrm{pH}$ conditions. Another possibility is a region of locally high $\mathrm{pH}$ associated with the dissolution of oxidized Fe minerals [e.g., equation (1)]. This should only occur, however, in close proximity to the Fe mineral in response to the released hydroxide, and the microcosm mineral surfaces were devoid of oxidized Fe coatings or phases. Microbes are also seen to be directly dissolving calcite, suggesting acidic $\mathrm{pH}$ conditions.

These data suggest that silicate dissolution is related to the microbial production of extracellular ligands. While a variety of organic ligands are present in the contaminated groundwater, a particularly reactive class of chelates known as siderophores has been tentatively isolated. Siderophores produced by bacteria to mobilize Fe for cellular metabolism also chelate and mobilize other metals. Our laboratory investigations of siderophore complexation and silicate dissolution kinetics show that tropolonates and dihydroxybenzoates (but not hydroxymates) are quite reactive toward $\mathrm{Al}$ and silica, and both accelerate silicate dissolution. Of these, dihydroxybenzoates have been tentatively identified in this aquifer.

We propose that silicate weathering is directly linked to microbial Fe reduction, primarily through the production of extracellular ligands. In the Bemidji aquifer, degradation of toluene appears to result in the microbial production of dihydroxybenzoates (a toluene degradation byproduct) that mobilizes ferric iron for use as an electron acceptor. The siderophore reacts with the silicate surface near the colonizing microbe, resulting in rapid chemical weathering. For microbes colonizing minerals containing nutritional elements, enhanced chemical weathering and release of nutrients may increase their chance of survival.

References: [1] Lovely D. R. et al. (1989) Nature, 339, 297300. [2] Eganhouse R. P. et al. (1993) Appl. Geochem., 8, 551-567.

HAFNIUM ISOTOPIC COMPOSITIONS DO NOT CON. STRAIN EARLY ARCHEAN NEODYMIUM EVOLUTION.
V.C. Bennett and A. P. Nutman, Research School of Earth Sciences, The Australian National University, Canberra, ACT 0200, Australia (vickie.bennett@anu.edu.au).

Initial Nd isotopic compositions from well-documented Archean rocks provide some of the strongest constraints on early Earth crustmantle dynamics. Many $>3.7-\mathrm{Ga}$ early Archean gneisses, including the well-preserved areas in the extensive, well-documented gneisses from Southwest Greenland, are characterized by initial $\varepsilon_{\mathrm{Nd}}$ values $\geq 2$ and up to 4 [ 1 and references therein]. These signatures require a mechanism to provide sufficient $\mathrm{Sm} / \mathrm{Nd}$ fractionation in the mantle to generate these extreme isotopic compositions early in Earth history. Various models have invoked rapid crust formation, crustal extraction from limited mantle volumes, magma ocean-style differentiation, and basalt storage [e.g., 2-5]. The significance of these highly positive $\varepsilon_{\mathrm{Nd}}$ values is currently controversial because all early Archean rocks are polymetamorphic and therefore may have suffered postcrystallization $\mathrm{Sm}$-Nd fractionation resulting in the calculation of erroneous initial Nd isotopic compositions. Although various criteria can be rigorously applied in sample selection, it is impossible to determine a priori the resistance of any given sample to isotopic resetting.

Vervoort et al. [6] have recently proposed that Hf isotopic compositions measured from zircons separated from the same early Archean samples from Southwest Greenland as were used for wholerock Nd isotopic studies [1] could provide a test of the Nd isotopic compositions. As the resulting $\mathrm{Hf}$ isotopic compositions did not follow their proposed mantle correlation line where $\varepsilon_{\mathrm{Hf}}=2 \varepsilon_{\mathrm{Nd}}$, these authors concluded that the Nd isotopic compositions reflect secondary disturbances.

Our purpose here is to discuss further the nature of these controversial samples and to argue that although $\mathrm{Hf}$ isotopic compositions can place new constraints on early Archean crust formation processes, they are not able to prove or disprove the validity of the initial $\mathrm{Nd}$ compositions. The Hf argument is dependent entirely on the validity of the proposed 2:1 $\varepsilon_{\mathrm{Hf}}-\varepsilon_{\mathrm{Nd}}$ correlation for the early Archean mantle, which is based on an extremely limited and diverse dataset. Recently determined Hf isotopic compositions of MORBs [7], continental basalts [8], and island arc rocks [9] all document the complex fractionation of $\mathrm{Lu} / \mathrm{Hf}-\mathrm{Sm} / \mathrm{Nd}$, resulting in a range of $\varepsilon_{\mathrm{Nd}^{-}}$ $\varepsilon_{\mathrm{Hf}}$ correlations. Modern ocean island basalts are the only suite for which the isotopic correlation is constant and with $\varepsilon_{\mathrm{Hf}}=1.4 \varepsilon_{\mathrm{Nd}}$ and this likely reflects two-component mixing. In contrast, modem MORBs are characterized by a large range in $\varepsilon_{\mathrm{Hf}}$ (>15 $\varepsilon$ units) over a narrow range of $\varepsilon_{\mathrm{Nd}}$. This has been attributed to melting of depleted spinel peridotites, which would yield a lower slope, with $\varepsilon_{\mathrm{Hf}}=\varepsilon_{\mathrm{Nd}}$, than melts derived from depleted garnet peridotite. Presupposing that the very early Archean mantle has a fixed $\mathrm{Hf} / \mathrm{Nd}$ isotopic correlation ignores the uncertainties in the processes of crust formation and mantle fractionation in the early Earth; simple and constant $\mathrm{Hf}$ and $\mathrm{Nd}$ isotopic relationships cannot be assumed.

Even if $\mathrm{L} u / \mathrm{Hf}$ and $\mathrm{Sm} / \mathrm{Nd}$ fractionation have been closely coupled such that the relationship $\varepsilon_{\mathrm{Hf}}=1.4-2 \varepsilon_{\mathrm{Nd}}$ characterizes the mantle throughout all of Earth history, then $\varepsilon_{\mathrm{Hf}}$ values as positive as 5 in $3.82-\mathrm{Ga}$ rocks requires $\varepsilon_{\mathrm{Nd}}$ values of $2.5-3.2$ in at least some portions of the mantle. Thus the conclusions based on the $\mathrm{Nd}$ isotopic data, that is, of the requirement of a different style of mantle depletion in the early Archean as compared to later time periods, are also required by the $\mathrm{Hf}$ isotopic data. Although the database is much 
more limited, $\varepsilon_{\mathrm{Hf}}$ values of 5 at 3.82 compared with values of 6 at $2.75 \mathrm{Ga}[10]$ require buffering mantle depletion, as has been suggested from $\mathrm{Nd}$ isotopic compositions of Archean rocks [3].

Given the current limited understanding of mantle depletion processes in the Archean, we suggest that $\mathrm{Hf}$ isotopes do not constrain the veracity of the $\mathrm{Nd}$ isotopic compositions from the same rocks. Until the meaning of the Hf isotopic compositions is examined more critically, they should not be accepted as rigorous constraints on early Earth history.

References: [1] Bennett et al. (1993) EPSL, 119, 299-317. [2] Armstrong (1981) Phil. Trans. R. Soc. London, A301, 443-472. [3] McCulloch and Bennett (1994) GCA, 58, 4717-4738. [4] Chase and Patchett (1988) EPSL, 91, 61-73. [5] Galer and Goldstein (1991) GCA, 55, 227-239. [6] Vervoor et al. (1996) Nature, 329, 624-627. [7] Salters (1996) EPSL, 141, 109-123. [8] Johnson and Beard (1993) Nature, 362, 441-444. [9] Pearce (1997) Geol. Soc. Aust. Abstr., 45, 69-71. [10] Corfu and Noble (1992) GCA, 56, 2081-2097.

THE OSMIUM MANTLE EVOLUTION CURVE AND LIMITS ON ACCRETION AND DIFFERENTIATION OF THE EARTH FROM ARCHEAN (2.9-3.8 Ga) ULTRAMAFIC ROCKS. V.C. Bennett, T. M. Esat, and A. P. Nutman, Research School of Earth Sciences, The Australian National University, Canberra ACT 0200, Australia (vickie.bennett@anu.edu.au).

The Os isotopic compositions of abyssal peridotites and fertile lithospheric mantle xenoliths [1-3], which are believed to represent depleted (MORB source) upper mantle are within the range of compositions measured in chondritic meteorites. In contrast the $O$ isotopic characteristics of modem ocean island basalts (OIB) are distinct from MORB source materials and require the existence of an isotopically distinct mantle source region. Although we now have a very general outline of the Os characteristics of the modern mantle, long-term mantle Os history remains obscure, largely because of the scarcity of data for Precambrian rocks. The situation is further complicated by the siderophile characteristics of $\mathrm{Re}$ and $\mathrm{Os}$ in that it is unclear what fractionation effects, if any, may be inherited from core formation, or from secondary accretionary processes if the highly siderophile elements were added as part of a "late meteoritic veneer" after core formation.

In order to establish the Os isotopic evolution of the early mantle we have analyzed well-characterized early Archean ultramafic rocks. Our approach is to analyze whole-rock samples and olivine, Alspinel, and chromite mineral separates with high Os concentrations (from 0.5 to $1000 \mathrm{ppb}$ ) and extremely low Re/Os ratios. In this way the accuracy of the calculated initial ratios is resistant to geological complications such as secondary Re mobility and crustal contamination, as well as being robust to uncertainties stemming from blank corrections and analytical difficulties associated with $\mathrm{Re}$ and $\mathrm{Os}$ spike calibrations. Additionally we have used severe leaching procedures, in particular for chromites, which result in more reproducible initial Os compositions.

The oldest Os isotopic constraints come from early Archean ultramafic rocks from southwest Greenland. These spinel peridotites occur as large (up to square kilometer) well-preserved enclaves within tonalitic gneisses; SHRIMP U-Pb dating of cross-cutting gneisses in three areas requires these peridotites to be $>3.81 \mathrm{Ga}$. The measured ratios from four samples are the lowest yet identified in terrestrial rocks with ${ }^{187} \mathrm{Os} / 188 \mathrm{Os}(0)=0.1026$ to $0.1041\left(\gamma_{O s}(0)=\right.$ -19.5 ). These data provide the strongest constraints on very early terrestrial mantle compositions. We have also analyzed chromites associated with 3.46-Ga komatiites from the Pilbara Block, Westem Australia, and from $\sim 3.0$ greenstones in Zimbabwe. These data, combined with initial isotopic compositions measured from $\mathrm{Fe}$ meteorite isochrons [4,5] and selected literature data for 1.9-2.7-Ga sample suites, define bulk silicate Earth (BSE) evolution; the projection of the curve indicates a modern BSE isotopic composition of $0.1286 \pm 0.0003$. The is within errors of the value of $0.1292 \pm$ 0.0007 from measurements of fertile spinel peridotites [3] and both are higher than other estimates of modem mantle compositions.

In contrast to modern OIB, the 3.45-Ga komatiites and 2.7-Ga komatiites [6] fall precisely on the BSE evolution curve. If both OIB and komatiites are products of deep mantle plumes, then the absence of radiogenic Os in komatiites places limits on the timescales of recycling and retum of high Re/Os material in the plume source. Alternatively if radiogenic Os compositions in modern OIB result from incorporation of minor amounts of high $\mathrm{Re} / \mathrm{Os}$ outer core material [7], then we predict that Archean komatiites should also have resolvable higher than BSE compositions. As this is not the case, either the dynamics at the core-mantie boundary must have changed or the incorporation of core material is not the explanation for the enriched component in modern plume materials.

The $3.81-\mathrm{Ga}$ spinel peridotites from southwest Greenland also constrain the timing of a late accretionary veneer in that their Os concentrations (1.7-2.5 ppb) are similar to the average concentrations measured in modern peridotites. Thus the PGE component must have been added to the Earth, and mixed homogeneously into the mantle by $3.81 \mathrm{Ga}$. We suggest it is thus unlikely that the late veneer is related to the lunar terminal bombardment, which occurred at 3.8-3.9 Ga.

References: [1] Snow and Reisberg, EPSL, 133, 411-421. [2] Roy-Barman and Allègre, $G C A, 58,5043-5054$. [3] Meisel et al. (1996) Nature, 383, 517-520. [4] Shen et al., GCA, 60, 2887-2900. [5] Smoliar et al., Science, 271, 1099-1 102. [6] Foster et al. (1996) Nature, 382,703-706. [7] Walker et al. (1995) Science, 269, 819 822.

THE SOLUBILITY OF CALCIUM- AND MAGNESIUMEXCHANGED CLINOPTILOLITE. L. G. Benning, R. T. Wilkin, and H. L. Barnes, Department of Geosciences, The Pennsylvania State University,University Park PA 16802,USA (liane@ essc.psu.edu).

Silica-rich zeolites such as clinoptilolite are prime targets for use as hydrochemical bariers to radionuclide transport in nuclear waste repositories (e.g., Yucca Mountain, Nevada). Nevertheless, the thermodynamic and kinetic properties of clinoptilolite required for modeling element transport processes are insufficiently known.

In this study the solubility of $\mathrm{Ca}$ - and $\mathrm{Mg}$-exchanged clinoptilolite (Ca-CPT and Mg-CPT) at hydrothermal conditions was measured, and equilibrium constants for the dissolution of $\mathrm{Ca}$ - and $\mathrm{Mg}$-CPT were calculated. Previous work on the solubility of clinoptilolite at hydrothermal temperatures was limited to $\mathrm{Na}$ and $\mathrm{K}$ exchanged forms $[1,2]$. In this paper the first equilibrium constants for $\mathrm{Ca}$ - and $\mathrm{Mg}$ CPT are reported and the importance of water content on the stability 
of clinoptilolite exchanged with monovalent ( $\mathrm{Na}$ and $\mathrm{K}$ ) and divalent ( $\mathrm{Ca}$ and $\mathrm{Mg}$ ) cations is discussed.

Clinoptilolite from Castle Creek (Idaho) with an Si/Al ratio of 4.50 , was cleaned and exchanged in concentrated $\mathrm{Ca}$ and $\mathrm{MgCl}$ solutions at $50^{\circ} \mathrm{C}$ and $120^{\circ} \mathrm{C}$ for up to 60 days. Exchange efficiency of $89.5 \%$ for $\mathrm{Ca}$ and $78.9 \%$ for $\mathrm{Mg}$ were reached. The natural and exchanged clinoptilolite were characterized by XRD and SEM and the chemical composition was determined by ICP analysis: untreated: $\mathrm{Na}_{0.52} \mathrm{~K}_{0.21} \mathrm{Ca}_{0.06} \mathrm{Mg}_{0.12}\left(\mathrm{Al}_{1.1} \mathrm{Si}_{4.9} \mathrm{O}_{12}\right)\left(3.3 \mathrm{H}_{2} \mathrm{O}\right)$; $\mathrm{Ca}$-CPT: $\mathrm{Na}_{0.02} \mathrm{~K}_{0.03} \mathrm{Ca}_{0.52} \mathrm{Mg}_{0.04}\left(\mathrm{Al}_{1.1} \mathrm{Si}_{4.9} \mathrm{O}_{12}\right)\left(3.8 \mathrm{H}_{2} \mathrm{O}\right) ; \mathrm{Mg}$-CPT: $\mathrm{Na}_{0.07} \mathrm{~K}_{0.08}$ $\mathrm{Ca}_{0.04} \mathrm{Mg}_{0.44}\left(\mathrm{Al}_{1.1} \mathrm{Si}_{4.9} \mathrm{O}_{12}\right)\left(3.8 \mathrm{H}_{2} \mathrm{O}\right)$. Solubility experiments were carried out at temperatures between $75^{\circ} \mathrm{C}$ and $265^{\circ} \mathrm{C}$ and saturated water vapor pressure. The $\mathrm{pH}_{25^{\circ} \mathrm{C}}$ was measured (6.5-7.9) and the high temperature values calculated. Under these conditions, the dominant $\mathrm{Al}$ and silica species are $\mathrm{Al}(\mathrm{OH})_{4}{ }^{-}[3,4]$ and $\mathrm{Si}(\mathrm{OH})_{4}{ }^{0}[5]$.

For this system an idealized equation for the dissolution of the $\mathrm{Ca}$ and $\mathrm{Mg}$ end members of clinoptilolite is

$$
\begin{gathered}
(\mathrm{Ca}, \mathrm{Mg})_{0.55} \mathrm{Al}_{1.1} \mathrm{Si}_{4.9} \mathrm{O}_{12} \times 3.8 \mathrm{H}_{2} \mathrm{O}+8.2 \mathrm{H}_{2} \mathrm{O}_{(1)} \Rightarrow \\
0.55\left(\mathrm{Ca}, \mathrm{Mg}_{(2+9)}^{2+}\right)+1.1 \mathrm{Al}(\mathrm{OH})_{4(39)}^{-}+4.9 \mathrm{Si}(\mathrm{OH})_{4(29)}^{0}
\end{gathered}
$$

In order to ensure charge balance, the sum of all cations (calculated in terms of $\mathrm{Ca}$ and $\mathrm{Mg}$ ) was set equal to the stoichiometric proportion of $\mathrm{Al}$.

The equilibrium constants for $\mathrm{Ca}$ - and $\mathrm{Mg}$-exchanged clinoptilolite have been calculated; for Ca-CPT the values vary from $\log \mathrm{K}=$ $-24.2\left(75^{\circ} \mathrm{C}\right)$ to $-19.3\left(265^{\circ} \mathrm{C}\right)$ and for $\mathrm{Mg}$-CPT from $\log \mathrm{K}=-21.7$ $\left(125^{\circ} \mathrm{C}\right)$ to $-19.0\left(225^{\circ} \mathrm{C}\right)$. These values were used to extrapolate to $25^{\circ} \mathrm{C}$ and to estimate preliminary free energies of formation for the hydrous and anhydrous $\mathrm{Ca}$ - and $\mathrm{Mg}$-exchanged clinoptilolite, $\Delta_{\mathrm{f}}$ $\mathrm{G}^{\circ}=-6355 /-5454 \mathrm{~kJ} / \mathrm{mol}$ and $-6295 /-5394 \mathrm{~kJ} / \mathrm{mol}$ respectively.

A comparison with $\mathrm{Na}-\left(\Delta_{\mathrm{f}} \mathrm{G}^{\circ}=-6272 /-5413 \mathrm{~kJ} / \mathrm{mol}\right)$ and $\mathrm{K}-\left(\Delta_{\mathrm{f}}\right.$ $\left.\mathrm{G}^{\circ}=-6091 /-5442 \mathrm{~kJ} / \mathrm{mol}\right)$ exchanged clinoptilolite ([7] and this study) and theoretical values after Iglesia and Aznar [6] indicates that the biggest effect on the free energy of formation is derived from the aluminosilicate framework and the $\mathrm{H}_{2} \mathrm{O}$ content of the exchanged clinoptilolite. The exchangeable cation does not appear to have a major influence on $\Delta_{f} G$.

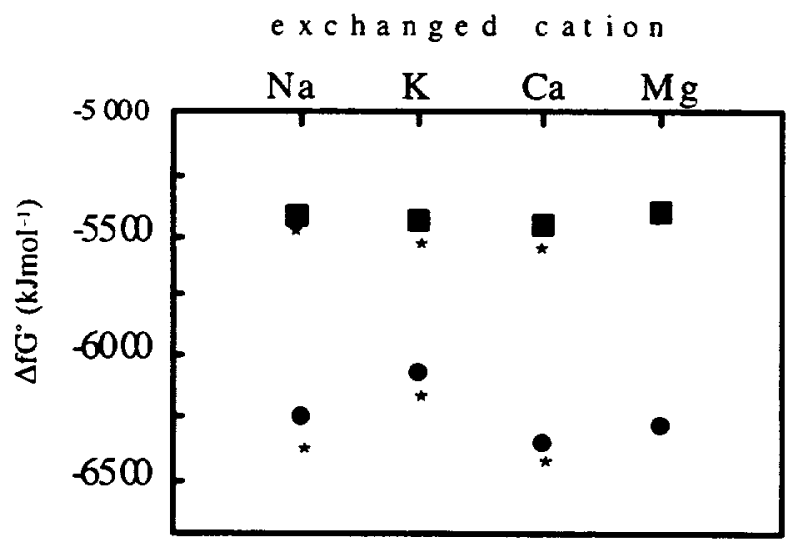

Fig. 1. Gibbs free energy of formation for hydrous (squares) and anhydrous (circles) $\mathrm{Na}-, \mathrm{K}-, \mathrm{Ca}-$, and $\mathrm{Mg}-\mathrm{CPT}$ at $25^{\circ} \mathrm{C}$; stars are calculated after Iglesia and Aznar [6].
Acknowledgments: The funding for this research was provided by the Swiss National Foundation (LGB) and the U.S. Department of Energy (RTW).

References: [1] Wilkin R. T. and Bames H. L. (1995) V. M. Goldschmidt Conference, Program and Abstracts, 97. [2] Wilkin R. T. and Barnes H. L. (1996) J. Conf. Abstr., 1,672. [3] Wesolowski D. J. and Palmer D. A. (1994) GCA, 58, 2947-2969. [4] Castet S. et al. (1993) GCA, 57, 4869-4884. [5] Johnson J. W. et al. (1992) Comp. Geosci., 18, 899-947. [6] Iglesia and Aznar (1986) Zeolites, 6, 26-29. [7] Wilkin et al. (1997) in preparation.

THE AGE AND ORIGIN OF HIMU VOLCANISM IN THE BALLENY ISLANDS: MELTING OF PLUME. DELIVERED DEEP MANTLE OR SHALLOW ASTHENOSPHERIC MANTLE? J. H. Berg', D. Weis ${ }^{2}$, W. C. McIntosh' ${ }^{3}$, and B. I. Cameron', 'Department of Geology, Northem Illinois University, DeKalb IL 60115,USA (jon@geol.niu.edu), 2Département des Sciences de la Terre et de L'Environnement, Université Libre de Bruxelles, B-1050 Brussels, Belgium, ${ }^{3}$ Department of Earth and Environmental Sciences, New Mexico Institute of Mining and Technology, Socorro NM 87801, USA.

The Balleny Islands form a $200-\mathrm{km}$-long linear chain of elongate islands in the Southem Ocean off the eastem Wilkes Land-northem Victoria Land coast of East Antarctica. To the north and on the opposite side of the Australian-Antarctic ridge, there is a long chain of seamounts that traverses the Tasman Sea floor of the Australian plate. These seamounts have been suggested by others to represent an earlier track of a Balleny plume. The Balleny magmas have erupted through oceanic crust that ranges in age from about $10 \mathrm{Ma}$ to $20 \mathrm{Ma}$.

The Balleny Islands are dominated by primitive lavas and pyroclastics of alkali basalt and basanite composition, but a few of the lavas are highly fractionated phonolites or trachytes. Tholeiites have not been found. The ocean-island geochemical signature is strongly HIMU in terms of $\mathrm{Sr}$ and $\mathrm{Nd}$ isotopes and trace elements $\left({ }^{87} \mathrm{Sr} /{ }^{86} \mathrm{Sr}=0.7029-0.7031,{ }^{143} \mathrm{Nd} /{ }^{144} \mathrm{Nd}=0.5128-0.5130, \mathrm{Ba} /\right.$ $\mathrm{Nb}=3-5, \mathrm{La} / \mathrm{Nb}=0.6-0.7, \mathrm{Ba} / \mathrm{La}=5-8, \mathrm{Rb} / \mathrm{Nb}=0.4-0.6, \mathrm{Zr} /$ $\mathrm{Nb}=3-4.5, \mathrm{Th} / \mathrm{Nb}=0.05-0.1$, though not as extreme as St. Helena, Tubuai, and Mangaia in terms of $\mathrm{Pb}$ isotopes $\left({ }^{206} \mathrm{~Pb} / 204 \mathrm{~Pb}=\right.$ $\left.19.6-20.1 ;{ }^{207} \mathrm{~Pb} / 204 \mathrm{~Pb}=15.6-15.7 ;{ }^{208} \mathrm{~Pb} / 204 \mathrm{~Pb}=39.4-40.1\right)$. The Balleny source has either had a shorter residence time in the mantle ( $\sim 50$ m.y.) or a lower U/Pb ratio than the extreme HIMU sources (HIMU derives from "high-U," where $\mathrm{U}$ is ${ }^{238} \mathrm{U} /{ }^{204} \mathrm{~Pb}$ ). The HIMU signature supports a deep-seated plume origin for the Balleny source. Argon-40/argon-39 dating of Balleny rocks indicates an age range from 2.6 Ma to $<10,000 \mathrm{yr}$ (activity was reported in 1839). The onset of volcanism on each island indicates a progression from south to north at a rate of about $7 \mathrm{~cm} / \mathrm{yr}$. This systematic age progression for a linear volcanic island chain is ironic on a tectonic plate that is essentially stationary.

Possible explanations for the origin of magmatism in the Balleny Islands include (1) leaky transform, (2) propagating fracture, and (3) laterally moving hotspot. The leaky transform hypothesis is contradicted by the fact that the islands lie to the east of the Balleny Fracture Zone, the systematic age progression, and the seamount track in the Tasman Sea. A single propagating fracture is an unlikely explanation because although each island is very linear, their orien- 
tations are not parallel. A series of fractures that open first in the south and last in the north is possible. Extension related to the development of the fractures could have caused decompression of the shallow mantle, resulting in the Balleny magmatism. This would suggest that the HIMU source resides in the shallow mantle. Such a scenario cannot easily explain the seamount track in the Tasman Sea.

Interestingly, the $7-\mathrm{cm} / \mathrm{yr}$ northward progression of volcanism is similar to the northward movement of the mid-ocean ridge away from the Antarctic plate. If the Balleny Islands have resulted from a plume, the plume would have been jumped by the spreading ridge approximately $10 \mathrm{~m} . y$. ago. If convective forces in the asthenosphere are stronger near the ridge and decrease away from the ridge, the lateral asthenospheric forces may have deflected the plume southward when the ridge was closer to the plume. As the ridge moved northward away from the plume, the plume could have rebounded to the north, leaving the northward progressing track of volcanism.

DEPTH PROFILING OF MINERAL HYDRATION REAC. TIONS BY ELASTIC RECOIL DETECTION ANALYSIS (ERDA). A. J. Berry', R. A. Wogelius ${ }^{2}$, D. G. Fraser ${ }^{1}$, and G. W. Grime ${ }^{3}$, 'Department of Earth Sciences, University of Oxford, Parks Road, Oxford OXI 3PR, UK, '2Department of Geology, University of Manchester, Oxford Road, Manchester M13 9PL, UK, ${ }^{3}$ Nuclear Physics, University of Oxford, Keble Road, Oxford OXI 3RH, UK.

Mineral hydration is an integral component of leaching and geochemical weathering processes. Hydration reactions involve proton penetration and proton-cation exchange in the near-surface region. ERDA is a technique for measuring $\mathrm{H}$ depth profiles down to $100-\AA$ resolution.

In the ERDA experiment, protons are recoiled from the sample by a beam of high-energy heavy ions. In the present case a tandem van de Graff accelerator was used to produce $7.5 \mathrm{MeV}{ }^{16} \mathrm{O}^{4+}$. The recoiled protons were counted as a function of energy using a surface barrier detector. Scattered 160 ions were rejected using a kapton filter. The optimal experimental geometry has the sample at $15^{\circ}$ and the detector at $40^{\circ}$ relative to the incident beam. At large detector angles the intensity is greatest due to the shorter path length and reduced scattering of the recoiled proton through the sample. This is offset by a decrease in the energy resolution, which can be improved by the use of detector slits, at the cost of signal intensity. Improvements in the resolution are currently limited by the beam intensity and resulting signal to noise. The detector energy was calibrated against the ${ }^{241} \mathrm{Am} \alpha$-particle radioactive decay by converting the energy loss of the $\alpha$ particle through the kapton filter into an effective proton stopping power. The proton concentration or intensity was calibrated using hydrous minerals and $\mathrm{H}$ implanted materials. Spectra were also normalized against the simultaneously recorded PIXE (particle induced X-ray emission) and RBS (Rutherford back scattering) signals.

The highest-energy recoils correspond to protons at the vacuummineral interface. Recoil energy decreases with increasing depth due to energy loss in the solid of both the incident $O$ beam and the exiting protons. The proton energy distribution can therefore be used to determine the $\mathrm{H}$ depth profile. The ERDA spectrum of $\mathrm{Mg}(\mathrm{OH})_{2}$ (brucite) is shown in Fig. la. The constant recoil intensity with decreasing energy is indicative of a uniform proton density.

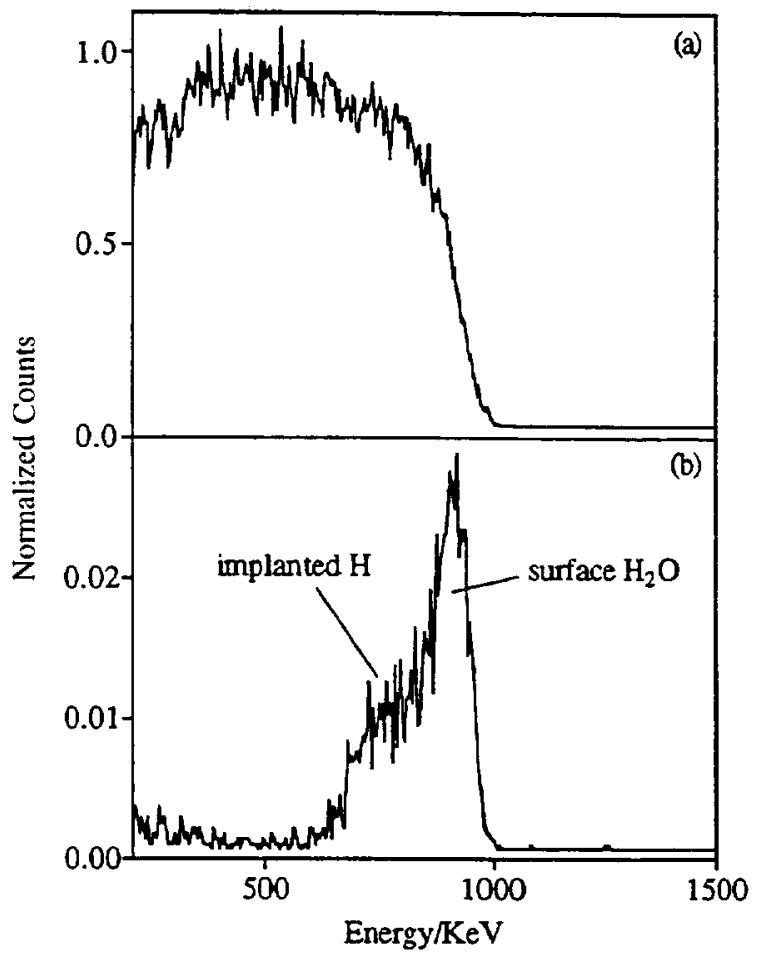

Fig. 1. ERDA spectra of (a) brucite and (b) H-implanted silicon. The spectra are normalized against acquisition time and brucite signal intensity.

Simulated ERDA spectra model the sample as a series of layers of variable $H$ composition. The spectrum represents the summation of intensity contributions from successive layers contributing an energy width $\Delta \mathrm{E}$, in the limit as $\Delta \mathrm{E} \rightarrow 0$. The spectrum of a thin hydrated layer of bucite on $\mathrm{MgO}$ (periclase) would therefore have similar intensity but with a width on the energy scale that is dependent upon the layer thickness. Figure $1 \mathrm{~b}$ shows the ERDA spectrum for $\mathrm{H}$-implanted $\mathrm{Si}$ with a gaussian-like proton distribution peaked at $1700 \AA$. These protons appear as the low-energy shoulder on the main peak, which corresponds to surface adsorbed water. This peak is not observed in the brucite spectrum because of the greater relative intensity of the brucite signal. An adsorbed surface-water peak appears on all samples analyzed that have not been heat treated, and may therefore interfere in the detection of surfacechemical hydration. The intensity of this peak may affect previous interpretations of ERDA results. Work is currently underway to remove the adsorbed water by in situ heating.

THE PARTICLESPECIFIC NATURE OF MICA WEATHERING: REAL-TIME OBSERVATION OF K+EXCHANGE IN CLAY-SIZED MICA PARTICLES USING FLUID CELL TMAFMTM. B. R. Bickmore and M. F. Hochella Jr., Department of Geological Sciences, 4044 Derring Hall, Virginia Polytechnic Institute, Blacksburg VA 24061, USA (bbickmor@vt.edu; hochella@vt.edu).

Weathering reactions on micas are of great geologic and environmental importance for a variety of reasons. For example, soil micas 
are a major source of $\mathrm{K}$ for plant growth, and the weathering products of micas typically include sheet silicate minerals with very high cation exchange capacities (CEC). These high-CEC minerals play a significant role in the sorption of toxic metals and nutrients, and to a large extent control the mobility of these ions.

Of specific interest is the mica to vermiculite transition because this reaction in part involves the creation of a large amount of new reactive surface area and CEC as $\mathrm{K}$ is replaced in the interlayer by hydrated cations. Naturally, quite a few studies have sought to elucidate the various mechanisms involved in this transition, but models of this process have failed to predict the exchange behavior of small particles of reacting mica. The reason for this difficulty appears to be that the $d(001)$ expansion of mica as the interlayer is exchanged causes a significant amount of strain in a reacting particle, which manifests itself differently in particles with different dimensions. That is, particle diameter, thickness, shape, and edge configuration may all play important roles in the weathering process, but no study has taken all of these factors into account. Therefore, our study probes the mechanisms controlling the micavermiculite transition by employing techniques that are capable of tracking the progress of such phenomena within single particles by observing the expansion of these particles as $\mathrm{K}^{+}$exchange occurs.

Such observations require accurate small-scale three-dimensional data on the morphology of single particles. Atomic Force Microscopy (AFM) is an ideal technique for characterizing the dimensions of mica particles because of the highly accurate threedimensional topographical data that can be obtained. However, real-time observations of reactions on clay-sized particles have been difficult to obtain in the past because traditional sample preparation techniques are not adequate. For example, a typical preparation technique for imaging in air is to evaporate a suspension of clay particles onto a cleaved muscovite substrate. But when fluid is introduced, the particles float away or do not remain stationary as the AFM tip scans across them.

In order to overcome this problem, we have developed a method in which we evaporate a suspension of clay-sized mica particles onto a polished sapphire substrate and take images of the particles using TappingMode ${ }^{\mathrm{TM}}$ Atomic Force Microscopy (TMAFM ${ }^{\mathrm{TM}}$ ) under solution. Polished sapphire has a positive surface charge at $\mathrm{pH}$ values below $8-8.5$, so the negatively charged mica particles are held more tightly to the surface when fluid is introduced. TMAFM ${ }^{\mathrm{TM}}$ reduces the lateral force exerted on the particles as the tip scans across them, allowing them to remain stationary for imaging and dimensional analysis. Preliminary results show that we can follow the interlayer exchange reaction in individual clay-sized particles.

\section{SURFACE CHEMISTRY OF MINERALS AND TEKTITES} AS CONSTRAINED BY X-RAY PHOTOELECTRON SPECTROSCOPY. G. G. Biino, Institute of Mineralogy and Petrography, University of Fribourg, Perolles, $\mathrm{CH}-1700$, Switzerland, and Materials Sciences Division, Lawrence Berkeley National Laboratory, Berkeley CA 94720, USA (giuseppe@electron.lbl.gov).

$\mathrm{X}$-ray photoelectron spectroscopy (XPS) is a valuable tool to investigate the chemical composition and chemical environment of elements at the surface of solids. The aim of this study is to provide a XPS systematic investigation of some minerals (micas, feldspar, gamet, $\mathrm{Al}_{2} \mathrm{SiO}_{5}$ ) and tektites. XPS yields chemical information on the near surface that are accurate $(5 \%)$ and reproducible $(0.1 \%)$. Every mineral surface produced in air shows a coating by adventitious material (mainly $\mathrm{C}$ ). The chemical composition of randomly oriented mineral samples is close to stoichiometry, but XPS measurements at grazing angle (small probing depth) along a major crystallographic direction clearly evidence the chemical anisotropy of mineral lattice. For example, the chemical composition of kyanite surface perpendicular to the main cleavage plane is richer in $\mathrm{Si}$ (i.e., cleavage exposes silicon). The chemistry of (001) natural micas is also never stoichiometric.

XPS provides the experimental evidence that natural micas (apparently unaltered) often cleave along very thin chlorite, talc, gibbsite, and kaolinite interlayers or along graphite-rich inclusion planes. These cryptic interlayers evidence the beginning of weathering. The interlayered phases change mechanical properties of micas and perturb the $\mathrm{Rb}-\mathrm{Sr}$ and $\mathrm{K}-\mathrm{Ar}$ isotopic systems. Muscovite equilibrated at very high pressure recrystallized as phengitic muscovite, but shows a very thin Al-rich (gibbsite-like) interlayer. This interlayer may not be related to weathering but to the lack of Al transport during very-high-pressure reequilibration.

Tektite is a natural glass formed from terrestrial material melted and displaced by the impact of an extraterrestrial body. Surface/ near-surface composition of tektite results from different processes like fractionation during flying, impact, and postsolidification weathering. One goal of this study was to evaluate the importance of weathering on fractionation during flying. Surface chemical composition of a tektite from an arid area is compared to the chemical composition of a tektite from a humid climate. XPS reveals that the surface chemistry evolved differently in the two tektites and both show the presence of a well-developed leached layer comparable to that observed in weathered glasses. Other processes than fractionation during flying and impact are responsible for the chemical composition of the surface/near-surface. The enrichment in $\mathrm{N}$ observed in one tektite is related to interactions between glass and fluid buffered by the organic material in the soil. The chemical environment of $\mathbf{O}$ was also investigated: it suggests that the depolymerization of tektites is comparable to artificial silicate melts.

\section{SOIL MICROBES AS INDICATORS OF ECOSYSTEM} POLLUTION BY HEAVY METALS. S. B. Bintrim ', J. S. Ireland $^{2}$, D. Joseph ${ }^{2}$, J. Handelsman ${ }^{1}$, and R. M. Goodman', 'Department of Plant Pathology, The University of WisconsinMadison, Madison WI 53706, USA (RGoodman@facstaff.wisc. edu), 2Department of Computer Science. The University of Wisconsin-Madison, Madison WI 53706, USA.

The improper disposal, misuse, and accidental release of heavy metals into the environment has resulted in widespread pollution of both soil and groundwater. As the adverse environmental and health effects of this pollution becomes better known, there is a growing interest to develop and implement new technologies for the detection and remediation of environmental pollution. Our overall goals are to develop new techniques for environmental monitoring based on a census of soil microbial communities and to how this census changes in response to pollution of heavy metals. The use of microbes as environmental indicators requires methods that are sensitive to subtle changes in the composition of microbial communities and that allow identification of the organisms responsible for those 
changes. However, recent studies have determined that assemblages of microbes in soil contain an astonishing diversity of as yet described organisms. To assess the vast diversity of organisms in soil demands new biological and computational techniques that can accommodate this complexity.

We are currently developing a molecular hybridization method, which utilizes an array of oligonucleotides derived from microbial small subunit ribosomal RNA ( $S S U$ rRNA) gene sequences, for the analysis of soil microbial communities. To assist in the design of oligonucleotides for this array, we employed molecular phylogenetic techniques to obtain SSU rRNA gene sequences from soil microbes. For this analysis, soil microbial communities were sampled directly by isolation of total DNA from soil and microbial SSU rRNA gene sequences were amplified by the polymerase chain reaction (PCR). The amplified SSU IRNA genes were cloned, sequenced, and characterized using phylogenetic algorithms. These analyses revealed a wide diversity of microbes from the two prokaryotic phylogenetic domains, Archaea and Bacteria, in soil. For the Archaea, we have identified a novel group of mesophilic Crenarchaeota, which is one of the two archaeal kingdoms that are comprised of thermophilic organisms. For the Bacteria, we have identified members representing several of the recognized phyla within the domain Bacteria. These phyla are the Proteobacteria, the high $\mathrm{G}+\mathrm{C}$ Gram positives, the low $\mathrm{G}+\mathrm{C}$ Gram positives, and the Cytophaga/Flexibacter/Bacteroides. However, the majority of the cloned bacterial SSU rRNA gene sequences could not be confidently placed into any of the known phyla of the Bacteria, indicating that these sequences may represent novel lineages of Bacteria.

The molecular identification of novel lineages of Archaea and Bacteria in soil provides a wealth of previously unknown SSU rRNA gene sequence information. This molecular information is useful for designing oligonucleotides for the hybridization array, for assessing the response of soil microbial communities to pollution by heavy metals, and for identifying microbes useful for bioremediation.

\section{CHONDRITIC LUTETIUM/HAFNIUM SOURCE COMPO-} SITION OF THE ISUA SUPRACRUSTAL SEQUENCE. J. Blichert-Toft, M. T. Rosing, F. Albarède, and D. Bridgwater, Ecole Normale Superieure de Lyon, 46 Allee d'Italie, Lyon Cedex 7 , 69364, France.

Lutetium-hafnium isotopic compositions for 10 rock samples from the early Archean Isua supracrustal belt were measured using the VG Elemental Plasma 54 mass spectrometer in Lyon. The suite includes metabasaltic and felsic rocks and banded iron formation (BIF). Three samples represent the Felsic Formation from an outcrop yielding $\mathrm{U}-\mathrm{Pb}$ zircon ages of $3813 \mathrm{Ma}$ and have been interpreted as metasomatized intrusive granitic sheets. Two samples of a felsic metasediment are taken from a part of the sequence inferred as tectonically intercalated between 3650 and $3700 \mathrm{Ma}$. Three samples of amphibolites, which from field relations are $3700 \mathrm{Ma}$ or older, have metatholeiitic chemical compositions. One sample of BIF predates the $3813 \mathrm{Ma}$ felsic sheets and another is impure associated with $3700 \mathrm{Ma}$ or older amphibolites. External precision of the Plasma 54 is better than $40 \mathrm{ppm}$. Analytical blank/sample ratios are less than $1 \%$. Current precision on the Lu/Hf ratio is $\sim 1 \%$. The average ${ }^{176} \mathrm{Hf} /{ }^{177} \mathrm{Hf}$ ratio of the JMC $475 \mathrm{Hf}$ standard is 0.282163 $\pm 9(2 \sigma)$. In ${ }^{176} \mathrm{Lu} / 177 \mathrm{Hf}$ and ${ }^{176} \mathrm{Hf} /{ }^{177} \mathrm{Hf}$ space the mafic and felsic samples fall close to a common best-fit line of $3665 \pm 28 \mathrm{Ma}$ (MSWD $=4.8$ ) with an initial ${ }^{176} \mathrm{Hf} /{ }^{177} \mathrm{Hf}$ ratio of $0.280335 \pm 5$. This corresponds to $\varepsilon_{\mathrm{Hf}}$ of $-0.13 \pm 0.18$ using the chondritic reference of Blichert-Toft and Albarède [1]. The uncertainty on the ${ }^{176} \mathrm{Lu}$ decay constant introduces at least $60 \mathrm{Ma}$ inaccuracy on this age. Removing two outliers results in a statistically significant isochron of $3676 \pm$ $28 \mathrm{Ma}(\mathrm{MSWD}=1.5$ ) with an initial $\mathrm{Hf}$ isotopic composition of $0.280329 \pm 5$ corresponding to $\varepsilon_{\mathrm{Hf}}$ of $-0.05 \pm 0.19$. The difference in age and $\varepsilon_{\mathrm{Hf}}$ between these two regressions is not significant. The age is within the error bracket of the Lu-Hf isochron of Amitsoq gneisses obtained by Pettingill and Patchett [2]. The initial Hf isotopic composition is well constrained by the low $\mathrm{Lu} / \mathrm{Hf}$ ratio of the felsic formation samples. Given that the chondritic ${ }^{176} \mathrm{Hf} / 177 \mathrm{Hf}$ is known to within $\pm 1 \varepsilon$ unit, the Hf isotopic composition of the source of the Isua metaigneous and detrital sediment samples is chondritic. The two samples of BIF yield an age of $3869 \pm 54 \mathrm{Ma}$ and an initial $\mathrm{Hf}$ isotopic composition of $0.281041 \pm 73$ corresponding to $\varepsilon_{\mathrm{Hf}}$ of $+30.1 \pm 2.6$. The CHUR model age of the pure BIF sample is $4100 \mathrm{Ma}$. As expected from the strong affinity of REE, but not $\mathrm{Hf}$, for iron hydroxides, the ${ }^{176} \mathrm{Lu} /{ }^{177} \mathrm{Hf}$ ratio of the pure BIF sample is 0.2 , significantly exceeding that of the other lsua rocks, which range from 0.00455 to 0.0497 . It is not known whether the small but significant dispersion of the points about the best-fit line is due to heterochronous formation or to secondary metamorphic remobilization of $\mathrm{Lu}$ and $\mathrm{Hf}$. The Lu-Hf data do not support previous suggestions from Sm-Nd studies for early fractionation of the mantle-crust system. If the Lu-Hf system of the BIF samples is undisturbed, the high initial Hf isotopic composition of these rocks attests to a radiogenic source in the depositional environment of BIF and therefore presumably in the Archean oceanic mantle.

References: [1] Blichert-Toft and Albarède (1997) EPSL, in press. [2] Pettingill and Patchett (1981) EPSL, 55, 150-156.

SILICATE WEATHERING RATES ALONG A STREAM CHANNEL DRAINING INTO LAKE FRYXELL, TAYLOR VALLEY, ANTARCTICA. A. E. Blum ${ }^{1}$, D. M. McKnight ${ }^{2}$, and W. B. Lyons ${ }^{3}$, ${ }^{1}$ U.S. Geological Survey, 321 5 Marine Street, Boulder CO 80303, USA (aeblum@usgs.gov), '2Department of Civil Engineering, University of Colorado, Boulder CO 80303, USA, ${ }^{3}$ Department of Geology, University of Alabama, Box 870338, Tuscaloosa AL 35487, USA.

Silicate weathering rates were calculated along Von Guerard stream during the Antarctic summer using three synoptic studies at differing flow conditions. The stream is analogous to a saturated flow column reactor with $\mathrm{pH}$ varying from 7 to 8 . Dilute surface flow from a dry-bottom glacier flows $\sim 5.2 \mathrm{~km}$ to Lake Fryxell, interacting along the channel with saturated gravels in the hyporheic zone, with no higher plants and with very limited biological activity. The hyporheic zone volume is well defined by the thawed region in the permafrost. Side slopes thaw to $<30 \mathrm{~cm}$ and sublimation » precipitation, so there is no runoff, and negligible contribution of solutes from the side slopes to the stream. The stream gravels are composed of subequal quantities of (1) granites, (2) intermediate intrusive and metamorphic rocks, and (3) diabase and basalt. BET surface areas (SA) were measured on 10 size fractions from $<63 \mu \mathrm{m}$ to $1.4 \mathrm{~mm}$, and yielded surface roughnesses of 230-580, which did not vary systematically with grain size. This indicates that internal porosity 
is the major contribution to SA. XRD analysis of the $<2-\mu \mathrm{m}$ size fraction indicates minor amounts of kaolinite and primary silicates, but predominately amorphous material. This suggests that in this cold, ephemeral stream the formation of secondary clay minerals is inhibited.

Elemental fluxes, calculated from changes in solution chemistry along the stream reach, are used to quantify weathering. Silicon is the best single indicator of weathering reactions. At high flow conditions, when the stream interacts strongly with the hyporheic zone, Si concentrations increase linearly downstream from 128 to $167 \mathrm{mM}\left(\mathrm{R}^{2}=0.94\right)$, yielding a silicate weathering rate of $8.26 \times$ $10^{-3} \mu \mathrm{mol} \mathrm{Si} \mathrm{m}^{-1}$ of stream reach. Using the total hyporheic zone volume and stream flow yields a specific weathering rate (mol Si/ $\mathrm{cm}^{2} / \mathrm{s}$ ) of $10^{-15.3}$ using BET SA and $10^{-12.8}$ using geometric SA. At lower flow, the $S i$ weathering rates are up to $60 \%$ slower, and less consistent along the stream reach. This decrease reflects reduced circulation through the gravels and recharge to the stream from the hyporheic zone.

Mass balance calculations between potential reactant and product phases were used to attempt to trace the sources and sinks of solutes. However, the large number and poorly constrained chemistry of the solid phases make the results poorly constrained. Nevertheless, the evolving solution chemistry is consistent with probable weathering reactions, and increases in $\mathrm{K}$ and $\mathrm{Mg}$ down the stream reach can only be accounted for by silicate weathering reactions occurring at appreciable rates.

The measured weathering rates based on $\mathrm{Si}$ concentrations are very rapid, greater than any reported watershed study or experimental dissolution rates for plagioclase, and similar to the most rapid experimental dissolution rates for homblende and augite. These rapid rates suggest that (1) saturated aqueous environments, with greater mineral surface/water contact, may be significantly more reactive than unsaturated soil environments, and (2) biological activity does not dramatically accelerate silicate weathering rates in watersheds, since this essentially abotic weathering is more rapid than has been reported for warmer, forested watersheds.

\section{THE EFFECT OF LATE CENOZOIC GLACIATION ON SILICATE WEATHERING RATES AND THE MARINE STRONTIUM ISOTOPE RECORD. J. D. Blum, Department of Earth Sciences, Dartmouth College, 6105 Fairchild, Hanover NH 03755 USA (jblum@dartmouth.edu).}

Long-term weathering rates $\left(\mathrm{R}_{\mathrm{LT}}\right)$ and changes in the ${ }^{87} \mathrm{Sr} /{ }^{86} \mathrm{Sr}$ ratio released by silicate weathering have recently been determined from geochemical studies of soil profiles developed on six granitic glacial moraines varying in age from 0.4 to $\sim 297 \mathrm{k} . \mathrm{y}$. in the Wind River Mountains, Wyoming. Weathering rates were found to decrease with soil age ( $t$ ) according to the power-law equation

$$
R_{L T}=220 \times i^{(-0.71)}
$$

where $R_{L T}$ is in meq $\times \mathrm{m}^{-2} \times y r^{-1}$, and $t i s$ in $k . y$. [ 1 ]. Comparable data from the literature are consistent with this function, and it is similar to power-law equations describing changes in laboratory weathering rates with time. A negative correlation was observed between the ${ }^{87} \mathrm{Sr} /{ }^{86} \mathrm{Sr}$ ratio of exchangeable $\mathrm{Sr}$ in soils and the soil age, indicating that the ${ }^{87} \mathrm{Sr} / 86 \mathrm{Sr}$ ratio of $\mathrm{Sr}$ released in the early stages of weathering is significantly higher than in later stages due to the rapid alteration of biotite to vermiculite and coincident release of highly radiogenic Sr $[2,3]$. The bedrock of the Wind River Mountains is similar in composition, mineralogy, and age to much of the Canadian Shield and thus the results of the soil chronosequence studies permit predictions about the effect of late Cenozoic glaciation on global riverine cation fluxes and ${ }^{87} \mathrm{Sr} /{ }^{86} \mathrm{Sr}$ ratios. Based on a simplified model of periodic glacial advance and retreat, the onset of late Cenozoic glaciation $\sim 2.5 \mathrm{~m} . \mathrm{y}$. ago is predicted to have resulted in an $\sim 40 \%$ increase in global silicate weathering and $\mathrm{CO}_{2}$ consumption compared to the period prior to late Cenozoic glaciation. Global riverine cation fluxes are predicted to have increased by a maximum of $8 \%$ and global average riverine ${ }^{87} \mathrm{Sr} /{ }^{86} \mathrm{Sr}$ is predicted to have increased by a maximum of 0.00016 . Deglaciation following each glacial maximum is predicted to have approximately doubled silicate weathering rates for a period of $\sim 5 \mathrm{k} . \mathrm{y}$. This may have provided a negative climate feedback mechanism whereby orbitally driven deglaciation enhanced the rate of $\mathrm{CO}_{2}$ consumption by silicate weathering and increases in marine productivity due to increased riverine nutrient fluxes during interglacial periods. The late Cenozoic marine ${ }^{87} \mathrm{Sr} /{ }^{86} \mathrm{Sr}$ record is used as a geological test of the plausibility of predictions that are made for changes in riverine $\mathrm{Sr}$ flux and isotopic composition based on the soil chronosequence studies. Reasonable agreement is found between the magnitude of the predictions made for changes at the onset of late Cenozoic glaciation and the response of the marine ${ }^{87} \mathrm{Sr} /{ }^{86} \mathrm{Sr}$ ratio. This does not prove that glaciation caused the observed changes in the marine ${ }^{87} \mathrm{Sr} / 86 \mathrm{Sr}$ ratio or negate the potential importance of tectonic factors or changes in global climate patterns. Nevertheless, the shift in the marine ${ }^{87} \mathrm{Sr} /{ }^{86} \mathrm{Sr}$ ratio is coincidental with the onset of northem hemisphere glaciation and this work demonstrates that estimates of the effect of glaciation on silicate weathering are of the proper magnitude to explain trends in the marine record. The chronosequence studies also shed light on the potential mechanisms linking tectonic uplift with increased silicate weathering rates, but a lack of understanding of soil residence times in rapidly uplifting areas precludes the application of the power law function to the quantitative prediction of weathering rates in these settings.

References: [1] Taylor A. and Blum J. D. (1995) Geology, 23, 979-982. [2] Blum J. D. and Erel Y. (1995) Nature, 373, 415-418. [3] Blum J. D. and Erel Y. (1997) GCA, submitted.

MODELING MANTLE MELTING WITH VARIABLE PARTITION COEFFICIENTS. J. Blundy and J. Brodie, CETSEI, Department of Geology, University of Bristol, Wills Memorial Building, Bristol BS8 IRJ, UK.

Trace-element partition coefficients (D) are thermodynamic variables that change during any process of chemical differentiation in response to changes in pressure $(P)$, temperature $(T)$, and composition $(X)$. Most geochemical models of mantle melting, however, assume constant D. A recent model of REE partitioning between clinopyroxene and melt [1], based on lattice strain theory [2], provides a complete quantitative description of $D_{\text {REE }}$ over the P-T$X$ conditions relevant to mantle melting. The model, which was calibrated on $>450$ experimentally determined $D_{R E E}$, enables us for the first time to incorporate the P-T-X dependence of $D_{R E E}$ into models of decompression mantle melting. 
We present models for three decompression melting scenarios, and compare the results using variable $D$ with those using constant $D$ [e.g., 3]. The scenarios investigated are (1) subaxial ridge melting, (2) "truncated" melting beneath thick lithosphere, and (3) "unaggregated" melting, wherein polybaric fractional melts are preserved without aggregation. The models assume passive, cornerflow upwelling and a two-dimensional triangular melting region. Melting reactions and mantle modes are taken from Kinzler and Grove [4]. Cpx composition and melt $\mathrm{Mg \#}$ are assumed to be invariant during melting. These simplifications introduce an imprecision of $\leq 14 \%$ relative in $D_{R E E}$. Constant $D_{R E E}$ were used for olivine, spinel, and opx, which contribute little to the REE budget of mantle melts.

For subaxial melting (case 1) variable and constant $D$ melts have similar REE concentrations, which plot within the primitive $\mathrm{N}$ MORB field of Sobolev and Shimizu [5]. Variable D melts have slightly lower HREE, and are also less sensitive to variations in mantle potential temperature. Many N-MORB require little $(<1 \%)$ or no contribution from melts generated in the garnet lherzolite field. This is a consequence of the high calculated $D_{(\text {HREE })}$ for $c p x$ at the mantle solidus $(\sim 0.6)$ relative to most models, which adopt $D$ obtained at inappropriate P-T-X conditions.

For truncated melting (case 2) with melt fractions $\leq 10 \mathrm{wt} \%$, variable D melts have HREE two times lower than constant D melts, but similar LREE. Such high LREE/HREE ratios are typical of melts in areas of very thin crust (e.g., Mid-Cayman Rise). Again there is no need to invoke $>\sim 1 \%$ melting of gamet lherzolite in their petrogenesis.

Unaggregated melting (case 3 ) yields a very wide range of LREE contents with comparatively little variation in HREE. Total REE contents decrease as the base of the melting column becomes shallower. For a melting path extending from 7.5 to $37.5 \mathrm{~km}$ below the ridge crest our model REE pattem is indistinguishable from that of an "ultradepleted MORB" melt inclusion [5], while the aggregated composition for the entire melting region is very similar to that of the matrix glass in the same sample. The overall spread in REE patterns produced by sampling different segments of the melting region strongly resembles that observed in melt inclusions from a variety of ridge settings.

Our results emphasize the pitfalls of using constant $D$ to model polybaric, polythermal processes. Specifically, $D_{R E E}$ for cpx along the mantle solidus are significantly larger $(1.5-10 \times)$ than previously recognized. This is especially true for HREE, with the result that melts generated exclusively from spinel lherzolite residua can acquire a "garnetlike" signature. The differences between variable and constant $D$ models are most pronounced for the small melt fractions $(<10 \%)$ inferred beneath slow-spreading ridges, and in melt inclusions. Our model reproduces many of the observed REE signatures of MORB liquids without the need to invoke significant (i.e., $>10 \%$ ) melting in the garnet field to account for HREE contents.

References: [1] Wood and Blundy, Contrib. Mineral. Petrol., in review. [2] Blundy and Wood (1994) Nature. [3] White et al. (1992) JGR. [4] Kinzler and Grove (1992, 1993) JGR. [5] Sobolev and Shimizu (1993) Nature.

TRACE-ELEMENT PARTITIONING BETWEEN CLINOPYROXENE, SILICATE MELT, AND CARBONATE MELT
IN THE SYSTEM DIOPSIDE-ALBITE-DOLOMITE. J. D. Blundy' and J. A. Dalton', 'CETSEI, Department of Geology, University of Bristol, Wills Memorial Building. Bristol BS8 IRJ, UK, ${ }^{2}$ Geoscience Program, University of Texas at Dallas, P.O. Box 830688, Richardson TX 75083-0688, USA.

Trace-element partitioning between cpx, silicate melt, and carbonate melt has been investigated experimentally in the simple system diopside-albite \pm dolomite doped with parts-per-million levels of $\mathrm{Li}, \mathrm{K}, \mathrm{Rb}, \mathrm{Cs}, \mathrm{Sr}, \mathrm{Ba}, \mathrm{Pb}, \mathrm{Ga}, \mathrm{La}, \mathrm{Nd}, \mathrm{Sm}, \mathrm{Y}, \mathrm{Yb}, \mathrm{Ti}, \mathrm{Zr}$, and $\mathrm{Nb}$. The aim of the experiments was to directly compare $\mathrm{cpx}$ carbonate melt partition coefficients (D) with cpx-silicate melt $D$ in similar systems under similar P-T conditions, and so isolate the $\mathrm{P}$ $T$ effects from those of composition.

For a $\mathrm{Di}_{40} \mathrm{Ab}_{10} \mathrm{Dol}_{50}$ mixture at $3 \mathrm{GPa}, 1375^{\circ} \mathrm{C}$, cpx \pm olivine coexist with carbonate melt containing 5-10 $\mathrm{wt}_{\mathrm{S}} \mathrm{SiO}_{2}$ and $<0.6 \mathrm{wt} \%$ $\mathrm{Al}_{2} \mathrm{O}_{3}$. In order to grow large crystals for trace-element analysis it was necessary to seed the starting material with a metamorphic diopside. Run times $\geq 12 \mathrm{hr}$ were required to produce homogenous cpx rims. Variation in phase proportions and compositions arose through variation in the amount of seed added. $\mathrm{A} \mathrm{Di}_{80} \mathrm{Ab}_{20}$ mixture (without seed) produced cpx + silicate glass $\left(57 \% \mathrm{SiO}_{2}\right)$ at $0.8 \mathrm{GPa}$, $1375^{\circ} \mathrm{C}$ and $3 \mathrm{GPa}, 1640^{\circ} \mathrm{C}$, thereby bracketing the conditions of the carbonate experiment.

Run products were analyzed for trace elements by ion microprobe (SIMS). In order to evaluate the effect of dissolved carbonate on secondary ion yields, a doped anhydrous $\mathrm{Di}_{40} \mathrm{Ab}_{10} \mathrm{Dol}_{50}$ glass standard was synthesized at $3 \mathrm{GPa}, 1560^{\circ} \mathrm{C}$. Comparison of SIMS and solution ICP-MS analyses of the glass indicates an increase of $20 \%$ in ion yield for all elements studied relative to SRM610. Silicate glass and silicate crystal have near identical ion yields in Fefree systems.

Partition coefficients for the two silicate runs are similar except for alkalis, which increase with $P$ [1]. There are significant differences between carbonate melt and silicate melt $D$, most notably for highly charged cations $(\mathrm{Al}, \mathrm{Zr}, \mathrm{Ti})$ that are considerably higher for carbonate melt. These differences appear to result from compositional effects rather than thermal or pressure effects. In particular there is a strong correlation between $\mathrm{D}$ and the $\mathrm{CaT}$ s content of the $\mathrm{cpx}$, which varies from $0.4 \mathrm{~mol} \%$ to $1 \mathrm{~mol} \%$ in the silicate runs, to $8 \mathrm{~mol} \%$ to $19 \mathrm{~mol} \%$ in the carbonate runs (depending on the added seed fraction). Dependence on CaTs varies according to cation valence: $D$ for $1+$ cations show very little dependence; $2+D$ decrease by $\leq 50 \%$ with increasing CaTs; $D_{\text {REE }}$ increase by a factor of $\leq 4$, while $\mathrm{D}_{\mathrm{Zr}_{\mathrm{r}}}$ and $\mathrm{D}_{\mathrm{Ti}}$ are $3-50 \times$ higher. $\mathrm{D}_{\mathrm{Al}}$ and $\mathrm{D}_{\mathrm{G}_{\mathrm{a}}}$ are $\leq 200 \times$ higher in the carbonate runs. For a given valence the dependence on $\mathrm{CaTs}$ varies systematically with ionic radius, e.g., for the REE $Y b$ is more depen-dent on CaTs than La.

The observed correlation with CaTs is similar to, but more extreme than, that observed for $\mathrm{Ce}$ and $\mathrm{Yb}$ in $\mathrm{l}$-atm experiments in CMAS [2]. In both cases the variation between isovalent cations of different size can be ascribed to the slightly smaller $\mathrm{M} 2$ site in CaTs relative to diopside [3]. However, the charge-dependent variation itself requires an alternative explanation. The consistency of the trends from silicate to carbonate systems suggests that configurational entropy in the crystal is the most likely control, specifically the availability of $\mathrm{Al}$ for charge balancing and the extent to which coupled cation defects are ordered.

We conclude that cpx D for trace elements are different for 
silicate melt and carbonate melt systems, but that this difference is largely a consequence of the different $\mathrm{cpx}$ compositions on their liquidi at high $\mathrm{P}$ and $\mathrm{T}$. In the context of mantle metasomatism carbonate and silicate melts will impart quite distinct signatures for more highly charged cations (REE, HFSE). However, the most ready indicator of carbonate melt involvement may be the elevated $\mathrm{CaTs}$ content of the associated $\mathrm{cpx}$. There is some suggestion of this in putative natural examples of carbonate metasomatism [e.g., 4,5].

References: [1] Blundy et al. (1995) JGR. [2] Gaetani and Grove (1995) GCA. [3] Blundy et al. (1996) GCA. [4] Hauri et al. (1993) Nature. [5] Ionov et al. (1997) Contrib. Mineral. Petrol., in press.

RHENIUM-OSMIUM SYSTEMATICS OF THE LOWER OCEANIC CRUST. J. Blusztajn, S. R. Hart, H. J. B. Dick, and G. Ravizza, Department of Geology and Geophysics, Woods Hole Oceanographic Institution, Woods Hole MA 02543, USA.

It is generally accepted that recycling of the oceanic crust into the mantle plays an important role in creating mantle heterogeneity. Recently, the Os isotopic system has shed new light on the ocean crust recycling processes in the mantle. Coupling of high ${ }^{206} \mathrm{~Pb} /{ }^{204} \mathrm{~Pb}$ and ${ }^{187} \mathrm{Os} /{ }^{186} \mathrm{Os}$ for HIMU basalts provides strong evidence for the role of ancient subducted oceanic crust. In all recycling models it is assumed that subducted crust has a composition similar to that of MORB, which comprises the upper oceanic crust. This is, of course, an oversimplification because at least some portion of the lower crust is subducted back into the mantle. The compatible nature of $O s$ suggests that the cumulate-type lower crust may contain high concentrations of Os. If this is true, then the amount and age of oceanic crust necessary for creation of the HIMU mantle component are very sensitive to the subducted fraction of the lower oceanic crust. In order to obtain direct constraints on the Os isotope systematics in the lower crust, we analyzed samples from Site 735B (Southwest Indian Ridge), which provides the deepest and most complete sections of the lower oceanic crust available. Site $735 \mathrm{~B}$ is located on 1112-m.y.-old crust, at the margin of the Atlantis II Fracture Zone, about $93 \mathrm{~km}$ south of the active spreading ridge. The recovered 500 -m section of layer 3 consists mostly of olivine gabbro with associated automagmatic and cogenetic oxide gabbros, gabbro norites, and troctolites.

In order to obtain representative analyses of the whole core, we cut 1-2-cm-wide, 1-2-m-long strip samples, which cover the whole range of lithologies and deformation observed in Site 735B. The Os content in the gabbros is very low and generally falling between 1 ppt to $17 \mathrm{ppt}$. Only one troctolite (olivine- and plagioclase-rich gabbro) sample contains 400 ppt of Os. Based on the Os distribution in Site 735B, we calculate an Os content in the lower crust of $12 \mathrm{ppt}$. The $R e$ concentrations in the gabbros vary over a large range, from $128 \mathrm{ppt}$ to $27 \mathrm{ppb}$. There is a relatively good correlation between the $S$ and $\operatorname{Re}$ content, which indicates that the Re content is controlled by sulfides occurrence. Although some overlap exists between the $\mathrm{Re}$ content in the gabbros and that in MORB, values higher than $1.5 \mathrm{ppb}$ have never been reported in MORB. Excluding samples with very high $\operatorname{Re}$ content, the average $\operatorname{Re}$ content in the lower crust is around $500 \mathrm{ppt}$. The present-day ${ }^{187} \mathrm{Os} /{ }^{186} \mathrm{Os}$ of the gabbros varies from 1.162 to 3.882 and correlates with $\mathrm{Rb} / \mathrm{Cs}$, suggesting that seawater alteration affected the Os isotopic system. It seems that the
Re and Os content and Os isotopic compositions of the lower oceanic crust reflect the integrated influence of magmatic processes responsible for their genesis and subsequent alteration. The low Os content in these gabbros indicates that the lower oceanic crust is not an important reservoir of oceanic crust Os. Results from Site $735 \mathrm{~B}$ show that the lower oceanic crust, similar to MORB, has a very high $\mathrm{Re} / \mathrm{Os}$, confirming that old, subducted oceanic crust may play an important role in the genesis of the HIMU mantle component.

MODEL FOR THE ORIGIN AND DISTRIBUTION OF METALS IN PORPHYRY COPPER SYSTEMS WITH APPLICATIONS TO EXPLORATION. R. J. Bodnar, Fluids Research Laboratory, Department of Geological Sciences, Virginia Polytechnic Institute, Blacksburg VA 24061-0420,USA (bubbles@ vt.edu).

Over the past decade remarkable advances have been made in our ability to obtain quantitative analyses of individual fluid inclusions. Application of these techniques to study fluid inclusions from porphyry $\mathrm{Cu}$ systems has provided abundant data related to the sources of metals and other ore-forming components in these economically important systems. These data, combined with an improved understanding of the chemical and physical processes associated with the emplacement and crystallization of epizonal silicic, hydrous plutons have led to the development of an internally consistent model for the evolution of magmatic systems associated with porphyry $\mathrm{Cu}$ deposits. These models have a direct application in the exploration for hidden porphyry deposits owing to the systematic variation in fluid inclusion characteristics in time and space relative to the major ore-depositing event(s).

Analyses of fluid inclusions from numerous porphyry $\mathrm{Cu}$ deposits from the southwestem U.S. porphyry province show a clear distribution of metal contents of ore fluids with respect to location within the porphyry system and alteration andor mineralization stage. Fluid inclusions representing the earliest magmatic fluids in all systems studied contain from a few thousand to tens of thousands of parts per million $\mathrm{Cu}$. Similar concentrations of $\mathrm{Fe}, \mathrm{Mn}, \mathrm{Zn}$, and $\mathrm{Pb}$ have also been detected. A systematic decrease in metal contents is noted as the early fluids migrate further from the source and cool and are diluted by fluids of meteoric origin. Fluids that are clearly of wallrock origin contain no detectable metals. The results of these studies provide convincing evidence that metals in the porphyry copper deposits studied were sourced in the magma.

Fluid inclusion characteristics and the distribution of metals in fluid inclusions within the porphyry environment are consistent with the vapor-plume model proposed by [1]. The Bingham Canyon, Red Mountain (Arizona), and Butte deposits all contain fluid inclusions that are thought to have trapped the "magmatic vapor," and analyses of these inclusions using synchrotron XRF techniques prove these fluids were responsible for transporting metals into the ore-forming environment. Moreover, results of theoretical and experimental studies of partitioning of metals between coexisting liquid and vapor at magmatic conditions are consistent with analytical results and provide a plausible mechanism for transporting metals such as $\mathrm{Au}, \mathrm{Ag}, \mathrm{Cu}, \mathrm{As}, \mathrm{Sb}, \mathrm{Hg}$, etc., from the deeper porphyry environment to the near-surface epithermal environment.

References: [1] Henley and McNabb (1978). 
SOLUBILITIES OF HIGHLY SIDEROPHILE ELEMENTS IN SILICATE MELTS: EXPERIMENTAL RESULTS AND GEOCHEMICAL IMPLICATIONS. A. Borisov and H. Palme, Institut für Mineralogie und Geochemie, Universität zu Köln, Zülpicher Strasse 49b, 50674 Köln, Germany.

Experimental: During the last five years we have studied the effects of $\mathrm{fO}_{2}$ and temperature on the solubilities of Ir [1,2], Pd [3], $\mathrm{Au}[4,5]$, and $\mathrm{Pt}[6,7]$ in silicate melts. The experiments were made at $1 \mathrm{~atm}$ total pressure with the loop technique. Silicates were equilibrated with pure metals or metal-alloys in a furnace with controlled $\mathrm{fO}_{2}$. Metal concentrations in the quenched glasses were analyzed by INAA.

Solubilities in Iron-free Systems: Solubilities are in the parsper-billion range for $\mathrm{Ir}$ and $\mathrm{Pt}$ and in the parts-per-million range for $\mathrm{Pd}$ and $\mathrm{Au}$. An important finding is that HSE concentrations decrease with decreasing $\mathrm{fO}_{2}$, implying that $\mathrm{HSE}$ are dissolved in silicate melts as oxides and not as metals. From the slope of log (solubility) vs. $\log \mathrm{fO}_{2}$, apparent valences of HSE in silicate melts can be determined. Formal valences of $1+$ were found for $I r, P d$, and $\mathrm{Au}$, and $2+$ for $\mathrm{Pt}$ at a wide range of $\mathrm{fO}_{2} \mathrm{~s}$. These valences are much lower than the most stable solid oxides $\left(\mathrm{IrO}_{2}, \mathrm{PdO}, \mathrm{PtO}_{2}\right)$ would suggest.

Most experiments were made with silicate melts of anorthitediopside eutectic composition. If recalculated to a single temperature and $\mathrm{fO}_{2}\left(1400^{\circ} \mathrm{C}, \mathrm{QFM}\right)$, the solubilities of the noble metals can be ranged in the following order: Pd (7 ppm)-Au (2 ppm)-Pt $(26 \mathrm{ppb})-\operatorname{Ir}(10 \mathrm{ppb})$. The effects of melt composition and temperature on the solubilities are small, compared with the effect of $\mathrm{fO}_{2}$.

Some noble metals ( $\mathrm{Ir}, \mathrm{Pt}$ ) show tendencies to form nuggets at reducing conditions $[2,7]$. This is probably the main reason for the large variations observed in experimental work on Pt- and Ir-solubilities. Formation of alloys of noble metals with reduced melt species (e.g., $\mathrm{Si}, \mathrm{Bi}, \mathrm{Ge}$ ) may favor the formation of PGE-nuggets [7].

Solubilities in Iron-containing Melts: The experimental determination of pure noble metal solubilities in natural basaltic melts is complicated by HSE-Fe alloy formation. The composition of such alloys strongly depends on $\mathrm{fO}_{2}$. Using activity coefficients of binary HSE-Fe solid solutions (mostly from [8]), solubilities of noble metals in FeO-containing melts were calculated for a wide $\mathrm{fO}_{2}$ range. Results indicate that solubilities of noble metals in $\mathrm{Fe}$ containing melts are significantly lower. For example, the solubility of $\mathrm{Pd}$ in a silicate melt with $10 \mathrm{~mol} \% \mathrm{FeO}$ and at $1400^{\circ} \mathrm{C}$ and QFM is $40 \%$ lower and the Pt-solubility is about two times lower than in $\mathrm{FeO}$-free melts. Moreover, decreasing $\mathrm{fO}_{2} \mathrm{~s}$ will produce more $\mathrm{Fe}$ rich alloys leading to lower noble metal solubilities and thus producing a steeper slope of the $\log$ (solubility) vs. $\log \mathrm{fO}_{2}$ line. This results in a higher apparent valence of the noble metal in the melt.

The formation of PtFe alloys is predicted to occur in melts from the upper mantle of the Earth. Such alloys may be important for fractionating Pt from other noble metals in terrestrial reservoirs.

Partition Coefficients (Iron Metal/Silicate Melt): Metal silicate partition coefficients of noble metals may be calculated from solubilities (see [3], for details). Calculated $D_{;} s$ at $1350^{\circ} \mathrm{C}$ and low O fugacities (IW-2), relevant for core formation in the Earth, are extremely high, from $10^{7}$ to $10^{15}$. The $\mathrm{D}_{\mathrm{i}} \mathrm{s}$ calculated for high temperatures $(3000 \mathrm{~K})$ are lower, but still as high as $10^{4}-10^{8}$. The two groups of HSE (Ir-Pt and Pd-Au), show a very different behavior at moderate and at very high temperatures. Murthy, in his model of global mantle/core equilibrium [9], suggested that all DHSE approach the same low values of about 400 at high temperatures. This is, however, incompatible with our finding. For example, the ratio of $\mathrm{D}^{\mathrm{r} / \mathrm{D}^{\mathrm{Pd}}}$ of $10^{5}-10^{4}$ can never impose a chondritic Ir/Pd ratio on upper mantle rocks. In addition, recent high-pressure solublity experiments with Pd have shown that the Pd solubility does not increase with increasing pressure [10].

References: [1] Borisov et al. (1992) LPS XXIII, 139. [2] Borisov and Palme (1995) GCA, 59, 481. [3] Borisov et al. (1994) GCA, 58, 705. [4] Borisov et al. (1993) LPS XXN, 147. [5] Borisov and Palme (1996) Mineral. Petrol., 56, 297. [6] Borisov et al. (1994) LPS XXV, 141. [7] Borisov and Palme (1997) GCA, submitted. [8] Hultgren et al. (1973) Selected Values of Thermody. namic Properties of Binary Alloys, Am. Soc. Metals, Metals Park, Ohio. [9] Murthy (1991) Science, 253, 303. [10] Holzheid et al. (1997) LPS XXVIII.

\section{SURFACE NUCLEATION ON ISOSTRUCTURAL SUL-} FATE MINERALS: IMPLICATIONS FOR MODELING CRYSTAL GROWTH RATES. D. Bosbach and A. Putnis, Institut für Mineralogie, Universität Münster, Corrensstrasse 24, 48149 Münster,Germany (bosbach@uni-muenster.de; putnis@nwz. uni-muenster.de).

Crystal growth is a very complex heterogeneous process involving bulk diffusion, surface adsorption, surface diffusion, and finally integration of molecules or ions into the crystal lattice. Furthermore, one has to consider different crystallographic surfaces with different reactivities. Different growth mechanisms (spiral growth or surface nucleation) might occur and their contribution to the overall growth rate changes with the saturation state. The fastest growth mechanism determines the bulk growth rate. However, it is the slowest step of that mechanism that limits the overall growth rate. In situ observations of crystal growth with Atomic Force Microscopy (AFM) in supersaturated solution on isostructural crystals are suitable to test theoretical predictions from crystal growth theory. Although surface nucleation has been studied with AFM ex situ [e.g., 1], we present surface nucleation data derived from in situ experiments of isostructural sulfate minerals (e.g., barite, $\mathrm{BaSO}_{4}$ ).

The bulk growth rate of barite follows a second-order rate law, which might be explained by applying the BCF growth model (spiral growth) to growth of sparingly soluble crystals in aqueous solution [2]. However, in situ AFM observations clearly show that surface nucleation on the $(001)$ cleavage surface is an important growth mechanism that contributes to the bulk rate significantly. Spiral growth, which is thought to be the dominant growth mechanism for crystal growth processes from aqueous solution following a second order rate law, rarely occurs.

The formation of surface nuclei in pure $\mathrm{MeSO}_{4}\left(\mathrm{Me}=\mathrm{Ba}^{2+}\right.$, $\mathrm{Pb}^{2+}, \ldots$ ) solutions has been observed in situ. The height of these islands represents one $\mathrm{MeSO}_{4}$ layer parallel $(001)$, i.e., one half unit cell layer, which has been predicted from PBC theory [3]. Furthermore, the spreading of these islands according to the birth and spread model [4] after nucleation could be observed as well. Consequently, monolayer step growth kinetics could be determined.

Certain organic molecules attach to sulfate mineral surfaces quite strongly via carboxylic acid or phosphonic acid functional 
groups and reduce the growth rate by actually blocking active growth sites. Although the effect of crystallization inhibitors has been studied extensively, a sound understanding of the actual inhibition mechanism is still lacking. In the presence of polyphosphonic acids (e.g., MDP, HEDP, NTMP) the rate of surface nucleation as well as the spreading of monolayer islands is reduced.

Induction periods, nucleation rates, and monolayer step growth kinetics on cleavage surfaces of the isostructural sulfate minerals could be determined by in situ AFM observations in pure metal sulfate solution and in the presence of different organic growth inhibitors as a function of supersaturation.

References: [1] D. Bosbach et al. (1996) GCA, 60, 32953304. [2] A. E. Nielsen (1984) J. Crystal Growth, 67, 289-310. [3] P. Hartman and W. M. M. Heijnen (1983) J. Crystal Growth, 63, 261-264. [4] M. O'Hara and R. C. Reid (1973) Modeling Crystal Growth Rates from Aqueous Solution, Prentice-Hall.

CONTROLS ON BACTERIAL SULFATE REDUCTION IN A DUAL-POROSITY AQUIFER. S. H. Bottrell'1, S. J. Moncaster ${ }^{1.2}$, J. H. Tellam², and J. W. Lloyd'2, 'Department of Earth Sciences, University of Leeds, Leeds LS2 9JT, UK (simon@earth. leeds.ac.uk), ${ }^{2}$ School of Earth Sciences, University of Birmingham, Birmingham B15 2TT, UK.

Bacterial sulfate reduction can be an important process controlling the chemistry of deep groundwater. The sulfide produced is toxic, rendering groundwater unsuitable for drinking and corrosive, limiting potential industrial usage. Dual-porosity aquifers contain groundwater both in open fissures and in pore spaces in the aquifer matrix in the blocks between fissures. The degree of chemical and physical interaction between these different groundwaters is controlled largely by physical properties of the aquifer, such as the porosity and permeability of the aquifer matrix and the spacing of the fissures defining the matrix blocks. Thus conclusions relating to bacterial sulfate reduction in such a system will also apply to other bacterial processes such as nitrate reduction, which may be important in the attenuation of nitrate pollution in groundwater.

We have studied groundwater affected by sulfate reduction in the Lincolnshire Limestone aquifer of E. England. This is a classic dualporosity aquifer with most groundwater flow via solutionally enlarged fissures on joints and bedding planes but high porosity (typically $25 \%$ ) in the limestone blocks between. The limestone is confined between clays and in the confined aquifer zones of $\mathrm{O}_{2}$ reduction, nitrate reduction and sulfate reduction are apparent in the chemistry of the fissure waters sampled from boreholes. In addition to sampling boreholes for chemical and $S$ isotopic analysis we also drilled to recover core from the full thickness of the aquifer in the sulfate-reducing zone for extraction and analysis of matrix pore water.

In the sulfate-reduction zone sulfate concentrations fall from $\sim 1 \mathrm{mM}$ to $<0.1 \mathrm{mM}$, but sulfide is only present at concentrations $<0.03 \mathrm{mM}$. The isotopic effects of sulfate reduction are clear, with large enrichments in ${ }^{34} \mathrm{~S}$ in the residual sulfate while sulfide is strongly ${ }^{34} \mathrm{~S}$ depleted. Pore water in the aquifer matrix have markedly different $\mathbf{S}$ chemistry. The picture is complicated by the fact that there is chemical and isotopic evidence for pore water of two different origins, but crucially: (1) sulfate concentrations are far higher than in the fissure waters, and (2) there is no $S$ isotopic evidence for the pore water having been significantly affected by sulfate reduction.

These data indicate that, on the timescales of bacterial sulfate reduction and diffusional exchange at least, the fissure and pore water have evolved independently. The fissure water has been profoundly affected by sulfate reducers while the pore water is unaffected. This is probably due to the exclusion of sulfate-reducing bacteria from the aquifer matrix blocks because the pore interconnections are too small for them to pass. The bacteria are therefore restricted to the immediate vicinity of the fissures and their walls. Other than historical data relating to groundwater exploitation (sulfide was present $\sim 100 \mathrm{yr}$ ago) we cannot know when sulfate reduction took place, but there has been negligible modification of pore water compositions by diffusional exchange with the fissure waters.

Following drilling to recover the core, the new well and preexisting wells in the vicinity were monitored. Drilling was undertaken under the strictest possible conditions, using only local, lowsulfate groundwater stored in N-purged tanks. However, following drilling there was a significant change in the $S$ chemistry of the fissure water with sulfate being converted to sulfide. Initial rates of sulfate reduction associated with this phase were of the order of $0.6 \mathrm{mmolL}^{-1} \mathrm{hr}^{-1}$, among the highest measured or inferred for sulfate reduction in groundwater. This strongly suggests that even at sulfate concentrations as low as $0.1 \mathrm{mM}$, sulfate availability is not limiting on sulfate reduction in groundwater. Rather, the limiting factor appears to be labile organic matter that would have been supplied in abundance during drilling since the kerf on the coring bit will have ground up substantial amounts of the limestone (which contains $0.5-3 w t \%$ organic $C$ in the form of "kerogen").

The primary limitation on bacterial sulfate reduction is the availability of organic matter. Reduction is limited to the fissure waters because bacteria are too large to pass pore throats into the aquifer matrix blocks and utilize the organic matter and sulfate therein. By analogy, the same constraints will apply to nitratereducing bacteria in this aquifer and we would predict that nitrate attenuation potential will be severely limited by this constraint.

PERIDOTITE XENOLITHS FROM THE SLAVE CRATON, NORTHWEST TERRITORIES. F. R. Boyd ${ }^{1}$ and D. Canil' 'Geophysical Laboratory, 5251 Broad Branch Road, Northwest, Washington DC, USA (boyd@gl.ciw.edu),2School of Earth and Ocean Science, University of Victoria, P.O. Box 1700, Victoria BC V8W 2Y2, Canada (dcanil@uvic.ca).

Xenoliths in core from the diamondiferous Grizzly kimberlite near Lac de Gras, made available by BHP Minerals, provide evidence of the rock types that comprise the Slave root. Coarse lherzolites and harzburgites are most abundant, with fewer eclogites and pyroxenites. Many of the small peridotite fragments lack gamet but the relatively low $\mathrm{Al}_{2} \mathrm{O}_{3}$ contents of the orthopyroxenes $(<1 \mathrm{wt} \%)$ and high $\mathrm{Cr}_{2} \mathrm{O}_{3}$ contents of the spinels (50-60 wt\%) are evidence that all are garnet facies. Sheared, high-temperature peridotites have not thus far been found at Grizzly but have been reported from the Jericho pipe, $150 \mathrm{~km}$ north-northeast of Lac de Gras [1].

The Grizzly peridotites are olivine-rich with grain sizes predominantly less than $5 \mathrm{~mm}$ but ranging up to $1 \mathrm{~cm}$. Orthopyroxene is markedly less abundant and more fine-grained than olivine. 


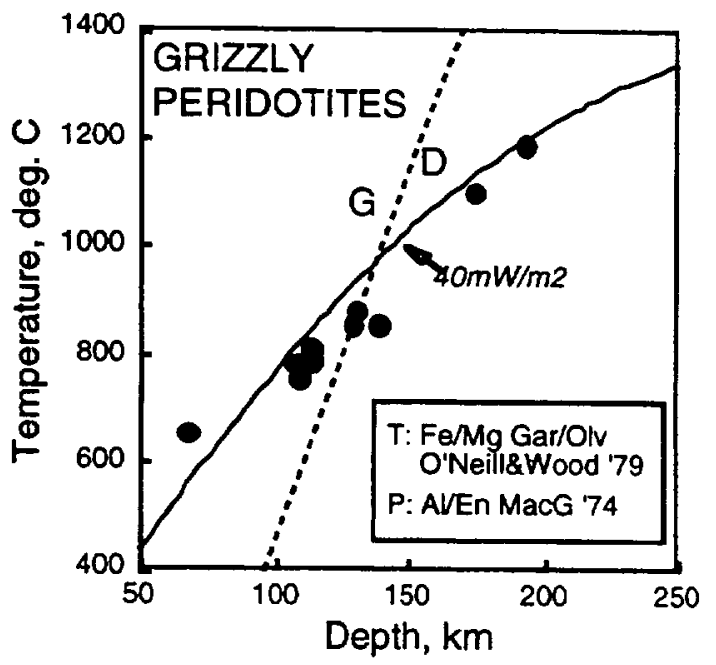

Fig. 1. Data from $[3,4]$.

Clinopyroxene, gamet, and spinel in the Grizzly peridotites range widely in abundance but are commonly sparse. Magnesium numbers for the harzburgites have the range 92.2-93.8 whereas those for the lherzolites are 91.5-92.5. The average for 20 Grizzly peridotites is 92.7 , very close to the averages for low-temperature peridotites from the Kaapvaal craton and Udachnaya (Siberia). Four harzburgites contain subcalcic garnets with $\mathrm{CaO}$ in the range 2-4 and $\mathrm{Cr}_{2} \mathrm{O}_{3} 4-$ 5 wt\%. These gamets are $\mathrm{Cr}$-poor and $\mathrm{Ca}$-rich in comparison to the most common garnet inclusions in diamonds. The Grizzly peridotites are markedly less serpentinized than counterparts from southem Africa and Siberia but they have experienced extensive latestage introduction of $\mathrm{Ca}$. Introduced $\mathrm{Ca}$ has crystallized as mantles of secondary clinopyroxene on grains of primary orthopyroxene and as intergranular monticellite.

Temperature-depth estimates for the Grizzly gamet harzburgites and lherzolites plot close to the $40 \mathrm{~mW} / \mathrm{m}^{2}$ craton geotherm and are in a range similar to plots obtained for peridotite xenolith suites from the Kaapvaal craton in southern Africa and Udachnaya, Siberia [2]. The Grizzly peridotites plot across the diamond-graphite transition with some having originated in the graphite field at shallower depths than peridotites and eclogites in the Jericho suite [1].

Xenoliths of low-temperature peridotite from the Kaapvaal craton in southem Africa and from Siberia have widely varying orthopyroxene contents that range up to $45 \mathrm{wt} \%$. Proportions of orthopyroxene observed in Grizzly thin sections appear less than in most peridotites from the Kaapvaal and Siberia. The Grizzly peridotites are comparable in high mg number to other cratonic peridotites, but their relative paucity in orthopyroxene may be evidence that their igneous history has differed.

References: [1] Kopylova et al. (1996) http://perseus.geology. ubc.ca/ maya/YelknPT.html. [2] Boyd et al. (1997) Contrib. Mineral Pet., in press. [3] O'Neil and Wood (1979) Contrib. Mineral Pet., 70, 59-70. [4] MacGregor (1974) Am. Mineral, 59, 110-119.

RHENIUM-187/OSMIUM-187 ISOTOPIC CONSTRAINTS ON THE CHEMICAL EVOLUTION OF THE MARTIAN MANTLE. A. D. Brandon' ${ }^{1}$, R. J. Walker ${ }^{1}$, J. W. Morgan ${ }^{1}$, and
G. G. Goles', 'Department of Geology, University of Maryland, College Park MD 20742, USA, ${ }^{2}$ Department of Geological Sciences, Campus Box 1272, University of Oregon, Eugene OR 97332-1272, USA.

Rhenium-187/osmium-187 isotopic systematics of martian meteorites should provide valuable information regarding the chemical evolution of the martian mantle, particularly with regard to the relative abundance of highly siderophile elements (HSE). For example, the Os isotopic composition of the Earth's mantle through time indicates that at least the upper mantle evolved with a generally chondritic ${ }^{187 R e} / 188 \mathrm{Os}$. This fact has been previously interpreted as indicating that the HSE budget of the upper mantle of the Earth was set by late accretion of chondritic materials following core segregation. Recent fine-scale examination of the Earth's primitive upper mantle composition suggests that it is most similar to enstatite and ordinary chondrites, which have ${ }^{187} \mathrm{Os} / 188 \mathrm{O}$ averaging 0.1286 , rather than the carbonaceous chondrite average of 0.1258 [1]. In order to test whether the martian mantle has had a similar history of late accretion and upper mantle mixing, we have begun to analyze the ${ }^{187} \mathrm{Re}-{ }^{187}$ Os systematics of SNC meteorites.

ALH 77005 (lherzolitic shergottite cumulate) gives $\operatorname{Re}=256 \mathrm{ppt}$, $\mathrm{Os}=3365 \mathrm{ppt}$, and ${ }^{187} \mathrm{Os} /{ }^{188} \mathrm{Os}=0.1317 \pm 0.0003$. The initial Os isotopic composition at the presumed time of crystallization of $\sim 160 \mathrm{Ma}$ is $0.13076 \pm 0.0004$, giving $\gamma_{\mathrm{os}}=3.7 \pm 0.3$. The initial ratio is not very time sensitive because of the subchondritic ${ }^{187} \mathrm{Re}$ / ${ }^{188} \mathrm{Os}$ ratio. Although the calculated initial Os isotopic composition is roughly "chondritic," the initial ${ }^{187} \mathrm{Os} /{ }^{188} \mathrm{Os}$ is $\sim 2-4 \%$ more radiogenic than any known chondrites. If Mars were affected by late accretion in a manner similar to the Earth, slightly suprachondritic initial ratios can potentially be explained via one of several mechanisms: (1) crustal contamination, (2) derivation from mantle sources with long-term enrichment in $\mathrm{Re} / \mathrm{Os}$ relative to chondrites (as with some terrestrial plumes), or (3) the late accretionary veneer was dominated by chondritic materials that had a higher Re/Os than the material added to the Earth. ALH 77005 has high ${ }^{143} \mathrm{Nd}^{144} \mathrm{Nd}$ of $>0.513$ [2] that is not consistent with crustal contamination having affected this sample. If the ${ }^{187} \mathrm{Re}-{ }^{187} \mathrm{O}$ s systematics were controlled by the composition of late-accreting materials (case 3 ), which is best supported by our data, then high-P/T metal-silicate partitioning of HSE during core formation [3], does not explain the systematics of these elements in the martian mantle, and a similar case may be made for Earth by comparison.

References: [1] Meisel T. et al. (1996) Nature, 383, 517-520. [2] Jagoutz E. et al. (1993) LPSC XXIV, 711-712. [3] Righter L. and Drake M. J. (1997) EPSL, in press.

\section{ISOTOPIC RATIOS AND RELEASE RATES OF STRON-} TIUM FROM WEATHERING FELDSPARS. S. L. Brantley', J. Chesley ${ }^{2}$, and L. L. Stillings ${ }^{3}$, 'Department of Geosciences, Pennsylvania State University, University Park PA 16802, USA (brantley@geosc.psu.edu),,2Department of Geosciences, University of Arizona, Tucson AZ 85721, USA, '3Department of Geology and Geophysics, University of Wyoming, Laramie WY, USA.

Rates of chemical weathering of silicates have been estimated as a function of geologic time by measuring $\mathrm{Sr}$ isotopes trapped in marine carbonates. Fluxes of Sr have also been used to investigate 
nutrient cycling, weathering rates of individual silicate phases, and kinetics and equilibrium of $\mathrm{Sr}$ exchange in soils. Interpretation of $\mathrm{Sr}$ isotopes with respect to weathering and exchange fluxes is based upon two assumptions: (1) Sr release from dissolving minerals is stoichiometric, and $(2)^{87} \mathrm{Sr} /{ }^{86} \mathrm{Sr}$ ratios in weathering fluxes are equivalent to ratios in the dissolving solids. These assumptions were tested by mineral dissolution experiments.

Strontium release from previously run dissolution experiments for plagioclase and microcline were analyzed. In these experiments, bytownite $\left(\mathrm{Ab}_{24} \mathrm{An}_{76} \mathrm{Or}_{0}\right)$ and microcline $\left(\mathrm{Ab}_{22} \mathrm{An}_{0} \mathrm{Or}_{78}\right)$ were powdered and then dissolved in stirred reactors at pH 3-4. Before each experiment, cells were soaked in $10 \% \mathrm{HNO}_{3}$ and rinsed with deionized water. Experiments were continued until major element concentrations were constant.

In the bytownite experiments, [Sr] in effluent solutions decreased with time until $1000 \mathrm{hr}\left(10^{-17} \mathrm{~mol} \mathrm{Sr} \mathrm{cm}^{-2} \mathrm{~s}^{-1}\right)$. Strontium87 /strontium-86 ratios also decreased from an initial high of $\sim 0.706$ until $\sim 1000 \mathrm{hr}$, when ${ }^{87} \mathrm{Sr} /{ }^{86} \mathrm{Sr}_{\text {effuent }}$ equaled ${ }^{87} \mathrm{Sr} /{ }^{86} \mathrm{Sr}_{\text {powder }}(0.703)$. At steady state, $\mathrm{Sr} / \mathrm{Si}$ mole ratios of effluent was only slightly larger than the mole ratio in powder. Total loss of Sr integrated during dissolution is consistent with $13 \% \mathrm{Sr}$ loss from bytownite powder. [Sr] in the bytownite experiments was $\geq 100 \times$ higher than $[\mathrm{Sr}]_{\text {blank. }}$. Blank correction of these values was therefore insignificant.

[Sr] in the effluent from the microcline experiment also decreased with time. For times $<500 \mathrm{hr}$, [Sr] was $\sim 100 \times$ more concentrated than blank solutions, but $>500 \mathrm{hr}$ [Sr] became similar to

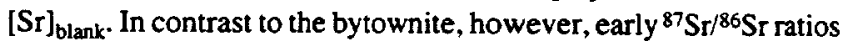
(time $<250 \mathrm{hr}$ ), where blank correction is insignificant $(<1 \%)$, are lower $(\sim 0.712)$ than ${ }^{87} \mathrm{Sr} /{ }^{86} \mathrm{Sr}$ in original powder $(\sim 1.0)$. Exact ${ }^{87} \mathrm{Sr} /$ ${ }^{86} \mathrm{Sr}$ ratios of later samples $\left(>500 \mathrm{hr}\right.$ ) is dependent upon the $[\mathrm{Sr}]_{\mathrm{blank}}$ for correction. However, during dissolution, ${ }^{87} \mathrm{Sr} /{ }^{86} \mathrm{Sr}$ values in effluent increase with time, approaching the final powder value rather than decreasing toward blank. The data suggest a steady-state Sr release rate of $1.3 \times 10^{-19} \mathrm{~mol} \mathrm{Sr} \mathrm{cm}^{-2} \mathrm{~s}^{-1}$, and a ratio of $\mathrm{Sr} / \mathrm{Si}$ in final effluent of $10^{-5}$. Total $\mathrm{Sr}$ released over $3000 \mathrm{hr}$ is similar to the value necessary to account for the change in $\mathrm{Sr}$ concentration in the powder.

In summary, release of Sr from both minerals changes over the duration of dissolution. In addition, $\mathrm{Sr}$ with a different isotopic ratio than the prereaction powder is released initially. Release of Sr with isotopic signature distinct from that in the bulk mineral requires one of two possibilities: either the presence of two or more Sr-containing phases or Sr-containing crystallographic sites. Backscattered electron microscopy yields evidence for perthitic textures in the microcline, and possibly lamellae of different composition in the by townite. These observations may explain the observations of $\mathrm{Sr}$ release from these feldspar phases.

EXPERIMENTAL CONSTRAINTS ON THE ROLE OF AQUEOUS FLUIDS IN THE ORIGIN OF BORON/BERYL LIUM VARIATIONS IN ARC MAGMAS. J. M. Brenan ${ }^{1}, H$. F. Shaw ${ }^{2}$, and F. J. Ryerson', ' Department of Geology, University of Toronto, Toronto ON M5S 3B1, Canada, ${ }^{2}$ Mail Code L-201, IGPP, Lawrence Livermore National Laboratory, Livermore CA. 94550 , USA.

The $B / B e$ ratio of many arc lavas decreases systematically with increasing depth to the Benioff zone [cf. 1]. Calculations using mineral/melt partition coefficients [2] indicate that $>5 \%$ partial melting of mantle peridotite cannot fractionate $\mathrm{B}$ from $\mathrm{Be}$, and therefore melting is unlikely to be the cause of the observed changes in $\mathrm{B} / \mathrm{Be}$. Instead, the variation in $\mathrm{B} / \mathrm{Be}$ ratio must be inherent to the mantle source that produces arc lavas and may be a result of metasomatism of the mantle wedge by $\mathrm{H}_{2} \mathrm{O}$-rich fluids derived from progressive dehydration of the oceanic crust. For this explanation to be correct, the bulk solid/fluid partition coefficient for B must be significantly less than both unity and that of Be.

To characterize $\mathrm{B} / \mathrm{Be}$ fractionation during high-pressure devolatilization of oceanic crust, we are measuring partition coefficients between aqueous fluid and clinopyroxene and garnet in experiments conducted at $900^{\circ} \mathrm{C}$ and $2 \mathrm{GPa}$ using the procedures of Brenan et al. [3]. Results to date indicate that clinopyroxene/fluid partition coefficients (D-B and D-Be) range from 0.010 to 0.046 for $B$ and from 0.5 to 19.7 for Be. Both D-Be and D-B are positively correlated with the Al/Ca ratio of the clinopyroxene and much of the reported variation in the partition coefficients is due to this effect. These results are in marked contrast to our previously measured clinopyroxene/silicate melt partition coefficients, which yielded values of $\sim 0.02$ for both $B$ and $B e$. Thus, comparison of the $\mathrm{cpx} /$ fluid vs. cpx/melt partitioning behavior for these elements suggests that $\mathrm{B} / \mathrm{Be}$ fractionation can be a fluid-mediated process under highpressure conditions.

Recent analytical results suggest that, in the absence of appreciable mica, clinopyroxene will be an important host for $\mathrm{B}$ and $\mathrm{Be}$ in mafic compositions at eclogite-facies conditions [4]. Our data imply that $B$ will behave as an incompatible element during dehydration of oceanic crust, while $\mathrm{Be}$ will be retained. Progressive dehydration of the subducting slab will therefore result in metasomatism of the mantle wedge by high $\mathrm{B} / \mathrm{Be}$ fluids in shallow portions of subduction zones, and lower $\mathrm{B} / \mathrm{Be}$ fluids in deeper portions. This is consistent with the variations in $\mathrm{B} / \mathrm{Be}$ ratio of the mantle wedge inferred from the observed trends in arc volcanics. Our results also indicate that, due to the preferential loss of $B$ from the oceanic crust, material with a low $\mathrm{B} / \mathrm{Be}$ ratio will be returned to the mantle as a result of subduction. Such a process is thus capable of preventing the excess $B$ acquired during near-surface alteration of oceanic crust from being cycled into the mantle, thus maintaining the distinction in $\mathrm{B} / \mathrm{Be}$ for mantle and crustal reservoirs.

References: [1] Ryan et al. (1995) GCA, 60, 415-422. [2] Neroda et al (1996) EOS, 77, S281. [3] Brenan et al. (1995) GCA, 59, 331-3350. [4] Domanik et al. (1993) GCA, 57, 49975010.

\section{ISOTOPE STRATIGRAPHY FOR THE LATE PALEOZOIC GREENHOUSE/ICEHOUSE TRANSITION: PROXY SIG- NALS FOR LINKS BETWEEN OCEAN CHEMISTRY, CLI- MATE, AND TECTONICS. P. Bruckschen ${ }^{1.2}$ and J. Veizer ${ }^{2.3}$, Department of Geology and Geophysics, Texas A\&M University, College Station TX 44783, USA (bruckschen@ geopsun.tamu.edu), Institut für Geologie, Ruhr-Universität Bochum, 44780 Bochum, Germany, ${ }^{3}$ Ottawa-Carleton Geoscience Centre, University of Ottawa, Ottawa K1N 6N5, Canada.}

The looming environmental issues of "global change" can be calibrated and tested only against a background long-term geological record. Isotopic variations in marine biogenic calcites play a 
premier role in this endeavor, serving as a proxy for the Pleistocene and Cenozoic climatic and paleoceanographic events. Their potential, however, has yet to be realized for the older intervals of the Phanerozoic. In this study, we utilized Carboniferous brachiopod shells from western Europe and the former USSR in order to test their potential as a recorder of paleoceanographic and paleoclimatic conditions during the late Paleozoic transition from a greenhouse to an icehouse. Specifically, the goals were (1) delineation of secular $\delta^{18} \mathrm{O}, \delta^{13} \mathrm{C}$, and ${ }^{87} \mathrm{Sr} /{ }^{86} \mathrm{Sr}$ variations for the coeval seawater and (2) search for the causative factors of the observed isotopic variations.

The mean values, calculated from a total of 444 samples for individual Carboniferous epochs, show clear $\delta^{18} \mathrm{O}$ overall increase of up to $3 \%$ from the early to the late Carboniferous. The rise in $\delta^{18} \mathrm{O}$, which commences at the Visean/Serpukhovian transition, coincides with the onset of the major phase of Permocarboniferous glaciation. This trend is intemupted by a negative excursion in the mear $\delta^{18} \mathrm{O}$ values during the mid Carboniferous (Bashkirian), possibly due to diagenetic alteration of the isotope signal. Following the plateau around $-4 \%$ during the Moscovian and Kasimovian, the subsequent $\delta^{18} \mathrm{O}$ record reaches its most positive value in the Gzhelian, the terminal epoch of the Carboniferous.

The Carboniferous $\delta^{13} \mathrm{C}$ record of comparable temporal resolution shows a similar mid-Carboniferous shift of more than $2.5 \%$, followed by a plateau around 5\%o during the Bashkirian and Moscovian, $3 \%$ decline during the Kasimovian, and another $2 \%$ rise during the Gzhelian.

The mid-Carboniferous $\delta^{13} \mathrm{C}$ shift may be, at least in part, a reflection of enhanced organic $\mathrm{C}$ storage due to Carboniferous coal formation, but its coincidence with the onset of glaciation indicates that paleoclimate may have been the triggering factor. In the same vein, the Kasimovian $\delta^{13} \mathrm{C}$ drop coincides with a warming phase within the late Carboniferous icehouse, a deduction based on global distribution of glacial deposits. Further consideration, based on stratigraphically better resolved $O$ isotope record, indicates that the onset of this $\delta^{13} \mathrm{C}$ decline coincides with a negative shift, of about $1.5 \%$, in $\delta^{18} \mathrm{O}$ during the early Kasimovian. This would suggest, in contrast to the poorly dated record of glacial depositş, that the late Carboniferous warm episode did not encompass the entire Stephanian, because $\mathrm{O}$ and $\mathrm{C}$ isotope data indicate strong cooling during the Gzhelian.

The existing ${ }^{87} \mathrm{SI} /{ }^{86} \mathrm{Sr}$ record for the Carboniferous, based on 225 measurements, is dominated by a mid-Visean minimum, followed by a rapid shift to more radiogenic values in the Serpukhovian. As for the $\delta^{13} \mathrm{C}$ and $\delta^{18} \mathrm{O}$, the $\mathrm{Sr}$ isotope record remains on a "radiogenic" plateau during the Bashkirian and Moscovian epochs, supporting a scenario of enhanced continental weathering in the early mid Carboniferous, probably due to increased uplift during the Hercynian orogeny. Such enhanced weathering and sedimentation rates, typical of waning phases of orogenic cycles, may be an essential prerequisite for significant storage of organic $\mathrm{C}$, with its consequences for the global $\mathrm{C}$ cycle, $\mathrm{CO}_{2}$ greenhouse, and ultimately the climate. If so, the long-term variations in ocean chemistry and climate may be coupled to the tectonic evolution of the Earth system.

VARIATION OF BARIUM/CALCIUM IN PLANKTONIC FORAMINIFERA AS AN INDICATOR OF GLACIAL
MELT-WATER DISCHARGE IN THE GULF OF MEXICO. T. P. Buerken and L. H. Chan, Department of Geology and Geophysics, Louisiana State University, Baton Rouge LA 70803, USA (glchan@lsuvm.sncc.lsu.edu).

The Gulf of Mexico, fed by the Mississippi River, has proven to be an effective location for studying the glacial meltwater discharge to the ocean. We present planktonic $\mathrm{Ba} / \mathrm{Ca}$ and ${ }^{87} \mathrm{Sr} /{ }^{86} \mathrm{Sr}$ records of meltwater inflow to the Gulf associated with the retreat of the Laurentide ice sheet.

Barium/calcium ratios have been measured in Orbulina universa and Globigerinoides sacculifer in cores from the southwestem Gulf Basin (water depth $3640 \mathrm{~m}$ ) and the westem slope of the Yucatan Platform (water depth $2590 \mathrm{~m}$ ) respectively. In the southwestem Gulf, a maximum shift of $-1.6 \%$ in $8^{18} \mathrm{O}$ was observed, corresponding to a salinity reduction of $2-3 \%$ at the peak of the meltwater inflow. Coincident with this isotopic shift, $\mathrm{Ba} / \mathrm{Ca}$ increases by $0.8 \mu \mathrm{mol} / \mathrm{mol}$ to a maximum of $2.0 \mu \mathrm{mol} / \mathrm{mol}$. This increase is consistent with surface-water freshening as inferred from the $O$ isotope record, assuming present-day $\mathrm{Ba}$ and $\mathrm{Ca}$ concentrations in the Mississippi and Gulf end members. Near the Yucatan Platform, the $\delta^{18} \mathrm{O}$ anomaly is somewhat diminished $(-1.0 \%)$. The $\mathrm{Ba} / \mathrm{Ca}$ increase, is larger however, registering a maximum value of $2.6 \mu \mathrm{mol}$ mol. Below the deglacial meltwater, $\mathrm{Ba} / \mathrm{Ca}$ reaches $4.0 \mu \mathrm{mol} / \mathrm{mol}$ at the last glacial maximum. Due to the proximity of the station to the carbonate platform, shelf-related input to the surface waters may be a source of $\mathrm{Ba}$ enrichment.

Strontium-87/strontium-86 provides further evidence of the meltwater inflow to the southwestem Gulf. Strontium-87/strontium-86 becomes more radiogenic from late Pleistocene $(0.70913)$ to Recent (0.70918). Superimposed on this trend is an increase of 0.00004 correlative with the meltwater pulse. In contrast, $\mathrm{Li} / \mathrm{Ca}$ displays no meltwater signal as expected from its low dissolved content in the Mississippi. The ratio, however, was higher by $50 \%$ during the last glacial maximum $\left(1.5 \times 10^{-5} \mathrm{~mol} / \mathrm{mol}\right)$ compared with the Holocene $\left(1.0 \times 10^{-5} \mathrm{~mol} / \mathrm{mol}\right)$. The elevated $\mathrm{Li} / \mathrm{Ca}$, together with lowered ${ }^{87} \mathrm{Sr} /{ }^{86} \mathrm{Sr}$ and enrichment in $\mathrm{Ba}$ inferted for the glacial surface waters, suggest enhanced groundwater input in the late Pleistocene when much of the continental shelves of the Gulf was exposed during lower sea-level conditions.

\section{ARGON-40/ARGON-39 LASER-PROBE DATING OF DIA-} MONDS. R. Burgess' 1 G. Turner, and J. W. Harris ${ }^{2}$, 'Department of Earth Sciences, University of Manchester, Oxford Road, Manchester, M13 9PL, UK (Ray.Burgess@man.ac.uk), 2Department of Geology and Applied Geology, University of Glasgow, Glasgow, G12 $8 Q Q$, UK.

Argon-40/argon-39 laser-probe analyses of individual K-bearing inclusions (e.g., clinopyroxene) in diamonds can potentially give both eruption and genesis ages. In diamonds that predate the host kimberlite or lamproite, radiogenic ${ }^{40} \mathrm{AI}$ will diffuse to the boundary of inclusions and be stored at the inclusion/diamond interface during mantle residence. During eruption to the surface, the temperature will fall below the blocking temperature for AT diffusion and from there on ${ }^{40} \mathrm{Ar}$ will accumulate within the inclusion. Therefore, laser drilling to inclusions completely encapsulated in diamond will initially liberate the interface $\mathrm{Ar}$, followed by $\mathrm{Ar}$ 
from the inclusion released during melting. The latter can be used to calculate an eruption age and, when combined with the interface gas, should give the diamond genesis age. This method is currently being applied to a suite of 10 clinopyroxene-bearing diamonds from Lethlekane, Botswana. Preliminary results have been obtained using a UV laser to extract the interface Ar. For each stone, 10-20 laser extractions, each of $5 \mathrm{~min}$ duration, are required to drill down to the inclusion. These initial extractions represent ablation of the host diamond only and release amounts of Ar that are, within error, equal to nonlaser blanks. This indicates that the diamond matrix does not contain trapped Ar gas. Once the inclusion has been reached, significant amounts of $\mathrm{K}$-derived ${ }^{39} \mathrm{Ar}\left({ }^{39} \mathrm{Ar}_{\mathrm{K}}\right)$ and ${ }^{40} \mathrm{Ar}$ are released that are many times greater than background levels. Amounts of ${ }^{36} \mathrm{Ar}$ and $\mathrm{Cl}$-derived ${ }^{38} \mathrm{Ar}$, however, remain unchanged from the background. We therefore interpret the release of ${ }^{39} \mathrm{Ar}$ 的 ${ }^{40} \mathrm{Ar}$ as being gas trapped at the inclusion/diamond interface. Apparent ages from these extractions range from $>4500$ to $\leq 600 \mathrm{Ma}$, but are all probably anomalous. It follows that because ${ }^{40} \mathrm{Ar}$ release is poorly correlated with ${ }^{39} \mathrm{Ar}_{\mathrm{K}}$, which is predicted from the interface model described above, these diamonds must be xenocrysts in the host kimberlite. The age of diamond genesis and eruption will be determined by IR laser melting of the inclusions.

\section{GEOCHEMISTRY AND MINERALOGY OF A GRANITIC SOIL CHRONOSEQUENCE IN THE SIERRA NEVADA,} CALIFORNIA. D. L. Burkins, J. D. Blum, K. Brown, and R. C. Reynolds, Department of Earth Sciences, Dartmouth College, Hanover NH 03755, USA (Derek.Burkins@Dartmouth.edu).

The major-element chemistry, mineral chemistry, and clay mineralogy of soils developed on granodiorite parent materials were investigated in Yosemite National Park in the Sierra Nevada, Califomia. Three of the soil profiles studied are developed on glacial moraines estimated to be $\sim 15 \mathrm{k} . \mathrm{y}$. (Tioga), $\sim 128 \mathrm{k} . \mathrm{y}$. (Tahoe), and $\sim 350$ k.y. (pre-Tahoe) in age, thus constituting a soil chronosequence. Three additional soil profiles studied are developed on bedrock scoured by glacial advances $\sim 15 \mathrm{k} . \mathrm{y}$. and $\sim 128 \mathrm{k} . \mathrm{y}$. ago. The study was originally designed to measure soil weathering rates as a function of soil age and to compare the weathering rates of soils developed on moraines with those developed on bedrock.

Major-element compositions of bulk $<2$-mm-size fractions were analyzed by ICP-OES, soil mineral chemistry was analyzed by SEM-EDX, and clay mineralogy of the $<2-\mu \mathrm{m}$ soil fraction was measured quantitatively using XRD standardized with an oriented internal standard.

For undisturbed soil profiles, the concentrations of the immobile elements $\mathrm{Ti}$ and $\mathrm{Zr}$ should decrease regularly from the top to the bottom of a soil profile. This is due to removal of soluble base cations from the active zone of weathering, resulting in enrichment of the weathered residuum with insoluble elements. This idealized behavior was not observed in the studied soil profiles. Titanium and $\mathrm{Zr}$ concentrations varied sporadically throughout the profiles and in several cases actually increased in concentration with increasing depth.

In addition to granodiorite bedrock minerals plagioclase, $\mathrm{K}$ feldspar, quartz, biotite, and homblende, fine volcanic glass was found disseminated throughout the soil profiles in amounts up to $20 \%$ of the $<2-\mathrm{mm}$ size fraction by volume. Glass concentrations decreased with increasing depth for all soil profiles suggesting initial deposition of glass on preexisting soil surfaces with subsequent translocation downward into the soil profile. This ash was presumably derived from Pleistocene and Holocene volcanic centers located approximately $60 \mathrm{~km}$ east of the site.

The clay mineralogy of the soils is dominated by kaolinite, gibbsite, and Al-hydroxy interlayered vermiculite, with lesser amounts of soil illite. The total amount of clay in the soil profiles increases with soil age. In the soil $<2-\mu \mathrm{m}$-size fractions, the weight proportion of kaolinite ranges from $20 \%$ to $70 \%$, gibbsite ranges from $10 \%$ to $45 \%$, vermiculite ranges from $10 \%$ to $40 \%$, and soil illite ranges from $1 \%$ to $15 \%$. In general, the proportions of vermiculite and soil illite decrease with increasing soil age, whereas the proportion of gibbsite increases from the $\sim 15-k . y$. to $\sim 128-k . y$. soils but decreases in the $\sim 350-k . y$. soil. The kaolinite weight proportion decreases from the $\sim 15-k . y$. to $\sim 128-k . y$. soil, but increases in the 2350-k.y. soil.

Several features of the soil chemistry and mineralogy are anomalous. First, the sporadic behavior of $\mathrm{Ti}$ and $\mathrm{Zr}$ concentrations in the soil profiles suggests either dramatic physical disruption of the soils or open system behavior of $\mathrm{Ti}$ and $\mathrm{Zr}$. Second, the dominance of gibbsite as a weathering product in young soils located in this cool, temperate setting is counter to the common notion that gibbsitedominated soils are restricted to old soils in humid tropical regions.

Mixing of considerable quantities of volcanic glass, with Ti and $\mathrm{Z}$ concentrations markedly different from the local bedrock, is a likely explanation for the unusual behavior of $\mathrm{Ti}$ and $\mathrm{Zr}$ in these soil profiles. This observation complicates interpretations of granitic weathering rates calculated from cation denudation in soils, and also complicates interpretations of mineral weathering reactions determined from stream water chemistry. The surprisingly large quantities of gibbsite in these soils may be the product of rapid weathering of volcanic ash, as has been observed in other predominantly volcanic soils.

ARGONIN THEMANTLE: RESOLVING ATMOSPHERIC CONTAMINANTS BY LASER PROBE. P.G. Bumard ${ }^{1}, D$. W. Graham $^{2}$, and G. Tumer ${ }^{1}$, 'Department of Earth Sciences, Manchester University, ManchesterM139PL,UK (peteb@man.ac.uk), ${ }^{2}$ College of Oceanic and Atmospheric Sciences, Oregon State University, Corvallis OR 97331, USA.

The isotopic composition of Ar in the Earth's mantle remains poorly constrained. The ${ }^{40} \mathrm{Ar} /{ }^{36} \mathrm{Ar}$ ratio most commonly used for the upper mantle (UM) is 30,000 , based on analyses of volatile-rich basalts [1]. However, due to contamination by atmosphere-derived Ar with ${ }^{40} \mathrm{Ar} /{ }^{36} \mathrm{Ar}$ ratio of $\sim 300$, these analyses are lower limits to the actual MORB value. The Ar isotopic composition in the lower mantle (LM) is even more contentious because the basalts may have been contaminated by upper mantle volatiles, as well as by atmospheric Ar. Current estimates for ${ }^{40} \mathrm{Ar} /{ }^{36} \mathrm{Ar}_{\mathrm{LM}}$ range between $<3000$ and $>12,000$, although these are largely based on geochemical modeling. The maximum (i.e., least air-contaminated) ${ }^{40} \mathrm{Ar} /{ }^{36} \mathrm{Ar}$ ratios analyzed in basalts and xenoliths erupted at high- ${ }^{3} \mathrm{He} /{ }^{4} \mathrm{He}$ hotspots are between 2000 (Loihi) and 20,000 (Samoa).

Laser extraction techniques can release gases from individual vesicles in a thick section of basaltic glass using a focused $1064 \mathrm{~nm}$ laser. The procedural blanks are significantly lower than traditional 
extraction techniques, and (by focusing the laser on a vesicle-free region of the section) we can estimate the proportion and isotopic composition of Ar liberated from the section surface.

Eighteen vesicles in the volatile-rich basaltic glass "popping rock" were analyzed. Argon-40/argon-36 ratios were between 5000 and 64,000 . However, the amount of ${ }^{36} \mathrm{Ar}$ released when targeting a vesicle was the same as that when analyzing vesicle-free regions of the glass. We were not able to detect any mantle-derived ${ }^{36} \mathrm{Ar}$.

It has been established that $\mathrm{He}$ and $\mathrm{Ne}$ abundances and isotopes in the mantle resemble "solar" noble gases that have been implanted into meteorites $[2,3]$. It is possible nonradiogenic mantle Ar (i.e., ${ }^{36} \mathrm{Ar}$ and ${ }^{38} \mathrm{Ar}$ ) is also "solar" in origin. "Solar" and atmospheric ${ }^{38} \mathrm{Ar} /{ }^{36} \mathrm{Ar}$ ratios are very similar $(0.188$ and 0.182 respectively) and it will not be possible to identify nonatmospheric ${ }^{38} \mathrm{Ar} /{ }^{36} \mathrm{Ar}$ ratios in mantle materials with the present levels of atmospheric contamination. However, ${ }^{3} \mathrm{He} /{ }^{36} \mathrm{Ar}$ ratios of "solar" and "planetary" noble gases are distinct ( $\sim 12$ and $<0.001$ respectively) and can be used to discriminate "solar" and "planetary" abundance pattems.

Like the ${ }^{40} \mathrm{Ar} /{ }^{36} \mathrm{Ar}$ ratio, ${ }^{3} \mathrm{He} /{ }^{36} \mathrm{Ar}$ ratios in mantle samples are also lower limits to the mantle value. Helium-3/Argon-36 ratios of 0.72 were analyzed in this study, but, when corrected for $\mathrm{He} / \mathrm{Ar}$ fractionation (based on predicted ${ }^{4} \mathrm{He} /{ }^{40} \mathrm{Ar}$ production in the mantle), a ${ }^{3} \mathrm{He}^{/ 36} \mathrm{Ar}$ ratio of $\geq 1.4$ for the mantle source region is obtained. Clearly this is closer to "solar" than to "planetary" "Hel ${ }^{36}$ Ar values, suggesting that "solar" Ar may be present in the mantle. If the relative abundances of nonradiogenic $\mathrm{He}, \mathrm{Ne}$, and $\mathrm{Ar}$ in the mantle are all "solar," then it is possible to predict upper mantle ${ }^{40} \mathrm{Ar} /{ }^{36} \mathrm{Ar}$ ratios of 400,000 and lower mantle ratios of 135,000 using well-known ${ }^{40} \mathrm{Ar} /{ }^{3} \mathrm{He}$ in mantle samples and assuming a solar ${ }^{3} \mathrm{He} /$ ${ }^{36} \mathrm{Ar}$ of 12.

References: [1] Staudacher T. et al. (1989) EPSL, 96, 119133. [2] Honda M. et al. (1991) Nature, 349, 149-151. [3] Sarda P. et al. (1988) EPSL, 91, 73-88.

CORAL-BASED RADIOCARBON CALIBRATION RESULTS TO 20 k.y. BP BASED ON THORIUM-230 AGES OF CORALS FROM THE SOUTH PACIFIC. G. S. Burr', K. Banks'2, S. C. Gray ${ }^{3}$, R. L. Edwards², J. Récy ${ }^{4}$, G. Cabioch ${ }^{4}$, F. W. Taylor', and J. M. O'Malley', 'NSF-Arizona AMS Facility, Physics Department, University of Arizona, Tucson AZ 85721, USA, ${ }_{2}^{2}$ Minnesota Isotope Laboratory, Department of Geology and Geophysics, University of Minnesota, 310 Pillsbury Drive SE, Minneapolis MN 55455, USA, ${ }^{3}$ Marine and Environmental Studies, University of San Diego, Alcala Park, San Diego CA 92110, USA, 4 ORSTOM, Laboratoire Géodynamique Sous-Marine, B.P. 4806230 Villefranche/mer, France, Institute for Geophysics, University of Texas at Austin, 8701 Mopac Boulevard, Austin TX 78759, USA.

This work presents an overview of radiocarbon calibration results from paired ${ }^{14} \mathrm{C}$ and ${ }^{230} \mathrm{Th}$ dates of corals from Vanuatu and Papua New Guinea. The data are compared with calibration results from the widely used CALIB [1], in the time range 11.5 to $20 \mathrm{k} . \mathrm{y}$. BP. The CALIB program uses a smoothed curve derived from coral data from Barbados and Mururoa [2] to calibrate ${ }^{14} \mathrm{C}$ dates. While the general trend of this curve is found to agree with our coral data, significant departures from the Barbados and Mururoa data are observed for certain time periods. The most notable departure observed is a ${ }^{14} \mathrm{C}$ plateau between about 14.1 and $14.8 \mathrm{k} . \mathrm{y}$. BP that does not appear in the CALIB program. The geologic setting of the drilling sites and the diagenetic alteration of certain samples will also be discussed.

References: [1] Stuiver M. et al. (1993) Radiocarbon, 35(1), 215-230. [2] Bard E. M. et al. (1993) Radiocarbon, 35(1), 191-199.

SAMARIUM-NEODYMIUM ISOTOPIC MODELING OF THE EVOLUTION OF THE EARTH'S DEPLETED MANTLE AND CRUST: 1. THE TIME OF CRUST-MANTLE DIFFERENTIATION AND THE MASS OF THE DEPLETED MANTLE. A. R. Calderwood, Department of Earth and Ocean Sciences, University of British Columbia, 6339 Stores Road, Vancouver BC V6T 2B4, Canada (acalderw@eos.ubc.ca).

Armstrong's [1,2] steady-state model for crustal growth involves substantial crustal recycling into the mantle and that the Earth is characterized by essentially constant volumes of crust through geologic time. Central to this model is early massive differentiation of the planet into constant volume reservoirs of enriched continental crust, depleted mantle, and core. While $\mathrm{Hf}-\mathrm{W}$ and $\mathrm{Pb}$ isotopes argue for the onset of major core segregation to have occurred early in Earth's history ( $\approx 60 \mathrm{~m} . \mathrm{y}$.) following Earth's accretion $[3,4]$ there is a persistent myth that differentiation to form continental crust and complementary depleted mantle did not occur until much later $(\approx 2.7 \mathrm{Ga})$ and was largely episodic [e.g., 5]. The crustal-age distribution as inferred from Sm-Nd isotope systematics, and the absence of abundant pre-3.5-Ga crust, and detritus shed from it, is often cited as compelling evidence for both (1) that large volumes of Archean and Hadean continental crust never existed and (2) that the subsequent crustal growth has been episodic. However, since the episodic crustal age distribution likely reflects the relative probability of preservation with time, it is invalid to assume the age distribution of crust preserved today directly reflects the volume of crust originally formed [e.g., 6,7].

To model the Sm-Nd isotopic evolution of continental crust and depleted mantle we utilize the analytical equations of Turcotte and Kellogg [8] but we adopt updated estimates for bulk silicate Earth and continental crust values [9]. We find that the time $\tau_{\text {diff }}$ before the present at which the continental crust differentiated from the mantle reservoir is $\tau_{\text {diff }} \geq 3.8 \mathrm{Ga}$. This time is older than $\tau_{\text {diff }}=3.3 \mathrm{Ga}$ originally obtained by Turcotte and Kellogg [8], a value that they chose to ignore in favor of a differentiation time of $\tau_{\text {diff }}=2.1 \mathrm{Ga}$ calculated for the Rb-Sr system. They adopted the Rb-Sr $\tau_{\text {diff }}$ time as valid for the Sm-Nd system and used this throughout their modeling. However, $\mathrm{Nd}$ and $\mathrm{S}$ t isotopes are decoupled in the continental crust and mantle reflecting the strong effect of weathering on the Rb-Sr system in contrast to that of Sm-Nd. Hence, the differentiation time of the mantle inferred from the Rb-Sr system is younger than the true age and not equivalent to the $\mathrm{Sm}-\mathrm{Nd}$ system [10]. The time of crust-mantle differentiation is important in that it affects the value of the predicted mass of the depleted mantle. The use of $\tau_{\text {diff }}=2.1 \mathrm{Ga}$ gives a predicted mass of the depleted mantle only slightly greater than the mass of the upper mantle and, consequently, Turcotte and Kellogg [8] adopted an isotopically layered mantle with the mass of the depleted mantle equal to the "seismic" upper mantle (<670 km depth). In contrast, for either $\tau_{\text {diff }}=3.3 \mathrm{Ga}$ or our preferred value of $\tau_{\text {diff }} \geq 3.8 \mathrm{Ga}$, we find that the mass of the 
depleted mantle is approximately equal to the whole mantle. The large range of initial $\varepsilon_{N d}(3.96)$ values $(\approx 4.0$ to -4.0$)$ for the Acasta gneiss (and other Archaean units) demands that crust-mantle differentiation occur significantly earlier than $4.0 \mathrm{Ga}$, further strengthening the argument that the whole mantle is depleted.

We conclude that the Sm-Nd system strongly supports Armstrong's [1,2] hypothesis of early Archean-Hadean massive differentiation of the Earth into constant volume reservoirs of enriched continental crust, depleted mantle, and core.

References: [1] Armstrong (1981). [2] Armstrong (1991). [3] Lee and Halliday (1995). [4] Halliday et al. (1996). [5] Taylor and McLennan (1995). [6] Gumis and Davies (1985). [7] Gumis and Davies (1986). [8] Turcotte and Kellogg (1986). [9] Hart and Zindler (1989). [10] Goldstein (1988).

SAMARIUM-NEODYMIUM ISOTOPIC MODELING OF THE EARTH'S DEPLETED MANTLE AND CRUST: 2. THE AGE OF CRUST-MANTLE DIFFERENTIATION AND THE MEAN SAMARIUM-147/NEODYMIUM144 AND NEODYMIUM-143/NEODYMIUM-144 RATIOS OF THE DEPLETED MANTLE-THE WHOLE MANTLE HAS A MID-OCEAN RIDGE BASALT ISOTOPIC COMPOSITION. A. R. Calderwood, Department of Earth and Ocean Sciences, University of British Columbia, Vancouver BC V6T 2B4, Canada (acalderw@eos.ubc.ca).

We consider the simplest crust-mantle mass balance where the continental crust (CC) and depleted mantle (DM) represent complementary reservoirs. Following Hart and Zindler (1989) the presentday average ${ }^{147} \mathrm{Sm}^{144} \mathrm{Nd}$ ratio of the depleted mantle is given by

$$
\left(\frac{147 \mathrm{Sm}}{{ }^{144} \mathrm{Nd}}\right)_{\mathrm{Dm}}^{\mathrm{Now}}-\frac{\left(\frac{\text { Mass }_{\mathrm{cc}}}{\text { Mass }_{\text {tocal }}}[\mathrm{Nd}]_{\mathrm{cc}}\left(\frac{{ }^{147} \mathrm{Sm}}{{ }^{144} \mathrm{Nd}}\right)_{c c}-[\mathrm{Nd}]_{\mathrm{BSE}}\left(\frac{{ }^{147} \mathrm{Sm}}{{ }^{144} \mathrm{Nd}}\right)\right)}{\left(\frac{\text { Mass }_{\mathrm{cc}}}{\text { Mass }_{\text {total }}}[\mathrm{Nd}]_{\mathrm{cc}}-[\mathrm{Nd}]_{\mathrm{BSE}}\right)}
$$

3

The value of $\left({ }^{147} \mathrm{Sm}^{144} \mathrm{Nd}\right){ }_{\mathrm{DM}}^{\text {Now }}$ can be used to calculate the average $\left({ }^{143} \mathrm{Nd} / 144 \mathrm{Nd}\right) \mathrm{NM}^{\mathrm{Now}}$ ratio of the depleted mantle with the use of a twostage isochron, if the time of crust-mantle differentiation $\left(\tau_{\mathrm{diff}}\right)$ can be estimated.

Hart and Zindler inferred that the time of crust-mantle differentiation was accurately recorded by the mean age of the continental crust and considered a range of "young" and "old" mean crustal ages (and hence, the differentiation age) of 2.0 and $3.1 \mathrm{Ga}$. The average age of the continental crust is based on the observed crustal-age distribution, which is often cited as compelling evidence that large volumes of continental crust never existed early in Earth's history. However, since the crustal age distribution likely reflects the relative probability of preservation with time, it is invalid to assume the age distribution of crust preserved today directly reflects the volume of crust originally formed [e.g., 1,2], and consequently, the mean age of the crust is not an accurate estimate of the time of crust-mantle differentiation.

We adopt as a range for the time of crust-mantle differentiation $\tau_{\text {diff }} \geq 3.88-4.47 \mathrm{Ga}$. The time of $3.88 \mathrm{Ga}$ corresponds to the minimum $\tau_{\text {diff }}$ obtained from evaluating the analytical equations of Turcotte and Kellogg [3] that describe the Sm-Nd isotopic evolution of continental crust and depleted mantle, but evaluated using updated parameters. The time of $4.47 \mathrm{Ga}$ is the time of onset of major core formation in the Earth, the formation of the Moon, and development of a lunar magma ocean based on $\mathrm{Hf}-\mathrm{W}$ and $\mathrm{Pb}$ isotope systematics [4]. Adopting $4.47 \mathrm{Ga}$ is consistent with Armstrong's [5-7] "continental big bang + recycling" crustal growth model that proposes early, massive differentiation of the planet into constant volume reservoirs of enriched continental crust, depleted mantle, and core. We find that for $\tau_{\text {diff }} \geq 3.88-4.47 \mathrm{Ga}$, the resultant ( ${ }^{143} \mathrm{Nd} /$ ${ }^{144} \mathrm{Nd}$ ) NM Dow completely overlaps the observed MORB field [e.g, 8]. This indicates that, on average, the whole mantle has a MORB isotopic composition and, consequently, the lower mantle does not comprise a primitive (e.g., BSE, CHUR, or flavors thereof) reservoir that is enriched relative to the MORB reservoir.

References: [1] Gumis and Davies (1985). [2] Gumis and Davies (1986). [3] Turcotte and Kellogg (1986). [4] Halliday et al. (1996). [5] Armstrong (1968). [6] Armstrong (1981). [7] Armstrong (1991). [8] White et al. (1987).

\section{SAMARIUM-NEODYMIUM ISOTOPIC MODELING OF THE EVOLUTION OF THE EARTH'S DEPLETED MAN- TLE AND CRUST: 3. TESTING CRUSTAL GROWTH MODELS WITH AND WITHOUT RECYCLING AGAINST A HADEAN TO RECENT $\varepsilon_{\mathrm{Nd}}(t)$ DATABASE. A. R. Calder- wood, Department of Earth and Ocean Sciences, University of British Columbia, Vancouver BC V6T 2B4, Canada (acalderw@ eos.ubc.ca).}

Most geochemical models that describe the evolution of Earth's crust and mantle invoke progressive and gradual crustal growth in which the volume of continental crust has increased with time at the expense of a primitive mantle, leaving a shallow, depleted MORB mantle reservoir that is approximately equal to the volume of the seismic upper mantle, along with a complementary deep, lower mantle reservoir that is enriched relative to the upper depleted mantle. In contrast, Armstrong's [1-3] "continental big bang + recycling" crustal growth model involves early (Hadean) massive differentiation of the planet into constant volume reservoirs of enriched continental crust, depleted mantle, and core. In this scenario, the Earth is characterized by an essentially constant volume of continental crust that undergoes diminishing rates of recycling through geologic time. Of fundamental difference between the two types of models is that the gradual growth models assume that the present-day crustal age distribution faithfully represents the Earth's crustal growth record, while the steady-state, crustal recycling model considers the crustal age distribution to reflect the changing relative probability of crustal preservation with time. In this case, the presentday crustal age distribution does not directly reflect the volume of crust originally formed at that age [e.g., 4,5].

To differentiate between these two classes of crustal growth models we numerically forward model the $\mathrm{Sm}-\mathrm{Nd}$ isotopic evolution of continental crust and depleted mantle utilizing the analytical equations of Turcotte and Kellogg [6], but with updated parameters. We first consider uniform crustal growth models that do not incorporate recycling where the prescribed period of growth closely matches the various proposed growth curves. Next we consider crustal recycling models where the mass of the continental crust is constant over time. We compare the predicted $\varepsilon_{\mathrm{Nd}}(t)$ curves for continental crust and depleted mantle for both classes of models 
against a compiled database of published Sm-Nd isotopic analyses.

This database contains virtually all published $\mathrm{Sm}-\mathrm{Nd}$ isotopic data from Archean to Recent rocks and for consistency, the initial $\varepsilon_{N d}(t)$ values have been recalculated at the reported crystallization age to a CHUR reservoir with present-day ${ }^{147} \mathrm{Sm} / 144 \mathrm{Nd}=0.1967$ and ${ }^{143} \mathrm{Nd} /{ }^{144} \mathrm{Nd}=0.512638$. This database comprises about 3500 "granitic," 2200 mafic and ultramafic, and 1500 sedimentary analyses. We have critically evaluated the data and removed those analyses where alteration has resulted in open-system behavior. The resultant database of $\varepsilon_{N d}(t)$ is used to evaluate the predicted curves for the gradual growth and recycling models described above.

We find that none of the gradual crustal growth models, for either a layered or whole mantle scenario, can encompass the field defined by the published $\varepsilon_{N d}(t)$ database. In contrast, for the crustal recycling models, only the whole-mantle (but not the layered mantle) crustal recycling model with an early Hadean crust-mantle differentiation fits the published $\varepsilon_{\mathrm{Nd}}(\mathrm{t})$ database. Thus, significant recycling is required to fit the observed isotopic evolution.

References: [1] Armstrong (1968). [2] Armstrong (1981). [3] Amstrong (1991). [4] Gurnis and Davies (1985). [5] Gumis and Davies (1986). [6] Turcotte and Kellog (1986).

\section{SYSTEMATIC DECLINES IN SLAB FLUXES REGISTER- ED ACROSS THE CENTRAL AMERICAN ARC AT OLDER BEHIND-THE-FRONT CENTRAL VOLCANOS IN SOUTH- EASTERN GUATEMALA. B. I. Cameron' ${ }^{1}$, J. A. Walker ${ }^{1}$, M. J. Carr $^{2}$, and L. C. Patino', 'Department of Geology, Northern Illinois University, DeKalb IL60115, USA (barry@geol.niu.edu), ${ }^{2}$ Depart- ment of Geological Sciences, Rutgers University, New Brunswick NJ 08903, USA.}

Subduction zones function as recycling centers for modified oceanic crust and sediments into the upper mantle, and as such, effectively represent the dominant source of mantle heterogeneity. Diverse volcanism in southeastem Guatemala offers an ideal opportunity to address chemical mass balance problems in subduction zones and to track elemental fluxes across a continental arc. In addition to classic composite cones at the volcañic front (VF), southeastem Guatemala hosts the most abundant behind-the-front (BVF) volcanism in the Central American arc.

Behind-the-front volcanism has undergone a fundamental change in eruptive style during the Quatemary from older polygenetic central volcanism to younger monogenetic cinder cone volcanism. The ubiquitous cinder cones have erupted almost exclusively basaltic lavas. In sharp contrast, older BVF central volcanos show a much larger compositional range from basalt to rhyolite. Thus, in terms of compositional spectrum of erupted lavas and eruptive style, the older B VF central volcanos show more petrogenetic kinship with the composite cones of the VFrepresented by Moyuta, Tecuamburro, and Pacaya. Definitive tracers of the subducted slab such as $\mathrm{Sb} / \mathrm{Ce}$ and U/La systematically decline at older BVF central volcanos with distance behind the front in southeastem Guatemala (see Fig. 1). Cinder cone lavas exhibit more sporadic trace-element behavior, some ratios diminish progressively to N-MORB levels (e.g., U/La), whereas others do not (e.g., $\mathrm{Pb} / \mathrm{Nb}$ ).

New geochemical data allow proposal of a preliminary petrological model for volcanism in southeastern Guatemala. Fluidmobile elements (like Cs, U, B, Sb, and As) from the subducted Cocos plate infiltrate the mantle wedge and cause fluid-flux melting

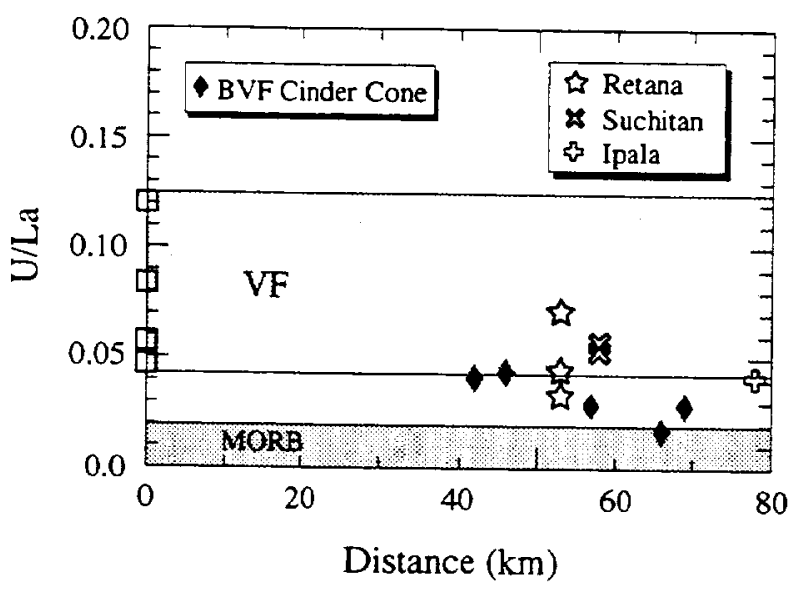

Fig. 1.

that produces high-degree, calc-alkaline magmas erupted at VF polygenetic, composite cones, or older BVF central volcanos. The larger, longer-lasting magma chambers beneath these edifice types favor the development of the more evolved compositions that char. acterize the prominent composite cones. Later, extension associated with interactions between the North American and Caribbean plates promoted decompression melting of the fertilized mantle wedge. Consumption of hydrous phases (e.g., phlogopite and amphibole) produced magmas with trace-element ratios elevated in $\mathrm{Ba} / \mathrm{Ce}, \mathrm{Sr}$ ' $\mathrm{La}$, and $\mathrm{K} / \mathrm{La}$, but comparable in $\mathrm{Sb} / \mathrm{Ce}, \mathrm{Cs} / \mathrm{La}$, and $\mathrm{U} / \mathrm{La}$ to $\mathrm{N}$. MORB. Relatively lower extents of melting translate into smaller magmatic plumbing systems that erupted largely basaltic compositions. This proposed model supports the concept of disparate elemental residency times in the mantle, and highlights the significant role of tectonic controls on melt generation, and eruptive style and frequency.

\section{SILICATE WEATHERING RATES AND ATMOSPHERIC} STRONTIUM FLUXES: A COMPARISON OF ARID SITES IN HAWAI'I AND NEW MEXICO. R. C. Capo', B. W. Stewart ${ }^{1}$, and O. A. Chadwick ${ }^{2}$, 'Department of Geology and Planetary Science, University of Pittsburgh, Pittsburgh PA 15260 , USA (rcapo@vms.cis.pitt.edu; bstewart@vms.cis.pitt.edu), 2Department of Geography, University of California, Santa Barbara CA 93106, USA (oac@geog.ucsb.edu).

Time-dependent models for evolution of labile Sr can be used to constrain weathering rates in soil profiles from Las Cruces, New Mexico, and the Kohala Peninsula, Hawai'i. These sites provide an opportunity to compare soil-forming factors from arid profiles with different parent materials and atmospheric fluxes. In Hawai'i, a high weathering rate $\left(0.1-1 \% \mathrm{k} . \mathrm{y} .^{-1}\right.$ of unweathered parent material remaining) is necessary to prevent atmospheric fluxes from dominating the labile $\mathrm{Sr}$ signal. In contrast, the weathering rate for the New Mexico profile must be 1-2 orders of magnitude less, even with the higher atmospheric input in that region. These estimates are consistent with independent data that show that the younger Hawai'ian flows have weathered to a much greater degree than the New Mexico alluvial parent material. Because temperatures and precipitation rates are similar in both sites, the contrasting weathering rates are most likely due to differences in weatherability of the 
basaltic and quartzofeldspathic parent materials.

The New Mexico profile developed on the Upper La Mesa geomorphic surface (estimated age of $2 \mathrm{Ma}$ ) on Camp Rice Formation alluvial sands. The long-term precipitation rate is $35-50 \mathrm{~cm} / \mathrm{yr}$. The parent material is noncalcareous, but the profile contains a 2m-thick petrocalcic $\mathrm{K}$ horizon. Labile (extracted with $\mathrm{NH}_{4} \mathrm{Cl}$ in methanol buffered to $\mathrm{pH} \sim 8$ ) and carbonate (extracted with acetic acid) $\mathrm{Sr}$ has ${ }^{87} \mathrm{Sr} /{ }^{86} \mathrm{Sr}$ ratios similar to local inputs $(0.7087-0.7093)$ and quite distinct from the alluvial parent material values of $0.7164-$ 0.7166 . These and other data indicate that $>95 \%$ of the $\mathrm{Ca}$ in the pedogenic carbonate originated from precipitation and eolian input.

Several profiles developed on the $\sim 170,000$-yr Hawai' $i$ a flows were sampled on the westem side of the Kohala Peninsula along a precipitation gradient. Small amounts of pedogenic dolomite are present in the most arid sites (rainfall $25-40 \mathrm{~cm} / \mathrm{yr}$ ). Parent alkalic basalt ${ }^{87} \mathrm{Sr} /{ }^{86} \mathrm{Sr}$ values fall in the range $0.7035-0.7036$, while rainfall carries an isotopic signature similar to seawater (0.7092). Measurements of carbonate and labile $\mathrm{Sr}$ isotope compositions from profiles in the arid to humid ( $<150 \mathrm{~cm} / \mathrm{yr}$ of rainfall) regions of the peninsula yield values close to those of the parent material $(0.7036$ 0.7041 ). Thus, most of the labile $\mathrm{Sr}$, and by inference, $\mathrm{Ca}$, were contributed by parent material weathering rather than from the atmosphere in these profiles.

The contrast between sources of labile Sr in the New Mexico and Hawai'i profiles may result in part from differences in atmospheric input. The continental setting of the New Mexico profile ensures a greater flux of Sr from atmospheric sources, primarily eolian carbonate and sulfate. Preliminary data on Sr concentrations from Hawai'ian precipitation suggest concentrations may be up to an order of magnitude less than in New Mexico. This can account for part of the difference in sources of labile $\mathrm{Sr}$ to the two profiles, but is not sufficient in and of itself. The differences in atmospheric fluxes must be combined with large differences in weathering rates to explain the $\mathrm{Sr}$ isotope data.

RUTHENIUM SOLUBHLITY IN HEMATITE. C. J. Capobianco, Lunar and Planetary Laboratory, University of Arizona, Tucson AZ 85721, USA (chrisc@lpl.arizona.edu).

Platinum-group elements (PGE) and oxide minerals have a longknown, though still not well-understood, association [e.g., 1,2]. Although experiments on oxides [e.g., 3,4] reveal their potential to fractionate PGE, doubt remains as to whether it occurs in igneous systems, primarily because no modem measurements yet demonstrate PGE dissolved in significant amounts in oxides from Earth's mantle. If such materials are pristine since their primary crystallization, then absence of evidence would be a strong constraint. Renewed skepticism about oxide hosts for PGE arises from experiments implying unusually low oxidation states for PGE dissolved in silicate melts [e.g., 5]. But oxides are not silicates, though they crystallize from them, and the activity of primary relevance is that of normal PGE oxide components at the conditions of interest. Here I report experiments bearing on the activity of $\mathrm{Ru}$ in an oxide of geologic significance, hematite.

Experimental: Pressed pellets of mechanical mixtures of $\mathrm{Fe}_{2} \mathrm{O}_{3}, \mathrm{RuO}_{2}$, and $\mathrm{Ru}$ were held in $\mathrm{Al}_{2} \mathrm{O}_{3}$ crucibles inside evacuated silica glass tubes. Run assemblies, suspended in a vertical tube fumace, were heated for durations between 336 and $1.5 \mathrm{hr}$ depend-

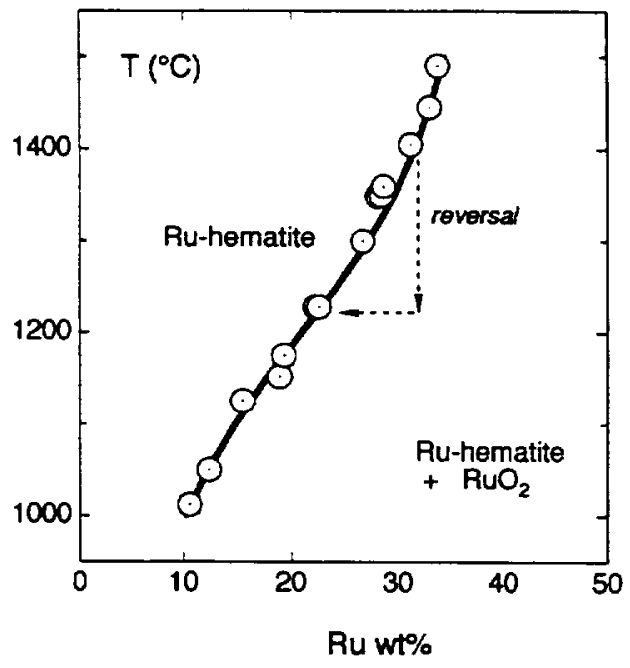

Fig. 1. Saturation concentrations of $\mathrm{Ru}$ in hematite with $\mathrm{O}$ fugacity at the $\mathrm{RuO}_{2} / \mathrm{Ru}$ buffer. Curve calculated from retrieved thermodynamic data. Reequilibrating $1405^{\circ} \mathrm{C}$ run product at $1228^{\circ} \mathrm{C}$ yielded hematite with exsolved $\mathrm{RuO}_{2}$ and Ru contents matching synthesis material from $1228^{\circ} \mathrm{C}$.

ing on run temperature (between $1012^{\circ}$ and $1490^{\circ} \mathrm{C}$ ). Air-quenched samples were examined petrographically, by electron microprobe, and by XRD.

Results and Discussion: Run products were three-phase assemblages containing $\mathrm{Ru}, \mathrm{RuO}_{2}$, and $\mathrm{Ru}$-bearing hematite. Ruthenium contents of Ru hematites are shown in Fig. 1. Because Ru and $\mathrm{RuO}_{2}$ phases were $\sim 99 \%$ pure, $\mathrm{fO}_{2}$ was buffered by $\mathrm{Ru}+\mathrm{O}_{2}=\mathrm{RuO}_{2}$ (rxn 1). Run durations long enough to yield homogeneous phases suggest that equilibrium was obtained. A successful experimental reversal (see Fig. 1) provided further evidence for $\mathrm{fO}_{2}$-buffered equilibrium.

Solution of a $\mathrm{Ru}$ component into hematite involves a redox reaction. A formation reaction for a hypothetical end member, $\mathrm{Ru}$ hematite, $2 \mathrm{RuO}_{2}+\mathrm{Fe}_{2} \mathrm{O}_{3}=2 \mathrm{FeRuO}_{3}+1 / 2 \mathrm{O}_{2}$, (rxn 2) may be used with rXn 1 and equilibrium Ru contents to interpret the thermodynamics of this system. Note, however, that this reaction does not specify whether $\mathrm{Fe}^{3+}$ or $\mathrm{Ru}^{4+}$ is reduced. Thus, the end member may be ilmenite-like or hematite-like; it is possible that $\mathrm{Fe}^{2+}, \mathrm{Fe}^{3+}, \mathrm{Ru}^{4+}$, and $\mathrm{Ru}^{3+}$ are all present. Yet, very low solubility of $\mathrm{Ru}$ in $\mathrm{Cr}_{2} \mathrm{O}_{3}$ under similar conditions (unpublished) hint that $\mathrm{Fe}^{3+}$ is reduced allowing an $\mathrm{Fe}^{2+} \mathrm{Ru}^{4+}$-ilmenite substitution.

An enthalpy for $\operatorname{rxn} 2\left(\notin H^{\circ} / \mathrm{R}=22600 \pm 100\right)$ and a regular solution interaction parameter $\left(\mathrm{w}_{\mathrm{Ru}-\mathrm{Fe}} / \mathrm{R}=2230 \pm 70\right.$ ) was fitted with a Latimer approximation [6] for the entropy of the Ru-hematite end member. These new data permit calculations for Ru solubility in hematite at lower $\mathrm{fO}_{2}$ and coexisting with $\mathrm{Ru}$ metal. If similar systematics apply to magnetite as is suggested by experiment [4], then Fe oxide at QFM can host $7000 \mathrm{ppb}$ at $1400^{\circ} \mathrm{C}$ but only 90 at $1000^{\circ} \mathrm{C}$.

Acknowledgments: EAR-9303676.

References: [1]Crocket, Can.Min., 17,391-402. [2] Gueddari et al., Chem. Geol., 134, 181-197. [3] Capobianco and Drake, GCA, 54, 869-874. [4] Capobianco et al., Chem. Geol., 113, 23-43. [5] O'Neill et al., 120, 255-273. [6] Latimer, J. Amer. Chem. Soc., $73,1480-1482$. 
THE GEOCHEMICAL EVOLUTION OF A LATE PALEOZOIC CONVERGENT MARGIN: THE NEW ENGLAND FOLD BELT CASE. G. Caprarelli and E. C. Leitch, Department of Applied Geology, University of Technology-Sydney, P.O. Box 123, Broadway, NSW 2007, Australia.

The western New England Fold Belt (New South Wales, Australia) preserves, in relatively undeformed strata, the magmatic evolution of a Paleozoic convergent margin [1]. Subduction-related igneous rocks range in age from Cambrian to Triassic but are most abundantly preserved in Devonian, Carboniferous, and Permian sections. At least some Devonian activity was tholeiitic and Carboniferous calc-alkaline volcanism is well documented [2,3]. During the Early Permian widespread rifting was accompanied by volcanic activity that spread westward into the newly formed SydneyGunnedah Basin, which was also the site of Late Permian shoshonitic activity [4].

Published [2-6] and new geochemical data obtained from variably altered rocks of basaltic to rhyolitic composition, ranging in age from Carboniferous to Late Permian, are here discussed. Diagrams based on silica concentrations, and $\mathrm{Zr} / \mathrm{TiO}_{2}$ and $\mathrm{Nb} / \mathrm{Y}$ ratios were used to determine the magmatic character of the rocks [7]. All plot well within the subalkaline rocks fields, consistent with a tholeiitic or calc-alkaline affinity.

MORB-normalized major- and trace-element spider diagrams of both Carboniferous and Early Permian basalts and andesites indicate a clear calc-alkaline signature, typical of a convergent margin setting. The only important geochemical difference between the Carboniferous and Early Permian volcanics lies in the relatively high $\mathrm{TiO}_{2}$ (up to $1.87 \mathrm{wt} \%$ ), $\mathrm{Fe}\left(\mathrm{Fe}_{2} \mathrm{O}_{3}\right.$ up to $12.07 \mathrm{wt} \%$ ), and $\mathrm{Zr}$ (up to $370 \mathrm{ppm}$ ) concentrations of the latter [5], which is considered briefly below. The first change in the geochemical signature of the volcanics occurs in the Late Permian basalts and andesites, which are considerably richer in $\mathrm{Rb}, \mathrm{K}, \mathrm{La}$, and $\mathrm{Ce}$ [4] than the older rocks.

Neodymium and $\mathrm{Sr}$ isotopic ratios of Carboniferous to Late Permian volcanics $[4,6$; this work] delineate an almost horizontal trend in an $\left.\varepsilon_{\mathrm{Nd}}-{ }^{-(87} \mathrm{S}^{8}{ }^{86} \mathrm{Sr}\right)$ diagram around an average $\varepsilon_{\mathrm{Nd}} \approx 4$. We interpret these values as indicating interaction of depleted mantlederived magmas with an older crustal component. Carboniferous rocks have the highest ${ }^{87} \mathrm{Sr} /{ }^{86} \mathrm{Sr}$ ratio $(\approx 0.706)$. The observed trend is consistent with input of seawater $\left({ }^{87} \mathrm{Sr} /{ }^{86} \mathrm{Sr} \approx 0.708\right)$, as expected in a subduction setting. Furthermore, the horizontal trend is in keeping with the established theory that the subducting slab does not contribute $\mathrm{Nd}$ isotopically different from that of mantle-derived magmas. The decrease of the $\mathrm{Sr}$ isotopic ratios from the Carboniferous to the Late Permian volcanics can therefore be easily explained in the context of a tectonic regime changing from one of subduction to one of intracontinental rifting.

The role of subduction in the depletion of high field strength elements, including $\mathrm{Ti}, \mathrm{V}, \mathrm{Zr}, \mathrm{Nb}, \mathrm{Hf}$, and $\mathrm{Ta}$, is surrounded by debate [e.g., 8 and references therein]. Although very plausible explanations have been proposed, based on geochemical and experimental studies [e.g., 8,9 and references therein], we believe that the Late Paleozoic rocks provide valuable insights into the process. We propose that regression (roll-back) of the subducting slab between the end of the Carboniferous and the Late Permian was responsible for the enrichment of $\mathrm{Ti}, \mathrm{Fe}$, and $\mathrm{Zr}$ in the Early Permian volcanics, in spite of their retaining an overall convergent margin signature. This implies that it was the very presence of the slab that caused the $\mathrm{Ti}, \mathrm{Fe}$, and $\mathrm{Zr}$ depletion in the Carboniferous magmas. Slab roll-back starting at the beginning of the Permian caused extension manifest by the opening of deep rift basins along the convergent margin [10] and a major increase in the relative volume of basaltic volcanism. The $\mathrm{Ti}, \mathrm{Fe}$, and $\mathrm{Zr}$ concentrations of magmas coming from the mantle wedge increased in response to one or more of the following mechanisms: (1) change in T regime; (2) change in the oxidation state of the mantle wedge toward lower $\mathrm{fO}_{2}$, causing instability of magnetite; (3) decrease in the $\mathrm{fH}_{2} \mathrm{O}$ in the mantle wedge, causing instability of amphibole; or (4) disappearance of ephemeral carbonate-rich fluids and melts of slab and/or mantle wedge provenance, which have affinity for $\mathrm{T}_{i}$ and $\mathrm{Fe}[11,12$ and references therein]. Further studies, involving stable isotope determinations also, are currently underway to try to better constrain these hypotheses.

References: [1] Leitch E. C. (1974) J. Geol. Soc. Aust. 2I, 133. [2] Wilkinson J. F. G. (1971) J. Petrol., 12, 587. [3] McPhie J. (1987) Tectonophys., 138, 269. [4] Carr P. F. (1994) S. Afr. Tydskr. Geol., 97, 486. [5] Vickers M. D. (1993) NEO Conf. Proc., 52. [6] Hensel H. D. et al. (1982)NEO Conf. Proc., 193. [7] Floyd P. A. and Winchester J. A. (1978) Chem. Geol., 21, 291. [8] Woodhead J. et al. (1993) EPSC, 114, 491. [9] Kelemen P. B. et al. (1990) Nature, 345, 521. [10] Leitch E. C. (1988) NEO Conf. Proc., 61. [11] Brenan J. M. and Watson E. B. (1991) GCA, 55, 2203. [12] Caprarelli G. and Takahashi E. (1993) Japan. EPS Joint Meet. Proc., 62.

\section{RHENIUM-OSMIUM SYSTEMATICS OF KIMBERLITE MEGACRYST INCLUSIONS: IMPLICATIONS FOR THE SOURCE OF KIMBERLITIC MAGMAS. R. W. Carlson' and D. R. Bell'2, 'Department of Terrestrial Magnetism, Camegie Insti- tution of Washington, 5241 Broad Branch Road, Northwest, Washington DC 20015, USA ${ }^{2}$ Geophysical Laboratory, Camegie Institution of Washington, 5241 Broad Branch Road, Northwest, Washington DC 20015, USA.}

Megacrysts of the Cr-poor (discrete nodule) and "Granny Smith" [1] suites are common mantle-derived inclusions in kimberlites. Their chemical compositions suggest precipitation from incompatible-element-rich magmas, which $\mathrm{Sr}-\mathrm{Nd}-\mathrm{Pb}$ isotope systematics indicate may be related to the host kimberlite, both in composition

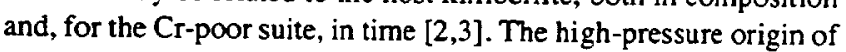
the Cr-poor megacrysts [4] suggests that they may record the isotopic characteristics of kimberlitic magmas during an early stage of their evolution, prior to contamination of the kimberlite by disaggregated lithospheric peridotite, and prior to assimilation of, and isotopic exchange with, crustal materials during and after emplacement.

Megacrysts occasionally contain inclusions of, or intergrowths with, Fe-Ni sulfide. On the basis of morphology (commonly spherical) and composition, these inclusions are interpreted to be of primary magmatic origin, cogenetic with their host minerals. To better define the crystallization age of the megacrysts and the source of the magmas from which they formed, we have analyzed the ReOs isotope systematics of these sulfides or their alteration pseudomorphs (consisting of magnetite and $\mathrm{Ni}-\mathrm{Cu}$ sulfides) in pyroxene megacrysts and pyroxenites of $\mathrm{Cr}_{\mathrm{r}}$-poor composition from the Kamfersdam and Koherab kimberlites and in a Granny Smith diopside from the Jagersfontein kimberlite. A discrete ilmenite megacryst 
from the Monastery kimberlite was also analyzed for comparison.

Rhenium-osmium analyses were performed by Carius tube digestions on single, or aggregates of, sulfide and/or magnetite grains ranging from 2 to $57 \mathrm{mg}$ in weight. The ilmenite analysis was on hand-picked fragments totaling $350 \mathrm{mg}$ broken from a single grain.

The Jagersfontein Granny Smith inclusion has high Os concentration (237 ppb), moderately high Re/Os (0.44), yet a low measured ${ }^{187} \mathrm{Os} /{ }^{188} \mathrm{O}$ s of 0.1124 . Corrected to the age of kimberlite eruption, the Jagersfontein inclusion gives a Re-depletion model age of $2.7 \mathrm{Ga}$, which is in the range observed for lithospheric peridotite xenoliths from Jagersfontein [5]. Thus, the Re-Os data for the Jagersfontein Granny Smith inclusion require a young (i.e., Mesozoic) formation age for the megacryst, but indicate that the Os present in the sulfide inclusion was derived primarily from Re-depleted peridotites typical of cratonic lithosphere [5].

In contrast to the Granny Smith inclusion, the inclusions in the Cr-poor pyroxenes have considerably lower Os concentrations $(0.6-$ $6 \mathrm{ppb}$ ) and very high $\mathrm{Re} / \mathrm{Os}(7-44)$, values that are unexpectedly low and high, respectively, for sulfides in equilibrium with kimberlitic magmas that generally have moderate Os contents $(>0.5 \mathrm{ppb})$ and much lower Re/Os $(<0.5)[6,7]$. Accompanying the high $\mathrm{Re} / \mathrm{Os}$ of the inclusions in Cr-poor pyroxenes are measured $187 \mathrm{Os} /{ }^{188} \mathrm{Os}$ of 0.315-0.865. Re-Os model ages for these inclusions range from 90 to $320 \mathrm{Ma}$, in all cases older than the age of the host kimberlites. These data could indicate that the $\mathrm{Cr}$-poor pyroxenes formed well prior to capture by the host kimberlite from magmas that had Os isotopic compositions overlapping those of typical ocean island basalts. Alternatively, if the $\mathrm{Cr}$-poor pyroxenes formed close in time to the age of their host kimberlites, as indicated by $\mathrm{Nd}$ and $\mathrm{Pb}$ isotope data $[2,3]$, then they precipitated from magmas characterized by relatively radiogenic Os. This possibility is supported by the data for the ilmenite megacryst that has low $\mathrm{Re}$ and Os contents (both about $0.04 \mathrm{ppb}$ ), a moderately low Re/Os (0.82), yet radiogenic Os isotopic composition (initial ${ }^{187} \mathrm{Os} /{ }^{188} \mathrm{Os}=0.1723$ ). The radiogenic $\mathrm{Os}$ isotopic compositions of the ilmenite, and possibly the inclusions in the $\mathrm{Cr}$-poor pyroxenes, suggest that the parental magmas of these megacrysts were not derived by melting typical peridotite, but may have been melts of mafic (pyroxenitic and/or eclogitic) materials in the mantle. Eclogite xenoliths derived from within Archean lithosphere have ${ }^{187} \mathrm{Os} / 188 \mathrm{Os}>0.8[8]$. The lower ${ }^{187} \mathrm{Os} /{ }^{188} \mathrm{Os}$ of the megacryst sulfides (0.17-0.59 at kimberlite eruption) suggests a younger mafic source for the megacryst magmas that may reside below the Archean lithosphere, either in compositionally distinct lower tectosphere [3], or in the convecting mantle.

References: [1] BoydF. R.etal.(1984) $G C A, 48,381$. [2] Jones R. A. (1987) Mantle Xenoliths (P. H. Nixon ed.), p. 711. [3] Smith C. B. et al. (1995) Sixth Int. Kimberlite Conf., 546. [4] Nixon P. H. and Boyd F. R. (1973) Lesotho Kimberlites (P. H. Nixon, ed.), p. 67. [5] Pearson D. G. et al. (1995) EPSL, 134, 341. [6] Pearson D. G. et al. (1994) Sixth Int. Kimberlite Conf., 430. [7] Carlson R. W. et al. (1996) Contrib. Mineral. Petrol., 125, 393. [8] Pearson D. G. et al. (1995) Nature, 374, 711.

$\delta^{13} \mathrm{C}-\delta^{15} \mathrm{~N}$ DIAMOND SYSTEMATICS AND THE ORIGIN OF THE LARGE $\delta^{13} \mathrm{C}$ RANGE IN ECLOGITIC DIA. MONDS: EVIDENCE FOR A HIGH-TEMPERATURE FRACTIONATION PROCESS. P. C. Cartigny', J. W. Hartis', and M. Javoy', 'Laboratoire de Géochimie des Isotopes Stables,
Institut de Physique du Globe, Université Paris 7, 2 place Jussieu, tour 54-64, ler étage, 75251 Paris Cedex 05, France (cartigny@ ipgp. jussieu.fr), 'Department of Geology and Applied Geology, University of Glasgow, Glasgow G12 8QQ, UK.

For more than three decades, the origin of the large range of $\delta^{13} \mathrm{C}$ values in diamonds bearing eclogitic inclusions has been open to question. The eclogitic diamonds $\delta^{13} \mathrm{C}$ range seems indeed larger than that of typical mantle-derived samples such as mid-ocean ridge basalts, carbonatites, carbonates from kimberlites, and peridotitic diamonds whose $\delta^{13} \mathrm{C}$ range extends mainly between $-10 \% 0$ and $0 \%$. Because the $\delta^{13} \mathrm{C}$ range covered by sediments and eclogitic diamonds, from $-35 \%$ to $5 \%$ is nearly identical and because eclogite is a plausible high-pressure form of basaltic oceanic crust, several authors suggested that eclogitic diamonds could be formed from the sedimentary organic $\mathrm{C}$ recycled within the subducted slab into the diamond stability field. Alternative hypotheses either argue for a global $\mathrm{C}$ isotopic heterogeneity within the mantle, as suggested by the different diamond subpopulations included within the same kimberlite, or isotopic fractionation in the same way as fractionation occurs between dissolved $\mathrm{C}$ and $\mathrm{CO}_{2}$ in MORBs during degassing.

Nitrogen, the main diamond impurity, could be used as a powerful tracer of recycling. Actually $\delta^{15} \mathrm{~N}$ values in sediments are clearly positive and are known to evolve toward even more positive $\delta^{15} \mathrm{~N}$ values with increasing metamorphism, whereas mantle $\mathrm{N}$ is characterized by mostly negative $\delta^{15} \mathrm{~N}$. Consequently, if some diamonds are formed from recycled organic $\mathrm{C}$ and $\mathrm{N}$, we should expect to find only positive $\delta^{15} \mathrm{~N}$ values in these diamonds.

Eclogitic diamonds both from Jwaneng (Botswana) and Kimberley Pool (South Africa) have been analyzed for $\delta^{13} \mathrm{C}, \delta^{15} \mathrm{~N}$, and $\mathrm{N}$ concentration. Most $\delta^{15} \mathrm{~N}$ values are negative, varying from $-11.1 \%$ to $4.6 \%$ and $-10.1 \%$ to $-1.1 \%$, and associated $\delta^{13} \mathrm{C}$ range from $16.0 \%$ to $-3.0 \% \circ$ and $-21.1 \%$ to $-2.7 \%$, and $\mathrm{N}$ contents from $1918 \mathrm{ppm}$ to $27 \mathrm{ppm}$ and $1528 \mathrm{ppm}$ to $11 \mathrm{ppm}$ for K-Pool and Jwaneng respectively. The $\mathrm{N}$ distributions are similar to other worldwide eclogitic diamonds for which $N$ concentrations are statistically higher than for peridotitic diamonds.

Because eclogitic diamonds are characterized by clearly and mostly negative $\delta^{15} \mathrm{~N}$-values, it is impossible to explain their formation from organic recycled $C$ and $N$, since such a model predicts only positive to highly positive $\delta^{15} \mathrm{~N}$ values.

Furthermore, the mean $\delta^{15} \mathrm{~N}$ values of both Jwaneng and Kimberley Pool eclogitic diamonds are nearly identical to the "wellmixed" mantle $\delta^{15} \mathrm{~N}$ value ( $\approx-5 \%$ to $-6 \%$ ) inferred from fibrous and peridotitic diamonds as well as MORBs. A formation of those eclogitic diamonds from a recycled material that would have lost most of its $\mathrm{N}$ components is also unlikely. According to this hypothesis, we would expect to find statistically lower $\mathrm{N}$ concentrations in eclogitic relative to peridotitic diamonds. This would reflect a mixing between a $\mathrm{N}$-rich (peridotitic $\approx$ mantle) and a $\mathrm{N}$-poor (eclogitic $\approx$ recycled oceanic crust deprived of its $N$ ) reservoir, in disagreement with worldwide observations.

Because eclogitic diamonds, in particular those from Jwaneng have very constant $\delta^{15} \mathrm{~N}$ values relative to the $\delta^{13} \mathrm{C}$ range, we suggest that it is also unlikely that these diamonds could be formed in several distinct environments. If this were the case, we would expect to obtain several distinct $\mathrm{N}$ isotopic signatures if eclogitic diamonds originated from several parts of an isotopically heterogeneous mantle.

We conclude therefore, that for eclogitic diamonds from Jwaneng 
and Kimberley Pool, the tightly centred $\delta^{15} \mathrm{~N}$ distributions over the whole $\delta^{13} \mathrm{C}$ range $(-20 \%$ to $-3 \%$ ) clearly support a high-temperature fractionation process. The absence of correlation between $\delta^{13} \mathrm{C}$ and $\delta^{15} \mathrm{~N}$ suggests that diamond is not the main $\mathrm{N}$ - and $\mathrm{C}$-bearing phase. This supports the view of diamond as a passive recorder of $\delta^{13} \mathrm{C}$ and $\delta^{15} \mathrm{~N}$ variations. If, for example, models such as that of [1] are operative then one could see mantle peridotites as rather good buffers of $C$ and thus of $\delta^{13} \mathrm{C}$ whereas this could not be the case for eclogites.

References: [1] Luth (1995) Contrib. Mineral. Petrol., 122, 152-158.

THE MANTLE NITROGEN ISOTOPIC COMPOSITION AND EVOLUTION: THE DIAMOND RECORD. P. C. Cartigny', J. W. Harris' ${ }^{2}$, S. R. Boyd', and M. Javoy', 'Laboratoire de Géochimie des Isotopes Stables, Institut de Physique du Globe, Université Paris 7, 2 place Jussieu, tour 54-64, ler étage, 75251 Paris, Cedex 05, France (cartigny@ipgp.jussieu.fr), 2Department of Geology and Applied Geology, University of Glasgow, Glasgow G12 $8 Q Q$, UK.

Although $\mathrm{Ni}$ is the dominant component of the atmosphere and is relatively abundant in sedimentary and metasedimentary rocks, both its abundance and isotopic composition in the upper mantle are presently badly constrained. Diamonds are among the most valuable samples: They can contain very high concentrations of $\mathrm{Ni}$, are mechanically hard and chemically inert, and thus preserve the isotopic compositions of their mantle source region.

To date, most attention has been focused on fibrous diamonds [1-3]. Fibrous diamonds are characterized by negative values of $\delta^{15} \mathrm{~N}(-8 \% \circ$ to $-2 \%$ ) relative to the external reservoirs (atmosphere + crust). The isotopic imbalance between internal and external reservoirs shows that the latter cannot be formed by a simple outgassing, and this led Javoy et al. [4] to propose a heterogeneous accretion model for the Earth. One potential problem was that fibrous diamonds may be anomalous and give a distorted picture of subcontinental upper mantle features, since they are probably quite young ( $<350 \mathrm{Ma}$ ) and related to kimberlite magmatism. The study of the major diamond group, the octahedrally-shaped diamonds, which are known to be xenocryts within their host kimberlite and could reach ages up to $3.3 \mathrm{Ga}$, is thus essential.

Since peridotitic diamonds are dominant and have $\delta^{13} \mathrm{C}$ values mostly between $-10 \%$ and $0 \%$ (average $-5.0 \%$ ), similar to those of other upper mantle materials (kimberlite carbonates, carbonatites, and undegassed mid-ocean ridge basalts), it is among such samples that we could find a representative and primitive picture of mantle $\mathrm{Ni}$. This contrasts with eclogitic diamonds, characterized by more variable $\delta^{13} \mathrm{C}$ values $(-34.5 \%$ and $2.7 \%$ ), sometimes described as originating from subducted organic $\mathrm{C}$.

We carried out the $\delta^{13} \mathrm{C}-\delta^{15} \mathrm{~N}$ analyses of more than $150 \mathrm{dia}$ monds belonging to the peridotitic paragenesis originating from Pipe 50 kimberlite (China), Finsch and Kimberley Pool (South Africa), or Siberian kimberlites. For a restricted range of $\delta^{13} \mathrm{C}$ values ( $-8 \%$ to $0 \%$ ), $\delta^{15} \mathrm{~N}$ values of peridotitic diamonds range mostly from $-12 \% \circ$ to $6 \%$, only Pipe 50 showing highly ${ }^{15} \mathrm{~N}$-depleted samples down to $-25 \%$. Relative to fibrous diamonds $\left(\delta^{15} \mathrm{~N}\right.$ from $-8 \%$ to $-2 \% o$ ), the origin of the large range of $\delta^{15} \mathrm{~N}$ values covered by peridotitic diamonds may be the consequence of their different growth conditions rather than to a ${ }^{15} \mathrm{~N}$ mantle heterogeneity. Indeed, as suggested by their different structures (i.e., fibrous' gem quality), peridotitic diamonds may have grown slowly and/or from a more limited supply of volatiles that may have differentiated during their percolation throughout the continental lithosphere. As a consequence the diamond $\delta^{15} \mathrm{~N}$ values range in every mine from $\approx-12 \%$ o to $\approx 6 \%$.

Despite their different variabilities, the modes of the $\delta^{15} \mathrm{~N}$ distribution of both fibrous and peridotitic diamonds are nearly identical and centered around $-5 \%$, suggesting a similar isotopic source for both diamond types and a present-day upper mantle $\delta^{15} \mathrm{~N}$ around $-5 \%$. Our results confirm the apparent "disequilibrium" of $\mathrm{N}$ i between external and internal reservoirs of the Earth, extend it to older geological periods, and support the heterogeneous accretion model of the Earth. As predicted, the low $\delta^{15} \mathrm{~N}$ value $(-25 \%$ c) obtained in a diamond from Pipe 50 is believed to be the fingerprint of the primordial enstatite chondrite material [4].

The mantle $\delta^{15} \mathrm{~N}$ would have evolved from its initial $\delta^{15} \mathrm{~N}$ value, below $-25 \%$ o to the actual value around $-5 \%$ as a consequence of the large recycling occurring during the early history of the Earth.

The origin of the low $\delta^{15} \mathrm{~N}$ contribution $(<-25 \%$ ) could be related to a lower-mantle influence or to a residual $\delta{ }^{15} \mathrm{~N}$ in an upperor sublithospheric-mantle portion. The solution could be approached by studying lower-mantle-derived diamonds such as those reported by Harte and Harris [5]. However, we must point out that a long-time isolated portion of sublithospheric mantle is the simplest hypothesis to account for the preservation of a low $\delta^{15} \mathrm{~N}$ source fingerprint, in agreement with the Archean Re-Os model ages obtained from mantle xenoliths.

References: [1] Javoy et al. (1984) EPSL, 68, 399-412. [2] Boyd et al. (1987) EPSL, 86, 341-353. [3] Boyd et al. (1992) EPSL, 109, 633-644. [4] Javoy et al. (1986) Chem. Geol., 57, 4162. [5] Harte and Harris (1994) Mineral. Mag., 58A, 384-385.

MINERALOGIC AND URANIUM ISOTOPIC DATA OF FRACTURE INFILLINGS FROM THE POTENTIAL UNDERGROUND LABORATORY SITE IN THE VIENNE GRANITOIDS(FRANCE). J.Casanova', M. Cuney², P. Négrel', M. Cathelineau², Y. Coulibaly ${ }^{2}$, A. Bourguignon ${ }^{1}$, and J.-F. Aranyossy33, 'BRGM, BP 6009, F 45060 Orléans Cedex 2, France (j. casanova@brgm.fr, p.negrel@brgm.fr, a.bourguignon@brgm.fr), ${ }^{2}$ CREGU, B.P. 23, 54501 Vandoeuvre-lès-Nancy Cedex, France (cuney@cregu.cnrs-nancy.fr; cathelineau@cregu.cnrs-nancy.fr). ${ }^{3}$ ANDRA, 1 rue J. Monnet, F 92298, Châtenay-Malabry, France (jf.aranyossy@andra.fr).

Introduction: As part of the preliminary geological characterization program to assess the feasibility of an underground laboratory in granitic formation, 17 boreholes, continuously cored and oriented (down to the maximum depth of $900 \mathrm{~m}$ ) have been drilled in the Charroux-Civray region ("Vienne" district). The concerned batholith, located below a 150 -m-thick Jurassic sedimentary cover, is mainly composed of dioritic, tonalitic-to-granodioritic plutons characteristically enriched in $\mathrm{Ca}, \mathrm{Fe}$, and $\mathrm{Mg}$. Owing to the chemistry of these rocks and the development of paleohydrothermal systems, most of the fractures are filled with $\mathrm{Ca}-\mathrm{Mg}-\mathrm{Fe}$ minerals. One of the main objectives of the ongoing investigations is to develop and test a conceptual model of the groundwater flow sys- 
tem. The present paper summarizes mineralogical and $U$ isotopic data obtained on fracture infillings to characterize the eventual traces of recent fluid circulations in the granite basement.

Methods: A selection 130 samples of fracture fillings have been made along 13 boreholes, according to the following criteria: (1) location in water-bearing zones, (2) observation of open spaces, drusy or dissolution cavities, (3) presence of loose material in the core section, and (4) fracture surfaces covered by poorly crystallized clay minerals or Fe-oxy-hydroxides. The nature of fracture infillings and their paragenetic order of crystallization have been determined to select the samples for $U$ series disequilibrium analyses (measured by $\alpha$-spectrometry).

Results and Interpretation: Textural and fluid inclusion data show that most of the fracture-filling minerals have crystallized during the geothermal system activities. Five main phases of crystallization sequences have been identified: (1) adularia (I)-hematite; (2) dolomite, with frequent dissolution cavities; (3) quartz, barite (I), fluorite, pyrite, chalcopyrite, clays, calcite; (4) adularia (II), clays, Fe-oxyhydroxides, barite (II), REE minerals, framboidal pyrite, tabular-to-lanceolate gypsum; and (5) needle-shaped gypsum. Small crystals of adularia, barite, and pyrite (sometimes framboidal) are frequently associated with Fe-oxy-hydroxides precipitated within finely crystallized clay mineral. The small-sized, late, poorly to noncrystallized phases have been assumed to be related to the most recent groundwater circulations.

In the $100-\mathrm{m}$ upper part of the granitoidic basement, the ${ }^{234} \mathrm{U} /$ ${ }^{238} \mathrm{U}$ disequilibrium (mainly carried by Fe-oxy-hydroxides) has been interpreted as a $U$ remobilization in relation with oxygenated, low-temperature, paleowater circulations. Preferential removal of ${ }^{234} \mathrm{U}$ in this zone is indicated by ${ }^{230} \mathrm{Th}^{234} \mathrm{U}$ activity ratios higher than unity. In deeper zones, ${ }^{230} \mathrm{Th} /{ }^{234} \mathrm{U}$ activity ratios lower than unity are interpreted as the correlative deposition of the mobile $U$ fraction, likely due to reducing conditions. In addition, a large part of the small disequilibrium is probably related to $\alpha$-recoil effect in finely and poorly crystallized phases. The direct calculation of $U$ residence time was possible on two samples, devoid of ${ }^{232} \mathrm{Th}$ : A Fe-oxyhydroxide sample, located $45 \mathrm{~m}$ below the granite-sedimentary cover, yields an age of $102 \pm 5 \mathrm{k}$.y., while an illite/chlorite-bearing sample, located $230 \mathrm{~m}$ below the unconformity, provides an age of $177 \pm$ 17 k.y.

TECTONIC AND GEOCHEMICAL CONSEQUENCES OF CRETACEOUS LIP FORMATION IN THE PACIFIC. P. R. Castillo' $^{1}$, P. E. Janney ${ }^{2}$, and R. L. Larson ${ }^{3}$, 'Scripps Institution of Oceanography, University of Califomia-San Diego, La Jolla CA 92093-0220, USA, ${ }^{2}$ Department of Geological Sciences, University of Cape Town, Rondebosch, South Africa, ${ }^{3}$ Graduate School of Oceanography, University of Rhode Island, Narragansett RI 02882 , USA.

The widespread mid-Cretaceous volcanism is the most recent of the great volcanic events in the history of the Earth. In the Pacific, the onset of this volcanic event coincided with the formation of the Ontong Java Plateau and was immediately followed by the emplacement of a large, flat-lying igneous complex in portions of the East Mariana, Nauru, Pigafetta, and Central Pacific basins adjacent to the plateau. We believe that the formation of the plateau and the origin of this complex are interrelated and have greatly affected the tectonic history of the old western Pacific. The complex could be a province of intraplate oceanic flood basalts erupted through the Jurassic crust via numerous, short-lived, nonedifice building fissures. These lithospheric fissures could have formed due to loading of the enormous Ontong Java Plateau on the surrounding sea floor. Alternatively, the complex could represent an area of mid-Cretaceous sea floor formed by rifting of Jurassic crust. This younger sea floor may have accreted along a spreading system initiated by the vigorous Ontong Java plume volcanism, similar to the way that other large plumes may have captured ridges or initiated continental rifting.

Samples of old Pacific crust collected during several legs of deep ocean drilling by DSDP and ODP show that the mid-Cretaceous LIP formation has also affected the regional composition of the Pacific upper mantle. Old Mesozoic Pacific MORB $(\approx 130-170 \mathrm{Ma})$ are compositionally similar to modem Pacific MORB in that they are depleted in highly incompatible elements and have high ${ }^{143} \mathrm{Nd}$ ${ }^{144} \mathrm{Nd}$, moderate ${ }^{206} \mathrm{~Pb} / 204 \mathrm{~Pb}$, and low ${ }^{87} \mathrm{Sr} /{ }^{86} \mathrm{Sr}$. In comparison, midCretaceous Pacific MORB ( $\approx 115-100 \mathrm{Ma}$ ) from the igneous complex and other locations in the western Pacific are variably enriched in highly incompatible elements and have lower ${ }^{143} \mathrm{Nd} /{ }^{144} \mathrm{Nd}$ and higher ${ }^{87} \mathrm{Sr} /{ }^{86} \mathrm{Sr}$ and $\mathrm{Pb} \Delta 8 / 4$. These mid-Cretaceous Pacific MORB are compositionally similar, although not identical, to moder $M O R B$ from the Indian and South Atlantic oceans. This shift in Pacific MORB composition reflects widespread contamination of the depleted upper mantle source of MORB with "enriched mantle" components. These are most probably deep mantle materials entrained by the upwelling plumes or plume heads responsible for formation of large seamounts and oceanic plateaus, such as the Ontong Java Plateau, during the mid-Cretaceous. In turn, the appearance of these large plumes during the mid-Cretaceous is consistent with both the superplume model of Larson [1] and the MOMO hypothesis of Stein and Hofmann [2]. In the superplume model, an instability at the core-lower mantle boundary is believed to have resulted in a massive upwelling of lower-mantle material into the Pacific upper mantle. In the MOMO hypothesis, episodic avalanches of upper-mantle materials into the lower mantle are postulated to trigger global mantle overtum and major orogeny events; the latest such event occurred in the mid-Cretaceous. Further analysis of old MORB from the Atlantic and Indian oceans (in progress) will be necessary to determine which of these two models is more appropriate.

References: [1] Larson R. L. (1991) Geology, 19, 547-550. [2] Stein M. and Hofmann A. W. (1994) Nature, 372, 63-68.

\section{EQUILIBRIUM AND KINETIC STUDIES OF HYDROGEN ISOTOPE FRACTIONATION BETWEEN HYDROUS MINERALS AND WATER USING THE ION MICROPROBE.} T. Chacko ${ }^{1.2}$, D. Cole ${ }^{1}$, L. Riciputi', J. Horita' ${ }^{1}$, and R. Ripperdan' ${ }^{1}$, 'Chemical and Analytical Sciences Division, Oak Ridge National Laboratory, Oak Ridge TN 37831-6110, USA, 2Department of Earth and Atmospheric Sciences, University of Alberta, Edmonton, Alberta, Canada, T6G 2E3.

Accurate experimental determinations of fractionation factors between minerals and fluids are essential for the correct interpretation of isotopic data generated for natural samples. Unfortunately, there is presently little consensus on $\mathrm{H}$ isotope fractionation factors 
for many important mineral-water systems. The experimental studies done to date obtained widely differing results with respect to both the absolute magnitude and the temperature dependence of these fractionation factors (see review in [1]). To help resolve this issue, we have explored the feasibility of using a different experimental technique for investigating $\mathrm{H}$ isotope fractionation behavior. Unlike all previous studies, which used finely powdered minerals as starting materials and analyzed the run products with bulk analytical techniques, we carried out mineral-water exchange experiments using large single crystals and analyzed these with the ion microprobe. The advantage of this technique over conventional methods is that it allows fractionation factors to be determined in systems where it can be demonstrated that isotopic exchange takes place solely by a diffusional mechanism. This makes for an ideal exchange experiment in that the only thermodynamic driving force for exchange is the free energy change associated with the isotope exchange reaction itself.

The viability of this technique is strongly tied to length scales over which isotopic equilibrium can be established during the course of an exchange experiment. This, in tum, is dependent on the diffusion rates of $\mathbf{H}$ in minerals. For layer-structure hydrous minerals such as the micas and brucite, diffusion rates are markedly anisotropic, with diffusion occurring much faster along the layers than perpendicular to the layers $[2,3]$. We have documented the magnitude of these effects for $\mathrm{H}$ diffusion by carrying out exchange experiments between brucite and $99 \%$ deuterated $\mathrm{H}_{2} \mathrm{O}$ at $500^{\circ} \mathrm{C}$, $1.5 \mathrm{kbar}$. Depth profiles measured both perpendicular and parallel to the layers indicate diffusion coefficients of $5.5 \times 10^{-16}$ and $>1 \times$ $10^{-12} \mathrm{~cm}^{2} / \mathrm{s}$ respectively. Model calculations made using these coefficients suggest that diffusional penetration parallel to the layers would allow isotopic equilibrium to be established (within analytical error) over the outer $6 \mu \mathrm{m}$ of the crystal in reasonable laboratory timescales ( 25 days). In contrast, over that same time frame, the equilibration distance perpendicular to the layers is less than $0.1 \mu \mathrm{m}$. Thus, precise isotopic analyses of run products with the ion probe require that crystals be oriented with cleavage planes normal to the analytical surface.

We tested this approach with experiments in which a large excess of $\mathrm{H}_{2} \mathrm{O}$ was exchanged with gem-quality crystals of brucite at $600^{\circ} \mathrm{C}, 2 \mathrm{kbar}$ in a cold-seal apparatus. Two experiments were run, identical in all respects except for containing isotopically different waters. We chose the waters such that the equilibrium fractionation could be approached from opposite directions. The brucite nun products were analyzed on the ion microprobe following the procedure developed by Deloule et al. [4]. We used the brucite starting material as a standard, which obviated the need for any matrix corrections. Analytical precision was on the order of $\pm 10 \%$ ( $1 \sigma)$. Despite initial brucite- $\mathrm{H}_{2} \mathrm{O}$ fractionations very far from equilibrium $\left(\Delta_{\text {initial }}=-116 \%\right.$ and $+253 \%$ ), the experiments showed a reasonable approach toward the equilibrium fractionation $\left(\Delta_{\text {final }}=-22 \%\right.$ and $+51 \%$, respectively). The fractionation given by the first experiment is in fact within analytical error of the $600^{\circ} \mathrm{C}$ brucite- $\mathrm{H}_{2} \mathrm{O}$ fractionation $(-18 \%)$ derived from bulk exchange experiments [5]. The reason why the second experiment did not yield an equilibrium fractionation is not clear but may be due to shifts in the isotopic composition of the D-depleted water $(\delta \mathrm{D}=-292 \%$ ) used in the experiment through exchange with the aqueous pressure medium. Our conclusion from these preliminary results is that the ion microprobe provides a promising alternative to conventional techniques for determining $\mathrm{H}$ isotope fractionation factors.

Acknowledgments: Research sponsored by Geoscience Research Program, Office of Basic Energy Research Corp, U.S. Department of Energy under contract DE-AC05-96OR22464 with Lockheed Martin Energy Corporation.

References: [1] Vennemann T. W. and O'Neil J. R. (1996) GCA, 60, 2437-2451. [2] Graham C. M. (1981) Contrib. Mineral. Petrol., 76, 216-228. [3] Fortier S. M. and Giletti B. J. (1991) GCA, 55, 1319-1330. [4] Deloule E. et al. (1991) Geochem. Soc. Spec. Publ. 3, 53-62. [5] Satake H. and Matsuo S. (1984) Contrib. Mineral. Petrol., 86, 19-24.

LITHIUM ISOTOPE COMPOSITION OF RIVERS. L. H. Chan $^{1}$, Y. Huh' ${ }^{2}$, and J. M. Edmond2, 'Department of Geology and Geophysics, Louisiana State University, Baton Rouge LA 70803, USA (glchan@lsuvm.sncc.lsu.edu), ${ }^{2}$ Department of Earth, Atmospheric, and Planetary Sciences, Massachusetts Institute of Technology, Cambridge MA 02139, USA (yhuh@mit.edu; jedmond@ mit.edu).

The principal sources of $\mathrm{Li}$ in the ocean are river run-off and ridge-crest hydrothermal solutions. The outstanding problems of marine Li cycle are the uncertainty of hydrothermal flux and insufficient sinks to balance the estimated inputs. We have determined the $\mathrm{Li}$ isotope compositions of the global rivers to gain understanding of the behavior of $\mathrm{Li}$ isotopes during weathering and to estimate the fluvial isotopic flux to the ocean. The latter in tum is used to constrain the $\mathrm{Li}$ balance in the ocean.

The study encompasses the world's large rivers and their tributaries, which display a wide range of $\mathrm{Li}$ isotopic compositions. The major rivers measured and their $\delta^{6} \mathrm{Li}$ values relative to the L-SVEC standard are the Amazon (-21.6\%o), Orinoco (-32.2\%o), Yangtze $(-35.5 \%)$, Ganges (-22.6\%o), Brahmaputra (-19.6\%o), Mississippi $(-15.3 \%$ to $-17.7 \%$ ) , Mackenzie $(-15.6 \%$ to $-17.6 \%$ ) and Lena $(-21 \%)$. There is no simple relationship between $\delta^{6} \mathrm{Li}$ and lithology. Rivers draining dominantly evaporites have values of -21 to $-22 \%$; carbonate, $-26 \%$ to $-35 \%$; black shale, $-26 \%$; varied siliceous terrains, $-11 \%$ to $-29 \%$; intensely weathered shields $-6.6 \%$ to $-17 \%$. The light isotopic values of the tropical shield rivers are derived from the degradation of residual weathering products rather than the parent rocks. The $\mathrm{Lj}$ isotopic compositions of rivers appear to reflect isotopic fractionation between the fluid and secondary minerals, degree of weathering, and possibly adsorption on clays. The lighter $\mathrm{Li}$ isotope is preferentially retained in clays. For example, the suspended sediments of the Amazon and Mississippi have $\delta^{6} \mathrm{Li}$ of $-1.1 \% \circ$ and $-3.8 \%$ respectively, $20 \% \circ$ and $14 \%$ lighter than the respective dissolved loads.

The global mean Li concentration and isotopic composition are calculated from 11 large rivers that represent over one-third of the world discharge. The flow-weighted averages are $180 \mathrm{nmol} / \mathrm{l}$ and $-20.4 \% 0$ respectively. The mean $\delta^{6} \mathrm{Li}$ of submarine hot springs is $-9 \%$. Seawater $(-32.2 \%)$ is thus isotopically heavier than its principal sources. If the steady-state isotopic composition in the ocean is maintained by preferential removal of ${ }^{6} \mathrm{Li}$ into authigenic clays with an isotopic fractionation factor of 1.019 , then the hydrothermal flux should be comparable to the river flux and not substantially larger as estimated on the basis of oceanic ${ }^{3} \mathrm{He}$ inventory. 
HOW DOES THE OCEANIC LITHOSPHERE CONTRIBUTE TO OCEAN-ISLAND-BASALT VOLCANISM? C. Chauvel', G. Guille' ${ }^{2}$, S. Blais' ${ }^{1}$, andR. Maury ${ }^{3}$, 'Géosciences Rennes, UPR 4661, CNRS, Université de Rennes 1, 35042 Rennes Cedex, France (cchauvel@univ-rennes1.fr), ${ }^{2} \mathrm{CEA}$, LDG, BP 12, 91680 Bnyyères le Chatel, France, ${ }^{3}$ UBO Av le Gorgeu, 29283 Brest Cédex, France.

The chemical composition of intraplate volcanic rocks results from the superposition of various effects including source composition, melting conditions, crystal fractionation, and assimilation of lithospheric mantle and crust en route to the surface. A contribution from the oceanic lithosphere may be significant [e.g., 1] and if this is true, the composition of oceanic island basalts might not represent that of their plume source. For example, if extreme isotopic compositions such HIMU and EM II have their origin in the oceanic lithosphere and not in deep plume sources, this raises important questions about the diversity and composition of the mantle and of its evolution through Earth history.

In order to evaluate and constrain the contribution of oceanic lithosphere to modem OIB volcanism, we concentrated on volcanics from Polynesia and we used two complementary and independent approaches: (1) We compared the compositions of basalts and associated fractionated liquids (phonolites and trachytes) from two different islands. Such magmas evolve at low pressure and might have inherited a lithospheric component. Any difference between their isotopic composition and those of associated basalts would then provide information about the composition of the lithosphere. (2) We took advantage of the peculiar situation seen in Rurutu Island where two plumes contributed to the construction of the island. These two plumes had different isotopic compositions and operated at a 10-m.y. interval. The composition of both plumes can be constrained using the composition of basalts from other islands located on the same plume trace. In Rurutu, magmas from the younger plume penetrated lithosphere that had interacted with products from the older plume. Differences between the composition of young volcanics in Rurutu and that of volcanics produced by the same plume trace on other islands can therefore be attributed to a contribution from the lithosphere.

Phonolites from Tubuai (a HMU island in the Austral chain in Polynesia) and trachytes from Raiatea (a EM II-type isiand in the Society chain) have isotopic compositions different from those of the associated basalts: lower and more variable ${ }^{206} \mathrm{~Pb} / 204 \mathrm{~Pb}$ for the Tubuai phonolites; higher ${ }^{87} \mathrm{Sr} /{ }^{86} \mathrm{Sr}$ for the Raiatea trachytes. We attribute these differences to interactions between plume and oceanic lithosphere during fractional crystallization that gave rise to the phonolites and trachytes. Data on trachytes demonstrate that the oceanic lithosphere underlying Raiatea Island has been severely modified by hydrothermal circulation, which increased significantly its ${ }^{87} \mathrm{Sr} / 86 \mathrm{Sr}$. The contribution of the lithosphere to phonolites in Tubuai was also important, but the main effect is observed on the $\mathrm{Pb}$ isotopic compositions and not on the $\mathrm{Sr}$ isotopes. This suggests that the magma chamber in which the phonolites were produced might have been located at a deeper level in the lithosphere where hydrothermal circulation did not penetrate.

In Rurutu Island, the old basalts erupted $\approx 12 \mathrm{Ma}$ ago and have compositions similar to those of neighbor islands Mangaia and Tubuai. Lead-206/lead-204 and ${ }^{87} \mathrm{Sr} /{ }^{86} \mathrm{Sr}$ ratios are uniform at about 21 and 0.7027 , while the trace-element patterns display the same depletion in very incompatible elements. However, the old Rurutu lavas are not characterized by elevated $\mathrm{Ce} / \mathrm{Pb}$ ratios as is the case in both Tubuai and Mangaia. The young lavas $(\approx 1.5 \mathrm{Ma})$ have isotopic compositions different from those of other islands located on the same plume trace (e.g., Atiu). All isotopic ratios $\left({ }^{206} \mathrm{~Pb} / 204 \mathrm{~Pb},{ }^{87} \mathrm{Sr} /\right.$ ${ }^{86} \mathrm{Sr}$, and ${ }^{143} \mathrm{Nd} /{ }^{144} \mathrm{Nd}$ ) are displaced from the composition of Atiu lavas towards that of the older lavas on Rurutu Island. The simplest interpretation is that the young plume digested lithosphere polluted by the old plume. The assimilated lithosphere is mainly characterized by peculiar trace-element ratios (high $\mathrm{P}_{2} \mathrm{O}_{5} / \mathrm{Nd}, \mathrm{Sm} / \mathrm{Ti}, \mathrm{Zr} / \mathrm{Hf}$, and $\mathrm{Ce} / \mathrm{Pb}$ ) associated with isotopic compositions similar to those of the first volcanic activity. These characteristics cannot be attributed to normal mantle processes and are best explained by the involvement of a carbonatitic component. This component separated from the silicate fraction during the first plume event, and was left in the lithosphere to be preferentially remobilized by the second plume.

This study shows that the lithosphere can strongly influence trace-element compositions, and can contribute to elevated ${ }^{87} \mathrm{~S} /$ ${ }^{86} \mathrm{Sr}$ in differentiated lavas. However, it can only account for a minor proportion of the OIB isotopic variations. Extreme compositions such as HIMU and EM I cannot be created by digestion of lithosphere because its life time is too small to allow sufficient radiogenic growth. When using isotopes and trace elements to constrain source compositions, it is best to avoid data obtained from highly evolved liquids and from islands that might have formed over a previous plume trace.

References: [1] Dupuy et al. (1993).

\section{CHEMICAL AND ISOTOPIC CHARACTERISTICS OF} XENOLITHS FROM HANNUOBA, CHINA: IMPLICATIONS FOR THE COMPOSITION AND EVOLUTION OF THE UPPER MANTLE. D. Chen, B. Li, and X. Zhi, Department of Earth and Space Sciences, University of Science and Technology of China, Hefei 230026, China (cdg@ms.ess.ustc.edu.cn).

Abundant and various ultramafic-to-mafic deep-seated xenoliths are distributed in the Hannuoba area, Northem China. They consist of lherzolites, websterite, pyroxenites, gabbros, and granulites, and belong to both the $\mathrm{C}_{\mathrm{r}}$-diopside suite and the Al-augite suite, as well as the transitional $\mathrm{Fe}$-rich $\mathrm{C}_{\mathrm{r}}$-diopside suite. Among them, spinel lherzolites of four mineral phases are dominant. Pyroxenites and gabbros are subordinate. The others are much less significant. Based on $\mathrm{Nd}, \mathrm{Sr}$, and $\mathrm{Pb}$ isotopes, major- and trace-element data of about 30 xenolith whole rocks and minerals, plus the data in the references, it is indicated that they show very large variation in compositions: Spinel lherzolites have depleted Nd (0.5135-0.5125) and $\mathrm{Sr}(0.702-0.704)$, similar to most OIB. Pyroxenites have the most divergent isotopic signatures. Many of them have enriched Nd $(<0.5121)$ and $\operatorname{Sr}(>0.7053)$ isotopes, but some are depleted $(>0.5129$, $<0.7037)$. Their model ages are in two groups, one Proterozoic to Archean, and another $0.0-1.0 \mathrm{Ga}$. Gabbros also show enrichment and large diversity in isotopes and incompatible and compatible trace elements. Granulites, gamet pyroxenites, and phlogpite pyroxenites are the most enriched in isotopes $(\mathrm{Nd}<0.5116, \mathrm{Sr}>0.708)$. All the $\mathrm{Pb}$ isotopes covered quite a large range (15.9-18.7, 15.2$15.6,36.8-38.7)$. From lherzolite to alkali and tholeiitic basalt, to gabbro and granulite, radiogenic $\mathrm{Pb}$ gradually decreases, whereas the $\mathrm{Pb}$ isotopes of pyroxenitic xenoliths scattered across the whole area. The isotopic and chemical characters of the xenoliths, com- 
bined with that of basaltic rocks, provide the following information: (1) The lithosphere mantle beneath northem China is very heterogeneous. In the case of Hannuoba, all kinds of xenoliths show quite different isotopic signatures from one another, and from host basaltic rocks. They belong to accident xenoliths and have no direct genetic relation to the host. (2) The lithosphere mantle in Hannuoba is depleted in the whole and part of it is very enriched. It has a longterm and complicated history of at least two metasomatic or enrichment events. The older one relates to the formation of gabbros and enriched pyroxenites, and the younger relates to the formation of fertile lherzolites and some pyroxenites that have PREMA or LoNd and high ${ }^{206} \mathrm{~Pb} / 204 \mathrm{~Pb}$. (3) The available xenolith data could not perfectly interpret the origin of tholeiitic basalt, which was generated at the asthenosphere and contaminated with lithosphere or low crust. We need a new lithospheric component. (4) According to geothermo-barometer and $\delta^{207} \mathrm{~Pb} /{ }^{204} \mathrm{~Pb} \sim{ }^{208} \mathrm{~Pb} / 204 \mathrm{~Pb}$ relations, a vertical stratified mantle upward is postulated. Most pyroxenites might sit in a shallower layer compared with lherzolite. Some pyroxenites could be ascribed to granulitic-phase low-crust xenoliths.

References: [1] Tatsumoto M. et al. (1992) EPSL, 113, 107128. [2] Song Y. and Frey F. A. (1989) GCA, 53, 97-113. [3] Basu A. R. et al. (1991) EPSL, 105, 149-169. [4] Song Y. et al. (1990) Chem. Geol., 85, 35-52.

THREE-STAGE EVOLUTION OF FLUID DURING CONTINENTAL COLLISION WITH SPECIAL REFERENCE TO THE STUDY OF THE ORE-FORMING FLUID OF GOLD DEPOSITS IN THE EASTERN QINLING MOUTAINS, CHINA. Y. Chen, Geology Department, Peking University, Beijing, China (ychen@geoms.geo.pku.edu.cn).

Collisional orogenesis and fluidization remain to be well studied although they have become the research frontier since the 1980 s. Being the outstanding feature and the geologic outline of the main- land of China, collisional orogenesis occurred most typically and extensively in the mainland of China, which makes China the best country to study fluidization and mineralization in a collisional orogenic regime. Taking the eastem Qinling Mountains as a typical collisional orogenic district, the author studies several representatives of the syncollisional Au deposits. Their fluid evolution is clearly divided into three stages, i.e., the upward deep-secreted (from reworking, metamorphism, and partial melting) fluid in the early compression stage, the mixed fluid by deep-secreted and shallowderived ones in the middle transition stage from compression to extension, and the downward shallow-derived fluid (mainly from meteoric $\mathrm{H}_{2} \mathrm{O}$ ) in the late extension stage, which can be supported by the isotopes of $\mathrm{O}$ and $\mathrm{H}$ (Table 1 ). Of these three stages, the middle mixed fluidization made the most significant contribution to Au mineralization, resulting in the formation of fine disseminated polymetallic sulfide networks. Appealing to the petrogenic and metallogenic model for collisional orogenesis or A subduction [1] and to the model for P.T-t paths of collisional orogenesis, the threestage evolution of the ore-forming fluid is interpreted logically. Hence, a three-stage evolution model for fluidization in collisional orogenesis is proposed (see Fig. 1), which may be suitable for areas with similar tectonic settings.

References: [1] Chen Y. and Zhang C. (1991) J. Changchun Univ. Earth Sci., 21(1), 61-66.

\section{RHENIUM-OSMIUM STUDIES OF EVOLVED CONTINEN- TAL BASALTS: PRESENT KNOWLEDGE AND FUTURE STUDIES. J. T. Chesley' and J. Ruiz', 'Department of Geo- sciences, University of Arizona, Tucson AZ8572 1,USA (Jchesley@ geo.arizona.edu).}

One of the most important debates over the formation of continental basaltic lithologies, in general, focuses on whether compositional variation in basalts can be attributed to mixing of melts from

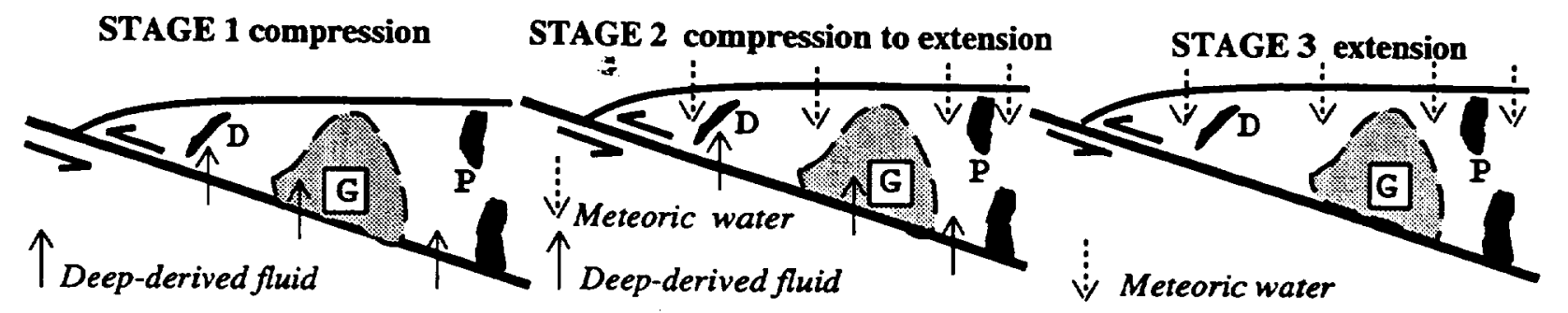

Fig. 1. Sketches showing the three-stage fluid evolution for A subduction as a concrete mechanism of continental collision. (D, G, and Prepresent the hydrothermal deposits, granites, and porphyries.)

TABLE $1 . \quad \delta^{18} \mathrm{O}$ and $\delta \mathrm{D}$ in ore-forming fluids of gold deposits, eastern Qinling Mountains.

\begin{tabular}{|c|c|c|c|c|c|c|c|c|}
\hline$\delta^{18} \mathrm{O}_{w}$ & Qiyugou & Shanggong & Kangshan & Shenjiayao & Yangshai & Yaogou & Bankuan & Yindongpo \\
\hline I: mean/num. & $7.7(3)$ & $7.43(19)$ & $7.3(2)$ & $4.74(5)$ & $4.20(8)$ & $4.88(4)$ & $7.45(2)$ & $3.41(2)$ \\
\hline $\mathrm{I}: \min / \max$ & 7.611 .8 & $4.29 / 12.39$ & $6.9 / 7.7$ & $3.75 / 6.51$ & $3.53 / 5.33$ & $4.31 / 5.63$ & $7.39 / 7.51$ & $3.22 / 3.59$ \\
\hline II: mean/num. & $4.37(6)$ & & $3.5(2)$ & $1.95(1)$ & $1.60(1)$ & $1.77(2)$ & $3.33(1)$ & \\
\hline II: $\min / \max$ & $3.19 / 5.79$ & & $3.1 / 3.9$ & & & $1.75 / 1.79$ & & \\
\hline III: mean/num. & $-3.10(5)$ & $-0.83(3)$ & & $-6.80(1)$ & $-4.04(21)$ & $1.51(1)$ & & $-7.16(4)$ \\
\hline III: $\min / \max$ & $-4.50 /-1.86$ & $1.99 / 0.085$ & & & $-8.63 i-1.85$ & & & $-9.71 /-4.63$ \\
\hline$\delta \mathrm{D}$ & $-77.71 /-61.6$ & $-94.0 /-56.4$ & $-73.2 /-62.1$ & & $-53.0 /-33.8$ & $-88.6 /-45.1$ & & \\
\hline
\end{tabular}


heterogeneous mantle-domains or from varying degrees of crustal assimilation by mantle-derived magmas. The Re-Os isotopic system has been shown to develop distinct isotopic signatures in crustal and mantle reservoirs, which are not greatly affected by later tectonic processes [1]. Thus, Os isotopic values can be used as highly effective tracers of crust/mantle processes.

The use of the Re-Os system in more evolved continental lithologies is in its infancy. Recently, however, investigations of the formation and evolution of the basalts from, Antarctica [2] and the northwestem U.S. $[3,4]$ have been reported, all of which demonstrate the potential for the Re-Os system to place constraints on genetic models of basalt formation and evolution. Osmium initial isotopic values range from these studies range from ${ }^{187} \mathrm{Os} / 188 \mathrm{Os}=$ 0.134 to $>1.0[2-4]$.

Simple two-component-mixing calculations can be used to evaluate possible Os sources for the magmas (Fig. 1a). In order to account for the trace-element and radiogenic isotopic $(\mathrm{Pb}, \mathrm{Sr}, \mathrm{Nd})$ signatures and elevated melting temperatures needed for the subcontinental lithospheric mantle (SCLM) to be a viable mixing component, several researchers have suggested that the SCLM has been variably altered by subduction processes. The high $O$ s concentration in the SCLM ( 3-5 ppb) makes it resistant to alteration or contamination. Metasomatism of the SCLM by a Re-bearing fluid and injection of basaltic veins into the SCLM can be shown to be unlikely scenarios (Fig. Ib). It should also be noted that although the majority of mantle xenoliths measured worldwide contain Os isotopic values less than chondritic, a few anomalous samples have recently been measured $[5,6]$, which are believed to have undergone alteration by either mixing or metasomatism and have $O s$ isotopic values greater than chondritic $\left({ }^{187} \mathrm{Os} /{ }^{188} \mathrm{Os}=0.13-0.14\right)$. However, these values cannot account for the elevated initial Os isotopic ratios measured in basalts $[2,4]$.

Important conclusions regarding the petrogenesis of these basaltic terranes can be reached from the Os data. The more enriched isotopic signatures observed can only be attributed to contamination of the primary magma by high $\mathrm{Re} / \mathrm{Os}$, evolved crustal domains, possibly, of mafic lower crustal origin. It is doubtful that the SCLM played any significant role in the formation of these basalts.

References: [1] Walker et al. (1989) GCA, 53, 1583. [2] Molzahn et al., EPSL, 144. [3] Chesley and Ruiz (1997) Science, in review. [4] Hart et al. (1997) EPSL, in review. [5] Brandon et al. (1996) Science, 272. [6] McBride et al. (1996) Geology, 24.

\section{LEAD-ISOTOPIC RECORDS OF TWO CENTRAL PACIFIC IRON MANGANESE CRUSTS: A POSSIBLE CONNEC-} TION WITH CENOZOIC CHANGES IN CONTINENTAL WEATHERING. J. N. Christensen ${ }^{1}$, A. N. Halliday' ${ }^{1}$, J. R. Hein ${ }^{2}$, D. K. Rea ${ }^{1}$, and L. V. Godfrey ${ }^{2}$, Department of Geological Sciences, University of Michigan, Ann Arbor MI, USA, 2U.S. Geological Survey, 345 Middlefield Road, Menlo Park CA 94025, USA, ${ }^{3}$ Department of Geological Sciences, Comell University, Ithaca NY 14853.

Hydrogenous $\mathrm{Fe}-\mathrm{Mn}$ crusts can provide a temporal record of $\mathrm{Pb}$ $[1,2]$, Nd [1], Hf [3], Os [4], and in some cases Sr isotopic compositions of the seawater from which they grew. The isotopic compositions of seawater $\mathrm{Sr}$ and $\mathrm{O}$ s have varied significantly during the Cenozoic. These changes have been related to changes in climate and weathering, and by some workers directly to the uplift of the Himalayas [e.g., 5]. Unlike these elements, the residence time of $\mathrm{Pb}$ in the oceans is much shorter than the ocean mixing time [6]. Therefore the $\mathrm{Pb}$ isotopic composition of seawater should be very sensitive to changes to both circulation and $\mathrm{Pb}$ sources on an ocean basin scale [7]. Establishing $\mathrm{Pb}$ isotopic records for separate oceans potentially may allow identification of regions that underwent significant Cenozoic changes in continental weathering that may have affected the global seawater $\mathrm{Sr}$ and $\mathrm{Os}$ isotopic signal.

We have determined detailed $\mathrm{Pb}$ isotopic records for two Pacific Fe-Mn crusts, CD29-2 (16 ${ }^{\circ} 41 \mathrm{~N}, 168^{\circ} 14^{\prime} \mathrm{W}, 2.3 \mathrm{~km}$ depth) and D1 1$1\left(11^{\circ} 39^{\prime} \mathrm{N}, 161^{\circ} 41^{\prime} \mathrm{E}, 1.8 \mathrm{~km}\right.$ depth), separated by $3300 \mathrm{~km}$. Both crusts are thick, $11 \mathrm{~cm}$ and $15 \mathrm{~cm}$ respectively, providing long-term records for the Central Pacific. Lead isotopic compositions were measured directly from cut slabs using UV laser ablation sampling coupled with multiple collector ICPMS. Ablated material is carried by an Ar flow directly to the ICP source of the mass spectrometer. Masses 202 through 208 are measured simultaneously using a set of Faraday collectors. Mass fractionation of $\mathrm{Pb}$ isotopic compositions is monitored and corrected for during analysis by measurement of

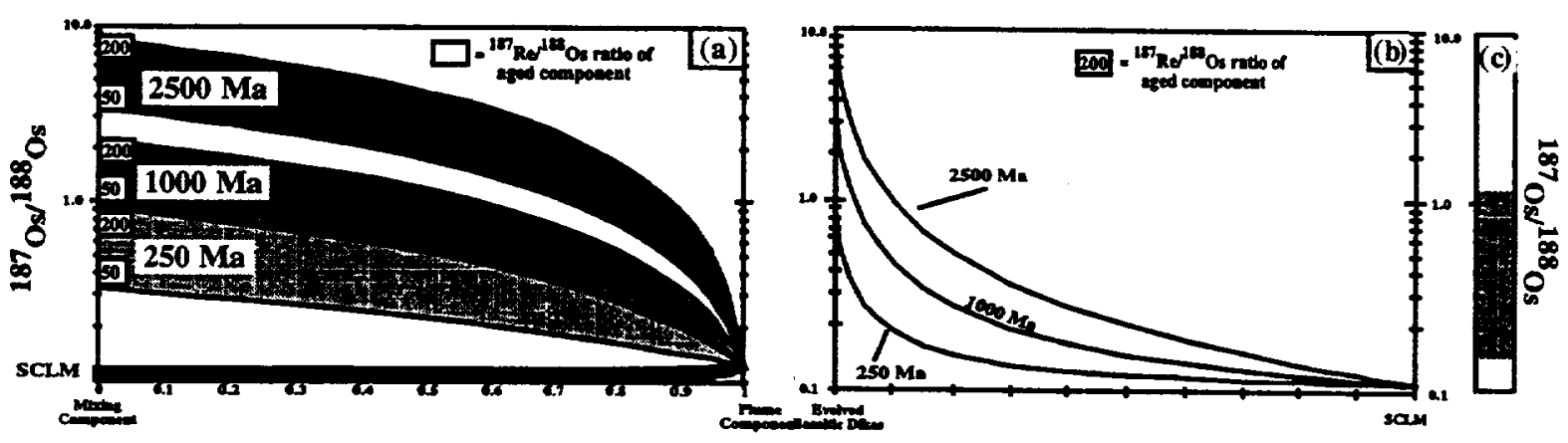

Fig. 1. Osmium isotopic two-component-mixing diagrams. (a) Mixing of a mantle plume $\left(\mathrm{Os}=0.05 \mathrm{ppb},{ }^{187} \mathrm{Os} / 188 \mathrm{Os}-0.13\right.$ ) with different hypothetical

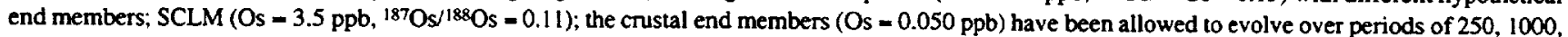
and $2500 \mathrm{~m} . y$. with ${ }^{187} \mathrm{Re} / 188 \mathrm{Os}=50$ or 200 . (b) Possible alteration of SCLM by emplacement of basaltic dikes (187Re/188 Os $\left.=200\right) 250,1000$, and $2500 \mathrm{~m}$.y. ago. (c) Range of ${ }^{187} \mathrm{Os} / 188 \mathrm{O}$ initial ratios from $[2,4]$. 
the ${ }^{203} \mathrm{TV}{ }^{205} \mathrm{Tl}[8]$ of the $\left.\mathrm{T}\right]$ that occurs naturally in the sample. Mass interference of ${ }^{204} \mathrm{Hg}$ on ${ }^{204} \mathrm{~Pb}$ was corrected for by monitoring ${ }^{202} \mathrm{Hg}$, and was typically $\leq 1 \%$. Typical run precisions are $\pm 0.09 \%$

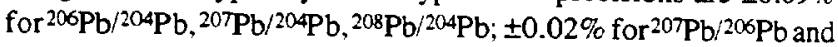
$\pm 0.03 \%$ for ${ }^{208} \mathrm{~Pb} / 206 \mathrm{~Pb}$.

Previous workers have determined growth rates for CD29-2 (2.1 mm/m.y.) and D1 1.1 (1.37 mm/Ma and $2.7 \mathrm{~mm} / \mathrm{m} . \mathrm{y}$.$) using$ ${ }^{10} \mathrm{Be} /{ }^{9} \mathrm{Be}[1]$. These rates apply to approximately the last $10 \mathrm{Ma}$ of growth, and are extrapolated back to $\sim 50 \mathrm{Ma}$ to calibrate the measured $\mathrm{Pb}$ isotopic records in time.

In the case of CD29-2, significant variations with time $\alpha$ cur in

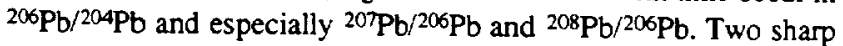
rises in ${ }^{207} \mathrm{~Pb} /{ }^{206} \mathrm{~Pb}$ and ${ }^{208} \mathrm{~Pb} /{ }^{206} \mathrm{~Pb}$ occur, one beginning at $-34 \mathrm{Ma}$ and peaking at $30 \mathrm{Ma}$, and a second begining at $\sim 16 \mathrm{Ma}$ and peaking at $\sim 10 \mathrm{Ma}$, followed by a mininum at $\sim 5 \mathrm{Ma}$. For D11-1 the overall

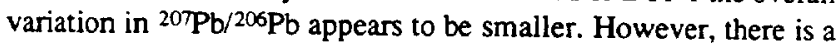
distinct rise and fall between $16 \mathrm{Ma}$ and $\sim 5 \mathrm{Ma}$ as in CD29-2. Prior to extrapolated ages of about $30 \mathrm{Ma}$, the $\mathrm{Pb}$ isotopic records of the two crusts appear not to correspond.

The ${ }^{207} \mathrm{~Pb} / 206 \mathrm{~Pb}$ record of $\mathrm{CD} 29-2$ in particular shows a remarkable correspondence with Cenozoic relative sea level [9], the $\delta^{18} \mathrm{O}$ of benthic formanifera [10], and chemical and physical indicators of weathering processes [11]. This suggests that the $\mathrm{Pb}$ isotopic composition of Central Pacific seawater may be climatically controlled through variations of chemical vs. physical weathering processes.

References: [1] Ling et al. (1996) J. Conf. Abst., 1, 361; Ling et al. (1997) EPSL, in press. [2] Christensen et al., Eos Trans. $A G U$, 77(46), 323. [3] Godfrey et al. (1997) EPSL, in revision. [4] Burnon et al., Eos Trans. AGU, 77(46), 321. [5] Edmond (1992) Science, 258, 1594; Richter et al. (1992) EPSL, 109, 11. [6] Schaule and Paterson (1981) EPSL, 54, 97. [7] von Blanckenburg and O'Nions, Eos Trans. AGU, 77(46), 321. [8] Walder et al., Spectrochem. Acta, 48B, 397. [9] Haq et al. (1987) Science, 235, 1156 . [10] Miller et al. (1987) Paleocean., 2, 1. [11] Rea (1993) GSA Today, 3, 205.

\section{SOURCE, TRANSPORT, ANDPARTITIONING OFMETALS} BETWEEN WATER, COLLOIDS, AND BED SEDIMENTS OF THE ANIMAS RIVER, COLORADO. S. E. Church, B. A. Kimball, D. L. Fey, D. A. Ferderer, T. J. Yager, and R. B. Vaughn, U.S. Geological Survey, P.O. Box 25046, Mail Stop 973, Denver CO 80225, USA (schurch@usgs.gov).

Studies of the sources, transport, and partitioning of metals in the Animas River in southwestern Colorado and northwestern New Mexico indicate that the dominant source of the metals is in the headwaters above Silverton, Colorado. These metals are derived from historical and recent mining activities, as well as from natural sources. Although most of the mass of metals in the Animas River resides in the bed sediments, a substantial component of the metal transported downstream seasonally is in the dissolved and colloidal phases. Much of the formation of the colloids occurs in the Animas River downstream of the major tributaries, which are acidic and contain substantial dissolved and colloidal metal loads. As the colloids aggregate, they settle to the bed mixing with algae and coating detrital sediment that results in a substantial partitioning of $\mathrm{Fe}$ and $\mathrm{Al}$ and their sorbed trace metals to the bed sediment. In contrast, there is very little transport of metals in the dissolved and colloidal phases in the Animas River above Silverton. There is, however, a substantial mass of metal in the bed sediments of the upper Animas River that have resulted from a long mining and milling history in the upper Animas basin.

Leach studies using warm $2 \mathrm{M} \mathrm{HCl}-1 \% \mathrm{H}_{2} \mathrm{O}_{2}$ of the $-149-\mu \mathrm{m}$ fraction of the bed-sediment samples indicate that most of the As, $\mathrm{Pb}, \mathrm{Cu}$, and $\mathrm{Cd}$ reside as sorbed metals on the Fe-hydroxide mineral phase. However, only about one-third of the $\mathrm{Zn}$ in the bed sediments below Silverton is sorbed to the Fe-hydroxide phase. Most of the $\mathrm{Zn}$ in the bed sediments is in detrital grains of sphalerite. The basemetal concentrations in the bed sediments drop off as a function of distance downstream from individual sources; however, the concentrations of $\mathrm{Co}, \mathrm{Sr}$, and $\mathrm{V}$ remain constant along the course of the streams. This indicate that the sources of the ore metals were from the areas mined above Silverton. Geochemical data from cores collected from the streams indicate that much lower metal concentrations were present in the bed sediments prior to mining.

Lead isotopic data from the acid leaches of the bed sediments indicate that there are at least five isotopically distinct periods of mineralization in the Silverton caldera. The lead isotopic data from the stream sediments indicate the relative distribution of these different mineralization episodes and provide a mass basis for estimating the relative importance of each deposit type to the environmental degradation in the Animas watershed above Silverton. Using the station below the confluence of the Animas River with Mineral Creek as a starting point and using the $\mathrm{Pb}$ isotopic data measured in the acid-soluble phase of the bed sediments from tributaries below Silverton, we calculate that $80 \%$ of the $\mathrm{Pb}$ in the acid-soluble phase at Durango $75 \mathrm{~km}$ downstream is from the Animas watershed above Silverton. The amount of sediment added to the Animas River increases substantially below Durango near the confluence of the Florida River (110 km downstream). Base-metal concentrations in bed sediments drop substantially below the confluence of the Florida River, but even at Aztec, New Mexico, ( $145 \mathrm{~km}$ downstream), $57 \%$ of the acid-soluble $\mathrm{Pb}$ in the bed sediments was derived from the Animas watershed above Silverton.

\section{STRONTIUM-THORIUM-RADIUM SYSTEMATICS IN OCEAN ISLAND BASALT: EVIDENCE FOR PLUME CON-} TAMINATION AND RAPID MAGMA EXTRACTION. C. Claude-Ivanaj, C.J.Allègre, andB. Bourdon, Laboratoire Géochimie et Cosmochimie, URA-CNRS 1758, IPGP, 4 Place Jussieu, 75252 Paris, Cédex 05, France.

The measurement of short-lived isotope disequilibrium in basalts provides a useful mean of estimating both the extent and timescale of incompatible element fractionation during magma fornation. Indeed, ${ }^{26}{ }^{26 \mathrm{Ra}}$ and ${ }^{230} \mathrm{Th}$, with a half-life of $1600 \mathrm{yr}$ and $75 \mathrm{k} . \mathrm{y}$., respectively, seem particularly appropriate for the measurement of magma transit times and for the study of fractionation events that may occur during melt formation and ascent.

Here, we present precise TIMS measurements of ${ }^{226} \mathrm{Ra}$ and ${ }^{230} \mathrm{Th}$ disequilibria in a suite of historic basalts from three different settings, Grande Comore in the Indian Ocean, and Canaries and Azores in the Atlantic Ocean.

In Grande Comore, our results show that there is a correlation between $\mathrm{Sr}$ isotopic ratios and $\mathrm{U}$-series data for $\mathrm{La}$ Grille and Karthala volcanos. This, coupled with evidence from major and trace elements, is interpreted as a mechanism of contamination of 
the Karthala plume by silicate metasomatic melts generated in the amphibole-bearing lithospheric source of La Grille basanites [1]. With this approach, the extreme uncontaminated plume end member can be identified. Additionally, as the magmas are only produced at the base of the lithosphere, their transit time can be constrained to be less than the ${ }^{226} \mathrm{Ra}$-decay half-life.

Our Tenerife samples come from a suite of differentiated lavas while the Lanzarote samples are very primitive basanites. In Tenerife, excess ${ }^{230} \mathrm{Th}$ and ${ }^{226} \mathrm{Ra}$ data clearly decrease during differentiation and are correlated with $\mathrm{Sr}$ isotopes and trace-element ratios $(\mathrm{Nb} / \mathrm{U}$, $\mathrm{K} / \mathrm{U})$. This evolution is interpreted by a process of interaction of the magmas with the lithosphere. In contrast, the variations observed in Lanzarote can be ascribed to partial melting of a phlogopite-bearing mantle and also display evidence for interactions with the lithosphere.

In the Azores, U-Th disequilibria, as well as $\mathrm{Th}, \mathrm{Sr}$, and $\mathrm{Pb}$ isotope data display large variations, where three components are thought to be involved: depleted upper mantle, sediments, and old recycled oceanic crust [2]. The composition of basalts erupted on the Azores islands consistently converges toward the composition of MORB erupted on the Azores plateau [3]. Hence, there must be some process of plume-lithosphere (or asthenosphere) interaction that contributes to the contamination of the Azores lavas.

These studies demonstrate that (1) the oceanic lithosphere may play a major role during oceanic island basalt genesis and (2) the transit time of magmas through an old lithosphere has to be very short (1000 yr). Our study also suggests that some of the large isotopic variations that have been described in oceanic basalts have to be taken with more caution as they could be attributed to local plume contamination.

References: [1] Class C. and Goldstein S. L. (1994) Mineral. Mag., 58A, 175-176. [2] Dupré B. et al. (1983) Nature, 299, 620622. [3] Bourdon B. et al. (1994) EPSL, 142, 175-189.

NEW METHODS FOR CHLORINE AND RUBIDIUM ISOTOPIC ANALYSIS: KILLING TWO ISOTOPIC BIRDS WITH ONE MOLECULAR STONE. R. A. Cliff and M. H. Dodson, Department of Earth Sciences, University of Leeds, Leeds, LS2 9JT, UK (bob@earth.leeds.ac.uk).

Chlorine isotopic compositions have been analyzed by TIMS using $\mathrm{Cs}_{2} \mathrm{Cl}^{+}$in several laboratories recently, particularly where the amount of $\mathrm{Cl}$ available is small. Even with the high masses involved with this method ( 301 and 303), fractionation in the course of and between analyses is the main source of uncertainty [e.g., 1]. We have developed a new approach based on production of the related ion, $\mathrm{Rb}_{2} \mathrm{Cl}^{+}$, which is formed with similar intensity under the same conditions as for Cs, viz. 2-20-pA ion beams from 5 to $10 \mu \mathrm{g}$ when loaded on Re filaments with graphite. Because both elements have two isotopes with a mass difference of 2 , ions of four different masses are produced; consequently interpretation of the data is more complex than with monoisotopic Cs. However, the presence of a fixed isotopic abundance (of $\mathrm{Rb}$ ) allows a correction for instrumental fractionation to be made. Equations for the isotopic abundances of the four masses ${ }^{85} \mathrm{Rb}_{2}{ }^{35} \mathrm{Cl}(\mathrm{A}=205)$ to ${ }^{87} \mathrm{Rb}_{2}{ }^{37} \mathrm{Cl}(\mathrm{A}=211)$ have been set up using the linear algebra of Dodson [2] yielding three independent equations for the two unknowns, namely instrument fractionation and natural fractionation of $\mathrm{Cl}$. These equations are poorly conditioned when natural $\mathrm{Rb}$ is used, but by using isotopi-

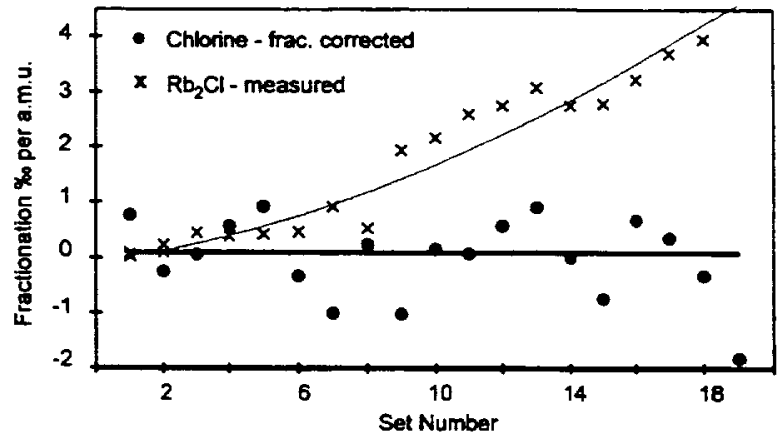

Fig. 1.

cally enriched $\mathrm{Rb}$ to produce the $\mathrm{RbCl}$ loaded onto the filament, the fractionation correction becomes more reliable. Experiments with a mixture in which ${ }^{85} \mathrm{Rb} /{ }^{87} \mathrm{Rb}=0.6$ demonstrate that the isotopic composition of 5-10 $\mathrm{gg}$ of $\mathrm{Cl}$ can be determined to better than $0.1 \%$ $(1 \sigma)$. Figure 1 shows results of a single run in which the ${ }^{207} \mathrm{Rb}_{2} \mathrm{Cl}$ beam was maintained at 1-2 pA; over the course of this run abundances of $\mathrm{Rb}_{2} \mathrm{Cl}^{+}$ions changed systematically by $4 \%$ per a.m.u. while the calculated $\mathrm{Cl}$ abundance remained constant with a mean fractionation of $0.09 \pm 0.09 \%$.

In Rb-Sr geochronology the biggest contribution to analytical uncertainty comes from $\mathrm{Rb}$ determination by isotope dilution. This is because with only two isotopes, instrumental fractionation during analysis cannot be corrected. Numerical simulations show that conversion of the $\mathrm{Rb}$ to $\mathrm{RbCl}$ using $\mathrm{Cl}$ of fixed composition and measuring $\mathrm{Rb}_{2} \mathrm{Cl}$ ions will allow determination of fractionationcorrected $\mathrm{Rb}$ isotopic compositions to better than $1 \%$.

References: [1] Rosenbaum J. R. et al. (1996) Eos Trans. $A G U, 77$, F773. [2] Dodson M. H. (1969) J. Sci. Instrum., 40, 289295.

HOW MONAZITE RECORDS GEOLOGICAL EVENTS: EVIDENCE FROM URANIUM-THORIUM-LEAD ${ }_{10 \ell}$ DETERMINATION WITH THE ELECTRON MICROPROBE. A. Cocherie ${ }^{1}$, O. Legendre', J. J. Peucat ${ }^{2}$, and A. Kouamelan ${ }^{2}$, 'BRGM, BP 6009, 45060 Orléans Cedex 02, France, ${ }^{2}$ Géosciences Rennes, 35042 Cedex, France.

The U-Th- $\mathrm{Pb}$ system in monazite has been studied on monazite grains from an Archean migmatite in the Ivory Coast known to present an early polycyclic history and to have undergone significant resetting during the Paleoproterozoic. Dating the migmatite on monazite was done using three different methods: U-Pb Concordia, $\mathrm{Pb}$-evaporation, and $\mathrm{U}-\mathrm{Th}-\mathrm{Pb}_{\text {tor }}$.

With the conventional U-Pb Concordia method, the analyzed monazite lies (within the limits of analytical error) on a single chord, a feature that is interpreted as indicating partial loss of radiogenic $\mathrm{Pb}$ during a young metamorphic event. The Concordia intercepts give two poorly defined ages at $2031 \pm 74 \mathrm{Ma}$ and $2825 \pm 197 \mathrm{Ma}$ for the low and high intercept respectively.

The grain-by-grain $\mathrm{Pb}$ evaporation method gives a young age of $2074 \pm 7 \mathrm{Ma}$ for some monazite grains. This is in agreement with the inaccurate low $\mathrm{U} \cdot \mathrm{Pb}$ Concordia intercept and must be considered as a maximum age for the younger event affecting the migmatite. Other grains show older ages, up to $2532 \pm 15 \mathrm{Ma}$, which result from a 
mixing of radiogenic $\mathrm{Pb}$ and which can only be used as minimum ages, far from the real inherited age.

The U-Th- $\mathrm{Pb}_{\mathrm{tot}}$ method, using an electron probe micro-analyser (EPMA), provides an opportunity to study the behavior of the U-Th$\mathrm{Pb}$ geochronometer in monazite at micrometer scale. Two grains were mounted on polished section and analyzed systematically along a grid of $10 \times 10-\mu \mathrm{m}$ steps. The first grain yielded two ages: two homogeneous age zones at $2028 \pm 23 \mathrm{Ma}$ and two others at $2721 \pm 24 \mathrm{Ma}$. The second grain yielded three ages: a small homogeneous zone at $2044 \pm 39 \mathrm{Ma}$, two zones at $2707 \pm 20 \mathrm{Ma}$, and a single zone at $2794 \pm 20 \mathrm{Ma}$. The oldest age is in agreement with the high U-Pb Concordia intercept (2825 $\pm 197 \mathrm{Ma})$ and is confirmed by a $U$-Th- $\mathrm{Pb}$ age of $2801 \pm 24 \mathrm{Ma}$ obtained on monogenic monazite from another sample (anatectic mobilizate). The youngest age around $2028-2044 \mathrm{Ma}$ is significantly younger than the ${ }^{207} \mathrm{~Pb}^{* / 206} \mathrm{~Pb}^{*}$ age of $2074 \pm 7 \mathrm{Ma}$ obtained by the $\mathrm{Pb}$ evaporation technique, which must be interpreted as a maximum age of the migmatization event. Thus the EPMA method has clearly indicated a second inheritance at 2707-2721 Ma; such an intermediate age could not be dated from whole-grain studies.

The two processes that enable monazite to record several ages in a single grain, i.e., recrystallization and replacement, will be discussed, as will processes such as continuous $\mathrm{Pb}$ diffusion or $\mathrm{Pb}$ loss due to radiation damage. Only rare inclusions, mostly silicates, found in the grains are a potential source of common $\mathrm{Pb}$, but these are not involved in the EPMA U-Th-Pb age calculations.

The ability of EPMA to date up to three different events in monazite with a precision close to $20 \mathrm{Ma}$ is now clearly established. The study also demonstrates that monazite is more refractory than normally thought, because migmatization cannot completely open the system.

PROBING THE STABILITY AND REACTIONS OF BIOMOLECULES UNDER HIGH-PRESSURE HYDROTHERMAL CONDITIONS. G. D. Cody', J. G. Blank ${ }^{1}$, R. Hazen ${ }^{1}, H$. Yoder Jr. ${ }^{1}$, and Sherwood Chang ${ }^{2},{ }^{1}$ Geophysical Laboratory, Camegie Institution of Washington, 5251 Broad Branch Road, Northwest, Washington DC 20015, USA, 2Sherwood Chang, NASA Ames Research Center, Moffet Field CA 94035, USA.

We present preliminary results of high-pressure hydrothermal experiments probing the reactions and stability of pyruvic acid and citric acid, respectively, in $\mathrm{CO}_{2}-\mathrm{H}_{2}$-bearing aqueous fluids in the temperature range of $150^{\circ}-350^{\circ} \mathrm{C}$ and $0.5-5.0 \mathrm{kbar}$. Our principal focus is on identifying the effect of pressure on reaction selectivity in biomolecular systems that exhibit multichannel reactions. Toward this end, we have focused on two relatively simple systems in order to gain fundamental information on the kinetics of reactions that typify biological processes, albeit under strictly abiotic conditions. These data will provide a foundation for subsequent work on the potential for abiotic synthesis of classically bio-organic compounds at extremes of temperature and pressure, that typify deep ocean hydrothermal vents.

In the pyruvic acid system we set out to determine whether pressure would favor the synthesis of oxaloacetic acid through an electrophilic addition of $\mathrm{CO}_{2}$ at elevated temperatures. Our results, thus far, have not revealed any evidence for the synthesis of oxaloacetic acid. Other interesting reactions, however, are operative within this pressure and temperature regime. We observe sub- stantial product yields from three reaction channels operating in series and parallel. One of these channels yields appreciable quantities of the five $\mathrm{C}$ diacid, methyl succinic acid, that forms through a cascade of reactions moving (evidently) through a number of intermediates. There is evidence that this reaction may be concerted. The reaction pathway is superficially similar to the citric acid cycle with the exception of the initial step; i.e., the initial step involves the formation of an Aldol condensation product rather than an electrophilic addition reaction.

A second reaction channel involves the straightforward decarboxylation of pyruvic acid and is not particularly interesting beyond helping to establish the limits of pyruvic acid stability. On the other hand, the third reaction channel produces a very interesting and complex suite of compounds with amphiphilic qualities. This particular reaction channel operates, in general, through sequential Aldol condensations, Diels-Alder cyclo-additions, decarboxylations, dehydrations, dehydrogenations, and/or hydrogenations. We are still working out the details on the exact reactions; however, systematic pressure- and temperature-induced changes in the distribution of molecules within this suite are observed.

In general, we observe that pynuvic acid is destabilized with increases in temperature and pressure, leading to the formation of the aforementioned products. Clearly evident are pressure effects manifested in the yields of methyl succinic acid and within the amphiphilic suite of compounds.

The system citric acid in $\mathrm{CO}_{2}-\mathrm{H}_{2}$-bearing aqueous fluids is equally interesting. As would be expected, the principal reactions involve mono, double, and triple decarboxylations; with and without dehydration, as well as hydrogenation. The product distributions exhibit strong temperature and pressure selectivity. Molecular mechanics calculations are used to relate the product distributions to specific serial reactions, which, in turn, can be used to better understand the role of pressure on a given reaction.

Work currently in progress builds on the results described above and involves additional components (representative of hydrothermal vent fluids) to these and other biomolecular systems. We hope to probe the role of catalysis within the same reaction space of elevated pressure and temperature.

PRECISE DETERMINATION OF SEASONAL TEMPERATURE VARIATION FROM THE PREPUBESCENT STAGE OF AN EXCEPTIONALLY PRESERVED FEMALE JURASSIC AMMONITE. M. L. Coleman', M. Gruszczynski1.2, J. D. Hudson $^{3}$, C. Kulicki², and M. C. Isaacs' ${ }^{1}$, 'Postgraduate Research Institute for Sedimentology, Reading University, Whiteknights, Reading RG6 6AB, UK (m.l.coleman@reading.ac.uk), 2Instytut Paleobiologii, Polska Akademia Nauk, al. Zwirki i Wigury 93, $02-$ 089 Warszawa, Poland, ${ }^{3}$ Department of Geology, Leicester University, University Road, Leicester LEl 7RH, UK.

Mollusk shells of Jurassic age (jason-lamberti ammonite zones) occur in carbonate concretions in clay of an abandoned brick pit. near Lukow (eastern Poland). They are exceptionally preserved, often hollow, and still with the original mineralogy. The specimen we have analyzed is a macroconch of the species Quenstedtoceras vertumnum, formed of pristine aragonite, and consists of 6.56 whorls (complete turns of the shell). We analyzed individual septa of the last three whorls geochemically and isotopically. However, not all septa give results that can be used for $O$ isotope temperature deter- 
minations. We have used the trace-element data combined with details of the ammonite's ontology to define which parts of the dataset give valid temperature information.

Measurements of the angular spacing between successive septa, which are independent of shape and diameter of whorls, indicate the stage of development [1]. On this basis, the septa we have analyzed include three stages: prepubescent, adolescent, and adult. In both the prepubescent and adolescent stages there are oscillatory variations of $\mathrm{O}$ isotope compositions. However, in the adolescent stage these oscillations correspond with the onset of sexual maturity indicated by increased angles between successive septa. In Recent squids, mature gonads represent a considerable percentage of body weight, e.g., 30-35\% of female Ommastrephidae. Their growth probably imposed a major metabolic stress that could have caused variation of the composition of extrapallial fluid from which the skeleton is precipitated. $\delta^{18} \mathrm{O}$ and $\delta^{13} \mathrm{C}$ in aragonite of the septa might be in disequilibrium with adjacent seawater at the time of maximal sexual maturation and thus the $O$ isotope data cannot be interpreted as palaeotemperatures with confidence.

There is no systematic correlation between $C$ and $O$ isotope values for the prepubescent stage. Interpretation of these data in terms of palaeotemperatures still may not be valid. More negative $\delta^{18} \mathrm{O}$ results from either higher temperature or influx of meteoric (fresh) water. The deposit contains abundant drifted wood suggesting nearby land, and hence the plausibility of run-off, giving dilution or (seasonal?) stratification of the water column. Elemental data can be used to assess the extent of nonmarine influence. Strontium calcium and $\mathrm{Mg} / \mathrm{Ca}$ are much higher in seawater than in fresh but there is no correlation between these ratios and $\delta^{18} \mathrm{O}$. More negative $\delta^{13} \mathrm{C}$ and higher $\mathrm{Ba} / \mathrm{Ca}$ both relate to degradation of organic matter and can characterize nun-off or in situ marine processes. However, there is no correlation between $\mathrm{Ba} / \mathrm{Ca}$ and $\delta^{18} \mathrm{O}$. Thus, there is no apparent effect of meteoric water, and $\delta^{18} \mathrm{O}$ can be interpreted in terms of palaeotemperature. Using the Grossman and $\mathrm{Ku}$ [2] equation for aragonite palaeotemperature, and assuming the isotopic composition of Jurassic seawater $\left(\delta_{w}\right)=-1 \%$ o SMOW, gives a range of calculated temperatures from $11^{\circ} \mathrm{C}$ to $20^{\circ} \mathrm{C}$ (see Fig. 1). A temperature range of $9^{\circ} \mathrm{C}$ in the open sea can only be seasonal, and

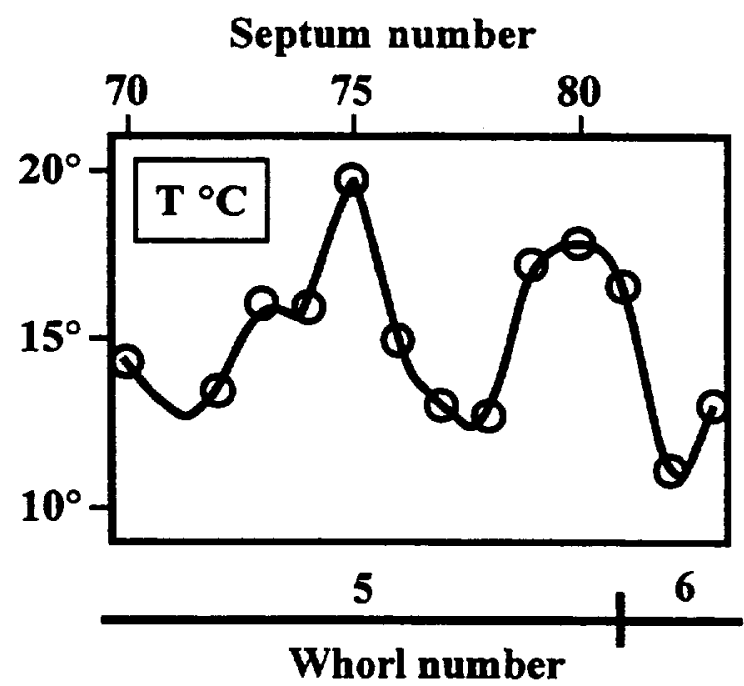

Fig. 1. Variation in Tover two years from successive septa. both the mean value and range are similar to those produced by independent GCM palaeoclimatic modeling for this area in the late Jurassic [3]. Thus this ammonite experienced three winters and two summers (2 yr) during the later prepubescent stage for which we have analyses.

References: [1] Kulicki C. (1974) Acta Palaeontol. Polonica, 19, 201-223. [2] Grossman E. L. and Ku T.-L. (1986) Chem. Geol. (Isotope Geosci.), 59, 59-74. [3] Valdes P. J. and Sellwood B. W. (1992) Palaeogeog. Palaeoclim. Palaeoecology, 95, 47-72.

MELTING CONDITIONS AND MANTLE ENRICHMENT AGES BENEATH THE NORTHWESTERN TIBETAN PLATEAU INFERRED FROM URANIUM-238/THORIUM230 DISEQUILIBRIA. K. M. Cooper ${ }^{1}$, M. R. Reid', N. W. Dunbar $^{2}$, W. C. McIntosh', and F. M. Phillips ${ }^{2}$, ${ }^{1}$ Department of Earth and Space Sciences, University of California-Los Angeles, Los Angeles CA 90095, USA (kcooper@ess.ucla.edu), ${ }^{2}$ New Mexico Bureau of Mines and Mineral Resources, New Mexico Institute of Mining and Technology, Socorro NM 87801, USA.

The Ashikol Basin, located on the northwestem margin of the Tibetan Plateau, contains several rhyolitic domes (500-250 k.y.) and associated potassic trachyandesite cinder cones and flows ( 300 $66 \mathrm{k.y}$.). These rocks are chemically similar to other Tibetan volcanic rocks, which have been interpreted as parial melts of an enriched lithospheric mantle source. The age of the lithosphere beneath northwestern Tibet is not precisely known, but is likely to be Precambrian. $\varepsilon_{\mathrm{Nd}}=-5$ to -8 in other Tibetan volcanic rocks has been suggested to delimit the timing of mantle enrichment to the late Proterozoic $(\sim 1.2 \mathrm{Ga})$, whereas single-stage $\mathrm{Pb}$ model ages suggest Archean enrichment $(\sim 3.0 \mathrm{Ga})$. Age-corrected $\left({ }^{230} \mathrm{Th}\right) /\left({ }^{238} \mathrm{U}\right)$ ratios in Ashikol mafic lavas range up to 1.36 . $\left({ }^{230} \mathrm{Th}\right) /\left({ }^{238} \mathrm{U}\right)>1.0$ requires (1) equilibration of melts with garnet and (2) small degrees of partial melting, as might be anticipated from the enrichment in incompatible elements. Low initial $\left({ }^{230} \mathrm{Th}\right) /(232 \mathrm{Th})$ ratios $(0.55-$ $0.68)$ suggest either high $T h / U$ in the source(s) of the Ashikol lavas $(\kappa(\mathrm{Th})>5)$, higher than that estimated from $\mathrm{Pb}$ isotopes $(\kappa(\mathrm{Pb})=$ 4.1 ), or significant decay of ${ }^{230} \mathrm{Th}$ after segregation of the magma from its source.

We modeled ${ }^{230} \mathrm{Th} /{ }^{238} \mathrm{U}$ and $\mathrm{Sm} / \mathrm{Nd}$ enrichments for a variety of melt generation/extraction processes involving partial melting of garnet- and spinel-peridotite and gamet pyroxenite. The largest uncertainty in the modeling stems from the latitude in possible partition coefficients; however, all models require very small degrees of partial melting $(0.1-0.5 \%)$ to reproduce the Ashikol Th data. At these small melt fractions, $\mathrm{Sm} / \mathrm{Nd}$ frationation varies significantly with the mineralogy of the source. Fractionation-corrected $\mathrm{Sm} / \mathrm{Nd}$ ratios inferred for the source range from 0.2 to 0.36 and indicate enrichment ages of $2 \mathrm{Ga}$ (garnet pyroxenite source) to $3 \mathrm{Ga}$ (garnet peridotite source).

Taken at face value, the $\mathrm{Nd}$ model ages suggest enrichment of the source in LREE between 2 and $3 \mathrm{Ga}$, consistent with the $\mathrm{Pb}$ model age. In this case, $50-75 \mathrm{k} . \mathrm{y}$. of decay of ${ }^{230} \mathrm{Th}$ during transport and residence would be required to reconcile $\kappa(\mathrm{Th})$ and $\kappa(\mathrm{Pb})$. An alternative explanation is that the mantle beneath northwestem Tibet experienced a more complex enrichment history and that the age-corrected $\left({ }^{230} \mathrm{Th}\right) /\left({ }^{232} \mathrm{Th}\right)$ ratios in the lavas reflect the presentday $\mathrm{Th} / \mathrm{U}$ ratio in the source. If this is the case, then $\mathrm{Pb}$ isotope considerations show that Thenrichment of the magnitude indicated 
by Th isotopes could not have persisted in the source for more than $\sim 0.5 \mathrm{Ga}$. Moreover, $\mathrm{Th} / \mathrm{U}$ enrichment is likely to be accompanied by $\mathrm{Sm} / \mathrm{Nd}$ decreases such that the Archean to Proterozoic Nd model ages would be minima. Extensive crustal thickening and possible intracontinental subduction in northwestern Tibet provides a mechanism for recent enrichment. The mechanism for producing melts beneath Tibet is not well understood; proposed mechanisms include intracontinental subduction, lithospheric delamination, convective erosion of the lower lithosphere, and shear-induced heating of the upper mantle. The pronounced Thenrichment in Ashikol lavas is uncharacteristic of subduction-related magmas and argues against magma generation related to intracontinental subduction. In addition, the model enrichment ages of the source inferred from isotopic data, if accurate, preclude wholesale delamination of the lower lithosphere as a mechanism for producing melts.

\section{FLEXURE OF THE MAIN CENTRAL THRUST IN THE} KATHMANDU AREA DUE TO RAMPING ON THE MAIN BOUNDARY THRUST. P. Copeland ${ }^{1}$, P. Le For ${ }^{2}$, B. N. Upreti ${ }^{3}$, and S.-M. Raï ${ }^{2.3}{ }^{1}$ 'Department of Geosciences, University of Houston, Houston TX 77204-5503, USA (copeland@uh.edu), 2CNRS, Laboratoire de Géodynamique des Chaînes Alpines, Grenoble, France, ${ }^{3}$ Department of Geology, Tri-Chandra Campus, Tribhuvan University, Ghantaghar, Kathmandu, Nepal.

The Gosainkund crystalline nappe (GCN) corresponds to the southward continuation of the High Himalayan Crystalline slab of the Langtang area of central Nepal [1]. To the south, the Kathmandu crystalline nappe (KCN) represents an exotic slice in the Lesser Himalaya. Few works are available on the nature of deformation and metamorphism in this part of central Nepal; in order to better understand the tectonic evolution of this area, we are conducting a study of distribution of muscovite ${ }^{40} \mathrm{Ar} /{ }^{39} \mathrm{Ar}$ cooling ages in the northem part of the $\mathrm{KCN}$ and of the GCN. The study area covers about $60 \mathrm{~km}$ distance from south to north (Kathmandu to Gosainkund range) and $50 \mathrm{~km}$ from east to west (Indrawati River to Trisuli Ganga), including the low- to medium-grade Lesser Himalaya Sequence (LHS) overthrusted by the high-grade Greater Himalayan Sequence (GHS) along the Main Central Thrust (MCT).

The metamorphic conditions plotted as a function of structural distance of the MCT show that the apparent pressure gradually decreases from the MCT to the higher part of the Tibetan Slab. The consistency of P-T estimates below and above the MCT zone suggests that the main deformation was synmetamorphic and records the underthrusting of the GHS over the LHS.

New ${ }^{40} \mathrm{Ar} /{ }^{39} \mathrm{Ar}$ data gathered by our group, as well as data previously published by Macfarlane et al. [2] show a distribution of muscovite ages that is neither related to the structural distance to the MCT nor to the present elevation. The data do show a strong correlation with geographic position, with the ages getting progressively younger to the north (Fig. 1). All samples, save some of the northemmost group [2], are from rocks that display exclusively ductile fabrics.

The observations that the metamorphic assemblages are highly correlated to their distance to the MCT, but the ${ }^{40} \mathrm{Ar} / 39 \mathrm{Ar}$ muscovite ages are not, suggests the distribution of cooling ages is related to a second, younger structure. The present data are consistent with the hypothesis [2] that the rocks surrounding the MCT (and particularly the hanging wall) were effected by movement over a ramp on the

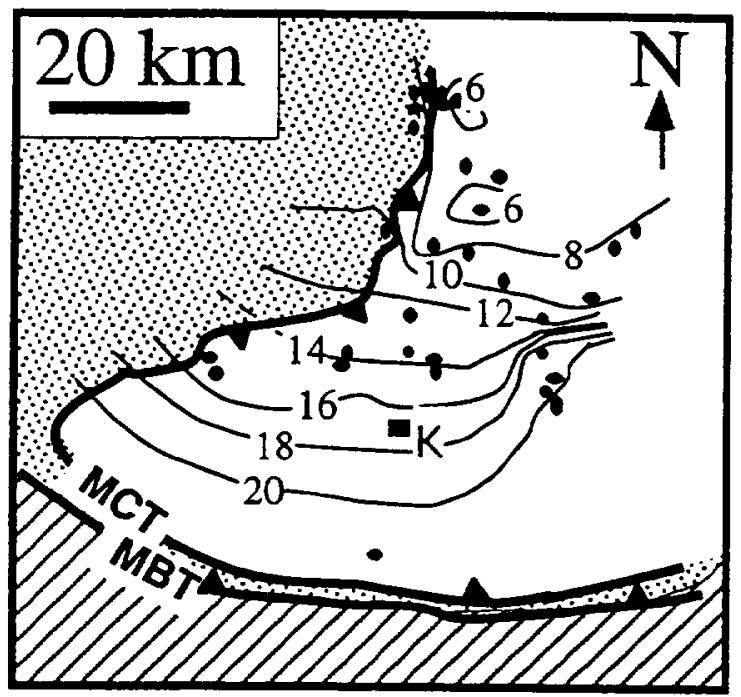

Fig. 1. Map showing the area around Kathmandu $(K)$ in central Nepal. The white area is the Greater Himalayan Sequence; the stippled pattern is the Lesser Himalayan Sequence; the diagonal lines are the Siwalik Group. MCT - Main Central Thrust, MBT - Main Boundary Thrust. Both of these thrusts are northdipping. Light solid lines are "chrontours" of ${ }^{40} \mathrm{Ar} /{ }^{39} \mathrm{Ar}$ muscovite cooling ages in millions of years. The cluster of seven data points in the northernmost portion of the diagram are from Macfarlane et a.. [1]. Black dots are data points.

Main Boundary Thrust (MB). This hypothesis makes the following predictions: (1) In the Kathmandu region, the MBT ramp is located beneath the region between Tadi Khola and Langtang Khola (the area of youngest ages); (2) motion on the MBT was occurring while the rocks in the northem part of the study area were still at temperatures greater than or equal to $350^{\circ} \pm 20^{\circ} \mathrm{C}$ (the nominal closure temperature of $\mathrm{Ar}$ in muscovite); and (3) the time of movement on the MBT responsible for the distribution of cooling ages in the hanging wall of the MCT was equal to, or slightly older than the youngest ages in the study area, $\sim 5 \mathrm{Ma}$.

Future tests of this working hypothesis will include a more detailed structual analysis and more thermochronologic analysis to the east.

References: [1] Upreti B. N.et al. (1997) Geol. Soc. Am. Spec. Paper, in press. [2] Macfarlane A. M. et al. (1992) Geol. Soc. Am. Bull., 104, 1389-1402.

SINGLE-PHASE LEAD-LEAD DATING OF COEXISTING GARNET AND STAUROLITE IN THE BLACK HILLS COLLISIONAL OROGEN (SOUTH DAKOTA), WITH IMPLICATIONS FOR EARLY PROTEROZOIC TECTONISM. P. S. Dahl ${ }^{1}$ and R. Frei ${ }^{2},{ }^{1}$ Department of Geology, Kent State University, Kent OH 44242, USA, ${ }^{2}$ Gruppe Isotopengeologie, Mineralogisch-Petrographisches Institut, Universität Bem, Erlachstrasse 9a, CH-3012 Bern, Switzerland.

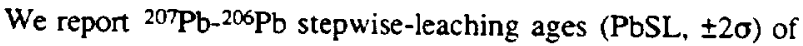
$1762 \pm 15 \mathrm{Ma}(\mathrm{MSWD}=0.2), 1759 \pm 8 \mathrm{Ma}(\mathrm{MSWD}=1.1)$, and $1760 \pm 7 \mathrm{Ma}$ (MSWD = 1.0) for syntectonic gamet, staurolite, and garnet-staurolite (combined) in an Early Proterozoic metapelite from the Black Hills collisional orogen, South Dakota. These results 
represent the first (ever) garnet-staurolite pair precisely dated by $\mathrm{PbSL}$ and the first PbSL mineral dates from North America. PbSLderived ${ }^{208} \mathrm{~Pb} /{ }^{206} \mathrm{~Pb}(\mathrm{Th} / \mathrm{U})$ mineral trends further reveal that staurolite contains inclusions of cogenetic monazite $(1760 \pm 7 \mathrm{Ma})$ and detrital zircon ( $\geq 2040 \mathrm{Ma}$ ), which were selectively attacked in the $8 \mathrm{~N} \mathrm{HBr}$ and $48 \%$ HF leach steps; coexisting garnet contains only the zircon. Thus, whereas conventional U/Pb dating would have yielded anomalously old (even if precise) ages for our garnet-staurolite pair, we can demonstrate that PbSL dating overcomes the "inclusions problem," yet without sacrificing host-phase age precision. Moreover, combined with petrologic data, our $\mathrm{PbSL}$ results point to the sequential growth of gamet, monazite, and staurolite within a $1760 \pm$ $7 \mathrm{Ma}$ time frame at prograde temperature ranges of $\sim 400^{\circ}-530^{\circ} \mathrm{C}$, $500^{\circ}-530^{\circ} \mathrm{C}$, and $500^{\circ}-550^{\circ} \mathrm{C}$ respectively. Preliminary heat-flow modeling suggests that peak regional-metamorphic temperature at the sample locality $\left(600^{\circ} \mathrm{C}\right)$ was achieved $\sim 10 \mathrm{~m}$.y. after the cessation of mineral growth, i.e., at $\sim 1750 \mathrm{Ma}$.

Characterizing metamorphic heat sources in space and time has been a longstanding problem in polymetamorphic high-T low-P terrains. In the Black Hills, where intrusion of the post-tectonic Hamey Peak granite (HPG, $1715 \mathrm{Ma}$ ) widely overprinted early regional-metamorphic assemblages, our syntectonic garnet and staurolite nevertheless retain $1760-\mathrm{Ma}$ growth ages indicative of the pre-HPG deformational event that formed them. Moreover, our $\mathrm{PbSL}$ data and the observation of kyanite inclusions in garnet indicate that the kyanite isograd, adjacent to our dated sample, was imposed at (or just before) $1760 \mathrm{Ma}$; subsequent HPG intrusion probably deformed (domed) this isograd, but cannot have imposed it. Only future PbSL dating will determine whether other isograds (gamet, staurolite, sillimanite) in the Black Hills were imposed by $\sim 1760-1730$-Ma conductive heating during tectonic burial or were superimposed later, during $\sim 1720-1690-\mathrm{Ma}$ advective heating related to the HPG.

Prior to this study, east-west collision of the Archean Wyoming and Superior cratons was broadly constrained between $1880 \mathrm{Ma}$ and $1715 \mathrm{Ma}$ in the Black Hills, with most published sources tentatively embracing an equivocal $1840 \mathrm{Ma}$ date. Our late-syncollisional 1760-Ma gamet-staurolite pair indicates that either (1) the TransHudson orogeny was time-transgressive by 60-70 m.y. from Saskatchewan to the younger Black Hills locality $1300 \mathrm{~km}$ to the south; or (2) a younger, separate, Black Hills orogeny affected only the Dakotas region. Moreover, our 1760-Ma ages for east-west compression in the Black Hills coincide with a recently published age of a N-directed compressional event in adjacent southeastem Wyoming [1], which suggests a common tectonic evolution for the two terrains during Early Proterozoic time.

References: [1] Resor et al. (1996) Geology.

A COMPARISON OF THE ADSORPTION OF 2,4,6TRICHLOROPHENOL ONTO $\alpha-\mathrm{Al}_{2} \mathrm{O}_{3}$ AND BACILLUS SUBTILIS. C. J. Daughney ${ }^{1}$ and J. B. Fein ${ }^{2}$, 'Earth and Planetary Sciences, McGill University, 3450 University Street, Montréal PQ H3A 2A7, Canada, ${ }^{2}$ Civil Engineering and Geological Sciences, University of Notre Dame, Notre Dame IN 46556-0767, USA.

The mobility of 2,4,6-trichlorophenol (TCP) in groundwater is controlled, in part, by its adsorption onto soil mineral and bacterial surfaces. In this study, we use a thermodynamic framework to

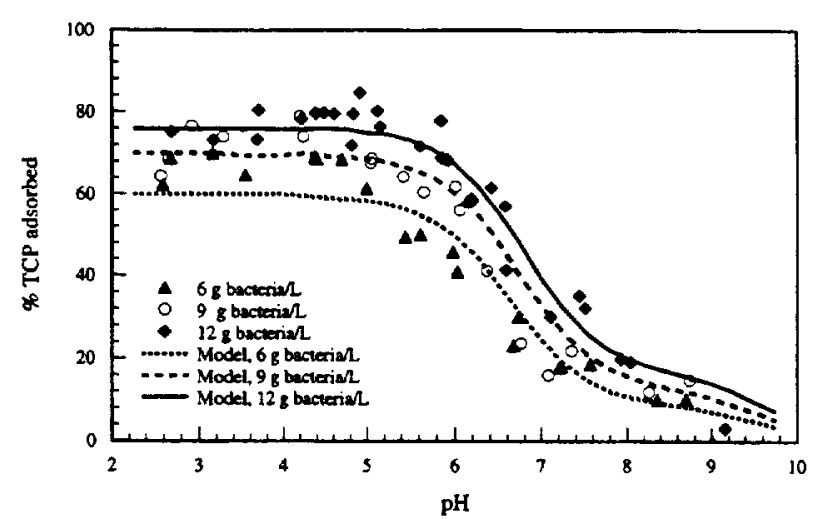

Fig. 1. Percent adsorption of TCP onto $B$. subtilis as a function of $\mathrm{pH}$. The solutions contain $10^{-4.0} \mathrm{M} \mathrm{TCP}, 10^{-1.0} \mathrm{M} \mathrm{NaNO}_{3}$, and either 6-, 9-, or 12-g bacteria/L. Model curves assume adsorption of both TCP- and $\mathrm{HTCP}^{\circ}$ onto neutral hydroxyl sites.

investigate the adsorption of TCP onto representative mineral ( $\alpha$ $\mathrm{Al}_{2} \mathrm{O}_{3}$ ) and bacterial (Bacillus subtilis) surfaces. We perform batch experiments as a function of both time and $\mathrm{pH}$ in order to determine stability constants describing the adsorption of both the negative and neutral forms of TCP onto specific functional groups present on the $\alpha-\mathrm{Al}_{2} \mathrm{O}_{3}$ and $B$. subtilis surfaces. Our experimental data indicate insignificant adsomtion of TCP to $\alpha-\mathrm{Al}_{2} \mathrm{O}_{3}$, but a strong pHdependent affinity between TCP and $B$. subtilis (see Fig. 1). The adsorption of TCP onto $B$. subtilis is best described by a model in which the negative form of TCP forms a 1:1 surface complex with the neutral hydroxyl functional groups of the bacteria

$$
\begin{gathered}
\mathrm{TCP}^{-}+\mathrm{R}-\mathrm{OH}^{0} \leftrightarrow\left(\mathrm{R}-\mathrm{OH}^{0}\right)\left(\mathrm{TCP}^{-}\right) \\
\log \mathrm{K}=2.48 \pm 0.25
\end{gathered}
$$

and the neutral form of TCP forms a 1:1 surface complex with either the neutral hydroxyl or phosphate surface functional groups

$$
\begin{gathered}
\mathrm{HTCP}^{0}+\mathrm{R}-\mathrm{OHO} \leftrightarrow\left(\mathrm{R}-\mathrm{OH}^{0}\right)\left(\mathrm{HTCP}^{0}\right) \\
\log \mathrm{K}=3.68 \pm 0.25 \\
\mathrm{HTCP}^{0}+\mathrm{R}-\mathrm{PO}_{4} \mathrm{H}^{0} \leftrightarrow\left(\mathrm{R}-\mathrm{PO}_{4} \mathrm{H}^{0}\right)\left(\mathrm{HTCP}^{0}\right) \\
\log \mathrm{K}=3.88 \pm 0.25
\end{gathered}
$$

The stability constants reported here may be readily incorporated into a thermodynamic model to predict the fate of TCP in complex natural systems.

RECONCILING GEOPHYSICAL AND GEOCHEMICAL CONSTRAINTS ON MANTLE RESERVOIRS AND MASS

FLUXES. G. F. Davies, Research School of Earth Sciences, Australian National University, Canberra ACT 0200, Australia (Geoff.Davies@anu.edu.au).

Inconsistencies between inferences from noble-gas isotopes on the one hand and refractory-trace-element (RTE) isotopes and geophysical constraints on the other indicate the continuing need for reexamination of assumptions.

RTE isotopes show that all mantle source types identified so far 
have been processed to some degree: No primitive mantle remains. Thus mass balances constraining the proportions of elements still in the mantle do not constrain the volumes of the strongly depleted (MORB source) mantle and less-depleted source(s), since concentrations in the latter cannot be assumed to be primitive. None of the mass balances strongly supports identifying the MORB source with the seismically defined upper mantle.

Suggestions of higher-than-primitive RTE concentrations in the plume source imply that its volume may be relatively small, as originally suggested by Hofmann and White. Indications of a substantial volume of mantle with only moderate depletion of RTEs have been plausibly interpreted as coming from the mid-mantle.

Recently resolved high ${ }^{40} \mathrm{Ar} / 36 \mathrm{Ar}$ ratios in OIBs indicate that the OIB (plume) source has been more strongly degassed than was previously assumed, while there are arguments [1] that the $\mathrm{He} / \mathrm{Ne}$ ratio of the MORB-source mantle is higher than in the plume source, which is not consistent with expectations from simple degassing models. All the above factors loosen the noble-gas constraints on the mass flux into the MORB source.

There is quite strong geophysical evidence for a substantial mass flux through the transition zone, of the order of the slab flux into the mantle. Seismic tomography provides snapshots, and recent results strongly suggest lithospheric slabs descending into the lower mantle in several locations [2]. Seafloor topography yields robust, global, longer-term constraints that require a substantial mass flux into the lower mantle within the past few hundred million years. The gravity field indicates both short-term penetration into the lower mantle and a long-term (200 Ma) correlation between surface subduction and lower mantle thermal structure.

There is also evidence from the gravity field and postglacial rebound that the lower mantle viscosity is relatively high. This suggests that the deeper mantle would be less processed and less well stirred, and therefore less depleted and more heterogeneous, implying both lateral and vertical gradational heterogeneity of trace elements in the deeper mantle. Gravitational settling and the persistence of high-viscosity blobs may enhance the stratification and heterogeneity. This geophysically inferred picture is broadly consistent with many features inferred from the geochemistry.

There are two main anomalies still requiring explanation. One is that there seems to be less ${ }^{40} \mathrm{Ar}$ in the mantle and atmosphere than would have been produced by the estimated ${ }^{40} \mathrm{~K}$ content of the Earth. The other is that there seem to be fewer heat sources $(K, U, T h)$ than required by the mantle's heat budget. Radical possibilities would be that the mantle-atmosphere system has lost $\mathrm{Ar}$, that the $\mathrm{K}$ content of the Earth is less than $200 \mu \mathrm{g} / \mathrm{g}$, that the mantle is far from thermal steady state, or that plumes do not reflect the heat coming from the core and deep mantle.

References: [1] Ozima and Honda (1996). [2] van der Hilst et al. (1996).

PROTEROZOIC GABBROIC INTRUSIONS FROM SOUTHEASTERN NORWAY: EVIDENCE FOR INTERACTION BETWEEN ASTHENOSPHERE AND METASOMATIZED LITHOSPHERICMANTLE. G. J. L. M. de Haas, Laboratorium for Isotopgeologi, Mineralogisk-Geologisk Museum, Sars'gate 1, 0562 Oslo, Norway.

One of the salient features of the Proterozoic Bamble Sector, southeastern Norway, is the occurrence of coronitic gabbro intrusions. Emplacement of the intrusions took place during both the Gothian (1.75-1.55 Ga) and Sveconorwegian ( $1.25-0.95 \mathrm{Ga}$ ) Orogenies. Their mineralogy is largely made up by plagioclase \pm olivine cumulates with clinopyroxene and ilmenite as intercumulus phases; some samples also contain cumulus orthopyroxene (Åmdal Gabbro).

The intrusions crystallized from relatively Fe-rich parental magmas $(\mathrm{Mg \#} \mathrm{<50).} \mathrm{The} \mathrm{range} \mathrm{in} \mathrm{Mg \#}$ values and the coherent trends for $\mathrm{Ni}, \mathrm{Sr}, \mathrm{TiO}_{2}$, and $\mathrm{Zr}$ indicate that all intrusions crystallized from grossly similar tholeiitic parental magmas with average $\mathrm{Ti} / \mathrm{Zr}$ and $\mathrm{Zr} / \mathrm{Y}$ ratios of 100 and 4 respectively. However, like many other continental tholeiitic rocks, $\mathrm{Ba} / \mathrm{Zr}, \mathrm{Zr} / \mathrm{La}, \mathrm{K} / \mathrm{Ba}$, and $(\mathrm{La} / \mathrm{Sm})_{N}$ ratios, as well as $\mathrm{Sr}$ and $\mathrm{Nd}$ isotopic compositions, are highly variable. Two groups of intrusions can be defined: (1) Enriched intrusions (Vestre Dale, Blengsvatn, and part of Jomåsknutene); samples from these intrusions have $\mathrm{Ba} / \mathrm{Zr}>1, \mathrm{~K} / \mathrm{Ba}<30,(\mathrm{La} / \mathrm{Sm})_{\mathrm{N}}$ between 1.1 and 1.8 , and $f_{S m}$ values less than $-0.10 ;{ }^{87} \mathrm{Sr} /{ }^{86} \mathrm{Sr}$ ratios and $\varepsilon_{\mathrm{Nd}}$ values at $1.2 \mathrm{Ga}$ range between 0.7030 and 0.7032 and between 1.7 and 3.4 respectively. (2) Less-enriched intrusions (Tromøy, Arendal, Åmdal, and part of Jomåsknutene); samples from these intrusions have $\mathrm{Ba} / \mathrm{Zr}<1, \mathrm{~K} / \mathrm{Ba}>30$, and $(\mathrm{La} / \mathrm{Sm})_{\mathrm{N}}$ between 0.7 and 1.1 , and $f_{S m}$ values greater than -0.10 ; most ${ }^{87} \mathrm{Sr} /$ ${ }^{86} \mathrm{Sr}$ ratios and $\varepsilon_{\mathrm{Nd}}$ values at $1.2 \mathrm{Ga}$ range between 0.7023 and 0.7027 and between 4.5 and 6.1 respectively.

The enriched composition of group 1 intrusions cannot be explained by crustal contamination, given the high amounts of crustal material required (20-30\%). The largely concurrent variation of the $\mathrm{Zr} / \mathrm{Nb}$ ratio argues against variable degrees of partial melting as a mechanism to explain the observed enrichments. Instead, it is proposed that the enrichments result from mixing between depleted, asthenosphere-derived magma with N-MORB-like composition and enriched melts extracted from metasomatic, phlogopiteapatite-bearing assemblages in the continental lithospheric mantle. Evidence for metasomatic processes in the Proterozoic lithospheric mantle is, among others, provided by the occurrence of Proterozoic ultrapotassic rocks in the Bamble Sector and adjacent terrains. Mixing between asthenospheric magmas with $0.5-5 \%$ of these enriched melts is required to explain the variations in trace-element chemistry observed among the intrusions.

Isotope data suggest the creation of two separate, enriched reservoirs for the intrusions. Mixing between asthenospheric magma and enriched melts during the Gothian Orogeny resulted in the creation of an enriched reservoir from which the group 1 intrusions have been derived during both Gothian and Sveconorwegian times. The second enriched reservoir, which acted as a source for the group 2 intrusions, was created by mixing processes during the Sveconorwegian Orogeny. The difference in trace-element chemistry and $\mathrm{f}_{\mathrm{Sm}_{\mathrm{m}}}$ between the group 1 and group 2 intrusions is attributed to differences in mineralogy, e.g., the amount of apatite, of the metasomatic assemblages. Variations within a group may similarly be ascribed to variations in their mineralogy and chemistry.

TRACE-ELEMENT DISTRIBUTIONS IN HAWAI'IAN SOILS: QUANTIFYING DUST INPUT AND WEATHERING LOSSES. L. A. Derry', M. J. Alfano', A. C. Kurtz', and O. A. Chadwick', 'Department of Geological Sciences, Comell University, Ithaca NY 14853, USA (derry@geology.comell.edu), 
2Department of Geology, Hartwick College, Oneonta NY, USA, ${ }^{3}$ Department of Geography, University of California-Santa Barbara, Santa Barbara CA, USA.

Introduction: Hawai'ian soils contain a mixture of material derived from in situ weathering and atmospheric inputs, including sea-salt aerosols and Asian dust. Mineralogical (XRD) analyses have shown that the dust component can be significant in some soil horizons [1]. Quartz and clay minerals introduced as dust are also susceptible to weathering, and their current abundance is not necessarily a quantitative measure of the integrated dust flux a soil profile has received.

We have sampled an established soil chronosequence on the Hawai'ian Islands, developed on basalt substrates ranging in age from $0.3 \mathrm{k} . y$. to $4.1 \mathrm{~m}$.y. All sites are located near $1200 \mathrm{~m}$ elevation, receive approximately $250 \mathrm{~cm} / \mathrm{yr}$ rainfall, and are dominated by the same tree species. Degree of soil development differs substantially across the age gradient. Secondary mineralogy of intermediate-aged soils is dominated by noncrystalline aluminosilicate "gels." Halloysite and $\mathrm{Fe}$-sesquioxides become increasingly important secondary minerals as weathering proceeds.

REE Patterns: Trace-element abundances were determined by ICP-MS on whole-soil digests. Chondrite-normalized REE patterns of soils at young sites resemble the underlying basalt flows, with $(\mathrm{La} / \mathrm{Yb})_{\mathrm{N}} \approx 5$, and $\mathrm{Eu} / \mathrm{Eu}^{*} \geq 1$. With increasing age, REE concentrations and $(\mathrm{La} / \mathrm{Yb})_{N}$ ratios tend to increase. Lanthanum rises from $\approx 10 \mathrm{ppm}$ at the young sites to as much as $260 \mathrm{ppm}$ at the oldest $\left(4.1 \mathrm{k.y}\right.$.) site. $(\mathrm{La} / \mathrm{Yb})_{\mathrm{N}}$ rises to $\approx 80$. These variations appear to reflect (1) residual enrichment during loss of more mobile major elements, and (2) preferential weathering loss of heavy REE relative to light REE. The evolution of the REE pattems varies significantly with depth in the soils. Some horizons at older sites have steep $(\mathrm{La} / \mathrm{Sm})_{N}$ and flat $(\mathrm{Sm} / \mathrm{Yb})_{N}$, with pronounced negative $\mathrm{Eu}$ anomalies. Some of these horizons also contain abundant ( $>30 \%$ ) quart $z$ and mica. The REE data demonstrate the addition of significant quantities of dust even in soil horizons that no longer have large quantitities of allocthonous minerals.

The introduction of dust can contribute significantly to the REE budgets of Hawai'ian soils, as well as for other elements. Because

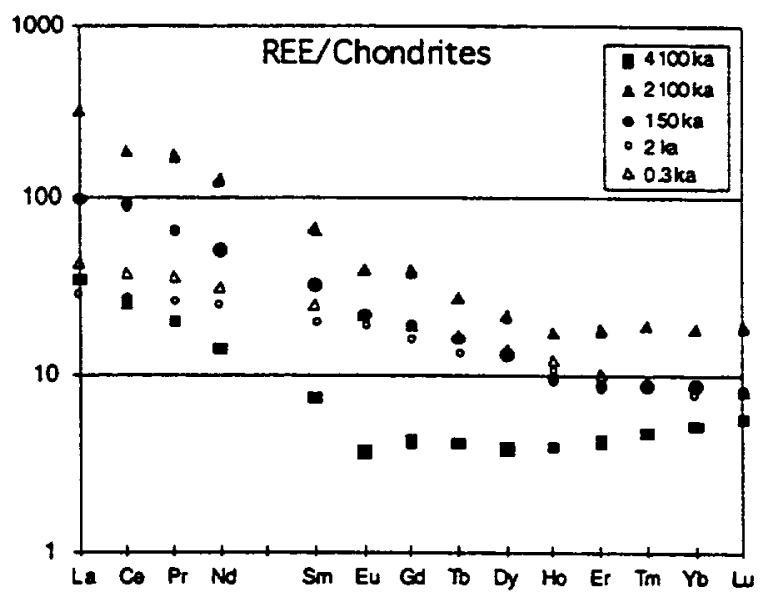

Fig. 1. REE pattems for Hawai'ian soils as a function of substrate age at depths of $5-30 \mathrm{~cm}$. Patterns from other depths vary considerably.
REE reside in different mineral phases in dust and basalt, weathering losses from each component may not be equal. Neodymium isotopic analysis is currently in progress to quantify dust components in the soil REE budget.

Other trace elements show similar behavior. "Conservative" trace elements such as $\mathrm{Zr}$ are enriched by a factor of 10 or more in old, heavily weathered soils. Element mobility can be modeled using "conservative" elements as normalizing species, but the fraction of dust-derived material must be assessed. The influx of dust may be very important for the soil budgets of soluble elements in older soils.

References: [1] Dymond J.et al. (1974) GSA Bull., 74, 37-40.

THE POTENTIOMETRIC DETERMINATION OF STA-
BILITY CONSTANTS FOR LANTHANUM ACETATE
COMPLEXES IN AQUEOUS SOLUTIONS TO $85^{\circ} \mathrm{C}$. R. Ding and S. A. Wood, Department of Geology and Geological Engineering, University of Idaho, Moscow ID 83844-3022, USA.

The behavior and mobility of the rare earth elements (REE) in aqueous solution is of considerable interest to economic geologists and aqueous geochemists. In particular, REE-acetate complexes may be important species in sedimentary basinal brines and in mixed organic-nuclear waste sites. Although the stability constants of REE-acetate complexes have been measured in a number of previous studies [e.g., 1-5], the temperature and ionic strength dependence of these complexes are not well known [6]. In this study, a potentiometric method is being used to determine the formation quotients of $\mathrm{La}$ acetate complexes in aqueous solutions from $0^{\circ}$ to $85^{\circ} \mathrm{C}$ at ionic strengths of $0.1,0.2,1.0$, and $2.0 \mathrm{~mol} / \mathrm{kg}^{-1}$. Sodium chloride is used as a supporting electrolyte. Experiments are conducted in $1000-\mathrm{mL}$ jacketed glass reaction vessels. The temperature is controlled by circulation of thermostatted water or ethylene glycol through the jacket and maintained to within $\pm 0.05^{\circ} \mathrm{C}$. Hydrogen ion concentrations were measured using a glass electrode, carefully standardized prior to each titration at the temperature and ionic strength of the run. The formation constants were calculated from the titration data using the program "BEST" [7]. At an acetate concentration of $0.02 \mathrm{~m}$ and a La concentration of $0.005 \mathrm{~m}$, only the first complex, LaAc ${ }^{2+}$, could be resolved. The stability constants obtained thus far $(0.1$ molal $\mathrm{NaCl})$ are given in Table 1 .

Our results at $25^{\circ} \mathrm{C}$ and ionic strength of $0.1 \mathrm{~m}$ agree very well with the data from previous work in $\mathrm{NaClO}_{4}$ medium $[1,2]$, which suggests that chloride complexation of $\mathrm{La}^{3+}$ is weak. However, there is no information in the literature at temperatures above $25^{\circ} \mathrm{C}$. Our results so far show that the stability constants for $\mathrm{La}$ acetate complexes have a weak temperature dependence.

TABLE 1.

\begin{tabular}{lccc}
\hline \hline Temp. & $25^{\circ} \mathrm{C}$ & $30^{\circ} \mathrm{C}$ & $40^{\circ} \mathrm{C}$ \\
\hline $\log \beta_{1}$ & $1.95 \pm 0.065$ & $2.15 \pm 0.01$ & $2.12 \pm 0.045$ \\
\hline Temp. & $50^{\circ} \mathrm{C}$ & $60^{\circ} \mathrm{C}$ & $70^{\circ} \mathrm{C}$ \\
\hline $\log \beta_{1}$ & $2.23 \pm 0.043$ & $2.27 \pm 0.03$ & $2.38 \pm 0.054$ \\
\hline \hline
\end{tabular}


References: [1] Kolat R. S. and Powell J. E. (1962) Inorg. Chem., 1, 293. [2] Kovar L. E. and Powell J. E. (1966) Report TID. 4500, Ames Laboratory, Iowa State University, 54 pp. [3] Grenthe I. (1962) Acta Chem. Scand., 16, 1695. [4] Archer D. W. and Monk C. B. (1964) J. Chem. Sac. (A), J964, 3117 . [5] Choppin G. R. and Schneider J. K. (1970) J. Inorg. Nucl. Chem., 32, 3283. [6] Wood S. A. (1993)J. Geol. Eng., 34, 229. [7] Martell A. E. and Motekaitis R. J. (1992) Determination and Use of Stability Constants, 2nd edition, VCH, New York.

NOBLE-GAS ISOTOPES IN TERTIARY BASALTS OF THE SOUTHWESTERN UNITED STATES. A. Dodson, D. J. DePaolo, and B. M. Kennedy, Berkeley Center for Isotope Geochemistry, Earth Sciences Division, E. O. Lawrence Berkeley National Laboratory, Berkeley CA 94720, USA.

Variations in the noble gas isotopic compositions of continental basalts may be caused by long-lived heterogeneities within the lithosphere, or by metasomatism and asthenospheric advection accompanying extensional tectonics. We are studying a suite of basalts from the western U.S. erupted over the last 15 m.y., to determine the magnitude of isotopic variations and whether there are spatial and temporal patterns that provide clues about the processes operating at depth. Twenty lavas have been analyzed for $\mathrm{He}, \mathrm{Ne}$, and $\mathrm{Ar}$ isotopic compositions, and additional analyses are in progress.

Basin and Range basalts have ${ }^{3} \mathrm{He} /{ }^{4} \mathrm{He}$ ratios between 3.0 and $6.5 \mathrm{R}_{\mathrm{a}}\left(1 \mathrm{R}_{\mathrm{a}}=\right.$ the value in air, $\left.1.4 \times 10^{-6}\right)$. There is reasonable correlation between ${ }^{3} \mathrm{He} / 4 \mathrm{He},{ }^{87} \mathrm{Sr} /{ }^{86} \mathrm{Sr}$, and $\varepsilon_{\mathrm{Nd}}$, and there is evidence of temporal trends as well. The earliest erupted basalts possess the lowest ${ }^{3} \mathrm{He}^{/ 4} \mathrm{He}\left(4-4.5 \mathrm{R}_{\mathrm{a}}\right)$ and $\varepsilon_{\mathrm{Nd}}(-6$ to -11$)$ and the highest ${ }^{87} \mathrm{Sr} /{ }^{86} \mathrm{Sr}(>0.706)$. These basalts also have high $\mathrm{La} / \mathrm{Nb}$, and consequently we infer that they are derived from the lithosphere. Later erupted basalts have higher ${ }^{3} \mathrm{He} /{ }^{4} \mathrm{He}$ and $\varepsilon_{\mathrm{Nd}}$ and lower ${ }^{87} \mathrm{Sr} /$ ${ }^{86} \mathrm{Sr}$ and $\mathrm{La} / \mathrm{Nb}$, indicating increasing proportions of asthenospheric mantle in the magma sources. The He-Nd correlation is in the same sense as that reported by Reid and Graham [1] for a smaller set of samples, but we have evidence of a lithospheric end member with a substantially lower ${ }^{3} \mathrm{He} /{ }^{4} \mathrm{He}$. Some samples deviate from a single mixing trend in that they have much lower ${ }^{3} \mathrm{He} /{ }^{4} \mathrm{He}$ in comparison to $\varepsilon_{\mathrm{Nd}}$. While there is much scatter in the $\mathrm{Ne}$ isotopic data, the $\mathrm{Ne}$ in these samples is consistently dominated by air, with lesser contributions of a MORB-like component. The data from the Basin and Range basalts suggest that magma sources evolve temporally during extension from lithosphere-dominated to asthenosphere-dominated, and that $\mathrm{He}$ is coupled with $\mathrm{Nd}$ and $\mathrm{Sr}$ such that there is little indication of fluid metasomatism of the lithosphere.

For basalts from the Colorado Plateau in southwestern Utah, where little crustal extension has taken place and variations in ${ }^{87} \mathrm{Sr} /$ ${ }^{86} \mathrm{Sr}$ and $\varepsilon_{\mathrm{Nd}}$ do not correlate well, there is still a relatively good correlation between ${ }^{3} \mathrm{He} /{ }^{4} \mathrm{He}$ and $\varepsilon_{\mathrm{Nd}}$, and $\mathrm{R} / \mathrm{R}_{\mathrm{a}}$ is in the range 4.7 to 6.4 . These basalts also have elevated ${ }^{40} \mathrm{Ar} / 36 \mathrm{Ar}$ isotopic ratios compared to the majority of other lavas; Ne isotopic ratios are similar to MORB but somewhat elevated in ${ }^{21} \mathrm{Ne}$. We interpret the isotopic variations in the Plateau lavas as arising from long-lived heterogeneities in the lithosphere or by metasomatic modification of the lithosphere by asthenosphere-derived melt or fluid enriched in $\mathrm{He}$ relative to $\mathrm{Nd}$ and $\mathrm{Sr}$.

Significant spatial variation in He isotopes has been detected in basalts from the Long Valley-Mono Lake area of eastem California Post-Bishop Tuff basalts enupted in the caldera moat lie along the main He-Nd trend $\left(R / R_{a}=5.8\right)$. Basalts from Owens Valley, Red Cone (southwest of the caldera), and other basalts erupted west of the edge of the Precambrian craton all conform reasonably well to the He-Nd correlation trend. In contrast, lavas from north of the caldera (June Lake and Black Point) have more radiogenic He (4.5$5.2 R_{a}$ ) as well as high K/P. These latter $H e$ ratios may reflect magma aging or incorporation of crustal He by assimilation.

References: [1] Reid and Graham (1996).

\section{PLUMBOTECTONICS OF ROCKS IN THE MINNESOTA RIVER VALLEY. B. R. Doe, 5508 Heming Avenue, Springfield VA 22151-3220, USA (71203.45@compuserve.com).}

The Minnesota River Valley has long been known to contain some of the oldest rocks in the world. The age of formation of the oldest gneisses has some uncertainty, but the oldest ${ }^{207 \mathrm{~Pb} / 206 \mathrm{~Pb}}$ zircon age has been given at $3384 \mathrm{Ma}$ by Goldich and Fisher in 1986, who determined a concordia age of $3662 \pm 42 \mathrm{Ma}$. A major thermal episode occurred at $2600 \mathrm{Ma}$ accompanied by intrusion of the mesozonal Sacred Heart Granite. Sparse intrusion of epizonal granite occurred at 1800 m.y. (e.g., granite of section 28), unaccompanied by metamorphism. The youngest age recorded is a fission track age of $460 \mathrm{Ma}$ made by $\mathrm{C}$. Naeser, perhaps representing the age of unloading of the rock section when the temperature fell below $100^{\circ} \mathrm{C}$ with accompanying dilatancy.

Two characteristics of cratonized crust outlined by Doe and Zartman [1] are that Cenozoic epizonal igneous rocks generally have

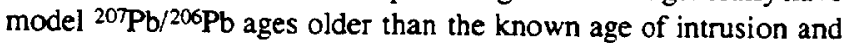
${ }^{208} \mathrm{~Pb} /{ }^{204} \mathrm{~Pb}$ vs. ${ }^{206} \mathrm{~Pb} / 204 \mathrm{~Pb}$ characteristics indicating a $\mathrm{Th} / \mathrm{U}$ value $>4$. In testing this finding on the granite of section 28 , the two criteria were found by Doe and Delevaux [2] to not only apply to this granite (model age of $1840 \mathrm{Ma}, \mathrm{Th} / \mathrm{U}$ of 7.3 ) but to the older Sacred Heart granite (model age of $2780 \mathrm{Ma}$, Th/ $\mathrm{U}$ of 8.0 ) as well. In addition. both granites also plot above the $\mathrm{Pb}$ isotope growth curve of Stacey and Kramers (S\&K) for ${ }^{207 \mathrm{~Pb} / 204} \mathrm{~Pb}$ vs. ${ }^{206} \mathrm{~Pb} / 204 \mathrm{~Pb}$. The U-Th- $\mathrm{Pb}$ systematics of the granite of section 28 were found to be remarkably undisturbed, even by the dilatancy. They also fit in with the later study of the $\mathrm{Pb}$ isotope system on mafic rocks of similar age about $150 \mathrm{~km}$ to the northeast in the St. Cloud area, for which Horan et al. in 1987 suggested a southward-dipping subduction zone at $1800 \mathrm{Ma}$ under the Archean gneisses.

The epizonal and mesozonal granites have penetrated an old gneiss complex of the Montevideo and Morton gneisses. The gneisses are informally separated into gray-foliated and red-massive phases. As with the younger granites, all uranogenic $\mathrm{Pb}$ isotope data on the gneisses have $\mathrm{Pb}$ isotope ratios that plot above the $\mathrm{Pb}$ isotope growth curve of S\&K. There is considerable scatter in the ratios; however, a trailing "isochron" for present-day ratios of feldspars and whole rocks extends from 13.25 to 16.880 and 14.65 to 16.444 for ${ }^{206} \mathrm{~Pb} /$ ${ }^{204} \mathrm{~Pb}$ and ${ }^{207} \mathrm{~Pb} /{ }^{204} \mathrm{~Pb}$ respectively, for a slope of 0.496 that does not intersect the S\&K growth curve. Using the $S \& K$ model $\mathrm{Pb}$ age of $2750 \mathrm{Ma}$, a "parent age" of $2950 \mathrm{Ma}$ is obtained. The trailing edge "isochron" for feldspars corrected for $2770 \mathrm{Ma}$ of radioactive decay for in situ U is 0.510 , yielding a "parent age" of $3020 \mathrm{Ma}$. Using the age of the known thermal event and the Sacred Heart granite, whose feldspar $\mathrm{Pb}$ isotopes nearly lies on the trailing edge "isochron," 
increases the "parent age" by $\sim 120$ m.y. An analysis of the cause of this "isochron" is similar to that given previously for the granites by Doe and Delevaux [2]. Starting with the $S \& \mathrm{~K}$ values for ${ }^{206} \mathrm{~Pb} /{ }^{204} \mathrm{~Pb}$

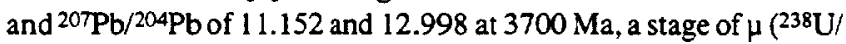
${ }^{204} \mathrm{~Pb}$ ) greater than 9.74 must have existed from $3700 \mathrm{Ma}$ (and similar to the age of the Morton gneiss) to about $3100 \mathrm{Ma}$ followed by a stage of reduced $\mu$. In their example, the high- $\mu$ stage might have had a value of 14.5 and the low- $\mu$ stage a value of about 5.65 . Variations in the low- $\mu$ stage are needed to explain the gneisses. Although most $\mathrm{Pb}$ isotope data indicate values of $\mathrm{Th} / \mathrm{U}>4$ (i.e., $7-$ 8), some samples have lower values (e.g., 2).

References: [1] Doe B. R. and Zartman R. E. (1979) in Geochemistry of Hydrothermal Ore Deposits, 2nd edition (H. Barnes, ed.), pp. 22-70, Wiley Interscience, New York. [2] Doe B. R. and Delevaux M. H. (1980) GSA Spec. Paper 182, pp. 105-1 12.

DATING OF MULTIPLE PROTEROZOIC THERMAL EVENTS BY SHRIMP URANIUM/LEAD GEOCHRONO. LOGY AT BROKEN HILL, NEW SOUTH WALES, AUSTRALIA. A. G. Donaghy', K. Ehlers' ${ }^{1}$, G. M. Gibson ${ }^{2}$, D. W. Maidment ${ }^{2}$, A. P. Nutman ${ }^{3}$, and C. J. Venn', 'Australian Crustal Research Centre, VIEPS, Department of Earth Sciences, Monash University, Wellington Drive, Clayton, VIC 3168, Australia, ${ }^{2}$ Australian Geological Survey Organization, Canberra, ACT 2601, Australia, ${ }^{3}$ Research School of Earth Sciences, Australian National University, Canberra, ACT 0200, Australia.

Sensitive High-Resolution Ion MicroProbe (SHRIMP) U/Pb geochronology of zircons and monazites has resolved at least six Proterozoic high-grade thermal events in the Palaeoproterozoic Willyama Supergroup of Broken Hill: pre-1690 Ma, 1690-1680 $\mathrm{Ma}, 1660-1640 \mathrm{Ma}, 1600-1570 \mathrm{Ma}, 1500-1460 \mathrm{Ma}$, and $1250 \mathrm{Ma}$. The first four resolved thermal events had been previously described as one continuous thermal event spanning from ca. $1660 \mathrm{Ma}$ to $\sim 1500 \mathrm{Ma}$. The 1250-Ma event is the first indication from zircon geochronology of Grenvillean age activity within southeast Australia. The extensive and systematic use of SHRIMP geochronology has led to a reevaluation of a large portion of the local stratigraphy and structure and provides valuable insights to possible thermal energy sources for deformation in a high-temperature, low-pressure metamorphic regime.

The Willyama Supergroup, host of the giant $300 \mathrm{Mt}$ Broken Hill $\mathrm{Pb}-\mathrm{Zn}$-Ag ore body, has previously been interpreted as a polydeformed "layer-cake" sequence of Proterozoic supracrustal sediments and bimodal volcanics, up to $7 \mathrm{~km}$ [1], deposited in a high heat-flow basin at $1690 \mathrm{Ma}$ [2]. The interpreted stratigraphy relies heavily on felsic and mafic gneiss marker horizons being extrusive in origin and discounts the possibility of intrusive relationships. Deformation occurred during high-temperature, low-pressure regional metamorphism $\left(500^{\circ}-800^{\circ} \mathrm{C}, 3-6 \mathrm{kbar}\right.$ [3]). The metamorphism has been interpreted as a continuous process, named the Olarian Orogeny, consisting of a prograde amphibolite assemblage, attaining granulite facies at $\sim 1600 \mathrm{Ma}$ and overprinted by an amphibolite to greenschist facies retrograde assemblage terminating at ca. $1500 \mathrm{Ma}$ [4].

The earliest dated thermal event consists of major widespread intrusion of felsic granitoids, synchronous with widespread mafic intrusions at 1690-1680 Ma. An undated, pre-1690 Ma thermal event is inferred from mylonitized partial melts of $\mathrm{Na}$-metasomatized metasediments crosscut by mafic dykes of the 1690-1680-Ma generation. The 1660-1640-Ma thermal event is characterized by widespread partial melt segregations and minor granitic intrusions. The 1600-1570-Ma thermal event is characterized by widespread leucocratic granitoid intrusion, mafic intrusions, partial melting, and widespread growth of metamorphic zircons. The 1500-1460-Ma thermal event is characterized by granitic intrusions and sporadic growth of metamorphic zircons. The 1250-Ma (Grenvillean) thermal event is characterized by in situ remelting of leucocratic granitoids and metasedimentary units.

One of the key problems in documenting high-temperature, lowpressure metamorphism in Broken Hill has been identifying a suitable heat engine within the middle crust. The identification of multiple granitic and mafic intrusive events may provide a suitable source of heat. The 1660-1640-Ma and 1600-1570-Ma thermal events reached metamorphic grades of upper amphibolite to granulite facies with temperatures of $650^{\circ}-800^{\circ} \mathrm{C}$ and pressures of 4$6 \mathrm{kbar}$. Such P-T conditions are unlikely to be caused by a conductive thermal regime, but require additional advective heat input in the middle crust. Such a heat input may be provided by the mafic intrusions that have been associated with the thermal events. Mafic intrusions may also be responsible for granite generation within the crust. However, age resolution is not yet accurate enough to enable us to see if mafic intrusions predate granite intrusions within the same thermal event. Further analyses will improve the resolution of the dataset.

References: [1] Willis I. L. et al. (1983) J. Geol. Soc. Australia, 30, 195-224. [2] Page R. W. and Laing W. P. (1992) Econ. Geol., 87, 2138-2168. [3] Phillips G. N. (1980) Contrib. Mineral. Petrol., 75, 377-386. [4] Hobbs B. E. et al. (1984) in Precambrian Tectonics Illustrated (A. Kroner and R. Greiling, eds.), pp. 353368, Stuttgart E. Schweiz Verlag.

\section{MODELING WETLAND CHEMASTRY USING ENDMEM-} BER MIXING ANALYSIS CONSTRAINED BY ISOTOPIC DATA. R. J. Donahoe, Department of Geology, The University of Alabama, Tuscaloosa AL 35487-0338, USA (rdonahoe@wgs.geo. ua.edu).

Endmember mixing analysis (EMMA) has been used previously to successfully model stream water chemistry as a mixture of endmember soil water types and to estimate the hydrologic contribution to the stream from each end member. In this study, EMMA has been applied to a freshwater wetland located in north-central Alabama, to better understand the chemical and hydrologic contributions from the various possible endmember solute sources. The data utilized in the model include chemical analyses of monthly rainwater, surface-water, soil-water, and groundwater samples collected over a two-year period, as well as $\delta^{18} \mathrm{O}$ and $\delta \mathrm{D}$ data for samples collected in July 1994.

Using the stable isotope dataset as the basis for conservative solute behavior, EMMA successfully predicts the isotopic compositions of wetland surface water and groundwater as binary mixtures of soil water and rainwater. In contrast, endmember mixing diagrams indicate that (1) very few solutes behave conservatively in the wetland system and/or (2) an end member is incorrectly characterized, or missing. Of the major solutes, only $\mathrm{Ca}$ and Alk behave conservatively, with all surface-water and groundwater compositions explained as mixtures of soil water and rainwater. While 
chloride, silicon, and $\mathrm{Mg}$ behave somewhat conservatively in the wetland system, some surface-water compositions cannot be adequately explained as mixtures of the observed end members. Groundwater chemistry can generally be modeled as mixtures of rainwater and deeper soil-water end members, even for solutes that appear to behave nonconservatively in the surface-water system.

Sulfate, $\mathrm{Fe}$, and $\mathrm{K}$ demonstrate highly nonconservative behavior, which is consistent with their known involvement in biogeochemi$\mathrm{cal}$ processes. The strongest nonconservative behavior for these solutes is seen in surface water, where most of the samples were collected from a $13,000-\mathrm{m}^{2}$ wetland pond that is chemically and biologically zoned. In addition, soil-water $\mathrm{Na}$ concentrations are up to 2 orders of magnitude higher than levels measured in surfacewater and groundwater samples.

These results indicate that leaf-litter runoff may be an important source of $\mathrm{K}$ as well as some $\mathrm{Mg}$ and $\mathrm{Si}$, and should be included as an end member in the mixing model. Bacterial processes taking place near the surface-water/sediment interface in the wetland pond concentrate $\mathrm{Fe}$ through dissimilatory reduction of ferrihydrite. Groundwater Fe concentrations are best explained as mixtures of high-Fe pore water and rainwater. Sulfate is also affected by microbial processes taking place in the pond and wetland sediment, which convert it to sulfide species. Saturation index calculations indicate that the deeper pore-water system is supersaturated with respect to Fe sulfide. Sodium may be concentrated in the upper soil profile by evaporative pumping and stored in the wetland biomass.

REEXAMINATION OF MANTLE TOPOLOGY IN ISOTOPIC MULTISPACE. R. Doucelance, C. J. Allègre, and E. Lewin, Laboratoire de Géochimie et Cosmochimie, Institut de Physique du Globe de Paris, URA CNRS D 1758, UER des Sciences de la Terre, Université Paris 7 Denis Diderot, 4, place Jussieu, 75252 Paris Cedex 05, France.

Past studies of isotopic mantle topology have considered midoceanic ridge basalts (MORB) and oceanic island basalts (OIB). These were based on multi-isotope tracing $[1,2]$, which considers the geometric relationships of the chosen samples in the space constructed from the different measured isotopic ratios. A very good oceanic basalt database is now available in the literature, permitting us to reexamine the OIB data structure, considering the following new approach: (1) The data space is extended to eight dimensions: ${ }^{206} \mathrm{~Pb} / 204 \mathrm{~Pb},{ }^{207 \mathrm{~Pb} / 204} \mathrm{~Pb},{ }^{208} \mathrm{~Pb} /{ }^{204} \mathrm{~Pb},{ }^{87} \mathrm{Sr} /{ }^{86} \mathrm{Sr},{ }^{143} \mathrm{Nd} / 1{ }^{44} \mathrm{Nd},{ }^{176} \mathrm{Hf} /$ ${ }^{177} \mathrm{Hf},{ }^{187} \mathrm{Os} / 188 \mathrm{Os}$, and ${ }^{4} \mathrm{He} /{ }^{3} \mathrm{He}$ isotopic ratios; (2) we examine separately the available dataset for each island or archipelago, filter out those affected by local contamination by the asthenosphere, lithosphere, or crust, then estimate one or several isotopic compositions as being representative of that of the plume; (3) we weigh each hotspot by its mass flux according to Sleep [3], or alternatively by the total mass of the island; (4) we apply the multispace analysis as in Allègre et al. [2] on the new set of data thus obtained.

We now have a set of 10 archipelagos (Austral, Canary, Hawai' $i$, Iceland, Kerguelen, Réunion, St. Helena, Samoa, Society, Tuamotu) for which we can give isotopic composition in an eight-dimension space and for which the mass flux is known. The observed dispersion is contained for more than $80 \%$ of the total variance in a single plane. The graphic representation in this plane comprises three lobes, Kerguelen-Pitcaim, Loihi-Iceland, and Mangaia-St. Helena respectively, centered on the Réunion Island hotspot. This leads to two different possible interpretations. Either this suggests three components to explain the observed variation of the isotopic composition, and the Réunion hotspot would be the result of mixing between the three components, or we can postulate a new component, similar in isotopic composition to the Reunion Hotspot, and each lobe would represent a mixing trend.

Considering less than 8 isotopic dimensions allows us to take into account a larger number of islands $(\sim 30)$ and gives similar results: We again obtain a lobe diagram. This time the number of end members is equal to the four or five previously identified $[4,5]$ plus one, similar in isotopic composition to the Réunion-CrozetAmsterdam hotspot.

Application of the same technique at the scale of an island or archipelago also gives similar results, in the way we can obtain several components. This suggests two scales of mixing: local and global.

References: [1] Zindler et al. (1982) Nature, 298, 519-523. [2] Allègre et al. (1986) EPSL, 81, 319-337. [3] Sleep (1990) JGR, 95, 6715-6736. [4] Allègre and Turcotte (1985) GRL, 12, 207-210. [5] White (1985) Geology, 13, 115-118.

\section{UNRA VELING THE PHYSICAL BASIS OF BIOMINERAL} IZATION. P. M. Dove, H. H. Teng, and Y. J. Zhao, School of Earth and Atmospheric Sciences, Georgia Institute of Technology, Allanta GA 30332, USA (dove@eas.gatech.edu).

Recent biological and biochemical investigations have demonstrated the ability of many living organisms to control mineral crystallization through a biomineralization process involving selective application of macromolecules. These enable nucleation and growth of crystalline structures of carbonates, phosphates, oxides, silicates, and other inorganic materials. The polymorphs of $\mathrm{Ca}$ carbonate, calcite, vaterite, and aragonite, are ubiquitous biominerals that naturally occur in marine and freshwater organisms. Each of these polymorphs can nucleate and grow in the exoskeletons and tissues of organisms ranging from simple bacteria or algae to crus-

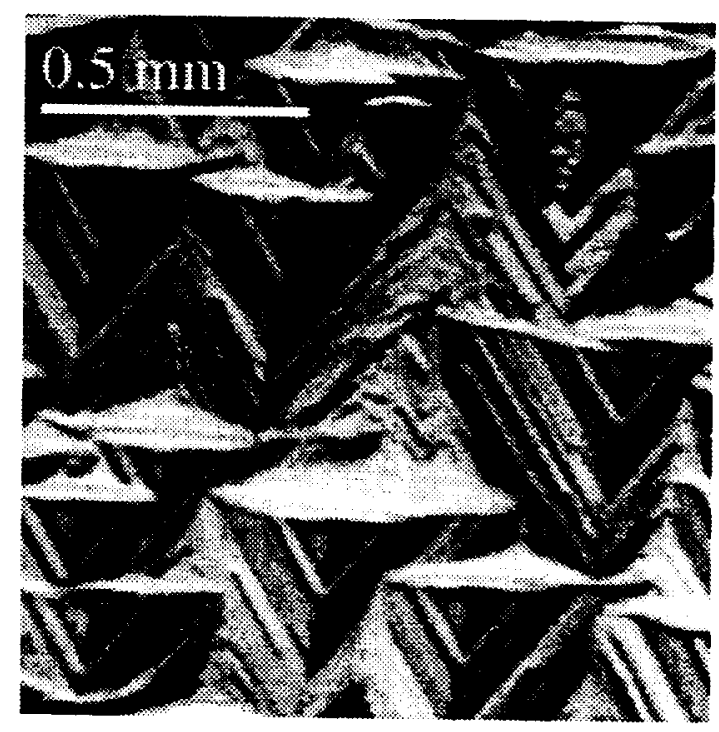

Fig. 1. 
taceans, mollusks, or sponges.

Naturally occurring matrix macromolecules involved in regulating biological growth of calcite are known to share a carboxylic-rich character that arises from an abundance of acidic amino acids, aspartate (Asp) and glutamate (Glu). Carbonates exposed to different polyamino acids are also known to exhibit different bulk growth morphologies. This and related evidence suggest that systematic relationships between crystal morphology and surface interactions with reactive groups of organic molecules must exist. However, the interplay between solution and surface chemistry and the physical processes of nucleation and crystal growth are unknown. Experimental evidence from biomineralization studies and our understanding of physical controls on crystallization lead us to hypothesize that $\mathrm{CaCO}_{3}$ biomineralization is successful because functional groups on proteins are able to provide preferential sites for nucleation by changing the surface free energies and are able to alter growth rates and surface morphologies by selectively binding to kink sites on $\mathrm{CaCO}_{3}$ surfaces.

This study investigates $\mathrm{CaCO}_{3}$ surface reactivity in the presence of organic macromolecules to investigate the physical basis of biomineralization. We examine interactions of Asp with calcite \{1014\} faces using in situ Fluid Cell Atomic Force Microscopy (AFM) and macroscopic ex situ optical methods. In control experiments, etch-pit morphologies produced by dissolution in simple undersaturated solutions reflect the inherent symmetry of $\{1014\}$ faces with a rhombus form. With Asp introduction, Teng and [1] find that surface site reactivities are modified to yield isosceles triangular etch pits and hillocks. With continued exposure to Asp-bearing solutions, these triangular pits coalesce and the surface evolves into a macroscopic network of interconnected tetrahedral etch hillocks shown below. The component tetrahedral "sides" have MillerBravais indices of $(0001),(1100)$, and (0110) which correspond to the $\{0001\}$ (basal) and $\{1100\}$ (prismatic) crystallographic calcite forms. These faces intersect the (1014) face in the [010], [431], and [501] directions to comprise the three edges of the triangular etch pits. Results of this dissolution study are consistent with previous growth experiments showing that Asp also causes preferential development of the $(1100),(0110)$ and $(0001)$ calcite crystallographic faces.

Our observations support mechanisms proposing that the new forms are stabilized by molecular recognition of Asp functional groups for specific surface sites. Because Asp stabilizes identical faces during growth and dissolution, we suggest that dissolution studies offer an alternative approach for predicting the crystal forms that can develop during biomineralizing processes and a more direct means of identifying those surface sites involved. In continuing work, we are investigating the effect of other amino acids on calcite surface structures. These were selected on the basis of chain length or functional group chemistry to probe the interaction mechanisms. Combining our experimental findings with molecular modeling of organic-calcite surface interactions, our goal is to construct a general model that can predict how organic compounds bind to carbonate surfaces and modify mineral surface reactivity.

References: [1] Teng and Dove (1997) Am. Mineral., in press.

NEODYMIUM, STRONTIUM, AND LEAD ISOTOPIC COMPOSITION OF LOWLAND CREEK VOLCANICS, WEST-CENTRAL MONTANA. F. Ö. Dudás and V. O. Ispo- latov, Geological Sciences Program, Old Dominion University, Norfolk VA 23529, USA (fod100f@giraffe.tech.odu.edu).

Absaroka, Challis, and Lowland Creek volcanics are the three largest, Eocene-aged, calc-alkaline volcanic fields of the northwestern U.S. Challis and alkaline Eocene igneous centers (Bearpaw, Highwood, and Crazy Mountains) have been studied in detail, and comparable work is underway on Absaroka and Lowland Creek. Lowland Creek is unique among these magmatic systems because it is dominated by rhyolitic and dacitic rocks that are arguably derived primarily from crustal sources, whereas mantle sources are clearly represented in the others. Argon-40/argon-39 dating indicates that Lowland Creek rocks span from 53 to $48 \mathrm{Ma}$, with early, voluminous pyroclastic activity $(5351 \mathrm{Ma})$ followed by predominantly effusive and intrusive magmatism. This time span requires prolonged heat input, presumably from the mantle. At $50 \mathrm{Ma}, \varepsilon_{\mathrm{Nd}}$ ranges from -16 to $-5,{ }^{87} \mathrm{Sr} /{ }^{86} \mathrm{Sr}$ is between 0.706 and 0.710 , and present-day ${ }^{206} \mathrm{~Pb} / 204 \mathrm{~Pb}$ varies from 16 to 19 . The large range of $\mathrm{Nd}$ and $\mathrm{Pb}$ compositions indicates that magmas derived from widely varying sources, whereas the limited range and low values of $\mathrm{Sr}$ compared to most old crustal materials indicate either Rb-poor crustal sources or a significant contribution from mantle. On Nd-Sr and $\mathrm{Nd}-\mathrm{Pb}$ correlation diagrams, the Lowland Creek data overlap the composition range of mantle-derived, Eocene alkaline rocks. Among the least-silicic, andesitic rocks of the Lowland Creek field, these isotopic ratios could reflect mantle compositions. Presently available isotopic data cannot distinguish crustal and mantle contributions. The Lowland Creek data also overlap compositions of late Cretaceous plutons (Boulder, Pioneer, and Idaho batholiths), indicating that Early Tertiary subduction did not contribute measurably to the source materials sampled by the Lowland Creek. Neodymium isotopic compositions are geographically zoned within the Lowland Creek field, with low values toward the southeast and higher values to the northwest. This isotopic change apparently maps the Proterozoic-Archean boundary in the subsurface.

STRATIFICATION OF $\mathbf{8}^{37} \mathrm{Cl}$ IN MIOCENE HALITE, CARPATHIAN MOUNTAINS: IMPLICATIONS FOR THE SOURCE OF CHLORIDE. C. J. Eastoe ${ }^{1}$ and T. Peryt ${ }^{2}$, 'Department of Geosciences, University of Arizona, Tucson AZ 85721, USA (eastoe@geo.arizona.edu), 2Panstwowy Instytut Geologiczny, Rakowiecka 4, 00-975 Warsawa, Poland (tper@ pgi.waw.pl).

Bedded evaporite of Badenian (middle Miocene) age occurs in the Forecarpathian and Transcarpathian Troughs. Sections at Chop (Transcarpathian Trough, Ukraine) and Wieliczka (Forecarpathian Trough, Poland) consist of halite with no potash facies. Values of $8^{37} \mathrm{Cl}$ range from -0.6 to $+0.8 \%$. There is one distinct interval of lower $\left(-0.2\right.$ to $0.0 \%$ ) $\delta^{37} \mathrm{Cl}$ values in each section, contrasting with higher values $\left(0.2-0.8 \%\right.$ ) elsewhere. The stratification of $\delta^{37} \mathrm{Cl}$ implies change in $\delta^{37} \mathrm{Cl}$ of the source brines, possibly because of (1) brine evolution within the troughs as a result of evaporation, (2) change in the $\delta^{37} \mathrm{Cl}$ of seawater supplied to the troughs, or (3) supply of brine with negative $\delta^{37} \mathrm{Cl}$ from some other source. At $25^{\circ} \mathrm{C}, \delta^{37} \mathrm{Cl}$ (halite-solution) is $0.24 \%$ [1]. Rayleigh fractionation in evaporating seawater produces halite with decreasing $\delta^{37} \mathrm{Cl}(+0.3$ to $-0.5 \%$ or less), and increasing $\mathrm{Br} / \mathrm{Cl}$ as the potash facies is approached. The 
positive $8^{37} \mathrm{Cl}$ values in most of the salt are consistent with halitefacies evaporation of seawater. In both the Chop and Wieliczka sections, the $\mathrm{Br} / \mathrm{Cl}$ range is also typical of the halite facies, and there is no systematic variation of $\mathrm{Br} / \mathrm{Cl}$ with $\delta^{37} \mathrm{Cl}$, suggesting that evaporation of a single batch of seawater is not the cause of the low $\delta^{37} \mathrm{Cl}$ values. Global changes of $8^{37} \mathrm{Cl}$ of seawater may occur if mantle-derived $\mathrm{Cl}$ differs from seawater in $\delta^{37} \mathrm{Cl}$, but the changes are slow; for fluxes given by Ito et al. [2], generation of the smallestmeasurable changes in $\delta^{37} \mathrm{Cl}$ of seawater would take $>10^{8} \mathrm{yr}$, precluding measurable change during the Miocene. Other sources of high-salinity, low- $\delta^{37} \mathrm{Cl}$ brine might include formation water expelled into the troughs, where the Badenian was a time of intense tectonic activity. Formation brines with low $\delta^{37} \mathrm{Cl}$ and low $\mathrm{Br} / \mathrm{Cl}$ are common in other basins, e.g., the Gulf Coast basin, where $8^{37} \mathrm{Cl}$ of formation brine ranges down to $-1.9 \%$, and the North Sea [1], where $8^{37} \mathrm{Cl}$ ranges down to $-4.3 \%$.

References: [1] Eggenkamp H.G. M. (1994) Geol. Ultraject., 116, 111-121. [2] Ito E. et al. (1983) GCA, 47, 1613-1624.

\section{FIXATION RATES OF CARBON DIOXIDE BY CHEMICAL WEATHERING IN THE CONTINENTAL ARC OF THE WESTERN AMERICAS, $1^{\circ} \mathrm{S}$ TO $70^{\circ} \mathrm{N}$. J. M. Edmond ${ }^{\prime}$ and Y. Huh' ${ }^{1.2}$, 'Department of Earth, Atmospheric and Planetary Sciences, Massachusetts Institute of Technology, E34-201, 42-44 Carleton Street, Cambridge MA 02139, USA (jedmond@mit.edu), ${ }^{2}$ Massachusetts Institute of Technology/Woods Hole Oceanographic Institute Joint Program in Oceanography, Cambridge MA 02139, USA (yhuh@mit.edu).}

Existing datasets from tributary streams draining the eastem slopes of the Andes in the watersheds of the Amazon and Orinoco and from the Canadian Rockies in the catchments of the Frazer, Yukon, and Mackenzie are used to search for a latitudinal climatic gradient in the consumption rate of atmospheric $\mathrm{CO}_{2}$ by the chemi$\mathrm{cal}$ weathering of aluminosilicate rocks. The environments in the various drainages vary from tropical to sub-Arctic. The dataset is very large ( $>450$ samples) and shows an enormous range (over 4 orders of magnitude) in concentrations and chemical signatures, reflecting the lithologic diversity of the rocks exposed in this continental arc.

Extraction of the rates of net uptake of $\mathrm{CO}_{2}$ is difficult because (1) bulk weathering yields are usually dominated by the dissolution of carbonates and evaporites; (2) at high latitudes the rivers are often impounded, leading to precipitation of Si by diatoms; and (3) anthropogenic inputs occur in populated areas, e.g., the Frazer. In pristine systems the consumption rate can be calculated as twice the dissolved Si flux. This is consistent with the global average estimates and with local studies on groundwater. In the presence of impoundments and pollution in aluminosilicate terrains the alkalinity flux can be used, provided the isotopic data for dissolved $\mathrm{Sr}$ negate the importance of carbonate weathering.

Using this approach it is found that the variability in the fluxes carried by tributaries draining a given arc segment is as great as that between segments. The outstanding exception is the Mackenzie, where the consumption rates for the eastern slope of the Rockies are found to be extremely low. In the Amazonian Andes the fluxes (expressed as thousands of moles $/ \mathrm{km}^{2} / \mathrm{yr}$ ) range from 220 to 550 , in the Eastern Andes of the Orinoco from 143 to 1000, in the Frazer from 128 to 1750, and in the Yukon headwaters 161. The Mackenzie values range from 19 in the drainage of the Peace to 30 in the Liard. This dramatic contrast between the eastem and western slopes of the Canadian Rockies is presumably controlled by lithology. This is clearly the case in the other arc segments.

From this preliminary survey no evidence is found for a climatic control on aluminosilicate weathering rates strong enough to dominate the effects of differences in lithology and the physical mechanisms of exposure.

MICROBIAL DISSOLUTION OF PYRITE: SURPRISING INSIGHTS FROM STUDIES USING ORGANISMS IN ENRICHMENT CULTURES FROM AN ACID-MINE DRAINAGE ENVIRONMENT. K. J. Edwards' ${ }^{1}$, M. O. Schrenk ${ }^{1}$. J. F. Banfield', and R. M. Goodman'2, 'Department of Geology and Geophysics, University of Wisconsin-Madison, Madison W153706, USA, 'Department of Plant Pathology, University of WisconsinMadison, Madison WI 53706, USA.

Acid-mine drainage (AMD) is an important problem of biogeochemical origin that results in serious environmental damage. Most geomicrobiological models for acid-mine drainage production have been based on studies carried out over a narrow range of conditions (typicaliy $30^{\circ} \mathrm{C}, \mathrm{pH} 2-3$ ) and involve only a few known chemolithotrophic species (Thiobacillus ferrooxidans and "Leptospirillum ferrooxidans"). However, conditions at AMD sites may be far more extreme. Temperatures $>50^{\circ} \mathrm{C}$ and $\mathrm{pH}$ values of 0.5 to -3.5 have been recorded at our Iron Mountain, California, study site. Mineral surfaces, pores in sediments, and solutions are probably colonized by distinct communities of microorganisms that may interact with mineral surfaces and dissolved species in complex ways to accelerate pyrite dissolution. Our work is designed to explore the physiologic and phylogenetic diversity of microorganisms in AMD environments, their role in oxidative pyrite dissolution, and their spatial distribution.

Here we report results of experiments on the dissolution and oxidation of pyrite by mixed cultures of microorganisms obtained from one location in the Richmond mine drift at Iron Mountain ( $T$ = $43^{\circ} \mathrm{C}, \mathrm{pH} 0.63$ ). Pyrite sediment provides the primary energy source. Two distinct consortia of organisms have been cultured using media differing only in the presence or absence of yeast extract in low concentrations. Cultures with yeast extract are composed of at least two morphologically distinct organisms, one that attaches firmly to pyrite surfaces and one that does not. Cultures without yeast extract are composed solely of organisms that have not been found to attach irreversibly to pyrite. Organisms that attach to pyrite surfaces and the organisms in cultures without yeast extract have been identified as belonging to Domain Bacteria using in situ hybridization with Domain-specific small subunit (SSU) ribosomal RNA (rRNA) oligonucleotide probes. The dominant nonattaching organism in cultures with yeast extract has been identified using an oligonucletide probe based on SSU rRNA sequence determined in our laboratories to be most closely related to the proposed genus "Leptospirillum." The predominance of the Leprospirillum-like bacteria in solution suggests their primary effect on pyrite dissolution is via the indirect mechanism involving oxidation of dissolved ferrous iron. Bacteria that attach to pyrite surfaces are rod shaped, and cell surface coverage ranges up to approximately $2.610^{5} \mathrm{cells} / \mathrm{cm}^{2}$. Genera-specific 
SSU rRNA probes indicate that these are neither $T$. ferrooxidans nor " $L$. ferrooxidans." Attachment is nonrandom, with alignment parallel to $\{100\}$. Site specificity for attachment is appears to be governed by several factors, including crystallographically controlled surface topography (growth steps), and noncrystallographic features such as scratches and grooves. Bacterial attachment results in euhedral dissolution pits. Pyrite incubated in the culture of nonattaching organisms has not been found to develop these selective dissolution features. Growth has been compared in two cultures using pyrite cubes of known weight, surface area, and composition. Results suggest that growth rates of the microorganisms and dissolution rates of pyrite are depressed in cultures of nonattaching bacteria compared to rates in cultures of attaching bacteria.

\section{COMPARISON OF CHLORINE AND BROMINE ISOTOPE} FRACTIONATION IN DIFFUSION: GEOCHEMICAL CONSEQUENCES. H. G. M. Eggenkamp and M. L. Coleman, Postgraduate Research Institute for Sedimentology, The University of Reading, P.O. Box 227, Whiteknights, Reading RG6 6AB, UK (H.G.M.Eggenkamp@reading.ac.uk; M.L.Coleman@reading.ac.uk).

Experimental aqueous diffusion of $\mathrm{NaCl}$ and $\mathrm{NaBr}$ has been conducted in polyacrylamide gel ( $85 \%$ porosity) to enable the comparison of diffusion coefficients and isotope fractionation of $\mathrm{Cl}$ and Br. Both of these halogens have two stable isotopes, of which, as expected, the lighter isotopes $\left({ }^{35} \mathrm{Cl},{ }^{79} \mathrm{Br}\right)$ move faster than the heavier isotopes $\left({ }^{37} \mathrm{Cl},{ }^{81} \mathrm{Br}\right)$ during diffusional transport. Isotope fractionation is related to the relative mass differences of the isotopes, so a smaller fractionation is expected for $\mathrm{Br}$ than for $\mathrm{Cl}$.

The experiments were conducted in glass tubing with 16-mm ID after a method developed by Schreiner et al. [1]. A polyacrylamide gel was prepared according to Davison et al. [2] and poured into the tubing, filling an $\sim 20-\mathrm{cm}$ length. After setting, another gel was prepared that contained $\mathrm{NaCl}$ or $\mathrm{NaBr}$ solution; this second gel was poured on top of the set gel. From that moment the $\mathrm{Cl}$ or $\mathrm{Br}$ could diffuse into the first gel. After an appropriate time the glass was broken, and the gel sliced. The gel slices were equilibrated with water, $\mathrm{Cl}$ or $\mathrm{Br}$ concentration determined by colorimetry, arîै $8^{37} \mathrm{Cl}$ and $\delta^{81} \mathrm{Br}$ determined using conventional mass spectrometry of $\mathrm{CH}_{3} \mathrm{Cl}$ or [3]. The diffusion coefficient and isotope fractionation were calculated from the $\mathrm{Cl}$ or $\mathrm{Br}$ concentrations and isotopic compositions of the samples.

The diffusion coefficients of aqueous $\mathrm{Cl}$ and $\mathrm{Br}$ are similar at specific temperatures but are highly temperature dependent, giving $\mathrm{D}_{\mathrm{C}}$ of $12 \times 10^{-10} \mathrm{~m}^{2} \mathrm{~s}^{-1}$ at $22^{\circ} \mathrm{C}$, and $6.5 \times 10^{-10} \mathrm{~m}^{2} \mathrm{~s}^{-1}$ at $2^{\circ} \mathrm{C}$. The isotope fractionation is less temperature dependent. However, for $\mathrm{Br}$ it is approximately half that of $\mathrm{Cl}$, giving an $\alpha$ of 1.0008 for $\mathrm{Br}$ and 1.0015 for $\mathrm{Cl}$, both at $22^{\circ} \mathrm{C}$.

Our results so far agree perfectly with expected isotope fractionation in the halogens. An isotope fractionation of $\mathrm{Br}$ that is about half that of $\mathrm{Cl}$ agrees with data obtained 30 years ago on liquid $\mathrm{PbCl}_{2}$ and $\mathrm{PbBr}_{2}[4,5]$. Also, $\mathrm{Cl}$ fractionation data agree with those measured in nature [6]. No other natural $\mathrm{Br}$ diffusion data have yet been reported.

These results indicate that measuring both the $\mathrm{Cl}$ and $\mathrm{Br}$ isotope composition of a suite of samples could be very important to determine the type of fractionation process that has occurred. If diffusion is the main cause of fractionation, $\mathrm{Cl}$ and $\mathrm{Br}$ isotope data should have a positive correlation, and when plotted, the slope should be $\sim 0.5$.

To date there have been no substantiated reports of $\mathrm{Br}$ isotope fractionation in natural samples, and it was always expected that fractionation of $\mathrm{Cl}$ and $\mathrm{Br}$ isotopes would be similar, as the elements have a very similar chemistry. However, as we have shown [7], while experimental precipitation of $\mathrm{NaCl}$ from a brine fractionates the heavier isotope into the solid phase, $\mathrm{NaBr}$ shows a depletion of the heavy isotope relative to the solution. This was the first valid indication that the isotopic fractionations of $\mathrm{Cl}$ and $\mathrm{Br}$ are not completely similar.

We have recently measured $\mathrm{Br}$ isotope data from a set of various waters from an oil field and have shown that this is also the case in nature. These samples, which have (very) negative $\delta^{37} \mathrm{Cl}$ values, show a range of positive $\delta^{81} \mathrm{Br}$ values up to $1.4 \%$ vs. standard mean ocean bromide (SMOB).

Standard mean ocean bromide is proposed as the standard for $\mathrm{Br}$ isotope measurements, as $\mathrm{SMOC}$ is for $\mathrm{Cl}$, and until we have contrary evidence we will assume isotope composition of $\mathrm{Br}$ is constant all over the oceans, as is $\mathrm{Cl}$, since the residence time for $\mathrm{Br}$ in the oceans is even longer than that of $\mathrm{Cl}$.

The fact that the $\mathrm{Cl}$ and $\mathrm{Br}$ isotope data of the oil-field samples do not correlate positively indicates that concerned diffusion is not the pertinent process in the system. We have defined a halide source for brines with distictive $\mathrm{Cl}$ and $\mathrm{Br}$ isotopic compositions, but much research will be necessary to determine the processes responsible for the different isotope fractionations found for $\mathrm{Cl}$ and $\mathrm{Br}$.

References: [1] Schreiner F. et al. (1982) Nucl. Tech., 59 , 429-438. [2] Davison W. et al. (1994) Environ. Sci Tech., 28, 16231632. [3] Willey J. F. and Taylor J. W. (1978) Anal. Chem., 50 , 1930-1933. [4] Klemm A. and Lundén A. (1955) Z. Naturforschg,. IOa, 282-284. [5] Cameron A. E. et al. (1956) Z. Naturforschg., IIa, 203-204. [6] Beekman H. E. et al. (1992) Proc. 7th Intl. Symp. Water-Rock Interaction, 209-212. [7] Eggenkamp H. G. M. and Coleman M. L. (1997) Terra Nova, Abstr. Suppl., 9(1).

URANIUM- AND THORIUM-SERIES DISEQUILIBRIUM DATING OF YOUNG MEDITERRANEAN VOLCANIC ROCKS. J. Eikenberg, S. Bajo, and I. Zumsteg, Paul Scherrer Institute,CH-5232 Villigen (PSI), Switzerland (jost.eikenberg@psi. ch).

Introduction: Naturally occurring radionuclides from the ${ }^{238} \mathrm{U}$ and ${ }^{232} \mathrm{Th}$ decay series may provide a powerful tool to obtain the eruption ages of young volcanic rocks and to investigate the genetic history of magmatic provinces. In the current study we analyzed volcanic rocks from the South Aegean island arc. The magmatic activity of this arc is most likely attributed to subduction of the African plate beneath the European continent. In the first stage, we investigated epigenetically related weak fractionated (primitive) basalts and basaltic andesites as well as highly differentiated andesites and (rhyo)dacites from geologically young volcanic settings, which are estimated to have been erupted less than $300,000 \mathrm{yr}$ ago. Under the assumption that fractionation between $U$ and $T h$ in the ascending magma has taken place recently (caused by partial melting and/or fractionated crystallization), radionuclide disequilibrium between geochemically important parent/daughter isotope pairs such as ${ }^{230} \mathrm{Th} /{ }^{234} \mathrm{U},{ }^{231} \mathrm{~Pa} /{ }^{235} \mathrm{U}$, and ${ }^{226} \mathrm{Ra} /{ }^{230} \mathrm{Th}$ is expected. 
We therefore performed low-level $\alpha$ - and $\gamma$-spectrometric analyses of ${ }^{238} \mathrm{U},{ }^{234} \mathrm{U},{ }^{232} \mathrm{Th},{ }^{230} \mathrm{Th},{ }^{226} \mathrm{Ra}$ (and progenies), as well as microprobe, $\mathrm{X}$-ray fluorescence, and atomic absorption spectrometry for bulk-rock and mineralogical composition. Detailed geochemical descriptions of the primarily basaltic, andesitic, and (rhyo)dazitic tuffs and lavas can be taken from [1]. The recently initiated U/Th disequilibrium study addresses the following topics: (1) dating of magma eruptions and deposition of eruptiva, (2) the genetic evolution (maturity) of the magma during differentiation, and (3) determination of the source-region chemical composition of the initia] melts.

Analytical Procedure: Bulk-rock samples were powdered and aliquots of about $300 \mathrm{mg}$ were spiked with ${ }^{232} \mathrm{U} / 228 \mathrm{Th}$ chemical yield tracer solutions. The spiked aliquots were then completely dissolved in $\mathrm{HF}-\mathrm{HNO}_{3}$ medium. Uranium and $\mathrm{Th}$ were subsequently purified in two consecutive steps using actinide exchange chromatography on a single column (product "U-TEVA,"EICHROM Industries Inc., Darien IL 60561, USA). Since the eluted fractions of $U$ and Th did not contain significant amounts of redox sensitive elements (such as $\mathrm{Fe}$ ) or other interfering ions, the procedure could be directly continued by electrodeposition in $\mathrm{NaHSO}_{4}$ medium for preparation of almost weightless sample disks. The planar sources were then measured using low-level $\alpha$-spectrometry. Radium-226 was determined via ${ }^{210} \mathrm{Po}$ (y ield spike ${ }^{209} \mathrm{Po}$ ) assuming secular equilibrium between ${ }^{226} \mathrm{Ra} / 210 \mathrm{~Pb} / 210 \mathrm{Po}$, which holds for samples not younger than $\sim 100 \mathrm{yr}$ old. Detection limits (in weight units, $\mathrm{g} / \mathrm{g}$ ) were ${ }^{238} \mathrm{U}, 1 \times 10^{-8} ;{ }^{234} \mathrm{U}, 6 \times 10^{-13} ;{ }^{230} \mathrm{Th}, 2 \times 10^{-13} ;{ }^{226} \mathrm{Ra}, 5 \times$ $10^{-15}$.

Results and Discussion: Since $U$ and $T h$ are incompatible elements, fractionation between ${ }^{230} \mathrm{Th}\left(\mathrm{T}_{1 / 2}=76,000 \mathrm{yr}\right)$ and ${ }^{238} \mathrm{U}$, ${ }^{234} \mathrm{U}$ is expected to be limited during magmatic processes. Therefore ${ }^{230} \mathrm{Th}^{232} \mathrm{Th}$ vs. ${ }^{234} \mathrm{U} / 232 \mathrm{Th}$ diagrams are commonly used for isochron dating of cogenetic materials and investigation of the initial $\mathrm{U} / \mathrm{Th}$ ratio before any magmatic differentiation had taken place. While analyses of fresh MORB and most recent volcanic materials yield ${ }^{230} \mathrm{Th}$ excesses relative to ${ }^{234} \mathrm{U},{ }^{230} \mathrm{Th}$ deficits or ${ }^{238} \mathrm{U}$ enrichments have been reported in arc lavas [2]. Our analyses confirmed the trend observed for young island arc samples, i.e., data on the right side of the equiline. This indicates partial melting with $D_{U}<$ $D_{T h}$, or a process such as recent addition of $U$ to the melt. If, however, addition of $U$ could be responsible for the observed disequilibrium, it is expected (as stated in [2]) that this should be most effective in lavas with the lowest $U$ concentrations. In contrast, our study yields the reverse, i.e., the most primitive basalts (with $U$ and Th concentrations $<1 \mathrm{ppm}$ ) are closer to equilibrium than the highly differentiated dacitic derivates (with $U$, Th up to $20 \mathrm{ppm}$ ). The latter are (as expected) also characterized by significantly higher ${ }^{234} \mathrm{U} /{ }^{232} \mathrm{Th}$ activity ratios between 1.2 and 1.4 . The basalt samples yield ${ }^{234} \mathrm{U} /$ ${ }^{232} \mathrm{Th}$ activity ratios close to chondritic values (i.e., 0.8 ), indicating generation from a primitive, almost unfractionated source melt. Without the performance of detailed mineral separation, isochron dating of magmatic rocks is rather unreliable. Nevertheless, cogenetic South Agean bulk-rock samples define an isochrone that intersects the equiline at the chondritic value, probably indicating fractionation from a primitive (deep) mantle source rather than subrecent addition of $U$ by metasomatic processes. The regression analysis yields an "maximum age" of about $80,000 \mathrm{yr}$, while the measured secular equilibrium between ${ }^{226} \mathrm{Ra}\left(\mathrm{T}_{1 / 2}=1600 \mathrm{y} r\right)$ and ${ }^{230} \mathrm{Th}$ indicates that melt fractionation and subsurface rock deposition must have occurred more than $6000 \mathrm{yr}$ ago.

References: [1] Dietrich V. et al. (1988) Schweiz. Mineral. Petrogr. Mitt., 68, 21-39. [2] Condomines M. and Sigmarsson O. (1993) GCA, 57, 4491-4497.

SLAB-DERIVED FLUIDS IN THE MANTLE: OXYGENISOTOPE EVIDENCE FROM MELT INCLUSIONS. J. M. Eiler $^{1}$, B. I. A. McInnes ${ }^{2}$, J. W. Valley ${ }^{3}$, C. M. Graham ${ }^{4}$, and E. M. Stolper', 'Division of Geological and Planetary Science, Califomia Institute of Technology, Pasadena CA 91125, USA, 2CSIRO Exploration and Mining, P.O. Box 136, North Ryde, New South Wales 2113 , Australia, ${ }^{3}$ Department of Geology and Geophysics, University of Wisconsin, Madison WI 53706, USA, ${ }^{4}$ Department of Geology and Geophysics, University of Edinburgh, Edinburgh, UK.

The subduction of rocks, sediments, and fluids of the oceanic crust at convergent margins is an important process for generating chemical and isotopic heterogeneity in the mantle. However, the mechanisms by which subducted material interacts with and hybrid. izes the mantle are poorly known, usually inferred from the properties of mantle-derived lavas rather than from study of mantlederived minerals or fluids with an unambiguous crustal origin. Oxygen-isotope variations of minerals and melv/fluid inclusions in xenoliths from subarc mantle can provide valuable constraints on the nature of subducted material and on processes by which they interact with the mantle and contribute to arc volcanism.

Alkali olivine basalts from Simberi and Lihir Islands, Papua, New Guinea, contain olivine xenocrysts and lherzolite and harzburgite xenoliths that sample the mantle above the Manus-Kilinauilau subduction zone (northeast of New Ireland), on which subduction ceased 6-10 m.y. ago. Olivine and clinopyroxene xenocrysts from Simberi Island contain inclusions of a phonolite glass that are texturally associated with Na-pyroxene, low-Ti magnetite, and/or phlogopite that formed as reaction products between phonolitic melt and the host phase. These glass inclusions contain daughter crystals of apatite, K-feldspar, calcite, and anhydrite. We analyzed silicate glass in these inclusions for ${ }^{18} \mathrm{O} / 16 \mathrm{O}, \mathrm{H}_{2} \mathrm{O}$ content, and trace-element concentrations by ion microprobe (20-30- $\mu \mathrm{m}$ spot size). Secondary Na-pyroxene was analyzed for trace-element concentrations. In order to obtain accurate values for the $O$-isotope ratios, considerable effort went into 40 silicate minerals and glass standards prior to analysis of the samples. Each measurement has a precision of $\pm 1 \% \circ(1 \sigma)$ and an accuracy of $\pm 1.5 \%$ ( $1 \sigma)$ based on cumulative uncertainties in measurement and standardization.

The $\delta^{18} \mathrm{O}_{\text {SMOw }}$ value of one $300 \times 600-\mu \mathrm{m}$ glass inclusion that is relatively free of the products of reaction with host olivine is $11.3 \pm$ $1.1 \%$ (the average and standard deviation of four analyses). The glass is isotopically homogeneous within the precision of the analyses. Two analyses of a smaller $(100-\mu \mathrm{m})$ inclusion, surrounded by $\mathrm{Na}$-rich pyroxene and appearing based on its petrography to have undergone extensive reaction with the host olivine, yielded a $\delta^{18} \mathrm{O}$ value of $9.0 \pm 0.9 \%$. These values are substantially higher than the range of 6.5-7.0\%o expected of silicate liquids of these chemical compositions in isotopic equilibrium with typical mantle olivine. The absence of devitrification or secondary sheet-silicates, the homogeneity of individual inclusions, and the lower $\delta^{18} \mathrm{O}$ of the glass in the inclusion that reacted more extensively to its host olivine all suggest that the $\delta^{18} \mathrm{O}$ value of $\sim 11 \%$ observed for the larger 
inclusion is nearly primary (i.e., not acquired by subsolidus alteration or ${ }^{18} \mathrm{O}$-enrichment). The ${ }^{18} \mathrm{O}$-enrichment of the silicate melt inclusions strongly suggests they are derived from a source that is rich in constituents from the top of the subducting slab (i.e., fluid, sediment, or altered basalt).

Trace-element abundances in silicate inclusions and secondary Na-pyroxene are characterized by MORB-like MREE abundances with moderate LREE enrichment (characteristic of arc lavas), extreme depletion in HFSE (e.g., $\sim 1 \mathrm{ppm} \mathrm{Zr}$ ), and strong enrichment in $\mathrm{Sr}$ (up to $2900 \mathrm{ppm}$ ), Rb (220-290 ppm), and B (35-40 ppm). These characteristics are inconsistent with direct partial melting of common peridotitic sources, basalt or sediment. They are consistent with either (1) a residual mineralogy producing partition coefficients during melting that are unusual relative to those for common mafic or ultramafic sources (i.e., HFSE compatibility; low ratio of LILEREE D), or (2) melting of a peridotite that has been depleted by melting and subsequently metasomatized by a slab-derived fluid (i.e., initial removal of incompatible elements followed by enrichment in fluid-soluble components). Variably fertile peridotitic xenoliths with evidence of hydrous metasomatism are common in Simberi and Lihir Island lavas, indicating that processes such as those required by (2) have taken place in the local mantle. We thus interpret high $\delta^{18} 0$ phonolitic melts to be derived by melting of previously depleted mantle sources that have been extensively metasomatized by slab-derived fluids.

Laser fluorination analysis $( \pm 0.1 \%$ ) of $\mathrm{O}$-isotope ratios of phenocrysts from Simberi and Lihir Island basalts show them to be elevated in $\delta^{18} \mathrm{O}$ by up to $0.7 \%$ relative to typical arc lavas. This is consistent with a substantial slab component $(\sim 10 \%)$ for the mantle sources of these lavas and suggests that the slab/mantle hybridization we infer for the sources of phonolitic melts is extensive in the local mantle.

STRONTIUM-ISOTOPE GEOCHEMISTRY OF LAPTEV SEA-SURFACE SEDIMENTS, ICE-RAFTED DETRITUS, AND SUSPENDED PARTICULATE MATERIAL OF EAST SIBERIAN RIVERS: IMPLICATIONS FOR SEDIMENTDISTRIBUTION PATTERNS IN THE ARCTIC OCEAN. A. Eisenhauer $^{1}$, V. Rachold ${ }^{2}$, H. Meyer ${ }^{1}$, H. Kassens ${ }^{3}$, F. Lindemann ${ }^{3}$, R. F. Spielhagen ${ }^{3}$, and B. Wiegand ${ }^{1.4}$, 'Geochemical Institute, University of Göttingen, Goldschmidtstrasse 1, 37077 Göttingen, Germany (aeisenh@gwdg.de; hmeyer1@gwdg.de), ${ }^{2}$ Alfred Wegener, Institute for Polar and Marine Research, Research Unit Potsdam, Telegrafenberg A43, 14473 Potsdam, Germany (vrachold@awipotsdam.de), ${ }^{3}$ GEOMAR Research Center, Wischhofstrasse 1-3, 24148 Kiel, Germany (hkassens@geomar.de; flindemann@geomar. de; rspielhagen@geomar.de), ${ }^{4}$ IGDL,University of Göttingen,Goldschmidtstrasse 3, 37077 Göttingen, Germany.

The detrital component of Arctic sediments is mainly formed from material derived from the Eurasian continent and supplied by the large Siberian rivers $\mathrm{Ob}$, Yenisey, and Lena. The rivers draining to the Laptev Sea, e.g., the Lena River, are of special interest. Today large amounts of sea ice feeding the Transpolar Drift are formed in the Laptev Sea shelf area. Material transported to the Laptev Sea by the Siberian rivers is partly incorporated into drifting sea ice and distributed throughout the Arctic Ocean and the North Atlantic. For this reason, the identification of recent and ancient paths of sedi- ment distribution reveal important information about the history of sea ice cover and drift patterns.

In order to determine the paths of sediment transport to the Laptev Sea and further to the Arctic Ocean we measured ${ }^{87} \mathrm{Sr} /{ }^{86} \mathrm{Sr}$ ratios and Sr concentrations of Laptev Sea surface sediments, icerafted detritus (IRD), and suspended particulate material (SPM) of the Lena, Yana, and Khatanga Rivers. The SPM exported to the Laptev Sea by the Lena River is characterized by average ${ }^{87} \mathrm{Sr} /{ }^{86} \mathrm{Sr}$ ratios of $0.7165 \pm 0.0005$ and Sr concentrations of $200 \pm 20 \mathrm{ppm}$ measured at the northernmost stations. The average ${ }^{87} \mathrm{Sr} /{ }^{86} \mathrm{Sr}$ ratio $(0.7141 \pm 0.0002)$ and $S r$ concentration $(152 \pm 5 \mathrm{ppm})$ of the Yana River SPM can clearly be distinguished from those of the Lena River SPM. Pronounced differences can be observed in the Khatanga River. Strontium isotopic ratios $(0.7102 \pm 0.0002)$ and $\mathrm{Sr}$ concentrations (181 $\pm 5 \mathrm{ppm}$ ) of the Khatanga River SPM are strongly influenced by volcanic rocks of the Siberian Trap, which are very common in the drainage area. In a ${ }^{87} \mathrm{Sr} /{ }^{86} \mathrm{Sr}$ ratio vs. $\mathrm{Rb} / \mathrm{S} r$ diagram, samples of each river plot along straight lines. The gradients of these lines are interpreted as apparent ages corresponding to provenance. The scatter along the lines results from grain-size separation processes, which do not significantly change the provenance information.

Strontium isotopic ratios and Sr concentrations of Laptev Sea surface sediments and IRD can be related to Sr data of river SPM, indicating that the Sr isotope geochemistry can be applied to identify the distribution of riverine material in the Laptev Sea and the Arctic Ocean. In a ${ }^{87} \mathrm{Sr} /{ }^{86} \mathrm{Sr}$ ratio vs. $\mathrm{Rb} / \mathrm{Sr}$ diagram, sediment and IRD samples exclusively originating from one river plot along the SPM line belonging to this river. Samples related to mixing of material supplied by two or more rivers plot between the river SPM lines. Considering this, it can be stated that sediments and IRD of the southern, central, and eastern Laptev Sea shelf are dominated by material supplied by the Lena River. The Yana River, which drains to the easternmost Laptev Sea, seems to be of minor imporance. Surface sediments and IRD of the westem Laptev Sea shelf, on the other hand, are additionally influenced by material supplied by the Khatanga River and/or imported from the Kara Sea.

LOW-TEMPERATURE REACTIONS BETWEEN SEAWATER AND OCEANIC CRUST AT RIDGE FLANKS. H. Elderfield $^{1}$, E. Suess ${ }^{2}$, M. J. Mottl ${ }^{3}$, G. Wheat ${ }^{4}$, and the ODP Leg 168 Scientific Party, 'Department of Earth Sciences, University of Cambridge, Downing Street, Cambridge, CB2 3EQ, UK (he101@ esc.cam.ac.uk), ${ }^{2}$ Geomar, 24148 Kiel, Germany, ${ }^{3}$ Department of Oceanography/School of Ocean and Earth Science and Technology, University of Hawai' $i$ at Manoa, Honolulu HI, USA, ${ }^{4}$ NURP/MLML Ship Operations, Moss Landing, USA.

There has been evidence from a number of regions in the Pacific and Atlantic Oceans that shows lateral flow of seawater through oceanic crust away from ridge axes. This off-axis flow is associated with heat loss from the cooling of the lithosphere, but the extent to which geochemical and isotopic exchange occurs in such lowtemperature systems is controversial. Pore water was extracted from Kastenlot cores collected during RV Sonne cruise SO109/1 from the eastern flank of the Juan de Fuca Ridge at about $46^{\circ} \mathrm{N}$ and analyzed for $\mathrm{Sr}$ isotopes. Contrary to previous studies, results show that there is $\mathrm{Sr}$ isotope exchange on ridge flanks. Detailed pore- 
water profiles have also been collected from 10 sites on a transect on the eastem flank of the Juan de Fuca Ridge along $48^{\circ} \mathrm{N}$ during ODP Leg 168. Fluid geochemical data imply that there is lateral hydrothermal fluid flow through the basement at all the sites that were drilled. Basement fluid compositions show, in general, an evolution from seawater-like near the ridge, where the temperature at the basalt-sediment interface was $15.5^{\circ} \mathrm{C}$, to fluids depleted in $\mathrm{Mg}$, sulfate, and alkalinity and enriched in $\mathrm{Ca}$ at $63^{\circ} \mathrm{C}$. Diffuse fluxes estimated from the pore-water concentration gradients have been used to constrain fluid residence times and geochemical reaction rates.

SUBDUCTION ZONE PROCESSING OF OCEANIC CRUST. T. Elliott ${ }^{i}$ and T. Plank ${ }^{2}$, 'Faculteit Aardwetenschappen, Vrije Universiteit, de Boelelaan 1085, 1081 HV Amsterdam, Netherlands (ellt@mailhost.geo.vu.nl), 2Department of Geology, Lindley Hall, University of Kansas, Lawrence KS 66045-2124, USA (tplank@ kuhub.cc.ukans.edu).

Recycled oceanic crust has long been proposed as the cause of many distinctive trace-element and isotopic signatures in ocean island basalts (OIB). Indeed, the subducted slab has some chemical features, or has the potential to develop them with time, that are required of many OIB sources. However, subducting oceanic crust also possesses some geochemical signatures that are inappropriate for the source of OIBs. This dilemma has been reconciled by invoking the effects of subduction zone processing in modifying the composition of the slab. Element contents of arc lavas that are present "in excess" of MORB compositions are assumed to be derived from the subducted assemblage. Subtraction of these element excesses from the input budget to the subduction zone enables calculation of the composition of material that is recycled to the deep mantle. Qualitatively, this approach appears to account for many troublesome features. For example, $K$ and $U$ added to the oceanic crust during basalt alteration results in a bulk composition unsuitable for any OIB reservoir. However, $K$ and $U$ are also highly enriched in arc lavas, and so it has been suggested that these elemental additions to the oceanic crust are stripped out in its passage through the subduction zone.

This approach requires more quantitative testing in a subduction zone where input, output, and the mechanisms of element transport are well understood. The Marianas provide such a suitable case study. Variations in the composition of Mariana arc lavas indicate that there are chemically distinct fluxes to the subarc mantle from subducted sediment and altered oceanic crust respectively. The effects of subduction zone processing are different on these different portions of the subducted slab, and the two budgets have to be assessed independently. It appears that sedimentary material is transferred to the subarc mantle as a melt with residual rutile. This process strongly fractionates elements such as $\mathrm{Th}$ and $\mathrm{La}$ from $\mathrm{Nb}$. The oceanic crust dehydrates and contributes a large flux of $\mathrm{Ba}, \mathrm{Pb}$, $\mathrm{Sr}$, and to a lesser extent $\mathrm{U}$ and alkalis to the arc. A potential OIB source may contain either subduction zone processed sediment, oceanic crust, or some mixture of these two components. However, no combination of these components, calculated for the Mariana arc system, appears to produce a suitable incompatible trace-element pattern for any OIB lava. For example, enrichments in $\mathrm{U}$ and $\mathrm{K}$, relative to $\mathrm{Nb}$ for example, of both subducted components are not sufficiently reduced by subduction zone processing to match OIB values. If recycled crust is to participate significantly in the OIB source, a large flux of these elements must be lost either very shallow in the subduction zone or even deeper than the region sampled by arc lavas. Additional investigation of this key behavior of alkalis in the subduction zone is currently being undertaken using $\mathrm{Li}$ isotopes.

\section{EARLIEST EVIDENCE FOR CHIRALITY IN THE SOLAR} SYSTEM: IMPLICATIONS FOR THE ORIGIN OF LIFE. M. H. Engel ${ }^{1}$ and S. A. Macko ${ }^{2},{ }^{1}$ School of Geology and Geophysics, 100 East Boyd Street, University of Oklahoma, Norman OK 73019 , USA (ab1635@ou.edu), 2Department of Environmental Sciences, University of Virginia, Charlottesville VA 22903, USA (sam8f@ faraday.clas.virginia.edu).

It is generally assumed that abiotic syntheses of amino acids that preceded life's origin resulted in racemic mixtures $(D / L=1)$. However, owing to conformational constraints, the origin of life required the almost exclusive selection of either the $\mathrm{L}$ - or $\mathrm{D}$-amino acid enantiomers. To date, no natural terrestrial process is known to break the parity derived from abiotic synthesis. Engel and Nagy [1] were the first to report that some amino acids in the Murchison meteorite exhibited an L-enantiomer excess. Since a substantial percentage of the Earth's early inventory of organic compounds may have been derived from cometary and meteorite impacts, they suggested that the requisite L-enantiomer excess already existed in the solar system and was introduced to Earth by impact events. The cause of the L-excess in Murchison is not known, but it has been speculated that it resulted from prolonged exposure of the the amino acids and their interstellar precursors to circularly polarized light emitted by neutron stars. A concern has been that the L-enantiomer excess in Murchison may have resulted from contamination subsequent to impact. However, stable $\mathrm{C}$ and $\mathrm{N}$ isotope analyses of the individual amino acid enantiomers in Murchison clearly indicate ${ }^{13} \mathrm{C}$ and ${ }^{15} \mathrm{~N}$ enrichments that are outside of the range of $\delta^{13} \mathrm{C}$ and $\delta^{15} \mathrm{~N}$ values reported for amino-acid constituents of living systems on Earth. 840.

References: [1] Engel and Nagy (1982) Nature, 296, 837-

\section{MODERN PECULIARITIES OF FREE RADICAL FORMA- TION MECHANISMS OF SEDIMENT STRUCTURE AND QUILITY IN TERRESTRIAL AQUATIC SYSTEMS. L. S.} Emestova, SPA Typhoon, Lenin Street 82, 249020 Obninsk, Kaluga Reg., Russia (typhoon@stom.iasnet.com).

Field studies on Chardarya water storage (r.Syr-Darya), Kiev water storage (r.Dnepr) before and after the Chemobyl NPP accident, Volgograd water storage basin (r.Volga), Valdai Lake, and other water objects of the former Soviet Union have shown that with excessive intensification of free radical processes, biogeochemical circulation is disrupted of other biogenic elements related to the $\mathrm{O}$ cycle, manganese ions in particular.

The hydroxyl radicals $(\mathrm{OH})$ are most active from the intermediate forms of activation and reduction of molecular $\mathrm{O}$, i.e., singlet oxygen $\left({ }^{1} \mathrm{O}_{2}\right)$, and superoxide radicals $\left(\mathrm{O}_{2}{ }^{-}\right)$, and hydrogen peroxide 
$\left(\mathrm{H}_{2} \mathrm{O}_{2}\right)$. The content of $\mathrm{OH}$ radicals in the aquatic environment is mainly specified by photochemical and photocatalytic processes. At the expense of these processes the steady-state concentration of $\mathrm{OH}$ radicals in a limnic zone of a water object during a season varies within more than 2 orders of magnitude, up to $10^{-14} \mathrm{M}$ [1].

According to literature data [2], in the process of radical oxidation of $\mathrm{Mn}$ (II), metastable, highly reactive microcolloidal particles of mixed-valent $\mathrm{Mn}$ (III,IV) are formed. It should be noted that in the natural biogeochemical cycle of $\mathrm{Mn}(\mathrm{II}, \mathrm{IV})$, the appearance of such active forms is not typical.

The formation of highly reactive microcolloid particles of mixedvalent $\mathrm{Mn}(\mathrm{III}, \mathrm{IV})$ can proceed at a high rate during the interaction between $\mathrm{Mn}(\mathrm{IV})$ oxide and $\mathrm{S}$ oxi-ions in the intermediate (oddelectron) states of oxidation $\left(S^{+5}, S^{+3}\right)$. These processes are primarily typical in the profundal zone of a water object.

Our field data show that the content increase of these highly reactive forms of $\mathrm{Mn}$ can significantly effect sediment composition and the rate of substance in a given water object.

It is well known that biogeochemical cycles of $\mathrm{O}, \mathrm{S}$, and $\mathrm{Mn}$ are based on the mechanism of synchronous two-electron charge transfer. Hence, as a result of intensified formation processes of intermediate highly reactive products of single-electron $\mathrm{O}_{2}$ and $\mathrm{H}_{2} \mathrm{O}_{2}$ activation in the limnic zone and the highly reactive odd-electron states of the $\mathrm{S}$ oxi-ions in the profundal zone of the water system, its biogeochemical cycle may be violated. The probability of this process grows with regional geochemical peculiarities, for example, with the increased $\mathrm{Mn}$ content in the environment. So, results of field observations may serve as an illustration of one of the modem peculiarities of free radical formation mechanisms of sediment structure and quility in terrestrial aquatic systems, which consists in synchronism violation of multielectron (even) charge transfer, first of all, in the O cycle.

References: [1] Emestova L. S. and Skurlatov Yu. I. (1995)J. Phiz. Khim., 69, 1157. [2] Baral S. et al. (1986) ACS, 90, 6025.

\section{EXPERIMENTALLY DETERMINED SOLUBILITIES OF PLATINUM AND RHODIUM IN A HAPLOBASALTIC SILICATE MELT AT $1300^{\circ} \mathrm{C}$, AND CALCULATED METAL/ SILICATE PARTITION COEFFICIENTS. W. Ertel, H. St. C. O'Neill, D. B. Dingwell, and P. J. Sylvester, CNRS-CRSCM, IA Rue de la Ferollerie, Orleans Cedex 2, 45071 Orleans, France.}

The solubilities of $\mathrm{Pt}$ and $\mathrm{Rh}$ in a haplobasaltic CMAS melt (AnDi eutectic composition) have been experimentally determined at $1300^{\circ} \mathrm{C}$ over a wide range of $O$ fugacities $\left(-12.4<\operatorname{logfO} O_{2}<0\right)$ using the mechanically assisted equilibration method of Dingwell et al. [1]. Experimental run products were analyzed for $P t$ and $R h$ by both isotope dilution ICP-MS and laser ablation ICP-MS.

The solubility of both $\mathrm{Pt}$ and $\mathrm{Rh}$ increases with increasing $\mathrm{fO}_{2}$ (as expected) in the experiments with $\operatorname{logfO} \mathrm{O}_{2}>-6$. The slope of the $\log$ (solubility) vs. $\operatorname{logfO} \mathrm{O}_{2}$ correlation indicates that both $\mathrm{Pt}$ and $\mathrm{Rh}$ are dissolving as divalent species $\left(\mathrm{Pt}^{2+}\right.$ and $\left.\mathrm{Rh}^{2+}\right)$. At lower $\mathrm{O}$ fugacities, however, the solubilities of both elements show an unexpected increase with decreasing $\mathrm{fO}_{2}$. In this region, the good correlation between $\log$ (solubility) and logpCO suggests that Pt and $\mathrm{Rh}$ are dissolving predominantly as carbonyl species. Similar behavior has been inferred for Ir [2].

Calculation of the metal/silicate partition coefficients based on these results for IW- 1 at $1300^{\circ} \mathrm{C}$ leads to $\mathrm{D}^{\mathrm{M} / \mathrm{S}}$ values of $6 \times 10^{9}$ for $\mathrm{Pt}$ and $4 \times 10^{7}$ for $\mathrm{Rh}$ for the $\mathrm{C}$-containing system, and $6 \times 10^{13}$ for $P t$ and $4 \times 10^{12}$ for $R h$ for the $C$-free system. Both $D^{M / S}$ values, even in the C-containing system, are $\sim 6$ orders of magnitude greater than that required to explain the observed abundances of $\mathrm{Pt}$ and $\mathrm{Rh}$ in the Earth's mantle, assuming chemical equilibrium between metal and silicate during core formation. The apparent overabundances of $\mathrm{Pt}$ and $\mathrm{Rh}$ are more likely to be explained by the addition of a late chondritic veneer.

Our results imply that $C$ has a large effect in enhancing the solubilities of $P t$ and $R h$, as well as Ir, and presumably other PGEs, at low $\mathrm{fO}_{2} \mathrm{~s}$ in silicate melts. Thus in planetary bodies where the abundance of $\mathrm{C}$ is low (e.g., the Moon), the PGEs will appear even more siderophile rich and much more compatible than on Earth. The very low solubilities inferred from our experiments in the C-free systems make it doubtful whether any of the PGEs (including Os isotopes) observed in lunar samples are indigenous.

References: [1] Dingwell et al. (1994). [2] O'Neill et al. (1995).

HELIUM-3 EVIDENCE FOR A COMET SHOWER IN THE LATE EOCENE. K.A.Farley' ${ }^{1}$,E.M.Shoemaker ${ }^{2}$,A.Montanari ${ }^{3}$, and D. B. Patterson', 'Mail Stop 170-25, California Institute of Technology, Pasadena CA 91125 , USA (farley@gps.caltech.edu), 2U.S. Geological Survey, Flagstaff AZ 86001, USA, 30sservatorio Geologico di Coldigioco, 62020 Frontale di Apiro, Italy, and Ecole des Mines de Paris, France.

There is abundant evidence for multiple extraterrestrial impact events in the Late Eocene, including the giant Popigai astrobleme in Siberia $(100 \mathrm{~km})$ and the Chesapeake Bay $(90 \mathrm{~km})$, Logoisk (Belarus, $17 \mathrm{~km}$ ), and Wanapitei (Ontario, $7.5 \mathrm{~km}$ ) impact craters. In addition, at least two microtektite/microkrystite layers and occurrences of shocked quartz, $\mathrm{Ni}$-rich spinel, and elevated Ir abundances are found in Late Eocene marine sediments throughout the world. Ages of these impact indicators cluster near 35.5 Ma [1]. The occurrence of multiple independent impact events in such a short time period is statistically unlikely, leading to the suggestion that a comet shower occurred at this time [2]. The theoretical foundation for the occurrence of comet showers, brief periods of enhanced cometary activity, is well established. Comet showers are the product of gravitational perturbations of the inner Oort cloud produced by passing stars or massive interstellar gas clouds, or by galactic tidal forces. Numerical modeling indicates that the enhanced cometary activity persists for $\sim 1.5 \mathrm{~m} . y$, and that comet showers leading to large terrestrial impact events should occur about once every $30-$ 35 m.y. [3]. However, aside from possible temporal clustering of impact indicators, there is no strong evidence for the occurrence of comet showers.

Helium- 3 may provide a new tracer of such cometary activity in the geologic record. In many seafloor sediments ${ }^{3} \mathrm{He}$ is overwhelmingly of extraterrestrial origin, carried by micrometer-sized interplanetary dust particles. The interplanetary dust accreting to the Earth is derived from both comets and from asteroidal collisions, with asteroids probably the dominant source. Particles from both sources are likely to be highly enriched in ${ }^{3} \mathrm{He}$ from implantation of solar-wind He. During atmospheric entry, dust particles are heated to varying degrees depending on their size and entry velocity, 
causing He loss from a large fraction of the particles. Cometary dust will generally have higher entry velocities than asteroidal dust (reflecting the orbital characteristics of the parent bodies), and is potentially severely outgassed and hence underrepresented by the accumulation of ${ }^{3} \mathrm{He}$ on the Earth's surface. However, recent modeling [4] indicates that interactions with Jupiter can slow a significant fraction of cometary particles to atmospheric entry velocities more typical of asteroidal debris, which should allow them to enter with their He intact.

A low-temporal-resolution study of the ${ }^{3} \mathrm{He}$ flux through the Cenozoic recorded by a pelagic clay in the Pacific Ocean revealed a very prominent peak in the Late Eocene [5]. To investigate whether this peak could be correlated with other Late Eocene impact indicators, we analyzed an Upper Eocene sequence of carbonate sediments in the global stratotype section for the Eocene-Oligocene boundary exposed in the Massignano Quarry in the Italian Apennines. This section includes a thin layer (a few centimeters) with a strong Ir anomaly, shocked quartz, altered microkrystites, and $\mathrm{Ni}$-rich spinel at 35.7 Ma [6]. Throughout the section we find elevated ${ }^{3} \mathrm{He} /{ }^{4} \mathrm{He}$ ratios consistent with a dominantly extraterrestrial ${ }^{3} \mathrm{He}$ source $(90-$ $98 \%$ ). Like the Ir, the ${ }^{3} \mathrm{He}$ concentration peaks at $\sim 35.7 \mathrm{Ma}$; however, the peak is much broader ( $>5 \mathrm{~m}$ ). Between the bottom of the section at $36.5 \mathrm{Ma}$ and $35.8 \mathrm{Ma}$ the ${ }^{3} \mathrm{He}$ concentration rises steadily by $\sim 4 \times$, then declines steadily back to its original value by $\sim 35 \mathrm{Ma}$. The coincidence of a large impact event (producing the Ir and shocked quartz) and a broad peak in ${ }^{3} \mathrm{He}$ argue against an asteroidal source for either indicator, as an asteroid impact will not in general be associated with elevated interplanetary dust levels. In contrast this is reasonable for a comet shower, as the multiple comets of a shower can make many passages through the inner solar system, emitting dust, both before and after a terrestrial impact. Furthermore, the shape of the ${ }^{3} \mathrm{He}$ peak is in striking agreement with predictions [3] for a comet shower, if we equate frequency of perihelion passages with the abundance of cometary dust accreting to the Earth. Additional work is in progress to verify that this broad peak is not local to Massignano by analyzing additional correlative sections, and to ascertain how unusual a ${ }^{3} \mathrm{He}$ peak of this magnitude is in the Eocene-Oligocene by analyzing at comparable temporal resolution sediments from above and below this horizon.

References: [1] Clymer et al. (1996) and references therein. [2] Shoemaker and Wolfe (1986). [3] Hut et al. (1987); Matese et al. (1995). [4] Liou and Zook (1996). [5] Farley (1995). [6] Robin et al. (1996); Montanari et al. (1993).

\section{IN SITU AND WHOLE-GRAIN LASER FLUORINATION OF SUBARC MANTLE MINERALS USING EXCIMER AND CARBON DIOXIDE LASERS: POTENTIAL INSIGHTS INTO OXYGEN MOBILITY AND METASOMATISM IN THE MANTLE WEDGE. J. Farquhar ${ }^{1}$, A.D. Brandon ${ }^{2}$, and D. Rumble III ${ }^{1}$, 'Geophysical Laboratory, Camegie Institution of Washington, 5251 Broad Brand Road, Northwest, Washington DC 20015, USA, 'Department of Geology, University of Maryland, College Park MD 21401, USA.}

We report $O$ isotope data for olivine (ol) and orthopyroxene (opx) grains from spinel peridotite xenoliths that sample the presentday sub arc mantle beneath Ichinomegata, Japan, and the Simcoe cinder cone, Washington. We construct a dataset that is used to

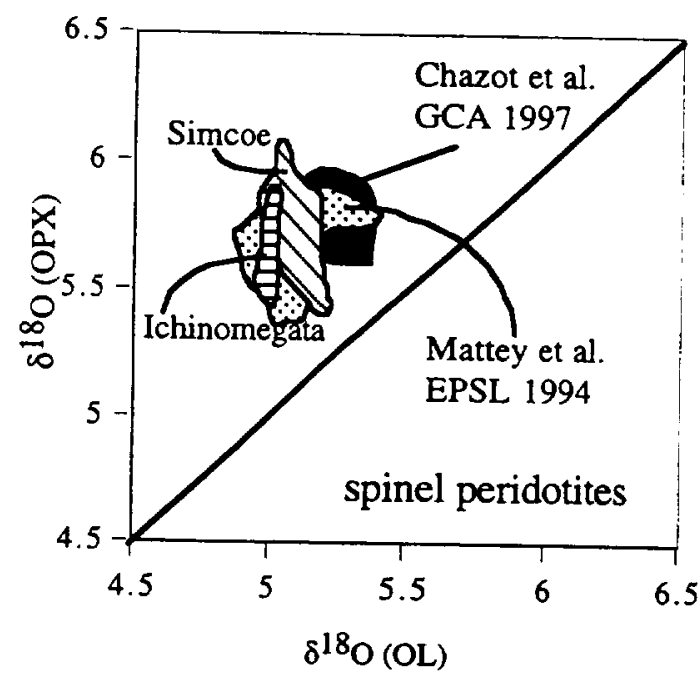

Fig. 1.

assess the accuracy of two laser-fluorination techniques: $\mathrm{CO}_{2}$ and excimer laser fluorination. We use the data to study sub arc mantle processes.

The two analytical techniques used in this study are fundamentally different. The $\mathrm{CO}_{2}$ laser thermally activates the fluorination reaction through coupling between $10.6-\mathrm{mm}$ radiation and infrared vibrational modes of the mineral lattice. The deep ultraviolet $(1=$ $248 \mathrm{~nm}$ ) excimer laser photons couple electronically with bonds in the sample, ablating material to form a plume that reacts with the fluorinating agent. Olivine analyses made using both laser techniques give similar $\delta^{18} \mathrm{O}$ values. The mean of $15 \mathrm{Simcoe}$ ol analyses is $5.08 \pm 0.18 \%$ and $5.09 \pm 0.07 \%$ for analyses done with the $\mathrm{CO}_{2}$ and excimer lasers respectively. The same comparison for four Ichinomegata samples gives $4.84 \pm 0.10 \%$ and $5.00 \pm 0.03 \%$.

Our data show very little variability for $\delta^{18} \mathrm{O}$ of opx and ol and overlap fields defined by Nd-YAG laser fluorination data of Mattey and coworkers. Our analyses are therefore consistent with observations made by these workers that metasomatizing agents do not impart significant variability in $\delta^{18} \mathrm{O}$ to samples of mantle peridotite.

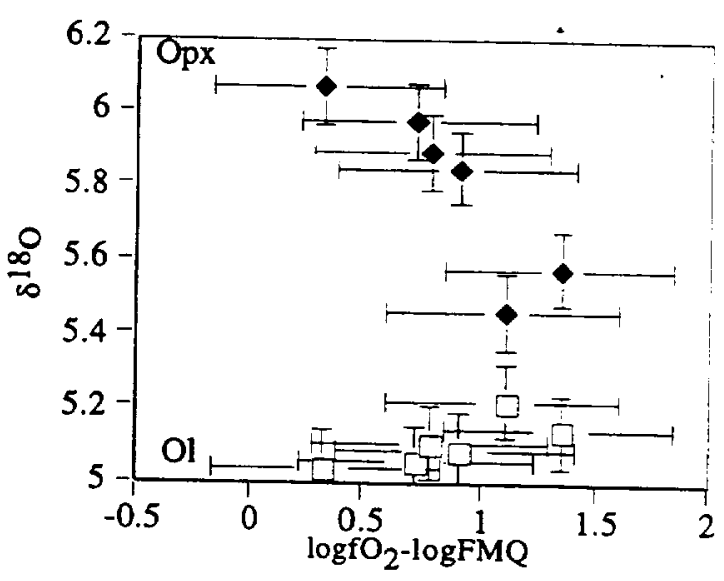

Fig. 2. Data from Simcoc Samples. 
Our results do not preclude the metasomatic agent inferred on the basis of enriched trace elements, Os and Nd isotope systematics, and oxidation state of these xenoliths [cf. 1,2]. In samples for which data exists, $\delta^{18} \mathrm{O}$ and oxidation state appear to be correlated.

This relationship may reflect operation of an oxidized metasomatizing agent that heated the country rocks, reducing ol-opx fractionations as a result of high-temperature $O$ isotope reequilibration. Mass-balance constraints require increases in $\delta^{18} \mathrm{O}(\mathrm{ol})$ for decreases in $\delta^{18} \mathrm{O}(\mathrm{opx})$, but increases in $\delta^{18} \mathrm{O}(\mathrm{ol})$ will be small because modal ol:opx is $\sim 7: 2$.

Alternatively, oxidized metasomatic agents that were slightly out of $\mathrm{O}$ isotope equilibrium with the country rocks could also be invoked. To explain our data by this process, lower $\mathrm{O}$ exchange rates for ol relative to opx are required. Otherwise this process would reduce both $\delta^{18} \mathrm{O}(\mathrm{ol})$ and $\delta^{18} \mathrm{O}(\mathrm{opx})$.

Our data raise questions about the relationship between the $O$ isotope systematics and oxidation state of the subarc mantle. They do not, however, provide an entirely unambiguous window into the nature of these interactions.

References: [1] Brandon et al. (1996) Science. [2] Brandon and Draper (1996) GCA.

ION MICROPROBE MEASUREMENTS OF CARBON-13/ CARBON-12 IN GRAPHITE: EVIDENCE FOR MULTIPLE FLUID INFLUX EVENTS IN THE DEEP CRUST OF SOUTH INDIA. J. Farquhar ${ }^{1}$, E. Hauri ${ }^{2}$, C. Alexander ${ }^{2}$, and J. Wang', 'Geophysical Laboratory, Carnegie Institution, 5251 Broad Branch Road, North west, Washington DC 20015, USA, ${ }^{2}$ Department of Terrestrial Magnetism, Camegie Institution, 524! Broad Branch Road, Northwest, Washington DC 20015, USA.

Intense controversy surrounds the role of $\mathrm{CO}_{2}$-bearing fluids during evolution of the South Indian Crust. One group of researchers has argued for crustal-scale influx of carbonic fluids during peak metamorphism. The other has argued that pervasive influx of fluids did not occur at peak conditions but that evidence for carbonic fluids was imprinted during cooling. Here, we present evidence for interaction of $\mathrm{CO}_{2}$-bearing fluids during both the high-temperature phases and on the retrograde path. We use ion microprobe data for $8^{13} \mathrm{C}$ variation in graphite to reconstruct a metamorphic history that involved prograde, peak, and retrograde fluid influx. This type of detailed information supports arguments provided by both groups of researchers and may also provide important insights pertinent to other terminal metamorphic events.

Graphite $\delta^{13} \mathrm{C}$ measurements were made with a 1-3-nA Cst beam $(30-60 \mu \mathrm{m})$ and an energy offset of $350 \pm 100 \mathrm{eV}$; hydride interferences or charging effects were not encountered under these conditions. Reproducibility of $8^{13} \mathrm{C}$ measurements on thin sections was $0.2-0.5 \% o$ depending on analysis time (20-60 min).

Graphite is an ideal mineral for the study of fluid-rock interactions because (1) it readily precipitates when $\mathrm{CO}_{2}$-bearing fluids enter reduced rocks; (2) even at high temperatures, ${ }^{13} \mathrm{C} /{ }^{12} \mathrm{C}$ fractionations and their temperature dependences are large between graphite and $\mathrm{CO}_{2}$; and (3) diffusion rates for $\mathrm{C}$ in graphite are extremely low. These properties of graphite provide a fingerprint of the environment in which graphite precipitated. Combined with petrography, isotopic zoning pattems in graphite can be used to gain insight into timing and mechanics of grain growth as well as the history of passage for $\mathrm{C}$-bearing fluids.
Ion microprobe analyses of graphite distinguish three generations of graphite. Graphite derived from C present in the protolith shows little evidence for isotopic zoning, but may be overgrown subsequent generations of graphite. Graphite that precipitated near peak conditions is ${ }^{13} \mathrm{C}$ enriched relative to other graphite in the rock and is isotopically zoned (higher $\delta^{13} \mathrm{C}$ at the grain edges perpendicular to the C-crystallographic axis). Some of this zoning may result from isotopic distillation processes that accompanied precipitation. Graphite that precipitated on the retrograde path has variable $\delta^{13} \mathrm{C}$ compositions, but is more ${ }^{13} \mathrm{C}$ depleted than the high-grade graphite. Isotopic zoning in this graphite is opposite in sense to that in highgrade graphite (more ${ }^{13} \mathrm{C}$ depleted near the grain edges), and isotopic variations exist both parallel to and perpendicular to the $C$ crystallographic axis. This zoning is attributed to graphite precipitation at lower temperature conditions (larger fluid-graphite $\mathrm{C}$ isotope fractionations).

The magnitude of isotopic variation in single grains approaches $10 \%$ at the micrometer scale. The geometry of isotopic zoning suggests that graphite growth can occur in any direction. Isotopically distinct overgrowths can nucleate at the edges of graphite books and progress outward, "enlarging the pages," or they can append to the surface of a graphite book, "adding new chapters." This threedimensional aspect of graphite grain growth has not been documented by previous workers and relies on interpretations made by isotopic studies that are based on layer-peeling techniques. A final advantage of the ion microprobe techniques is that the petrographic context is preserved and can provide additional insight into the timing, mechanics, and chemistry of growth for specific generations of graphite. These techniques have tremendous potential to provide new and interesting insights into other environments where graphite precipitation occurs.

\section{EXPERIMENTAL STUDY OF ADSORPTION/DESORP-} TION KINETICS AND THERMODYNAMICS OF EDTABACTERIA INTERACTIONS. J. B. Fein, Civil Engineering and Geological Sciences, University of Notre Dame, Notre Dame IN 46556, USA (fein.1@nd.edu).

Interactions between dissolved organic acids and bacterial surfaces can control the subsurface mobility of aqueous contaminants. Not only can these interactions affect organic molecule transport, but because organic acid anions can form both aqueous and surface complexes with contaminant metals, the interactions can strongly influence metal mobility as well. Our ability to quantify these interactions is extremely limited due to a lack of quantitative data on dissolved organic-bacteria adsorption behavior.

Adsorption of EDTA onto a single species of bacteria (Bacillus subtilis) was measured as a function of $\mathrm{pH}$, time, and solute:surface area ratio in a fixed ionic strength electrolyte. Desorption experiments were also conducted to investigate the rate and extent of the reversibility of the adsorption reactions. EDTA was studied as a representative multifunctional carboxylic acid and because it occurs as a co-contaminant with radionuclides at several DOE contaminated groundwater sites. $B$. subtilis, a gram-positive species, was chosen because it represents a common type of subsurface aerobic bacteria and because its surface chemistry is well characterized [1].

The adsorption of EDTA onto $B$. subtilis is rapid (equilibrating within $60 \mathrm{~min}$ ) and reversible. Although EDTA sequentially deprotonates over the $\mathrm{pH}$ range 2.5 to 11.0 , there is no $\mathrm{pH}$ depen- 
dence to the adsorption behavior. These results suggest that hydrophobic solute-surface interactions control EDTA adsorption, rather than the electrostatic effects that dominate metal-bacterial interactions.

The experimental results are modeled with an equilibrium thermodynamics approach, and the resulting equilibrium constants for the dominant adsorption reactions provide a quantitative framework for including the effects of bacteria on organic transport in fluid-rock systems. Therefore, this approach enables the extent of adsorption to be estimated for more complex systems.

References: [1] Rein et al. (1997).

MONSOONAL CIRCULATION AND CHEMICAL WEATHERING IN THE LATE MIOCENE. G. M. Filippelli, Department of Geology, Indiana University, 723 West Michigan Street, Indianapolis IN 46202-5132, USA (gfilippe@iupui.edu).

Massive warm rainfall events in late summer from the Asian monsoon, combined with high elevations, result in a disproportionate amount of chemical weathering occurring in the HimalayanTibetan Plateau; dissolved chemical fluxes in rivers draining this region account for about $25 \%$ of the global total, even though this region constitutes only slightly more than $4 \%$ of the global drainage area. Oceanic and continental records have led many researchers to suggest that the Asian monsoon may have intensified about $8 \mathrm{~m}$.y. ago, possibly as a result of an uplift event in the Himalayan-Tibetan Plateau. The goal of this paper is to thoroughly document the effect that the proposed intensification of the Asian monsoon and monsoonal circulation in the Andes/Amazon Basin at about $8 \mathrm{Ma}$ had on continental weathering, geochemical and sedimentological fluxes to the ocean, and biogeochemical cycles in the ocean, and suggest the possible feedbacks to global climate.

Several sedimentary, geochemical, and isotopic records indicate that the hypothesized intensification of the Asian monsoon at about $8 \mathrm{Ma}$ triggered a physical and chemical weathering event in the Himalayan-Tibetan Plateau. Evidence also exists for a similar event that may have occurred simultaneously in the Andes Mountains. Records of sediment input and clay composition from the northem Indian Ocean reveal clear weathering changes in the plateau at this time, and $\mathrm{Ge} / \mathrm{Si}$ ratios of opaline silica as well as biogenic sedimentation rates indicate that increased dissolved element fluxes from this weathering event had an oceanwide effect. Perhaps the most important impact of this weathering event was to increase the net flux of the biolimiting nutrient phosphorus to the ocean, as evidenced by a peak in phosphorus accumulation rates at this time. The temporary increase in nutrient inputs to the ocean triggered increased oceanic productivity and organic $\mathrm{C}$ burial (recorded in $\mathrm{C}$ isotopic records and paleooxygen concentrations). The net result of this weathering event may have been an increase in the rate of drawdown of atmospheric $C$ through the Late Miocene-Early Pliocene, via direct silicate weathering reactions and increased burial of organic $\mathrm{C}$ in the ocean. This increased rate of atmospheric $\mathrm{CO}_{2}$ drawdown may have destabilized the climate system by the Late Pliocene, thus initiating a period of intense cooling and ice buildup leading to the present.

MOLECULAR MODELS OF CALCITE: STRUCTURE, DEFECTS, AND DIFFUSION. D. K. Fisler and R. T. Cygan,
Geochemistry Department, Sandia National Laboratories, Albuquerque NM 87185-0750, USA.

Computer simulations of the defect structure and diffusion of cations in calcite provides an atomistic framework for understanding the solid-state kinetic behavior of carbonate minerals. By using the observed crystal structure and the dielectric and elastic constants for calcite to obtain the appropriate interatomic potentials, we are able to perform energy minimization and molecular dynamic (MD) simulations for the ideal calcite structure and for various defect conditions. The computer simulations rely on an empirical forcefield that describes the energies associated with bond stretch, bond angle bend, and out-of-plane torsion for the carbonate ions, in addition to the nonbonded energies associated with electrostatics and short-range interactions (repulsion and van der Waals energies) for all atoms. We allow all atomic positions of the crystal structure and the cell parameters (to simulate constant pressure conditions) to optimize during an energy minimization calculation with periodic boundary conditions. Partial charges are assigned for the $\mathrm{C}$ and $\mathrm{O}$ atoms of the carbonate ion, and a formal charge of $2+$ for the $\mathrm{Ca}$ cation. Simulations provide an energy-optimized structure for calcite that is in very good agreement with the observed structure.

The MD calculations are performed at elevated temperatures (required to ensure cation migration for practical computational times), thereby providing a method of determining the relative rates of cation diffusion at various temperatures. Point defects such as Schottky vacancies and Frenkel interstitials are introduced into the calcite structure so that vacant sites are available for the $\mathrm{Ca}$ ion (or other cation such as $\mathrm{Mn}^{2+}, \mathrm{Mg}^{2+}$, and $\mathrm{Fe}^{2+}$ ) to diffuse in the structure. We perform energy minimization for each defect structure, then MD simulations to calculate the self-diffusion coefficients for

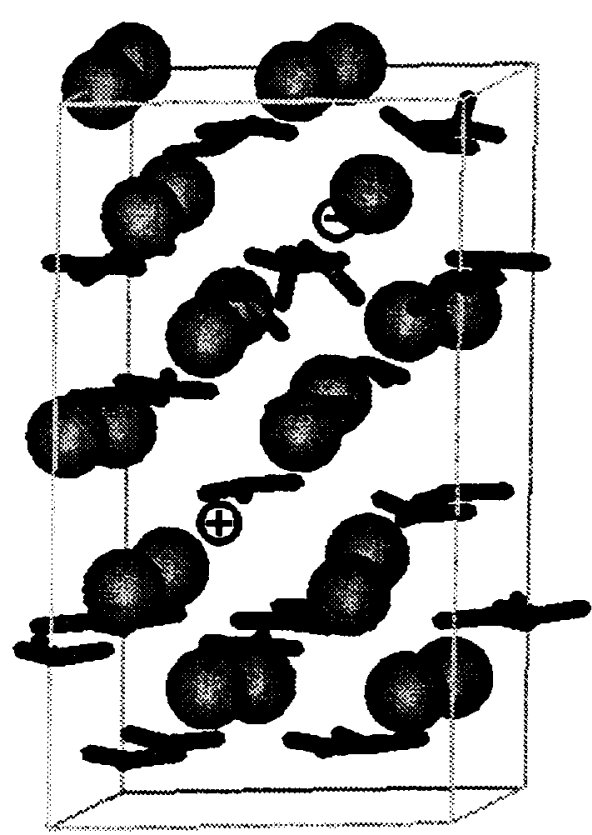

Fig. 1. Energy-minimized structure of calcite containing a single Schottky pair defect $\left(\mathrm{Ca}^{2+}\right.$ and $\mathrm{CO}_{3}{ }^{2-}$-vacancies, as denoted by - and +circles respectively) based on an expanded assemblage of four unit cells. P1 symmetry, and periodic boundary conditions. 
$\mathrm{Ca}$ at various defect conditions. Assuming that there is no change of cation diffusion mechanism for a large temperature range, the calculated rates can be used to obtain appropriate Arhenius parameters. The calcite structure with a Schottky defect added (removal of $\mathrm{Ca}^{2+}$ and $\mathrm{CO}_{3}{ }^{2-}$ pair) has been energy minimized at constant pressure and is shown in the Fig. 1. Note the distortion and rotation of the carbonate groups (nonplanar) about the two defect sites due to the strong influence of electrostatics associated with each defect site. The calculated defect formation and cation migration energies can be compared to the activation energies obtained from our experimental measurements of $\mathrm{Ca}$ self-diffusion in carbonates at $500^{\circ}$ $700^{\circ} \mathrm{C}$

Acknowledgments: This research was supported by the U.S. Department of Energy, Office of Basic Energy Sciences, Geosciences Research, under contract DE-AC04-94AL85000 with Sandia National Laboratories.

RHEOLOGY AND KINETICS OF REPLACEMENT. R. C. Fletcher' ${ }^{1}$ and E. Merino' ' 'Earth and Environmental Sciences, New Mexico Institute of Mining and Technology, Socorro NM 87801, USA, ${ }^{2}$ Geological Sciences, Indiana University, Bloomington IN 47405, USA.

Replacement is isovolumetric and preserves the delicate structure of the replaced phase; host dissolution is restricted to the guest/ host interface [1]. Replacement implies (1) coupling of guestmineral growth and dissolution of host; (2) growth rate = dissolution rate, an equality established by the increasing interface normal stress; and (3) host phase remains at saturation away from the interface. When growth of guest $A$ is accommodated by dissolution of the B host phase alone [2], the increase in normal stress and the linear-kinetics growth rate are

$$
\begin{gathered}
s_{\pi}(\infty)-\sigma_{\pi}(a)=K_{A} \Delta \mu^{A}\left(K_{A} V_{0}^{A}+K_{B} V_{0}^{B}\right)^{-1} \\
d a / d t=K_{A} \Delta \mu^{A}\left[K_{B} V_{0}^{B} /\left(K_{A} V_{0}^{A}+K_{B} V_{0}^{B}\right)\right]
\end{gathered}
$$

where a is the radius of a spherical crystal (or crystal aggregate), $\sigma_{\pi}(\infty)$ is the far-field radial stress, $K_{A}$ and $K_{B}$ are kinetic constants, $V_{0}{ }^{A}$ and $V_{0} B$ are specific volumes, and the chemical potential of component $A$ exceeds the equilibrium value at hydrostatic stress $\sigma_{\pi}(\infty)$ by $\Delta \mu^{A}$. The factor in brackets, $<1$, reduces the growth rate below its unconstrained value.

We extend these results by analysis of host stress and deformation. Transport is assumed sufficiently rapid to be ignored. A crystal growing in a host rock is simulated by embedding it in a spherical shell of radius $b$, with $\sigma_{\pi}$ (b) equal to the imposed stress. Results for an isolated crystal are obtained by letting $b \rightarrow \infty$.

Let the increment $\Delta \mu^{A}$ be applied to a system at equilibrium. For an incompressible viscoelastic (Maxwell) host with viscosity $\eta$ and Young's modulus $E$, and for $b \rightarrow \infty$, we obtain da/dt $=K_{A}\left\{\Delta \mu^{A}+\right.$ $\left.\left[\sigma_{\pi}(a, t)-\sigma_{\pi}(\infty)\right] V_{0}^{A}\right\}$ and $\sigma_{\pi}(\infty)-\sigma_{\pi}(a, t)=4 \eta K_{A} \Delta \mu^{A}[1+4 \eta$ $\left.\left(\mathrm{K}_{\mathrm{A}} \mathrm{V}_{0}{ }^{A}+\mathrm{K}_{\mathrm{B}} \mathrm{V}_{0}^{\mathrm{B}}\right)\right]^{-1}\left(1-\mathrm{e}^{-1 / t^{*}}\right)$, with $\mathrm{t}^{*}=(3 \eta / E)\left[1+4 \eta\left(\mathrm{K}_{\mathrm{A}} \mathrm{V}_{0}{ }^{A}+\right.\right.$ $\left.\left.K_{B} V_{0}^{B}\right)\right\}^{-1}$. The growth rate of $A$ starts at the unconstrained value. The dissolution rate of $B$ starts at zero. Growth is now accommodated by both host dissolution and deformation. Reduction from the unconstrained rate is less than in equation ( $1 \mathrm{~b})$.

The finite-b model gives the long-time limit da/dt $=K_{A} \Delta \mu^{A}$
$\left\{\left\{1-\mathrm{K}_{\mathrm{A}} \mathrm{V}_{0} \mathrm{~A} /\left\{\mathrm{K}_{\mathrm{A}} \mathrm{V}_{0}{ }^{A}+\mathrm{K}_{\mathrm{B}} \mathrm{V}_{0}{ }^{\mathrm{B}}+(\mathrm{a} / \mathbf{4} \eta)\left[1-(\mathrm{a} / \mathrm{b})^{3}\right]^{-1}\right\}\right\}\right\}$. If viscous flow is important, the growth rate of nearby crystals with the same radius, $a$, increases, since $b$ is smaller. This provides a feedback for segregation, but its sensitivity is small unless $a / b \approx 1$. The ratio of accommodation by viscous flow to that by dissolution is $F=(a / 4 \eta)$ $\left[1-(a / b)^{3}\right]^{-1} / K_{B} V_{0}{ }^{B}$.

Overlap of stress "halos" around several growing grains may cause rock failure. Host shells are subject to circumferential tensions. For an elastic-plastic host with maximum shear stress at yield $\tau_{Y}$, equation (1b) describes the growth rate until the radius of the region of plastic yielding is the entire host shell, $R=b$. The relation

$$
\begin{aligned}
& (1 / 3)\left[1-(R / a)^{3}(a / b)^{3}\right]+\ln (R / a)= \\
& \mathrm{K}_{\mathrm{A}} \Delta \mathrm{m}^{\mathrm{A} /} /\left\{\left(\mathrm{K}_{\mathrm{A}} \mathrm{V}_{\mathrm{O}}^{\mathrm{A}}+\mathrm{K}_{\mathrm{B}} \mathrm{V}_{0}{ }^{\mathrm{B}}\right) 2 \sqrt{3 \tau_{\mathrm{Y}}}\right\}
\end{aligned}
$$

gives the supersaturation at initial yielding, $R=a$, and at yielding of the entire shell, $\mathbf{R}=\mathbf{b}$. For greater supersaturation, growth is also accommodated by plastic flow.

References: [1] Maliva and Siever (1988). [2] Merino et al. (1993).

ELEMENTAL FLUX RATES AND RESIDENCE TIMES IN SUBDUCTION-INFLUENCED MANTLE. J. D. Foden and M. Elburg1, 'Department of Geology and Geophysics, University of Adelaide, Adelaide, South Australia 5005, Australia (joden@ geology.adelaide.edu.au).

The magmatic rocks that build island- and continental marginal arcs show great geochemical diversity. This variation involves changing concentrations of incompatible and lithophile trace and minor elements, which are concentrated in evolved continental cnust. The concentrations of some of these elements (e.g., $\mathrm{Ba}, \mathrm{Rb}, \mathrm{Cs}$ ) show intra- and interarc variations of $<3$ orders of magnitude. Combined radiogenic isotope and trace-element studies have regularly demonstrated that this elemental diversity (exclusive of magmatic fractionation), both within single-arcs and between different arcs, is a multicomponent mixing process.

In addition to components from the supra Benioff Zone wedge and from fluid derived from the slab, at least a third component is required, providing are magmas with isotopic and geochemical characteristics matching those of evolved continental crust. This is particularly recognized in arcs in complex tectonic settings such as the Mediterranean, the Aegean, and in Indonesia and leads to the development of $\mathrm{K}_{2} \mathrm{O}$-rich suites. In question is whether this component is present but at lower concentrations in oceanic arcs such as the Marianas.

Geochemical characteristics of this source (or sources) include very high $\mathrm{K} / \mathrm{Nb}, \mathrm{Ba} / \mathrm{Nb}$, and high $\mathrm{Ce} / \mathrm{Y}$. It also has high $\mathrm{Th} / \mathrm{Yb}$ and $\mathrm{Th} / \mathrm{Ce}$ and low U/Th. Magmas enriched in this component don't show U-series disequilibrium and have low ${ }^{230} \mathrm{Th} /{ }^{232} \mathrm{Th}$ and ${ }^{238} \mathrm{U} /$ ${ }^{232}$ Th values. They have $\kappa_{\mathrm{Th}}$ values that reflect a source with a longterm history of high Th/U. The Nd- and SI-isotopic characteristics imply a source with a moderately long history of LREE enrichment at moderate $\mathrm{Rb} / \mathrm{Sr}$ and $\mathrm{U} / \mathrm{Pb}$.

In order to identify and resolve separate end members in arc systems, in the Eastern Sunda Arc, Indonesia, we have tracked the addition and then gradual loss of new exotic components to the magmatic mix by documenting temporal or spatial variation in arc 
magmatic chemistry. These eastern Indonesian magmatic arc systems are of Early Miocene through Recent age and show geochemical anomalies that are the response to at least three microcontinental collisions. For instance, Pliocene and modern data from the Eastem Sunda arc show that the K-rich component increased dramatically in the Sumbawa arc sector over a 2-m.y. period, but remained low in adjacent arc sectors. This reflects the localized introduction of a new and different source to the subduction zone following the collision of the island of Sumba (micro-continent) with the forearc and trench. Our data suggest that geochemical anomalies have quite short residence times in the wedge ( $<10 \mathrm{~m} . \mathrm{y}$.). Geochemical anomalies that originate in the slab and pass through the wedge en route to the crust have relatively gradational spatial limits, while geochemical variation with very high frequency spatial variation $(>100 \%$ / $50 \mathrm{~km}$ ), such as those observed in Central Sulawesi, must originate from lithospheric contamination.

THE SHIANT ISLES MAIN SILL: NEODYMIUM AND STRONTIUM ISOTOPES TELL THE TALE OF TWO MAGMAS AND SUBSOLIDUS ALTERATION. K. A. Foland ${ }^{1}$, F. G. F. Gibb ${ }^{2}$, and C. M. B. Henderson ${ }^{3}$, 'Department of Geological Sciences, Ohio State University, Columbus OH 43210 , USA, 'Department of Earth Sciences, University of Sheffield, Brookhill, Sheffield S3 7HF, UK, ${ }^{3}$ Department of Earth Sciences, University of Manchester, Manchester M13 9PL, UK.

The Shiant Isles Main Sill in the Outer Hebrides, which is of Tertiary age, is a classic example of a composite, differentiated alkaline basic sill. A recent petrographic and chemical study by Gibb and Henderson has shown that this well-known locality is composed of four intrusions. The first unit to be intruded was a 2m-thick olivine teschenite that was then intruded by a 24 -m-thick picrite sill. A subsequent intrusion that produced a 140 -m-thick picrodolerite-crinanite unit was emplaced before the host was completely solidified. The last intrusion unit formed, a 2-m-thick granular olivine picrodolerite, was emplaced into the upper crinanites before the host was entirely solidified. Neodymium and Sr isotopic study of the sill from bottom to top clarifies the petrogenesis and extensive subsolidus alteration by deuteric and hydrothermal fluids that produced the extensive formation of analcime and zeolites that appears to be preferential along the margins. Overall, the initial

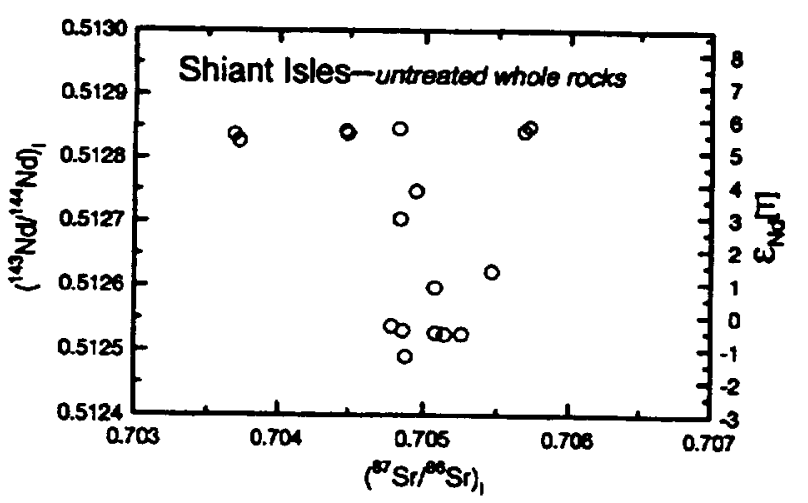

Fig. 1.

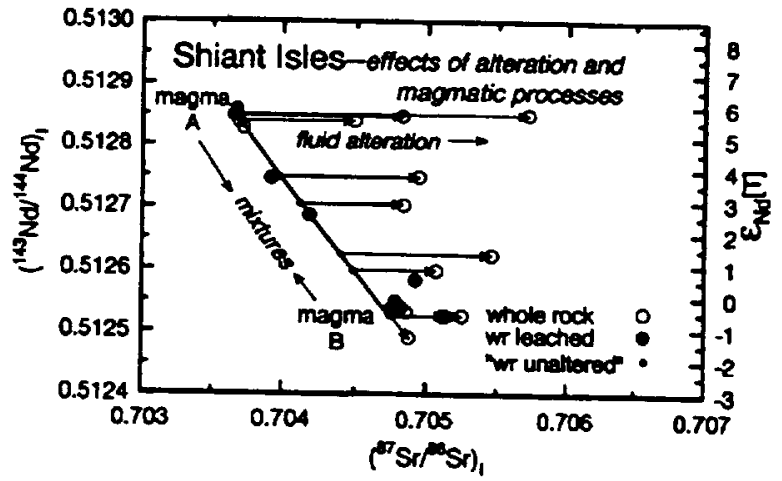

Fig. 2.

${ }^{87} \mathrm{Sr} / 86 \mathrm{Sr}$ ratios show considerable dispersion from $\sim 0.7036$ to -0.7057 , while initial ${ }^{143} \mathrm{Nd} / 144 \mathrm{Nd}$ ratios vary from $\sim 0.51250$ to 0.51285 . As illustrated in Fig. 1, the initial ratios are not well correlated, falling in a large triangular field.

Much of the scatter in ${ }^{87} \mathrm{Sr} /{ }^{86} \mathrm{Sr}$ for whole-rock samples may be anticipated to reflect the ubiquitous subsolidus, aqueous alteration. To investigate this effect, whole-rock powders where leached in $2 \mathrm{~N}$ $\mathrm{HCl}$ at room temperature. With only a 100 -min immersion, considerable $\mathrm{Sr}$ (generally $30 \%$ or more) is removed and the resulting ${ }^{87} \mathrm{Sr}$; ${ }^{86} \mathrm{Sr}$ ratios and calculated initial ratios are substantially reduced. The ${ }^{143} \mathrm{Nd} / 144 \mathrm{Nd}$ ratios and calculated initials are virtually unchanged, although a large fraction (generally more than 60\%) of the Nd is removed. Analysis of the powders by X-ray diffraction shows that the analcime is completely dissolved. This treatment appears to remove radiogenic Sr that may be attributed to subsolidus alteration, some of which has apparently involved fluids that have interacted with the country rock and become enriched in ${ }^{87} \mathrm{Sr}$. It appears to do so effectively since multiple samples produce the same residual values. Analysis of zeolites and the dissolved components confirms higher ratios, as high as 0.7063 . With this treatment, the original magmatic signatures are revealed and the initial ${ }^{87} \mathrm{Sr}$; ${ }^{86} \mathrm{Sr}$ and ratios are seen to be well correlated inversely with ${ }^{143} \mathrm{Nd} /$ ${ }^{144} \mathrm{Nd}$ ratios. As seen with initial ${ }^{143} \mathrm{Nd} /{ }^{144} \mathrm{Nd}$ ratios, the samples are not well distributed between the two extremes but rather cluster near the lowest and highest values with only a handful of samples in between.

Thus, the initial ${ }^{143} \mathrm{Nd} /{ }^{144} \mathrm{Nd}$ ratios and the initial ${ }^{87} \mathrm{Sr} /{ }^{86} \mathrm{Sr}$ ratios of leached samples point to two isotopic compositions, near 0.7036 and 0.51285 and about 0.7048 and 0.51250 . These compositions characterize two magmas, A and B. Apparently the composite sill involved just two magmas that by the time of emplacement were isotopically distinct but fairly uniform. Only limited mixing is observed, and is restricted to the contact zones between the two main intrusions. The first two intrusions were formed from magma A with magma $B$ producing the main picrodolerite-crinanites. Magma $B$ appears to be a contaminated and somewhat fractionated batch of the A-type primary magma; this was probably produced by crustal contamination during a short interval at depth, during which extensive olivine fractionation occurred.

XENOTIME: ITS COMPOSITIONAL DIVERSITY AND BEARING ON THE HREE EVOLUTION IN PERALUMI- 
NOUS GRANITES. H.-J. Förster, GeoForschungsZentrum Potsdam, Telegrafenberg, 14473 Potsdam, Germany (forhj@gfzpotsdam.de).

Accessory minerals constitute the major hosts of lanthanides and actinides in a variety of crustal rocks, especially in peraluminous granites. In contrast to minerals such as zircon and monazite, the ( $Y$, HREE) phosphate xenotime is rarely studied. Comprehensive analytical data for this mineral are almost completely lacking, and its compositional dependence on the geochemistry of the host granites is only poorly understood.

In our study of xenotime, some 250 grains from weakly to strongly peraluminous granites ( $\mathrm{A} / \mathrm{CNK}=1.0-1.35$ ) of the Erzgebirge metallogenic province (Germany) have been analyzed by WDSelectron microprobe. The geochemically diverse and partly highly differentiated rocks comprise low-F biotite $[\mathrm{A}]$ and two-mica granites [B] of mixed I-S-type affinity, high-F, high-P S-type Li-mica granites $[\mathrm{C}]$, and high-F, low-P biotite and Li-mica granites of Atype affinity [D]. The presence of xenotime in this variety of granites offers an ideal opportunity to investigate the compositional variability of granitic xenotimes in general.

In fresh xenotimes, the sum of thorite $\left(\mathrm{ThSiO}_{4}\right)$, coffinite $\left(\mathrm{USiO}_{4}\right)$. monazite $\left((\mathrm{La}-\mathrm{Sm}) \mathrm{PO}_{4}\right)$, and brabantite $\left((\mathrm{Ca}, \mathrm{Th}, \mathrm{U})\left(\mathrm{PO}_{4}\right)_{2}\right)$ substitutions was found never to exceed $10 \mathrm{~mol} \%$. Xenotime does not accept significant $(\mathrm{La}-\mathrm{Sm}) \mathrm{PO}_{4}$ substitution, which rarely amounted to $2 \mathrm{~mol} \%$. It usually shows a substantial preference of $U$ over $T h$, contrary to the case of monazite. However, some xenotimes, especially in group $\mathrm{D}$ granites, have $\mathrm{Th} / \mathrm{U}$ ratios greater than 5 . Uranium and Th concentrations reach maximum values close to $6 \mathrm{wt} \%$ (in group $\mathrm{C}$ granites) and $5 \mathrm{wt} \%$ (in group D granites) respectively.

The analytical data support a complete miscibility between the theoretical end members HREE-PO ${ }_{4}$ and $\mathrm{YPO}_{4}$ in the range of 16$42 \mathrm{~mol} \%$. Xenotimes from group $\mathrm{C}$ granites are the most depleted in HREE, and those from group D granites are the most enriched. Usually, the proportions between (Gd-Ho) $\mathrm{PO}_{4}(20 \mathrm{~mol} \%$ at a maximum) and ( $\mathrm{Er}-\mathrm{Lu}) \mathrm{PO}_{4}$ (27 mol\% at a maximum) do not deviate strongly from unity and closely resemble those in the host rocks. Important exceptions are displayed by xenotimes from S-type granites, which have a predominance of the lighter HREE, whereas those from granites of A-type affinity are particularly rich in the heavier HREE. The entire ranges of HREEs of even atomic number was determined as follows: Gd: $2.0-4.8 w t \%$, Dy: 2.8-7.6 wt\%, Er: 1.6$6.4 \mathrm{wt} \%, \mathrm{Yb}: 0.6-12.3 \mathrm{wt} \%$.

This study revealed that the composition of granitic xenotime may vary considerably with respect to the absolute concentrations of lanthanides and actinides and the relative proportions among them. There is a strong dependence of xenotime chemistry on the composition of the host rock. Xenotime is rarely considered in discussing the HREE evolution of granites. However, our study implies that this mineral is present in a wide variety of granitic rocks and often occurs in an abundance sufficiently large to account for more of the HREE budget of a given rock than "common" accessories such as monazite, zircon, apatite, and gamet.

The chemical variability of xenotime from granites of the Erzgebirge is greater than previously reported from granitic pegmatites [1,2], metapelites [3], and other granites [4], the only occurrences from which sufficient data are available in the literature to allow comparison.

References: [1] Åmli R. (1975). Am. Mineral., 60, 607-620. [2] Demartin F. et al. (1991). Can. Mineral., 29, 69-75. [3] Franz
G. et al. (1996) Eur. J. Mineral., 8, 1097-1118.[4] Casillas R. et al. (1995). Eur. J. Mineral., 7, 989-1006.

AN ARCHEAN ALKALINE PICRITE SUITE AND THE TEMPORAL EVOLUTION OF THE MANTLE SOURCES OF TERRESTRIAL MAGMAS. D. Francis ${ }^{1}$ and R. Johnstone ${ }^{2}$, 'Department of Earth and Planetary Sciences, McGill University, 3450 University Street, Montréal, Québec H3A 2A7, Canada, ${ }^{2}$ Resources, Wildlife, and Development, Government of the Northwest Territories, Yellowknife, P.O. Box 1320, N.T. X1A 2L9, Canada.

The observed temporal evolution of igneous activity on both the Moon and Mars calls into question the commonly held assumption that the petrogenesis of Precambrian volcanic suites can be understood in terms of models developed for Phanerozoic volcanism. Until recently, a meaningful comparison of Precambrian and modem volcanism has been hampered by the apparent absence of ocean island basalt (OIB)-type suites in Precambrian terranes. Recently, however, alkaline picrite suites have been discovered in the early Proterozoic of the Baltic Shield [1] and the Cape Smith fold belt [2] of northern Québec, and now in the Lake of the Enemy greenstone belt in the Archean Slave Province of the Canadian Shield. These alkaline picrites are characterized by high $\mathrm{Nb}$ and $\mathrm{Fe}$ and low, $\mathrm{Si}$ contents, and appear to be the Precambrian equivalents of Hawai' ianlike picritic lavas. A comparison of the spectrum of Precambrian lavas with $<12$ wt\% $\mathrm{MgO}$ with that established for Phanerozoic lavas [3] reveals that both are characterized by a bimodal population in terms of AlTi ratio. A high AlTi group comprises modem interplatepicrites Proterozoic komatiitic basalts, and Archean komatiites, while a low AlTi group comprises modern intraplate picrites, and both Proterozoic and Archean alkaline picrites. Despite this similar bimodality, however, the Precambrian high-MgO lavas are shifted to higher Fe contents than their Phanerozoic equivalents. This is particularly true for the Precambrian alkaline picrites which contain $50 \%$ or more $\mathrm{Fe}$ than Phanerozoic picrites with equivalent $\mathrm{Al} / \mathrm{Ti}$ ratios. The fact that the $\mathrm{Mg}$ contents of both Phanerozoic and Precambrian alkaline picritic lavas are similar suggests that the $\mathrm{Fe}$ rich nature of the latter was not simply a function of higher mantle temperatures in the Precambrian, but rather a more Fe-rich mantle source. These features suggest that Phanerozoic and Precambrain picrites share similar bimodal mantle source regions that have become less Fe-rich with time.

References: [1] Hanski E. J. and Smolkin V. F. (1989). [2] Gaonc'h et al. (1992). [3] Francis (1995).

THE DISSOLUTION MECHANISMS OF PERICLASE AND FORSTERITE: A MECHANISM FOR THE INCORPORATION OF WATER IN THE DEEP MANTLE. D. G. Fraser', A. J. Berry ${ }^{1}$, K. Refson ${ }^{1}$, J. A. Mejias ${ }^{1}$, and R. A. Wogelius ${ }^{2}$, 'Department of Earth Sciences, University of Oxford, Parks Road, Oxford OXI 3PR,UK (donald.fraser@worc.ox.ac.uk), ${ }^{2}$ Department of Geology, The University of Manchester, Manchester M13 9PL, UK.

Periclase $(\mathrm{MgO})$ and forsteritic olivine are major constituents of the Earth's mantle. Their rheology and the kinetics of reactions with other mantle phases are thought to be strongly influenced by small 
amounts of $\mathrm{H}_{2} \mathrm{O}$. Water may be physisorbed or chemisorbed on these minerals. Subsequently hydration and dissolution takes place by proton-cation exchange and hydrolysis of the oxide framework.

In the present paper we shall show results of studies of $\mathrm{MgO}$ surfaces during dissolution at different $\mathrm{pH}$ values. In agreement with our previous work, $\mathrm{MgO}$ dissolves in high-pH solutions by crystallographically controlled dissolution from particular planes to form an etched surface with pyramidal etch pits. SEM studies show that etching takes place on cleaved (100) surfaces, but only at sparsely scattered sites. In contrast, pre-prepared chemo-mechanically polished (100) surfaces react readily with $\mathrm{H}_{2} \mathrm{O}$ and low-pH solutions to form dense arrays of aligned pyramidal etch pits on the nominal (100) surface. Careful measurement of the angles of the inclined surfaces of these etch pits by scanning probe microscopy gives a range of values and suggests that hydration of $\mathrm{MgO}$ may not proceed by the simple topotactic growth of $\mathrm{Mg}(\mathrm{OH})_{2}$ along $\mathrm{MgO}$ (111) planes as previously proposed by us. In addition, observation of highly localized birefringent platelets on the $\mathrm{MgO}$ surface by scanning confocal microscopy indicates that simple ERDA (Elastic Recoil Detection Analysis) measurements of $\mathbf{H}$-penetration into mineral surfaces may be in error.

To understand the reactions of $\mathrm{MgO}$ surfaces with $\mathrm{H}_{2} \mathrm{O}$ we have carried out a quantum mechanical study using the density functional theory (DFT). The calculations were based on the plane wave pseudopotential method using a generalized gradient approximation (GGA) for the exchange correlation energy. Surface energies of the anhydrous and fully hydroxylated (100), (310), and (111) planes in periclase were calculated. Although the $\mathrm{MgO}(100)$ planes form stable surfaces by cleavage, hydration of these planes to form a hydroxylated $(001)$ surface by the reaction

$$
\mathrm{MgO}^{(100)}+\mathrm{H}_{2} \mathrm{O}^{(v)}=\mathrm{Mg}(\mathrm{OH})_{2}^{(100)}
$$

is unfavorable with $\Delta \mathrm{E}=1.8 \mathrm{~J} \mathrm{~m}^{-2}$.

In contrast, hydration of the (310) and (111) surfaces has a negative energy

$$
\mathrm{MgO}^{(310)}+\mathrm{H}_{2} \mathrm{O}^{(\mathrm{v})}=\mathrm{Mg}(\mathrm{OH})_{2}^{(310)}
$$

with $\Delta \mathrm{E}=-0.47 \mathrm{~J} \mathrm{~m}^{-2}$, and

$$
\mathrm{MgO}^{(111)}+\mathrm{H}_{2} \mathrm{O}^{(v)}=\mathrm{Mg}(\mathrm{OH})_{2}^{(111)}
$$

with $\Delta \mathrm{E}=-2.90 \mathrm{~J} \mathrm{~m}^{-2}$.

An important step in many geochemical reactions involves the detachment of ions from the mineral surface and their diffusion through the near-surface region. The initial detachment step may be rate-determining and involves formation of an ordered surfacesolution complex followed by proton-cation exchange. Calculations of the energetics of $\mathrm{H}_{2} \mathrm{O}$ reactions at edge and corner defects show that $\mathrm{H}_{2} \mathrm{O}$ molecules react readily at such positions. Dissolution occurs when sufficient $\mathrm{H}_{2} \mathrm{O}$ molecules surround a cation to enable its detachment from the surface.

We have followed reactions of this sort in the adsorbed surface boundary layer and in aqueous solution by in situ synchrotron Glancing Incidence X-ray Reflectivity (GIXR). This allows in situ determination of layers of differing electron density on a mineral surface caused by hydration and cation depletion.

The hydroxylation of low-coordination sites such as those present on (310) or (111) surfaces may provide a mechanism for the incorporation of $\mathrm{H}_{2} \mathrm{O}$ in "anhydrous" mantle minerals as hydroxylated defects. For example, OH-bearing defects of this sort have been observed as planes of intercalated $\mathrm{Mg}(\mathrm{OH})_{2}$ defects in olivine. Intercalated $\mathrm{OH}$ defects in olivine and in $\mathrm{MgO}$ may play an important role as water reservoirs in the upper and deep mantle.

\section{RHENIUM-OSMIUM ISOTOPE SYSTEMATICS OF BASE- METAL PORPHYRY AND MANTO-TYPE COPPER DEPOSITS IN CHILE: EVIDENCE FOR A DIFFERENT} SOURCE FOR COPPER. C. Freydier' ${ }^{1}$ J. Ruiz ${ }^{1}$, and F. Munizaga'2, 'Department of Geosciences, University of Arizona, Tucson AZ 85721, USA, ${ }^{2}$ Departamento de Geologia, Universidad de Chile, Santiago, Chile (freydier@geo.arizona.edu).

Chile is the premier copper producer in the world. The largest deposits are porphyry base-metal deposits related to MesozoicCenozoic intrusive activity. Most, if not all, the copper in these deposits is thought to be of magmatic origin, although there is debate as to the source of the copper in the magmatic system. Another significant category of copper mineralization in Chile is the mantotype deposits, which occur in volcanic and volcano-sedimentary sequences of Middle Jurassic to Early Tertiary in age. The genesis of these copper deposits is much more enigmatic than the porphyry base-metal deposits. In many cases the precise age of mineralization is not properly constrained, and in all cases the source of the copper is not known since the copper may have been leached from crustal rocks by a variety of crustal fluids. We analyzed samples for Re-Os isotopes for El Teniente, Andacollo, Pelambres, and La Disputada as typical examples of porphyry base-metal deposits spanning in age from $4 \mathrm{Ma}$ (for example, El Teniente) to $100 \mathrm{Ma}$, (for example, Andacollo). We also analyzed samples of manto deposits such as $\mathrm{El}$ Soldado ( 100 Ma), Talcuna ( $80 \mathrm{Ma})$, and Candelaria in an effort to determine if the Re-Os system can successfully be used to date the age of the mineralization for these types of deposits and to constrain the ultimate source of ore-forming metals in these deposits.

The Re-Os isotopic system is most suitable to date the time of the ore-forming event(s) and constrain the source of the ore-forming elements because $\operatorname{Re}$ and $O$ s are chalcophile and are therefore found in the sulfides themselves. This behavior is in contrast to the lithophile character of all other radiogenic isotopes commonly used (Rb-Sr, Sm-Nd, Lu-Hf) in geosciences. A notable exception is $\mathrm{Pb}$, but the systematics of this element are complex and the metalogenetic studies will benefit from the Re-Os isotope data. A key characteristic of the Re-Os isotope system is the large differences in both concentration and Os isotopic ratios between different Os reservoirs (mantle and crust). This specific characteristic should permit us to properly constrain the source of the $O s$, and by inference, other oreforming metals, in hydrothermal and magmatic systems.

Sulfide separates from El Teniente and Andacollo yield isochrons that are consistent with ${ }^{40} \mathrm{Ar} /{ }^{39} \mathrm{Ar}$ ages for the mineralization. An important characteristic of the sulfides is that they can have ${ }^{187} \mathrm{Re} /{ }^{188}$ Os ratios much greater than 100 , demonstrating that the $\mathrm{Re}-\mathrm{Os}$ isotope system is robust and independent of minor variations in the initial ratio of the samples caused by complexities of hydrothermal systems. Bornite, chalcopyrite, pyrite, and sphalerite from the porphyry copper deposits yield initial ${ }^{187} \mathrm{Os} / 188 \mathrm{O}$ ratios ranging from 0.16 to 0.22 and $O$ s contents of $30 \mathrm{ppt}$ up to $2 \mathrm{ppb}$. The 
relatively homogeneous and radiogenic character of the sulfides suggest that the Os was derived from the causal intrusive and that the magmas had assimilated significant crust. A paragnetically late pyrite with an elevated ${ }^{187} \mathrm{Os} /{ }^{188} \mathrm{Os}$ ratio close to 1 was probably derived by meteoric waters in the periphery of the magmatic system leaching Os from wall rocks. The initial ${ }^{187} \mathrm{Os} /{ }^{188} \mathrm{Os}$ ratios of the manto-type samples are more radiogenic ( $>2$ ) and the Os contents are also higher $(2-70 \mathrm{ppb})$. These radiogenic values require that the Os come from a reservoir with a high $\mathrm{Re} / \mathrm{Os}$ ratio. Black shales may be such a reservoir. The Re-Os data indicate that both porphyry and manto-type deposits acquired their Os from the crust.

HORNBLENDE DISSOLUTION KINETICS AT $25^{\circ} \mathrm{C}$. P. Frogner and P. Schweda, Department of Geology and Geochemistry, Stockholm University, S-10691 Stockholm, Sweden (paul. frogner@geo.su.se).

Hornblende is the most common calcic amphibole; it is also rich in $\mathrm{Mg}, \mathrm{Fe}$, and $\mathrm{Al}$, and represents a key mineral in the PROFILE model [1], which assesses the resistance of soil acidification by rain. This resistance is due to very high dissolution rates for hornblende as compared with other common silicates. This study was initiated to understand the discrepancies between reported amphibole dissolution rates. Rates and stoichiometry of homblende dissolution have been obtained through experiments with flow-through reactors and pure $\mathrm{HCl}$ solutions, at $\mathrm{pH} 1-5$. The effects of electrolytes were

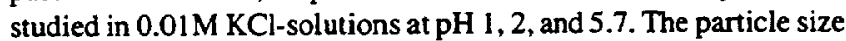
used for a homblende sample from Kragerö was 125-250 $\mu \mathrm{m}$ with BET initial surface areas of $0.283 \mathrm{~m}^{2} \mathrm{~g}^{-1}$. Similar Si release rates, $1.96 \times 10^{-11} \mathrm{~mole} / \mathrm{m}^{2} / \mathrm{s}$, were obtained at $\mathrm{pH} 1$ and 2 , after $2000 \mathrm{hr}$, but the logarithm of the dissolution rate for homblende is proportional to $-0.47 \mathrm{pH}$ at $\mathrm{pH} 3-5$. This $\mathrm{pH}$ dependence is lower than reported previously by Zhang et al. [2] and Sverdrup [3], but similar to values obtained with feldspars [4]. The surface-area-normalized rate agrees well with the data of Zhang et al. [2], at pH 3.6-4.0, whereas rates by Sverdrup[3] are over $100 \times$ higher at $\mathrm{pH} 2.4-5.4$.

Two leaching "regimes" are suggested with regard to homblende dissolution stoichiometry. At pH 5, Ca is depleted from the near surface with a maximum of $12-15 \mathrm{~nm}$, which is already reached during the first $100 \mathrm{hr}$ at the same time that $\mathrm{Al}, \mathrm{Mg}$, and $\mathrm{Fe}$ become stoichiometric with respect to $\mathrm{Si}$. In more acidic solution with $\mathrm{pH} 4$, $\mathrm{Al}$ (but also $\mathrm{Mg}$ and $\mathrm{Fe}$ ) most prominently undergoes preferential leaching. The growth rate and thereby thickness of the Al depleted layer vary with $\mathrm{pH}$ and become higher at low $\mathrm{pH}$. A maximum Aldepletion depth of about $100 \mathrm{~nm}$ is obtained after 2000 and $6000 \mathrm{hr}$ at $\mathrm{pH} 1$ and 2 respectively, but at $\mathrm{pH} 3$ and 4 this depth still was increasing after $7000 \mathrm{hr}$, having reached 50 and $20 \mathrm{~nm}$ respectively.

Stoichiometry for $\mathrm{Fe}, \mathrm{Mg}$, and $\mathrm{Ca}$ with respect to $\mathrm{Si}$ and the calculations of residual layer depth for $\mathrm{Al}$ thus show that steady state for the dissolution of hornblende is obtained after $3000 \mathrm{hr}$ at $\mathrm{pH}$ I and after $6000 \mathrm{hr}$ at $\mathrm{pH} 2$. However, at $\mathrm{pH} 3$ and 4 , steady state is not obtained during the 7000-hr study. At pH 5.0-5.7, on the other hand, steady state was obtained during the first $100 \mathrm{hr}$.

References: [1] Sverdrup H. and Warfvinge P. (1992) Appl. Geochem., 27. [2] Zhang H. et al. (1996) GCA, 60, 941-950. [3] Sverdrup H. (1990) The Kinetics of Base Cation Release Due to Chemical Weathering, Lund Univ., 245 pp. [4] Schweda P. (1990) Kinetics and Mechanisms of Alkali Feldspar Dissolution at Low
Temperatures, Medelande från Stockholms universitets institution für geologi och geokemi, \#281, 99 pp.

EXPERIMENTAL DETERMINATION OF THE PARTIAL MOLAR VOLUME AND COMPRESSIBILITY OF SILICON DIOXWE IN SILICATE LIQUWS AT PRESSURES UP TO 35 kbar. G. A. Gaetani, P. D. Asimow, and E. M. Stolper, Division of Geological and Planetary Sciences, California Institute of Technology, Pasadena CA 91125 , USA.

The molar volumes of silicate liquids provide constraints on the rates of buoyancy-driven melt segregation, on the structure of silicate liquids, and on the nature of crystal-liquid differentiation processes. Available experimental data on the density and compressibility of silicate liquids primarily comprise high-temperature volume and compressibility determinations performed at 1 bar, supplemented by limited measurements at higher pressures. Molar volumes (and partial molar volumes) determined at 1 bar cannot be reliably extrapolated to high pressures because structural changes may occur in the silicate melt. Although, in principle, density measurements of melts covering a sufficiently wide compositional range at elevated pressures could be used to derive partial molar volumes of oxide components under these conditions, in practice, such information is not currently available.

Here we present preliminary results from a new approach to determine the partial molar volume of $\mathrm{SiO}_{2}$ in silicate melts at elevated pressures. The pressure-dependent change in the solubility of quartz in a particular base-melt composition is measured at constant temperature (Fig. 1). Given (1) knowledge of the chemical potential of $\mathrm{SiO}_{2}$ in silicate meits at 1 bar as a function of composition (calculated using MELTS, the mixing model of Ghiorso and Sack [1]), (2) that the chemical potential of $\mathrm{SiO}_{2}$ in the $\beta$-quartzsaturated melt at each pressure can be determined given knowledge of the thermochemistry and volume of $\beta$-quartz, (3) that the pressure derivative of the chemical potential of $\mathrm{SiO}_{2}$ is simply related to the

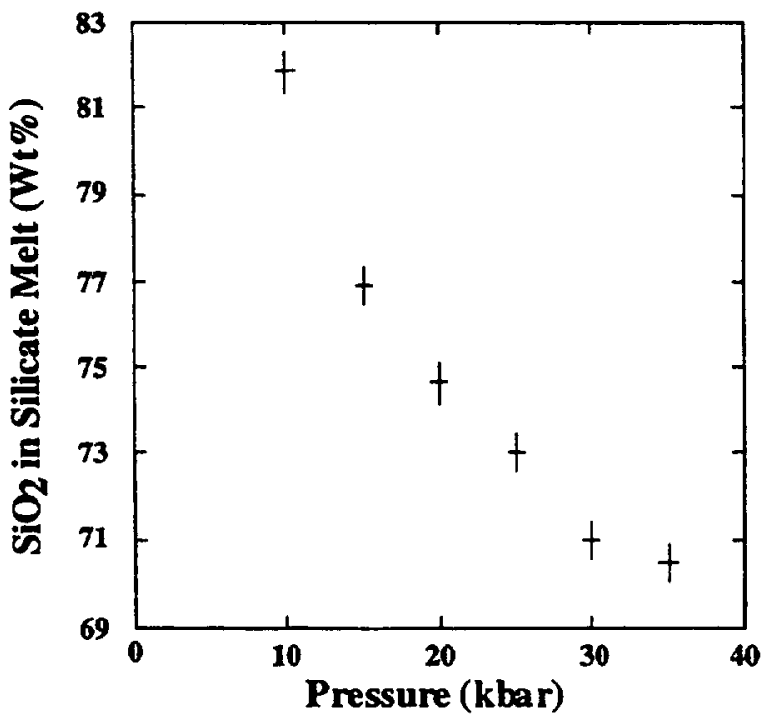

Fig 1. Plot of pressure vs. $\mathrm{SiO}_{2}$ content of experimentally-produced silicate liquids saturated with $\beta$-quartz. Error bars are 10 . 
partial molar volume of $\mathrm{SiO}_{2}$, and (4) the assumption (validated over the compositional range of interest at 1 bar) that the partial molar volume of $\mathrm{SiO}_{2}$ in silicate melts is independent of composition, it is possible to derive from these measurements the partial molar volume of $\mathrm{SiO}_{2}$ in these melts as a function of pressure. Although we apply the technique here to $\mathrm{SiO}_{2}$ by measuring quartz solubility, the technique is equally applicable to determining the partial molar volume of alumina (by measuring the pressure dependence of corundum solubility), titania (by measuring rutile solubility), and so on for a wide range of oxide or mineral components.

Experiments to produce silicate liquids saturated with $\beta$-quartz were carried out at pressures of 10,15,20,25, 30, and $35 \mathrm{kbar}$ and a temperature of $1350^{\circ} \mathrm{C}$ using a piston-cylinder device. Starting materials consisted of either a natural high- $\mathrm{SiO}_{2}$ rhyolite $(77.1 \mathrm{wt} \%$ $\mathrm{SiO}_{2}$ ) from Glass Buttes, Oregon, or a mixture of this rhyolite and amorphous $\mathrm{SiO}_{2}$. Liquid compositions were determined by electron microprobe, and the stable silica polymorph was determined to be quartz by $\mathrm{X}$-ray diffraction.

Assuming that the partial molar volume of $\mathrm{SiO}_{2}$ is linear in pressure, we derive the following expression:

$$
\overline{\mathrm{V}}_{\mathrm{SiO}_{2}}=-8.50 \times 10^{-6}(\mathrm{P}-1)+2.63
$$

where partial molar volume is in $\mathrm{J} / \mathrm{bar}$ and $\mathrm{P}$ is in bars. The 1 -bar partial molar volume for $\mathrm{SiO}_{2}$ determined in this way, $2.63 \pm 0.01$ $\mathrm{J} / \mathrm{bar}$, is slightly smaller than the $2.692 \pm 0.006 \mathrm{~J} / \mathrm{bar}$ determined by Lange and Carmichael [2], but we think the agreement is very promising (all uncertainties are $1 \mathrm{~s}$ ). The pressure dependence of the partial molar volume $\left(-8.50 \times 10^{-6} \pm 7.2 \times 10^{-7} \mathrm{~J} / \mathrm{bar}^{2}\right)$ is approximately one-half the value determined by Lange and Carmichael at $1 \mathrm{bar}\left(-1.73 \times 10^{-5} \pm 0.4 \times 10^{-6} \mathrm{~J} / \mathrm{bar}^{2}\right)$; this difference could reflect the fact that their value is based on 1-bar data, whereas our data are all from $10 \mathrm{kbar}$ or higher, or it could reflect errors or uncertainties in the 1-bar model of melt activities or some other limitation in the assumptions underlying our data analysis. Although these differences will be explored in future work, our preliminary assessment based on this comparison is that this new technique has the potential to provide accurate and precise information on the partial molar volumes of oxide components of silicate melts directly at high pressures.

References: [1] Ghiorso and Sack (1995) Contrib. Mineral. Petrol., 119, 197-212. [2] Lange and Carmichael (1987) GCA, 51, 2931-2946.

\section{COUPLING MODERN CHEMICAL AND MECHANICAL} WEATHERING RATES OF SILICATES USING RIVERS. J. Gaillardet ${ }^{1}$, P. Louvat ${ }^{1}$, B. Dupré ${ }^{2}$, and C. J. Allègre ${ }^{1},{ }^{1}$ Laboratoire de Géochimie et Cosmochimie, Institut de Physique du Globe de Paris, URA CNRS D1758, UER des Sciences de la Terre Université Paris VII Denis Diderot, 4 Place Jussieu, 75252 Paris Cedex 05, France, 'Laboratoire de Géochimie, CNRS OMP, Université Paul Sabatier, 38 rue des 36 ponts, Toulouse, France.

On a global scale, the control of modern weathering rates and hence $\mathrm{CO}_{2}$ consumption by rock weathering is a subject of great debate. Among the factors that may exert a role in determining the method and the rate whereby continental material is transferred from land to sea, temperature and precipitation (hence climate) and relief (hence tectonics) have been suspected as being key parameters. Whether climate or tectonics play a major role is still debated $[1,2]$. However, the role of physical erosion, which creates surfaces and hence produces chemical weathering, has attracted little attention.

In addition to experimental results, field data are clearly needed to address this issue. Rivers (especially large rivers) because they integrate large portions of the continental crust, are particularly well suited to identify the parameters controlling the modem weathering rates. Their dissolved and suspended loads give insights into the chemical and mechanical weathering processes respectively. Although the number of studies focusing on river chemistry is increasing, these studies are still focused on the chemical load rather than on an integrated study of suspended and dissolved load, and thus the relationships between chemical and mechanical denudation.

We have made an effort to fill in this gap by systematically associating the sampling of dissolved and suspended loads in large basins such as the Congo, Niger, Amazon, Mackenzie, St. Lawrence, Huanghe, Yangtze, Red, and Mekong River systems and in volcanic islands under variable climatic conditions, such as Reunion, Azores, Iceland, and Java.

The chemical composition of river sediments in these settings together with the scarce data from the literature show that modem products of physical erosion are characterized by a huge depletion in all the most-soluble elements compared to the bed rocks from which they are derived. The less-depleted sediments are those from volcanic islands. On a world scale, the contrast between lowland rivers (with sediments strongly depleted in solutes) and mountainous or volcanic island rivers (which are much less depleted) is evident. The influence of climate on the intensity of the solubility of the solute is therefore not obvious.

Extending a formalism previously described, the dissolved load of each river can be used to derive chemical weathering rates for silicates. Again, on a global scale, the influence of climatic factors is secondary and the lithology appears to be the predominant factor.

Finally, the dissolved loads (once corrected from nonsilicate weathering inputs) complement the suspended loads, enabling one to calculate a mechanical weathering rate for each river. These rates are calculated according to a steady-state hypothesis, and are independent of field estimations of mechanical denudation. Such estimations suffer from numerous problems, such as the deposition of suspended sediments within the basins. A correlation between the mechanical erosion rates calculated in this way and the chemical rates of silicate weathering is observed in a log-log space, which tends to show that the physical degradation of continental rock plus a major role on a global scale on chemical weathering and hence $\mathrm{CO}_{2}$ consumption.

References: [1] Bemer (1996). [2] Edmond (1996).

TRACER DIFFUSION OF SAMARIUM AND NEODYMIUM
IN GARNET: EXPERIMENTAL DETERMINATION AND
IMPLICATIONS FOR GEOCHRONOLOGY. J. Ganguly',
M. Tirone', and R. Hervig', 'Department of Geosciences, Univer-
sity of Arizona, Tucson AZ 85721 , USA (Ganguly@geo.arizona.
edu), '2 Center for Solid State Science, Arizona State University,
Tempe AZ 85287, USA.

Gamet is one of the few minerals in metamorphic rocks that is 
suitable for mineral age determination using the Sm-Nd decay scheme. However, the interpretation of the Sm-Nd mineral ages of garnet in metamorphic rocks (i.e., metamorphic vs. cooling age) has been a subject of major controversy [1]. While there is observational evidence to support both viewpoints, an understanding of the problem of the closure temperature of the $\mathrm{Sm}-\mathrm{Nd}$ isotopic system in garnet requires tracer-diffusion data for these elements in garnet. We have thus undertaken the task of determining these diffusion coefficients as function of temperature, pressure, and $\mathrm{fO}_{2}$.

The experiments were carried out by depositing a noncorrosive mixed solution enriched in ${ }^{149} \mathrm{Sm}$ and ${ }^{145} \mathrm{Nd}$ on ultrapolished surfaces of natural almandine and pyrope gamets, ensuring the removal of the thin disordered layer that is usually present on a surface subjected to mechanical polishing. The samples were annealed at $827^{\circ}$ and $927^{\circ} \mathrm{C}, 1 \mathrm{bar}$, and $\mathrm{fO}_{2}$ corresponding to wustite-iron (WI) buffer (imposed by a controlled mixture of $\mathrm{CO}$ and $\mathrm{CO}_{2}$ ). The metastable survival of the gamet crystals were checked by optical examination of the surfaces of the quenched crystals. After an acid treatment to remove the solution still left on the surfaces, the annealed samples were depth-profiled in an ion microprobe to simultaneously determine the diffusion penetrations of the ${ }^{149} \mathrm{Sm}$ and ${ }^{145} \mathrm{Nd}$ isotopes (Fig. 1).

The measured concentration profiles of ${ }^{149} \mathrm{Sm}$ and ${ }^{145} \mathrm{Nd}$ were modeled using both infinite source and thin film solutions of the diffusion equation with constant diffusion coefficient. The former model always yielded statistically better fits to the measured data. Figure 1 is an example of the match between the measured data (circles) at $1 \mathrm{bar}, 827^{\circ} \mathrm{C}, \operatorname{logfO} \mathrm{O}_{2}=-18.5 \mathrm{bar}$, and the calculated (solid lines) diffusion profiles $\left(\mathrm{D}(\mathrm{Nd})=4\left(10^{-17}\right)\right.$ and $\mathrm{D}(\mathrm{Sm})=5$ $\left.\left(10^{-17}\right) \mathrm{cm}^{2} / \mathrm{s}\right)$. Our results lead to the following observations: (1) $D(S m)$ and $D(N d)$ are almost the same, with $D(S m)$ probably slightly [-25\% greater than $D(N d)]$. (2) There is no significant dependence of the tracer diffusivities on Fe/Mg ratio of gamets, at least within the compositional range of the natural almandine and pyrope gamets used in our experiments. (3) The D values of the REE are in the range of the tracer diffusion coefficients of $\mathrm{Mg}$ and $\mathrm{Fe}^{2+}$ in pyrope-almandine garnets, which were measured by tracer isotope [2] and diffusion couple experiments [3]; this is compatible with the conclusion based on compositional zoning in naturalgamet [4]. (4) The measured diffusivity of the REE is $\sim 3$ orders of magnitude lower than that obtained from the extrapolation of the hightemperature $\left(1300^{\circ}-1500^{\circ} \mathrm{C}\right) \mathrm{Sm}$ diffusion data in garnet [5], which was used to calculate a closure temperature of the $\mathrm{Sm}-\mathrm{Nd}$ system in garnet as $500^{\circ}-700^{\circ} \mathrm{C}[6]$.
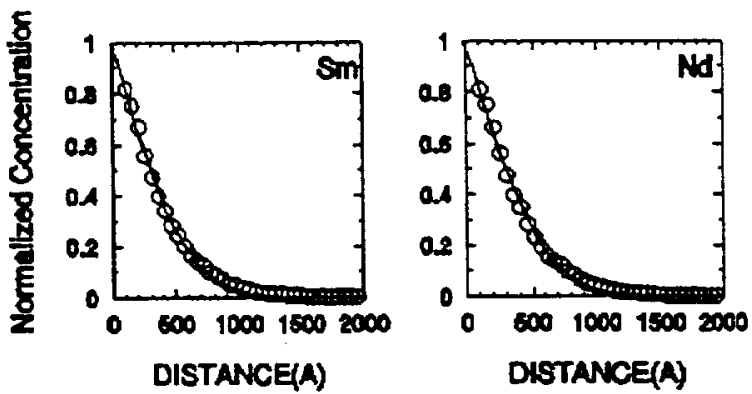

Fig. 1. Experimental (circle) and modeled (lines) diffusion profiles of $\mathrm{Sm}$ and $\mathrm{Nd}$ at $1 \mathrm{bar}, 827^{\circ} \mathrm{C} . \log \mathrm{fO}_{2}=-18.5$ bar.
The closure temperature $\left(T_{c}\right)$ of $\mathrm{Sm}-\mathrm{Nd}$ in natural garnet depends on the response of $\mathrm{Sm}-\mathrm{Nd}$ fractionation between gamet and its coexisting matrix phase to temperature change and the diffusivities of the REE in both minerals. Using the above diffusion data (and additional experimental data obtained in the mean while) along with the data extracted from the literature, we would present calculations of $T_{c}-s$ for selected parageneses and thermal regimes.

References: [1] Mezger K. et al. (1992) EPSL, 1/3, 397. [2] Chakraborty S. and Rubie D. (1996) Contrib. Mineral. Petrol., 122, 406. [3] Ganguly J. et al. (1997) in preparation. [4] Cohen A. S. (1988) Contrib. Mineral. Petrol., 98, 303. [5] Harrison W. J. and Wood B. J. (1980) Contrib. Mineral. Petrol., 72, 145. [6] Humphries F. J. and Cliff R. A. (1982) Nature, 295, 515.

DISTRIBUTION OF TRACE ELEMENTS IN ANHYDROUS SPINEL PERIDOTITES FROM RONDA ULTRAMAFIC MASSIF: IMPLICATIONS FOR THE NATURE OF LARGE-ION-LITHOPHILE-ELEMENT, RARE-EARTHELEMENT, AND HIGH-FIELD-STRENGTH-ELEMENT RESERVOIRS AND MANTLE FLUIDS IN THE SUBCONTINENTAL LITHOSPHERIC MANTLE. C. J. GaTrido ${ }^{1}$ and J.-L. Bodinier ${ }^{2}$, 'Department of Geology and Geophysics, Woods Hole Oceanographic Institution, Woods Hole MA, USA (cgarrido@ whoi.edu), 2 ISTEEM, Université de Montpellier II, Montpellier, France (bodin@sajou.dstu.univ-montp2.fr).

We report ICP-MS analyses of $\mathrm{Rb}, \mathrm{Ba}, \mathrm{Th}, \mathrm{U}, \mathrm{Nb}, \mathrm{Ta}, \mathrm{REE}, \mathrm{Sr}$, $\mathrm{Zr}, \mathrm{Hf}$, and $\mathrm{Sc}$ in leached separates of clinopyroxene, orthopyroxene, olivine, and spinel in anhydrous spinel peridotites from Ronda peridotite (southem Spain). As plotted in increasing order of compatibility in a melt/peridotite system, the mineral/clinopyroxene (cpx) ratio systematically increases from the MREE to the highly incompatible elements ( $R b, B a, T h, U, N b$, and $T a$ ). This feature is more marked in the olivine/cpx and spinel/cpx partitioning. The distribution of MREE, HREE, $\mathrm{Zr}$, and $\mathrm{Hf}$ in clinopyroxenes, orthopyroxenes, and, partly, in olivines might be accounted for by crystallographic control in these minerals. However, the distribution of $\mathrm{Rb}, \mathrm{Ba}, \mathrm{Th}, \mathrm{U}, \mathrm{Nb}$, and $\mathrm{Ta}$ is inconsistent with a crystallographic control, especially in the case of spinels and olivines. The fact that the relative increase of the mineral/cpx of the highly incompatible elements is correlated with their degree of incompatibility in a melt/peridotite system, and that olivines and spinels from different samples display similar normalized trace-element patterns (and abundances) for $\mathrm{Rb}, \mathrm{Ba}, \mathrm{Th}, \mathrm{U}, \mathrm{Nb}$, and $\mathrm{Ta}$, indicates that an important part of the budget of the highly incompatible elements may be hosted in melt/fluid inclusions in these minerals.

In Ronda minerals, two-phase fluid (melt?) inclusions typically occur as healed cracks similar to secondary fluid/meit inclusions documented in peridotite xenoliths worldwide [1], although their volumetric proportion is usually lower. In Ronda minerals, healed cracks and trails of fluid inclusions were affected (cut and transposed) during high-temperature $\left(>900^{\circ} \mathrm{C}\right)$ recrystallization of olivine. This textural observation indicates that melt/fluid inclusions in Ronda minerals are of mantle origin, and thereby might represent trapped metasomatic melts in the subcontinental lithosphere.

Assuming that the concentration of the highly incompatible elements in olivines and spinels is dominated by fluid inclusions, 
some inferences about the composition and nature of these melt' fluids can be inferred from the ratio of incompatible elements in those minerals. First of all, these melvfluids would be characterized by a strong fractionation of incompatible elements. This fractionation is expected in small melt fractions (SMF) migrating throughout the conductive lithospheric mantle [2]. Furthermore, the ratios of the highly incompatible elements in olivines suggest that these fluid/melts would have geochemical characteristics akin to the continental crust and arc lavas. Their low $T h / U$ ratios $(\sim 1)$ might indicate a high activity of volatiles, probably as a result of progressive crystal fractionation of these SMF during cooling and decompression in the lithosphere. However, their unusually high $\mathrm{Ta} / \mathrm{La}$ and $\mathrm{Nb} / \mathrm{La}$ ratios $(\sim 4)$ might imply that these inclusions are mixtures of melts/fluids and a $\mathrm{Nb}$-(Ta)-rich phase (probably rutile). These phases might have been precipitated during cooling (and increasing silica activity) of these SMF, which would account for the two-phase inclusions observed in Ronda minerals. Therefore, we anticipate that the end products of such SMF may play a significant role in the genesis of the continental crust and arc volcanism.

To better characterize the reservoirs of trace elements in spinel peridotites, we conducted a mass balance calculation in a remarkably fresh peridotite from Ronda. This calculation shows that the whole-rock budget of trace elements in spinel peridotites is dominated by several contrasting reservoirs. The REE, $\mathrm{Zr}$, and $\mathrm{Hf}$ budget is controlled by the crystallographic contribution of clinopyroxene and, to a lesser extent, orthopyroxene. Conversely, about $50 \%$ of the $\mathrm{Rb}, \mathrm{Ba}, \mathrm{Nb}$, and $\mathrm{Ta}$ budget is hosted by a "grain boundary component." This grain boundary component consists of a Ti-oxide (+phlogopite) micrometer-layer of metasomatic origin coating spinel surfaces [3]. The rest of the $\mathrm{Rb}, \mathrm{Ba}, \mathrm{Nb}$, and $\mathrm{Ta}$ and over $70 \%$ of the $\mathrm{U}$ and Th budget is hosted by fluid inclusions in silicates, especially in olivine. Therefore, a significant part of the budget of some radiogenic elements might be hosted in fluid inclusions in the continental lithosphere instead of being controlled by crystallographic partitioning in mantle phases.

References: [1] Schiano P. and Clocchiatti R. (1994) Nature, 368, 621-623. [2] McKenzie D. (1989) EPSL, 95, 53-72. [3] Bodinier J. L. et al. (1996) GCA, 60, 545-550.

\section{ICELANDIC LOW 818$^{18}$ OCEAN-CRUST CONTAMINA-} TION OR MANTLE SOURCE? M. A. M. Gee', M. F. Thirlwall $^{1}$, D. Lowry', R. N. Taylor ${ }^{2}$, and B. J. Murton ${ }^{3}$, ' Department of Geology, Royal Holloway, University of London, Egham, Surrey, TW20 0EX, UK (M.Gee@ALPHA1.rhbnc.ac.uk), 2Geology Department, University of Southampton, Southampton Oceanography Centre, European Way, Empress Dock, Southampton, UK, ${ }^{3}$ Southampton Oceanography Centre, European Way, Empress Dock, Southampton, UK.

Three alternatives have been proposed that could generate the range of isotopic and trace-element ratios characteristic of the tholeiites erupted along the ridge axis in Iceland. All these models require contributions from more than one isotopically distinct source, and can be summarized as mixtures of the following: (1) mid-oceanridge-basalt (MORB) mantle and Icelandic plume mantle, which has a time-integrated enrichment relative to MORB source [e.g., 1], (2) a multicomponent Iceland plume consisting of at least two components, both isotopically distinct from present-day MORB mantle [e.g., 2], (3) the mantle beneath Iceland and variably altered Icelandic crust with ingrowth of the required isotopic characteristics [e.g., 3], and finally (4) a complex interplay between all three of these models [e.g., 4].

While the last model is perhaps more geologically realistic, identifying individual sources should be less complicated in Iceland than the more usual oceanic intraplate magmatism. This is primarily due to the relatively thin, zero-aged crust at the extensive ridge axis in Iceland.

Before allotting characteristics to mantle sources, any contribution from crustal contamination must be identified. Iceland has historically been regarded as an example of increasing assimilation with residence time in fractionating magma chambers. Correlations between $\mathrm{SiO}_{2}$ and indexes affected by assimilation of hydrothermally affected crustal rocks such as ${ }^{87} \mathrm{Sr} /{ }^{86} \mathrm{Sr}$ and $\mathrm{O}$ isotopes, have been used to identify contamination by hydrothermally altered crust in silicic volcanos of Central Iceland.

On the Reykjanes Peninsula crustal assimilation has been invoked as the main agent responsible for the following range of chemical characteristics: (1) elevated $\mathrm{Sr}$ abundance (relative to $\mathrm{Ce}$ and $\mathrm{Nd}$ ) in some rocks, (2) high ${ }^{87} \mathrm{Sr} /{ }^{86} \mathrm{Sr}$ at a given ${ }^{143} \mathrm{Nd}^{1 / 44} \mathrm{Nd}$, and (3) all Icelandic characteristics not satisfied by melting MORB mantle.

Oxygen isotopes have played an increasing role in fingerprinting hydrothermal contamination; however, most of the published data from Iceland are from whole-rock samples. Analyses produced during this study have been determined by laser-assisted fluorination using a Nd:YAG laser linked to a VG PRISM on mineral separates, primarily olivine, to avoid the pervasive secondary alteration seen in all lavas, including those less than $800 \mathrm{yr}$ old.

$\delta^{18} \mathrm{O}$ analyses from this study show broadly negative correlations with $\mathrm{Sr}$ and $\mathrm{Pb}$ isotope ratios, and melting indexes such as $\mathrm{CaO} /$ $\mathrm{Na}_{2} \mathrm{O}, \mathrm{Ba} / \mathrm{Zr}, \mathrm{Nb} / \mathrm{Zr}$, and $\mathrm{Zr} / \mathrm{Y}$, and broadly positive correlations with $\mathrm{Nd}$ isotopic ratios and $\mathrm{Mg}$ number, but no correlation with $\mathrm{MgO}, \mathrm{SiO}_{2}$, and $\mathrm{Sr}^{*}$ ( $\mathrm{Sr}$ anomaly relative to $\mathrm{P}$ and $\mathrm{Zr}$ ). At present only one sample representative of the enriched Iceland source has $O$ isotope ratios in equilibrium with MORB mantle. Other samples with similar $\mathrm{Pb}$ and $\mathrm{Nd}$ isotope characteristics, but elevated ${ }^{87} \mathrm{Sr}$ ' ${ }^{86} \mathrm{Sr}$, show a progressive decrease in $\delta^{18} \mathrm{O}$ values with increasing ${ }^{87} \mathrm{Sr} /{ }^{86} \mathrm{Sr}$, although the whole range is only from 4 to $4.8 \%$ (SMOW). Conversely, all the samples analyzed to date that are representative of a more depleted source are in equilibrium with a MORB mantle source.

Consequently, these data imply that crustal assimilation does produce some of the higher ${ }^{87} \mathrm{Sr} /{ }^{86} \mathrm{Sr}$ seen on the Reykjanes Penin. sula. But the range in $\mathrm{Nd}$ and $\mathrm{Pb}$ isotopes, and most of the range in ${ }^{87} \mathrm{Sr} /{ }^{86} \mathrm{Sr}$, is primarily a result of heterogeneous mantie, coupled with magma chamber processes that normally homogenize any melt heterogeneity, and enpt the low $\delta^{18} \mathrm{O}$ values previously reported to be representative of the mantle source. However, age relationships within the sample set suggest that these magma chambers are periodically destabilized, albeit infrequently, permitting enuption of lavas with non-steady-state chemistry.

References: [1] Schilling J.-G. (1973) Nature, 242, 565-571. [2] Elliott T. R. et al. (1991) Nature, 351, 201-206. [3] Oskarsson N. et al. (1985) JGR, 90, 10011-10025. [4] Hemond C. et al. (1993) $J G R, 98,15833-15850$. 
STABLE-ISOTOPE EVIDENCE FOR LIMITED FLUID FLOW IN THE ADAMELLO CONTACT AUREOLE, NORTHERN ITALY. M. L. Gerdes ${ }^{1}$, L. P. Baumgartner ${ }^{2}$, and J. W. Valley ${ }^{2}$, 'Department of Earth and Planetary Sciences, Johns Hopkins University, Baltimore MD21218,USA (mgerdes@jhu.edu), ${ }^{2}$ Department of Geology and Geophysics, University of Wisconsin, Madison WI 53706, USA.

Numerical modeling and field studies have shown that largescale fluid flow around shallow crustal plutons is physically plausible for a wide range of conditions. Despite strong driving forces, the development of such regional hydrothermal systems is highly variable, reflecting complex interactions between permeability, pressure, temperature, deformation, reactions, and fluid sources. In a continued effort to evaluate the regional extent of fluid-rock interaction in the crust, we present $O$ and $C$ isotope data from dolomites and related carbonate lithologies in the Adamello contact aureole (Southem Alps, northem Italy). The 29-45-Ma Adamello batholith was emplaced at shallow crustal levels into Hercynian basement and sedimentary cover. This large tonalitic batholith $\left(\sim 700 \mathrm{~km}^{2}\right)$ and smaller mafic intrusions caused contact metamorphism ( $P \sim 1 \mathrm{kbar}$ ) in Triassic carbonates along its southern margin. The Cima Uzza area exposes a portion of the aureole where a thick sequence of Triassic dolomites can be traced from outside the aureole up to forsterite-grade dolomites, siliceous calcite marbles, and brucite (after periclase) marbles near intrusion contacts. BucherNurminen [1] proposed a hydrothermal origin for both siliceous calcite marble xenoliths and for centimeter-scale siliceous layers and nodules irregularly distributed throughout the silica-poor dolomite sequence at Cima Uzza. Channelized infiltration of tonalitederived fluids through sedimentary pore structures was suggested as a mechanism for this $\mathrm{Si}$ and $\mathrm{Al}$ metasomatism.

Stable isotope data reveal that typical nongraphitic dolomites within the thermal aureole $\left(\delta^{18} \mathrm{O}=29.7 \% \circ \pm 1.3 \%\right.$ ( $(1 \sigma)$ and $\delta^{13} \mathrm{C}=$ $2.2 \% \circ \pm 1.3 \% \circ(1 \sigma), \mathrm{n}=25)$ are isotopically indistinguishable from similar dolomites outside the aureole $\left(\delta^{18} \mathrm{O}=28.8 \% \circ \pm 1.1 \% \circ\right.$ and $\delta^{13} \mathrm{C}=2.5 \% \circ \pm 0.2 \%, \mathrm{n}=11$ ). Graphitic dolomites have lower $\delta^{13} \mathrm{C}$ values than nongraphitic dolomites, as a result of closed-system exchange with graphite, but similar $\delta^{18} \mathrm{O}$ values $\left(\delta^{18} \mathrm{O}=30.0 \% \textrm{ } \pm\right.$ $0.9 \%$ and $\delta^{13} \mathrm{C}=-0.9 \% \circ \pm 0.9 \%, \mathrm{n}=13$ ). Oxygen isotopic compositions in all silica-poor dolomites are homogeneous and show no systematic variation with distance toward the Adamello batholith, indicating that pervasive fluid infiltration did not occur through the dominant lithology in the aureole. Localized exchange with low$\delta^{18} \mathrm{O}$ and low- $\delta^{13} \mathrm{C}$ magmatic fluids along with $\mathrm{Si}$ and $\mathrm{Al}$ metasomatism in siliceous calcite marble xenoliths are entrained in volumetrically minor mafic intrusions at the margin of the larger tonalite. Brucite marbles, which occur both in xenoliths and near mafic dikes within the contact aureole, show isotopic alteration intermediate between siliceous xenoliths and dolomite. Most isotopic alteration in carbonates occurs within a few meters of mafic stocks and dikes, while little isotopic alteration has been identified near tonalite. Most small siliceous nodules $(<20 \mathrm{~cm}$ diameter) and layers $(<10 \mathrm{~cm}$ thick), dispersed within the dolomite section, show carbonate $O$ and $\mathrm{C}$ isotope ratios only slightly lower than typical dolomite. The absence of a low- $\delta^{18} \mathrm{O}$ magmatic signature in these siliceous zones indicates a sedimentary origin. Limited isotopic and petrologic alteration in dolomites at Cima Uzza shows that infiltration of magmatic fluids was extremely localized, reflecting either a limited supply of magmatic fluids or low permeabilities within the thick silica-poor dolomite sequence.

References: [1] Bucher-Nurminen (1982) Am. Mineral.

GEOCHEMISTRY AND MINERALOGY OF THE LEMHI PASS RARE-EARTH-ELEMENT/THORIUM DEPOSITS: AN EXAMPLE OF RARE-EARTH-ELEMENT/THORIUM MOBILITY. P. E. Gibson, S. A. Wood, and L. Lang, Department of Geology, University of Idaho, Moscow ID 83843-3022, USA.

The Lemhi Pass REE-Th deposits sit astride the continental divide partially in Beaverhead County, Montana, and partially in Lemhi County, Idaho. Mineralization occurs in veins with potassic alteration halos, and replacement textures are observed in the veins, suggesting hydrothermal activity. Rare-earth-element-Th minerals consist primarily of thorianite $\left(T_{0-0.80} \mathrm{U}_{0-0.04} \mathrm{REE}_{0-12} \mathrm{Al}_{0-0.26} \mathrm{Si}_{0-}\right.$ $\left.{ }_{1.00} \mathrm{P}_{0-0.51} \mathrm{O}_{4}\right)$, monazite $\left(\mathrm{Th}_{0-0.107} \mathrm{REE}_{0.76-0.95} \mathrm{Ca}_{0-0.06} \mathrm{P}_{0.95-1.05} \mathrm{O}_{4}\right)$, xenotime [Y, REE) $\left.\mathrm{PO}_{4}\right]$, and allanite $\left[(\mathrm{REE}, \mathrm{Ca}, \mathrm{Y})_{2}\left(\mathrm{Al}, \mathrm{Fe}^{3+}\right)_{3}\right.$ $\left.\left(\mathrm{SiO}_{4}\right)_{4}(\mathrm{OH})\right]$, with monazite hosting much of the REE. Xenotime and allanite compositions have only been determined qualitatively thus far. Substitution of $\mathrm{Si}^{4+}$ for $\mathrm{P}^{5+}$ seems to be an imporant process in monazite and thorite and is expected to play an important role in xenotime as well (e.g., $\mathrm{Th}^{4+}+\mathrm{Si}^{4+} \leftrightarrow \mathrm{REE}^{3+}+\mathrm{P}^{5+}$ ). Gangue minerals consist of $\mathrm{K}$-feldspar, quartz, and Fe oxides. It is interesting that allanite has been identified in only one vein (Lucky Horseshoe) in the area, and tends to be associated with the monazite. This vein differs from other veins with respect to the presence and foliation of sheet silicates (chlorite, biotite, muscovite) as gangue. A carbonatite is also present in the field and it consists primarily of coarse calcite, dolomite, apatite, and magnetite with accessory barite

Geochemical analyses have been carried out on both the carbonatite and the veins in order to (1) determine the relationship of the carbonatite to the mineralization in the veins, (2) determine the nature of the fluid(s) responsible for the mobility of the REEs and $\mathrm{Th}$, and (3) determine the reasons for the presence of allanite in the Lucky Horseshoe vein and its absence elsewhere. Rare-earthelement-Th minerals are closely associated on a microscopic scale with $\mathrm{Fe}$ oxides in both the carbonatite and the veins. Chondritenormalized REE plots for the veins show MREE enrichment while the carbonatite shows LREE enrichment. This result throws doubt on a direct relationship of the Lemhi Pass mineralization to carbonatite activity. Microprobe analyses indicate that the monazite and thorite in the veins are MREE enriched (thorite is an order of magnitude less abundant), whereas the monazite from the carbonatite is LREE enriched. However, the monazite and the thorite cannot account for the total REE from the whole-rock analyses. Therefore, some REEs may be associated with the Fe oxides, or other REEbearing minerals. Qualitative SEM analyses show xenotime to be depleted in the LREE with respect to the MREE and HREE. Xenotime is currently being analyzed quantitatively for its REE content and its presence may solve the mass balance problem for the REEs. Apatite contributes negligible amounts of REE. To quantify the mobility of the REE and Th, a mass transfer study of an alteration halo from one vein (Lucky Horseshoe) is being conducted. This study may also aid in determining why allanite is present at the Lucky Horseshoe deposit. Isotope and fluid inclusion studies are also being conducted in order to corroborate the current findings and give us a further understanding of these deposits. These geochemical data will be 
used to construct a model for the origin of these deposits and give us a better understanding of the mobility of the REE and Th. Our study of the Lemhi Pass deposits should further aid in understanding the formation of other hydrothermal REE deposits around the world and may provide information relevant to performance assessment of deeply buried nuclear waste repositories.

\section{EFFECTS OF VEGETATIVE AND GLACIAL COVER ON THE CHEMICAL WEATHERING OF BASALT IN SOUTH-} WEST ICELAND. S. R. Gislason, Science Institute, University of Iceland, Dunhagi 3, IS-107 Reykjavik, Iceland.

Compared to the global average, the chemical weathering rates of basalt in southwest Iceland are high and rather variable. This can be attributed to soluble rock type (basalt) and mechanical weathering, variation in run-off and age of rocks, and variable vegetative/ glacial cover. The average temperature of the catchments in this study is near constant, $5^{\circ} \mathrm{C}$. Chemical weathering of the basalt is incongruent. Some of the primary minerals do not dissolve, and secondary minerals form, resulting in the fact that fluxes of all elements increase with run-off, and there is an enormous variation in the relative mobility of elements in the basalt during weathering. The relative mobility, in decreasing order, is $\mathrm{SO} 4>\mathrm{F}>\mathrm{Na}>\mathrm{K}>>$ $\mathrm{Ca}>\mathrm{SiO} 2>\mathrm{Mg}>\mathrm{PO} 4>\mathrm{Sr}>>>\mathrm{Mn}>\mathrm{Al}>\mathrm{Ti}>\mathrm{Fe}$. Relative to $\mathrm{Na}$, close to $90 \%$ of $\mathrm{Mg}$ and $\mathrm{Ca}$ in the original rocks is left behind at the weathering site. The run-off dependence of fluxes and the variation in relative mobility is less in old rocks than in young ones. In old rocks the number of saturated minerals with respect to soil solutions has decreased because of lesser amount of soluble basaltic glass and an increased vegetative cover on old rocks. The saturation state of basaltic minerals is the most important variable for the dissolution and precipitation rate of minerals during weathering in southwest Iceland and is dictated by the $\mathrm{pH}$ of the weathering solutions.

The overall rate of chemical denudation rate in southwest Iceland is independent of vegetative cover. However, fluxes of $\mathrm{Ca}, \mathrm{Mg}$, and $\mathrm{Sr}$ increase with increasing vegetative cover at constant run-off, whereas fluxes of $\mathrm{Na}$ and $\mathrm{K}$ decrease. With a continuous vegetative cover the $\mathrm{pH}$ of the soil solutions tends to be low $(<7)$ and glass, olivine, pyroxene, and plagioclase are unstable, but the solutions are decreasingly saturated or more undersaturated with respect to zeolites and smectite, thus increasing the relative mobility and fluxes of $\mathrm{Ca}, \mathrm{Mg}$, and $\mathrm{Sr}$. Since the weathering of $\mathrm{Ca}-\mathrm{Mg}$ silicate rocks is the principal process by which $\mathrm{CO}_{2}$ is removed from the atmosphere on a geological timescale [1], the spread of vascular plants on the continents during the mid-Paleozoic may have resulted in a drop in $\mathrm{CO}_{2}$, not necessarily because of greatly enhanced bulk chemical weathering, as suggested by Trendall [2] and Berner [3], but rather due to the enhanced relative mobility and fluxes of $\mathrm{Ca}$ and $\mathrm{Mg}$.

Glacial cover slows down the overall chemical denudation rates in southwest Iceland. It increases the probability of high $\mathrm{pH}$ weathering solutions. A high $\mathrm{pH}(8-10)$ makes the primary $\mathrm{Ca}$ silicates stable and the $\mathrm{Mg}$ silicates stable or less unstable, and the high $\mathrm{pH}$ increases the probability of deposition of zeolites and smectites. Thus, the relative mobility and fluxes of $\mathrm{Ca}$ and $\mathrm{Mg}$ slow down during glacial cover and therefore retard the permanent long-term consumption of atmospheric $\mathrm{CO}_{2}$. This process supports the theory of a negative feedback mechanism for the long-term stabilization of the Earth's surface temperature [4].
References: [1] Bemer (1992). [2] Trendall (1966). [3] Bemer (1993). [4] Walker et al. (1981).

\section{DIVERGENT MANTLE EVOLUTION ON EARTH AND MARS AND THE ORIGIN OF DEPLETED PLANETARY} MANTLES. J. D. Gleason, D. A. Kring, and W. V. Boynton, Lunar and Planetary Laboratory, University of Arizona, 1629 East University Boulevard, Tucson AZ85721,USA (jgleason@gammal. lpl.arizona.edu).

Mantle reservoirs depleted in incompatible elements exist on several planetary bodies, notably Earth, the Moon, and Mars. The composition of Earth's depleted mantle (that giving rise to MORB) has been continually modified over time by plate-tectonic recycling of crustallithospheric material back into the mantle, coupled with convective mixing, but the extent of this recycling has been difficult to quantify [e.g., 1]. Furthermore, depending on the model, terrestrial incompatible-element-rich reservoirs thought to be complementary to the depleted mantle have been variously identified as the continental crust, enriched subcontinental lithosphere, and (for early Archean times) ancient basaltic crust long since reincorporated into the mantle $[1,2]$.

It is generally agreed that partial melting processes produced the observed depletion in incompatible elements in all cases, but the evolution of depleted reservoirs may in other ways be quite different from one planet to the next. While depleted mantle reservoirs on the Moon are thought to be largely complementary to the ancient lunar crust that fractionated from an early global magma ocean, mantle differentiation on the Moon was frozen in time early in its history [35]. Mars, on the other hand, offers a unique opportunity to study the long-term evolution of a depleted mantle reservoir on a planet lacking plate tectonic recycling processes, and thus may provide constraints on the degree of recycling required to model the evolution of Earth's depleted mantle.

The evidence from Mars comes from 12 SNC-related meteorites, which, fortuitously, provide a snapshot of basaltic magmatism and mantle evolution on Mars at three distinct times over the course of its long geologic history: 4.5 Ga (ALH 84001), 1.26 Ga (nakhlites and Chassigny), and $180 \mathrm{Ma}$ (shergottites). These unique samples of martian crust thus offer a contrasting view of planetary mantle evolution that has largely been developed from a terrestrial and lunar perspective. First, ALH 84001 indicates that a mafic-toultramafic planetary crust was extracted from the martian mantle as early as $4.5 \mathrm{Ga}$ [6-8]. Second, recent isotopic studies of SNCrelated meteorites indicate the mantle was already depleted at $4.5 \mathrm{Ga}[6,7]$, had evolved to $\varepsilon_{\mathrm{Nd}}=15$ by $1.26 \mathrm{Ga}$, and was at least 21 at $180 \mathrm{Ma}$, though probably higher $[6-10]$. The 180-Ma shergottites range from $\varepsilon_{\mathrm{Nd}}=-7$ to +21 , but isotopic and REE modeling indicate they were all derived by AFC processes from a single depleted mantle reservoir with $\varepsilon_{\mathrm{Nd}}>21$ [9-11]. Neodymium isotopic analysis of the new, highly LREE-depleted shergottite QUE 94201 [12-14] will likely expand the range of shergottite Nd isotopic compositions toward even more depleted (positive) values more representative of the shergottite source. (Strontium isotopic analyses already indicate a much smaller crustal component in QUE 94201 than in the other shergottites [15].) Together, these data indicate an essentially linear and rapid evolution for the depleted mantle of Mars following early planetary differentiation. 
In contrast to Mars, Earth's depleted mantle has evolved at a relatively suppressed rate to much lower $\varepsilon_{\mathrm{Nd}}$ values of $8-12$, as observed in present-day MORB $[1,17]$. Mars' depleted mantle evolution may therefore provide an upper limit for the evolution of depleted terrestrial mantle, minus the effects of recycling processes, allowing additional constraints to be placed on the amount of crust and lithosphere recycled back into the terrestrial mantle over time. Such calculations are, however, highly dependent upon volume estimates for depleted mantle reservoirs [18], which are currently not well constrained on either planet.

References: [1] Silver P. G. et al. (1988) Annu. Rev. Earth Planet. Sci., 16, 477-541. [2] Chase C. G. and Patchett P. J. (1988) EPSL, 91, 66-72. [3] Taylor S. R. and McLennan S. M. (1985) in The Continental Crust: Its Composition and Evolution, Blackwell. [4] Basaltic Volcanism Study Project (1981) in Basaltic Volcanism on the Terrestrial Planets, Pergamon. [5] Heiken G. et al. (1991) Lunar Sourcebook, Cambridge. [6] Harper C. L. et al. (1995) Science, 267, 213-216. [7] Nyquist et al. (1995) LPS XXVI, 10651066. [8] Jagoutz E. et al. (1994) Meteoritics, 29, 478-479. [9] Gleason J. D. et al. (1996) LPS XXVII, 425-426. [10] Gleason J. D. et al. (1997) GCA, in review. [11] Jones J. H. (1989) Proc. LPSC 19th, pp. 465-474. [12] Kring D. A. et al. (1996) LPS XXVII, 705-706. [13] McSween H. Y. et al. (1997) GCA, 60, 4563-4569. [14] Mittlefehldt D. W. and Lindstrom M. M. (1996) LPS XXVII, 887-888. [15] Borg L. E. et al. (1996)Meteoritics \& Planet. Sci., 31, 19. [16] Vervoort J. D. et al. (1996) Nature, 379, 624-627. [17] DePaolo D. J. (1983) GRL, 10, 705-708. [18] McCulloch M. T. and Bennett V. C. (1994) GCA, 58, 4717-4738.

PHOSPHORUS SCAVENGING AT THE MIXING OF ACIDIC VOLCANIC WATER AND SEAWATER. S. V. Golubev, E. A. Erofeeva, A. V. Savenko, and V. S. Savenko, Geographical Department, Moscow State University, Vorobyovy Gory, Moscow 119899, Russia.

Acidic springs are widespread in regions of volcanic activity. These waters contain high concentrations of $\mathrm{Fe}, \mathrm{Al}$, and other metals. When acidic volcanic waters discharge into the sea, Fe (III) and $\mathrm{Al}$ hydroxides are formed in the zones of neutralization. Many chemical elements are scavenged together with $\mathrm{Fe}-\mathrm{Al}$ hydroxides. Strong sorption of $\mathrm{P}$ on the $\mathrm{Fe}-\mathrm{Al}$ hydroxide precipitates is well known, and the discharge of acidic volcanic waters into the sea may be the cause of the decrease of primary production in the coastal waters because of scavenging of dissolved phosphates.

Phosphorus scavenging during the mixing of acidic volcanic waters and seawater was studied in laboratory experiments. Two acidic solutions imitating water from the Juryev and the Gryaznaya rivers, Kamchatka Peninsula, containing 4.9 and $6.9 \mathrm{mmol} \mathrm{Fe} /$, 15.5 and $9.2 \mathrm{mmol} A \mathrm{~V} /, 0.010$ and $0.011 \mathrm{mmol} P / \mathrm{l}, 13.7$, and 11.9 mmol $\mathrm{H}^{+} / 1$, respectively, were the subject of this study. The seawater contained $0.003 \mathrm{mmol} P / \mathrm{l}$, and $\mathrm{Fe}$ and $\mathrm{Al}$ were not added. Iron hydroxide precipitation occurred at $\mathrm{pH}>2.8-3.0$, Al hydroxide precipitated at $\mathrm{pH}>3.8-4.3$. When $\mathrm{Fe}$ and $\mathrm{Al}$ hydroxides reform, the dissolved $\mathrm{P}$ is removed from the solution. When $\mathrm{pH}$ increases, the $\mathrm{P} / \mathrm{Fe}$ and $\mathrm{P} / \mathrm{Al}$ ratios in the hydroxide phase increase as well. Iron hydroxide is a more effective sorbent for $\mathrm{P}$ than $\mathrm{Al}$ hydroxide: Maximum atomic ratio at $\mathrm{pH} \sim 8$ was 0.15 for $\mathrm{Fe}$ hydroxide and 0.02 for $\mathrm{Al}$ hydroxide. These experiments allow us to consider that the input of $\mathrm{Al}$ and $\mathrm{Fe}$ with acidic volcanic waters into the ocean may result in the substantial decrease of $P$ concentrations in the coastal waters and, as a consequence, the decrease of the primary production of organic matter.

EXPERIMENTAL GROWTH AND BEHAVIOR OF MONAZITE WITH IMPLICATIONS FOR NATURAL METAMORPHIC ROCKS. E. B. Gorisch ${ }^{1}$ and J. C. Ayers ${ }^{2}$, 1 Vanderbilt University, Box 1805, Station B, Vanderbilt University, Nashville TN 37235, USA (gorisceb@ctrvax.vanderbilt.edu), 2Vanderbilt University, Box 105B, Nashville TN 37235, USA (ayersj@ctrvax. vanderbilt.edu).

In experiments attempting to quantify the growth behavior of monazite $\left[(\mathrm{Ce}, \mathrm{La}, \mathrm{Y}, \mathrm{Th}) \mathrm{PO}_{4}\right]$, we have determined that monazite displays apparently unique growth characteristics. Our experimental starting material consisted of $2 \%$ powdered monazite (as mechanically reduced grains $1-2 \mu \mathrm{m}$ in diameter) mixed with $98 \%$ coarsely ground quartz. We subjected this material to a temperature of $1000^{\circ} \mathrm{C}$ and pressure of $10 \mathrm{kbar}$ in an piston cylinder apparatus for hydrous experiment durations of 24,72 , and $168 \mathrm{hr}(\sim 1.5-2.0 \%$ $\mathrm{H}_{2} \mathrm{O}$ ), and an anhydrous experiment of $72 \mathrm{hr}$. SEM observation of the products in backscattered electron mode reveals a distinct progression with time toward equilibrium textures, as well as growth of quartz grains such that the monazite grains do not appear to "pin" the migrating quartz boundaries. Most monazite grains occur as linear arrays of inclusions within and subparallel to the observed quartz grain boundaries, with smaller amounts distributed along grain boundaries and in pores that contained fluid at experimental conditions. This is in contrast to the results of a parallel study of zircon growth, in which zircons is primarily located on quartz grain boundaries [1]. The monazite grain size appears not to have altered during the experiments, a probable consequence of the extremely low measured solubility of monazite $(\sim 0.12-0.18 \mathrm{wt} \%$ [2]). We conclude that monazite behaves as a virtually inert mineral, in both experiments and natural rocks. Once formed under lower-grade metamorphic conditions (greenschist-lower amphibolite facies), monazite itself does not appear to alter appreciably in size, and is fixed in intragranular position. At higher grades, it appears ubiquitously as an inclusion in other minerals. Further growth by Ostwald ripening at higher metamorphic grades (up to but not through migmatization) is precluded by isolation of individual grains as inclusions or, in the case of monazites present on grain boundaries, by the low growth rate.

References: [1] Ayers et al. (1996). [2] Ayers and Watson (1991).

SECULAR VARIATION IN THE COMPOSITION OF THE SUBCONTINENTAL LITHOSPHERIC MANTLE. W. L. Griffin $^{1.2}$, S. Y. O'Reilly' ${ }^{1}$, C. G. Ryan ${ }^{2}$, O. Gaul' ${ }^{1}$, and D. A. Ionov, 'National Key Centre for Geochemical Evolution and Metallogeny of Continents, School of Earth Sciences, Macquarie University, Sydney, NSW 2109, Australia (bill.griffin@mq.edu.au), ${ }^{2}$ CSIRO Exploration and Mining, P.O. Box 136, North Ryde, NSW 2113 , Australia.

A synthesis of modal and compositional data for mantle-derived 
peridotites, and the major-and trace-element compositions of $>8000$ mantle-derived $\mathrm{Cr}$-pyrope garnets indicates that lithospheric mantle has formed episodically from the Archean to the present. The data document a secular and apparently irreversible change in the chemical composition of newly created lithospheric mantle throughout the Earth's history. This change suggests an evolution in fundamental large-scale Earth processes. It also has important implications for the interpretation of seismic tomography, and means that lithosphere erosion or replacement will have major tectonic consequences.

The average composition of peridotitic garnet xenocrysts from volcanic rocks is strongly correlated with the tectonothermal age of the continental crust penetrated by the eruptions. Gamet composition can be correlated with lithology by comparison with data from mantle-derived xenoliths, and used to estimate the relative abundances of different rock types in individual mantle sections. Strongly subcalcic harzburgites, representing extremely depleted compositions, are found only in lithospheric mantle beneath Archean terrains. Mildly subcalcic harzburgites are common beneath Archean terrains, less abundant beneath Proterozoic terrains, and essentially absent beneath terrains with tectonothermal ages $<1 \mathrm{Ga}$. Lherzolites (clinopyroxene-bearing peridotites) are the most common rock type even in Archean mantle, and make up essentially all of the lithospheric mantle beneath younger terrains. Garnets from lherzolites show a decrease of mean $\mathrm{Cr}$ content and $\mathrm{Zr} / \mathrm{Y}$, and a rise in $\mathrm{Y}$ and $\mathrm{Y} / \mathrm{Ga}$, with decreasing crustal age. Observed correlations between garnet composition and xenolith bulk-rock chemistry and modelling using empirical element distribution coefficients suggest that these changes in gamet composition reflect a rise in the average (cpx+gnt) and cpx/gnt of the peridotitic subcontinental lithosphere from Early Proterozoic time to the present. This indicates that the average composition of subcontinental lithospheric mantle has become progressively less depleted in basaltic components throughout Earth's history, corresponding to a progressive decrease in the average degree of melt extraction from the material that became lithospheric mantle.

The Archean-Proterozoic boundary represents a major change in the processes that form continental lithospheric mantle; since $2.5 \mathrm{Ga}$ there has been a pronounced, but more gradual, secular change in the nature of these processes. Actualistic models of lithosphere formation based on modern processes may be inadequate, even for Proterozoic time. The correlation between mantle composition and crustal age indicates that the continental crust and the underlying lithospheric mantle are formed together, and generally stay coupled together for periods of eons. The stability and thickness of Archean lithospheric mantle is directly related to its low density, which in turn reflects both its high degree of geochemical depletion and its low $\mathrm{Mg} / \mathrm{Si}$. The latter characteristics produce high seismic velocities, and compositional factors may account for at least half the velocity contrast between Archean and younger areas seen in seismic tomography. The higher density and mantle heat flow of younger, less-depleted mantle lithosphere impose severe limits on its thickness and ultimate stability, because the cooler upper parts of Proterozoic or Phanerozoic lithospheric sections will be negatively buoyant relative to the underlying asthenosphere. The replacement of Archean lithosphere by Phanerozoic lithosphere, as in eastern China [1] may initially lead to large-scale uplift due to thermal effects, but ultimately will lead to subsidence and basin formation as a result of the changes in thickness and density of the lithospheric column.
References: [1] Griffin W. L. et al. (1997) in Mantle Dynamics and Plate Interactions in East Asia (M. Flower et al., eds), AGU Spec. Publ., in press.

SEASONAL AND SPATIAL IRON CYCLING IN A SHAL-
LOW ALLUVIAL AQUIFER ADJACENT TO AN ALPINE STREAM. A. R. Groffman and L. J. Crossey, Department of Earth and Planetary Sciences, University of New Mexico, Albuquerque NM 87131, USA (groffman@unm.edu; lcrossey@unm.edu).

Biogeochemical cycling of the redox-sensitive elements Fe and $\mathrm{Mn}$ in surface and groundwater are being investigated in a intensely instrumented (over 200 wells) shallow alluvial aquifer adjacent to a first-order subalpine stream in the Jemez Mountains of northern New Mexico. This research focuses on the biogeochemical interaction between surface and groundwater, the lateral and vertical distribution of redox-sensitive elements, the influence of seasonal infiltration to the aquifer, and how $\mathrm{Fe}$ and $\mathrm{Mn}$ control the distribution of trace elements.

Two years of hydrochemical data collected from both surface water and groundwater show seasonal and spatial variability of major cations $(\mathrm{Ca}, \mathrm{Mg}, \mathrm{Na}, \mathrm{K})$ and anions $\left(\mathrm{Cl}, \mathrm{SO}_{4}, \mathrm{HCO}_{3}\right)$, redoxsensitive elements ( $\mathrm{Fe}, \mathrm{Mn}, \mathrm{N}, \mathrm{C}$ ), and gases of $\mathrm{O}_{2}, \mathrm{CO}_{2}$, and $\mathrm{CH}_{4}$. The lateral distribution of biogeochemical parameters appears to be partially controlled by residence time of groundwater. Stream and spring water entering the aquifer evolves from a relatively oxidizing water high in $\mathrm{DO}$ and $\mathrm{NO}_{3}$ and low in $\mathrm{Fe}$ and $\mathrm{Mn}$ to a moderately reducing groundwater high in $\mathrm{Fe}$ and $\mathrm{Mn}$. Up to $15 \mathrm{mg} / \mathrm{L} \mathrm{Fe}$ and 2 $\mathrm{mg} / \mathrm{L} \mathrm{Mn}$ are present in groundwater at the terminus of flow paths traversing the flood plain between meanders. Vertical profiles of the hydrochemical parameters ( $\mathrm{Ca}, \mathrm{Mg}, \mathrm{Na}, \mathrm{K}, \mathrm{Cl}, \mathrm{Br}$, and temperature) and biogeochemical parameters ( $\mathrm{pH}, \mathrm{Eh}, \mathrm{DO}, \mathrm{Fe}, \mathrm{Mn}, \mathrm{SO}_{4}$, and $\mathrm{NO}_{3}$ ) were measured using dialysis cells with a vertical resolution of $7 \mathrm{~cm}$ deployed in continuously screened wells at select locations in the aquifer. Preliminary data indicate a greater variability of biogeochemical parameters at the top of the water table with more stability at depth. Generally, vertical down-hole trends show a decrease in DO, increase in $\mathrm{pH}$, decrease in $\mathrm{Eh}$, decrease in $\mathrm{NO}_{3}$, and a somewhat more complicated behavior of $\mathrm{Fe}, \mathrm{Mn}$, and $\mathrm{SO}_{4}$. Hydrochemical parameters show less variability. The region of greatest variability corresponds with the transient sediment pore water/air interface (water table), which defines a zone of intermittent saturation (ZIS) as it fluctuates by as much as $80 \mathrm{~cm}$ throughout an annual cycle. Seasonal fluctuations are thought to be controlled by (1) strong infiltration pulses of snow melt during the spring, and (2) weaker infiltration events during winter partial melts and infiltration from summer monsoons. Strong infiltration events (spring snow melt) "swamp" biological processes that attenuate $O$ in the vadose zone. This allows molecular $O$ transport to the saturated zone, which is utilized for biological processes as an electron acceptor (respiration processes) and abiotic oxidation of Fe (inorganic reactions). Both of these processes reduce concentrations of $\mathrm{Fe}$ and $\mathrm{Mn}$ in groundwater during robust infiltration events. Weaker infiltration events affect $\mathrm{Fe}$ in groundwater to a lesser extent, probably due to transformation of molecular $O$ in the vadose zone. Excavations into the vadose zone reveal discrete regions with abundant solid ferric phases adjacent to dark fine-grained sediments rich in organic material. Hydroxylamine extractable Fe (ferrihydrite) and 
$\mathrm{Mn}$ and dithionite citrate extractable $\mathrm{Fe}$ (Fe oxides and organically bound $\mathrm{Fe}$ ) are more abundant above the water table and decrease with depth. These data indicate that ferric oxyhydroxide phases are more abundant in the vadose zone especially where the water table fluctuates in the ZIS.

\section{PARTITIONING OF MINOR ELEMENTS BETWEEN OLIVINE AND WADSLEYITE AND THEIR EFFECTS ON} THE 410-km DISCONTINUITY. G. H. Gudfinnsson and B. J. Wood, Department of Geology, University of Bristol, Wills Memorial Building, Queens Road, Bristol BS8 IRJ, UK (G.H.Gudfin-nsson@ bris.ac.uk; B.J.Wood@bris.ac.uk).

Most of the theoretical and experimental studies regarding the olivine-wadsleyite transformation have been conducted on compositions in the system $\mathrm{Mg}_{2} \mathrm{SiO}_{4}-\mathrm{Fe}_{2} \mathrm{SiO}_{4}$, and have ignored the effects of minor elements in the two phases. It has been shown recently, however, that minor elements have the potential to influence the transition width, and hence the width of the $410-\mathrm{km}$ seismic discontinuity. Experiments indicate that the partitioning of $\mathrm{H}_{2} \mathrm{O}$ between wadsleyite and olivine is approximately 10:1 [1]. By applying a Henry's Law solution model, Wood [2] showed that the presence of small amounts of $\mathrm{H}_{2} \mathrm{O}$ would strongly affect the thickness of the olivine-wadsleyite loop, making the loop wider, and would also stabilize wadsleyite to lower pressure. Other minor components in mantle olivine could similarly broaden or narrow the transition interval, but as yet the partitioning behavior of important trace elements, such as $\mathrm{Ni}$ and $\mathrm{Cr}$, between the two phases, is unknown.

In order to elucidate the chemical equilibria that control the width of the olivine to wadsleyite transition interval in the mantle, we are systematically investigating the partitioning and solution mechanisms of different minor elements in olivine and wadsleyite by performing high-pressure experiments on various bulk compositions. Results to date indicate that the partitioning of $\mathrm{Ni}$ between olivine and wadsleyite at $1600^{\circ} \mathrm{C}$ is about $1: 2$, and that of $\mathrm{Cr}, \mathrm{Al}$, and $\mathrm{Ti}$ is about $\mathrm{i}: 10$. At $1600^{\circ} \mathrm{C}$ the solubility of $\mathrm{Cr}_{2} \mathrm{O}_{3}$ in wadsleyite in equilibrium with olivine and $\mathrm{Cr}$-rich spinel is about $2 \mathrm{wt} \%$, and the solubility of $\mathrm{Al}_{2} \mathrm{O}_{3}$ and $\mathrm{TiO}_{2}$ in wadsleyite in equilibrium with olivine, garnet, and ilmenite is about $0.3 \mathrm{wt} \%$ and $0.4 \mathrm{wt} \%$ respectively.

Assuming that these elements are randomly distributed between the cation sites in the two phases, this indicates that their presence in the mantle should, like $\mathrm{H}_{2} \mathrm{O}$, tend to broaden the olivine-wadsleyite transition interval. This is because all elements prefer the latter phase and hence increase the partial molar entropies of the $\mathrm{Mg}_{2} \mathrm{SiO}_{4}$ and $\mathrm{Fe}_{2} \mathrm{SiO}_{4}$ components. Nevertheless, recent experiments by Fei and Bertka [3] on natural peridotite compositions suggest that the transition interval is actually smaller than in the pure $\mathrm{Mg}_{2} \mathrm{SiO}_{4}$ $\mathrm{Fe}_{2} \mathrm{SiO}_{4}$ system. The latter results, if due to the presence of minor components, require an unusually high degree of order in the threecation $\mathrm{M}$ sites.

References: [1] Kohlstedt D. L. et al. (1994)Eos Trans. AGU, 75, F652. [2] Wood B. J. (1995) Science, 268, 74-76. [3] Fei Y. and Bertka C. M. (1996) Eos Trans. AGU, 77, F649.

BIOACCUMULATION OF AQUEOUS URANIUM BY LICHENS: THE INFLUENCE OF SURFACE PHOSPHATE GROUPS ON SHORT-TERM UPTAKE AND RELEASE?
J. R. Haas' 1 , E. H. Bailey², and O. W. Purvis ${ }^{3}$, 'Department of Geography and Earth Sciences, University of North Carolina at Charlotte, Charlotte NC 28223, USA (jrhaas@unccvm.uncc.edu), 2Environmental Science Section, Department of Physiology and Environmental Sciences, University of Nottingham, Sutton Bonington Campus, Loughborough, Leicestershire LE12 5RD, UK (sbzeb@sbn2. phes.nottingham.ac.uk), ${ }^{3}$ Department of Botany, The Natural History Museum, Cromwell Road, London SW7 5BD, UK (owp@ mailserver.nhm.ac.uk).

Environmental pollution resulting from the release of radionuclides into soils and natural waters is a serious threat to human and ecological health in many parts of the world. Actinide elements, including $\mathrm{U}$ and the transuranics $\mathrm{Pu}, \mathrm{Am}$, and $\mathrm{Cm}$, are particularly problematic because they are both highly toxic and soluble in aqueous solutions. The environmental mobility of aqueous actinides is dictated by a host of geochemical influences involving ground, surface, and soil water compositions, mineral surfaces, and biological systems. In particular, the effect of organisms within the soil horizon, including roots, soil bacteria, fungi and lichens, and chelating compounds secreted by living organisms, can exert a profound influence on the behavior of aqueous cations. We have begun an investigation of the effects of lichens (symbiotic associations of fungi and algae) on $\mathbf{U}$ cycling in natural settings. We report here the results of laboratory experiments measuring the U uptake capacity of one lichen species, Peltigera membranacea, as a function of time and water $\mathrm{pH}$. $P$. membranacea is a foliose lichen species that grows on damp soil in bog or marsh habitats, and has been shown by previous workers to have a high capacity for accumulation of $\mathrm{Ni}, \mathrm{Zn}$, and $\mathrm{Pb}$ from solution $[1,2]$. Batch experiments were carried out on cut disks of clean $P$. membranacea thalli massing $~ 3-6 \mathrm{mg}$. Disks were placed in $5 \mathrm{~mL}$ of solution containing $\sim 80 \mu \mathrm{g} / \mathrm{g}$ U for periods of $15,30,45,60,75,90,105$, and $120 \mathrm{~min}$, then removed, washed in DI water, and dried in air. Solution $\mathrm{pH}$ values were $2,4,7$, and 10. Lichen disks were digested in $\mathrm{HNO}_{3}$ for $\mathrm{U}$ analysis using ICPAES. Maximum uptake of $\mathrm{U}$ by lichens averaged $\sim 11,200 \mu \mathrm{g} \mathrm{U} / \mathrm{g}$ dry lichen $(\sim 1.1 \%$ dry weight $)$ at $\mathrm{pH}=4$. Maximum $\mathrm{U}$ uptake was $\sim 2000 \mu \mathrm{g} / \mathrm{g}, \sim 3400 \mu \mathrm{g} / \mathrm{g}$, and $\sim 1500 \mu \mathrm{g} / \mathrm{g}$ at $\mathrm{pH}=2,7$, and 10 respectively. Our value of maximum $U$ uptake at $\mathrm{pH}=4$ appears to be the highest recorded level of $\mathrm{U}$ accumulation by any lichen, relative to aqueous $U$ activity, reported to date. In contrast to previous lichen studies [e.g., 3], our results indicate that uptake over short timescales is not necessarily a monotonic process of ionexchange site saturation. For trials at $\mathrm{pH}=4$ and $7, \mathrm{U}$ uptake reached a maximum at $\sim 75$ min duration of exposure to the experimental solutions, followed by a systematic decrease in lichen $U$ concentrations throughout the remainder of the experiment. Final $U$ concentrations in lichen samples at $\mathrm{pH}=4$ and 7 averaged $-6500 \mu \mathrm{g} / \mathrm{g}$ and $\sim 2600 \mu \mathrm{g} / \mathrm{g}$ respectively. Electron microprobe analysis of lichen samples from $\mathrm{pH}=4$ trials revealed $U$ enrichment of cortical surfaces at levels above the detection limit of $\sim 5000 \mu \mathrm{g} / \mathrm{g}$. In addition, microscopic $(\sim 50-100 \mu \mathrm{m})$ hirsute structures called tomentum that project from upper cortical surfaces on $P$. membranacea displayed particular enrichment in $U$ and $P$ relative to surrounding tissues. Semiquantitative peak-height analyses of U-enriched tomentum indicate a U-P stoichiometry of $\sim 1: 1$. These data suggest that $U$ enrichment on tomentum occurs by complexation of $U$ with surface phosphate functional groups, probably within external cell wall proteins or structural macromolecules in fungal biomass, such as chitin phosphate or chitosan phosphate [4]. Loss of accumulated 
$\mathrm{U}$ by the lichen after $\sim 75$ min probably occurs by desorption of soluble U-P complexes from molecular surfaces. Theoretical calculations indicate that $\mathrm{U}$ speciation in our experimental fluids at $\mathrm{pH}=$ 4 and $\log a_{p}=-4 \mathrm{~mol} / \mathrm{L}$ (upper limit based on initial lichen $P$ content) should be dominated by $\mathrm{UO}_{2}{ }^{2+}(\sim 59 \%), \mathrm{UO}_{2} \mathrm{HPO}_{4}(\mathrm{aq})(\sim 28 \%)$, $\mathrm{UO}_{2} \mathrm{H}_{2} \mathrm{PO}_{4}{ }^{+}(\sim 5 \%)$, and mixed uranyl-hydroxide species, and should be undersaturated with respect to $\mathrm{UO}_{2} \mathrm{HPO}_{4}(\mathrm{~s})$ and other $\mathrm{U}-\mathrm{P}$ phases. Our results suggest that soil-growing lichens in nature can serve as more effective accumulators of $U$ than has been reported previously. In persistently wet soils, characteristic of tundra, bog, or wetland habitats, lichens (and possibly fungi) could both accumulate $U$ and act as sources of $P$ for aqueous uranyl-phosphate complexation, and could therefore significantly influence the cycling of $U$ in natural settings.

References: [1] Goyal and Seaward (1981) New Phytologist, 89,631-645. [2] Richardson and Nieboer (1983) Lichenologist, 15, 81-88. [3] Puckett et al., New Phytologist, 72, 329-342. [4] Sakaguchi and Nakajima (1982) in Chitin and Chitosan.

TRANSPORT BEHAVIOR OF ZINC AND ARSENIC (VANADIUM) AS INFLUENCED BY PH AND SULFATE: COLUMN EXPERIMENTS AND MODELING. A. Hadeler ${ }^{1}$, M. Isenbeck-Schröter ${ }^{2}$, and M. Kofod', 'University of Bremen, FB Geowissenschaft, P.O. Box 330440, D-28334 Bremen, Germany (ahadeler@geochemie.uni-bremen.de),2University of Heidelberg, Institute for Environmental Geochemistry, Im Neuenheimer Feld 236, D-69120 Heidelberg, Germany.

Transport models often use batch-generated isotherms to calculate the partitioning of ions between the aqueous and the solid phase, which cannot be transferred to different geochemical conditions. Flow systems more closely approximate field conditions by maintaining narrow solid/solution ratios. In this study column experiments were carried out to determine the effect of $\mathrm{pH}$ and sulfate on $\mathrm{Zn}$ and $\mathrm{As}$ adsorption.

The purpose of this investigation was to obtain sorption data that can be interpretated using the surface complexation theory [e.g., 1]. In order to describe nonequilibrium situations in the flow field, sorption kinetics also have to be derived.

The simplest aquifer material investigated was quartz sand. Other solid phases were quartz sand-goethite and quartz sandgibbsite mixtures. Instead of using a so-called indifferent background electrolyte, the water used was prepared artificially according to a natural groundwater of $\mathrm{Ca} / \mathrm{Mg}$-sulfate type. The column was filled with aquifer material under $\mathrm{H}_{2} \mathrm{O}$ saturation and percolated by the groundwater from the bottom to the top. During percolation, the solid phase reacts with the $\mathrm{H}_{2} \mathrm{O}$ until constant $\mathrm{pH}$ and conductivity values are reached depending on the buffer capacity of the solid phase.

After the geochemical conditioning phase, a tracer experiment was conducted to determine the hydrodynamic properties using bromide as a conservative tracer. The breakthrough curve of this tracer was fitted to an analytical model to obtain the effective porosity and dispersivity.

In the presence of $\mathrm{H}_{2} \mathrm{O}$ the surfaces of the $\mathrm{Si}, \mathrm{Fe}$, and $\mathrm{Al}$ hydroxides are generally covered with surface hydroxyl groups (reactive surface). The adsorption of $\mathrm{Zn}$ and $\mathrm{As}(\mathrm{V})$ by surface hydroxyl groups is strongly $\mathrm{pH}$ dependent, both reacting inversely. In order to simulate natural conditions of acidification like pyrite oxidation, the $\mathrm{pH}$ variations were made by addition of $\mathrm{H}_{2} \mathrm{SO}_{4}$.

Additionally, surface characterization (surface charge, specific surface, and zeta potential) of solids has been considered as well as their variations as a result of sorption processes. Surface analyses were made at three times during column experiments: after conditioning of the columns, after the sorption experiments with $\mathrm{Zn}$ and As(V), and after desorption with unspiked water.

Experimentally breakthrough curves of $\mathrm{Zn}$ and $\mathrm{As}(\mathrm{V})$ were modeled using the transport model CoTAM/CoTREM considering surface complexation and first-order sorption kinetics.

References: [1] Dzombak D. A. and Morel F. M. M. (1990) Surface Complexation Modeling: Hydrous Ferric Oxide, Wiley and Sons, New York.

\section{PLASMAS, THE EARLY SOLAR SYSTEM, AND CLIMATE} DYNAMICS. A. N. Halliday, D.-C. Lee, J. N. Christensen, M. Rehkämper, W. Yi, and X. Luo, Department of Geological Sciences, University of Michigan, Ann Arbor MI 48109-1063, USA (anh@ umich.edu).

The development of multiple collector ICPMS has resulted in a range of exciting new lines of isotopic and trace-element study in the Earth, planetary, ocean, and environmental sciences [1]. The instrument interfaces two reasonably well-established technologies, multiple collector magnetic sector mass spectrometry and inductively coupled plasma sources. The addition of a laser facilitates studies for which spatially resolved isotopic information is required. The further development of established fields as different as U-Th dating [2], Hf isotope geochemistry [3], and the abundances of siderophile and chalcophile elements in the mantle [4,5], are made easier with this technique. However, the potential for exploration of very new areas is also considerable.

Several short-lived nuclide systems relevant to early solar system evolution are of particular interest. Thus far, the most significant has been ${ }^{182} \mathrm{Hf}-182 \mathrm{~W}\left(T_{1 / 2}=9 \mathrm{~m} . \mathrm{y}\right.$.). Hafnium and $\mathrm{W}$ are both highly refractory elements and should be in chondritic relative proportions $(\sim 1: 1)$ in early-formed planets and planetesimals. Deviations in $\mathrm{W}$ isotopic composition of inner solar system objects are a function of the timing and magnitude of fractionation in $\mathrm{Hf} / \mathrm{W}$, relative to chondrites [6,7]. However, $W$ has a very high first ionization potential $(\sim 8 \mathrm{eV})$ rendering isotopic measurement difficult by other techniques. Early phases with low Hf/W such as the metal phases in ordinary chondrites and iron meteorites, all have unradiogenic $W$ (typically $\varepsilon_{W} \sim-4$ ), consistent with parent bodies that accreted and segregated metal within about $10 \mathrm{~m} . \mathrm{y}$. of the iron meteorite Arispe (with the least radiogenic W yet measured) $[7,8]$. Conversely, the eucrites with very high $\mathrm{Hf} / \mathrm{W}$, have highly radiogenic $W\left(\varepsilon_{W}>20\right)$, consistent with differentiation from a parent body with chondritic Hf/W, within 15 m.y. of Arispe [9]. These results are very consistent with the available constraints from ${ }^{53} \mathrm{Mn}-{ }^{53} \mathrm{Cr}$ and

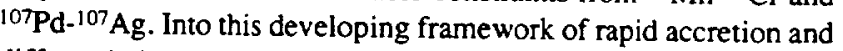
differentiation of planetesimals, we can now place the history of the larger bodies Earth, Moon, and Mars. The Earth has a chondritic W isotopic composition, consistent with late core formation (>50 m.y. post-Arispe) if the planet accreted rapidly [7], or a protracted history of concomitant accretion and core formation with an accretionary mean life of $\geq 25$ m.y. [6]. In contrast, those martian meteorites with radiogenic Nd (Nakhla, Lafayette, EETA79001) [10], have radiogenic $W\left(\varepsilon_{W}=2-3\right)$ [9], despite a primitive mantle $H f / W$ ratio 
estimated to be about a factor of 5 smaller than Earth's [11]. Therefore, it appears that most of Mars had accreted and already developed differentiated reservoirs with high $\mathrm{Hf} / \mathrm{W}$ and $\mathrm{Sm} / \mathrm{Nd}$ by about $15 \mathrm{~m} . y$. post-Arispe. The preservation of this extremely early mantle heterogeneity in relatively young rocks such as the Nakhlites, precludes the kind of long-term, highly efficient, planetary-scale convective mixing found on Earth. Perhaps even more exciting is the new discovery of $W$ isotopic heterogeneity on the Moon [12] providing evidence that portions of the Moon accreted within about 50 m.y. post-Arispe-the most precise upper age limits yet available.

Although the applications of this technique to the study of early solar system evolution have only just started, entirely different realms of study can be developed by hamessing the spatial resolution achievable with laser ablation [1,13-15]. This is already the most precise in sifu isotopic method for trace elements. The ultimate goal is for laser ablation MC-ICPMS to provide precise isotopic information at the scale of a few micrometers in a routine manner. The most spectacular success with this approach has been with the study of Mn crusts, which provide an isotopic record of sources of $\mathrm{Pb}$ transported through the deep oceans away from the strong scavenging effects of the particulate-rich ocean margins and hydrothermal vents [15]. These data may provide a powerful new approach to studying climate dynamics, continental erosion, and paleoceanography.

References: [1] Halliday A. N. et al. (1995) Intl.J. Mass Spec. Ion Process., 146/147, 21-33. [2] Luo X. et al. (1996) Eos Trans. $A G U, 77$, F774. [3] Blichert-Toft J. and Albarède F. (1997) EPSL, in press. [4] Rehkämper M. and Halliday A. N. (1997) Talanta, in press. [5] Yi W. et al. (1996) Eos Trans. $A G U, 77$, F810. [6] Halliday A. N. et al. (1996) EPSL, 142, 75-89. [7] Lee D.-C. and Halliday A. N. (1995) Nature, 378, 771-774. [8] Lee D.-C. and Halliday A. N. (1996) Science, 274, 1876-1879. [9] Lee D.-C. and Halliday A. N., this volume. [10] Harper C. L. et al. (1995) Science, 267, 213-217. [11] Treiman A. H. et al. (1986) GCA, 50, 1071-1091. [12] Lee D.-C. et al., this volume. [13] Walder A. J. et al. (1993) I. Spectrochim. Acta, 48B, 397-402. [14] Christensen J. N. et al. (1995) EPSL, 136, 79-85. [15] Christensen J. N. et al., this volume.

MICROSCOPIC INVESTIGATION OF DISSOLUTION AND ALTERATION OF METAL SULFIDE MINERALS. R. J. Hamers', S. R. Higgins', B. Hu', M. Cardona ${ }^{1}$, J. Banfield ${ }^{2}$, K. Rodgers $^{2}$, and H. Henkel ${ }^{2}$, ${ }^{1}$ Department of Chemistry, University of Wisconsin-Madison, 110 University Avenue, Madison WI 53706, USA (rjhamers@facstaff.wisc.edu), 2Department of Geology and Geophysics, University of Wisconsin-Madison, 110 University A venue, Madison WI 53706, USA.

We have investigated the structural and chemical transformation occurring at the surfaces of metal sulfide minerals using a variety a microscopic structural and chemical probes. Scanning tunneling microscopy (STM) has been used to image the surfaces of galena and pyrite with nanometer spatial resolution, permitting individual defects and atomic steps to be observed directly in electrolyte solutions. STM has been combined with differential interference contrast microscopy and high-resolution scanning electron microscopy to establish links from the atomic-length scale to the millimeter-length scale. $\mathrm{X}$-ray photoelectron spectroscopy has been used as a probe of the chemical changes occurring, revealing the formation of oxides, sulfates, and $\mathrm{Cu}$ alteration products.
Virtually all the chemical changes are observed to take place very heterogeneously. Scanning tunneling microscopy reveals the importance of surface steps in controlling the surface reactivity on small length scales. Experiments on larger length scales show that steps and other crystallographic imperfections also control the attachment of microbes to the surfaces.

Our recent work has investigated the role of microscopic heterogeneities in initiating and controlling reactions at the surfaces of metal sulfide minerals.

THE BEHAVIOR OF RHENIUM AND OSMIUM DURING MELT EXTRACTION AND METASOMATISM IN THE MANTLE: TIGHTENING AGE CONSTRAINTS ON LITHOSPHERICMANTLE EVOLUTION. M. Handler, V. C. Bennett, and T. M. Esat, Research School of Earth Sciences, The Australian National University, Canberra, ACT 0200, Australia (Monica.Handler@anu.edu.au).

The development, evolution, and long-term stability of continental lithospheric mantle (CLM) in post-Archean regions is at present poorly constrained owing largely to the difficulty of obtaining reliable age information from peridotites. Rhenium-osmium isotopic studies on mantle xenoliths have begun to provide the necessary age constraints on the timing of formation of CLM. Most upper mantle xenoliths, however, have been metasomatized to some degree, and while Os is considered fairly impervious to alteration, the behavior of the moderately incompatible Re during metasomatism is unknown. As a consequence, age constraints on melt-extraction events recorded in peridotite xenoliths rely on model ages that assume total removal of Re during melt extraction and are thus independent of the measured Re/Os. These "Re-depletion" model ages [1] provide robust minimum ages, but in many cases are much younger than the true melt extraction age and limit the potential application of the method for resolving growth episodes.

Here, we present Re-Os isotopic data along with major- and trace-element results for a suite of variably melt-depleted and metasomatized spinel peridotite xenoliths from eastem Australia in order to constrain the behavior of Re during partial melt extraction and for different styles of metasomatism in the mantle, and to assess the validity of Re-Os model ages under different conditions. The degree of metasomatism experienced by the xenolith suite varies from unmetasomatized samples through to cryptic and modally metasomatized xenoliths, the latter containing phlogopite or apatite \pm amphibole.

Measured $\mathrm{Re} / \mathrm{Os}\left({ }^{187} \mathrm{Re}^{188} \mathrm{Os}=0.027-0.294\right)$ of nine variably melt-depleted, anhydrous lherzolite xenoliths are strongly correlated with indexes of melt extraction, such as $\mathrm{Al}_{2} \mathrm{O}_{3}(0.86-3.13 \mathrm{wt} \%$ ) and $\mathrm{CaO}(0.76-2.84 \mathrm{wt} \%)$. The data indicate that the bulk partitioning behavior of $\mathrm{Re}$ is comparable to that of $\mathrm{Yb}$ over a large range of melt extraction.

Although the anhydrous xenoliths do not contain any secondary metasomatic phases, the majority have experienced cryptic metasomatism resulting in a wide range of incompatible trace-element enrichment [e.g., $(\mathrm{La} / \mathrm{Yb}) \mathrm{n}=0.36-23]$. The correlations of $\mathrm{Re} / \mathrm{Os}$ with melt extraction indexes are preserved in the cryptically metasomatized samples, indicating that $\operatorname{Re}$ can remain unaffected by this style of metasomatism. A comparison of the dry xenoliths with apatite-bearing peridotites suggests that neither Re nor Os are introduced during carbonatitic [2] metasomatism. In contrast, mea- 
sured $\mathrm{Re} / \mathrm{Os}$ of the two phlogopite-bearing samples are disturbed, with measured $\mathrm{Re} /$ Os lying significantly below the melt extraction trends toward lower $\mathrm{Re} / \mathrm{Os}$ values. The measured $\mathrm{Re} / \mathrm{O}$ s of a sample that has been infiltrated by the host basanite [3] lies off most trends, toward higher $\mathrm{Re} / \mathrm{Os}$, consistent with the introduction of a high-Re component.

Measured $\mathrm{Re} / \mathrm{Os}$ values that fall on the melt extraction trends can thus be used with the Os isotopic compositions to calculate model ages. The southeast Australian xenoliths are from five localities forming a 220-km-long lithospheric mantle transect, east of and perpendicular to the presumed Australian Precambrian shield margin. Rhenium-osmium model ages from this suite indicate at least three distinct periods of melt depletion at $\sim 1930 \mathrm{Ma}, \sim 800-1000 \mathrm{Ma}$. and during the Phanerozoic. All three age groups can be correlated with known regional crustal events. The oldest model age group is found only in the two westernmost localities where four samples also define a mantle isochron of $1960 \pm 100 \mathrm{Ma}$ with a chondritic initial $y \mathrm{O} s=0.19$, confirming the veracity of the measured Re-Os values. Model ages of $\sim 800-1000 \mathrm{Ma}$ are common to all but one locality indicating at least two temporally distinct melt-extraction events in the westermmost localities, and suggesting widespread late-Proterozoic melt extraction. Phanerozoic ages are only identified in the eastemmost localities [4], suggesting an overall age decrease in CLM from west to east.

These data thus place strong constraints on the Proterozoic evolution of this post-Archean continental region, and provide further evidence for both the complexity and persistence of lithospheric mantle in tectonically complex regions.

References: [1] Walker et al. (1989) GCA, 53, 1583-1595. [2] Yaxley et al. (1991) EPSL, 107, 306-317. [3] Norman (1997) Contrib. Mineral. Petrol., submitted. [4] McBride et al. (1996) Geology, 24, 631-634, and 1053.

\section{AMINO ACIDS ON THE MOON? NASA'S APOLLO PROGRAM AND THE SEARCH FOR EXTRATERRES- TRIAL ORGANIC MATTER. P. E. Hare, Geophysical Lab- oratory, Carnegie Institution of Washington, 5241 Broad Branch Road, Northwest, Washington DC 20015, USA.}

Predictions on finding measurable amounts of organic matter on the Moon varied widely among NASA working groups and investigators. Sensitive methods were developed for the detection and characterization of amino acids at nanogram levels using ion exchange and gas chromatography. Problems were encountered in avoiding environmental amino acid contaminants. Amino acids were detected in most lunar samples, but levels were so close to background that controversy over interpretation could not be avoided.

SYSTEMATIC CHANGES IN LEAD ISOTOPIC COMPOSITION WITH SOIL AGE IN GLACIAL GRANITIC TERRAINS. Y. Harlavan 1, Y. Erel', and J. D. Blum ${ }^{2}$, Institute of Earth Sciences, The Hebrew University, Jerusalem 91904, Israel, ${ }^{2}$ Department of Earth Sciences, Dartmouth College, Hanover NH 03755, USA.

Variations in the isotopic composition of $\mathrm{Pb}$ in soils developed on glacial moraines in granitoid terrains were investigated. Samples were collected from field sites in the Mesozoic Sierra Nevada batholith, California, and the Archean Wind River Mountains, Wyoming. Lead isotopes were measured in whole-soil samples and in weak-acid leaches of soil and fresh rock samples. In the Sierra Nevada, the isotopic composition of $\mathrm{Pb}$ in total soil digests from three moraines of varying ages (approximately 15,118 , and $\sim 330 \mathrm{k.y}$.) and in the underlying bedrock are essentially constant; however, the isotopic composition of $\mathrm{Pb}$ in the weak-acid leached fraction of the same soils decreases systematically with moraine age. The ${ }^{206 \mathrm{~Pb}}$ ${ }^{20} \mathrm{~Pb}$ ratio drops from 1.314 in a soil developed on a $15-\mathrm{k} . \mathrm{y}$. moraine to 1.289 in a soil developed on a $\sim 18$-k.y. moraine, and to 1.278 in a soil developed on a $\sim 330-k . y$. moraine. In the Wind River Mountains, $\mathrm{Pb}$ isotopes were measured in soils developed on six moraines of varying ages $(0.4,2.0,11.7,21.7, \sim 115$, and $\sim 300 \mathrm{k} . \mathrm{y}$.). The isotopic composition of $\mathrm{Pb}$ in total soil digests developed on five moraines decreases systematically with moraine age. For example, the ${ }^{206} \mathrm{~Pb} / 204 \mathrm{~Pb}$ ratio changes from 20.47 in a soil developed on a moraine 2.0 k.y. in age to 15.78 in a soil developed on a moraine $\sim 300 \mathrm{k} . \mathrm{y}$. in age. The isotopic composition of $\mathrm{Pb}$ in the soil developed on the youngest (0.4-k.y.) moraine is less radiogenic than the isotopic composition of $\mathrm{Pb}$ in the soil developed on the $2.0-\mathrm{k} . \mathrm{y}$. moraine. Of all the isotopic ratios only ${ }^{208} \mathrm{~Pb} /{ }^{204} \mathrm{~Pb}$ values of $\mathrm{Pb}$ in the weak-acid leached fraction of four of these soils $(11.7,21.7$, $\sim 115$, and $\sim 300$ k.y.) decreases systematically with moraine age. The ${ }^{208} \mathrm{~Pb} / 204 \mathrm{~Pb}$ ratio changes from 60.8 in a soil developed on a moraine $11.7 \mathrm{k.y}$. in age to 38.8 in a soil developed on a moraine $\sim 300 \mathrm{k} . \mathrm{y}$. in age. Lead in the weak-acid leached fraction of the $0.4-, 2.0-$, and 11.7-k.y. soils becomes slightly more radiogenic with soil age, reflecting the low mobility of $\mathrm{Pb}$ in soils. Six whole-soil samples and their acid leaches from the Wind River Mountains yield the same ${ }^{207} \mathrm{~Pb}-206 \mathrm{~Pb}$ isochron age as the Archean bedrock, which indicates that $\mathrm{Pb}$ in the soil is derived from in situ sources and thus excludes significant eolian contributions from the volcanic rocks of the Green River Basin. Based on successive leaching experiments it appears that the rock contains an homogenized pool of labile $\mathrm{Pb}$ that is more radiogenic than the whole rock. Only after depletion of the homogenized pool of labile $\mathrm{Pb}$ in the rock (or the soil), is $\mathrm{Pb}$ released from monazite (or other Th-bearing minerals) reflected in the $\mathrm{Pb}$ isotopic composition.

\section{EVIDENCE FOR POTASSIUM-RICH FLUIDS DURING THE GENESIS OF GRANULITES FROM THE IVREA- VERBANO ZONE, NORTHERN ITALY. D. E. Harlov and L. Franz, GeoForschungsZentrum Potsdam, D-14407 Potsdam, Germany (dharlov@gfz-potsdam.de; leo@gfz-potsdam.de).}

The Ivrea-Verbano Zone represents a traverse of steeply dipping lower crustal rocks consisting of basal metagabbros in the northwest followed by amphibolite-free, relatively reduced, metasedimentary and metavolcanic, granulite facies rocks (Opx, Grt, Plg, Qtz, Ti-rich $\mathrm{Bt}, \mathrm{Rt}$, Ilm $\left(\mathrm{X}_{\mathrm{Hm}}^{\mathrm{Ilm}}<0.01\right.$ ), Po) toward the southeast. Continuous decrease in P-T from granulite to amphibolite facies as a steady continuous dipping succession $\left(P=8.1 \rightarrow 4.1 \mathrm{kbar}, \mathrm{T}=810^{\circ} \rightarrow\right.$ $615^{\circ} \mathrm{C}$ ) is observed [1].

BSE images of the granulite facies samples show an extensive and continuous system of Ba-enriched (1.0 wt\% $\mathrm{BaO}) \mathrm{Kfs}$ veins $\left(\mathrm{Or}_{89} \mathrm{Ab}_{8} \mathrm{An}_{1} \mathrm{Ce}_{2}\right)$ along Qtz $\mathrm{Plg}\left(\mathrm{Ab}_{54} \mathrm{An}_{43} \mathrm{Or}_{2}\right)$ and $\mathrm{Plg} / \mathrm{Plg}$ grain boundaries that can be easily traced across the entire length of the sample. Quartz grain rims in contact with these veins show evidence of extensive corrosion. In contrast, contact between the veins and the 
Opx and $\mathrm{Gt}$ grains is always very clean, with no signs of secondary alteration. Kfs, of the same composition as the veins, along with coexisting Qtz, are commonly found as inclusions within Gt and Opx. Microprobe traverses from the interior of the $\mathrm{Kfs}$ veins into the interior of neighboring $\mathrm{Plg}$ show no gradations in $\mathrm{Na}, \mathrm{Ca}$, or $\mathrm{K}$ in either the $\mathrm{Kfs}$ veins or the Plg. Both observations suggest that these $\mathrm{Kfs}$ veins must have been introduced at relatively high $\mathrm{P}-\mathrm{T}$, i.e., close to peak metamorphic conditions. The $\mathrm{Kfs}$ also takes the form of patches of variable size (5-50\% of the grain) of what superficially resembles mesoperthite in an uneven scattering of the Plg grains. Again, the composition of the Kfs "lamellae" in the mesoperthite is the same as that of the veins, especially with regard to the $\mathrm{Ba}$ content. Approximately half the Plg grains contain no Kfs. The Kfs veins and patches diminish with decreasing metamorphic grade and eventually disappear once amphibolite facies is reached.

These features, termed "replacement antiperthite," have been seen in other high-grade terrains, mostly granulite grade, such as the Canadian Shield in northem Minnesota [2], the Seward penninsula, Alaska [3], Siberian and Finnish charnockites [4], the Shevaroy Massif, southern India [5], and the Bamble Sector, Norway [6]. Kfs veins in both the Shevaroy Massif and the Bamble Sector are also characterized by a high Ba content.

Following Hansen et al. [5] we postulate that the Kfs veins seen in the Ivrea-Verbano Zone granulites are evidence of a pervasive, high-temperature, low- $\mathrm{H}_{2} \mathrm{O}$ activity, $\mathrm{K}$-rich brine, coupled with a separate $\mathrm{CO}_{2}$-rich phase, and that these brines were the principle dehydration mechanism for these rocks. Additional evidence for the presence of these fluids takes the form of primary $\mathrm{N}_{2}-\mathrm{CH}_{4}-\mathrm{CO}_{2}-$ $\mathrm{H}_{2} \mathrm{O}-\mathrm{NaCl}-\mathrm{CaCl}_{2}$-rich fluid inclusions [e.g., 7-10]. Recent experimental work by Aranovich and Newton [11] and Shmulovich and Graham [12] indicates that under granulite P-T conditions the activity of $\mathrm{H}_{2} \mathrm{O}$ in these $\mathrm{KCl}-\mathrm{NaCl}$ brines goes at least as $\mathrm{X}_{\mathrm{H}_{2} \mathrm{O}}^{2}$, thus allowing for them to be more $\mathrm{H}_{2} \mathrm{O}$ rich than previously thought. Alkali and volatile-rich basalt underplating, represented today by the basal metagabbros in the Ivrea Zone [cf. 1], is the most likely source of the heat and fluids responsible for the genesis of these granulites [cf. 13].

References: [1] Henk et al. (1997) J. Geol., in press. [2] Griffin (1969) Lithos, 2, 171. [3] Todd and Evans (1994) J. Petrol., 35 , 1213. [4] Perchuk and Gerya (1992) Geochem. Intl., 34, 1. [5] Hansen et al. (1995) J. Geol., 103,629. [6] Harlov and Hansen (1997) Chem. Geol., in press. [7] Istrate and Althaus (1992) Eur. J. Mineral., 4(1), 128. [8] Andersen et al., Chem. Geol., 108, 113. [9] Klemd et al., Contrib. Mineral. Petrol., 111, 409. [10] Herms and Shenk (1992) Contrib. Mineral. Petrol., 112, 393. [11] Aranovich and Newton (1997) Contrib. Mineral. Petrol., 125, 200. [12] Shmulovich and Graham (1996) Contrib. Mineral. Petrol., 124, 370. [13] Bohlen (1987) J. Geol., 95, 617.

EXPERIMENTAL CALIBRATION OF THE EQUILIBRIUM: 6 BUDDINGTONITE $+3 \mathrm{O}_{2}=2$ TOBELITE + 12 QUARTZ $+2 \mathrm{~N}_{2}+6 \mathrm{H}_{2} \mathrm{O}$ AT 2 kbar. D. E. Harlov, W. Heinrich, and M. Gottschalk, GeoForschungsZentrum-Potsdam, D14407 Potsdam, Germany (dharlov@gfz-potsdam.de; wheinrich@ gfz-potsdam.de; gottschalk@gfz-potsdam.de).

We present experimental data for the $\mathrm{Al}_{2} \mathrm{O}_{3}-\mathrm{SiO}_{2}-\mathrm{NH}_{4}-\mathrm{H}_{2} \mathrm{O}$ system in $\mathrm{T}-\mathrm{X}_{\mathrm{N}_{2}}-\mathrm{X}_{\mathrm{H}_{2} \mathrm{O}}$ space at $500^{\circ} \mathrm{C}, 550^{\circ} \mathrm{C}$, and $600^{\circ} \mathrm{C}$ and $2 \pm$
-0.1 kbars for the following equilibrium

$$
\begin{aligned}
& 6\left(\mathrm{NH}_{4}\right) \mathrm{AlSi}_{3} \mathrm{O}_{8}+3 \mathrm{O}_{2}=2 \mathrm{~N}_{2}+6 \mathrm{H}_{2} \mathrm{O} \\
& \text { Buddingtonite } \\
& +12 \mathrm{SiO}_{2}+2\left(\mathrm{NH}_{4}\right)\left[\mathrm{Al}_{3} \mathrm{Si}_{3} \mathrm{O}_{10}\right](\mathrm{OH})_{2} \\
& \text { Tobelite }
\end{aligned}
$$

buffered to $\mathrm{Mt}-\mathrm{Hm} \mathrm{f}\left(\mathrm{O}_{2}\right)$. Nitrogen was introduced in the form of $\mathrm{AgN}_{3}$ [cf. 1]. Both the amount of $\mathrm{AgN}_{3}$ and $\mathrm{H}_{2} \mathrm{O}$ before the experiment and after, as $\mathrm{N}_{2}$ and $\mathrm{H}_{2} \mathrm{O}$, were carefully measured using standard weighing techniques. Two Pt capsules, containing mineral phase in proper molar abundances on either side of the equilibrium, along with the appropriate ratio of $\mathrm{N}_{2} / \mathrm{H}_{2} \mathrm{O}$, were welded shut and placed, along with $300-400 \mathrm{mg}$ of $\mathrm{Hm}$ and $100 \mathrm{mg}$ of $\mathrm{H}_{2} \mathrm{O}$, into a large Au capsule, which was also welded shut. Experiments were performed in cold seal, $\mathrm{Ni}-\mathrm{NiO}$ buffered, hydrothermal autoclaves with an internal $\mathrm{NiCr}-\mathrm{Ni}$ thermocouple $\left( \pm 3^{\circ} \mathrm{C}\right)$. After runs of $1-4$ weeks, the $\mathrm{Mt}-\mathrm{Hm}$ charge in the Au capsule was tested for both $\mathrm{Mt}$ and $\mathrm{Hm}$ to make sure that the $\mathrm{Hm}$ had not been totally reduced to $\mathrm{Mt}$.

Buddingtonite $(99.5 \%$ pure) and tobelite $(90 \%$ pure with a minor buddingtonite component) were synthesized from stoichiometric mixes of $\mathrm{Al}_{2} \mathrm{O}_{3}$ and $\mathrm{SiO}_{2}$ and a $25 \% \mathrm{NH}_{4} \mathrm{OH}$ solution with an excess of $\mathrm{NH}_{4}(-50 \%)$ in large Au capsules. The capsules were placed in $\mathrm{Ni}-\mathrm{NiO}$-buffered, cold-seal, hydrothermal, autoclaves (external thermocouple) at $500^{\circ} \mathrm{C}$ and $5 \mathrm{kbar}$ for the buddingtonite syntheses and $600^{\circ} \mathrm{C}$ and $2 \mathrm{kbar}$ for the tobelite syntheses with runs of 3 weeks for both minerals. This resulted in $>50-\mu \mathrm{m}$-sized grains of either mineral.

Experimental results indicate that at $2 \mathrm{kbar}$ the assemblage buddingtonite + tobelite + Qtz is stable at the following temperatures and values of $\mathrm{X}_{\mathrm{N}_{2}}: 500^{\circ} \mathrm{C}, 0.02 ; 550^{\circ} \mathrm{C}, 0.03 ;$ and $600^{\circ} \mathrm{C}, 0.04$. Above $650^{\circ} \mathrm{C}$, buddingtonite breaks down.

Preliminary experimental results on the oxidation of tobelite buffered to $\mathrm{Mt}$ - $\mathrm{Hm} \mathrm{f}\left(\mathrm{O}_{2}\right)$, also in the $\mathrm{H}_{2} \mathrm{O}$-rich region of T- $\mathrm{X}_{\mathrm{N}_{2}}-\mathrm{X}_{\mathrm{H}_{2} \mathrm{O}}$ space, at $2 \mathrm{kbar}$ and at $500^{\circ}-600^{\circ} \mathrm{C}$, utilizing the technique outlined above, indicate that it coexists with $\mathrm{SiO}_{2}$ plus an unknown phase at the following temperatures and values of $\mathrm{X}_{\mathrm{N} 2}: 500^{\circ} \mathrm{C}, 0.01 ; 550^{\circ} \mathrm{C}$, 0.015 ; and $600^{\circ} \mathrm{C}, 0.020$. Again, above $650^{\circ} \mathrm{C}$ tobelite is not stable.

Recent thermodynamic data for buddingtonite and tobelite $\left(\Delta \mathrm{G}_{\mathrm{f}}=\right.$ -3525.1 and $-5383.0 \mathrm{~kJ} /$ mole respectively) contained in Mader et al. [2] indicate that both minerals should not be stable at $500^{\circ}-$ $650^{\circ} \mathrm{C}$ and $2 \mathrm{kbar}$ buffered to $\mathrm{Mt}-\mathrm{Hm} \mathrm{f}\left(\mathrm{O}_{2}\right)$. The above experimental results suggest that the correct $\Delta \mathrm{G}_{\mathrm{f}}$ for the two phases are more likely near $-3600 \mathrm{~kJ} / \mathrm{mole}$ for buddingtonite and $-5475 \mathrm{~kJ} / \mathrm{mole}$ for tobelite.

Information concerning the P-T- $f\left(\mathrm{O}_{2}\right)-\mathrm{f}\left(\mathrm{H}_{2} \mathrm{O}\right)$ stability field of buddingtonite and tobelite is of great interest since either mineral may serve as a potential reservoir of $\mathrm{N}$ in the deep crust. Nitrogen is a common component in fluid inclusions in high-grade rocks and it has been suggested by a number of workers that it is deposited during peak metamorphic conditions [cf. 3-9].

References: [1] Keppler (1989) Eur. J. Mineral., I, 135. [2] Mader et al. (1996) Eur. J. Mineral., 8, 755. [3] Istrate and Althaus (1992) Eur. J. Mineral., 4(1), 128. [4] Andersen et al. (1993) Chem. Geol., 108, 113. [5] Visser (1992)Nor. Geol. Tid., 72, 385. [6] Elvevold and Andersen (1993) Contrib. Mineral. Petrol., 114, 236. [7] Herms and Shenk (1992) Contrib. Mineral. Petrol., 112, 393. [8] Istrate and Althaus (1989) N.Jb. Mineral. Mh., 1989, 97. [9] Klemd et al. (1992) Contrib. Mineral. Petrol., 111, 409. 
THE ORIGIN OF HIMALAYAN INVERTED METAMORPHISM AND ANATEXIS INFERRED FROM THORIUMLEAD ION-MICROPROBE DATING. T. M. Harison' ${ }^{1}$ O. M Lovera', M. Grove', E. J. Catlos ${ }^{1}$, A. Yin ${ }^{1}$, and F. J. Ryerson ${ }^{2}$, 'Department of Earth and Space Sciences, University of CaliforniaLos Angeles, Los Angeles CA 90095, USA, '2Lawrence Livermore National Laboratory, Livermore CA 94550, USA.

A long-standing question in Himalayan geology is the origin of the two parallel granite belts, the High Himalayan leucogranites (HHL) and North Himalayan granites (NHG). The HHL comprise a discontinuous chain of 24-19-Ma, minimum-melt, sheetlike intrusions and dikes that were generally emplaced above the Main Central Thrust (MCT) and below the South Tibetan Detachment System (STDS), a north-dipping normal fault. The NHG belt runs parallel to, and $\sim 100 \mathrm{~km}$ to the north of, the HHL chain and is composed of elliptical shaped plutons. They differ from the HHLs in their diapiric emplacement style, younger ages (17-9 Ma), and higher melting temperatures. Perhaps the most significant problem faced by past attempts to explain anatexis in the MCT hanging wall is how to explain their juxtaposition against footwall rocks that display the classic inverted metamorphic sequences that apparently existed at substantially lower temperatures. Thus models seeking to explain the origin of the HHL invoked some extraordinary source of heat such as very high heat production, mantle delamination, or very high ( $\geq 100 \mathrm{MPa}$ ) flow stresses. Because the monazite and gamet isograds are essentially coincident in pelitic rocks, dating monazite inclusions in gamets yields the timing of recrystallization. In situ ${ }^{208} \mathrm{~Pb} / 232 \mathrm{Th}$ ion microprobe monazite ages from two inverted metamorphic sequences in the central Himalayas yield ages between 4.5 and $8.0 \mathrm{Ma}$, including monazite ages from within gamets. Garnetbiotite-plagioclase-muscovite-quartz thermobarometry yields P-T conditions of $\sim 7 \mathrm{kbar}$ and $550^{\circ} \mathrm{C}$, indicating that gamet growth was occurring at a depth of $\sim 25 \mathrm{~km}$ at ca. $6 \mathrm{Ma}$. The hypothesis that appears to best explain these data is that the MCT ramp was reactivated during the Late Miocene. Slip was initially restricted to the MCT fault, resulting in burial metamorphism of footwall. Deformation subsequently moved to a broad shear zone underlying the MCT resulting in the juxtaposition of two right-way-up metamorphic sequences. Recognizing that inverted metamorphism is not temporally related to Tibetan Slab anatexis relieves the need to restrict the site of anatexis to the MCT thrust ramp and the necessity of an extraordinary hear source.

We suggest that the origin of the HHL and NHG results from modest shear heating along a continuously active decollement. We assume that Eo-himalayan metamorphism produced a stratified paragenic sequence in which grade increases as a function of depth. Because of the initially stratified hydrous mineralogy, slip along the fault can potentially produce two horizontally separated zones of melting corresponding to the vapor-present $\left(680^{\circ} \mathrm{C}\right)$ and vaporabsent $\left(780^{\circ} \mathrm{C}\right)$ melting of muscovite. Melting histories along the Himalayan thrust were calculated using a two-dimensional finitedifference scheme based upon the present fault geometry and convergence rate across the Himalayas and a shear stress of $30 \mathrm{MPa}$. The first phase of anatexis resulting from minimum melting begins at $24 \mathrm{Ma}$ at a horizontal distance of $\sim 80 \mathrm{~km}$ from the fault vertex. The progress of this feature toward the ramp is determined by the interplay between the magnitude of shear heating and heat loss to the lower plate. The refrigeration of the shear zone near the fault ramp and the propagation of the muscovite reaction front toward the ramp cause melt production to cease at $20 \mathrm{Ma}$. The second phase of melting bégins when temperatures reach muscovite dehydration melting at $18 \mathrm{Ma}$ and continues until $14 \mathrm{Ma}$. The model successfully predicts (1) the $\sim 100-\mathrm{km}$ offset between the HHL and NHG belts; (2) HHL and NHG crystallization ages of 24-20 Ma and 18-10 Ma respectively: and (3) the differing emplacement styles and melting temperatures of the HHL and NHG belts.

DEEP-SEA CORALS AND CLAMS: CHEMICAL MONITORS OF HYDROTHERMAL VENT FIELD ACTIVITY. S. R. Hart and J. Blusztajn, Woods Hole Oceanographic Institution, Woods Hole MA 02543, USA.

Hydrothermal vent systems on mid-ocean ridges are a major controlling influence on the chemistry of the oceans, as well as a semaphore for the underlying magmatic activity that drives them. These vent systems can show significant thermochemical variations on almost all timescales. In order to characterize the global hydrothermal fluxes associated with ridge magmatism, it will be important to understand the temporal variability of ridge-crest phenomena. Thus far, it has been very difficult to quantify the history of vent systems on decadal to centennial timescales. We are appraising the utility of corals and clams as chemical vent monitors, as they have aragonitic skeletons, which preserve thermal and chemical information about their environment, and both have life spans of $30-50 \mathrm{yr}$ or more.

We use corals (such as Lophelia pertusa) as far-field monitors, as they live independently of the vent systems. Clams (such as Calyprogena magnifica) are used as near-field monitors, as they require warm hydrothermal fluid for their existence. Chemical analyses are done with the WHOI ion microprobes, as they have both high sensitivity and excellent spatial resolution (equivalent to subweekly growth durations). We have completed a time series (for the approximate period 1975-1980) for B, F, Mg, St, and Ba in a Calyptogena from the biotransect area, EPR (using the Cameca $3 \mathrm{f}$ ionprobe). The total range of variability (relative to $\mathrm{Ca}$ ) is similar for all these elements $(32-46 \%)$. To produce chemical variations this large in the clams' host water by conservative mixing of seawater and hot smoker fluid would lead to waters with temperatures of $20^{\circ}-$ $40^{\circ} \mathrm{C}$. This is significantly warmer than what is normally measured directly. It is more likely that the variations reflect a temperature dependence of the water/shell bio partition coefficient of the clam.

We have calibrated this temperature dependence in a shallow coastal water clam (Arctica islandica) from an environment of constant water chemistry but variable and known temperature. Remarkably, the average elemental concentrations are similar in both the Arctica and the Calyptogena (4 ppm B, $70 \mathrm{ppm} \mathrm{F}, 40 \mathrm{ppm}$ $\mathrm{Mg}, 1070 \mathrm{ppm} \mathrm{Sr}$, and $8 \mathrm{ppm} \mathrm{Ba}$ ). The metal/Ca ratios vary by $4.3-$ $8.6 \%$ per ${ }^{\circ} \mathrm{C}$ in the Arctica. Applying this calibration to the Calyprogena, as a first step, leads to estimates for temperature variability in this Calyptogeno of $4-8^{\circ} \mathrm{C}$. Further efforts are underway to validate this temperature calibration by microanalysis of $\delta^{18} \mathrm{O}$ and ${ }^{87} \mathrm{Sr} /{ }^{86} \mathrm{Sr}$ from the same shell-section traverse.

Preliminary work has been done for $\mathrm{Mn} / \mathrm{Ca}$ in both corals and clams. For this, we have utilized the new Cameca 1270, as highmass resolution is required to separate the ${ }^{55} \mathrm{Mn}$ and ${ }^{43} \mathrm{Ca}^{12} \mathrm{C}$ isobars. Manganese in the Calyptogena shows a large variation, from 
$0.35 \mathrm{ppm}$ to $1.54 \mathrm{ppm}$ ( 6 spots). This high and variable concentration likely reflects input of hot smoker fluids, which are typically enriched in $\mathrm{Mg}$ by $10^{6}$ over ambient seawater. Reconnaissance on a coral (Lophelia) from the Menez Gwen hydrothermal field (MAR) gave $3.9 \mathrm{ppm} \mathrm{Mn}$, compared to only $0.22 \mathrm{ppm}$ for a Lophelia far from any vent field. Again, we believe this large enrichment is due to the coral "seeing" Mn-rich water advected out from the vent field plume. We will repon detailed $\mathrm{Mn} / \mathrm{Ca}$ time-series data for both corals and clams.

STABILITY RELATIONS OF AN ALUMINOUS PHASE IN THE UPPERMOST LOWER MANTLE. B. Harte ${ }^{1}$, J. W. Harris $^{2}$, and M. T. Hutchison', 'Department of Geology and Geophysics, University of Edinburgh, Edinburgh EH9 3JW, UK, 2Department of Geology and Applied Geology, University of Glasgow, Glasgow G12 8QQ, UK.

Inclusions within diamonds from Sao Luiz, Brazil [1] indicate a mineral assemblage $\mathrm{fPer}+\mathrm{MgSiPvk}+\mathrm{CaSiPvk}$, where fPer refers to ferropericlase, $\mathrm{MgSiPvK}$ is magnesium-silicate perovskite, and CaSiPvk is calcium-silicate perovskite. This assemblage is believed to form the dominant mineralogy of peridotite or pyrolite rock compositions in the lower mantle (below the $660-\mathrm{km}$-deep discontinuity). In the same diamonds as the above there are also occasional inclusions with compositions $(\mathrm{Mg}, \mathrm{Fe})_{3} \mathrm{Al}_{2} \mathrm{Si}_{3} \mathrm{O}_{12}$ corresponding to pyrope-almandine garnet, but which have been shown to have a tetragonal structure markedly distinct to garnet [2], and this new phase is referred to here as TAPP (tetragonal almandine-pyrope phase). A phase corresponding structurally to TAPP has not been reported in high-pressure experimental studies, despite careful consideration of the relative importance of majoritic garnet (mGrt), alumina-bearing MgSiPvk, or new experimental phases as the location of $\mathrm{Al}$ in the uppermost part of the lower mantle (e.g., [3] and references therein). This abstract considers the possible location of a stability field for TAPP, which involves relatively little readjustment of lower mantle phase relations elicited by experimental work.

Much experimental work indicates that at relatively low pressures within the lower mantle, significant amounts of $\mathrm{Al}_{2} \mathrm{O}_{3}$ become soluble in MgSiPvk and the assemblage MgSiPvk + corundum $(\mathrm{Cm})$ also becomes stable, thus restricting the stability of phases having gamet, majoritic gamet, or TAPP compositions to the shallowest depths in the lower mantle. A possible version of the stability relationships for the join $\mathrm{MgSiPvk}-\mathrm{Al}_{2} \mathrm{O}_{3}$ in the system $\mathrm{MgO}^{-\mathrm{SiO}_{2}-}$ $\mathrm{Al}_{2} \mathrm{O}_{3}$ is shown in Fig. 1. The solid lines are based largely on the experimental work for $1500^{\circ} \mathrm{C}$ presented by Irifune et al. [3], with the exception that fields of stability of TAPP and MgSiPvk + TAPP have been inserted between the fields of stability of $\mathrm{mGrt}$ and $\mathrm{MgSiPvk}+\mathrm{Cm}$. TAPP has the composition of pyrope garnet $\left(\mathrm{Mg}_{3} \mathrm{Al}_{2} \mathrm{Si}_{3} \mathrm{O}_{12}\right)$ and shows no majoritic solid solution. Some displacement, probably to higher pressure, of the field boundaries of Fig. I will occur with some partial substitution of $\mathrm{Fe}$ for $\mathrm{Mg}$.

The solid lines of Fig.1 fit the general assemblage information from the Sao Luiz inclusions, but there is one case where MgSiPvk and TAPP inclusions are in actual contact and the MgSiPvk contains $2.7 \mathrm{wt} \% \mathrm{Al}_{2} \mathrm{O}_{3}$ and a calculated $1.8 \mathrm{~mol} \%$ of trivalent cations. This is substantially less than the amount of $\mathrm{Al}_{2} \mathrm{O}_{3}$ solid solution in MgSiPrk shown by the solid lines in Fig. 1, which are based on experimental data. If the compositions of the natural inclusions

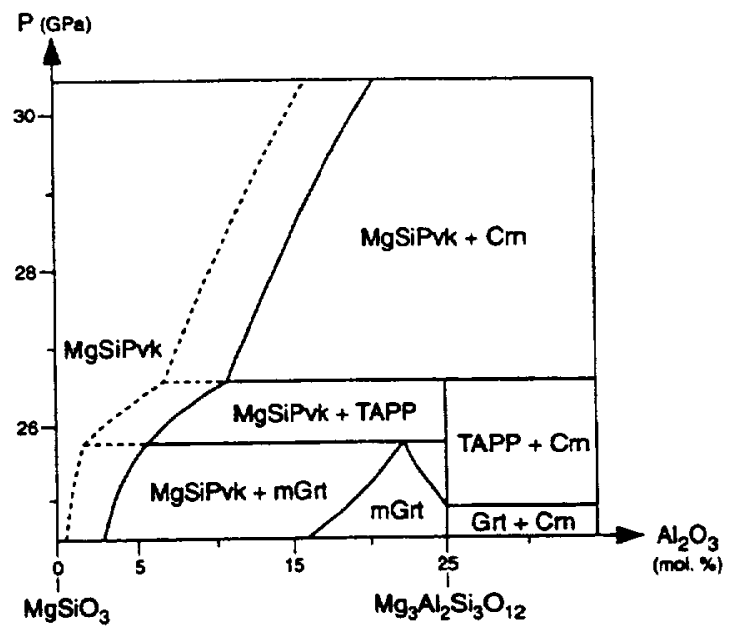

Fig.1. Possible phase relations of TAPP in the $\mathrm{MgO}-\mathrm{SiO}_{2}-\mathrm{Al}_{2} \mathrm{O}_{3}$ system, partly based on [3].

reflect true high-pressure equilibrium, then the dashed field boundaries of Fig. 1 become more appropriate. Even with the dashed boundaries, all the $\mathrm{Al}_{2} \mathrm{O}_{3}$ of a pyrolite-peridotite composition may be accommodated in $\mathrm{MgSiPvk}$ at depths greater than about $26 \mathrm{GPa}$. TAPP would be a more widespread phase in basic than ultrabasic compositions, and may help to make basic compositions relatively bouyant compared with ultrabasic ones.

References: [1] Harte B. and Harris J. W. (1994) Mineral. Mag., 58A, 384-385. [2] Harris et al. (1997) Nature, submitted. [3] Irifune T. et al. (1996) Phys. Earth Planet. Inter., 96, 147-157.

DECOMPRESSION MELTING MODELS FOR LITHOSPHERE-DERIVED CONTINENTAL FLOOD BASALTS IN THE PARANÁ-ETENDEKA PROVINCE. C. J. Hawkesworth $^{1}$, K. Gallagher' ${ }^{2}$, L. Kirstein ${ }^{1}$, D. W. Peate', S. P. Tumer' ${ }^{1}$, and M.S. M. Mantovani' ${ }^{3}$ ' Department of Earth Sciences, Open University, Milton Keynes MK7 6AA, UK, '2Department of Geology, Imperial College, London SW7 2AZ, UK, 'Instituto Astronomico e Geofisico, Rua do Matao, 1226, Sao Paulo 05508-900 S.P., Brazil.

The Parana-Etendeka is the largest preserved continental flood basalt (CFB) province on Earth, and increasingly one of the best studied. Major- and trace-element analyses of over 2000 samples from outcrop and borehole samples have allowed six basalt magma types to be recognized and the internal structure of the lava pile to be determined [1]. The regional distribution of distinct high- and low-TVY magma types in the lavas and associated dike swarms indicates that magma generation occurred over a wide area and involved different mantle sources. Most lavas have low $\mathrm{Nb} / \mathrm{La}$ ratios, enriched $\mathrm{Sr}, \mathrm{Nd}$, and $\mathrm{Pb}$ isotope signatures, and high $\mathrm{SiO}_{2}$ and low $\mathrm{FeO}$ relative to plume-related oceanic basalts. In some units these features in part reflect crustal contamination processes, but most basalt magma types appear to have been largely derived from old, trace-element-enriched source regions within the mantle lithosphere.

Models for melt generation require good constraints on eruption rates, from which melt generation rates may be inferred, and on the 
amounts of lithospheric extension. Over 75 high-precision Ar-Ar ages are now available on the lavas and dikes of the ParanáEtendeka [e.g., 2,3]. The main pulse of magmatism lasted for several million years (134-129 Ma), but it was preceded by an earlier minor pulse from 138-135 Ma. Calculated eruption rates vary from $\sim 0.03 \mathrm{~km}^{3} \mathrm{yr}^{-1}$ in the early pulse to $\sim 0.15 \mathrm{~km}^{3} \mathrm{yr}^{-1}$ in the main pulse of magmatism [4]. Geochemical correlations from the lavas to the dikes allow the orientations of the stress fields, and even the amounts of extension, to be inferred for the different magma pulses. The early magmatism is characterized by high Ti/Y ratios, relatively small amounts of extension $(\sim 10 \%)$ across northwestsoutheast-trending dikes, and low eruption rates. This magmatism continued until $129 \mathrm{Ma}$, a duration of $\sim 9 \mathrm{~m} . y$. In contrast, the main pulse of magmatism is predominantly of low-Ti/Y magmas, and they appear to have been erupted along coast-parallel dikes, which were therefore also parallel to the maximum extension direction associated with the opening of the South Atlantic.

The melt generation rates may be linked to the amounts of extension associated with the two dike orientations, and a model has been developed to investigate the extent to which magmas may be generated in the mantle lithosphere in response to lithospheric extension. The calculations allow for finite duration extension over anomalously hot mantle, with a hydrous peridotite solidus in the lithosphere and anhydrous peridotite below. The simulations show that the inferred time dependence in the melt source region could be the result of decompression melting of the lower continental lithosphere under small amounts of extension $(\beta<1.1)$, as may be inferred for the northwest-southeast dikes. Increased extension on a different orientation (related to the initial rifting of the margin) can produce more melt from the lithosphere and ultimately results in melting of the underlying asthenosphere. The timing and relative volumes of melt from different source regions depend primarily on the extension rate and the mantle temperature. Overall, the role of the Tristan plume appears to have been largely passive, perhaps facilitating melt generation in old continental mantle lithosphere through conductive heating. The flood basalts postdate the JurassicCretaceous boundary, ruling out any link to a faunal extinction.

References: [1] Peate D. W. et al. (1992) Bull. Volcanol., 55 , 119-139. [2] Tumer S.P. et al. (1994)EPSL, 121, 333-348. [3] Renne P. R. et al. (1996) EPSL, 144, 199-212. [4] Stewart K. et al. (1996) EPSL, 143, 95-109.

HIGH-PRESSURE HYDROTHERMAL ORGANIC SYNTHESIS: EXPERIMENTAL CONSTRAINTS ON THE ORIGIN OF LIFE. R. M. Hazen ${ }^{1}$, J. G. Blank', G. D. Cody ${ }^{1}$, R. J. Hemley ${ }^{1}$, H.-K. Mao', H. S. Yoder Jr. ', H. Morowitz', and S. Chang', 'Geophysical Laboratory, Camegie Institution of Washington, 5251 Broad Branch Road, Northwest, Washington DC 20015, USA, 2Mail Stop 1D6, George Mason University, Fairfax VA 22030, USA, ${ }^{3}$ NASA Ames Research Center, P.O. Box 1000, Moffett Field CA 940351000 , USA.

Previous research on the abiotic synthesis of organic molecules essential to life has focused primarily on simulations of low-pressure aqueous environments characteristic of the Earth's surface. However, discoveries of hyperbaric organisms in a variety of subsurface environments and recent thermodynamic modeling support the hypothesis that high-pressure aqueous environments character- istic of the deep ocean and crustal hydrothermal systems may also be favorable for prebiotic organic synthesis. Accordingly, two experimental protocols have been developed to study effects of temperature and pressure on organic reactions. In one, samples sealed in gold capsules are subjected to elevated pressures (500-5000 bar) and temperatures $\left(150^{\circ}-350^{\circ} \mathrm{C}\right)$ inside an internally heated gasmedia pressure apparatus, quenched, and analyzed at ambient conditions. In subsequent experiments, samples confined in a fixedvolume hydrothermal diamond-anvil cell are monitored in situ during heating using Raman and IR spectroscopy. Initial experiments incorporating compounds in the $\mathrm{C}-\mathrm{O}-\mathrm{H}$ system have addressed the potential for pressure-enhanced electrophilic addition of $\mathrm{CO}_{2}$ to pyruvic acid to form oxaloacetic acid-a key step in the metabolic TCA cycle common to all cellular life.

HYDROGEN PENETRATION OF MINERALS AND GLASSES DURING HYDROLYSIS AT HYDROTHERMAL CONDITIONS. R. Hellmann, Crustal Fluids Group, CNRS LGIT-IRIGM BP 53X, 38041 Grenoble Cedex, France (hellmann@ obs.ujf-grenoble.fr).

An important aspect of the dissolution process of minerals and glasses at hydrothermal conditions is the penetration of aqueous species into the bulk structure. The penetration of $\mathrm{H}$-bearing species, such as $\mathrm{H}^{+}, \mathrm{H}_{2} \mathrm{O}, \mathrm{H}_{3} \mathrm{O}^{+}, \mathrm{OH}^{-}$, etc., has an important bearing on the hydrolysis of bonds within the structure, and therefore is important with respect to the overall rate of dissolution. In this study, the influx of $\mathrm{H}$ species has been documented by the measurement of $\mathrm{H}$ profiles via resonant nuclear reaction analysis (RNRA) of several types of minerals and glasses: quartz, albite, albite glass, and fluorite. Penetration of $\mathbf{H}$ species was measured after dissolution in aqueous solutions at temperatures of $150^{\circ}-300^{\circ} \mathrm{C}$ and $\mathrm{pH}$ ranging from 3 to 11 . Preliminary results show that at a given temperature, both the structure and the $\mathrm{pH}$ of the solution play a critical role in the depth and amount of $\mathrm{H}$ penetration. Minerals with no easily exchangeable cations do not show significant $H$ penetration. On the other hand, feldspars (mineral and glass structure) show significant depths of $\mathrm{H}$ penetration, but the degree of $\mathrm{H}$ penetration is a strong function of $\mathrm{pH}\left(\mathrm{H}_{\text {acid }} \gg \mathrm{H}_{\text {neutral }} \gg \mathrm{H}_{\text {basic }}\right)$. In addition, albite glass shows a higher amount of $\mathrm{H}$ penetration than its crystalline counterpart. This illustrates how a difference in structure influences $H$ penetration, which in turn is potentially related to differences in overall dissolution rates.

\section{CONSTRAINTS ON DESERT VARNISH PROVENANCE} USING RADIOGENIC ISOTOPE SIGNATURES. N. G. Hemming1, T. Liu ${ }^{1}$, and W. S. Broecker ${ }^{1}$, Lamont-Doherty Earth Observatory of Columbia University, Route $9 \mathrm{~W}$, Palisades NY 10964, USA (hemming@lamont.ldeo.columbia.edu).

There has been recent interest in using the chemical stratigraphy in desert vamish as a paleoclimate indicator for the basins in which they form. Black, Mn-rich layers appear to correspond to wet conditions, while yellow, Mn-poor layers correspond to dry conditions, and these layers can be related to glacial and interglacial periods respectively. It is essential to understand the process of desert vamish formation, and the source of the chemical constituents in 
TABLE 1 .

\begin{tabular}{lcc}
\hline Sample & Location or Source & ${ }^{87} \mathrm{Sr} / 86 \mathrm{Sr}$ \\
\hline DV-3 & South-central Oregon & 0.70478 \\
DV-6 & South-central Idaho & 0.70993 \\
DV-7 & Searles Lake & 0.70854 \\
DV-1] & Southwestern Idaho & 0.70967 \\
987 avg. & & $0.71024(3)$ \\
Modem seawater & & 0.70914 \\
Saharan dust [2] & E. Washington State & $0.715-0.721$ \\
Moses Lake [3] & Central China & 0.70732 \\
Lanzhou loess [3] & Asian origin & 0.71404 \\
Greenland ice core dust [2] &
\end{tabular}

deser varnish, in order to gain more information from this potentially valuable tool. We present evidence from $\mathrm{Sr}$ isotopes of a local source for desert varnish constituents.

The ingredients in rock vamish are thought to be delivered by rain and dust. Radiogenic isotopes have been used extensively to track the sources of dust, so are ideal for determining whether sources of these elements are local or are far-traveled. Our first data from Holocene rock vamish samples collected across the Great Basin preclude long-distance transport of dust, unlike the dust sources documented in the Greenland ice core (see Table 1). In fact, the Sr data are consistent with the isotopic compositions of the respective $\mathrm{Sr}$ isotopic provinces [e.g., 1] where the desert vamish formed (see Fig. 1). Regardless of the substrate on which the varnish formed, there is little variation in the composition of the vamish, so the rock substrate cannot be the source of the rock varnish constituents. Therefore, our data are consistent with a local (basinal) source, but not a substrate or distant (extrabasinal) source.

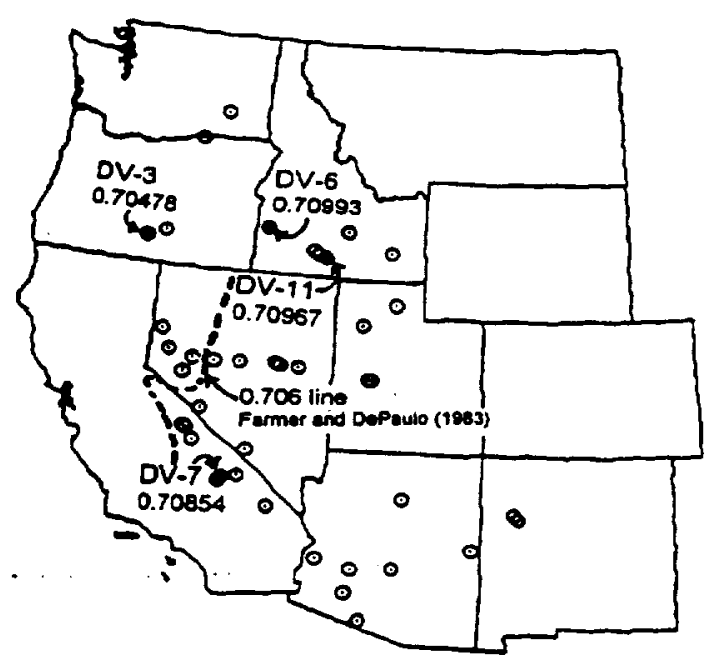

Fig. 1. Map of western United States showing locations from which Holocene age varnish was recovered by [4]. Filled circles on map are locations for which we have Sr data (see Table 1). The 0.706 line is the isopleth separating Sr iotopic provinces.
References: [1] Farmer G. L. and DePaolo D. J. (1983) JGR, 88, 3379-3401. [2] Biscaye P. E. et al. (1974)J. Recherches Atmospheriques, 8, 819-829. [3] Nakai S. et al. (1993) EPSL, 119, 145157. [4] Liu T. and Dom R. I. (1996) Ann. Assoc. Am. Geographers, $86,187-212$.

ARGON-40/ARGON-39 GEOCHRONOLOGY OF FINEGRAINED SEDIMENTS FROM HEINRICH LAYER 2: FURTHER EVIDENCE FOR A DOMINANT LABRADOR SEA SOURCE FOR THE HEINRICH LAYERS. S. R. Hemming ${ }^{\text {, C. M. Hall }}{ }^{2}$, W. S. Broecker ${ }^{1}$, P. E. Biscaye ${ }^{1}$, and G. C. Bond', 'Lamont-Doherty Earth Observatory of Columbia University, Route 9W, Palisades NY 10964, USA (sidney@lamont.ldeo. columbia.edu), ${ }^{2}$ Department of Geological Sciences, University of Michigan, 2534 C. C. Little Building, Ann Arbor MI 48 109-1063, USA.

It is now well known that the Heinrich layers of the North Atlantic have anomalous compositions that can be seen in measures of magnetic susceptibility, grain counts, and geochemical/ isotopic approaches. One of the earliest geochemical approaches employed on the Heinrich layers was the K/Ar age of the fine fraction of sediments from the Dreizack sea mount in the eastern Atlantic Ocean [1]. Although on the finest fraction of sediments that could have been transported by a variety of mechanisms, the $\mathrm{K} / \mathrm{Ar}$ ages of Heinrich layers $1,2,4$, and 5 stand out dramatically. The values measured are near 1 b.y., in contrast to the fine fraction from the background and from Heinrich layers 3 and 6, which give 400-m.y. $\mathrm{K}$ Ar apparent ages. Argon-40/argon-39 data from hornblende grains give a strong peak at 1.8 b.y. [2], and the content of homblende, feldspar, and mica is high within these fine sediments [1]. Thus, the 1-b.y. ages are likely to represent mixtures between 1.8-b.y. basement sources that are documented by the homblende grains, and reworked Paleozoic sediment sources. The question is, is this (1) a mixture between background sediment with an approximately 400 m.y. age $[1,3]$ and ice-rafted sediment with 1.8-b.y. age, or (2) a mixture that reflects the ice-rafted composition? To address this question we have gathered ${ }^{40} \mathrm{Ar}-{ }^{39} \mathrm{Ar}$ data from the fine fraction of Heinrich layer 2 from core V28-82 in the eastern Atlantic and from core GGC-29 on Orphan Knoll. Extensive geochemical data exist for the Heinrich layers in V28-82. The location of core GGC-29 at the outlet of the Labrador Sea makes it an ideal location to measure the average composition of sediments transported by icebergs derived from sources surrounding the Labrador Sea.

Argon-40/argon-39 geochronology has the advantage over conventional $\mathrm{K} / \mathrm{Ar}$ of single measurements on very small samples, but it has the potential weakness of recoil loss of Ar during irradiation. By encapsulating the samples in a glass tube evacuated to $1 \times$ $10^{-8}$ torr, the recoil loss is minimized and the Ar lost during recoil can be measured. Thus an age exactly equivalent to a conventional $\mathrm{K} / \mathrm{Ar}$ age can be obtained and additional information may come from step heating the sample. A sample from $\mathrm{H} 2$ at $108 \mathrm{~cm}$ in core GGC29 gives a total gas (= conventional K/Ar) age of $970 \pm 4 \mathrm{Ma}(6.8 \%$ recoil loss). From $98 \mathrm{~cm}$ in core $\mathrm{V} 28-82, \mathrm{H} 2$ gives a total gas age of $1059 \pm 3$ (8.3\% recoil loss). Thus, our results are entirely overlapping with those of Jantschick and Huon [1] in the easternmost part of the North Atlantic, and accordingly provide further indication that the Labrador Sea is the dominant outlet of icebergs contributing 
sediments to the detrital carbonate-bearing Heinrich layers.

References: [1] Jantschick and Huon (1992) Eclogae Geol. Helv., 85, 195-212. [2] Gwiazda et al. (1996) J. Glaciol., 440-446. [3] Hurley et al. (1963) GCA, 27, 393-399.

UNDERSTANDING NATURAL LEAD ISOTOPE DISTRIBUTIONS IN THE OCEAN: A GENERAL-CIRCULATIONMODEL APPROACH. G. M. Henderson ${ }^{1}$ and E. Maier-Reimer ${ }^{2}$, 'Lamont-Doherty Earth Observatory, Columbia University, Palisades NY 10964, USA (gideon@lamont.columbia.edu), 2Max-PlanckInstitut für Meteorologie, Hamburg, Germany.

The distribution of dissolved $\mathrm{Pb}$ isotopes in the oceans is controlled by the sources of $\mathrm{Pb}$, by ocean circulation, and by the removal of $\mathrm{Pb}$. Understanding the relative influence of these three controls on the natural distribution of oceanic $\mathrm{Pb}$ is made difficult by the large anthropogenic $\mathrm{Pb}$ contamination of the surface Earth. But achieving such understanding is a worthwhile goal as the $\mathrm{Pb}$ isotope distribution in the past oceans will then provide information about paleo-ocean circulation and about the pattern and style of past continental weathering.

In this study, we investigate the distribution of natural $\mathrm{Pb}$ in the oceans using the Hamburg Large Scale Geostrophic Ocean General Circulation Model (GCM) [1,2]. The ocean circulation and productivity patterns in this model are close to those in the modern ocean so the model constrains the advection of $\mathrm{Pb}$ by circulation. We constrain removal of $\mathrm{Pb}$ through the use of ${ }^{210} \mathrm{~Pb}$. The ${ }^{210} \mathrm{~Pb}$ distribution in the ocean is not anthropogenically perturbed and its input is well known from atmospheric models of ${ }^{222} \mathrm{Rn}$ circulation and from the $2326^{226} \mathrm{Ra}$ measurements of the GEOSECS program. We have collated a total of $1800^{210} \mathrm{~Pb}$ measurements with good $\propto$ ceanic coverage from GEOSECS and other published sources (the $210 \mathrm{~Pb}$ and ${ }^{226} \mathrm{Ra}$ datasets are available at http://www.ldeo.columbia.edw $\sim$ gideon/). Using the known input of $210 \mathrm{~Pb}$ and the model-derived productivity, we adjust the scavenging onto biogenic particles and at the sediment/water interface to give a good fit to the $210 \mathrm{~Pb}$ observations. This requires some regeneration of scavenged $\mathrm{Pb}$ at depth due to the remineralization of biogenic particles (dissolution profiles as in [1]). But total particle/dissolved equilibration of $\mathrm{Pb}$ cannot occur with the flat or decreasing $210 \mathrm{~Pb}$ depth profile observed throughout the oceans.

The combined use of the GCM and $210 \mathrm{~Pb}$ observations provides a well-constrained three-dimensional map of the advection and removal of $\mathrm{Pb}$. We use this map to investigate the relative importance of eolian vs. riverine sources in controlling open-ocean $\mathrm{Pb}$ isotopes and to look at the length scale of advection of $\mathrm{Pb}$ isotope signatures. We have used a simplified stable $\mathrm{Pb}$ input, which assumes $13 \%$ of the dissolved $\mathrm{Pb}$ reaching the oceans is through dissolution of eolian material. This value is based on the relative magnitudes of the riverine vs. eolian particle fluxes to the ocean adjusted to allow for $50 \%$ removal of riverine $\mathrm{Pb}$ in the estuarine and near-shore environment. The distribution of eolian inputs follows that of [3]. We approximate the riverine input by the five largest riverine systems scaled relative to their dissolve loads. This somewhat simplistic stable- $\mathrm{Pb}$ input scheme results in eolian inputs contributing up to $60 \%$ of the $\mathrm{Pb}$ in the surface waters of the southern ocean and at least $10 \%$ of the $\mathrm{Pb}$ in the global deep waters with this value rising as high as $40 \%$ in some areas of the southem ocean.
Individual riverine $\mathrm{Pb}$ signatures are important in the ocean basin into which they flow, but are significantly reduced by the time they are advected to other ocean basins.

A more thorough investigation of the stable $\mathrm{Pb}$ input to the ocean will require tuning the $\mathrm{Pb}$ inputs in the model to replicate the observed $\mathrm{Pb}$ isotope distributions seen in $\mathrm{Mn}$ crusts [4-6]. This continuing work will also allow investigation of the $\mathrm{Pb}$ isotope response to changing sources of $\mathrm{Pb}$ and changing ocean circulation in the past.

References: [1] Maier-ReimerE. (1993) GlobalBiogeochemical Cycles, 7, 645-677. [2] Maier-Reimer E. et al. (1993) J. Phys. Oceanogr., 23, 731-757. [3] Tegen I. and Fung I. (1994) JGR, 99, 22897-22914. [4] Chow T. J. and Patterson C. C. (1959) GCA, 17, 21-31. [5] Abouchami W. and Goldstein S. L. (1995) GCA, 59, 1809-1820. [6] von Blanckenburg F. et al. (1996) GCA, 60, 49574964.

\section{LARGE BORON ISOTOPE FRACTIONATION BETWEEN HYDROUS VAPOR AND SILICATE MELT AT IGNEOUS} TEMPERATURES. R. L. Hervig', D. London ${ }^{2}$, G. B. Morgan ${ }^{2}$, and M. B. Wolf ${ }^{\mathfrak{y}}$, 'Center for Solid State Science, Arizona State University, Tempe AZ 85287, USA, ${ }^{2}$ School of Geology and Geophysics, University of Oklahoma, Norman OK 73019, USA, ${ }^{3}$ Department of Geology, Augustana College, Rock Island IL 61201, USA.

The fractionation of $\mathrm{B}$ isotopes between aqueous vapor and peraluminous high-silica melt derived from macusanite, a rhyolitic obsidian from southeastern Peru, was determined at $200 \mathrm{MPa}$ and $650^{\circ}$ and $750^{\circ} \mathrm{C}$. 2-3-mm pieces of bubble-free macusanite were placed in a Au capsule with an equal mass of $\mathrm{H}_{2} \mathrm{O}$. Run duration was 30 days. Run products and starting glass were analyzed by secondary ion mass spectrometry (SIMS) at sufficient mass resolving power to eliminate hydrides and multiply charged $\mathrm{Si}$ from the mass spectrum. One additional experiment was run at water-undersaturated conditions to test if the presence of water influenced the SIMS analyses. The raw data show that the glass from water-saturated runs is homogeneous and 3.5-4.5\% lighter in B than the starting material. The glass from the water-undersaturated experiment showed $<1 \%$ difference in $\mathbf{B}$ isotope composition compared to the starting material. Knowing the initial and final $B$ and $H$ contents of the experiments allows the $B$ isotopic composition of the fluid to be calculated by mass balance. From this, we determine that $1000 \ln \alpha$ (where $\alpha$ $\left.=\left[{ }^{11} \mathrm{~B} /{ }^{10} \mathrm{~B}_{\text {fluid }}\right] /\left[{ }^{11} \mathrm{~B} /{ }^{10} \mathrm{~B}_{\text {mett }}\right]\right)$ is between 5 and 7 at these temperatures.

The observation that heavy $\mathbf{B}$ is enriched in the fluid compared to melt is similar to $\mathrm{O}$ and $\mathrm{H}$ isotope systematics, but the magnitude of the fractionation is larger than for $O$ (at the same temperatures) despite the similar difference in mass of the isotopes ( 10\%). The measured B isotope fractionation is also larger than previously observed in studies of vapor/tourmaline, and vapor/liquid water.

Extrapolation of theoretical calculations for B isotope fractionation between trigonal and tetrahedral coordination to the temperatures of this study agree within 1-2\%o with the experimentally determined fractionation between vapor and melt. However, while it is accepted that $B$ in hydrous vapor is dominantly trigonally coordinated, there is very little information on the coordination of $B$ in low-B, dry, or hydrous silicate melts. The available data on dry 
melts suggests that most $B$ is in threefold coordination. Thus, an explanation for the large isotopic fractionation awaits detailed spectroscopic study of samples similar to those described above.

HIGH-PRESSURE REACTIONS BETWEEN IRON METAL AND MANTLE SILICATES. V. J. Hillgren and R. Boehler, Hochdruck Mineralphysik, Max-Planck Institut für Chemie, Postfach 3060, 55020 Mainz, Germany (hillgren@mpch-mainz.mpg.de).

Introduction: Two long-standing problems in the origin and evolution of the Earth's core are the identity of the light alloying element(s) and the origin and nature of the seismically anomalous $D^{\prime \prime}$ layer directly overlying it. It is possible that the key to both these problems lies in high-pressure and -temperature chemistry. Ringwood and colleagues $[1,2]$ showed that high-pressure increased the solubility of $\mathrm{O}$ and other oxides in Fe metal. Thus, at high pressures $\mathrm{O}$ and $\mathrm{Si}$ may become soluble enough in Fe metal for them to contribute significantly to the light-element budget in the core. In addition, one proposed origin of the $\mathrm{D}^{\prime \prime}$ layer is a chemical reaction between the liquid metal outer core and the solid silicate mantle overlying it $[3,4]$. In order to investigate the nature and extent of these possible chemical interactions, we have begun a diamond anvil cell study of the high-pressure and-temperature reactions between Fe metal and silicate.

Experimental Procedures: Our sample consisted of a plate of pure $\mathrm{Fe}$ in contact $\mathrm{San}$ Carlos olivine $\left(\mathrm{Fo}_{88}\right)$, which was covered with either a San Carlos olivine, San Carlos enstatite, or $\mathrm{Al}_{2} \mathrm{O}_{3}$ plate. Normally the diamond cell was placed in a $100^{\circ} \mathrm{C}$ vacuum oven overnight to ensure that the sample was thoroughly dried. The oven was then repressurized with $\mathrm{Ar}$ and the cell was sealed. In order to study the effects of redox state on any possible chemical interactions, we also performed "wet" runs in which undried samples were breathed on immediately prior to sealing the cell. The interface between the Fe metal and San Carlos olivine was heated with an YLF laser with a hot spot size ranging from 20 to $40 \mu \mathrm{m}$. There is an average temperature gradient across the hot spot of 15 to $25 \mathrm{~K}$ $\mu \mathrm{m}$. However this is not indicative of the true temperature distribution across the hot spot as the temperature gradient is very flat across the central part but increases dramatically as the edges are approached. We did not scan the laser across the sample as has been done in previous studies [3-5] where hot spot sizes were significantly smaller, but held it in one spot to ensure as close an approach to equilibrium as possible under these conditions. In most runs the Fe metal was melted during heating, and the initially clear San Carlos olivine darkened, presumably due to the transformation to perovskite and magnesiowüstite. The run pressure was determined through the position of fluorescence peaks of rubies distributed throughout the sample. After the run the sample was recovered and polished down to the heated surface.

Results: To date, three samples have been analyzed by the electron microprobe. The run conditions for these three samples varied considerably: Pressures ranged from 450 to $600 \mathrm{kbar}$, two samples were dry and one was wet; the maximum temperatures extended from below the melting point of $\mathrm{Fe}$ to several hundred $\mathrm{K}$ above; and the cover plates of all three samples were different. However, in all three samples very little $\mathrm{O}$ and $\mathrm{Si}$ were detected in the metal. The Si values varied from 0.06 to $0.1 \mathrm{wt} \%$, and the $\mathrm{O}$ values from 0.27 to $0.4 \mathrm{wt} \%$. Because of the variability of the run conditions for each sample, we cannot say any thing about systematic trends of the partitioning of $\mathrm{O}$ or $\mathrm{Si}$ into $\mathrm{Fe}$ metal with temperature, pressure, or redox state. However, our results do indicate that in general $\mathrm{O}$ and $\mathrm{Si}$ are not very soluble in Fe metal and are therefore unlikely to comprise a major portion of the light element in the Earth's core. The only notable chemical interaction we observe is an increase in the FeO content in the silicates that is most dramatic in the wet sample. Thus, the only significant chemistry we see occurring is the oxidation of some of the Fe metal to FeO in the silicate at higher redox states.

We will present new results for six as yet unanalyzed samples. The pressures of these samples extend up to $1 \mathrm{Mbar}$.

References: [1] Ringwood and Hibberson (1990)Phys. Chem. Mineral., 17, 313-319. [2] Ringwood et al. (1990) Nature, 347, 174-176. [3] Knittle and Jeanloz (1989) GRL, 16, 609-612. [4] Knittle and Jeanloz (1991) Science, 251, 1438-1443. [5] Goarant et al. (1992) JGR, 97, 4477-4487.

COUPLED VOLATILE (HELIUM, ARGON, WATER) BEHAVIOR IN THE SOUTHERN MARIANA TROUGH. D. R. Hilton', C. G. Macpherson', and K. Hammerschmidt ${ }^{2}$, 'Scripps Institution of Oceanography, GRD-0220, La Jolla CA 92093, USA (drhilton@ucsd.edu; cmacpherson@ucsd.edu), 2Free University Berlin, FR Geochemie, Boltzmannstrasse 18-20, D-14195 Berlin, Germany (chemie@zedat.fu-berlin.de).

Basalts from the southem Mariana Trough (SMT) exhibit systematic geographic variations in trace-element and radiogenic-isotope characteristics [1]. The shallower northem section (N-SMT), between $16^{\circ}$ and $17^{\circ} \mathrm{N}$, erupts basalts with evidence (LILE and LREE enrichment) for the involvement of a subduction-related component in their petrogenesis. In contrast, basalts from the deeper southern portion of the basin (S-SMT), between $15^{\circ}$ and $16^{\circ} \mathrm{N}$, have a smaller or sometimes negligible proportion of the subduction component, some samples being entirely MORB-like in trace element and radiogenic isotopes. We exploit the differences between these two segments of the basin to contrast the behavior of the volatile elements ( $\mathrm{He}, \mathrm{Ar}$, and $\mathrm{H}_{2} \mathrm{O}$ ) between basalts showing MORB-like and "arc-type" geochemical characteristics.

A total of eight N-SMT basalts have MORB-like ${ }^{3} \mathrm{He}^{4}{ }^{4} \mathrm{He}$ ratios $\left(\sim 8 \mathrm{R}_{\mathrm{A}}\right.$ where $\mathrm{R}_{\mathrm{A}}=\mathrm{air}^{3} \mathrm{He}^{/ 4} \mathrm{He}$ ) with a variation in He content ([He]) from 0.1 to $6.6 \mu \mathrm{cm}^{3} \mathrm{STP} / \mathrm{g}$. Argon-40/argon-36 ratios, derived by stepped heating (at $800^{\circ} \mathrm{C}$ ), cluster close to atmospheric values (296-432) and ${ }^{4} \mathrm{He}^{140} \mathrm{Ar} *$ ratios vary between 23 and 200 (mean = 95). Water contents are high (1.0-2.1 wt\%). Six S-SMT basalts also have MORB-like ${ }^{3} \mathrm{He}^{/ 4} \mathrm{He}$ ratios but slightly higher [He]: from 0.10 to $11.3 \mathrm{\mu cm}^{3} \mathrm{STP} / \mathrm{g}$. Argon-40/argon-36 values are generally higher (307-2734 in the $800^{\circ} \mathrm{C}$ step) and ${ }^{4} \mathrm{He}^{\prime 40} \mathrm{Ar}{ }^{*}$ generally lower (4-85; mean $=31$ ). Water contents are also lower $(0.4-1.5 w t \%)$.

We interpret the volatile systematics as a variable admixture of gases of mantle, subducted slab, and seawater/upper crustal derivation. Observed volatile characteristics are largely controlled by two effects: (1) the concentration contrast of a particular species between the three end members; and (2) the effects of preeruptive degassing, which results in loss of any mantle wedge component (mantle + slab) allowing enhancement of the (upper) crustal signal. In the S-SMT, mantle $\mathrm{He}, \mathrm{Ar}$, and $\mathrm{H}_{2} \mathrm{O}$ components predominate (MORB-like ${ }^{3} \mathrm{He}^{4}{ }^{4} \mathrm{He}$, higher ${ }^{40} \mathrm{Ar} /{ }^{36} \mathrm{Ar}$, low $\left[\mathrm{H}_{2} \mathrm{O}\right]$ ) due to minimal 
interaction with the slab coupled with a relatively low degree of degassing. This is not the case for the N-SMT: Atmospheric-like ${ }^{40} \mathrm{Ar} /{ }^{36} \mathrm{Ar}$ ratios testify to a dominant crustal/seawater signal, observed as a consequence of extensive degassing of the mantle wedge component. Given that bathymetry and volatile content appear not to be linked (either between or within the two segments of the basin), we suggest that the overriding control on the volatile behavior of the N-SMT is the presence of a slab-derived water component that acts to reduce $\mathrm{CO}_{2}$ solubility (the carrier phase for rare gases) thereby increasing pre-eruptive degassing and the likelihood of observing upper-level contamination. In this case, two volatile signatures (high $\mathrm{H}_{2} \mathrm{O}$ and airlike ${ }^{40} \mathrm{Ar} /{ }^{36} \mathrm{Ar}$ ) are coupled, not by provenance (slab vs. upper crust respectively), but by the effects of one $\left(\mathrm{H}_{2} \mathrm{O}\right.$ on melt structure) on the behavior of the other (preeruptive degassing and loss of mantle wedge Ar). Interestingly, He isotope variations are not affected in the same way due to the fact that the N-SMT mantle He completely dominates any possible contribution of the slab and upper crust even after extensive degassing.

References: [1] Gribble et al. (1996) GCA, 60.

\section{MINETTES OF THE SCHIRMACHER OASIS, EAST ANTARCTICA: IMPLICATIONS FOR THE INVOLVE- MENT OF AN ANCIENT SUBDUCTION ZONE IN LAM- PROPHYRE GENESIS. M. Hoch, H. J. Tobschall Universität Erlangen-Nürnberg, Institut für Geologie und Mineralogie, Schloss- garten 5, 9 I 054Erlangen, Germany (mhoch@geol.uni-erlangen.de).}

The studied minettes have high abundances of compatible elements and high mg\# values (58-75) indicating a mantle-derived component in the petrogenesis of these rocks. They also exhibit high concentrations of incompatible elements, especially $\mathrm{Ba}, \mathrm{Rb}, \mathrm{K}, \mathrm{Sr}$, and LREE. Chondrite-normalized distribution patterns of the REE show high and variable enrichments of the LREE $(240-530 \times$ chondrite) compared with low and nearly constant enrichments of the HREE (11-15 $\times$ chondrite) and $\mathrm{La} / \mathrm{Yb}$ ratios between 28 and 52 . The samples have high ${ }^{87} \mathrm{Sr} /{ }^{86} \mathrm{Sr}(0.70775-0.71337)$ and low ${ }^{143} \mathrm{Nd}$ ${ }^{144} \mathrm{Nd}(0.51229-0.51135)$ with $\varepsilon_{\mathrm{Nd}}=-6.5$ to -21.5 . They show

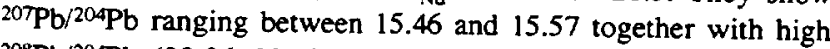
${ }^{208} \mathrm{~Pb} / 204 \mathrm{~Pb}(38.06-39.79)$ and unradiogenic ${ }^{206} \mathrm{~Pb} / 204 \mathrm{~Pb}(16.77-$ 18.08). Rubidium/strontium dating (whole-rock biotite isochrone) yielded two different age groups for the intrusion of the lamprophyre dikes, $430 \mathrm{Ma}$ and $703 \mathrm{Ma}$.

The contents of incompatible elements are too high to be caused by interactions with the continental crust. Barium concentrations in the minettes range between 3850 and $7430 \mathrm{ppm}$, while the upper continental crust is characterized by $550 \mathrm{ppm} \mathrm{Ba}$. High abundances of $\mathrm{Sr}, \mathrm{Nd}$, and $\mathrm{Pb}$ make the minettes insensitive to crustal contamination processes during ascent. The isotopic signatures are assumed to indicate the derivation from the upper mantle enriched in incompatible elements (high $\mathrm{Rb} / \mathrm{Sr}$, low $\mathrm{Sm} / \mathrm{Nd}$ ). Although the Schirmacher Oasis does not border an active subduction zone, the minettes show geochemical features suggesting a subduction-related origin like strong enrichments of LILE ( $\mathrm{Ba}, \mathrm{Rb}, \mathrm{Sr}, \mathrm{K}$ ) in contrast to moderately enriched HFSE $(\mathrm{Zr}, \mathrm{Y})$ combined with negative $\mathrm{Nb}$ and $\mathrm{Ti}$ anomalies. The patterns of the mantle-normalized element concentrations of the minettes are similar to pelagic sediments. Ratios of highly incompatible elements, which are relatively unaffected by partial melting or differentiation processes, closely resemble those found in subduction-related magmas and pelagic sediments. For some element ratios the minette samples present curves that can be interpreted as a mixing hyperbola between a P-MORB like component and pelagic sediments.

A strong negative correlation between the initial ${ }^{87} \mathrm{Sr} /{ }^{86} \mathrm{Sr}$ and ${ }^{143} \mathrm{Nd} /{ }^{14} \mathrm{Nd}$ ratios exists that probably indicates a mixing between two isotopically distinct components. The $\mathrm{Pb}$ isotopic composition is consistent with an early period of high $\mathrm{U} / \mathrm{Pb}$ followed by a low $\mathrm{U} /$ $\mathrm{Pb}$ ratio in the source. This evolution can be caused by the involvement of oceanic sediments with low U/Pb ratios. The isotopic signatures of the minettes require a long period of time ( $>1$ b.y.) between the enrichment event and the formation of the lamprophyric magma.

VARIATION IN SOIL SURFACE AREA IN A CHRONOSEQUENCE OF SOILS FROM GLEN FESHIE, SCOTLAND, AND ITS IMPLICATIONS FOR MINERAL WEATHERING RATE CALCULATIONS. M. E. Hodson' ${ }^{1}$, S. J. Langan' ${ }^{1}$, F. M. Kennedy ${ }^{2}$, and D. C. Bain', 'Macaulay Land Use Research Institute, Craigiebuckler, Aberdeen AB15 8QH, UK, 2Department of Soil Science, University of Reading, Whiteknights, Reading RG6 6DW, UK.

The inorganic component of soil horizons from a chronosequence of six soils, developed in Glen Feshie, Scotland, show an increase in surface area with soil age and a decrease in surface area with increasing depth in the soil profiles. Surface area increases due to the development of discontinuous porous coatings on mineral grains, a reduction in grain size, and preferential dissolution of specific areas of individual minerals resulting in complex, highly irregular grain shapes. The discontinuous coatings consist, predominantly, of oxalate extractable Al-Si oxyhydroxides and account for between $61 \%$ and $94 \%$ of the total inorganic surface area.

Failure to take into account the increase of mineral surface area with time can lead to underestimates of mineral dissolution rates if these are calculated from elemental release rates measured in the field and normalized to total mineral surface area. This may help to explain the discrepancies between laboratory and field-measured mineral dissolution rates, which can be up to several orders of magnitude.

\section{GEOCHEMISTRY OF 3-Ga TERRAINS OF THE SUPERIOR} PROVINCE, CANADA: GENERATION OF FELSIC MELTS IN ARCHEAN OCEANIC PLATEAU? P. Hollings and D. Wyman, Department of Geological Sciences, University of Saskatchewan, Saskatoon, S7N 5E2, Canada.

Extensive tracts of compositionally uniform ocean plateau basalts are present in 3-Ga greenstone belts of the Northern Superior Province, Canada. This study reports high-precision trace-element data from volcanic suites in the Lumby Lake greenstone belt, Wabigoon subprovince; Red Lake and Pickle Lake greenstone belts, Uchi subprovince; and the North Caribou greenstone belt of the Sachigo subprovince.

The volcanic suites are dominantly comprised of mafic pillowed and massive tholeiites, characterized by uniformly flat chondrite- 
normalized REE $\left[(\mathrm{La} / \mathrm{Sm})_{n}=0.9-1.1 ;(\mathrm{Gd} / \mathrm{Yb})_{n}=1.0-1.2\right]$ and primitive-mantle-normalized trace-element patterns $\left[(\mathrm{Th} / \mathrm{La})_{\mathrm{n}}=\right.$ $\left.0.8-1.2 ;(\mathrm{Nb} / \mathrm{La})_{\mathrm{n}}=0.9-1.1 ;(\mathrm{Ti} / \mathrm{Gd})_{\mathrm{n}}=0.8-1.1\right]$. In addition, Alundepleted komatiites with flat to LREE-depleted trace-element patterns have been identified within two of the five assemblages $\left[\mathrm{MgO}=18-24 \mathrm{wt} \%,(\mathrm{La} / \mathrm{Sm})_{\mathrm{n}}=0.7-1.1\right]$. Collectively, these features have been interpreted as the result of plume-related volcanism in a within-plate oceanic geodynamic environment, comparable to a modem-day oceanic plateau such as Ontong Java.

Intermediate to felsic volcanic rocks are characterized by highly fractionated REE $\left[(\mathrm{La} / \mathrm{Sm})_{n}=4-7 ;(\mathrm{Gd} / \mathrm{Yb})_{n}=2-4\right]$ and pronounced negative $\mathrm{Nb}$ anomalies $\left[(\mathrm{Nb} / \mathrm{La})_{n}=0.1-0.8\right]$, comparable to Archean high- $\mathrm{Al}_{2} \mathrm{O}_{3}$ TTG suites. A subtype of the felsic suite displays flatter HREE $\left(\mathrm{Gd} / \mathrm{Yb}_{\mathrm{n}}=1.2-2.0\right)$ in conjunction with enriched LREE $\left(\mathrm{La} / \mathrm{Sm}_{\mathrm{n}}=2-5\right)$ and is interpreted as the result of mixing between plateau tholeiite and 30-40\% HREE-fractionated felsic melts. Within the Lumby Lake greenstone belt both types of extrusive felsic rock can be demonstrated to have coeval intrusive counterparts.

Some geodynamic models for Archean greenstone belts propose arc development on top of accreted plateau long after plume activity ceased. However, in these 3.Ga greenstone belts intermediate to felsic rock types can be recognized intercalated throughout the tholeiitic plateau basalt sequences, requiring that the mafic and felsic magmas must have been generated coevally. HREE fractionated felsic volcanic rocks, and comagmatic TTG plutonic rocks are typically associated with melting of hot subducting oceanic crust. However, the strongly bimodal nature of the volcanic suites, the relative scarcity of calc-alkaline volcanic material, and sedimentological studies of the Lumby Lake belt that indicate that no trench assemblage exists, collectively argue against the presence of an active subduction zone adjacent to any of these plateau sequences. Rather, we suggest that the felsic volcanics may have been generated by melting of over-thickened plateau crust. This model may only be applicable to older 3-Ga terrains, as subduction beneath an active plateau is recognized in 2.7-Ga terrains of the Uchi subprovince, Superior Province.

SUBDUCTION AT THE MARGINS OF AN ACTIVE OCEANIC PLATEAU: GEOCHEMICAL EVIDENCE FROM THE 2.7-Ga CONFEDERATION ASSEMBLAGE, UCHI SUBPROVINCE, NORTHERN SUPERIOR PROVINCE, CANADA. P. Hollings, D. Wyman, R. Kerrich, and A. Polat, Department of Geological Sciences, University of Saskatchewan, Saskatoon, S7N 5E2, Canada.

The Confederation assemblage comprises a distinct association of mafic to felsic metavolcanic sequences that are present within all the greenstone belts of the Uchi subprovince in the northem Superior Province. Over 200 high-precision ICP MS trace-element analyses have been obtained from five greenstone belts, ranging in age from 2740 to $2730 \mathrm{Ma}$, that comprise a $400-\mathrm{km}$ sector along the paleocontinental margin of the western Uchi subprovince.

Two distinct associations of volcanic rocks have been recognized within the Confederation assemblage. The first association comprises a set of compositionally uniform tholeiitic basalts characterized by flat chondrite-normalized REE $\left[(\mathrm{La} / \mathrm{Sm})_{n}=0.9-1.1 ;(\mathrm{Gd}\right.$ $\left.\mathrm{Yb})_{\mathrm{n}}=0.9-1.2\right]$ and primitive-mantle-normalized trace-element patterns lacking any significant primitive-mantle-normalized highfield-strength-element (HFSE) anomalies $\left[(\mathrm{Nb} / \mathrm{La})_{\mathrm{n}}=0.8-1.2 ;(\mathrm{Zr})\right.$ $\left.\mathrm{Sm})_{\mathrm{n}}=0.8-1.1 ;(\mathrm{T} / \mathrm{La})_{\mathrm{n}}=1.1-1.3\right]$. These tholeiites were likely derived from a nondepleted mantle source, possibly related to a plume, given that geochemically similar tholeiites have been found in association with komatiites elsewhere in the northern Superior Province. Flat REE patterns and the absence of negative Nb anomalies are consistent with these lavas having been erupted in an oceanic within-plate setting comparable to modern-day oceanic plateaus.

The second association ranges from basalt to dacite $\left(\mathrm{SiO}_{2}=49-\right.$ $70 \mathrm{wt} \%$ ) in composition, and is characterized by variable LREE enrichment [(La/Sm $)_{n}>2$ ] coupled with pronounced negative $\mathrm{Nb}$ and $\mathrm{Ti}$ anomalies $\left[(\mathrm{La} / \mathrm{Nb})_{\mathfrak{n}}<0.5 ;(\mathrm{Ti} / \mathrm{Gd})_{\mathfrak{n}}<0.7\right]$, consistent with lavas erupted above a subduction zone. Volcanic rocks of the second association display a range of trace-element characteristics comparable to the variation seen between modern primitive and evolved island arcs.

A number of recent models for Archean greenstone sequences infer that buoyant oceanic plateaus resist subduction, causing migration of the trench and construction of an arc on top of the extinct plateau. Detailed mapping of the Rice Lake greenstone belt at the westem end of the Uchi subprovince demonstrates that the two volcanic associations are repeatedly interlayered with no evidence for tectonic contacts between distinct volcanic sequences. The fact that significant volumes of volcanic rocks of arc and plateau affinity are apparently stratigraphically repeated implies that mantle-plumerelated volcanism was active concurrently with subduction. We propose that the $2.7-\mathrm{Ga}$ Confederation assemblage provides evidence for subduction at the margins of an active oceanic plateau fed by a mantle plume.

GENERATION OF SUBDUCTION ZONE MAGMAS: EXPERIMENTAL CONSTRAINTS. J. R. Holloway, Departments of Chemistry and Geology, Arizona State University, Tempe AZ 85287-1404, USA (jholloway@asu.edu).

Recent experiments [1-3] on hydrous basaltic compositions more precisely define solidus temperature and the upper pressure stability of amphibole in the down-going slab (Fig. 1). A review of the $\mathrm{H}_{2} \mathrm{O}$-saturated solidus for peridotite, including unpublished experiments by the author, indicates that it is below $900^{\circ} \mathrm{C}$ at $2.9 \mathrm{GPa}$ and that the upper stability pressure of homblende is 3.2$2.9 \mathrm{GPa}$ from $800^{\circ}$ to $900^{\circ} \mathrm{C}$ (Fig. 2).

Two possibilities for transfer of $\mathrm{H}_{2} \mathrm{O}$ from slab to mantle-wedge have been much discussed: subsolidus dehydration of amphibole [4] and slab melting [5]. Either would inject $\mathrm{H}_{2} \mathrm{O}$ into the mantle wedge (Fig. 2). A third possibility for very cold slabs may be dehydration of lawsonite (Fig. 1), which would occur at greater depths [3]. The three mechanisms result in three scenarios:

1. Amphibole dehydration releases aqueous fluid that reacts with the overlying peridotite to form homblende. Competing processes are (a) homblende-peridotite is downdragged until the upper pressure limit of homblende is reached, releasing $\mathrm{H}_{2} \mathrm{O}$ to the overlying, anhydrous mantle [6], and (b) continued injection of $\mathrm{H}_{2} \mathrm{O}$ into the peridotite depletes the homblende-limiting cations $(\mathrm{K}, \mathrm{Na})$ and then an aqueous fluid forms.

2. Rising partial melt encounters an inverted thermal gradient 


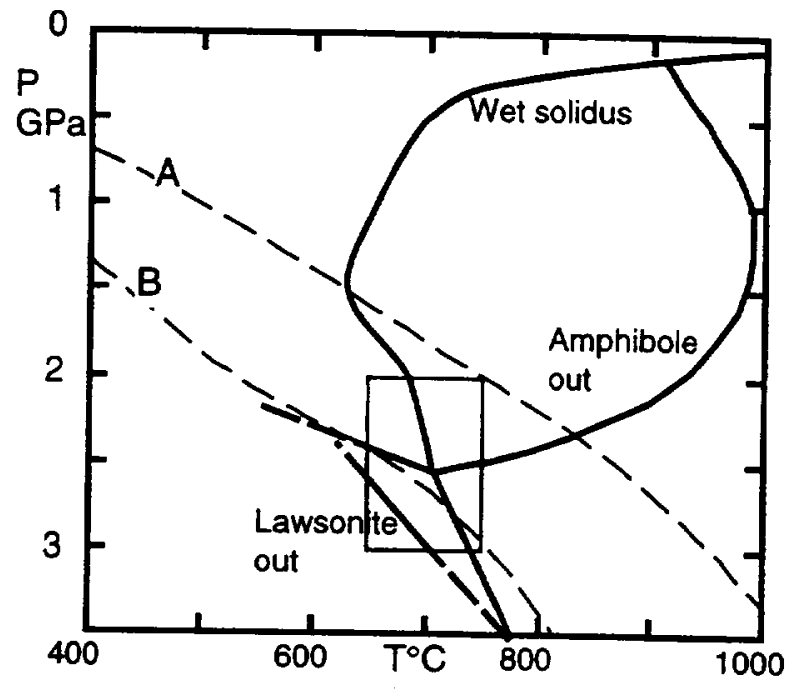

Fig. 1. Simplified equilibria for a wet, partially altered MOR basalt. The rectangle is the area where most of the recent experiments were done. Dashed lines A-B are P-T trajectories for the top of a steady-state downgoing slab with velocity of $10 \mathrm{~cm} / \mathrm{yr}[8]$.

and partially assimilates peridotite until the melt volume is great enough to rise as an independent body.

3. Lawsonite dehydration releases aqueous fluid that is stable in the mantle wedge until $\mathrm{H}_{2} \mathrm{O}$-saturated solidus temperatures are reached [7]. In each case the $\mathrm{H}_{2} \mathrm{O}$-saturated magma eventually formed can rise only because of the inverted thermal gradient. The $\mathrm{H}_{2} \mathrm{O}$ content of the melt decreases as the rising magma partially assimilates anhydrous peridotite and becomes increasingly mafic.

References: [1] Bohlen S. R. et al. (1994) Eos Trans. AGU, 75, 748. [2] Pawley A. R. and Holloway J. R. (1993) Science, 260,

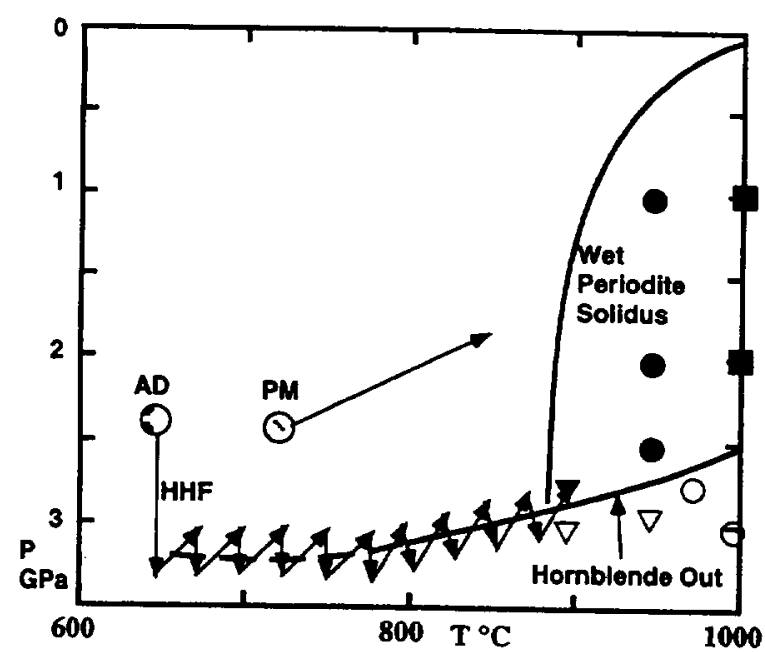

Fig. 2. Wet solidus and homblende-out for peridotice based on unpublished data (inverted triangles) and literature data [9.10]. AD is the beginning of path followed by $\mathrm{H}_{2} \mathrm{O}$ released by slab dehydration. $\mathrm{PM}$ is the beginning of path for slab partial melt.
664-667. [3] Poli S. and Schmidt M. W. (1995) JGR, 100, 22299 22314. [4] Tatsumi Y. (1989) JGR, 94, 4697-4707. [5] Green T. H. and Ringwood A. E. (1968) Contrib. Mineral. Petrol., 18, 105-162. [6] Davies J. H. and Stevenson D. J. (1992) JGR, 97, 2037-2070. [7] Kawamoto T. and Holloway J. R. (1997) Science, in press. [8] Peacock S. M. et al. (1994) EPSL, 121, 227-244. [9] Millhollen G. L. et al. (1974) J. Geol., 82, 575-587. [10] Mysen B. O. and Boettcher A. L. (1975) J. Petrol., 16, 520-548.

DIFFERENCES BETWEEN MEASURED AND MODELED MINERALOGY AND THE EFFECT ON THE WEATHERING RATE. J. Holmqvist' , H. Sverdrup' , and D. Kurz' ${ }^{2}$ ' Department of Chemical Engineering II, Institute of Technology, Box 124, S-221 00 Lund, Sweden, 'EKG GEO-SCIENCE, Ralligweg 10 , 3012 Bem, Switzerland.

The use of weathering rates in acidification and sustainability assessment has led to increased demand for regional information concerning soil mineralogy. Direct determination of mineralogy is time consuming and expensive, and not feasible on a regional level. One way to overcome the problem is to develop normative models using low-cost total chemical analyses as the principal input.

The aim of this study was to investigate differences in weathering rates as calculated by the PROFILE model using the measured mineralogy and mineralogy based on normative models. The normative models have been developed from regression analyses of bulk soil elemental composition and measured mineralogies in 115 Swedish forest soils. Data from 43 sites that have previously been analyzed with respect to their mineralogy and total element composition have been included in this investigation.

It is concluded that the normative calculation of mineralogy is an acceptable method for generating regional input data to weathering rate calculations. Use of normative mineralogy tends to slightly overestimate the weathering rate compared to direct mineralogical analyses.

Reasons for these differences include (1) uncerainties in the quantitative analyses of the mineralogical compositions, (2) variable stoichiometry of naturally occurring minerals, and (3) difficulties in establishing an equation system for the normalization that has an exact solution.

The variability of the stoichiometric content of $\mathrm{Ca}$ in plagioclase, hornblende, and epidote under field condition appeared as an important source of differences between measured and modeled mineralogy. The model is able to reconstruct the assemblage of different mineral groups reasonably well, but has problems in assigning it to specific mineral species. The effect of the uncertainty in mineralogy has less impact on the weathering rate calculations on a regional scale because overestimation of one mineral species results in a underestimation of another. The normative calculation with regard to its use in weathering rate assessment therefore appears to perform better on a regional scale than on an individual site.

THE PRESSURE DEPENDENCE OF METAL/SILICATE PARTITION COEFFICIENTS OF HIGHLY SIDEROPHILE ELEMENTS. A. Holzheid ${ }^{1}$, P. Sylvester ${ }^{2}$, H. Palme ${ }^{1}$, H. St. C. $\mathrm{O}^{\prime} \mathrm{Neill}^{2}$, and D. C. Rubie', 'Universität zu Köln, Institut für Mineralogie und Geochemie, Zülpicherstrasse 49b, 50674 Köln, 
Germany, ${ }^{2}$ Australian National University, Canberra, Australia, ${ }^{3}$ Bayerisches Geoinstitut, Bayreuth, Germany.

We report here on the first experiments to determine highpressure metal/silicate partition coefficients of the highly siderophile elements $\mathrm{Pd}, \mathrm{l}$, and $\mathrm{Pt}$. The 1 -atm. metal/silicate partition coefficients of these elements are so high that equilibrium between the Earth's mantle and core would result in mantle concentrations orders of magnitude below those observed today. Equilibration of core-forming metal with mantle silicates at higher temperatures and/or pressures could significantly reduce the metal/silicate partition coefficients and they could eventually be compatible with core/ mantle equilibrium. Such models have been suggested by several authors [e.g., 1-3]. The temperature dependence of the Pd-metal silicate partition coefficients has been determined at 1 -atm. over a narrow temperature range [4]. The increase of the Pd partition coefficients with temperature is small and not sufficient to reduce the partition coefficient to a value required for equilibrium even when extrapolated to very high temperatures [4]. So far pressure effects are unknown. The purpose of the present work is, therefore, to study the effect of pressure on the partition coefficients of Pd, Ir, and Pt.

Experiments were performed in piston cylinder (PC) and multianvil (MA) apparati within a pressure range of 1-20 GPa and a temperature range of $1300^{\circ}-1500^{\circ} \mathrm{C} . \mathrm{Pd}_{90} \mathrm{Fe}_{10}, \mathrm{Pt}_{90} \mathrm{Fe}_{10}$, and $\mathrm{Pt}_{90} \mathrm{Ir}_{10}$ alloys were equilibrated with molten silicates $\left(\mathrm{SiO}_{2} 49.1 \mathrm{wt} \%, \mathrm{CaO}\right.$ $19.2 \%, \mathrm{MgO} 10.6 \%, \mathrm{Al}_{2} \mathrm{O}_{3} 14.1 \%, \mathrm{FeO} 7.0 \%$ ). Metal alloys were used as capsule material. Experimental conditions were chosen in such a way that solid metal and liquid silicate coexist during the experiments. Run durations were $24 \mathrm{hr}$, except for experiments with $\mathrm{Pd}_{90} \mathrm{Fe}_{10}$ alloys at $2 \mathrm{GPa}$ where a time series $(8-43 \mathrm{hr}$ ) was performed to demonstrate that chemical equilibrium between solid metal and liquid silicate is obtained. Silicate liquids were quenched to glass by turming off power. Metal contents and major-element silicate compositions were determined by electron microprobe (Cameca Camebax, Jeol Superprobe). Highly siderophile element concentrations in silicates were analyzed by an UV ArF excimer laser ablation PlasmaQuad PQ-2+ ICP-MS at ANU, Canberra. As ICP-MS standards Pd-containing glasses that had been analyzed by neutron activation analysis were used. Calcium content in each individual silicate sample was used as an internal standard. Up to four individual ICP-MS analyses were made. The scatter of the individual analyses was, in many cases, larger than the statistical error. Glasses produced in 1-atm. experiments with $\mathrm{Pd}$ and $\mathrm{FeO}-$ free silicates showed in all cases uniform Pd contents [4]. The absence of nugget formation in the low-pressure experiments was the prime reason for selecting Pd to determine high-pressure effects. It is possible, however, that nugget formation in the high-pressure experiments occurred during cooling, as these experiments cannot be quenched as fast as the 1-atm. experiments. Despite these uncertainties it is clear that the solubility of Pd in silicate melt decreases at high pressures rather than increases as required by the equilibrium model (Pd contents range from $30 \mathrm{ppm}$ at $1 \mathrm{GPa}$ to $\sim 1 \mathrm{ppm}$ at $20 \mathrm{GPa}$ ). Glasses produced in experiments with Pt and Ir metal alloys are not yet analyzed. Metal-silicate partition coefficients were calculated from solubilities. Within a pressure range of 1-20 $\mathrm{GPa}$ the $\mathrm{Pd}$ metal/silicate partition coefficients increase from $\sim 10^{4}$ (1 GPa) to $6 \times 10^{6}(20 \mathrm{GPa})$. Core/mantle equilibrium would require partition coefficients of around 800 for all HSEs. The effective $O$ fugacities of the experiments with $\mathrm{Pd}_{90} \mathrm{Fe}_{10}$ and $\mathrm{Pt}_{90} \mathrm{Fe}_{10}$ alloys were estimated based on the Fe content in the metal and FeO content in the silicate. Considering the rather oxidizing conditions of the present experiments (IW +4 for $\mathrm{Pd}_{90} \mathrm{Fe}_{10}$ runs; appropriate $\mathrm{fO}_{2}$ value for core formation is $\mathrm{TW}-2.3$ ) the calculated partition coefficients would further increase.

Together with earlier results on the temperature dependence of the Pd metal/silicate partition coefficients at 1 atm [4] the new highpressure data on metal/silicate partition coefficients of $\mathrm{Pd}$ show that the abundances of the highly siderophile elements in the upper mantle are not the result of equilibrium partitioning of $\mathrm{Pd}$ and other HSEs between core-metal and mantle-silicates. The results of the high-pressure experiments support the "late veneer hypothesis" where late accreting material, which it is not in equilibrium with the metal core of the Earth, was added in one (or more) late impact event(s).

References: [1] Murthy V.R. (1991) Science, 253, 303-306, 1467. [2] Righter K. and Drake M. J. (1996) Meteoritics \& Planet. Sci., 31, A1 15-A116. [3] Li J. and Agee C. B. (1996) Nature, 381, 686-689. [4] Borisov A. et al. (1994) GCA, 58, 705-716.

PRIMORDIAL HELIUM AND NEON IN THE EARTH: A SPECULATION ON EARLY DEGASSING. M. Honda and I. McDougall, Research School of Earth Sciences, The Australian National University, Canberra, ACT 0200, Australia (Masahiko. Honda@anu.edu.au).

Neon isotopic compositions found in OIBs and MORBs differ in systematic ways from the atmospheric composition and from each other. They show remarkable correlations with He isotopic compositions. The correlated $\mathrm{Ne}$ and $\mathrm{He}$ isotopic compositions provide powerful evidence in favor of a primordial component within the Earth [e.g., 1]. This relationship can be explicitly stated as

$$
\begin{gathered}
{ }^{22} \mathrm{Ne}_{\mathrm{P}} /{ }^{3} \mathrm{He}_{\mathrm{P}}=\left\{\left({ }^{4} \mathrm{He} /{ }^{3} \mathrm{He}\right)_{\text {observed }}-\left({ }^{4} \mathrm{He} /{ }^{3} \mathrm{He}\right)_{\mathrm{P}}\right\} \times \\
{ }^{21} \mathrm{Ne}^{* / 4} \mathrm{He}^{*} \times{ }^{22} \mathrm{Ne}_{\mathrm{P}} /{ }^{21} \mathrm{Ne}^{*}
\end{gathered}
$$

where the subscript $P$ denotes the Earth's inferred primordial solar $\mathrm{He}$ and $\mathrm{Ne}$ isotopic compositions, and ${ }^{4} \mathrm{He}{ }^{*}$ and ${ }^{21} \mathrm{Ne}^{*}$ are radiogenic ${ }^{4} \mathrm{He}$ and nucleogenic ${ }^{21} \mathrm{Ne}$, respectively, produced as a result of $U$ and Th decay in the Earth.

Recently Yatsevich and Honda [2] estimated the production of nucleogenic $\mathrm{Ne}$ in the Earth, using up-to-date yields from the ${ }^{17.18} \mathrm{O}(\alpha, n)^{20.21} \mathrm{Ne}$ reactions and a new algorithm to calculate the neutron energy spectrum responsible for the reactions $24.25 \mathrm{Mg}$ $(n, \alpha)^{21.22} \mathrm{Ne}$ in the mantle. They obtained a lower ${ }^{21} \mathrm{Ne}^{* / 4} \mathrm{He}^{*}$ production ratio of $4.5 \times 10^{-8}$, compared with the previous estimate of $\sim 1 \times 10^{-?}$.

Based on the new and more reliable ${ }^{21} \mathrm{Ne}^{*} /{ }^{4} \mathrm{He}^{*}$ production ratio in the mantle, we calculated primordial ${ }^{3} \mathrm{He} /{ }^{22} \mathrm{Ne}$ ratios in MORB and Hawai' ian OIB samples using equation (1). Amounts of ${ }^{21} \mathrm{Ne}^{*}$ and ${ }^{22} \mathrm{Ne}_{\mathrm{p}}$ are calculated from the deconvolution of the three $\mathrm{Ne}$ components: atmospheric, nucleogenic, and solar. The results are shown in Fig. 1.

The average primordial ${ }^{3} \mathrm{He} / 22 \mathrm{Ne}$ ratios calculated from 19 MORB samples and 15 Hawai' ian OIB samples are $9.4 \pm 2.0$ and $6.0 \pm 1.4$ respectively. The gross average is $6.9 \pm 0.3$. Thus, the primordial ${ }^{3} \mathrm{He}^{/ 22} \mathrm{Ne}$ ratios in the mantle appear to be systematically 


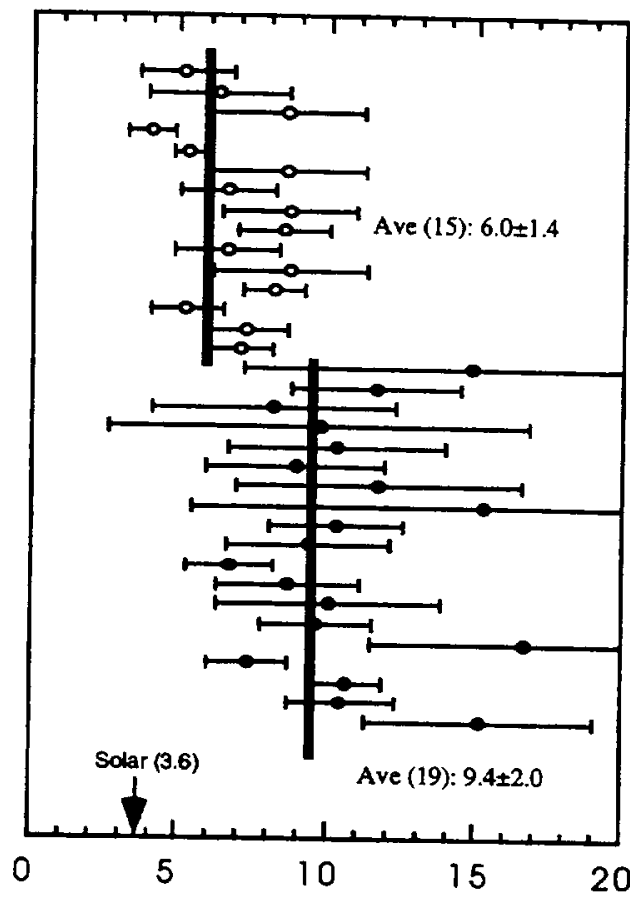

Fig. 1. Primordial ${ }^{3} \mathrm{He} / 22 \mathrm{Ne}$.

higher than the ${ }^{3} \mathrm{He}^{22} \mathrm{Ne}$ ratio observed in the present-day solar wind ( $=3.6[3])$. As the solar ${ }^{3} \mathrm{He}^{/ 22} \mathrm{Ne}$ ratio is believed to have been essentially constant over the last $4.5 \mathrm{Ga}$, the primitive Earth is expected to have had a ${ }^{3} \mathrm{He} /{ }^{22} \mathrm{Ne}$ ratio similar to that found in the present-day solar wind. Thus, the higher ${ }^{3} \mathrm{He} /{ }^{22} \mathrm{Ne}$ ratios calculated from MORBs and Hawai'ian OIBs are likely to be related to Earth degassing processes, believed to have occurred within a few hundred million years after the formation of the Earth.

The ${ }^{3} \mathrm{He}$ enrichment by a factor of 2 with respect to ${ }^{22} \mathrm{Ne}$ in MORBs and Hawai'ian OIBs could be explained by a solubilitycontrolled process, as the solubility constant of He is about twice that of $\mathrm{Ne}$ [e.g., 4]. Thus, if a magma ocean existed at an early stage after the Earth's formation, the majority of the volatiles would be expected to outgas to form the primitive Earth's atmosphere, and the noble gases that remained in the magma ocean would be enriched in He. If this hypothesis is correct, it would further imply that the OIB source may also have experienced significant degassing.

References: [1] Honda M. et al. (1991) Nature, 349, 149-151. [2] Yatsevich I. and Honda M. (1997) JGR, in press. [3] Benkert J.-P. et al. (1993) JGR, 98, 13147-13162. [4] Lux G. (1987) GCA, $51,1549-1560$.

METEORITIC NANOFOSSILS AND MICROFOSSILS. R. B. Hoover, Space Science Laboratory, NASA Marshall Space Flight Center, Marshall Space Flight Center AL 35812, USA.

The discovery of possible evidence of biogenic activity and microfossils in the SNC meteorite ALH 84001 has profound implications. The existence of complex organic chemicals, biomarkers, and complex organized structures that may represent nanofossils or microfossils in ALH 84001 and other meteorites may have triggered a paradigm shift regarding the possibility of extraterrestrial microbial life. Efforts are currently underway to obtain additional data on biomarkers, chemical fossils, nanofossils, and microfossils that can be obtained from other SNC meteorites and carbonaceous chondrites. New methods are also being developed to obtain more definitive proof of extant or ancient extraterrestrial microbial life. This paper will review prior observations of possible biogenic chemicals and microfossils in meteorites and present new images of possible nanofossils and microfossils obtained with the Field Emission Scanning Electron Microscope in carbonaceous chondrites and SNC meteorites.

BIMODAL DISTRIBUTION OF SOIL ORGANIC CARBON POOLS AND THEIR SIGNIFICANCE. Y.-P. Hsieh, Wetland Ecology Program, Florida A\&M University, Tallahassee FL 32307 , USA (yhsieh@famu.edu).

Soil organic carbon ( $S O C$ ) dynamics determines critically the productivity, nutrient cycling, and $C$ budget of an ecosystem. The dynamics of SOC are complicated due to the multiple $C$ pools that decompose at very different rates. No standard method has been established to physically separate those SOC pools, and for that reason SOC dynamics in most ecosystems are still poorly understood.

Recent developments in $\mathrm{C}$ isotope $\left({ }^{14} \mathrm{C}\right.$ and $\left.{ }^{13} \mathrm{C}\right)$ technology and the use of long-term agricultural experimental plots enable researchers to deduce sizes and mean residence time (MRT) of SOC pools in some temperate soils. The results of those studies confirm the bimodal distribution hypothesis of SOC pools, i.e., SOC pools are distributed in two distinct categories according to their MRT. One category of SOC pools turns over in less than a few decades and the other turns over in more than a few hundred years.

The great separation of MRT in those two categories of SOC pools has important ecological and geological implications. The labile (or bioactive) SOC pools represent the intrinsic soil productivity and $C$ (energy) flow of an ecosystem. They are responsive to land use management changes in a human's life span. The stable (or recalcitrant) SOC pools represent an inert background that plays little part in the productivity or $C$ flow of an ecosystem. The SOC preserved in the depth of a soil or a geologic material consists of, most likely, stable pools.

It is still not clear what properties of SOC make the distinction between the labile and the stable pools. Current data suggest, however, that physical protection (micro-aggregates and association with clay particles) rather than chemical differences separates the two categories.

Studies of Morrow Plots in Illinois indicate that 100 years of cultivation has resulted in great differences in the sizes of labile SOC pools in the surface layer (from $1.9 \mathrm{~g} / \mathrm{kg}$ of an unfertilized, continuous com (Zea mays) plot to $21 \mathrm{~g} / \mathrm{kg}$ of a pasture plot). The current sink'source relationship of SOC to the atmospheric $C$ is mainly determined by the size of labile SOC pools in the surface soil, which in tum is determined by land use and management practices.

\section{RADIOCARBON CALIBRATION AND $\triangle^{14} \mathrm{C}$ DURING DEGLACIATION FROM VARVED SEDIMENTS OF THE CARIACO BASIN. K. A. Hughen ${ }^{1}$, J. T. Overpeck ${ }^{1.2}$, S. J.}


Lehman' ${ }^{1}$, M. Kashgarian ${ }^{3}$,L.C.Peterson ${ }^{4}$, R. Alley ${ }^{5}$, and D. Sigman 6 , 1 INSTAAR and Department of Geological Sciences, University of Colorado, Boulder CO 80906, USA, 2NOAA, Paleoclimatology Program, NGDC, Boulder CO 80906, USA, ${ }^{3}$ CAMS, Lawrence Livermore National Laboratory, Livermore CA 94550, USA, ${ }^{4}$ RSMAS, University of Miami, Miami FL, USA, ${ }^{5}$ Department of Geosciences and Earth System Science Center, The Pennsylvania State University, University Park PA 16802, USA, ${ }^{6}$ Woods Hole Oceanographic Institute, Woods Hole MA 02543, USA.

Calibrating the radiocarbon timescale during deglaciation is essential to determining the relative timing and rates of abrupt climate changes occurring at this time. Presently, the highest resolution calibration curve based on tree-rings $[1,2]$ ends around 12 calendar k.y. BP $\left(10^{14} \mathrm{C} \mathrm{k.y.} \mathrm{BP}\right)$, and studies attempting to extend the curve bases on coral U/Th dating [3-5] and European lake varves $[6,7]$ show conflicting results. A new series of $\mathrm{AMS}^{14} \mathrm{C}$ dates on the planktonic foram Globigerina bulloides have been calibrated using annually laminated sediments from the marine Cariaco Basin. A 5500-yr-long floating-varve chronology was anchored to the calendar timescale by objectively "wiggle matching" ${ }^{14} \mathrm{C}$ vs. calendarage variations to those generated from absolutely dated tree-ring data. The correlation between the datasets is excellent $\left(r^{2}=0.986\right)$, confirming the recently revised offset between German oak and floating German pine chronologies reported by [1]. The ${ }^{14} \mathrm{C}$ calibration curve generated from Cariaco Basin varves extends continuously from 9 calendar k.y. BP $\left(8{ }^{14} \mathrm{C}\right.$ k.y. BP $)$ to about 14.5 calendar k.y. BP ( $13{ }^{14} \mathrm{C}$ k.y. BP). For the period beyond tree rings, 12-14.5 calendar k.y., our curve agrees with calibrations based on coral $\mathrm{U} /$ Th dates [3-5], but disagrees with varve data from European Lakes Soppensee [7] and Holzmaar [6]. It appears that either the Soppensee and Holzmaar varve chronologies are missing varve years, due, for example, to the lakes being intermittently frozen during the Younger Dryas, or the macrofossils selected for ${ }^{14} \mathrm{C}$ dating were as much as 1000 years old when deposited. Paired ${ }^{14} \mathrm{C}$-calendar ages from the Cariaco Basin were used to calculate $\Delta^{14} \mathrm{C}$ from 9-14.5 calendar k.y. BP. Comparing the $\Delta^{14} \mathrm{C}$ record to a paleoclimate record from the same Cariaco Basin core shows a large, asymmetrical increase in $\Delta^{14} \mathrm{C}$ during the Younger Dryas climatic event. Geochemical ocean-atmosphere box model experiments show that an abrupt shutdown of North Atlantic Deep Water (NADW) formation at the beginning of the Younger Dryas, followed by a gradual increase in North Atlantic Intermediate Water (NAIW) production throughout the Younger Dryas, and finally an abrupt shutdown of NAIW and reinitiation of NADW formation at the Younger Dryas termination can explain observed changes in both $\Delta^{14} \mathrm{C}$ and paleoclimatic records of the North Atlantic region.

References: [1] Björk S. et al. (1996) Science, 274, 11551160. [2] Kromer B. and Becker B. (1993) Radiocarbon, 35, 125135. [3] Bard E. et al. (1996) Nature, 382, 241-244. [4] Bard E. et al. (1993) Radiocarbon, 35, 191-199. [5] Edwards R. L. et al. (1993) Science, 260, 962-967. [6] Hajdas I. et al. (1995) Quaternary Sci. Rev., 14, 137-143. [7] Hajdas I. et al. (1993) Climate Dynamics, 9, 107-116.

CHEMICAL WEATHERING YIELDS AND STRONTIUM ISOTOPE SYSTEMATICS FROM MAJOR SIBERIAN RIVERS. Y. Huh and J. M. Edmond, MIT/WHOI Joint Program in Oceanography, Department of Earth, Atmospheric, and Planetary Sciences, Massachusetts Institute of Technology, 42-44 Carleton Street, Mail Code E34166, Cambridge MA 02139, USA (yhuh@ mit.edu; jedmond@mit.edu).

The extent to which chemical weathering yields are influenced by climate (temperature/run-off) is a subject of some controversy. Reported data from the continental arc of the westem Americas cast doubt upon the existence of a simple relationship; the weathering yields do not vary systematically from the Amazonian Andes to the Yukon. The situation for the basement terrain is less well understood since most detailed studies have been in the Tropics.

Systematic measurements of major elements and $\mathrm{Sr}$ isotopic ratios have been made in the basins of the major rivers of Eastern Siberia (Lena, 120 stations, Yana, 22; Indigirka, 21; Kolyma, 22). These are in periglacial, Sub-Arctic to Arctic terrains that, due to the aridity of the extreme continental climate, have never experienced extensive glaciation. They provide a basis for comparison with the much better studied systems at lower latitudes in regimes of similar geology and topography.

The left bank tributaries of the Lena drain the vast sedimentary basin of the Siberian Shield. The $\mathrm{Sr}$ isotope ratios range from 0.708 to 0.710 , as is expected from Cambrian to Ordovician limestones and dolomites with higher values from sandstones and shales. The chemical composition is dominantly $\mathrm{Ca}-\mathrm{HCO}_{3}$, with some rivers draining interbedded evaporites showing high concentrations of $\mathrm{NaCl}$ and $\mathrm{CaSO}_{4}$.

The right bank tributaries of the Lower Lena that are fed from the Verkhoyansk collisional mountains are more radiogenic, 0.709 to 0.714 , as are the left bank tributaries of the Yana, east of the range. The right bank tributaries of the Yana, the Indigirka, and the Kolyma drain the complex collisional unit of the Mesozoic. The Sr isotope ratios range from 0.706 to 0.714 , lower ratios from the arc intrusions

The headwater streams of the Vitim, Chara, Olekma, and Aldan, the major Lena tributaries, drain the Archean to Proterozoic Aldan Shield and the Proterozoic Trans Baikal Highlands (TBH). Strontium isotope ratios are $0.709-0.740$, in agreement with their Rbpoor granulite facies rocks. (The one exception is the Kurkulik, a small stream draining from an extension of the TBH into Lake Baikal, which at 0.860 is the most extreme of the dataset analyzed to date). The rivers are relatively dilute (alkalinity between 200 and $700 \mathrm{ueq} / \mathrm{L})$; the ratio of $\mathrm{Si}$ to total cations is low (0.05-0.37).

The $\mathrm{Sr}$ isotopes are very useful at diagnosing geological terrains but are not noticeably influenced by the severe climates. The $\mathrm{Sr}$ fluxes are generally higher but much less radiogenic than in comparable low latitude terrains.

A comparison can be made between the areal consumption rates of $\mathrm{CO}_{2}$ due to fixation by aluminosilicate weathering (in thousands of $\mathrm{mol} / \mathrm{km}^{2} / \mathrm{yr}$ ) from the exposures in Southeastem Siberia with those from the Guayana Shield in the drainage of the Orinoco. The values are comparable, from 29 to 179 in the Sub-Arctic and 16 to 205 in the Tropics. There is no indication of a climatic influence on this uptake rate, although the chemical systematics are quite different. In the Tropics weathering is complete to kaolinite and gibbsite but occurs very slowly under a lateritic seal. In the periglacial environments frost action prevents the accumulation of a weathered mantle and thus exposure is maintained. This appears to counteract the climatic effects of low temperatures and precipitation. 
IRIDIUM/OSMIUM CONSTRAINTS ON TERRESTRIAL ACCRETION AND CORE FORMATION. M. Humayun 1.2 , A. D. Brandon 1.3, H. J. B. Dick', and S. B. Shirey', 'Department of Terrestrial Magnetism, Camegie Institution of Washington, Washington DC 20015, USA, 'Department of Geophysical Sciences, University of Chicago, Chicago IL 60637, USA, 3Department of Geology, University of Maryland, College Park MD 20742, USA, ${ }^{4}$ Woods Hole Oceanographic Institution, Woods Hole MA 02543 , USA.

Highly siderophile elements such as Re, Os, and Ir are present in the Earth's upper mantle in chondritic-relative proportions at $\approx 2$ $3 \times 10^{-3} \mathrm{CI}$ concentrations. This may represent a signature of late accretion of chondritic material [1] or high-P/T equilibrium during core formation [2]. Isotopic systematics for ${ }^{187} \mathrm{Re}-{ }^{187} \mathrm{Os}$ also require a precise definition of the upper mantle's siderophile element pattern. We approached these issues by the analysis of $\mathrm{Re}, \mathrm{Os}$, and Ir by ID-NTIMS in abyssal peridotites and arc xenoliths.

Precise determination of Ir/Os ratios by isotope-dilution negative thermal ion mass spectrometry (ID-NTIMS) indicates a chondritic value for the extensive suboceanic depleted mantle reservoir represented by abyssal peridotites. Abyssal peridotites from two separate dredges show control of Ir and $O s$ abundances by nugget effects, in one dredge (RC 27-9:6) yielding a precise Ir $/ O s=1.00 \pm$ 5 , while the other dredge (RC 27-9:18) yields a variable Ir/Os = $1.4 \pm 4$ due to mineralogical control of Ir and Os by separate microphases, perhaps iridosmines. The presence of a chondritic I $/$ / Os value is consistent with heterogeneous accretion, or high P/T core formation only if $\mathrm{D}^{\text {metalsilicare }}$ for Ir and Os are identical to $5 \%$, which awaits substantial refinement of experimental techniques.

Since most mantle samples have suffered net loss of melt, information on terrestrial accretion and core formation processes are robustly derived from compatible PGEs (Ir, Os, Ru?). Abyssal peridotites differ from "primitive" mantle by the operation of at least three processes: mantle differentiation, serpentinization, and submarine weathering. The abundances of Ir and $O s$ in seawater are extremely low [3], so that weathering and hydrothermal alteration of peridotite play an insignificant role in determining the Ir/Os ratio. The ${ }^{187} \mathrm{Os} / 188 \mathrm{Os}$ of seawater is quite distinct from mantle values $\Leftrightarrow 1.0$ vs. $0.125 \pm 5)$, providing a tracer of seawater interaction. Our data indicate a negligible role for seawater in determining the $1 \mathrm{r} / \mathrm{Os}$ ratio since these peridotites yielded ${ }^{187} \mathrm{Os} / 188 \mathrm{O} s \leq 0.129$, with $187 \mathrm{Re} /$ ${ }^{188} \mathrm{Os}=0.18-0.32$, depleted relative to chondrite values of ${ }^{187} \mathrm{Re}$ ${ }^{188} \mathrm{Os}=0.396[4,5]$ by melt removal. Island arc mantle wedge xenoliths from Ichinomegata and Simcoe yielded $\mathrm{I} / \mathrm{O} s=1.4 \pm 0.2$, with normal mantle abundances of $2-4 \mathrm{ppb}$ Ir and Os. This systematic difference between arc xenoliths and abyssal peridotites may reflect PGE mobility, previously recognized using ${ }^{187} \mathrm{Os} / 188 \mathrm{O}$ s [6]. The "average" mantle value of Morgan [7] is very similar (Ir/Os = $1.2 \pm 0.2)$, perhaps indicating the influence of subduction zone processes on the BVSP xenolith suite.

A "best" value of the mantle Ir/Os $=1.00 \pm 0.05$ is obtained from RC 27-9:6 peridotites. This value is similar to those of ordinary (Ir/ $\mathrm{O} s=0.93 \pm 0.05$ ) and carbonaceous chondrites ( $\mathrm{Ir} / \mathrm{O} s=0.95 \pm 0.04$ ). It is also similar to our results for a komatiite standard, KAL-1, from Alexo, Ontario. This Ir/Os is distinct from the mean value of Morgan [7].

New metal-silicate partition coefficients for Re indicate that homogeneous accretion might account for the mantle's Re abun- dance by formation of the core at appropriate $P, T$, and compositional values [2]. The existence of chondritic $\mathrm{Ir} / \mathrm{Os}$ and $\mathrm{Re} / \mathrm{Os}$ [7] in the mantle is a challenge for "homogeneous accretion" models since it imposes the condition that the partition coefficients for these elements must be virtually identical. Given that these are controlled by $P, T, f_{\mathrm{O}_{2}}, f_{S_{2}}$, and other compositional parameters, this must be

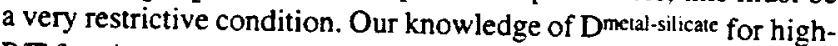
$\mathrm{P} / \mathrm{T}$ fractionation of Re, Os, and Ir needs to be refined so that these are comparable to the mantle database in precision. A precise Ir/Os ratio for the mantle is a useful experimental constraint on issues of core formation, and complements constraints based on Re/Os ratios.

References: [1] Kimura et al. (1974)GCA, 38, 683. [2] Righter and Drake (1997) EPSL, in press. [3] Anbar et al. (1996) Science, 273, 1524. [4] Anders and Grevesse (1989)GCA, 53, 197. [5] Jochum (1996) GCA, 60, 3353. [6] Brandon et al. (1996) Science, 272, 861. [7] Morgan J. W. (1986) JGR, 91, 12375.

\section{NITROGEN SOLUBILITY IN SILICATE MELT UNDER OXIDIZED AND REDUCED CONDITIONS USING LASER EXTRACTION/STATIC MASS SPECTROMETRY ANALY-} SIS. F. Humbert ${ }^{1}$, G. Libourel ${ }^{1.2}$, B. Mary ${ }^{1.3}$, and C. FranceLanord', 'CRPG-CNRS, BP 20,54501 Vandoeuvre-lès-Nancy Cedex, France, ${ }^{2} \mathrm{UHP}-\mathrm{Nancy} 1, \mathrm{BP} 239,54506$ Vandœuvre-lès-Nancy Cedex, France, ' ${ }^{3}$ ENSG, Campus INPL, BP 40,54501 Vandœuvre-lèsNancy Cedex, France (franckh@crpg.cnrs-nancy.fr).

Measurement of $\mathrm{N}$ solubility in silicate melts is essential to understand the origin and evolution of terrestrial atmosphere. Because the early Earth might have experienced highly reducing conditions (e.g., $\mathrm{H}_{2}$-rich atmosphere), it is essential to investigate the dependency of $\mathrm{N}$ solubility on $\mathrm{O}$ fugacity. Moreover, the solubility of $\mathrm{N}$ in silicate melts is poorly documented, preventing quantification of $\mathrm{N}$ exchange between the mantle and the atmosphere. Therefore, we have developed the following experimental and analytical techniques: (1) high-temperature equilibration of silicate melts with $\mathbf{N}$ gas under controlled $\mathrm{O}$ fugacity, (2) laser extraction of $\mathrm{N}$ of the run products, and (3) static mass spectrometric measurements.

Nitrogen solubility experiments were performed on $300 \mathrm{mg}$ of degassed glasses of a N-MORB-like composition free of Fe. Experiments were carried out at a temperature of $1400^{\circ} \mathrm{C}$ and under $\mathrm{O}$ fugacities varying over a range of $17 \mathrm{log}$ units. The $O$ partial pressures were set up using the following gas mixtures: $\mathrm{N}_{2}-\mathrm{CO} /$ $\mathrm{CO}_{2}, \mathrm{~N}_{2}-\mathrm{C} / \mathrm{CO}$ and $\mathrm{N}_{2}-\mathrm{CO}_{2} / \mathrm{H}_{2}, \mathrm{~N}_{2}-\mathrm{C} / \mathrm{CO} / \mathrm{H}_{2}$. Depending on the imposed $\mathrm{O}$ partial pressure, $\mathrm{Pt}$ or graphite crucibles were used to hold the samples. In order to determine equilibrium conditions, experiment was run from hours to several days. Each experiment was terminated by quenching the samples in the imposed atmosphere.

Because of the low solubility of $\mathrm{N}$ in oxidizing conditions, we have designed a new technique for the extraction and purification of subnanomole quantities and stable isotopic analysis on synthetic silicate glasses. A few milligrams of samples are heated under vacuum with a $\mathrm{CO}_{2}$ laser. The extracted gas is purified using a $\mathrm{CuO}$ furnace, a Pt catalyzer, and a cold trap. Nitrogen is then introduced in a static mass spectrometer (modified VG 5400). The procedural blanks are about $5 \times 10^{-12}$ mole $\mathrm{N}_{2}$, which allows the analysis of samples as low as $5 \times 10^{-11} \mathrm{~mol} \mathrm{~N}_{2}$ with a precision on the $\mathrm{N}$ isotopic ratio of typically $\sim 1-2 \%$. 
These experiments show that equilibrium conditions were reached for a run duration close to $24 \mathrm{hr}$. Under oxidizing conditions at NNO, $\mathrm{N}$ content is $<0.14 \mathrm{ppm}$ at $50 \% \mathrm{CO} / \mathrm{CO}_{2}$ and $50 \% \mathrm{~N}_{2}$. Nitrogen content dramatically increases with decreasing $\mathrm{fO}_{2}$ and reaches values of $1350 \mathrm{ppm} \mathrm{N}$ for the most reduced conditions close to $\mathrm{CCO}$ buffer $\left(20 \% \mathrm{CO}\right.$ and $\left.80 \% \mathrm{~N}_{2}\right)$.

These results allow the calculation of $\mathrm{N}$ solubility. Under highly reducing conditions, the solubility- $\mathrm{fO}_{2}$ dependency suggests that $\mathrm{N}$ dissolves as a $\mathrm{N}$ radical. For each run, these data are then compared to partial pressures of $\mathrm{N}$-bearing gaseous species obtained by thermodynamic calculations. Results concerning $N$ solubility in the presence of $\mathrm{H}_{2}$ will be also presented.

\section{A NEW TYPE OF MANTLE METASOMATISM? TRACE- ELEMENT COMPOSITION OF FELDSPAR-BEARING PERIDOTITE XENOLITHS IN BASALTS FROM SOUTH- ERN SIBERIA. D. A. Ionov ${ }^{1}$, W. L. Griffin ${ }^{1}$, V. S. Prikhodko ${ }^{2}$, and S. Y. O'Reilly', 'GEMOC, School of Earth Sciences, Macquarie University, 2109 NSW, Australia (dmitri.ionov@mq.edu.au),,Insti- tute of Tectonics and Geophysics, Far-Eastern Branch, Russian Academy of Sciences, $65 \mathrm{Kim}$ Yu Chen Street, Khabarovsk 680063, Russia.}

Alkali-rich feldspar has been found in lherzolite xenoliths in Cenozoic alkali basalts in the Hamar-Daban range in southern Siberia [1] and southern far east of Russia (southeast of Habarovsk). "Anhydrous" spinel therzolite is the most common xenolith rock type at both localities; about half of them contain interstitial feldspar and some have feldspar-rich veins. The interstitial feldspar occurs as fine-grained aggregates in reaction zones adjacent to corroded spinel and orthopyroxene in association with secondary olivine (apparently formed by the reaction: $\mathrm{spl}+\mathrm{opx}+\mathrm{cpx}+$ fluid $\rightarrow \mathrm{fs}+$ ol). The feldspar-rich veins are thin, irregular, and are cross-cutting or follow grain boundaries. Associated with feldspar are tiny grains of Ti-rich oxides (ilmenite, armalcolite, rutile) and $\mathrm{Cr}$-spinel; no silicate glass was found. The feldspars are generally alkali rich; their $\mathrm{K}_{2} \mathrm{O}$ content ranges from $0.3 \%$ to $11.2 \%$ and is much higher than in plagioclase from massif lherzolites (usually $<0.1 \% \mathrm{~K}_{2} \mathrm{O}$ ). The Ca-opx temperature estimates range from $950^{\circ}$ to $1010^{\circ} \mathrm{C}$ for the Hamar-Daban samples and $900^{\circ}-950^{\circ} \mathrm{C}$ for the Habarovsk lherzolites.

Trace elements were determined in minerals by laser ablation ICP-MS and in whole rocks by solution ICP-MS. Common for the xenoliths from both localities are high contents of $\mathrm{Rb}$ and $\mathrm{Ba}$ in the feldspar (reaching 200x primitive mantle (PM) values) and the enrichment of whole rocks in alkalis $(\mathrm{Na}, \mathrm{K}, \mathrm{Rb})$ relative to unmetasomatized mantle lherzolites, but the abundances of other incompatible elements vary broadly. Most Hamar-Daban xenoliths and their clinopyroxenes (cpx) are depleted in light REE, Nb, and Th; few are slightly enriched in LREE, Sr, Th, and U. Their feldspars show REE patterns similar to those of coexisting cpx at somewhat lower levels, but have moderate to strong positive anomalies for $\mathrm{Sr}, \mathrm{Pb}, \mathrm{Th}, \mathrm{Ba}$, and $\mathrm{Rb}$. In contrast, the feldspar-oxide aggregates in xenoliths from the Habarovsk site show consistent enrichment in incompatible elements from heavy to light REE (40$200 \times \mathrm{PM}$ for $\mathrm{La}$ ), Nb, Th, U, Ba, and $\mathrm{Rb}$. Their compositions in individual samples are heterogeneous; some analyses have yielded very high contents (100-500 $\times \mathrm{PM})$ of $\mathrm{Nb}, \mathrm{Th}, \mathrm{U}, \mathrm{Zr}$, and Hf that may largely reside in the Ti-rich [2]. The contents of medium and light $\mathrm{REE}, \mathrm{Sr}, \mathrm{Pb}, \mathrm{Zr}, \mathrm{Hf}, \mathrm{Nb}, \mathrm{Th}$, and $\mathrm{U}$ are much higher in the feldspar-oxide aggregate than in the coexisting cpx. The cpx is moderately enriched in LREE and Th; this enrichment is stronger in the rims of cpx grains than in the cores, indicating lack of chemical equilibrium.

The formation of the alkali feldspar (accompanied by Ti-rich oxides) appears to be a relatively recent phenomenon related to infiltration of an alkali-rich fluid into spinel peridotites. The absence of amphibole and mica in peridotite xenoliths at both localities may indicate low $\mathrm{H}_{2} \mathrm{O}$ contents in the fluid. The unusual mineralogical composition and trace-element signatures of the feldsparbearing xenoliths indicate a specific type of mantle metasomatism, distinct from those commonly attributed to $\mathrm{H}_{2} \mathrm{O}$-rich fluids, carbonate melts, or Fe-Ti-rich silicate melts.

References: [1] Ionov D. A. et al. (1995) Contrib. Mineral. Petrol., 122, 174-190. [2] Haggerty S. E. (1991)Miner. Soc. Amer., $25,355-416$.

MANTLE DOMAINS AND CRUST-MANTLE COUPLING IN SOUTHEASTERN SIBERIA (RUSSIA) AND MONGOLIA. D. A. Ionov' 1 S. Y. O'Reilly', and W. L. Griffin', ' 'GEMOC, School of Earth Sciences, Macquarie University, Sydney NSW 2109, Australia (dmitri.ionov@mq.edu.au).

Mantle xenoliths occur in Cenozoic alkali basalts in southem and southeastem Siberia and in central and southeastern Mongolia. Together with xenoliths in Yakutian kimberlites they provide a "cross section" of subcontinental mantle in a traverse from the Precambrian Siberian platform through Baikal Rift Zone, Paleozoic-Mesozoic fold beits in Mongolia and Siberia, to the Pacific continental margin of Siberia. These xenoliths sample upper mantle from different tectonic environments and provide evidence for majorand trace-element and isotope differences between these mantle domains and on thickness and thermal structure of the lithosphere.

Average major-element compositions of the upper mantle sampled by peridotite xenoliths are different in major tectonic units in the area. The mantle beneath the Siberian Platform is most depleted and magnesian. In contrast, peridotite xenolith suites in areas east and south of Lake Baikal (Hamar-Daban, Bartoy, Vitim, and Udokan) and in central Mongolia (Tariat) have fertile average compositions (rich in basaltic components, e.g., $\mathrm{CaO} 2.7-2.9 \%, \mathrm{Al}_{2} \mathrm{O}_{3} 3.3-3.5 \%$; $\mathrm{MgO} \leq 40 \%$ ). The combination of the nonrefractory compositions and the moderately high geothermal gradient (established from studies of gamet-bearing xenoliths) is consistent with low seismic velocities right below the Moho in that region. Peridotite xenoliths found further east and south (Dariganga in southeastern Mongolia, Tok-Stanovik in southern Aldan Shield) have more refractory average compositions $\left(1.6-2.0 \% \mathrm{CaO} ; 1.9-2.3 \% \mathrm{Al}_{2} \mathrm{O}_{3}\right)$ and generally lower equilibration temperatures. LREE-depleted peridotite xenoliths from that area also differ in $\mathrm{Sr}-\mathrm{Nd}$ isotope compositions from those in and around the Baikal Rift zone (the ${ }^{87} \mathrm{Sr} /{ }^{86} \mathrm{Sr}$ ratios in the former commonly are higher). Peridotite xenolith suites from the southern Russian Far East near the Japan Sea coast usually have moderately fertile major-element compositions (av. $\mathrm{CaO} 2.6 \%$, $\mathrm{Al}_{2} \mathrm{O}_{3} 3.1 \%$ ), but some (i.e., those located within Precambrian lithospheric blocks) are more refractory.

Chemical and isotopic composition and T-P estimates of peridot- 
ite xenoliths define a few large-scale domains in the lithospheric mantle between the Siberian Platform and the Pacific coast of Siberia that appear to be consistent with their tectonic setting, age, and geologic history of the overlying crust as well as seismic data These results are in line with the secular variation in the composition of subcontinental lithospheric mantle [1,2] and indicate longterm crust-mantle coupling.

References: [1] Pearson D. G et al. (1995) EPSL, 134, 341357. [2] Griffin W. L et al. (1997) $A G U$, in press.

MORAINE FORMATION IN THE EUROPEAN ALPS MIRRORS NORTH ATLANTIC HEINRICH EVENTS. S. Ivy-Ochs ${ }^{1,2}$, H. Kerschner ${ }^{3}$, P.W. Kubik ${ }^{4}$, H.-A. Synal ${ }^{4}$, G. Patzelt ${ }^{3}$, and $\mathrm{C}$. Schlüchter ${ }^{1},{ }^{1}$ Geologisches Institut, Universität Bem, $\mathrm{CH}$ 3012 Bem, Switzerland, 'Teilchenphysik, ETH-Hönggerberg, $\mathrm{CH}$ 8093 Zürich, Switzerland, 'Institut für Geographie, Innrain 52, Universität Innsbruck, A-6020 Innsbruck, Austria, ${ }^{4}$ Paul Scherrer Institut, c/o Teilchenphysik, ETH-Hönggerberg, CH-8093 Zürich, Switzerland.

Beryllium-10, ${ }^{26} \mathrm{Al}$, and ${ }^{36} \mathrm{Cl}$ measured in boulder surfaces from moraines in the Swiss and Austrian Alps point to glacier expansions synchronous with North Atlantic Heinrich ice-rafting events $\mathrm{H}-2$, $\mathrm{H}-1$, and the Younger Dryas. Present-day limitations of comparing timescales established with radiocarbon, ice core layer counting, or ice-flow modeling, and in situ-produced cosmogenic isotopes should not be overlooked. Production rates used are from Nishiizumi et al. [1] for ${ }^{10} \mathrm{Be}$ and ${ }^{26} \mathrm{Al}$, and Phillips et al. [2] for ${ }^{36} \mathrm{Cl}$. Exposure dates have not been erosion-corrected.

Erratic blocks that mark the maximum terminal position of the Solothum lobe of the Rhone Glacier (Switzerland) associated with the last glacial cycle have yielded exposure ages close to the timing of $\mathrm{H}-2$, which occurred 20,000 radiocarbon yr ago (in North Atlantic sediment cores 609 and V23-81) or $\sim 24,000-22,000 \mathrm{yr}$ ago (in GRIP and GISP2 ice cores) [3].

Preliminary exposure dates for the type locality of the Gschnitz family of moraines (Austria) indicate a readvance of Alpine glaciers coincident with $\mathrm{H}-1$, i.e., at $15,000-14,000$ radiocarbon yr or roughly 16,000 years ago in GRIP and GISP2 [3].

The equivalence of the family of Alpine moraines known as Egesen to the Younger Dryas has been shown by radiocarbon dating at several locations [4-6] and more recently by surface exposure dating at Julier Pass, Switzerland [7].

References: [1] Nishiizumi K. et al. (1989) JGR, 94, 1790717915. [2] Phillips F. M. et al. (1996) GRL, 23, 949-952. [3] Bond G. C. and Lotti R. (1995) Science, 267, 1005-1010. [4] Patzelt G. (1972) Ber. deutsch. Botan. Ges., 85, 47-57. [5] Kerschner H. (1978) Geogr. Jber. aus Österreich, 36, 26-49. [6] Bortenschlager S. (1984) Ber. natw.-med. Ver. Innsbruck, 71, 19-56. [7] Ivy-Ochs S. et al. (1996) Eclogae geol. Helv., 89/3, 1049-1063.

SEAWATER ISOTOPE RECORDS, CRUSTAL EVOLUTION, TECTONICS, GLACIATION, AND ATMOSPHERIC EVOLUTION. S. B. Jacobsen, J. Wills, and Q. Yin, Department of Earth and Planetary Sciences, Harvard University, 20 Oxford Street, Cambridge MA 02138,USA (jacobsen@neodymium.harvard.edu).

The Sr, Nd, Os, and C isotopic records of ancient seawater may be used to address questions relating to the evolution of the Earth's crust, oceans and atmosphere and sedimentary cycling. Simple firstorder models to interpret these records provide insight into the application of these isotope records as potential proxies for crustal evolution, climate change, etc.

Large variations in $\varepsilon_{\mathrm{Nd}}$ are often found between various ocean basins through time, due to the short residence time of $\mathrm{Nd}$ in seawater. Smaller variations are found within single basins. The $\varepsilon_{\mathrm{Nd}}$ value of an ocean in general reflects whether it is predominantly surrounded by active (high $\varepsilon_{\mathrm{Nd}}$ ) vs. passive continental margins (low $\left.\varepsilon_{\mathrm{Nd}}\right)$. The global average seawater $\varepsilon_{\mathrm{Nd}}$ curve exhibits large fluctuations. The present $\mathrm{Nd}$ budget of the oceans is dominated by the river water flux (continental sources), while the midocean ridge hydrothermal water Nd flux contributes about $1 \%$ of the total Nd input to the oceans. Thus, the Nd isotopic variation in seawater is primarily due to changes in the $\mathrm{Nd}$ isotopic composition of the continental flux and is therefore a proxy for the mean age of the continental mass flux to the oceans.

Changes in ${ }^{87} \mathrm{Sr} /{ }^{86} \mathrm{Sr}$ of seawater are primarily controlled by changes in the river water flux (the erosional flux) of Sr from the continents and the hydrothermal flux of $\mathrm{Sr}$ through ocean ridges, as well as changes in the isotopic composition of these fluxes. $\mathrm{The} \mathrm{Sr}$ isotope mass balance, $\mathrm{Nd}$ and $\mathrm{Sr}$ isotopic variations in river waters, and the seawater $\mathrm{Sr}$ and $\mathrm{Nd}$ isotope curves can be used to constrain the river water flux of Sr. Since the global dissolved flux of $\mathrm{Sr}$ in rivers is proportional to the global erosion rate, the river water flux of $\mathrm{Sr}$ is a proxy of erosion rates through time. We note that this does not necessarily imply that ${ }^{87} \mathrm{Sr} /{ }^{86} \mathrm{Sr}$ in seawater is a proxy for erosion rates. Most likely the ${ }^{87} \mathrm{Sr} /{ }^{86} \mathrm{Sr}$ of seawater is a function of both varying erosion rates as well as changes in the ${ }^{87} \mathrm{Sr} /{ }^{86} \mathrm{Sr}$ of the river flux. Model results indicate three distinct episodes of high global continental erosion rates due to uplift caused by continental collision at $\sim 0 \mathrm{Ma}, \sim 0.4 \mathrm{Ga}$, and $\sim 0.6 \mathrm{Ga}$ ago. There is, in general, only a limited correlation between the Sr isotope curve and high vs. low erosional fluxes. The processes operating during the Vendian and Cambrian periods resulted in the largest change observed in ${ }^{87} \mathrm{Sr} /$ ${ }^{86} \mathrm{Sr}$ of seawater at any time during Earth history. While ice ages mark both the Neoproterozoic and Cenozoic, different stratigraphic relationships between the strong increase in ${ }^{87} \mathrm{Sr} /{ }^{86} \mathrm{Sr}$ and continental glaciation indicate that uplift-driven models proposed to explain Cenozoic climatic change cannot account for Neoproterozoic ice ages.

The variation of $\delta^{13} \mathrm{C}$ of seawater (and marine carbonates) over timescales of crustal recycling is controlled both by changes in the global organic $C$ erosion rate and by changes in the rate of $C$ burial. Coupling the $\mathrm{Sr}$ and $\mathrm{C}$ cycles, it can be shown that the burial rate of organic $\mathrm{C}$ shows a simple relationship to overall erosion rates and secular variations in $\delta^{13} \mathrm{C}$ in seawater. This provides the basis for obtaining changes in erosion and organic $\mathrm{C}$ burial rates as a function of time based on the $\mathrm{Sr}, \mathrm{C}$, and $\mathrm{Nd}$ isotopic records of seawater. It is thus possible to have relatively low $\delta^{13} \mathrm{C}$ values $(1-2)$ in marine carbonates during periods of high organic $\mathrm{C}$ burial if the erosion rate is very high. We note that the $\delta^{13} C_{\text {carb }}$ is not a proxy for organic $C$ burial rates, while estimates of organic $C$ burial rates from both $\mathrm{Sr}$ and $C$ isotope records are more likely to reflect real global variations in organic $\mathrm{C}$ burial rates. In the latest Proterozoic, high erosion rates contributed to a significant increase in the burial rate of organic $C$ at $\sim 575 \mathrm{Ma}$ that, coupled with lower fluxes of reducing hydrothermal fluids, most likely gave rise to a large increase in $\mathrm{O}_{2}$ in the atmosphere after the Varanger glaciation. 
Compared with $\mathrm{Nd}$ isotopes, the Os isotope record in seawater indicates a relatively uniform isotopic composition, reflecting a much longer ocean residence time for Os than for $\mathrm{Nd}$. The data obtained for river water suspended loads show a strong negative correlation between $\mathrm{Os}$ and $\mathrm{Nd}$ isotopic composition, a natural consequence of the extraction of the crust from the mantle. This correlation allows us to model the Os isotope record with that of other isotopic records. The Os isotopic record to some extent mimics the $\mathrm{Sr}$ isotopic record. High $\mathrm{C}$ burial rates produced (at various times) a black shale reservoir. This reservoir may affect ${ }^{187} \mathrm{Os} /{ }^{188} \mathrm{Os}$ of the continental input of Os to the oceans. The relationship between $\varepsilon_{\mathrm{Nd}}$ and ${ }^{187} \mathrm{Os} / 188 \mathrm{Os}$ in the suspended loads and mantle samples may indicate that currently eroding continental crust recorded in suspended loads may be less radiogenic in terms of Os, perhaps due to a hidden radiogenic sink such as black shales.

ISOTOPIC CONSTRAINTS ON THE ACCRETION AND EARLY DIFFERENTIATION HISTORY OF THE EARTH.

S. B. Jacobsen, Q. Yin, W. F. McDonough, and C. L. Harper, Department of Earth and Planetary Sciences, Harvard University, 20 Oxford Street, Cambridge MA 02138, USA (jacobsen@ neodymium. harvard.edu).

Isotopic variations due to decay of extinct nuclides ( ${ }^{129} \mathrm{I},{ }^{244} \mathrm{Pu}$, ${ }^{182} \mathrm{Hf}$, and ${ }^{146} \mathrm{Sm}$ ) as well as the noble gas isotopic records provide a record of cosmo/geochemical differentiation (such as accretion, core formation, and early crust formation) that took place within the earliest history of the Earth. The I-Pu-Xe and U-Pb systems are fundamentally unreliable as chronometers of accretion and core formation. They are consistent with a very early formation and short time interval for the accretion of the Earth, but may primarily date gas/dust and volatile fractionation in the solar nebula rather than accretion itself.

The Earth is likely to have accreted in two stages corresponding to conditions before and after removal of gas from the nebular disk. Helium and $\mathrm{Ne}$ in the mantle record primarily a solar component likely incorporated during the first stage by solution into a magma ocean blanketed under a massive $\mathrm{H}_{2}-\mathrm{He}$ protoatmosphere [1]. The heavier noble gases reflect primarily a meteoritic (planetary) component trapped in accreted planetesimals. This provides a possible explanation for the reduced and oxidized accretion stages inferred from siderophile elements, and may explain why the present mantle appears to be too oxidized to be in equilibrium with the core.

The timescale for accretion and core formation of the Earth can be constrained by using the ${ }^{182} \mathrm{Hf}-{ }^{182} \mathrm{~W}$ system [2-4]. In principle, this system offers the most geochemically direct way to determine the timescale for the Earth's accretion and core formation with excellent time resolution, because its physical basis is reliably identifiable with chemical fractionation during the core formation process itself. However, it still requires precise calibration based on internal ${ }^{182} \mathrm{Hf}-182 \mathrm{~W}$ isochron studies of meteorites of independently known age.

Tungsten isotopic measurements of meteorites [2-4] suggest an initial solar value of $182 \mathrm{~W} / 183 \mathrm{~W}$ [thought to be represented by $\mathrm{Fe}$ meteorites free of the radioactive parent ${ }^{182} \mathrm{Hf}$ (half-life $9 \mathrm{Ma}$ )] about $4 \varepsilon$ units lower than the average terrestrial value. Chondrite data are within 0.5 to $1 \varepsilon$ units of the terrestrial value. Since the Hf/ $W$ ratio is $\sim 0$ for iron meteorites, $\sim 1$ for the chondrites, and $\sim 10-40$ for the silicate Earth $[2,3]$, the absence of a radiogenic effect in the silicate Earth relative to chondrites suggests fractionation in the absence of significant live ${ }^{182} \mathrm{Hf}$. In a simple two-stage model this result would imply that the core formed $>50 \mathrm{Ma}$ subsequent to the initial formation of the Earth. The two-stage model assumes a single time for core formation.

However, it is more likely that accretion and core formation for the Earth was a quasicontinuous process that may have lasted as long as $\sim 100 \mathrm{Ma}$, and that core formation is primarily rate-limited by accretion [2,3]. According to Wetherill [5], the total accretion interval is about $100 \mathrm{Ma}$, but the mean time of formation is only $\sim 12 \mathrm{Ma}$. A number of $\mathrm{U}-\mathrm{Pb}$ isotope studies refer to a $\sim 50-100 \mathrm{Ma}$ mean time for accretion, citing stochastic Safronov-Wetherill-type accretion models, in support of $\mathrm{W}$ and $\mathrm{U}-\mathrm{Pb}$ model ages suggesting late core formation. They are mistaking the total accretion interval for the actual mean time, which is shorter by about a factor of 8 . Based on Wetherill's 100-Ma timescale, there is no need for a late (50-100 Ma) mean time of core formation. Considerations of continuous accretion/core formation $[2,3]$ demonstrate that it is possible to have a long timescale and end up with a small isotope effect in the Earth relative to chondrites. The data are roughly consistent with Wetherill's average model (mean time of formation of $\sim 12 \mathrm{Ma}$ ) for the case of equilibrative partitioning of $W$ isotopes during siderophile element segregation. This is what would be expected for a magma ocean scenario. In this model, the late tail $(\sim 10 \%)$ of accretion coming effectively after the ${ }^{182} \mathrm{Hf}$ system is dead, removes the difference in ${ }^{182} \mathrm{~W} / 183 \mathrm{~W}$ between the silicate Earth and chondrites. Thus, when one considers interpretation of isotope data in terms of continuous accretion models, one obtains a quite different result than that obtained with a simple two-stage model. The twostage model time might be $>50 \mathrm{Ma}$, but the mean time of the core formation would in fact be only $\sim 10-20 \mathrm{Ma}$.

References: [1] Harper C. L. Jr. and Jacobsen S. B. (1996) Science, 273, 1814-1818. [2] Harper C. L. Jr. and Jacobsen S. B. (1996) GCA, 60, 1131-1 153. [3] Jacobsen S. B. and Harper C. L. Jr. (1996) Geopys. Monograph, 95, 47-74. [4] Lee D.-C. and Halliday A. N. (1995) Nature, 378, 77 1-774. [5] Wetherill G. W. (1986) in Origin of the Moon, LPI, Houston, pp. 519-550.

\section{SOLUBILITIES OF TUNGSTEN AND COBALT IN SILI- CATE MELTS AS A FUNCTION OF MELT COMPOSITION.} W. L. Jaeger, M. J. Drake, and C. J. Capobianco, Lunar and Planetary Laboratory, University of Arizona, Tucson AZ 85721-0092, USA.

During Earth's core formation trace elements were distributed between the core and the bulk silicate Earth as a function of their Femetal/silicate partition coefficients. Recent studies have indicated that metalsilicate partitioning of trace elements is a function of silicate melt composition [e.g., 1,2]. Here we report on the solubilities of $\mathrm{W}$ and $\mathrm{Co}$ as a function of melt basicity in the system MgO$\mathrm{CaO}-\mathrm{Al}_{2} \mathrm{O}_{3}-\mathrm{TiO}_{2}-\mathrm{SiO}_{2}$.

Five melt compositions were investigated, with nbo/t [3] varying from 0.25 to 1.52 . Chips of these glasses were placed in conical spirals of $W$ or Co wire and suspended in a gas-mixing vertical tube fumace under controlled temperature and $O$ fugacity $\left(1300^{\circ} \mathrm{C}\right.$ and $10^{-12}$ atm $\mathrm{O}_{2}$ ). Four different compositions with either $W$ or $C o$ were placed in the furnace simultaneously.

To demonstrate equilibrium, experiments on $\mathrm{W}$ were run for 


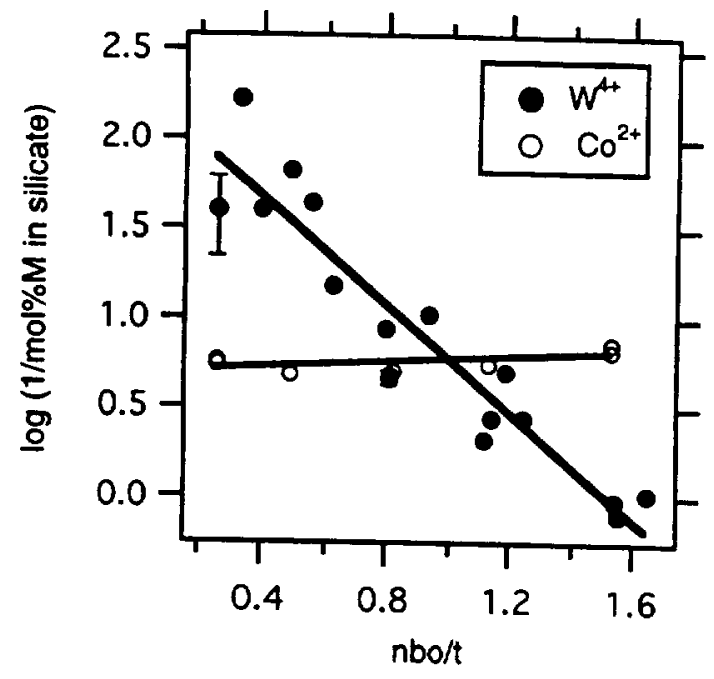

Fig. 1. The dependence of $\mathrm{W}$ and Co partitioning behavior on nbo/t of the silicate melt at $1300^{\circ} \mathrm{C}$ and $10^{-12} \mathrm{~atm} \mathrm{O}_{2}$. The $2 \sigma$ error bars on $W$ data are considerable at the lowest nbo/t, but shrink to smaller than the plotted symbol at basic compositions. This probably accounts for the larger scatter in acidic W data. Enor bars on $\mathrm{Co}$ are approximately the size of their symbols.

$2 \mathrm{hr}, 1$ day, 4 days, and 7 days. Air-quenched samples were analyzed using an electron microprobe. Solubilities measured from the 1,4 , and 7-day $W$ experiments agree with each other within error (Fig. 1) while values from the 2-hr run (not shown in Fig. 1) are consistent for the two most basic glasses, but deviate from this trend at lower nbo/t. We interpret this as evidence that $2 \mathrm{hr}$ is not enough time to equilibrate the more acidic samples, but experiments of 1 day or longer duration have achieved equilibrium for all compositions. All Co experiments had durations of 1 day.

Our results indicate that $\mathrm{W}$ solubility depends strongly on melt basicity while the effect on Co is relatively small (Fig. 1). Although it is not apparent on Fig. 1, both $\mathrm{W}$ and Co show a slightly concave upwards trend for samples simultaneously placed in the fumace; however, the linear fit shown here are good approximations for each trend.

Figure 1 shows that over this range of nbo/t and under the specified temperature and $\mathrm{fO}_{2}$ conditions, $\mathrm{W}$ solubility increases with increasing melt basicity, but Co solubility is essentially unchanged. This difference in the way melt basicity affects the partitioning behavior of these two elements is attributed to their different oxidation states. Tungsten, a quadrivalent cation, can be dissolved more readily in depolymerized melts where more nonbridging oxygens are available, whereas, the divalent oxidation state of $\mathrm{Co}$ is relatively insensitive to the concentration of nonbridging oxygens. It is predicted that a trivalent cation would have a slope intermediate to the two plotted above.

This study is the first to investigate the effect of melt composition on $W$ and Co solubility under controlled $O$ fugacity. Our results for W agree with those of Ertel et al. [4] for the composition they investigated, and are consistent with the trends shown in the high pressure experiments of Walter and Thibault [1] and Hillgren et al. [2].

References: [1] Walter and Thibault (1995) Science, 270. 1186-1189. [2] Hillgren et al. (1996)GCA, 60, 2257-2263. [3] Mills
(1993) ISIJ International, 33(1), 148-155. [4] Entel et al. (1996) $G C A, 60,1171-1180$.

EQUILIBRIUM BETWEEN GARNET AND CLINOPYROXENE IN ECLOGITIC ROCKS. E. Jagoutz ${ }^{1}$, E. Zinner ${ }^{2}$, and D. Jacob $^{3}$, 'Max-Planck-Institut für Chemie, Abteilung Kosmochemie, Saarstrasse 23, D-55128 Mainz, Germany, 2Department of Earth and Planetary Sciences, Washington University, St. Louis MO 63130 , USA ${ }^{3}$ Mineralogie-Petrologie Institut, Universität Göttingen, D-37077 Göttingen, Germany.

From Sm-Nd isotopic studies on garnet-clinopyroxene pairs we know that in some cases these minerals are not in chemical equilibrium [1]. In this study we selected eclogites with equilibrated and some with unequilibrated minerals. Trace-element abundances were measured by ion microprobe in the constituent garnet (Gnt) and clinopyroxene (Cpx) of six samples. A large variation in REE abundances is observed and reproduces the total variation of REE concentrations reported in the literature for comparable eclogites. LREE mainly reside in Cpx while HREE are concentrated in Gnt. The ratios of REE between Gnt and Cpx vary over two orders of magnitude. Trace-element-poor Gnt frequently has small positive Eu anomalies indicating that these Gnt are replacing plagioclase. This evidence indicates that the eclogites may be metamorphosed gabbros [2]. Textural evidence for the exsolution of Gnt from Cpx is commonly observed in eclogites and garnet pyroxenites. Garnets formed by this reaction are in isotopic disequilibrium and have low HREE as demonstrated by one of our samples. These new data indicate that most eclogites record a prograde path of metamorphism in their isotopes and trace-elements. The common deficit of LREE is a strong indication of an open chemical system. For example, a partial melt may have been lost during the dehydration process. Consequently, most eclogites are dry and chemically residual. Nonetheless, we still observe characteristic trace element patterns and isotopic heterogeneity that can only be explained as a record of the premetamorphic history. Although some of these eclogites contain diamonds indicating a minimum pressure of $40 \mathrm{kbar}$ and $800^{\circ} \mathrm{C}$, the metamorphism was not sufficient to completely equilibrate the minerals. LREE are not soluble in Gnt and HREE are not soluble in $\mathrm{Cpx}$. The Gnt might not be equilibrated to mantle conditions because the surrounding Cpx does not transport the REE suitable for Gnt because of limited solubility. The Cpx on the other hand might be locked by the Gnt for the same reason. This interlocking diffusion system might actually be the reason that eclogites do not equilibrate and contain premetamorphic isotopic and traceelement relicts.

References: [1] Jagoutz (1986). [2] Jagoutz et al. (1984).

A TERRESTRIAL RECORD OF CHANGING CARBON DIOXIDE LEVELS IN THE CRETACEOUS. A. H. Jahren ${ }^{1}$ and N. C. Arens ${ }^{2}$, 'School of Earth and Atmospheric Science, Georgia Institute of Technology, Atlanta GA 30332-0340, USA (jahren@ eas.gatech.edu), ${ }^{2}$ Department of Integrative Biology, University of California-Berkeley, Berkeley CA 94720-3140, USA.

Stable C isotopic data from terrestrial organic material preserved in a Cretaceous sequence from the Andes of Colombia, South 
America, show significant changes in atmospheric $\mathrm{pCO}_{2}$ levels during the latest Barremian and early Aptian. Bulk organic material, vitrinite, and cuticle were isolated and analyzed for stable $\mathrm{C}$ isotope values from estuarian and near-shore sediments of Cretaceous age at four localities in the Cordillera Oriental of the Colombian Andes under the assumption that land plants sampled the ancient atmosphere according to known pattems of isotopic fractionation.

Although the strata sampled were chosen because of the probability of dominantly terrestrial input, we wished to address the possible incorporation of any $\mathrm{C}$ derived from marine and bacterial productivity. After analysis of the bulk organic $\mathrm{C}$ in these sediments, we proceeded to further isolate two components: vitrinite and cuticle. Vitrinite is the remains of highly lignified plant tissues; cuticle is a waxy compound that coats the surface of land plants to inhibit water loss. Both materials are restricted to vascular land plants and therefore represent uniquely terrestrial $C$ compounds. Both vitrinite and cuticle are easily recognized at low magnification and were isolated to calibrate the bulk sample for terrestrial influence. Thermal alteration of organic constituents analyzed in this study was estimated based on the color of palynomorphs and cuticle. All constituents analyzed for terrestrial organic C fell within Batten's (1981) maturation categories 4 and 5 .

Determinations of $\delta^{13} \mathrm{C}$ in tissues suggest fluctuating $\mathrm{pCO}_{2}$ levels during the latter part of the Early Cretaceous, with a peak in the latest Barremian. Bulk organic $\mathrm{C}$ data show $\delta^{13} \mathrm{C} \approx-23 \%$ in the Hauterivian, decreasing steadily through the Barremian, and becoming strongly negative $\left(\delta^{13} \mathrm{C} \approx-28 \% 0\right)$ in the upper portion of the Barremian. In the Aptian/Albian, bulk organic $\mathrm{C}$ becomes strongly isotopically positive $\left(\delta^{13} \mathrm{C} \approx-21.5 \%\right.$ ), and again becoming more negative $\left(\delta^{13} \mathrm{C} \approx-24 \%\right.$ ) at the Cenomanian. $\delta^{13} \mathrm{C}$ determinations from vitrinite and cuticle components closely mirror the $\delta^{13} \mathrm{C}$ value of bulk organic $\mathrm{C}$, reflecting the same trends with time. Cuticle $\delta^{13} \mathrm{C}$ values have a strong tendency to have $\delta^{13} \mathrm{C}=\delta^{13} \mathrm{C}$ (bulk organic) $-1 \%$, but occasionally exhibit much less isotopic difference with the bulk $\mathbf{C}$ fraction.

Consideration of 166 cases from the literature measuring $\delta^{13} \mathrm{C}$ in plant tissue vs. $\mathrm{pCO}_{2}$ yields the following relationship: ppm $\mathrm{CO}_{2}=-268.41-21.358\left(\delta^{13} \mathrm{C}\right)$ with $\mathrm{R}^{2}=0.821$. Application of this relationship to our data implies an upper Barremian high of $330 \mathrm{ppm}$ $\mathrm{CO}_{2}$ and an Aptian low of $176 \mathrm{ppm} \mathrm{CO}_{2}$. We compare these values with other workers' estimates of Cretaceous $\mathrm{pCO}_{2}$.

The temporal pattem of these data are consistent with and corroborate model predictions made based on global mass balance assumptions. This approach offers a useful new method for elucidating evidence of elevated $\mathrm{CO}_{2}$ in terrestrial ecosystems and offers significantly finer stratigraphic resolution of such changes than can be achieved with global models.

GEOCHEMICAL CONSEQUENCES OF CORE FORMATION IN THE PRESENCE OF SOME VOLATILES. D. Jana and D. Walker, Lamont-Doherty Earth Observatory and Department of Earth and Environmental Sciences, Columbia University, Palisades NY 10964, USA (jana@lamont.columbia.edu; dwalker@lamont. columbia.edu).

The potential impact of various $\mathrm{C}-\mathrm{O}-\mathrm{H}$ volatiles upon $\mathrm{Fe}, \mathrm{Ni}, \mathrm{Co}$, W, Ge, P, and Mo partitioning during core formation was evaluated experimentally at $1400^{\circ} \mathrm{C}$ and $10 \mathrm{kbar}$ in graphite. Relatively oxidizing $\mathrm{C}-\mathrm{O}-\mathrm{H}$ or $\mathrm{C}-\mathrm{O}$ vapors generated by decomposition of either brucite or magnesite or both have a much stronger effect on element distribution than the reducing $\mathrm{C}-\mathrm{H}$ vapors generated by anthracene decomposition. The effects are opposite to each other and consistent with the sense expected from $\mathrm{pO}_{2}$ control. Iron, $\mathrm{W}$, $P$, and Mo are greatly reduced in siderophility to the point of becoming lithophile when oxidized by $\mathrm{C}-\mathrm{O}$ or $\mathrm{C}-\mathrm{O}-\mathrm{H}$ fluids. By contrast, $\mathrm{C}$-H fluids produce only a modest increase in siderophility. Oxidants can be quite potent in remediating some of the excesses in the siderophile element chemistry of the mantle. However, it is unclear whether physically plausible scenarios for incorporation and action of oxidizing volatiles can be effected. It is also not clear yet whether the effects can be fine tuned to give chondritic relative abundance values in the mantle when needed. Nevertheless, the possible effects of oxidizing volatiles is commensurate in importance with pressure and temperature effects upon siderophile-element distribution during core formation. An analysis of control parameters such as pressure and temperature is unlikely to be relevant to core formation without also considering compositional effects.

THE INFLUENCE OF SILICATE MELT COMPOSITION ON DISTRIBUTION OF SIDEROPHILE ELEMENTS AMONG METAL AND SILICATE LIQUIDS. D. Jana and D. Walker, Lamont-Doherty Earth Observatory and Department of Earth and Environmental Sciences, Columbia University, Palisades NY 10964, USA (jana@lamont.columbia.edu; dwalker@lamont. columbia.edu).

Liquid metal-liquid silicate partitioning of $\mathrm{Fe}, \mathrm{Ni}, \mathrm{Co}, \mathrm{P}, \mathrm{Ge}, \mathrm{W}$, and Mo among a $\mathrm{C}$-saturated metal and a variety of silicate melts (magnesian, tholeiitic, siliceous, aluminous, and aluminosiliceous basalts) depends modestly to strongly upon silicate melt structure and composition. Low-valency siderophiles, $\mathrm{Fe}, \mathrm{Ni}$, and $\mathrm{Co}$, show a modest influence of silicate melt composition on partitioning. Germanium shows a moderate but consistent preference for the depolymerized magnesian melt. High-valency siderophiles, P, Mo, and $W$, show more than an order of magnitude decrease in metalsilicate partition coefficients as the silicate melt becomes more depolymerized. Detailed inspection of our and other published $W$ data show that polymerization state, temperature, and pressure are more important controls on $\mathrm{W}$ partitioning than oxidation state. For this to be true for a high- and variable-valence element implies a secondary role in general for oxidation state even though some role must be present. Equilibrium core segregation through a magma ocean of "ultrabasic" composition could provide a resolution to the "excess" abundances of $\mathrm{Ge}, \mathrm{P}, \mathrm{W}$, and Mo in the mantle, but the mantle composition alone cannot explain the excess abundances of $\mathrm{Ni}$ and $\mathrm{Co}$ in chondritic proportions.

BASALTIC MAGMA DEGASSING IN VARIOUS TEC. TONIC ENVIRONMENTS: CHEMICAL AND ISOTOPIC BEHAVIOR OF CARBON DIOXIDE, NITROGEN, AND WATER. M. Javoy, F. Pineau, and N. Jendrzejewski, Laboratoire Géochimie des Isotopes Stables, IPG and Université Paris VII, URA 1762 CNRS, 4 Place Jussieu, 75251 Paris Cedex 05, France (mja@ccr.jussieu.fr). 
Magmas of basaltic composition are characterized by similar and pseudo-ideal (linear dependence vs. pressure due to compensating effects of fluid and liquid nonideality) solubilities of $\mathrm{CO}_{2}$ and $\mathrm{N}$ in the range $0-10 \mathrm{kbar}$. In the same pressure range $\mathrm{H}_{2} \mathrm{O}$ is $100-1000 \times$ more soluble with a quasi-quadratic dependence vs. pressure of the total $\mathrm{H}_{2} \mathrm{O}$ content and increasing proportions of molecular vs. hydroxyl $\mathrm{H}_{2} \mathrm{O}$ vs. $\mathrm{H}_{2} \mathrm{O}$ pressure. This leads to very variable situations in the degassing record of basaltic magmas due to very different volatile proportions in the starting magma at depth. Nitrogen concentrations up to now are documented mainly in MORB where the initial $\mathrm{C} / \mathrm{N}$ ratio is around 450 . Preliminary results indicate that the same ratio in Hot Spot magmas could be $3-5 \times$ higher, whereas very little is known about subduction zone magmas ( $C / N>1200$ ?). In any case, such high ratios combined to similar $\mathrm{C}$ and $\mathrm{N}$ solubilities ensure that $N$ degassing follows smoothly $C$ degassing with a moderate decrease of the $\mathrm{C} / \mathrm{N}$ ratio during degassing due to slightly higher $\mathrm{N}$ solubility.

The $\mathrm{CO}_{2}-\mathrm{H}_{2} \mathrm{O}$ relationships are much more contrasted among the different tectonic environments. The initial $\mathrm{H}_{2} \mathrm{O}$ concentration in MORB is most generally $<0.5 \%$, resulting in very small concentrations in outgassed fluids up to very shallow levels ( $\sim 5 \%$ at $350 \mathrm{bar}$ on Mid-Atlantic Ridge for a tholeite with $0.5 \%$ dissolved $\mathrm{H}_{2} \mathrm{O}$ ). Under similar pressure conditions, outgassed fluids of Hot Spot magmas contain $50-70 \% \mathrm{H}_{2} \mathrm{O}$, due to starting concentrations of the order of $1 \%$. Finally, subduction zone magmas, with initial $\mathrm{H}_{2} \mathrm{O}$ concentrations $>5 \%$ show already very important water outgassing at pressures in excess of $5 \mathrm{kbar}$.

Whether observed at moderate pressures (200-500 bar) in submarine glasses or at higher pressure as trapped in glassy inclusions, $\mathrm{C}-\mathrm{H}_{2} \mathrm{O}$ ratios fail to be completely accounted for by either closed-or open-system thermodynamic equilibrium models or even by more realistic differential diffusion models. In most cases it seems unavoidable to consider mixing of magmas at different outgassing stages.

From an isotopic point of view, $\mathrm{C}$ and $\mathrm{N}$ outgassing can be approximated by a two-stage model, the first one corresponding to equilibrium during slow ascent at depth, the second one corresponding to eruptional conditions and leading to distillation effects. Both episodes lead to opposite effects for $\mathrm{C}$ and $\mathrm{N}$ because of opposite fluid-magma fractionation. The isotopic outgassing pattern may be used in inferring the depth of the outgassing discontinuity (depth of magma chamber).

For $\mathrm{H}$, the moderate $\mathrm{H}_{2} \mathrm{O}$ outgassing in MORB but also in $\mathrm{Hot}$ Spot basalts leads to moderate isotope effects except for subaerial eruptions. In subduction zones, however, the isotopic effect can be as large as $150 \%$, leading from $\mathrm{dD}>40 \%$ to residual $\mathrm{dDs}<$ $-200 \%$ /SMOW.

\section{THE ORIGIN OF MIDDLE RARE-EARTH-ELEMENT} ENRICHMENTS IN ACIDIC NATURAL WATERS. $K$. H. Johannesson, X. Zhou, and C. Guo, Harry Reid Center for Environmental Studies, University of Nevada-Las Vegas, Las Vegas NE 89154-4009, USA (khj@nevada.edu).

Shale-normalized middle-rare-earth-element (MREE) (i.e., SmHo) enrichments have been recognized in a variety of natural water including groundwater, lake water, and river water [1-5]. All this water, except some of the river water, is acidic. The shale-normal- ized MREE enrichments of the acidic water are unlike REE pattems reported for neutral to high pH natural water as well as rock signatures. However, ancient biogenic apatite and various ferromanganese oxides/oxyhydroxides, secondary vug filling minerals, and "dirty" carbonates have been reported to exhibit similar MREE-enriched signatures.

Earlier investigations evaluated the possible effects of solution complexation in this acidic water on the formation of the observed shale-normalized MREE enrichments. Unlike high $\mathrm{pH}$ alkaline lakes and seawater, where solution complexation with carbonate ions play important roles in the formation of heavy REE- (HREE) enriched shale-normalized patterns, solution complexation does not appear to contribute to the formation of MREE-enriched patterns in this acid water. Free metal species (e.g., $\mathrm{Ln}^{3+}$, where $\mathrm{Ln}=\mathrm{lan}-$ thanide series element or REE) and sulfate complexes ( $\mathrm{LnSO}^{4+}$ ) dominate the speciation of the REE in this low pH waters. Stability constants that describe the formation of REE-sulfate complexes in natural water do not vary substantially with atomic number (only by a factor of 3.6) compared to, for example, the stability constants for $\mathrm{REE}$ carbonate complexes. Instead, solid-liquid exchange reactions such as adsorption/desorption and/or cation exchange between natural water and MREE-enriched minerals or amorphous mineral surface coatings and/or weathering/dissolution of these same solid materials are suspected as the source of the MREE enrichments in acid water [2-5].

We chose to investigate the origin of the MREE enrichments in the acidic lake water from Colour Lake in the Canadian High Arctic. The MREE enrichments in Colour Lake water were previously proposed to be the result of dissolution of a MREE-enriched secondary phase in the rocks of the catchment basin by the acid lake water [3]. Consequently, we collected a suite of 11 rock samples representative of the catchment basin including diabase, clastic sedimentary rocks (i.e., sandstones, siltstones, and shales), and gypsum from an evaporite diapir. Clastic sedimentary rocks are the dominant rock type in the Colour Lake catchment basin. The rock samples were crushed and separated into three different sample sets on which three different leach tests were performed. Because we are, in part, interested in the acid leachable fraction of the REEs for each of the rocks examined, two different acidic solutions were prepared for batch leaching tests. The first solution consisted of $1 \mathrm{~N}$ ultra-pure nitric acid (Seastar, Inc.), whereas the second acid solution was prepared from the same ultra-pure nitric acid ( $16 \mathrm{~N}$ originally) but adjusted to $\mathrm{pH}=3.6$, in order to mimic the $\mathrm{pH}$ of the Colour Lake water. Each rock sample was leached for $20 \mathrm{~min}$ in the $1 \mathrm{~N}$ nitric acid solution and approximately 6 weeks with the $\mathrm{pH}=3.6$ nitric acid solution. Because we were also interested in the signature of REEs bound to ferromanganese oxides and/or oxyhydroxides in the sedimentary rocks of the Colour Lake catchment basin, each rock sample was also leached for $5 \mathrm{hr}$ with a $0.04-\mathrm{M}$ hydroxylamine- $\mathrm{HCl}$ in $25 \%$ $v / v$ ultra-pure acetic acid solution [6]. Following the leaching period, the solutions were centrifuged, filtered through $0.45-\mu \mathrm{m}$ clean membrane filters, and analyzed by inductively coupled plasma mass spectrometry for the REE. In each case, the leachate solutions from reaction with the clastic sedimentary rocks had MREE enrichments that closely resembled the Colour Lake water. In the case of the $1 \mathrm{~N}$ nitric acid solution, the leaching results indicate that Colour Lake water obtained its REE signature by dissolution of a MREE-enriched mineral or amorphous phase that occurs in the clastic sedimentary rocks. More specifically, however, the results of the hy- 
droxylamine $-\mathrm{HCl}$ in $25 \% \mathrm{v} / \mathrm{v}$ acetic acid leach test strongly suggests that the important mineral or, more likely, amorphous phase, in these clastic sedimentary rocks is a MREE-enriched ferromanganese oxideioxyhydroxide. At the $\mathrm{pH}$ values of the Colour Lake waters (i.e., $\mathrm{pH}=3.6$ ), it is reasonable to expect that ferromanganese oxides/oxyhydroxides would readily dissolve [7].

References: [1] Elderfield H. et al. (1990) GCA, 54, 971. [2] Gosselin D. G. et al. (1992) GCA, 56, 1495. [3] Johannesson K. J. and Lyons W. B. (1995) Chem. Geol., 119, 209. [4] Nordstrom D. K. et al. (1995) Geol.Soc. Am. Abstr.Prog., 27, A 199. [5] Sholkovitz E. R. (1995) Aquat. Geochem., 1, 1. [6] Tessier A. et al. (1979) Anal. Chem., 51, 844. [7] Zinder B. et al. (1986) GCA, 50, 1861.

\section{MASS-BALANCE RELATIONSHIPS IN JURASSIC IRON- OXIDE-(COPPER-RARE-EARTH-ELEMENT) DEPOSITS IN THE GREAT BASIN. D. A. Johnson and M. D. Barton, De- partment of Geosciences, University of Arizona, Tucson AZ 85721, USA (djohnson@geo.arizona.edu; barton@geo.arizona.edu).}

Igneous-related $\mathrm{Fe}$-oxide-(Cu-Au) systems pose enigmas both in the source and trapping of mineral components. We have examined mass balance constraints on regionally extensive, broadly coeval mafic (Humboldt Complex, HC) and felsic (Cortez Mountains, CM) hydrothermal systems in Jurassic arc-related rocks of central Nevada. Both systems show many similarities with many such systems of Proterozoic and Phanerozoic age worldwide [1]. Whole-rock compositions, mineral chemistry, and isotopic constraints, when combined with field mapping, demonstrate that enormous mass transfer accompanied development of moderate- to high-temperature sodic(-calcic) alteration assemblages. In both areas, deep/early mineralization is dominantly $\mathrm{Mt}+\mathrm{Ap}+\operatorname{Act}(\mathrm{Cpx}) / \mathrm{Scap}(\mathrm{Ab})$ to shallow/late $\mathrm{Hm} \pm \mathrm{Py} \pm \mathrm{Cpy}+\mathrm{Ap}(\mathrm{REE}$ minerals)//hydrolytic $[\mathrm{Ab}+$ $\mathrm{Chl}+\mathrm{Carb}(\mathrm{HC})$ or Ser + Clay $+\mathrm{Qz}(\mathrm{CM})]$. These systems are interpreted as reflecting magmatic-driven circulation of predominantly or entirely external fluids of evaporitic origin.

In both areas, leaching of many metals, notably $\mathrm{Fe}, \mathrm{Cu}, \mathrm{Pb}$, and REE, can be demonstrated in the deeper portions of the systems. Masses (tonnes $/ \mathrm{km}^{3}$ ) include approximately $3.3 \times 10^{7} \mathrm{Fe}, 6.8 \times 10^{4}$ $\mathrm{Cu}, 3.9 \times 10^{4} \mathrm{~Pb}$, and $4.22 \times 10^{5} \mathrm{La}(\mathrm{CM})$ and $9.3 \times 10^{7} \mathrm{Fe}, 5.5 \times$ $10^{5} \mathrm{Cu}, 2.4 \times 10^{4} \mathrm{~Pb}$, and $3.1 \times 10^{4} \mathrm{La}(\mathrm{HC})$. Minimum alteration volumes exceed $280 \mathrm{~km}^{3}$ in $\mathrm{CM}$ and $660 \mathrm{~km}^{3}$ in HC. Principal differences in materials trapped reflect the source rocks. Some components, such as $\mathrm{Pb}, \mathrm{Zn}$, and $\mathrm{Ba}$ are strongly removed from the source, but seemingly not trapped in the shallower parts of the hydrothermal systems. This reflects the oxidized, high- $\mathrm{Cl}$, low-S fluids and is not controlled by differences in the respective source rocks. The results demonstrate (1) both source and trapping mechanisms govem associated metal suites; (2) far more material is transferred out of plausible sources than is known to be trapped; (3) trapping mechanisms are selective in terms of retention of components; (4) evaporitic fluid sources best fit the full range of observations.

References: [1] Barton and Johnson (1996) Geology.

CONTRASTING STYLES OF DIFFERENTIATION FOR THE EARTH, MOON, AND MARS. J. H. Jones, L. E. Borg, and L. E. Nyquist, Mail Code SN4, NASA Johnson Space Center,
Houston TX 77058, USA.

The recent discovery and isotopic analysis of the QUE 94201 shergottite (hereafter, Q) has served to emphasize the highly depleted nature of the martian mantle. The young age of $Q$ (327 m.y. [1]) indicates that its isotopic initials are representative of almost the entire history of its mantle source region-integrated over 4 b.y. In this regard $Q$ is important because its isotopic characteristics are extreme end members of isotopic signatures observed in other martian meteorites. The initial ${ }^{87} \mathrm{Sr} /{ }^{86} \mathrm{Sr}$ of $\mathrm{Q}$ is $\sim 0.7013$ and its initial $\varepsilon_{\mathrm{Nd}}$ is $\sim 50$ [1]. These values contrast with values for terrestrial oceanic basalts, which can be approximated as mixing between end members: ${ }^{87} \mathrm{Sr} /{ }^{86} \mathrm{Sr} \sim 0.702$ and $\varepsilon_{\mathrm{Nd}} \sim 12$ for mid-ocean ridge basalts (MORB); ${ }^{87} \mathrm{Sr} /{ }^{86} \mathrm{Sr} \sim 0.705$ and $\varepsilon_{N d} \sim 0$ for ocean island basalts (OIB). It is not yet known how representative $Q$ is of the entire martian mantle. However, using data from the nakhlites and Chassigny, Jones [3] estimated that 180 m.y. ago the martian mantle had values of 0.7036 and 20 for ${ }^{87} \mathrm{Sr} /{ }^{86} \mathrm{Sr}$ and $\varepsilon_{\mathrm{Nd}}$, respectively. Jones [3] also showed that the then-known shergottites were consistent with a model whereby they were derived from magmas with isotopic signatures like those of the nakhlite mantle, coupled with various amounts of crustal contamination.

Using $\mathrm{Sr}$ isotopes alone, it is difficult to gauge the degree of depletion of the martian mantle, because the martian $\mathrm{Rb} / \mathrm{Sr}$ ratio is not known exactly. However, because it is reasonable to assume that the $\mathrm{Sm} / \mathrm{Nd}$ ratio of Mars is chondritic, recent initial values of $+20-$ 50 indicate that the martian mantle has been highly depleted for a very long time. This observation is reinforced by isotopic anomalies in ${ }^{142} \mathrm{Nd}$ that are observed in $\mathrm{Q}$ and the nakhlites. Neodymium-142 is produced by the decay of short-lived ${ }^{146} \mathrm{Sm}\left(t_{1 / 2} \sim 100 \mathrm{~m}\right.$.y.). Thus, the source regions of $Q$ and the nakhlites must have been depleted within a few half-lives of ${ }^{146} \mathrm{Sm}$. In fact, if the mean $\mathrm{Sm} / \mathrm{Nd}$ ratio needed to produce the nakhlite initial $\varepsilon_{143 \mathrm{Nd}}$ is used to calculate a time of mantle depletion using $\varepsilon_{142}$, a negative age is derived [4]. The martian mantle is very depleted in incompatible elements and that depletion event is very ancient.

It has been suggested that core formation in both the Earth and Mars occurred in conjunction with global magma oceans $[5,6]$ and that the siderophile element signatures in the present-day mantles of the Earth and Mars were established by equilibrium between metal and silicate liquid at temperatures that are inferred to be similar (1900-2200 K [4,5]). Thus, we may also infer that, except for pressure, the physical conditions of both magma oceans were similar. For example, both magma oceans are inferred to be several hundred kilometers deep [5-7].

Differences in styles of magma ocean differentiation have been attributed to the detailed relationships between adiabats and solidus-liquidus loops [7]. If this is the case, it would be predicted that the differentiation of Mars during a magma ocean would be an intermediate case to that of the Earth and Moon. In fact, however, the martian mantle seems to be comparably depleted to that of the Moon [8]. One possibility is that differences in the styles of magma ocean differentiation are not a simple function of planet size. Another possibility is that not all the bodies being compared experienced magma oceans.

The evidence for a global magma ocean is strongest for the Mon. However, considering the similar magnitudes of early Sm/ Nd fractionation in the Moon and Mars [8], a case could be made that Mars, too, had a magma ocean. By analogy, the general lack of evidence of such extreme fractionations on Earth suggests that the 
Earth did not pass through a magma ocean stage. One means ofescaping this conclusion is for turbulent convection to minimize differentiation during magma ocean solidification [7], although it is unclear how this mechanism will work after 80-90\% crystallization. It is also possible that, like Mars and the Moon, the Earth also differentiated efficiently and that subsequent subduction and convective mixing have remixed complementary reservoirs over geologic time. The strongest evidence against early magma oceans comes not from basalts, but from mantle xenoliths that approach chondritic compositions in terms of their major elements and Os isotopes, that have been isolated from mantle convection for substantial periods of Earth history, and that have young Nd model ages $[9,10]$.

Currently, there is little actual evidence that the Earth ever passed through a magma ocean stage. This conclusion is consistent with the observation that the predicted conditions of metal-silicate liquid equilibrium in the Earth [4] were deeply below the solidus of anhydrous mantle $[6,11]$.

References: [1] Borg L. E. et al. (1997) GCA, submitted. [2] Hofmann A. W. (1997) Nature, 385, 219-229. [3] Jone J. H. (1989) Proc. LPSC 19th, 465-474. [4] Happer C. L. Jr. et al. (1995) Science, 267, 213-217. [5] Righter K. et al. (1997) Phys. Earth Planet. Inter., submitted. [6] Righter K. and Drake M. J. (1996) Icarus, 124, 513-529. [7] Tonks W. B. and Melosh H. J. (1990) in Origin of the Earth (Newsom and Jones, eds.), pp. 151-174. [8] Nyquist L. E. et al. (1995) GCA, 59, 2817-2837. [9] Jones J. H. (1996) Phil. Trans. R. Soc. London, 354A, 1481-1494. [10] Meisel T. et al. (1996) Nature, 383, 517-520. [11] Zhang J. and Herzberg C. (1994) JGR, 99, 17729-17742.

TRACE-ELEMENT SYSTEMATICS IN BASALT STRUCTURE AND EVOLUTION OF THE EARTH'S MANTLE. J. L. Joron, M. Treuil, E. Lewin, and C. J. Allègre, Institut de Physique du Globe, CNRS URA 1758, 4 Place Jussieu, 75252 Paris Cedex 05, France (jljoron@nimitz.saclay.cea.fr).

The analysis of 10,000 oceanic basalt samples and almost 1000 glasses for the trace elements $\mathrm{Sc}, \mathrm{Cr}, \mathrm{Co}, \mathrm{Ni}, \mathrm{Fe}, \mathrm{Rb}, \mathrm{Cs}, \mathrm{Sr}, \mathrm{Ba}, \mathrm{Sb}$, $\mathrm{La}, \mathrm{Ce}, \mathrm{Sm}, \mathrm{Eu}, \mathrm{Tb}, \mathrm{Yb}, \mathrm{Zr}, \mathrm{Hf}, \mathrm{Ta}, \mathrm{Th}, \mathrm{U}, \mathrm{W}, \mathrm{As}, \mathrm{Mo}$, and $\mathrm{Br}$ has made it possible to build an extensive data bank and extract a certain amount of information about fractionation processes in the Earth's mantle.

The study of the histograms element by element separating OIB and MORB is an extension of the work on Schiano et al. [1] and permits us to define for each element a mean standard deviation and skewness. A clear systematics appears linked with the bulk partition solid/magma coefficients of each element. The $(X / Y, X)$ diagrams as developed by Treuil and Joron [2] permit definition of the relative bulk partition coefficients between $X$ and $Y$ in the same spirit as Hofmann did it except that we did it in linear, not log, scale.

Linking the two approaches, we have defined the set of relative bulk partition coefficients for most of the Mendeleiff Table. Those bulk partition coefficients are similar for OIB and MORB except for some trace elements like $\mathrm{Rb}, \mathrm{Cs}, \mathrm{Ba}, \mathrm{U}$, and $\mathrm{Ni}$. The main result is that we do not have any two of the trace elements that have the same partition coefficients. Those like $\mathrm{Hf}-\mathrm{Sm}, \mathrm{Ce}-\mathrm{Pb}$, and $\mathrm{Nb}-\mathrm{U}$, previously proposed are alike but not identical. The differences are masked on logarithmic diagrams but clear on linear ones.
On the other hand, the study of the multispace topology of OIB as done by Allègre et al. [3] confirms the existence of four end members all of them outside the MORB domain St. Helena, Hawai' $i$, Sao Miguel, Kerguelen.

The study of several local-series evolutions shows that for OIB the batch melting modeling with the bulk partition coefficient as a free parameter fits the data.

For MORB a kind of zone-refining modeling should be added.

References: [1] Schiano et al. (1995). [2] Treuil and Joron (1985). [3] Allègre et al. (1985).

\section{ELECTROLYTE EFFECTS ON THE DISSOLUTION KINETICS OF BIOTITE AND PHLOGOPITE AT ROOM} TEMPERATURE. B. E. Kalinowski, Department of Geology and Geochemistry, Stockholm University, S-10691 Stockholm, Sweden (Birgitta.Kalinowski@geo.su.se).

The effect of electrolytes on the kinetics of mineral dissolution is of high interest, since natural weathering in soils takes place in the presence of a number of different electrolytes. It has long been known that low concentrations of certain ions and molecules have significant influence on the rates of dissolution. In laboratory experiments with flow-through reactors phlogopite and biotite dissolve nonstoichiometrically in the $\mathrm{pH}$ range $1-4$ [1]. Interlayer $\mathrm{K}$ and octahedral ions, $\mathrm{Mg}$ and $\mathrm{Fe}$, leach preferentially from both minerals in solutions with high $\mathrm{H}$ activities. The two investigated minerals have about the same chemical composition, but with the difference that the octahedral sheet in phlogopite is mainly built up by $\mathrm{Mg}$, while it is built up by $\mathrm{Fe}^{2+}$ and $\mathrm{Mg}$ in biotite. The high content of $\mathrm{Fe}^{2+}$ makes biotite more sensitive to oxidation, which in turn results in higher $\mathrm{K}$ leaching compared to phlogopite, in order to preserve charge balance. Mössbauer analysis shows that additions of $\mathrm{KCl}$ and $\mathrm{AlCl}_{3}$ with concentrations of $200 \mu \mathrm{M}$ and $1000 \mu \mathrm{M}$, inhibits this process, while $200 \mu \mathrm{M} \mathrm{BaCl}_{2}$ shows little or negligable effect on oxidation. Dissolution experiments show that the slowest leaching rates of all elements are observed, where $1000 \mu \mathrm{M} \mathrm{KCl}$ was added in the influent, while $\mathrm{BaCl}_{2}$ seems to speed up the reaction (Table 1). For biotite, element release ratios do not vary much with addition of salts and are close to stoichiometry in all experiments. However, a preferential release of $\mathrm{Al}$ can be observed in the biotite experiment with the highest concentration of $\mathrm{KCl}$.

TABLE 1.

\begin{tabular}{lcccc}
\hline Mineral & Sample & $\operatorname{logR}\left(\mathrm{molm}^{-2} \mathrm{~s}^{-1}\right)$ & Electrolyte & Conc. $(\mu \mathrm{M})$ \\
\hline Biotite & D31 & -11.75 & - & - \\
& D32 & -11.78 & $\mathrm{KCl}$ & 50 \\
& D33 & -11.94 & $\mathrm{KCl}$ & 200 \\
& D39 & -12.31 & $\mathrm{KCl}$ & 1000 \\
& D40 & -11.85 & $\mathrm{AlCl}$ & 200 \\
& D48 & -12.01 & $\mathrm{AlCl}_{3}$ & 1000 \\
& D41 & -11.64 & $\mathrm{BaCl}_{2}$ & 200 \\
& D28 & -11.96 & - & - \\
& D29 & -12.37 & $\mathrm{KCl}$ & 50 \\
& D30 & -12.62 & $\mathrm{KCl}$ & 200 \\
& D36 & -12.67 & $\mathrm{KCl}$ & 1000 \\
& D37 & -12.06 & $\mathrm{AlCl}_{3}$ & 200 \\
& D51 & -12.10 & $\mathrm{AlCl}_{3}$ & 1000 \\
& D38 & -11.94 & $\mathrm{BaCl}_{2}$ & 200 \\
\hline
\end{tabular}


Preferential release of $\mathrm{K}$ is noted in all phlogopite experiments. In $\mathrm{X}$-ray diffractorgrams after dissolution experiments at $\mathrm{pH} 2$ and 3 , both biotite and phlogopite show $d$ values of $1.4 \mathrm{~nm}$, implying that expansion has taken place and thus some of the interlayer $\mathrm{K}$ have been replaced by hydrated cations [1]. The addition of $\mathrm{KCl}$ and $\mathrm{AlCl}_{3}$ possibly inhibits this reaction, since no expanded phases are found in experiments with elements containing at least $200 \mu \mathrm{M}$ of either $\mathrm{KCl}$ or $\mathrm{AlCl}_{3}$.

References: [1] Kalinowski B. E. and Schweda P. (1996) $G C A, 60,367-385$.

DEPOSITION OF BANDED-IRON FORMATION BY ISOLATION OF CONTINENTAL BASINS. B. S. Kamber', M. Bau ${ }^{2}$, N. J. Beukes ${ }^{3}$, R. K. O'Nions', and R. M. Corfield ${ }^{1}$, 'Department of Earth Science, University of Oxford, Parks Road, Oxford OX1 3PR, UK, 2Department of Geology, Rand Africaans University, Johannesburg 2000, RSA, ${ }^{3} \mathrm{GFZ}$, Potsdam, Telegraphenberg A-50, D-14473 Potsdam, Germany.

Banded-iron formation (BIF) and associated sediments testify to the coexistence of anoxic and oxic water masses. Understanding to what extent such water bodies typified ancient oceans bears many implications for the sources of Precambrian sediments, the atmospheric $O$ level, and the $C$ cycle.

We report a geochemical study of carbonate cements sampling the transition from the shallow 2.58-Ga Campbellrand carbonate platform into the 2.52-Ga Kuruman BIF, Transvaal Supergroup, South Africa.

Microdrilled cements were analyzed for REY (REE and $\mathrm{Y}$ ), $\mathrm{Zr}$, $\mathrm{Hf}, \mathrm{Cs}, \mathrm{U}, \mathrm{Th}, \mathrm{Pb}, \mathrm{Ba}, \mathrm{Rb}$, and $\mathrm{Sr}$ concentration, and $\mathrm{C}, \mathrm{O}$, and $\mathrm{Sr}$ isotope composition. Samples with discemible clastic contamination or postdeposition alteration were omitted.

Shale normalized REY patterns of petrologically defined sample groups are very similar. In order of inferred increasing water depth, oolites display patterns similar to present-day river water, algal mats and precipitated stromatolites have flat patterns with weak positive $\mathrm{Y}$ and negative $\mathrm{Ce}$ anomalies, filamentous strọmatolites show a clear HREE enrichment ( $[\mathrm{Sm} / \mathrm{Yb}] \mathrm{SN}=0.3-0.6)$, strong positive $\mathrm{La}, \mathrm{Eu}\left(\left[\mathrm{Eu} / \mathrm{Eu}^{*}\right] \mathrm{SN}=1.6-1.8\right)$, and $\mathrm{Y}$ anomalies $([\mathrm{Y} / \mathrm{Ho}]$ $\mathrm{SN}=2.8-4.33)$. Iron-carbonates from deeper water chert and BIF show HREE enrichment similar to present-day seawater ([Sm/Yb] $\mathrm{SN}=0.21$ ). They lack the negative $\mathrm{Ce}$ anomaly but show a positive Eu anomaly ( $\left.\left[\mathrm{Eu} / \mathrm{Eu}^{*}\right] \mathrm{SN}=1.52\right)$. The REY data thus suggest the existence of a chemocline separating oxic shallow and anoxic deep water. The picture is, nevertheless, complicated by the fact that the strongest positive Eu anomaly is not found in siderites from BIF but in filamentous stromatolites.

The clearest signal for the hypothetical end member for anoxic bottom water is thus present in shallower carbonate but blurred in the BIF and chert siderites.

Carbon and $O$ isotopes are in accord with previous studies. All samples but the siderites show $\delta^{13} \mathrm{C}$ values between 0 and -2 and $a$ spread in the $\delta^{18} \mathrm{O}$ values between -6 and -12 (relative to PDB). The siderites, however, show mantlelike $\delta^{13} \mathrm{C}$ values of -6 to -9 , which could either reflect primary seawater or siderite growth involving some organic $C$.

Strontium isotope data were obtained on the same aliquots as the REY data. Initial ${ }^{87} \mathrm{Sr} /{ }^{86} \mathrm{Sr}$ ratios are primitive $(0.702-0.704)$ in platform carbonates. In deeper carbonates $S r$ isotopes become highly variable and range between 0.714 and 0.760 in the most radiogenic siderites. This strong increase of continental $\mathrm{Sr}$ cannot be a global seawater feature but indicates substantial restriction of the Kuruman BIF basin. Nevertheless, the $\mathrm{Sr}$ isotopes and positive $(\mathrm{Eu} / \mathrm{Eu} *) \mathrm{SN}$ ratios in the deeper carbonates are too variable to be explained by a simple progressive restriction model. Scatter in these ratios within the stratigraphy rather requires either occasional connection to open marine seawater (one possible source providing water with positive $\left[\mathrm{Eu} / \mathrm{Eu}^{*}\right] \mathrm{SN}$ anomalies and primitive $\mathrm{Sr}$ ) or basin intemal ridge activity.

The implications of this study are (1) Proterozoic carbonate cements are a valuable proxy for ancient seawater, and their REY patterns reflect the depositional environment; (2) Late Archaean $\mathrm{Sr}$ was mantlelike in the ocean. Continental-derived dissolved $\mathrm{Sr}$ was as radiogenic as in present-day rivers; (3) The Kuruman BIFs formed as a result of basin restriction and the chemocline in this euxinic basin was not a global feature. Nevertheless, the basin was occasionally connected to the ocean.

TRACE-ELEMENT THERMOBAROMETRY USING TITANIUM IN GARNET. S. D. Keane ${ }^{1}$, E. J. Essene ${ }^{1}$, and C. E. Manning', 'Department of Geological Sciences, University of Michigan, Ann Arbor MI 48109-1063,USA (skeane@umich.edu; essene@umich.edu), 2Department of Earth and Space Sciences, University of California-Los Angeles, Los Angeles CA 900241567, USA (manning@ucla.edu).

Two reactions that buffer the $\mathrm{Ti}$ concentration in almandine gamet have been investigated for use as thermobarometers in the system $\mathrm{FeO}-\mathrm{Al}_{2} \mathrm{O}_{3}-\mathrm{SiO}_{2}-\mathrm{TiO}_{2}$ (FAST). The two reactions

$$
\mathrm{Fe}_{3} \mathrm{Al}_{2} \mathrm{Si}_{3} \mathrm{O}_{12}+\mathrm{TiO}_{2}=\mathrm{Fe}_{3}(\mathrm{TiAl})\left(\mathrm{Si}_{2} \mathrm{Al}\right) \mathrm{O}_{12}+\mathrm{SiO}_{2}
$$

and

$\mathrm{Fe}_{3} \mathrm{Al}_{2} \mathrm{Si}_{3} \mathrm{O}_{12}+\mathrm{TiO}_{2}+\mathrm{Al}_{2} \mathrm{O}_{3}=\mathrm{Fe}_{3}(\mathrm{TiAl})\left(\mathrm{Si}_{2} \mathrm{Al}\right) \mathrm{O}_{12}+\mathrm{Al}_{2} \mathrm{SiO}_{5}(2)$

limit the amount of Ti substitution in gamet in the presence of rutilequartz and rutile-corundum-kyanite respectively. The STP volume of $\mathrm{Fe}_{3}(\mathrm{TiAl})\left(\mathrm{Si}_{2} \mathrm{Al}\right) \mathrm{O}_{12}$ was estimated to be $125.4 \mathrm{cc} / \mathrm{mol}$ based on unit cell and cation distribution data on schorlomite in combination with cell volumes of other gamet solid solutions. Therefore, $\Delta \mathrm{V}=$ $8.5 \mathrm{cc} / \mathrm{mol}$ for reaction (1) and $\Delta \mathrm{V}=-8.0 \mathrm{cc} / \mathrm{mol}$ for reaction (2), suggesting that (1) proceeds to the left and (2) to the right with increasing pressure. To test these two predictions, we have initiated precise EMP measurements of $\mathrm{Ti}$ concentrations in almandine run products from the piston-cylinder experiments of Bohlen et al. [1], who bracketed the reaction

$$
\mathrm{Fe}_{3} \mathrm{Al}_{2} \mathrm{Si}_{3} \mathrm{O}_{12}+3 \mathrm{TiO}_{2}=\mathrm{Al}_{2} \mathrm{SiO}_{5}+3 \mathrm{FeTiO}_{3}+2 \mathrm{SiO}_{2}
$$

and those of Manning and Bohlen [2], who bracketed the reaction

$$
\mathrm{Fe}_{3} \mathrm{Al}_{2} \mathrm{Si}_{3} \mathrm{O}_{12}+3 \mathrm{TiO}_{2}+2 \mathrm{Al}_{2} \mathrm{O}_{3}=3 \mathrm{Al}_{2} \mathrm{SiO}_{5}+3 \mathrm{FeTiO}_{3}
$$

Run products from reaction (3) have yet to be measured, but results from reaction (4), which simultaneously constrains reaction (2), indicate that, as predicted, the level of $\mathrm{Ti}$ dissolved in garnet increases with pressure resulting in a maximum $\mathrm{Ti}$ concentration of 
$6430 \pm 140 \mathrm{ppm}$ at $20 \mathrm{kbar}$. Isopleths of $\mathrm{Ti}$ in P-T space have been calculated for this system and are slightly steeper than kyanite = sillimanite. Translation of these results to reaction (1) can be accomplished using thermodynamic and experimental data on the reaction quartz + corundum = sillimanite and is currently underway. A provisional calibration of reaction (1) for calcian almandine $\left(A m_{2} \mathrm{Gr}_{1}\right.$ ) has been calculated from the phase equilibrium reversals of Bohlen and Liotta [3] using the reported Ti levels in the garnet run products. Isopleths of Ti in P-T space for this system are markedly steeper than kyanite $=$ sillimanite, and the $T i$ concentration in garnet increases with decreasing pressure and increasing temperature. The results of these calculations indicate that the Ti content in garnet is driven in different directions with $\mathrm{P}$ and $\mathrm{T}$ depending on the buffering assemblage. In addition, contrary to assumptions made in many geochemical studies, it is evident that rutile alone does not necessarily saturate nor even buffer Ti substitution in garnet. Final calibration of reactions (1) and (2) as thermobarometers should have wide applicability in P-T studies due to the common occurrence of the phases involved.

References: [1] Bohlen et al. (1983). [2] Manning and Bohlen, unpublished data. [3] Bohlen and Liotta (1986).

\section{THE IMPORTANCE OF ATMOSPHERIC ADDITIONS IN MAINTAINING ECOSYSTEM NUTRIENT STATUS IN} HAWAI'IAN RAINFORESTS. M. J. Kennedy', O. A. Chadwick $^{2}$,L. A. Derry ${ }^{3}$, and P. Vitousek ${ }^{4},{ }^{1}$ Earth and Space Sciences, University of California-Los Angeles, Los Angeles CA 90095, USA, 'Department of Geography, University of California-Santa Barbara, Santa Barbara CA 93 106, USA, ${ }^{3}$ Department of Geological Sciences, Comell University, Ithaca NY 14853, USA, ${ }^{4}$ Department of Biological Sciences, Stanford University, Stanford CA 94305 , USA.

Strontium-87/strontium-86 isotopic measurements from soils and plants collected within a soil chronosequence in the Hawai'ian Islands reveals a progressive shift from basaltic values in younger

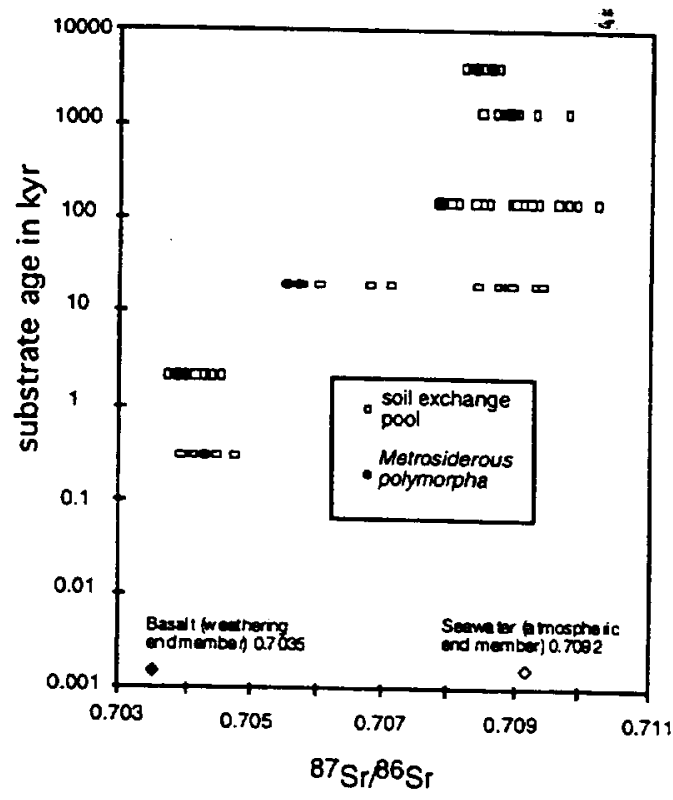

Fig. 1. soils to seawater-like values in older soils, indicating a shift in nutrient supply from weathering sources to atmospheric deposition. The $1 \mathrm{M} \mathrm{NH}_{4} \mathrm{Ac}$ extractable component of soils and leaves from the dominant canopy-forming species (Metrosiderous polymorpha) were analyzed from six study sites on geochemically similar but variously aged basalt flows ranging from $0.2 \mathrm{k} . \mathrm{y}$. to $4100 \mathrm{k}$.y. The sites were selected in order to hold other variables such as slope, temperature (average $15^{\circ} \mathrm{C}$ ), rainfall $(2.5 \mathrm{~m} / \mathrm{a})$, and species composition constant. Soils developed on young basalt flows $(<2.1$ k.y.) show exchangeable ${ }^{87} \mathrm{Sr} /{ }^{86} \mathrm{Sr}$ ratios close to that of the underlying basalt indicating bedrock weathering as the dominant source $(>90 \%)$ of exchangeable $\mathrm{Sr}^{+2}$ (and by proxy $\mathrm{Ca}^{+2}$ ) for these young soils (average ${ }^{87} \mathrm{Sr} /{ }^{86} \mathrm{Sr}=0.7041$ ). At the $20-k . y$. site, approximately $50 \%$ of soil exchangeable $\mathrm{Sr}^{+2}$ is atmospherically derived (average ${ }^{87} \mathrm{Sr}$ ' ${ }^{86} \mathrm{Sr}=0.7076$, a ratio that further increases to $>90 \%$ atmospheric $\mathrm{Sr}^{+2}$ by $150 \mathrm{k.y}$. (average ${ }^{87} \mathrm{Sr} / 86 \mathrm{Sr}=0.7089$ ) and subsequently stabilizes in the 1400 and $4100 \mathrm{k} . \mathrm{y}$. sites (average ${ }^{87} \mathrm{Sr} /{ }^{86} \mathrm{Sr}=$ 0.7089). Metrosiderous polymorpha leaf samples closely reflect soil values $\left({ }^{87} \mathrm{Sr} /{ }^{86} \mathrm{Sr}\right.$ for $2.1 \mathrm{k.y} .=0.7041 ; 20 \mathrm{k} . \mathrm{y} .=0.7056 ; 150 \mathrm{k} . \mathrm{y}$. $=$ $0.7079 ; 1400 \mathrm{k} . \mathrm{y} .=0.7089 ; 4100 \mathrm{k} . \mathrm{y} .=0.7089$ ) also con-firming the relationship between substrate age and base cation source within the plant available pool. We conclude from these results that there is a strong inverse relationship between atmospheric and bedrock sources of exchangeable base cations as a function of substrate age that occurs even in a system with rapidly weathering, base-rich bedrock substrate.

HIGH WATER CONTENTS OF GLASSES AND MELT INCLUSIONS FROM THE LOIHI SEAMOUNT: EVIDENCE FOR ASSIMILATION OF A MODIFIED SEAWATER COMPONENT. A. J. R. Kent ${ }^{\prime}$, M. D. Norman ${ }^{2}$, I. D. Hutcheon ${ }^{3}$, and E. M. Stolper ${ }^{1}$, 'Division of Geological and Planetary Sciences, Mail Stop 170-25, California Institute of Technology, Pasadena CA 91125, USA (adam@expet.gps.caltech.edu), ${ }^{2}$ GEMOC, School of Earth Sciences, Macquarie University, North Ryde NSW 2109, Australia, 'Isotope Sciences Division, Lawrence Livermore National Laboratory, Livermore CA 94551, USA.

Melt inclusions and submarine glasses are frequently analyzed for $\mathrm{H}_{2} \mathrm{O}$ and $\mathrm{CO}_{2}$ contents in an effort to characterize preeruptive volatile contents of magmas. It is usually assumed that volatile contents have been influenced primarily by processes such as crystal fractionation or degassing (and thus, for basaltic magmas, can be used to set limits on the volatile contents of primitive magmas); however, care must be taken to rule out the influence of assimilation of volatile-rich material. This can be an important process: e.g., incorporation of a modified seawater component is thought to have significantly altered the $\mathrm{H}_{2} \mathrm{O}$ and $\mathrm{Cl}$ compositions of some MORB [1]. Here we report a case of preeruptive incorporation of a volatilerich component, probably derived from modified seawater, into Hawai'ian magma.

We have analyzed two samples from Loihi seamount, Hawai'i, using SIMS ( $\mathrm{H}, \mathrm{Li}, \mathrm{Be}, \mathrm{B})$, FTIR $\left(\mathrm{H}_{2} \mathrm{O}, \mathrm{OH}^{-}, \mathrm{CO}_{2}\right)$, and the electron microprobe (major and minor elements, including $\mathrm{Cl}$ and $\mathrm{S}$ ). Both samples consist primarily of glass plus olivine phenocrysts with glass inclusions. Host glasses from both samples have similar major-element compositions with average $\mathrm{MgO}$ and $\mathrm{K}_{2} \mathrm{O}$ contents of 8.90 and $0.55 w t \%$. Melt inclusions have compositions indicating that they represent relatively unevolved melt samples $(\mathrm{MgO}$ con- 


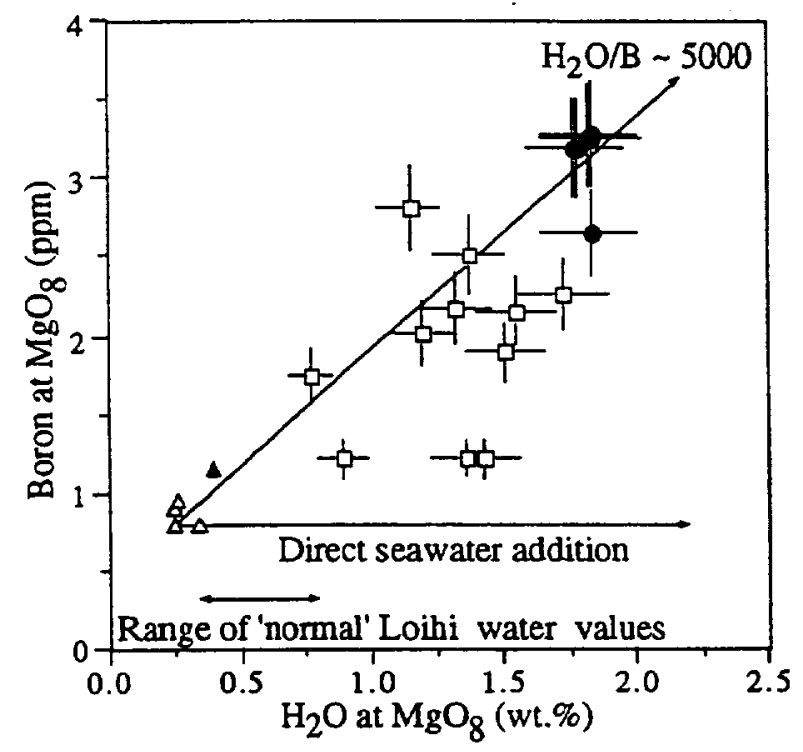

Fig. 1. Boron vs. $\mathrm{H}_{2} \mathrm{O}$ for Loihi samples L0 02-02 and Lo 02-04 (• host glass, melt inclusions). Also shown are samples from the Kileaua East Rift Zone $(\Delta)$ and Loihi ( 4 ) from [2]. Error bars show l $\sigma$ errors.

tents of 9.4-12.6 wt\%). This is also suggested by the forsterite-rich nature of the olivine phenocrysts that host the melt inclusions (Fo 85.9-88.3). Water contents of the host glasses, based on FTIR measurements, are $1.70 \pm 0.21 \%$ and $1.78 \pm 0.12 \mathrm{wt} \%$. Water contents in glass inclusions in olivine phenocrysts, measured by SIMS, are $0.68-1.67 w t \%$.

Water concentrations in host glasses and some melt inclusions are high compared to other samples from Loihi seamount (Fig. 1). Water contents in glasses and melt inclusions also correlate with $\mathrm{Cl}$ and $\mathrm{B}$ (Fig. 1), and $\mathrm{H}_{2} \mathrm{O}, \mathrm{B}$, and $\mathrm{Cl}$ contents of melt inclusions all decrease with increasing forsterite content of the host olivines. However, $\mathrm{H}_{2} \mathrm{O}$ contents do not correlate with the concentrations of elements such as $\mathrm{K}$ and $\mathrm{P}$ that have partition coefficients comparable to that of $\mathrm{H}_{2} \mathrm{O}$ during mantle melting. Furthermore, glass and melt inclusion compositions are not highly alkalic (maximum $\mathrm{K}_{2} \mathrm{O}$ $0.72 w t \%$ ). These observations strongly suggest that the high $\mathrm{H}_{2} \mathrm{O}$, $\mathrm{Cl}$, and $\mathrm{B}$ contents result neither from concentration in residual liquids as a result of crystallization nor from significantly lower degrees of melting.

The elevated $\mathrm{H}_{2} \mathrm{O}$ contents of these samples probably reflect addition of a $\mathrm{H}_{2} \mathrm{O}$ - (and $\mathrm{B}+\mathrm{Cl}$-) bearing component within the magma chamber environments in which the olivine phenocrysts grew and trapped melt inclusions, and from which the melts now quenched to the host glasses were erupted. The $\mathrm{MgO}$-rich nature of the host olivines implies that this occurred during the early stages of magma evolution, but the observed increase in the $\mathrm{H}_{2} \mathrm{O}$ contents of melt inclusions with decreasing Fo content of the enclosing olivine (and the fact that the host glass has the highest water content) suggests that incorporation of this component was not limited to the early stages of the history of the magma chamber. Based on the trend shown in Fig. 1, the $\mathrm{H}_{2} \mathrm{O} / \mathrm{B}$ ratio of the $\mathrm{H}_{2} \mathrm{O}$-rich component is $\sim 5000$, substantially less than that of seawater $(\sim 175,000)$. Hightemperature brines and/or seawater-altered basaltic material from within the volcanic edifice are possible candidates for the assimilated component. Assimilation of seawater or seawater-altered ba- salt has been suggested previously to account for $B$ and $H$ isotope systematics of some Hawai'ian basalts [2,3].

References: [1] Michael P. J. and Schilling J.-G. (1989) GCA, 53, 3131-3143. [2] Chaussidon M. and Jambon A. (1994) EPSL, 121, 277-291. [3] Kyser T. K. and O'Neil J. R. (1984) GCA, 48, 2123-2133.

IDENTIFYING THE NATURE, DEGREE, AND TIMING OF ISOTOPIC EXCHANGE IN A DEVELOPING PYRENEAN THRUST SYSTEM. J. G. Kirby' ${ }^{1}$ and A. M. McCaig' ${ }^{2}$ ' Department of Earth Sciences, University of Leeds, LS2 9JT, UK (jonathan@earth.leeds.ac.uk), 2Department of Earth Sciences, University of Leeds, LS2 9JT, UK (andrew@earth.leeds.ac.uk).

Introduction: Isotopic exchange in a deformational zone is enhanced, if not controlled, by the flow of fluid through that zone. The nature, timing, and degree of exchange depends on the development of structures and fluid pathways during the evolution of the fold-thrust belt, and on the deformation mechanisms that occur.

In a structurally complex zone [1], the potential conduits for isotopic exchange are numerous, and only with the highest density sampling can the true nature of the exchange be quantified. Such data is presented here to attempt to describe the intimacies of the exchange process.

Geological Setting: At the Pic de Port Vieux, Cambro-Ordovician basement is unconformably overlain by Triassic redbeds and Cretaceous carbonates. The Triassic-Cretaceous sequence is repeated by the Pic de Port Vieux Thrust (PPVT), which is overlain by the Gavamie Thrust (GT) sheet containing Silurian slates. A $10-\mathrm{m}$ layer of Cretaceous carbonates is therefore sandwiched between two layers of Triassic redbeds, which are folded and interthrust. This has resulted in the complex isotopic exchange between the lithologies involved.

Results: With knowledge of the isotopic signatures of the local reservoirs, it is possible to formulate fluid exchange pathways and mixing models [3]. The Cretaceous carbonates are considered isotopically unaltered if ${ }^{87} \mathrm{Sr} /{ }^{86} \mathrm{Sr}<0.709$ (Cretaceous seawater is 0.7077 ) and $\delta^{18} \mathrm{O}>25 \%$ (SMOW). The Triassic redbeds however have ${ }^{87} \mathrm{Sr} /{ }^{86} \mathrm{Sr}>0.730$ and $\delta^{18} \mathrm{O}<16 \%$, as does the Silurian [3].

The detailed sampling within the well-constrained structural framework [1] has allowed differing isotopic exchange pathways to be studied. The four sections below show how the variable deformation of the area has resulted in differing degrees of isotopic exchange.

Deformed unconformity. The Triassic-Cretaceous unconformity is heavily folded and a penetrative pressure-solution cleavage has developed. Strontium-87/strontium-86 values range from 0.708 to 0.715 , indicating substantial isotopic exchange between the Triassic and Cretaceous. The high density of analysis points has allowed the precise contouring of exchange, and it can be seen to relate to the intense cleavage. Exchange is substantial up to $0.8 \mathrm{~m}$ from the unconformity, and has probably been further enhanced by diffusion along and across the foliation.

Less-deformed unconformity. The cleavage is less penetrative, and ${ }^{87} \mathrm{Sr} /{ }^{86} \mathrm{Sr}$ and $\delta^{18} \mathrm{O}$ indicate a smaller exchange distance $(<0.3 \mathrm{~m})$ into the Cretaceous. Triassic values indicate that bedding-parallel flow complicates matters as it wipes out any preexisting front that would have occurred and results in a profile of a diffusive side into the Cretaceous carbonates. 
Small displacement thrust. A 20-30-m displacement, unconformity-cutting thrust, is associated with elevated ${ }^{87} \mathrm{Sr} /{ }^{86} \mathrm{Sr}$ of 0.714 and depleted $\delta^{18} \mathrm{O}$ of $22 \%$. The thrust has focused fluid and at least doubled the exchange distance compared to the deformed unconformity. Exchange is also significant parallel to the fault, where it may be enhanced by small-scale fractures, recrystallization and diffusion.

Large displacement thrust (PPVT). The PPVT has a much larger displacement, and a 1-m-wide, "stolen" portion of the GT mylonite zone [1]. Strontium-87/strontium-86 is 0.719 and $\delta^{18} \mathrm{O}$ is $17 \% c$ adjacent to the thrust. The exchange distance is at least an order of magnitude greater than elsewhere in the system, as would be expected when a greater flux has passed through it. The exchange is also kinetically enhanced by dynamic recrystallization in the mylonite zone, as has also been seen in some syndeformational veins [2].

Conclusions: Isotopic exchange in a developing thrust system is shown to be heterogenous, with the degree of exchange varying by up to 2 orders of magnitude between adjacent localities. This variation has been shown to be due to the type and intensity of the deformation.

References: [1] Grant N. T. (1990) J. Struct. Geol., 12, 835850. [2] Kirby J. G. et al. (1997) in press. [3] McCaig A. M. et al. (1995) Am. J. Sci., 295, 309-343.

THE REACTION $\mathrm{MgCr}_{2} \mathrm{O}_{4}+\mathrm{SiO}_{2}=\mathrm{Cr}_{2} \mathrm{O}_{3}+\mathrm{MgSiO}_{3} \mathrm{AND}$ THE FREE ENERGY OF FORMATION OF MAGNESIOCHROMITE $\left(\mathrm{MgCr}_{2} \mathrm{O}_{4}\right)$. S. Klemme and H. St. C. O'Neill, Research School of Earth Sciences, The Australian National University, Canberra ACT 0200, Australia.

$\mathrm{Cr}_{2} \mathrm{O}_{3}$ is the sixth most abundant oxide component in the Earth's upper mantle. At lower and moderate mantle pressures $\mathrm{Cr}_{2} \mathrm{O}_{3}$ is largely contained in spinels, i.e., as the endmember component magnesiochromite $\left(\mathrm{MgCr}_{2} \mathrm{O}_{4}\right)$. The strong partitioning of $\mathrm{Cr}$ into spinel can greatly stabilize this phase relative to garnet or aluminous pyroxenes, and thus influence the trace-element characteristics of partial melts as a function of the pressure of melt segregation in the mantle. Thermodynamic modeling of the phase relations of $\mathrm{Cr}$ in mantle assemblages requires accurate thermodynamic data for $\mathrm{MgCr}_{2} \mathrm{O}_{4}$. These, however, are much less well known than what might be expected for such a key geological substance, which is also a commercially important refractory material. Low-temperature heat capacity measurements for $\mathrm{MgCr}_{2} \mathrm{O}_{4}$ have only been performed down to $52 \mathrm{~K}$ [1], and the entropy at $298 \mathrm{~K}\left(106 \mathrm{~J} \mathrm{~K}^{-1} \mathrm{~mol}^{-1}\right)$ was obtained by empirical extrapolation of these measurements to $0 \mathrm{~K}$ without considering the magnetic or electronic ordering contributions to the entropy. Subsequent magnetic measurements at low temperature reveal that the Neel temperature, at which magnetic ordering of the $\mathrm{Cr}^{3+}$ ions in $\mathrm{MgCr}_{2} \mathrm{O}_{4}$ occurs, is at $\sim 10 \mathrm{~K}$. Hence a substantial contribution to the entropy of $\mathrm{MgCr}_{2} \mathrm{O}_{4}$ has been missed.

In this study we have determined the position of the nearunivariant reaction $\mathrm{MgCr}_{2} \mathrm{O}_{4}+\mathrm{SiO}_{2}=\mathrm{MgSiO}_{3}+\mathrm{Cr}_{2} \mathrm{O}_{3}$ (the reaction is slightly divariant because of the presence of $\mathrm{Cr}^{2+}$ in $\mathrm{MgSiO}_{3}$, but this can be measured and allowed for). The reaction, which has a small positive slope in P-T space, has been bracketed at $100^{\circ} \mathrm{C}$ intervals between $1100^{\circ} \mathrm{C}$ and $1500^{\circ} \mathrm{C}$ by reversal experiments. The reaction is extremely sluggish, and lengthy run times with a $\mathrm{BaO}$ $\mathrm{B}_{2} \mathrm{O}_{3}$ flux are needed to produce tight reversal brackets. At $1100^{\circ} \mathrm{C}$, the reaction occurs between 17 and $19 \mathrm{kbar}$, and between 20 and
$21 \mathrm{kbar}$ at $1500^{\circ} \mathrm{C}$. These results, combined with assessed thermodynamic data for $\mathrm{Cr}_{2} \mathrm{O}_{3}, \mathrm{MgSiO}_{3}$, and $\mathrm{SiO}_{2}$, give the entropy and enthalpy of formation of $\mathrm{MgCr}_{2} \mathrm{O}_{4}$ spinel. As expected, our experimental results are not in good agreement with the presently available thermodynamic data. Due to the magnetic transition at $\sim 10 \mathrm{~K}$, the currently recommended entropy for $\mathrm{MgCr}_{2} \mathrm{O}_{4}$ at $298 \mathrm{~K}$ is too low by $\sim 15 \mathrm{~J} \mathrm{~K}^{-1} \mathrm{~mol}^{-1}$. The magnetic entropy of $\mathrm{MgCr}_{2} \mathrm{O}_{4}$ is consistent with an effective spin quantum number $\left(S^{\prime}\right)$ for $\mathrm{Cr}^{3+}$ of $1 / 2$ rather than the theoretical $3 / 2$, indicating. as in other spinels, spin quenching.

References: [1] Shomate (1944).

\section{STRONTIUM ISOTOPE SYSTEMATICS DURING BASALT -} CRUST INTERACTION. K. M. Knesel and J. P. Davidson, Department of Earth and Space Sciences, University of CalifomiaLos Angeles, Los Angeles CA 90095, USA (knesel@ess.ucla.edu; davidson@ess.ucla.edu).

Despite the growing number of geochemical studies suggesting mantie-derived magmas that traverse the continental crust suffer considerable crustal contamination, little is known concerning the physiochemical nature of crust-magma interactions. Most studies of crustal contamination of magmas result in an "end product" perspective as initial and intermediate stages of crustal melting and assimilation are typically not preserved. We present preliminary results of a study of $\mathrm{Sr}$ isotopic exchange during crust-magma interaction "caught in the act" during progressive partial melting and mechanical assimilation of granodiorite by a Pleistocene basaltic dike in the Tungsten Hills, Sierra Nevada batholith, California. The fluid dynamical structure of the irregular dike-country rock contact consists of three zones: a region of partially molten granodiorite, a hybrid zone of granodiorite partial melt and restite mechanically mixed with basalt, and a region of contaminated basalt containing wisps of granodiorite partial melt aligned parallel to flow textures within the basalt. To constrain contaminant compositions, our initial efforts have focused on the partial melt zone where rapid heating of the low-temperature granodiorite mineral assemblage produced clear to dark brown liquids in a state of $\mathrm{Sr}$ isotopic disequilibrium. We note that the Tungsten Hills anatectic melts are remarkably similar in texture and isotopic composition to clear and brown liquids described elsewhere in the Sierra [1] and those generated during experimental melting of biotite granite [2].

Figure 1 illustrates the $\mathrm{Sr}$ isotopic systematics of progressive melting of a low-temperature multiphase crustal assemblage during high-temperature basalt-crust interaction. Strontium-87/strontium86 ratios of anatectic liquids correlate inversely with Sr concentration, reflecting the relative contributions of biotite (high ${ }^{87} \mathrm{Sr} /{ }^{86} \mathrm{Sr}$, low $\mathrm{Sr}$ content) and feldspars (low ${ }^{87} \mathrm{Sr} /{ }^{86} \mathrm{Sr}$, high $\mathrm{Sr}$ content), which are to a first order controlled by the degree of partial melting and textural composition of the protolith. Lower degrees of melting yield liquids with higher ${ }^{87} \mathrm{Sr} /{ }^{86} \mathrm{Sr}$ ratios and lower $\mathrm{Sr}$ concentrations in comparison with regions of greater melting. As a consequence, clear glasses in zones experiencing lesser extents of melting are more radiogenic than brown glasses from regions of higher degrees of melting (Fig. 1). These composition-melt fraction relations support incongruent crustal melting models such as proposed by Duffield and Ruiz [3] in that the Sr isotopic composition of early crustal melts reflects the initial breakdown of hydrous phases such as biotite leading to high ${ }^{87} \mathrm{Sr} /{ }^{86} \mathrm{Sr}$, low-Sr concentration melts. As 


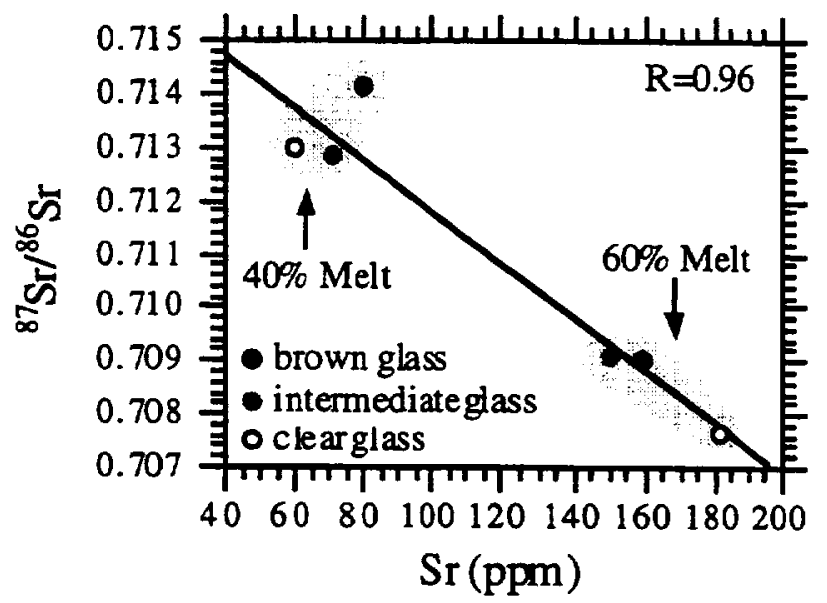

Fig.1. Strontium isotopic composition of natural glasses from partially melted granodiorite. Tungsten Hills. Sierra Nevada batholith, California.

the degree of melting increases with time, anatectic melts become less radiogenic yet are more enriched in elemental $\mathrm{Sr}$ due to depletion of biotite from the residual assemblage and/or increased input from feldspars. Thus, progressive melting of a low-temperature multiphase crustal assemblage during basalt-crust interaction may result in the production of a series of liquids, the isotopic and chemical composition of which changes with time as a function of the thermal evolution of the wall-rock melting zone rather than simply reflecting the bulk composition of the crustal protolith.

References: [1] Tommasini S. and Davies G. R. (1997) EPSL, in review. [2] Knesel K. M. and Davidson J. P. (1996) Geology, 23. 243-246. [3] Duffield W. A. and Ruiz J. (1994) U.S. Geol. Surv. Open-File Rept. 94-423.

CARBONADOS FROM CENTRAL AFRICA AND BRAZIL: ARE THEY RELATED TO IMPACT EVENTS? A GEOCHEMICAL, SPECTROSCOPIC, AND X-RAY STUZY. C.

Koeberl ${ }^{1}$, M. Schrauder ${ }^{1}$, M. A. G. Andreoli ${ }^{2}$, F. Brandstä̆ter ${ }^{3}$, C. Lengauer, and I. Gilmour ${ }^{5}$, 'Institute of Geochemistry, University of Vienna, Althanstrasse 14, A-1090 Vienna, Austria (christian. koeberl@univie.ac.at), 2AEC, P.O. Box 582, Pretoria 0001, South Africa, ${ }^{3}$ Naturhistorisches Museum, P.O. Box 417, A-1014 Vienna, Austria, ${ }^{4}$ Institute of Mineralogy and Crystallography, University of Vienna, Althanstrasse 14, A-1090 Vienna, Austria, 'SPlanetary Sciences Research Institute, Open University, Milton Keynes MK7 6AA, UK.

Carbonado is a grey to black polycrystalline diamond variety that has been found in placer deposits in Central Africa and Brazil. Various hypotheses have been proposed for the origin of this unusual diamond type, including derivation from the Earth's mantle, formation in metamorphic processes related to subduction, meteorite impact, extraterrestrial sources, or irradiation of carbonaceous materials at or near the surface of the Earth. However, detailed studies of carbonados are scarce and their origin remains unknown. In discussing their origin, any scenario needs to be able to explain the formation of individual carbonados with sizes of up to about $600 \mathrm{~g}$. We studied six carbonados from Diamantia (Brazil) and four from Ubangi (Central Africa) by infrared spectroscopy, X-ray diffrac-

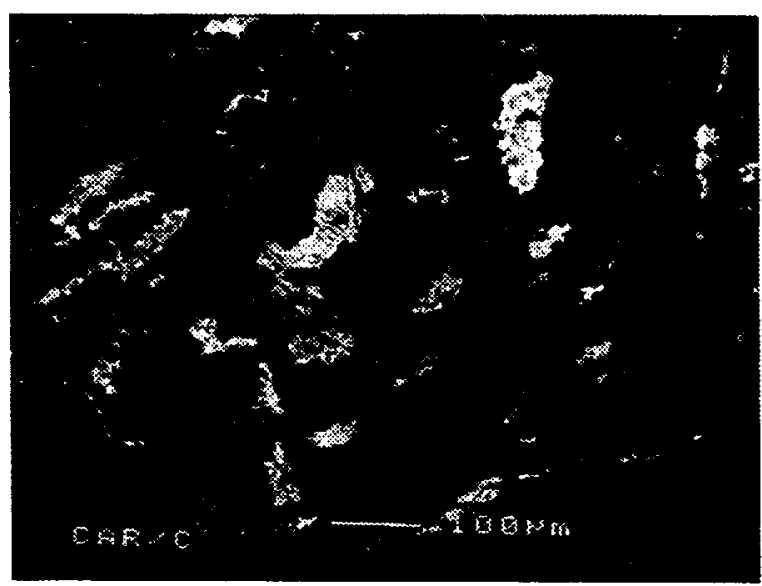

Fig. 1. Backscattered electron image of REE, Al,P-rich inclusions in Central African carbonado CAR/C.

trometry, electron probe microanalysis, electron microscopy, mass spectrometry, and neutron activation analysis. The samples were prepared using a laser sawing technique. Slices $0.1-0.3 \mathrm{~mm}$ thick were cut from the central parts of the carbonado samples. Preliminary $\mathrm{X}$-ray diffraction data (on several square millimeters of the carbonado sections) suggest that all Brazilian diamonds consist of relatively pure diamond without any detectable lonsdaleite component. The occurrence of lonsdaleite, which is often associated with the varieties of impact-derived diamonds that have formed after graphite (e.g., at the Popigai impact structure), would be an indication for an impact origin. The XRD data show the presence of quartz (up to a few $w t \%$ ) and a not-yet-identified sheet silicate. Infrared spec-tra of Brazilian carbonados show all the intrinsic diamond modes and absorption bands that are due to impurities in this porous diamond type. Quartz $\left(\sim 1100 \mathrm{~cm}^{-1}\right)$, sheet silicates $\left(\sim 1100 \mathrm{~cm}^{-1}\right)$, carbonate $\left(1430 \mathrm{~cm}^{-1}\right), \mathrm{H}_{2} \mathrm{O}\left(1640,3420,3700 \mathrm{~cm}^{-1}\right)$, and $\mathrm{CO}_{2}$ $\left(\sim 2350 \mathrm{~cm}^{-1}\right)$ are present in all samples. Water is present probably within the sheet silicate and other inclusions. The $\mathrm{H}_{2} \mathrm{O}$ content of the bulk carbonados reaches a few thousand parts per million. Carbonate is pre-sent in all samples and is identified by an absorption at $1430 \mathrm{~cm}^{-1}$. The ratio between $\mathrm{H}_{2} \mathrm{O}$ and carbonate is variable. Infrared spectra of African diamonds are similar, but the $\mathrm{H}_{2} \mathrm{O}$ and carbonate absorption bands are split into two bands. Electron microscopic (SEM and BSE) studies with mineral analysis by EDX on several carbonados shows the presence of rather unusual inclusions. One sample (shown in Fig. 1) contains irregular inclusions of a REE alumino-phosphate mineral (with La contents varying between about 3.8 and $9 w t \%$, and Ce contents of 5-11 wt\%), probably florencite. Also found were various small metal-rich inclusions (e.g., containing $\mathrm{Ta}, \mathrm{Sn}$, and a $\mathrm{Fe}-\mathrm{Cr}-\mathrm{Ni}$ spinel), rutile, and anhydrite. It is hoped that upon completion of our study some clues regarding the origin of the carbonados will have emerged.

Acknowledgments: Supported by the Austrian FWF, project Y-58-GEO (to CK).

\section{SURFACE CHARGE OF HYDROUS FERRIC OXIDES IN} SEDIMENTS AND AQUIFER SOLIDS. M. Kofod ${ }^{1}, A$. Hadeler', and M. Isenbeck-Schröter' ${ }^{2}$ ' University of Bremen, FB Geowissenschaften, P.O. Box 330 440, D-28334 Bremen, Germany 
(maxkofod@geochemie.uni-bremen.de), ${ }^{2}$ Institute of Environmental Geochemistry, University of Heidelberg. Im Neuenheimer Feld 236, D-69120 Heidelberg, Germany.

In aquifers and sediments, hydrous ferric oxides (HFO) precipitate where the redox milieu changes from reduced to oxidized. This may be the case at the outflow zone of groundwater into surface water or at the boundary between groundwater and oxidized soil horizons. Hydrous ferric oxides are also produced during the oxygenation of reduced raw water in drinking-water plants. Many studies show that the HFO acts as a sink for enviromentally important substances.

Therefore the physicochemical properties of these HFO are studied intensively. These experiments are done mostly with synthetic materials [1]. It is well known that specific sorbing substances modify the surface properties of the HFO [2]. The sorption of multivalent counterions or organic substance can lead to a charge reversal $[3,4]$. In natural geosystems the phosphate is a specific sorbing ion that is always present and has the ability to alter the suface charge [5]. Naturally the precipitation of HFO will occur with the coprecipitation and the specific sorption of phosphate and other diluted substances. The question is to what extent the specific sorbed ions influence the surface properties of the HFO. The surface charge and the isoelectrical point (IEP) of natural HFO should never be the same as synthetic HFO. It is expected that the sorption of phosphate will lower the IEP. Consequently this HFO will not react as an anion exchanger in the range of $5 \mathrm{pH}$ to $8 \mathrm{pH}$.

We collected different materials with a high HFO content (aquifersand with Fe coatings, Fe precipitation from drainage ditches and oxic horizon of gley soils, Fe precipition from water treatment plants). A $<0.63-\mu \mathrm{m}$ fraction was separated and analyzed for $\mathrm{Fe}$ content, $\mathrm{P}, \mathrm{Ca}, \mathrm{Mg}, \mathrm{Mn}, \mathrm{Zn}$, and organic $\mathrm{C}$. The surface area was analyzed by the BET-method. The IEP was calculated from titration data. The surface charge was measured with a particle charge detector (PCD).

As an indicator of the influence of phosphate on the surface properties of the samples we used the Fe:P ratio. The collected samples show a wide range of Fe:P ratios ( $4: 1$ to $35: 1$ ). Iron:phosphorous ratios below 10 are typical for limnic sediments from anthropogenic-influenced surface waters. Jensen et al. [6] give such results for limnic sediments in Denmark. The sediments of German waterways have a Fe:P ratio of about $6: 1$ [7]. In natural materials with no anthropogenic-influence the $F e: P$ ratio is wider. Data from Sposito and Mattegod [8] give Fe:P ratios in soils of $33: 1$, data from Lindsay [9] give a ratio of $35: 1$. The Fe:P ratio of clay sediments is about 38:1 [10].

All samples also have organic $C$ contents of 3-5\% dry weight, but the total surface area of the samples correlates significantly only with the HFO content, so it can be assumed that HFO builds up the important reactive surface.

The pH-dependent surface charge measured with the PCD is negative for all collected samples. The IEP of all samples is below the measuring range $(\mathrm{pH}<3.5)$. The amount of negative charge correlates significantly with the Fe:P ratio and also with the organic $\mathrm{C}$ content. Likely both phosphate and organic $\mathrm{C}$ are lower the IEP and alter the surface charge. Because of the co-correlation between the phosphate and the organic $C$ content it is not possible to distinguish which is influencing the surface charge more.

Despite this problem of interpretation, our conclusion is that the surface properties of HFO built in natural systems differ strongly from synthetic HFO. The natural HFO in aquifer solids and sediments is indeed acting over the relevant range of $\mathrm{pH}$. mainly as a cation exchanger and not as a anion exchanger.

References: [1] Dzombak D. A. and Morel F. M. M. (1990) Surface Complexation Modeling-Hydrous Ferric Oxide, Wiley and Sons, New York. [2] Scheffer F. and Schachtschabel P. (1992) Lehrbuch der Bodenkunde, 13, Aufl., Enke Verlag, Stuttgart, S. 101 ff. [3] Wann S. S. and Uehara G. (1978) Soil Sci. Soc. Am. J., 42, 565-570. [4] Stumm W. and Morgan J. J. (1996) Aquatic Chemistry-Chemical Equilibria and Rates in Natural Waters, Wiley and Sons, New York. [5] Ryden J. C. et al. (1977) J. Soil Sci., 28, 72 92. [6] Jensen H. S. et al. (1992) Hydrobiologia, 235/236, 731-743. [7] Kofod M. (1994) Die Bedeutung frühdiagenetischer Prozesse für die Porenwasserzusammen-setzung in anaeroben Baggerschlämmen, Hamburger Bodenkundliche Arbeiten, Bd. 28. [8] Sposito G. and Mattegod S. V. (1981) Geochem: A Computer Code for the Calculation of Chemical Equilibria in Soil Solutions and Other Natural Water Systems, Keamy Foundation of Soil Sciences, University of California, Riverside. [9] Lindsay W. L. (1979) Chemical Equilibria in Soils, Wiley and Sons, New York. [10] Wedepohl K. H., ed. (1978) Handbook of Geochemistry, Springer-Verlag, Heidelberg.

\section{BACTERIAL CLAY AUTHIGENESIS: IMPLICATIONS} FOR RIVER CHEMISTRY. K. O. Konhauser, Department of Earth Sciences, University of Leeds, Leeds LS2 9JT, UK.

Transmission electron microscopy of freshwater biofilms has shown the common presence of clay minerals associated with individual bacterial cells. In a variety of rivers, all bacterial populations, regardless of physiology, substrate type (i.e., sediment, plants, different rock types), and aqueous composition, consistently formed complex $\mathrm{Fe}, \mathrm{Al}$ silicates with variable composition, and sizes generally $<1 \mu \mathrm{m}$. The formation of these authigenic mineral phases involved a two-step process, whereby dissolved ferric Fe initially reacted with the anionically charged cell wall and extracellular polymers providing a special microenvironment for continued deposition of soluble components. If sufficient molecules of $\mathrm{Si}$ and $\mathrm{Al}$ were also present in solution, then the formation of $\mathrm{Fe}, \mathrm{Al}$ silicates could be expected (via $\mathrm{H}$ bonding between the hydroxyl groups in the bound $\mathrm{Fe}$ with the hydroxyl groups in the dissolved silica and $\mathrm{Al}$ ) given the large surface area of bacterial cell surfaces and a high chemical reactivity of ferrihydrite for additional counter ions. Initially aggregation of these hydrous precursors resulted in the formation of amorphous phases with chemical composition similar to chamosite $\left[\left(\mathrm{Fe}_{5} \mathrm{Al}\right)\left(\mathrm{Si}_{3} \mathrm{Al}\right) 0_{10}(\mathrm{OH})_{8}\right]$. However, because these compounds lacked a regular crystal structure, they were unstable and eventually dehydrated, converting to more crystalline forms that became increasingly siliceous, and more similar in composition to kaolinite $\left[\mathrm{Al}_{4}\left(\mathrm{Si}_{4} \mathrm{O}_{10}\right)(\mathrm{OH})_{4}\right]$.

The ability of freshwater bacterial populations to bind, immobilize, and retain $\mathrm{Fe}, \mathrm{Al}, \mathrm{Si}$, and other trace metals from solution has important implications for their transfer from the hydrosphere to the sediment. In the microenvironment overlying a biofilm, the aqueous chemistry will invariably be determined by the activity of the microorganisms present. Although only the microbe-water interface is involved, when one takes into consideration the large surface area of solid substratum on a river bed that is colonized by biofilms, the volume of water that falls directly under microbial contact is sub- 
stantial. Planktonic bacterial populations are similarly capable of binding metals from solution, and it is not difficult to imagine that these microorganisms could effectively cleanse the water of dilute metals and further partition them into the sediments. Furthermore, all bacterial populations examined similarly precipitated these clay phases, and because rivers typically contain high concentrations of $\mathrm{Fe}, \mathrm{Si}$, and $\mathrm{Al}$ in solution, this form of biomineralization appears to be extremely common and widespread in riverine systems. Through diagenesis, the cellularly bound metals may either be recycled to the overlying water column or become immobilized as stable microdeposits of Fe,Al silicates. From a geological standpoint then, freshwater bacterial populations can be viewed as important agents in metal deposition, low-temperature clay formation, and, invariably, mudstone diagenesis. These processes ultimately contribute to the formation of river bed sediment and may be somewhat analogous to the reverse weathering hypothesis in which major dissolved constituents transported by rivers must be precipitated from the oceans as common mineral phases (i.e., clays) to attain a masselemental balance.

STRUCTURE OF SURFACE SITES PREDICTED FROM CRYSTAL CHEMISTRY: IMPLICATIONS FOR INTERPRETATION OF INFRARED AND X-RAY ABSORPTION FINE-STRUCTURE SPECTROSCOPY DATA. C. M. Koretsky and D. A. Sverjensky, The Morton K. Blaustein Department of Earth and Planetary Sciences, Olin Hall, Johns Hopkins University, Baltimore MD 21218, USA.

The structure of mineral surface sites plays a critical role in both adsorption and dissolution processes. The density of surface sites limits the amount of adsorption that can occur on a given surface, while the structure of surface sites influences their affinities for adsorbates. It has also been shown [e.g., 1] that silicate dissolution rates may depend on the speciation of $\mathrm{H}$, hydroxyl, and electrolyte species over sites on the mineral surface.

The structure of surface sites on a given mineral cleavage or growth face depends on the placement of the cleavage or growth plane with respect to the mineral structure. In this study, the sum of the Brown bond strengths of the bonds broken to generate each possible slice on a given plane was calculated. Planes that minimized the total Brown bond strength of broken bonds, subject to the additional constraint that they have an overall charge of zero or nearly zero, were used to examine the coordination and depth of atoms with respect to the mineral surface (i.e., the highest plane of atoms). Two separate assumptions concerning the formation of surface hydroxyl groups were tested. In the first, it was assumed that coordinatively unsaturated atoms bond to enough hydroxyl or $\mathrm{H}$ atoms to regain their bulk coordination number. In the second, coordinatively unsaturated atoms were assigned a charge equal to the Brown strength of their broken bonds. The charge was assumed to be positive for coordinatively unsaturated cations and negative for coordinatively unsaturated anions. It was further assumed that the coordinatively unsaturated atoms would bond only to enough hydroxyl or $\mathrm{H}$ groups to bring their charge as close to zero as possible.

Infrared spectroscopy is an extremely valuable tool for studying surface hydroxyl groups because it is quite sensitive to the presence of hydroxyl groups. However, most surface infrared spectra are measured on powdered samples. The mophologies of such samples are rarely reported, which complicates interpretation of the spectra based on surface site types predicted for individual mineral surface planes. Nonetheless, periclase, rutile, quartz, goethite, and corundum infrared spectra are all consistent with the surface site types predicted in this study.

In situ measurements of adsorbed metals at the mineral-water interface can be made using X-ray absorption fine-structure (XAFS) spectroscopy. Recently, Bargar et al. [2] used XAFS to study $\mathrm{Pb}^{+2}$ adsorption on conndum $(001)$ and $(1-12)$. Their study provides extremely useful information conceming the number and type of nearest and second-nearest neighbors surounding the adsorbed $\mathrm{Pb}^{+2}$. In addition, their XAFS data yield distances between these neighbors and the adsorbed $\mathrm{Pb}^{+2}$. Interpretation of single-crystal XAFS data such as these may be aided by consideration of surface-site structures predicted from the method described above.

References: [1] Dove and Elston (1992) GCA, 56, 4147. [2] Bargar et al. (1996) GCA, 60, 3541.

\section{USING THE GEOCHEMISTRY OF REGOLITH MATER-} IALS TO DO PLANETARY GEOLOGY. R. L. Korotev, L. A. Haskin, and B. L. Jolliff, Department of Earth and Planetary Sciences, Washington University, St. Louis MO 63130,USA (rlk@ levee.wustl.edu).

On a planet surfaced with regolith, many geologic issues must necessarily be addressed by the study of regolith materials. Some issues are broad in scope: To understand the mode and extent of mantle-crust differentiation we must identify all major igneous rock types and determine their compositions. Other issues are narrower: In a locally complex regolith, the order in which materials were added to the regolith constrains provenance and relative timing of major events. Given only robotic analysis or collection only of material redistributed by impacts, what selection of samples yields the most information? We suggest that the chemical and mineralogical characterization of many fragments $2-5 \mathrm{~mm}$ in diameter, plus a suite of finer regolith materials, can provide much of the needed geologic information.

Lithic Fragments: The diversity of lithologies that we have observed among $\sim 1800$ individual $2-4-\mathrm{mm}$ lithic fragments $(20 \mathrm{mg}$ mean mass) from the Apollo lunar sites [1-4] is as great or greater than that observed in the many studies of larger rocks from those same sites, including breccias and breccia clasts. Although we have not observed among lithic fragments a few of the lithologies that have occurred as (or as clasts in) rock samples, we have found several others that have not been previously described or are very rare (quartz monzodiorite, sodic ferrogabbro, very-low-Ti basalt, new types of melt breccias and regolith breccias, and meteorite fragments). Many lunar lithologies are sufficiently fine grained that 2-5-mm fragments are reasonably representative of larger rocks of the same lithology. However, for lithologies such as coarse-grained mare basalts, $2-5-\mathrm{mm}$ particles may only contain a few mineral grains. Also, large-scale textural relationships, such as that between the anorthositic and the melt-breccia phases of the Apollo 16 dimict breccias [5], may not be evident in the small lithic fragments (although the two component lithologies are abundant). Nevertheless, since sample allocation masses for extraterrestrial materials are necessarily small, the acquisition only of pea-sized "rocks" is not a serious shortcoming. In some cases, information can be obtained from the study of numerous small samples that is not evident from a few large samples. For example, at Apollo 16 small fragments of 
some types of impact-melt breccia are all very uniform in composition (dimict breccia) whereas others (poikilitic) are more variable. We have also been able to show that 148 particles from a regolith sample from North Ray Crater are probably all fragments that derive from a single noritic anorthosite pluton [2].

Bulk Samples of Soils: Over the last 3 g.y. the principal geologic force acting upon the Moon has been meteoroid impacts, thus the regolith is a mechanical mixture of many lithologies. Some geologic information can be obtained from the bulk composition of soils ( $<1-m m$ fines) even without knowledge of the rocks they comprise. For example, the Apollo 17 site was at the interface between the mare and highlands and all soils contain material of both provenances. The ratio of highland to mare material in the soil varies significantly, laterally over hundreds of meters and vertically (cores) over centimeters. Such observations put a first-order constraint on the efficiency of the impact-mixing process. On many twoelement plots, Apollo 17 soils define a linear trend between soils dominated by mare and highlands lithologies [6]. Even without a sample of mare basalt, the average composition of the basalt can be inferred from extrapolation of the trend. Given knowledge of the identity and composition of the soil components from the study of lithic fragments, their relative abundances can be determined [e.g., 6]. On the Cayley plains (Apollo 16) we would learn that mature (not recently disturbed) soil is very uniform in composition from place to place (unlike at Apollo 17), yet the particles that make up the soils are compositionally diverse [4]. This tells us that the mixing occurred on a large scale during a basin-forming impact, not by numerous small impacts.

Strategy: Much information of this type could be obtained from the soil remotely by a geochemical rover [7]. For a sampleacquisition mission to a regolith-covered, airless body, $10 \mathrm{~g}$ of granule-sized samples and $1 \mathrm{~g}$ of $<1-\mathrm{mm}$ fines collected at several locations would provide more geologic information than the equivalent mass of a few rocks.

Acknowledgments: This work was supported by NASA grant NAGW-3343.

References: [1] Jolliff et al. (1991) Proc. LPS, Vol. 21, 193219. [2] Jolliff and Haskin (1995) GCA, 59, 2345-2374. [3] Jolliff et al. (1996) Meteoritics \& Planet. Sci., 31, 116-145. [4] Korotev et al. (1997) LPS XXVIII. [5] James et al. (1984) Proc. LPSC 15th, in JGR, 89, C63-C86. [6] Korotev and Kremser (1992) Proc. LPSC, Vol. 22, 275-301. [7] Korotev et al. (1995)JGR, 100, 14403-14420.

\section{STRONTIUM, OXYGEN, AND CARBON ISOTOPE EVO.} LUTION OF TRIASSIC SEAWATER. C. Korte' and J. Veizer ${ }^{1.2}$, ${ }^{1}$ Institut für Geologie, Ruhr-Universität Bochum, D-44801 Bochum, Germany (Christoph.Korte@rz.ruhr-uni-bochum.de), 2Department of Geology, University of Ottawa, Ottawa, Ontario K1N6N5, Canada (veizer@geol.uottawa.ca).

Introduction: The isotopic composition of Phanerozoic seawater can serve as a proxy signal that reflects the vagaries of exogenic processes during geological past, such as the intensity of volcanism and continental erosion [1] or the build-up of polar ice caps [2]. In addition, the high-resolution seawater isotope curves can be employed for correlation purposes [3]. The precondition to application of these techniques is that the studied isotope signals should reflect faithfully the composition of coeval seawater [4].

Methods: In order to obtain well-preserved $\mathrm{Sr}, \mathrm{O}$, and $\mathrm{C}$ isotope signals, we have concentrated on low-Mg calcitic brachiopod shells and on conodonts with a CAl of less than 1.5 [5]. The reliance on both fossil groups was dictated by the fact that several Triassic intervals, such as the Scythian, do not contain brachiopods, the scarcity being a consequence of faunal depauperization following the P/T mass extinction. In such cases, the gaps, at least for $\mathrm{Sr}$ isotopes, were filled by conodont samples. The latter also possess the additional advantage of high temporal resolution that enables good correlation of distant sedimentary sequences. The present sample population yields $200^{87} \mathrm{Sr} /{ }^{86} \mathrm{Sr}$ and $140 \delta^{18} \mathrm{O}$ and $\delta^{13} \mathrm{C}$ measurements on Triassic brachiopods and conodonts. All these samples were screened for any indication of postdepositional alteration by optical (microscope, cathodoluminescence, SEM) and chemical (ICP/AAS, PIXE) techniques.

Results and Discussion: The ${ }^{87} \mathrm{Sr} /{ }^{86} \mathrm{SI}$ data cover the entire Triassic period, except for a mid-Scythian gap of about $2.5 \mathrm{Ma}$ duration. The apparent temporal resolution of this sample set is thus better than $1 \mathrm{Ma}$. The ${ }^{87} \mathrm{Sr} /{ }^{86} \mathrm{Sr}$ value at the P/T boundary is 0.7073 , followed by a steep rise to 0.7082 throughout the Scythian. A similar radiogenic peak, at 0.7080 , was also detected in the upper Norian. The nonradiogenic peaks, on the other hand, were observed in the lower Carnian (0.7075) and upper Rhetian (0.7076). These Sr isotope oscillations appear to reflect the coeval tectonic and climatic effects [6], such as the enhanced rate of continental weathering during the Scythian resulting from the dispersal of the Pangean supercontinent. The $\delta^{18} \mathrm{O}$ and $\delta^{13} \mathrm{C}$ temporal trends contain two gaps, mid-Scythian to early Anisian and early to mid-Norian, both due to the general scarcity of coeval brachiopods. The $\delta^{18} \mathrm{O}$ values for the Tethyan realm range from -1 to $-3 \%$ PDB, but in the Muschelkalk profiles of Germany they are as light as $-4 \%$. The $\delta^{13} \mathrm{C}$ values for both regions form a band ranging from -1 to $3 \%$. PDB.

References: [1] Holland H. D. (1984) The Chemical Evolution of the Atmosphere and Oceans, Princeton Univ. [2] Shackleton N. J. and Opdyke N. D. (1973) Quarternary Res., 3, 39-55. [3] Williams D. F. et al. (1988) Isotope Chronostratigraphy: Theory and Methods, Academic, New York. [4] Brand U. and Veizer J. (1980) J. Sediment. Petrol., 50, 1219-1236. [5] Veizer J. et al. (1997) Palaeogeog. Palaeoclim. Palaeoecol., in press. [6] Koepnick R. B. et al. (1990) Chem. Geol., 80, 327-349.

\section{COMPOSITION OF EARTH'S CONTINENTAL CRUST AS INFERRED FROM IMPACT MELTS IN THE MAYA BLOCK AND KAAPVAAL CRATON. D. A. Kring, E. Pierazzo, and E. P. Turtle, Lunar and Planetary Laboratory, University of Arizona, 1629 East University Boulevard, Tucson AZ 85721, USA (kring@ lpl.arizona.edu).}

The composition of the continental crust is a critical parameter when testing models of crustal genesis, crustal evolution, crustmantle relationships, and many other global geochemical processes. While several compositions have been proposed, no single set of chemical abundances has yet been widely accepted. Discrepancies occur parly because the lower crust is heterogeneous in ways that are not yet understood and because some proposed compositions are based on assumed models of crustal genesis.

We recently suggested [1] that it may be more straightforward to determine the composition of the continental crust by measuring the compositions of melt sheets in large impact craters, because shock processes can produce homogeneous bulk melts of large volumes of 
crustal material. If the cratering event is sufficiently large, then both upper and lower crust should be involved. For example, in the case of the $\sim 180-\mathrm{km}$-diameter Chicxulub Crater, scaling relationships suggest the crust of the Maya block was melted to a depth approaching 29-34 km [2], which is comparable to the 30-35-km depth of the crust inferred from seismic studies [3].

To further explore this method, we calculated the volume of crust that was melted during the Chicxulub and Vredefort impact events using CSQIII, a two-dimensional hydrocode widely used for simulations of impact events [e.g., 4,5]. In the case of the Chicxulub impact, we assumed a $10-\mathrm{km}$ projectile and an impact velocity of $20 \mathrm{~km} / \mathrm{s}$, which produces a $180-\mathrm{km}$-diameter crater. The target consisted of $100 \mathrm{~m}$ of seawater, a 2.9-km-thick sequence of interlayered carbonate and evaporite, a $30-\mathrm{km}$-thick granitic basement, and an underlying dunitic mantle. In the case of Vredefort, we assumed projectile diameters of $10-14 \mathrm{~km}$ and an impact velocity of $20 \mathrm{~km} / \mathrm{s}$, which produces $\sim 150-260-\mathrm{km}$-diameter craters, consistent with estimates based on the distribution of shock-metamorphic features [6]. The target in the simulation is based on a reconstruction of the Kaapvaal craton $2.0 \mathrm{Ga}$ [7] and consisted of $14 \mathrm{~km}$ of sediments (modeled as quartzite), a $31.5-\mathrm{km}$-thick granitic basement, and an underlying dunitic mantle.

The hydrocode simulations indicate the Chicxulub event produced $\sim 11,600 \mathrm{~km}^{3}$ of melted material throughout the crust to a depth of $26-28 \mathrm{~km}$. The impact melt incorporated roughly equal proportions of upper and lower crustal material, so the composition of the Chicxulub impact melt sheet should be a good proxy for the composition of the continental crust in the Maya block. The simulations indicate the Vredefort event produced $-5850 \mathrm{~km}^{3}$ of melted material throughout the crust to a depth of $24-26 \mathrm{~km}(10-\mathrm{km}$ projectile) or $\sim 20,000 \mathrm{~km}^{3}$ of melt to a depth of $35-39 \mathrm{~km}(14 \mathrm{~km}$ projectile). These depths are not as great as the reconstructed base of the crust in the Kaapvaal craton $(45.5 \mathrm{~km})$, so the Vredefort melt compositions may be biased toward upper crustal compositions.

Analyses of the Chicxulub melt sheet suggest the continental crust represented by the Maya block contains $64.4 \mathrm{wt} \% \mathrm{SiO}_{2}$, $2.7 \mathrm{wt} \% \mathrm{~K}_{2} \mathrm{O}, \mathrm{K} / \mathrm{U} \approx 10,900$, and $\mathrm{Th} / \mathrm{U} \approx 3.5[8,9]$. Analyses of the Vredefort Granophyre suggest the continental crust represented by the Kaapvaal craton contains $66.9 \mathrm{wt} \% \mathrm{SiO}_{2}$ and $2.25 \mathrm{wt} \% \mathrm{~K}_{2} \mathrm{O}$ [10]. In addition, the Sudbury Crater, which was the same size or slightly larger than Chicxulub, has a melt sheet composition with $64.3 \mathrm{wt} \% \mathrm{SiO}_{2}$ and $2.97 \mathrm{wt} \% \mathrm{~K}_{2} \mathrm{O}$ [11]. While these values are more siliceous and potassic than the crustal compositions recently proposed by Rudnick and Fountain [12], the ratios of heat-producing elements are roughly consistent with previously accepted values (e.g., $\mathrm{K} / \mathrm{U} \approx 10,000$ and $\mathrm{Th} / \mathrm{U} \approx 3.8$ [13]). Additional analyses of these impact melts will be needed to fully evaluate their usefulness as proxies for continental crust compositions. In some cases, the effects of postimpact alteration and/or regional metamorphism, which are currently thought to be insignificant, will need to be examined more closely. However, this type of estimated crustal composition may prove to be more robust than previous ones because it does not rely on any assumed model for crustal genesis. Furthermore, by comparing craters of different sizes and different ages, it may be possible to determine the chemical stratification of the crust and determine if it has changed with time.

References: [1] Kring D. A. (1997) LPS XXVIII. [2] Kring D. A. (1995) JGR, 100, 16979-16986. [3] Sawyer D. S. et al. (1991) in The Geology of North America, Vol. J., The Gulf of Mexico Basin, pp. 53-72. [4] Pierazzo E. et al. (1996) LPS XXVII, 1029-1030. [5] Pierazzo et al. (1997) Icarus, in press. [6] Turtle E. P. and Pierazzo E. (1997) LPS XXVIII. [7] Reimold W. U. (1990) personal communication. [8] Sharpton V. L. et al. (1992) Nature, 359, 819821. [9] Schuraytz B. C. et al. (1994) Geology, 22, 868-872. [10] Therriault A. M. et al. (1996) S. Afr. J. Geol., in press. [11] Grieve R. A. F. et al. (1991) JGR, 96, 22753-22764. [12] Rudnick R. L. and Fountain D. M. (1995) Rev. Geophys., 33, 267-309. [13] McLennan S. M. (1997) personal communication.

KINETICS OF XENON RELEASE AND Xe $\mathrm{e}_{\mathrm{s}}-\mathrm{Xe}_{\mathrm{n}}$ AGE-SPECTRUM DATES OF ZIRCONS FROM POLYMETAMORPHIC HIGH-GRADE TERRAINS: A CASE STUDY OF SAMPLES FROM THE RAYNER COMPLEX (EAST ANTARCTICA). D. P. Krylov, Institute of Precambrian Geology and Geochronology, Russian Academy of Sciences, Nab. Makarova 2, 199034 St. Petersburg, Russia (dkrylov@wings.spb.ru).

Kinetics of Xe release was studied in zircon aliquots using step heating, combined with age determinations by the $\mathrm{Xe}_{\mathrm{s}}-\mathrm{Xe}_{\mathrm{n}}$ method [1]. Zircons were separated from granulite-facies acidic rocks representing the Proterozoic high-grade Rayner complex of East Antarctica. Experimentally determined activation energies show a broad variation, mostly within the range $150-170$ to $200-230 \mathrm{kcal} / \mathrm{mol}$. Corresponding closure temperatures $\left(T_{c}\right)$, estimated as a measure of Xe stability using the model of Dodson [2], fall within the temperature intervals of $550^{\circ}-710^{\circ} \mathrm{C}$ and $750^{\circ}-1100^{\circ} \mathrm{C}$.

$\mathrm{Xe}_{\mathrm{s}}-\mathrm{X} \mathrm{e}_{\mathrm{n}}$ plateau ages are found to depend upon the estimated stability: the most stable $\mathrm{Xe}$ [i.e., $\mathrm{T}_{\mathrm{c}}\left(750^{\circ} \mathrm{C}\right)$ ] reflects Grenville events [1025 (31 m.y. on average)], while the least stable [ $T_{c}$ $\left\{700^{\circ} \mathrm{C}\right)$ ] yields Pan African dates [565 (28 m.y.)]. Cationic and $O$ isotope geothermometry yield peak metamorphic temperatures of $720^{\circ}-750^{\circ} \mathrm{C}$ for the rock studied, which fall between the estimated $T_{c}$ intervals for Xe stability in zircon. The experimentally derived kinetics for Xe release, extrapolated to the natural conditions via $T_{c}$ calculations, is thus supported by independent data. The results show, that the Pan African ages in Rayner complex may reflect granulite-facies metamorphism rather than currently postulated retrogression under amphibolite to greenschist facies.

Acknowledgments: This work was supported by RFBR (9305-9043, 96-05-64779) and INTAS (94-2037).

References: [1] Shukolyukov Yu. A. et al. (1974) EPSL, 24, 271-281. [2] Dodson M. H. (1973) Contrib. Mineral. Petrol., 40, 259-274.

AGE AND GENESIS OF VOSTOK-2 SCHEELITE DEPOSIT (RUSSIA) AS A RESULT OF CRUST-MANTLE INTERACTION (SAMARIUM-NEODYMIUM AND RUBIDIUMSTRONTIUM ISOTOPE DATA). R. Sh. Krymsky', B. V. Belyatsky', and M. G. Rub', 'Institute of Precambrian Geology and Geochronology, Russian Academy of Sciences, Makarova Emb. 2, 199034 St. Petersburg, Russia (robert@mail.nevalink.ru; boris@ ger.ras.spb.ru), ${ }^{2}$ IGEM, Russian Academy of Sciences, Staromonetny Per. 35, 109017 Moscow, Russia (sharkov@igem.msk.su).

One of the most important goals of ore geology is to clear up the nature of the connection between granite formation and ore miner- 
alization. Based on our current isotopic investigations of $\mathrm{Sn}-\mathrm{W}$ deposits of Far East (Russia), there was discovered for some of them the existence of the time interval (20-30 Ma) between the intrusion of granite massifs and ore formation, which excludes a direct connection between these processes. However, the fact that ore minerals and granitoids have close values of $\varepsilon_{\mathrm{Nd}}$ and $\mathrm{I}_{\mathrm{Sr}}$ suggests the same source for their formations. Such a source is formed due to the intrusion of fluids of mantle origin into the crust. The share of the mantle substance and degree of homogeneity of the source depend on local geological conditions. Neodymium-strontium isotope systematics of Vostok-2 ore deposit are shown as an example of this mantle-crust interaction.

This deposit is situated in the western part of the Main Synclinorium of Sikhote-Alin (Primorie, Russia). Scheelite scam-greisen ore deposit Vostok-2 attends to granodiorite stock that cuts a sandstone-carbonate layer of Permian age. At this ore deposit the following stages are distinguishable: scamation, greisenization, and formation of scheelite-quartz veins, sulfide, and quartz-carbonatic veins. The large granomonzonite Dalnensky massif $\left(80 \mathrm{~km}^{2}\right)$ crops out to the south of the deposit. Its age is $103 \mathrm{Ma}$ according to $\mathrm{Rb}-\mathrm{Sr}$ isotopic data.

The age of granodiorite stock is $100 \pm 1 \mathrm{Ma}\left(\mathrm{I}_{\mathrm{Sr}_{\mathrm{r}}}<0.7067\right)$ and $\varepsilon_{\mathrm{Nd}}$ of granodiorite varies from -3.1 to -5.0 showing a different degree of contamination of magmatic melt by host rocks-sandstones $\left(\varepsilon_{\mathrm{Nd}}=-14.5\right)$ and limestones $\left(\varepsilon_{\mathrm{Nd}}=-6.0\right)$. In model calculations of granodiorite formation due to the process of mantle mixing $\left(\varepsilon_{\mathrm{Nd}}=+10 ; \mathrm{I}_{\mathrm{Sr}}=0.7025\right)$ and crustal material $\left(\varepsilon_{\mathrm{Nd}}=-14.5 ; \mathrm{I}_{\mathrm{Sr}}=\right.$ $0.7124)$ the proportion of these sources has to be 1:1. The age of greisen and ore deposit formation coincides within the error limits and corresponds to $101 \pm 1 \mathrm{Ma}(\mathrm{Rb}-\mathrm{Sr})$. According to $\mathrm{Nd}$ and $\mathrm{Sr}$ isotope data $\left(\varepsilon_{\mathrm{Nd}}=-3.5\right.$ to $\left.-4.5 ; \mathrm{I}_{\mathrm{Sr}}=0.708\right)$ greisens and ores of Vostok-2 originated from fluid component of the same magmatic source as the stock granitoids. The share of material from this source within ore fluid was $85 \%$. Thus the formation of $\mathrm{W}$ mineralization (scheelite) at Vostok-2 took place at late stages of granite stock formation with active participation of fluids that had reworked the rocks of granite stock and host sand-limestone rocks as well extracting from the first ones, $\mathrm{W}(\mathrm{Nd})$ and from the second, $\mathrm{Ca}(\mathrm{Sr})$.

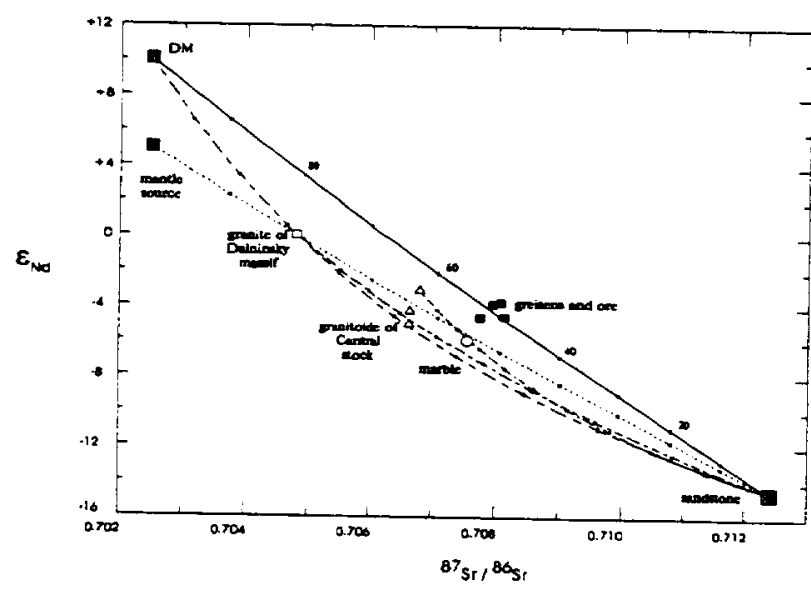

Fig. 1. Diagram of ${ }^{87} \mathrm{Sr}^{86} \mathrm{Sr}-\varepsilon_{\mathrm{Nd}}(100 \mathrm{Ma})$ for the host rocks and gangue minerals from the Vostok-2 ore deposit.

\section{DIFFERENCES IN GEOCHEMICAL FEATURES BETWEEN PERMIAN AND TRIASSIC CHERTS FROM THE SOUTH- ERN CHICHIBU TERRANE, SOUTHWEST JAPAN: RARE-EARTH-ELEMENT ABUNDANCES, MAJOR-ELE- MENT COMPOSITIONS, AND STRONTIUM ISOTOPE RATIOS. T. Kunimaru ${ }^{1.3}$, H. Shimizu ${ }^{1.2}$, K. Takahashi ${ }^{3}$, and $S$. Yabuki $^{3}$, 'Department of Environmental Science, Graduate School of Science and Technology, Kumamoto University, Kumamoto 860 . Japan, ${ }^{2}$ Department of Earth Sciences, Faculty of Science, Kumamoto University, Kumamoto 860, Japan, ${ }^{3}$ The Institute of Physical and Chemical Research, Saitama 351-01, Japan.}

Rare-earth-element abundances, $\mathrm{Sr}$ isotope data, and majorelement compositions were reported for the Permian and Triassic cherts from Kuma and Saiki areas in the Southern Chichibu (Sambosan) terrain, the Outer Zone of Southwest Japan, in order to elucidate the nature of sources, depositional environment, and their change from Permian to Triassic.

A higher contribution of detrital components for the Triassic Sambosan cherts than for the Permian Sambosan cherts is suggested by the degree of $\mathrm{Ce}$ anomaly $\mathrm{REE}$ pattem, $\mathrm{MnO} / \mathrm{TiO}_{2}$ ratio, and initial ${ }^{87} \mathrm{Sr} /{ }^{86} \mathrm{Sr}$ ratio of these cherts. Small negative $\mathrm{Ce}$ anomalies $\left(\mathrm{Ce} / \mathrm{Ce}^{*}=0.750 .95\right)$ are observed for the Permian cherts from both Kuma and Saiki areas, in contrast to small positive $\mathrm{Ce}$ anomalies $\left(\mathrm{Ce} / \mathrm{Ce}^{*}=1.1-1.3\right)$ for the Triassic cherts from both areas. It should be noted that the Sambosan cherts show neither large negative $\mathrm{Ce}$ anomalies $\left(\mathrm{Ce} / \mathrm{Ce}^{*}=0.2-0.5\right)$ observed for deep-sea cherts nor large variation in $\mathrm{Ce}$ anomalies $(\mathrm{Ce} / \mathrm{Ce} *=0.3-1.5$ ) observed for cherts from the Franciscan terrain, Califomia. $\mathrm{MnO} / \mathrm{TiO}_{2}$ ratios are larger than 0.5 for the most of the Permian Kuma cherts and the early Permian Saiki cherts, while the ratios are smaller than 0.5 for the Triassic Kuma cherts and late Permian and Triassic cherts from the Saiki area. Initial ${ }^{87} \mathrm{Sr} /{ }^{86} \mathrm{Sr}$ ratios for the Permian Saiki cherts are 0.706-0.707 and are slightly lower than those for the Triassic Kuma cherts (0.707-0.709). These ${ }^{87} \mathrm{Sr} /{ }^{86} \mathrm{Sr}$ ratios for the Permian and Triassic Sambosan cherts are close to the coeval marine ${ }^{87} \mathrm{Sr} /{ }^{86} \mathrm{Sr}$ ratios [1] and are clearly lower than that for cherts from the Mino terrain (0.713), Inner Zone of Southwest Japan [2].

Our geochemical and isotopic data of the Sambosan cherts suggest the change of depositional environments from more or less ocean-basin floor feature at Permian to a less pelagic one at Triassic, although geochemical features showing deposition at typical deepocean floor are not observed even for the Permian cherts. The following depositional environments are suggested: (1) The late Permian Kuma cherts and the early Permian Saiki cherts were deposited between continental margin and ocean-basin floor or deposited at the location ranging from continental margin to oceanbasin floor. (2) The Triassic cherts from the Kuma and Saiki areas and the middle and late Permian Saiki cherts were deposited at marginal sea or continental shelf and slope. (3) The Permian and Triassic Sambosan cherts were deposited at more open-ocean environment than the Triassic cherts in the Mino terrain.

References: [1] Burke et al. (1982). [2] Shibata and Mizutani (1982).

MANTLE XENOLOGY: CONSTRAINTS ON THE DEGASSING HISTORY OF THE EARTH. J. Kunz', M. Moreira', Th. Staudacher ${ }^{2}$, and C. J. Allègre', 'IPGP, Laboratoire de Géochimie 
et Cosmochimie, 4 place Jussieu, 75252 Paris, Cedex 05, France (kunz@ipgp.jussieu.fr), 2IPGP, Observatoire Volcanologique du Piton de la Foumaise, 14 RN3, le 27 km, 97418 La plaine de Caffres, La Réunion, France.

During the last few years we have improved the analytical precision of our noble gas mass spectrometer ARESIBO I by the implantation of a new single-ion-counting facility for detection. The suppression of the background noise, especially, ameliorates our results on noble gas isotopy. In the beginning we intended to use the single-ion counting only for the intensities of the Xe isotopes. By decreasing the deadtime of the counting electronics we were able to extend the measurable range and we now profit by the high accuracy for all noble gases. However, at the center of interest of this study are the Xe isotopes. Our technical improvement enables us for the first time to address to an open question in terrestrial xenology: Is there a contribution of now extinct ${ }^{244} \mathrm{Pu}$ to the fission Xe budget of the upper mantle?

We have selected previously analyzed MORB glasses with high $\mathrm{Xe}$ anomalies for precise remeasurement and find excesses in ${ }^{129} \mathrm{Xe}$ as high as ${ }^{129} \mathrm{Xe} /{ }^{130} \mathrm{Xe}=7.5$ that are closely correlated with ex-

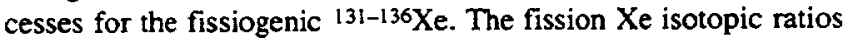
fall between the production ratios of ${ }^{244} \mathrm{Pu}$ and ${ }^{238} \mathrm{U}$. There is no hint for any other source of fission Xe, like, e.g., n-induced fission of ${ }^{235} \mathrm{U}$, as suggested by [1]. So we also have no reason to assume any other source for the ${ }^{129} \mathrm{Xe}$ excesses than the decay of primordial, now extinct ${ }^{129}$. Our new database is now sufficiently large (and precise) to quantify the contribution of ${ }^{244} \mathrm{Pu}$ to the fissiogenic Xe. We use the ratios of radiogenic and fissiogenic $\mathrm{Xe}$ isotopes as one cornerstone for degassing models of the Earth. The other important one is the correction for atmospheric contamination of noble gases trapped in MORB glasses by an extended study of all noble gases in the socalled "popping rock" 2ПD43 from the north Atlantic ridge [2]. This study restricts quite reliably the true upper mantle Xe excesses (e.g., ${ }^{129} \mathrm{Xe}^{/ 130} \mathrm{Xe} \leq 8.2$ ).

Our degassing models is quite similar to the suggestion by [3] for explaining the evolution of the ${ }^{40} \mathrm{Ar} /{ }^{36} \mathrm{Ar}$ ratio of the atmosphere and the mantle that was reapplied by [4] for all noble gases. It treats the atmosphere and the mantle as a coupled system. In contrast to previous work our new approach to this model by I-Xe, Pu-Xe, and U-Xe systematics, together with our experimental comerstones, is rather independent of initial concentrations and chemical ratios that are difficult to constrain. The only remaining problem is the question which initial $\mathrm{Xe}$ isotopy should be used. However, our calculations demonstrate that the degassing took place in (at least) two different stages: a quite rapid release at the beginning (timescale of a few million years) followed by a more extended degassing afterwards (timescale of at least several hundreds of million years). One may speculate that the transition of the fast to the slow degassing regime indicates the breakdown of whole-mantle convection into the separated convections of the upper and the lower mantle, further degassing only the upper mantle.

References: [1] Meshik et al. (1996) 1996 Goldschmidt Conference, J. Conf. Abs., 1, 400. [2] Moreira et al., this volume. [3] Sarda et al. (1985) EPSL, 72, 357. [4] Allègre et al. (1986/1987) EPSL, 81, 127.

GERMANIUM/SILICON FRACTIONATION DURING WEATHERING OF HAWAI'IAN BASALTS. A. C. Kurtz',
L. A. Derry', O. A. Chadwick ${ }^{2}$, and M. J. Alfano ${ }^{3},{ }^{1}$ Department of Geological Sciences, Cornell University, Ithaca NY 14853, USA (kurtz@geology.cornell.edu),2Department of Geography, University of California-Santa Barbara, Santa Barbara CA 93106, USA, ${ }^{3}$ Department of Geology, Hartwick College, Oneonta NY 13820, USA.

Introduction: Germanium is a trace element with chemical behavior similar to that of Si. Germanium may be used as a tracer of the global cycle of $\mathrm{Si}$, provided that the processes that fractionate $\mathrm{Ge} / \mathrm{Si}$ are sufficiently understood. Mortlock and Froelich [1] observed that $\mathrm{Ge} / \mathrm{Si}$ ratios in streamwaters are generally lower than those in the rocks they drain, requiring that some mechanism is capable of sequestering $\mathrm{Ge}$ within the watershed. We have begun to investigate Ge behavior in a series of Hawai' ian soils in an effort to understand the mechanisms responsible for fractionating $\mathrm{Ge} / \mathrm{Si}$. This is an important step toward making Ge a viable tracer of silicate weathering.

Hawai'i Long Substrate Age Gradient: Our study takes advantage of an established soil chronosequence on the Hawai'ian Islands, developed on basalt substrates ranging in age from $0.3 \mathrm{ka}$ to 4.1 Ma. All sites are located near $1200-\mathrm{m}$ elevation, receive approximately $250 \mathrm{~cm} / \mathrm{yr}$ rainfall, and are dominated by the same tree species. Degree of soil development differs substantially across the age gradient. Soils developed on the youngest sites $(0.3$ and $2.1 \mathrm{ka}$ ) have lost very little $\mathrm{Si}$, while soils greater than $20 \mathrm{ka}$ have lost as much as $95 \%$ of their original Si. Secondary mineralogy of intermediate-aged soils is dominated by noncrystalline aluminosilicate "gels." Halloysite becomes an increasingly important secondary mineral as weathering proceeds. Smectite and other 2: 1 clays are not present.

Germanium/Silicon Fractionation: Whole-soil Ge was determined by a hydride-generation isotope-dilution ICP-MS technique similar to that of Mortlock and Froelich [2]. Unweathered Hawai'ian basalts have fairly uniform Ge/Si averaging $2.40 \times$ $10^{-6}$ molar ratio in tholeiites and $2.56 \times 10^{-6}$ in alkali basalts [3]. Soils developed on these rocks become increasingly fractionated in $\mathrm{Ge} / \mathrm{Si}$ as weathering proceeds (Fig. 1). Soils developed on young

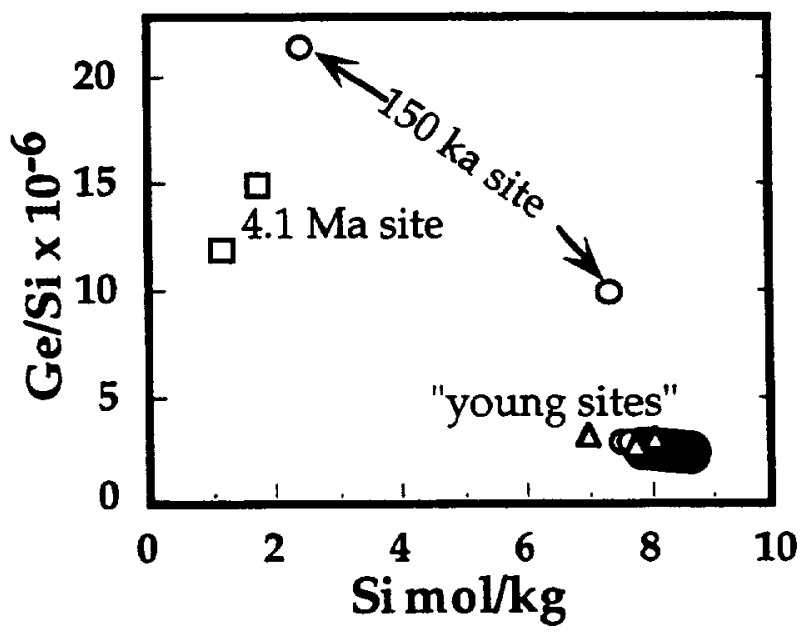

Fig. 1. Plot showing Ge/Si fractionation as weathering and silicaloss develop. Black field represents unweathered Hawai' ian basalts. 
parent material $(0.3 \mathrm{k} . \mathrm{y}$. and $2.1 \mathrm{k.y}$.) have Ge/Si only marginally enriched $\left(2.9 \times 10^{-6}\right)$ over unweathered Hawai'ian basalts. Soils developed on older ( 150 k.y. and 4100 k.y.), more deeply weathered parent material have highly fractionated $\mathrm{Ge} / \mathrm{Si}$, ranging from $10 \times$ $10^{-6}$ to $21 \times 10^{-6}$. Soils from the 150 -ka site are more enriched in Ge than the other samples, and fall above the fractionation trend defined by the other sites. This site is unusual in that it is the only site developed on late-stage alkalic rather than tholeiitic basalt, and is also characterized by a large proportion of continental dust, as indicated by the presence of quartz and mica and by "continental" REE pattems.

Ongoing Work: These initial data confirm the role of pedogenic processes in fractionating $\mathrm{Ge} / \mathrm{Si}$. Further work will be aimed at understanding and quantifying the mechanisms that fractionate $\mathrm{Ge} / \mathrm{Si}$ through selective soil dissolutions and through work in other types of weathering regimes. Improved understanding of the $\mathrm{Ge} / \mathrm{Si}$ system will be useful as a tracer of silicate weathering in modern environments, and will improve interpretations of opaline silicate $\mathrm{Ge} / \mathrm{Si}$ records in terms of past changes in continental weathering.

References: [1] Mortlock R. A. and Froelich P. N. (1987) GCA, 51, 2075-2082. [2] Mortlock R. A. and Froelich P. N. (1996) Anal. Chem. Acta, 332, 5638-5645. [3] DeArgollo R. and Schilling J.-G. (1978) GCA, 42, 623-630.

RADIOCARBON DATING OF CLIMATIC AND CULTURAL CHANGES ON THE RUSSIAN FAR EAST DURING THE LATE GLACIAL AND HOLOCENE. Y. V. Kuzmin ${ }^{1}$, G. S. Burr $^{2}$, J. M. O'Malley', and A. J. T. Jull'2, 'Pacific Institute of Geography, Radio Street 7, Vladivostok 690041, Russia, 2NSFArizona AMS Facility, PAS Building, University of Arizona, Tucson AZ 85721-0081, USA.

The complex geoarchaeological research of both Late Paleolithic and Neolithic sites in the southern Russian Far East are discussed. Results from the Primorye, Maritime Province, and Amur River basin allow us to establish chronocultural boundaries within the last $15,000{ }^{14} \mathrm{C}$ yr. In the Late Glacial, birch-hazel forests indicate a comparatively warm climate at the Paleolithic site Suvorovo 4 in central Primorye (15,100 BP: AA-9463). On the Malyie Kuruktachi Paleolithic site of the Amur River basin, a transition to a relatively warmer climate, from forest tundra to larch forests with an admixture of broadleaved species, was dated between 14,200 and 11,700 BP (average date $12,700 \mathrm{BP}$ [1]). This site probably corresponds to the Kokorevo interstadial, which occurred between 13,000 and $12,200 \mathrm{BP}$. In the same area, the first evidence for the manufacture of pottery demonstrates the presence of a Neolithic culture between 13,260 and 10,340 BP. The coexistence of these two distinct cultural traditions in the Late Glacial and Early Holocene extends beyond the Russian Far East and is a characteristic of the whole of East Asia. Evidence for their coexistence during the Paleolithic/ Neolithic transition (ca. 14,000-8000 BP) is found in China, Japan, and the Transbaikal, as well as the Russian Far East.

The early phase of the Holocene Climatic Optimum, with birchalder forests and an admixture of broadleaved species, was dated at the Almazinka site, northem Primorye, between 7540 and 7410 BP. The warmest phase identified, with broadleaved forests, was dated at the Boisman 2 site, southem Primorye, at $6355 \pm 60 \mathrm{BP}$ (AA9461). The sea level at this time on the Peter the Great Gulf coast, Sea of Japan, probably did not rise more than $1.5 \mathrm{~m}$ above the present level. A definite change in climate began to occur by about 5300 BP $(5275 \pm 50[1])$. The climate in southern Primorye was cooler and dryer than today at around $3800 \mathrm{BP}(3710 \pm 40$ : OS-2341; $3840 \pm$ 70: AA-13400; [2]). The presence of pollen from cultivated cereals (Cerealia) in Late Neolithic cultural layers from 4150 to $3710 \mathrm{BP}$ shows the simultaneous character of both natural and cultural changes on the Atlantic/Subboreal transition.

Acknowledgments: This study was partly supported by grants from the US-NSF (\#EAR 9508413) and Russia-RFFI (\#96-0680688).

References: [1] Jull A. J. T. et al. (1997) in Traditional Culture of East Asia, Teacher Training College, Blagoveschensk, in Russian. [2] Kuzmin Y. V. et al. (1997 in Review of Siberian Anthropology: 1994-1996. Institute of Archaeology and Ethnography, Novosibirsk in Russian.

\section{PROXY RECORDS OF LONG-LIVED COSMOGENIC NUCLIDES: IMPLICATIONS FOR TEMPORAL VARIA. TIONS IN COSMIC-RAY FLUX AND CLIMATE. D. Lal, Scripps Institution of Oceanography, Geosciences Research Divi- sion, Mail Code 0220, La Jolla CA 92093-0220, USA.}

A large database now exists on the proxy records of atmospheric concentrations of several long-lived cosmogenic radionuclides, ${ }^{14} \mathrm{C}$ ${ }^{36} \mathrm{Cl}$, and ${ }^{10} \mathrm{Be}$, which can be related to their concentrations in the atmosphere where they are initially produced. We discuss the available data and show that in several cases, an unambiguous interpretation is severely hampered because of lack of adequate information on the climatic variability in large-scale atmospheric and oceanic circulation. The availability of several nuclides apparently makes the task easier, but we show that, at present, the atmospheric scavenging processes in the case of ${ }^{10} \mathrm{Be}$ and ${ }^{36} \mathrm{Cl}$, and exchange between the $\mathrm{C}$-cycle reservoirs in the case of ${ }^{14} \mathrm{C}$, introduce significant uncertainties in estimation of their removal from the atmosphere. Plausible mixing models show that changes in solar activity produce changes in the proxy records of the nuclides in the same direction that would be expected because of the corresponding solar-activity-induced climatic changes. It is therefore generally not possible to reach definitive conclusions about the relative roles played by solar-activity-induced changes in cosmic-ray flux incident on the Earth and climatic forcing in the atmosphere-ocean coupled system. Examples of slow and fast changes in the proxy record are exemplified.

LEAD, STRONTIUM, AND NEODYMIUM ISOTOPIC VARIATIONS ALONG THE NEW HEBRIDES ARC: EVIDENCE FOR MANTLE SOURCE MIXING AND CRUST CONTAMINATION RELATED TO THE COLLISION OF D'ENTRECASTEAUX RIDGE. C. Laporte ${ }^{1.2}$ and L. Briqueu ${ }^{2}$, 'Laboratoire de Géosciences, Université Française du Pacifique, BP 4477, Nouméa, France (laporte@ufp.nc or laporte@dstu.univmontp2.fr), 2Laboratoire de Géochimie Isotopique, URA $1371 \mathrm{du}$ CNRS, Département des Sciences de la Terre, Case Courrier 66, 
Université Montpellier II, Place Eugene Bataillon, 34095 Montpellier Cedex 05 France (briqueu@dstu.univ-montp2.fr).

A suite of volcanic rocks selected from the New Hebrides Volcanic Arc (NHVA, Vanuatu, South Pacific) have been analyzed for $\mathrm{Sr}, \mathrm{Nd}$, and $\mathrm{Pb}$ isotopes to investigate the variations in space of the geochemistry of volcanic rocks. The NHVA displays unusual features with respect to other West Pacific arcs: (1) subduction is eastdirected, and (2) a major submarine ridge, the D'Entrecasteaux Zone (DEZ), collides almost perpendicular with the central part of the arc. Pleistocene to recent volcanic rocks sampled in the collision region display ${ }^{87} \mathrm{Sr} /{ }^{86} \mathrm{Sr},{ }^{206} \mathrm{~Pb} /{ }^{204} \mathrm{~Pb}$, and ${ }^{143} \mathrm{Nd} /{ }^{144} \mathrm{Nd}$ ratios that significantly differ from lavas erupted away from this zone, and also differ from other southwest Pacific intra-oceanic arcs. Noncollisionrelated magmas have been generated from normal, depleted, suboceanic upper mantle; in contrast, the magmatism in the central part of the arc shows influences of a more enriched mantle. The variations of $\mathrm{Sr}, \mathrm{Pb}$, and $\mathrm{Nd}$ isotopic compositions of volcanic rocks from both arc volcanos and the intra-arc North Aoba basin (from 832 and 833 ODP 134 holes) illustrate how the collision of DEZ has affected the geochemical and isotopic signatures in the central part of the arc in a complex way. Lead isotopic compositions reveal that source contamination does not result from direct mixing between the DEZ crust and a MORB-type mantle. Lavas with abnormal major- and trace-element concentrations due to magma contamination are located in a narrow zone centered on DEZ; in contrast, decreasingly enriched isotopic compositions related to mantle source mixing are located in a wider area centered on the same point. This and an appraisal of the geophysical features of the NHVA support the hypothesis of (1) a contamination of normal upper mantle source by an abnormal (enriched) mantle diapir indirectly triggered by the collision, and (2) a direct magma contamination by the partial melting of a Paleocene or older crust driven by the DEZ.

COUPLED PLAGIOCLASE EXCHANGE REACTIONS IN A NATURAL HYDROTHERMAL SYSTEM. P. B. Larson, Department of Geology, Washington State University, P.O. Box 642812, Pullman WA 99164-2812, USA (plarson@wsu.edu).

Stable isotope, electron microprobe, and X-ray diffraction studies of plagioclase reaction products in the Rico hydrothermal system, Colorado, show that every ion in the plagioclase structure can exchange or move during alteration. However, the mineral structures are preserved during this ion exchange. Surficial dissolutionreprecipitation (D-R) does not appear to provide a reasonable reaction mechanism. At Rico, a young ( $<5 \mathrm{Ma}$ ) hydrothermal system has pervasively altered rocks for up to $8 \mathrm{~km}$ from the system's center. Reaction-rim textures in the distal parts of the system suggest that plagioclase reaction there was "trapped" in progress. Comparisons among these samples and those in which reaction is complete provide a plagioclase reaction model.

Studies have focused on minerals in a 65-Ma hornblende latite porphyry, which is widespread as dikes and sills in the Rico area, and which provided a homogeneous reactant to the hydrothermal fluid. Initial, magmatic, plagioclase phenocrysts in the latite had compositions in the range An(30-40). Primary crystals exhibit oscillatory zoning. Product plagioclase is nearly pure unzoned albite, An $(<1)$. X-ray diffraction studies of Al-Si ordering $(\Delta 131$ method) show that these ions are highly ordered in the product albite tetrahedral sites, but are poorly ordered in the magmatic plagioclase. Oxygen isotope ratios of the fresh plagioclase are close to $9 \%$, but altered plagioclase ratios are as low as $-4 \%$. Thus, all ions in the plagioclase can move during alteration: $\mathrm{Na}, \mathrm{Ca}$, and $\mathrm{K}$ are exchangeable and the An number of the plagioclase becomes altered; the Al and Si become ordered in the plagioclase tetrahedral sites; and the $O$ isotope ratios change as the feldspar exchanges $O$ with the hydrothermal fluid.

Petrographic observations show that the plagioclase alteration proceeds along a front that moves inward from grain boundaries and fracture and cleavage surfaces. Albite twin planes cross undisturbed from unaltered grain cores to altered rims in partially reacted phenocrysts. The crystal outlines do not change size or shape during alteration. These data suggest that the reaction occurs without altering the silicate frame structure of the feldspar. The frame structure is undisturbed as $\mathrm{Ca}, \mathrm{Na}$, and $\mathrm{K}$ are exchanged, as the $\mathrm{Al}$ and $\mathrm{Si}$ become ordered, and as the $\mathrm{O}$ is exchanged. The reaction rim most likely shields the reaction front from external fluids. This, and the persistence of the feldspar structure across the reaction front, suggest that $D-R$ is not a viable reaction mechanism. Diffusion through structural defects in the reaction rim probably transports ions to and removes ions from the reaction front. This reaction mechanism is probably common to many hydrothermal systems, and fluid-rock exchange models that invoke a D-R kinetic exchange mechanism are probably not valid for most plagioclase reactions.

\section{MONTE CARLO INVESTIGATION OF THE COMPLEX GROWTH/DISSOLUTION MECHANISM OF ALUMINO- SILICATES: KAOLINITE. A. C. Lasaga and V. W. Sletten, Department of Geology and Geophysics, Yale University, New Haven CT 06520-8109, USA.}

In order to assess the significance of elementary reactions including the results of $a b$ initio calculations, it is important to relate the $a b$ initio results to the overall rate law and mechanism of mineral growth and dissolution. To this end, we have developed for the first time a "bond-based"Monte Carlo scheme that directly involves the crystal structure, as opposed to previous schemes that have employed Ising-like box structures. This approach enables us to study the effects of complex growth and dissolution mechanisms on the overall rate law. The current model tracks hydrolysis and reverse hydrolysis reactions of all possible surface complexes. In addition, the actual rate of one of these elementary reactions may depend on neighbor interactions. For instance, the rate constant for hydrolysis of a Si-O-Si bridging O may depend on the number, if any, of other $\mathrm{O}$ attached to the $\mathrm{Si}$ that have been hydrolyzed (i.e., the number of $\mathrm{Si}-\mathrm{OH})$. Therefore, our model allows the rate constant for an elementary reaction to vary depending on whether neighboring bonds have been hydrolyzed. This "bond-based" Monte Carlo scheme now can be linked directly to $a b$ initio studies of surface reactions.

The new Monte Carlo scheme has been applied to kaolinite to explore the interaction between the complex mechanism and the overall growth and dissolution behavior. For kaolinite, consideration of all possible adsorption, desorption, and forward and reverse hydrolysis reactions for all possible surface complexes and neighbor configurations leads to a total of 158 possible rate constants. We used the results of Monte Carlo simulations to investigate the effect 
of the relative magnitude of the various rate constants for kaolinite on aspects of the overall growth and dissolution behavior such as surface speciation of $\mathrm{Si}$ and $\mathrm{Al}$ and the experimentally measured overall growth and dissolution rates. In addition, we have used Monte Carlo results to assess the effect of initial surface topography in the form of steps and hillocks on the overall growth and dissolution behavior. New advances in in situ observational techniques (e.g., atomic force microscopy, differential phase-shift interferometry) allow the measurement of intrinsic rate constants for the overall growth and dissolution processes by monitoring the rate of adyance/retreat of individual atomic steps on the mineral surface. The results of the Monte Carlo scheme described above now can be compared directly to experimental results without the complication of determining reactive surface area. Finally, Monte Carlo results are used to examine the nature of the dependence of the rates of growth and dissolution on $\Delta \mathrm{G}$ near equilibrium.

\section{MEASUREMENT OF LEAD ISOTOPE RATIOS IN PLA- GIOCLASE USING THE CAMECA IMS 1270 ION MICRO-} PROBE. G. D. Layne', N. Shimizu', and S. A. Morse'2, 'Woods Hole Oceanographic Institution, Woods Hole MA 02543, USA, 2Department of Geology, University of Massachusetts, Amherst MA 01003, USA.

The Cameca IMS 1270 ion microprobe is a large-format, highresolution, high-transmission Secondary Ion Mass Spectrometer (SIMS) designed to maintain high elemental sensitivity at the massresolving powers (MRP) required for geochemical problems such as the U-Pb geochronology of individual zircon crystals.

The improved sensitivity of the IMS 1270 can also be utilized in the microbeam determination of $\mathrm{Pb}$ isotope ratios in magmatic plagioclase. The relative simplicity of the mass spectra for $\mathrm{Pb}$ in these feldspars enables this analysis to be made at a MRP as low as 2000 , compared to the approximately $5000 \mathrm{MRP}$ required for radiometric analysis of zircon. In plagioclase with accepted total $\mathrm{Pb}$

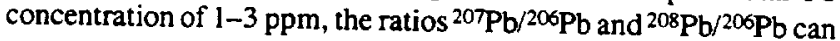
easily be determined with a precision of better than $1 \%(1 \sigma)$ for a 1-hr analysis. Further developments are planned that will reduce this precision to better than $0.2-0.5 \%$.

SIMS analysis of plagioclase in a gabbro from the 1.4-Ga Kiglapait Intrusion in Labrador yielded ${ }^{207} \mathrm{~Pb} /{ }^{206} \mathrm{~Pb}$ and ${ }^{208} \mathrm{~Pb} /{ }^{206} \mathrm{~Pb}$ in agreement with conventional TIMS analyses. In contrast, microbeam analyses of included sulfide phases ( $\mathrm{py}, \mathrm{cpy}$ ) yielded $\mathrm{Pb}$ ratios that were substantially more radiogenic. In broad terms, the possible sources of this more radiogenic $\mathrm{Pb}$ are (1) postdepositional decay of $\mathrm{U}$ and Th originally partitioned within the sulfides or (2) genesis of the sulfides from postmagmatic metasomatic or hydrothermal fluids enriched in radiogenic $\mathrm{Pb}$. Textural features of the sulfides (including veinlike morphologies) and the general expectation of very high initial $\mathrm{Pb} / \mathrm{U}$ and $\mathrm{Pb} / \mathrm{Th}$ ratios for most sulfide phases suggests that the pyrite and chalcopyrite are, in fact, postmagmatic.

This preliminary example demonstrates the potential utility of microbeam $\mathrm{Pb}$-isotope analysis by SIMS in the study of postmagmatic processes in classical layered intrusions such as the Kiglapait.

CARBON ISOTOPES AND SOIL ORGANIC CARBON IN 1995-1996 WHEAT FREE-AIR CARBONDIOXIDE ENRICH-
MENT EXPERIMENTS AT MARICOPA, ARIZONA. S. W. Leavitt', E. Pendall', T. Brooks' ${ }^{2}$, E. A. Paul ${ }^{3}$, B. Kimball ${ }^{2}$, and H Johnson ${ }^{4}$, 'Laboratory of Tree-Ring Research, The University of Arizona, Tucson AZ 85721, USA, '2U.S. Water Conservation Laboratory, USDA-ARS, 4331 East Broadway Road, Phoenix AZ 85040, USA, ' ${ }^{3}$ Department of Crop and Soil Sciences, Michigan State University, East Lansing MI 48824-1325, USA, ${ }^{4}$ USDA. ARS, Grassland Soil and Water Research Laboratory, 808 Blackland Road, Temple TX 76502, USA.

Changes in soil $\mathrm{C}$ pools in response to future elevated atmospheric $\mathrm{CO}_{2}$ concentrations are uncertain. Free-air $\mathrm{CO}_{2}$ enrichment (FACE) experiments offer realistic simulation of future environment with which to assess plant and soil acclimation. We have been using isotopic methods to determine FACE C inputs to soil organic $\mathrm{C}$ (SOC) pools in the Maricopa replicated wheat experiments in 1992-1993/1993-1994, and 1995-1996/1996-1997 (in progress), with special interest in the baseline SOC inputs to the Control plots in the most recent experiment. This paper presents our 1995-1996 results.

The ${ }^{13} \mathrm{C}$-depleted commercial $\mathrm{CO}_{2}\left(\delta^{13} \mathrm{C}=\sim-41 \%\right.$ used to elevate $\mathrm{CO}_{2}$ concentrations above FACE plots provided an isotopic tracer. When mixed with background air $\left(\delta^{13} \mathrm{C}=\sim-8.4 \%\right)$, the air above the FACE plants became ${ }^{13} \mathrm{C}$-depleted $\left(\delta^{13} \mathrm{C}=\sim-16.4 \%\right.$ ) The plant $\delta^{13} \mathrm{C}$ values in the FACE plots $(-39.1 \%$ ) were $\sim 11.7 \%$ ${ }^{13} \mathrm{C}$-depleted compared to the control plots $(-27.4 \%$ ) . Soil pretreatment involved $\mathrm{HCl}$ to eliminate carbonates and extraction of plant fragments by floating, skimming, and manual removal under $20 x$ magnification to isolate the SOC pool of interest. No previous experiments had been done on these plots, but soil samples collected before the beginning of the experiment in November 1995 tended to have slightly lower $8^{13} \mathrm{C}$ and SOC in the FACE plot locations. At May 1996 harvest, we saw no significant change in $S O C$ or $\delta^{13} \mathrm{C}$ to evidence input of new SOC into the FACE plots.

We also employed canopy gas-exchange chambers within control plots to pulse in pure ${ }^{13} \mathrm{CO}_{2}$ at a rate that minimally changed atmospheric $\mathrm{CO}_{2}$ concentration, while imparting a plant $\delta^{13} \mathrm{C}$ value $10-12 \%$ more ${ }^{13} \mathrm{C}$-enriched than that of the regular control wheat plants. This is equivalent to the $10-12 \%$ depletion in plants grown in FACE plots, but the ${ }^{13} \mathrm{CO}_{2}$ tracers were only pulsed onto a small area $\left(\sim 1.5 \mathrm{~m}^{2}\right)$ of control plots (replicates 1 and 2 ) for six days during the growing season. Carbon-13-enrichment was achieved, although the wheat plants in control 2 were $4 \%$ o more ${ }^{13} \mathrm{C}$-enriched than in control 1 and interplant variability was high. The SOC within the chamber area was ${ }^{13} \mathrm{C}$-enriched by $-0.4 \%$ above that of the soils outside. If this difference is representative, and not some artifact of pulsing, the isotopic shift would be consistent with $\sim 5 \%$ new $\mathrm{C}$ input in control plots alone.

Finally, we utilized two exotic soils, ${ }^{13} \mathrm{C}$-enriched by their development with $\mathrm{C} 4$ plants growing in them, as a substrate to follow $\mathrm{C}$ entry from the $\mathrm{C} 3$ wheat plants in both FACE and control plots (replicates 1 and 2). The initial $\delta^{13} \mathrm{C}$ and SOC content of these soils were $-17.1 \pm 0.6 \%$ and $2.0 \pm 0.3 \%$, and $-20.3 \pm 0.2 \%$ and $0.9 \pm$ $0.2 \%$ respectively, i.e., $\sim 0.3-1.3 \%$ more SOC-enriched and 3-6\% more ${ }^{13} \mathrm{C}$-enriched than the local soil. Small subplots of these soils $\left(\sim 0.12 \mathrm{~m}^{2}, 15 \mathrm{~cm}\right.$ deep) were placed into the plots. There was a notable $0.5 \%$ decline in SOC of the high SOC soil, but only the low $S O C$ soil in FACE plots showed a $\delta^{13} \mathrm{C}$ decline (perhaps significant) of $\sim 0.4 \%$. By isotopic mass balance this is consistent with a $\sim 5 \%$ 
C input, but control plot results are confusing as they show an increase in SOC $\delta^{13} \mathrm{C}$.

Isotopic mass balance results from the 1991 FACE cotton experiment [1] and the first two years of wheat [2] suggest $C$ inputs of $\sim 10 \%$ and $5 \%$ respectively from $\mathrm{CO}_{2}$ enrichment. Isotopic results from the 1995-1996 experiment give an inconclusive picture of $\mathrm{C}$ inputs. This may be consistent with small ( $2 \%$ ) inputs at the end of the initial growing season (1992-1993) of the first experiment, although $5 \%$ was measured immediately prior to the second (19931994) season. There may be similar influence of delayed decomposition at work in the current experiment with amplification of the signal through time as FACE plant matter decomposes and enters the SOC pools.

References: [1] Leavitt S. W et al. (1994) Agric. Meteorol., 70, 87-101. [2] Leavitt S. W. et al. (1997) Plant and Soil, in press.

TUNGSTEN ISOTOPIC CONSTRAINTS ON THE DIFFERENTIATION OF MARS AND THE EUCRITE PARENT

BODY. D.-C. Lee and A. N. Halliday, Department of Geological Sciences, University of Michigan, Ann Arbor MI 48109-1063, USA (dclee@umich.edu; anh@umich.edu).

The $\mathrm{W}$ isotopic compositions and $\mathrm{Hf} / \mathrm{W}$ ratios have been determined for eucrites and SNC meteorites in an attempt to better understand the accretion and differentiation of their respective parent bodies.

The $\mathrm{W}$ isotopic compositions of the martian meteorites fall into two groups. ALH 84001 and the shergottites (Shergotty and Zagami) have $\mathrm{W}$ isotopic compositions close to chondritic and $\mathrm{Hf} / \mathrm{W}$ ratios $(\sim 5)$ that are close to estimates of the primitive martian mantle [1]. The nakhlites (Nakhla and Lafayette) and EETA 79001, however, display excess ${ }^{182} W\left(\varepsilon_{w}=2-3\right)$, relative to the mean of carbonaceous chondrites [2]. Data for Chassigny are not yet available. The two eucrites ALHA 78132 and Juvinas display exceedingly radiogenic $W$ with $\varepsilon_{w}$ of 22 and 32 respectively. These are the first reported measurements of excess ${ }^{182} \mathrm{~W}$, and the results can be best explained by differentiation of the meteorite protoliths, or just their parent bodies, during the lifetime of ${ }^{182} \mathrm{Hf}$. The eucrites yield $\mathrm{Hf}-\mathrm{W} \mathrm{T}_{\mathrm{CHUR}}$ model ages in the range 8-12 m.y. post-Arispe (assuming a ${ }^{182} \mathrm{Hf} /$ ${ }^{180} \mathrm{Hf}=2.4 \times 10^{-4}$ at the time of formation of Arispe [3]). These $\mathrm{W}$ model ages are comparable to those reported for ${ }^{53} \mathrm{Mn}$ and ${ }^{60} \mathrm{Fe}$ studies on eucrites $[4,5]$.

The Hf/W ratios of the martian meteorites display no relationship with $W$ isotopic compositions, consistent with the young absolute ages of most of these samples. Assuming a martian mantle source with a Hf/W in the range 3-4 [1], Lafayette, Nakhla and EETA 79001 yield $\mathrm{Hf}-\mathrm{W} \mathrm{T}_{\text {CHUR }}$ model ages in the range $5-15$ m.y. post-Arispe, whereas ALH 84001 and the shergottites yield approximate source model ages of $30 \mathrm{~m} . y$. post-Arispe. That this ancient $W$ isotope heterogeneity has survived provides powerful evidence for extremely early, rapid accretion and differentiation and a lack of subsequent large-scale mixing for major portions of the martian mantle. A similar result was obtained from the ${ }^{146} \mathrm{Sm}-{ }^{142} \mathrm{Nd}$ study of the same SNC meteorites [6]. The Hf-W data presented here also display a correspondence with the ${ }^{147} \mathrm{Sm}-{ }^{143} \mathrm{Nd}$ data for the same SNC meteorites [6]. Those with radiogenic Nd, reflectingtime-integrated depletion in more incompatible elements, also have radiogenic $W$. Those with less-radiogenic $\mathrm{Nd}$ have $\mathrm{W}$ isotopic compositions that are closer to chondritic. There are two explanations for this. First, the process of core formation that left the mantle with high $\mathrm{Hf} / \mathrm{W}$ occurred simultaneously with major silicate melting and depletion of the mantle in lithophile incompatible trace elements, hence high $\mathrm{Sm} / \mathrm{Nd}$. This requires a close relationship between the mechanism of core formation and mantle melting. It also requires that portions of the mantle, as sampled by the source regions of ALH 84001 and the shergottites, did not undergo either process to any great extent until later. Alternatively, the $W$ isotopic data of the SNC meteorites may simply reflect the effects of early silicate melting with $\mathrm{W}$ more incompatible than $\mathrm{Hf}$. In this model, core formation was later ( $\geq 30$ m.y. post-Arispe), and had little impact on the $\mathrm{W}$ isotopic composition of the martian mantle. Even though the inferred timing of core formation on Mars may be different, it is evident that large-scale heterogeneity exists in the mantle of Mars, probably due to insufficient mantle convection.

References: [1] Treiman A. H. et al. (1986) GCA, 50, 10711091. [2] Lee D.-C. and Halliday A. N. (1996) Science, 274, 18761879. [3] Lee D.-C. and Halliday A. N. (1995) Nature, 378, 771774. [4] Lugmair G. W. et al. (1994) Meteoritics, 29, 493-494. [5] Shukolyukov A. and Lugmair G. W. (1993) EPSL, 119, 159 166. [6] Harper C. L. et al. (1995) Science, 267, 213-217.

\section{TUNGSTEN ISOTOPIC EVIDENCE FOR THE ACCRETION} OF THE MOON. D.-C. Lee ${ }^{1}$, A. N. Halliday ${ }^{1}$, G. A. Snyder ${ }^{2}$, and L. A. Taylor ${ }^{2}$, 'Department of Geological Sciences, University of Michigan, Ann Arbor MI 48109-1063,USA (dclee@umich.edu), 2Planetary Geoscience Institute, University of Tennessee, Knoxville TN 37996, USA.

The $\mathrm{W}$ isotopic compositions and $\mathrm{Hf} / \mathrm{W}$ ratios have been determined for a variety of lunar samples in an attempt to better understand the accretion, differentiation, and core formation history of the Moon.

Based on a single $W$ isotopic measurement of mare basalt 14053 , the Moon was thought to have chondritic W isotopic composition [1]. This result is consistent with the chondritic W of the silicate Earth, inasmuch as the Moon, being deficient in Fe, is generally thought to postdate formation of the Earth's core $[1,2]$. However, a more thorough study of lunar rocks is justified for the following reasons. First, this initial $\mathrm{W}$ isotopic analysis was relatively imprecise [1]. Second, there has been considerable debate over whether the majority of material that formed the Moon was derived from the silicate Earth $[3,4]$ or the putative Moon-forming giant impactor [5]. Third, some lunar samples, such as the highland's ferroan anorthosites, are very ancient, and W isotopic data might provide clues to the early history of the Moon. Last, some lunar sources, such as those that supplied the orange and green volcanic glasses, appear to be chemically quite different from the mare basalt source. In particular, the case has been made that a deep portion of the lunar mantle is not as depleted in volatile and siderophile elements as the source of mare basalt. We have therefore measured a variety of lunar samples, including ferroan anorthosites, mare basalts, a Mg-granulite, and Apollo 17 orange glasses, in an attempt to better constrain the origin of the Moon.

A more precise replicate analysis of 14053 , and $W$ isotopic compositions of early ferroan anorthosites, mare basalts, and a $\mathrm{Mg}$ granulite, have $\mathrm{W}$ that is chondritic within analytical uncertainty. 
However, the Apollo 17 orange glasses display radiogenic $W\left(\varepsilon_{w}=\right.$ $1-5)$ that correlates positively with $\mathrm{Hf} / \mathrm{W}$ ratios. These volcanic glasses are thought to have originated by fire fountaining of magmas derived from deep regions of the lunar mantle [6,7]. Their strikingly different chemical composition has led previous workers to propose that they are derived from a separate source that is less depleted in volatile and siderophile elements relative to the mare basalt source $[6,7]$. The explanation for this lunar heterogeneity has been unclear, because such volatile-undepleted compositions are difficult to reconcile with the other accretionary products of the giant impact, which are dramatically depleted in volatiles. In particular, the source regions of the glasses have been considered to be more like terrestrial mantle [7]. Our preliminary $W$ data indicate that this source may be significantly older than the mare basalt source. Replicate measurements of Apollo 17 orange glass 74220 yield consistent Hf-W model ages of $50 \pm 10 \mathrm{~m}$.y post-Arispe [1]. This age is entirely consistent with the proposed time of formation of the Earth's core [1,2], supporting the previous claim that the Moon postdated or formed contemporaneously with the Earth's core [1,2]. If this isotopic signature of radiogenic $W$ is confirmed with further measurements, the W isotopic heterogeneity of the Moon has important implications for its accretion history.

References: [1] Lee D.-C. and Halliday A. N. (1995) Nature, 378, 771-774. [2] Halliday A. N. et al. (1996) EPSL, 142, 75-89. [3] Ringwood A. E. (1979) in Origin of the Earth and the Moon, Springer, New York. [4] Wänke H. and Dreibus G. (1986) in Origin of the Moon, pp. 649-672, LPI. [5] Cameron A. G. W. and Benz W. (1991) Icarus, 92, 204-216. [6] Delano J. W. (1996) LPS XXVII, 303-304. [7] Ringwood A. E. (1992) EPSL, /11, 537-555.

THE ROLE OF MICROTEXTURE IN WEATHERING RATES: DIRECT COMPARISONS OF EXPERIMENTALLY AND NATURALLY WEATHERED FELDSPARS. M. R. Lee', M. E. Hodson ${ }^{2}$, and I. Parsons' ${ }^{1}$, Department of Geology and Geophysics, University of Edinburgh, West Mains Road, Edinburgh EH9 3JW, UK (Martin.Lee@ed.ac.uk; Jan.Parsons@ ed.ac.uk), 2M.L.U.R.I., Craigiebuckler, Aberdeen AB9 2QJ, UK (M.Hodson@mluri.sari.ac.uk).

Laboratory experiments on a number of different types of rockforming minerals have shown little or no correlation between rates of dissolution and dislocation density. These results imply that each mineral species will dissolve at an intrinsic rate under a given set of conditions regardless of its geological background. These experimental results are difficult to reconcile with SEM observations of naturally weathered mineral grains that reveal the almost ubiquitous occurrence of etch pits. The presence of etch pits demonstrates that dissolution is concentrated at discrete sites on grain surfaces, such as dislocation outcrops.

In order to better understand the role of dislocations and microtexture in determining rates of both experimental and natural weathering, we performed dissolution experiments on alkali feldspars from three very different geological backgrounds. The experiments used $106-53 \mu \mathrm{m}$ powders that were reacted with $\mathrm{pH} 2 \mathrm{HCl}$ for $2200 \mathrm{hr}\left(\sim 3\right.$ months) at $25^{\circ} \mathrm{C}$. Naturally weathered feldspars from the Shap Granite have also been studied for comparison with the experiments.
TABLE 1.

\begin{tabular}{lcc}
\hline Sample Name and Origin & Microtexture & $\begin{array}{c}\text { Dissolution Rate } \\
(\text { moles Si/cm } 2 / s)\end{array}$ \\
\hline $\begin{array}{l}\text { Eifel sanidine, } \\
\text { Laachar See volcanos, } \\
\text { Germany }\end{array}$ & $\begin{array}{c}\text { None, with very } \\
\text { few dislocations }\end{array}$ & $3.8 \times 10^{-15}$ \\
$\begin{array}{l}140130, \\
\text { Klokken syenite, } \\
\text { Greenland }\end{array}$ & $\begin{array}{c}\text { Braid microperthite } \\
\text { with few dislocations }\end{array}$ & $2.6 \times 10^{-15}$ \\
$\begin{array}{l}\text { Shap, Shap Granite, } \\
\text { England }\end{array}$ & $\begin{array}{c}\text { Film microperthite } \\
\text { with many dislocations }\end{array}$ & $3.3 \times 10^{-15}$ \\
\hline
\end{tabular}

The dissolution rate data are normalized to BET surface area as it changed through the experiment. The net change in surface area was: Eifel sanidine, $117 \%$ increase; 140130, 174\% increase; and Shap, $301 \%$ increase. If dissolution of these three samples was dominated by etch pitting at dislocation outcrops, we would have expected Shap to dissolve at a greater rate than Eifel and Klokken. Results from the experiments do not support our expectations. The BET surface area did, however, increase from Eifel to Klokken to Shap. SEM images of reacted feldspar surfaces show that few dislocation etch pits are present. We conclude that microtexture and dislocation density play no significant role in determining rates of feldspar dissolution under the experimental conditions ( $\mathrm{pH} 2$ ) used. In addition, etch pitting at dislocation outcrops was not responsible for increases in BET surface area.

In marked contrast, natural weathering of Shap Granite feldspars is dominated by the nucleation and growth of etch pits at edge dislocation outcrops on grain surfaces. After a period of chemical weathering, the etch pits enlarge to such a point that grain surfaces become mechanically unstable and disintegrate. Mechanical weathering strips the top layer from grain surfaces, exposing the lessweathered grain interior, which then continues to dissolve (see Fig. 1). The role of dislocation in natural weathering is therefore both chemical and mechanical.

Alkali feldspars clearly weather by very different mechanisms in the laboratory and in nature. This may be simply due to the duration

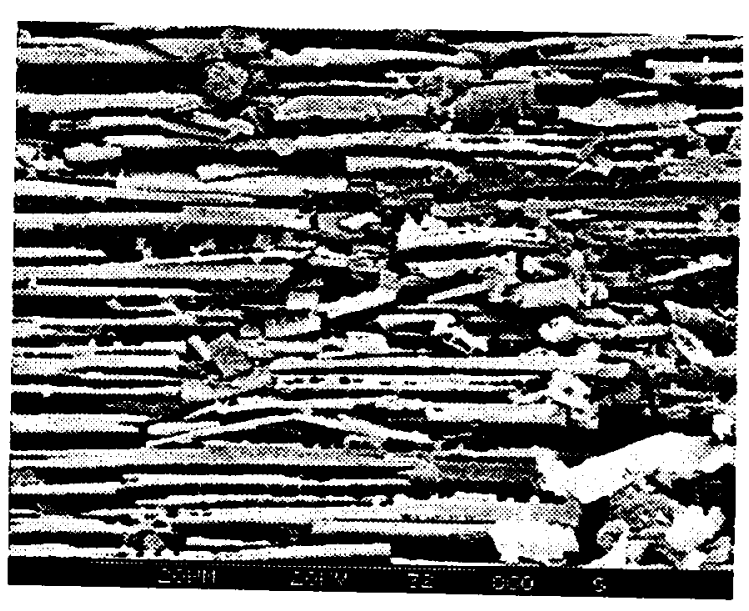

Fig. 1. 
of exposure of grain surfaces to acids or a more fundamental difference in the kinetics of reactions at fluid-mineral interfaces related to the use of concentrated acids in experiments. Regardless of the explanation, we suggest that in nature dislocation density and microtexture are much more important determinants of dissolution rates than experimental results suggest.

PARTITIONING OF VOLATILE ELEMENTS DURING CORE FORMATION. J. Li and C. B. Agee, Harvard University, 20 Oxford Street, Cambridge MA 02138,USA (li@eps.harvard. edu; agee@eps.harvard.edu).

Introduction: The depletion of volatile elements in the mantle relative to $\mathrm{Cl}$ chondrites holds important information on the accretion and early evolution of the Earth. We report here new data on the partitioning of volatile elements $(\mathrm{Pb}$ and $\mathrm{S})$ between molten alloy and molten silicate that argue for mantle-core equilibrium and differentiation at very high pressures. Our results do not support the hypothesis that the core formed from the metallic fraction of planetismals that differentiated at low pressure before accreting to the Earth. Instead, the data are consistent with mantle-core segregation at the bottom of a deep magma ocean as constrained by the partitioning of $\mathrm{Ni}$ and $\mathrm{Co}[1]$.

Experimental: Experiments were performed at pressures of 5,10 , and $16 \mathrm{GPa}$ under isothermal conditions of $2000^{\circ} \mathrm{C}$ with a Walker-style octahedral multianvil device. Starting material was finely abraded powder of the Homestead (L5) meteorite, doped with $\mathrm{Pb}$. Sample capsules were fashioned from a high-purity $\mathrm{MgO}$ rod. All experiments contained coexisting immiscible liquids of Fe-rich alloy and silicate. The average compositions of the quenched liquids were determined by multiple broad-beam analyses using a Cameca electron microprobe.

The effects of pressure on partitioning of $\mathrm{S}$ and $\mathrm{Pb}$ are remarkable. Over a pressure range of $\sim 20 \mathrm{GPa}$, the partition coefficient of $S$ ( $D_{S}$ liquid alloy/liquid silicate) increases by an order of magnitude (from 100 to 1000 ), while that of $\mathrm{Pb}\left(\mathrm{D}_{\mathrm{Pb}}\right)$ decreases by a comparable amount (from 24 to 2).

Discussion: In the following discussion, the abundance of $S$ and $\mathrm{Pb}$ are normalized to $\mathrm{Cl}$ chondrites. Since $\mathrm{S}$ is less volatile than $\mathrm{Pb}$ during condensation and evaporation, the Earth must have acquired more $\mathrm{S}$ than $\mathrm{Pb}$ during accretion, and lost less $\mathrm{S}$ than $\mathrm{Pb}$ during any possible postaccretion heating processes. Therefore, bulk Earth should have more $S$ than $\mathrm{Pb}$, that is [1]

$$
\begin{aligned}
& \mathrm{S}_{\text {mantle }} \times \text { Mass }_{\text {mantle }}+\mathrm{D}_{\mathrm{S}} \times \mathrm{S}_{\text {mantle }} \times \text { Mass }_{\text {Corc }}> \\
& \mathrm{Pb}_{\text {mantle }} \times \text { Mass }_{\text {mante }}+\mathrm{D}_{\mathrm{Pb}} \times \mathrm{Pb}_{\text {mantle }} \times \text { Mass } \\
& \text { Core }
\end{aligned}
$$

Taking the high estimate for mantle abundance of $S$, the low estimate for mantle abundance of $\mathrm{Pb}$ [2]

$$
\begin{aligned}
& \mathrm{S}_{\text {mantle }}=0.0024 \times \mathrm{Cl} \\
& \mathrm{Pb}_{\text {mantle }}=0.025 \times \mathrm{Cl}
\end{aligned}
$$

and the masses of the mantle and the core [1]

$$
\begin{aligned}
\text { Mass }_{\text {mantle }} & =0.68 \times \text { Earth } \\
\text { Mass }_{\text {Core }} & =0.32 \times \text { Earth }
\end{aligned}
$$

reduces to $D_{S}>12 \times D_{P b}+22$. This is a constraint for bulk partition coefficients of $\mathrm{Pb}$ and $\mathrm{S}$ between the core and the mantle. It is satisfied only at pressures greater than $8 \mathrm{GPa}$.

Moreover, if the volatility trend represents the bulk Earth inventory of volatile elements, a maximum $D_{\mathrm{Pb}}$ can be calculated by taking the upper bound of bulk Earth $\mathrm{Pb}(0.05 \times \mathrm{Cl})$ from the trend [2]. The maximum $D_{P_{b}}$ is found to be 4 , but is smaller than 4 only at pressures greater than $14 \mathrm{GPa}$.

In summary, our new results on partitioning of $\mathrm{Pb}$ and $\mathrm{S}$ exclude core-mantle equilibrium at 1 bar and argue for core formation at elevated pressure. This is consistent with core-mantle equilibrium in a magma ocean down to $750-1100 \mathrm{~km}$, as suggested by the convergence of $\mathrm{Ni}$ and $\mathrm{Co}$ partition coefficients at high pressure.

References: [1] Li and Agee (1996). [2] McDonough and Sun (1996).

\section{MINERAL REACTION MECHANISMS AND KINETICS IN} THE MATRIX DURING METAMORPHISM. I. I. Likhanov, V. V. Reverdatto, and A. A. Ten, Institute of Mineralogy and Petrography, Novosibirsk, Russia.

Based on detailed mineral chemistry and phase-relation investigations, we propose the following different mineral reaction mechanisms at the isograds of contact aureoles of the Kharlovo gabbro massif (Russia): (1) topochemical mineral transformation mechanism with inheritance of some sheet silicate fragments at "biotitein" isograde; (2) congruent dissolution of old mineral phases with the total transfer of all petrogenic components in solution and migration to the nucleation and growth centers of new stable minerals at the "epidote-out" isograde [1]; and (3) incongruent dissolution of old minerals (unstable at higher temperatures) with a partial transfer of components to the intergranular solution and migration to the nucleation centers of newly formed minerals and conservation at the place of low-mobility components in the structure of stable minerals at the "arfvedsonite-in" isograde [2].

Mass-balance analysis shows that the mass transfer of the primary petrogenic components was limited by the smallest volumes (microsites), $\sim 0.01 \mathrm{~mm}^{3}$ (biotite-forming reaction), $\sim 0.03 \mathrm{~mm}^{3}$ (epidote-consuming reaction), and $\sim 0.1 \mathrm{~mm}^{3}$ (arfvedsonite-forming reaction).

The method of calculation of the temperature field evolution for bodies of different configurations, taking into consideration the heat of phase transition [3], provides the reaction rate at the "biotite-in" isograde $\left(V=3.4 \times 10^{-13} \mathrm{~s}^{-1}\right)$. The obtained reaction rate allows us to estimate the diffusion coefficient at the known volume equal to $1.7 \times 10^{-16} \mathrm{~cm}^{2} \mathrm{~s}^{-1}$.

References: [1] Likhanov et al. (1994). [2] Likhanov et al. (1995). [3] Likhanov et al. (1996).

BASIN FLUIDS CONNECTED WITH SEDIMENT-HOSTED MICRODISSEMINATED GOLD. J. Liu' and J. Liu' ${ }^{2},{ }^{1}$ Mineral Resources Center, Chinese Academy of Sciences, P.O. Box 9701, 100101 Beijing,China (mrerc@mimi.cnc.ac.cn), 2 Mineral Resources Department, Chengdu College of Technology, 610059 Chengdu, China.

In southem China, over 20 deposits of sediment-hosted micro- 
disseminated gold were investigated. The following features were documented: (1) remarkably stratabound; (2) silt, shale, and cher as host rock; (3) ore occuring on the marginal slope of submarine highs, along syndepositional faults surrounding the submarine highs; (4) many soft-deformation fabrics and water-escape and liquefaction fabrics in ore and host rock, indicating strong syndepositional faulting and fluid transport during basin evolution; and (5) high content of organic matter and various types of biofabrics.

$\delta^{18} \mathrm{O}$ and $\delta \mathrm{D}$ data of more than 56 samples imply complex fluid sources and interactions of seawater, meteoric water, clay minerals, and organic matter. $\delta^{13} \mathrm{C}$ and $\delta^{18} \mathrm{O}$ data of 73 samples from ores and host rocks indicate that $\mathrm{CO}_{22}$ in the fluids was produced mainly by dissolution of carbonate minerals of host rocks. Pyrite $\delta^{34} S$ data of 98 ore and 60 host-rock samples reflect a combination of seawater sulfates with organic $S$, as well as a close affiliation between ore and host rock. Lead isotope data of over 100 samples support complex sources of ore-building materials, clearly arguing against a unifying source from magma or from deep lithosphere. $\delta \mathrm{Eu}-\delta \mathrm{Ce},(\mathrm{La} / \mathrm{Sm}) \mathrm{n}-$ $(\mathrm{La} / \mathrm{Yb}) \mathrm{n}$, and $\mathrm{Aw} / \mathrm{Ag}-\mathrm{Au} / \mathrm{As}-\mathrm{Au} / \mathrm{Sb}$ discrimination diagrams of ores and their host rocks show no differences, indicating a close affiliation between ores and host rocks. Chert shows a $8 \mathrm{Ce}$ of $0.3-0.8$, indicating a connection to submarine hydrothermal processes.

Conclusion: Basin fluids produced during basin evolution moved along syndepositional faults surrounding submarine highs and deposited metals and other matter within faults or on the sea bottom.

\section{IN SITU MEASUREMENT OF MINERAL (SILICATE) DISSOLUTION KINETICS UNDER HYDROTHERMAL CONDITIONS USING SCANNING WHITE LIGHT INTERFEROMETRY. A. Lüttge, I. N. MacInnis, and A. C. Lasaga, Department of Geology and Geophysics, Yale University, P.O. Box 208109, New Haven CT 06520-8109, USA (andreas@ labamba.geology.yale.edu; ian@labamba.geology.yale.edu; lasaga@ quantm.geology.yale.edu).}

Mineral surfaces in contact with a solution or fluid are involved in several key processes that govern many geologically important reactions. Such processes include weathering, sedimentary basin dynamics, reactions in subduction zones, formation of ore deposits, and waste containment. Models of such complex systems require kinetic data on mineral surface processes during dissolution and growth.

The results of mineral powder experiments reflect the influence of a variety of different surface sites on dissolution/precipitation rates. Therefore, we need to measure reaction rates of specific surface features in order to distinguish the role of reactive vs. total (BET) surface area.

We have developed an optical interferometry system for in situ studies of the dynamics of dissolving/precipitating mineral surfaces. The system (Fig. 1) merges the capabilities of a hydrothermal flow-through cell [1] with the resolution of low-temperature interferometric techniques [e.g., 2,3]. For the first time, it is possible to study even aluminosilicates with this new technique.

Vertical scanning white light interferometry provides near-atomicscale vertical resolution (on the order of 1-10 nm) for surface features up to $100 \mu \mathrm{m}$ high and $1 \mu \mathrm{m}$ lateral resolution (see Fig. 2). A custom Mirau objective lens facilitates measurement through a

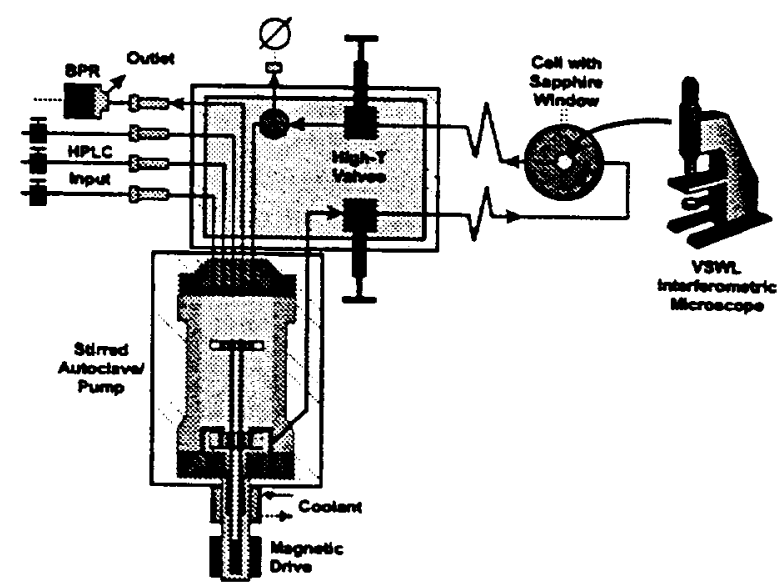

Fig. 1. Schematic diagram of the new experimental setup for hydrothermalin situ surface measurement.

sapphire window and aqueous solution. Reaction rates are determined from the surface-normal retreat or advance of the mineral surface over time.

The slow rates of aluminosilicate growth/dissolution require hydrothermal conditions for the application of this method. Therefore, the recirculating optical cell system operates at up to $300^{\circ} \mathrm{C}$ and 300 bar and includes an intemal pump that provides solution flow rates exceeding $10 \mathrm{ml} / \mathrm{min}$. The solution chemistry is controlled by injecting reagent solutions with HPLC pumps.

This experimental approach adds a whole new dimension to the study of the key factors in mineral-solution kinetic rate laws (e.g., the effect of saturation state, catalysis or inhibition, $\mathrm{pH}$, and organic acids). In addition, the kinetic behavior at specific surface sites such as steps or etch pits can be compared to that occurring in flat areas, leading to a better understanding of the role of reactive surface area. Preliminary results on the study of mineral dissolution will be presented.

References: [1] Ohmoto $\mathrm{H}$. et al. (1991) Nature, 351, 634636. [2] Onuma K. et al. (1993) J. Crystal Growth, 129, 706-622. [3] MacInnis I. N. et al. (1993) Proc. 6th Topical Meeting on Crystal Growth Mechanism, pp. 233-238, Awara, Japan.

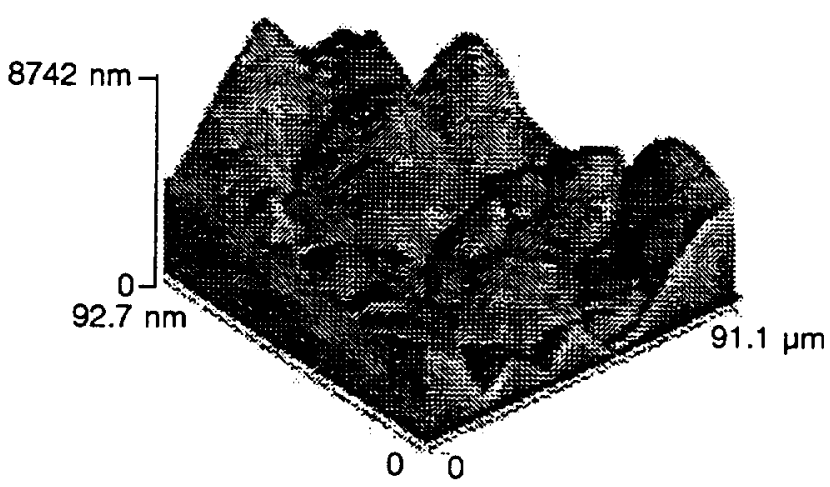

Fig. 2. An ex situ image showing hillocks on a hydrothermally etched quartz surface. 
PATHWAYS OF ORGANIC REMINERALIZATION IN HOLOCENE AND LATEST PLEISTOCENE SEDIMENTS OF THE ANOXIC CARIACO BASIN. T. W. Lyons', R. W. Murray $^{2}$, D. G. Pearson ${ }^{3}$, L. C. Peterson 4 , D. J. Hollander ${ }^{5}$, J. P. Werne $^{5}$, and ODP Leg 165 Shipboard Scientific Party, 'Department of Geological Sciences, University of Missouri, Columbia MO 65211, USA, 2Department of Earth Sciences, Boston University, Boston MA 02215, USA, 'Department of Geological Sciences, Durham University, Durham DH1 3LE, UK, ${ }^{4}$ Rosenstiel School of Marine and Atmospheric Science, University of Miami, Miami FL 33149, USA, 5Department of Geological Sciences, Northwestern University, Evanston IL 60208, USA.

The Cariaco Basin, a structural depression on the continental shelf of Venezuela, is the world's second-largest modern anoxic basin. The present study is focused on a high-resolution evaluation of the biogeochemical cycling of organic $\mathrm{C}(\mathrm{OC})$, nutrients, $\mathrm{S}$, and a broad suite of trace metals in sediments collected at Site 1002 during ODP Leg 165 . In conjunction with an ongoing comprehensive evaluation of geochemical variation over the complete $170-\mathrm{m}$ section recovered at Site 1002, we are currently analyzing the upper $\sim 7 \mathrm{~m}$ of sediment. These most recent deposits record the oxic conditions present during the last glacial lowstand, the anoxic regime that has persisted throughout the Holocene, and the productivity-driven transition from oxic to anoxic deposition at roughly 12.6 k.y. BP.

Pore-water profiles reveal a systematic drop in sulfate concentration to roughly $15 \%$ of the seawater value and a corresponding downcore increase in phosphate and ammonium over the $\sim 6-\mathrm{m}$ section that spans the $12.6-\mathrm{k} . \mathrm{y}$. record of anoxic deposition. The disappearance of dissolved sulfate corresponds with a dramatic downcore increase in methane concentration. Pyrite $S$ concentrations show a subtle increase with increasing depth over the uppermost interval and level off at a mean value of $\sim 1.6 \mathrm{wt} \%$ by $\sim 1.5 \mathrm{~m}$ below the sea floor. OC concentrations show a systematic drop over the same interval from a surface high of $-6.0 \mathrm{wt} \%$ to relatively invariant values with a mean of $\sim 4.2 \mathrm{wt} \%$. These trends are perturbed at depths $>3-4 \mathrm{~m}$ due to dramatic productivity-driven variations in OC input and corresponding dilution effects associated with biogenic opal and $\mathrm{Ca}$-carbonate production. These effects reflect, in part, elevated productivity during the Younger Dryas. Despite persistent conditions of water-column anoxia, the post-glacial microlaminated sediments do not show $S$ enrichments relative to oxically deposited marine sediments with similar levels of $O C$. This relationship is thought to record Fe limitation in conjunction with comparatively high levels of $\mathrm{OC}$, which is analogous to conditions in the modern anoxic Black Sea.

Conclusions regarding $\mathrm{Fe}$ limitation have been further addressed through a systematic evaluation of $\mathrm{Fe}$ speciation over the same interval. For example, despite evidence for iron limitation, degreeof-pyritization (DOP) values-as determined via the conventional boiling, $12 \mathrm{~N} \mathrm{HCl}$ method-fall in the range of $\sim 0.56$, thus challenging widely held views on the utility of DOP as a paleoredox proxy. However, when viewed in light of recent advances in Black Sea research, these results are consistent with arguments that present DOP as a product of the complex interplay between water-column Fe cycling, syngenetic Fe sulfide formation, and transport of Febearing siliciclastic sediments to the deep basin. Finally, these results will be evaluated within the context of a high-resolution organic geochemical record that, through applications of isotopic and biomarker approaches, documents the balance between primary productivity and intensity of upwelling over the last $12.6 \mathrm{k}$.y.

\section{IN SITU MEASUREMENT OF CALCITE DISSOLUTION} RATES USING REAL-TIME PHASE SHIFT INTERFEROMETRY. I.N.MacInnis ${ }^{1}$, K. Onuma ${ }^{2}$, and K. Tsukamoto ${ }^{3}$, 'Lepartment of Geology and Geophysics, Box 208109, Yale University, New Haven CT 06520-8109, USA (ian@labamba. geology.yale.edu), ${ }^{2}$ National Institute of Materials and Chemical Research, Higasi 1-1, Tsukuba, Ibaraki 305, Japan, 'Institute of Mineralogy, Petrology, and Econamic Geology, Tohoku University, Aramaki Aoba, Sendai 980, Japan.

The rate of dissolution of calcite was measured in situ using a real-time phase shift interferometer (Fig. 1 [1]). The role of reactive sites can be investigated because this approach allows the rates to be compared at specific features on the mineral surface, such as etch pits vs. flat areas. The real-time phase shift interferometer provides $100 \times$ greater vertical resolution than conventional interferometry by using polarized light to produce three interferograms, each out of phase by $90^{\circ}$. Transformation of the interferograms results in a twodimensional eight-bit phase map that can be converted to mineral surface elevation with a resolution on the order of $1 \mathrm{~nm}$. The discrete fringes of the conventional interferogram are thus replaced by a continuous phase map in the phase shift interferogram (Fig. 2). Dissolution rates are based on the change in height of the surface over time. Interferograms are collected at the rate of $60 \times$ per second.

Dissolution experiments were conducted with small cleavage rhombs mounted in a flow-through optical cell. The recirculating system provides flow rates up to $40 \mathrm{~cm} / \mathrm{s}$ over the crystal surface and

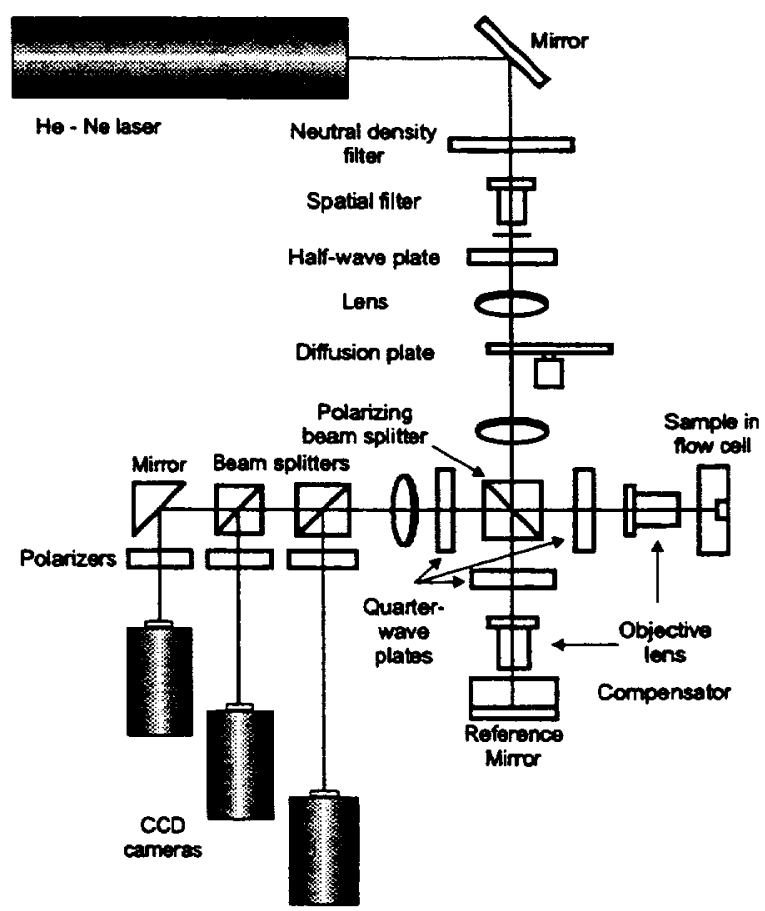

Fig. 1. Real-time phase shift interferometer (after [1]). 


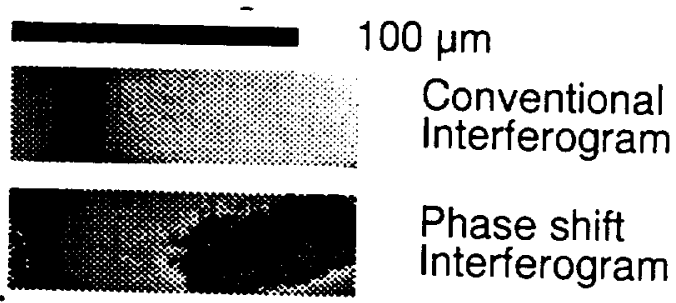

Fig. 2.

includes a constant temperature bath. The advantage of the system is that solution composition, temperature, and flow rate can be varied for extended periods of time up to weeks or months.

The variation in dissolution rate as a function of saturation state and etch pit wall slope at $\mathrm{pH} 8$ between $9^{\circ}$ and $40^{\circ} \mathrm{C}$ will be discussed. However, the flow rate is an important factor due to the mixed surface and transport control under these conditions. Both the rates and pit morphology change with the flow rate (see the transformation to a fan-shaped morphology at low flow rate in Fig. 3).

References: [1] Onuma et al. (1994) J. Crystal Growth, 137, 610-622.

\section{TRACING PLUME, MID-OCEAN RIDGE BASALT, AND}

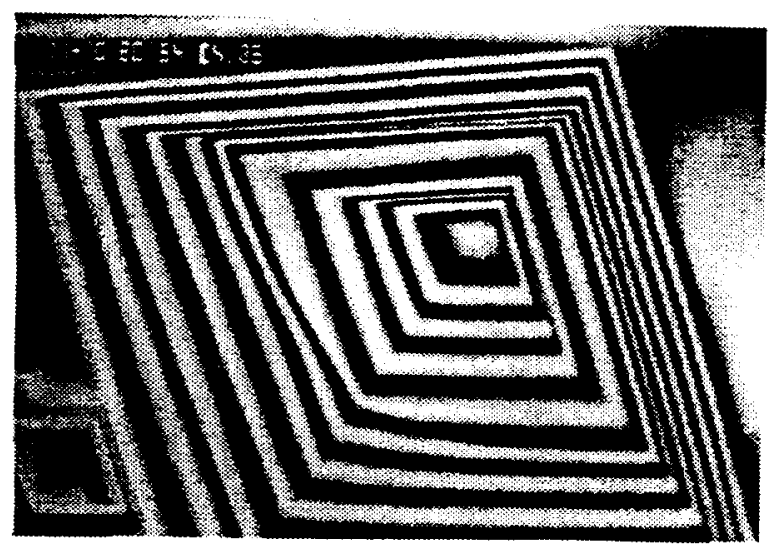

(b)

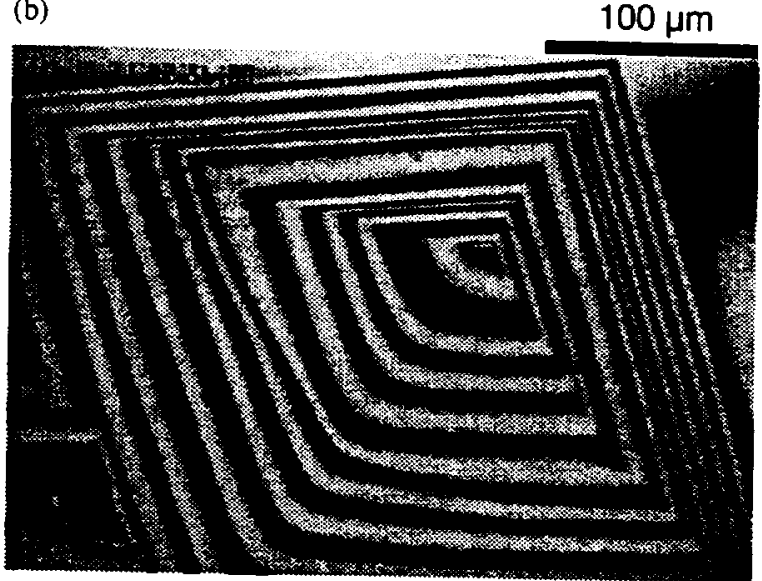

Fig. 3. (a) Flow $-38.5 \mathrm{~cm} / \mathrm{s}, \mathrm{T}-40.5^{\circ} \mathrm{C}$. (b) Flow $=10 \mathrm{~cm} / \mathrm{s}, 100 \mu \mathrm{m}$.
ATMOSPHERE CONTRIBUTIONS TO KOLBEINSEY RIDGE BASALTS: HELIUM, NEON, AND ARGON ISOTOPE EVIDENCE. C. G. Macpherson ${ }^{1}$, D. R. Hilton ${ }^{1}$, D. F. Mertz $^{2}$, and T. Dunai ${ }^{3}$, 'Scripps Institution of Oceanography, GRD0220, La Jolla CA 92093, USA (cmacpherson@ucsd.edu; dhilton@ ucsd.edu), ${ }^{2}$ Johannes Gutenberg-Universitat, Institut für Geowissenschaften, 55099 Mainz, Germany (Mertz@dzdmzb.zdv.unimainz. de), ${ }^{3}$ Vrije Universiteit, De Boelelaan 1085, 1081 HV Amsterdam, The Netherlands (dunt@geo.vu.nl).

The Kolbeinsey Ridge (KR) extends $-600 \mathrm{~km}$ from the Tjörnes fracture zone $\left(\sim 66^{\circ} \mathrm{N}\right)$ to the Jan Mayen fracture zone $\left(\sim 72^{\circ} \mathrm{N}\right)$, and is offset into northern, central, and southem segments by an overlapping spreading center at $70^{\circ} 30^{\prime} \mathrm{N}$ and by the Spar fracture zone at $69^{\circ} \mathrm{N}$. Shallow eruption depths $(90-1250 \mathrm{~m})$ and proximity to Iceland provide an opportunity to (1) investigate the effects of extreme degassing on the volatile systematics of ridge magmas and (2) consider the sensitivity of $\mathrm{He}, \mathrm{Ne}$, and $\mathrm{Ar}$ to monitor interactions between upper- and lower-mantle magma sources. Light rare gas analyses were performed on $23 \mathrm{KR}$ basaltic glasses by crushing for ${ }^{3} \mathrm{He}^{/ 4} \mathrm{He}$ ratios, and by incremental heating for $\mathrm{Ne}$ and $\mathrm{Ar}$ isotopes and ${ }^{4} \mathrm{He}$ content.

In all samples, ${ }^{3} \mathrm{He} /{ }^{4} \mathrm{He}$ ratios are significantly greater than ratios typically found in N-MORB $\left(\sim 8 \mathrm{R}_{\mathrm{A}}\right.$ where $\mathrm{R}_{\mathrm{A}}=$ air $\left.{ }^{3} \mathrm{He}^{/ 4} \mathrm{He}\right)$, in agreement with previous work [1]. The highest values, $\sim 14 R_{A}$, cluster near the Tjörnes fracture zone, with most of the KR characterized by a remarkably constant value of $11.1 R_{A}( \pm 0.9, n=16)$. Neon isotope ratios $\left(0.0293-0.0373\right.$ for ${ }^{21} \mathrm{Ne} / 22 \mathrm{Ne}$ and $9.70-10.86$ for ${ }^{20} \mathrm{Ne} / 22 \mathrm{Ne}$ ) are dominated by an atmospheric component that is most evident in Ne-rich lavas, and there are no significant correlations with latitude. KR basalts retaining vestiges of mantle Ne tend to occur in deeper water and resemble MORB in ${ }^{21} \mathrm{Ne}^{22} \mathrm{Ne}-20 \mathrm{Ne} /$ ${ }^{22} \mathrm{Ne}$ space. Deeper eruption sites along the northem portion of the $\mathrm{KR}$ possess the highest ${ }^{40} \mathrm{Ar} /{ }^{36} \mathrm{Ar}$ ratios (up to 5100 ), but atmospheric values (296) are not uncommon and increase in frequency to the south, particularly in Ar-rich samples.

Concentrations of $\mathrm{He}, \mathrm{Ne}$, and $\mathrm{Ar}$ (in $\mathrm{ncm}^{3} \mathrm{STP} / \mathrm{g}$ ) range from 63.2 to $1340,0.021$ to 6.22 , and 42.7 to 5050 respectively. Helium concentrations are lowest in very shallow basalts and increase with depth to $1000 \mathrm{~m}$. In this depth range, Ne and Ar concentrations show no correlation with eruption depth, and high concentrations are found at both shallow and deep eruption sites. Compared to typical $\mathrm{N}$-type MORB, the rare gas concentrations are low and reflect extensive degassing along the entire $\mathrm{KR}$.

Despite extreme degassing, the $\mathrm{He}$ isotope ratios of $\mathrm{KR}$ magmas remain a robust indicator of their mantle sources due to eruption through crust young enough to preclude the effects of accumulated radiogenic ${ }^{4} \mathrm{He}$. The Jan Mayen fracture zone marks a major He isotope discontinuity in the North Atlantic, south of which a ${ }^{3} \mathrm{He}-$ rich component, presumably associated with the Iceland plume, mixes with MORB-source He. In contrast, $\mathrm{Ar}$ isotope systematics record addition of a shallow-level, airlike component to a mantle component with ${ }^{40} \mathrm{Ar} / 36 \mathrm{Ar}$ in excess of 5000 . In this respect shallow spreading ridges and submarine plume lavas can be similarly prone to the effects of disrupted mantle Ar signatures. Neon isotopes in $\mathrm{KR}$ basalts also display evidence for significant atmospheric contamination, but a mantle provenance can be still identified (although this is more akin to MORB-source Ne). This raises the possibility that $\mathrm{He}$ and $\mathrm{Ne}$ isotope systematics have become decoupled 
in the mantle north of Iceland.

References: [1] Poreda et al. (1986) EPSL.

CHLORINE CONTAMINATION OF MID-OCEAN RIDGE LAVAS: NEW INSIGHT FROM CHLORINE STABLE ISOTOPE RATIOS. A. J. Magenheim ${ }^{1}$, B. B. Hanan ${ }^{1}$, and M. R. Perfit ${ }^{2}$, 'Department of Geological Sciences, San Diego State University, San Diego CA, USA, ${ }^{2}$ Department of Geology, University of Florida-Gainesville, Gainesville FL, USA.

Evolved mid-ocean ridge basalts (MORB) from fast- and medium-spreading ridges are often enriched in $\mathrm{Cl}$ relative to spatially associated primitive MORB to an extent that cannot be explained by fractional crystallization alone [1]. Assimilation of Cl-rich material could account for the "excess $\mathrm{Cl}$," but the low $\mathrm{Cl}$ content of altered crust requires selective assimilation of either rare $\mathrm{Cl}$-rich amphibole or brine to account for "excess $\mathrm{Cl}$ " $[1,2]$.

Chlorine stable isotope ratios $\left({ }^{37} \mathrm{CV}^{35} \mathrm{Cl}\right.$; expressed as $8^{37} \mathrm{Cl}$, the per mil deviation from the seawater ${ }^{37} \mathrm{Cl}^{35} \mathrm{Cl}$ ratio) of pristine depleted MORB are enriched in ${ }^{37} \mathrm{Cl}$ relative to $\mathrm{Cl}$ in Earth's surface reservoir [3]. MORB with "excess $\mathrm{Cl}$ " (based on $\mathrm{Cl} / \mathrm{K}$ and $\mathrm{Cl} / \mathrm{F}$ ratios) have $\delta^{37} \mathrm{Cl}$ closer to seawater, suggesting addition of seawater-derived $\mathrm{Cl}$ during residence of MORB melts in the crust.

Chlorine isotope analyses of spatially related basaltic andesites from the Galapagos spreading center at $85.5^{\circ} \mathrm{W}[4]$ were conducted to evaluate the effect of $\mathrm{Cl}$ overenrichment on $\delta^{37} \mathrm{Cl}$ and to elucidate the mechanism of $\mathrm{Cl}$ enrichment in MORB. The new data include negative values of $\delta^{37} \mathrm{Cl}\left(\delta^{37} \mathrm{Cl}\right.$ ranges $+0.5 \% 0$ to $-1.7 \%$ ) and an inverse correlation between $\mathrm{Cl}$ content (or overenrichment) and isotopic ratio. Simple mixing of seawater- and mantle-derived $\mathrm{Cl}$ during direct wall-rock or seawater assimilation cannot explain these observations. The $\mathrm{Cl}$ isotope variations may be controlled by isotopic fractionation associated with the process that adds seawater-derived $\mathrm{Cl}$ into the magma.

Diffusion-driven fractionation of $\mathrm{Cl}$ isotopes is an important process in aqueous systems at low temperature, and provides a basis for considering this process in a silicate liquid. We envision that seawater (or a supercritical hydrothermal fluid) comes into proximity of the margins of a crustal-level magma reservoir. Rapid equilibration of the outermost surface of this silicate liquid with the fluid should result in a boundary layer of hydrous melt with $\mathrm{Cl}$ concentration controlled by its solubility. The direction of diffusion is reverse to other volatiles; $\mathrm{Cl}$ diffuses into the magma from seawater-derived fluid due to the large concentration gradient between melt and aqueous phase.

Mathematical simulations indicate that diffusion-driven $\mathrm{Cl}$ enrichment can explain both the elevated $\mathrm{Cl}$ concentration and light values of $\delta^{37} \mathrm{Cl}$. The magnitude of $\mathrm{Cl}$ enrichment is controlled by crustal residence time and the surface area to volume ratio of the magma body (and for nonstatic cases, the rate of movement through the crust). The observation that $\mathrm{Cl}$ overenrichment coincides with fractional crystallization [6] can be explained by diffusion operating over similar timescales as crystallization. The extent of crystallization only serves as a proxy for the progress of $\mathrm{Cl}$ enrichment, and lack of significant crystal fractionation does not a priori preclude $\mathrm{Cl}$ contamination. Combined modeling of diffusion and low-pressure fractionation of data from a cogenetic suite of lavas should allow an estimate of the primary $\mathrm{Cl}$ content and isotope composi- tion.

This diffusion-driven mechanism for $\mathrm{Cl}$ enrichment is consistent with observations that "excess $\mathrm{Cl}$ " is observed predominantly at medium- and fast-spreading ridges and in complex tectonic environs such as propagating rifts [7]. In a simplistic sense, seawater can more readily penetrate to a shallow magma chamber at a fastspreading ridge, in comparison to a deep-seated magma source at a slow-spreading ridge.

Other elements that have large concentration gradients between seawater/hydrothermal fluid and magma should be affected by similar processes (e.g., $\mathrm{H}_{2} \mathrm{O}$, alkalis, and $\mathrm{Br}$ ). Study of interactions occurring at the magma-fluid interface may have importance for understanding the chemistry of hydrothermal fluids, sulfide deposits, and lavas sampled on the seafloor.

References: [1] Michael P. J. and Schilling J.-G. (1989) GCA, 53, 3131-3143. [2] Jambon A. et al. (1995) Chem. Geol., 126, 101117. [3] Magenheim A. J. et al. (1995) EPSL, 131, 427-432. [4] Embley R. W. et al. (1988) Can. Mineral., 26, 517-539. [5] Eggenkamp H. G. M. et al. (1994) Chem. Geol., 116, 317-325. [6] Perfit M. R. et al. (1983) JGR, 88, 10551-10572. [7] Michael P. J. and Comell W. C. (1995) Eos Trans. AGU, 76, 695.

ARGON-ARGON DATING OF BASANITES FROM VOLCANIC PIPES OF NORTH MINUSA DEPRESSION, KHAKASSIA, RUSSIA. V.G.Malkovets, A. V.Travin, Yu.D.Litasov, and K. D. Litasov, Department of Geophysics and Mineralogy, United Institute of Geology, Universitetskii pr. 3, Novosibirsk 630090, Russia.

The North Minusa Depression, of Devonian-Carboniferous age, is located within the Caledonian fold belt and neighbors the Kuznetskiy Alatau ridge at the west and the Sayan Mountains at the southeast. The depression seems to have a complicated tectonic origin. Its formation was accompanied by intensive alkalinesubalkaline Devonian volcanism [1].

Basanite volcanic pipes within the Kop'evo Uplift of the North Minusa Depression are well known because of appearance of abundant xenoliths of garnet peridotites and pyroxenites. Along the uplift circumference, there are 3 fields maintaining more than 12 pipes. The structure of the bodies is rather simple: They are comprised of eruptive breccias and basanites; some pipes are multiple and join two or three simple bodies. The age of diatrems is still under discussion.

The first K-Ar dating of basanites [2] showed that the ages range within 71-28 Ma: Sestra Pipe-71 (4 Ma); Kongarovskaya Pipe-45 (2 Ma); Tergeshskaya Pipe-65 (3 Ma); Bele Pipe-62 (3 Ma); Krasnoozerskaya Pipe (major)-62 (3 Ma); Krasnoozerskaya Pipe (satellite)-28 (2 Ma); Tri Brata Pipe-58 (3 Ma); Boradzhulskaya Pipe-49 ( $3 \mathrm{Ma}$ ). Such a wide range of intrusions is unlikely according to geological position and relationships, e.g., the age difference is about $30 \mathrm{Ma}$ between the Krasnoozerskaya major and satellite pipes. This discrepancy may come from the lack of accuracy of the K-Ar method.

Isotope dating of zircons from a heavy separate of the Bele Pipe performed in the Geophysical Laboratory at the Camegie Institution, USA, has yielded a U-Pb age of $77.9 \mathrm{Ma} \mathrm{[3].}$

The first Ar-Ar dating was performed for three pipes of the region and showed the following results as following: Kongarovskaya 
Pipe-73 (2.8 Ma); Krasnoozerskaya Pipe (major)-76.2 (3.9 Ma); Krasnoozerskaya Pipe (satellite)-73.7 (2 Ma). These data provide evidence for a simultaneous age of the basanitic intrusions and vary within the method error. The detailed petrographic study of thin sections showed that the samples taken for analysis were perfectly fresh and did not undergo any secondary alteration. Good agreement among the obtained ages and their proximity to U-Pb data allow us to consider them as more realistic compared to K-Ar ages.

Therefore, our new data on dating of basanites of the region show that volcanic activity was a single event. Also, it correlates well with reconsumption of the Late Mesozoic tectonomagmatic activity of Central Asia. The study of various mantle-derived xenoliths from basanites as well will result in detailed information on mantle composition and structure beneath the region for the Mesozoic.

References: [1] Ashchepkov I. V. et al. (1995) Field Guide Book of the 6th Intl. Kimb. Conf., Novosibirsk, Russia, $39 \mathrm{pp}$. [2] Zubkov V. S. et al. (1988) Dokl. AN USSR, 307(6), 1466-1469. [3] Sobolev N. V. et al. (1988) Field Trip Guide of Intl. Symp. Composition and Processes in the Deep Seated Continental Lithosphere, Novosibirsk, $76 \mathrm{pp}$.

URANIUM-LEAD CHRONOLOGY OF METEORITES: A REVIEW OF INVESTIGATIONS DURING THE LAST 25 YEARS. G. Manhès, C. Göpel, and C. J. Allègre, Laboratoire de Géochimie et Cosmochimie, IPGP, 4, Place Jussieu, 75252 Paris Cedex 05, France.

Since the major work of Tatsumoto [1], significant $\mathrm{U}-\mathrm{Pb}$ investigations, mostly by groups in Denver, Oxford, Paris, Pasadena, Santa Barbara, San Diego, and Washington, have been accomplished, in part because of a steady improvement in the analytical technique.

Unshocked silicate meteorites define single-stage $\mathrm{Pb}-\mathrm{Pb}$ model ages ranging from 4.57 to $4.45 \mathrm{Ga}$. However, the majority of the whole rocks show an apparent excess of radiogenic $\mathrm{Pb}$ in respect to the in situ decay of $\mathrm{U}$ and the primordial $\mathrm{Pb}$ composition as determined in Canyon Diablo. This open behavior of the U-Pb system does not allow validation of the $\mathrm{Pb}-\mathrm{Pb}$ ages at the level of their analytical uncertainty. Three different interpretations have been proposed to explain this feature: (1) complex (more than one stage) $\mathrm{U}-\mathrm{Pb}$ evolutionary histories; (2) terrestrial $\mathrm{Pb}$ contamination in excess of that accounted for by the analytical blank; (3) variable primordial $\mathrm{Pb}$ isotope compositions. While the uniformity of primordial $\mathrm{Pb}$ is attested by the $\mathrm{Pb}$ measured in iron meteorites and primitive chondrites, the first two explanations still coexist.

The resolution of one to a few million years of the $\mathrm{Pb}-\mathrm{Pb}$ chronometer has been achieved for meteoritic materials with high ${ }^{238} \mathrm{U}$ / ${ }^{204} \mathrm{~Pb}$ ratios: refractory inclusions of Allende meteorite, ordinary chondrites, and achondrites. Their $\mathrm{Pb}-\mathrm{Pb}$ age can be used as key boundaries when establishing meteorite parent body formation and evolution. However, the apparent concordant character observed with the current precision of the measured $\mathrm{U} / \mathrm{Pb}$ ratios is not a guarantee of the closure of the U-Pb clock since the precise time defined the $\mathrm{Pb}$ - $\mathrm{Pb}$ chronometer. This ambiguity has to be considered for comparison with the other chronometric informations derived from long- and short-lived nuclides.

Refractory inclusions of Allende are mineralogical objects that crystallized during nebular processes that occurred during, or shortly after, the isolation of the solar nebula. The $\mathrm{Pb}-\mathrm{Pb}$ age of their most radiogenic components are compatible with an age corresponding to $4.556 \pm 0.002 \mathrm{Ga}$. This represents the best estimate for the age of the solar system.

The $\mathrm{Pb}-\mathrm{Pb}$ ages of phosphates from equilibrated $\mathrm{H}$ chondrites range between 4.563 and $4.50 \mathrm{Ga}$ and correlate with the degree of metamorphism. They confirm the early formation of this planetary material. However, the significance of this time interval as a record of the regular cooling of the parent body or as a result of secondary events is an open question.

The U-Pb systematics of noncumulate eucrites and angrites show that magmatic activity occurred in some parent bodies during or a few million years after the formation of chondritic parent bodies.

References: [1] M. Tatsumoto et al. (1973) Science, 180, 1279.

NATURAL VARIATIONS OF COPPER AND ZINC ISOTOPIC COMPOSITIONS. C. N. Maréchal ${ }^{1}$, F. Albarède ${ }^{1}$, and N. Emmanuel'2, 'Ecole Normale Supérieure de Lyon, UMR CNRS 5570, 69364 Lyon Cédex 07, France (cmarecha@geologie.enslyon.fr), ${ }^{2}$ L.P.C.M., Observatoire Océanologique, URA CNRS 2076 , 06230 Villefranche-sur-Mer, France.

Because of the lack of an adequate mass spectrometry method, the stable isotope geochemistry of $\mathrm{Cu}$ and $\mathrm{Zn}$ is virtually unknown. Their isotope composition can be now measured by plasma source mass spectrometry on the Plasma 54 of Lyon in the multicollection mode. Each measurement produces the ${ }^{65} \mathrm{Cu} /{ }^{63} \mathrm{Cu},{ }^{66} \mathrm{Zn}^{164} \mathrm{Zn},{ }^{67} \mathrm{Zn}$ ' ${ }^{64} \mathrm{Zn}$, and ${ }^{68} \mathrm{Zn} /{ }^{64} \mathrm{Zn}$ ratios. No detectable isobaric interference is observed in this mass range. Instrumental mass fractionation is corrected in two stages: (1) with respect to the isotopic composition of a standard of a different element added to the purified sample ( $\mathrm{Zn}$ for a $\mathrm{Cu}$ sample, $\mathrm{Cu}$ for a $\mathrm{Zn}$ sample) and (2) with respect to the standard solution of the same element run alternately with the samples. The internal reproducibility of the isotopic measurements is $0.04 \%$. We have adopted the $65 / 63$ ratio of the NIST $976 \mathrm{Cu}$ standard and a shelf JMC $\mathrm{Zn}$ solution for reference. The elements are isolated by anion exchange chemistry.

Very little isotopic variation $(<0.3 \%$ ) is observed in the $\mathrm{Zn}$ of sphalerite and MORB. More substantial isotopic fractionation is observed for $\mathrm{Cu}$. In particular, low-temperature $\mathrm{Cu}$ ores and some black-smoker chalcopyrite may be enriched in ${ }^{65} \mathrm{Cu}$ by up to $3 \%$ with respect to MORB.

Zinc and $\mathrm{Cu}$ are trace elements in seawater. Their concentration increases with depth in the ocean. Zinc is a nutrient-type element that is well correlated with $\mathrm{Si}$, while scavenging by sinking particles controls $\mathrm{Cu}$. Sediment trap material collected at 1000 and $2500 \mathrm{~m}$ west of the coast of Mauritania at $18^{\circ} 30 \mathrm{~N} 21^{\circ} 06 \mathrm{~W}$ (mesotrophic conditions) shows isotopic variations of $0.8 \% \circ$ for $\delta^{65} \mathrm{Cu}$ and 0.4 for $\delta^{66} \mathrm{Zn}$, well above the limit of detection. The variations of the two elements are both regular and coherent, but the modulation by the seasonal signal is ambiguous. The two signals are somewhat shifted in time with respect to each other. Occasionally, a vertical gradient of $\mathrm{Cu}$ and $\mathrm{Zn}$ isotopic composition may appear. Because of the short interval of observation, the role of surface biological processes and that of vertical advection on the isotopic variability of $\mathrm{Zn}$ and $\mathrm{Cu}$ are not elucidated. We suggest, however, that this variability may be 
controlled by the preferential uptake of the light isotope by biological material.

STRONTIUM ISOTOPES IN PORE WATER FROM THE UNSATURATED ZONE AT YUCCA MOUNTAIN, NEVADA. B. D. Marshall, K. Futa, and Z. E. Peterman, Mail Stop 963, U.S. Geological Survey, Denver CO 80225-0046, USA.

Yucca Mountain, a ridge of Tertiary pyroclastic units in southwest Nevada, is being elvaluated to determine its suitability for siting a potential repository for high-level radioactive waste. It is underlain by both welded and nonwelded ash-flow tuffs of Miocene age. The water table at the site is approximately $2000 \mathrm{ft}$ below ground surface; water movement through this rather thick unsaturated zone is one of the keys to the performance of the potential repository.

Strontium isotope analyses of groundwater, perched water, soil carbonate, and calcite fracture coatings in the unsaturated zone indicate a soil carbonate source as well as a surficial link for perched water encountered deep in some wells. These data are consistent with downward percolation of water in the unsaturated zone, and that part of this flow must be transported through the fracture system at times.

Complete characterization of the $\mathrm{Sr}$ isotope systematics of the unsaturated zone requires analysis of pore water. Although some of the nonwelded units contain enough pore water to generate a few deciliters from a compression apparatus, the welded units contain very little water and are too strong to allow collapse of the waterbearing pores. Efforts to analyze water squeezed from the nonwelded units were further hampered by low Sr concentrations.

Drill Hole USW SD-7 was drilled using air as the drilling fluid, and no free water was encountered until a depth of $1600 \mathrm{ft}$ at a

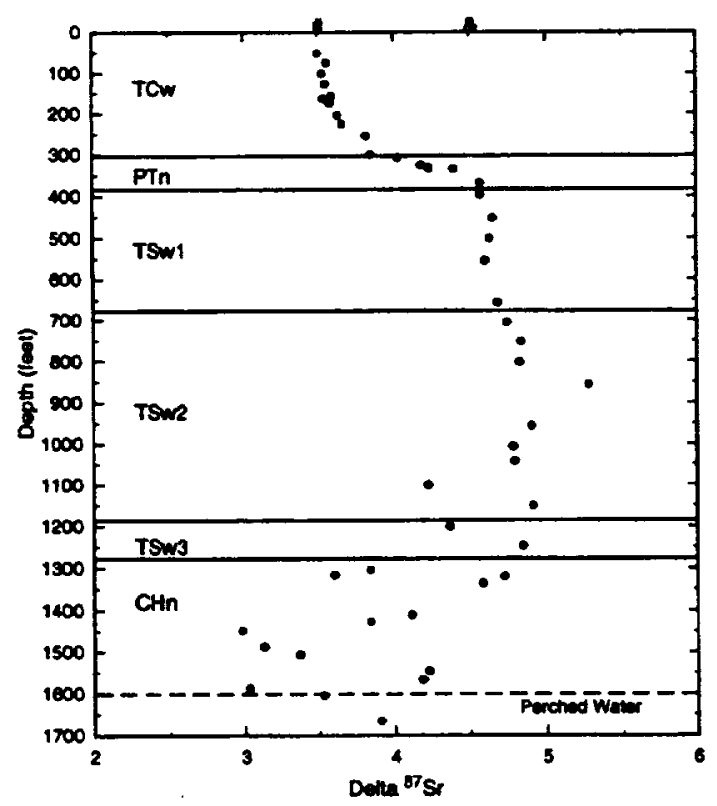

Fig. 1. perched water zone. Core samples were selected for study after storage for about 15 months at ambient conditions. Samples were selected to adequately represent the stratigraphy above the perched water, secondary calcite and natural fractures were avoided. Soluble pore-water salts were leached from 20 to 60 mesh fractions of crushed core using deionized water, and $\mathrm{Sr}$ was concentrated from this leachate using conventional ion-exchange methods.

Near the top of the core, the $\delta^{87} \mathrm{Sr}$ (permil deviation from seawater) value is about 3.6 , similar to the values found for calcite coatings on bedrock (\#) and the perched water in this hole. $\delta^{87} \mathrm{Sr}$ increases with depth in the Tiva Canyon welded tuff (TCw), and then increases sharply with depth in the more permeable nonwelded units of the Paintbrush Group (PTn). In the upper part of the Topopah Spring welded tuff (TSw 1 ), $\delta^{87} \mathrm{Sr}$ is fairly constant at values similar to those found in thick calcitic soils (\&) at the surface. There is no correlation of the pore-water $\delta^{87} \mathrm{Sr}$ with rock $\delta^{87} \mathrm{Sr}$, indicating that there is little rock influence on the pore water and that the laboratory leaching did not remove $\mathrm{Sr}$ from the rock. About $100 \mathrm{ft}$ above the basal vitrophyre of the Topopah Spring Tuff (TSw3), the systematic variations in $\delta^{87} \mathrm{Sr}$ with depth cease, especially in the underlying Calico Hills Formation. The $8^{87} \mathrm{Sr}$ values from below the perched water table are consistent with saturation of the rock with the perched water.

One hypothesis for this dataset is that mixing of two waters (a dilute water containing Sr dissolved from calcite coatings and eolian dust and a more concentrated water containing Sr derived from thick calcitic soils in drainages) occurs in the PTn; slight increases in $\delta^{87} \mathrm{Sr}$ with depth in the welded units are due to a small amount of water-rock interaction, and the scatter of values starting above TSw 3 is due to alteration including zeolitization. We are collecting data from other dry-drilled cores to test this and other hypotheses.

PETROGENESIS OF OVERSATURATED TRACHYTES ASSOCIATED WITH ALKALINE BASALTS IN THE CONTINENTAL CAMEROON VOLCANIC LINE (WEST AFRICA): CONSTRAINTS FROM ARGON-40ARGON-39 DATING AND FROM STRONTIUM, NEODYMIUM, AND OXYGEN ISOTOPES. A. Marzoli 1.2, P. Renne', and E. M. Piccirillo2, 'Berkeley Geochronology Center, Berkeley CA, USA, 'Dipartimento Scienze della Terra, Universitá Trieste, Italy.

Despite the broad similarity of basic alkaline volcanics, the most evolved rocks of the Cameroon Volcanic Line (CVL) oceanic and continental sectors are markedly different: The former are mainly undersaturated phonolites, and the latter are mainly oversaturated trachytes. This distinct association could suggest that assimilation of continental crustal material was crucial in the petrogenesis of continental trachytes.

New high-precision ${ }^{40} \mathrm{Ar} / 39 \mathrm{Ar}$ dating on sanidine separates of the Miocenic trachytes $(17.86 \pm 0.03$ to $16.05 \pm 0.02 \mathrm{Ma})$ of $\mathrm{Mt}$. Bambouto, in the continental sector of the CVL, allow calculation of precise initial $\mathrm{Sr}$ isotopic composition of the generally $\mathrm{Sr}$-poor, $\mathrm{Rb}$-rich trachytes (e.g., $\mathrm{Sr}<50 \mathrm{ppm}$; $\mathrm{Rb}>100 \mathrm{ppm}$ ). Some of the trachytes (uncontaminated trachytes, or UT), even highly evolved peralkaline ones, have initial ${ }^{87} \mathrm{Sr} /{ }^{86} \mathrm{Sr}$ compositions $(<0.70380)$ that are similar to that of the basalts, suggesting closed-system evolution from alkaline basalts to trachytes. This conclusion is supported by $\mathrm{Nd}$ and $\mathrm{O}$ isotopes $\left(\varepsilon_{\mathrm{Nd}}>5, \delta^{18} \mathrm{O}=6.3-6.7\right.$ in basalts 
and in UT). The possibility of deriving trachytes from alkaline basalts through closed-system, low-pressure (1 kbar) crystal fractionation was tested and supported using MELTS modeling [1]. Magnetite fractionation seems to play a fundamental role in pushing the magma to $\mathrm{SiO}_{2}$ enrichment and oversaturation.

Only a few trachytes have probably been strongly contaminated by crustal melts, having crustally signed isotopic $\mathrm{Sr}, \mathrm{Nd}$, and $\mathrm{O}$ compositions ( $>0.706,<0.5125,>7$ respectively) and distinctly low $\mathrm{Nb}$ and high $\mathrm{Ba}$ and $\mathrm{K}_{2} \mathrm{O}\left(\mathrm{K}_{2} \mathrm{O}>\mathrm{Na}_{2} \mathrm{O}\right.$, compared to $\mathrm{K}_{2} \mathrm{O}<\mathrm{Na}_{2} \mathrm{O}$ in UT).

On the Ngaoundere plateau, north of Mt. Bambouto, both undersaturated trachyphonolites and oversaturated trachytes have been sampled and dated $(11.3-8 \pm 0.02-9.28 \pm 0.02 \mathrm{Ma})$. Although the trachyphonolites have a lower initial $\mathrm{Sr}$ isotopic composition compared to trachytes (<0.70393 vs. $0.70563-0.70642$ ), AFC modeling suggests that both the Sr-rich trachyphonolites and the $\mathrm{Sr}$-poor trachytes ( $>500$ vs. $<80 \mathrm{ppm} \mathrm{Sr}$ ) have probably been contaminated very little by granitic material. The compositive difference between Ngaoundere undersaturated trachyphonolites and oversaurated trachytes cannot be simply explained by different degrees of crustal assimilation.

References: [1] Ghiorso and Sack (1995).

\section{CHARACTERIZATION OF CARBON IN ROCKS BY TIME- OF-FLIGHT SECONDARY MASS SPECTROMETRY. E. A.} Mathez ${ }^{1}$ and D. Mogk ${ }^{2},{ }^{1}$ Department of Earth and Planetary Sciences, American Museum of Natural History, New York NY 10024, USA, ${ }^{2}$ Department of Earth Sciences, Montana State University, Bozeman MT 59717, USA.

Nearly all crystalline rocks contain at least small quantities of C. In metamompic rocks formed from carbonaceous sedimentary protoliths, carbonates and graphite are common and their origins are obvious. In other crystalline rocks, $\mathrm{C}$ may exist as films on microcrack surfaces and as discrete particulates in cracks. Such C could well be relegated to the status of mere curiosities except that the films can influence bulk electrical conductivity, and the $C$ in nearsurface rocks may be related to a subsurface biological community. A major obstacle to deducing how the $\mathrm{C}$ forms is the few means of characterizing them. Accordingly, we report the applicability of time-of-flight secondary ion mass spectroscopy (TOF-SIMS).

In contrast to the more familiar dynamic SIMS, the aim of TOFSIMS is analysis of the immediate surface, which requires that it not be damaged by primary beam bombardment. This is accomplished by operating below the "static limit," or primary beam current at which modification of the analytical surface is not observable in the secondary ion spectrum. This is made possible by use of a time-offlight mass spectrometer coupled with a liquid metal primary beam source. The high spatial resolution $(<1 \mu \mathrm{m})$ of the primary beam and transmission of the spectrometer combine to allow acquisition of a complete mass spectrum to masses of thousands of amu. A particularly powerful feature of the modern instruments is that a spectrum is associated with every pixel in an image. The analytical depth resolution of TOF-SIMS is one or two monolayers, which is shallower than that of electron spectroscopic techniques. A disadvantage is that surface analytical information is difficult to quantify.

The instrument used in the present study is a PHI-Evans T-2000. The primary beam was ${ }^{69} \mathrm{Ga}$ operated at $15 \mathrm{KeV}$ with a sample bias of $\pm 3 \mathrm{KeV}$ (for positive or negative secondary ion spectra). Ion images $(60 \mu \mathrm{m}$ on a side and collected for $10 \mathrm{~min}$ ) were collected by rastering the primary beam, and analyses of individual regions were made at a mass resolution of $\approx 10,000$. The problem of working with nonconductive surfaces was ameliorated by placing a conductive grid on the surface. In order to preserve petrographic context, it is possible to polish samples and examine microcracks intersecting the polished surface at low angles. Polished samples were exposed to water and alumina slumies, but no obvious contaminants from the treatment were identified. Quasiflat microcrack surfaces may also be analyzed, the advantage being that the analytical surface is exposed only to air. Atmospheric contamination was removed by altemately sputtering $\left(\mathrm{Ga}^{+}\right)$and charge compensating with electrons for 2-s intervals. Sputtering obviously destroys the original surface, so the initial concem was that indigenous, high-mass molecules originally on the surface could be removed or destroyed by the process. Therefore, spectra were acquired both before and after sputtering.

Samples from several different settings have been studied. The mass spectra from an olivine gabbro xenolith from the Hualalai 1801 flow proved to be most complex and is illustrative. Pyroxene cleavage surfaces were extracted from the interior of the xenolith by mechanical disaggregation of the rock. In the positive mass spectra $\mathbf{H}$ is prominent but decreases with sputtering. Lithium and B are discemible, and $\mathrm{Li}$ remained after sputtering. Carbon and the fragments $\mathrm{CH}, \mathrm{CH}_{2}$, and $\mathrm{CH}_{3}$ are present in all spectra, and the latter decrease in abundance relative to $\mathrm{C}$ with sputtering. In the mass range $20-30 \mathrm{Na}, \mathrm{Mg}, \mathrm{Al}$, and $\mathrm{Si}$, the less-abundant isotopes ${ }^{25} \mathrm{Mg}$ and ${ }^{29} \mathrm{Si}$, fragments of the metal ions with $\mathrm{H}$, and various $\mathrm{C}-\mathrm{H}$ fragments are present. For example, two peaks representing $\mathrm{C}_{2} \mathrm{H}_{2}$ and $\mathrm{H}_{2} \mathrm{Mg}$, both nominally at mass 26 , are clearly resolved. In the mass range 37-57 there are numerous, uniquely identifiable $\mathrm{C}-\mathrm{H}$ fragments present on the unsputtered surface but generally absent from the sputtered one. Peaks representing $\mathrm{C} \times \mathrm{H}$ fragments with odd numbers of $\mathrm{H}$ are more intense than those with even numbers of $\mathrm{H}$, e.g., $\mathrm{C}_{2} \mathrm{H}_{3}$ vs. $\mathrm{C}_{2} \mathrm{H}_{4}$. The various isotopes of the first-row transition elements dominate in the mass range 50-70. Copper (masses 63 and 65) was found on the unsputtered surfaces but disappeared with sputtering. With few exceptions, peaks up to about mass 70 can be uniquely identified, but for those $>70$ identification becomes uncertain. There are several sets of low-intensity peaks in the mass ranges $70-110$ and $440-500$ in the unsputtered spectrum that, upon sputtering, disappeared. These heavy masses probably represent hydrocarbons since we can find no mineral fragments that sensibly account for them. Copper and masses $>150$ amu have not been observed in spectra from other samples. The major peaks in the negative spectra represent $\mathrm{H}, \mathrm{O}$, and $\mathrm{OH}$. Carbon and the $\mathrm{CH}$ fragments at masses 13,14 , and $15, \mathrm{HN}$, and $\mathrm{F}$ are all present. When masses 24,25 , and 26 are assigned to $\mathrm{C}_{2}, \mathrm{C}_{2} \mathrm{H}$, and $\mathrm{CN}$, an excellent fit is obtained for spectral masses representing $\mathrm{O}_{2}$ (32), S (32), $\mathrm{Cl}$ (35), and CNO (42). Additional evidence for the existence of $\mathrm{C}-\mathrm{N}$ fragments are the presence of small but resolvable peaks representing $\mathrm{C}_{2} \mathrm{~N}$ and $\mathrm{C}_{2} \mathrm{NH}$ at the shoulders of larger peaks from $\mathrm{C}_{3} \mathrm{H}_{2}$ and $\mathrm{C}_{3} \mathrm{H}_{3}$ (masses 38 and 39). These $\mathrm{C}-\mathrm{N}$ bearing fragments may be indicative of biogenic compounds. They are not removed with sputtering and are unique to the Hualalai samples. Peaks in the negative spectra above about mass 50 cannot be uniquely identified, but they are consistent with various fragments containing $\mathrm{COH}, \mathrm{COHS}$, and $\mathrm{COCl}$. 
PRESSURE AND TEMPERATURE DEPENDENCE OF SULFIDE SOLUBILITY IN MAFIC MAGMAS. J. A. Mavrogenes and H. St. C. O'Neill, Research School of Earth Sciences, Australian National University, Canberra, ACT 0200, Australia (John. Mavrogenes@anu.edu.au).

Sulfur in magmas affects a wide range of processes, including melt generation and fractionation, trace-element behavior, magmatic sulfide deposition, and mantle/core formation. However, its behavior in magmatic systems remains remarkably poorly understood. Although it is widely accepted that the factors controlling $S$ capacity at sulfide saturation (SCSS) in silicate melts are $\mathrm{fS}_{2}, \mathrm{fO}_{2}$, temperature, pressure, and melt composition, the relative effects of each of these variables is unknown. We undertook a series of pistoncylinder/multianvil experiments in which representative basaltic and picritic compositions were studied as a function of pressure, temperature, and $\mathrm{fO}_{2}$. Runs were rapidly quenched, polished, and viewed optically to ensure that an immiscible sulfide phase was present in the charge. Major elements and $S$ were then determined by EMPA-WDS. Experiments were considered successful if the capsule had sealed, it contained an immiscible sulfide phase, and the bulk composition of the melt remained unchanged during the experiment. At constant composition and temperature, S capacity decreases exponentially with pressure over the range of 5-90 kbar (Fig. 1).

Experiments in Fe capsules buffer $\mathrm{fO}_{2}$ at IW-2 log units ( $6 \mathrm{log}$ units below QFM) provide very reduced conditions, and the liquid sulfide phase has a metal-rich composition with molar Fe/S $>1$, which quenches to a mixture of $\mathrm{Fe}$ and $\mathrm{FeS}$. Experiments at higher $\mathrm{fO}_{2}$ were performed using capsules of Fe-Ir alloy, which also allows experimentation at higher temperatures (experiments in Fe capsules are limited to $1400^{\circ} \mathrm{C}$ because of the melting point of $\mathrm{Fe}$ ). The exponential decrease in SCSS shown for basalt $\left(1400^{\circ}-1800^{\circ} \mathrm{C}\right.$ and 5-90 kbar) also holds for picritic melts. Over this range the pressure is a more important control on SCSS than temperature, such that a melt generated in equilibrium with residual sulfide in the mantle (i.e., $\mathrm{S}$ saturated) that ascends along an adiabat cannot arrive at the surface saturated in $S$ unless a significant compositional change occurs (via fractionation or assimilation). This simple obsèrvation is of extreme importance in understanding the origin of magmatic

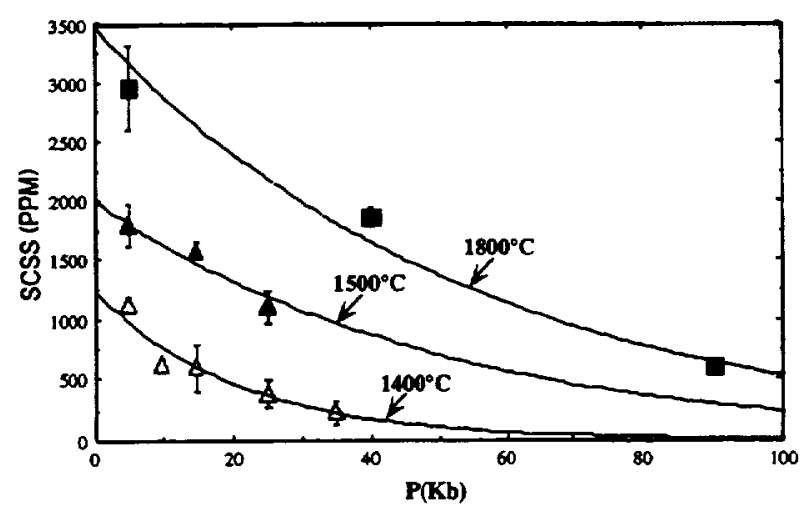

Fig. 1. Sulfide capacity at sulfide saturation (SCSS) of basalt at $1400^{\circ}$ (Fecapsule), $1500^{\circ}$ (Felr-capsule), and $1800^{\circ} \mathrm{C}$ (Felr-capsule). sulfide deposits, and suggests that sedimentary $S$ assimilation plays an important role in the genesis of these deposits.

MAGMA AND PLATINUM-GROUP-ELEMENT SOURCES IN THE BUSHVELD COMPLEX INFERRED FROM RHENIUM-OSMIUM, RUBIDIUM-STRONTIUM, AND PLATINUM-GROUP-ELEMENT SYSTEMATICS. T. E. McCandless' ${ }^{1}$ J. Ruiz' ${ }^{1}$, and B. I. Adair ${ }^{2},{ }^{1}$ Department of Geosciences, University of Arizona, Tucson AZ 85721, USA (diamonds@geo. arizona.edu), ${ }^{2}$ CSIRO, Brisbane, Australia.

The Bushveld Complex qualifies as a large igneous province because it covers nearly $70,000 \mathrm{~km}^{2}$. The Rustenburg Layered Series averages $5-7 \mathrm{~km}$ in thickness with a volume of at least $350,000 \mathrm{~km}^{3}$, twice the volume of the Columbia River Basalts. The Rustenburg Layered Series is famous for laterally extensive layers of anorthosite and chromitite that are correlated in outcrops over $300 \mathrm{~km}$ apart and contain $90 \%$ of the world's is platinum-groupelement (PGE) reserves. Research spanning nearly a century has recently focused on determining magma and PGE sources. In spite of these voluminous studies, the magmatic history and the processes responsible for the PGE mineralization remain unclear.

We address these problems by focusing on chromitites from the Brits graben in the westem Bushveld and from the Winterveld area in the eastern Bushveld. The samples span the upper $600-1000 \mathrm{~m}$ of the Upper Critical Zone, where the greatest textural and chemical changes occur. The chromitites are comprised of chromite, poikilitically enclosed in plagioclase + orthopyroxene, with base metal and PGE sulfides in chromite or as intergranular phases. Samples were crushed such that chromite grains separated from the orthopyroxene and plagioclase as unbroken crystals. Several grams of crushed sample were heated in $16 \mathrm{~N} \mathrm{HNO}_{3}$ to recover Os [1], and bulk ${ }^{187} \mathrm{OS} /{ }^{188}$ Os ratios were obtained via ICP-MS. The residue solution was analyzed for PGE ratios using ICP-MS. The solid residues were cleaned and chromite and plagioclase separated using electromagnetic techniques. The chromites were sieved and size fractions with the most unbroken chromite crystals were treated using modified Carius tube dissolution and distillation [2] and subjected to $R e$ and Os isotope analysis via NTIMS [3]. Plagioclase separates were analyzed for $\mathrm{Rb}$ and $\mathrm{Sr}$ isotopes.

Bulk ${ }^{187} \mathrm{Os} / 188$ Os ratios at the lowest chromitite $(\sim \mathrm{LGS}, 6)$ are more radiogenic than expected for a mantle-derived magma at $2.0 \mathrm{Ga}(-0.13$ vs. 0.11$)$ and become more radiogenic with height. The similar increase at both sample localities suggests that the magma source became more radiogenic in Os prior to emplacement into the Transvaal Supergroup country rocks. For the chromite separates, Re and Os range from 0.17 to $36.0 \mathrm{ppb}$ and 13 to $300 \mathrm{ppb}$ respectively. Initial ${ }^{187} \mathrm{Os} / 188 \mathrm{Os}$ ratios for the $\mathrm{LG} 6$ in the eastem Bushveld are near mantle values $(0.11)$ but more radiogenic in higher chromitites (UGI, UG2 $=0.14$ ). Initial ${ }^{187} \mathrm{Os} /{ }^{188} \mathrm{Os}$ ratios in the Brits graben are radiogenic (0.13-0.16), with less-radiogenic values lower in the section. Paladium/rubidium ratios (Pd is more mobile than $\mathrm{Ru}$ in hydrothermal fluids) increase with height in intergranular phases but remain constant in chromite. The observations suggest that the magma source for the Bushveld was crustally contaminated by the time of emplacement of the upper critical zone, and that subsequent to emplacement, Os and other PGE were enriched upward to the Merensky Reef by fluids that postdated 
crystallization of the chromite.

References: [1] McCandless T. E. and Ruiz J. (1991) Geology, 19, 1225-1228. [2] Freydier C. et al. (1997) Geology, submitted. [3] Creaser R. A. et al. (1991) GCA, 55, 397-401.

\section{EXPERIMENTAL TESTS OF ABIOTIC ORGANIC SYN.} THESIS IN HYDROTHERMAL SYSTEMS. T. McCollom, B. Simoneit, and G. Ritter, College of Oceanic and Atmospheric Sciences, Building 104, Oregon State University, Corvallis OR 97331, USA (tmccoll@@oce.orst.edu).

Ever since their discovery in the late 1970s, mid-ocean-ridge hydrothermal systems have received a great deal of attention as a possible site for the origin of life on Earth (and for potential origins of life on Mars and elsewhere as well). One of the principal reasons that these systems have attracted such attention is that the physical and chemical conditions present in submarine hydrothermal environments favor the synthesis of organic compounds from inorganic precursors (such as $\mathrm{CO}_{2}, \mathrm{H}_{2}, \mathrm{~N}_{2}, \mathrm{H}_{2} \mathrm{O}, \mathrm{H}_{2} \mathrm{~S}$ and $\mathrm{SO}_{4}{ }^{-2}$ ), providing a source of organic substrates for the evolution of the first metabolism [1]. Because no modern-day hydrothermal systems are free from the influence of organic compounds derived from biologic processes, confirmation of the potential for organic synthesis in hydrothermal systems must come from laboratory experiments.

There have been a number of experimental studies that have produced organic compounds from inorganic substrates in the presence of $\mathrm{H}_{2} \mathrm{O}$ using heat as an energy source. In almost every case, however, the physical and chemical conditions within the reaction vessels in these studies have been quite different from conditions that were likely to have been present in prebiotic hydrothermal systems [2]. For example, although the synthesis of amino acids and purines have been reported in several laboratory experiments, these compounds were only produced when highly reactive compounds (e.g., formaldehyde, HCN, hydroxylamine) were included among the reactants in concentrations many orders of magnitude higher than can reasonably be expected to have occurred in hydrothermal environments. These experimental mixtures are frequently so reactive that the reaction proceeds readily at $25^{\circ} \mathrm{C}$. In addition, laboratory systems often include extremely reducing conditions and the presence of a gas phase, which may not be appropriate for the hydrothermal systems under study.

While the experimental studies performed to date leave little doubt that chemical pathways exist for the abiotic synthesis of organic compounds, the differences between laboratory and natural hydrothermal conditions leaves it unclear whether the observed pathways represent reactions that could produce significant amounts of organics in hydrothermal systems. Assessing the potential for organic synthesis in prebiotic hydrothermal systems requires a better understanding of reaction pathways and how they are affected by the chemical and physical variables of the environment, and additional laboratory experiments are needed under conditions that more closely resemble the physical and chemical conditions of hydrothermal environments.

Several ongoing research projects in our lab are directed toward addressing these issues. Presently, our research focuses on three areas: (1) understanding the factors (kinetic vs. thermodynamic) that control reactions involving organic compounds in hydrothermal systems, (2) the formation of oxygenated hydrocarbons during
Fischer-Tropsch-type synthesis in an aqueous environment, and (3) synthesis of amino acids under mineral-buffered hydrothermal conditions. We will discuss our efforts to use numerical models to define physical and geochemical conditions in prebiotic hydrothermal environments that are likely sites for prebiotic synthesis, contrast these conditions with those that have been used in experimental studies, and discuss ways that experiments may be improved to more closely represent hydrothermal environments. We will also present results from our current experimental investigations, including the hydrothermal reactivity of aromatic compounds, the formation of organic compounds from decomposition of Fe oxalate and formic acid, and synthesis of amino acids during serpenitization of olivine.

References: [1] Shock E. L. (1992) Orig. Life Evol. Biosph., 22, 67-107. [2] Shock E. L. (1992) Orig. Life Evol. Biosph., 22, $135-146$.

\section{TRACE-ELEMENT SYSTEMATICS IN PORTESS CORAL:} HIGH-RESOLUTION PROXIES OF SEA-SURFACE TEMPERATURE. M. T. McCulloch, C. Alibert, D. Sinclair, G. Mortimer, and L. Kinsley, Research School of Earth Sciences, Australian National University, Canberra, ACT 0200, Australia.

Porites corals can live for up to $300-400$ years, and preserve within their carbonate skeleton a continuous record of the ambient sea-surface temperature (SST). Retrieving these high-resolution (approximately weekly) records of SST is important not only for understanding the past history of climate change, but also for distinguishing between the effects of recent twentieth-century anthropogenic forcing vs. "natural" fluctuations in climate. Stochiometric trace-element constituents of the aragonitic coral skeleton have temperature-dependent seawater/coral partition coefficients that provide a first-order proxy for SST. Here we report the results of a high-resolution laser-ablation (LA) ICP-MS calibration of the B! $\mathrm{Ca}, \mathrm{Mg} / \mathrm{Ca}, \mathrm{Sr} / \mathrm{Ca}$, and $\mathrm{U} / \mathrm{Ca}$ ratios, vs. measured $\mathrm{SST}$ for Porites coral from Davies Reef, in the Great Barrier Reef of Australia. Proxy SSTs derived from high precision (TIMS) $\mathrm{Sr} / \mathrm{Ca}$ ratios are also shown for an $\sim 30$-yr record, sampled at fortnightly intervals.

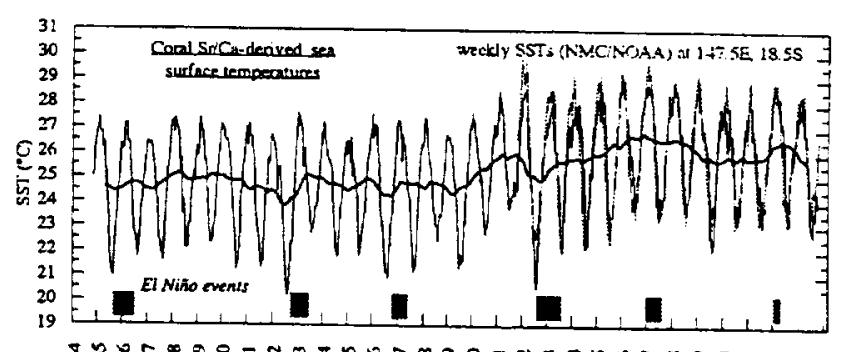

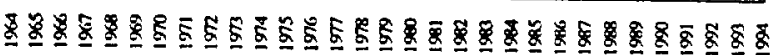

Fig. 1. Sea-surface temperature record from high-precision (TIMS) $\mathrm{Sr} / \mathrm{Ca}$ ratios for a Porites mayeri coral from the Great Barrier Reef of Australia for the $\sim 30$-yr period from 1965 to 1993 . The coral has been sampled at approximately weekly resolution with a total of 1034 samples analyzed. The coral record is in good agreement with the available satellite-derived weekly SSTs (light gray) for the years 1982-1993 $(r=0.9)$. The heavy solid line shows the mean annual temperature with a pronounced increase beginning in 1979. 
A UV excimer laser with an $\sim 20 \times 500-\mu \mathrm{m}$ rectangular beam has been used in conjunction with an ICP-MS for continuous in situ trace-element analyses of $\sim 5-\mathrm{cm}$-long coral slices. For an $\sim 6^{\circ} \mathrm{C}$ seasonal range, the $\mathrm{Mg} / \mathrm{Ca}, \mathrm{U} / \mathrm{Ca}$, and $\mathrm{B} / \mathrm{Ca}$ ratios exhibit large variations $(\sim \pm 15 \%, \pm 12 \%, \pm 10 \%)$ that are well correlated $(r=0.78$, $-0.83,-0.91)$ with SST, whereas Sr/Ca shows much smaller $( \pm 2 \%)$ variations.

Calibrations of elemental ratios vs. SST have a linear relation-

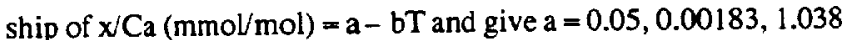
and $b=-0.192,3.75 \times 10^{-5}, 0.0213$, where $x$ refers to $\mathrm{Mg}, \mathrm{U}$, and $\mathrm{B}$ respectively. High-precision TIMS Sr/Ca analyses using $0.250 \times$ $2.5-\mathrm{mm}$ slices gives $\mathrm{a}=10.48$ and $\mathrm{b}=0.0615(\mathrm{r}=-0.98)$. The LAICP-MS analyses thus provide well-resolved seasonal SST signals, but the TIMS Sr/Ca gives higher-fidelity $\left( \pm 0.3^{\circ} \mathrm{C}\right)$ temperatures.

A 30-yr high-resolution TIMS Sr/Ca record (Fig. 1) clearly shows the cooler winters that predate the mature phase of 1965 , 1972, and 1982-1983 El Niños in the Great Barrier Reef region of Australia. The mean coral-derived $\mathrm{Sr} / \mathrm{Ca}$ temperatures also show a pronounced increase of $\sim 1.3^{\circ} \mathrm{C}$, commencing in 1979. This warming is consistent with, but of larger amplitude than, the overall increase in land-ocean temperatures of the southem hemisphere $\left(\sim 0.4^{\circ} \mathrm{C}\right)$, the latter often being attributed to greenhouse warming. Longer, multicentury, high-resolution records of the type presented here thus have the potential of better constraining the relative magnitude of greenhouse-induced global warming vs. natural climate variability on decadal and century timescales.

\section{A COMPARISON OF PROVENANCE INFORMATION OBTAINED FROM DETRITAL ZIRCON AND FELDSPAR GRAINS IN A SANDSTONE FROM THE DEVONIAN CATSKILL CLASTIC WEDGE. D. K. McDaniel ${ }^{1}$ and S. M. McLennan', 'Department of Earth and Space Sciences, State University of New York, Stony Brook NY 11794-2100, USA (mcdaniel@pbisotopes.ess.sunysb.edu; smclennan@ccmail. sunysb.edu).}

Modern studies of sedimentary provenance rely heavily on $\mathrm{U}-\mathrm{Pb}$ ages of detrital zircon grains. Because of the durability of zircon in the sedimentary environment, detrital zircons may survive many cycies of erosion and sedimentation. Thus, in a multicycle sedimentary rock, U-Pb zircon ages will tend to reflect relatively old and varied sources. Zircons generally make up $\ll 1 \%$ of the mass of a sediment, whereas feldspar can comprise nearly $50 \%$ of some sandstones. Thus, an understanding of the sources of feldspar may provide an understanding of the provenance of a significant fraction of the rock. Feldspar is degraded early in the sedimentary environment and rarely survives multiple cycles of sedimentation. Hence, provenance information obtained from feldspar should be more biased toward first-cycle sources.

We undertook a study to contrast provenance information obtained from detrital zircons and feldspar. We selected an arkosic sandstone from the Devonian "Catskill redbeds" of the Appalachian foreland. These rocks represent molasse sedimentation during the Acadian Orogeny (ca. 380-400 Ma) of the North American margin. Uranium-lead ages of 45 randomly chosen detrital zircon grains, determined by the SHRIMP-1 ion microprobe, are bimodal, with approximately $60 \%$ having 1000-1300-Ma (Grenville) ages [1]. The remaining $40 \%$ have ages between 420 and $480 \mathrm{Ma}$, consistent

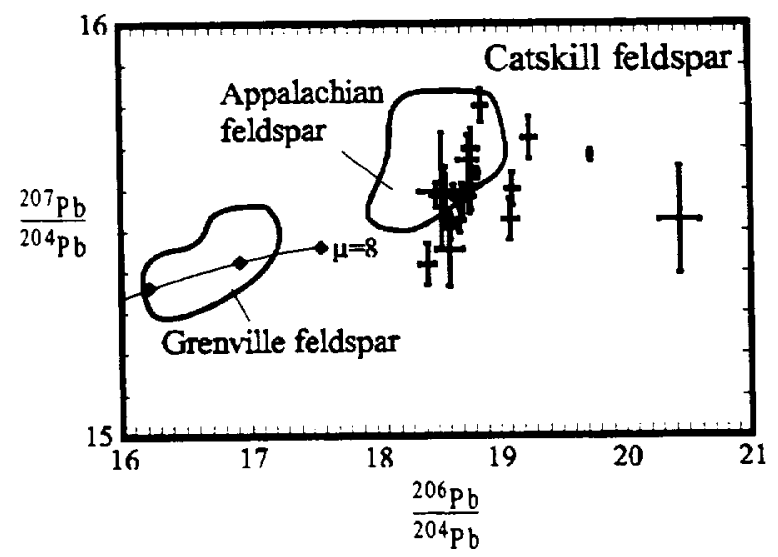

Fig. 1. Plot of ${ }^{207} \mathrm{~Pb} / 204 \mathrm{~Pb}$ vs. ${ }^{206} \mathrm{~Pb} / 204 \mathrm{~Pb}$ for detrital feldspar from the Devonian Catskill clastic wedge. Fields of Appalachian and Grenville igneous feldsparcompiled from several sources.

with derivation from rocks formed during the Taconian orogeny. Out of $\mathbf{4 5}$ zircons, none recorded unambiguous Acadian ages.

Since feldspar favors $\mathrm{Pb}$ greatly over $\mathrm{U}, \mu\left({ }^{238} \mathrm{U} /{ }^{204} \mathrm{~Pb}\right)$ in feldspar approaches 0 , and $\mathrm{Pb}$ isotopic compositions provide an accurate estimate of initial $\mathrm{Pb}$ isotopic compositions. Detrital feldspars can therefore be used to isotopically "fingerprint" terranes of different ages and composition. We have analyzed both single grains and populations comprising four or more grains of detrital feldspar from the same Catskill sample from which the zircons were analyzed. These are plotted on Figure 1 along with fields of published feldspar compositions for Grenville- and Appalachian-aged igneous rocks. Of the Catskill feldspars, none fall within or near the field of published Grenville analyses. Instead, most of the detrital feldspar compositions indicate derivation from Paleozoic Appalachian sources. The origin of some of the more radiogenic feldspar is not clear, but they may be derived from rocks metamorphosed in a Paleozoic high- $\mu$ environment.

Grenville ages make up $60 \%$ of the U-Pb ages in detrital zircons from the Catskill sample, whereas none of the analyzed feldspars record Grenville provenance. The disparity indicates that the zircons preferentially record the age of a multicycle component. Conversely, more readily weathered feldspar grains favor first- and/or second-cycle sources (i.e., Taconian and/or Acadian).

Our results serve to underline the question of the definition and interpretation of sedimentary provenance. In such studies, it is necessary to explicitly define the aspect of provenance being assessed. For example, zircon geochronology provides an understanding of the long-term history of sedimentary sources, whereas feldspar compositions provide information about minimally processed sources. Both of these methods, in turn, contrast with whole-rock Nd and $\mathrm{Pb}$ isotopic compositions that provide valuable insight into the average source of the carriers of $\mathrm{Nd}$ (e.g., trace minerals and clays) and $\mathrm{Pb}$ (e.g., feldspar, trace minerals and clays).

References: [1] McLennan S. M. et al. (1995) V. M. Goldschmidt Conference, Prog. \& Abstr., 72.

REGIONAL GRADIENTS IN EUROPEAN HOLOCENE CLIMATE: NEW EVIDENCE FROM SPELEOTHEM 
CALCITE. F. McDermott ${ }^{1}$, S. Frisia ${ }^{2}$, I. J. Fairchild ${ }^{3}$, Y. Huang ${ }^{4}$, A. Longinelli5, B. Spiro ${ }^{6}$, C. J. Hawkesworth 4 , E. Keppens ${ }^{7}$, and K. van der Borg8, 'Department of Geology, University College Dublin, Belfield, Dublin 4, Ireland, ${ }^{2}$ Museo Tridentino di Scienze Naturali, via Calepina 14, 38100 Trento, Italy, ${ }^{3}$ Department of Earth Sciences, Keele University, Staffs ST5 5BG, UK, 'Department of Earth Sciences, The Open University, Milton Keynes, UK, SIMPUT, Dipartimento Scienze della Terra, via E. Weiss 6, Trieste 34100 , Italy, ${ }^{6}$ NERC Isotope Geosciences Laboratory, Keyworth, Nottingham NG12 5GG, UK, 'Department of Geochronology, Vrije Universiteit Brussel, Pleinlaan 2, B-1045, Brussels, Belgium, ${ }^{8}$ Department of Subatomic Physics, Universiteit Utrecht, Princetonplein 5, Postbus 80.000,3508 TA Utrecht, The Netherlands.

An important challenge in palaeoclimatology is to establish well-dated quantitative records of past climatic conditions on the continents. Under favorable conditions, secondary cave calcites (e.g., stalagmites) can record such conditions because (1) cave air temperatures are buffered and reflect long-term $(2-3 \mathrm{yr})$ average annual atmospheric temperatures, (2) cave interiors are high-humidity environments where the stable isotope ratios of $O$ and $C$ in secondary calcite may be precipitated in isotopic equilibrium with cave seepage water, and (3) selected trace-element ratios in speleothem calcite (e.g., $\mathrm{Mg} / \mathrm{Ca}, \mathrm{Sr} / \mathrm{Ca}$ ) are sensitive to changes in palaeohydrological conditions. Here we present a new multi-approach study of four Holocene stalagmites, from caves selected along a northwest-southeast traverse across Europe (southwestem Ireland, Belgium, southeastern France, and northern Italy). Speleothem calcite is an ideal material for high-precision ${ }^{230} \mathrm{Th}$ ${ }^{234} \mathrm{U}$ dating, and in this study, tight chronological control is provided by 8-12 thermal ionization mass-spectrometric (TIMS) dates along the growth axis of each speleothem. Accelerator-mass-spectrometric (AMS) ${ }^{14} \mathrm{C}$ dates have also been completed on the same axial samples and provide unique constraints on changes with time in the climate-driven $\mathrm{C}$ budget (biogenic vs. host-rock) of each speleothem. Time-series $\delta^{18} \mathrm{O}$ data obtained on samples drilled along the axes of

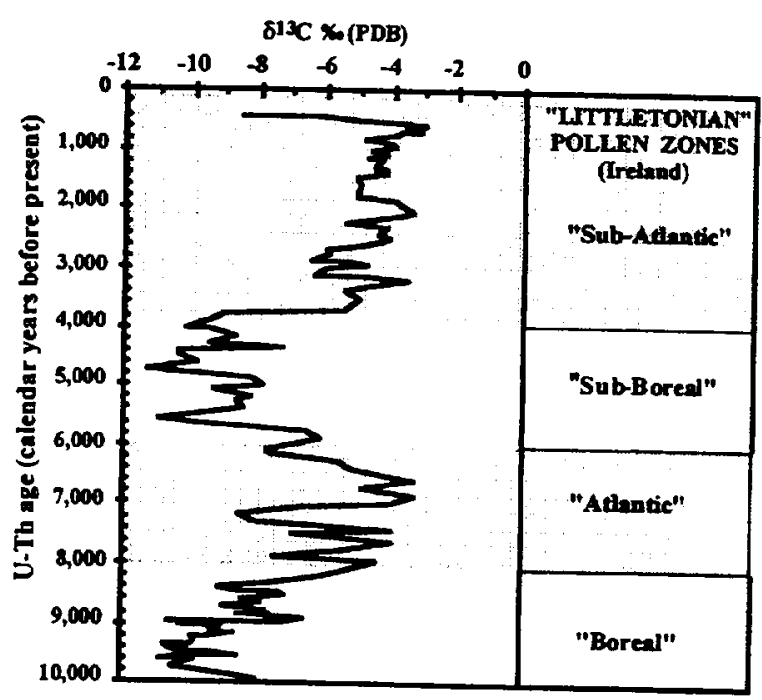

Fig. 1. each speleothem show the following ranges: $-4.29 \%$ to $-1.95 \%$ $-6.54 \%$ to $-3.97 \%$ o $-5.34 \%$ o to $-2.88 \%$ and $-8.04 \%$ to $-6.22 \%$ o for the Irish, Belgian, French and Italian stalagmites respectively. In these regions of Westem Europe where Holocene palaeotemperature changes can be constrained independently by other proxy data (e.g. pollen and beetle data), the speleothem $O$ isotope results may be used to reconstruct changing regional gradients in the $\delta^{18} \mathrm{O}$ of precipitation through the Holocene. The possible implications of these changes for atmospheric circulation and storm track pattems will also be discussed. Carbon isotopes along the same axial profiles exhibit large but coherent variations, typically in the range $-11 \%$ to $-3 \%$ for $\delta^{13} \mathrm{C}$. Carbon isotope shifts of up to $8 \%$ in the Irish stalagmite coincide with previously recognized $\left({ }^{14} \mathrm{C}\right.$ dated) pollen zones for the region (Fig. 1), and a model to account for these large shifts will be presented. The first-order changes in $\delta^{13} \mathrm{C}$ along the French and Italian stalagmites are similar to each other, and reflect precipitation-driven vegetation changes. The new trace-element data will be presented, and the reasons for correlated and uncorrelated changes in $\mathrm{Mg} / \mathrm{Ca}$ and $\mathrm{Mg} / \mathrm{Sr}$ with $\delta^{13} \mathrm{C}$ will be explored.

THE COMPOSITION OF ARCHEAN KOMATIITES. W. F. McDonough ${ }^{1.2}$, S. M. Eggins ${ }^{2}$, S.-S. Sun ${ }^{2.3}$, and I. H. Campbell2, 'Earth and Planetary Sciences, Harvard University, 200xford Street, Cambridge MA 02138, USA (mcdonough@eps.harvard.edu), ${ }^{2}$ Geology and Research School of Earth Sciences, Australian National University, Canberra, Australia, ${ }^{3}$ Australian Geological Survey Organisation, Canberra, Australia.

Archean komatiites are samples from the earliest portions of our geological record that provide important constraints on a wide variety of petrological, geochemical, and geophysical properties and processes of the early Earth's mantle. Their compositions have been used to demonstrate that larger degrees of partial melting are involved in their genesis relative to modem magmas. The large degree of partial melting associated with their genesis means that the compositions for a large number of elements are comparable to that of their source region. Their geological settings and compositional characteristics have led researchers to suggest that these magmas were erupted in intraplate settings, analogous to modern ocean island basalts.

We have undertaken a comprehensive trace-element study of well-characterized komatiites from southem Africa, westem Aus-

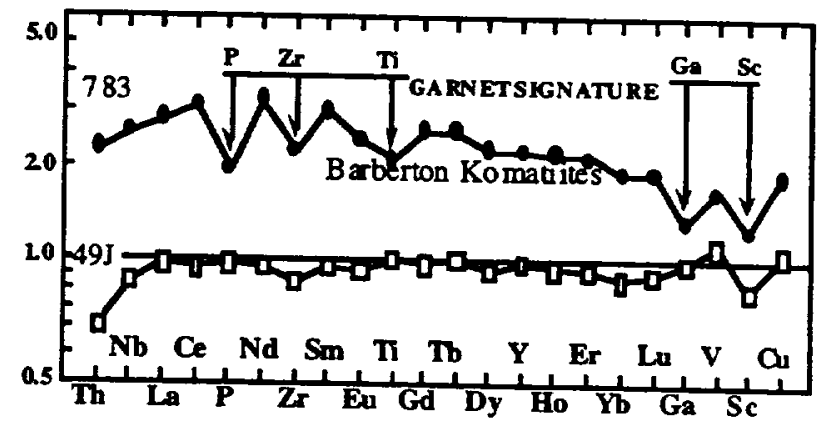

Fig. 1. Mantle-normalized abundances for komatiites from Barberton. South Africa. 


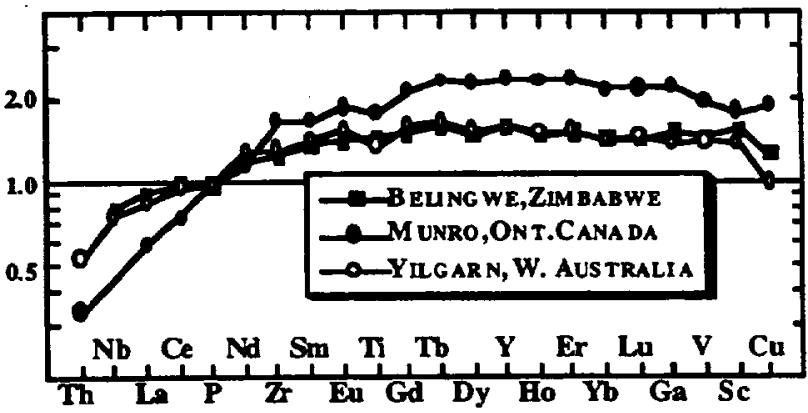

Fig. 2. Mantle-normalized abundances for komatiites from Africa, Canada, and Australia.

tralia, and eastern Canada [1-3]. Our sample set includes both Aldepleted (or Barberton-type) and Al-undepleted (or non-Barberton type) komatiites. Barberton-type komatiites, which are generally restricted to the early Archean, have high $\mathrm{Ca} / \mathrm{Al}$ and $\mathrm{Ti} / \mathrm{Al}(\sim 2 \mathrm{x}$ chondrite) and depletions in P, Sc, and heavy REE compared to the non-Barberton-type komatiites, which are common throughout the Archean. Our ICP-MS data are combined with previously published data to provide a basis for the following observations and discussion.

There are marked differences in the REE and mantle-normalized patterns (Fig. 1) for the Al-depleted (783) and Al-undepleted (49J) type komatiites from Barberton Mountain Land, South Africa. Previous work $[4,5]$ demonstrated that these lavas are from isotopically similar sources with near-chondritic $\mathrm{Nd}$ and $\mathrm{Hf}$ isotopic compositions. Similar isotopic compositions and differences in trace-element abundances are consistent with the suite being derived from a single melting column tapped at different levels in the mantle. The Al-depleted komatiites from Barberton are derived from a source with residual majoritic garnet or experienced majorite separation during ascent. Thus, these later magmas have been generated at pressures near to or within the Transition Zone ( $\geq 10 \mathrm{GPa}$ ), where majorite is a volumetrically important phase. The Al-undepleted komatiites from Barberton are derived from a source with no residual majoritic gamet and thus may be from similar depth and higher degrees of melting, or more likely are from shallower depths, where gamet is less modally abundant relative to pyroxenes. No evidence for melt separation in the Lower Mantle (perovskite field) is recognized.

The REE and mantle-normalized patterns (Fig. 2) for the Alundepleted komatiites from various $2.7-\mathrm{Ga}$ localities show strikingly similar characteristics. These samples show no evidence for gamet or clinopyroxene involvement in their generation and commonly have $\varepsilon_{\mathrm{Nd}}$ isotopic compositions in the range 3 to 4 , implying their derivation from a source that has experienced a time-integrated depletion of $\mathrm{Nd}$ relative to $\mathrm{Sm}$. In sharp contrast to the A]undepleted early Archean sample (49J, Fig. 1), these younger komatiites have marked light REE depletions, implying that significant crustal extraction had affected the mantle by this time.

These samples also provide key observations about incompatible element ratios in the Archean mantle. Values of P/Nd, Sc/V, and $\mathrm{Ga} / \mathrm{Al}$ are comparable to those in modern MORBs and peridotites and thus constrain core formation processes to predate the sampling of these Archean lavas.
References: [1] Nesbitt R. W. and Sun S.-S. (1976) EPSL, 31 , 433-453. [2] Sun S.-S. and Nesbitt R. W. (1978) Contrib. Mineral. Petrol., 65, 301-325. [3] Nesbitt R. W. et al. (1979) Can. Mineral., 17, 165-186. [4] Jahn B. M. et al. (1982) Contrib. Mineral. Petrol., 80, 25-40. [5] Gruau G. et al. (1990) GCA, 54, 3095-3101.

LEAD-NEODYMIUM ISOTOPIC EVIDENCE FOR PROVENANCE AND POSTDEPOSITIONAL LEAD TRANSPORT IN THE EARLY PROTEROZOIC HURONIAN SUPERGROUP, CANADA. S. M. McLennan ${ }^{1,2}$, A. Simonetti ${ }^{1.3}$, and S. L. Goldstein ${ }^{1.4}$, 'Max-Planck-Institut für Chemie, Mainz, Germany, ${ }^{2}$ Department of Earth and Space Sciences, State University of New York, Stony Brook NY 1 1794-2100, USA (smclennan@ ccmail.sunysb.edu), ${ }^{3}$ GEOTOP, Université du Quebec à Montreal, Montreal PQ, H3C 3P8, Canada (c3204@er.uqam.ca), 'LamontDoherty Earth Observatory, Palisades NY 10964, USA (sgoldst@ ldgo.columbia.edu).

The Huronian Supergroup comprises up to $12 \mathrm{~km}$ of mostly siliciclastic sedimentary rocks deposited at an evolving rift/passive margin sometime between 2496 and $2215 \mathrm{Ma}$. The sequence was deformed and metamorphosed during development of the Penokean Orogeny, to the south, at about 1850-1800 Ma. The southern, more deformed parts of the Huronian were intruded by felsic plutons at about 1750-1700 Ma and again at about $1450 \mathrm{Ma}$.

Neodymium isotopic data for fine-grained formations (McKim, Pecors, Gowganda, and Gordon Lake) indicate the provenance was dominated by the Late Archean Superior Province to the north and west. The stratigraphically highest Gordon Lake Formation has a distinctive $\mathrm{Nd}$ isotopic composition with $\mathrm{T}_{\mathrm{DM}}$ being $100-400 \mathrm{Ma}$ younger than the underlying mudstones. This suggests that the provenance changed toward the end of Huronian deposition, consistent with a change toward more negative Eu anomalies in the Gordon Lake [1].

Lead isotopes provide evidence for two episodes of regional post depositional disturbance of the U-Pb system. Lower Huronian (McKim, Pecors) samples align along ${ }^{207} \mathrm{~Pb} /{ }^{204} \mathrm{~Pb}-206 \mathrm{~Pb} /{ }^{204} \mathrm{~Pb}$ slopes equivalent to $2166 \pm 75 \mathrm{Ma}(\mathrm{MSWD}=117, \mathrm{n}=9$ ) and $2212 \pm 92 \mathrm{Ma}$ (MSWD $=9.1, n=5$ ) respectively. These ages are at the youngest limit of the sedimentation age and are within uncertainty of the Nipissing Diabase (2219 $\pm 4 \mathrm{Ma}$ ) [2], a ubiquitous feature in the region that may have intruded while parts of the Huronian were unconsolidated [3]. We interpret these ages to represent widespread diagenetic processes, possibly associated with Nipissing Diabase intrusion. Lead-206/lead-204 varies mostly from 19 to 34 (up to 59), whereas values for $\kappa\left({ }^{232} \mathrm{Th} /{ }^{238} \mathrm{U}\right)$ are mostly between 2 and 4 , only slightly below the upper crustal value of 4 . Changes in ${ }^{206} \mathrm{~Pb} /{ }^{204} \mathrm{~Pb}$ imply changes in $\mu\left({ }^{238} \mathrm{U} /{ }^{204} \mathrm{~Pb}\right)$ by factors of $<1$ to 5 and, given the likely changes in $\kappa$, suggest that resetting of the $\mathrm{U}-\mathrm{Pb}$ system involved some degree of $\mathrm{Pb}$ loss, with or without $\mathrm{U}$ gain.

The upper Huronian displays more complex $\mathrm{Pb}$-isotope systematics. Data align most closely to ${ }^{207} \mathrm{~Pb} / 204 \mathrm{~Pb}-206 \mathrm{~Pb} / 204 \mathrm{~Pb}$ slopes of ca. $1700 \mathrm{Ma}$, with regional variations in $207 \mathrm{~Pb} / 204 \mathrm{~Pb}$. For the Gowganda and Gordon Lake Formations, ${ }^{206} \mathrm{~Pb} /{ }^{204} \mathrm{~Pb}$ ratios are in the ranges 23-43 and 30-115 respectively and imply changes in $\mu$ by factors commonly $>2$ (and up to 12.5). Values for $\kappa$ are in the range of 2-4 and, accordingly, $\mathrm{Pb}$ loss appears to dominate this disturbance. 
In both the Gowganda and Gordon Lake Formations, elevated ${ }^{206} \mathrm{~Pb} / 204 \mathrm{~Pb}$ correlates with postdepositional addition of K. Potassium-metasomatism has been demonstrated in the Serpent Formation and in paleosols developed at the unconformity beneath the Huronian Supergroup [4], the latter being dated at 1690-1730 Ma by whole-rock Rb-Sr methods [5]. Widespread metasomatism, resulting in $\mathrm{K}$ addition and $\mathrm{Pb}$ loss, was likely related to northerly directed basinwide fluid movement in response to the development of the Penokean Orogen to the south [4]. Since $\mathrm{Pb}$ isotope systematics in the lower Huronian appear unaffected by this second disturbance, apart from the natural conduits provided by unconformity surfaces, it appears that fluid movement was mainly restricted to the upper levels of this sedimentary succession.

References: [1] McLennan S. M. et al. (1979) GCA, 43, 375388. [2] Corfu G. and Andrews A. J. (1986) Can. J. Earth Sci., 23, 107-109. [3] Young G. M. (1995) Can. Mineral, 33, 921-922; Young G. M., personal communication. [4] Fedo C. M. et al. (1997) Precambrian Res., in press. [5] Roscoe S. M. et al. (1992) Geol. Surv. Canada Paper 92-1, 119-124.

OXIDE PHASES IN MID-CA YMAN-RISE GABBROS. J. K. Meen and D. Elthon, Department of Chemistry, University of Houston, Houston TX77204-5641,USA (Jmeen@uh.edu; Elthon@ uh.edu).

Individual Mid-Cayman-Rise (MCR) gabbroic rocks each contain an array of oxide minerals that formed at different times and that record different processes that acted to form the cumulate rocks and their protoliths. Many of the rocks that contain more magnesian olivine ( $\mathrm{Mg \#} \mathrm{>} \mathrm{80)} \mathrm{also} \mathrm{contain} \mathrm{a} \mathrm{Cr}$-rich spinel that quite plausibly co-crystallized from primitive basaltic liquids with the olivine and plagioclase. Oxide grains with a very different chemistry are located in the same thin section of the gabbro. They are composite grains that appear to have unmixed during cooling of the rock and are composed of ilmenite, rutile, and baddeleyite. The ilmenite parts of the grain contain almost identical cation fractions of $\mathrm{Fe}$ and $\mathrm{Ti}$, suggesting that the grains contain very little hematite component. If the rutile was formed by oxidation of ilmenite, the ferric Fe produced in the reaction did not dissolve in the remaining ilmenite. Ilmenite subgrains were determined to have $2000-2200 \mathrm{ppm} \mathrm{Zr}$ and $\sim 800 \mathrm{ppm} \mathrm{Nb}$; rutile has $4100-4500 \mathrm{ppm} \mathrm{Zr}$ and $\sim 850 \mathrm{ppm} \mathrm{Nb}$. Baddeleyite occurs as blebs $<1 \mu \mathrm{m}$ across that are scattered throughout the ilmenite areas. The composite grains are typically in excess of $100 \mu \mathrm{m}$ across and occur in clusters associated with apatite. These clusters must have an important effect on the gabbro's balance of trace elements such as $\mathrm{Nb}, \mathrm{Zr}$, and $\mathrm{Hf}$. They also presumably explain why the contents of $\mathrm{Zr}$ and REE in whole-rock powders are much higher than expected for simple adcumulate rocks that formed from liquids like dredged MCR glasses. (Glasses contain 200-300 ppm $\mathrm{Zr}$; one cumulate contains $>400 \mathrm{ppm} \mathrm{Zr}$ and many have $>20 \mathrm{ppm}$.)

The plagioclase near the ilmenite-rutile grains has $\mathrm{Ca} / \mathrm{Na}$ identical to that near the Cr-spinel in the same section. Plagioclase in the former areas, however, has a Ti content up to $800 \mathrm{ppm}$, whereas plagioclase around the $\mathrm{C}_{\mathrm{r}}$-spinel has an almost constant $\mathrm{Ti}$ content near $300 \mathrm{ppm}$. Furthermore, the Ti-rich plagioclase grains have rodlike inclusions of rutile. All these grains typically have one dimension $<1 \mu \mathrm{m}$ so quantitative analysis is not possible. They do not appear to be associated with any Fe-bearing phase nor do they generate measurable amounts of $\mathrm{X}$-rays characteristic of $\mathrm{Zr}$ or $\mathrm{Nb}$. If they are composed of titania that was dissolved in the plagioclase at magmatic temperatures, the latter locally had $\mathrm{Ti}$ contents $>800 \mathrm{ppm}$. The spatial association of Ti-rich plagioclase and incompatible-trace-element-enriched oxides is most simply explained by their co-crystallization from a late-stage liquid.

Portions of the gabbros that were intensely affected by hydrothermal fluids and that contain substantial amphibole and clinozoisite also contain rutile and baddeleyite that plausibly formed by mobilization of oxide grains. No baddeleyite of clearly magmatic origin occurs in these gabbros.

The compositions of the oxide minerals of the gabbroic rocks give a clearer recording of the origin of these rocks from more than one liquid than do the major-element contents of the silicate minerals with which they formed. Plausibly, the huge volumes of olivine and plagioclase in the cumulate pile dominated the $\mathrm{Mg} / \mathrm{Fe}$ and $\mathrm{Ca}^{\prime}$ $\mathrm{Na}$ of late-stage processes so the major-element compositions of the liquids were changed during interaction. The oxide grains have compositions that reflect the liquids' contents of less compatible elements, so those minerals are more representative of the processes that affected the cumulate pile.

\section{STRONTIUM ISOTOPIC EXCHANGE ON A SUBMIL- LIMETER SCALE AND THE IMPLICATIONS FOR RUBIDIUM-STRONTIUM DATING OF BASEMENT} GNEISSES. S. Meffan-Main and R. A. Cliff, Department of Earth Sciences, University of Leeds, Leeds LS2 9JT, UK (smm@ earth.leeds.ac.uk).

Introduction: Rubidium-strontium dating is a very powerful method of dating deformation in metamorphic belts. However, in basement rocks Rb-Sr mineral separate dating is fraught with difficulties due to previous radiogenic growth and multiple mineral generations. Ages obtained often appear to be unrelated to a specific event. Microsampling for $\mathrm{Sr}$ isotopic analysis has proven to be an extremely valuable method of obtaining reliable ages from such rocks [1]. Combining microsampling with petrography and electron-optical analysis allows both chemical and isotopic exchange during deformation to be characterized on a submillimeter scale.

Contrasting results obtained for two samples from the same outcrop will be presented as an illustration of effective dating using Rb-Sr microsampling.

Geological Setting: The timing of Alpine metamorphism in the orthogneisses of the Monte Rosa basement massif (Switzerland, Italy) is unclear. Frey et al. [2] described white mica ages ranging from 30 to $250 \mathrm{Ma}$. The lack of consistency in white mica ages is due to multiple mica populations and inadequate estimation of initial ${ }^{87} \mathrm{Sr} /{ }^{86} \mathrm{Sr}$.

Results: 58622 shows comparatively little foliation development with white mica distributed in clusters. Two "generations" of white mica exist: coarse grains (cwm) up to $1 \mathrm{~mm}$ across and fine grains (fwm) less than $0.1 \mathrm{~mm}$ across. Electron-probe analysis shows both grain sizes to have essentially the same major-element compositions. Extraction of single grains of cwm and clusters of fwm highlight substantial isotopic variations (Fig. 1). Cwm grains are relatively enriched in radiogenic $\mathrm{Sr}$ but no systematic relationships are observed, preventing the construction of a meaningful isochron. The apparent lack of isotopic equilibrium between cwm 


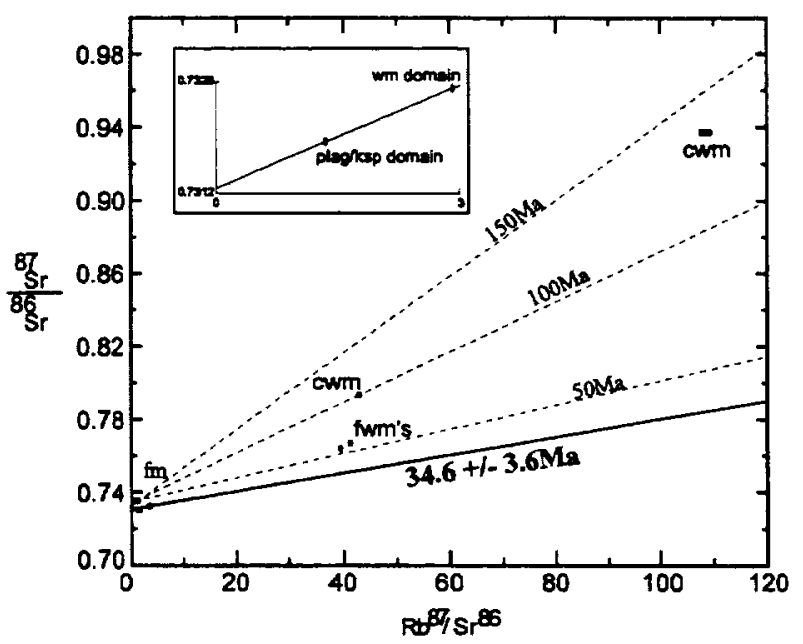

Fig. 1. Rubidium-strontium "isochron" plot for 58622 and 58244. Coarsewhite mica (cwm) and fine-white mica (fwm) and feldspar mosaic (fm) data are for 58622 . Hypothetical age contours have been applied for 58622 . Inset shows two-point isochron for white mica domain and plag/ksp domain used for age calculation in 58244 .

and the feldspar mosaic means that the cwm/feldpsar Rb-Sr evidence for an Eo-Alpine event in these rocks (100-130 Ma [2]) must be treated with caution. Fwm grains show less radiogenic enrichment but the age calculated does not appear to be reliable $(54 \pm 21$ Ma). Feldspar mosaic, which is a characteristic Alpine recrystallization product in basement gneisses [3], has been used for estimation of initial ${ }^{87} \mathrm{Sr} /{ }^{86} \mathrm{Sr}$ during the Alpine event.

58244 (collected $5 \mathrm{~m}$ from 58622) has a well-developed metamorphic fabric defined by white mica and lenticular K-feldspar augen. Minerals that have crystallized in the tails of augen during fabric formation appear to be in textural equilibrium. Rubidiumstrontium analysis of two domains within an augen tail has enabled a two-point isochron age of $34.6 \pm 3.6 \mathrm{Ma}$ to be calculated for fabric generation. Work is in progress to build upon this dataset thus making it more reliable. Data will also be presented for the large $\mathrm{K}$ feldspar augen. The ${ }^{87} \mathrm{Sr} /{ }^{86} \mathrm{Sr}$ of the augen indicates a lack of isotopic exchange between $\mathrm{K}$-feldspar augen and the recrystallized domains during the Alpine event. Such a lack of isotopic exchange may hamper the ability to obtain reliable ages for deformation using conventional mineral separate analysis.

Conclusions: Results presented will clearly indicate that isotopic exchange may occur on a submillimeter scale when disequilibrium exists on a hand-specimen scale. However, careful petrography combined with new microsampling techniques allows analysis of domains that have achieved isotopic equilibrium and reliable ages obtained in previously undatable rocks.

References: [1] Meffan-Main S. and Cliff R. A. (1996) J. Conf. Abs. V. M. Goldschmidt, 395. [2] Frey M. et al. (1971) Contrib. Mineral. Petrol., 55, 147-179. [3] Cliff R. A. et al. (1971) Jb. Geol. Bundesant. Vienna, 114, 121-272.

2.0-BILLION-YEAR-OLD ISOTOPICALLY HEAVY CARBONATE CARBON: COMPARISON OF DISTAL AND
PROXIMAL CARBONATE SEQUENCES FROM THE ONEGA PALAEOBASIN, KARELIA, RUSSIA. V. A. Melezhik $^{1}$, A.E. Fallick ${ }^{2}$, P. V. Medvedev ${ }^{3}$, and V. V. Makarikhin ${ }^{3}$, 'Geological Survey of Nonway, P.O. Box 3006 Lade, 7002 Trondheim, Norway, ${ }^{2}$ Scottish Universities Research and Reactor Centre, G75 OQF, East Kilbride, Glasgow, UK, ${ }^{3}$ Institute of Geology, Karelian Science Centre, 185610, Petrozavodsk, Russia.

Closely spaced samples (286 in number) of shallow-water, red, stromatolotic dolomite and magnesite from the Palaeoproterozoic ( $1980 \pm 27 \mathrm{Ma}$ as a minimum age) Tulomozerskaya Formation of the Onega palaeobasin, Russian Karelia, have been analyzed for $\delta^{13} C_{c a r b}$, $\delta^{18} \mathrm{O}_{\text {carb }}$, trace elements and major elements. The 800 -m-thick terrigenous-carbonate succession is interpreted as having formed in lacustrine evaporitic settings prograding to sabkha and then to marine environments. The carbonate rocks (essentially stromatolitic dolostones with minor magnesites) exhibit isotopically heavy $\mathrm{C}$ throughout. In the distal sequence the $\delta^{13} \mathrm{C}$ values range from $5.7 \%$ to $17.2 \%$ (mean $9.9 \pm 2.3 \%$ ) and $\delta^{18}$ O from $18.6 \%$ to $26.0 \%$ (mean $22 \pm 1.6 \%$ ). The proximal sequence shows the $\delta^{13} \mathrm{C}$ values ranging from $5.6 \% \circ$ to $17.1 \%$ (mean $11.5 \pm 2.6 \% \circ$ ) and $\delta^{18} \mathrm{O}$ from $11.9 \%$ to $27.6 \%$ (mean $20.6 \pm 2.1 \%$ ). In both sequences the $\delta^{13} \mathrm{C}$ records show a substantial increase from $8 \%$ up to $17.2 \%$ downward in the stratigraphy, while the $\delta^{18} \mathrm{O}$ values display no systematic variations.

Dolostones were precipitated from the diagenetic pore water, which was apparently isotopically similar to the basinal water. Magnesite occurs in a number of 1-2-m-thick layers and formed as a secondary phase during early diagenesis under evaporitic conditions. The magnesite mineralization is considered to be similar to the Coorong type (playa lake).

No recent environment developed under normal conditions is known to provide a model that results in the formation of large amounts of carbonate with $\delta^{13} \mathrm{C}$ falling between $5 \%$ and $17 \%$, as is the case for the Tulomozerskaya dolostones. Diagenetic and evaporative models, as well as a restricted basin model with high bioproduction, are not applicable as they are in conflict with existing data. The rise of $\delta^{13} \mathrm{C}$ in the Onega palaeobasin must have been generated on a global or semiglobal scale as indicated by its continuity across the Fennoscandian Shield through Scotland and North America. If excess $C_{\text {org }}$ deposition caused the $\delta^{13} \mathrm{C}$ excursion, it took place in an area external to the Onega palaeobasin. The tectonic model [1], the stratified ocean as proposed by Keith [2], and a stromatolitic basin model (Shark Bay model) are discussed as possible mechanisms leading to the rise in $8^{13} \mathrm{C}$ in the carbonate formation studied. Based on world data [e.g., 3,4], the global background for the isotopic shift at $2.1 \pm 0.1 \mathrm{Ga}$, caused by enhanced $\mathrm{C}_{\text {org }}$ burial in deepwater basins, may be estimated to be between $5 \% \circ$ and $10 \%$. This could be enhanced up to $17 \%$ for the sequences studied as they formed in shallow-water restricted environments inhabited by stromatolite-forming microbial communities. The enhanced $\delta^{13} C_{\text {carb }}$ was perhaps due to development of high biomass, enhanced uptake of ${ }^{12} \mathrm{C}$, and production and consequently loss of $\mathrm{CH}_{4}$

Acknowledgments: This study was supported by INTASRFBR 95-0928, the Geological Survey of Norway, the Natural Environment Research Council, and the Consortiun of Scottish Universities.

References: [1] Des Marais et al. (1992). [2] Keith (1992). [3] Baker and Fallick (1989). [4] Gauthier-Lafaye and Weber (1989). 
CARBONATE FORMATIONS OF NEOPROTEROZOIC AGE IN THE NORTH-CENTRAL NORWEGIAN CALEDONIDES AS REVEALED BY CARBON, STRONTIUM, URANIUM, AND LEAD ISOTOPES. V. A. Melezhik', B. G. Pokrovsky²,I.M. Gorokhov ${ }^{3}$,G. V. Ovchinnikova ${ }^{3}$, and D. Robents ${ }^{\prime}$ Geological Survey of Norway, P.O. Box 3006 Lade, 7002 Trondheim, Nonway, 2Institute of Geology, Pyzhevsky Per. 7, 109017 Moscow, Russia, 3Institute of Precambrian Geology and Geochronology, Nab. Makarova 2, 199034 St. Petersburg, Russia.

Carbonate formations occur within most of the major nappe complexes in the Norwegian Caledonides, and are generally considered to range in age from Neoproterozoic to Silurian. Although the carbonates are extensively developed in some allochthons, there is very little known about the absolute timing of carbonate deposition. In general, the rocks are unfossiliferous and have been metamorphosed at medium to high grade. Fossils occur in some of the lowergrade successions but they are comparatively rare.

We report on isotopic data from unfossiliferous carbonate formations of the Ofotfjorden area in the north-central Norwegian Caledonides. Some of these carbonates have been correlated over long distances to the north with fossiliferous, Late OrdovicianSilurian, low-grade sequences, whereas an altemative correlation links them with higher-grade rocks of uncertain age.

The 130 carbonate samples from the Melkedalen (Narvik Group), Evenes, Fuglevann, and Hekkelstrand Marbles (Evenes Group) were analyzed for major and trace elements as well as for $\delta^{13} C_{\text {cart }}$ and $8^{18} \mathrm{O}_{\text {cart }}$ values. The ${ }^{87} \mathrm{Sr} /{ }^{66} \mathrm{Sr}$ ratios were measured on the 38 selected samples. The U-Pb isotopic system was studied and $\mathrm{Pb}-\mathrm{Pb}$ isotope ages were obtained for 20 carbonates.

The ${ }^{13} \mathrm{C}_{\text {carb }}$ and $\mathrm{Sr}$ isotopic data obtained for the Norwegian carbonates have been used along with ${ }^{87} \mathrm{~S} r /{ }^{86} \mathrm{~S}_{\mathrm{I}}$ and $\delta^{13} \mathrm{C}_{\mathrm{carb}}$ calibration curves for indirect age determination. The best-preserved ${ }^{87} \mathrm{~S} r i$ ${ }^{86} \mathrm{Sr}$ and $8^{13} \mathrm{C}_{\text {carb }}$ values obtained for the Evenes and Fuglevann carbonates are consistent with an apparent depositional age of 615 $635 \mathrm{Ma}$ (Fig. 1). Applying the $\mathrm{Pb}-\mathrm{Pb}$ isochron method to the Evenes carbonates has yielded an age of $600 \pm 80 \mathrm{Ma}$. As the measured $\mu_{1}=$ $8.12 \pm 0.05$ differs from an average of $\mu_{1}=8.4 \pm 0.4$ for sedimentary carbonates (from 2600 to $180 \mathrm{Ma}$ ), the obtained date of $600 \pm 80 \mathrm{Ma}$ is considered to represent an age of metamorphism rather than of deposition.

Acknowledgments: This study was supported by the Geological Survey of Norway, Project 270500.

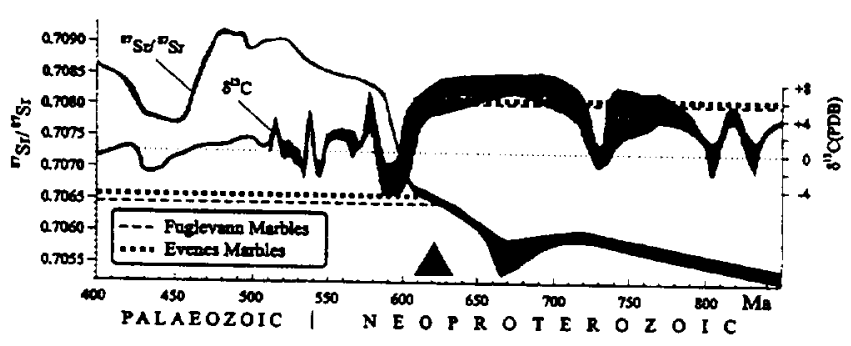

Fig. 1. Apparent depositional age of the Evenes and Fuglevann carbonates.
PRESERVATION OF OCEAN ISLAND BASALTS AND ARCLIKE RARE-EARTH-ELEMENT PATTERNS IN ECLOGITES: A CASE STUDY OF THE ACATLAN COMPLEX, SOUTHERN MEXICO. D. Meza-Figueroa and J. Ruiz, Department of Geosciences. University of Arizona, Tucson AZ 85721, USA (jruiz@geo.arizona.edu).

The idea that eclogite-facies metamorphism would be incapable of erasing an initial trace-element chemical signature of the protolith is still a subject of debate [1-4]. Eclogites from Cabo Ortegal, Spain, constitutes an example of REE immobility during high-grade metamorphic events [4,5] preserving MORB-like REE patterns. However, C- and B-type eclogites from many other localities [6-10] show inconsistencies in the REE pattems, in most cases a depletion in the LREE.

Eclogites and eclogite-facies rocks from the Paleozoic Acatlan Complex in Southern Mexico show REE patterns consistent with OIB, MORB, and arc affinities.

The regularity and parallelism of the LREE patterns suggest that if some REE mobility had occurred during postmagmatic open behavior, it occurred in a coherent manner and thus without a modification of the $\mathrm{Sm}-\mathrm{Nd}$ ratios (measured). In this way, we argue for immobility of the REE patterns, and thus it is assumed that the patterns are primary.

Because eclogites are formed by $70 \%$ garnet and pyroxene content, garnet separates were analyzed by ICP-MS. The REE patterns for such mineral separates show that some gamets could have not chemically equilibrated during the high-grade metamorphism.

References: [1] Wood et al. (1976). [2] Humphris and Thompson (1978). [3] Hellman et al. (1979). [4] Bernard-Griffiths et al. (1985). [5] Bernard-Griffiths et al. (1993). [6] Von Quandt and Gebauer (1993). [7] Aurisicchio et al. (1985). [8] Griffiths et al. (1991). [9] Taylor and Neal (1988). [10] Wendlandt et al. (1993).

\section{ALUMINOSILICATE MINERAL FORMATION IN AMA- ZON DELTA SEDIMENTS DURING EARLY DIAGENESIS: RESULTS FROM SUBSTRATE INCUBATION EXPERI- MENTS AND STUDIES OF NATURAL PARTICLES. P. Michalopoulos and R. C. Aller, Marine Sciences Research Center, State University of New York at Stony Brook, Stony Brook NY 11794-5000,USA (pmichal@@ic.sunysb.edu; raller@ccmail.sunysb. edu).}

Formation of disseminated aluminosilicate phases during early diagenesis of deltaic and continental shelf deposits apparently plays an important role in elemental cycling. Incorporation of dissolved constituents such as $\mathrm{Si}, \mathrm{K}, \mathrm{Mg}$, and $\mathrm{F}$ into authigenic phases can significantly alter budget estimates in the oceans. Studies of Amazon shelf sediments show that multiple reaction paths involving different types of substrates can rapidly lead to the formation of aluminosilicate phases. Anoxic incubations of several types of substrates indicate that there is a relationship between the availability of key constituents and the resulting authigenic phases. FeOOH coatings on quartz grains are converted to Fe-rich aluminosilicate phases over timescales of 12-50 months. Elemental microanalyses and high-resolution XRD with synchrotron radiation provide evidence for the structural incorporation of $\mathrm{Fe}$ into the aluminosilicate 
phases. Similar authigenic phases formed on adjacent quartz grains with no $\mathrm{FeOOH}$ coatings showed less incorporation of $\mathrm{Fe}$ in the aluminosilicate phases. These observations and previous studies on oxide coatings on natural grains from the Amazon shelf sediments [1] show that reconstitution of $\mathrm{FeOOH}$ coatings is one mode of aluminosilicate phase formation in Amazon delta sediments. Studies on discoid grains separated from Amazon delta sediments also show the direct relationship between biogenic silica supply and authigenic clay mineral formation. These grains comprise a pyritic core surrounded by an aluminosiliocate layer that consists of authigenic aluminosilicate components and agglutinated particles from the sediment matrix. The degree of biogenic silica alteration to aluminosilicates ranges from slight to complete conversion. The presence of $\mathrm{K}$-aluminosilicate coatings on preserved frustules can explain protection of biogenic silica from complete conversion. In addition, diatom-specific characteristics of the siliceous frustule may explain differences in the reactivity and preservation of the biogenic silica. The occurrence of these composite aluminosilicate phases is closely associated with FeS-rich layers that represent organic matter (diatomaceous) pulses to the seafloor. Such layers are formed rapidly after deposition and serve as proof that most of composite grains were formed in situ and at timescales comparable to the formation of the Fe-S layers and sediment accumulation $(\sim 1 \mathrm{yr})$.

References: [1] Rude and Aller (1989).

EARLY MARS EVOLUTION: CLUES FROM MARTIAN METEORITES. D. W. Mittlefehldt' ${ }^{1}$ and M. M. Lindstrom ${ }^{2}$, 'Lockheed Martin Earth and Space Sciences, 2400 NASA Road 1, Houston TX 77058, USA (duck@snmail.jsc.nasa.gov), ${ }^{2}$ Mail Code SN2, NASA Johnson Space Center, Houston TX 77058, USA.

Just as the geochemistry of modem terrestrial basalts yields clues to the past history of the Earth's mantle, the martian meteorites can be used to constrain the early petrologic evolution of Mars. The 12 martian meteorites can be divided into seven petrologic/ geochemical types: basalt (Shergotty, Zagami), depleted basalt (EETA 79001 lithology B, QUE 94201), plagioclase lherzolite (ALHA 77005, LEW 88516, Y 793605), clinopyroxenite (Governador Valadares, Lafayette, Nakhla), orthopyroxenite (ALH 84001), dunite (Chassigny), and impact melt (EETA 79001 lithology A). EETA 79001 lithology B and QUE 94201 represent melt compositions, although neither of them are primary melts. The remainder of these rocks are mixtures of cumulus minerals, phenocrysts, or xenocrysts and melt. Except for some samples of ALH 84001, the melt component dominates the ratios of the highly incompatible lithophile (IL) elements, and these elements can be used to constrain the petrogenesis of the rocks.

The martian meteorites show wide ranges in the ratios of some IL compared to expectations based on terrestrial experience. For example, the $P / L$ a ratio varies from $\sim 280$ to $\sim 28,000$ in the martian rocks, while for a wide range of terrestrial mafic melts and ultramafic to anorthositic cumulates the range is less ( $\sim 9$ to $\sim 300$; Fig. 1 ). This suggests that the IL are more heterogeneously distributed in Mars' mantle than in the terrestrial mantle.

Based on isotopic systematics and trace-element geochemistry, the martian meteorites (except for ALH 84001) are known to have formed from one or more sources that were depleted early in Mars'

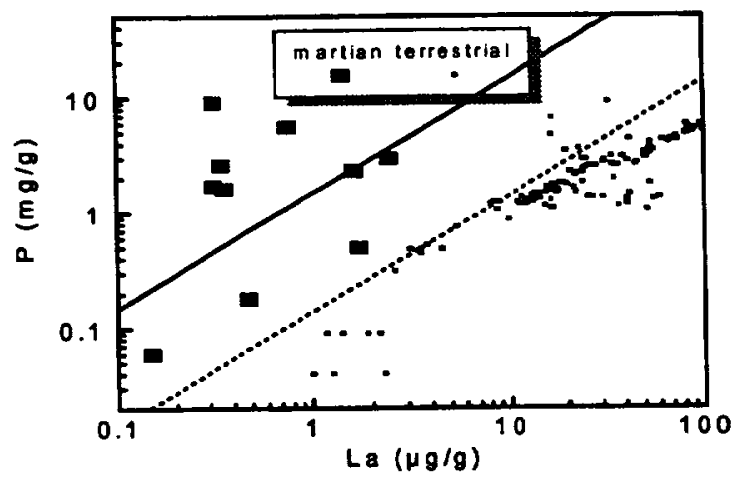

Fig. 1. Phosphorous vs. La distributions in martian vs. terrestrial mafic ultramafic igneous rocks. Bulk Mars (solid) and Earth (dashed) ratios shown for comparison.

history [1]. Can the variable IL-element ratios of martian rocks be a consequence of formation from depleted sources? This can be tested using nonmodal, fractional fusion models for trace-element fractionation.

Figure 2 shows an example model for $(\mathrm{Sm} / \mathrm{P})_{\mathrm{Cl}}$ vs. $(\mathrm{La} / \mathrm{Yb})_{\mathrm{Cl}}(\mathrm{CI}$ chondrite-normalized ratios). For this model, the bulk primitive Mars mantle REE and $P$ were taken from [2], phase proportions were taken from [3], and partition coefficients were taken or estimated from numerous sources. Melts derived from the bulk primitive Mars mantle are constrained to lie within the field defined by the residual source, the instantaneous melt compositions (for pure fractional fusion), and the collected melt compositions (e.g., batch melting). Based on our preliminary modeling, the two martian meteorites that most closely represent melt compositions fall outside this field. This implies that the source region for these rocks was not simply derived from a primitive martian mantle by partial melting processes. Other geochemical fractionations were important. One possibility is that the martian rocks were formed by remelting magma ocean cumulates, as were many types of lunar basalt.

The Earth may also have undergone magma ocean processes. Why, then, are terrestrial mafic igneous rocks more uniform in ILelement ratios than martian rocks? Convection in the martian mantle

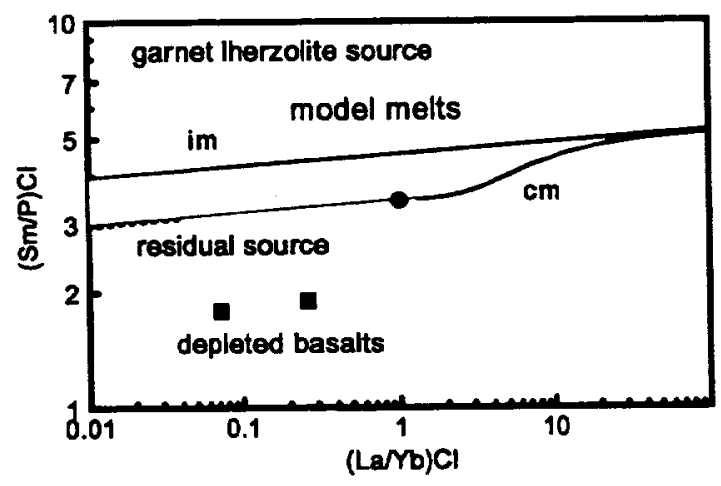

Fig. 2. Martian basalts should lie within the region (stippled) defined by the residual source and the instantaneous (im) and collected $(\mathrm{cm})$ melts. 
is calculated to be less vigorous than in the terrestrial mantle [4]. It is possible that the difference is due to incomplete mixing of the martian mantle subsequent to planetary differentiation.

References: [1] Harper et al. (1995) Science, 267, 213. [2] Longhi et al. (1992) Mars (Kieffer et al., eds.), p. 184, Univ. of Arizona, Tucson. [3] Bertka and Fei (1996) JGR, in press. [4] Harder and Christensen (1996) Nature, 380, 507.

\section{NONDETRITAL ORIGINS OF URANIUM-BEARING MINERALS AND PYRITES IN EARLY PROTEROZOIC QUARTZ-PEBBLE CONGLOMERATES OF THE ELLIOT} LAKE DISTRICT, ONTARIO. R. L. Mock and H. Ohmoto, Geosciences Department, The Pennsylvania State University, University Park PA 16802, USA.

Uranium ore deposits occurring in quartz-pebble conglomerate beds of $>2.0 \mathrm{Ga}$ have been interpreted by many (but not all) previous investigators as detrital in origin. Since both uraninite and pyrite are highly soluble in oxygenated water, large amounts of "detrital" uraninite and pyrite in these deposits have been used by some investigators as evidence for a reduced atmosphere. In order to identify the detrital components in this type of deposit, we have conducted an investigation of the mineralogy, mineral textures, and chemical compositions of minerals within ore samples collected from the Stanleigh Mine in Elliot Lake, Ontario. The ore occurs in three quartz pebble beds, each $\sim 2 \mathrm{~m}$ thick and $\sim 2.3 \mathrm{Ga}$ in age.

Grain shape alone is rejected as a means of identification of detrital grains since overgrowths are abundant, postdepositional fracturing of grains prevalent, and dissolution textures ubiquitous. Pyrite grains are broadly divided into grungy altered, often fractured, pyrite (earlier stage) and clean unfractured subhedral to euhedral pyrite (later stage). Grading between these end members is common. Pyrites of both categories are found in close proximity to alteration zones, suggesting both may be hydrothermal in origin. Some pyrites within quartz and chert pebbles appear secondary, formed in pressure solution sutures, while a few may be primary. The earliest formed pyrites may be those whose edges coincide with adjacent angular pyrite grain edges and abut larger quartz grains. These pyrite have experienced some breakage, possibly during compaction of sediments; thus, they are either detrital or early diagenetic.

The U-bearing minerals identified here include uraninite $\left(\mathrm{CO}_{2}\right)$, uranothorite $(\mathrm{Th}, \mathrm{U}) \mathrm{SiO}_{4}$, brannerite $\left(\mathrm{UTi}_{2} \mathrm{O}_{6}\right)$, and monazite

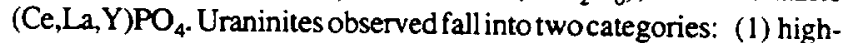
$\mathrm{Pb}$ content (i.e., older) uraninite/uranothorite grains often with rims of uraninite, and (2) low- $\mathrm{Pb}$ content (i.e., younger) uraninite grains with interspersed alumina silicates and/or brannerite. The first group, although frequently associated with the second, are also found in areas with little/no oxides or sulfides, and may represent detrital fraction of $U$ minerals. They are rarely rounded or spherical, but the presence of secondary $\mathrm{U}$ mineralization as well as observed dissolution features suggest modification of original shapes. Solid uranothorite grains as well as monazite grains (dated at $\sim 2.5 \mathrm{Ga}$ ) with uranothorite inclusions are likely to be detrital. The second group of uraninites are associated with brannerite grains, brannerite bands, highly altered zones, and pyrites. Such associations may indicate these minerals formed by hydrothermal fluids during diagenesis or metamorphism. Dates of $\sim 1.7 \mathrm{Ga}$ obtained on Elliot
Lake uraninites agree with a postdepositional origin. Brannerites, although more variable in texture than uraninites, also fall into two

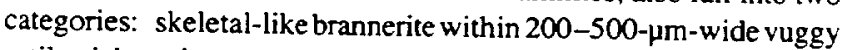
rutile-rich grains and ultramicroscopic blebs in bands or veinlets. Association with rutile is ubiquitous. In general, brannerite appears to have formed on rutile and grown into cavities. These features suggest brannerites and rutiles formed by reactions with $\mathrm{U}^{6+}$-bearing solution and detrital ilmenite during diagenesis. This is supported by dates of $\sim 1.7 \mathrm{Ga}$ for brannerites.

In past studies, relatively high Th contents in Elliot Lake uraninites were used as evidence that they were detrital minerals from pegmatites or high-temperature vein mineralization. However, our study shows that high Th contents of the ores reflect the high uranothorite content in the original sediments, rather than an abundance of Th-rich uraninite. Solitary uraninite grains are mostly $T$ hpoor and appear secondary in origin. Some secondary uraninites became Th-rich due to addition of Th from hydrothermal fluids from dissolution of earlier uranothorite. Argument for a reduced early Proterozoic atmosphere has relied heavily on the presence of pure detrital uraninite grains. The evidence presented here suggests that the U-bearing detrital minerals were mostly uranothorite, which is far more stable in oxygenated water than Th-poor uraninite. Observed uranothorite grains in quartz pebbles lend credence to an argument that the pegmatitic uranothorite and uraninite were trapped within quarzz pebbles during much of transport and that these remaining grains represent the fraction that was liberated near the source, thus explaining preservation of $U$ phases and the lack of rounding.

\section{MODIFICATION OF BIOORGANIC CARBON IN EARLY} ARCHEAN SEDIMENTS. S. J. Mojzsis ${ }^{1}$, A. Lepland ${ }^{2}$, J. Fessenden ${ }^{1}$, and $G$. Arthenius ${ }^{1}$, 'Scripps Institution of Oceanography, University of California-San Diego, La Jolla CA 92093-0220, USA, 2Department of Geology, Earth Sciences Centre, Göteborg University, S-41381 Göteborg, Sweden.

The distribution of inorganic and organic $\delta^{13} \mathrm{C}$ values from mineral fractions separated magnetically and by density methods from early to mid-Archean banded iron formations (BIF) (3.25-3.85 Ga) and Proterozoic cherts $(2.0 \mathrm{Ga})$ is interpreted as reflecting the differential metamorphic alteration of isotopic signals of carbonaceous matter in different host mineral phases. We assume that the $C$ isotopic compositions measured for apatite inclusions and other mineral phases (e.g., pyroxene) in amphibolite to granulite metamorphic facies BIF from Akilia Island and the Isua supracrustal belt (ISB) in southern West Greenland $\left(3.85-3.77 \mathrm{Ga}\right.$; mean $\delta^{13} \mathrm{C}_{\text {org }}=$ $-30 \%$ to $-35 \%$ ) constrain the upper limits of the $\delta^{13} \mathrm{C}_{\text {org }}$ of the precursor carbonaceous matter. The heavier $\delta^{13} \mathrm{C}_{\text {org }}$ values of all other C-carrying mineral phases, e.g., quartz, magnetite/pyrnotite, amphibole (range $\delta^{13} \mathrm{C}_{\text {org }}=-19 \%$ to $-27 \%$, Akilia Island BIF; range $\delta^{13} C_{\text {org }}=-10 \%$ to $-15 \%$, ISB BIF), would then reflect the effect of metamorphism on the initial bioorganic signal.

The relatively light isotopic composition $\left(\delta^{13} C_{\text {carb }}=2-5 \%\right.$ of bulk carbonate $C$ in Archean BIFs, including Akilia, may point to (1) negative intrinsic $\delta^{13} \mathrm{C}_{\text {carb }}$ values; (2) thermal decarbonation, as this causes depletion in ${ }^{13} \mathrm{C}$ of residual carbonate; (3) isotopic exchange reactions with ${ }^{12} \mathrm{C}$-enriched precursor bioorganic matter residual in the rock during metamorphism; (4) the oxidation of characteristi- 
cally light biologically fixed organic $\mathbf{C}$ and reprecipitation as carbonate; or (5) relation to volcanically transported mantle $\mathrm{C}$.

The age of the earliest sediments known on Earth $(33.85 \mathrm{Ga})$ overlaps in time with the terminal bombardment of the Moon and extrapolated to Earth. Therefore, it is necessary to evaluate extraterrestrial carbonaceous matter that could possibly contribute to the signal in sediments of the earliest Archean.

RARE-GAS SYSTEMATICS IN THE UPPER MANTLE: A COMPLETE STUDY OF A POPPING ROCK. M. Moreira, J. Kunz, and C. J. Allègre, Université Denis Diderot, Laboratoire de Géchimie et Cosmochimie, T14, 3eme étage, 4 Place Jussieu, 75252 Paris Cedex 05, France (moreira@ipgp.jussieu.fr).

We have studied rare-gas sytematics into the so-called " $2 \Pi D 43$ " MORB popping rock, coming from $14^{\circ} \mathrm{N}$ on the mid Atlantic Ridge. This sample has a vesicularity of $17 \%$ and shows very high concentrations of noble gases (up to $10^{-4} \mathrm{ccSTP}$ of $\left.{ }^{4} \mathrm{He}\right)([1,2]$ and this study), which make it a very good witness of the upper mantle.

We used the stepwise crushing method to release the gas from the vesicules. We did two independent studies of this sample: In the first study we performed five crushing steps, and eight steps in the second one. The ${ }^{4} \mathrm{He}^{3} \mathrm{He}$ ratios are very constant in all steps with a mean ${ }^{4} \mathrm{He} /{ }^{3} \mathrm{He}$ ratio of $85,000(\mathrm{R} / \mathrm{Ra}=8.5)$. The ${ }^{20} \mathrm{Ne} / 22 \mathrm{Ne}$ ratio varies between 9.96 and 12.5 and ${ }^{21} \mathrm{Ne}^{22} \mathrm{Ne}$ varies between 0.030 and 0.060 . In a three-isotope Ne diagram, the points fall on the MORB line defined by Sarda et al. [1]. The two (study 1) and the three (study 2) final steps of crushing give the same ${ }^{20} \mathrm{Ne} / 22 \mathrm{Ne}$ $(\sim 12.5)$. This may indicate that this ratio is a upper limit for this sample. The ${ }^{40} \mathrm{Ar} /{ }^{36} \mathrm{Ar}$ varies between the air value and 24,000 , which is one of the highest values measured in MORB $(28,000$ is the maximum values measured). The ${ }^{129} \mathrm{Xe}^{130} \mathrm{Xe}$ ratio varies between air value to a value as high as 7.8 , and all the steps fall in isotopic $\mathrm{Xe}$ diagrams on the MORB line. An extremely interesting point is the corelation between different rare gases that support a geochemical coherence.

The ${ }^{40} \mathrm{Ar} /{ }^{36} \mathrm{Ar}$ and ${ }^{129} \mathrm{Xe} /{ }^{130} \mathrm{Xe}$ ratios are perfectly correlated to the $20 \mathrm{Ne}^{/ 22} \mathrm{Ne}$ ratios and reflect a mixing between the MORB component with high ${ }^{20} \mathrm{Ne} /{ }^{22} \mathrm{Ne},{ }^{21} \mathrm{Ne} /{ }^{22} \mathrm{Ne},{ }^{40} \mathrm{Ar} /{ }^{36} \mathrm{Ar}$, and ${ }^{129} \mathrm{Xe} /$ ${ }^{130 \mathrm{Xe}}$ ratios and an air component. We use a correlation between ${ }^{20} \mathrm{Ne} /{ }^{22} \mathrm{Ne}$ and other isotopic ratios to estimate the ${ }^{40} \mathrm{Ar} /{ }^{36} \mathrm{Ar}$ and ${ }^{129} \mathrm{Xe}^{/ 130} \mathrm{Xe}$ of the upper mantle. Taking ${ }^{20} \mathrm{Ne}^{22} \mathrm{Ne}$ between 12.5 and solar (13.8) we estimate that the ${ }^{40} \mathrm{Ar} /{ }^{36} \mathrm{Ar}$ of the upper mantle is certainly higher than 25,000 and cannot be above 44,000 , and the ${ }^{129} \mathrm{Xe} / 1{ }^{130} \mathrm{Xe}$ cannot be higher than $8.2(>7.8)$.

We used the same systematic with elemental ratios $\left({ }^{3} \mathrm{He}^{22} \mathrm{Ne}\right.$, ${ }^{3} \mathrm{He} /{ }^{36} \mathrm{Ar}$, and ${ }^{3} \mathrm{He} /{ }^{130} \mathrm{Xe}$ ) and conclude that the ${ }^{3} \mathrm{He} / 22 \mathrm{Ne}$ is between 4.9 and $7.3,0.42<{ }^{3} \mathrm{He}^{36} \mathrm{Ar}<0.74$, and $760<{ }^{3} \mathrm{He}^{/ 130} \mathrm{Xe}<1110$ in the upper mantle.

There are important constraints for the so-called "steady-state model" that proposes that all the noble gas stable isotopes come from the lower mantle.

References: [1] Sarda et al. (1988). [2] Staudacher et al. (1989).

AN APPRAISAL OF ENDMEMBER ENERGY AND MIXING PROPERTIES OF RARE-EARTH GARNETS. R.
Moretti and G. Ottonello, Department of Earth Sciences, University of Genova, Corso Europa 26, 16132 Genova, Italy.

Energetics of rare earth $\mathrm{Al}\left(\mathrm{REE}_{3} \mathrm{Al}_{5} \mathrm{O}_{12}\right)$, $\mathrm{Fe}\left(\mathrm{REE}_{3} \mathrm{Fe}_{5} \mathrm{O}_{12}\right)$, and $\mathrm{Ga}\left(\mathrm{REE}_{3} \mathrm{Ga}_{5} \mathrm{O}_{12}\right)$ garnets are assessed through a critical evaluation of all the existing experimental data and a thermodynamic treatment of vibrational, static, and volumetric properties of the various substances.

Application of the developed thermodynamic database, coupled with the interionic static potential model previously developed for major silicate gamet end members [1], allows us to establish the mixing properties of the various substances with the major isostructural silicate components and to determine the limits of Henry's law behavior for REE in natural garnets. Based on calculations, mixing of REE gamet components at trace level (i.e., below about $10^{2} \mathrm{ppm}$ ) with major silicate components is virtually ideal, and deviations from ideality become sensible at trace concentrations exceeding $10^{3} \mathrm{ppm}$. Corresponding deviations from Nernst's law behavior in garnet/fluid REE equilibria follows exponential trends whose nature is analogous to what has been experimentally observed in silicate/fluid equilibria involving other solid phases and other trace elements.

It is finally stressed that the light REE-heavy REE (LREE HREE) fractionation observed in natural gamet specimens is due to the intrinsic energy properties of the various REE-gamet end members, and not to a structural effect dictated by the carrier, as commonly assumed in literature.

References: [1] Ottonello G. et al. (1996) Am. Mineral, 81, 429-447.

MASS AND ELEMENT RECYCLING AT CONVERGENT MARGINS. J. D. Morris ${ }^{1}$ and F. Tera ${ }^{2}$, ${ }^{1}$ Department of Earth and Planetary Sciences, Washington University, St. Louis MO 63130 , USA (jmorris@levee.wustl.edu),2Department of Terrestrial Magnetism, Carnegie Institution of Washington, Washington DC 20015, USA (tera@clrs1.ciw.edu).

Subduction of sediments and seafloor alteration products, and their recycling behavior from trench to deep mantle, affects the chemical mass balance of the oceans, deformation in accretionary prisms, the nature and behavior of the seismogenic zone, net growth rates of the continental crust, ore formation, explosive volcanism and climate modification, and the chemical and thermal evolution of the deep mantle. Understanding fluxes into subduction trenches and out of fore-arcs, arc and rear-arc volcanos, and back-arc spreading centers provides a means of quantifying mass and element transfer, evaluating subduction zone processes, and constraining the subduction flux to the deep mantle.

Quantifying mass transfer of sediments from the trench to the region of arc magma generation is best done with tracers having a depth-dependent variation in the incoming sediment column, such as ${ }^{10} \mathrm{Be}$. Under the assumption of steady-state conditions, total inventories and the exponentially decreasing depth profiles of ${ }^{10} \mathrm{Be}$ in sediments outboard of the trench and in the fore-arc sedimentary prism may be compared with the flux of ${ }^{\circ} \mathrm{Be}$ out of the volcanic arc to quantify volumes of sediments subducted to the mantle. Estimates of sediment subduction from this "geochemical imaging" may be checked against seismic imaging [e.g., 1] in the shallower 
parts of the subduction zone $(<\sim 30 \mathrm{~km})$. At Guatemala, both imaging techniques are consistent with complete subduction of the entire incoming sediment column. New low-blank measurements on Mariana arc lavas show low but real ${ }^{10} \mathrm{Be}$ enrichments requiring complete subduction of the incoming sediment column, which is itself low in ${ }^{10} \mathrm{Be}$ relative to other margins. While significant offscraping is observed off the Aleutians, both ${ }^{10} \mathrm{Be}$ and seismic imaging are consistent with $>95 \%$ of the pelagic section being subducted to depth. Off Costa Rica, the data require $>40 \%$ underplating or offscraping of the incoming section. Off Japan, seismic imaging and ${ }^{10} \mathrm{Be}$ argue for large amounts of subduction erosion of the Cretaceous accretionary prism.

Using these constraints on the volumes of sediments subducted to depth, the efficiency of ${ }^{10} \mathrm{Be}$ recycling can be estimated from flux calculations. The largest source of uncertainty in any element flux calculation is the poorly known errors in estimating magma production rates [e.g., 2]. Approximately $40 \%$ of the subducted ${ }^{10} \mathrm{Be}$ (correcting for decay during subduction) is retumed to the surface in volcanic front lavas in the Aleutian, El Salvador-GuatemalaNicaragua, and Mariana arc segments. Less than $1 \%$ of the ${ }^{10} \mathrm{Be}$ fed to the trench off Japan is retumed in the volcanos. These recycling efficiencies cannot be directly applied to all other elements, due to element fractionation during subduction.

Beryllium-10 data for rear-arc volcanos from the Kurile, Bismarck, and Aleutian arcs shows that some slab-derived elements may be returned to the surface as much as $80 \mathrm{~km}$ behind the main volcanic front, above slabs as deep as $180 \mathrm{~km}$. Strikingly, rear-arc volcanos have ${ }^{10} \mathrm{Be} /{ }^{\circ} \mathrm{Be}$ atom ratios greater than expected; in several transects, rear-arc ${ }^{10} \mathrm{Be} / 9 \mathrm{Be}$ ratios are actually higher than for the corresponding volcano at the front, requiring either much faster transport rates to rear-arc positions, or a greater proportion of sediment-derived ${ }^{10} \mathrm{Be}$ in rear-arc lavas. Although ${ }^{10} \mathrm{Be}$ concentrations can be high in rear-arc volcanos, the relatively small mass flux suggests that rear-arc volcanism does not significantly affect the mass balance of elements recycled in the arc vs. subducted to the deep mantle, assuming that little ${ }^{10} \mathrm{Be}$ is left behind in subduction modified, but unmelted mantle over timescales greater than those of the mass flux calculations, $1 \mathrm{~m} . \mathrm{y}$. On shorter timescales accessible to U-series disequilibria isotopes ( $<350 \mathrm{k} . \mathrm{y}$.), subduction modification of the mantle sometimes seems to occur in several stages [3].

The recycling behavior of altered oceanic crust is currently more difficult to quantify. Estimates of the relative contributions to the subduction component in different arcs range from nearly $100 \%$ altered basalt to nearly $100 \%$ sediment. If real, these hint at tantalizing differences between subduction zones that are not explained by the observed variation in the amounts of sediment accretion. These different estimates often derive from different tracers, however, and may reflect the difficulties in linking element behavior directly to the fate of total mass, fluids, and melts in the subduction environment. Further progress in understanding the effects of subduction zone processes on the mantle depends critically on understanding the behavior of key elements during prograde metamorphism, dehydration, and hydrous melting conditions.

References: [1] von Huene and Scholl (1991) Rev. Geophys. [2] Reymer and Schubert (1984) Tectonics. [3] Reagan et al. (1994) GCA.

\section{CONSTRAINTS ON FLUIDS INVOLVED IN DETACH-}

MENT FAULTING: A LASER-MICROPROBE STUDY IN THE WHIPPLE MOUNTAINS METAMORPHIC CORE COMPLEX. J. Morrison, Department of Earth Sciences, University of Southem California, Los Angeles CA 90089-0740, USA.

Metamorphic core complexes of the western U.S. manifest profound crustal extension during the Cenozoic. Core complexes consist of a mylonitically deformed lower plate that is separated from a brittle deformed upper plate by a low-angle detachment fault. Mechanical analysis of low-angle detachment faults suggests that high fluid pressures are necessary for movement along such faults. It has also been proposed that high-pressure fluids originate at depth from either magmatic or metamorphic sources and move up the fault. Although evidence of hydrothermal fluid flow along detachment faults is common (e.g., chloritic alteration, economic mineralization), the timing of fluid flow relative to movement along the fault and fluid sources are poorly understood.

In the Whipple Mountains metamorphic core complex of southeastern California, the detachment fault is underlain by a chloritic breccia that varies in thickness from $\sim 300 \mathrm{~m}$ down to a few meters. In Bowman's Wash, an $89 \pm 3 \mathrm{Ma}$ leucocratic tonalite underlies the detachment fault and shows increasing brecciation and hydrothermal alteration toward the detachment fault. Major-element variations with distance from the fault are consistent with silicification, reflecting the addition of $\mathrm{Si}$ in the $10 \mathrm{~m}$ below the fault and a marked addition of $\mathrm{K}$ and $\mathrm{Fe}$ in the $3 \mathrm{~m}$ below the fault. The aphanitic cataclasite that forms the fault surface is markedly enriched in $\mathrm{FeO}_{\mathrm{T}}$ and $\mathrm{K}_{2} \mathrm{O}$, which otherwise do not show any systematic variations. Quartz, separated using conventional mineral separation techniques, decreases erratically in $\delta^{18} \mathrm{O}$ from $9.7 \%$ at $50 \mathrm{~m}$ from the fault to $7.9 \%$ within $3 \mathrm{~m}$ of the fault. The whole-rock $\delta^{18} \mathrm{O}$ of the aphanitic cataclasite is $8.3 \%$.

Values of $8^{18} \mathrm{O}$ in quartz and epidote grains have been determined using a $\mathrm{CO}_{2}$ laser extraction system. Individual adjacent quartz and epidote grains were removed from $\sim 1$-mm-thick sections of rock in three samples collected at distances of 25,40 , and $50 \mathrm{~m}$ from the fault. Epidote $\delta^{18} \mathrm{O}$ values range from $5.45 \%$ to $2.88 \%$ o and quartz $\delta^{18} \mathrm{O}$ values range from $10.03 \%$ to $8.71 \%$. Values of $\Delta_{\mathrm{Qtz}-E_{\mathrm{p}}}$ for adjacent pairs range from $4.41 \%$ to $5.83 \%$ and yield temperatures from $440^{\circ}$ to $350^{\circ} \mathrm{C}$ using the calibration of Matthews [1]. Decreasing $\Delta_{\text {Qtz-Ep }}$ values correlate with decreases in both quartz and epidote $\delta^{18} \mathrm{O}$ values, which is interpreted to indicate that as the temperature of fluid-rock interaction decreased, the fluid $\delta^{18} \mathrm{O}$ also decreased. Calculated fluid $\delta^{18} \mathrm{O}$ values vary from $\sim 7 \%$ at $440^{\circ} \mathrm{C}$ to $\sim 3 \%$ at $350^{\circ} \mathrm{C}$. Quartz-epidote $\delta^{18} \mathrm{O}$ systematics indicate that millimeter-scale determinations of $\delta^{18} \mathrm{O}$ values with good textural constraints are necessary to decipher the complex fluidrock interaction history related to processes of detachment faulting.

References: [1] Matthews (1994).

HYDROSULFIDE COMPLEXES OF COPPER AT $22^{\circ} \mathrm{C}$ : A NOVEL APPROACH TO THE MEASUREMENT OF STABILITY CONSTANTS BY THE SOLUBILITY METHOD. B. W. Mountain and T. M. Seward, Institute for Mineralogy and Petrography, ETH Zentrum, Sonneggstrasse 5, 8092 Zürich, Switzerland.

Introduction: High-quality thermodynamic data are essential 
in the study of the behavior of metals in the natural environment. Unfortunately, most minerals are highly insoluble, consequently, many metal-ligand systems are difficult to study by solubility methods. The determination of the speciation of metals in solutions containing reduced $\mathrm{S}\left(\mathrm{H}_{2} \mathrm{~S}+\mathrm{HS}^{-}\right)$represents an example of this problem. This information has important implications for the mobility of metals in reducing environments such as anoxic porewaters in soils and sediments, anoxic bottom waters in lakes, estuaries, and oceans, and in the formation of mineralization of many types.

This study was undertaken to determine the speciation of $\mathrm{Cu}(\mathrm{I})$ in reduced $\mathrm{S}$ solutions at room temperature.

Apparatus: An new approach, using a continuous flow column, has been used to measure the solubility of $\mathrm{Cu}_{2} \mathrm{~S}$ in reduced sulfur solutions. This method provides the following advantages over the standard sealed bottle approach: (1) large sample volumes can be taken (up to $500 \mathrm{ml}$ ), (2) many replicate samples are possible, (3) experimental time is short, (4) contemporaneous monitoring of solubility is possible, and (5) low fluid volume/surface area ratio speeds reaction rates.

Results: Continuous flow experiments were made at various values of $\Sigma S$ and $\mathrm{pH}$. Figure 1 shows the results from five examples of the experiments. Note that highly reliable solubility measurements can be determined because of the number of replicate samples. In total, 47 experiments were performed and the median values from these form the basis of the best-fit speciation model. It should be emphasized that these 47 median data points are derived from a set of 750 measurements.

Theory: The combination of the equation for the base solubility of chalcocite

$$
\mathrm{Cu}_{2} \mathrm{~S}+\mathrm{H}^{+} \rightarrow 2 \mathrm{Cu}^{+}+\mathrm{HS}^{-} \quad \mathrm{K}_{\mathrm{sp}}=10^{-34.02}
$$

and the general equation for the speciation of $\mathrm{Cu}(\mathrm{I})$ as sulfide/ bisulfide complexes

$$
x \mathrm{Cu}^{+}+\mathrm{yHS}^{-}+(\mathrm{z}-\mathrm{y}) \mathrm{H}^{+} \rightarrow \mathrm{Cu}_{\mathrm{x}} \mathrm{S}_{\mathrm{y}} \mathrm{H}_{\mathrm{z}}^{\mathrm{x}+\mathrm{z}-2 \mathrm{y}} \quad \mathrm{B}_{\mathrm{xyz}}=\text { ? }
$$

gives the general equation for the solubility of chalcocite as sulfide/ bisulfide complexes when summed over all complexes

$$
E C u=\sum^{x} \Sigma^{y} \Sigma^{z} \times K_{S p}^{x / 2} B_{x y 2} a_{H S^{-}}^{y-x / 2} a_{H_{+}}^{z-y+x / 2} \gamma_{C_{x} S_{y} H_{z}} x+z-2 y
$$

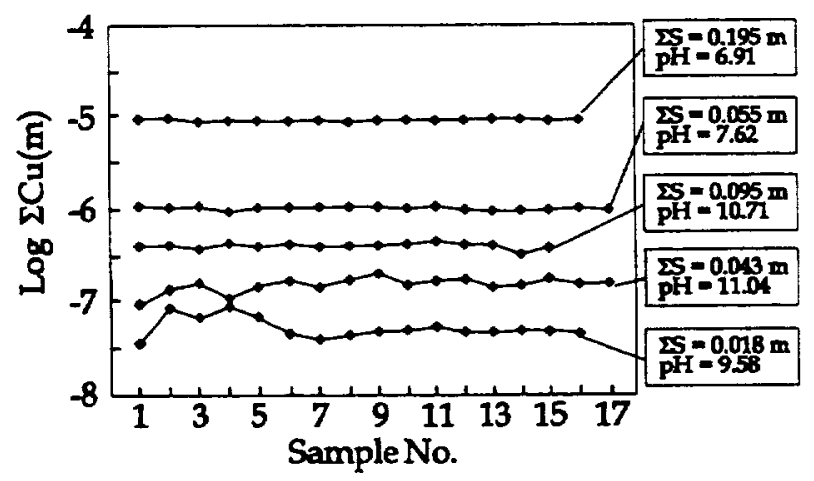

Fig. 1. Example log solubility vs. sample number plots for five continuous flow experiments.

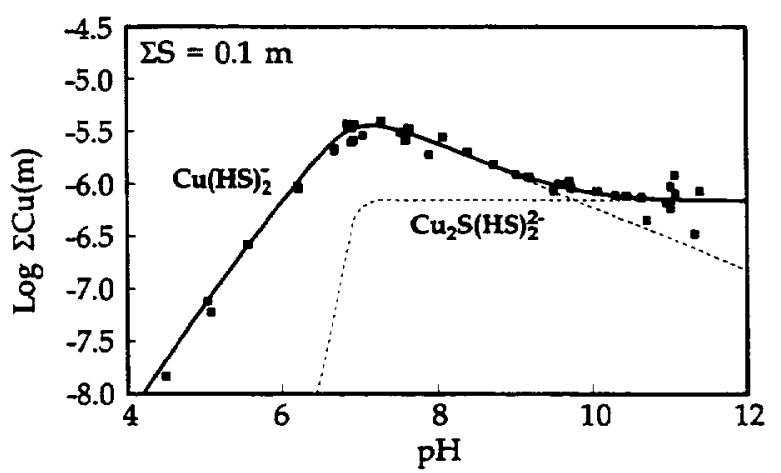

Fig. 2. Nonlinear least-squares fit of the 47 median data points using the speciation model $\mathrm{Cu}(\mathrm{HS})_{2}{ }^{-}+\mathrm{Cu}_{2} \mathrm{~S}(\mathrm{HS})_{2}{ }^{2-}$.

By choosing various sets of complexes, the above equation can be fit using nonlinear least-squares regression of the data (Fig. 2).

Conclusions: The best-fit speciation model gives the following cumulative stability constants

$$
\begin{gathered}
\mathrm{Cu}^{+}+2 \mathrm{HS}^{-} \rightarrow \mathrm{Cu}(\mathrm{HS})_{2}-\log \mathrm{B}_{122}=16.91 \pm 0.02 \\
2 \mathrm{Cu}^{+}+3 \mathrm{HS}^{-} \rightarrow \mathrm{Cu}_{2} \mathrm{~S}(\mathrm{HS})_{2}{ }^{2-}+\mathrm{H}^{+} \\
\log \beta_{232}=29.83 \pm 0.04
\end{gathered}
$$
stant

Comparison with Ag gives the following tentative stability con-

$$
\mathrm{Cu}^{+}+\mathrm{HS}^{-} \rightarrow \mathrm{Cu}(\mathrm{HS})^{\circ} \quad \log \beta_{111}=12.9
$$

\section{MELTING EXPERIMENTS ON SUBCONTINENTAL MAN-} TLE VEIN ASSEMBLAGES. D.S. Musselwhite and S. F. Foley, Mineralogisch-Petrologisches Institut, Universität Göttingen, Goldschmidtstrasse 1, 37077 Göttingen, Germany.

Introduction: Mantle vein assemblages are found in xenoliths associated with ultrapotassic volcanics in both cratonic and noncratonic settings. Examples include amphibole-apatite xenoliths from Kiama, New South Wales, Australia [1], micaclinopyroxene assemblages from Katwe-Kikorongo, Uganda [2], and MARIDs associated with kimberlites [3].

It has been proposed by Foley [4] that ultrapotassic volcanics originate from the hybridization of components derived from the melting of vein assemblages and the melting and dissolution of the surrounding peridotitic mantle.

Melting Experiments on Vein Assemblages: Previous experimental work by Foley et al. [5] on MARID mineral assemblages addressed the problem of producing lamproites from nonperidotic mantle assemblages in a lower cratonic lithosphere environment where K-richterite is expected to be stable. As a follow-on to this work, we are conducting melting experiments in order to determine the melting points and detailed reaction mechanisms for selected mantle vein assemblages from noncratonic settings. Experiments so far conducted have been run at $15 \mathrm{kbar}$ at temperatures between $1000^{\circ}$ and $1200^{\circ} \mathrm{C}$ using a piston-cylinder apparatus. Starting materials are run in graphite capsules inside sealed platinum capsules. Five mineral assemblages are being investigated: apat + amph 
(50:50), apat + amph + mica $(45: 45: 10)$, apat + amph + cpx (45:45:10), apat + amph + mica + cpx (40:40:10:10), and mica + cpx (50:50). Natural minerals are used. Compositions for the minerals were chosen to be close to those for the amphibole-apatite vein assemblages of Kiama, New South Wales, Australia, and the micaclinopyroxynite vein assemblages of Uganda. Both amphibole and mica have high $\mathrm{Ti}$ contents and apatite is $\mathrm{F}$ rich.

Results: In all assemblages, melting begins below $1050^{\circ} \mathrm{C}$. In all mineral assemblages containing amphibole and apatite, similar initial melt compositions are found. These melts are enriched in $\mathrm{SiO} 2(\sim 45 \%)$ and $\mathrm{CaO}$ and lower in $\mathrm{K}$ than the bulk compositions. They contain approximately $2.7 \% \mathrm{TiO}_{2}$ that appears to come from amphibole and not mica. Further experiments and analyses are planned.

References: [1] Wass S. Y. et al. (1980) Philos. Trans. R. Soc. London, A297, 333-346. [2] Lloyd F. E. and Bailey D. K. (1975) Phys. Chem. Earth, 9, 389-416. [3] Waters F. G. (1987) Contrib. Mineral. Petrol., 95, 523-533. [4] Foley S. F. (1992) Lithos, 28, 435-453. [5] Foley S. F. et al. (1996) J. Conf. Abstr., 6th Goldschmidt Conf., 1, 172.

AMPHIBOLE INCLUSIONS IN SNC METEORITES: EVIDENCE FOR A DRY MARTIAN INTERIOR? B. O. Mysen', D. Virgo', R. K. Popp ${ }^{2}$, and C. M. Bertka' ${ }^{1}$ 'Geophysical Laboratory, Carnegie Institution of Washington, 5251 Broad Branch Road, Northwest, Washington DC 20015, USA (mysen@gl.ciw.edu; virg@@gl.ciw.edu; bertka@gl.ciw.edu),2Department of Geology and Geophysics, Texas A\&M University, College Station TX 77843, USA (rkp@geopsun.tamu.edu).

Recently published $\mathrm{H}_{2} \mathrm{O}$ contents for Chassigny and Zagami SNC meteorite kaersutite amphibole inclusions, presumably derived from Mars, indicate that these amphiboles contain between 0.1 and $0.2 \mathrm{wt} \% \mathrm{H}_{2} \mathrm{O}$ [1]. By using the experimental data of Popp et al. [2], which interrelate the redox state of $\mathrm{Fe}$ and $\mathrm{H}$ deficiency in kaersutitic amphibole, the $\mathrm{Fe}^{3+} / \Sigma \mathrm{Fe}$ in Chassigny is $\sim 0.6$ and in Zagami $\sim 0.35$. From the experimental data of Popp et al. [2], these kaersutites crystallized at $1000^{\circ} \mathrm{C}$ in a $\mathrm{fH}_{2}$ range between 0.0002 and 0.05 depending on pressure and exact $\mathrm{H}_{2} \mathrm{O}$ content of the amphibole. The $\mathrm{fH}_{2}$ increases slightly with increasing assumed pressure of crystallization and is also positively correlated with the $\mathrm{H}_{2} \mathrm{O}$ content of the amphibole.

The activity of $\mathrm{H}_{2} \mathrm{O}$ during crystallization, assuming an $\mathrm{O}$ fugacity near that of the quarz-fayalite-magnetite buffer, ranges from 0.00001 to 0.6 in the pressure range between $0.1 \mathrm{MPa}$ and $0.6 \mathrm{Gpa}$ at an assumed crystallization temperature of $1000^{\circ} \mathrm{C}$. The activity of $\mathrm{H}_{2} \mathrm{O}$ decreases with increasing assumed pressure of crystallization.

The composition of glass coexisting with the amphiboles is a nearly pure feldspar composition glass. By using the Bumham model $[3,4]$ for activity-water composition relations of $\mathrm{H}_{2} \mathrm{O}$ in feldspar melts, the activity of $\mathrm{H}_{2} \mathrm{O}$ is converted to water concentration. In the assumed temperature and pressure range of $800^{\circ}$ $1000^{\circ} \mathrm{C}$ and $0.1-600 \mathrm{MPa}$, these amphiboles crystallized from a melt containing $100-1000 \mathrm{ppm} \mathrm{H}_{2} \mathrm{O}$. This water content could reflect $1-35 \mathrm{ppm} \mathrm{H}_{2} \mathrm{O}$ in the martian mantle at the time of SNC parental magma formation. This water estimate is less than $10 \%$ of that of the terrestrial mantle. The 1-35-ppm estimate agrees with those from planetary element abundance and abundance ratios. The $\mathrm{H}_{2} \mathrm{O}$ abundance data are consistent with the homogeneous accretion model for Mars with whole-planet equilibrium and $\mathrm{H}$ escape during the planet's early history.

References: [1] Watson L. L. et al. (1994) Science, 265, 86. [2] Popp R. K. et al. (1995) Am. Mineral., 80, 534. [3] Burnham C. W. (1975) GCA, 39, 1077-1084. [4] Bumham C. W. (1994) in Volatiles in Magmas (M. R. Carroll and J. R. Holloway, eds.), pp. 123-130, Mineralogical Soc. Am., Washington, DC.

\section{EVIDENCE FOR SUBCONTINENTAL MANTLE IN MAG-} MATISM WITHIN THE ZIMBABWE CRATON AND RHENIUM-OSMIUM MANTLE MODELING. Th. F. Nagler ${ }^{1}$, J. D. Kramers ${ }^{1}$, B. S. Kamber ${ }^{2}$, R. Frei1, and M. D. A. Prendergast $^{3}$, 'Gruppe Isotopengeologie, Mineralogisch-Petrographisches Institut, University of Bern, CH-3012 Bern, Switzerland (naegler@mpi.unibe.ch), ${ }^{2}$ Department of Earth Science, University of Oxford, Parks Road, Oxford, OXI 3PR, UK, ${ }^{3}$ Greendale, Harare, Zimbabwe.

Rhenium-osmium isotope results on chromites separated from Archean ultramafic intrusions in the Zimbabwe craton are presented. The respective intrusion ages (2.7-3.8 Ga) are constrained independently (stratigraphically and/or U-Pb geochronology of related rocks). Initial ${ }^{187} \mathrm{Os} /{ }^{188} \mathrm{Os}$ (OsIC) define an apparent evolution line, signifying an environment depleted in $\mathrm{Re}$ since $3.8 \mathrm{Ga}$ ago. Chromites average a present-day OsIC of 0.1066. As an Archean Re depletion of the subcontinental lithospheric mantle (SCLM) is evident from published results on xenoliths from southern Africa, Siberia, and the Wyoming Craton [1-4], we interprete the low OsIC values as being derived from the SCLM, implying that this reservoir was already important in the Archean.

In order to assess the possible Os isotope effect of SCLM formation involving Re depletion on the Os isotope character of the upper mantle, we have carried out Re-Os forward modeling. The transport balance model we used includes lower mantle (LM), upper mantle (UM), continental crust (CC), oceanic crust (OC), and SCLM reservoirs. It is identical to the model used by Kramers and Tolstikhin [5] to model terrestrial $\mathrm{U}-\mathrm{Th}-\mathrm{Pb}$ characteristics, except for the addition of the SCLM. Generation of OC (MORB) follows a simple batch melting relationship; that of protocontinental crust involves a mixing-fractionation zone, the locus of which is thought of as a subduction zone. Formation and growth of the SLCM is modeled as the sequestering of a portion of the residue of MORB formation, in 5: 1 proportion to $\mathrm{CC}$ growth until the end of the Archean. The crustal history scenario used starts with no $\mathrm{CC}$ at the end of Earth accretion; the $\mathrm{CC}$ grows to $75 \%$ of its present mass by $2 \mathrm{Ga}$. This fairly uniquely satisfies both $\mathrm{U}-\mathrm{Th}-\mathrm{Pb}$ and $\mathrm{Sm}-\mathrm{Nd}$ data $[5,6]$. The accreting Earth is taken as chondritic on average $[7,8]$. Target values for the modeling were present-day CC: $[O s]=50 \mathrm{ppt},[\mathrm{Re}]=390 \mathrm{ppt}$, OsIC $=1.3$ [9]; present-day SCLM: OsIC $=0.12$.

The amount of $\mathrm{Re}$ and Os stored in the crust is too small to have any effect on the evolution of either the SCLM or the UM. The SLCM raises the OsIC of the convecting UM only insignificantly above BSE. It is not possible to model the SLCM as a residue of Archean CC formation, as this entails no significant Re depletion in the residue (the effective melt fraction is too small for that). Furthermore, the Re-Os and OsIC balance rules this out for any reasonable size of the reservoirs.

References: [1] Walker et al. (1989) GCA, 53, 1583-1595. [2] Pearson et al. (1995) GCA, 59, 959-977. [3] Pearson et al. 
(1995) EPSL, 134, 341-357. [4] Carison and Irving (1994) EPSL, 126, 457-472. [5] Kramers and Tolstikhin (1997) Chem. Geol. [6] Nägler and Kramers (1997) Precambrian Res., submitted. [7] Shen et al. (1996) GCA, 60. [8] Yin (1995) Ph.D. thesis, Univ. Mainz. [9] Esser and Turekian (1992).

GROWTH OF GIBBSITE ON MUSCOVITE: THE IMPORTANCE OF BASAL-PLANE REACTIVE SURFACE AREA. K. L. Nagy, Geochemistry Department, Mail Stop 0750, Sandia National Laboratories, Albuquerque NM 87185-0750, USA (klnagy@sandia.gov).

Field observations have shown that both the basal and edge surfaces of layered silicates provide nucleation sites for secondary phases. An example is the growth of kaolinite on expanded micas in soils and sedimentary rocks. In this case, kaolinite does not grow laterally beyond the extent of original basal surfaces of the micas. The mica basal planes are pushed apart as growth occurs in the $c$ direction. In contrast, during dissolution of sheet silicates, edge surfaces are assumed to be more reactive than basal surfaces. Here, it is shown experimentally that basal surfaces comprise a significant proportion of reactive surface area during growth.

Growth of layered metal hydroxides is a step in the construction of sheet silicates. Formation of layered metal hydroxides is also considered to be a mechanism for irreversible sorption of certain contaminants in the subsurface. An understanding of substrate controls on metal hydroxide formation is important in a wide variety of geochemical processes.

Gibbsite is a dioctahedral Al-hydroxide with a sheet structure. The muscovite surface is composed of hexagonally linked tetrahedra in which one of four silicons is replaced by $\mathrm{Al}$. The basal plane structures of both minerals match to within $<3 \%$, suggesting that epitaxial growth of gibbsite could occur on muscovite.

Gibbsite was precipitated onto freshly cleaved muscovite at $80^{\circ} \mathrm{C}, \mathrm{pH}$ 3. The saturation states investigated ranged from $\Delta \mathrm{G}_{\mathrm{r}}=$ $0.1-2.1$, where $\Delta G_{r}=R T[\ln (\mathrm{Q} / \mathrm{K})]$ for the reaction $\mathrm{Al}^{3+}+3 \mathrm{H}_{2} \mathrm{O}=$ $\mathrm{Al}(\mathrm{OH})_{3}+3 \mathrm{H}^{+}$. ( $\mathrm{Q}$ and $\mathrm{K}$ are ion activity products in the supersaturated solution and at equilibrium respectively, $\mathrm{T}$ is temperature in $\mathrm{K}$, and $\mathrm{R}$ is the gas constant.) Rotating anode $\mathrm{X}$-ray analysis has been applied to confirm that gibbsite is the precipitating phase from solutions of these compositions [1].

Kinetic experiments were conducted in stirred-flow reactors that were comparmentalized to separate a stir bar from a square of single-crystal muscovite. The muscovite was freshly cleaved with adhesive tape immediately prior to filling the reactor with solution. The single crystal was free to float in the upper compartment during reaction, but was not able to rotate vertically. The absolute amount of surface area was so low that a steady-state growth rate could not be measured by comparing inlet and outlet fluid compositions. The geometric ratio of basal to edge surface area was $\sim 10$.

Growth rate was calculated by determining the volume of precipitate from images obtained using tapping mode atomic force microscopy (TMAFM). The base height of an image was assumed to represent the original muscovite surface. Precipitate morphology varied as a function of saturation state, reaction time, and hydrodynamic conditions within the reactor. However, many morphological features reflect the hexagonal pattem of the linked tetrahedra in the muscovite basal plane. Despite the morphological variation, growth rates that are in agreement with published rates [2] are obtained, provided that the area examined is above a threshold value and the full range of crystallite sizes is captured in an image.

For example, the calculated growth rate on the muscovite basal plane at $\Delta G_{\mathrm{r}}=2.1$ is $6.4 \times 10^{-10} \mathrm{~mol} / \mathrm{m}^{2} / \mathrm{s}$, where surface area is that of the original muscovite basal plane imaged and the maximum height of surface features is $\sim 400 \mathrm{~nm}$. This rate is consistent with that calculated using the rate law obtained for gibbsite growth on gibbsite powders where rate is a nearly linear function of $\Delta G_{\mathrm{r}}$ [2]. For smaller imaged areas with growth features of smaller dimensions, calculated rates can be lower, indicating that growth does not occur evenly over the surface. Growth rate can be scale-dependent below an imaged surface area of about $1.44 \times 10^{-10} \mathrm{~m}^{2}$.

Agreement between previously measured rates from powder experiments and rates derived from the TMAFM images indicates that much of the gibbsite forms on the muscovite basal plane. This implies that basal planes are an important component of reactive surface area during mineral growth.

Acknowledgments: This work was supported by the U.S. Department of Energy under contract DE-AC0494AL85000. Sandia is a multiprogram laboratory operated by Sandia Corporation, a Lockheed Martin Company, for the U.S. Department of Energy.

References: [1] Nagy K. L. and Sturchio N. C. (1997) 11th Intl. Clay Conf., Ottawa. [2] Nagy K. L. and Lasaga A. C. (1992) GCA, 56, 3093-3111.

THE WHOLE ENCHLADA: CONSISTENCY, CORRECTNESS, AND PHYSICAL INSIGHT IN HIGH PRESSURETEMPERATURE MINERAL PHYSICS DATA FOR HYDROUS MANTLE PHASES. A. Navrotsky ${ }^{1}$, K. Bose ${ }^{1}$, P. Schields' ${ }^{2}$, Y. Wang ${ }^{2}$, and D. J. Weidner ${ }^{2},{ }^{1}$ Center for High Pressure Research (CHiPR) and Department of Geosciences, Princeton University, Princeton NJ 08544, USA, 2Department of Earth and Space Sciences, State University of New York-Stony Brook, Stony Brook NY 11794, USA.

The question of how much water persists in subducting slabs is addressed, in part, by obtaining high-quality calorimetric, phase-

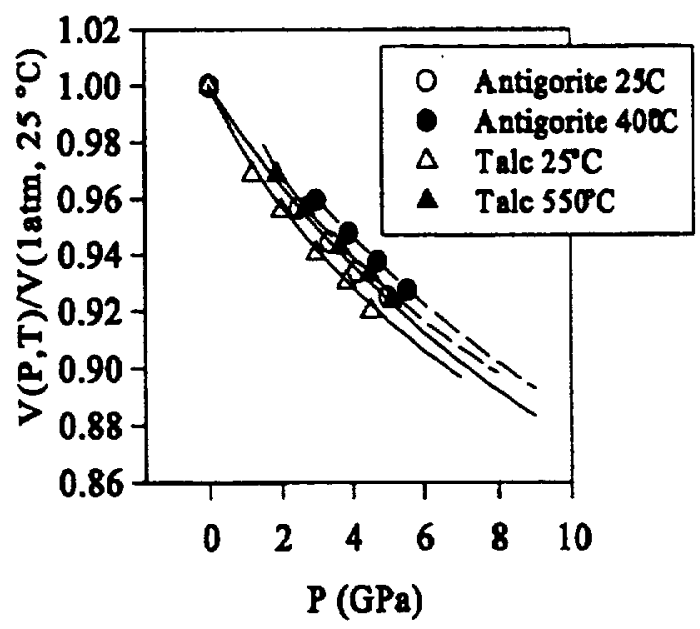

Fig. 1. 
TABLE 1. Parameters obtained using optimization procedure.

\begin{tabular}{lccccc}
\hline & $\begin{array}{c}\Delta \mathrm{H}^{\circ}{ }_{\text {(clements) }} 298 \\
(\mathrm{~kJ} / \mathrm{mol})\end{array}$ & $\begin{array}{c}\mathrm{S}^{\circ} 298 \\
(\mathrm{~J} / \mathrm{mol} \mathrm{K})\end{array}$ & $\mathrm{K}(\mathrm{GPa})$ & $\mathrm{K}^{\prime}$ & $\alpha\left(\mathrm{K}^{-1}\right)$ \\
\hline Talc & -5897 & 261 & 35.5 & 12.1 & $2.16 \mathrm{e}-5$ \\
Antigorite & -70956 & 3584 & 49.6 & 6.1 & $2.93 \mathrm{c}-5$ \\
Phase A & -7129 & 351 & 145 & 4 & $8.26 \mathrm{c}-5$ \\
\hline
\end{tabular}

*Volumetric properties of phase A from [1].

equilibrium, and equation-of-state data for dense hydrous magnesium silicates (DHMS). Because each of these measurements stretches the technical capability of the respective technique to near its limit, especially for anisotropic and complex hydrous phases, the individual sets of data are sparse and not readily analyzed to give unique "best" values of $\Delta \mathrm{H}, \Delta \mathrm{S}$, and $\Delta \mathrm{V}$ as functions of pressure and temperature. Rather than regressing each set of data individually to obtain $\Delta \mathrm{H}^{\circ}, \Delta \mathrm{S}^{\circ}$, and $\Delta \mathrm{V}(\mathrm{P}, \mathrm{T})$, we present an approach that seeks internal consistency, well-balanced extrapolation, and physically reasonable values of $\Delta \mathrm{H}^{\circ}, \Delta \mathrm{S}^{\circ}, \Delta \mathrm{V}^{\circ}, \mathrm{K}, \mathrm{K}^{\prime}$, and $\alpha$ for talc, antigorite, and hydrous phase $A$ such that the calorimetric, phase-equilibrium, and in situ high P,T crystallographic observations are all satisfied. This procedure leads to iterative analysis of the $V(P, T)$ data because the thermodynamic relations are especially sensitive to the equation of state of the layer silicates.

To get satisfactory results, it is not sufficient to optimize the parameters after each type of data is fit independently. Rather, it is necessary to constantly monitor the effect of change in each type of parameter on the calculated equilibria. In situ measurement of volume at high $\mathrm{P}$ and $\mathrm{T}$ for talc and antigorite result in a bulk modulus of talc that is less than that of antigorite.

Although existing databases predict the opposite relationship (based on low-pressure phase equilibria), our optimization procedure satisfies both the low- and high-P phase equilibria. Using this approach, the parameters given in Table 1 are obtained.

The calculated phase equilibria show that there is no barrier to subducting substantial amounts of water to depths of $400-600 \mathrm{~km}$ in cooler slabs, because the slab can remain in the stability field of hydrous phases throughout its descent. Once water is brought to these depths, it can probably diffuse into hotter mantle regions via hydrous $\mathrm{B}-\mathrm{Mg}_{2} \mathrm{SiO}_{4}$ or other mechanisms. Thus the transition zone is unlikely to be dry.

References: [1] Pawley et al. (1995).

\section{STRONTIUM ISOTOPIC CHARACTERIZATION OF} GROUNDWATER AND CALCITE FROM THE POTENTIAL UNDERGROUND LABORATORY SITE IN THE VIENNE GRANITOIDS (FRANCE). P. Négrel ${ }^{1}$, J. Casanova ${ }^{\sharp}$, and J. -F. Aranyossy'2, 'BRGM, BP 6009, F 45060 Orléans Cedex 2 (p.negrel@brgm.fr; j.casanova@brgm.fr), 2ANDRA, 1 rue J. Monnet, F 92298, Châtenay-Malabry (jf.aranyossy@andra.fr).

Introduction: Strontium isotope ratios are often used as traces of the degree of water-rock interaction and mixing processes in groundwater [1]; they can also be used as indicators of fluid origin for calcites in fracture fillings in granitic environments [2]. Thus, $\mathrm{Sr}$ analyses have been performed on groundwater and calcite samples,

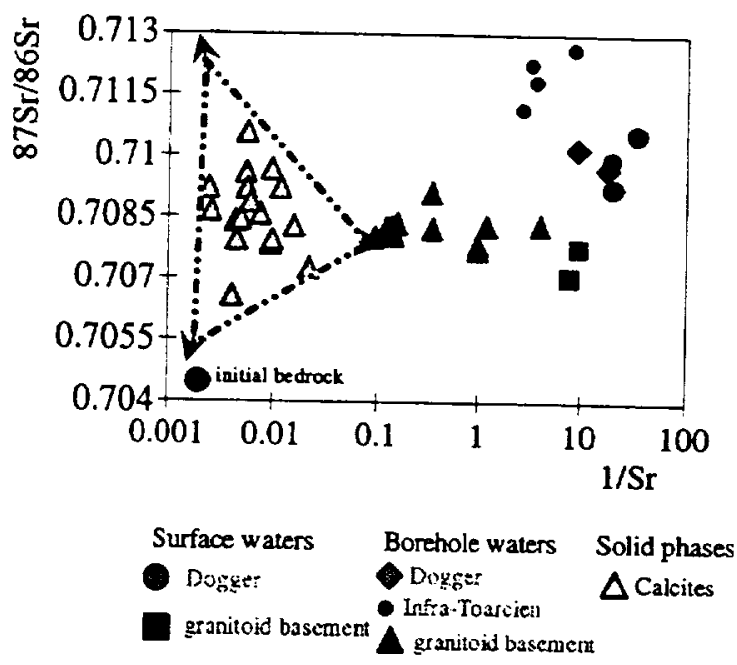

Fig. 1.

in the framework of the preliminary geological characterization of the crystalline potential underground laboratory site. This study should contribute to the understanding of present and past water circulations and the design of the conceptual groundwater flow model.

Methods: The Sr content and isotopic ratio measurements were performed on (1) surface waters springing from the two overlying sedimentary aquifers, Dogger/Infra-Toarcian, and from the granite outcrops of Limousin; (2) shallow groundwater from boreholes in the two sedimentary aquifers; (3) deep groundwater from the ANDRA boreholes located in the granitoid basement; and (4) calcite crystallizations from fracture fillings in core sections from the ANDRA boreholes.

Results and Interpretation: The presentation of the complete set of data on a ${ }^{87} \mathrm{Sr} /{ }^{86} \mathrm{Sr}$ vs. 1/Sr diagram (Fig. 1) shows evidence of three distinct groups of waters: (1) the deep granitic waters $(n=12)$, characterized by a homogeneous low isotopic ratio $\left({ }^{87} \mathrm{Sr} /{ }^{86} \mathrm{Sr}=0.70831 \pm 0.0004\right)$ and high $\mathrm{Sr}$ content $([\mathrm{Sr}]=4.06 \pm 2.9$ ppm); granitic surface waters, although more diluted, present simjlar isotopic ratios; (2) the Infra-Toarcien waters $(n=4)$, showing the highest isotopic ratio $\left({ }^{87} \mathrm{Sr} /{ }^{86} \mathrm{Sr}=0.71196 \pm 0.00063\right)$ and low $\mathrm{Sr}$ content $([\mathrm{Sr}]=0.27 \pm 0.11 \mathrm{ppm})$; and $(3)$ the Dogger waters $(n=5)$, with intermediate isotopic ratio $\left({ }^{87} \mathrm{Sr}_{\mathrm{r}} /{ }^{66} \mathrm{Sr}=0.70993 \pm 0.00033\right)$ and low Sr content $([\mathrm{Sr}]=0.09 \pm 0.04 \mathrm{ppm})$. Surface water from the Dogger, although more diluted, presents a similar range of isotopic ratios

The repartition of the data in three separated groups on the graph (Fig. 1) suggests that only very weak communication, if any, occurs between the different formations.

The Sr data from the calcite $(n=17)$ form a cluster of points that can be interpreted by the influence of three end members: (1) a radiogenic component $\left({ }^{87} \mathrm{Sr} /{ }^{86} \mathrm{Sr}>0.7115\right)$, of which isotopic characteristics are compatible with that of the Infra-Toarcien aquifer; (2) a component $\left({ }^{87} \mathrm{Sr} /{ }^{86} \mathrm{Sr}\right.$ close to 0.708$)$ that reflects the granitic groundwater composition (deep water from boreholes and surface water springing from granite outcrops); and (3) a low radiogenic component $\left({ }^{87} \mathrm{Sr}^{186} \mathrm{Sr}<0.705\right)$. This component can be approached through the initial isotopic ratio of the granitoids $\left({ }^{87} \mathrm{Sr} /{ }^{86} \mathrm{Sr}=0.70447\right)$ 
and can be related to an early water-rock interaction with low ${ }^{87} \mathrm{Sr} /$ ${ }^{86} \mathrm{Sr}$ value $\mathrm{Sr}$-bearing phases, like plagioclase.

References: [1] Franklyn et al. (1991) Chem. Geol., 86. [2] McNutt et al. (1990) GCA, 54.

ORIGIN OF HERCYNIAN LEUCOGRANITES FROM CENTRAL KAZAKHSTAN: CRUSTAL AFFINITY VS. PRIMITIVE ISOTOPIC COMPOSITION. E. V. Negrey and K. N. Shatagin, Institute of Geology of Ore Deposits, IGEM, Russian Academy of Sciences, 35, Staromonetny Per., Moscow, 109017, Russia (shat@igem.msk.su).

Late orogenic leucogranites are known to be a typical part of Hercynian foldbelts worldwide. These crustal derivatives bear indications of their source material. Isotopic characteristics of the leucogranites are typically crustal (high initial $\varepsilon_{\mathrm{Sr}}$, low $\varepsilon_{\mathrm{Nd}}$ values). However, this is not the case for the Central Kazakhstan region, which comprises many late orogenic plutons with an unusually primitive isotopic composition.

The leucogranites are exposed over $20 \%$ of the JunggaroBalkhash section of the Kazakhstanian Uplands. The rocks make up separate multiple intrusions or chains and even belts (up to $250 \mathrm{~km}$ long and up to $50 \mathrm{~km}$ wide) of plutons. The leucogranites are intrusive into various types of rocks from Riphean to Carboniferous in age. The host rocks vary in composition from sedimentary to volcanic and often occur as roof pendants over some plutons. The internal structure of the plutons comprises multiple facies of leucogranites separated by active magmatic interfaces. From the earliest facies to the latest, the leucogranites become more and more felsic.

Mineral composition of the leucogranites is stable over exposed parts of the plutons; characteristic contents are 27-39 vol\% of quartz; 0-31 vol\% of oligoclase; 36-65 vol\% of $\mathrm{K}-\mathrm{Na}$-feldspar; $0.5-2$ vol\% of biotite, and $0.5-0.8$ vol\% of opaque minerals, mainly magnetite. Rare muscovite is always secondary.

Silica content in the leucogranites is very high, some 73-76 wt\%. The alkali content is also high: $\mathrm{K}_{2} \mathrm{O}=4.3-4.8 \mathrm{wt} \%, \mathrm{Na}_{2} \mathrm{O}=3.8$ $4.2 \mathrm{wt} \%\left(\mathrm{~K}_{2} \mathrm{O} / \mathrm{Na}_{2} \mathrm{O}>1.0\right)$. The rocks are characterized by low $\mathrm{CaO}$ $(0.4-1.2 \mathrm{wt} \%)$ and high $\mathrm{F}(0.10-0.35 \mathrm{wt} \%)$ contents and are metaluminous to alumina-saturated, with the molecular ratio $\mathrm{Al}_{2} \mathrm{O}_{3}$ ' $\left(\mathrm{CaO}+\mathrm{K}_{2} \mathrm{O}+\mathrm{Na}_{2} \mathrm{O}\right)$ in the range $0.85-1.05$.

The Hercynian leucogranitic plutons of the area have $\mathrm{Rb}-\mathrm{Sr}$ isochron ages between 303 and $283 \mathrm{Ma}$. During this period there were at least three main magmatic pulses dated at $303 \pm 2,293 \pm 3$, and $288 \pm 2 \mathrm{Ma}$. The mineral and whole-rock $\mathrm{Rb}-\mathrm{Sr}$ isochrons are indistinguishable. Geochronological findings imply relatively short formation timescales for the plutons, generally less than 1.5-2.0 m.y. The ages of associated greizen and hydrothermal W-Mo mineralization are indistinguishable from that of the respective granites.

The abundance of high-silica rocks, the lack of less-evolved rocks (granites and granodiorites) in the plutons from different parts of the area, and the relatively constant chemical composition of the rocks suggest that the leucogranites crystallized from a primary high-silica magma.

Isotopic studies were carried out for five typical plutons of the area. Regardless of the age, the early facies leucogranites of the plutons have regionally reproducible values of $\left({ }^{87} \mathrm{Sr} /{ }^{86} \mathrm{Sr}\right) 0=0.7051-$ 0.7060 , and $\varepsilon_{\mathrm{Nd}}(T)=0.4-1.2$. The isotopic homogeneity suggests a common deep source for the rocks. There are two formal explanations of the current isotopic data: (1) The leucogranites may originate from a crustal reservoir that was extracted from the depleted mantle at about $0.7-1.0 \mathrm{Ga}$ (as evidenced from $T_{D M}(\mathrm{Nd})$ of the samples); (2) the primary leucogranitic magma were melted from a mixed source with a predominance of a juvenile component and a very stable juvenile/ancient component proportion across the area.

Both possibilities consider the young continental crust: In the first case it most likely was accreted during the Riphean; in the second case it underplated the ancient lower crust during the Paleozoic. However, the composition of this part of the crust and the history of relatively rapid transformation of its mantle-born rocks into typical (fertile for leucogranitic magmas) crustal material still need to be studied.

TEMPERATURE AND COMPOSITIONAL CONTROLS ON THE MINERAL-MELT PARTITIONING OF THE HIGH FIELD STRENGTH AND RARE EARTH ELEMENTS FOR AMPHIBOLE AND MAGNETITE. R. L. Nielsen' ${ }^{\text {, J. S. Beard }}{ }^{2}$, and M. L. Hilyard ${ }^{1},{ }^{1}$ College of Oceanic and Atmospheric Sciences, 104 Oceanography Administration, Oregon State University, Corvallis OR 97330-5506, USA (mielsen@oce.orst.edu), ${ }^{2}$ Virginia Museum of Natural History, 1001 Douglas Avenue, Martinsville VA 24112 , USA.

Interest in the mineral-melt partitioning behavior of the REE and HFSE for amphibole and magnetite is linked to the fact that these phases are considered by many to control the concentrations of these trace-element groups in many silicic systems. Existing partitioning data for each element exhibit a wide range of values (factor of 10+).

For magnetite, Nielsen et al. [1] showed that there was a strong correlation between $D_{T i}$ and those of the HFSE in basaltic systems. It was inferred that the relationship was due to the similarity of the mixing behavior of those elements in spinel-group minerals. Based on these observations, it was concluded that magnetite would have an important influence in the HSFE budget of an evolving igneous system only when the $\mathrm{Al}$ content of the oxide was low $\left(>4 \% \mathrm{Al}_{2} \mathrm{O}_{3}\right.$ ) in magnetite and titanomagnetite.

Most existing amphibole-melt partitioning data are for mafic systems at relatively high temperature, or are phenocryst/matrix determinations. Reported values for each element exhibit a range of 1-2 orders of magnitude with many elements straddling the compatible/incompatible boundary. This makes any model of the traceelement systematics of intermediate to silicic systems dependent on an adequate knowledge of the details of their partitioning behavior.

In order to evaluate the controls on partitioning for these element groups, we have conducted a set of melting experiments using mafic to intermediate starting compositions. The experiments were conducted at pressures ranging from 2 to $8 \mathrm{kbar}$ and $850^{\circ}-950^{\circ} \mathrm{C}$ (water saturated) in internally heated pressure vessels at Oak Ridge $\mathrm{Na}$ tional Laboratory and at VPI. The starting compositions were doped with $0.25 \mathrm{wt} \%$ of the elements of interest, and the run products were analyzed by electron probe. Our results indicate that the amphibolemelt partitioning behavior of the REE and HFSE is strongly, and positively, correlated to alkalinity and Si content of the melt, $\mathrm{Ca}$ and Al content of the amphibole, $\mathrm{D}_{\mathrm{Ti}}$, and reciprocal temperature. Thus the controls are similar to those observed for the same elements in pyroxene-saturated systems [2-4]. The correlation with alkalinity is 
related to the effect of alkalinity on the activity of Tshermak components in the amphibole, the major mechanism for the incorporation of the $+3,+4$, and +5 cations into the structure. The experimental liquid compositions range from dacite to tonalite to low-silica rhyolite. We have incorporated existing data with our new data and derived expressions that can be used to predict the partitioning behavior of the REE and HFSE for systems ranging from basalts to rhyolite and $2-20 \mathrm{kbar}$.

Magnetite-melt HFSE partition coefficients derived from these same experiments were correlated with $\mathrm{D}_{\mathrm{T}}$; however, the slope of the correlation was significantly lower (factor of 10 ) than observed in more mafic, higher-temperature systems at any given $\mathrm{D}_{\mathrm{Ti}}$. This is consistent with our earlier conclusion that the mixing properties of the HFSE in spinel-group minerals are more nonideal than $\mathrm{Ti}$. However, these new results suggest that the mixing behavior of the HFSE is also significantly more temperature dependent than that of $\mathrm{Ti}$.

Conclusions: Magnetite has a very small influence on the REE and HFSE budget in hydrous, aluminous, silicic systems. In contrast, the amphibole-melt partition coefficients for the REE and HFSE are highest in those same compositions. Dehydration reactions wherein amphibole breaks down to pyroxene plus melt will result in a melt with positive HFSE anomaly relative to the REE. A hydrous melt reacting with mantle containing pyroxene will result in negative anomalies for (in order of decreasing magnitude) $\mathrm{Ti}, \mathrm{Hf}$, $\mathrm{Zr}, \mathrm{Ta}$, and $\mathrm{Nb}$.

References: [1] Nielsen R. L. et al. (1994) Chem. Geol., 117, 167-193. [2] McKay G. A. et al. (1986) GCA, 50,927-937. [3] Hack P. J. et al. (1994) Chem. Geol., 117, 89-106. [4] Forsythe L. M. et al. (1994) Chem. Geol., 117, 107-126.

\section{CARBON AND HELIUM ISOTOPE SYSTEMATICS OF} NORTH FIJI BASIN BASALT GLASSES. Y. Nishio', S. Sasaki $^{1}$, T. Gamo ${ }^{2}$, H. Hiyagon ${ }^{3}$, and Y.Sano ${ }^{4}$, 'Geological Institute, School of Science, University of Tokyo, Tokyo 113,Japan(nishio@ geol.s.u-tokyo.ac.jp), ${ }^{2}$ Ocean Research Institute, University of Tokyo, Tokyo 164, Japan, 'Bepartment of Earth and Planetary Physics, School of Science, University of Tokyo, Tokyo 113, Japan, ${ }^{4}$ Department of Earth and Planetary Science, Hiroshima University, HigashiHiroshima 739, Japan.

We have measured $\delta^{13} \mathrm{C}$ values and $\mathrm{CO}_{2} /{ }^{3} \mathrm{He}$ ratios of vesicle gas, and chemical compositions of North Fiji Basin basalt glasses, in order to estimate the contribution of subducted $\mathrm{C}$ in back-arc basin basalt quantitatively. The $\mathrm{CO}_{2} /{ }^{3} \mathrm{He}$ ratio increases and $8^{13} \mathrm{C}$ value decreases with $\mathrm{K}_{2} \mathrm{O}$ content (Fig. 1). These $\mathrm{CO}_{2} /{ }^{3} \mathrm{He}$ and $\delta^{13} \mathrm{C}$ trends should be produced by the mixing between mantle component (low $-\mathrm{CO}_{2} /{ }^{3} \mathrm{He}$, high $-\delta^{13} \mathrm{C}$, and low- $\mathrm{K}_{2} \mathrm{O}$ ) and subducted component (high- $\mathrm{CO}_{2}{ }^{3} \mathrm{He}$, low $-\delta{ }^{13} \mathrm{C}$, and high-K $\mathrm{K}_{2} \mathrm{O}$ ), because REE and $\mathrm{Sr}-\mathrm{Nd}$ isotopic data suggest that the variety of $\mathrm{K}_{2} \mathrm{O}$ content of the North Fiji Basin basalt is the result of two-component mixing $[1,2]$. Based on the mass-balance calculation of Sano and Marty [3], we estimate that carbonate and organic $\mathrm{C}$ in North Fiji Basin basalts have a ratio of 7:3 (Fig. 2). Assuming complete decomposition of the subducted organic C, more than $90 \%$ of the subducted carbonate survives and may be injected into the mantle in the area studied, since carbonate and organic $C$ in subducting marine sediment through the North Fiji subduction zone should occur in 20:1 ratio [4].

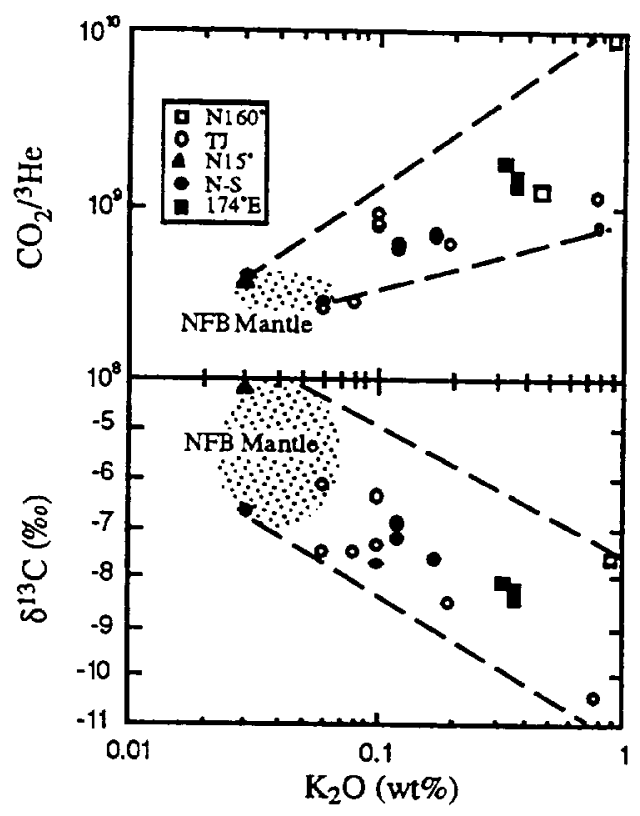

Fig. 1. $\mathrm{N} 160^{\circ}$ (northern part). TJ (Triple Junction), $\mathrm{N} 15^{\circ}$ (southern par), $\mathrm{N}$ $\mathrm{S}$ (southern part), and $174^{\circ} \mathrm{E}$ (southem part) refer to the major central ridge in North Fiji Basin.

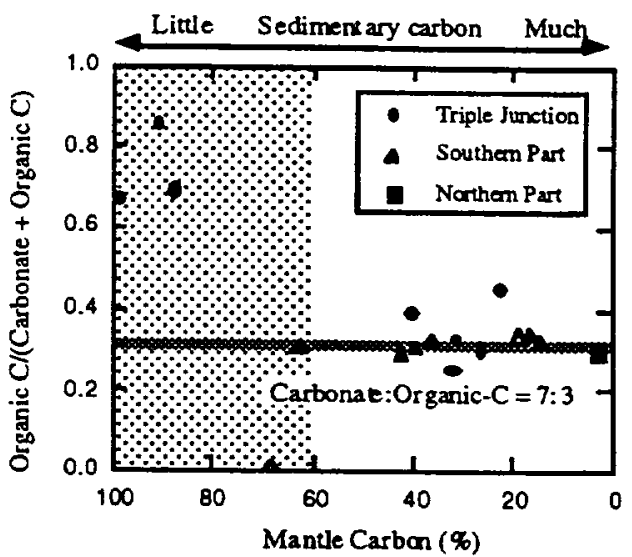

Fig. 2. $\mathrm{N} 160^{\circ}$ (northem part), TJ (Triple Junction), $\mathrm{N} 15^{\circ}$ (southern part), $\mathrm{N}$ $S$ (southern part), and $174^{\circ} \mathrm{E}$ (southem part) refer to the major central ridge in North Fiji Basin.

References: [1] Eissen et al. (1994). [2] Nohara et al. (1994). [3] Sano and Marty (1995). [4] Collot et al. (1992).

COMPOSITIONS OF PRIMUTIVE MAGMAS AND SOURCE CHARACTERISTICS OF THE HAWAI'IAN PLUME: CONSTRAINTS FROM PICRITIC LAVAS. M. D. Norman ${ }^{1}$ and M. O. Garcia'2, 'GEMOC, School of Earth Sciences, Macquarie University, North Ryde, NSW 2109, Australia (marc.norman@ mq.edu.au), 2Geology and Geophysics Department, University of Hawai'i, Honolulu HI 96822, USA (garcia@soest.hawaii.edu).

The Hawai'ian plume is the largest, hottest, longest-lived mantle plume currently active on Earth. Moderately evolved tholeiites (7- 
$8 \% \mathrm{MgO}$ ) are volumetrically dominant but are subject to modification by high-level magmatic processes. To provide better constraints on primitive magma compositions and source characteristics of the Hawai'ian plume, we have studied picritic lavas ( $>15 \%$ modal olivine) from 7 volcanos. Picrites are abundant on the flanks of Hawai'ian volcanos and may sample deeper levels of the magmatic system. Some appear to have escaped the complexities of shallow magma chambers $[1,2]$, and therefore may provide the clearest picture available of primitive magmatic characteristics of the Hawai'ian plume.

Picrites in our suite contain 13-30\% MgO. Log-log plots of compatible vs. incompatible elements show trends consistent with accumulation of olivine into parental magmas with $\sim 14 \% \mathrm{MgO}$, so the least-magnesian picrites in our study represent close approaches to parental magma compositions, and include samples from Kilauea, Hualalai, and Koolau.

Common-denominator plots, such as $\mathrm{Al} / \mathrm{Ni}$ vs. $\mathrm{l} / \mathrm{Ni}$ and $\mathrm{Al} / \mathrm{Mg}$ vs. $1 / \mathrm{Mg}$, that include all our picrites as well as more-evolved tholeitites show well-defined linear trends consistent with twocomponent mixtures of olivine and melt. The tight trends are somewhat surprising considering the range of possible olivine and melt endmember compositions, and suggest that these lavas formed by processes that are common to Hawal'ian volcanos.

Linear regressions for these arrays indicate an Fo88 olivine end member with $2829 \mathrm{ppm} \mathrm{Ni}$, consistent with the compositions of olivines in these and other Hawai' ian picrites [2-4]. Fo88 olivine would be in equilibrium with a $12 \% \mathrm{MgO}$ melt $\left(\mathrm{Kd}=0.3, \mathrm{Fe}^{3+} / \mathrm{Fe}-\right.$ total $=0.1$ ), and regression analysis indicates this melt would contain $449 \mathrm{ppm} \mathrm{Ni}$. A similar analysis for Co indicates $166 \mathrm{ppm}$ in the olivine and $59 \mathrm{ppm}$ in the melt. These compositions correspond to olivine/melt $\mathrm{Kd}$ of 6.3 for $\mathrm{Ni}$ and 2.8 for $\mathrm{Co}$, and a $\mathrm{Ni} / \mathrm{Co}$ of 17.0 in the olivine, similar to experimentally determined values for melts of this composition at $\mathrm{fO}_{2}>$ IW [5].

Major-element, trace-element, and isotopic compositions of Hawai'ian lavas demonstrate the presence of at least two and possibly three distinct components within the Hawai'ian plume $[6,7]$. Figure 1 compares near-parental lavas from Koolau and Kilauea as an illustration of the trace-element characteristics that distinguish these two end members. The third end member is similar in trace-element characteristics to Kilauea, but can be distinguished by isotopic compositions [6]. Figure 1 shows that relatively primitive lavas from $\mathrm{Koolau}$ are enriched in $\mathrm{Sr}$ and $\mathrm{Pb}$ abun-

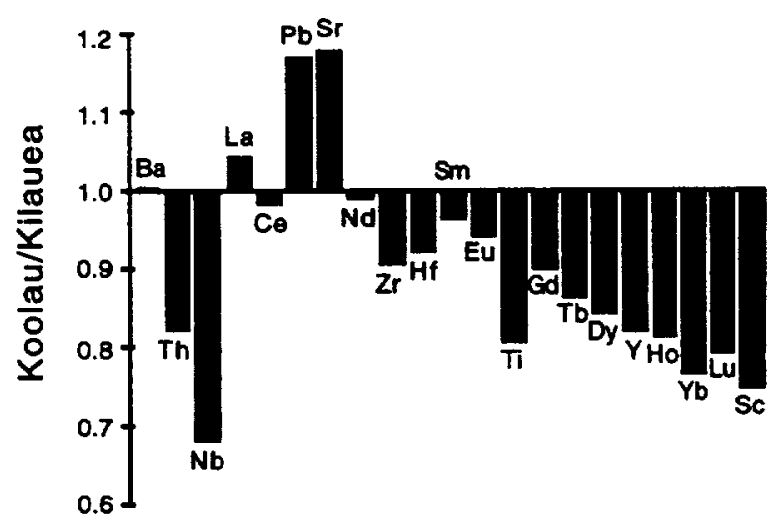

Fig. 1. dances, have similar Ba and LREE abundances, and are depleted in $\mathrm{Th}, \mathrm{Nb}, \mathrm{Zr}, \mathrm{Hf}, \mathrm{Sc}$, and HREE compared to lavas with similar MgO contents from Kilauea.

The increasing depletion of the HREE and $\mathrm{Sc}$, the fractionation of $\mathrm{Zr}$ and $\mathrm{Hf}$ from the LREE, and the enrichment in $\mathrm{Sr}$ and $\mathrm{Pb}$ suggest a larger fraction of residual garnet in the source region for Koolau lavas compared to those from Kilauea. Variable amounts of gamet in the Koolau source was also suggested by Frey et al. [8]. Ratios that are sensitive to melting ( $\mathrm{La} / \mathrm{Yb}, \mathrm{Sm} / \mathrm{Nd}, \mathrm{Lu} / \mathrm{Hf}$ ) suggest that for these picrites, the degree of melting increases over the sequence Loihi, Koolau, Kilauea, Hualalai, Mauna Loa, and is not related directly to isotopically defined source components. The depletions of $\mathrm{Nb}, \mathrm{Ti}$, and $\mathrm{Th}$ in the Koolau lavas are difficult to explain by melting, and must be an intrinsic feature of the Koolau component in the Hawai'ian plume.

References: [1] Garcia et al. (1989) JGR, 94, 10525-10538. [2] Clague et al. (1995) J. Petrol., 36, 299-349. [3] Garcia et al. (1995) in Mauna Loa Revealed, pp. 219-239. [4] Rhodes (1995) in Mauna Loa Revealed, pp. 241-262. [5] Ehlers et al. (1992) GCA, 56, 3733-3743. [6] Hauri (1996) Nature, 382, 415-419. [7] Bennett et al. (1996) Nature, 381, 221-224. [8] Frey et al. (1994) GCA, 58, 1441-1462.

TEMPORAL EVOLUTION OF FELDSPAR SURFACES DURING THE INITIAL STAGES OF IN SITU WEATHERING. M. A. Nugent ${ }^{1}$, S. L. Brantleyl , C. Pantano $0^{2}$, and P. Maurice $^{3}$, 'Department of Geosciences, Pennsylvania State University, University Park PA 16802, USA (nugent@farallon.geosc.psu.edu), 2Department of Material Science and Engineering, Pennsylvania State University, University Park PA 16802 , USA, ${ }^{3}$ Department of Geology, Kent State University, Kent OH 44242, USA.

The rates of silicate dissolution in the laboratory are nearly always faster than field weathering rates. We suggest that there is a difference in the temporal microscale evolution of the mineral surface under laboratory and field conditions. This difference may contribute to the observed weathering rate discrepancy.

Polished tablets of albite and labradorite were buried in the unsaturated zone of a soil and recovered after different time periods ( 6 months and 1, 2, 3, and $3.5 \mathrm{yr}$ ). Over 20 samples were buried so that new samples were removed at each sampling. Pore-water chemistry and $\mathrm{pH}$, rainfall chemistry, and soil characteristics at the field site have been characterized. Mineral samples were analyzed by SEM, XPS, SIMS, AES (auger electron microscopy), and AFM to evaluate the development of weathered surfaces.

Surface Topography: SEM pictures reveal plucking features on the polished, unweathered (blank) samples, which we attribute to polishing. None of the weathered samples show etch-pit development under SEM, and even after three years, the plucking features do not seem to have grown appreciably larger. After six months, we observe no particulate matter on the surface. A second phase appears on the surface of the 1-, 2-, 3- and 3.5-yr samples. The phase becomes more abundant as burial time increases. It occurs as particles that vary in size from 1 to $100 \mu \mathrm{m}$, and larger particles appear to be aggregates of smaller ones. Still other areas on the weathered surfaces appear smooth under SEM. The chemical composition of the particles could not be obtained by EDX.

AFM reveals microtopography on a scale unresolvable by SEM. 
For instance, smooth areas seen with SEM, when imaged by AFM, are often rough, and twin lamellae are highlighted, suggesting microscale dissolution not imaged by SEM.

Surface Chemistry: After six months, the albite Al/Si surface ratio, measured by XPS, is slightly depleted compared to the blank. After one year of weathering, the Al/Si ratios of the surfaces are constant at 0.47 , which is distinct from the blank [albite, 0.37 (XPS), labradorite, 0.61 (microprobe)]. The weathered ratio remains constant in all albite and labradorite samples removed after one year.

AES was performed on albite samples to assess microscale chemical heterogeneity. Areas that appear smooth under SEM on the two-year sample have surface chemistry similar to unweathered albite. No evidence supports the presence of a leached or precipitated layer in these areas. However, AES resolution is $\sim 75 \mu \mathrm{m}$, so these areas may contain small particles that may affect the signal. In contrast, AES spectra obtained on $100 \mu \mathrm{m}$-sized particles have an elevated Al/Si ratio and Fe content.

Feldspar samples dissolved in the lab at $\mathrm{pH} 4.0$ (soil pore water $\mathrm{pH}$ is $\mathbf{4 . 5}$ for our site) typically show depletion of Al after $1400 \mathrm{hr}$ of dissolution. The surface chemistry and topography of both albite and labradorite, when weathered in the field, is therefore distinctly different from samples dissolved in the lab. Microheterogeneity requires analysis using tools with high spatial resolution, as well as depth resolution, such as AES and AFM. The XPS signal alone is not enough to chemically characterize a weathered mineral surface, since microheterogeneity is obviously important and XPS samples a relatively large surface area. Similarly, AFM provides higherresolution observations that SEM cannot.

\section{KINETICS OF THE INTERSITE CATION EXCHANGE IN $\mathrm{MgAl}_{2} \mathrm{O}_{4}$ SPINEL: THE INFLUENCE OF NONSTOICHIO-} METRY. H. St. C. O'Neill, Research School of Earth Sciences, The Australian National University, Canberra, ACT 0200, Australia.

Many spinels, including $\mathrm{MgAl}_{2} \mathrm{O}_{4}$, show temperature-dependent disordering of their $2+$ and $3+$ cations (i.e., $\mathrm{Mg}$ and $\mathrm{Al}$ in $\mathrm{MgAl}_{2} \mathrm{O}_{4}$ ) between the octahedrally and tetrahedrany coordinated cation sites in the spinel structure. Since this disordering is not accompanied by any change of symmetry and is nonconvergent, it is qualitatively similar to the $\mathrm{Mg}$ - $\mathrm{Fe}^{2+}$ intersite exchange in pyroxenes and amphiboles, the study of the rates of which as a function of temperature have often been undertaken as a means of quantifying cooling rates in rocks and meteorites ("geospeedometry"). For meteorites, this approach is of particular interest as it might be hoped that cooling rates can in turn be related to parent-body size and stratigraphy.

It is probable, however, that rates of cation exchange depend on other variables, such as defect structure and variations in stoichiometry, which in turn depend on the chemical potentials of the constituent components. $\mathrm{MgAl}_{2} \mathrm{O}_{4}$ is an ideal substance in which to begin the study of these influences, as only a single variable, the $\mathrm{MgO}$ / $\mathrm{Al}_{2} \mathrm{O}_{3}$ ratio, is involved, and the change in chemical potentials of $\mathrm{MgO}$ and $\mathrm{Al}_{2} \mathrm{O}_{3}$ with this variable can be measured directly using the Pd equilibration technique of Chamberlin et al. [1].

Eight batches of " $\mathrm{MgAl}_{2} \mathrm{O}_{4}$ " were synthesized with different $\mathrm{MgO} / \mathrm{Al}_{2} \mathrm{O}_{3}$ stoichiometries using various methods: three batches with cation-deficient compositions (molar $\mathrm{MgO} / \mathrm{Al}_{2} \mathrm{O}_{3}=0.95,0.97$, and 0.98), three batches on stoichiometry (molar $\mathrm{MgO} / \mathrm{Al}_{2} \mathrm{O}_{3}=1$ as exactly as possible), and two with cation excesses (molar $\mathrm{MgO}$ / $\mathrm{Al}_{2} \mathrm{O}_{3}>1$ ). Each composition was annealed at $100^{\circ} \mathrm{C}$ intervals between $700^{\circ}$ and $1300^{\circ} \mathrm{C}$ and drop-quenched into water. The lattice parameter (a) of the samples was then determined by powder XRD using an intemal standard of NBS Si, with a reproducibility of $\pm 0.00015 \AA$, one standard deviation. The lattice parameter of " $\mathrm{MgAl}_{2} \mathrm{O}_{4}$ " increases with increasing $\mathrm{MgO} / \mathrm{Al}_{2} \mathrm{O}_{3}$ but decreases with temperature of anneal, i.e., with increasing $\mathrm{Mg} / \mathrm{Al}$ disordering, and all data can be fitted by the linear equation: $a \AA A=7.9829+$ $0.1052\left(\mathrm{MgO} / \mathrm{Al}_{2} \mathrm{O}_{3}\right)-4.01 \times 10^{-6} \mathrm{~T} / \mathrm{K}$.

Since for each stoichiometry the lattice parameter depends on the degree of $\mathrm{Mg} / \mathrm{Al}$ order-disorder, it can be used to monitor the rate of approach to equilibrium of a sample that has previously been disordered at high temperatures and is then annealed at a lower temperature. Accordingly, samples quenched from $1100^{\circ}$ to $1200^{\circ} \mathrm{C}$ from all eight batches were annealed at $700^{\circ}$ and $800^{\circ} \mathrm{C}$ for varying lengths of time, from 5 min to several months. The change of the lattice parameter with time as it approaches its new equilibrium value $\left(a_{\text {final }}\right)$ can be described within the accuracy of the measurements by an empirical expression with the form of a simple firstorder rate equation: $d a / d t=D\left(a-a_{\text {final }}\right)$. The rate constant, $D$, is found to be an extremely sensitive function of stoichiometry. For example, at $700^{\circ} \mathrm{C}, \mathrm{D}$ is of the order of a few minutes for samples with $\mathrm{MgO} / \mathrm{Al}_{2} \mathrm{O}_{3}<1.0$ (cation deficient), but is inferred to be several years for samples with $\mathrm{MgO} / \mathrm{Al}_{2} \mathrm{O}_{3}>1.0$ (cation excess). So sensitive is the rate of ordering to small variations in stoichiometry in the region of stoichiometric spinel $\left(\mathrm{MgO} / \mathrm{Al}_{2} \mathrm{O}_{3}=1\right)$ that differences in stoichiometry that are too small to measure can produce differences in rate constants of half an order of magnitude. This variation is equivalent to a $<100^{\circ}$ change in temperature. The sensitivity of the kinetics of intracrystalline cation ordering to minor changes in stoichiometry, at least in spinels. does not bode well for "geospeedometry."

References: [1] Chamberlin et al. (1994).

SECULAR CHANGES IN NEODYMIUM AND LEAD ISOTOPES IN ATLANTIC, INDIAN, AND PACIFIC FERROMANGANESE CRUSTS AND DEEPWATER CIRCULATION. R. K. O'Nions' ${ }^{1}$, H. F. Ling', M. Frank', and F. von Blanckenburg ', 'Department of Earth Sciences, University of Oxford, Parks Road, Oxford OX1 3PR, UK.

$\varepsilon_{\mathrm{Nd}}$ values and $\mathrm{Pb}$ isotope ratios show a marked change in a ${ }^{10} \mathrm{Be}$ dated ferromanganese crust from $39^{\circ} \mathrm{N}$ in the western north Atlantic between ca. $5 \mathrm{Ma}$ and the present [1]. These changes have been attributed to an increase in the NADW component at this latitude over this time interval and particularly that component from the Labrador Sea. A shift of $\varepsilon_{\mathrm{Nd}}$ in central Pacific crusts to more negative values over the same time interval is consistent with a change in the composition of NADW in Pacific deepwater [2]. The relative constancy of $\mathrm{Pacific} \mathrm{Pb}$ isotope compositions reflects the shorter advective length scale of $\mathrm{Pb}$ relative to $\mathrm{Nd}$ in ocean deepwater. In the case of the north Atlantic and central Pacific, these observations are temporally and possibly causally related to the closure of the Panama gateway. Results for a second crust, ALV539 from $35^{\circ} \mathrm{N}$ and a depth of $2.7 \mathrm{~km}$ in the westem north Atlantic, give a ${ }^{10} \mathrm{Be}$ growth rate and variation in $\mathrm{Nd}$ and $\mathrm{Pb}$ isotopes very similar to the crust from $39^{\circ} \mathrm{N}$. 
Two crusts from the Indian Ocean have also been analyzed. One, SS-663, is from $13^{\circ} \mathrm{S}, 76^{\circ} \mathrm{E}$ and a depth of $5.3 \mathrm{~km}$, and the other, $109 \mathrm{D}-\mathrm{C}$, is from $28^{\circ} \mathrm{S}, 61^{\circ} \mathrm{E}$ and a depth of $\sim 5.4 \mathrm{~km}$. Beryllium-10/ beryllium- 9 ratios determined by SIMS provide growth rates for the crusts in the range of $2-4 \mathrm{~mm} \mathrm{Ma}^{-1}$. The two crusts show only small variations in $\varepsilon_{\mathrm{Nd}}$ over the last $20 \mathrm{Ma}$, with $-7.7<\varepsilon_{\mathrm{Nd}}<7.0$ for $S \$ 663$ and $-8.0<\varepsilon_{\mathrm{Nd}}<7.5$ for 109D-C. These observations are not immediately reconciled with the large component of NADW entering the Indian Ocean via circumpolar deepwater (CDW). At present, this is estimated to be $\sim 14 \mathrm{Tgs}^{-1}$. This could be because NADW joining CDW differs from that in the north Atlantic in terms of secular variation of $\varepsilon_{\mathrm{Nd}}$ or because deepwater in the Indian Ocean has a different source. In either case it is not obvious that the shift in $\varepsilon_{\mathrm{Nd}}$ in central Pacific deepwater is due to a change in compositon of the NADW component.

Lead isotope ratios in the Indian crust SS.663 show a variation of ${ }^{206} \mathrm{~Pb} / 204 \mathrm{~Pb}$ between 18.9 at the surface to 18.6 at a depth corresponding to $20 \mathrm{Ma}$, whereas crust 109D-C has a relatively constant $206 \mathrm{~Pb} / 204 \mathrm{~Pb}$ between 18.8 and 18.9 over the same time interval. There is no clear response in the $\varepsilon_{\mathrm{Nd}}$ or $\mathrm{Pb}$ composition of Indian deepwater to the uplift of the Himalayas.

References: [1] Burton K. et al. (1997) Nature, in press. [2] Ling H. et al. (1997) EPSL, 146, 1-12.

MANTLE APATITE REVISITED: MAJOR RESERVOIR FOR URANIUM AND THORIUM IN THE MANTLE AND REFLECTOR OF MANTLE-FLUID SOURCES. S. $Y$. O'Reilly', W. L. Griffin $^{1.2}$, P. Morgan ${ }^{1.3}$, D. A. Ionov', and M. D. Norman', 'GEMOC National Key Centre, School of Earth Sciences, Macquarie University, Sydney, NSW 2109, Australia (sue.oreilly@mq.edu.au), ${ }^{2} \mathrm{CSIRO}$ Division of Exploration and Mining, Box 136, North Ryde, NSW 21 13, Australia, ${ }^{3}$ Department of Geology, University of Northem Arizona, Flagstaff AZ, USA.

Laser-ablation microprobe ICPMS analyses of apatites from mantle-derived xenoliths from eastem Australia, France (Massif Central), Germany (Eifel), and Alaska have confirmed two distinct populations of apatites reflecting high-pressure precipitation from fluids of different origins. One compositional type (apatite A) occurs as veins of apatite $+\mathrm{Cr}$-diopside and apatite + amphibole \pm mica and as dispersed polygonal grains in microstructural equilibrium in metasomatized mantle wall rock ( $\mathrm{Cr}$-diopside or type $\mathrm{I}$ ) lherzolites. Most of these are from the Bullenmerri/Gnotuk locality in western Victoria, but also include two examples from Alaska. The apatite is commonly associated with abundant fluid inclusions (dominantly $\mathrm{CO}_{2}$ with up to $10 \% \mathrm{H}_{2} \mathrm{O}$ ) that may be up $1010 \mathrm{~mm}$ across and constitute up to $3 \%$ by volume of the mantle rocks [e.g., 1]. Carbonates coat the walls of these fluid cavities as well as crystals of amphibole, pyroxene, and carbonate that project into the cavities.

The other compositional type (apatite B) is associated with Alaugite (type II) rock types and also may occur as veins (and reequilibrated polygonal grains) in lherzolites that can be related to infiltration of parental type II magmatic fluids. The apatite-bearing type II rocks represent fractions of magma frozen within the mantle, and most of these appear to have MARID-type affinities [2], although they occur in mantle with a Phanerozoic rather than Archean or Proterozoic tectonothermal age. Most of the type II xenoliths analyzed are from the Kiama locality, New South Wales, Australia [e.g., 3], and include amphibole-rich clinopyroxenites, cpx-apatitespinel rocks, and apatite-spinel rocks. All contain coexisting carbonate in textural equilibrium, and are interpreted as mantle crystal lization products of kimberlitic/carbonatitic magmas. Xenoliths from Massif Central and Eifel resemble the cpx-apatite-spinel rocks from Kiama.

Apatite $\mathrm{A}$ in mantle lherzolites contains significant structural $\mathrm{CO}_{2}$ and is a carbonate-bearing hydroxy-chlorapatite with relatively high $\mathrm{Cl}(1-3 \%)$ and $\mathrm{Br}(5-40 \mathrm{ppm})$, and low $\mathrm{F}(0-0.25 \%)$. This appears to be a unique composition specific to this rock type. The Kiama and other $B$ apatites are hydroxy-apatites with relatively low $\mathrm{Br}(1-3 \mathrm{ppm})$ and $\mathrm{Cl}(<0.01-0.6 \%)$ and moderate $\mathrm{F}(0.08-2 \%)$. Other significant differences for $\mathrm{A}$ and $\mathrm{B}$ apatites respectively include $\mathrm{La} / \mathrm{Nd}_{\mathrm{CN}} 3$ vs. $2 ; \mathrm{Sr}, 0.5-2.2 \%$ vs. $0.2-0.8 \% ; \mathrm{Ba}, 100$ 400 ppm vs. $<60$ ppm (and not correlated with Sr); U, 30-140 vs. 1-4; Th, $90-640$ vs. $4-12$; ThU, 3-5 (3.5 avg.) vs. $2.9 ; \mathrm{Pb}, 2-70$ vs. $<1 ;$ Sr/Y $42-67$ vs. $25-32$.

Average abundances (where significant) of $U \mathrm{ppm}$, Th ppm, and $\mathrm{K}_{2} \mathrm{O}$ wt $\%$ in common mantle minerals from Bullenmerri/Gnotuk Iherzolites are apatite $\sim 60,200,0 \%$; amphibole, $-0.5,1.5,1 \%$; mica, $<0.5,<0.5,10 \%$; and metasomatized cpx, $-0.2,1,0.01 \%$. Apatite is thus the major reservoir for heat-producing elements in the mantle if present in abundances $>0.05 \%$. Calculations of heat production show that $0.1 \%$ apatite, $1 \%$ amphibole, and mica and $10 \%$ metasomatized cpx would account for $0.033,0.004,0.01$, and $0.015 \mu \mathrm{W} / \mathrm{m}^{3}$ respectively, compared with a standard geophysical model mantle heat production of $0.015 \mu \mathrm{W} / \mathrm{m}^{3}$. For a lithosphere $100 \mathrm{~km}$ thick, a mantle with this mode would account for a heat flow of about $6 \mathrm{~mW} / \mathrm{m}^{2}$, which is about $30 \%$ of the total heat flow normally attributed to the mantle (for conductive heat loss). This heat flow model is dominated by the $0.1 \%$ apatite; the $10 \%$ metasomatized cpx accounts for $\sim 1.2 \mathrm{~mW} / \mathrm{m}^{2}$.

Apatite may be overlooked in many mantle xenolith suites and may be ubiquitous globally in Phanerozoic mantle that has metasomatic imprints. In addition to its importance for the mantle heat budget, the presence of apatite in the lithospheric mantle can affect $\mathrm{REE}, \mathrm{Sr}, \mathrm{Ba}, \mathrm{U}, \mathrm{Th}$, and halogen contents of basaltic melts that traverse apatite-bearing metasomatized lithosphere, either by disequilibrium partitioning or by apatite melting. The distinct traceelement signatures of different apatite types also reflect different source origins and the nature of metasomatic fluids in the mantle.

References: [1] Andersen T. et al. (1984) Contrib. Mineral. Petrol., 88, 72-85. [2] Dawson J. B. and Smith J. V. (1977) GCA, 41, 309-323. [3] Wass S. Y. et al. (1980) Philos. Trans. R. Soc. London, A297, 333-346.

THE IMPORTANCE OF ARIDITY AS A CONTROL ON CHEMICAL WEATHERING: EVIDENCE FROM THE MARINE OSMIUM RECORD. R. Oxburgh, Department of Geochemistry, Lamont-Doherty Earth Observatory, P.O. Box 1000, Palisades NY 10964, USA.

The weathering of continental rocks plays a central role in the global $\mathbf{C}$ cycle, and thus in planetary temperature regulation. However, the factors that control the long-term rates of chemical weathering on a global scale (e.g., glaciation, orogenic activity, temperature) are poorly resolved. The isotope composition of Os in marine sediments can be used to monitor the flux of dissolved solids from the continents to the ocean over time because Os has a relatively 
short residence time in the oceans and Os derived from the continents $\left({ }^{187} \mathrm{Os} /{ }^{186} \mathrm{Os}=10-30\right)$ has an isotope signature that distinguishes it from mantle or cosmic sources $\left({ }^{187} \mathrm{Os} /{ }^{186} \mathrm{Os} \approx 1\right)$.

Osmium isotope records from two sediment cores from the East Pacific rise presented here span the past $200 \mathrm{k.y}$. and are argued to reflect variations in the composition of the seawater from which the metal oxides precipitated. They demonstrate two main features. First, there is no evidence that oceanic Os has ever been more radiogenic over this period than at present or during the previous interglacial, and so it is inferred that the delivery of radiogenic Os from the continents has never been higher. It has been suggested that chemical erosion may be enhanced by glacial erosion $[1,2]$ and that radiogenic Os may be preferentially released from recently glaciated material [3]. The data presented here provide no support for these hypotheses.

Second, the records demonstrate excursions of about $5 \%$ to less radiogenic values during isotopic stage 2 and in one of the cores late in stage 6 that indicate reduced delivery of radiogenic Os to the oceans. These periods correspond to times of increased global aridity as reflected in the enhanced dust content of polar ice cores and lowered levels of African and Australian lakes [4,5]. Thus the major control on chemical weathering on these timescales appears to be variations in global aridty. This is consistent with modern data that demonstrate a strong correlation between chemical flux and annual run-off even between sites that differ in catchment lithology, mean annual temperature, and relief.

There is also no correlation between mean global temperature (as reflected in the $\mathrm{O}$ isotopic composition of foraminifer from the two cores and Os isotopic composition. Thus, to the degree that $O$ in the oceans is influenced by changes in continental run-off, neither global temperature nor continental glaciation exerts a major influence on chemical weathering, which, on these timescales, appears to be controlled dominantly by changes in global aridity.

References: [1] Anderson R. L. (1971)Nature Phys. Sci., 230, 130-131. [2] Hodell D. A. et al. (1989) EPSL, 92, 165-178. [3] Peucker-Ehrenbrink B. and Blum J. D. (1996) Eos Trans. AGU, 77, F324. [4] Petit J. R. et al. (1990) Nature, 343, 56-58. [5] Street F. A. and Grove A. T. (1979) Quaternary Res., 12, 83-118.

\section{INPUT AND REMOVAL FLUXES OF OSMIUM IN THE} OCEANS: CONSTRAINTS FROM RESIDENCE-TIME ESTIMATES. R. Oxburgh, Department of Geochemistry, Lamont-Doherty Earth Observatory, P.O. Box 1000, Palisades NY 10964, USA.

One of the limitations in the use of Os as a tracer of continental and marine processes is that its aqueous geochemistry is not well characterized. The residence time of an element in the oceans is the ratio of the input or output fluxes to the oceanic inventory. Thus armed with a relatively accurate estimate of oceanic Os content based on new seawater data [1], estimates of the residence time of Os in seawater $\left(\mathrm{T}_{\text {res }} \mathrm{Os}_{\mathrm{s}}\right.$ ) provide an indirect means to quantify the Os input and output fluxes.

Variations in the composition of Os inputs to the oceans lead to oceanic heterogeneities depending on $\mathrm{T}_{\text {res }} \mathrm{Os}$ and on the difference in source composition. Burton et al. [2] asser, based on analyses of Mn crust surfaces, that the Atlantic is about $2.5 \%$ more radiogenic in Os than the Pacific. As the input compositions are not well known, it is not possible to estimate an accurate $T_{\text {res }}$ os from this data; however, simple modeling shows that such heterogeneities can not persist if $T_{\text {res }}$ Os is greater than $20 \mathrm{k.y}$. A more likely estimate is 68 k.y.

The rate at which the oceans approach steady-state composition following a perturbation in input flux is directly related to the residence time of the element of interest. It has been argued that the Os isotopic composition of the oceans was lower by about $5 \%$ during the last glacia] maximum than it is today [3]. If it is assumed that the preglacial oceans were at steady state, then the modern oceans have recovered about $80 \%$ of the way to steady state since the last glacial maximum. If the onset of the Holocene $(10,000 \mathrm{yr}$ ago $)$ triggered the change in input flux, then it can be shown that $T_{\text {res } O s}$ must lie in the range $2-8 \mathrm{k} . \mathrm{y}$.

A residence time of 4-8 k.y. combined with an oceanic inventory of Os of $5.4 \times 10^{6} \mathrm{~kg}[1]$ implies an input or output flux of about 700 $1300 \mathrm{~kg} / \mathrm{yr}$. This is at least an order of magnitude larger than estimates based on the isotopic mass balance of the Baltic [4] and analyses of $O s$ in river sediments [5]; however, large uncertainties are inherent in both these approaches. Osmium burial in pelagic clays, marine carbonates, organic-rich reducing sediments, and metalliferous carbonates is estimated at about $140 \mathrm{~kg} / \mathrm{yr}$ [6]. However, burial of $O s$ in shelf sediments in association with organic $C$ may be on the order of $700 \mathrm{~kg} / \mathrm{yr}[6,7]$. This approach may therefore provide suppor for the importance of shelf sediments as a marine sink of Os.

References: [1] Sharma et al. (1997). [2] Burton K. W. et al. (1996) J. Conf. Abstr., 1, 92. [3] Oxburgh R. and Shackleton N. J. (1996) J. Conf. Abstr., 1, 447. [4] Peucker-Ehrenbrink B. and Ravizza G. (1996) Geology, 24, 327-320. [5] Pegram W. J. et al. (1994) EPSL, 128, 591-599. [6] Oxburgh R. (1996) Ph.D. thesis, Columbia Univ. [7] Ravizza G. (1995) $A G U, 76,303$.

\section{ORIGIN OF CARBONADO DIAMOND AND NANO- DIAMOND IN PRIMITIVE METEORITES: RADIATION-} INDUCED DIAMOND CRYSTALLIZATION. M. Ozima' and M. Tatsumoto ${ }^{2},{ }^{1}$ Department of Earth and Planetary Physics, University of Tokyo, Bunkyo-Ku, Tokyo 113, Japan, 2Mail Stop 963, U.S. Geological Survey, P.O. Box 25046, Denver CO 80225 , USA.

Diamond carries unique information about ancient mantle because of its antiquity and its stability under high temperature and pressure. Studies of trace elements in diamonds would yield invaluable clues in resolving mantle chronology and mantle dynamics. Unfortunately, however, these studies have been hampered because of difficulty in analyzing trace elements in diamond due to its enormous resistance against chemicals. A conventional approach such as combustion of diamond under high $\mathrm{O}$ atmosphere may result in loss of volatile elements and in the introduction of contamination. We developed a new technique "cold combustion," in which diamond was bumed in liquid $O$ to liberate trace elements. The technique is very effective in liberating trace elements from diamond matrix with low contamination. We analyzed carbonados from Central Africa for U-Th-Pb isotopic compositions.

Carbonado is an aggregate of randomly polycrystallized microdiamonds and geologically distinct from all other diamond varieties. Its unique features includes a very light $C$ isotopic ratio $\left(\delta^{13} \mathrm{C}=\right.$ $-30 \%$ ) that is almost identical to biogenic $C$, typically crustal assemblage of inclusion minerals, no association with kimberlite 
magma [1], and a considerable amount of parentless fission Xe and $\mathrm{Kr}$ [2]. After very thorough acid treatments of the carbonados with hot $\mathrm{HNO}_{3}, \mathrm{HF}$, and $\mathrm{HCl}$ over one week, most of the $\mathrm{U}, \mathrm{Th}$, and $\mathrm{Pb}$ were removed from the samples. We then applied "cold combustion" to these chemically treated samples to extract $\mathrm{U}, \mathrm{Th}$, and $\mathrm{Pb}$. Lead in the acid-leached diamonds was highly radiogenic $(206 \mathrm{~Pb} /$ ${ }^{204} \mathrm{~Pb}$ up to 470 ). However, the amounts of $\mathrm{U}$ and $\mathrm{Th}$ in the acidleached diamonds are too low to account for the radiogenic $\mathrm{Pb}$ even if we assume $4.5 \mathrm{Ga}$ for the age of the diamonds. Therefore, we conclude that the radiogenic $\mathrm{Pb}$ was implanted into the diamonds from the surroundings by means of recoil energy of radioactive decays of $\mathrm{U}$ and $\mathrm{Th}$. From the radiogenic $\mathrm{Pb}$ isotopic composition, we estimate a minimum age of $2.6 \mathrm{Ga}$ and a maximum age of $3.8 \mathrm{Ga}$ for the formation of the carbonados.

The implantation of recoiled radiogenic $\mathrm{Pb}$ into carbonados can be well understood on the basis of a radiation-induced crystallization mechanism, which was proposed for the origin of carbonado by Kaminsky [3]. We also show from theoretical considerations that when highly energetic particles, such as those emitted from radioactive decay of $\mathrm{U}$ and $\mathrm{Th}$, interact with carbonaceous materials, they give rise to cascades of atomic disturbance (over regions of about a few nanometers) and the disturbed atoms are likely to recrystallize to form microdiamonds because of increasing surface energy due to the small size.

The radiation-induced diamond formation mechanism may be relevant to the origin of nanodiamonds in primitive meteorites. Nanodiamonds in primitive meteorites are characterized by the unique occurrence of $\mathrm{Xe}-\mathrm{HL}$ of which the origin is generally attributed to super-nova explosion, and by their nanometer size. We speculate that highly energetic $\mathrm{Xe}-\mathrm{HL}$ particles emitted from supernovae interacted with circumstellar carbonaceous matter to have formed nanodiamonds.

References: [1] Orlov Yu. L. (1973) The Mineralogy of Diamond, Wiley. [2] Ozima M. et al. (1991) Nature, 351, 472. [3] Kaminsky F. V. (1987) Proc. Intl. Kimberlite Conf., 5, 214.

\section{A MOLECULAR RECORD OF ORGANIC BURIAL AND CARBON DIOXIDE VARIABILITY IN THE MIDDLE MIO- CENE. M. Pagani, M. A. Arthur, and K. H. Freeman, Department of Geosciences, Pennsylvania State University, Deike Building, University Park PA 16802, USA.}

The extent of $\mathrm{C}$ fractionation in Haptophyte algae and their molecular biomarkers (alkenones) is primarily controlled by ambient $\mathrm{CO}_{2}$ concentration and algal growth rate. With this in mind, we have been developing a detailed record of the $\delta^{13} \mathrm{C}$ for di-unsaturated alkenones from several pelagic cores extending from the early to late-middle Miocene ( $25-8 \mathrm{Ma})$. In conjunction with carbonate$C$ isotopes from surface-dwelling planktonic foraminifera picked from the same samples, this record $\left(\varepsilon_{\mathrm{p}}\right)$ may be a proxy for $\mathrm{CO}_{2(\mathrm{aq})}$ in the surface water.

Global cooling during the middle Miocene is well documented. Factors responsible for this climatic transition have been attributed to variations in $\mathrm{pCO}_{2}$, as well as to reorganization of deep-water circulation and heat transport. Our results, emerging from site 588 in the southwest Pacific, reveal a broad decline in $\varepsilon_{\mathrm{p}}$ values throughout the middle Miocene "Monterey excursion" of Vincent and Berger [1]. Sharp declines in $\varepsilon_{p}$ coincide with inorganic $\delta^{13} \mathrm{C}$ maxi- ma (CM2-CM7) within the "Monterey excursion." These C maxima are associated with positive shifts in benthic $\delta^{18} \mathrm{O}$ and increased carbonate preservation [2], suggesting a relationship between increased rates of organic $\mathrm{C}$ burial, decreasing $\mathrm{pCO}_{2}$, and deep-water cooling.

Considering the controls on alkenone $\delta^{13} \mathrm{C}$, our data allow for either $\mathrm{CO}_{2}$ drawdown and/or increasing Haptophyte growth rate with declining $\varepsilon_{\mathrm{p}}$ values. However, preliminary results from site 608 in the North Atlantic follow the general isotopic trend recorded in the southwest Pacific, lending support for an interpretation of global $\mathrm{CO}_{2}$ change.

Recently, a calibration was established that relates $\varepsilon_{\mathrm{p}}$, derived from diunsaturated alkenones, to surface water $\mathrm{CO}_{2(\mathrm{aq})}$ [3]. Reconstruction of paleo- $\mathrm{CO}_{2(\mathrm{a})}$ using this calibration requires an estimation of surface-water phosphate concentration. Sites 588 and 608 are believed to have underlain oligotrophic surface waters during the Miocene as demonstrated by both their low organic $\mathrm{C}$ content and low sedimentation rate $(\sim 2 \mathrm{~cm} / \mathrm{k} . \mathrm{y}$.). Using phosphate concentrations characteristic of low to moderately productive regions $(0.25-$ $0.5 \mathrm{~mm} / \mathrm{L}$ ) we estimate surface-water $\mathrm{CO}_{2(\mathrm{aq})}$ for the middle Miocene. Our results indicate that before and following the middle Miocene "Monterey excursion," maximum $\mathrm{CO}_{2}$ concentrations were approximately $75 \%$ the modern value (equivalent to pre-industrial concentrations). A $25 \%$ decline during the early stages of the "Monterey" event brings $\mathrm{CO}_{2}$ to levels as low as those recorded during Pleistocene glacials.

Following the period of low $\mathrm{CO}_{2}$ in the middle Miocene, rapid expansion of East Antarctic ice sheet (EAIS) ensued. From the above discussion several implications emerge from our work. Carbon dioxide appears to be linked to the dramatic climatic change during this time. However, it appears that extraordinarily low concentrations were not needed to trigger the climatic response. Furthermore, rising $\mathrm{CO}_{2}$ levels following EAIS growth implicates the increasing importance of ice albedo in regulating global climate.

The coincidence of positive shifts in the $\varepsilon_{\mathrm{p}}$ record with positive shifts in the inorganic $\delta^{13} \mathrm{C}$ record demonstrate the link between organic $\mathrm{C}$ burial and $\mathrm{CO}_{2}$. There are, however, significant shifts in $\varepsilon_{\mathrm{p}}$ that occur in the early Miocene that have no correlative inorganic $\delta^{13} \mathrm{C}$ shift. We are actively working to determine the regional extent of these variations, as well as their implications regarding the controls on $\mathrm{CO}_{2}$ variability.

References: [1] Vincent and Berger (1985). [2] Woodruff and Savin (1991). [3] Bidigare et al. (1997) in press.

\section{LATE CRETACEOUS-NEOGENE BASALTS FROM CHAT- HAM ISLAND: IMPLICATIONS FOR HIMU MANTLE BENEATH CONTINENTAL BORDERLANDS OF THE SOUTHWEST PACIFIC. K. Panter', J Blusztajn ${ }^{2}$, S. Hart ${ }^{2}$, and P. Kyle ${ }^{1}, 1$ Department of Earth and Environmental Science, New Mexico Institute of Mining and Technology, Socorro NM 87801 , USA, ${ }^{2}$ Department of Geology and Geophysics, Woods Hole Oceanographic Institution, Woods Hole MA 02543, USA.}

Alkaline volcanism in New Zealand, Tasmania, and Antarctica (Marie Byrd Land and Western Ross Sea) is characterized by basalts with a strong HIMU mantle plume component $\left({ }^{87} \mathrm{Sr} /{ }^{86} \mathrm{Sr}<0.703\right.$, ${ }^{206} \mathrm{~Pb} / 204 \mathrm{~Pb}>19.5$ ). Because these areas represent previously contiguous Gondwanan fragments, plume-assisted continental break- 
up has been proposed. Basalts from the Chatham Islands furnish an 80-m.y. history of this HIMU source and insight into its origin.

The Chatham Islands, located $\sim 900 \mathrm{~km}$ east of the South Island of New Zealand $\left(44^{\circ} \mathrm{S}, 176^{\circ} \mathrm{W}\right)$, are part of the Chatham Rise, a major elongate submarine extension of the New Zealand microcontinent. The Chatham Rise, together with the mostly submerged Campbell Plateau, separated from West Antarctica shortly before $84 \mathrm{Ma}$. Further extension opened the southern ocean along the Pacific-Antarctic Ridge and transferred the Chatham Rise-Campbell Plateau crustal block to the northward-moving Pacific plate. Volcanism on the Chatham Islands began shortly after separation and continued, episodically, as the block moved toward its present position. Basalts erupted during this interval provide a unique geochemical record of the mantle beneath this crustal block-one of several that were juxtaposed along the east margin of Gondwana during the Cretaceous.

Volcanism on the Chatham Islands occurred in three episodes: Late Cretaceous (80-70 Ma; Southem Volcanics), Eocene-Oligocene (40-35 Ma; Northern Volcanics) and Miocene-Pliocene (6$3 \mathrm{Ma}$; Rangitihi Volcanics). The Southem Volcanics are olivinerich alkali basalts ( $\sim 5 \%$ hy, $\mathrm{Mg} \# 47-60$ ) that occur as voluminous lava flow sequences up to $300 \mathrm{~m}$ thick. The Northern Volcanics consist of alkali basalts and basanites ( $\sim 5 \% \mathrm{ne}, \mathrm{Mg \#} \mathrm{53-63)}$ produced by explosive strombolian-style eruptions from numerous small vents. The volumetrically minor, Rangitihi Volcanics are strongly silica-undersaturated ( $11 \% \mathrm{ne})$, kaersutite-rich basanites (Mg\# 41-57) deposited as submarine flows and pyroclastic breccias. All the basalts show typical OIB-type incompatible-element enrichments (e.g., (La/Yb) ${ }_{p m} 15-25, \mathrm{~K} / \mathrm{Rb} 320-560, \mathrm{~K} / \mathrm{Nb} 100$ 220, $\mathrm{Ba} / \mathrm{La} \mathrm{5-10,} \mathrm{and} \mathrm{Ba} / \mathrm{Nb} 4-7)$.

Isotopic compositions are ${ }^{87} \mathrm{Sr} / 86 \mathrm{Sr}_{0} 0.7028-0.7033,{ }^{143} \mathrm{Nd}^{144} \mathrm{Nd}_{0}$ $0.5127-0.5128,{ }^{206} \mathrm{~Pb} / 204 \mathrm{~Pb} 19.8-20.8,207 \mathrm{~Pb} / 204 \mathrm{~Pb} 15.6-15.7$, and ${ }^{208} \mathrm{~Pb} / 204 \mathrm{~Pb} 39.7-40.5$. The high ${ }^{206} \mathrm{~Pb} / 204 \mathrm{~Pb}$ (most $>20.4$ ) and low ${ }^{87} \mathrm{Sr}^{86} \mathrm{Sr}_{0}$ (most $<0.703$ ) ratios for Chatham Island basalts indicate a HIMU mantle source-a chemical feature typically associated with plume activity.

The Chatham Island volcanics together with alkaline rocks from the mid-Cretaceous Tapuaenuku Complex $\left({ }^{87} \mathrm{Sr}^{86} \mathrm{Sr}_{0} 0.7028\right.$ $0.7030,{ }^{206 \mathrm{~Pb} / 204} \mathrm{~Pb} 20.1$ [1]) and Late Pleistocene basanites from the Antipodes Islands $\left({ }^{87} \mathrm{Sr}^{86} \mathrm{Sr}_{0} 0.7029,{ }^{206 \mathrm{~Pb}} /{ }^{204} \mathrm{~Pb}>20.5\right.$; this study) indicate that HIMU mantle has been present beneath New Zealand for the past $100 \mathrm{Ma}$. Considering the fact that no known plume-related seamount chains occur between New Zealand and the West Antarctic coast, the HIMU source must exist within the lithosphere as a "fossil-plume" component, at least since the time of separation.

A sudden change from subduction to rift-related magmatism at approximately $100 \mathrm{Ma}$ along the Pacific margin of West Antarctica may be related to the inception of a mantle plume [2]. Although, mid-Cretaceous rocks from West Antarctica do not have HMU isotopic signatures $\left({ }^{87} \mathrm{Sr} /{ }^{86} \mathrm{Sr}>0.704,{ }^{206} \mathrm{~Pb} /{ }^{204} \mathrm{~Pb}<19\right)$, normalized trace-element patterns for olivine tholeiites (95-110 Ma [2]) are typical of continental flood basalts.

A mid-Cretaceous mantle plume origin for the prevalent " $\mathrm{HIMU}$ type" volcanism of the Southwest Pacific seems likely. Chatham Island basalts record it as a fossil feature of the New Zealand lithosphere.

References: [1] Baker J. et al. (1994) N. Z.J. Geol. Geophys., 37, 249-268. [2] Weaver S. et al. (1994) Geology, 22, 811-814.
REPLACEMENT REACTIONS IN ALKALI FELDSPARS AT NEAR-SURFACE TEMPERATURES. I. Parsons and M. R. Lee, Department of Geology and Geophysics, The University of Edinburgh, West Mains Road, Edinburgh EH9 3JW, UK (ian parsons@ed.ac.uk,martin.lee@ed.ac.uk).

The weathering of alkali feldspars in nature is clearly very strongly influenced by crystal microtexture [1]. As well as undergoing mechanical degradation and dissolution, however, feldspar is known to grow readily in sediments near the sediment-water interface, and the replacement process known as albitization has been widely recognized in both igneous rocks and in sedimentary basins. Using TEM and SEM we have investigated the way in which replacement microtextures in alkali feldspar phenocrysts form and evolve down-temperature in the final cooling stages of the Lower Devonian Shap (northwestern England) granite and subsequently after their incorporation as detrital grains in nearby outcrops of Carboniferous conglomerate. This approach shows clearly that a continuum of exsolution and low-temperature replacement events has affected the feldspars throughout both stages in their history, and we have considered the means by which igneous albitization can be distinguished from diagenetic albitization in clastic grains.

Two-feldspar geothermometry and textural information can be combined to show the sequence of exsolution and of replacement events in the final stages of igneous cooling. Although the twofeldspar geothermometer is of poor accuracy and precision at low $\mathrm{T}$, it may be used reliably to establish the down-T order of microtextural changes. Two types of replacive albite occur. One type $\left(A b_{90} A n_{9}\right.$ $\mathrm{Or}_{1}$ ) occurs together with replacive microcline as irregular, microporous veins cross-cutting early, regular film perthitic microtextures; the prexisting microtexture exerts little or no microtextural control. Two-feldspar geothermometry suggests $T$ of $\sim 410^{\circ} \mathrm{C}$ for the formation of this texture. The second type of replacive albite is compositionally pure $\left(A b_{>99}\right)$, occurs as $<0.5-\mathrm{mm}$ rectangular patches only $<0.7 \mathrm{~mm}$ from crystal boundaries, and is strongly guided by preexisting microtexture, developing by replacement of volumes of highly strained orthoclase around dislocations on semicoherent albite films, at $\leq 370^{\circ} \mathrm{C}$. The dislocations, which subsequently dominate weathering and replacement behavior, therefore form at $\leq 410^{\circ}-370^{\circ} \mathrm{C}$.

After transport into the conglomerate, albite films and albite veins were replaced by irregular microcline during burial diagenesis. Thus, what appear, by light microscopy, to be conventional lamellar perthites prove, using TEM, to be lamellae of microcline in orthoclase, and strictly not perthites at all. Evidence of major mass transfer of $\mathrm{Or}$ and $\mathrm{Ab}$ in the sedimentary pile would be missed using normal petrographic methods. Conversely, we were able to establish that replacive albite was of late igneous rather than diagenetic origin only by textural comparison with crystals collected from the igneous protolith. We therefore suggest that petrographic interpretation of replacement microtextures in clastic feldspar grains should be treated with caution in the absence of observations of crystals in the protolith, and that replacive development of microcline may often have been overlooked.

References: [1] Lee et al., this volume.

NEODYMIUM ISOTOPES AND THE ORIGIN OF PHANEROZOIC SEDIMENTS AT A CONTINENTAL SCALE IN 
NORTH AMERICA. P. J. Patchett, N. D. Boghossian, B. S. Canale, C. N. Garzione, J. D. Gleason, and M. A. Roth, Department of Geosciences, University of Arizona, Tucson AZ 85721, USA.

Neodymium isotopic studies of shales and sandstones in North America from the South to the far Arctic document a very similar history of provenance. Studies have been conducted at the southem end of North America (Ouachita Foldbelt), the western margin (three latitudinal traverses in the Cordilleran Miogeocline), and in the northemmost North America (Innuitian Foldbelt). All datasets show $\varepsilon_{\mathrm{Nd}}$ values less than -15 for Neoproterozoic, Cambrian, and Ordovician strata, consistent with cratonic North American derivation. At times that vary between 450 and $400 \mathrm{Ma}$, but occurring in all regions, another $\mathrm{Nd}$ signature appears, with $\varepsilon_{\mathrm{Nd}}$ values in the -10 to -5 range. This signature then dominates the provenance for the remainder of Paleozoic time, and until late Jurassic in one region where younger units have been studied.

This less-negative $\varepsilon_{\mathrm{Nd}}$ signature corresponds approximately to that which would occur in continental crust differentiated from mantle sources 1.6-1.2 Ga. Large regions of of the Grenville orogenic belt have this characteristic, but so do large regions of the Caledonian-Appalachian orogenic belt, based on our data and that of others.

In the Ouachita sequence, paleogeography of river systems clearly suggests that drainage was southwestward along an Appalachian foreland depression. In the North, the trough that later became the Innuitian Foldbelt appears to have served as a throughway for sediments originating in northem Caledonian foldbelts. This material dominated the provenance of northern and western North America from $\sim 450 \mathrm{Ma}$ onward. The availability of large amounts of Cordilleran detritus from late Jurassic onward ended this domination, at least in western North America. Generally, it is clear that the Caledonian-Appalachian mountains overwhelmed all low-lying sediment sources during the late Paleozoic, and even into the Mesozoic. This is consistent with expectations based on topography/ erosion rate relationships.

CONSTRAINTS ON SEDIMENT RECYCLING FROM WESTERN NICARAGUA. L. C. Patino and M. J. Carr, Department of Geological Sciences, Rutgers University, New Brunswick NJ 08903, USA (patino@rci.rutgers.edu; carr@rci. rutgers.edu).

Volcanos from western Nicaragua have special characteristics that make them excellent case studies for sediment/slab recycling. Of primary importance is the bimodal nature of Cocos Plate sediments and the near complete subduction of the sediment package. The two sedimentary units subducting along the Middle America Trench are carbonate oozes covered by hemipelagic muds. The hemipelagic unit is formed from detrital material derived from the continent and siliceous biogenic material. In contrast, the carbonate oozes have very little detrital material and are mostly formed by calcareous biogenic material. All the volcanos have large variations in $\mathrm{Ba} / \mathrm{Th}, \mathrm{U} / \mathrm{La}, \mathrm{Ba} / \mathrm{U}, \mathrm{Sr} / \mathrm{Cs}$, and $\mathrm{Sr} / \mathrm{U}$, reflecting the large variation in these ratios in the two subducted sedimentary units. The distinctive incompatible-element chemistry of the two sediments is mirrored in apparent mixing arrays within the statigraphy of individual volcanos. At one end is a melt that can be roughly modeled as a melt of asthenosphere fluxed by hydrous fluid from subducted MORB plus dissolved carbonate. At the other end of the array is a melt that is difficult to model with existing experimental data but contains components of MORB, carbonate, and hemipelagic mud. We interpret the apparent mixing arrays as mixes of two melts produced sequentially, one from MORB plus carbonate and the other from MORB plus carbonate plus hemipelagic mud. In Nicaragua then there are two endmember melts that differ in the presence or absence of the uppermost sedimentary component, hemipelagic muds.

Neither end of the Nicarguan data array can be modeled satisfactorily. At the carbonate end, how does MORB-derived fluid react with nearly pure carbonate? At the other end the high LIL content of hemipelagic muds causes the hemipelagic component to dominate. Using partition coefficients for eclogite and hornblende eclogite mixtures, the melts derived from hemipelagic mud have REE contents too high, whereas fluids have difficulty matching several incompatible-element ratios, especially $\mathrm{Ba} / \mathrm{Th}$. Is $\mathrm{Ba}$ extracted in shallower parts of the subduction zone, or are other minerals dominating the incompatible-element partitioning?

HELIUM-4 AS A TRACER OF EOLIAN DUST: A TWO. MILLION-YEAR RECORD FROM ODP SITE 806, ONTONG JAVA PLATEAU. D. B. Patterson and K. A. Farley, Division of Geological and Planetary Sciences, California Institute of Technology, Pasadena CA 91125, USA (desmond@gps.caltech.edu).

Helium in seafloor sediments is primarily derived from two sources: terrestrial continental dust rich in radiogenic ${ }^{4} \mathrm{He}$ and characterized by low ${ }^{3} \mathrm{He} /{ }^{4} \mathrm{He}$ ratios of less than $0.1 \mathrm{R}_{\mathrm{A}}\left(\mathrm{R}_{\mathrm{A}}=\left({ }^{3} \mathrm{He} /\right.\right.$ $\left.{ }^{4} \mathrm{He}\right)_{\text {Observed }}\left({ }^{3} \mathrm{He} /{ }^{4} \mathrm{He}\right)_{\mathrm{Air}}$ and $\left.\left({ }^{3} \mathrm{He} /{ }^{4} \mathrm{He}\right)_{\text {Air }}=1.4 \times 10^{-6}\right)$, and extraterrestrial interplanetary dust particles (IDPs) rich in implanted solar-wind $\mathrm{H}$ characterized by high ${ }^{3} \mathrm{He} /{ }^{4} \mathrm{He}$ ratios of greater than $100 R_{A}[1,2]$. By assuming the isotopic composition of the end members it is possible to calculate the relative contribution of each, which, when combined with the bulk sediment mass accumulation rate (MAR), yields a measure of the flux of terrigenous ${ }^{4} \mathrm{He}$ and extraterrestrial ${ }^{3} \mathrm{He}[3,4]$.

We have determined the mass flux of terrigenous ${ }^{4} \mathrm{He}$ in 72 homogenized strip samples covering the last $1.9 \mathrm{Ma}$ from ODP Hole $806 \mathrm{~B}$, located on the northeast margin of the Ongtong Java Plateau in the equatorial western Pacific $\left(0^{\circ} 19.11^{\prime} \mathrm{N}, 159^{\circ} 21.70^{\prime} \mathrm{E}, 2521 \mathrm{~m}\right.$ water). The core is predominantly foraminiferal nannofossil ooze, and carries a continuous high-resolution global climate record between 0 and $1.91 \mathrm{Ma}$. Chronostratigraphic control is provided by tuning the $\delta^{18} \mathrm{O}$ climate record to the Earth's orbital obliquity signal [5].

Observed total ${ }^{4} \mathrm{He}$ abundances vary between 3.7 and 15.4 ncc $\mathrm{g}^{-1}$, and ${ }^{3} \mathrm{He} /{ }^{4} \mathrm{He}$ ratios range from 12 to $89 \mathrm{R}_{\mathrm{A}}$. Taking reasonable ${ }^{3} \mathrm{He} /{ }^{4} \mathrm{He}$ ratios for the terrestrial and extraterrestrial end members, we calculate that the fraction of terrestrial ${ }^{4} \mathrm{He}$ in the core varies between $96 \%$ and $83 \%$ of the total ${ }^{4} \mathrm{He}$. Combining the deconvolved amounts of terrigenous ${ }^{4} \mathrm{He}$ with bulk sediment MARs shows that the terrigenous ${ }^{4} \mathrm{He}$ flux to this site over the last $1.9 \mathrm{Ma}$ varies between 10 and 30 ncc $\mathrm{cm}^{-2} \mathrm{k.y.} .^{-1}$. Importantly, the ${ }^{4} \mathrm{He}$ flux shows a remarkable correlation with the $\delta^{18} \mathrm{O}$ climate record for this site throughout the last $2 \mathrm{Ma}$, and clearly shows the onset of strong 100 k.y. glacial-interglacial cycling at about $1 \mathrm{~m} . y$. ago.

We stress that although selection of different ${ }^{3} \mathrm{He} /{ }^{4} \mathrm{He}$ ratios for the end members may alter these values slightly, there is little 
uncertainty in our result. In particular, because the majority of ${ }^{4} \mathrm{He}$ in the samples is terrestrial in origin, the systematic oscillation in ${ }^{4} \mathrm{He}$ flux remains, irrespective of the choice of endmember compositions. Similarly, changes in the $\mathrm{CaCO}_{3}$ content of the core, or other errors in bulk MARs arising out of chronostratigraphic inaccuracy, cannot generate the observed systematic variations in terrigenous ${ }^{4}$ He flux.

As this site is sufficiently distant from land masses that hemipelagic sediment is unlikely to be a problem, the noncarbonate, nonauthigenic component of the sediment is considered to be eolian dust [6]. We therefore interpret the variation in ${ }^{4} \mathrm{He}$ flux to be a measure of the eolian mass accumulation rate at site 806 with increased dust supply associated with glacial periods.

Analysis of the mineralogy of the eolian dust from the Ontong Java Plateau [6] suggests that over the last $5 \mathrm{Ma}$ the dominant sources of dust were continental Asia and local volcanics. Because the abundance of ${ }^{4} \mathrm{He}$ in the local young volcanics is likely much less than that of the older $\mathrm{U}$ - and Th-rich continental dusts of eastern and central Asia, we suggest that ${ }^{4} \mathrm{He}$ may be a unique tracer of Asian dust, with the local volcanic dust having little effect. As dust supply is linked to the aridity of the source region [7], we interpret the ${ }^{4} \mathrm{He}$ variations observed at ODP $806 \mathrm{~B}$ as a $2-\mathrm{Ma}$ record of the climatecontrolled aridity of Asian dust sources with increased aridity associated with glacial maxima.

This interpretation is supported by the observation that ${ }^{4} \mathrm{He}$ flux variations at ODP $806 \mathrm{~B}$ correlate with eolian MARs of Asian dust over the last $500 \mathrm{k} . \mathrm{y}$. in core V21-146, located off the eastem coast of Japan $[8,9]$. In addition, the ${ }^{4} \mathrm{He}$ flux at ODP $806 \mathrm{~B}$ shows a longterm increase consistent with a slow increase in the aridity of Asia previously suggested [10].

If our interpretation is correct, then the ${ }^{4} \mathrm{He}$ flux and eolian MAR at site $806 \mathrm{~B}$ may be decoupled, as the ${ }^{4} \mathrm{He}$ flux will be dominated by Asian dust, whereas the eolian MAR will record the sum of the Asian and local volcanic dust supplies. Thus, the measurement of ${ }^{4} \mathrm{He}$ in well-controlled cores provides a new tool for the study of the eolian dust transport and source region aridity. Further work on the relationship between ${ }^{4} \mathrm{He}$ fluxes and eolian MARs is presently underway.

References: [1] Ozima M. et al. (1984) Nature, 311, 449451. [2] Takayanagi M. and Ozima M. (1987) JGR, 92, 1253112538. [3] Farley K. A. (1995) Nature, 376, 153-156. [4] Farley K. A. and Patterson D. B. (1995) Nature, 378, 600-603. [5] Berger W. H. et al. (1993) Proc. Ocean Drill. Prog. Sci. Res., 130, 381395. [6] Krissek L. A. and Janecek T. R. (1993) Proc. Ocean Drill. Prog. Sci. Res., 130, 471-490. [7] Rea D. K. (1994) Rev. Geophys., 32, 159-195. [8] Hovan S. A. et al. Space Nature, 340, 296-298. [9] Hovan S. A. et al. (1991) Paleoceanogr., 6, 349-370. [10] Pye K. and Zhou L. P. (1989) Paleogeog. Paleoclim. Paleo-Ecol., 73 , $11-23$.

STRONTIUM/CALCIUM RATIOS IN MARINE BARITE OVER THE PAST 35 MILLION YEARS. A. Paytan and M. Kastner, Scripps Institution of Oceanography, University of Califomia-San Diego, La Jolla CA 92093-0212, USA (apaytan@ ucsd.edu).

At any given time, the $\mathrm{Sr} / \mathrm{Ca}$ ratio in seawater depends on the relative rates of the input and removal of these elements. The main

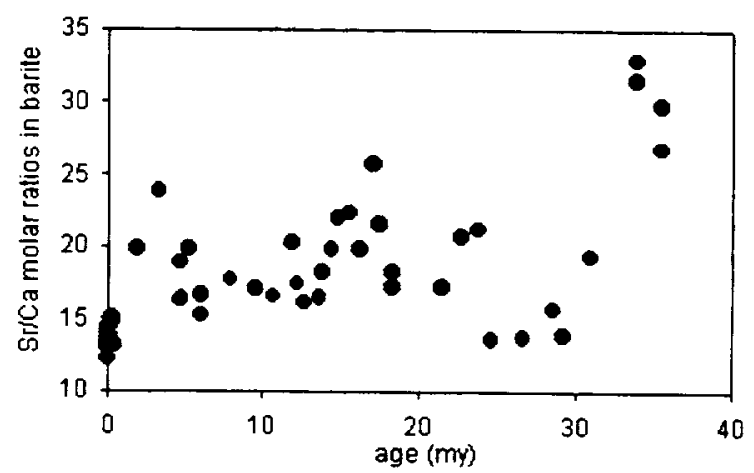

Fig. 1.

sources are rivers and hydrothermal fluids, the main sinks are marine carbonates and sulfates. The $\mathrm{Sr} / \mathrm{Ca}$ ratios of each of these sources and sinks are different; consequently, even moderate changes in the relative intensities controlling these input and output processes would be reflected in changes in the $\mathrm{Sr} / \mathrm{Ca}$ ratio of seawater. At chemical equilibrium the extent to which an element is incorporated in a mineral is expressed by its distribution coefficient, that is its concentration ratio in the mineral to that in the original reservoir. Therefore, the distribution coefficient of $\mathrm{Sr}$ (the $\mathrm{Sr} / \mathrm{Ca}$ ratio) in calcareous fossils has been interpreted to indicate changes in seawater $\mathrm{Sr} / \mathrm{Ca}$ ratio. Because of their biogenic origin, "vital effects" may, however, affect the initial $\mathrm{Sr} / \mathrm{Ca}$ ratio of calcite and aragonite. Both minerals are highly susceptible to diagenetic recrystallization that alters the $\mathrm{Sr} / \mathrm{Ca}$ ratio.

Marine barite is a rather insoluble phase, less prone to diagenetic alteration in oxic sediments, thus could be a more suitable phase for the reconstruction of seawater $\mathrm{Sr} / \mathrm{Ca}$ ratio. In order to investigate this possibility, $\mathrm{Sr}$ and $\mathrm{Ca}$ concentrations and $\mathrm{Sr} / \mathrm{Ca}$ ratios were determined in marine barite samples separated from Pacific Ocean sediments spanning the last $35 \mathrm{~m} . \mathrm{y}$. In barite both $\mathrm{Sr}$ and $\mathrm{Ca}$ are minor components.

Although the determinations of the $\mathrm{Sr}$ and $\mathrm{Ca}$ distribution coefficients in barite are still in progress, assuming that marine barite forms in equilibrium with seawater the preliminary results suggest that significant changes in the seawater $\mathrm{Sr} / \mathrm{Ca}$ ratio, on the order of $40 \%$, have occurred over the past $35 \mathrm{~m}$.y. (see Fig. 1). The observed fluctuations in the $\mathrm{Sr} / \mathrm{Ca}$ ratio in barite coincide with the most significant geological-oceanographic events over this time interval.

TOTAL BARIUM VS. AMOUNT OF BARITE IN SEDIMENTS AS INDICATORS OF PRODUCTIVITY. A.Paytan', R. W. Murray ${ }^{2}$, M. Kastner' ${ }^{1}$, and M. Leinen ${ }^{3}$, 'Scripps Institution of Oceanography, University of California-San Diego, La Jolla CA 92093-0212, USA (apaytan@ucsd.edu), 2Department of Earth Sciences, Boston University, Boston MA 02215, USA, ${ }^{3}$ Graduate School of Oceanography, University of Rhode Island, Narragansett RI 02881, USA.

Organic $\mathrm{C}$ and biogenic $\mathrm{Ba}$ (excess $\mathrm{Ba}$ or $\mathrm{Ba}_{\mathrm{cx}}$ ) fluxes show a positive correlation in particulate matter [1-6]. Therefore, $B a_{c x}$ accumulation in marine sediments, determined from the total $\mathrm{Ba}$ content minus the terrigenous $\mathrm{Ba}$ that is derived from the $\mathrm{Ba} / \mathrm{Al}$ or $\mathrm{Ba} / \mathrm{Ti}$ ratios in shale, has been employed for marine productivity 


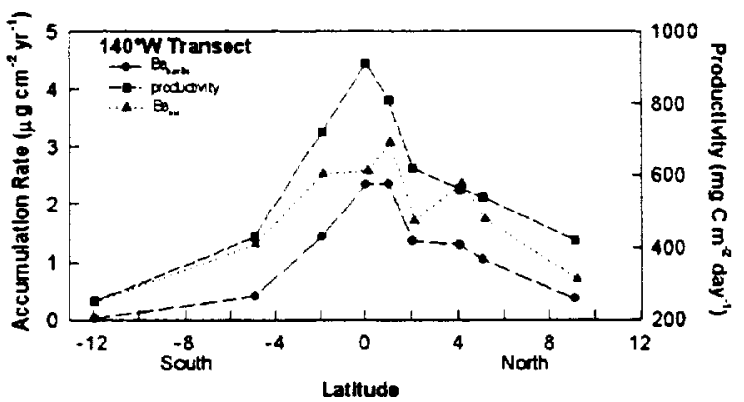

Fig. 1. Primary productivity, barite, and $\mathrm{Ba}_{\mathrm{ex}}$ accumulation in the central equatorial Pacific.

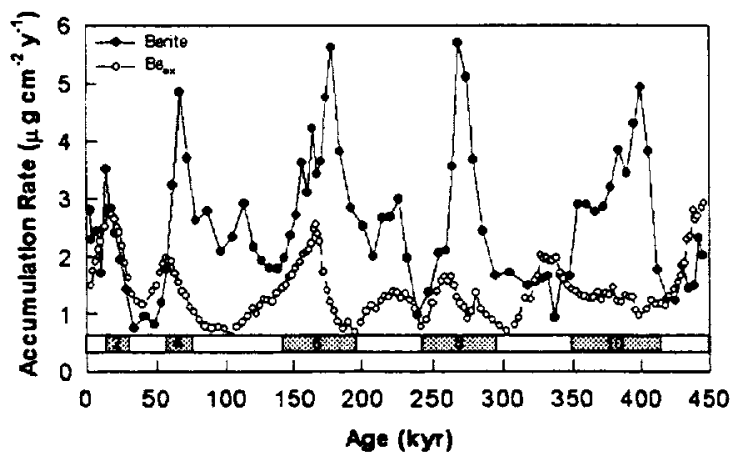

Fig. 2. Barite and $\mathrm{Ba}_{\mathrm{ex}}$ accumulation changes with age in the central equatorial Pacific.

reconstruction [4,7-9]. The relation between $\mathrm{Ba}_{\mathrm{ex}}$ and productivity in the sediment, however, can be modified by the adsorption of $\mathrm{Ba}$ onto Fe-Mn oxyhydroxide coatings of particles, a process not related to productivity [10]. Most $\mathrm{Ba}$ in particulate matter resides in the mineral barite, the most important Ba-carrying phase associated with biogenic activity. It is suggested, therefore, that barite content in the sediment is a better proxy for productivity [11].

Our study compared the reliability of both $\mathrm{Ba}_{\mathrm{ex}}$ and barite accumulation in marine sediments as indicators for paleoproductivity. Accumulation rates of $\mathrm{Ba}_{\mathrm{ex}}$ and barite in core-top sediments, along a transect at $140^{\circ} \mathrm{W}$ in the equatorial Pacific, were compared with productivity data (Fig. 1). Barite accumulation correlates well with the overlying biological productivity; $\mathrm{Ba}_{\mathrm{ex}}$ accumulation does not. The observed maximum in $\mathrm{Ba}_{\mathrm{ex}}$ accumulation at $4^{\circ} \mathrm{N}$ is most likely due to $\mathrm{Ba}$ adsorption onto abundant eolian particles transported to this location [12]. In high-productivity areas, more than $90 \%$ of $\mathrm{Ba}_{\mathrm{ex}}$ occurs as barite $\mathrm{Ba}$ but only $20 \%$ or less of $\mathrm{Ba}_{\mathrm{ex}}$ is derived from barite in areas of low productivity.

Because the intensity of the biological production should fluctuate with climate changes, we further compared the $\mathrm{Ba}_{\mathrm{ex}}$ and barite accumulation rates in a piston core from the equatorial Pacific at $0^{\circ}$ (Fig. 2). The data show that $\mathrm{Ba}_{\mathrm{ex}}$ accumulation is not strongly related to climatic changes, whereas barite accumulation rates correlate well with glacial-interglacial fluctuations.

References: [1] Dehairs F. et al. (1980) EPSL, 49, 529. [2] Dehairs F. et al. (1992) Science, 258, 1332. [3] Bishop J. K. B. (1988) Nature, 331, 341-343. [4] Dymond J. et al. (1992) Paleoceanogr., 7, 163. [5] Francois R. et al. (1995) Global
Biogeochem. Cycles, 9, 289. [6] Dymond J. and Collier R. (1996) Deep Sea Res., 43, 1283. [7] Schmitz B. (1987) Paleoceanogr., 2, 63. [8] Shimmield G. B. et al. (1988) Chem. Geol., 70, 112. [9] Gingele F. and Dahmke A. (1994) Paleoceanogr., 9, 151. [10] Schroeder J.O.etal. (1997) Paleoceanogr., 12, 125. [11] Paytan A. et al., Science, 247, 1355. [12] Murray R. W. et al. (1993) Paleoceanogr., 8, 651 .

SINGLE-CRYSTAL RHENIUM-OSMIUM ISOTOPIC DATING OF SULFIDE INCLUSIONS WITHIN A ZONED SIBERIAN DIAMOND. D. G. Pearson', S. B. Shirey ${ }^{2}$, G. P. Bulanova $^{3}$, R. W. Carlson' ${ }^{2}$, and H. J. Milledge ${ }^{4}$, 'Department of Geological Sciences, Durham University, South Road, Durham DH1 3LE, UK (d.g.pearson@durham.ac.uk), 2Department of Terrestrial Magnetism, Carnegie Institution of Washington, 5241 Broad Branch Road, Northwest, Washington DC 20015, USA, ${ }^{3}$ TsNIGRI, Varshavskoe shosse, 129B, Moscow 113545, Russia, ${ }^{4}$ Department of Geological Sciences, University College London, Gower Street, London, UK.

The age and origin of diamonds, especially peridotitic-suite diamonds is a subject of much debate [1,2]. Most Rb-Sr and Sm-Nd isotopic dating of diamonds has necessitated compositing of many, possibly noncogenetic, crystals. In situ $\mathrm{Pb}$ isotopic analyses by SHRIMP permit analyses of individual sulfide inclusions [3], but the data are imprecise and lack parent-daughter ratio measurements. Individual sulfide inclusions contain sufficient $O$ s to allow Re-Os isotopic measurement by microchemistry and NTIMS.

In situ $\mathrm{Pb}$ isotopic analysis of sulfide inclusions within a large Siberian diamond from the $350-\mathrm{Ma}$ Udachnaya kimberlite suggested several phases of diamond growth over a period of $\sim 2$ b.y. [3]. In luminescence, the diamond shows two distinct growth zones and thus provides an opportunity to assess both its absolute age and multiple growth stages. The diamond plate was laser-cut into fragments containing individual sulfide inclusions to analyze for $\mathrm{Re}$-Os isotopes. Also, FTIR spectroscopy was used to determine the level and aggregation state of $\mathrm{N}$.

Sulfides were analyzed from the inner, blue luminescent zone and an intermediate region (all termed inner zone here) and one from the clear, outer zone. Osmium abundances range from 2295 to $6845 \mathrm{ppb}$ in the inner zone sulfides and reach $20533 \mathrm{ppb}$ in the outer zone inclusion. Rhenium is lower, with only 19 to $46 \mathrm{ppb}$ in the inner zones. Rhenium is greatly enhanced in the outer zone sulfide, mirroring variations found for $\mathrm{Pb}$ abundance $[3,4]$. Osmium-187/ osmium- 188 also varies from $\sim 0.108$ to 0.1089 in the inner zones, to 0.1149 in the outer zone, a trend accompanied by increasing ${ }^{187} \mathrm{Re} /{ }^{188} \mathrm{Os}$.

Rhenium-osmium model ages of the inner and outer zone sulfides are similar at 3.1-3.4 Ga. Although the low $\mathrm{Re} / \mathrm{Os}$ sulfides scatter (due to Re blank correction at the 3-5 pg total analyzed), on the low end of an isochron diagram all the data define a $2.8 \pm 0.7$ $\mathrm{Ga}$ regression line with a chondritic initial, supporting an Archean age for these sulfides and hence the diamond. This contrasts with a Mesozoic Re-Os isochron age on two P-type sulfide inclusions from one South African diamond [5].

Nitrogen is low at the rim $(\sim 15 \mathrm{ppm})$ and higher in the inner zone of the diamond $(\sim 290 \mathrm{ppm})$. Variation in aggregation state defines a tight isothermal trend consistent with a $2.7-\mathrm{Ga}$ mantle residence time at temperatures of $\sim 1160^{\circ} \mathrm{C}$. 
The combined Re-Os and $\mathrm{N}$ aggregation data suggest that both zones of the diamond grew at a similar time, in the Archean, not separated by billion-year timescales as suggested by the $\mathrm{Pb}$ isotope data [3].

Although the variation in sulfide $\mathrm{Pb}$ isotope compositions [3] could be a function of varying $\mathrm{U} / \mathrm{Pb}$, the outer, more radiogenic sulfides have very high $\mathrm{Pb}$ in some instances so their radiogenic $\mathrm{Pb}$ is unlikely to be due to variation in $\mathrm{U} / \mathrm{Pb}$. We note that the high- $\mathrm{Pb}$ outer zone sulfides also have the highest Os contents.

Rhenium-osmium dating of diamond sulfides is a sensitive and accurate means of assessing diamond growth and appears to indicate a variety of crystallization ages for both E- and P-type diamonds, from Archean to recent.

References: [1] Richardson S. H. et al., Nature, 310, 198202. [2] Shimizu N. and Sobolev N. V. (1995) Nature, 375, 394397. [3] Rudnick R. L.et al. (1993) Geology, 21, 13-16. [4] Bulanova G. P. et al., Contrib. Mineral. Petrol., 124, 111 -125. [5] Pearson et al., Eos Trans. $A G U, 77,816$.

\section{A DESCRIPTION OF THE PALEOCLIMATE IN THE SOUTH CHINA SEA BY MEANS OF MOLECULAR BIOMARKERS IN DEEP-SEA SEDIMENTS. C. Pelejero', J. O. Grimalt', M. Sarnthein'2, and L. Wang', 'Department of Environmental Chemistry, C.I.D.-C.S.I.C., Barcelona, Catalonia, Spain, ${ }^{2}$ Geologisch-Paläontologisches Institut, Kiel University, Germany.}

In the last decade, studies of deep-sea sediment molecular biomarkers have raised interest in the paleoceanographic community, in part due to the development of the sea-surface paleothermometer $\mathrm{Uk}_{37}$ index. This index, a ratio between $\mathrm{C}_{37} \mathrm{di}$ - and triunsaturated methyl ketones [1], shows a strong linear correlation with the temperature at which the alkenones are synthesized. $\mathrm{Uk}_{37}$ determinations in laboratory cultures at different temperatures of Emiliania huxleyi, the main alkenone producer present in the oceans, have shown a very good linear correspondence with temperature [2], which has also been observed by means of water column particulate matter and top-core sediment calibrations.

In this work, the usefulness of the $\mathrm{Uk}_{37}$ index as a paleothermometer for the South China Sea has been evaluated. This is the first work that attempts to calibrate the $U^{k}{ }_{37}$ index in the warm boundary (waters over $25^{\circ} \mathrm{C}$ ). Other calibrations have been more centered in the cold end $\left(-0.7^{\circ}-12.2^{\circ} \mathrm{C}\right)$ and mid temperatures (below $25^{\circ} \mathrm{C}$ ). The paleotemperature reconstruction of warm water oceans is of relevant interest, due to the important role of these water masses in the atmosphere-ocean interaction, particularly in regard to the Intertropical Convergence Zone, the intensity of the trade winds, and the changes in the Hadley Circulation.

The alkenone compounds in the South China Sea have been analyzed in a series of top-core sediments obtained during the $R / V$ SONNE cruise in April-June 1994, which cover most of the areas situated far from the influence of riverine inputs. The resulting $U^{k_{37}}$ indexes have been correlated with the present-day sea-surface temperature (SST) for the overlying waters at various depth levels and seasons. Curve fitting of these parameters has shown that the linear $\mathrm{Uk}_{37} / \mathrm{SST}$ relationship is maintained at the warm end, which strongly contrasts with the lack of correlation at low SSTs reported in other studies. The best curve fittings of the $\mathrm{Uk}_{37}$ measurements are obtained for the annually averaged $0-30$-m-water-column tempera- tures, providing a linear equation that is the same within error limits as those previously obtained in open ocean sites or Emiliania huxleyi cultures.

After calibration, $\mathrm{Uk}_{37} / \mathrm{SST}$ data from gravity core 17961-2 $\left(8^{\circ} 30.4^{\prime} \mathrm{N}, 112^{\circ} 19.9^{\prime} \mathrm{E}, 1968 \mathrm{~m}\right.$ depth$)$, obtained during the same campaign, has been calculated. This core covers a span of the last $130,000 \mathrm{yr}$ and is located on the Sunda Slope, an area affected during glacial times by the marine sediment discharge of the Moolengraaf or Sunda River that existed when the sea level was low. SST data obtained with the new Uk $37 / \mathrm{SST}$ calibration for the South China Sea will be compared to the most-used calibrations.

Finally, other molecular biomarkers studied in the same core will be presented, like long-chain n-alkane abundances. In this particular core location they are probably indicators of sea-level changes due to the close influence of the Moolengraaf River discharge.

References: [1] Brassell S. C. et al. (1986) Nature, 320, 129133. [2] Prahl F. G. and Wakeham S. G. (1987) Nature, 330, $367-$ 369 .

\section{EL NIÑO'S WINTER PRECIPITATION RECORDED IN PINE CELLULOSE DEUTERIUM/HYDROGEN RATIOS.} E. Pendall ${ }^{1}$ and S. W. Leavitt ${ }^{1}$, 'Laboratory of Tree-Ring Research, University of Arizona, Tucson AZ 85721, USA.

We investigated the potential for reconstructing seasonality of precipitation using stable $\mathrm{H}$ isotopes of nitrated cellulose of piñon pine (Pinus edulis and $P$. monophylla). We analyzed $\mathrm{D} / \mathrm{H}$ ratios of single-year needle cohorts, subannual wood increments, and source water (precipitation, stem and soil water) along a transect of decreasing proportion of summer precipitation from New Mexico to Arizona to Nevada. Sites were located on hill slopes with shallow, rocky soils, at the lower elevational limit of piñon pine.

$\delta \mathrm{D}$ in annual average precipitation was most depleted in $\mathrm{Ne}$ vada, the site with most winter precipitation, and most enriched in New Mexico. Seasonal variations in $\delta \mathrm{D}$ of precipitation were damped in soil profiles, especially below $50 \mathrm{~cm}$ depth. Xylem sap extracted from tree trunks showed a smaller seasonal range than did soil profiles, and was used to estimate depth of water sources for the trees. In Nevada, trees used water from below $50 \mathrm{~cm}$ depth during most of the growing season, while at the Arizona and New Mexico sites receiving more summer rain, water use shifted from deeper to shallower depths as the summer rains occurred.

$\delta \mathrm{D}$ in wood and needle cellulose of piñon pine reflected variations in $\delta \mathrm{D}$ of source water modified by climatic conditions. Source water isotopic variation due to variation in precipitation seasonality was a primary influence on wood and needle cellulose. For example, a large amount of isotopically light winter precipitation during the $1992 \mathrm{El}$ Niño event was incorporated into cellulose in New Mexico and Arizona.

However, precipitation $\delta \mathrm{D}$ was modified prior to plant uptake by mixing and evaporation in the soil. Lag effects, due to storage of source water in soils or in tree trunks as carbohydrates, increased intertree variation.

Precipitation amount was inversely correlated with $\delta D$ of cellulose of these semiarid pines. In New Mexico, early wood $\delta D$ was correlated with December-March precipitation $\left(r^{2}=0.69\right)$ and late wood $\delta \mathrm{D}$ was correlated with May-August precipitation $\left(\mathrm{r}^{2}=0.59\right)$. Cellulose $\delta D$ from annual cohorts of needles was inversely correlated with May-August precipitation $\left(r^{2}=0.67\right)$. Relative humidity 
also affected $\delta \mathrm{D}$ of needle cellulose via evaporation. Interannual temperature variations were poorly correlated with cellulose $\delta \mathrm{D}$ time series, but averaged site temperature was positively correlated with averaged cellulose $\delta \mathrm{D}$ among sites.

ENHANCED SOIL RESPIRATION AND DECOMPOSITION UNDER ELEVATED CARBON DIOXIDE. E. Pendall ${ }^{1}, \mathrm{~S}$. W. Leavitt', T. Brooks ${ }^{2}$, and B. Kimball ${ }^{2}$, ${ }^{1}$ Laboratory of Tree-Ring Research, University of Arizona, Tucson AZ 85721, USA, 2U.S. Water Conservation Laboratory, USDA-ARS, 4331 East Broadway Road, Phoenix AZ 85040, USA.

In this study, we evaluate the efflux of soil C during the 19951996 winter wheat FACE (Free-Air $\mathrm{CO}_{2}$ Enrichment) experiment at Maricopa, Arizona. Carbon dioxide fertilization of crop plants has been well documented in FACE experiments; for instance, wheat yields increased by $20 \%$ when fertilized with $200 \mathrm{ppmv}$ (parts per million by volume) above background $\mathrm{CO}_{2}$ levels [1]. The fate of this $\mathrm{C}$ will determine the potential for long-term $\mathrm{C}$ sequestration due to $\mathrm{CO}_{2}$ fertilization of crop plants. Leavitt et al. [2] showed that the soil $\mathrm{C}$ pool increased by up to $10 \%$ after 3 yr of FACE cotton at Maricopa, Arizona. However, Nakayama [3] found that soil respiration rates were enhanced due to $\mathrm{CO}_{2}$ enrichment during and after a cotton FACE experiment. This suggests that some of the $\mathrm{C}$ stored in the soil might be released as a result of increased microbial activity in FACE soils.

To determine whether soil respiration is enhanced under FACE conditions, we measured soil respiration rates with a custom-made chamber attached to a portable gas exchange system, and isotopic composition of the evolved $\mathrm{CO}_{2}$. To distinguish soil $\mathrm{CO}_{2}$ produced by decomposition of original organic matter from that produced by root respiration, we measured the $C$ isotopic composition of wheat plants, soil $\mathrm{C}$, and in situ soil $\mathrm{CO}_{2}$. The $8^{13} \mathrm{C}$ is a useful tracer for FACE $C$ because the tank gas used in the experiment is much lighter than background air.

Respiration rates increased slightly over the growing season in control plots, due to both increased temperatures and root respiration. Respiration rates in FACE plots were spatially and temporally variable, but $\mathrm{CO}_{2}$ efflux from FACE plots was roughly double that from control plots.

The isotopic composition of soil-respired $\mathrm{CO}_{2}$ (corrected for background) increased during the middle of the growing season for both FACE and control plots. Atmospheric $\mathrm{CO}_{2}$ may have been introduced into the soil chamber during sampling, through cracks that formed when the soil was dry, making the $\delta^{13} \mathrm{C}$ more positive than expected especially for the control plots.

Early in the growing season, the in situ (standing crop) $\mathrm{CO}_{2}$ was dominated by decomposition of original organic matter in both treatments. The maximum contribution from root respiration was observed during the third month of growth. During this time, we estimate based on isotopic mass balance that root respiration contributes $\sim 55 \%$ of the in situ $\mathrm{CO}_{2}$ in FACE plots and $-90 \%$ in control plots, assuming a two-component system. Apparently, enhanced microbial decomposition is partly responsible for the increased respired $\mathrm{CO}_{2}$ flux observed on FACE plots. Isotopic mass balance may underestimate decomposition on control plots because $\delta^{13} \mathrm{C}$ of root respiration is close to the value for organic matter.

The $\mathrm{CO}_{2}$ flux from FACE plots is roughly double that from control plots, and the results above suggest this increase is due mainly to enhanced microbial decomposition rather than to increased root respiration. Although organic matter is being added to FACE soils at a higher rate than to control soils, increased decomposition rates may diminish the possibility of long-term sequestration. Incubation experiments on soil collected after years 1 and 2 of the current FACE wheat experiment should provide further evidence for the possibility of sequestering $C$ from FACE plots in the soil.

References: [1] Kimball B. A. et al. (1995) Global Change Biology, 1, 429-442. [2] Leavitt S. W. et al. (1994) Agric. For. Meteorol., 70, 87-101. [3] Nakayama, unpublished data.

\section{GEOCHEMICAL AND ISOTOPE EVOLUTION OF HYDRO- THERMAL-MAGMATIC SYSTEMS OF THE UKSICHAN VOLCANO (KAMCHATKA ISLAND ARC SYSTEM). A. B.} Perepelov, V. Yu. Prokofiev, and S. I. Dril', Vinogradov Institute of Geochemistry, Russian Academy of Sciences, Favorsky Street 1A, 664033, Irkutsk, Russia (region@igc.irkutsk.su).

The main types of fresh and hydrothermally altered rocks of the Uksichan volcano, one of the largest ( $50 \mathrm{~km}$ in diameter) in the Pliocene-Quatemary volcanic center of the Kamchatka island arc system, were studied in order to identify compositions of the primary melts, to analyze magma differentiation from data on melt inclusions, and to investigate features of hydrothermal processes in the caldera on the basis of data on pressure, temperatures, geochemistry, and isotopy.

The Uksichan volcano is located in the back volcanic belt of Kamchatka, in the Sredinny Range (Fig.1). The geological structure of the volcano comprises the Middle Miocene (?)-Pliocene $\left(\mathrm{N}_{1}{ }^{2-}\right.$ $\mathrm{N}_{2}$ ) volcanogenic basement, the Upper Pliocene-Middle-UpperPleistocene $\left(\mathrm{N}_{2}{ }^{3}-\mathrm{Q}_{2}\left(\mathrm{Q}_{3}\right.\right.$ ?)) edifice of the volcano proper, and an Upper Pleistocene-Holocene $\left(Q_{3}-Q_{4}\right)$ assemblage of small shield volcanos and cinder lava cones. The basement rocks are strongly affected by hydrothermal alteration; hydrotherms are widely distributed at present near basement exposures. The volcano has gone through three stages of evolution. The first, stratovolcano stage $\left(\mathrm{N}_{2}{ }^{3}-\mathrm{Q}_{1}\right)$, involved the formation of high-K basalt lavas, high-K basaltic andesites, and andesites. The second, shield volcano, stage $\left(Q_{1}-Q_{2}\right)$, was associated with voluminous shoshonite and latite lavas and their ignimbrites. The third, caldera, stage $\left(Q_{2}-Q_{3}\right.$ ?), was marked by eruptions of quartz latites and their ignimbrites, accompanied by the collapse of the central block of the edifice on a system of concentric faults. Thus a complex of high- $K$ andesites, latites, high- $K$ dacites, trachydacites, and trachyrhyodacites came into existence in the caldera center. The final stage of the magmatic activity was followed by hydrothermal rework of the caldera rocks with zeolitization, alunitization, sulphidization, propylitization, and quartzitization on high- $\mathrm{K}$ andesites and latites. Chloride-sulfate in $7^{\circ}-65^{\circ} \mathrm{Chot} \mathrm{springs}$ in the Uksichan River valley and the associated epithermal $\mathrm{Au}-\mathrm{Ag}$ mineralization of the basement showed no direct geochemical relationship with the magmatic system of the volcano, whereas the mineral springs in the caldera were related to the evolution of the volcanic center.

Inclusions of siliceous melts in plagioclase from basement, the volcano itself, and caldera magmatics were studied separately by air-hardening with subsequent $X$-ray microprobing using "Superprob- 


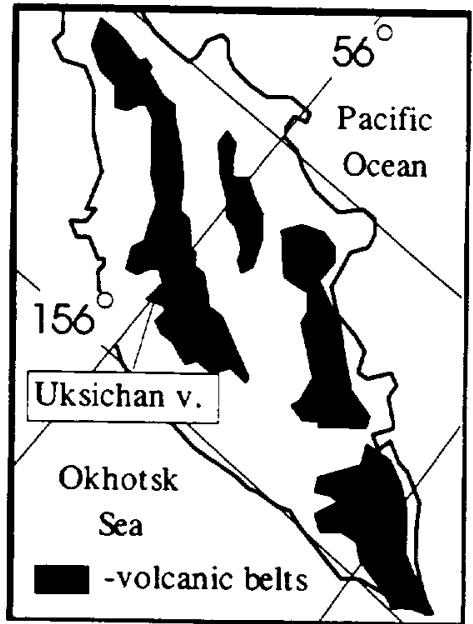

Fig. 1.

733" for compositions of the yielded glass of the largest homogenous inclusions. In the quartz and calcite of quartz-carbonate veins, hydrotherm-derived inclusions were investigated.

Petrochemical and PT studies show that high-K and subalkalic shoshonite-latite rocks of the volcano were produced by fractional crystallization of high-K aluminous basaltic primary magmas. The crystallization point for plagioclase was found to decrease from basalts $\left(1200^{\circ} \mathrm{C}\right)$ to rhyodacites $\left(960^{\circ} \mathrm{C}\right)$ in the basement and from $1240^{\circ} \mathrm{C}$ in Uksichan basalts to $920^{\circ} \mathrm{C}$ in dacites of its extrusions, the latter exhibiting elevated water contents. The fluid pressure in the dacite melt from the central extrusion was estimated to be within 2.5-1.9 kbar at $780^{\circ} \mathrm{C}$ and its $\mathrm{H}_{2} \mathrm{O}$ content to range from 4.3 to 1.3 wt \% The presence of $\mathrm{H}_{2} \mathrm{O}$ is possibly due to the accumulation of volatiles during crystallization.

Studies of inclusions in hydrothermal quarz and calcite showed that they proceeded from chloride-magnesian-sodium $\mathrm{H}_{2} \mathrm{O}$ solutions, usually involved in heterogenization (boiling) processes, with salt concentrations of $3.5-0.2 \mathrm{wt} \%$, in $\mathrm{NaCl}$ equivalent, at temperatures ranging from $275^{\circ}$ to $150^{\circ} \mathrm{C}$ and pressures between 55 and 8 bar. The Au-Ag mineralization of the basement originated from solutions with salt concentrations of $3.5-1.4 \mathrm{wt} \%$, in $\mathrm{NaCl}$ equivalent, at temperatures from $275^{\circ}$ to $175^{\circ} \mathrm{C}$ and pressures from 55 to 9 bar, whereas the same parameters for caldera metasomatites are shown to be considerably lower: salt concentrations of 2.1-0.2 wt \%, in $\mathrm{NaCl}$ equivalent, temperatures between $220^{\circ}$ and $150^{\circ} \mathrm{C}$, and pressures within 20-8 bar.

Markedly higher ${ }^{87} \mathrm{Sr} /{ }^{86} \mathrm{Sr}$ ratios in the altered rocks with respect to the fresh Uksichan volcanics $(0.70325-0.70767$ compared to $0.7032-0.70343$ ) attest to the fact that the seawater may have played a meaningful role at the beginning of evolution of the hydrothermal system. The present-day mineral waters in the Uksichan caldera and hot springs around the volcano have formed uniquely due to low-mineralized meteoric water.

Acknowledgments: The studies were supported by the Russian Science Foundation, grant N 95-05-14358.

MANTLE HETEROGENEITIES AT THE ASIAN CONTINENTAL MARGIN INDUCED BY CENOZOIC SUBDUCTION COMPONENTS. T. V. Petrova ${ }^{1}$, S. V. Esin' ${ }^{2}$, and V. A.
Kutolin2, IInstitute of Mineralogy and Petrography, Room 135, Bernoullistrasse 30, Basel CH-4056, Switzerland, 'Department of Geophysics and Mineralogy, United Institute of Geology, Novosibirsk 630090, Russia.

Miocene-Pliocene extension-related alkaline basalts of the Sikhote-Alin and Primorye (Far East) are related genetically to the provinces of alkaline basalts in China (continental rifting) and western Japan (back-arc basin and island-arc system). Alkaline basalts include $\mathrm{Ne}$-normative and transitional basalts with $\mathrm{TiO}_{2}$ $(1.7-2.4 \%), \mathrm{Zr}(\sim 180 \mathrm{ppm}), \mathrm{V}(100-150 \mathrm{ppm}), \mathrm{Rb} / \mathrm{Sr}(0.073-$ $0.114), \mathrm{Zr} / \mathrm{Nb}(6.2-7.4), \mathrm{Y} / \mathrm{Nb}(0.9-1.1)$, increased contents of LREE, and 15-28 La/Yb. The geochemistry of the basalts differs slightly from that of Chinese and Japanese provinces. The general mantle source is similar to OIB. However, the major, trace, and REE composition of alkaline basalts from different volcanos over the territory of $500 \mathrm{~km}^{2}$ varies widely, since the alkaline volcanism in the province was superimposed over the volcanic belt, which was formed during Paleogene-Early Miocene in the typical subductionrelated continental margin. The influence of the subduction component over the regional mantle is reflected in the composition of the basalts and related mantle xenoliths. The mantle xenoliths include (1) a "black" series (pyroxenites and olivine pyroxenites) and (2) a "green" series (spinel lherzolites, olivine websterites, harzburgites, olivine enstatites, enstatitites, wehrlites, and websterites). Crustal xenoliths include basic and ultrabasic granulites. There are clear changes in composition of the xenolith and phenocryst minerals in direction from the Chinese rifting province to the Japanese island arc system through the areas of Sikhote-Alin and Primorye, with a general decrease in the $\mathrm{mg} \#$ of olivines. The P-T-fO ${ }_{2}$ estimates show a decrease of temperature of the xenoliths from west to east with the increase of $\mathrm{fO}_{2}$. Besides, the petrology of alkaline basalts varies from a predominance of nephelinites to transitional basalts with the appearance of a picrobasaltic series. The level of magma segregation decreases steadily from west to east. The observed variations in the mineralogy of xenoliths and petrology of alkaline basalts from the Chinese rifting province to the Japanese island-arc and back-arc basin system reflects the gradual influence of subduction components over the mantle on a scale of at least $500 \mathrm{~km}^{2}$ from the Japanese Sea coast at Primorye toward the continent.

NEODYMIUM, STRONTIUM, AND LEAD ISOTOPIC SIGNATURES AND EOLIAN MASS-ACCUMULATE-RATE VARIATIONS OF CENTRAL NORTH PACIFIC DUST CHARACTERIZE THE PALEOCLIMATE OF CENTRAL AND EASTERN ASIA FOR THE PAST 11 MILLION YEARS. T. Pettke, D. K. Rea, and A. N. Halliday, Department of Geological Sciences, The University of Michigan, Ann Arbor MI 48109, USA (tpettke@umich.edu; davidrea@umich.edu; anh@umich.edu).

Records of the eolian dust fraction of pelagic sediments provide a reliable proxy indicator of continental climates and atmospheric transport processes through time. The principal present-day eolian input to the central north Pacific is Asian dust, transported via the westerlies. The eolian Mass Accumulation Rates (MAR) in this region have varied by more than an order of magnitude over the past 12 m.y. To interpret properly this variability it is important to determine whether the provenance of dust varied. We investigated 
20 samples taken from an $11-m . y$. continuous record of eolian dust input to the central north Pacific, found at ODP site $885 / 586\left(44.68^{\circ} \mathrm{N} /\right.$ $168.25^{\circ} \mathrm{W}$ ).

The MAR of the eolian silicate fraction [given in $\mathrm{mg} /\left(\mathrm{cm}^{2} \times\right.$ k.y. $)^{-1}$ ] varies as a function of the age of deposition along core, describing six different zones (A-F). The oldest (zone F: 11-8 Ma) is characterized by a constant and low MAR of 20-30. About $7.5 \mathrm{~m} . y$. ago, an accumulation spike peaking at 130 (zone E: 8.0 $7.2 \mathrm{Ma}$ ) is then followed by a period (zone $\mathrm{D}: 7.2-4.8 \mathrm{Ma}$ ) where eolian MAR scattered between 10 and 70. Zone $\mathrm{C}$ (4.8-3.6 Ma) shows low values tending to rise from 10 to 20 . A sudden increase to values as high as 170 (zone $B$ : $3.6-2.6 \mathrm{Ma}$ ) is a transition zone leading to a less variable, high MAR of 90-150 (zone A: 2.6O Ma).

The eolian dust fraction was isolated by removing amorphous Fe-Mn oxides, hydroxides, zeolites, and biogenic silica. For isotopic analyses, bulk dry dust fractions of $\sim 25 \mathrm{mg}$ were surface cleaned in a $1 \mathrm{M}$ ammonium acetate solution, in order to remove $\mathrm{U}, \mathrm{Pb}, \mathrm{Rb}$, $\mathrm{Sr}, \mathrm{Sm}$, and $\mathrm{Nd}$ that may have been adsorbed on the sample surface. Isotopic compositions were determined by conventional TIMS techniques. Isotopic compositions for the ammonium acetate leachate fraction significantly differ from those obtained on the leached dust, demonstrating that surface cleaning is crucial for obtaining the pristine isotopic signatures of eolian dust.

Unradiogenic present-day $\varepsilon_{\mathrm{Nd}}$ values of -8.5 to -10.5 characterize the principal eolian dust component over the whole investigated time span. Three more radiogenic $\varepsilon_{\mathrm{Nd}}$ values $(-6.5,-8.0$, and -8.5$)$ were obtained from samples younger than $3.6 \mathrm{Ma}$ (i.e., zone $\mathrm{B}$ and A). Present-day ${ }^{87} \mathrm{Sr} /{ }^{80} \mathrm{Sr}$ ratios, in contrast, are variable between 0.711 and 0.721 . Lead isotope compositions are again uniform, their present-day $\mu 2$ values range between 9.8 and 10 , with one outlier at $\mu 2=9.64$.

The principal source endmember component identified is Asian loess, the uniform present-day isotopic signatures of which is $\varepsilon_{\mathrm{Nd}}$ around $-10,{ }^{87} \mathrm{Sr} /{ }^{86} \mathrm{Sr} \geq 0.714$, and $\mathrm{Pb}$ with a $\mu 2$ value of $\sim 10$. Some samples are characterized by more radiogenic Nd and less radiogenic $\mathrm{Sr}$ and $\mathrm{Pb}$ isotope compositions, pointing to contamination of the eolian dust component by young volcanic island arc material (ash or weathered surface sediments with $\varepsilon_{\mathrm{Nd}}$ values $\geq-3$ and unradiogenic $\mathrm{Sr}$ isotopic compositions $\geq 0.709$ ). There is no need to invoke a contribution from either the north or the south American continent, both of which are characterized by intermediate $\mathrm{Nd}\left(\varepsilon_{\mathrm{Nd}}\right.$ -3.2 to -4.3 and about -6 , respectively) and $\mathrm{Sr}$ isotope compositions.

Our results provide strong support for the observation that northern hemisphere wind patterns over the Pacific were dominated by the westerlies loaded with variable amounts of Asian dust over the past $11 \mathrm{~m}$.y. Further, we demonstrate that the general source for the eolian material has remained constant over this time period.

Eolian dust from the north-central Pacific of the same and higher present-day latitudes monitors the paleoclimatic evolution of the mid-Asian continent: more arid climates provide more dust for transport and deposition. A stable, more humid climate (zones $F$ and C) is interrupted by a sudden dry-out (zone E) followed by variably dry conditions (zone D). At $\sim 3.6 \mathrm{Ma}$ the sudden, pronounced increase in eolian dust flux represents the late Cenozoic drying of the northem hemisphere. Culmination of late Cenozoic climatic change resulted in significant northem hemisphere glaciation beginning about 2.6 m.y. ago. Since then, high eolian MARs indicative of a long-term drying of central and eastern Asia are characteristic until present (zone A).

These effects, given above, monitored by the eolian dust profile of ODP site 885/886 in the central north Pacific, allow speculations on their causes, such as (1) the relationship between loess formation and continental ice volume, (2) the amount of dust transported in the atmosphere and its effects on the annual mean temperature on the Earth's surface, hence the degree of glaciation and'or sea-level changes, or (3) the effect of the Himalayas and Tibetan Plateau on the atmospheric circulation pattern and hence on the climate of central and eastern Asia and elsewhere.

EXPERIMENTAL STUDY OF TRACE-ELEMENT PARTITIONING IN FLUIDS AND MELTS GENERATED DURING SEDIMENT SUBDUCTION. T. Plank ${ }^{1}$ and M. Johnson'2, 'Department of Geology, University of Kansas, 120 Lindley Hall, Lawrence KS 66045, USA (tplank@kuhub.cc.ukans.edu), ${ }^{2 D e p a r t-~}$ ment of Geography and Environmental Engineering, U.S. Military Academy, West Point NY 10996,USA (bm6894@usmal.usma.edu).

Sediment recycling at subduction zones is "imaged" largely through geochemical tracers $\left({ }^{10} \mathrm{Be}, \mathrm{Pb}, \mathrm{Ba}\right)$. Inverse geochemical modeling of arc lavas has proceeded to where the sediment phase that recycles to the volcanic arc can be fairly uniquely identified. It has high ${ }^{10} \mathrm{Be}$, and $\mathrm{Be}$ recycling from sediment to arc must be $>40 \%$ efficient [1]. The sediment phase is also rich in Th [2], and mass balance of sediment input and arc output fluxes indicates that subducted sediment loses $20-50 \%$ of its Th to the are [3]. Thus any successful recycling model must account for the efficient loss of Be and Th from subducted sediments. Two endmember models, sediment dehydration and melting, can be tested by measuring the partitioning of $\mathrm{Be}$ and $\mathrm{Th}$ (and other tracers) in melts and fluids generated during sediment subduction, the purpose of this study. We report here preliminary results obtained at $20 \mathrm{kbar}$ and $600^{\circ}$ $800^{\circ} \mathrm{C}$, crossing the solidus of a red clay (containing $15 \% \mathrm{H}_{2} \mathrm{O}$ ). Diamond powder, loaded above the starting sediment, traps fluid or melt generated during the $\sim 96-\mathrm{hr}$ experiment. After quench, diamonds and sediment residue are dissolved and analyzed separately in bulk by ICP-MS. Because both fluid solute and solid are recovered, mass balance for each element provides an independent estimate of the liquid fraction lost from the sediment (14-18\% from $600^{\circ}$ to $800^{\circ} \mathrm{C}$ ). Bulk partition coefficients $\left(\mathrm{D}=\mathrm{C}_{\text {residuc }} / \mathrm{C}_{\text {fluid }}\right.$ ) can also be calculated directly (mass balance again giving the fluid fraction present in the diamonds), without consideration of the individual contributions by numerous residual mineral phases (including cpx, gar, amph, musc, bio, mag, coes, ky, ap, fluid, and melt). Clear differences exist between $600^{\circ} \mathrm{C}$ and $800^{\circ} \mathrm{C}$. At $600^{\circ} \mathrm{C}$, below the solidus, only the alkalis, alkaline earths, and $\mathrm{Pb}$ are transported to the diamond trap (bulk $\mathrm{D}$ for $\mathrm{Rb}, \mathrm{Ba}, \mathrm{Be}$, and Th are $1.5,0.7,50$, and 100). Above the solidus, the sediment loses more LREE, $\mathrm{Be}, \mathrm{Th}$, and $\mathrm{Nb}\left(\mathrm{D}\right.$ at $800^{\circ} \mathrm{C}$ for $\mathrm{Rb}, \mathrm{Ba}, \mathrm{Be}$, and $\mathrm{Th}$ are 1.6, 1.6, 0.8, and 1.7). Thus, this 20-kbar experimental transect across the solidus suggests that mobilizing significant $\mathrm{Th}, \mathrm{Be}, \mathrm{Nd}$, and $\mathrm{Nb}$ from sediments in the slab may require temperatures in excess of the sediment solidus $\left(600^{\circ}-700^{\circ} \mathrm{C}\right)$.

References: [1] Zheng et al. (1994) ICOG, 8. [2] Plank and Langmuir (1993) Nature, 362, 739-743. [3] Plank and Langmuir (1992) Eos Trans. AGU, 73, 637. 
ARCHEAN ALUMINUM-DEPLETED KOMATIITES AND KOMATITIC BASALTS WITH MAJORITE-GARNET AND OCEAN-ISLAND-BASALT-LIKE TRACE-ELEMENT CHARACTERISTICS: RECYCLING OF OCEANIC LITHOSPHERE INTO DEEP MANTLE. A. Polat and R. Kerrich, Department of Geological Sciences, University of Saskatchewan, Saskatoon S7N 5E2, Canada (polat@pangea.usask.ca).

Aluminum-depleted komatiites with unusual incompatible-element-enriched signatures occur sporadically, together with abundant flat REE ocean plateau and REE-enriched arc-basalt sequences, in several greenstone belts of the 2.75-Ga Wawa Subprovince, Ontario, Canada. The komatiites ( $\mathrm{MgO}=28-30 \mathrm{wt} \%, \mathrm{Ni}=1540-$ $1820 \mathrm{ppm}$ ) are characterized by low $\mathrm{Al}_{2} \mathrm{O}_{3}$ and $\mathrm{Al}_{2} \mathrm{O}_{3} / \mathrm{TiO}_{2}$ (3-7) ratios, extremely high $\mathrm{Fe}_{2} \mathrm{O}_{3}(20-22 \mathrm{wt} \%)$, and fractionated REE $\left(\mathrm{La} / \mathrm{Sm}_{\mathrm{n}}=1.1-2.3, \mathrm{Gd} / \mathrm{Yb}_{\mathrm{n}}=2.2-2.9\right)$, in common with other early and late Archean Al-depleted komatiites. They also share variably negative $\mathrm{Zr}$ and $\mathrm{Hf}$ anomalies relative to MREE, consistent with residual majorite-garnet at depths of $300-600 \mathrm{~km}$, and $\mathrm{P} / \mathrm{Nd}_{\mathrm{n}}<1$.

However, these komatiites from the Wawa Subprovince are distinctive in terms of variable depletions of $\mathrm{Th}$ over $\mathrm{La}$ and $\mathrm{Ce}$, coupled with variably positive $\mathrm{Nb}$ anomalies $\left(\mathrm{Th} / \mathrm{La}_{\mathrm{n}}=0.6-0.85\right.$; $\mathrm{Nb} / \mathrm{La}_{\mathrm{n}}=1-3$ ). Other Al-depleted komatiites typically possess zero to negative $\mathrm{Nb}$ anomalies. Modem HIMU-OIB are distinctive in possessing positive anomalies of $\mathrm{Nb}$ relative to LILE and LREE stemming from preferential transfer of LILE and LREE relative to $\mathrm{Nb}$ from the subducting slab to the subarc wedge, and reactivation of the residual slab as a mantle plume. Accordingly, the Wawa Aldepleted komatiites are interpreted to have been derived from a compositionally heterogeneous mantle plume where melt segregated in the majorite stability field; mantle sources included a depleted component $\left(\mathrm{Th} / \mathrm{La}_{\mathrm{n}}<1, \mathrm{La} / \mathrm{Ce}_{\mathrm{n}}<1\right)$, and an enriched component $\left(\mathrm{Nb} / \mathrm{La}_{\mathrm{n}}>1\right)$ of oceanic crust processed through a subduction zone and recycled into the deep mantle.

\section{GEOCHEMICAL DIVERSITY OF ULTRAMAFIC AND MAFIC VOLCANIC ROCKS IN THE LATE ARCHEAN GREENSTONE BELTS, SUPERIOR PROVINCE, CANADA.} A. Polat, R. Kerrich, P. Hollings, and D. Wyman, Department of Geological Sciences, University of Saskatchewan, Saskatoon S7N 5E2, Canada (polat@pangea.usask.ca).

Late Archean (2.9-2.7 Ga) greenstone beits in the eastern Wawa Subprovince of the Superior Province, Canada, include a tectonic collage of greenschist to amphibolite facies ultramafic (komatiitic) to felsic volcanic and siliciclastic sedimentary rocks, multiply intruded by TTG plutons, that are interpreted as collages of oceanic plateaus and island arcs juxtaposed in a subduction-accretion complex.

Major- and trace-element characteristics of the komatiitic-topicritic and basaltic volcanic sequences are indicative of both heterogeneous mantle sources and diverse geodynamic tectonic settings. Four distictive compositional groups can be recognized. Group I ultramafic $(\mathrm{Mg}=18-24 \mathrm{wt} \%, \mathrm{Ni}=980-1000 \mathrm{ppm})$ and mafic volcanic rocks are characterized by LREE depletion, but with flat HREE, consistent with depleted mantle sources. Komatiites are relatively more depleted than basalts as expressed by lower $\mathrm{La} / \mathrm{Sm}_{n}$ in the former (0.54-0.64 vs. 0.58-0.90). Group I komatites are comparable to Al-undepleted Munro-type komatiites with near chodritic $\mathrm{Al}_{2} \mathrm{O}_{3} / \mathrm{TiO}_{2}(22-25)$ ratios. Basalts are comparable to modern $\mathrm{N}$-type MORB.

Group II komatiites ( $\mathrm{Mg}=20-22 \mathrm{wt} \%, \mathrm{Ni}=500-600 \mathrm{ppm})$ and associated tholeitic basalts are characterized by flat REE pattems with minor $\mathrm{Th}$ and $\mathrm{Nb}$ depletion, where $\mathrm{La} / \mathrm{Sm}_{\mathrm{n}}=0.95-1.1$, Th/ $\mathrm{La}_{\mathrm{n}}=0.75-0.95$, and $\mathrm{Nb} / \mathrm{La}_{\mathrm{n}}=0.8-0.9$, signifying a relatively undepleted mantle source. Group III komatiites ( $\mathrm{MgO}=14-32 \mathrm{wt} \%$, $\mathrm{Ni}=250-1800 \mathrm{ppm})$ and tholeitic basalts have similar REE patterns to Group II counterparts, but are depleted in $\mathrm{Nb}$ with respect to Th and $\mathrm{La}$, as indicated by $\mathrm{Th} / \mathrm{La}_{\mathrm{n}}=1.1-1.9$, and $\mathrm{Nb} / \mathrm{La}_{\mathrm{n}}=0.4-$ 0.8 . The depletion of $\mathrm{Nb}$ may reflect mantle residual mineralogy, or interaction and/or a mixture of mantle plume magmas with a $\mathrm{Nb}$ depleted recycled component.

Group IV ultramafic (18-22 wt\%, $\mathrm{Ni}=400-1000 \mathrm{ppm})$ and mafic volcanic rocks of the eastern Wawa Subprovince tend to occur toward the top of the stratigraphic sequence. They are characterized by moderately to significantly fractionated LREE patterns, where $\mathrm{La} / \mathrm{Sm}_{n}=1.5-3.8$, and moderate to large negative $\mathrm{Nb}$ and $\mathrm{Ti}$ anomalies $\left(\mathrm{Th} / \mathrm{La}_{\mathrm{n}}=0.9-2, \mathrm{Nb} / \mathrm{La}_{\mathrm{n}}=0.2-0.8 \mathrm{Ti} / \mathrm{Gd}_{\mathrm{n}}=0.3-0.9\right)$. The enrichment of Th and LREE with depletion of HFSE in Group IV volcanic rocks of the Wawa Subprovince are comparable to those of Phanerozoic magmatic arcs. Modem magmatic arc picrites may be analogs for Group V ultramafic volcanic rocks. Altematively, they may have been derived from the interaction of an arc and mantle plume.

Collectively, high-precision trace-element data obtained from a series of ultramafic to mafic volcanic sequences in the late Archean Wawa Subprovince reveal diverse mantle sources including depleted, undepleted, and enriched sources, and a variety of geodynamic settings including oceanic plateaus and island arcss. The diverse belts may have been amalgamated through subduction-accretion procesess similar to those of Phanerozoic accreted terranes.

\section{RUBIDIUM AND STRONTIUM ISOTOPES IN HYDRO- THERMAL MINERALS FROM IRON ORE DEPOSITS OF THE SIBERIAN PLATFORM AND SOME APPLICATIONS FOR AN INTERNAL ISOCHRON. A. G. Polozov, G. P. Sandimirova, and Yu. A. Pakhol'chenko, Institute of Geochemistry, SB Russian Academy of Sciences, P.O. Box 4019, Irkutsk 664033, Russia (poloz@igc.irkutsk.su; isotope@igc.irkutsk.su).}

Rubidium and $\mathrm{Sr}$ isotopes were studied in late, primarily $\mathrm{Ca}$ containing hydrothermal minerals (anorthite, diopside, garnet, orthoclase, epidote, amphibole, apatite, fluorite, celestite, calcite, anhydrite, and gypsum) from Fe ore deposits of the Siberian platform. The mineral sequence in various associations was determined from mineralogical research. The concentration of $\mathrm{Rb}$ varies from 0.1 to $85 \mathrm{ppm}$, Sr from 10 to $2800 \mathrm{ppm}$ (except celestite), and isotopic ratios of ${ }^{87} \mathrm{Rb} / 86 \mathrm{Sr}$ and ${ }^{87} \mathrm{Sr}_{\mathrm{r}} /{ }^{86} \mathrm{Sr}$ change from 0.0001 to 0.35 and from 0.70670 to 0.71406 correspondingly.

It was established that $\mathrm{Na}-\mathrm{K}$ silicates (orthoclase) are characterized by maximum $\mathrm{Rb}$ and $\mathrm{Sr}$ concentrations; $\mathrm{Ca}$ silicates (anorthite. diopside, garnet, epidote, and amphibole) contain average $\mathrm{Rb}$ concentration at wide $\mathrm{Sr}$ variations, and other minerals (apatite, fluorite, calcite, anhydrite, and gypsum) are characterized by minimum $\mathrm{Rb}$ concentration at wide $\mathrm{Sr}$ variation. This conclusion agrees well with the results of $\mathrm{Rb}-\mathrm{Sr}$ isotope study in minerals from the Khibine 
massif [1]

Analysis of diagrams (the "concentration-mineral sequence") has shown that, on the whole, $\mathrm{Rb}$ concentration in any mineral decreases toward the end of the process and the curve is wavy, which, in our opinion, is caused by the redistribution of $\mathrm{Rb}$ and $\mathrm{SI}$ between $\mathrm{Na}-\mathrm{K}$ silicates, $\mathrm{Ca}$ silicates, and other minerals, which form close to and/or simultaneously with each other.

Based on the analysis of "concentration-mineral sequence" diagrams and mineralogical occurrences, two groups of minerals, suitable for the construction of an intemal $\mathrm{Rb}-\mathrm{Sr}$ isochron, were revealed for drusy association of anorthite with diopside, orthoclase, epidote, and calcite. For a "late calcite-late diopside" pair the model age tumed out to be $167 \mathrm{Ma}$, and for the "two orthoclases-epidote" group the model age was revealed as $358 \mathrm{Ma}$. In the course of isotope dating of these orthoclases by the K/Ar method, ages of 284 and 362 Ma have been obtained, which coordinate with the calculated model age. Nevertheless, we consider the results as preliminary ones that can be applied to the thorough interpretation of $\mathrm{Rb}-\mathrm{Sr}$ isotopic data of hydrothermal minerals.

Acknowledgments: This work was supported by the Russian Foundation for Basic Research, grant 94-05-17362-a.

References: [1] Kramm et al. (1993).

SPECIATION OF IRON IN SUSPENDED SEDIMENTS FROM WORLD RIVERS. S. W. Poulton and R. Raiswell, Department of Earth Sciences, University of Leeds, Leeds, LS29JT, UK (poulton@earth.leeds.ac.uk; raiswell@earth.leeds.ac.uk).

The Fe content of sediments can be divided into three operationally-defined fractions: "highly reactive" (dithionite soluble; largely Fe oxyhydroxides), "poorly reactive" ( $\mathrm{HCl}$ soluble-dithionite soluble; some silicate $\mathrm{Fe}$ ), and "unreactive" (residual silicate Fe). These fractions relate to their potential to form pyrite upon exposure to dissolved sulfide in oceanic sediments. In order to quantify the proportions of the Fe fractions delivered to oceanic sediments, suspended river particulates (as the major source of Fe minerals to the oceans) from 60 world rivers have been analyzed. Existing data concerning 23 U.S. rivers [1] and the Amazon and Yukon [2] have been incorporated into the dataset, which currently represents approximately $15 \%$ of the world's sediment discharge to the oceans [3].

Plots of highly reactive $\mathrm{Fe}$ as a function of total Fe show a good linear relationship $(R=0.89$ ), which would appear to be applicable on a global scale, provided chemical weathering (as opposed to physical weathering) is the dominant weathering process. Glacial particulates contribute approximately $10 \%$ of the global sediment supply to the oceans, and therefore particulates from 35 glacial meltwaters have been analyzed. Highly reactive Fe contents are low $(<1 \mathrm{wt} \% \mathrm{Fe}$ ) and show little tendency to covary with total Fe, observations that are readily explained by the dominance of physical weathering in the glacial environment.

By weighting the river data for sediment discharge and combining this with a $10 \%$ glacial flux, a global highly reactive:total Fe ratio of 0.40 is obtained for particulates discharged to the oceans. Recent coastal marine and deep-sea sediments deposited in well oxygenated bottom waters and sampled from various localities, at depths of $0-400 \mathrm{~cm}$ (representing ages of $1-3000 \mathrm{yr}$ ), have averaged ratios of poorly reactive and unreactive Fe to total Fe that are comparable to those in the river particulates. However, there would appear to be a substantial loss of highly reactive Fe(Fe oxyhydroxides + pyrite $\mathrm{Fe}$ ) relative to total $\mathrm{Fe}$ in the marine sediments (marine ratio $=0.27 \pm 0.09$ ).

The behavior of $\mathrm{Fe}$ in the estuarine environment may provide an explanation for the lower highly reactive Fe contents of oceanic sediments. The coagulation of fine-grained, organic-rich particles (which transport considerably more highly reactive Fe relative to coarser particles) may lead to preferential settling of these particles in the estuarine environment. However, fine-grained flocs tend to have low densities, and may therefore actually have increased residence times in coastal waters, relative to coarser inorganic particles. Both of these mechanisms could result in a loss of highly reactive $\mathrm{Fe}$ in oceanic sediments, relative to current riverine inputs. In addition, more detailed analysis of marine sediments suggests that the highly reactive:total Fe ratio decreases with increasing depth and sediment age, attributable to enhanced chemical weathering as a direct result of anthropogenic effects (primarily deforestation) in younger sediments. However, even surface sediments are depleted in highly reactive Fe relative to riverine inputs. If correct, this finding may have important implications for primary productivity (and possibly $\mathrm{CO}_{2}$ drawdown) in the oceans. Iron has been shown to limit phytoplankton growth, and much of the Fe present in the highly reactive fraction of suspended sediments may become available for phytoplankton uptake [4].

The glacial data provide additional information with regard to the estimated two- to three-fold increase in primary productivity during the last glacial period [5]. This increase has been attributed to an increase (by a factor of 10-20) in sediment supply (as atmospheric glacial dust) to the polar seas, and has been cited as a possible explanation for lower glacial atmospheric $\mathrm{CO}_{2}$ levels. The concentrations of highly reactive Fe transported by rivers and glacial meltwaters are $2.25 \mathrm{wt} \%$ and $0.46 \mathrm{wt} \%$ respectively. Therefore, an increase in sediment supply by a factor of 15 would result in a factor of 3 increase in the delivery of highly reactive Fe to the polar seas, which is consistent with the estimated increase in primary productivity during the last glaciation.

References: [1] Canfield D. E., in preparation. [2] Gibbs R. J. (1967) Geol. Soc. Am. Bull., 88, 829-843. [3] Milliman J. D. and Syvitski P. M. (1992) J. Geol., 100, 525-544. [4] Martin J. H. et al. (1994) Nature, 371, 123-129. [5] Martin J. H. and Fitzwater S. E. (1988) Nature, 331, 341-343.

GENERATION OF HAWAI'IAN THOLEITES AT ABOUT 5 GPa FROM A CARBONATED GARNET LHERZOLITE MANTLE. D. C. Presnall, Y.-H. Weng, and J. A. Dalton, Magmalogy Laboratory, Department of Geosciences, University of Texas at Dallas, Richardson TX 75083-0688, USA (presnall@ utdallas.edu).

Rare earth element (REE) data require that Hawai'ian tholeiites are generated from a source that contains gamet, and for conventional assumptions about REE concentrations in the source, the amount of melting would be small $(<10 \%)$. In contrast, experimental data are consistent with generation of parental magmas in the spinel lherzolite field, and in this case, a large amount of melting $(\sim 30 \%)$ is required. We develop a new model based on pistoncylinder and multianvil phase-equilibrium data for melting of model 
lherzolite in the systems $\mathrm{CaO}-\mathrm{MgO}-\mathrm{Al}_{2} \mathrm{O}_{3}-\mathrm{SiO}_{2}$ (CMAS) up to $5 \mathrm{GPa}, \mathrm{CMAS}-\mathrm{Na}_{2} \mathrm{O}$ (CMASN) up to $3.5 \mathrm{GPa}, \mathrm{CMAS}-\mathrm{FeO}$ (CMASF) up to $2.8 \mathrm{GPa}$, and $\mathrm{CMAS}-\mathrm{CO}_{2}$ (CMASC) at $6 \mathrm{GPa}$ that reconciles this disagreement. By combining the CMAS data at $5 \mathrm{GPa}$ with an extrapolation of CMASN data to this same pressure, we find that a suitable parental magma containing, by weight, 18$21 \% \mathrm{MgO}, \sim 1.5 \% \mathrm{Na}_{2} \mathrm{O}$, and $\mathrm{CaO} / \mathrm{Al}_{2} \mathrm{O}_{3} \approx 0.8$ can be produced either as an initial or low melt-fraction liquid in equilibrium with olivine, diopside, enstatite, and gamet in the CMASN system. On the basis of extrapolation from lower-pressure data on melting of model lherzolite in CMASF, FeO is not expected to change these phase relations significantly. In apparent conflict with this model, several studies have found that enstatite is absent from the solidus of fertile, $\mathrm{CO}_{2}$-free peridotite at $5 \mathrm{GPa}$ due to narrowing of the pyroxene solvus as temperature increases. Under these conditions, low melt-fraction liquids are too low in normative enstatite to be parental to Hawai'ian tholeiites. However, the effect of $\mathrm{CO}_{2}$ on melting behavior of peridotite at high pressures is dramatic, an effect that occurs even for the very low $\mathrm{CO}_{2}$ concentrations of about 0.02-0.1 wt\% likely for the upper mantle. In CMASC at $6 \mathrm{GPa}$, the model carbonated lherzolite solidus ( $\mathrm{ol}+\mathrm{en}+\mathrm{di}+\mathrm{gt}+\mathrm{mag}+$ liquid) is $\sim 550^{\circ} \mathrm{C}$ lower than the model lherzolite solidus $(\mathrm{ol}+\mathrm{en}+\mathrm{di}+\mathrm{gt}$ + liquid) in the $\mathrm{CO}_{2}$-free CMAS system, and the solidus melt is carbonatitic. As temperature rises isobarically toward the $\mathrm{CO}_{2}$-free solidus, the composition of the melt changes rapidly toward that of the $\mathrm{CO}_{2}$-free solidus melt (model picritic basalt) and is essentially identical to it at temperatures within $150^{\circ} \mathrm{C}$ of the CMAS solidus. For a carbonated gamet peridotite, generation of a melt $150^{\circ} \mathrm{C}$ below the $\mathrm{CO}_{2}$-free solidus at $5 \mathrm{GPa}$ would occur in the presence of enstatite because of a widened pyroxene solvus, and the liquid composition in equilibrium with gamet lherzolite at this lowered temperature would be essentially the same as that in equilibrium with ol, en, di, and gt in the $\mathrm{CO}_{2}$-free system. Thus, we find that the phase relations are consistent with generation of a suitable tholeiitic parental magma from a carbonated garnet lherzolite in a pressure range centered at about $5 \mathrm{GPa}(\sim 150 \mathrm{~km}$ depth), at small melt percentages, and at temperatures as much as $150^{\circ} \mathrm{C}$ below that of the $\mathrm{CO}_{2}$-free solidus.

\section{TRACE ELEMENTS IN RESIDUAL AND SEDIMENTARY} DEPOSITS OF KAOLINS FROM MINHO (NORTHWESTERN PORTUGAL). M. I. Prudêncio', M. A. Gouveia', and M. A. Sequeira Braga'2, 'Instituto Tecnológicoe Nuclear, Estrada Nacional 10, 2685 Sacavém, Portugal, 2Universidade do Minho, 4719 Braga, Portugal.

Residual and sedimentary deposits of kaolins exploited nowadays from the northwestem part of Portugal (Cavado River Basin and Alvaraes Basin) were studied. Mineralogical and chemical analyses of whole samples and the respective $<2-\mu \mathrm{m}$ fractions were made by $X$-ray diffraction and instrumental neutron activation analysis, with a view to characterizing and differentiating both types of kaolin deposits.

The residual kaolins are in general richer in $\mathrm{K}, \mathrm{Rb}$, and $\mathrm{Cs}$, which is in agreement with higher proportions of alkali feldspars and micas. The sedimentary kaolines are richer in clay minerals, with a high content of kaolinite, which is associated with higher concentrations of trace elements namely rare earth elements (REE), $\mathrm{Sc}, \mathrm{Cr}$,
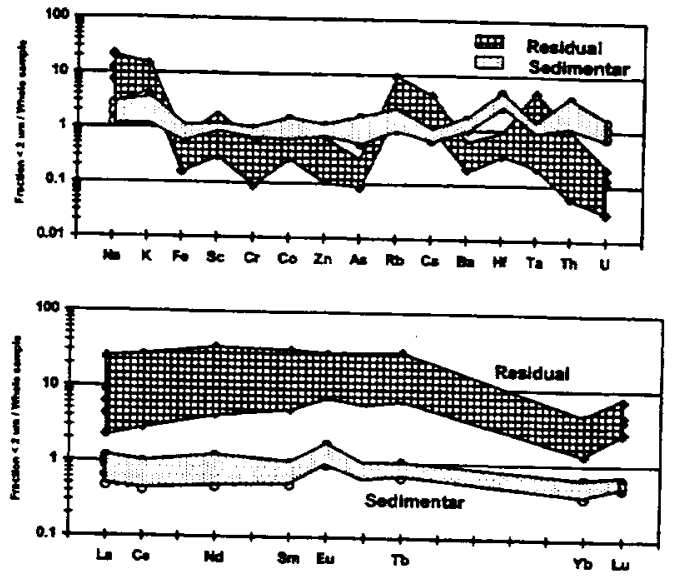

Fig. 1. Distribution of chemical elements in the $<2-\mu \mathrm{m}$ fraction relative to the respective whole samples in residual and sedimentary kaolin deposits.

Co, and Th.

The distribution of the elements analyzed in the $<2-\mu \mathrm{m}$ fraction relative to the whole samples is significantly different in the two types of deposits (Fig. 1). In general the elements are more uniformly distributed in the fine fraction of the sedimentary deposits. The REE are enriched in the residule deposits with a relative concentration of the intermediate REE, while Eu is concentrated during the sedimentary processes.

\section{LASER PROBE OXYGEN ISOTOPE STUDIES OF META- GABBROIC MINERALS: TRACERS OF FLUID-ROCK} EXCHANGE IN OROGENESIS. B. Putlitz' A. Matthews ${ }^{\prime}$, J. W. Valley', and Y. Katzir', 'Institute of Earth Sciences, Hebrew University of Jenusalem, 91904 Jerusalem. Israel (benita@vms. huji.ac.il), ${ }^{2}$ Department of Geology and Geophysics, University of Wisconsin-Madison, Madison WI 53706, USA.

Oxygen isotope studies of gabbroic rocks have largely focused on oceanic varieties. The isotopic record, based on sampling from the present-day sea floor and from intact ophiolite sequences, shows that gabbros typically have MORB-type $\delta^{18} \mathrm{O}$ values, or lower values indicative of high-temperature exchange with seawater. Such gabbros may also find themselves incorporated within orogens, either as subducted high-pressure metamorphic rocks or as higherlevel metamorphozed ophiolite sequences that escaped subduction. The coarse-grained nature of gabbroic rocks frequently dictates that they exhibit polyphase mineral growth textures. Thus, potentially. isotopic studies of the different mineral generations can provide important data on the fluid-rock interactions occurring during orogenesis. However, texturally these rocks are often very complex and characterized by intimately intergrown mineralogical domains. The $\mathrm{CO}_{2}$ Laser Probe method with its ability to analyze submilligram size samples is an excellent tool to examine such rocks when combined with hand-picking of minerals from petrographically characterized specimens.

This study examines $O$ isotope compositions of minerals of metagabbros in the Tertiary Alpine orogen of the Cyclades islands of Greece:

Syros. Metagabbroic blocks up to $1 \mathrm{~km}$ wide developed the 
eclogite-facies assemblage glaucophane + gamet + omphacite + epidote. Oxygen isotope compositions mostly fall either in the MORB range or lower $\left(\delta^{18} \mathrm{O}\right.$ gamet $=2.54$ to $5.48 \% 0^{;} \delta^{18} \mathrm{O}$ glaucophane $=4.25-6.94 \%$ ) . Fractionations among the HP minerals are consistent with isotopic equilibrium (the uncalibrated glaucophane-gamet pair showing a fractionation of $1.46 \pm 0.15 \%$ at $\sim 500^{\circ} \mathrm{C}$ ). Relict actinolite (presumed to have formed during seafloor alteration and overgrown by HP minerals) is $4.01-5.42 \%$, i.e., within the range of the HP minerals.

Tinos. Metagabbroic rocks comprising the ophiolitic "Upper tectonic unit" of the Cyclades consist of both massive gabbros and meter-sized boulders. Sequentially formed mineral generations include augite (relict igneous), patchy brown and green hormblende (high-temperature sea-floor alteration), and actinolite/tremolite + plagioclase (regional greenschist metamorphism). Representative isotopic results are shown in Fig. 1. Relict igneous augite shows $\delta^{18} \mathrm{O}$ values of $4.27-5.64 \%$ and the brown homblende $5.36-7.43 \%$, i.e., in the general MORB range. The regional greenschist mineral generation shows significant differences: actinolite/tremolite in the massive gabbroic varieties has $\delta^{18} \mathrm{O}$ values close to but slightly above the homblende, whereas in gabbroic boulders it shows significant disequilibrium enrichments with respect to the earlier minerals. Plagioclase (albite) in the gabbroic boulders has high $\delta^{18} \mathrm{O}$ values of $15 \%$. The host rocks enclosing the boulders are ${ }^{18} \mathrm{O}$ enriched metabasaltic rocks with $\delta^{18} O$ values of $11-14 \%$.

The isotopic results testify to the ability of the gabbroic rocks to record their fluid-rock interaction history and to the scale of these interactions. The eclogitic gabbros and massive gabbros show compositions reflecting both primary igneous MORB values and hightemperature sea-floor alteration. These compositions are inherited by subsequent mineral generations, thus implying low fluid-rock ratios during metamorphism. In contrast, the gabbro boulders on Tinos show that the metamorphic overprint occurred in the presence of high- $\delta^{18} \mathrm{O}$ fluids $(\sim 12-13 \%$ based on the albite-water fractionation at $400^{\circ} \mathrm{C}$ ). These enrichments imply meter-scale (or less) exchange with fluids derived from the host rocks, at high water-rock ratios. The driving force for isotopic exchange is the mineral growth.

The high-temperature sea-floor alteration $\delta^{18} \mathrm{O}$ values in the metagabbroic rocks contrast with low-temperature ( ${ }^{18} \mathrm{O}$-eniriched)

\section{TINOS OPHIOLITE}

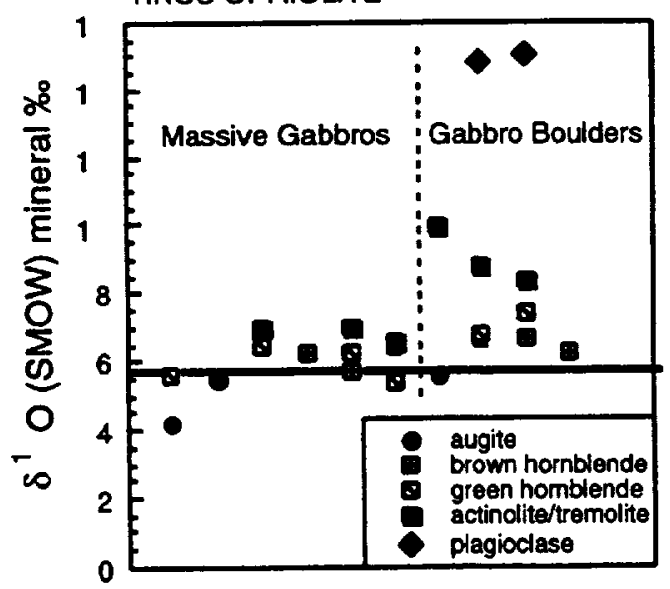

Fig. 1. alteration signatures typically found in orogenic metabasalts

THE THERMODYNAMICS AND KINETICS OF THE CRYSTALLIZATION OF SOLID SOLUTIONS FROM AQUEOUS SOLUTIONS: IMPLICATIONS FOR TRACEELEMENT SORPTION. A. Putnis' ${ }^{1}$, M. Prieto ${ }^{2}$, A. FemándezGonzález ${ }^{2}$, and L. Fernández-Diaz ${ }^{3}$, 'Institut für Mineralogie, Universität Münster, 48149 Münster, Germany, ${ }^{2}$ Departamento de Geologia, Universidad de Oviedo, 33005 Oviedo, Spain, '3epartamento de Cristalogografia y Mineralogía, Universidad, Complutense, 28040 Madrid, Spain.

When a solid solution crystallizes from an aqueous solution the composition of the crystalline phase in equilibrium with the aqueous solution is described by a Lippmann diagram $[1,2]$. The same theory applies to the sorption of a minor element that forms a solid solution with a growing crystal, but this is rarely considered in the growing geochemical literature on sorption processes. For example, in the crystallization of a solid solution such as $(\mathrm{Ca}, \mathrm{Cd}) \mathrm{CO}_{3}$ it is not sufficient to consider only the endmember solubilities nor to describe the equilibrium by a single equilibrium partitioning constant for the reaction $\mathrm{CaCO}_{3}+\mathrm{Cd}^{2}+\mathrm{pCdCO}_{3}+\mathrm{Ca}^{2+}$ because it does not include the solubility of the solid solution. In fact an aqueous solution that is saturated with respect to one end member but undersaturated with respect to the other may still be supersaturated with respect to intermediate compositions. This has important implications for the thermodynamic treatment of problems of traceelement sorption and for the discussion of whether the uptake process is by adsorption or by precipitation. The relevant thermodynamic theory will be briefly reviewed and the supersaturation function for solid-solution aqueous solution systems defined.

Supersaturation is not in itself a sufficient criterion for precipitation of a solid solution to occur. The supersaturation at which various crystal growth mechanisms occur at measurable rates (nucleation within the fluid phase, two-dimensional nucleation on the mineral surface, or step growth) depends in part on the solubility of the specific solid-solution composition. When the solubility is low, an aqueous solution may have to be appreciably supersaturated for precipitation to take place, while other sorption processes that are not kinetically difficult may still be possible. Furthermore, in a solid solution where the two end members differ widely in solubility, the composition of the phase that precipitates is not necessarily that for which the supersaturation is greatest.

We report experimental observations of the crystal growth of various solid solutions from aqueous solutions. The effect of differing endmember solubilities on the solid-solution compositions will be described. In systems where the end members differ greatly in solubility, crystallization is "bimodal," i.e., intermediate compositions do not occur and the solid changes composition vary markedly in response to very small changes in the composition of the aqueous solution. When the local composition of the fluid phase changes due to diffusion control, phenomena such as oscillatory zoning result. This is demonstrated by the systems $(\mathrm{Ca}, \mathrm{Cd}) \mathrm{CO}_{3}$ and $(\mathrm{Ba}, \mathrm{Sr}) \mathrm{SO}_{4}$. This is not the case when the end members have a similar solubility, such as in $(\mathrm{Ba}, \mathrm{Sr}) \mathrm{CO}_{3}$ and $\mathrm{Ba}\left(\mathrm{SO}_{4}, \mathrm{CrO}_{4}\right)$.

References: [1] Lippmann F. (1980) N. Jb. Mineral. Abh., 139, 1-25. [2] Glynn P. D. and Reardon E. J. (1990) Amer. J. Sci., $290,164-201$. 
CARBON SEQUESTRATION UNDER CHAPARRAL AND PINE AFTER FOUR DECADES OF SOIL DEVELOPMENT. S. A. Quideau', O. A. Chadwick², R. C. Graham!, and M. A. Anderson', 'Department of Soil and Environmental Sciences, University of California, Riverside CA 92521, USA, 'Department of Geography, University of California, Santa Barbara CA 93106 , USA.

After four decades of soil development, organic $C$ sequestration in chaparral and pine lysimeters at the San Dimas Experimental Forest in southem Califomia ranges from 45.6 to $175.6 \mathrm{Mg} \mathrm{ha}^{-1}$. Carbon accumulation in the mineral soils $(0-1 \mathrm{~m})$ under chaparral vegetation represents a larger percentage of the total ecosystem accretion $(20 \%)$ as compared to the pine $(11 \%)$. In the surface horizons, $\mathrm{C}$ sequestration is related to earthworm activity, which is intense under scrub oak, but absent under pine. The lysimeter installation allows us to quantify the effects of vegetation on $O C$ sequestration as all other environmental factors (i.e., climate, topography, parent material, and time) are kept constant. Each of the lysimeters was filled in 1937 with a homogenized parent material (fine sandy loam) and planted in 1946 with monocultures of native woody species: chamise (Adenostoma fasciculatum Hook. and Am.), hoaryleaf ceanothus (Ceanothus crassifolius Torr.), scrub oak (Quercus dumosa Nutt.) and Coulter pine (Pinus coulteri B. Don). Solid-state cross-polarization magic angle spinning (CPMAS) ${ }^{13} \mathrm{C}$ NMR spectroscopy was used to characterize $O C$ in samples with increasing degree of humification: litter, light fraction (rapid tumover rate), and silt- and clay-sized separates (longer turnover rate). Under chaparral, a greater proportion of total soil OC is recovered in the light fraction than under the pine. The carbohydrate content (i.e., O-alkyl C) decreases with increasing degree of humification, while the concentrations of alkyl and carbonyl $C$ increase. Chemical changes between the litter and light fraction are less pronounced under chaparral than under pine vegetation. Additionally, the $\mathrm{C} / \mathrm{N}$ ratio of sand-sized organic matter is higher under chaparral than under pine. This is indicative of fresh plant residues that may not contribute to the long-term OC sequestration in soils.

\section{A NEW MODEL INVOKING SORET EFFECT FOR THE ORIGIN OF IRON-TITANIUM OXIDE DEPOSITS AS-} SOCIATED WITH THE PROTEROZOIC ANORTHOSITES. A. S. P. Rao ${ }^{1,2}$ and K. Srinivas ${ }^{3},{ }^{1}$ Department of Geology, Osmania University, Hyderabad 500 007, India, 2B5, Ravi Apartments, Saroornagar, Huda Complex, Hyderabad 500 035, India (address for correspondence), ${ }^{3}$ Department of Geology, Kakatiya University, Warangal 500009 , India.

The authors propose that Fe-Ti oxide deposits that occur in association with a large number of Proterozoic anorthosite massifs are due to Soret diffusion of Fe, Ti, and P from the magma toward the cold margins of the massifs. Soret effect has geologically observable magnitude [1]. Iron-rich dioritic rocks (Jotunites and monzonorites) occur widely in association with anorthosite massifs as small bodies along the margins of anorthosite. Iron-rich dioritic rocks have chemical compositions that are typically high in $\mathrm{Fe}, \mathrm{Ti}$, and $P$ [2]. The Fe-rich dioritic rocks, in view of (1) their restricted occurrence at or near the margins of the massifs, (2) the systematic increase in mafic silicates and oxides from coarse core-zone an- orthosite to finer-grained border zone [3], (3) older crystallization ages of dioritic rocks than the core anorthosite, and (4) the absence of negative Eu anomalies in the dioritic rocks, are considered as products of Soret effect (diffusion of $\mathrm{Fe}, \mathrm{Ti}, \mathrm{Mg}$, and Ca toward cold margins of deep-seated magmatic intrusion). The cold margins of magma got enriched in $\mathrm{Fe}, \mathrm{Ti}, \mathrm{P}, \mathrm{Mg}$, and $\mathrm{Ca}$ due to Soret diffusion while the core portion got depleted in these same elements. The FeTi oxide, deposits that occur as conformable layers within the Ferich gabbroic or dioritic rocks, are considered as cumulates from the Fe-Ti-rich liquids formed at or near the cold margins of massif by Soret diffusion of $\mathrm{Fe}-\mathrm{Ti}$ (reminiscent of liquid immiscibility), and the massive cross-cutting ore bodies in the host anorthosite are due to collision, coalescence, and settling of droplets of high-density FeTi oxide liquid from the Fe-Ti-rich dioritic magma formed due to Soret diffusion as the roof of the magmatic intrusion.

The domical massifs have been unroofed exposing the $\mathrm{Fe}-\mathrm{Ti}$ rich dioritic rocks at the margins of the massifs and the massive, cross-cutting ore bodies in the host anorthosite massif. This model explains the paucity or absence of apatite in the massive ore bodies and its abundance in the nelsonites, and derives support from the fact that immiscibile magnetite-apatite melts were not formed in the case of such intrusions such as the Skaergaard and Bushveld where there has been extreme $\mathrm{Fe}$ enrichment during differentiation and also explains why the important magmatic ilmenite (one of the earliest constituents of magma to crystallize) deposits, as a rule, occur in rocks rich in Opx rather than in olivine.

References: [1] Hildreth W. (1979) GSA Spec. Pap., 180, 4375. [2] Wiebe R. A. (1992) in Proterozoic Crustal Evolution, K. C. Condie, ed.), 215-261, Elsevier, Amsterdam. [3] Ashwal L. D. (1982) Am. Min., 67, 14-27.

\section{A NEW TECTONIC AND PETROLOGIC MODEL FOR THE ORIGIN OF THE PROTEROZOIC ANORTHOSITES. A. S. P. Rao ${ }^{1.2}$ and K. Srinivas ${ }^{3},{ }^{1}$ Department of Geology, Osmania University, Hyderabad 500007 , India, ${ }^{2} \mathrm{~B} 5$, Ravi Apartments, Saroornagar, Huda Complex, Hyderabad 500 035, India (address for correspondence), ${ }^{3}$ Department of Geology, Kakatiya University, Warangal 500009 , India.}

The origin of Proterozoic anorthositic massifs is not yet completely understood. We have, therefore, reinterpreted the experimental phase equilibria studies, the isotopic ( $\varepsilon_{\mathrm{Nd}}$ values and $\mathrm{Sr}$ ratios) and geochemical (Xmg and $\mathrm{Rb}$ values), characteristics, and field data [absence of coeval mafics, concentric mafic borders and the associated orthopyroxene megacrysts (OPMS) in massifs, and variable depth of emplacement of anorthositic rocks] of the anorthosites, along with the experimental evidence for the production of feldspathic magmas by partial melting of basalt under anhydrous and hydrous conditions, and propose that anorthositic rocks form from hydrous magma formed above low-angle subduction zones by partial melting of amphibolite under high water pressure $(\sim 5 \mathrm{kbar})$ and temperature $\left(\sim 1200^{\circ} \mathrm{C}\right)$. The strong Fe-enrichment trend characteristic of most anorthositic suites, believed to be the strongest evidence for anhydrous magmas, is ascribed to Soret effect, which has geologically observable magnitude [1]. The distinctive intermediate plagioclase composition characteristic of anorthositic, massifs is attributed to Soret diffusion of Ca toward cold margins (plagioclase from margins is more calcic) from the magma after its em- 
placement. It is further argued, in view of the low and high initial ${ }^{87} \mathrm{Sr} /{ }^{86} \mathrm{Sr}$ ratios for the Labrador and for the Grenville anorthosites respectively, that least-altered and highly altered depleted mantle (i.e., basalt to spilite leading to the introduction of $\mathrm{H}_{2} \mathrm{O}$ and $\mathrm{Na}_{2} \mathrm{O}$, the decrease of $\mathrm{CaO}$, and absorption of $\mathrm{Sr}$ and $\mathrm{K}$ from the seawater) by partial melting under hydrous conditions produced magmas parental to the Labrador layered type and the Grenville/Rogaland (massif) anorthosites respectively. The magmatic melts thus generated ascend through crust driven by the push and buoyancy of the melts. Orthopyroxene as a primary phase (in fact, Opx was not produced at $5 \mathrm{kbar}$ in the experiment [2]) instead of forsteritic olivine crystallized due to the escape of water from the magma during its ascent [3] to higher levels, and much of the early-formed orthopyroxene ( $\mathrm{Mg}$-rich) could not reach the site of emplacement due to "lag effect," thereby producing hyperfeldspathic magmas and, due to slow cooling in volatile-rich magma at the site of emplacement, the OPMs with calcic plagioclase lamellae grew. Lag effect coupled with Soret effect was responsible for the production of orthopyroxene-bearing andesine-rich anorthosites with OPMs. Magmas in central Labrador, on the other hand, which formed leucotroctolites, lost water due to exsolution of $\mathrm{H}_{2} \mathrm{O}$ from the magmas [4] at about $3 \mathrm{kbar}$ pressure (corresponding to a depth of $10-$ $13 \mathrm{~km}$ ) and reached their solidus, crystallized, and were emplaced at shallow depths. Soret differentiation (i.e., the simultaneous diffusion of $\mathrm{Fe}, \mathrm{Ti}, \mathrm{P}, \mathrm{Ca}$, and $\mathrm{Mg}$ toward the cold margins of a pluton and the concentration of $\mathrm{Si}, \mathrm{Al}, \mathrm{Na}$, and $\mathrm{K}$ in the hot central region) of magma, especially after its emplacement, played a very crucial role, prior to the normal crystallization of the hyperfeldspathic magma, in the genesis of the concentric border gabbroic zone and the associated ferrodiorites, and also led to modification of the magma composition (hyperfeldspathic) producing the orthopyroxene-bearing anorthositic massifs, besides the strong Fe-enrichment trend and the associated Fe-Ti oxide deposits. The ferrodioritic rocks are early products of Soret differentiation of feldspathic magma. The occurrence of OPMs + clinopyroxene megacrysts (CPMs) with calcic-plagioclase lamellae only in andesine-type anorthosite massifs clearly provides irrefutable evidence regarding their role in producing andesine-type anorthosites. The En-An paradox, $\mathrm{Sr} / \mathrm{Ca}$ ratio puzzle, high $\mathrm{Rb}$ values, low augite content and lack of inverse relation between $\mathrm{Sr}$ and $\mathrm{Ca}$, the characteristic concentric mafic border zones and ferrodiorites bodering the massive anorthositicrich cores, and the variable depth of emplacement of anorthosites are attributed to Soret diffusion and to the thermodynamics of crystallization of anorthositic magmas. We conclude that all the characteristics of anorthositic massifs are consistent with the origin and evolution of anorthositic massifs from hydrous feldspathic magma generated above low-angle subduction zones involving overprinting of normal crystallization trend with Soret fractionation effects (reminiscent of liquid immiscibility).

References: [1] Hildreth W. (1979) GSA Spec. Paper, 180, 43-75. [2] Vander Auwera J. and Longhi J. (1994) Contrib. Mineral. Petrol., 118, 60-78. [3] Kushiro I. (1969) AJS, 267-A, 269294. [4] Cann J. R. (1970) Geol. Mag., 107, 335-340.

TRACE-ELEMENT CHARACTERISTICS OF PRISTINE AND MANTLE-HYBRIDIZED SLAB MELTS: IMPLICATIONS FOR THE PETROGENESIS OF ADAKITE AND HIGH-MAGNESIUM ANDESITE. R. P. Rapp ${ }^{1}$ and N. Shimizu ${ }^{2},{ }^{1}$ Mineral Physics Institute and Center for High Pressure
Research, Department of Earth and Space Sciences, State University of New York, Stony Brook NY 11794, USA (rapp@sbmp04.ess. sunysb.edu), ${ }^{2}$ Woods Hole Oceanographic Institute, Woods Hole MA, USA.

There is ample geochemical evidence to indicate that under unusual circumstances, basaltic oceanic crust partially melts during subduction. The evidence ranges from hydrous-dacitic melt inclusions [1] and trondhjemitic veins [2] in peridotite xenoliths from the subarc mantle wedge, to adakite arc magmas that appear to represent relatively pristine melts of subducted oceanic crust [3]. Slab melts have also been implicated as the agent of metasomatic enrichment in the mantle source region for high-Mg andesites (HMA) [4]. These examples suggest that slab melting and interaction of adakite magmas with the overlying mantle wedge produce a continuum of effects, with "pristine" slab melts (adakite arc magmas) at one end, and metasomatic enrichment of the mantle source region for HMA (and K-rich arc magmas in general [5]) at the other. The hybridized products of adakite magma-mantle peridotite interaction should range somewhere between these extremes. Criteria that distinguish "pristine" slab melts, hybridized slab melts, and melts of adakitemetasomatized mantle are useful in gauging the relative importance of slab vs. mantle wedge sources for arc magmatism in "hot" subduction zones.

We have measured by ion microprobe the abundances of a range of trace elements (REEs, Y, Sr, $\mathrm{Zr}, \mathrm{Ti}, \mathrm{V}, \mathrm{Cr}$ ) in partial melts of several MORB-like amphibolitized basalts at $1-4 \mathrm{GPa}$ in order to broadly constrain the nature of pristine adakite melts coming off the slab. Experimental adakite liquids up to $4 \mathrm{GPa}$ have $\mathrm{Mg}<45$, high $\mathrm{Sr} / \mathrm{Y}, \mathrm{La} / \mathrm{Yb}$, and $\mathrm{Sr} / \mathrm{Nd}$ ratios, are strongly depleted in $\mathrm{Y}$ and heavyREE, and coexist with eclogitic residues. To assess the effects of the initial encounter between these "slab melts" and overlying mantle peridotite, we conducted a series of multi-anvil experiments at 3.5$4.0 \mathrm{GPa}$ in which adakite melts from the basalt source infiltrate and react with an overlying layer of either primitive or depleted peridotite. Hybridization of the slab melt produces high-Mg adakite liquids $(\mathrm{Mg}=52-55$ ), and higher abundances of REEs (i.e., $\mathrm{Ce}=1.5-2.0 \times$; $\mathrm{Nd}=1.5-1.9 x ;$ and $\mathrm{Yb}=1.5-2.3 \times$ pristine slab melt $)$ and $\mathrm{Cr}(2-3 x$ pristine slab melt), but little change in overall trace element patterns or element ratios (e.g., Sr/Y, La/Yb, K/La, St/Nd). Phases present in the reaction zone include pyrope-rich garnet and orthopyroxene, and phengitic mica when $<10 \%$ depleted peridotite is assimilated.

When trace-element characteristics of adakite and HMA are compared to those of the pristine and mantle-hybridized slab melts produced experimentally, it becomes clear that a full continuum exists from low- $\mathrm{Mg}(\mathrm{Mg}<45)$ adakites comparable to pristine slab melts to transitional adakites $(\mathrm{Mg}=45-55)$ that resemble mantlehybridized slab melts to HMA (Mg > 55) that can reasonably be interpreted as the product of melting of adakite-metasomatized mantle.

References: [1] Schiano P. et al. (1995) Nature, 377, 595. [2] Kepezhinskas et al. (1995) J. Petrology, 36, 1505. [3] Defant M. J. and Drummond M. S. (1990) Nature, 347, 662. [4] Yogodzinski et al. (1995) Bull. Geol. Soc. Amer., 107, 505. [5] Stolz A. J. et al. (1996) Geology, 24, 587.

VARIATIONS IN NIOBIUM/TANTALUM RATIOS BETWEEN CALCALKALINE AND HIGH-NIOBIUM BASALTS FROM COSTA RICA: IMPLICATIONS FOR THE 
PRESENCE OF RUTILE IN ARC MAGMA SOURCES. M. K. Reagan ${ }^{1}$ and T. A. Plank ${ }^{2}$, 'Department of Geology, University of Iowa, Iowa City IA 52242-1379, USA, ${ }^{2}$ Department of Geology, 120 Lindley Hall, University of Kansas, Lawrence KS 66045-2124, USA.

Turrialba volcano, the southeasternmost volcano in the Central American arc, has periodically erupted high-K calcalkaline basalts (CAB) together with volumetrically minor basalts with unusually high Nb concentrations. Turrialba's $\mathrm{CAB}$ and high-Nb basalts (HNB) have some compositional characteristics in common. For example, both have relatively high incompatible trace-element abundances (e.g., Th ppm = 4.7-5.0 ppm; La ppm = 31-42), and both have strongly enriched REE pattems $(\mathrm{La} / \mathrm{Yb}=18-24)$. Potassium/rubidium ratios are similar to each other and those of ocean island basalts (OIB). Baryium/rubidium ratios for both (18-20) are higher than those of most OIB, but are within the range of reported values for OIB from Pacific islands. However, the HNB and CAB differ in other geochemical characteristics. The $\mathrm{HNB}$ have $\mathrm{Ba} / \mathrm{La}=13, \mathrm{La}$ $\mathrm{Nb}=1.0$, and $\mathrm{Ce} / \mathrm{Pb}=27$, which are typical values for OIB, whereas the $\mathrm{CAB}$ have $\mathrm{Ba} / \mathrm{La}=16-21, \mathrm{La} / \mathrm{Nb}=2.0$, and $\mathrm{Ce} / \mathrm{Pb}=18$, which are common values for high- $\mathrm{K}$ calcalkaline basalts from other volcanic arcs. In addition, $\mathrm{Nb} / \mathrm{Ta}$ ratios for the $\mathrm{HNB}$ are chondritic and typical of OIB (17.7), whereas the $\mathrm{Nb} / \mathrm{Ta}$ values for $\mathrm{CAB}$ are significantly higher (20.4-20.9). Overall, $\mathrm{Nb} / \mathrm{Ta}$ ratios correlate negatively with $\mathrm{Ce} / \mathrm{Pb}$ and positively with $\mathrm{Ba} / \mathrm{La}$ and $\mathrm{La} / \mathrm{Nb}$ ratios, indicating that there is a tie between elevated $\mathrm{Nb} / \mathrm{Ta}$ ratios and the involvement of fluid from the subducting slab in magma genesis. High $\mathrm{La} / \mathrm{Nb}$ and $\mathrm{Nb} / \mathrm{Ta}$ ratios require equilibration with a mineral such as rutile that partitions $\mathrm{Nb}$ and $\mathrm{Ta}$ strongly with $\mathrm{D}_{\mathrm{Ta}}>\mathrm{D}_{\mathrm{Nb}}$. The question addressed here is whether the high $\mathrm{Nb} / \mathrm{Ta}$ ratios in the $\mathrm{CAB}$ result from rutile or an equivalent phase in the mantle source or in the slab. If the high $\mathrm{Nb} / \mathrm{Ta}$ ratios of the $\mathrm{CAB}$ result from rutile in the slab, then all the incompatible elements, including $\mathrm{Nb}, \mathrm{Th}, \mathrm{Sr}$, and $\mathrm{Nd}$, would have to have high concentrations in the slab fluid. This would require the fluid to be a melt with variable $\mathrm{Nb} / \mathrm{Ta}, \mathrm{La} / \mathrm{Nb}, \mathrm{Ba}$ $\mathrm{La}$, and $\mathrm{Ce} / \mathrm{Pb}$, but constant $\mathrm{Th}, \mathrm{Sr}$, and $\mathrm{Nd}$ isotopic compositions and consistent enrichments in ${ }^{230} \mathrm{Th}$ over ${ }^{238} \mathrm{U}$. A simpler explanation for the geochemical similarities between the CAB and HNB is that both suites of lavas are derived from similar OIB mantle sources. The correlated differences in $\mathrm{Nb} / \mathrm{Ta}, \mathrm{Ce} / \mathrm{Pb}, \mathrm{La} / \mathrm{Nb}$, and $\mathrm{Ba} / \mathrm{La}$ between the $\mathrm{CAB}$ and $\mathrm{HNB}$ suites result from residual nutile in the mantle that is stabilized by a large-ion-lithophile element bearing fluid from the subducting slab during genesis of the $\mathrm{CAB}$ but not the HNB. This explanation requires rutile saturation in at least a portion of the magma that aggregates to form the $C A B$, a phenomenon that has yet to be experimentally tested.

SURFACE-SYMMETRY CONSTRAINTS ON THE SELECTIVE INCORPORATION OF TRACE ELEMENTS AT GROWTHSTEPS: EXAMPLE OFCALCITE. R. J. Reeder, Department of Earth and Space Sciences, State University of New York at Stony Brook, Stony Brook NY 11794-2100, USA.

On a crystal face growing by a layer mechanism, incorporation of trace elements at advancing growth steps has been shown to vary among symmetrically nonequivalent steps, which differ by their orientation and direction of advance. This has been demonstrated for a wide variety of trace elements on growth surfaces of calcite, but is also known for apatite and topaz, and may be important on many other mineral surfaces. For growth on polygonized spirals, the differential uptake of trace elements results in the formation of welldefined, compositionally distinct subsectors within the bulk corresponding to vicinal faces of the spiral, i.e., regions on the surface with equivalent steps. For calcite, the compositional difference in incorporation for divalent transition metals is as large as tenfold. Step-selective incorporation also occurs for complex anions in $\mathrm{CO}_{3}$ surface sites on calcite $\{10 \overline{1} 4\}$ surfaces. XAFS spectroscopy confirms that incorporated trace ions reside in structural sites, indicating that uptake and discrimination occur at corresponding surface sites, e.g., kink sites.

The step-specific discrimination is always found to be consistent with the subset of crystal symmetry for the plane face. Growth-step velocities, which also differ between symmetrically nonequivalent steps, are similarly found to be consistent with the face symmetry. These observations indicate that detailed structural aspects of the kink sites are responsible for both the differing kinetics and element discrimination between nonequivalent steps. However, observed trends among differential incorporation pattems for various trace elements indicate that factors such as trace ion size and electronic configuration play an important role in determining step- and sitespecific preferences. Consequently, it may be unlikely that a single factor can be identified as the unique control of surface discrimination of trace elements.

The role of surface symmetry may also affect incorporation (and kinetics) at individual growth steps, depending on their orientation relative to specific symmetry elements. Steps that posses a mirror symmetry element of the face will have fewer unique kink sites than steps lacking mirror symmetry. Dominant growth steps on calcite \{1014\}faces lack mirror symmetry, hence multiple incorporation sites for a given structural site occur within individual steps. Detailed differences in coordination geometry are then expected to determine the degree of element discrimination in different types of surface sites.

\section{FRACTIONATION OF PLATINUM-GROUP-ELEMENT ABUNDANCES IN THE LITHOSPHERIC MANTLE. $M$.} Rehkämper', A. N. Halliday', and J. G. Fitton', 'Department of Geological Sciences, University of Michigan, Ann Arbor MI 48109, USA (markrehk@umich.edu; anh@umich.edu),2Department of Geology and Geophysics, University of Edinburgh, Edinburgh EH9 $3 \mathrm{JW}$, UK.

We have analyzed the concentrations of the Pt-group elements (PGE) Ir, Ru, Pd, and Pt in mantle-derived xenoliths from the Olmani Cinder Cone (Tanzania) and the Cameroon Line, as well as in six samples from the Horoman Peridotite (Japan). All PGE abundances were determined by ID techniques with the multiple collector ICP-MS instrument Plasma 54, following digestion of 510-g-sized samples with the Carius-tube technique.

Seven dunite and harzburgite xenoliths from Olmani were analyzed and typical examples of the PGE patterns obtained are shown in Fig.1.

The xenoliths display variations of absolute PGE abundances covering more than two orders of magnitude and are characterized by strongly fractionated PGE pattems. With one exception, all Pd Ir ratios, however, are chondritic to highly subchondritic. This, and the low Ir and Ru abundances of many samples suggests that some 


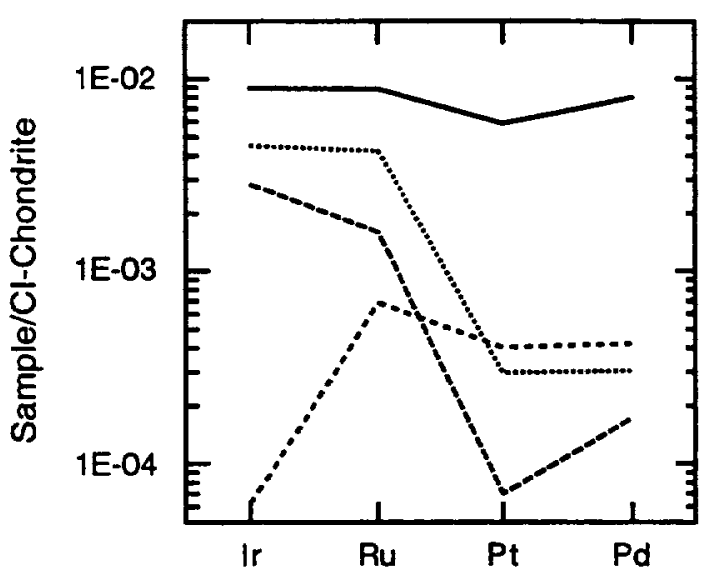

Fig. 1.

Olmani xenoliths may represent magmatic cumulates. Previous geochemical studies, on the other hand, have interpreted the refractory nature of the Olmani xenoliths solely as the result of partial melt extraction.

Typical examples of chondrite-normalized PGE patterns of lherzolites and harzburgites from the Horoman Peridotite and of spinel lherzolites xenoliths from the Cameroon Line are shown in Fig. 2 (bold and dotted lines, respectively).

The Horoman peridotite body, which is believed to represent former suboceanic mantle lithosphere, is characterized by highly variable PGE abundance patterns. Harzburgites, with low $\mathrm{Pd} / \mathrm{Ir}$ ratios and positive $\mathrm{Pt}$ anomalies, stand in contrast to samples with superchondritic Pd/Ir and PGE patterns more akin to mantle melts than melt residues. Previous studies have indicated interaction of the Horoman peridotites with small-degree partial melts and these processes may be partially responsible for the observed variability of the PGE concentration patterns.

Unmetasomatized xenoliths from the Cameroon Line, on the other hand, generally display simple PGE patterns. The chondritenormalized PGE abundances of these samples decrease from if to $\mathrm{Pd}$ (Fig. 2), indicating derivation from a source that has previously

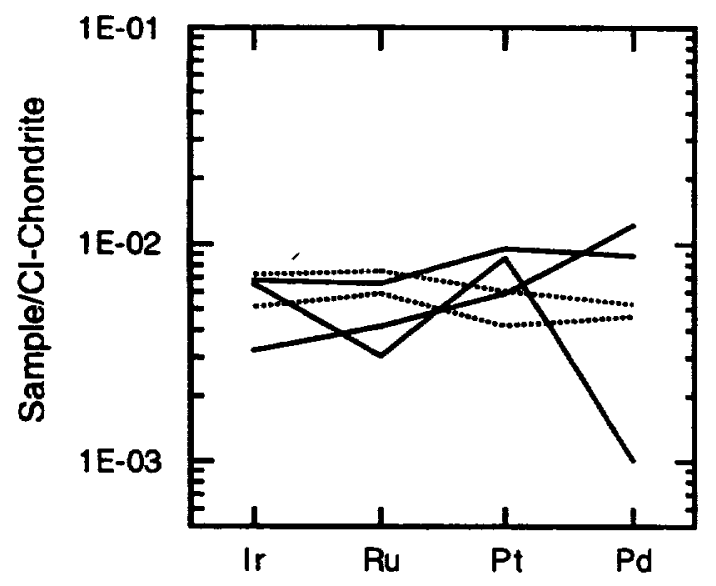

Fig. 2. experienced melt extraction, in accord with the results of previous studies.

Particularly interesting in this respect is sample C235D, since this is characterized by a chondritic $\mathrm{Ru} / \mathrm{Ir}$ ratio and abundances of $\mathrm{Ir}, \mathrm{Ru}$, and other compatible elements (e.g., $\mathrm{Ni}, \mathrm{Cr}$ ) that are within error of primitive mantle estimates. While $\mathrm{Pt}$ and $\mathrm{Pd}$ are depleted by $\sim 15 \%$ and $\sim 25 \%$ respectively relative to Ir due to melt extraction, the smooth decrease appears to suggest an original PGE concentrations pattern (prior to melt loss) with approximately $( \pm 15 \%) \mathrm{Cl}$ chondritic relative abundances of $\mathrm{Ir}, \mathrm{Ru}, \mathrm{Pt}$, and $\mathrm{Pd}$.

ION MICROPROBE THORIUM-230/URANIUM-238 DATING OF ZIRCON DELIMITS THE THERMAL EVOLU. TION OF RHYOLITIC MAGMAS BENEATH LONG VALLEY CALDERA. M. R. Reid, C. D. Coath, T. M. Hartison, and K. D. McKeegan, W. M. Keck Foundation Center for Isotope Geochemistry, Department of Earth and Space Sciences and Institute of Geophysics and Planetary Physics, University of California-Los Angeles, Los Angeles CA 90095-1567, USA (reid@ess.ucla.edu).

Zircon crystallization ages provide a bound on the cooling history of young silicic magmas. We obtained ${ }^{238} \mathrm{U}-230 \mathrm{Th}$ model ages by ion microprobe analyses of individual zircons from two rhyolite domes and a large rhyolite flow that erupted near the westem margin of Long Valley caldera in eastern California. The dome samples are from Deer Mountain, an 115 \pm 3-ka low-silica "moat" rhyolite, and the coarsely porphyritic low-silica rhyolite of South Deadman dome, one of the $\sim 0.6-\mathrm{ka}$ Inyo Domes. The $5-\mathrm{km}$-long $\left(1 \mathrm{~km}^{3}\right)$ flow is compositionally similar to the dome rhyolites and erupted nearly contemporaneously with, but $\sim 5 \mathrm{~km}$ away, from the Deer Mountain rhyolite at $\sim 105 \mathrm{ka}$. A subset of the zircon model ages ( 9 of 56 ), corrected for inherited ${ }^{230} \mathrm{Th}$ using ${ }^{230} \mathrm{Th} /{ }^{232} \mathrm{Th}$ obtained for the whole rock, are within error of that for eruption of the older rhyolites. For the domes, the majority of zircons cluster around an age of $\sim 230 \mathrm{ka}$ while for the flow, the majority of zircons cluster around an age of $\sim 200 \mathrm{ka}$. Where multiple spot analyses of individual zircons was possible, the scatter in ages can be attributed to analytical uncertainty but mean ages are distinct. Consequently, individual zircons may not have experienced protracted crystallization but the zircon population as a whole may have been produced over an extended time interval.

Reported ages assume secular equilibrium between ${ }^{234} \mathrm{U}$ and ${ }^{238} \mathrm{U}$. If $\left({ }^{234} \mathrm{U}\right) /\left({ }^{238} \mathrm{U}\right)>1$, as might occur if the rhyolites assimilated hydrothermally altered wall rocks, ${ }^{238} \mathrm{U} /{ }^{230} \mathrm{Th}$ model ages will overestimate the true age. Preliminary ion microprobe $U$ isotope analyses of the dome zircons are permissive of $\left({ }^{234} \mathrm{U}\right) /\left({ }^{238} \mathrm{U}\right)$ as high as 1.05 , in which case the true crystallization ages would be $\sim 10 \%$ younger than those reported. Nevertheless, the bimodal distribution of ages is robust and indicates that most of the zircons crystallized well before eruption.

The $\sim 200 \mathrm{ka}{ }^{238} \mathrm{U} / 230 \mathrm{Th}$ zircon crystallization ages in the rhyolites studied postdate previous episodes of silicic volcanism in Long Valley caldera, suggesting that the rhyolites may have been generated during development of a silicic upper crustal magma chamber like that inferred from geophysical measurements to underlie the western portion of Long Valley caldera. The difference in zircon crystallization ages between the domes and the lava flow is statistically significant and could indicate zircon crystallization in physi- 
cally isolated intrusive bodies or during progressive cooling of a single large magma body. Zircon saturation temperatures for the dome rhyolites $\left(795^{\circ}-810^{\circ} \mathrm{C}\right.$ ) are the same as those obtained from coexisting Fe-Ti oxides $\left(809^{\circ} \pm 4^{\circ} \mathrm{C}\right)$, showing that the magma cooled to $<815^{\circ} \mathrm{C}$ more than $200 \mathrm{k} . \mathrm{y}$. ago. The surprising consequence of these temperatures is the apparent longevity of relatively high $\mathbf{T}$ conditions in the shallow magma reservoir from which relatively small $\left(<1 \mathrm{~km}^{3}\right)$ volume magmas erupted. The magma reservoir could have remained molten because of the regular influx and differentiation of mafic magma, resulting in accumulation of a large volume of silicic magma.

URANIUM-SERIES DISEQUILIBRIA IN SPELEOTHEMS FROM THE BAHAMAS: SEA LEVELS, CARBONATE DEPOSITION, AND DIAGENESIS. D. A. Richards ${ }^{1.2}$, C. J. Borton $^{3}$, P. L. Smart ${ }^{2}$, R. L. Edwards ${ }^{3}$, and M. S. Roberts ${ }^{2}$, 'Department of Earth Sciences, University of Leeds, Leeds LS2 9JT, UK (d.richards@earth.leeds.ac.uk),2 2 Department of Geography, University of Bristol, Bristol BS8 1SS, UK, ${ }^{3}$ Minnesota Isotope Laboratory, Department of Geology and Geophysics, University of Minnesota, Minneapolis MN 55455, USA.

Introduction: The pattern of calcite growth in a submerged speleothem sequence (flowstones and stalagmites) from a cave in tectonically stable Grand Bahama serves as an important source of sea-level and palaeoclimate information for the middle and late Pleistocene. TIMS ${ }^{238} \mathrm{U}-{ }^{234} \mathrm{U}-230 \mathrm{Th}$ ages of multiple phases of calcite growth in submerged speleothems provide constraints on the timing of sea-level change because calcite deposition could only have occurred when caves were air-filled. Depositional hiatuses can be attributed to submergence during high sea stands or cessation of drip during periods of aridity, lack of soil cover or fissure blockage. Also, high-resolution subsampling and TIMS ${ }^{238} \mathrm{U}-234 \mathrm{U}-230 \mathrm{Th}$ analysis along the axis calcite growth provides a record of the $U$. series systematics of dissolution and precipitation in carbonate platforms.

Samples and Methods: Six speleothem samples from -13 to $-18 \mathrm{~m}$ below present sea level in Sagittarius Cave, eastem Grand Bahama, show multiple phases of calcite growth separated by hiatuses. Uranium and Th isotope measurements $[1,2]$ were made on 45 submillimeter wafers, typically $0.2-0.5 \mathrm{~g}\left({ }^{238} \mathrm{U}\right.$ conc. $=100-500$

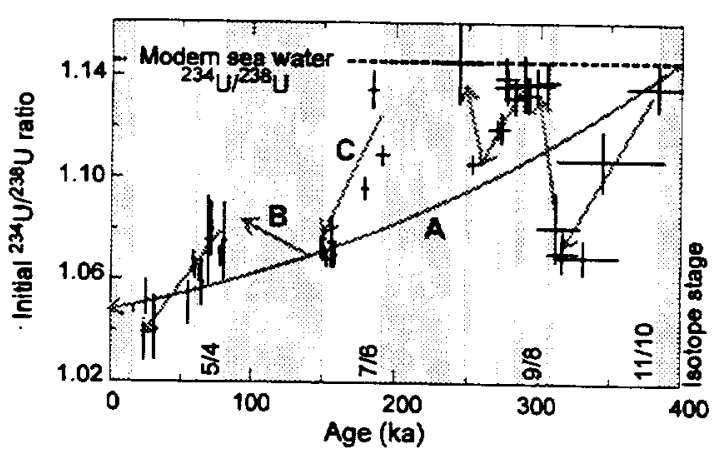

Fig. 1. Age vs. initial ${ }^{234} U / 238 \mathrm{U}$ for the Sagittarius speleothem sequence. Shaded regions are growth hianuses, $\mathrm{O}$-isotope stage boundaries are labeled. $A, B$, and $C$ denote first- and second-order $U$ isotope trends outlined in text. ng $g^{-1}$ ).

Hiatuses and Sea-Level (or Palaeoclimate?) Events: The composite speleothem sequence exhibits nine or more depositional hiatuses. Some of these can be attributed, in part, to submergence during high sea stands because at least three middle-to-late Pleistocene platform-flooding events are recorded in shallow marine carbonates from the Bahamas [3]. Our data provide useful estimates for the maximum or minimum ages of stage boundaries for the Pleistocene. Deposition of calcite commences immediately after sea-level regression to below -13 to $-18 \mathrm{~m}$ based on ages of high sea levels from coral reef terraces. The minimum age estimates for $\mathrm{O}$ isotope stage boundaries $11 / 10\left(384 \pm 20{ }_{17} \mathrm{k} . \mathrm{y}\right.$.), $9 / 8$ (315 $\pm 13 \mathrm{k} . \mathrm{y}$.), $7 / 6(190 \pm 5 \mathrm{k} . y$.$) , and 5 / 4(80 \pm 2 \mathrm{k} . y$.$) can, therefore, be considered$ as excellent chronological control points. The timing of sea-level rise prior to high sea stands is less well constrained.

Initial ( $\left.{ }^{234} U /{ }^{238} U\right)_{\text {act }}$ Variation: The Sagittarius sequence preserves a record of the secular variation of $\left({ }^{234} \mathrm{U} / 238 \mathrm{U}\right)_{\text {act }}$ in meteoric water. Uranium in the secondary calcite is primarily inherited from the marine carbonates overlying the cave that were deposited with $\left({ }^{234} \mathrm{U} /{ }^{238} \mathrm{U}\right)_{\text {act }}$ similar to present seawater $(\sim 1.144)$. The first-order trend (A; Fig. 1) toward lower values along the axis of growth can be explained by radioactive decay of $U$ in the overlying carbonates towards secular equilibrium. Superimposed on this is a saw-tooth, or step-like, second-order trend. This is likely to be caused by (B) deposition of additional marine carbonates with marine $\left({ }^{234} \mathrm{U} / 238 \mathrm{U}\right)_{\mathrm{act}}$ during high sea stands and, subsequently, preferential leaching of ${ }^{234} \mathrm{U}$, and $(\mathrm{C})$ dissolution of increasingly lower and older material during glacials because of stabilization, fissure development, and input of organic material. We intend to present elemental $\mathrm{Mg}$ and $\mathrm{Sr}$ data for the speleothems and U-Th measurements on cave wall rock to provide further insight regarding the timing of carbonate sedimentation and diagenetic processes.

References: [1] Edwards R. L. et al. (1987) EPSL, 18, 175192. [2] Richards D. A. et al. (1994) Narure, 367, 357-360. [3] Aurell M. et al. (1995) J. Sed. Res., B65, 170-182.

CHEMICAL CHANGES IN SOIL PORE WATER DURING RECHARGE: IMPLICATIONS FOR WATER MOVEMENT. P. L. Richards, Land Analysis Laboratory, Department of Agronomy, Pennsylvania State University, University Park PA 16802, USA.

The unique geology of a hillslope within the Valley and Ridge province of central Pennsylvania causes the underlying water table to respond linearly to rainfall events. This characteristic of the hill makes the site an ideal field laboratory to study the transpor of water and solute through a natural soil profile. A transect of lysimeters and wells was placed in the middle of the hill to evaluate chemistry changes in soil and groundwater during infiltration. These pore water histories were then used to document the kinds of flow paths that are active in the hill during recharge events.

Water samples were analyzed for $\mathrm{pH}, \mathrm{EC}$, major cations, and anions. Soil moisture profiles were obtained periodically. Detailed information on groundwater elevation, rainfall, and climate was also collected. During the course of the study, four recharge events took place, two of which were intensively monitored to evaluate daily changes in pore and groundwater chemistry.

The data suggest that soil pore water chemistry is extremely 
variable, with chemistry variability decreasing in the following order: $\mathrm{Al}>\mathrm{pH}>\mathrm{NO}_{3}>\mathrm{SO}_{4}>\mathrm{Ca}>\mathrm{Mg}>\mathrm{Si}>\mathrm{Na}>\mathrm{Cl}>\mathrm{K}$. Chemistry variability generally decreased with depth, with shallow lysimeters exhibiting the most extreme changes in chemistry, and the wells exhibiting the least. Soil pore water was much more concentrated than well water. Highest dissolved silica values (15 ppm) were associated with shallow lysimeters.

The higher concentrations of soil pore water chemistry relative to well chemistry probably reflect a bias in sampling toward immobile, longer-residence-time pore waters [1-4].

Such waters will probably have undergone more evaporation than "mobile" water and be more concentrated in all solutes. They also have been exposed to longer mineral-water contact times $[5,6]$.

Observations of dilution and concentration trends in the lysimeters suggest that water is moving laterally, and that older pore water is sometimes flushed into the collection regions of lysimeters or that the water in the collection region is displaced by new water with lower chemical concentrations. Significant changes in well water $\mathrm{pH}$ and ion chemistry during storm events indicate that recharging waters varied in concentration. Differences in the amount of dissolved $\mathrm{Si}, \mathrm{Mg}, \mathrm{K}$, and $\mathrm{SO}_{4}$ between deep lysimeters and the wells suggest that the wells are integrating water from a variety of sources, some of which were not characterized by the lysimeter array in this study. The evidence suggests that water flow through soil at the site is not uniform, and that flow paths with distinct chemistries are intermittantly active during recharge events.

References: [1] Haines et al., Soil Sci. Soc. Am. J., 46, 658660. [2] Cozarelli etal.,WaterResourcesRes., 23, 859-874. [3] Litaor M. I., Water Resources Res., 24, 727-733. [4] Swistock et al., Water, Air and Soil Pollution, 50, 387-396. [5] Parnell R. A., Chem. Geol., 105, 101-115. [6] Swoboda-Coburg and Drever,Chem. Geol., 105, 51-69.

CORE FORMATION IN EARTH AND MARS. K. Righter and M. J. Drake, Lunar and Planetary Laboratory, University of Arizona, Tucson AZ 85721, USA.

The dominant paradigm for the formation of the Earth has been the heterogeneous accretion hypothesis [e.g., 1]. Support for this hypothesis comes principally from the stepped pattern of lithophile, moderately siderophile, and highly siderophile elements in the Earth's mantle (Fig. 1), and the inability of metal-silicate partition coefficients obtained at low pressures and temperatures to produce a match to the pattern under conditions of metal-silicate equilibrium. The abundance pattem in the martian mantle is quite different (Fig. 2), leading Dreibus and Wänke [2] and Treiman et al. [3] to conclude independently that Mars accreted homogeneously.

Other hypotheses, such as inefficient core formation [4], have also been proposed to account for the elemental abundance pattern of the Earth's mantle, but have been largely discounted because of the special conditions required to match observed abundances. However, a detailed examination of abundance patterns in the Earth shows that the heterogeneous accretion hypothesis also requires special pleading. For example, Ga belongs to the moderately siderophile group of elements like $\mathrm{Ni}$ and $\mathrm{Co}$ in Fig. 1, yet it plots with the refractory lithophile elements, an observation difficult to explain by heterogeneous accretion.

The shortcomings of the accretion hypotheses discussed above,

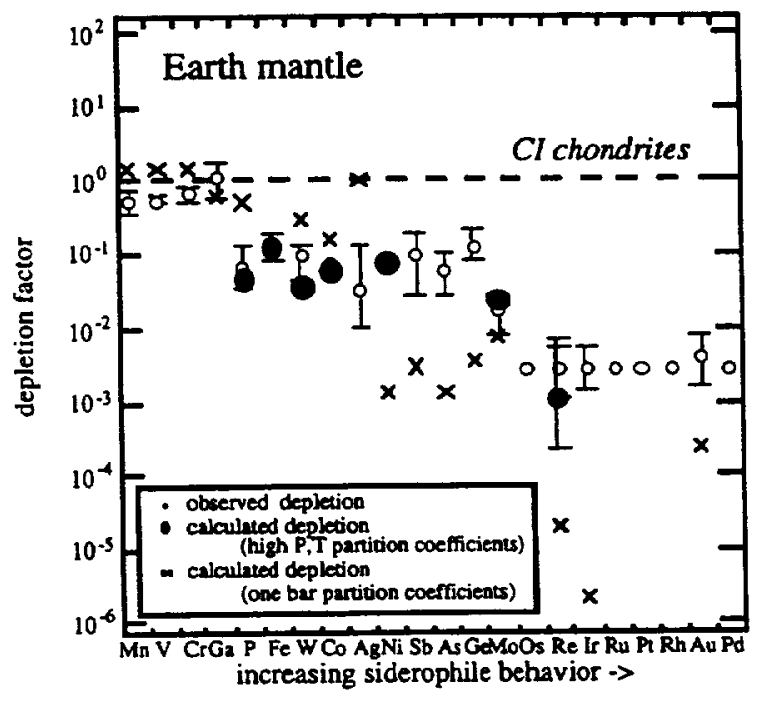

Fig. 1.

coupled with the recognition that planetary accretion involved extremely energetic impacts and advances in large-volume, highpressure technology in the 1990s, have led to a reexamination of homogeneous accretion in the context of a magma ocean. Several groups have reported metal/silicate partition coefficients at high pressures and temperatures. Righter et al. [5] and Li and Agee [6] show that moderately siderophile elements in the Earth's mantle can be matched by equilibrium between metal and silicate in a magma ocean with a depth corresponding to about 250 kbar (approximately $800-900 \mathrm{~km}$ deep). Righter and Drake [7] extended this conclusion to include the highly siderophile element $\operatorname{Re}$ (Fig. 1). Righter and Drake [8] showed that abundances in Mars (Fig. 2) are also consistent with core formation by metal/silicate equilibrium in a planetary-scale magma ocean with a depth corresponding to about 60-90 kbar (approximately $450-675 \mathrm{~km}$ deep).

References: [1] Wänke (1981) Phil. Trans. R. Soc. London,

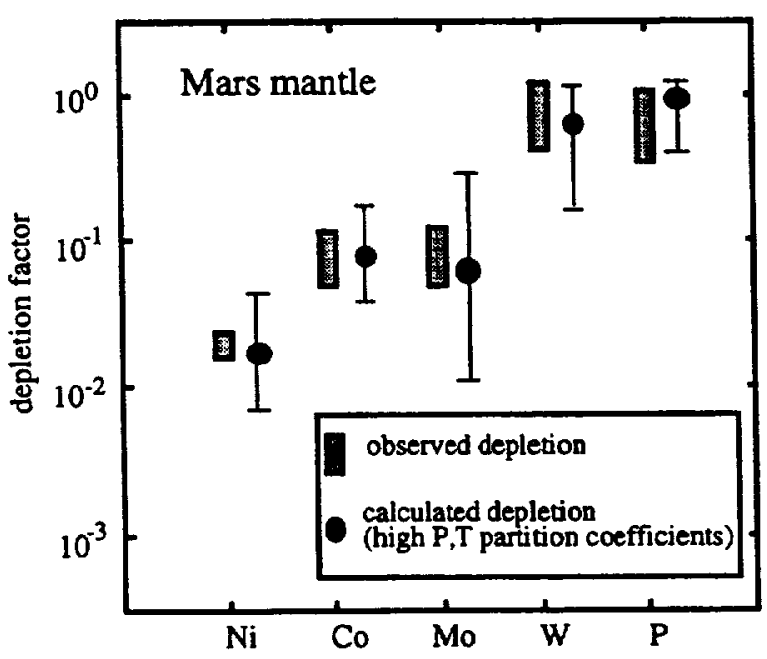

Fig. 2. 
(A)303, 287. [2] Dreibus and Wänke (1987) Icarus, 71, 225. [3] Treiman et al. (1987) JGR, 92, E627. [4] Jones and Drake (1986) Nature, 322, 221. [5] Righter et al. (1997) Phys. Earth Planes. Int., in press. [6] $\mathrm{Li}$ and Agee (1996) Nature, 381, 686. [7] Righter and Drake (1997) EPSL, 146, 541. [8] Righter and Drake (1996) Icarus, $124,513$.

RHENIUM IS COMPATIBLE IN GARNET DURING MANTLE MELTING AND MAGMA GENESIS. K. Righter ${ }^{1}$ and E. H. Hauri'2, 'Lunar and Planetary Laboratory, University of Arizona, Tucson AZ, USA, 'Department of Terrestrial Magnetism. Camegie Institution of Washington, 5241 Broad Branch Road, Northwest, Washington DC 20015, USA.

The partitioning of Re between garnet, orthopyroxene, and silicate liquid has been measured at $15-18.5 \mathrm{kbar}, 1250^{\circ} \mathrm{C}$ across a range of terrestrial $O$ fugacities. Rhenium is compatible in garnet, with a partition coefficient of $5 \pm 1$, thus making gamet a host phase for Re during mantle melting processes. On the other hand, $R e$ is incompatible in orthopyroxene, with a partition coefficient of approximately 0.1 . Using the new partition coefficient for garnet, and assuming a peridotite with $20 \%$ gamet and $0.088 \%$ sulfide (amount required if peridotite contains $300 \mathrm{ppm} \mathrm{S}$ ), $36-72 \%$ of the Re in the peridotite could be hosted by garnet, depending on the value chosen for $\mathrm{D}(\mathrm{Re})$ sulfide/liquid-for these calculations the values were 2000 and 450 as upper and lower limits [1]. Modeling of the meiting behavior of $\mathrm{Re}$ and $\mathrm{Yb}$ indicates that various basic magma suites can be derived with either gamet or sulfide as residual phases in the mantle. Komatiites and some tholeiites can be derived by melting with no residual gamet or sulfide left in the source (Fig. 1). MORB can be derived by melting with a garnet-free, but $S$-bearing residuum (Fig. 1), consistent with their low PGE abundances. OIB can be generated with a garnet- and sulfide-bearing residuum (Fig. 2). Picrites can be derived by melting with a garnet-bearing but sulfidefree residuum, consistent with their REE and high PPGE abundances. The ability of gamet to host Re indicates that subducted

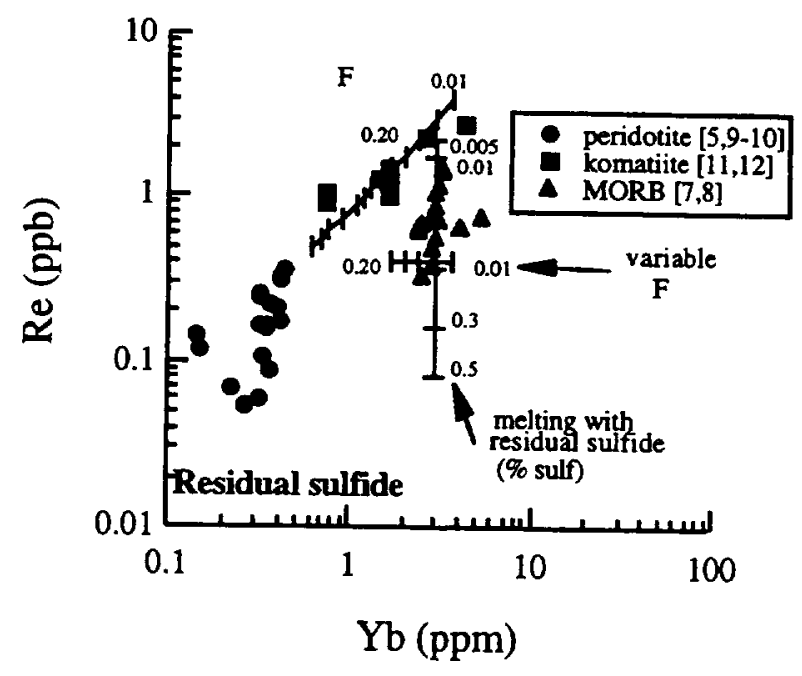

Fig. 1.

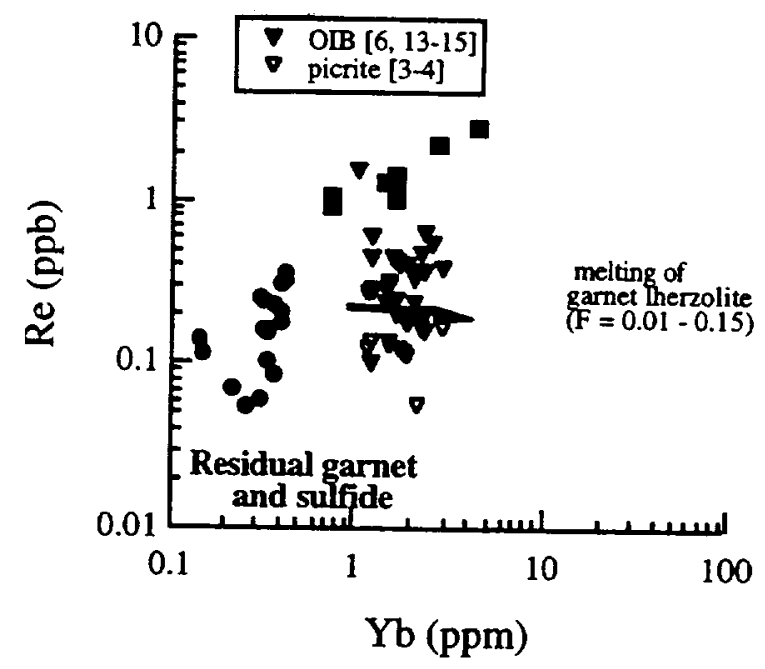

Fig. 2.

eclogitic material (with high Re/Os) could become enriched in radiogenic $O s$ and thus be a sensitive indicator of recycled oceanic crust. The latter may also harbor the "missing Re" required from mass balance constraints between depleted mantle, continental crust and primitive upper mantle [1].

Experimental and Analytical Details: The composition investigated is a eucritic basalt prepared from oxide powders and doped with 1-2 wt\% $\mathrm{ReO}_{2}$. Experiments were done in a $1 / 2$ " piston cylinder apparatus. Basalt samples were held in either graphitelined $\mathrm{Pt}$, or in FeNiCo alloy capsules; O fugacities in these capsules are approximately 2.5 and $4.0 \log \mathrm{fO}_{2}$ units below the FMQ buffer, within the range of terrestrial mantle $O$ fugacities (e.g., [2]). Samples were pressurized to the desired run pressure plus $15 \%$, heated at a rate of approximately $40^{\circ} \mathrm{C} / \mathrm{min}$ and held at the set-point temperature for $24-48 \mathrm{hr}$ before quenching. Phases from the experimental run products were analyzed for major elements with a CAMECA SX50 electron microprobe at the University of Arizona. Rhenium$187+$ and the rare earth elements, ${ }^{139} \mathrm{La}^{+},{ }^{155} \mathrm{Gd}^{+}$, and ${ }^{171} \mathrm{Yb}^{+}$, were analyzed by SIMS on a CAMECA IMS $6 f$ ion probe at the Department of Terrestrial Magnetism, using standard energy fittering techniques. Rhenium-187+/silicon-30+ ratios were corrected for interferences from ${ }^{171} \mathrm{YbO}^{+}$. Calibration curves of ${ }^{187} \mathrm{Re}^{+/ 30} \mathrm{Sj}^{+} \mathrm{vs}$. Re were constructed from analyses of four Re-bearing glasses.

Acknowledgments: Research supported by NASA grant NAGW 3348 to M. J. Drake.

References: [1] Hauri E. H. and Hart S. R. (1997) Chem. Geol., in press. [2] Carmichael I. S. E. (1991) Contrib. Mineral. Petrol., 106, 129. [3] Horan M. F. et al. (1995) GCA, 59, 5159. [4] Ellam R. et al. (1992) Nature, 359, 718. [5] Reisberg L. and Lorand J. P. (1995) Nature, 376, 159. [6] Hauri E. H. et al. (1996) JGR, 101, 11701. [7] Hertogen J. et al. (1980) GCA, 44, 2125. [8] Pyle D. G., unpublished data. [9] Morgan J. W. et al. (1981) Tectonophys., 75, 47. [10] Brueckner H. K. et al. (1995) JGR, 100, 22283. [11] Walker R. J. et al. (1988) EPSL, 87, 1. [12] Walker R. J. et al. (1991) Contrib. Mineral. Petrol., 107, 150. [13] Hauri E. H. and Hart S. R. (1993) EPSL, 114, 353. [14] Reisberg L. et al. (1993) EPSL, 120, 149. [15] Martin C. E. et al. (1994) EPSL, 128, 287. [16] Green T. H. (1994) Chem. Geol., 117, 1. [17] Righter K. et al. (1995) Eos Trans. AGU, 76, F698. 
EFFECT OF WATER ON NICKEL, COBALT, AND TUNGSTEN METAL/SILICATE PARTITIONING AT $10 \mathrm{kbar}$, $1300^{\circ}$ C. K. Righter', M. J. Drake' , and R. L. Hervig', 'Lunar and Planetary Laboratory, University of Arizona, Tucson AZ, USA, ${ }^{2}$ Center for Solid State Science, Arizona State University, Tempe AZ, USA.

The partitioning of siderophile elements between metal and silicate liquid is a function of $\mathrm{T}, \mathrm{P}, \mathrm{fO}_{2}$, and melt composition, and has been used to constrain conditions prevailing during accretion and core formation in the early Earth [1]. Recent calculations and experiments $[2,3]$ have indicated a specific P-T- $\mathrm{fO}_{2}-\mathrm{X}$ condition whereby the abundances of $\mathrm{Ni}, \mathrm{Co}, \mathrm{Mo}, \mathrm{W}, \mathrm{P}$, and Re in Earth's primitive upper mantle may have been set by simple metal-silicate equilibrium at the base of a deep (250-kbar, $1925^{\circ} \mathrm{C}$ ) magma ocean. Such P-T conditions are just below the liquidus of many dry peridotitic and chondritic compositions, suggesting that a hydrous magma ocean may be required for such a scenario. The amount of primordial water in Earth's mantle is likely to be less than the $\sim 3.0 \mathrm{wt} \%$ contained in undifferentiated planetesimals [4]. Since all metalsilicate partition coefficients have been measured in dry systems, we have undertaken a series of experiments with an aim to isolate any effect that dissolved $\mathrm{H}_{2} \mathrm{O}$ may have on the partitioning behavior of the moderately siderophile elements $\mathrm{Ni}, \mathrm{Co}$, and $\mathrm{W}$.

For all three elements, the partition coefficients do not change with increasing $\mathrm{H}_{2} \mathrm{O}$ content, up to $\sim 2 \mathrm{wt} \%$. Although there are minor differences in the partition coefficients between runs, the values fall within the $2 \sigma$ error of the partition coefficients calculated for the same $T, P$, and $\mathrm{fO}_{2}$ in a dry system [2]. The insensitivity of the metal-silicate redox equilibria to dissolved $\mathrm{H}_{2} \mathrm{O}$ content parallels recent findings for $\mathrm{Fe}_{2} \mathrm{O}_{3}$ - $\mathrm{FeO}$ equilibria in hydrous basic magmas [5]. These new findings indicate that the partitioning of moderately siderophile elements between metal and silicate liquid is not affected by small amounts of $\mathrm{H}_{2} \mathrm{O}$. Partition coefficients determined

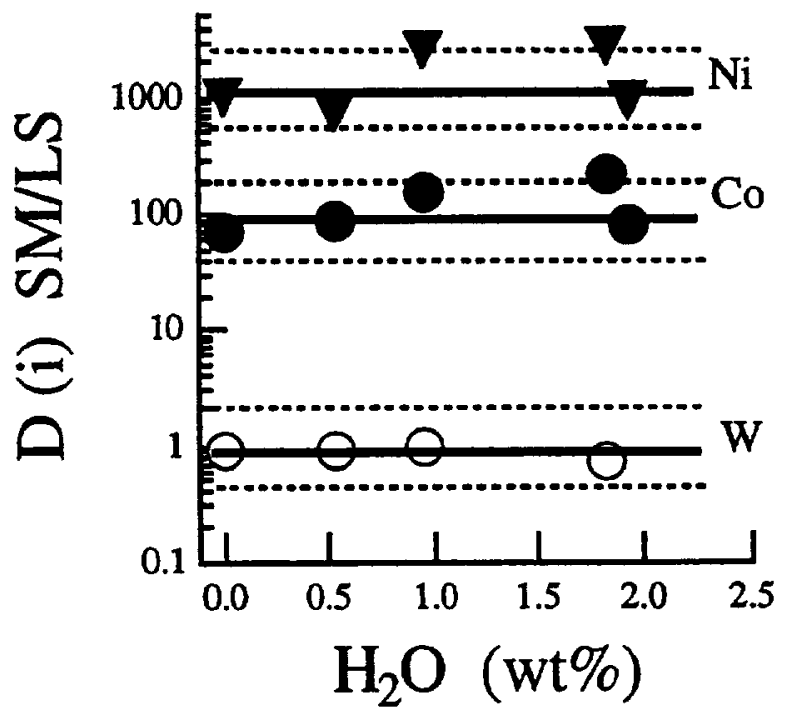

Fig. 1. Metal-silicate partition coefficients for $\mathrm{Ni}, \mathrm{Co}$, and $\mathrm{W}$. Solid lines are the calculated $\mathrm{D}$ (solid metal/ liquid silicate) from [2], at $10 \mathrm{kbar}, 1300^{\circ} \mathrm{C}, \Delta \mathrm{IW}$ from Table 1, and nbo/t - 1.2. Dashed lines are 2oerror on the calculated values.
TABLE I. Summary of experimental results $\left(10 \mathrm{kbar}, 1300^{\circ} \mathrm{C}\right)$.

\begin{tabular}{lccccc}
\hline & 33 & 49 & 51 & 52 & 41 \\
\hline $\operatorname{logfO}_{2}(\Delta \mathrm{IW})$ & +0.04 & +0.19 & -0.06 & -0.13 & +0.23 \\
duration $(\mathrm{hrs})$. & 4 & 19 & 6 & 4 & 6 \\
$\mathrm{H}_{2} \mathrm{O}(\mathrm{wt} \%)$ & 0.50 & 1.83 & 0.92 & 1.96 & 0.00 \\
$\mathrm{D}^{\mathrm{w}}(\mathrm{SM} / \mathrm{LS})$ & 0.89 & 0.74 & 0.95 & - & 0.90 \\
$\mathrm{D}^{\mathrm{Ni}}(\mathrm{SM} / \mathrm{LS})$ & 764 & 2830 & 2580 & 946 & 1000 \\
$\mathrm{D}^{\mathrm{co}}(\mathrm{SM} / \mathrm{LS})$ & 86 & 220 & 160 & 80 & 68 \\
\hline
\end{tabular}

in $\mathrm{H}_{2} \mathrm{O}$-free compositions will thus be applicable to models involving a hydrous magma ocean.

Experimental and Analytical Details: Experiments were done in a $1 / 2$ " piston cylinder apparatus. The silicate melt composition investigated is a eucritic basalt prepared from oxide powders, and doped with 4-5 wt\% $\mathrm{WO}_{3}$. Water was added to the basalt mix in incremental steps so that a range of $\mathrm{H}_{2} \mathrm{O}$ contents could be investigated at constant $\mathrm{T}, \mathrm{P}, \mathrm{fO}_{2}$, and $\mathrm{X}$. Basalt samples were held in FeNiCo alloy tubes that were closed off at both ends using caps of the same composition. Oxygen fugacities at run conditions in these capsules are close to the IW buffer. The pressure medium used was barium carbonate; temperature was imposed by graphite heaters, and controlled with a type $C\left(W_{3} R e-W_{26} R e\right)$ thermocouple. Samples were pressurized to the desired run pressure plus $15 \%$, heated at a rate of $\sim 40^{\circ} \mathrm{C} / \mathrm{min}$ and held at the set point temperature for $4-6 \mathrm{hr}$. Metal, glass, and olivines from experimental runs were analyzed for major elements with a CAMECA SX50 electron microprobe at the University of Arizona. Equilibrium is attained on such timescales, as calculated, and measured olivine-liquid $\mathrm{MgO}-\mathrm{FeO}$ $\mathrm{K}_{\mathrm{d}}$ are in good agreement. Operating conditions for analysis of major elements in crystalline phases were $150 \mathrm{kV}$ accelerating voltage, 30-nA sample current, 10-s counting times, and a point beam; a PAP correction procedure was used. Water contents of the glasses were analyzed by SIMS on a CAMECA $3 \mathrm{f}$-series ion probe at Arizona State University. Basaltic glass standards with up to $2.5 \mathrm{wt} \% \mathrm{H}_{2} \mathrm{O}$ were used to construct a calibration line for $\mathrm{H}^{+} /{ }^{30} \mathrm{Si}$ intensities and $\mathrm{H}_{2} \mathrm{O}$ content.

Acknowledgments: This research is supported by NASA grant NAGW 3348 to M. J. Drake.

References: [1] Jones J. H. and Drake M. J. (1986) Nature, 322, 221-228. [2] Righter K. et al. (1997) PEPI, in press. [3] Righter K. and Drake M. J. (1997) EPSL, 146, 541-554. [4] Ahrens T. J. (1989) Nature, 342, 122-123. [5] Moore G. M. et al. (1995) Contrib. Mineral. Petrol., 120, 170-179.

THE LEACHED LAYER ON DISSOLVING WOLLASTONITE. J. D. Rimstidt, E. J. Weissbart, and J. J. Rosso, Department of Geological Sciences, Virginia Polytechnic Institute and State University, Blacksburg VA 24061, USA.

Measurements of the rate of dissolution of wollastonite in a mixed-flow reactor showed that the reaction proceeds from an initial incongruent stage characterized by very rapid $\mathrm{Ca}$ release toward a steady state where the rate of $\mathrm{Ca}$ release equals the rate of Si release. This process produces a leached layer at the mineral 
surface that consists of hydrated silica that acts as a diffusional barrier to the release of $\mathrm{Ca}$ (Fig. 1). The dissolution rate of this silica is $2.13 \times 10^{-9} \mathrm{~mol} \mathrm{~m}^{-2} \mathrm{~s}^{-1}$ over the $\mathrm{pH}$ range of 2-6 (average of 70 measurements).

The highly incongruent nature of the dissolution process suggests that the $\mathrm{CaO}$ and $\mathrm{SiO}_{2}$ components act as independent polyhedra so that dissolution proceeds by two steps: (1) $\mathrm{nCaSiO}_{3}+2 \mathrm{n}$ $\mathrm{H}^{+} \rightarrow \mathrm{nCa}^{2+}+\left(\mathrm{H}_{2} \mathrm{SiO}_{3}\right)_{n}$ and $(2)\left(\mathrm{H}_{2} \mathrm{SiO}_{3}\right)_{\mathrm{n}}+\mathrm{nH}_{2} \mathrm{O} \rightarrow \mathrm{nH}_{4} \mathrm{SiO}_{4}(\mathrm{aq})$. This behavior is consistent with additivity models of the thermodynamic properties of silicates that suggest that they act as collections of oxide components [1].

The rate of silica release from the leached layer is 3.5 orders of magnitude higher than the rate of dissolution of completely polymerized silica glass and 2.5 orders of magnitude larger than the estimated rate of dissolution of $\left(\mathrm{H}_{2} \mathrm{SiO}_{3}\right)_{\mathrm{n}}$ polymer via the release of monomer $\mathrm{H}_{4} \mathrm{SiO}_{4}(\mathrm{aq})$ as described by the model of Rimstidt and Barnes [2]. We propose that this high rate is best explained by a model where large polymer units of the linear $\left(\mathrm{H}_{2} \mathrm{SiO}_{3}\right)_{\mathrm{n}}$ polymer chain (Fig. 1) are released by the hydrolysis of $\mathrm{Si}-\mathrm{O}-\mathrm{Si}$ bonds.

Finally, the rate of growth of the thickness, $x(\mathrm{~m})$, of the leached layer is

$$
(d x / d t)=V_{m}\left(I_{C a}-I_{S i}\right) / 10^{6}
$$

where $\mathrm{V}_{\mathrm{m}}\left(\mathrm{cm}^{3 / \mathrm{mol}}\right)$ is the molar volume of wollastonite and $\mathrm{r}_{\mathrm{Ca}_{\mathrm{a}}}$ and

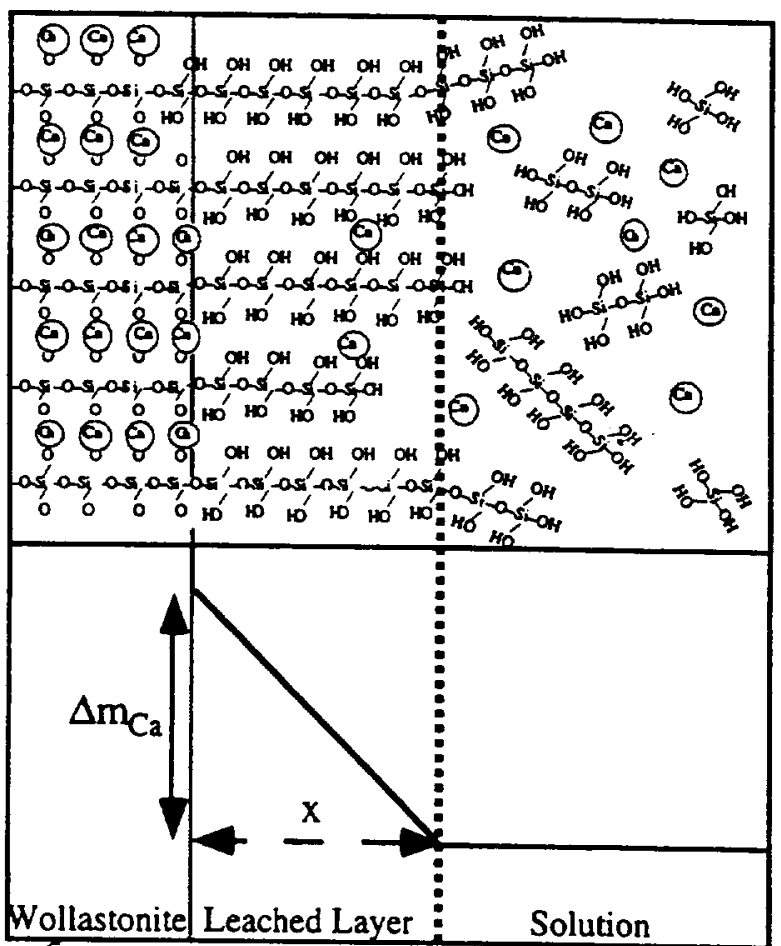

Fig. 1. Schematic diagram showing some essential features of our conceprual model of a leached layer on wollastonite. The $\mathrm{CaO}$ component reacts as an independent entity in the structure and is rapidly leached at the mineral/leached layer interface and the rate of $\mathrm{Ca}^{2+}$ release to solution is controlled by diffusion through the leached layer of hydrated silica. This silica dissolves by shedding relatively large polymers as a result of the hydrolysis of Si-O-Si bonds in the chains.
$\mathrm{r}_{\mathrm{Si}}$ are the rates $\left(\mathrm{mol} / \mathrm{m}^{2} \mathrm{~s}\right)$ of release of $\mathrm{Ca}$ and $\mathrm{Si}$ respectively. If the rate of $\mathrm{Ca}$ release is modeled as a diffusional process

$$
\mathrm{r}_{\mathrm{Ca}}=(\mathrm{D} / 10 \mathrm{x})\left(\Delta \mathrm{m}_{\mathrm{Ca}}\right)
$$

where $\mathrm{D}$ is the diffusion coefficient $\left(\mathrm{cm}^{2} / \mathrm{s}\right)$ of $\mathrm{Ca}$ in the leached layer, and $\Delta \mathrm{m}_{\mathrm{Ca}}(\mathrm{mol} / \mathrm{L})$ is the concentration difference between the wollastonite/leached layer interface and the leached layer/solution interface, the steady-state thickness, $x_{s s}$, of the leached layer is

$$
\mathrm{x}_{\mathrm{ss}}=\mathrm{D} \Delta \mathrm{m}_{\mathrm{Ca}} / 10 \mathrm{r}_{\mathrm{Si}}
$$

This is consistent with our observation that the leached layer is thickest at low $\mathrm{pH}$ where the concentration of $\mathrm{Ca}$ at the wollastonite/ leached layer interface is highest, so $\Delta \mathrm{m}_{\mathrm{Ca}}$ is highest.

References: [1] Chermak and Rimstidt (1989). [2] Rimstidt and Barnes (1980).

\section{GEOCHEMISTRY AND TRACE-ELEMENT VARIATIONS} IN MUNTELE MIC GRANITOID, SOUTHERN CARPATHIANS, ROMANIA. I. N. Robu, L. Robu, and M. Stoian, Geological Institute of Romania , Caransebes Street 1, Sector 1, 78344-Bucuresti-32, Romania.

The Muntele Mic massif is included in the old granitoids of the Southem Carpathians. It has intruded in the crystalline formations of the Danubian Realm. Its orientation (northeast-southwest) is determined by a directional major dislocation. Petrographically, it is composed of a normal suit of granitoid rocks, characterized by granites, granodiorites, and quartz diorites. Petrographic characteristics are determined by the chemical composition of the initial magma and its evolution. All major chemical variations point out a normal evolution of the calco-alkaline magma; some anomalies of femic and alkali parameters have been identified [1]. REE contents characterize granitic rocks [2] [ $\Sigma \mathrm{REE}=75.37-127.970 ;(\mathrm{Cc} / \mathrm{Yb})_{\mathrm{N}}=$ 9.215-26.194; $\left.(\mathrm{Eu} / \mathrm{Sm})_{\mathrm{N}}=0.397-1.619\right]$. No differences exist between identified petrotypes. REE patterns and all characteristic ratios emphasized little or no residual plagioclase and some homblende and garnets in the initial source.

References: [1] Gherasi N. and Savu H. (1967)D. S., LN , 5581, Bucuresti. [2] Henderson P. (1984) Amsterdam, 510 pp.

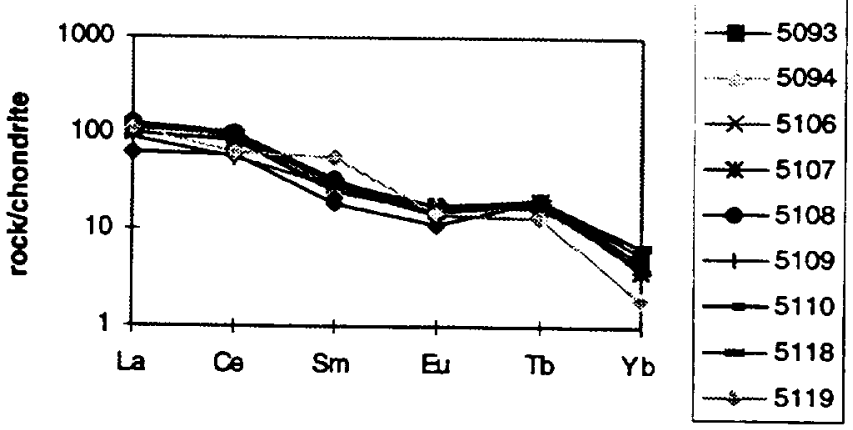

Fig. 1. REE pattern. 
RARE-EARTH-ELEMENT CONTENT AND VARIATIONS IN SOME VOLCANIC ROCKS FROM METALIFERI MOUNTAINS, BRAD-SACARIMB ZONE (ROMANIA). L. Robu, I. N. Robu, and I. Tiepac, Geological Institute of Romania, Caransebes Street 1, Sector 1, 78344-Bucuresti-32, Romania.

The volcanic areas considered, which are in the Brad-Sacarimb Zone, are Bucuresci-Rovina, Barza, Cetras, Sacarimb, and TrestiaMagura. Included in the second evolutionary cycle of Tertiary volcanism, they are characterized by rocks of the andesitic suite: andesites, quartz \pm hornblende \pm pyroxene andesites, homblende \pm pyroxene \pm biotite andesites [1]. Three specific andesites, Barza, Sacarimb, and Cetras, recognized in all studied volcanic areas, have been investigated. The time succession, established using mineralogic, petrographic, and field relations for considered andesites, are as follows: Barza, Sacarimb, Cetras. The variation of the major elements is characteristic for calco-alkaline magma, sometimes with some sodic tendency. REE contents and their variation suggest two different evolutionary trends: a similar one for Barza, Cetras, and Sacarimb andesites from the Barza, Cetras, Sacarimb, and Trestia-Magura volcanic areas, and a different one for the Barza andesite type from Bucuresci-Rovina.

Their REE patterns emphasize two different scenarios: (1) very similar positive Eu anomalies for Barza, Cetras, and Sacarimb andesites from the Barza-Cetras, Sacarimb, and Trestia-Magura areas; and (2) no Eu anomaly, with a relatively flat REE pattem, for the Barza type from the Bucuresci-Rovina area (samples 4000 and 4001).

REE information emphasized little or no residual plagioclase associated with homblende-gamet-pyroxene, or homblende-pyroxene-garnet, in the parent magma. They could have the same initial source, but evolved differently in time (successive stages) and space.

References: [1] Bleahu M. (1976) Bucuresti, 631pp.

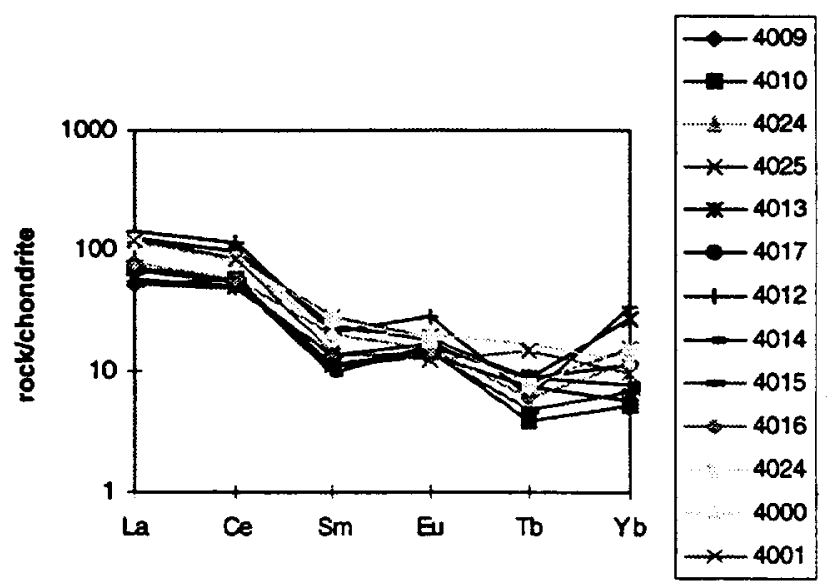

Fig. 1. REE pattern.

STRONTIUM-NEODYMIUM ISOTOPE SYSTEMATICS OF THE PLATINUM-BEARING BELT OF THE URALS, RUSSIA. Y. L. Ronkin, K. S. Ivanov, V. R. Shmelev, and O. P. Lepikhina, Institute of Geology and Geochemistry, Urals Branch,
Russian Academy of Sciences, Ekaterinburg 620151, Russia (root@igg.e-burg.su).

According to prevailing ideas, the Pt-bearing belt of the Urals (PBU) is a gigantic chain extending from the Cispolar to the Middle Urals, almost $1000 \mathrm{~km}$ long (Fig. 1). It is composed of complicated zonal complexes, formed mainly by the association of ultrabasites (dunites, clinopyroxenites), olivine, and two-pyroxene gabbro. The eastem part of the PBU extends even more in the direction of the submeridional ophiolitic belt, related in turn to the zone of the Main Uralian Fault (MUF). If the details of internal structure and peculiarities of the majority of the Belt's massifs have been studied in enough detail, then the questions of the nature of the PBU itself, its age and geodynamical position, its place and role in geological history, and the structure of the Urals are the subject of discussion.

For isotope-geochronologic study a relatively unchanged sample of two-pyroxene gabbro collected from the northem part of the Chistop mafic-ultramafic massif (CUM) has been used. The CUM is shown in Fig. 1 (position 12) by the southem part of the elongated,

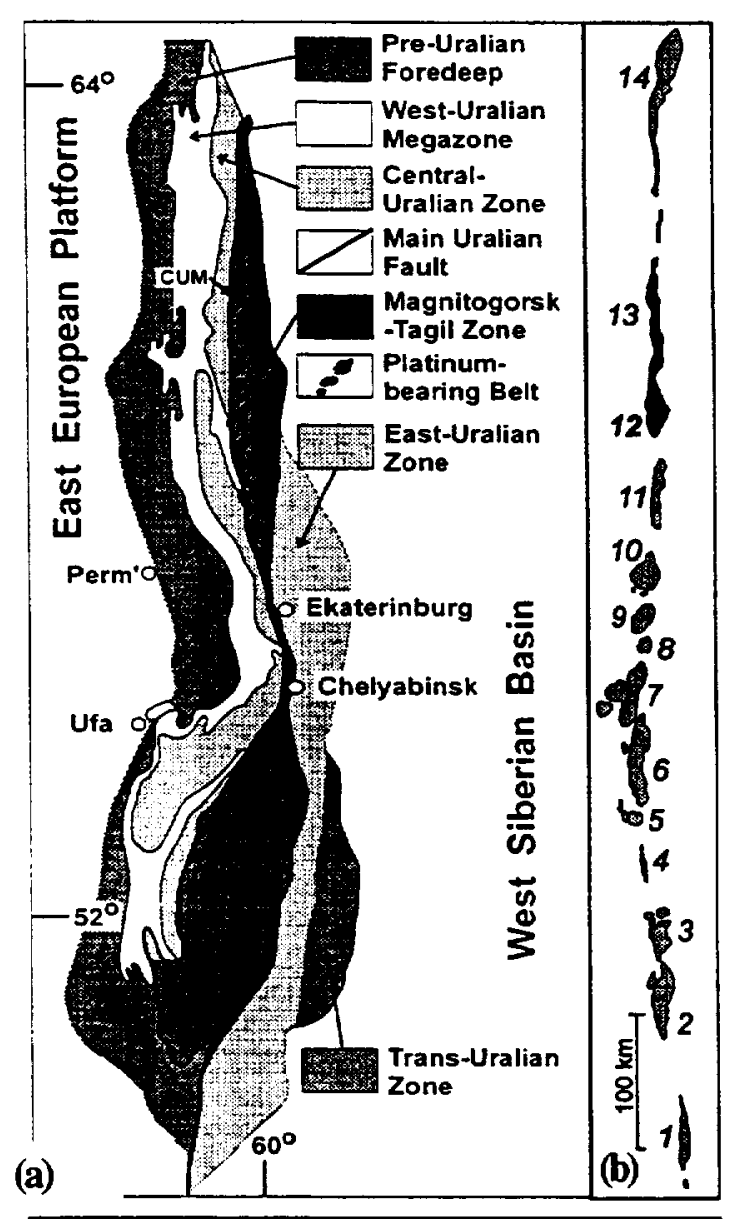

Fig. 1. (a) Sketch map of zonation of the Urals [after 1]. (b) Complexes of Pt-bearing belt of the Urals [after 2]: 1-Revda: 2-Tagil:3-Barancha:4Arbat; 5-Kachkanar,6-Pavda; 7-Kytlym;8-Knyaspa:9-Kumba: 10Denezhin Kamen'; 11-Pomur; 12-Chistop; 13-Yalpig Nyor; 14Khorasyur. 
relatively large, compound-outlined complex, the northern end of which is the Yalpig Nyor gabbroid massif.

The obtained isotope results on the whole contents of gabbro and their mineral fraction of plagioclase, orthopyroxene, and a mixture of clinopyroxene and amphibole form a plot with the coordinates ${ }^{147} \mathrm{Sm}^{144} \mathrm{Nd}-{ }^{143} \mathrm{Nd} / 144 \mathrm{Nd}$ on a regression line whose slope corresponds to an age of $419 \pm 12 \mathrm{Ma}$; parameter $\varepsilon^{t}{ }_{C H U R}=6.1$; and MSWD $=1.71$, which affirms isochron dependence. The obtained age of homogenization of the $\mathrm{Sm}-\mathrm{Nd}$ isotope system at the mineral level is interpreted as the time of "closing" of the Sm-Nd isotope system in minerals, with the whole content being, in fact, a minimum estimation of the studied CUM's gabbro. Consideration in coordinates $\varepsilon^{t}{ }_{U R}-\varepsilon^{t}{ }_{C H U R}$ of $S r$ and Nd isotope contents corrected for decay after the time of formation of CUM makes it possible to note the fact that figurative points for the studied formations are located in quadrant II of the correlation diagram and follow the line of the mantle array. The Sm-Nd model age calculation on the whole content of CUM's relatively gabbro-depleted reservoir is complicated by the value of the ${ }^{147} \mathrm{Sm} /{ }^{144} \mathrm{Nd}$ ratio $(0.1963 \pm 0.0009)$, which makes it difficult to estimate the time of protolith separation for the studied types from the trend of the DM evolution.

The obtained $\mathrm{Rb}-\mathrm{Sr}$ and $\mathrm{Sm}-\mathrm{Nd}$ isotopic systematics of the Ptbearing belt of the Urals testify to the studied substance belonging mainly to the mantle trend.

References: [1] Ivanov et al. (1975). [2] Efimor et al. (1993).

ESTIMATION OF MANTLE AND CRUSTAL MATERIAL PARTICIPATION IN THE EVOLUTION OF THE HUGE KACHAR ORE-GEOCHEMICAL SYSTEM OF THE URALS, RUSSIA: STRONTIUM-NEODYMUM-LEAD ISOTOPE LIMITATIONS. Y. L. Ronkin, Y. A. Poltavets, O. P. Lepikhina, and Z. I. Poltavets, Institute of Geology and Geochemistry, Urals Branch, Russian Academy of Sciences, Pochtovy per., 7, Ekaterinburg, 620151, Russia (root@igg.e-burg.su).

Modem views of the Fe-ore-bearing ore-geochemical Urals system (IOGS) allow us to consider the processes of ore formation, wall-rock alteration, and endogenic geochemical halos in close connection with magmatism, which in turn is closely related to Feore-bearing magmatic rocks. Such systems show extensive vertical spreading and, in fact, envelop practically all genetic types of Fe-ore deposits [late-magmatic, metasomatic (proper skam-magnetite), and volcanogenic-sedimentary ores], which are formed at different stages of IOGS evolution. In terms of structural relation, Fe-ore deposits of skam formation are placed mainly in the eugeosyncline part of the Urals folded belt and located in the shape of linearstretched ore-bearing zones. Within the limits of ore-productive zones, the deposits are situated discretely, in the form of separate ore nodes or ore areas, appearing as separate structure-tectonic blocks limited as a rule by deep faults. The inner structure of such blocks in connection with their differentiating mobility is different, as are the peculiarities of magmatic activity. The characteristics of magnetite mineralization (morphological peculiarities, composition, structure intensity, and the scales of skam-ore zones) are predetermined for the most part by its position in the volcano-plutonic structure, by the level of a deep shear at which the deposits are removed, and by the dependence upon the depth of formation of the fluid-magmatic center feeding the ore-magmatic system.
The huge (more than 2000 million tons of ore) Kachar deposit (KD) is associated with alkaline andesite-basalt-gabbro-diorite and is related to the Valer'ayanov volcano-plutonic belt in the Tyumen'Kustanaisk zone. The Kachar deposit is situated among carboniferous sedimentary volcanogenic rocks overlapped by a cover of the platform of Mezozoic-Kainozoic deposits.

In ${ }^{87} \mathrm{Rb} /{ }^{86} \mathrm{Sr}-{ }^{87} \mathrm{Sr} /{ }^{86} \mathrm{Sr}$ coordinates, the position of points of dacite porphyries composing an extrusive dome located in the limits of the northeastem blocks of the Kachar ore field are approximated by linear dependence (MSWD $=2.75$ ), determining an isotope age of $315 \pm 24 \mathrm{Ma}$. The close age testifies that the synchronicity (within the limits of the observed analytical uncertainties) of the magmatism and ore formation is fixed by the Sm-Nd isotope system of apatite and two magnetites separated from the ore substance of the central part of the deposit. The obtained data on the initial isotope characteristics of $\mathrm{Sr}\left({ }^{87} \mathrm{Sr}^{8}{ }^{86} \mathrm{Sr}_{\mathrm{i}}=0.70443 \pm 0.00012\right)$ and $\mathrm{Nd}\left(\varepsilon_{\text {chur }}^{\mathrm{t}}=5.9 \pm\right.$ 0.4 ) on the one hand testify to a considerable role of mantle substance in $\mathrm{KD}$ formation. On the other hand, relatively "stable" isotope ratios of $\mathrm{Pb}$ in the sulfide phase in impregnated magnetite ore prove the relative participation of intercrustal magmatism products.

The obtained $\mathrm{Sr}-\mathrm{Nd}-\mathrm{Pb}$ isotope systematics of the huge Kachar ore deposit allow us, with a certain degree of validity, to draw a conclusion about the participation of a minimum of two different deep fluid-magmatic sources in the ore-forming process.

\section{ISOTOPE GEOCHEMISTRY OF QUARTZ-CARBONATE} VEINS ASSOCIA TED WITH THE COEUR D'ALENE MINERALIZATION. P. E. Rosenberg and P. B. Larson, Department of Geology, Washington State University, Pullman WA 99164 , USA.

A series of dilatational, quartz-carbonate veins intrude the Belt Supergroup within and adjacent to the Coeur d'Alene Mining District (CAMD). The veins are of three types: (1) siderite-dominant, confined mainly within the CAMD; (2) ankerite-dominant, along a northwest-southeast zone transecting the CAMD; and (3) ankeritecalcite veins, following the same trend, extending southeast of the CAMD. Siderite-dominant veins are cross-cut by ankerite-dominant veins at all locations where they occur together and thus are older. Ankerite-calcite veins and ankerite-dominant veins are found in close proximity at several locations, but cross-cutting relationships have not been observed. Argon/argon isochron ages of $1018 \pm$ 7 and $946 \pm 7 \mathrm{Ma}$ have been determined, respectively, for phlogopite-bearing, ankerite-calcite, and ankerite-dominant veins in the Bitterroot Mountains along the Idaho-Montana border, $\sim 14$ miles southeast of Mullan, Idaho. Despite their close spatial relationship and their similar mineralogy, these veins appear to represent separate events, the ankerite-dominant veins following the same channels as the earlier ankerite-calcite veins.

Quartz $\delta^{18} \mathrm{O}$ values of ankerite-dominant and ankerite-calcite veins range from $14.2 \%$ to $17.2 \% 0$ and $16.8 \%$ to $18.6 \%$ respectively. These values are significantly higher than the average value, 14.6\% reported for siderite-dominant veins within the CAMD. A linear relationship appears to exist between $\delta^{18} \mathrm{O}(11.0-15.6)$ and $\delta^{13} \mathrm{C}(-11.9$ to -1.7$)$ in ankerites from the ankerite-dominant veins, which is compatible with a regional thermal (and/or mixing) gradient in the hydrothermal system. $\Delta$ qtz-ank values are between 1.1 
and 3.5; estimated temperatures range from approximately $320^{\circ}$ to $250^{\circ} \mathrm{C}$. At $300^{\circ} \mathrm{C} 8^{18} \mathrm{O}$ of aqueous fluids in equilibrium with ankerite-bearing assemblages average about $10 \%$. This relatively high value probably reflects isotopic exchange with high ${ }^{18} \mathrm{O}$ metasedimentary rocks at depth.

Initial ankerite ${ }^{87} \mathrm{Sr} /{ }^{86} \mathrm{Sr}$ ratios have been determined for two ankerite-dominant $(0.771,0.750)$ and an ankerite-calcite (0.787) vein. These high ratios could have been derived by leaching of Belt rocks, which range in age from $\sim 1100$ to $1450 \mathrm{Ma}$, and had ${ }^{87} \mathrm{Sr} / 86 \mathrm{Sr}$ ratios between 0.616 and 0.817 a billion years ago [1]. Thus, the ${ }^{87} \mathrm{Sr} /{ }^{86} \mathrm{Sr}$ ratios of carbonates from ankerite-bearing veins could have been derived by leaching of Belt rocks. However, if the ages of all the quartz-carbonate veins related to the Coeur d'Alene mineralization are approximately $1000 \mathrm{Ma}$, then the higher ${ }^{87} \mathrm{Sr}$ / ${ }^{86} \mathrm{Sr}$ ratios (0.919-1.075) for siderite-dominant veins reported by Eaton et al. [2] could not have been derived by leaching of Belt rocks exclusively. A component must have been leached from older preBelt rocks that were already ${ }^{87} \mathrm{Sr}$-rich a billion years ago.

References: [1] Criss and Fleck (1987). [2] Eaton et al. (1995).

\section{LINKED DISSOLUTION/PRECIPITATION REACTIONS} AT SILICATE SURFACES. J. J. Rosso and J. D. Rimstidt, Department of Geological Sciences, Virginia Polytechnic Institute and State University, 4044 Derring Hall, Blacksburg VA 20461, USA (junta@vt.edu; jdr02@vt.edu).

To better understand secondary mineral formation in the natural weathering environment, we performed a combined study of the acidic dissolution of two silicate minerals, forsterite $\left(\mathrm{Mg}_{2} \mathrm{SiO}_{4}\right)$ and enstatite $\left(\mathrm{MgSiO}_{3}\right)$, and the effectiveness of those reacted mineral surfaces as templates for secondary mineral precipitation.

The first part of our experiments involved measurement and/or characterization of the kinetics, surface microtopography, and surface composition of dissolving silicate surfaces. The weathering experiments on forsterite and enstatite were conducted in mixedflow reactors, at $25^{\circ} \mathrm{C}$, using aerated, nitric acid solutions between $\mathrm{pH} 1.8$ and 3.8. Using the rates of $\mathrm{Si}$ and $\mathrm{Mg}$ release over the course of the experiment, the following overall dissolution rates (mol $\mathrm{Mg}_{2} \mathrm{SiO}_{4} / \mathrm{m}^{2} / \mathrm{s}$ ) at $\mathrm{pH} 1.8,2.8$, and 3.8 for forsterite were obtained: $1.04 \times 10^{-9}, 6.22 \times 10^{-10}$, and $1.30 \times 10^{-10}$ respectively. For enstatite, the rates $\left(\mathrm{mol} \mathrm{MgSiO}_{3} / \mathrm{m}^{2} / \mathrm{s}\right.$ ) of dissolution at $\mathrm{pH} 1.8$ and 2.8 are $1.91 \times 10^{-11}$ and $2.73 \times 10^{-11}$ respectively. The steady-state dissolution kinetics for both of these materials are comparable to previously reported rates.

Inosilicates such as enstatite should have a $\mathrm{Si}$-rich leached layer form as a result of incongruent dissolution, whereas forsterite, a nesosilicate, should dissolve congruently. Our results for the dissolution of forsterite and enstatite agree with this theory. However, although the forsterite appears to dissolve congruently and the system is undersaturated with respect to $\mathrm{Si}$ - or $\mathrm{Mg}$-bearing phases, a closer observation of the reacted forsterite surfaces with SEM reveals that there are localized regimes where condensation of a $\mathrm{Si}$ rich phase occurs.

The SEM image shown in Fig. 1 is of a reacted forsterite grain. Note the prominent dissolution etch pits. Several of the etch pits (in the lower left) have been occluded with a Si-rich precipitate. This grain was dissolved in $\mathrm{pH} 1.8 \mathrm{HNO}_{3}$ for $75 \mathrm{hr}$ and was extensively rinsed with doubly deionized $\mathrm{H}_{2} \mathrm{O}$ prior to imaging. The formation

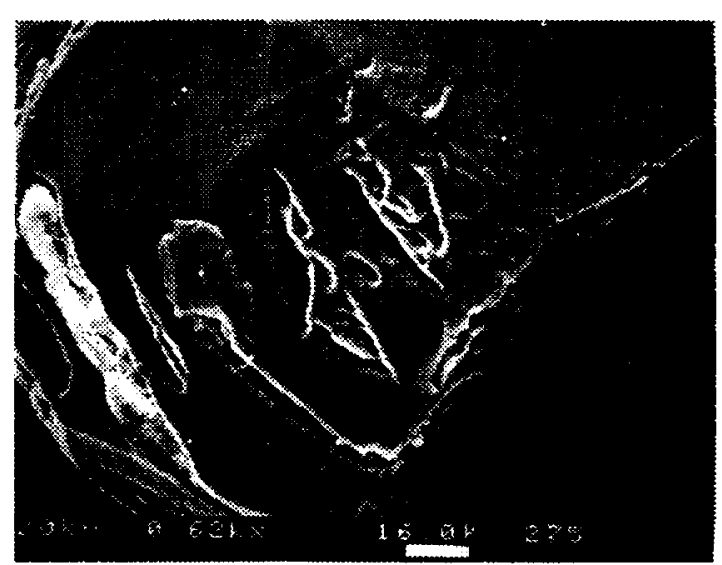

Fig. 1. SEM photomictograph of a reacted forsterite grain. Scale bar is $16 \mu \mathrm{m}$. See text for discussion.

of these Si-rich precipitates is likely due to a hydrodynamic control on $\mathrm{Mg}$ and $\mathrm{Si}$ transport away from the reacting mineral surface.

To further investigate how reacted mineral surfaces promote the heterogeneous precipitation of clays, we are presently conducting experiments in which our reacted $\mathrm{Mg}$ silicates are exposed to $\mathrm{pH} 5.0,5$-ppm Al(III)-bearing solutions at $25^{\circ} \mathrm{C}$. The solutions are slightly oversaturated with respect to the common Al oxyhydroxides, such as gibbsite or amorphous $\mathrm{Al}(\mathrm{OH})_{3}$. Given that the surfaces are enriched with amorphous silica (in the form of leached layers or Sirich residues), these conditions are also favorable for the formation of any number of aluminosilicates, such as smectite or montmorillonite.

These linked dissolution/precipitation reactions are important because they may be characteristic of the processes that form secondary minerals, such as clays, in natural soils.

THE ROLE OF SECONDARY IRON MINERALS ON THE MOBILITY OF ARSENIC DURING THE FLOODING OF LIGNITE MINES. T.R.Rüde, S. Wohnlich, and A. Vogelgsang, Institute of Geology and Applied Geology, Ludwig-MaximiliansUniversität, Luisenstrasse 37, 80333 München, Germany (thomas. ruede.@iaag.geo.uni-muenchen.de).

The flooding of open pits of former lignite mining in Eastem Germany produces severe risks for the groundwater quality due to the potential mobilization of acid, sulfate, and toxic elements. These contaminants are the result of the oxidation of commonly distributed pyrites in the coal-bearing bedrocks and the dumped materials. The unsaturated conditions during open-pit mining enable the widespread weathering of the sulfides and the deposition of the weathering products, e.g., acid, sulfate, secondary Fe minerals, and toxic trace constituents of the pyrites, in the pore spaces of the rocks, which could readily be mobilized by the rising groundwater after coal production has ceased.

To model and forecast these processes, it is of special interest to establish the real nature of the secondary Fe minerals and their stability during the change from the chemistry of unsaturated to that of saturated conditions. For example, minerals like jarosite and 
schwertmannite will not only stabilize the Fe but also a high proportion of the sulfate and could also fix high concentrations of toxic trace elements like As. The potential release of these constituents will then depend on the stability of such secondary Fe minerals and their recrystallization to, e.g., goethite.

We investigated the distribution of $\mathrm{Fe}$ and $\mathrm{As}$ - as an example of toxic aquoanions - in samples of a core drilled into a dump of a former open lignite pit. The 50-m-long drill core reaches the top of an older dump under a $17-m$-thick younger cover of different strata. This older dump consists of a heterogenous mixture of different units of Lower Tertiary stratigraphy with pyrite contents up to $50 \mathrm{~g} / \mathrm{kg}$ in the unweathered materials. This older dump was exposed to air for around $10 \mathrm{yr}$ before it was covered by the younger one.

In the upper $5 \mathrm{~m}$ of the older dump the total $\mathrm{Fe}$ concentration increases (top down) from $15 \mathrm{~g} / \mathrm{kg}$ to $30 \mathrm{~g} / \mathrm{kg}$ and As from $10 \mathrm{mg} / \mathrm{kg}$ to $\sim 25 \mathrm{mg} / \mathrm{kg}$. Besides this total element concentration, sequential extraction procedures and mineral determinations show that up to $60 \%$ of the $\mathrm{Fe}$ is fixed in secondary minerals like jarosite in the top $2 \mathrm{~m}$. Deeper in the dump a high-Fe mobilization occurs. In $\mathrm{H}_{2} \mathrm{O}$ extracts, up to $10 \mathrm{~g} / \mathrm{L}$ of Fe were analyzed, which represents up to $40 \%$ of the total Fe concentration of the material.

Minerals like ferrihydrite or schwertmannite contribute only a few percent to the total Fe concentration. In contrast to this, they are very important for the fixation of trace elements due to their high specific surface. Up to $50 \%$ of the total As concentrations are mainly sorbed by these minerals. Like Fe, As is also mobilized in samples below the upper $2 \mathrm{~m}$.

These preliminary results indicate a layer roughly $2 \mathrm{~m}$ thick in the top of such dumps with low element mobilities due to stable secondary Fe minerals. This layer is followed by reactive zones with potentially mobile elements.

Acknowledgments: This paper represents Publication No. 6 of the Priority Program 546 "Geochemical Processes with LongTerm Effects in Anthropogenically Affected Seepage and Groundwater." Financial support was provided by Deutsche Forschungsgemeinschaft.

THERMAL STRUCTURE OF ARCHEAN CRATONS: A NEW LOOK AT CONDUCTIVE GEOTHERMS AND XENO. LITH PRESSURE-TEMPERATURE ARRAYS. R. L. Rudnick, Department of Earth and Planetary Sciences, Harvard University, 20Oxford Street, Cambridge MA 02138,USA (rudnick@ eps.harvard.edu).

For a surface heat flow of $41 \mathrm{~mW} / \mathrm{m}^{2}$ (typical of Archean cratons), calculated conductive geotherms are highly variable at lithospheric mantle depths and are most sensitive to the absolute concentration of heat-producing elements (HPE) in the crust and lithospheric mantle. For a range of plausible Archean crust compositions, mantle roots beneath Archean cratons cannot have HPE concentra. tions as high as those observed in average gamet peridotite xenoliths carried in kimberlites, as this produces strongly curved geotherms that do not intersect the mantle adiabat.

Using a best estimate of lithospheric mantle heat production of $0.02 \mu \mathrm{W} / \mathrm{m}^{3}$ (derived from cratonic-like peridotites carried in nonkimberlitic host magmas), I show that only very unradiogenic bulk crust compositions are consistent with the pressure and temperature points calculated for cratonic garnet peridotite xenoliths (see Fig. 1). If lithospheric mantle heat production is higher than the above

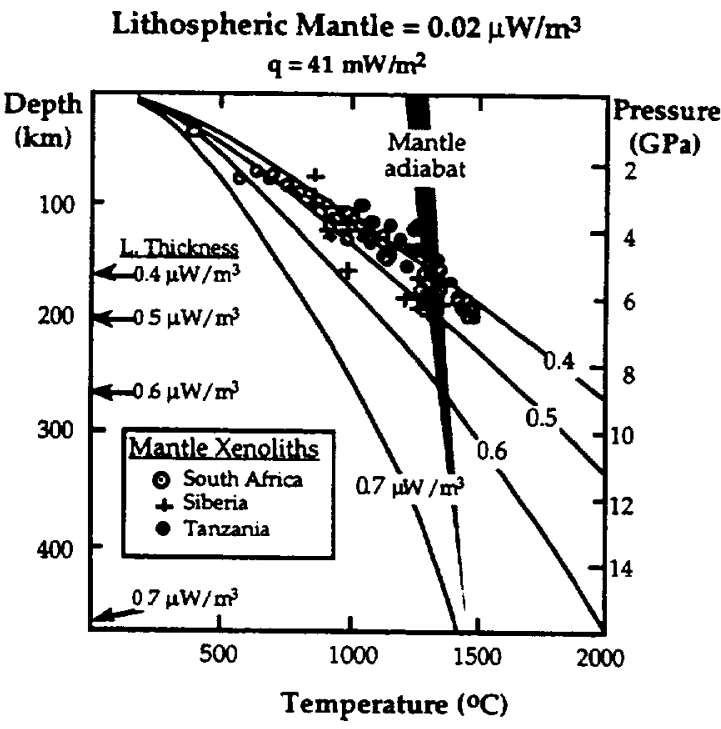

Fig. 1. Conductive geotherms for surface heat flow of $41 \mathrm{~mW} / \mathrm{m}^{2}$ and different bulk crust compositions $\left(0.4,0.5, \mu \mathrm{W} / \mathrm{m}^{3}\right.$, etc.) compared to $\mathrm{P}-\mathrm{T}$ arrays for cratonic mantle xenoliths. The lithospheric mantle is assumed to have a $\mathrm{K}_{2} \mathrm{O}$ content of $0.03 \mathrm{wt} \%$, corresponding to heat production of $0.02 \mu \mathrm{W} / \mathrm{m}^{3}$. A higher HPE content in the lithosphere will cause the geotherms to curve more strongly.

estimate, the discrepancy between the xenolith $\mathrm{P}-\mathrm{T}$ points and conductive geotherms is even greater. Thus a discrepancy exists between models of the deep structure of cratons based on seismic data (which show regions of anomalously fast mantle underlying Archean cratons to depths of $300-400 \mathrm{~km}$ ) and the P-T characteristics of cratonic xenoliths.

If the xenolith P-T array does indeed reflect equilibration to a conductive geotherm, then Archean lithosphere is relatively thin ( $<200 \mathrm{~km}$ thick, based on the intersection of the xenolith P-T array with the mantle adiabat) and the primary reason for the lower surface heat flow in Archean compared to post-Archean crustal regions is differences in crustal radioactivity rather than the insulating effects of thick lithospheric roots. On the other hand, if the xenolith P-T points are regarded as frozen-in mineral equilibria or perturbed geotherms (possibly due to convective heat transport associated with flood basalt magmatism?), then the Archean crust can have higher HPE concentrations, lithospheric thickness can range to greater depths, and the difference between Archean and post-Archean surface heat flow is due, at least in part, to the insulating effects of thick lithospheric roots.

An uppermost limit on Archean crustal heat production is $0.7 \mu$ $\mathrm{W} / \mathrm{m}^{3}$, which corresponds to a heat flux across the Moho of $12 \mathrm{~mW} /$ $\mathrm{m}^{2}$ and a lithospheric thickness of at least $450 \mathrm{~km}$. The lowermost limit on Archean crustal heat production $\left(0.5 \mathrm{~mW} / \mathrm{m}^{2}\right)$ corresponds to a Moho heat flux of $21 \mathrm{~mW} / \mathrm{m}^{2}$ and minimum lithospheric thickness of $200 \mathrm{~km}$.

\section{CHEMICALTRANSFER EVENTS IN SUBDUCTIONZONES} AS A FUNCTION OF SLAB DEPTH. J. G. Ryan, Depantment of Geology, University of South Florida, 4202 East Fowler A venue, Tampa FL 33620, USA (ryan@chuma.cas.usf.edu).

In order to assess the effects of subduction-related chemical 
recyling, one must first develop a complete picture of the slab enrichment process. Results from recent studies of subductionrelated igneous and metamorphic rocks are leading to detailed chemical descriptions of the materials released from subducting plates and insights into the timing of these releases.

While information on slab fluxes drawn from arc-volcanic data is necessarily indirect, multi-element studies of arc suites in which data from related arc centers are compared (either along an arc segment [1-3] or a volcanic cross-chain) indicate the involvement of two distinguishable slab-derived "fluxes": one with enrichments of $\mathrm{B}, \mathrm{Cs}, \mathrm{As}, \mathrm{Sb}, \mathrm{Pb}$, and $\mathrm{N} \pm \mathrm{U}$ and $\mathrm{Ba}$ that vary with depth to the slab beneath the volcanos and/or mean extents of slab inputs, and one with more or less uniformly elevated contents of $\mathrm{K}, \mathrm{Ba}, \mathrm{Sr}$, LREE, ${ }^{10} \mathrm{Be}$, and like species.

Patterns of B-Cs-As-Sb enrichment in arcs mirror abundance decline observed in "subduction complex" metamorphic massifs formed at P-T conditions analogous to slabs at fore-arc depths $[4,5]$. These patterns suggest a progressive distillation of hydrous fluids from the subducting plate, as opposed to stepwise releases due to mineral decompositions. Alkaline elements such as $\mathrm{K}$ and $\mathrm{Ba}$ show little abundance change in these rocks. Diapiric serpentinites produced during mantle-slab fluid reactions beneath fore-arcs show enrichments of $B$ and like species, and no enhancements in $\mathrm{K}, \mathrm{Ba}$, or Sr. Thus, hydrous slab fluids transport a very limited menu of elements, and they do so at shallow depths, as ratios such as $\mathrm{B} / \mathrm{Be}$ and $\mathrm{Cs} / \mathrm{Th}$ approach $\mathrm{MORB} / \mathrm{OIB}$ values in lavas from volcanos above deep slabs.

The "second" slab flux matches aspects of published descriptions of both "sediment melt"[6], and "slab melt" [7,8] inputs: rich in $\mathrm{SiO}_{2}$, high in $\mathrm{K}, \mathrm{Na}, \mathrm{Ba}, \mathrm{Sr}$, and other alkaline elements; with elevated LREE, Th, and (sometimes) ${ }^{10} \mathrm{Be}$. Fluid/solid D values are very small for many of these species [see 9], pointing to a "melt-like" medium for their transport. This flux is a high $\mathrm{P}-\mathrm{T}^{\circ}$ phenomenon, as fore-arc samples exhibit little mobility for these elements, and enrichment factors for these elements are high in back-arc settings.

This current picture of the slab input process places constraints on subduction recycling: (1) B and other species that follow $\mathrm{H}_{2} \mathrm{O}$ recycle poorly, if at all, so the chemical cycles of these "fluidmobile" elements must include a large retum flux in fore-arc regions to balance extensive inputs to trenches. (2) Deeply recycled "subducted material" may represent some flavor of the "melt" flux released from slabs, or the refractory and dehydrated slab itself, all of which will be markedly depleted in the "fluid mobile" elements released early in the subduction process. The tools to resolve among the possible deep recycled components are incomplete, but the geochemical systematics of OIB sources (uniformly low $\mathrm{Pb} / \mathrm{Ce}, \mathrm{U} /$ $\mathrm{Nb}, \mathrm{Cs} / \mathrm{Rb}$ [10], and $\mathrm{B} / \mathrm{K}$ despite significant radiogenic isotope variability) is consistent to a first order with a "subducted" influence in many mantle reservoirs.

References: [1] Miller D. et al. (1992) JGR, 97, 321. [2] Miller D. et al. (1994) Nature, 368, 514. [3] Edwards et al. (1993) Nature, 362, 530. [4] Bebout G. et al. (1993) GCA, 57, 2227. [5] Bebout G. (1996) GSA Abs. Prog., A-254. [6] Plank T., Ph.D. dissertation, Columbia Univ. [7] Kepezhinskas P. et al. (1996) GCA, 60, 1217. [8] Schiano P. et al. (1996) Nature, 377, 595. [9] Kepler H. (1996) Nature, 380, 237. [10] Hart S. R. and Reid M. R. (1991) GCA, 55, 2379.

OSMIUM ISOTOPE SYSTEMATICS IN THE HOROMAN
PERIDOTITE. A. Saall, E. Takazawa ${ }^{2}$, F. Frey ${ }^{2}$, N. Shimizul, and S. Hart', 'Department of Geology and Geophysics, Woods Hole Oceanographic Institution, Woods Hole MA 02543, USA, 2Deparment of Earth Atmospheric and Planetary Sciences, Massachusetts Institute of Technology, Cambridge MA 02138, USA.

The Os isotopic composition in the Horoman peridotite massif shows large isotopic heterogeneities. The Horoman peridotite is a layered ultramafic massif tectonically emplaced in the Hidaka metamorphic belt in Hokkaido, Japan. Geochemically well-characterized samples from a $140-\mathrm{m}$ section across the layers, from plagioclase lherzolite to lherzolite to harzburgite, define a progressive depletion of basaltic components. This major-element compositional trend is associated with an increasing extent of metasomatism defined by enrichment in LREE ([1] and references therein). The ${ }^{187} \mathrm{Os} / 188 \mathrm{Os}$ ratios in Horoman peridotites range from 0.11577 to 0.12829 , similar to the isotopic range observed in other peridotitic massifs [2-4]. Considering all the lithologic types, the harzburgites and Iherzolites have Os isotopic ratios intermediate $(0.11902-$ 0.12263 ) to the isotopic range shown by the plagioclase lherzolites (0.11577-0.12829); therefore, only a weak correlation exists between ${ }^{187} \mathrm{Os} /{ }^{188} \mathrm{O}$ s ratios and major-element content (e.g., $\mathrm{Al}_{2} \mathrm{O}_{3}$, $\mathrm{CaO}$, and $\mathrm{MgO}$ ). The plagioclase lherzolites exhibit two distinctive types: (1) a "normal" type in major-element abundance with depleted LREE contents, and without any indication of metasomatism; and (2) an "enriched" type, slightly depleted in basaltic components, and with LREE enrichment indicating metasomatism [1]. For these types of plagioclase lherzolites, ${ }^{187} \mathrm{Os} / 188 \mathrm{Os}$ ratios correlate positively with $\mathrm{Al}_{2} \mathrm{O}_{3}, \mathrm{CaO}, \mathrm{Sc}$, and $\mathrm{Sr}$ and correlate negatively with $\mathrm{MgO}, \mathrm{Mg \#}, \mathrm{Rb}, \mathrm{Rb} / \mathrm{Sr}$, and ${ }^{87} \mathrm{Sr} /{ }^{86} \mathrm{Sr}$ ratios. The correlations between $O s$ isotopes and the major-and trace-element contents can be explained as an earlier depletion produced by melting, followed by a relatively young metasomatism that only affected the most incompatible trace elements (e.g., Rb) in the "enriched" plagioclase Iherzolite. The inverse correlation between ${ }^{87} \mathrm{Sr} /{ }^{86} \mathrm{Sr}$ and ${ }^{187} \mathrm{OS} /{ }^{188} \mathrm{OS}$ ratios and the fact that the samples with the extremes of $\mathrm{Os}$ and $\mathrm{Sr}$ isotopic ratios are situated only $5 \mathrm{~m}$ apart require specific conditions to explain this variation by different extents of melting followed by metasomatism over such short length scale. For example, the metasomatic event was very young or did not affect the Re/Os ratios of the "enriched" plagioclase lherzolite, and the melt extraction occurred in short length scale. A second possible explanation, although no less controversial, is that the observed correlations may indicate that melt/rock reaction processes [5] are responsible not only for the change in trace elements but also the change in major elements and isotopic ratios in the plagioclase lherzolites.

References: [1] Takazawa E. et al. (1996) Chem. Geol., 134, 3-26. [2] Reisberg L. et al. (1991) EPSL, 105, 196-213. [3] Reisberg L. and Lorand J. P. (1995) Nature, 376, 159-162. [4] Roy-Barman M. et al. (1996) Chem. Geol., 130, 55-64. [5] Kelemen P. et al. (1995) Nature, 375, 747-753.

RESPONSE OF $\alpha-\mathrm{Fe}_{2} \mathrm{O}_{3}$ DISSOLUTION RATES TO $\mathrm{pH}$ JUMPS. S. D. Samson and C. M. Eggleston, Department of Geology and Geophysics, University of Wyoming, Laramie WY 82071, USA (ssamson@uwyo.edu).

Surface complexation-based rate laws for proton-promoted dissolution of metal oxides predict that, in response to a sudden $\mathrm{pH}$ 
jump, a new steady state will be reached as rapidly as protons can adsorb or desorb to change the population of $>\mathrm{FeOH}_{2}{ }^{+}$sites: Rate $=\mathrm{k}\left[>\mathrm{FeOH}_{2}+\right]^{\mathrm{n}}$. This "surface charge" approach ignores the potentially important role of the metal centers themselves. In contrast to the surface-complexation approach, Burton-Cabrera-Frank (BCF)type models explicitly consider the role of adsorbed "nutrients" (e.g., $\mathrm{Fe}^{3+}$ on $\mathrm{Fe}_{2} \mathrm{O}_{3}$ ). Our work is designed to investigate the role of "adsorbed" Fe using non-steady-state kinetics.

Our experiments were conducted in a continuously stirred, flowthrough reactor with the $\mathrm{pH}$ changes made simultaneously in the reactor cell and the input reservoir. In a well-stirred, mixed-flow reactor, a change in input concentration will result in an exponential change in output concentration. An instantaneous change in $\mathrm{pH}$ accompanied by a nearly instantaneous change in dissolution rate would be mathematically equivalent to a change in input concentration. The solid line in Fig. 1 represents the predicted reactor response if the $\mathrm{pH}$ is suddenly changed to $\mathrm{pH} 1$, and if the dissolution rate is a step function.

The rates of hematite dissolution in $\mathrm{pH}$ jumps from $\mathrm{pH} 6,4.5,3$, and 2.5 to $\mathrm{pH} 1$ all exhibited a similar behavior (see Fig. 1): an initial spike reaching its maximum approximately $2 \mathrm{hr}$ after the $\mathrm{pH}$ jump followed by an exponential decay to a new steady state at $\sim 35 \mathrm{hr}$. The peak dissolution rate was highest at $\mathrm{pH} 6$ and the maximum rates decreased with decreasing $\mathrm{pH}$.

One explanation for this behavior is that there is a reservoir of adsorbed $\mathrm{Fe}$ and the amount of that reservoir is $\mathrm{pH}$ dependent. Ferric $\mathrm{Fe}$ has an adsorption edge on other metal oxides between $\mathrm{pH} 2$ and $\mathrm{pH} 4$, so if the hematite is dissolving at a given $\mathrm{pH}$ greater than 2 and the $\mathrm{pH}$ is suddenly changed to a lower $\mathrm{pH}$, we might expect this adsorbed or "labile" Fe to be released from the surface before a new steady state is reached. Indeed, our data from an earlier experiment show minimal response in a jump from $\mathrm{pH} 2$ to $\mathrm{pH} 1$, and this most recent experiment shows the same response whether the initial $\mathrm{pH}$ is 4.5 or 5.9. Thus, the amount of Fe involved is closely related to the expected $\mathrm{Fe}$ adsorption behavior.

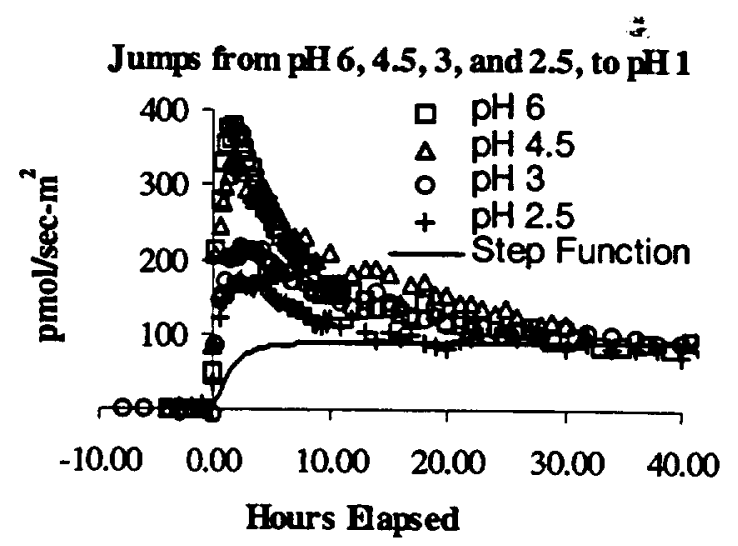

Fig. 1. Coupling the simple rate law for surface complexation models with an equation for the reactor response as a function of time, we propose the reac-tor output as a function of time should have the functional form of a double exponential, i.e., exponential chemical response convolved with exponential reactor response. Deconvolution of the reactor response from the chemical response shows that rate relaxation times exist: It takes time, $\sim 1$ day in this case, to transition from one steady state to another, implying that reactions other than proton adsorption and desorption are taking place.
The initial transient in response to a $\mathrm{pH}$ jump is reproducible; these experiments were conducted with a single sample of hematite that was cycled in $\mathrm{pH}$. This implies a form of labile Fe that can be regenerated in a predictable way. In this case, it is not an artifact of an initially "damaged" surface.

\section{URANIUM-LEAD GEOCHRONOLOGICAL INVESTIGA-} TION OF EXPOSED BASEMENT WITHIN THE CADOMIA TERRANE, CHANNEL ISLANDS: A TEST OF INDIRECT METHODS OF BASEMENT CHARACTERIZATION. S. D. Samson', B. V. Miller', and R. D'Lemos', 'Department of Earth Sciences, Syracuse University, Syracuse NY 13244, US A, ${ }^{2}$ Department of Geology, Oxford Brookes University, Oxford, UK.

Exposures of ancient basement within accreted terranes in many of the world's orogens is often limited or nonexistent. Geochemical characterization of basement in such regions must rely on indirect methods, such as analysis of plutons that may have substantially interacted with basement, or the characterization of clastic sediments that may have been partially derived from once-exposed basement rocks.

The Cadomia terrane provides a good test area for the success of indirect basement characterization of the numerous circum-Atlantic terranes because a region of known Cadomian basement is exposed in the British Channel Islands. Thus the geochemical and isotopic characteristics of Neoproterozoic granitoids and clastic sedimentary rocks can be directly compared to the characteristics of basement gneisses, collectively referred to as the Icartian gneisses.

The $\mathrm{U}-\mathrm{Pb}$ age of the dominant Icartian gneiss on the island of Guernsey is $2061+1.7 /-1.5 \mathrm{Ma}$. Similar $\mathrm{Pb}-\mathrm{Pb}$ ages have been determined from two other Icartian gneisses, including the Peastacks gneiss $(\sim 2.03 \mathrm{Ga})$ and the Castle Cornet Orthogneiss $(\sim 2.01 \mathrm{Ga})$, firmly establishing an Early Proterozoic age of Cadomian basement. Neodymium-depleted mantle model ages of the Icartian gneisses range from 2.22 to $2.36 \mathrm{Ga}$, only slightly older than their crystallization ages. An orthogneiss from the island of Sark, traditionally considered part of the Icarian basement, has a U-Pb age of $615.6+$ 4.2/-2.3 Ma, demonstrating that it is not exposed Cadomian basement, but rather is one of the many syntectonic Cadomian plutons. Its interaction with Cadomian basement is indicated, however, by the presence of zircon xenocrysts. The upper intercept age of three xenocryst-bearing zircon fractions is $2120 \pm 7 \mathrm{Ma}$. The intermediate Nd model age of the Sark orthogneiss, $1590 \mathrm{Ma}$, demonstrates that although the gneiss interacted with Icartian basement, it was not directly formed by basement anatexis. Two additional plutons emplaced during the Cadomian orogeny also show evidence of extensive interaction with Early Proterozoic basement. The $\sim 611-\mathrm{Ma}$ Perelle quartz diorite has a Tdm age of $1800 \mathrm{Ma}$, vastly older than its crystallization age, suggesting significant interaction with Early Proterozoic crust. The presence of abundant xenocrystic zircons in this granitoid is consistent with extensive interaction with older crust. Neodymium isotopic data for the 615-Ma L'Eree granite are also consistent with an anatectic origin for this syntectonic pluton $\left(\mathrm{Tdm}=1820 \mathrm{Ma}, \varepsilon_{\mathrm{Nd}}(615)=-10.5\right)$, but it is the U-Pb age of xenocrystic zircons in this body that directly point to the Icart gneiss as the major source of the older crustal component: an upper intercept age of $2065 \pm 15 \mathrm{Ma}$ is defined by a xenocrystic component and the concordant 615-Ma zircons. The upper intercept age is identical to that of the Saint's Bay Icart gneiss. 
A sandstone from the Brioverian sediments of the island of Jersey was collected for detrital zircon U-Pb geochronology. A single purplish grain yields a slightly discordant $\mathrm{Pb}-\mathrm{Pb}$ age of $\sim 2.4 \mathrm{Ga}$, further documenting the presence of ancient material in Cadomia.

Taken as a whole, determining the $\mathrm{Pb}$ isotopic composition of zircon xenocrysts from Neoproterozoic plutons and the ages of detrital zircons from Neoproterozoic turbidites appears to be an excellent method of indirectly characterizing the nature of Cadomian basement, increasing the confidence that isotopic characterization studies of other circum-Atlantic terranes, such as Avalon and the Carolina terrane, should provide a wealth of knowledge about the unexposed basement of these regions.

NOBLE GAS AND CARBON ISOTOPES IN MARIANA TROUGHBASALT GLASSES. Y. Sano ${ }^{1}, \mathrm{Y} . \mathrm{Nishio}^{2}, \mathrm{~T} . \mathrm{Gamo}^{3}$, A. Jambon ${ }^{4}$, and B. Marty', 'Department of Earth and Planetary Sciences, Hiroshima University, Kagamiyama, Higashi Hiroshima 739, Japan(ysano@ue.ipc.hiroshima-u.ac.jp), ${ }^{2}$ Geological Institute, The University of Tokyo, Bunkyo-ku, Tokyo 113, Japan, ${ }^{3}$ Ocean Research Institute, The University of Tokyo, Nakano-ku, Tokyo 164, Japan, ${ }^{4}$ Laboratoire de Magmatologie et Géochimie Inorganique et Expérimentale, Université Pierre et Marie Curie, F-75252 Paris Cédex 05, France, ${ }^{5}$ Centre de Recherches Pétrographiques et Géochimiques, Centre National de la Recherche Scientifique, Rue Notre-Dame des Pauvres, BP 20, 54501 Vandoeuvre Cédex, France.

We have measured noble gas elemental and isotopic compositions as well as abundance of $C$ and its isotopic ratios of 11 glasses from submarine pillow basalts collected from the Mariana Trough. The mean ${ }^{3} \mathrm{He} /{ }^{4} \mathrm{He}$ ratio of $8.37 \pm 0.15 \mathrm{R}_{\text {atm }}$ of samples dredged from the central Mariana Trough $\left(\sim 18^{\circ} \mathrm{N}\right.$; MARA) agrees well with that of mid- $\propto$ cean ridge basalt (MORB) glasses $\left(8.4 \pm 0.3 R_{a t m}\right.$ ), whereas a mean ratio of $8.06 \pm 0.35 R_{\mathrm{atm}}$ in samples from the northern Mariana Trough $\left(-20^{\circ} \mathrm{N} ; \mathrm{KH} 84\right)$ is slightly lower than those of MORB. One sample shows apparent excess ${ }^{20} \mathrm{Ne}$ and ${ }^{21} \mathrm{Ne}$ relative to atmospheric Ne, suggesting incorporation of solar-type $\mathrm{Ne}$ in the magma source. There is a positive correlation between ${ }^{3} \mathrm{He} /{ }^{4} \mathrm{He}$ and ${ }^{40} \mathrm{Ar} /{ }^{36} \mathrm{Ar}$ ratios, which is well explained by mixing between MORBtype and atmospheric noble gases. Excess ${ }^{129} \mathrm{Xe}$ is observed in the sample, which also shows ${ }^{20} \mathrm{Ne}$ and ${ }^{21} \mathrm{Ne}$ excesses. Thus, noble gas isotope data of the Mariana Trough samples indicate the occurrence of three components: MORB-type mantle-derived, atmospheric, and radiogenic noble gases. This signature is similar to that observed in island-arc volcanic gas samples.

Observed ${ }^{13} \mathrm{C}$ values of $\sim 20^{\circ} \mathrm{N}$ samples vary from $-3.76 \%$ o to $-2.80 \%$ and appear higher than those of MORB, and the corresponding $\mathrm{CO}_{2} /{ }^{3} \mathrm{He}$ ratios are higher than those of MARA samples at $\sim 18^{\circ} \mathrm{N}$. The elemental fractionation of $\mathrm{CO}_{2}$ and ${ }^{3} \mathrm{He}$, and the isotopic fractionation of $\mathrm{C}$ due to the magma degassing cannot explain the trend of MARA and KH84 samples in the diagram between the $\delta^{13} \mathrm{C}$ value and $\mathrm{CO}_{2} /{ }^{3} \mathrm{He}$ ratio. In contrast, the data are compatible with the two-component-mixing hypothesis between MORB-type and limestone-type $C$, suggesting $C$ contribution from the subducted slab in the KH84 samples.

INFLUENCE OF pH AND DISSOLVED PHOSPHATE ON THE SORPTION OF URANIUM ONTO CALCIUM CAR-
BONATE. A. V. Savenko, Geographical Department, Moscow State University, Vorobyovy Gory, Moscow 119899, Russia.

Calcium carbonate is one of the most important components of seawater suspended matter. During the $\mathrm{CaCO}_{3}$ precipitation in the euphotic layer many dissolved elements may be released. In the deep-sea waters the decrease of $\mathrm{pH}$ and the increase of the phosphate concentration occur. It may bring to displacement of sorption equilibrium during sedimentation of $\mathrm{CaCO}_{3}$. This hypothesis was checked by laboratory experiments. Uranium sorption onto $\mathrm{CaCO}_{3}$ from seawater with the concentration of phosphate from 0 to $3 \mu \mathrm{mol}$ $\mathrm{l}$ and at $\mathrm{pH} 7.6-7.9$ was studied. The experiments allowed us to determine the relationship between the value of specific sorption $(\mathrm{G}, \mu \mathrm{mol} / \mathrm{l})$ and the concentration of dissolved $\mathrm{U}(\mathrm{C}, \mu \mathrm{mol} / \mathrm{l})$

$$
G=(0.0104 \pm 0.000846) \times C
$$

The presence of $\mathrm{P}$ does not affect the sorption equilibrium. Based on the result of the study, one can suggest that the state of sorption equilibrium does not change during sedimentation. Thus, the results by Tatsumoto and Goldberg [1] obtained for the euphotic layer can be directly used for the estimation of the $U$ flux connected with the sedimentation of $\mathrm{CaCO}_{3}$ on the ocean floor.

References: [1] Tatsumoto M. and Goldberg E. D. (1959) GCA, 17, 201-212.

\section{DEPOSITION OF HEA VY METALS IN THE FLOOD PLAIN} SEDIMENTS OF THE YAMNUA RIVER (TRIBUTARY OF GANGA), INDIA. D. P. Saxena and V. Subramanian, School of Environmental Sciences, Jawaharlal Nehru University, New Delhi 110067, India.

The development of human civilizations in the Yamuna River basin has caused much environmental change; the flood plain sediments have recorded the process of such changes. The Yamuna River is of great interest because it covers an area ranging from highly industrialized to underdeveloped.

In the present study the heavy metal analysis of five sediment cores of flood plains-Sharanpur (near the Himalayas), Delhi, Jagmanpur (midstream), Hamirpur, and Allahabad (end of river)were studied using XRF techniques.

The enrichment of $\mathrm{Pb}, \mathrm{Cu}$, and $\mathrm{Zn}$ in the upper part of the sediment core is in agreement with the increase of anthropogenic influx (pollution) as a result of development. The average heavy metal content is lower at Sharanpur and increases downstream, although the highest average value is at Delhi, because of high industrial effluent and sedimentation rate $[1,2]$ in this region. At Jagmanpur the average metal content was low, although the rate of sedimentation here is the highest [2] because it is close to the confluence of many tributaries with the main stream and brings sediment load mainly from an undistributed area, thereby diluting the pollution in the river load.

The grain size of the flood plain reflects the river dynamics and depositional environment. The coarser grains near the Himalayas define the high rate of weathering and erosion in the Himalayas because of continuous deforestation in this region due to human development. The sand/clay ratio defines the climatic condition at microlevel, while the high content of clay reflects the flood conditions due to heavy rainfall in the catchment area. 
The S, C, and P transported by the Yamuna River and their deposition on the flood plain show spatial variation and diverse origins and heterogeneous composition due to mixing of autochthonous and allochthonous materials. In the upper part of the sediment core the values of $\mathrm{C}, \mathrm{S}$, and $\mathrm{P}$ are higher, reflecting the heavy use of fertilizers and pesticides with the increase of agricultural practices in recent decades.

References: [1] Subramian et al. (1986). [2] Saxena and Subramanian (1996).

\section{PALAEOPROTEROZOIC CRUSTAL EVOLUTION OF} THE SOUTHERN EYRE PENINSULA, GAWLER CRATON, AUSTRALIA. B. F. Schaefer, J. Foden, and M. Sandiford, Department of Geology and Geophysics, University of Adelaide, Adelaide 5005, South Australia (bschaefe@geology.adelaide.edu.au).

Palaeoproterozoic sequences on the Gawler Craton, South Australia, provide a well-constrained opportunity to investigate processes controlling and contributing to the growth and destruction of continental crust. Integration of geochemical, isotopic, structural, and metamorphic evidence not only places first-order constraints on the rate and volume of crustal addition, but also places broad limits on the rate and process of the return of crustal material to the mantle.

The southem Gawler Craton contains four distinct packages of rocks, each recording differing proportions of crustal recycling and input of new material to the crust from the mantle over the period $\sim 2500-1700 \mathrm{Ma}$. Broadly speaking, these comprise the dominantly upper-crustal paragneissic Sleaford Complex ( $2600-2400 \mathrm{Ma})$, the unconformably overlying shallow water, amphibolite facies Hutchison Group Metasediments ( $1900-1845 \mathrm{Ma}$ ), voluminous, dominantly felsic Lincoln Batholith magmatism (1848-1841 Ma), and the Moody Suite Granitoids ( $1750-1700 \mathrm{Ma})$, a synorogenic granitoid suite restricted within the Hutchison Group.

Extensive Rb-Sr, Sm-Nd, and geochemical studies of the Lincoln Batholith and contemporary crustal lithologies place constraints on the volume, proportion, and rate of addition of material to the continental crust on the southern Gawler Craton during the period of Lincoln Batholith magmatism. The Lincoln Batholith comprises dominantly $\left(>95 \%\right.$ ) siliceous magmas ( $>62 \mathrm{wt} \% \mathrm{SiO}_{2}$ ) containing $\varepsilon_{\mathrm{Nd}}$ values that may be modeled as mixtures between existing continental crust (i.e., the Sleaford Complex) and contemporary mantle. Trace-element characteristics of the felsic portions of the Lincoln Batholith also show signs of interaction with significant volumes (locally $>50 \mathrm{vol} \%$ ) of continental crust, notably in relative depletion of $\mathrm{Nb}, \mathrm{Ti}$, and $\mathrm{P}$. A series of comagmatic mafic dykes and enclaves, the Jussieu Dykes ( $<5 \%$ of the Lincoln Batholith), preserve (in regions of low strain) physical features reminiscent of Cordilleran-style magmatic processes; however, the batholith as a whole does not chemically follow a typical calc-alkaline trend. Neodymium-strontium isotopic studies reveal the Lincoln Batholith as a dynamically evolving and interacting mixture of new crustal material from the mantle (i.e., the Jussieu Dykes; $\varepsilon_{\mathrm{Nd}}=1845+1.4 /$ $-1.0)$ and large volumes of contemporary crustal material of the Sleaford Complex $\left(\varepsilon_{\mathrm{Nd}} 1845-5 /-10\right)$. Locally, isotopic signatures of Lincoln Batholith magmas are derived entirely from adjacent basement enclaves. Trace-element discrimination diagrams are indicative of within-platetectonic settings for emplacement of the Lincoln Batholith. The Kimban Orogeny, responsible for deforming both the
Lincoln Batholith and the Hutchison Group, preserves features atypical of modem orogens, and is typified by high-T, low-P metamorphism.

Some previous workers have appealed to nonuniformitarian processes of orogenesis and associated magmatism in Australian Proterozoic terrains [e.g., 1], suggesting significantly different mechanisms for both crustal growth and return of continental material to the mantle than presently in operation on the plate-tectonic Earth. Most scenarios, however, involve mass-balance arguments that require mechanisms for not only the input of significant volumes of new material to the continental crust, but the recycling and ultimate destruction of existing continental crust. Regardless of the specific mechanisms that may have operated, the net flux of material preserved in the continental crust of southern Eyre Peninsula suggests a protracted history over which relatively large volumes of crust are grown in short periods of time, against a constant background of material retum to the mantle. Subsequent crustal-scale recycling and homogenization (e.g., through sedimentation) have led to an evolving crustal isotopic signature for the Palaeoproterozoic crust. With further isotopic and geochemical studies, ultimately an understanding of the processes controlling the physical and chemical evolution of magmatic systems will allow the establishment of criteria for comparison and/or discrimination between modem platetectonic settings and ancient magmatic systems.

References: Etheridge M. A. et al. (1987) AGU Geodyn. Ser., 17. 131-147.

MANTLE FLOW AND PARTIAL MELTING: EVIDENCE FROM ULTRAMAFIC NODULES IN ALKALI BASALTS FROM INTRAPLATE VOLCANOS. P. Schiano and Y. Bottinga, Laboratoire de Géochimie et Cosmochimie, Institut de Physique du Globe, 4, Place Jussieu, 75252 Paris, France.

Observations: The spinel-lherzolite and harzburgite nodules are from volcanos fed by five different hotspots. Except for neoblasts, all crystals in the nodules bear witness of different shear deformation events and contain fluid and glass inclusions. All nodules show signs of partial melting and crystallization of new minerals from melt.

Deformation is indicated by kink-banding, deformation lamellae, and subparallel linear fractures and alignments of fluid and glass inclusions cutting across different minerals. The aligned inclusions mark fractures healed by recrystallization or filled up with glass. Different orientations of these subparallel arrays cause offsets and indicate different stages of deformation apparently separated by pauses of rest, permitting healing of the fracture scars.

The very numerous glass inclusions, amounting to $<0.1 \mathrm{vol} \%$, are predominantly associated with fractures. Inclusions have rounded shapes and may have been deformed viscously. They may contain one or more gas bubbles and secondary minerals belonging to either of two parageneses: (1) amphibole, rutile, clinopyroxene, $\mathrm{Mg}$ carbonate; (2) orthopyroxene, clinopyroxene, $\mathrm{Mg}$ carbonate. The minimum temperature of formation is $\sim 1250^{\circ} \mathrm{C}$. Gas bubbles in these glass inclusions contain only measurable quantities of $\mathrm{CO}_{2}$; the ratio $\mathrm{CO}_{2}$ /melt can vary greatly for different inclusions. Dissolved in the glass are $\mathrm{Cl}, \mathrm{H}_{2} \mathrm{O}$, and $\mathrm{CO}_{2}$. Glass compositions are $\mathrm{SiO}_{2}(54-$ $66 \%), \mathrm{Al}_{2} \mathrm{O}_{3}(15-23 \%), \mathrm{FeO}(0.7-5 \%), \mathrm{MgO}(0.6-4 \%), \mathrm{CaO}(1-$ $6 \%), \mathrm{Na}_{2} \mathrm{O}(2-8 \%), \mathrm{K}_{2} \mathrm{O}(1-7 \%)$, and $\mathrm{TiO}_{2}(0.1-2 \%)$. The densities 
of the $\mathrm{CO}_{2}$ in the fluid inclusions correspond to pressures between 0.7 and $1.4 \mathrm{GPa}$ at $1250^{\circ} \mathrm{C}$.

Primary glass inclusions are found in orthopyroxene and clinopyroxene, whose compositions fall in the range $\mathrm{SiO}_{2}(51-55 \%)$, $\mathrm{Al}_{2} \mathrm{O}_{3}(14-16 \%), \mathrm{FeO}(4-6 \%), \mathrm{MgO}(10-14 \%), \mathrm{CaO}(10-15 \%)$, $\mathrm{Na}_{2} \mathrm{O}(1-2 \%), \mathrm{K}_{2} \mathrm{O}(<1 \%), \mathrm{TiO}_{2}(<0.5 \%)$. Primary fluid inclusions contain chiefly $\mathrm{CO}_{2}$. In contrast to secondary glass inclusions, many primary glass inclusions have decrepitated, suggesting that they were more leakproof than the secondary inclusions, which were formed at higher pressure.

Conclusions: These inclusions show polybaric partial melting: (1) a very fluid melt associated with the primary inclusions, and (2) a very viscous melt in the secondary inclusions, in fractures, and as interstitial glass. Partial melting is not eutectic and may take place in the central regions of pyroxenes, where it is preceded by the exsolution of clinopyroxene lamellae. Melt is not concentrated in triple junctions. Porosity and permeability are due to fracturing and partial melting and are affected by recrystallization. Deformation is due to shearing; no signs of compression have been observed. Brittle failure occurs during time intervals of motion, which alternate with periods of rest, permitting annealing and recrystallization. The observed displacements are relatively small and strain does not amount to more than a few percent.

CARBON ISOTOPE RECORD AND ANTIQUITY OF TERRESTRIAL LIFE: A STATUS REPORT. M. Schidlowski, Max-Planck-Institut für Chemie, Postfach 3060, D-55020 Mainz, Germany.

Apart from the paleontological record, there also exists a biogeochemical record of former life whose most conspicuous manifestation is in the form of kerogen, i.e., the acid-insoluble, polycondensed end-product of diagenetic alteration of organic matter that had entered newly formed sediments as a residuum of primary bioorganic substances. These kerogeneous materials basically preserve the ${ }^{13} \mathrm{C} /{ }^{12} \mathrm{C}$ ratio of their biogenic precursor substances, thus confirming for the fossil record that the conversion of inorganic $\mathrm{C}$ (mostly $\mathrm{CO}_{2}$ ) into living matter had entailed a sizeable fractionation of the stable $\mathrm{C}$ isotopes. Hence, fossil organic substances display a similar bias in favor of isotopically light $\mathrm{C}\left({ }^{12} \mathrm{C}\right)$ as does living biomass, the heavy complement being retained in the inorganic $\mathrm{C}$ reservoir (mostly in the form of carbonate). Continuous biological processing of terrestrial $\mathrm{C}$ in the surficial exchange reservoir and subsequent burial of both $\mathrm{C}$ species in the Earth's sedimentary shell have, over geologic time, obviously propagated the isotopic disparity between carbonate and organic $C$ into the rock section of the $C$ cycle and thus into the geological record. Accordingly, differences in isotopic composition between carbonate and organic $C$ showing the magnitude and direction of biological fractionations may serve as biogeochemical recorders of ancient life processes [1].

The currently known $\mathrm{C}$ isotope record indicates that biologically mediated isotope fractionations unquestionably date back to $\sim 3.5 \mathrm{Ga}$, whereas all older sediments $(3.5-3.85 \mathrm{Ga}$ ) bear a metamorphic overprint that could have reset the ${ }^{13} \mathrm{C} /{ }^{12} \mathrm{C}$ ratios encoded in the primary rocks. In the case of the $\sim 3.8-\mathrm{Ga}$ metasediments from Isua (West Greenland), the observed secondary isotope shifts are fully consistent with the predictable results of an isotopic reequilibration between coexisting organic $\mathrm{C}$ and carbonate in response to the amphibolite-grade reconstitution experienced by the suite. Both currently available thermodynamic data on ${ }^{13} \mathrm{C} /{ }^{12} \mathrm{C}$ exchange between reduced and oxidized $\mathrm{C}$ as a function of increasing metamorphic temperatures and observational evidence from a host of geological younger metamorphic terrains make it virtually certain that the "normal" sedimentary $\mathrm{C}$ isotope record had originally extended back to $\sim 3.8 \mathrm{Ga}$ [2]. Moreover, organic trace constituents of an $~ 3.885-\mathrm{Ga}$ Isua banded-ironstone member that had missed an opportunity for isotope exchange due to the absence of coexisting carbonate have furnished ${ }^{13} \mathrm{C}$ values decidedly consistent with a biogenic pedigree [3]. Given the presently available data and our current background knowledge of $C$ isotope systematics in hightemperature systems, the $\mathrm{C}$ isotopic evidence at hand seems more than adequate to build a cogent case for the initiation of life processes as early as $\sim 3.85 \mathrm{Ga}$.

References: [1] Schidlowski M. (1987) Annu. Rev. Earth Planet. Sci., 15, 47. [2] Schidlowski M. et al. (1979) GCA, 43, 189; Schidlowski M. et al. (1983) in Earth's Earliest Biosphere (J. W. Schopf, ed.), p. 149, Princeton Univ.; Schidlowski M. (1988) $\mathrm{Na}$ ture, 333, 313. [3] Mojzsis S. J. et al. (1996) Nature, 384, 55.

TRANSPORT OF LEAD IN NATURAL GAS. A. P. Schmidt ${ }^{1}$ and Th. W. De Loos', 'Department of Geochemistry, Utrecht University,P.O.Box 80.021,3508 TA Utrecht, Netherlands (aschmidt@ earth.ruu.nl), ${ }^{2}$ Laboratory of Applied Thermodynamics and Phase Equilibria, Delft University of Technology, Julianalaan 136, 2628 BL Delft, Netherlands.

Oil and gas field brines are often regarded as potential oreforming fluids because of their high concentrations of $\mathrm{Pb}$ and $\mathrm{Zn}$. In oil or gas production installations, precipitation of metallic $\mathrm{Pb}$ can occur from coproduced formation waters as a consequence of these high concentrations. Recently, however, accumulation of metallic lead scale was reported from several installations treating "dry" natural gas. The absence of coproduced formation water indicates that natural gas itself is capable of transporting $\mathrm{Pb}$. The gas is saturated with the formation water in the reservoir and this equilibrium water condenses out of the gas during its way to the surface. It is suggested that the $\mathrm{Pb}$ transport takes place in association with the water vapor dissolved in the gas.

Experiments are currently carried out to determine the influence of reservoir temperature and pressure on the $\mathrm{Pb}$ content of dry natural gas. In a gas saturation apparatus, methane is equilibrated with a saturated $\mathrm{PbCl}_{2}$ solution in the temperature range of $60^{\circ}-$ $120^{\circ} \mathrm{C}$ and at pressures from 50 to $200 \mathrm{bar}$. The water condensed from the methane phase is not only analyzed for $\mathrm{Pb}$ and $\mathrm{Cl}$, but also for $\mathrm{Fe}$. The presence of $\mathrm{Fe}^{2+}$ could indicate a loss of $\mathrm{Pb}$ from the water due to reaction with the stainless-steel tubes of the saturation apparatus.

\section{PLATINUM GROUP ELEMENTS (PGE) IN ABYSSAL} PERIDOTITES FROM THE OCEANIC UPPER MANTLE. G. Schmidt' and J. E. Snow', 'Institut für Kemchemie, Universität Mainz, Fritz-Strassmannweg 2, D-55099 Mainz, Germany (gschmidt@vkcmzd.chemie.uni-mainz.de),2Max-Planck- 
Institut für Chemie, D-55099 Mainz, Germany.

There is a large database for PGE contents of the continental upper mantle. Little is known, however, about the oceanic upper mantle beneath mid-ocean ridges. Abyssal peridotites are fragments of the oceanic upper mantle and have a much shorter and lesscomplicated geologic history than most continental peridotites. These rocks are therefore ideal for the determination of the PGE content of the oceanic upper mantle.

Nine peridotite samples from dredges (Bouvet; AIl-107:40-35; All 107:61-83; and Dingaan samples, Indian Ocean) and from boreholes (Leg 147; Hess Deep, Pacific Ocean; Leg 153; MARK Area, Atlantic Ocean) were analyzed for $\mathrm{Re}, \mathrm{Os}, \mathrm{Ir}, \mathrm{Ru}, \mathrm{Pt}, \mathrm{Rh}, \mathrm{Pd}$, and $\mathrm{Au}$ by the fire-assay neutron activation method [1].

Standard reference material is analyzed in order to check for reproducibility and yield. Osmium, $\mathrm{Re}, \mathrm{Ir}, \mathrm{Ru}, \mathrm{Pt}, \mathrm{Rh}, \mathrm{Pd}$, and $\mathrm{Au}$ contents range from 1.52 to $3.36 \mathrm{ng} / \mathrm{g}, 0.04$ to $0.20 \mathrm{ng} / \mathrm{g}, 1.39$ to $3.44 \mathrm{ng} / \mathrm{g}, 2.68$ to $7.63 \mathrm{ng} / \mathrm{g}, 6.14$ to $11.64 \mathrm{ng} / \mathrm{g}, 0.72$ to $1.52 \mathrm{ng} / \mathrm{g}$, 2.33 to $7.79 \mathrm{ng} / \mathrm{g}$, and 0.19 to $1.23 \mathrm{ng} / \mathrm{g}$ respectively.

All nine samples have the essentially flat $\mathrm{CI}$-chondrite-normalized patterns (Figs. 1-4) of the PGEs. On a smaller scale, the samples exhibit a uniform positive slope from Os $\sim \mathrm{Ir}<\mathrm{Ru}<\mathrm{Pt}<$ $\mathrm{Rh} \geq \mathrm{Pd}$. A late-stage accreted "veneer" of strictly CI-chondritic composition is not compatible with this observation. The data indicate that additional components of PGEs exist in the oceanic upper mantle, or that some process has fractionated these elements.

Mixing of differentiated outer core material back into CI-chondritic veneer mantle could account for the observed noble metal ratios. The data also differ from those in continental mantle rocks, e.g., the Pd-anomaly is less pronounced. High $\mathrm{Pd} / \mathrm{Ir}$ ratios may be characteristic of continental mantle reservoirs [2].

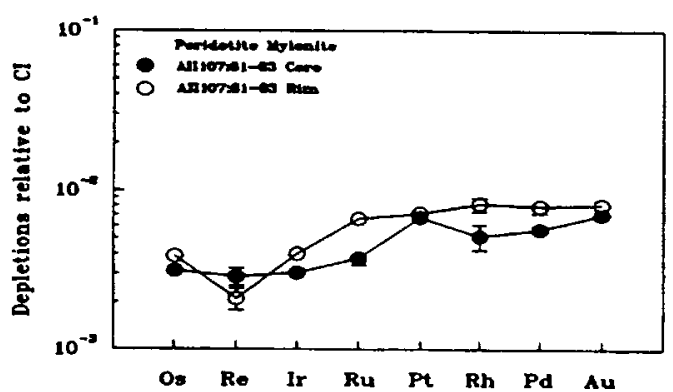

Fig. 1. Shaka Fracture Zone, Indian Ocean.

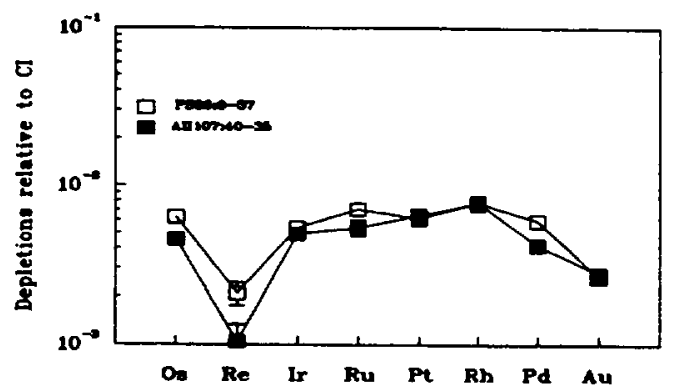

Fig. 2. Bouvet and Dingaan Fracture Zones.

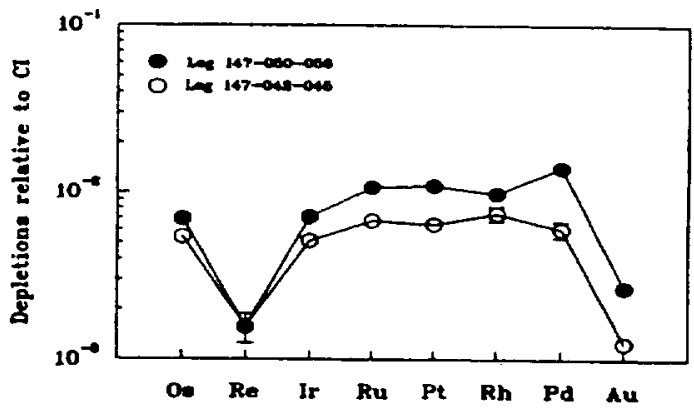

Fig. 3. Hess Deep, Pacific Ocean.

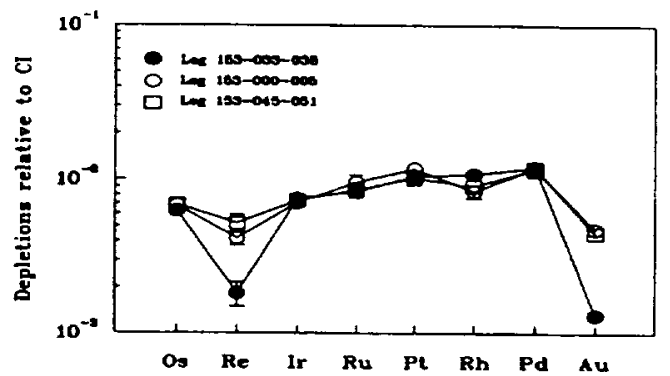

Fig. 4. MARK Area, Atlantic Ocean.

References: [1] Schmidt G. et al. (1997) GCA, in press. [2] Schmidt G. and Palme H. (1996) V. M. Goldschmidt Conference, J. Conf. Abs., I, 544.

DISTRIBUTION AND IDENTIFICATION OF MICROORGANISMS IN ACIDIC MINE DRAINAGE AS DETERMINED BY FLUORESCENCE IN SITU HYBRIDIZATION FOR ENVIRONMENTAL SAMPLES. M. O. Schrenk ${ }^{1}, K$. J. Edwards', J. F. Banfield', and R. M. Goodman'2, 'Department of Geology and Geophysics, University of Wisconsin-Madison, Madison WI 53706, USA, ${ }^{2}$ Department of Plant Pathology, University of Wisconsin-Madison, Madison WI 53706, USA.

The acidic mine drainage (AMD) environment at Iron Mountain, California, is among the most extreme ever recorded in terms of $\mathrm{pH}$ $(<0)$ and temperature $\left(>50^{\circ} \mathrm{C}\right)$. The production of AMD at this site is believed to be greatly accelerated by microbially mediated weathering of sulfide mineral. Studies of the microorganisms involved in the production of AMD have focused on a relatively limited range of $\mathrm{pH}$ and temperature values, although a far greater range of conditions frequently exists. This study reports the results of a comprehensive evaluation of the microbial populations present throughout a range of conditions, and the potential impact that discreet consortia might have upon niches within AMD. Earlier work in our laboratories on the microbial diversity of environments in Iron Mountain, involving the sequencing and analysis of the small subunit (SSU) ribosomal RNA gene, has provided phylogenetic information about selected organisms within the mine [1]. To determine the ecological roles of organisms containing these sequences 
and of chemolithotrophic bacteria that have typically been identified in AMD, we are using the fluorescence in situ hybridization of oligonucleotide probes to SSU rRNA in fixed environmental samples.

A survey to investigate the microbial diversity in the various environments of the Iron Mountain Mine has used oligonucleotide probes specific at the domain (Eukarya, Archaea, Eubacteria) and species ("Leptospirillum ferrooxidans," Thiobacillus ferrooxidans) levels. Environments sampled include spillways, pools, and sediments inside the mine $\left(\mathrm{pH} 0-2,30^{\circ}-50^{\circ} \mathrm{C}\right)$. Seepage from tailings piles, and holding portals for AMD runoff from outside the mine (pH 2-4, $10^{\circ}-25^{\circ} \mathrm{C}$ ), were also collected. The initial molecular analysis of samples from Iron Mountain indicated that a variety of microbes were present that had not previously been characterized. Past identification of $T$. ferrooxidans and " $L$. ferrooxidans" as the predominant species in AMD environments has largely been based upon the success of laboratory enrichment culturing methods and the extraction of DNA from solution. Results from our study have shown that at Iron Mountain Mine, these microbes are not attached directly to the surfaces of pyrite. Instead, an unidentified rod-shaped bacterium appears to colonize the mineral surfaces. A morphologically distinct microbial population appears in the solution associated with these minerals ( $\mathrm{pH} 0.5, \mathrm{~T}=45^{\circ} \mathrm{C}$ ), including bacteria of the genus "Leptospirillum." The species $T$. ferrooxidans was not found within the most acidic parts of the mine, where the AMD originates. However, $T$. ferrooxidans has been found embedded in a "slime matrix" in the higher-pH (1.4), lower-temperature $\left(25^{\circ} \mathrm{C}\right)$ tunnel leading into the mine. These new data from Iron Mountain Mine have provided further insight into the identity of microbial communities that play an important role in the dissolution of pyrite in this example of an extreme AMD environment.

References: [1] Rodgers et al. (1996).

SYNTHESIS OF ORGANIC COMPOUNDS DURING AQUEOUS ALTERATION OF THE MURCHISON METEORITE PARENT BODY. M. Schulte and E. Shock, GEOPIG, Department of Earth and Planetary Sciences, Washington University, One Brookings Drive, St. Louis MO 63130, USA (schulte@zonvark. wustl.edu).

The great abundance of hydrated silicate and carbonate minerals in the Murchison meteorite provides compelling evidence (corroborated by $O$ isotope data) that aqueous processes occurred on the Murchison parent body. We are investigating the likelihood that organic compounds found in the meteorite were formed in the same aqueous fluids responsible for the alteration of the primary, anhydrous minerals that originally coalesced to form the parent body. This work builds upon our earlier efforts in this area [1], and includes major improvements in the models now that we can take into explicit account the mineral alteration that attends the simultaneous organic compound synthesis, include many more groups of organic compounds in the calculation, and consider a wider variety of starting compositions for fluids and minerals.

Using bulk compositions of the Murchison meteorite from Jarosewich [2] and Fuchs [3], and initial fluid compositions based on cometary ice [4], we have minimized the Gibbs free energy of closed chemical systems using stable and metastable equilibrium constraints at various temperatures that may have been obtained during the alteration process. Closed-system behavior is consistent with studies showing that, with the exception of the most volatile elements, the Murchison meteorite (and the CM group as a whole) contains approximately solar abundances of the major rock-forming elements. Open-system calculations that model volatile loss can be compared with closed-system results to assess whether open systems provide additional thermodynamic drives to alter minerals or synthesize organic compounds. We have modeled heating events on the parent body that raised the temperature of the system to $150^{\circ} \mathrm{C}$. The pressure is sufficient in these calculations to prevent boiling. Oxygen isotope evidence has been interpreted to indicate that the temperature of alteration of the mineral phases was not greater than about $25^{\circ} \mathrm{C}$ [5], but it is possible that these resuits reflect the final steps of alteration and do not preclude earlier alteration events at higher temperatures that may have been subsequently overprinted.

Reaction-path calculations that simulate heating from the icemelting point to $150^{\circ} \mathrm{C}$ yield mineral assemblages remarkably similar to those observed in the matrix of the Murchison meteorite. The minerals calculated to form during alteration include serpentines, magnetite, clays, chlorites, olivine, pyroxene, carbonates, and sulfates. Departures from equilibrium, caused by changes in the flow of fluid through pore spaces and/or dissipation of water from the parent body, could result in preservation of any or all the minerals calculated to precipitate over the course of reaction progress in preference to the final equilibrium assemblage.

The organic compounds calculated to occur in the alteration sequence are also consistent with those observed in the meteorite. We are somewhat limited by the availability of thermodynamic data, but alcohols, amino acids, carboxylic acids, ketones, hydroxy acids, amides, and amines all appear in the models during the alteration sequences. Members of each of these groups of organic compounds are present in the Murchison meteorite [6]. We can now test various reaction pathways to see if relative concentrations of various groups of organic compounds are consistent with the mineral assemblages present in Murchison. For example, we can test whether a Strecker synthesis mechanism for amino and hydroxy acids [7] is consistent with the type and extent of mineral hydration recorded in the meteorite. We can also explore the entire range of fluid compositions that can be derived from known cometary compositions, and we can narrow the range of fluid/rock ratios that are consistent with the combined organic and mineralogic record of the meteorite. These results will, in tum, place constraints on the temperatures, durations, and mechanisms of parent-body heating.

References: [1] Shock and Schulte (1990) Nature, 343, 728. [2] Jarosewich (1971) Meteoritics, 6, 49. [3] Fuchs (1973) Smithsonian Contrib. Earth Sci., 10. [4] Fegley (1993) in The Chemistry of Life's Origins, p. 75. [5] Clayton and Mayeda (1984) EPSL, 67, 151. [6] Cronin et al. (1988) in Meteorites and the Early Solar System, p. 819. [7] Schulte and Shock (1995) OLEB, 25, 161.

RATE OF QUARTZ DISSOLUTION IN A TROPICAL WEATHERING ENVIRONMENT. M. S. Schulz, A. F. White, and D. V. Vivit, U.S. Geological Survey, WRD 345 Middlefield Road, Menlo Park CA 94025, USA.

Tropical weathering has been investigated in detail on an $8.5-\mathrm{m}$ thick weathering profile in the Loquillo Mountains, Puerto Rico. The study site is located on a relatively flat shoulder of a ridge divide (elevation $680 \mathrm{~m}$ ) separating two first-order streams in the Rio 
Icacos basin. Mean annual temperature is $22^{\circ} \mathrm{C}$. Average rainfall is $4200 \mathrm{~mm} \mathrm{y}^{-1}$; rain falls consistantly throughout the year. The weathering profile has developed on a quartz diorite intrusion and consists of a $1-\mathrm{m}$-thick soil and $7.5 \mathrm{~m}$ of saprolite. The bedrock mineralogy is plagioclase (An 0.40), quartz, and biotite with lesser amounts of homblende and alkali feldspar. The saprolite contains quartz, biotite, kaolinite, Fe-oxyhydroxides, and very limited amounts of feldspar and homblende.

The site was instrumented with suction water samplers to a depth of $8.5 \mathrm{~m}$. In addition, bulk precipitation and throughfall collectors were installed and surface water sampling sites were established.

Mass balance calculations applied to saprolite pore waters, using NETPATH, indicate that quartz dissolution occurs within the saprolite (38-61 $\mu$ moles $\mathbf{L}^{-1}$ ). Quartz dissolution is substantiated by etch pitting observed with scanning electron microscopy (SEM). Small triangular etch pits are found in the deepest portion of the saprolite; they are sparsely distributed, and mainly found along fractures. At the top of the saprolite etch pits, quartz grains are larger and more abundant. Atomic force microscopy (AFM) images of selected quartz grain surfaces reveal smaller "step" features at the submicrometer range.

Morphologic observations and mass balance calculations show that quartz is dissolving in this system. However, the pore-water silica concentrations exceed the commonly cited value for equilibrium solubility of quartz $\left(110 \mu\right.$ moles $\mathrm{L}^{-1}$ at $\left.25^{\circ} \mathrm{C}[1]\right)$, but agree more closely with a value of $180 \mu$ moles $\mathrm{L}^{-1}$ at $25^{\circ} \mathrm{C}$ determined by Rimstidt [2].

Surface areas measured (by BET method) on quartz grains from several depths and over several grain size intervals varied from 0.11 to $0.38 \mathrm{~m}^{2} \mathrm{~g}^{-1}$. There is no strong correlation of BET surface areas with grain size, probably due to microporosity in the quartz grains. Microfracturing of quartz grains is the product of normal stressing of plutonic quartz between the time of crystallization and its emergence and is ubiquitous in granitoid rocks.

The rate of quartz dissolution was calculated using (1) the mass loss computed by NETPATH $\left(5.65 \times 10^{-5}\right.$ moles $/ \mathrm{kg}$ water $),(2)$ a measured unsaturated hydraulic conductivity $\left(3.8 \times 10^{-6} \mathrm{~cm} \mathrm{~s}^{-1}\right)$,

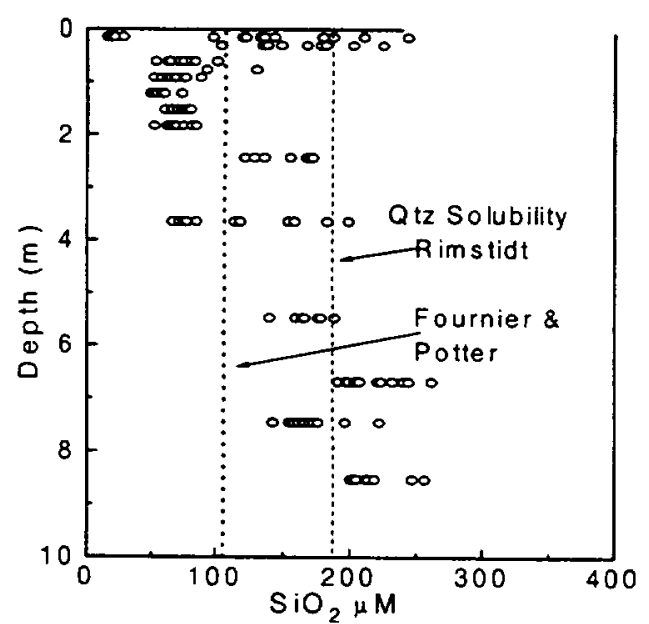

Fig. 1. Pore water $\mathrm{SiO}_{2}$.
(3) an averaged BET surface area $\left(0.22 \mathrm{~m}^{2} \mathrm{~g}^{-1}\right)$, and (4) the quartz abundance within the saprolite of $22.7 \%$. The calculated residence time of water in the weathering profile is $7.1 \mathrm{yr}$. The weathering rate constant for quartz is $4.92 \times 10^{-15} \mathrm{~mol} \mathrm{~m}^{-2} \mathrm{~s}^{-1}$. This rate constant agrees with published experimental rates.

References: [1] Foumier and Potter (1982). [2] Rimstidt (1984).

LICHEN WEATHERING AT CONE POND, NEW HAMPSHIRE. D. W. Schwartzman'1, R. Aghamiri', and S. W. Bailey², 'Department of Biology, Howard University, Washington DC 20059, USA, ${ }^{2}$ Northeastern Forest Experiment Station, USDA Forest Service, Campton NH 03223, USA.

Determination of the elemental runoff fluxes from lichen-covered bedrock could potentially provide quantitative estimates of biotic enhancement of weathering over the abiotic weathering regime, with implications for the evolution of the carbonate-silicate biogeochemical cycle over geologic time. Previous field studies of chemical denudation in alpine areas have implicitly included lichen weathering effects, since lichens are ubiquitous on exposed rock surfaces.

We have approached this problem by constructing miniwatersheds with areas of $0.05-1 \mathrm{~m}^{2}$ on lichen-covered and bare rock surfaces (mica schist) in the Cone Pond Watershed, near Hubbard Brook, New Hampshire. Polyurethane foam boundaries were created to constrain runoff into collection bottles for two summer field seasons. Sites were selected to avoid throughfall, with precipitation collectors providing rain samples for each storm event. Bare rock sites were created by splitting local bedrock with incipient fractures, and in one case on a surface exposed by treefall. Since all sites were at elevations less than $1 \mathrm{~km}$, the preferential capture of elements at lichen sites from a fog-derived deposition flux can be excluded. Filtered water $(<0.45 \mu \mathrm{m})$ samples were analyzed by ICP for $\mathrm{Mg}$. $\mathrm{Ca}, \mathrm{Na}, \mathrm{K}, \mathrm{Al}, \mathrm{Si}$, and $\mathrm{Fe}$. Experiments equilibrating polyurethane foam with rain indicate insignificant artifact contributions to measured elemental levels in runoff.

For each storm event, the ratio of elemental concentrations in runoff, corrected for precipitation levels, from lichen to bare rock sites (" $R$ ") gives an apparent ratio in chemical denudation rates for lichen to bare rock weathering at the same climatic conditions. $R$ values for $\mathrm{Mg}$ range from about 3 to 20 , for $\mathrm{Si}$ from 2 to 16 . $\mathrm{R}$ values for $\mathrm{Ca}, \mathrm{K}$, and $\mathrm{Na}$ are $>1$, while $\mathrm{R}<1$ for $\mathrm{Al}$ and $\mathrm{Fe}$, i.e., levels are higher from bare rock sites. This pattern is consistent with progressive accumulation of $\mathrm{Fe}$ and $\mathrm{Al}$ in the lichen thallus and its associated products of weathering since these two elements have consistently higher concentrations in analyzed lichen relative to the other elements.

Assuming a steady-state lichen biomass at lichen-covered sites, the computed $\mathrm{R}$ values for $\mathrm{Mg}, \mathrm{Si}, \mathrm{Ca}, \mathrm{K}$, and $\mathrm{Na}$ represent minimum estimates of lichen enhancement of chemical weathering over abiotic conditions, since these derived values neglect the loss of abraded lichen fragments from the sites during storms and compensating new growth (in addition, bare rock sites are not sterile, with likely microbial dissolution taking place).

Lichen weathering enhancement of one or more orders of magnitude are consistent with previous estimates from studies of weathering rind development under lichens of known ages. 
FIXATION AND MOBILIZATION OF FLUORINE IN TWO NEIGHBORING GEOCHEMICAL PROVINCES IN SRI LANKA. A. Senaratne, Lehrstuhl Angewandtegeologie, Institut für Geologie und Mineralogie, Schlossgarten 5, 91054, Erlangen, Germany (asenarat@geol.uni-erlangen.de).

Fluorine is a very common element found in rock, soil, water, and air. It is found in lattices of many common minerals such as pyroxene, amphibole, mica, and apatite in addition to its major presence in fluospar [1].

With $90 \%$ of its basement made up of granulite facies and amphibolite facies with varied types of pyroxene, amphibole, and mica-bearing rocks, Sri Lankan soils are rich in various forms of fluorine. However, the availability of this element for solutions is controlled by the geochemical characteristics of the soil.

On the basis of soil characteristics, Sri Lanka can be divided into two main geochemical provinces [2]. The soil mineralogies of these two provinces are entirely different and impart a strong influence on the chemical characteristics of groundwater.

Fluorine in Geochemical Province l (GP1) is easily mobilized as it was found in saline soils formed as a result of evaporative precipitation. The groundwater table, artificially raised because of the presence of a large number of manmade lakes in this region, has facilitated this evaporative process [4]. In the Geochemical Province 2(GP2) it is tightly bound to hydrated Fe oxide [3], which is the most common soil constituent in GP2. This has led to high levels of fluoride ion concentrations in GPI and serious fluorine deficiency in GP2 groundwater, causing the geochemical provinces to become areas of health risk.

References: [1] Dissanayake C. B. and Senaratne A. (1982) WASP, 17, 17-28. [2] Dissanayake C. B. (1991) IJES, 38, 137-156. [3] Jinadasa K. B.P. N. et al. (1993) EG, 21, 251-255. [4] Senaratne A. (1996) IIMI/IFAD7NCP, 45 pp.

ION PAIRING AND CLUSTER FORMATION IN HYDROTHERMALSOLUTIONS. T.M. Seward ', C.M. B. Henderson', J. M. Chamock', and T. Driesner', 'Institute for Mineralogy and Petrology, Swiss Federal Institute of Technology (ETH), 8092 Zürich, Switzerland, 'Department of Geology, The University, Manchester M13 9PL, UK.

With increasing temperature, liquid water becomes an expanded, low dielectric, protic solvent that is, nevertheless, still extensively $\mathrm{H}$ bonded. In addition to fundamental changes in ion solvation with increasing temperature, aqueous solutions become extensively associated. It has been generally assumed that such ion pairing leads to formation of simple monomeric species as $\mathrm{NaCl}^{\circ}$, although more recently the formation of polynuclear species such as $\mathrm{Na}_{2} \mathrm{Cl}^{+}$and $\mathrm{Na}_{2} \mathrm{Cl}_{2}{ }^{\circ}$ has been proposed in supercritical $\mathrm{NaCl}$ solutions [1]. Until now, there has been no direct experimental evidence (i.e., spectroscopic) for the existence of such species. In this study, we report our results for $\mathrm{SrCl}_{2}$ solutions as part of our ongoing $\mathrm{X}$-ray absorption (EXAFS) spectroscopic studies of ion pairing in hydrothermal fluids.

The EXAFS spectra were obtained using the 2-GeV synchrotron facility at Daresbury (UK). The solutions were contained in a hightemperature cell with silica windows that allow measurements to be made routinely up to $350^{\circ} \mathrm{C}$ at saturated vapor pressures. The background subtracted spectra were analyzed in k-space using the EXCURV92 program [2]. The experimental methods and data treatment are described in more detail by Seward et al. [3].

In a $1.0-\mathrm{m} \mathrm{SrCl} 2 / 3.0-\mathrm{m} \mathrm{HCl}$ solution at $25^{\circ} \mathrm{C}$, the EXAFS measurements provide evidence of appreciable ion pairing. Each $\mathrm{Sr}$ is coordinated, on average, to two chloride ions and three oxygens (water) in the first shell, suggesting the presence of $\mathrm{SrCl}_{2}{ }^{\circ}$ species in solution. The average $\mathrm{SrCl}$ distance is $2.86 \AA$. The average $\mathrm{Sr}^{2+}$. $O$ (water) distance of $2.56 \AA$ is similar to that obtained for dilute solutions (i.e., $0.01 \mathrm{~m} \mathrm{SrCl}$ ) in which the predominant species is the free aquated ion, $\mathrm{Sr}\left(\mathrm{H}_{2} \mathrm{O}\right)_{8}{ }^{2+}$.

At $270^{\circ} \mathrm{C}$, the EXAFS data exhibit evidence of Sr-Sr interactions in concentrated $1.0-\mathrm{m} \mathrm{SrCl}_{2} / 3.0-\mathrm{m} \mathrm{HCl}$ solution. These data suggest the presence of a chloride bridged dinuclear species of the type $\mathrm{Sr}_{2} \mathrm{Cl}_{3}{ }^{+}$in which the average $\mathrm{Sr}^{2+}-\mathrm{Cl}-$ bond is $2.82 \AA$ and the $\mathrm{Sr}^{2+}$. $\mathrm{Sr}^{2+}$ distance is $3.77 \AA$. These overall observations are supported by our molecular dynamics simulations of $1.0-\mathrm{m} \mathrm{SrCl} 2$ solutions at $300^{\circ} \mathrm{C}$ in which the presence of the free hydrated ion (i.e., $\mathrm{Sr}^{2+}$ ), as well as $\mathrm{SrCl}^{+}, \mathrm{SrCl}_{2}{ }^{\circ}, \mathrm{Sr}_{2} \mathrm{Cl}_{3}{ }^{+}$with minor amounts of short-lived higher molecular weight clusters, is demonstrated.

Insight into ion pair and polynuclear species formation is of importance to the understanding of many phenomena operating in hydrothermal systems such as stable isotope fractionation and mineral equilibria.

References: [1] Oelkers E. H. and Helgeson H. C. (1990) GCA, 51, 727-738. [2] Binsted N. et al. (1991) CLRC Daresbury Laboratory EXCUR V92 Programme. [3] Seward T. M. et al. (1996) $G C A, 60,2273-2282$.

\section{PROBLEM OF HETEROGENIC ACCUMULATION OF} THE EARTH AND THE MOON: EVIDENCE FROM TITANIFEROUS MAGMATISM. E. V. Sharkov, Institute of Ore Deposits Geology, Petrology, Mineralogy, and Geochemistry, Russian Academy of Sciences, Moscow 109017, Russia (sharkov@ igem.msk.su).

Studying of magmatic processes on the Earth and the Moon makes it possible to receive prompt information about the composition of melting substrates during all their geological histories. Taking into account the phenomena of mantle convection and mantle metasomatism (MM), these processes practically "sampled" all planets' matter.

Such data show that melting mantle substrates on the Earth in the Early Precambrian were rather different from those in the Phanerozoic. If those for the Early Precambrian were characterized by komatiite-basaltic and siliceous high-Mg series, derived from the low and high depleted ultramafic mantle, geoche mically enriched $\mathrm{Fe}$-Ti picrites and basalts of different alkalinity first appeared only around 2.2-2 Ga. Such melts are the main type found in the Earth's intraplate magmas. They derived from metasomatized ultramafic mantle and have the most deep-seated sources of the material. The magmas of such affinities were practically absent in the Archean and Paleoproterozoic, which is probable, evidence of the time that the mantle metasomatism phenomenon first appeared.

There are some similarities in the characteristics of magmatic evolution on the Earth and the Moon. On the Moon the earliest continental magmatic rocks were represented by depleted ANT series and high-Al basalts; high-Ti mare basalts appeared only 0.6- 
0.8 G.y. later. Thus, in the case of these planetary bodies, a new material, which did not previously take part in the processes of magma generation, began to be involved. It suggests that the evolution of the magmatic processes of the Earth and the Moon was linked with gradual warming of the bodies inward, and the composition of their outer and inner layer material were primarily different. Hence, accumulation of these bodies could be heterogenic.

PALEOPROTEROZOIC LARGE BALTIC IGNEOUS PROVINCE OF SILICEOUS HIGH-MAGNESIUM (BONINITELIKE) SERIES ROCKS AS A RESULT OF ANCIENT PLUME ACTIVITY: GEOLOGICAL AND PETROLOGICAL EVIDENCE. E. V. Sharkov' ${ }^{1}$, I. S. Krassivskaya ${ }^{1}$, and V. F. Smol'kin'2, Institute of Ore Deposits, Geology, Petrology, Mineralogy, and Geochemistry, Russian Academy of Sciences, Moscow 109017, Russia, ${ }^{2}$ Geological Institute of Kola Science Center, Russian Academy of Sciences, Apatity 184200, Russia.

The Paleoproterozoic Baltic province of siliceous high- $\mathrm{Mg}$ series (BPSHMS) is located in the eastern part of the Baltic Shield. It has about $1000 \mathrm{~km}$ in length and $\sim 700 \mathrm{~km}$ in width; however, its primary size is unknown, because all boundaries are secondary ones. It consists from volcanic rocks (low-Ti picrites, $\mathrm{Mg}$ basalts, andesites, dacites, and thyolites) in large grabenlike structures (Pechenga-Varzuga Belt, Vetreny Poyas, Pana-Kuolajarvi, etc.); large layered intrusions of basic and ultrabasic rocks (Monchetundra, Burakovsky, Fedorovo-Pansky, etc.) with PGE, $\mathrm{Cu}-\mathrm{Ni}$ and chromite ore deposits; Druzite complex of small intrusions with the same composition in the Belomorian Belt; and dyke swarms of gabbronorites. The BPSHMS looks like the Phanerozoic continental rift province, and was formed in two stages: Sumian (2.55-2.4 Ga ago), and Sariolian (2.4-2.3 Ga ago) with the same type of magmatic rocks.

Feature of these rocks are high contents of $\mathrm{SiO}_{2}, \mathrm{LREE}, \mathrm{Mg}, \mathrm{Cr}$, $\mathrm{Ni}, \mathrm{Zr}$, and low $\mathrm{Ti}$ and alkalies. In their major-, rare, and rare-earthelement patterns they are rather similar to the Phanerozoic islandarc magmatic rocks. The only difference is in isotopic characteristics: instead of subduction-related rocks, they have negative values of $\varepsilon_{\mathrm{Nd}(T)}=-1$ and -2 , similar to Archean crustal rocks.

It suggests that the origin of the Paleoproterozoic SHMS melts was linked to contamination of the mantle-derived low-Ti picrites by crustal material during the rise of magma bodies through the Archean continental crust by the way of zone refinement. Geochemical and isotopic data evidence regarding a highly depleted mantle source differ from the mantle sources of Phanerozoic continental flood basalts, which are often derived from the metasomatized mantle, enriched in $\mathrm{Ti}$ and alkalies. This leads to the conclusion that the plumes at the beginning of the Paleoproterozoic could be formed by highly depleted mantle material.

MODIFICATION OF SANIDINE RUBIDIUM-STRONTIUM AND OXYGEN ISOTOPIC SYSTEMS DURING STRUCTURE ORDERING. K. N. Shatagin ${ }^{1}$, V. N. Volkov', and B. G. Pokrovsky2. 'Institute of Geology of Ore Deposits, Geology, Petrology, Mineralogy, and Geochemistry, Russian Academy of Sciences, 35, Staromonetny Per., 109017, Moscow, Russia (shat@ igem.msk.su), ${ }^{2}$ Geological Institute, Russian Academy of Sciences,
7, Pyzhevsky Per., 109017, Moscow, Russia (pokrov@ginran. msk.su).

It is widely accepted that sanidine is a very reliable geochronometer for dating volcanic rocks. Unfortunately, it is the exception rather than the rule to find sanidine in acid volcanic rocks, as it commonly is modified to a low-temperature feldspar with a higher degree of ordering. Transformation of the former to the latter commonly occurs under hydrothermal conditions when solutions either promote structural ordering of the feldspar or serve as a transport media. Therefore, it is critical for geochronological interpretation to realize what happens with sanidine isotopic systems during the alteration.

We studied sanidine and products of its alteration separated from a subvolcanic rhyolite sample. The age of the studied rhyolite is estimated to be older than $299 \pm 4$ Ma from the K-Ar age of stratigraphically younger basaltic layers overlying the rhyolitic part of the sequence.

Limpid sanidine of the sample forms phenocrysts that are partially altered to different degrees. Weakly altered grains may have slightly turbid, white, nebular-like parts at the grain boundaries and along cracks, whereas the rest of grain is limpid. More altered grains became completely turbid; however, one may still see small crystalclear parts. These grains are macroscopically white. Finally, completely altered grains consist of turbid pink feldspar.

Thoroughly separated fractions of limpid sanidine, partially altered sanidine, and white and pink feldspars have a wide range of ${ }^{87} \mathrm{Rb} /{ }^{86} \mathrm{Sr}$ ratios, from 15.99 (sanidine) to 48.05 (pink feldspar). The differences in $\mathrm{Rb}$ and $\mathrm{Sr}$ content are also observed. Isochrons give an age through the points of $263 \pm 5 \mathrm{Ma}$, which is presumably lower than the true age of the rhyolite. So, the process of sanidine alteration took place much later than the emplacement of the subvolcanic body. Our data imply that this process was accompanied by loss of $\mathrm{Sr}$ from the altering sanidine and gain of $\mathrm{Rb}$.

Value of $\delta^{18} \mathrm{O}$ in the studied fractions ranges from $8.05 \%$ in sanidine to $9.15 \%$ in pink feldspar. If sanidine crystallized in equilibrium with quartz $\left(\delta^{18} \mathrm{O}=9.1 \%\right)$, then the temperature of their formation was more than $900^{\circ} \mathrm{C}$, which is consistent with magmatic origin of both minerals. The $\mathrm{O}$ isotope composition of the low-temperature feldspar is not in equilibrium with that of the quartz; this may be explained by the fact that colored feldspars are the products of some low-temperature process.

The foregoing study suggests that despite the alteration process that occurred, limpid sanidine kept its $\mathrm{Rb}-\mathrm{Sr}$ and $\mathrm{O}$-isotope systems closed. This allows us to use remnants of a primary sanidine for reliable dating and isotope geochemistry study.

TRACE-ELEMENT PARTITIONING IN PIGEONITE-GARNET-MELT ASSEMBLAGES IN NATURAL PERIDOTITE COMPOSITION AT HIGH PRESSURES. N. Shimizu ${ }^{1}, \mathrm{G}$. Layne', and M. Walter', 'Woods Hole Oceanographic Institution, Woods Hole MA 02543, USA, 'Institute for the Study of Earth's Interior, Misasa, Japan.

It has been suggested that the $\mathrm{CaO}$ content of clinopyroxene (cpx) at peridotite solidus decreases continuously with increasing pressure, and that the solidus cpx becomes pigeonitic at depths comparable to the spinel-gamet facies transition [e.g., 1,2]. Since 
partitioning of large ion lithophile elements between pyroxene and melt is strongly influenced by the $\mathrm{CaO}$ content of pyroxene [e.g., 3], trace-element partitioning directly relevant to the genesis of MORB, OIB, and komatiites must be determined in pigeonite-garnet-melt assemblages at peridotite solidus. We report here initial results of trace-element analyses of mineral phases and glass produced in partial-melting experiments of a natural peridotite composition. The starting material is a powdered spinel peridotite from Kittle River, British Columbia (KR4003), with fertile major-element chemistry $\left(3.45 \% \mathrm{CaO}, 4.26 \% \mathrm{Al}_{2} \mathrm{O}_{3}\right.$ and $\left.\mathrm{Mg \#}=0.892\right)$ and an unfractionated REE pattern at $2.5 \times \mathrm{Cl}$ chondrite [4]. Melting experiments were conducted in piston -cylinder and multianvil apparatus at pressures ranging from 3 to $7 \mathrm{GPa}$ [5]. Trace-element analyses were made with Cameca IMS $3 f$ and IMS 1270 ion microprobes at WHOI. It was found that with a spatial resolution of $5 \mathrm{~mm}$, the IMS 1270 operated with MRP $=5000$ has a sensitivity (cps/ppm) $\sim 200 \times$ greater for $\mathrm{Sr}$ than the IMS 3 f operated with energy filtering. REE partition coefficients determined for cpx with $\mathrm{CaO}$ ranging from $9.7 \%$ at $3 \mathrm{GPa}$ to $6.6 \%$ at $7 \mathrm{GPa}$ are greater than those of McKay [3] for cpx with corresponding $\mathrm{CaO}$ contents due to the "compensation" effects of $\mathrm{Al}_{2} \mathrm{O}_{3}$ discussed by Gaetani and Grove [6]. The cpx-melt REE partition coefficients are clearly correlated with $\mathrm{CaO}$ : 0.038 for $\mathrm{Ce}, 0.238$ for $\mathrm{Er}, 0.232$ for $\mathrm{Yb}$ with $\mathrm{CaO}=9.7 \%$ vs. 0.019 for $\mathrm{Ce}, 0.167$ for $\mathrm{Er}, 0.130$ for $\mathrm{Yb}$ with $\mathrm{CaO}=7.4 \%$. The latter values were obtained at $5 \mathrm{GPa}$ and agree well with those by Salters and Longhi [7] at $2.8 \mathrm{GPa}$ with comparable $\mathrm{CaO}$ (7.3\%). The gamet-melt REE partition coefficients at $5 \mathrm{GPa}$ are similar to those for the cpx-melt for $\mathrm{La}$ and $\mathrm{Ce}$, and near unity for $\mathrm{Er}(0.80)$ and $\mathrm{Yb}$ (1.16), indicating that HREE (and $Y$ ) compatibility decreases with increasing pressure. This indicates that melts produced at various degrees of melting in the presence of gamet at relatively low pressures (e.g., $3 \mathrm{GPa}$ ) would display "fan"-shaped HREE-buffered REE variations, whereas at high pressures (e.g., $>5 \mathrm{GPa}$ ) melts would display less-fractionated and parallel REE pattems.

References: [1] Bertka and Holloway (1993) JGR, 98, 19755. [2] Longhi and Bertka (1996) Am. Mineral., 81, 685. [3] McKay (1989) Rev. Mineral., 21, 45. [4] Xue et al. (1990) JGR, 95, 15879. [5] Walter (1997) J. Petrol. [6] Gaetani and Grove (1995) GCA, 59 , 1951. [7] Salters and Longhi (1997) Nature.

HIGH-PRESSURE PHASE EQUILIBRIUM IN THE SYSTEM MORB-H $\mathrm{H}_{2} \mathrm{O}-\mathrm{CaCO}_{3}$ ： THE ROLE OF CARBON DIOXIDE IN SUBDUCTION ZONES. M. Shirasaka and M. Arima, Geological Institute, Faculty of Education, Yokohama National University, 79-2 Tokiwadai, Hodogaya-ku, Yokohama 240, Japan (96m1063@server3.ed.ynu.ac.jp; arima@.ed.ynu.ac.jp).

Calcite is the most abundant C-bearing phase in the oceanic crust. To better understand the role of calcite in the subduction process, we carried out a series of high-pressure melting experiments in the system MORB- $\mathrm{H}_{2} \mathrm{O}-\mathrm{CaCO}_{3}$ at $1.0-2.5 \mathrm{GPa}$ and $900-$ $1300^{\circ} \mathrm{C}$. Different proportions of $\mathrm{CaCO}_{3}(5,10,30 \mathrm{wt} \%)$ and $\mathrm{H}_{2} \mathrm{O}$ $\left(\mathrm{H}_{2} \mathrm{O} / \mathrm{CaCO} \mathrm{CO}_{3}=1\right.$, mole ratio) were added to the synthetic glass powder of MORB composition.

Results: Phase relations in the system MORB $\cdot \mathrm{H}_{2} \mathrm{O}-\mathrm{CaCO}$ at 1.5 GPa. $\mathrm{Cpx}+\mathrm{Pl}+\mathrm{Mag}+\mathrm{Qtz} \pm \mathrm{Cal} \pm \mathrm{Gr} \pm \mathrm{Amp}+\mathrm{V}$ are stable phases in the subsolidus field. Solidus temperature is determined between $900^{\circ}$ and $1000^{\circ} \mathrm{C}$ in the pressure range $1.0-1.5 \mathrm{GPa}$.
Clinopyroxene is the primary liquidus phase over a wide range of $\mathrm{T}$ $\mathrm{X}$ condition, and is characterized by high $\mathrm{Na}_{2} \mathrm{O}$ (up to $3 \mathrm{wt} \%$ ), $\mathrm{Al}_{2} \mathrm{O}_{3}$ (up to $15 \mathrm{wt} \%$ ) and CaTs $(>15 \%)$. In the runs with MORB-rich compositions, amphibole, orthopyroxene, and gamet are stable phases in subsolidus and/or suprasolidus fields. With increasing $\mathrm{CaCO}_{3}$ in the starting compositions, amphibole, orthopyroxene, and gamet $\left(\mathrm{Grs}_{15-19}, \mathrm{Pyr}_{48-63}, \mathrm{Alm}_{22-33}\right)$ disappear, plagioclase $\left(\mathrm{An}_{46-58}\right)$ and magnetite abundance decrease, and calcite becomes a major crystalline phase.

In the run with $70 \% \mathrm{MORB}-30 \% \mathrm{CaCO}_{3}$, euhedral calcite coexists with melts of andesitic composition at $1000^{\circ} \mathrm{C}$, whereas at $1100^{\circ} \mathrm{C}$, anhedral calcite, clinopyroxene, and silica-undersaturated melts were stable phases. In the run with $95 \% \mathrm{MORB}-5 \% \mathrm{CaCO}_{3}$, calcite coexists with $\mathrm{Cpx}+\mathrm{Qtz}+\mathrm{Grt}+\mathrm{Mag}+\mathrm{Pl}+\mathrm{V}+$ melt at $1000^{\circ} \mathrm{C}$, whereas at $1050^{\circ} \mathrm{C}$, calcite breaks down and an assemblage of $\mathrm{Cpx}+\mathrm{Opx}+\mathrm{Pl}+\mathrm{Mag}+\mathrm{V}$ coexists with melt of andesitic composition.

Pressure-temperature phase relations for 95\% MORB-5\% $\mathrm{CaCO}_{3}$. Clinopyroxene is the liquidus phase over a wide range of P-T. The garnet stability field is limited at relatively higher-pressure conditions.

At 1.0 GPa, $\mathrm{Cpx}+\mathrm{Mag} \pm \mathrm{Opx} \pm \mathrm{Sp}$ is a stable assemblage. At $2.0 \mathrm{GPa}, \mathrm{Cpx}+\mathrm{Mag}+\mathrm{Qtz}+\mathrm{Grt}+\mathrm{Ky}+$ melt $+\mathrm{V}$ are stable between $900^{\circ}$ and $1100^{\circ} \mathrm{C}$. Interestingly, kyanite crystallized at $2.0 \mathrm{GPa}$.

At $900^{\circ} \mathrm{C}$, amphibole is a stable phase between 1.0 and $1.5 \mathrm{GPa}$, which breaks down to Opx + melt with increasing temperature. In our experiments, a stability field of calcite-bearing assemblage is located at a higher-temperature side than that of the amphibolebearing assemblage.

Sen and Dunn [1] carried out melting experiments in the MORB$\mathrm{H}_{2} \mathrm{O}$ system ( $1.5 \mathrm{wt} \% \mathrm{H}_{2} \mathrm{O}$ added). The stability field of the amphibole-bearing assemblage in this study is located at about $100^{\circ} \mathrm{C}$ lower-temperature side, and the quartz-out reaction is about $100^{\circ} \mathrm{C}$ higher-temperature side than Sen and Dunn's experiments. The melts in our experiments are higher in $\mathrm{Al}$ and $\mathrm{Ca}$ and lower in $\mathrm{Fe}$,

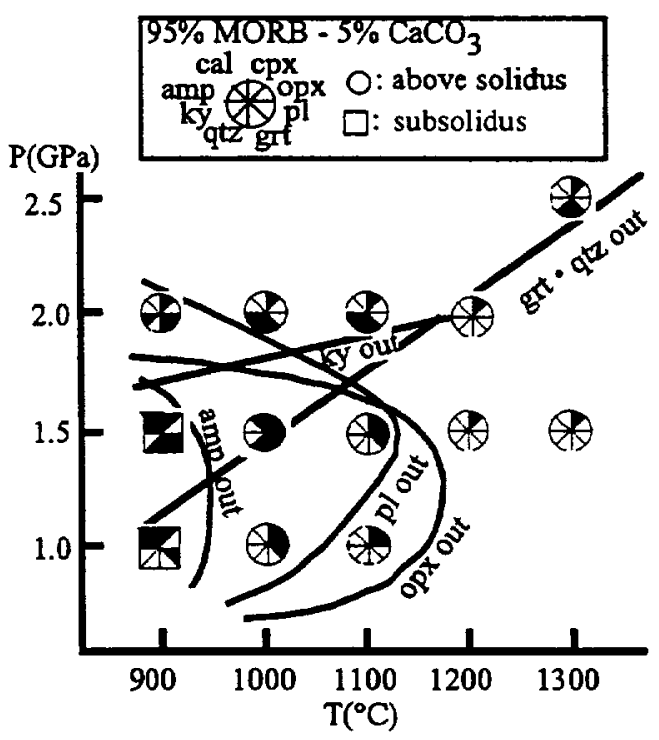

Fig. 1. 
$\mathrm{Mg}, \mathrm{Ti}, \mathrm{Na}$, and $\mathrm{K}$ than their results. The meits occurring in the kyanite-bearing assemblages show distinct compositions that are characterized by higher $\mathrm{Mg}$ and $\mathrm{Ca}$ and lower $\mathrm{Al}, \mathrm{Na}$, and $\mathrm{K}$ than those in the amphibole-bearing assemblages.

A wide range of variations is observed in the analyzed melt compositions. Among these, the melt coexisting with gamet and kyanite (at $2.0 \mathrm{GPa}, 900^{\circ}-1000^{\circ} \mathrm{C}$ ) are comparable to the adakite compositions of Mt. St. Helens and other localities. The results show well-defined variation trends comparable to those observed in adakites. The present result experimentally demonstrates for the first time that calcite is stable in a narrow suprasolidus field, just above the solidus. This result suggests that calcite would be a stable $C$ reservoir in the descending oceanic crust even under the relatively higher geothermal gradient.

References: [1] Sen and Dunn (1994).

INITIAL OSMIUM ISOTOPIC COMPOSITIONS OF MUNRO TOWNSHIP, ONTARIO, KOMATIITES REVISITED: ADDITIONAL EVIDENCE FOR NEAR-CHONDRITIC, LATE-ARCHEAN CONVECTING MANTLE BENEATH THE SUPERIOR PROVINCE. S. B. Shirey, Carnegie Institution of Washington, Department of Terrestrial Magnetism, 5241 Broad Branch Road, Northwest, Washington DC 20015, USA.

Archean komatiites are of great interest as indicators of Archean mantle composition; they derive from deep sources in the convecting mantle and form by high extents of melting [1]. Their sources are perhaps the Archean analog to modern hotspots. Komatiites should be excellent for Os isotopic studies of mantle source composition because they have high Os content relative to the crust and parentdaughter variations that permit isochrons on closely related flow sequences [2]. The locality at Pyke Hill, Munro Township, Ontario, Canada, is important for understanding late Archean komatiites because of the good preservation of complete cooling units, the flowto-flow regularity of incompatible-trace-element pattems, the lack of evidence of crustal contamination, the absence of sulfide ores, and the rather uniformly depleted Nd isotopic compositions [2-4]. Komatiites here are close to $2715 \mathrm{Ma}$ in age [5], and are A]undepleted, having trace-element pattems similar to N-MORB [6] and high $\mathrm{MgO}$ (19.90-34.74 wt\%), $\mathrm{Ni}$ (582-1754 ppm), and $\mathrm{Cr}$ (2542-3391 ppm) contents [2].

The first terrestrial Re-Os isochron was obtained on komatiites from Pyke Hill [2]. As Re-Os isotopic analytical procedures improved $[7,8]$, numerous attempts were made to improve this isochron; all ended in failure due to the irreducibility of replicates and poor isochron systematics. Contamination of the original powders with $\mathrm{Fe}$, which can have up to $18.5 \mathrm{ppb}$ Os and $64 \mathrm{ppb} \operatorname{Re}$ [9], during initial crushing elsewhere and incomplete dissolution of magnetite, which can contain substantial $R e$ and Os [10], were suspected. To circumvent these problems, uncrushed samples [11] of the same flows previously analyzed were crushed at the Department of Terrestrial Magnatism in all-alumina apparati. These powders were subjected to a two-step Carius tube attack, first in $\mathrm{HCl}$ to dissolve magnetite, then in aqua regia to finish dissolution and achieve spike-sample equilibration. These procedures yield a much-improved $\mathrm{Re}-\mathrm{Os}$ isochron with good systematics on all samples analyzed.

The new Re-Os data from Pyke Hill yield an ISOPLOT [12] model 3 age of $2675 \pm 130 \mathrm{Ma}$ and an initial ${ }^{187} \mathrm{Os} / 188 \mathrm{Os}$ of $0.1098 \pm$ 0.0041 at the $95 \%$ confidence limit $\left(\gamma_{o s}=0.67 \pm 3.7\right)$. This is a factor of 1.6 and 2.5 lower uncertainty on the age and initial ratio, respectively, over the older data [2]. Limited Re/Os spread on the isochron and lack of low $\mathrm{Re} / \mathrm{Os}$ whole rocks leads to an initial Os isotopic whose geological uncertainty is overestimated from the error envelope on the isochron alone. Since these flows are all contemporaneous, emplaced within tens of meters of one another, have very similar trace-element characteristics, and have an age known from $\mathrm{U}-\mathrm{Pb}$ zircon work to better than $10 \mathrm{Ma}$, another way to estimate the initial ratio uncertainty is to take the weighted average of the initial Os isotopic compositions calculated for each sample. This gives an average ${ }^{187} \mathrm{Os} /{ }^{188} \mathrm{Os}$ for the Pyke Hill locality of $0.1087 \pm 0.0019$ $\left(\gamma_{O}=-0.3 \pm 1.7 ;\right.$ MSWD $\left.=25\right)$ at the $95 \%$ confidence limit.

The revised initial Os isotopic composition for the Pyke Hill komatiite source is within errors of a mantle composition with a long-term chondritic Re/Os. It is virtually identical to the initial Os isotopic composition of an isochron on $2.7-\mathrm{Ga}$ komatiite-hosted magmatic sulfides from the Norseman-Wiluna belt, Western Australia [13]. These data provide evidence that the convecting upper mantle was well mixed with regard to the siderophile elements added during late accretion by the late Archean and displayed no enrichment in ${ }^{187} \mathrm{Os}$ as do modern hotspots. Subsequently, retum of Archean recycled oceanic crust, or interaction between the mantle and the core, led to enrichments of ${ }^{187} \mathrm{Os}$ in convecting mantle reservoirs starting during the Proterozoic $[14,15]$.

References: [1] Nisbet E. G. et al. (1993) Lithos, 30, 291307. [2] Walker R. J. et al. (1988) EPSL, 87, 1-12. [3] Pyke D. R. et al. (1973) GSA Bull., 84, 944-951. [4] Amdt N. T. et al. (1977) J. Petrol., 18, 319-369. [5] Nunes P. D. and Pyke D. R. (1981) Econ. Geol., 76, 944-951. [6] Arth J. G. et al.(1977) Geology, 5, 590-594. [7] Creaser R. et al. (1991) GCA, 55, 397-401. [8] Shirey S. B. and Walker R. J. (1995) Anal. Chem., 67, 2136-2141. [9] Johnson C. M. and Shirey S. B., unpublished data. [10] Johnson C. M. et al. (1996) J. Geol. Soc. Edinburgh, 87, 339-352. [11] Stecher O. (1995) personal communication. [12] Ludwig K. R. (1996) USGS OpenFile Rpt., 91-445. [13] Foster J. G. et al. (1996) Naiure, 382, 703706. [14] Shirey S. B. (1997) Can. J. Earth Sci, 34, in press. [15] Walker R. J. et al. (1997) EPSL, in press.

CRUSTAL GROWTH AND PALEOGEOGRAPHY IN HERCYNIAN AND APPALACHIAN BELTS BY SAMARIUMNEODYMIUM ISOTOPIC STUDY OF SHALES. F. Simien', M. Mattauer ${ }^{2}$, and C. J. Allègre ${ }^{1},{ }^{1}$ Laboratoire de Géochimie et Cosmochimie, Institut de Physique du Globe de Paris-URA CNRS D1758-UER des Sciences de la Terre, Université Paris VII Denis Diderot, 4Place Jussieu, 75252 Paris Cedex 05, France, ${ }^{2}$ Laboratoire de Tectonique et Géophysique, ISTEEM, Place Bataillon, 34095 Montpellier, France.

In the last 30 years, antagonistic models have tried to better understand whether the present mass of continents was formed early in the Earth's history or has been continuously extracted from the mantle. The study of shales with the Sm-Nd isotopic system may result in important chronological information about crustal growth as shales integrate the diversity of eroded rocks and this isotopic system is left undisturbed by surface processes. The Nd isotopic composition of shales reflects a balance between juvenile inputs 
from the mantle by volcanism and reworked inputs from the continental crust. However, this signal is a biased mean of the different mechanically eroded sources. For example, preexisting sediments and young mountains are more readily eroded. From a different perspective, we will also compare the $\mathrm{Nd}$ isotopic signal between different basins, and we depict this in terms of paleogeographic setting.

We have analyzed 70 shales from Montagne Noire (Southern France), with stratigraphic ages ranging from 570 to $180 \mathrm{Ma}$, for $\mathrm{Sm}-\mathrm{Nd}$ isotopes. The initial ${ }^{143} \mathrm{Nd} /{ }^{144} \mathrm{Nd}$ isotopic ratios range from -10.6 to $-4.4 \varepsilon_{\mathrm{Nd}(\mathrm{T})}$ units and the calculated $\mathrm{Nd}$ model ages range from 2.03 to $1.22 \mathrm{Ga}$. Three major $\varepsilon_{\mathrm{Nd}(\mathrm{T})}$ shifts toward more radiogenic values were detected just after well-known volcanic and orogenic events (at 560 and $300 \mathrm{Ma}$ ) or only volcanic (at $460 \mathrm{Ma}$ ). In order to havee a mass balance, we analyzed volcano-sedimentary materials, lavas, and granitoids. Moreover, in order to test for the presence of a volcanogenic component, we used trace elements such as $\mathrm{Cr}$. Thus, we are able to distinguish between short timescale volcanic inputs from long-term juvenile contributions. This allows us to identify a Palaeozoic crustal growth episode in the area. Of particular interest is the Frasnian/Famennian boundary, when one of the largest Phanerozoic extinctions (370 Ma: upper Devonian) took place. In this very well constrained stratigraphic section (the stratotype), we tested for some short-timescale and lateral variations. This succession of black shales and limestone shows anomalous concentrations in some trace elements as well as in Nd isotope ratios. We will also show a similar study in the eastern Pyrénées and eastern Canada (Dunnage/Gander, Avalon, and Meguma terranes), but with a less-well-calibrated stratigraphic timescale.

The paleogeographic implications of our data will be discussed and compared with other published datasets. These results indicate that Spain and Brittany were connected for most of the Palaeozoic and that Montagne Noire had a different palaeogeographic history from 500 to $340 \mathrm{Ma}$.

SPATIAL AND TEMPORAL VARIATIONS IN MID-OCEANRIDGE BASALT GEOCHEMISTRY ALONG THE EAST PACIFIC RISE CREST: URANIUM-SERIES DISEQUILIBRIA, RADIOGENIC ISOTOPES, AND ELEMENTAL VARIABILITY IN A CLOSELY SPACED, TWO-DIMENSIONAL GRID OF SAMPLES FROM $9^{\circ} 48^{\prime}-52 ' N$. K. W. W. Sims $^{1}$, S. J. Goldstein ${ }^{2}$, M. R. Perfit ${ }^{3}$, D. J. Fomari', S. R. Hart', M. C. Smith ${ }^{3}$, and M. T. Murrel12, 'Department of Geology and Geophysics, Woods Hole Oceanographic Institution, Woods Hole MA 02543, USA, ${ }^{2}$ Chemical Science and Technology Division, Los Alamos National Laboratory, Los Alamos NM 87545, USA, 3Department of Geology, University of Florida, Gainesville FL 32611 , USA.

The mid-ocean ridge (MOR) is the largest, most continuous volcanic lineament on Earth. Despite its significance, we have directly observed, mapped, and sampled $<1 \%$ of the MOR's total surface area, and have only just begun to comprehend the complex temporal and spatial distribution of volcanism that occurs both on and off the ridge axis.

To better understand how the chemistry of mid-ocean ridge basalts (MORB) vary through space and time as function of source chemistry, melt generation and transport, and crustal fractionation, we have begun to measure U-series disequilibria and radiogenic isotopes in a spatially and geologically well-characterized, twodimensional grid of MORB samples from the $9^{\circ} 50^{\prime} \mathrm{N}$ area of the EPR. These samples include: (1) a suite of young MORBs collected exclusively within the axial summit caldera between $9^{\circ} 49^{\prime}-5 I^{\prime} \mathrm{N}$, and (2) a closely spaced gridded suite of over 200 off-axis samples that span the ridge crest from $9^{\circ} 48^{\prime}-52^{\prime} \mathrm{N}$ and across it for $4 \mathrm{~km}$ on either side. Both suites were collected during the AdVenture research cruises (1991-1995) using the deep-sea submersible Alvin and a precision rock corer. The young ages for the axial samples are confirmed by observed field relations and by $\mathrm{Po}-\mathrm{Pb}$ ages for the 1991-1992 samples [1]. The major- and trace-element compositions of both the on-and off-axis samples have previously been well characterized [2].

Among the young axial MORB samples, there is a subtle range of compositions from more primitive to slightly more evolved (e.g., Mg\# ranges from 63 to 66), a range of $\mathrm{Sr}$ isotopes (0.7024-0.7026), and a range of $\left({ }^{231} \mathrm{~Pa} / 235 \mathrm{U}\right)$ disequilibria $(2.45-2.71)$. These variations imply that not all the young axial samples can be related to the 1991-1992 event or, if they are, it indicates that these eruptions had a significant degree of heterogeneity. In contrast, the off-axis lavas on the crustal plateau show a much wider range of magmatic fractionation (Mg\# ranges from 53 to 66 ) and chemical characteristics (e.g., transitional MORB are common). Field observations suggest that the off-axis lavas (up to $4 \mathrm{~km}$ from the ridge axis) are volumetrically small, more chemically evolved and/or enriched, and often younger than surrounding lava flows. Young ages for these offaxis samples are corroborated by their measured $\left({ }^{231} \mathrm{~Pa}^{235} \mathrm{U}\right)$ disequilibria activity ratios $(2.60-2.66)$, which are similar to those measured in the young axial samples. Calculated U.Pa "model" ages for these more evolved, off-axis MORBs $(0 \pm 8000 \mathrm{yr})$ indicate that they are younger than would be inferred by "model ages" based on the average crustal spreading rate $(\approx 60,000-80,000 \mathrm{yr})$.

These initial results are in general agreement with U-series evidence for off-axis volcanism at other locations $\left(9^{\circ} 30^{\prime} \mathrm{N}\right.$ EPR, Juan de Fuca and Gorda Ridges) [3]. The observation that the basaltic compositions and U-Pa "model" ages vary significantly, over short distances, places important constraints on the petrogenetic and accretionary processes occurring in this area of the EPR.

References: [1] Rubin et al. (1994) Nature, 368. [2] Perfit et al. (1994) Geology, 22; Smith et al. (1996) Eos Trans. AGU, 77. [3] Goldstein et al. (1994) Nature, 367.

\section{MICROBIALLY INDUCED CORROSION AND PRECIPI- TATION OF IRON PHOSPHATES BY DEEP SUBSURFACE BACTERIA GROWN AS BIOFILMS ON 1020 CARBON STEEL. G. Southam ', R. Donald ${ }^{1}$, P. Castro ${ }^{2}$, B. Pitonzo ${ }^{2}$, and P. Amy', 'Department of Biological Sciences, Northern Arizona University, Flagstaff AZ 86011-5640, USA, 'Department of Bio- logical Sciences, University of Nevada-Las Vegas, Las Vegas NV 89154, USA.}

Iron-oxidizing and dissimilatory sulfate-reducing bacterial enrichments and a consortium of exopolymer (EPS)-producing bacteria were isolated from the deep subsurface at Yucca Mountain. These bacterial groups were used individually and in combination in a comosion study of $1020 \mathrm{C}$ steel. Colonization of the steel coupons in soft R2A agar prepared with simulated groundwater 
occurred as biofilms. Biofilms were fixed with $2 \%$ glutaraldehyde, dehydrated using acetone, and embedded in Epon 812 resin on the surface of the steel coupons. After embedding, the biofilms were freeze-fractured off the surface of the coupons and re-embedded so the biofilms could be cross-sectioned. Examination of the coupon surfaces after the biofilms were removed revealed bacteria-sized corrosion pits in all the biological systems and larger pits in the systems containing EPS-producing and sulfate-reducing bacteria. Light microscopy of the biofilm samples showed a thin $(\sim 5 \mu \mathrm{m})$ mineralized layer in the control and Fe-oxidizing enrichments. All the remaining systems involving EPS-producing and sulfate-reducing bacteria, alone or in combination, possessed a heavily mineralized matrix $>20 \mu \mathrm{m}$ thick. The sulfate-reducing enrichment also contained microcolonies at the fluid interface, held together by a mineralized capsule. Energy-dispersive spectroscopy demonstrated that all the mineralized biofilms contained Fe-phosphate and $\mathrm{Fe}$ oxyhydroxide precipitates. In the sulfate-reducing and EPS-producing systems, low levels of iron sulfides were also detected. These corrosion studies involving Yucca Mountain bacteria suggest a generalized corrosion mechanism in which the bacterial biofilms concentrate the available phosphate from solution followed by mineral diagenesis and Fe-phosphate precipitation.

PETROGRAPHIC AND GEOCHEMICAL EVIDENCE FOR EVOLUTION OF SIBERIAN LITHOSPHERE IN XENOLITHS FROM KIMBERLITES OF YAKUTIA. Z V. Spetsius, Institute of Diamond Industry, Mimy, Yakutia, Russia(yna@ mimy.rospac.ru).

Introduction: Ancient origin for Siberian lithosphere supported by $\mathrm{Re}-\mathrm{Os}$ and $\mathrm{Sm}-\mathrm{Nd}$ model ages for eclogite and peridotite xenoliths from pipe Udachnaya is obtained by different authors [13]. The age of formation of xenoliths and their differentiation in the mantle, according to isotopic data and other petrologic evidence, is not less than $3.0 \mathrm{Ga}$. The lowest peridotite Os isotopic compositions require $R e$ depletion in the mid-Archean $(3.2 \mathrm{Ga})$ and this age is interpreted as the time of differentiation of the Siberian lithospheric mantle [2]. The age of some samples of diamondiferous eclogites from Udachnaya varies between 2.8 and $3.5 \mathrm{Ga}$ according to initial Os isotopic composition [4], but some eclogites gave a Sm-Nd age that approximates the time of emplacement of kimberlite [5].

Discussion: The indications of mantle metasomatism manifested in deep-seated xenoliths are noted in many pipes of Yakutia among the rocks of mafic and ultramafic composition [6]. The melt pockets and zoned grain of gamets were found in peridotite xenoliths from the Udachnaya and Mir pipes. The only and relatively revealing criteria of infiltration metasomatism is mica and amphibole that undoubtedly have a metasomatic origin in mantle xenoliths. There are not sufficient data to judge the manifestation intensity of these processes in various areas of the Siberian Platform. The peculiarities of the phlogopite occurring in mantle rocks encountered as large grains commensurable with other minerals and in the composition of kelyphite rims leads us to believe that the metasomatic processes at the mantle level were probably repeated. The most striking features of metasomatose and partial melting have been reported in eclogites from Udachnaya, where association of such melted phases as spine.

In rare instances, diamonds extracted from mantle xenoliths contain silicate inclusions whose composition can be compared to minerals in the host xenolith in order to constrain the history both of the diamond and rock in the upper mantle $[7,8]$. These studies have demonstrated differences in trace-element abundance between included in diamonds and rock-forming minerals, which have been interpreted as being due to metasomatic enrichment of the rock after diamond growth [7] or depletion of the rock by partial melting after diamond growth [5]. In both cases, it is clear that the inclusions record the earliest composition of the eclogites at the time of diamond growth, which have subsequently been overprinted by later events.

Besides, there is some petrographic evidence, such as inhomogeneous distribution in the sample and growth features for late and multistage formation of diamonds in eclogite xenoliths, that probably is connected with the processes of partial melting and mantle metasomatism [9].

Conclusion: The mantle xenoliths from kimberlites of Siberia contain different metasomatic and partial-melting phenomena. The trace-element and isotopic data for eclogite xenoliths from Udachnaya provide evidence that Siberian eclogites have experienced complex multistage histories after their formation. To understand the evolution of the lithospheric mantle it is necessary to determine both the age of origin of mantle rocks and the age of subsequent mantle processes.

References: [1] Jacob D. et al. (1994) GCA, 59, 5191-5207. [2] Pearson D. G. et al. (1995) GCA, 59, 959-977. [3] Snyder G. A. et al. (1993) EPSL, 118, 91-100. [4] Pearson D. G. et al. (1995) Nature, 374, 711-713. [5] Snyder G. A. et al. (1995) Ext. Abst. 6th Int. Kimb. Conf., 549-551. [6] Spetsius Z. V. and Serenco V. P. (1990) Composition of Continental Upper Mantle and Lower Crust Beneath the Siberian Platform, Nauka, Moscow, in Russian. [7] Ireland T. R. et al. (1994) EPSL, 128, 199-213. [8] Taylor L. A. et al. (1996) EPSL, 142, 535-551. [9] Spetsius Z. V. (1995) Ext. Abst. 6th Int. Kimb. Conf., 572-574.

RHENIUM-OSMIUM ISOTOPIC CONSTRAINTS ON THE GENESIS OF MAGMATIC NICKEL-COPPER-COBALTPLATINUM-GROUP-ELEMENT ORES, EAST KIMBERLEY, WESTERN AUSTRALIA. R. A. Sproule' 'D. D. Lambert', and D. M. Hoatson', 'Victorian Institute of Earth and Planetary Sciences, Department of Earth Sciences, Monash University, Clayton VIC 3168, Australia, ${ }^{2}$ Australian Geological Survey Organisation, GPO Box 378, Canberra, ACT, 2601, Australia.

The Halls Creek Mobile Zone (HCMZ) was intruded by at least 46 Proterozoic mafic-ultramafic intrusions in three age pulses; $\sim 1855 \mathrm{Ma}, \sim 1840 \mathrm{Ma}$, and $\sim 1830 \mathrm{Ma}$ [1]. The $\sim 1840$-Ma maficultramafic Sally Malay intrusion hosts a basal massive $\mathrm{Ni}-\mathrm{Cu}-\mathrm{Co} \pm$ PGE sulfide deposit consisting of pyrrhotite, pentiandite, chalcopyrite, and magnetite and displays many similarities to the recently discovered Voisey's Bay Ni-Cu-Co deposit in Labrador, Canada, including tectonic setting, Proterozoic age, sulfide mineralogy and textures, and troctolite-bearing host intrusion [2]. We present new Re-Os isotopic data from Sally Malay to better constrain the genesis of this important style of magmatic sulfide deposit.

Massive sulfide ores from Sally Malay have low to medium common Os concentrations (2-4 ppb) and high Re/Os ratios ( 20), similar to data for Duluth Complex (USA) massive sulfide ores [3]. These data are consistent with derivation of the ores from a basaltic parental magma at a relatively low $\mathbf{R}$ factor (effective mass of 
silicate melt with which a given mass of sulfide melt has equilibrated). Modeling of $\mathrm{Ni}, \mathrm{Cu}, \mathrm{Re}$, and common Os data from the massive sulfide ores is consistent with $R$ factors in the range of 200 300.

Massive sulfide ores from Sally Malay yield exceptionally radiogenic initial Os isotopic compositions ( $\left.\gamma_{O S}=1100-1300\right)$. Matrixdisseminated sulfide ores in troctolites ( $\sim 40$ vol\% sulfide) range from $\gamma_{O s}=450-470$, whereas weakly mineralized troctolites and peridotites range from $\gamma_{O s}=60-369$. The Os isotopic data strongly suggest that the ores were derived from crustally contaminated mantle melts. However, the effects of contamination can be masked by the R-factor process in which sulfide melt equilibrates with extensive amounts of uncontaminated chondritic mantle melts [4]. Thus, we now incorporate the R-factor parameter in our modelling of Re-Os isotopic data from dynamic magmatic ore systems using equations developed by Foster et al. [4]. This modeling demonstrates that the variation observed in the initial Os isotopic compositions in different parts of the Sally Malay ore system may be due to a variable $R$ factor: Massive ores appear to have experienced a lower $R$ factor $(\sim 200)$ than the matrix-disseminated ores $(\sim 500-$ 800).

We therefore prefer a two-stage model for ore formation at Sally Malay that may be appropriate for other magmatic sulfide ore systems (Duluth, Noril'sk-Talnakh, Sudbury, Voisey's Bay [3]). In this model, sulfide-undersaturated basaltic melts assimilated old crustal materials enroute to their crustal magma chambers, which promoted sulfide saturation in conduits. The immiscible sulfide "proto-ore" was then entrained in the silicate magma and tranported to the crustal magma chamber, where sulfide melt was deposited as a result of fluid dynamic contrasts accompanying the change from a narrow, near-vertical conduit to a broader, open magma chamber. As this process resulted in a low $\mathrm{R}$ factor, the sulfide melt retained an old crustal $\gamma_{O S}$ value inherited from the contaminant. In contrast, disseminated sulfide ores from Sally Malay preserve a record of higher $\mathbf{R}$ factors in some portions of the magmatic system, potentially the result of greater transport or more extensive/effective mixing in a replenished magma chamber.

Acknowledgments: Financial assistance and permission to publish were kindly provided by Helix Resources NL; samples were provided by Normandy Exploration Lid.

References: [1] Page R. W. et al. (1995) AGSO Research Newsletter, 22, 7-8. [2] Naldrett A. J. et al. (1996) Expl. Mining J., 5, 169-179. [3] Lambert D. D. et al. (1997) Econ. Geol., submitted. [4] Foster J. G. et al. (1996) Nature, 382, 703-706.

EXPERIMENTAL MINERAL-AQUEOUS FLUID PARTITIONING OF TRACE ELEMENTS AT $1000^{\circ}-1200^{\circ} \mathrm{C}$ AND 3.0-5.5 GPa: IMPLICATIONS FOR THE GENERATION OF ISLAND ARC BASALTS. R. Stalder', S. F. Foley², G. P. $\mathrm{Brey}^{3}$, and I. Hom ${ }^{4}$, 'Institut für Geochemie, University of Frankfurt, Senckenberganlage 28,60325 Frankfurt, Germany (stalder@em.unifrankfurt.de), ${ }^{2}$ Mineralogy-Petrology Institut, University of Göttingen, Goldschmidtstrasse 1, 37077 Göttingen, Germany, ${ }^{3}$ Institut für Geochemie, University of Frankfurt, Senckenberganlage 28, 60325 Frankfurt, Germany, ${ }^{4}$ Department of Earth Sciences, Memorial University of Newfoundland, St. John's, Newfoundland AIB 3X5, Canada.
In order to constrain the role of fluid phases during metasomatic processes in the upper mantle, trace-element partition coefficients for $\mathrm{Ba}, \mathrm{Sr}, \mathrm{Pb}, \mathrm{Nb}, \mathrm{Ta}, \mathrm{Zr}, \mathrm{Hf}, \mathrm{Ti}, \mathrm{La}, \mathrm{Ce}, \mathrm{Sm}, \mathrm{Tb}$, and $\mathrm{Yb}$ between aqueous fluids and mantle minerals (gamet, cpx, rutile) have been determined experimentally. By using diamond aggregates the fluid could be separated from the solid residue and both quenched solute and residual minerals could be analyzed directly. Trace-element concentrations were determined in situ by laser ablation microprobe (LAM).

In contrast to previous assumptions, LFSE and LREE may not be easily fractionated from the HFSE simply by assigning a role to

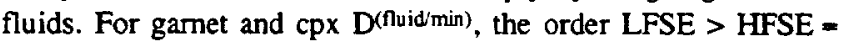
LREE > HREE follows.

At $5 \mathrm{GPa}$ and $1000^{\circ} \mathrm{C}$ fluid-garnet partition coefficients for $\mathrm{Nb}$, $\mathrm{La}$, and $\mathrm{Yb}$ are 5.3, 2.1, and 0.02 and fluid-cpx partition coefficients are 5.3, 3.3, and 0.8 respectively. Neither gamet nor cpx reveal a significant decoupling of the HFSE ( $\mathrm{Ti}, \mathrm{Nb}, \mathrm{Ta}, \mathrm{Zr}, \mathrm{Hf}$ ) from the LREE and only for residual rutile $D^{(\text {(fuid/min })}<1$ for HFSE could be found. Partitioning behavior rather is controlled by the crystal chemistry of the solid phases such as that proposed for mineral-melt equilibria by [1]. With increasing deviation of a cation radius from the size of the preferred lattice site at a given ionic charge, increasing $\mathrm{D}^{\text {(fluid/min) }}$ could be observed. Addition of $5 \mathrm{M}$ hydrochloric acid to the experimental charge causes no significant difference in partitioning behavior.

Fluid/mineral trace-element partitioning has important implications for arc magma genesis. In this study we compare a $D^{\text {(fluideclogite) }}$ modeled from our partitioning data with the $D^{\text {(fluidslab) }}$ predicted by [2]. A model is proposed in which aqueous fluids derived from a rutile-bearing subducted slab cause a selective enrichment of the mantle wedge, which has previously been depleted by melt extraction [3]. The depleted and reenriched upper mantle is the source region for island arc magmas. A similar model has previously been favored by [4] based on Ti-saturation levels of magmas.

References: [1] Blundy J. and Wood B. J. (1994) Nature, 372, 452-454. [2] Green D. H. (1972) Tectonophysics, 13, 47-71. [3] McCulloch M. T. and Gamble J. A. (1991) EPSL, 102, 358-374. [4] Ryerson F. J. and Watson E. B. (1987) EPSL, 86, 225-239.

BIOLOGICALLY MEDIATED ALTERATIONOF VOLCANIC ASH IN SEAWATER: LITHO-, BIO-, AND HYDROSPHERE INTERACTION. H. Staudigel ${ }^{1,2}$, E. Verdurmen ${ }^{2}$, G. Davies $^{2}$, R. A. Chastain 2 , A. Yayanos 2 , H. DeBaar ${ }^{3}$, and W. B. Bourcier,' 'Scripps Institution of Oceanography, La Jolla CA 92093 0225, USA (hstaudig@igpp.ucsd.edu),2Center for Isotope Geology, Netherlands Research School of Sedimentology, Vrije University Amsterdam, Netherlands, ${ }^{3}$ Netherlands Institute for Ocean Research, Texel, Netherlands, ${ }^{4}$ Lawrence Livermore National Laboratories, Livermore CA 94550 , USA.

Mantle-derived volcanic glass is introduced into the oceans as ash from subaerial volcanism and various occurrences of volcanic glass from submarine eruptions. Marine alteration of glass (including volcanic ash) is long known to be a major contributor to geochemical fluxes between seawater and basalt. Recently, strong evidence suggests that the dissolution of glass in the oceans is mediated by biological processes, even though there is very little quantitative evidence for the actual chemical effects of microbial activity. We 
carried out a feasibility study where we designed and tested a flowthough apparatus that allows the study of chemical exchange between seawater and glass under biologically controlled conditions (including a sterile control). In this study we analyzed solutions and solid run products chemically and isotopically.

Solution $\mathrm{SiO}_{2}$ in the sterile experiments displays a characteristic dissolution-precipitation behavior with an equilibrium saturation of $\sim 100=\mathrm{B} 5$ moles Sill. The biological experiment maintains lowsolution $\mathrm{SiO}_{2}$, due to utilization of dissolved silica by diatoms. Reaction products formed sediments within the reactor and in the main water container of the flow-through apparatus. In particular, the biologically active experiment produced significant quantities of diatomaceous sediment, with $\mathrm{SiO}_{2}$ inventory far exceeding the amount of $\mathrm{SiO}_{2}$ available from seawater. This experimentally demonstrated a potential causal relationship between the deposition of volcanic glass and deposition of diatomaceous sediments. Diatomaceous cherts and volcaniclastics are commonly associated in the geological record, and the origin of this association is not well understood. The production rate of reactor sediments in the sterile experiment is about half the rate in the biological experiment, and their composition is substantially different. The reactor sediments produced in a sterile environment are enriched in $\mathrm{Mg}$ (mostly in pyroaurite), while the reactor sediments in the biotic experiment and sediments are highly enriched in $\mathrm{Ca}$ (aragonite). Chemical transfer rates of $\mathrm{Sr}$ from fresh glass into sediment and water are up to $40 \times$ higher for biologically mediated alteration; transfer rates of Sr from seawater into glass are $4 \times$ higher.

These observations show that (1) biologically mediated alteration of glass can be simulated in the laboratory, (2) there are marked differences between glass alteration in a sterile and biologically active environment, (3) at least some exchange rates are dramatically enhanced in the biologically active environment, and (4) by simulating a geologically common association of volcaniclastics and diatomaceous sediment, we could establish a link to a common geological process.

\section{A LARGE, MANTLE-DERIVED IGNEOUS PROVINCE} DOMINATED BY FELSIC MAGMATIC ROCKS. K. P. Stewart, Department of Geology and Geophysics, University of Adelaide, Adelaide, South Australia, Australia (kstewart@geology. adelaide.edu.au).

Large-volume igneous provinces are typically regarded to be characterised by outpourings of large volumes of mafic magma, such as flood basalt provinces (Deccan, Paraná-Etendeka) and oceanic plateaus (Ontong-Java). In contrast, a Meso-Proterozoic magmatic province in central South Australia is an area where generation of large volumes of mafic-mantle-derived magma resulted in the more cryptic surface manifestation of large areas of felsic volcanism and plutonism.

The province is comprised of a large area of dominantly felsic Gawler Range Volcanics (GRV), which outcrop over an area in excess of $>25,000 \mathrm{~km}^{2}$. This volcanic area is surrounded by basement that has been intruded by a large number of granite plutons (the Hiltaba granites). The total area affected by the felsic magmatism is on the order of $300,000 \mathrm{~km}^{2}$. Both the felsic volcanics and the granites fall into chemical classification of A-types or within plate categories.
The presence of large volumes of mafic magma in the generation of the felsic volcanics has been demonstrated in associated studies that have illustrated that the felsic volcanics were formed by combined assimilation fractional crystallization processes (AFC). The granites have a similar genesis.

Basaltic rocks occur as a volumetrically minor component of the volcanic sequence. They exhibit spiky primitive mantle-normalized chemical patterns similar in many respects to continental crust. However, ratios such as $\mathrm{Ba} / \mathrm{Th}, \mathrm{Rb} / \mathrm{Ba}, \mathrm{Zr} / \mathrm{Nb}, \mathrm{Nd} / \mathrm{P}$, and $\mathrm{Ti} / \mathrm{Zr}$, together with ${ }^{143} \mathrm{Nd} / 144 \mathrm{Nd}$ ratios, vary in a manner inconsistent with crustal contamination of asthenospheric mantle melts with the basement (Archaean and Palaeoproterozoic granitoids with typical crustal chemistry). The chemical and isotopic characteristics of the basalts are interpreted to have been derived largely from the mantle lithosphere. A few basalts that do appear to have undergone minor contamination by crust are distinguished by lower $\mathrm{Ba} / \mathrm{Th}$ and $\mathrm{Ti} / \mathrm{Zr}$, higher $\mathrm{Rb} / \mathrm{Ba}$, and typically contain some other evidence of contamination such as quartz or potassium feldspar xenocrysts, or a combination of high compatible-element values, e.g., $\mathrm{Ni}$ and $\mathrm{Cr}$, together with increased levels of $\mathrm{SiO}_{2}$ and very high levels of incompatible elements such as $\mathrm{Zr}, \mathrm{Rb}$, and $\mathrm{REEs}$ compared with uncontaminated members of the same units.

Abundant geophysical evidence exists for the presence of a large mafic intrusion at midcrustal levels beneath the volcanics. Despite the fact that the volcanics are dominated by felsic compositions, the gravity anomaly associated with them is positive rather than negative, and has been modeled by spectral analysis as a large gabbroic body located at $12-15 \mathrm{~km}$ in depth. This has been substantiated by analysis of two different types of magnetic data, both of which indicate a magnetic body coincident with the gravity high. Drillholes into an apophysis off the main body intersected olivine and two pyroxene gabbros. Samarium/neodymium isotopic work determined that these gabbros are equivalent in age to the volcanics and that the midcrustal geophysical anomaly represents, at least in part, mafic intrusive rocks.

The granites and volcanics that make up the GRV/Hiltaba magmatic event outcrop over an area $>300,000 \mathrm{~km}^{2}$. Even if the average thickness of granite and/or volcanics is $1-2 \mathrm{~km}$ (and gravity data suggests it may sometimes be more), the original volume of magma must have been on the order of $300,000-600,000 \mathrm{~km}^{3}$. Modeling of the volcanics suggests that all the volcanics are more than $50 \%$ mantle derived, via AFC. This suggests that the amount of mantle magma needed to form the felsic magmatic rocks would be $150,000-$ $300,000 \mathrm{~km}^{3}$. While this cannot be considered to be anything other than a rough calculation, it nevertheless illustrates the order of magnitude of mafic magma required to form the felsic volcanics and granites. Mafic magma was also required to provide a heat flux into the crust to maintain the volcanic system and to form the midcrustal gabbroic body.

Many, if not all, flood basalt provinces have erupted in extensional settings, often over thick sedimentary sequences (e.g., Deccan, Paraná). In contrast, the GRV/Hiltaba magmatism erupted onto basement-dominated older granitoids and gneisses, not over a sedimentary basin. It could therefore be argued that this represents one type of large igneous province that occurs as a result of elevated mantle temperatures in a region of nonthinned crust that is not undergoing active extension. In this type of province the mantle magmas are not able to be erupted without having undergone considerable modification by assimilation and fractionation. 
LEAD AND NEODYMUUM ISOTOPIC EQUILIBRIUM AND CLOSED SYSTEMS IN BITUMINOUS CLASTIC SEDIMENTS? P. Stille and F. Gauthier-Lafaye, Centre de Géochimie de la Surface (CNRS), 1 Rue Blessig, 67084 Strasbourg, France.

Considerable efforts have been made over the last decades to date and understand the complex diagenetic processes in finegrained clastic sediments. However, investigations were not always successful because clay-rich sediments generally consist of a complex assemblage of detrital, transformed, and newly formed compounts of different origin. Even clay minerals formed during dissolution-crystallization processes may still have preserved smaller portions of inherited $\mathrm{Nd}$ and $\mathrm{Pb}$. This possibility might be the main reason isotope-geochemists have avoided sediments and prefered magmatic rocks. Apart from the research in the field of diagenesis and petroleum exploration, isotope studies, especially of clayey sediments, have become increasingly important in the context of nuclear-waste disposal in upper crustal environments. The longterm safety of a nuclear-waste repository mainly relies on the capacity of the geological barrier (e.g., clays) to retain or retard radionuclides released from the waste packages. Isotopic tracer studies on natural analogs allow us to decipher the behavior of actinides and fission products (e.g., REE) within such geological barriers. Lead, $\mathrm{U}, \mathrm{Sm}$, and Nd isotope studies on strongly reducing black shales neighboring the Oklo natural fission reactors point to the good sorption properties and hence to the high suitability of this clayey material as a secondary barrier in the confinement of radionuclides. Additionally, these studies indicate that alteration of organic matter, $\mathrm{S}$ and Fe(III) reduction, and generation of acidic aqueous solutions are important mechanisms that lead to dissolution of $\mathrm{K}$ feldspars and in situ crystallization of illite and chlorite. They also allow $\mathrm{Nd}$ and $\mathrm{Pb}$ isotopic equilibration in the leachable fraction of these authigenic clay minerals, as demonstrated by the identical $\mathrm{Pb}$ $\mathrm{Pb}$ and $\mathrm{Sm}-\mathrm{Nd}$ isochron ages of clay-leachates. This points to closed-system behavior, probably due to the good sorption properties of the strongly reducing black shales for REE and $\mathrm{Pb}$. Therefore, the organic matter in clastic sediments plays an important role not only for the in situ crystallization of isotopically homogeneous clay minerals, but also for the closed-system behavior of REE anđ $\mathrm{Pb}$. Its high sorption capacity is of particular importance for the retention of radionuclides released from waste packages.

THE SURFACE OF DISSOLVING CORUNDUM $\left(\alpha-\mathrm{Al}_{2} \mathrm{O}_{3}\right)$ UNDER VARIABLE pH CONDITIONS. L. L. Stillings, S. D. Samson, and C. M. Eggleston, Department of Geology and Geophysics, University of Wyoming, Laramie WY 82071-3006, USA (stilling@uwyo.edu).

Proton-promoted dissolution rates of metal oxides are usually predicted by surface complexation models of the form rate $=\mathrm{k}^{*}$ $\left[\equiv \mathrm{SOH}_{2}+\right]$, where $\left[\equiv \mathrm{SOH}_{2}^{+}\right]=$the concentration of $\mathrm{H}^{+}$at a mineral surface and is a function of $\mathrm{pH}$. This model predicts that, given an instantaneous change in $\mathrm{pH}$, the observed dissolution rate should change as quickly as $\left[\mathrm{SOH}_{2}{ }^{+}\right]$can reequilibrate at the surface. Adsorption of $\mathrm{H}^{+}$at oxide surfaces is a very fast reaction, on the order of seconds or less. Therefore dissolution rate should respond by changing within a similar time frame, given a step-change in $\mathrm{pH}$.

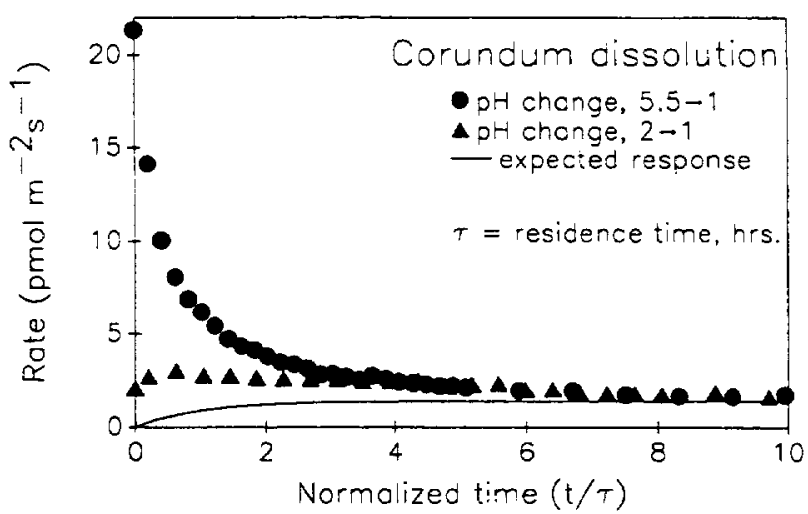

Fig. 1. $v \tau-0$ at the time of the $\mathrm{pH}$ shift.

Adsorption and desorption of nutrient species at mineral surfaces is a factor that can complicate interpretation of a pH-dependent dissolution rate. Adsorbed species, those not bound within the surface structure, would respond quickly to changes in solution composition, and thus may cause a transient, apparent rate of mineral dissolution that is different from bulk, steady-state dissolution.

We are investigating these ideas by observing the change in dissolution rate of $\alpha-\mathrm{Al}_{2} \mathrm{O}_{3}$ as a function of $\mathrm{pH}$. Our experimental apparatus consists of a continuously stirred tank reactor (CSTR) fitted with a pH electrode, buret, and automatic titrator. This setup allows us to observe the change in rate due to an instantaneous change in $\mathrm{pH}$ within the reactor and in the inlet solution. The response of a CSTR to a step-change in inlet chemistry is mathematically well-defined, and illustrated by the smooth curve shown in Fig. 1. However, the change in dissolution rate (filled symbols) due to a instantaneous $\mathrm{pH}$ change from 5.5-1 to 2.0-1 does not exhibit the same response. Instead, we observe an initially high dissolution rate that decays over approximately eight residence times to the steady-state rate. The difference between the expected and actual concentration response is attributed to the presence of a labile form of Al present at the mineral surface.

Integrating the space between the observed and expected responses, provides the mass of $\mathrm{Al}$ that desorbs from the surface as a result of the instantaneous $\mathrm{pH}$ change. We calculate a release of 0.35 $\mu \mathrm{mol} \mathrm{Al} \mathrm{m}-2$ from the surface due to a change from $\mathrm{pH} 2-1$, whereas $0.60-\mu \mathrm{mol} \mathrm{Al} \mathrm{m}^{-2}$ desorbs from the surface during a shift from $\mathrm{pH}$ 5.5-1. These figures are roughly 1 order of magnitude less than the amount of $\mathrm{Al}$ expected in one monolayer. The adsorption edge for $\mathrm{Al}$ on oxide surfaces is between pH 4 and 6 , so we would expect to desorb even more $\mathrm{Al}$ from the surface given a larger $\mathrm{pH}$ shift (e.g., 6.5-1).

We have also conducted similar experiments for hematite dissolution as a function of changing $\mathrm{pH}$ conditions [1]. A comparison of pH 1 steady-state dissolution rates between corundum and hematite shows that hematite dissolves approximately 1 order of magnitude faster, at $\sim 10$ pmoles Fe $\mathrm{m}^{-2} \mathrm{~s}^{-1}$, compared to corundum, which dissolves at 1.5 pmoles $\mathrm{Al} \mathrm{m}^{-2} \mathrm{~s}^{-1}$. This behavior is predicted from rates of water exchange between aqueous metal ions and bulk solution, which show that exchange rates for $\mathrm{Fe}^{3+}$ are at least 1 order of magnitude greater than exchange rates for $\mathrm{Al}^{3+}$.

References: [1] Samson and Eggleston (1997) this volume. 
TIMING AND DURATION OF THE LAST INTERGLACIAL: CONSTRAINTS FROM WESTERN AUSTRALIA. C. H. Stirling, T. M. Esat, M. T. McCulloch, and K. Lambeck, Research School of Earth Sciences, The Australian National University, Canberra, ACT 0200, Australia (claudine@rses.anu.edu.au).

More than 70 mass spectrometric $U$-series ages have been determined for Last Interglacial fossil reefs along the coastal margin of Western Australia: Corals in growth position have been selected from localities that are characterized by apparently low levels of diagenesis and relative tectonic stability so that the fossil reefs provide critical information on Last Interglacial sea levels without requiring models of tectonic movements. Biases in the ages resulting from erosion or burial of the reefs have been largely overcome by sampling a large number of reef localities a total of 11 . Drill-core coral has been recovered from the base of two of the fossil reefs to better constrain the timing of onset of reef growth along the coastal margin of Westem Australia. Uranium and Th isotopes were measured with permil to subpermil levels of precision, leading to improvements in age resolution and allowing samples that have undergone diagenetic exchange of $U$ and $T h$ to be more easily identified and discarded. Strict criteria were adopted to screen the new Westem Australian data.

Last Interglacial relative sea-level curves have been derived for the west coast of Australia by combining the new $\mathrm{U}$-series data with the heights of the fossil corals, measured with respect to the present mean low water springs (MLWS) datum. Because Westem Australia is located far from the former penultimate glacial maximum ice sheets, the reef and coral heights are not significantly affected by the isostatic adjustment of the crust and mantle to glacial unloading. They record primarily eustatic sea-level change, and the relative sea-level curves allow precise estimates to be placed on the timing of onset of the Last Interglacial period. Reef growth started contemporaneously at $128 \pm 1 \mathrm{ka}$ along the entire continental margin of Western Australia, while relative sea levels were at least $3 \mathrm{~m}$ above the present level. This age constraint is based on a sharply defined boundary in the data, defined by 10 data points satisfying strict criteria $\left(\delta^{234} \mathrm{U}(\mathrm{T})_{\text {acceptable }}=149 \pm 10 \%\right.$ ) and 25 data points satisfying slightly relaxed criteria $\left(\delta^{234} \mathrm{U}(\mathrm{T})_{\text {accepable }}=149 \pm 10 \%\right.$ ). This result constrains the timing of onset of the Last Interglacial period to $128 \pm 1 \mathrm{ka}$, assuming reef growth started soon after sea level approached its present value.

To constrain the duration of the Last Interglacial interval, the eustatic sea-level component has been isolated from the total relative sea-level signal by comparing the new Western Australian data, as well as published data from other reef localities, with glaciohydro-isostatic rebound models. No previous TIMS U-series workers have attempted to remove the glacio- and hydro-isostatic effects from their reef-growth curves. A comparison of reef observations with model predictions indicate that the Last Interglacial sea-level highstand persisted from $128 \pm 1 \mathrm{ka}$ to $116 \pm 1 \mathrm{ka}$. Globally, the main episode of reef-building is confined to a narrow interval occurring from about $128 \mathrm{ka}$ to $122 \mathrm{ka}$. The abrupt termination of the main episode of reef growth at $122 \mathrm{ka}$ may be indicative of a global cooling event at this time that triggered subsequent climate instability. This has been suggested independently by some other paleoclimate records. Alternatively, the major episode of reef building between $128 \mathrm{ka}$ and $122 \mathrm{ka}$ may reflect a period of stable sea level during the earlier part of the interglacial interval only.
QUANTUM CHEMICAL STUDIES ON DISSOLUTION OF SILICATE MINERALS. H. Strandh' and L. G. M. Pettersson ${ }^{2}$, 'Department of Geology and Geochemistry, University of Stockholm, S-10691 Stockholm, Sweden (helene.strandh@geo.su.se),2Department of Physics, University of Stockholm, Box 6730, S-113 85 Stockholm, Sweden (Igm@physto.se).

The $\mathrm{pH}$ dependence and dependence on alkali metal cations when dissolving silicate minerals such as quartz and feldspar have been studied using a quantum chemical model calculation. The model used is a siloxane bond terminated by hydroxyl groups that are in equilibrium with solution $\mathrm{pH}$ and composition of alkali metal cations. The model reactions were formulated as

Acid solution:

$$
\begin{gathered}
\left(\mathrm{Si}(\mathrm{OH})_{2} \mathrm{OMH}-\mathrm{O}-\mathrm{Si}(\mathrm{OH})_{3}\right)^{+}+\mathrm{H}_{2} \mathrm{O} \rightarrow \\
\left(\mathrm{Si}(\mathrm{OH})_{3} \mathrm{OMH}\right)^{+}+\mathrm{Si}(\mathrm{OH})_{4}
\end{gathered}
$$

Neutral solution:

$\mathrm{Si}(\mathrm{OH})_{2} \mathrm{OM}-\mathrm{O}-\mathrm{Si}(\mathrm{OH})_{3}+\mathrm{H}_{2} \mathrm{O} \rightarrow \mathrm{Si}(\mathrm{OH})_{3} \mathrm{OM}+\mathrm{Si}(\mathrm{OH})_{4}$

Alkaline solution:

$\mathrm{Si}(\mathrm{OH})_{2} \mathrm{OM}-\mathrm{O}-\mathrm{Si}(\mathrm{OH})_{3}+\mathrm{OH}^{-} \rightarrow \mathrm{Si}(\mathrm{OH})_{3} \mathrm{OM}+\mathrm{Si}(\mathrm{OH})_{3} \mathrm{O}^{-}$

where $\mathrm{M}$ is an alkali metal cation adsorbed at the surface model.

The present study was performed using the density functional method B3L YP. Geometry optimization of all reactants and products was performed using the $6-311 \mathrm{G}$ basis set and a double $\zeta$ basis set with effective core potentials for $K, R b$, and Cs. A substantially larger $O(11 s 7 \mathrm{p} 2 \mathrm{~d}) /[4 \mathrm{~s} 3 \mathrm{p} 2 \mathrm{~d}]$ and $\mathrm{H}(6 \mathrm{~s} 1 \mathrm{p}) /[3 \mathrm{~s} 1 \mathrm{p}]$ basis set was used when calculating the energies.

The results from the calculations show that adsorbed alkali metals change both the siloxane bridge geometry and the $\mathrm{Si}-\mathrm{O}$ bond strength. In the acid model calculations, the alkali metal ions inhibit the dissolution, in accordance with feldspar experiments by Sjöberg [1], and in recent quartz experiments by Strandh et al. [2]. Protons are found to stabilize the siloxane bridge, contrary to what has been found in earlier models without the $\mathrm{OH}$ groups. In the alkaline region the alkali metals weaken the bond strength, as has been observed in quartz experiments by Dove and Crerar [3] where the dissolution rate is increased in the presence of alkali metals, in the order $\mathrm{Li}<\mathrm{Na}=\mathrm{K}$, and in feldspar experiments by Sjöberg [1] in the order $\mathrm{Li}>\mathrm{Na}>\mathrm{K}$.

Although the model predicts the overall trend of the experimental results, there are discrepancies between the calculated and experimental results in acid solution. Calculations show decreasing inhibiting effect with increasing atomic number of the alkali metals while the experiments show the opposite order. Including hydration in the form of one to three water molecules around the adsorbed alkali metal ion indicate that full solvation may change the order of the alkali metal ion effect; solvation of the ions and the mineral surface thus give important contributions to the energetics and must be considered in theoretical models of dissolution processes.

Work has been initiated to develop models including up to four silica atoms, i.e. three siloxane bonds, where one advantage is that not all hydroxyl groups can participate in adsorption processes, which is a more descriptive model for the true surface. Furthermore, these models can be used to distinguish between the neutral and alkaline surfaces, since the neutral surface then can have a net 
surface charge of 0 and still have negatively charged hydroxyl groups. With these larger models it is also possible to investigate the transition state in breaking siloxane bonds. Furthermore, using these models, feldspar dissolution could be investigated by exchanging silica for $\mathrm{Al}$.

References: [1] Sjöberg L. (1989) Proc. 6th Intl. Symp. Water-Rock Interaction, 609-612. [2] Strandh H. et al. (1996) GFF, 118, A55-A56. [3] Dove P. M. and Crerar D. A. (1990) GCA, 54, 955-969.

ENSTATITE CHONDRITE EARTH: MMLICATIONS FOR GLOBAL ARGON ISOTOPE SYSTEMATICS. F. M. Stuart, Isotope Geosciences Unit, S.U.R.R.C., East Kilbride G75 0QF, UK.

Less than $5 \%$ of the heat presently leaving the Earth's mantle originates from radioactive decay above the $670-\mathrm{km}$ discontinuity. In the currently preferred paradigm, plumes of upwelling lower mantle transfer heat and mass to the upper mantle. Constraints from isotope geochemistry predict that upper mantle replacement times (UMRT) - the time required for the flux of lower mantle to replace the upper mantle volume - are up to $30 \mathrm{Ga}$. This contrasts markedly with geophysical estimates based on seismic tomography and ocean floor topography, which infer much greater interaction between convectively isolated mantle reservoirs and consequently UMRT as low as $200-300$ m.y. Reconciling these observations remains a fundamental problem.

Geochemical models based on rare gas isotopes provide support for the presence of an outgassed upper mantle that is essentially isolated from a convecting lower mantle layer below $670 \mathrm{~km}$. The high ${ }^{3} \mathrm{He} /{ }^{4} \mathrm{He}$-high ${ }^{20} \mathrm{Ne} * / 21 \mathrm{Ne}{ }^{*}$ of plume-related volcanism is cited as evidence that the lower mantle retains primordial volatiles trapped during Earth accretion. Further support comes from Ar isotope systematics. Since all ${ }^{40} \mathrm{Ar}$ in the Earth has been generated by radioactive decay of $\mathrm{K}$, the ${ }^{40} \mathrm{Ar}$ content of the atmosphere can be used to determine the extent of Earth outgassing. The atmosphere contains approximately $50 \%$ of the ${ }^{40} \mathrm{Ar}$ generated since accretion. Assuming that the core plays no significant role in global K-Ar systematics, an essentially undegassed lower mantle with $\mathrm{K}$ content of $\sim 230 \mathrm{ppm}$ nicely accounts for the missing ${ }^{40} \mathrm{Ar}$.

Accretion from enstatite chondrites is one possible model for Earth formation. E chondrites are the only primitive meteorite group with stable isotope compositions, redox states, and metal + sulfide contents close to Earth. Aubrites, igneous fractionates of $E$ chondrites, contain alkali-metal sulfides that represent precipitates of the sulfide liquid that separated to form the parent body core [1]. Mass balance calculations predict that, in the E-chondrite model of Earth formation, the core may contain up to $500 \mathrm{ppm} \mathrm{K}$. This can account for the depletion of heavy alkali elements relative to volatile-depleted chondrites and, crucially, is enough to account for the ${ }^{40} \mathrm{Ar}$ deficit in the Earth's mantle. The consequences for global ${ }^{40} \mathrm{Ar}$ budgets, mantle convection, and heat fluxes will be discussed.

This scenario does not resolve the source of the high ${ }^{3} \mathrm{He}$-solar Ne reservoir in the Earth. Neon in E chondrites is planetary $\left({ }^{20} \mathrm{Ne} /\right.$ ${ }^{22} \mathrm{Ne}=8.5$ ) and cannot account for the solar rare gases that dominate the assumed deep-source plume magmatism.

References: [1] Lodders et al. (1993) Meteoritics, 28, 538551.
CARBONATE GROWTH STUDIED BY SYNCHROTRON X-RAY SCATTERING. N. C. Sturchio ${ }^{1}$ and R. P. Chiarello, 'Argonne National Laboratory, ER-203, 9700 South Cass Avenue, Argonne IL 60439, USA, 'Stanford University, $106 \mathrm{McCullough}$ Building, Stanford CA 94305, USA.

In natural waters most minerals form by heterogeneous nucleation and growth because of the generally small extent of mineral supersaturation and the relatively large energy barrier to homogeneous nucleation. Accurate knowledge of the mechanisms and rates of heterogeneous nucleation and growth of minerals is needed to develop realistic models of low-temperature geochemical systems.

Kinetic data for mineral-fluid systems are typically obtained by reacting single-phase powders with aqueous solutions. There are important drawbacks to this approach. First, reactive surface areas of powders are difficult to determine thus absolute growth rates measured from powders are uncertain. Furthermore, because the amount of material precipitated is small relative to the amount of powder, unambiguous identification of the precipitating phase, its growth mechanism, and its crystallographic relation to the substrate may be tedious or impossible. The situation is more complicated when multiple crystal faces react with the solution.

Uncertainties inherent in heterogeneous nucleation and growth studies are being reduced by the use of in situ atomic force microscopy (AFM). Nonetheless, because AFM has neither compositional sensitivity nor precise atomic-scale resolution, there remains a clear need for improved experimental methods. In response to this need, we have performed experiments that demonstrate the utility of using synchrotron $X$-ray radiation for in situ measurements of the mechanisms and rates of heterogeneous nucleation and growth of carbonates on single-crystal calcite substrates.

One experiment examined the growth of otavite on the (104) cleavage surface of calcite [1]. The otavite precipitated from a 1-mL volume of otavite-saturated solution as $\mathrm{CO}_{2}$ diffused out of the solution. The otavite grew epitaxially with a (104) growth plane parallel to that of the calcite substrate, at a rate of $15 \pm 1 \AA / \mathrm{hr}$ during the first $10 \mathrm{hr}$ of the experiment. The growth rate was measured from glancing-incidence X-ray reflectivity (GIXR) as well as from the $2 \theta$ width of the otavite (104) Bragg reflection. The otavite (104) dspacing was compressed by as much as $2.2 \%$ during the early growth stage $(<50 \AA)$, and approached that of bulk otavite as growth proceeded. At a thickness of $440 \AA$, the otavite was of single-crystal quality, having both in-plane and out-of-plane mosaic spreads of $0.4^{\circ}$.

A subsequent experiment examined the nucleation and growth of otavite-calcite solid-solutions on the (104) cleavage surface of calcite from three EDTA-bearing solutions having varied initial saturation states of otavite and calcite and varied initial $\mathrm{Cd} /(\mathrm{Cd}+$ Ca) ratios [2]. The solid-solution phases grew epitaxially with (104) growth faces parallel to those of the calcite substrates, and with nearly constant growth rates ranging from $10-54 \AA \mathrm{hr}$ during the first $10 \mathrm{hr}$ of reaction. The compositions of the solid solutions showed increasing $\mathrm{Cd} /(\mathrm{Cd}+\mathrm{Ca})$ ratios during the first few hours, followed by an approach to steady-state composition. GIXR scans indicated no significant roughening. The data are consistent with nucleation at step edges and growth by layer spreading.

These preliminary experiments show that this new $\mathrm{X}$-ray approach provides a superior level of detail in structural characterization of the growth phase along with an unprecedented accuracy in 
face-specific growth-rate determination.

References: [1] Chiarello R. P. and Sturchio N. C. (1994) $G C A, 58,5633-5638$. [2] Chiarello R. P. et al. (1997) GCA, 61, in press.

\section{EXPOSURE AGES FROM CONTRASTING GEOMORPHIC} SETTINGS IN THE DRY VALLEYS, SOUTH VICTORIA LAND, ANTARCTICA, FROM COSMOGENIC NEON-21 ISOTOPE ANALYSIS. M. A. Summerfield 1, F. Stuart ${ }^{2}$, T. Dunai $^{3}$, D. E. Sugden ${ }^{1}$, H. A. P. Cockburn ${ }^{1}$, and G. H. Denton ${ }^{4}$, 'Department of Geography, University of Edinburgh, Edinburgh, UK, IIsotope Geosciences Unit, S.U.R.R.C., East Kilbride, UK, ${ }^{3}$ Faculty of Earth Sciences, Vrije Universiteit, Amsterdam, Netherlands, ${ }^{4}$ Department of Geological Sciences, University of Maine, Orono ME, USA.

Exposure ages of bedrock surfaces and rates of bedrock erosion over the past several million years are a critical issue in assessing conflicting interpretations of the stability of the East Antarctic Ice Sheet. One view, based largely on the presence of Pliocene marine diatoms in the high-elevation glaciogenic Sirius deposits of the Transantarctic Mountains, argues for a dynamic East Antarctic Ice Sheet that contracted during the warmer climatic conditions of the Pliocene. In contrast, geomorphological and geochronological evidence strongly indicates very low rates of erosion and landscape change for at least the last 10-15 m.y. and therefore very little alteration in the size of the ice sheet over this period.

Analyses of cosmogenic isotopes from surface outcrops at strategic locations in the Transantarctic Mountains provide a valuable means of establishing past erosion rates and thereby differentiating between the two models of ice sheet behavior. Research to date has revealed some very old exposure ages of up to $\sim 5 \mathrm{Ma}$, but the variability of exposure ages and erosion rates across a range of landscape elements has yet to be established. Here we repon cosmogenic ${ }^{21} \mathrm{Ne}$ and ${ }^{3} \mathrm{He}$ concentrations in $250-500$ - $\mu \mathrm{m}$ quartz samples. Samples were collected from contrasting geomorphic settings in the Dry Valleys region of the Transantarctic Mountains in South Victoria Land in order to assess these variations in exposure age and rates of landscape change. Two distinct landscape components were selected for sampling-flat, high-elevation surfaces, and thinly veneered, bedrock valley slopes. The high-elevation samples $(\sim 2400 \mathrm{~m})$ of coarse-grained, quartzose sandstone (Beacon Supergroup) were collected from surfaces immediately to the east of Mount Fleming at the head of Wright Valley. The valley-side slope samples of granitic basement or Beacon Supergroup sandstone were collected from sites in lower Taylor Valley $(\sim 800 \mathrm{~m})$, adjacent to Sollas Glacier, and from Arena Valley at the head of Taylor Valley $(\sim 1600 \mathrm{~m})$. At both sites, independent data on rates of landscape change are available from ${ }^{40} \mathrm{Ar} /{ }^{39} \mathrm{Ar}$-dated ash fall deposits or small volcanic cones on immediately adjacent valley-side sites.

All four samples from high-elevation surfaces yielded remarkably consistent ${ }^{21} \mathrm{Ne}$ minimum exposure durations ranging from 3.95 to 4.26 m.y. Samples from rectilinear slopes on the sides of Arena Valley at $1600 \mathrm{~m}$ have been exposed for a minimum of 1 $2.7 \mathrm{~m} . y$. The sample from a lower elevation slope $(800 \mathrm{~m})$ adjacent to Sollas Glacier in Taylor Valley has a minimum exposure age of $\sim 700 \mathrm{k} . y$. Exposure durations calculated from ${ }^{3} \mathrm{He}$ abundances on the same samples are between 2.5 and $55 \times$ lower than those derived from ${ }^{21} \mathrm{Ne}$ abundances. The ${ }^{21} \mathrm{Ne}$ minimum exposure ages for both the high-elevation surfaces and rectilinear slope environments are consistent with existing geochronometric data from volcanic deposits and with geomorphological interpretations favoring a very slow rate of landscape modification over the past few million years.

\section{RHENIUM-OSMIUM SYSTEMATICS OF THE ROTTEN-} STONE NICKEL-COPPER-PLATINUM-GROUP-ELEMENT DEPOSIT, CANADA. K. Suzuki', L. Hulbert ${ }^{2}, Y$. Miyata $^{3}$, H. Amakawa ${ }^{3}$, and Y. Nozaki ${ }^{3}$, 'Department of General Systems Studies, Graduate School of Arts and Sciences, University of Tokyo, Komaba Meguro, Tokyo 153, Japan (ckatz@komaba. ecc.u-tokyo.ac.jp), ${ }^{2}$ Geological Survey of Canada, 601 Booth Street, Ottawa, Ontario K1 A OE8, Canada, ${ }^{3}$ Ocean Research Institute, University of Tokyo, Minami-dai, Nakano, Tokyo 164, Japan.

The Re-Os system is uniquely suited to ascertain the crystalization age of the host mafic-ultramafic intrusions and the metallogenesis of contained magmatic sulfides, which are generally not amenable to other isotopic systems. Recent improvements in ionization efficiency for $R e$ and Os by negative thermal ionization mass spectrometry (N-TIMS [e.g., 1]) have resulted in extensive work on the ReOs system. In this study, Re-Os isotope systematics were applied to investigate the Rottenstone Ni-Cu-PGE sulfide deposit of northem Saskatchewan, Canada.

The Rottenstone deposit is known to contain significant concentration of $\mathrm{Ni}, \mathrm{Cu}$, and PGEs. Although a relatively small deposit, Rottenstone is particularly noteworthy because it contained the richest PGE and Au among Ni-Cu ores in Canada. There are two main mineralized occurrences in Rottenstone area: the Hall and Tremblay-Olson deposits, which are $2.5 \mathrm{~km}$ apart.

Osmium and Re concentrations of the samples were determined through isotope dilution mass spectrometry. Samples were decomposed by the method modified from Suzuki et al. [2]. One- to 3-g samples, together with $\mathrm{Os}$ and $\mathrm{Re}$ spikes, were added with $\mathrm{HCl}$ and heated with flow of $\mathrm{N}_{2}$ for a few hours. After $\mathrm{HNO}_{3}$ and $\mathrm{H}_{2} \mathrm{SO}_{4}$ were added, the vessel was closed and the samples decomposed by microwave dissolution. Separation of Os and $\operatorname{Re}$ was performed using the method of Martin [3]. Isotopic abundances were measured using the Finnigan Mat THQ. In this study, Os and Re impurities in mass spectrometric technique are described. High-purity $P t$ filaments have been generally used for mass spectrometric analysis of Os and Re. Although Os blank contents in filaments are negligible, Re blanks from different Pt filaments ranges from 20 to $1000 \mathrm{pg}$ $[4,5]$. Shen et al. [6] used a Ni wire ( $99 \%$, Johnson Matthey) that

TABLE

\begin{tabular}{lcccr}
\hline & $\operatorname{Re}(\mathrm{ppb})$ & Os (ppb) & \multicolumn{1}{c}{${ }^{187} \mathrm{Os}^{/ 188}$ Os } & \multicolumn{1}{c}{${ }^{187} \operatorname{Re}^{188} \mathrm{Os}$} \\
\hline HL 84-13 & 82.27 & 106.61 & $0.2321 \pm 0.0055$ & $3.766 \pm 0.026$ \\
HL 84-15 & 55.58 & 108.43 & $0.2109 \pm 0.0018$ & $2.495 \pm 0.034$ \\
HL 84-17 & 29.20 & 12.08 & $0.7190 \pm 0.0077$ & $12.543 \pm 0.109$ \\
HL 84-21 & 45.19 & 100.98 & $0.2215 \pm 0.0018$ & $2.180 \pm 0.039$ \\
HL 84-22 & 63.02 & 187.20 & $0.2103 \pm 0.0003$ & $1.639 \pm 0.062$ \\
HL 84-24 & 50.80 & 145.43 & $0.2055 \pm 0.0022$ & $1.699 \pm 0.027$ \\
TO 85-115B1 & 100.72 & 14.20 & $0.2152 \pm 0.0047$ & $34.49 \pm 1.22$ \\
TO 85-115C & 2850 & 8.52 & $3.72 \pm 0.0964$ & $1627 \pm 356$ \\
\hline
\end{tabular}


yielded the $\operatorname{Re}$ content of $94 \mathrm{ppb}$, the lowest among materials they have checked. We used Pt filaments from Tanaka Precious Metal Co., which showed a lower Re content $(6.6 \mathrm{ppb})$ than those of Shen et al. For the construction of the filament, we made use of an apparatus that includes a filament holder and is used for Re analysis only.

Analysis from the Rottenstone deposits using this new approach are presented in Table 1. HL and TO represent Hall and TremblayOlson respectively. Rhenium-osmium data from the Hall samples regress to give an isochronous age of $2765 \pm 50 \mathrm{Ma}$ with initial ${ }^{187} \mathrm{Os} /{ }^{188} \mathrm{Os}$ of $0.1252 \pm 0.0024$. The $\gamma_{0 \text { s }}$ is 14 and suggests that crustal contamination is evident in the Hall mineralization. On the other hand, data from the Tremblay-Olson deposit demonstrate values $>14$, suggesting significant crustal contamination in these samples with higher $\mathrm{Re} / \mathrm{Os}$ ratios.

The results of the Re-Os study supports previous hypothesis [7] based on geology, mineralogy, $\mathrm{S} / \mathrm{Se}$ ratios, and $\mathrm{S}$ isotope data. Although geology and mineralization of Tremblay-Olson is superficially similar to that of Hall, the Ni, PGE, and Au grade are markedly lower. The Tremblay-Olson sulfides also have a higher $\mathbf{S}$ Se ratio (5500) than that of Hall (2500), which is close to the mantle value. In the Rottenstone Lake area, the synsedimentary sulfides have high S/Se ratios (avg. 28,000). Tremblay-Olson is either a product of greater crustal contamination than Hall or both are products of similar degrees of initial crustal contamination from sulfidic sediments and the present variations in $\mathrm{Ni}, \mathrm{Cu}, \mathrm{PGE}$, and Re-Os isotope compositions are controlled by the mass of silicate melt, which the sulfide melt later had an opportunity to equilibrate with (R-factor).

References: [1] Creaser et al. (1991). [2] Suzuki et al. (1992). [3] Martin (1991). [4] Walczyk et al. (1994). [5] Yin (1995). [6] Shen et al. (1996). [7] Hulbert et al. (1988).

\section{DETECTION OF MOLYBDENITE ALTERATION AND RESULTING RHENIUM-OSMIUM FRACTIONATION THROUGH NEAR-INFRARED MICROSPECTROSCOPY AND MICRO-X-RAY DIFFRACTION. K. Suzuki' , H. Kagi ${ }^{2}$, M. Nara ${ }^{3}$, B. Takano', and Y. Nozaki, 'Department of General Systems Studies, Graduate School of Arts and Sciences, University of Tokyo, Komaba, Meguro, Tokyo 153, Japan (ckatz@komaba.ecc. u-tokyo.ac.jp), 2Institute of Material Sciences, University of Tsukuba, Tsukuba 305, Japan, ${ }^{3}$ Water Research Institute, Sengen, Tsukuba 305 , Japan, ${ }^{4}$ Ocean Research Institute, University of Tokyo, Minami- dai, Nakano, Tokyo 164, Japan.}

Rhenium-osmium geochronometry is a useful tool to determine the formation age and origin of the sulfides and ultramafic rocks. Molybdenite $\left(\mathrm{MoS}_{2}\right)$ was the first target for this tool. Recently, McCandless et al. [1] and Suzuki et al. [2] suggested that the Re-Os system in molybdenite could be possibly disturbed during alteration after primary mineralization. In this study, experiments have been carried out to develop a tool to detect the alteration of molybdenite and the remobilization of the Re-Os system in molybdenite.

Natural molybdenite from Brejui, Brazil, was heated at $180^{\circ} \mathrm{C}$ for 20 days in various aqueous solutions, such as $\mathrm{NaCl}, \mathrm{NaHCO}_{3}$, $\mathrm{CaCl}_{2}, \mathrm{AlCl}_{3}$, and $\mathrm{H}_{2} \mathrm{O}$, in sealed quartz tubes. After 20 days, $\mathrm{Re}$ and $O s$ in the molybdenites were determined by isotope dilution. Also, polished thin sections $(0.2 \mathrm{~mm})$ of the same molybdenites were observed using near-infrared (NIR) microspectroscopy and micro$\mathrm{X}$-ray diffraction (XRD).

The molybdenite treated with $\mathrm{NaCl}$ and $\mathrm{NaHCO}_{3}$ gave Re-Os ages of $358 \mathrm{Ma}$ and $477 \mathrm{Ma}$ respectively, which are considerably lower than that of the original molybdenite $(554 \mathrm{Ma})$. This strongly suggests that both elements are likely to be fractionated during natural alteration similar to this experimental condition. Meanwhile, $\mathrm{Re}-\mathrm{Os}$ ages of the molybdenite heated in $\mathrm{CaCl}_{2}$ and $\mathrm{AlCl}_{3}$ were in good agreement with that of the untreated molybdenite.

The original molybdenite is completely opaque in the entire NIR region $\left(10,000-4,000 \mathrm{~cm}^{-1}\right)$. The molybdenites altered in $\mathrm{NaCl}$ and $\mathrm{NaHCO}_{3}$ remained opaque, while others showed high transparency in the NIR range. All the altered products have a shoulder absorption at $4344 \mathrm{~cm}^{-1}(2.3 \mu \mathrm{m})$ in their NIR spectra, suggesting that this spectroscopic feature could be used for detection of alteration. No specific absorption peak other than this was observed in NIR range in all products. Micro-XRD showed that the altered molybdenites, in which $\mathrm{Re}-\mathrm{Os}$ was fractionated, gave a reduced peak intensity as a whole. This indicates that reduced crystallinity of the molybdenite may result in mobilization of $\mathrm{Os}$ and/or $\mathrm{Re}$ in the degraded lattices.

In the case of the molybdenites leached in $\mathrm{AlCl}_{3}, \mathrm{CaCl}_{2}$, and $\mathrm{H}_{2} \mathrm{O}$, Re-Os was not fractionated and the intensity of diffraction peaks did not change much. Since the peak positions in all XRD spectra did not shift even after experimental alteration, it is concluded that the crystallographic structure of the molybdenite does not change in the process of this kind of alteration.

The electric structure of the minerals altered in $\mathrm{AlCl}_{3}$ and $\mathrm{CaCl}_{2}$ might have changed, resulting in increased NIR transparency. Since these samples showed high transparency in the region of NIR $\left(10,000-4,000 \mathrm{~cm}^{-1}\right)$ and no specific absorption peak was observed in this range, the energy level of an absorption edge possibly increased by alteration. In these samples, crystallinity of the mineral might not have changed, because little change in the intensity of peaks was observed in the micro-XRD spectra. On the other hand, in cases of molybdenites altered in $\mathrm{NaCl}$ and $\mathrm{NaHCO}_{3}$, no explicit change was observed in NIR transparency, indicating that the energy level of the absorption edge has not increased in these cases, while reduction of the intensity in micro-XRD pattem and deviation of Re-Os dates showed that crystallinity of the materials was reduced and trace elements such as $R e$ and/or Os were readily leached.

In conclusion, alteration of molybdenites was successfully detected by observing a shoulder absorption at $4344 \mathrm{~cm}^{-1}$ in the NIR spectra. Also, micro-XRDeffectively detects Re-Os fractionation in altered molybdenites. The technique used here is also expected to be useful for the investigation of sulfide weathering processes.

References: [1] McCandless et al. (1993). [2] Suzuki et al. (1995).

BORON ISOTOPIC MASS BALANCE IN BORON-AFFECTED AGRICULTURAL SOIL. G. H. Swihart', Y. Xiao', D. L. Suarez ${ }^{2}$, E. H. McBay ${ }^{3}$, and D. H. Smith', 'Department of Geological Sciences, University of Memphis, Memphis TN 38152, USA, ${ }^{2}$ USDAARS-PWA, U.S. Salinity Laboratory, 450 West Big Springs Road, Riverside CA 92507-4617, USA, ${ }^{3}$ Chemical and Analytical Sciences Division, Oak Ridge National Laboratory, Building 5505, Mail Stop 6375, P.O. Box 2008, Oak Ridge TN 37831-6375, USA.

Salinization of soil and water is a significant agricultural and 
environmental problem associated with irrigation in some states in the westem U.S. and other regions of the world. One particular concern is the buildup of B in soil and water. Boron presents a special problem for soil reclamation in that it is adsorbed to soil constituents as well as being present in slowly soluble form. It has been expected that irrigation with high-B agricultural drainage waters would cause buildup of B in soils resulting in B toxicity to crops. Soluble B may be removed by repeated flushing but may regenerate through release from slowly soluble forms.

Quickly and slowly soluble B were investigated in three soils from the western San Joaquin Valley, California. The Twisselman (TW) silty loam is a high-native-B soil THAT has never been cultivated. The second soil is a clay from the Murietta Farms (MF) Agroforest Experimental Project that was irrigated with relatively high-B agricultural drainage water for about a decade. The third soil is a clay loam from the University of California-Davis' West Side (WS) Field Station, which has been irrigated only with low-B aqueduct water.

Boron was desorbed from the three soils by multiple batch leaching cycles in $0.0005 \mathrm{M}$ mannitol solution, and was also isolated from the leached residues by sequential extraction procedures. Boron concentration and isotopic analyses were performed on the leachates and on the extractions from the residual soil fractions. The fractions of the soil residues that were investigated are the weak acid soluble carbonate, peroxide oxidizable organic, and free Fe portions and the remaining clay, silt, and nonmagnetic sand size portions.

In both the TW and MF soils the individual fractions arranged from highest to lowest $\mathrm{B}$ concentration are carbonate, free $\mathrm{Fe}$, organic, clay, silt, and nonmagnetic sand. Because of the large weight proportion of the clay size fractions in the soils, the largest proportion of the total B in both soils is held in this fraction, which consists of clay minerals, mica, and quartz.

The leachate $B$ concentration data suggest that slowly soluble B dominates the leachate after only 12-15 min of leaching of the TW and MF soils. The WS soil contained very little leachable B. Boron isotopic data for the TW and MF leachates are helpful in the interpretation of the B release data. Furthermore, the isotopic data suggest that the soil fractions that are sources of slowly soluble B are, in decreasing order of contribution, the carbonate, organic, and free Fe portions.

By comparison of the concentration and isotopic results from the three soils it appears that irrigation of soil with high-B drainage water can lead to incorporation of $B$ into sites that are not readily desorbed, and that significant incorporation can occur in a period of time on the order of a decade. Comparison of the soil makeup of the three soils suggests that the incorporation of B into slowly soluble sites is associated with the growth of secondary carbonate, $\mathrm{Fe}$ and Al oxyhydroxides, and organic content.

The results of the study are relevant to the potential to sustain irrigated agriculture in the Central Valley of Califomia as well as in other irrigated areas in the western U.S. Elevated B concentrations are a major obstacle to reusing drainage water on the western side of the Central Valley. In order to manage these drainage waters it is necessary to know the long-term capacity of soils to sorb and release $\mathrm{B}$.

Acknowledgments: This research was sponsored in part by the U.S. Department of Agriculture and by the U.S. Department of Energy, Office of Basic Energy Sciences, under contract DE-AC05840 R2 1400 with Lockheed Martin Energy Systems, Inc.
NOBLE GASES ON MARS AND EARTH: KEY SIMILARITIES AND DIFFERENCES. T. D. Swindle, Lunar and Planetary Laboratory, University of Arizona, Tucson AZ 85721, USA.

The noble gases are perhaps the most important tracers of the history of a planet's atmosphere and its interaction with the solid planet. With the recognition that SNC meteorites come from Mars $[1,2]$, the identification of the abundant trapped noble gases in shock-melted portions of meteorite EET 79001 as unfractionated marian atmosphere [1-3], and the measurement of distinctly different noble gases in the dunite meteorite Chassigny (mantle gas?) [4], we can study how the evolution of noble gas reservoirs on Mars compares to that on Earth. Pepin [5] has reviewed many models in detail. This abstract will focus on some of the key similarities and differences, with some recent ideas highlighted.

Both Mars and Earth have elemental abundance pattems that are fractionated relative to the solar wind [5], suggesting a common source of gas (from planetesimals?). Both planets also have much less $\mathrm{Xe}$ than would be expected from fractionated solar (the "missing Xe"). Although this has been attributed to metallization of Xe in some models [6], high-pressure partitioning experiments [7] do not support this idea. For Mars, it could be the result of some Xe being sequestered in clathrates in the polar caps [8], although this would not work for Earth. In addition, for both planets the isotopic composition of $\mathrm{Xe}$ is fractionated (relative to solar) by roughly the same amount. It is not clear whether this is the result of some process (such as hydrodynamic escape) operating to the same extent on both planets [6], or some preplanetary process, such as gravitational escape from porous planetesimals [9], that affected the gas supplied to both planets,

On Earth, it is generally believed that the composition of atmospheric noble gases has evolved very little over the last billion years or so. Mars' atmosphere may not be so constant. Neon and Ar may be lost from the atmosphere by sputtering $[10,11]$, and variable fractions of the atmospheric $\mathrm{Kr}$ and $\mathrm{Xe}$ inventory might be stored in polar caps [8].

Solarlike He and Ne seem to be present in the Earth's mantle [12], but it is not clear whether the mantle contains solar Ar and Xe [13]. Although we believe we don't have identifiable samples of martian mantle $\mathrm{He}$ and $\mathrm{Ne}$, martian interior Xe seems to be solar in composition [4], although there is some question about what "solar" composition should be used $[6,14]$.

On Earth, the $\mathrm{Ar}$ and $\mathrm{Xe}$ atmosphere are less radiogenic than their counterparts in the mantle [e.g., 15], while on Mars, the opposite seems to be true $[3,4]$. This must be the result of details of the timing and extent of outgassing and atmospheric loss. In addition, previous models of the evolution of martian Xe left no room for any contribution from actinide fission [3,6], although it may be possible to have an actinide contribution comparable to that on Earth if a different "solar" composition is used [14].

References: [1] Bogard D. and Johnson P. (1983) Science, 221, 651. [2] Becker R. and Pepin R. (1984) EPSL, 69, 225. [3] Swindle T. et al. (1986) GCA, 50, 1001. [4] Ott U. (1988) GCA, 52, 1937. [5] Pepin R. (1992)Annu. Rev. Earth Planet. Sci., 20, 389. [6] Pepin R. (1991) Icarus, 92, 2. [7] Matsuda J. et al. (1993) Science, 259, 788. [8] Musselwhite D. and Lunine J. (1995) JGR, 100, 23301. [9] Zahnle K. et al. (1990) GCA, 54, 2577. [10] Pepin R. (1994) Icarus, 111, 289. [11] Hutchins K. and Jakosky B. (1996) JGR, 101, 14933. [12] Honda M. et al. (1991) Nature, 349, 149. [13] 
Pepin R. (1995) LPS XXVI, 1109. [14] Swindle T. and Jones J. (1997) JGR, 102, 1671. [15] Ozima M. and Igarashi G. (1989) in Origin and Evolution of Planetary and Satellite Atmospheres, 306.

THE INTERACTION OF Mn ${ }^{2+}$ AND Zn ${ }^{2+}$ IONS WITH (1014) SURFACES OF CALCITE DURING GROWTH AS A FUNCTION OF CHLORINITY: FROM ISOMORPHOUS SUBSTITUTION TO TWO-PHASE COPRECIPITATION? M. Temmam, J. Paquette, and H. Vali, Department of Earth and Planetary Sciences, McGill University, Montréal, Québec H2A 3A7,Canada(mounir@geosci.lan.mcgill.ca; jeanne_p@geosci.lan. mcgill.ca; vali_h@geosci.lan.mcgill.ca).

Introduction: During spiral growth of the calcite rhombohedron $\{1014\}$, divalent metals substituting for $\mathrm{Ca}^{2+}$ are differentially incorporated due to steric differences inherent to the asymmetric kink sites exposed at nonequivalent growth steps [1]. Hence, ions larger than $\mathrm{Ca}^{2+}$ (e.g., $\mathrm{Pb}^{2+}$ ) exhibit an incorporation trend opposite to that of small ions (e.g., $\mathrm{Mn}^{2+}$ ). However, $\mathrm{Zn}^{2+}$ exhibits the same incorporation trend as large ions in coprecipitation experiments from highly saline, $2 \mathrm{M} \mathrm{NH}_{4} \mathrm{Cl}$ electrolytes [2]. We compared the incorporation trends of $\mathrm{Zn}^{2+}$ and $\mathrm{Mn}^{2+}$ at different values of chlorinity to test the possibility that the adsorption of "large" $\mathrm{ZnCl}_{n}{ }^{2-n}$ complexes influences the site preference of $\mathrm{Zn}^{2+}$.

Methodology: Using a free-drift technique, millimeter-sized calcite single crystals were synthesized at $25^{\circ} \mathrm{C}$ from $\mathrm{NH}_{4}-\mathrm{Cl}-\mathrm{Ca}$ $\mathrm{CO}_{3}$ solutions. In experiment $\mathrm{FD} 1, \mathrm{Mn}^{2+}(22.7 \mu \mathrm{M})$ and $\mathrm{Zn}^{2+}$ $(15.3 \mu \mathrm{M})$ were added simultaneously to the solutions, whereas in experiment $\mathrm{FD} 2, \mathrm{Zn}^{2+}(45.9 \mu \mathrm{M})$ was added 3 days after $\mathrm{Mn}^{2+}$ $(22.7 \mu \mathrm{M})$. Coprecipitation was conducted in aqueous solutions with 1.6-, 0.8-, and 0.4- $\mathrm{M} \mathrm{NH}_{4} \mathrm{Cl}$, moderately supersaturated relative to calcite $\left(\Omega_{\text {calcite }} \sim 1-5\right)$ but undersaturated with respect to $\mathrm{Mn}$ and $\mathrm{Zn}$ solids. Changes in calcite surface microtopography were documented by SEM. The relationship between solution chemistry and the concentric and sectoral zoning of $\mathrm{Mn}$ was documented by cathodoluminescence microscopy (CL). $\mathrm{CL}$ maps guided the location of EPMA traverses within growth hillocks of $\{1014\}$ sectors.

Results and Discussion: In FDl, the spiral growth mechanism prevailed over the entire salinity range, and across growth hillocks the incorporation trends of $\mathrm{Mn}^{2+}$ and $\mathrm{Zn}^{2+}$ were opposite at nonequivalent sites. Hillock sizes decreased and their number increased at lower chlorinity. As chlorinity decreased from 0.8 to $0.4 \mathrm{M} \mathrm{NH}_{4} \mathrm{Cl}$, the preference of $\mathrm{Zn}^{2+}$ for the less-constrained surface sites increased, indicating that its site preference is not controlled by the size of $\mathrm{ZnCl}_{n}{ }^{2-n}$ complexes.

In FD2, calcite seeds were slightly rough and grew by the spiral mechanism from the $1.6-\mathrm{M} \mathrm{NH}_{4} \mathrm{Cl}$ solution. Once $\mathrm{Zn}^{2+}$ was added to the solution, the zoning related to spiral mechanism became imperceptible, the growth rate normal to surfaces was reduced, and surfaces developed a high roughness, suggesting a strong adsorption of $\mathrm{Zn}$. A decrease in salinity from 1.6 to $0.8 \mathrm{M}$ increased $\mathrm{Zn}^{2+}$ incorporation from the range $2500-8000$ to $14,000 \mathrm{ppm}$. Electron microprobe scans showed that the highest concentrations correspond to a thin layer $(10 \mu \mathrm{m})$ that may contain a discrete $\mathrm{Zn}$ solid phase (SEM and TEM investigations are underway).

The differential incorporation of $\mathrm{Mn}^{2+}$ and $\mathrm{Zn}^{2+}$ across growth hillocks at low $\mathrm{Zn}$ concentrations is consistent with isomorphous substitution for $\mathrm{Ca}^{2+}$ in the calcite structure. Chloride complexation decreases the magnitude of incorporation of $\mathrm{Mn}^{2+}$ and $\mathrm{Zn}^{2+}$ but does not modify their opposite site preferences. Other explanations such as electronic configuration must be considered. The sorptive character of $\mathrm{Zn}^{2+}$ affects the growth mechanism of the $\{1014\}$ rhombohedron and may contribute to the formation of discrete precipitates by concentrating the reactive ions at crystal surfaces.

References: [1] Paquette and Reeder (1995) GCA, 59, 735749. [2] Reeder (1996) GCA, 60, 1543-1552.

\section{MICROSCOPIC CHARACTERIZATION OF MECHAN.} ISMS AND FUNDAMENTAL PARAMETERS GOVERNING CALCITE MineRAlization. H. H. Teng ${ }^{1}$, P. M. Dove', C. Orme ${ }^{2}$, and J. J. DeYoreo', 'School of Earth and Atmospheric Sciences, Georgia Institute of Technology, Atlanta GA 30332, USA, ${ }^{2}$ Department of Chemistry and Materiais Science, Lawrence Livermore National Laboratory, Livermore CA 94550, USA.

Calcite is the most abundant carbonate mineral and occurs in a wide variety of natural inorganic and biological systems. Although there is an enormous array of literature reporting investigations of carbonate growth, few have pursued microscopic characterization of the mechanisms and fundamental parameters governing calcite mineralization. Recent progress in biomineralization demonstrates that factors such as step kinetics and facet stability have important controls in producing crystals with specific forms that fulfill biological functions. For example, these materials can function as structural support, porous filtration media, grinding and cutting tools, lenses, or magnetic guidance systems. Ex situ bulk experimental studies indicate that the spiral growth mechanism is the dominant process goveming calcite growth in inorganic system. With the introduction of atomic force microscopy (AFM), it is now possible to quantify this process by characterizing microscopic kinetics of step migration and determining fundamental growth parameters that govern the formation of new steps and the accretion of new

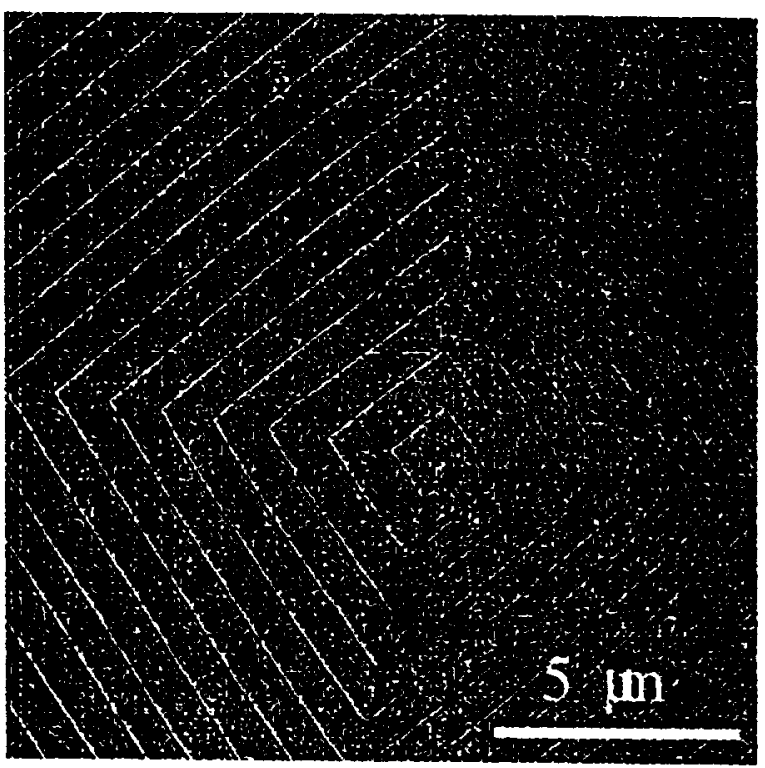

Fig. 1. 
surfaces.

Using fluid-cell AFM, we are examining the growth of $\{10 \overline{1} 4\}$ calcite faces in $\mathrm{Ca}-\mathrm{CO}_{3}$ solutions at various supersaturations, $\sigma$, where

$$
\sigma=\Delta \mu / k_{B} T=1 / 2 \ln \left(a_{\mathrm{Ca}^{2}}{ }^{2+a} \mathrm{CO}_{3}{ }^{2-/ \mathrm{K}_{\mathrm{sp}}}\right)
$$

A series of experiments have been conducted to (1) determine an appropriate supersaturation range to study step kinetics and (2) quantify rates of step motion and the geometry of spiral growth hillocks. In situ AFM imaging reveals that spiral rotation and heterogeneous two-dimensional nucleation dominate the generation of new growth steps at low and high supersaturations respectively. Rhombus symmetry is observed for hillocks of both spiral growth and two-dimensional nucleation. Individual $3-\AA$ steps of the spiral hillocks are observed as shown below. Because the two-dimensional nucleation hillocks had relatively steep slopes, we could not resolve individual terraces and only relative flat vicinal faces emerged. We found that the supersaturation value for the transition from spiral growth to heterogeneous two-dimensional nucleation was approximately $\sigma=$ 0.81 .

Measured step velocities ranged from 1 to $12 \mathrm{~nm} / \mathrm{s}$, depending upon the supersaturation, but the growth of individual monomolecular layers was anisotropic at all supersaturations. Velocities in the $[\overline{4} 41]_{+}$and $[48 \overline{1}]_{+}$directions were approximately $70 \%$ higher than that at the $[\overline{4} 41]$. and $[48 \overline{1}]$ _ directions, resulting in skewed growth hillocks. The ratios of step heights to step widths were used to estimate the slopes of the vicinal faces on the spiral hillocks. The lengths of the first legs in these spiral hillocks were measured to estimate the critical nucleus sizes.

These data are used to determine the kinetic coefficient of step migration and the edge free energies. Kinetic coefficient, $\beta$, reflects the energy barrier of kink sites for solute incorporation at the step edges and was obtained from the relationship between step velocity and the solute concentration. The edge-free energy, $\alpha$, which controls the size of a critical nucleus and the steepness of a growth hillock, was derived from the relationship between $\alpha, \sigma$, and the critical nucleus radius, $\mathbf{r}_{c}$.

Surface diffusion of adsorbed solutes has been shown to produce step homogenization if the amount of surface that feeds the step controls step velocity. We found that step spacing at the micrometer scale did not change over time, and hence no step homogenization was observed. This result suggests that growth is controlled by step kinetics rather than by surface diffusion, which indicates that the diffusion length is much less than the step spacing or the ratelimiting step is solute incorporation.

The findings of our microscopic study of the simple $\mathrm{Ca}-\mathrm{CO}_{3}$ system provide a baseline for further investigations of calcite crystallization in geologic environments. These results can also serve as a physical basis for understanding diverse carbonate mineralization processes in biological systems or the engineering of biomaterials.

MAGMA INTERACTIONS AT CHAOS CRAGS, LASSEN VOLCANIC NATIONAL PARK, CALIFORNIA. F. J. Tepley III', J. P. Davidson', and M. A. Clynne', 'Department of Earth and Space Sciences, University of California-Los Angeles, Los Angeles CA 90095, USA (tepley@ess.ucla.edu; davidson@ ess.ucla.edu), '2U.S. Geological Survey, 345 Middlefield Road, Mail Stop 910, Menlo Park CA 94025, USA.
Chaos Crags comprises a group of silicic lava domes and associated tephra deposits that form part of the Lassen Volcanic Center, the southernmost extension of current subduction-related magmatic activity of the Cascades. The domes contain a suite of mafic (basaltic andesite) magmatic inclusions that increase in volumetric abundance with time throughout the emplacement sequence. The inclusions have distinctly lower ${ }^{87} \mathrm{Sr} / 86 \mathrm{Sr}$ ratios $(\sim 0.7037-0.7038)$ than the host dacite ( $0.704-0.7041)$, which can be used to fingerprint the origin of mineral components in the mingled magmas. The difference in the isotope ratios between the magmatic inclusions and their host domes becomes smaller through the sequence of dome emplacement, which suggests that mixing between endmember sources is becoming more thorough before eruption.

Large plagioclase crystals are found in both the inclusions and the host dacites. Electron probe traverses conducted on several plagioclase crystals enclosed within basaltic andesite inclusions show that the crystals are compositionally $\left(\mathrm{An}_{40}\right)$ similar to those in the host dacite. Many have spongy-texture overgrowths, interpreted as reflecting immersion of crystals originally crystallized in the dacite, into the hotter, higher $\mathrm{Ca}$ basaltic andesite magma. The ${ }^{87} \mathrm{Sr}$ / ${ }^{86} \mathrm{Sr}$ ratios from the cores of the crystals in the inclusions are similar to those of the bulk host dacite, whereas the ${ }^{87} \mathrm{Sr} /{ }^{86} \mathrm{Sr}$ ratios of the rims are close to those of the basaltic andesite inclusions in which the crystal now resides, again suggesting derivation from the dacite. Microdrilling of these plagioclase crystals has revealed a significant range in ${ }^{87} \mathrm{Sr} /{ }^{86} \mathrm{Sr}$ ratios across the crystals, revealing a more complex history than simple incorporation of host phenocrysts into the inclusion magma. Nomarski imaging shows that the growth history of plagioclase crystals in both host and inclusions is defined by many fine oscillatory zones punctuated by multiple, major dissolution surfaces with irregular boundaries. Examination of phenocrysts in the dacite reveals that they too display core-rim variations in ${ }^{87} \mathrm{SI} /$ ${ }^{86} \mathrm{Sr}$, but do not have the $1 \mathrm{w}^{87} \mathrm{Sr} /{ }^{86} \mathrm{Sr}$ spongy-textured overgrowths seen in crystals from the inclusions. It appears then that recharge by basaltic andesite magmas occurred on several occasions, the most recent of which is represented by the mafic inclusions, preserved as evidence of incomplete hybridization by quenching on dome emplacement. The earlier recharge events are recorded by the mafic clots and resorbed olivine crystals in the dacite, which are believed to represent thoroughly disaggregated inclusions. More significantly, though, the variability of ${ }^{87} \mathrm{Sr} /{ }^{86} \mathrm{Sr}$ in the interiors of the crystals and the core-to-rim decrease in ${ }^{87} \mathrm{Sr} /{ }^{86} \mathrm{Sr}$ ratios in both resorbed and unresorbed dacite plagioclase crystals suggest that mafic recharges occurred during earlier phases of crystal growth.

\section{THE EFFECT OF CLIMATE ON MASS TRANSPORT OF MINOR AND TRACE ELEMENTS IN SOILS DEVELOPED} ON BASALTIC BEDROCK. N. Teutsch', Y. Erel', L. Halicz ${ }^{2}$, and O. A. Chadwick ${ }^{3},{ }^{1}$ Institute of Earth Sciences, Hebrew University of Jerusalem, 91904 Jerusalem , Israel, ${ }^{2}$ Geological Survey of Israel, 30 Malkhei Yisrael Street, 95501 Jerusalem, Israel, ${ }^{3}$ Department of Geography, University of California-Santa Barbara, Santa Barbara CA 93106, USA.

The effect of differences in rainfall patterns on $\mathrm{Mn}, \mathrm{Fe}, \mathrm{Al}, \mathrm{Cu}$, $\mathrm{Zn}, \mathrm{Pb}$, and $\mathrm{Ti}$ behavior in soil profiles developed on basaltic bedrock of the same age was studied in a detailed transect on the southwest slope of Kohala Mountain, Hawai'i. Total and acid- 
leached concentrations of soil and bedrock samples were analyzed. Mass-transport calculations yielded the amounts accumulated or depleted in the soil relative to the bedrock. There is no significant effect of rainfall amount in the dry sites ( 3 sites, $160-570 \mathrm{~mm} / \mathrm{yr}$ ) on the accumulation or depletion of all elements (with the exception of $\mathrm{Cu}$ ) within the soil. In the intermediate (4 sites, $930-1380 \mathrm{~mm}$ $\mathrm{yr}$ ) and wet ( 1 site, $2500 \mathrm{~mm} / \mathrm{yr}$ ) sites, most metals show a strong rainfall effect. The extent of rainfall effect varies from one element to the other, but there is a general trend of less accumulation and more leaching from the soil with increasing amounts of rainfall. Iron is enriched in all the sites, and has a systematic variation with rainfall only in the intermediate (strong rainfall effect) and wet (small effect) sites. Less of the Fe in the soil is accumulated with increasing rainfall above $930 \mathrm{~mm} / \mathrm{yr}$. This indicates that at this rainfall range $\mathrm{Fe}$-rich phases in the soil (mostly $\mathrm{Fe}$ oxides and hydrous oxides) become less stable. The entire range of Fe accumulation is rather small (7-18\%), which reflects the high correlation between the total concentrations of $\mathrm{Fe}$ and $\mathrm{Ti}$ used as the normalizing element. Manganese is enriched in all the sites except for the wet site. Like Al and $\mathrm{Fe}$, in the dry sites the enrichment is variable (5$29 \%$ ), and in the intermediate sites there is a strong rainfall effect. Like $\mathrm{Al}$, the transition from the intermediate to the wet site is accompanied by a strong depletion $(-70 \%)$ of $\mathrm{Mn}$. The strong depletion of $\mathrm{Mn}$ in the wet sites is probably related to reductive dissolution of Mn(IV)-rich hydrous oxides. The rainfall effect on the relative accumulation or depletion of $\mathrm{Al}, \mathrm{Mn}$, and $\mathrm{Fe}$, which are the main oxide- and hydrous-oxide-forming elements in the soil, is remarkably similar. The effect of rainfall on the accumulation of $\mathrm{Zn}$ starts only at $1060 \mathrm{~mm} / \mathrm{yr}$ and is evident all the way to $2500 \mathrm{~mm} / \mathrm{yr}$. As in the case of $\mathrm{Mn}$, at $1380 \mathrm{~mm} / \mathrm{yr}$ there is no gain or loss and in the wet site there is a strong depletion of $\mathrm{Zn}$ relative to the bedrock $(45 \%)$. The effect of rainfall on $\mathrm{Cu}$ accumulation/depletion in the soils is unique. Unlike all other elements, there is a strong rainfall effect on $\mathrm{Cu}$ in the dry sites, and there is no effect in the intermediate and wet sites. In the dry sites there is less accumulation of $\mathrm{Cu}$ with increasing rainfall. Lead is remarkably enriched in all sites and in general the enrichment increases with increasing rainfall from $78 \pm$ 23 in the dry sites, $143 \pm 46 \%$ in the intermediate sites, and $176 \%$ in the wet site.

SOME ISOTOPIC THOUGHTS ON CRUST-MANTLE EVOLUTION. G. R. Tilton, Department of Geological Sciences, University of Califomia, Santa Barbara CA 93106, USA.

The isotopic heterogeneity of the modem mantle and crust are well established, which dictates that models for mantle evolution must rely upon suites of samples, preferably ones including a range in ages. The early Earth was hotter, thus possibly more homogeneous due to better stirring, but even that is uncertain. The present studies utilize data from galena from two suites of samples covering age ranges of $0-2.6 \mathrm{Ga}$ and $3.8-2.6 \mathrm{Ga}$, covering two time periods in Earth evolution. Substituting the parameter, $\mathrm{e}^{\lambda t}-1$, for the age, $t$, allows the data to be tested in linear diagrams [1], greatly simplifying interpretation. The first suite consists of five samples spanning an interval from 3.8 to $2.6 \mathrm{Ga}$, which is virtually all the reasonably reliable $\mathrm{Pb}$ isotope data available in that range. The second suite consists of 10 galenas from the so-called conformable ore group. These evaluations do not rely upon the details of the differentiation
TABLE 1 .

\begin{tabular}{lccc}
\hline \hline Suite, $\mathrm{Ga}$ & ${ }^{206} \mathrm{~Pb} /{ }^{204} \mathrm{~Pb}$ & ${ }^{207} \mathrm{~Pb} /{ }^{204} \mathrm{~Pb}$ & ${ }^{208} \mathrm{~Pb} / 204 \mathrm{~Pb}$ \\
\hline $3.8-2.6$ & $17.58+0.13$ & $15.36+0.08$ & $37.74+0.47$ \\
$2.6-0$ & $18.75+0.05$ & $15.63+0.02$ & $38.81+0.11$ \\
\hline Suite, $\mathrm{Ga}$ & $\mu\left({ }^{238} \mathrm{U}\right)$ & $\mu\left({ }^{235} \mathrm{U}\right)$ & \\
\hline $3.8-2.6$ & $8.00+0.20$ & $7.78+0.43$ & \\
$2.6-0$ & $9.65+0.13$ & $8.83+0.25$ & \\
\hline \hline
\end{tabular}

processes in the first $100+\mathrm{Ga}$ of Earth history. They also have the advantage of separate evaluations of $206 \mathrm{~Pb} / 204 \mathrm{~Pb}$ and $207 \mathrm{~Pb} / 204 \mathrm{~Pb}$ evolution. Table 1 lists the $\mathrm{Pb}$ ratios for each suite projected to the present, along with two separate $\mu$ values from each of the two $U$ decay series. The uncertainties are standard deviations (10).

3.8-2.6-Ga Group: The two $\mu$ ratios in the sources agree within uncertainty limits, and yield isotope patterns that would plot close to the MORB group today. The ratios are low compared to estimates of bulk silicate Earth in the literature (summary in [2]), suggesting that "depleted" mantle reservoirs existed early in Earth

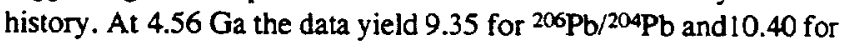

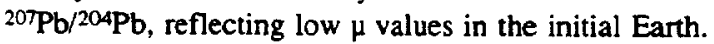

2.6-0-Ga Group: Here the two $\mu$ values do not agree within uncertainties. This results from participation of younger sources, e.g., $2+\mathrm{Ga}$ average age. When both age groups above are plotted in a single ${ }^{206} \mathrm{~Pb} / 204 \mathrm{~Pb}$ or ${ }^{207 \mathrm{~Pb} / 204} \mathrm{~Pb}$ vs. $\mathrm{e}^{\lambda t}-1$ diagram, there is no continuity between the two fields. Rather they define two distinct trends that intersect around $3.5-3.8 \mathrm{Ga}$, as was suggested in [1]. That possibly signals the beginning of magma sources for the production of sialic crust on a global scale. That concept fits data for ${ }^{143} \mathrm{Nd} /{ }^{144} \mathrm{Nd}$ ratios in authigenic oceanic sediments, for which $\varepsilon_{\mathrm{Nd}}$ becomes 2-4 at $\sim 3 \mathrm{Ga} \mathrm{[3].}$

References: [1] Albarede F. and Juteau M. (1984) GCA, 48, 207. [2] Galer S. J. G. and Goldstein S. L. (1996) AGU Monograph, 95, 75. [3] Jacobsen S. and Pimentel-Klose M. R. (1988) GRL, 15, 393.

BORON ISOTOPIC AND LIGHT-ELEMENT VARIATIONS IN AEOLIAN VOLCANIC ARC LAVAS. S. Tonarini', W. P. Leeman $^{2}$, M. Pennisi', and G. Ferrara ${ }^{1}$, 'Istituto di Geocronologia e Geochimica Isotopica, C.N.R., Via Cardinale Maffi 36, 56100 Pisa, Italy, ${ }^{2}$ Keith-Wiess Geological Laboratories, Rice University, Houston TX 77005, USA.

Subduction in the southern Tyrrhenian Sea produced the Aeolian volcanic arc. Aeolian mafic lavas exhibit significant variations in $B$, $\mathrm{Be}$, and $\mathrm{Li}$ contents and $\mathrm{B}$ isotope composition $\left(\delta^{\prime \prime} \mathrm{B}\right)$ across the arc: $\delta^{11} \mathrm{~B}(-5.9$ to $+2.3 \%), \mathrm{B} / \mathrm{Be}(4.5-20)$, and $\mathrm{Li} / \mathrm{Be}(8.5-16$, excluding a single value of 23$). \delta^{1} \mathrm{~B}$ is positively correlated with mobile/ immobile element ratios (e.g., $\mathrm{B} / \mathrm{Th}, \mathrm{B} / \mathrm{Nb}, \mathrm{B} / \mathrm{Be}, \mathrm{Cs} / \mathrm{Nb}$ ), whereas there is no correlation between $\delta^{1} \mathrm{~B}$ and radiogenic isotopic ( $\mathrm{Sr}, \mathrm{Nd}$, and $\mathrm{Pb}$ ) compositions. In evolved lavas (latite, thyolite) from the eastem Aeolian Islands (Stromboli, Lipari, Panarea, Vulcano) the latter parameters appear to be influenced by assimilation of continental crust; in contrast, $\delta^{11} \mathrm{~B}$ values are nearly constant in basaltic to rhyolitic lavas from Vulcano, and apparently are unaffected by 
crustal contamination owing to relatively high $B$ contents of the lavas compared to the contaminants (low-B high-grade metamorphic rocks).

Thus, we interpret cross-arc variations in $\delta^{11} \mathrm{~B}$ as essentially reflecting lateral isotopic differences within magma sources that arose due to addition of slab-derived components to the mantle wedge in decreasing amounts toward the backarc region (west). Lavas of the westem islands (Alicudi, Filicudi) exhibit the lowest $\mathrm{B}$ contents, $\mathrm{B} / \mathrm{immobile}$ element ratios (e.g., B/Nb, B/Zr, B/La, etc.), and $\delta^{\prime \prime} B$; sources of these lavas are inferred to have the least slab contribution. In plots of $\delta^{11} \mathrm{~B}$ vs. B/immobile trace-element ratios, very similar $\delta^{11} \mathrm{~B}$ intercepts $(-6.5 \pm 0.5 \%)$ are taken as representative of the original subarc mantle prior to addition of subduction components. This model requires a subduction component with relatively high $\delta^{11} \mathrm{~B}(>3 \%)$ to account for the total range in $\delta^{\prime \prime} \mathrm{B}$ observed in the lavas.

With respect to $\delta^{\prime \prime} \mathrm{B}, \mathrm{B} / \mathrm{Be}, \mathrm{B} / \mathrm{K}$, etc., Aeolian lavas have systematically lower values than their counterparts from western $\mathrm{Pa}$ cific arcs, although cross-arc variations for Japan and the Aeolian arc are qualitatively similar. In both cases the observed variations could result from either (1) progressively smaller amounts of a high $\delta^{11} \mathrm{~B}$ subduction component (hydrous fluids?) added to the subarc mantle wedge as the downgoing slab warms and dehydrates, or (2) selective loss of " $\mathrm{B}$ beneath forearc regions during early stages of slab dehydration. With increasing distance behind the volcanic fronts, the first scenario involves diminishing slab contributions to the $B$ budget of arc magma sources, whereas the second scenario primarily involves isotopic fractionation between evolved fluids and residual slab material. The Aeolian arc is characterized by a relatively low subduction rate and higher temperature with respect to westem Pacific arcs. Because the thermal state of subduction zones likely controls slab dehydration rates, differences in B isotopic systematics between arcs also may be controlled mainly by those physical parameters that influence slab temperature.

\section{CHROMATOGRAPHIC DETERMINATION OF THE STABILITY OF ALUMINUM-ORGANIC COMPLEXES: LIGANDS PRODUCED AND EXCRETED BY ENVIRON- MENTAL MICROORGANISMS. K. A. Traexler ${ }^{3}$, S. A. Welch', and W. J. Ullman', 'College of Marine Studies, University of Delaware, Lewes DE 19958, USA (ullman@udel.edu), ${ }^{2}$ Depar- ment of Geology and Geophysics, University of Wisconsin, Madison WI 53706, USA.}

There are a number of organic ligands that are excreted by environmental microorganisms that can increase the rates of Alsilicate mineral dissolution in soils and aquifers by a mechanism involving adsorption, surface complex formation, and dissolution. Oxalate and citrate are among the ligands for which stability constants have been determined. The stability constants of other complexes with ligands that have dissolution-enhancing properties, such as gluconate and 2-ketoglutarate, are not known. A chromatographic method has been developed to determine the stability constants of a suite of Al-organic complexes that may be important in metabolite-mediated Al-silicate mineral dissolution.

The technique uses ion chromatography with a cation exchange column to separate cationic species from neutral and anionic species in acid solution, postcolumn addition of lumogallion, and fluores-
TABLE 1 .

\begin{tabular}{lccc}
\hline $\mathrm{KNO}_{3}$ & $\log _{1}{ }^{\circ}\left(\mathrm{AlOx}^{+}\right)$ & $\log _{2}{ }^{*}\left(\mathrm{AlOx}_{2}{ }^{-}\right)$ & $\log _{3}{ }^{*}\left(\mathrm{AlOx}_{3}{ }^{2}\right)$ \\
\hline $0.1 \mathrm{M}$ & $4.79 \pm 0.2$ & $7.54 \pm 0.3$ & $7.90 \pm 1.0$ \\
$0.2 \mathrm{M}$ & $4.78 \pm 0.4$ & $7.90 \pm 0.4$ & $9.90 \pm 0.4$ \\
$0.5 \mathrm{M}$ & $4.85 \pm 0.2$ & $7.77 \pm 0.3$ & $10.0 \pm 0.3$ \\
\hline
\end{tabular}

cence detection. Free $\mathrm{Al}$ and $\mathrm{Al}$-organic complexes are identified and quantified on the basis of distinct peaks associated with Allumogallion fluorophore (observed at $600 \mathrm{~nm}$ after excitation at 436 $\mathrm{nm}$ ). It was found that satisfactory separation of some peaks (e.g., oxalato-complexes) required only a shor guard column. Other ligands (e.g., gluconato- and fluoro-complexes) required a fulllength column for satisfactory peak separation and detection. In the absence of complexing ligands, free $\mathrm{Al}$ concentrations at the $<1-\mu \mathrm{M}$ level are easily detectable. This permits the determination of stability constants at total $\mathrm{Al}$ concentrations approximating those found in natural waters. Total $\mathrm{Al}$ concentrations up to $40 \mu \mathrm{M}$ were used in our experiments.

The method yields stability constants in $\mathrm{KNO}_{3}$ solutions similar to those previously reported for the oxalato- and fluoro-complexes. Only one oxalato-complex, presumably $\mathrm{AlOx}^{+}$, was detected in addition to $\mathrm{Al}^{3+}$, but there is clear evidence of the formation of at least a second, presumably $\mathrm{AlOx}_{2}{ }^{-}$, and possibly a third, $\mathrm{AlOx}_{3}{ }^{3-}$, although these are not detected directly. For the fluoro-complexes, only two complexes are detected directly in addition to $\mathrm{Al}^{3+}$, presumably $\mathrm{AlF}^{2+}$ and $\mathrm{AlF}_{2}+$. There is strong evidence for at least one additional complex, presumably AlFo, although it may not be possible to fully distinguish between neutral and anionic complexes under the conditions of these experiments. This method is being applied to additional ligands of interest.

The preliminary conditional aluminum-oxalate constants are similar to those previously reported (see Table 1).

Acknowledgments: Work supported by the Subsurface Science Program of the Department of Energy.

EARLY SILICATE DIFFERENTIATION IN MARS. A. $\mathrm{H}$. Treiman, Lunar and Planetary Institute, 3600 Bay Area Boulevard, Houston TX 77058, USA (treiman@lpi.jsc.nasa.gov).

The martian (SNC) meteorites, all basaltic, provide a geochemical window into Mars' mantle and its early differentiation [1-3]. The mantle source of the SNC meteorites differentiated very early, with approximately three-fifths of $\mathrm{Al}$ in the SNC source regions being removed. The $\mathrm{Al}$ was probably not lost as plagioclase, because the SNC basalts are not enriched or depleted in Eu or Sr. More likely, at least part of the Al went into the early crust; some could also have been sunk into the mantle as basalt magma, spinel, or garnet.

Primordial Differentiation Age: It is perhaps surprising that the SNC meteorites retain any isotopic signatures of a primordial differentiation. Their source mantle was depleted in siderophile elements, which presumably reflects fractionations associated with core formation in Mars [2-5]. Very early differentiation appears as detectable excesses of daughter isotopes in extinct isotope systems, which imply metal/silicate and silicate/silicate differentiation ear- 
TABLE 1. Model martian crusts.

\begin{tabular}{lccc}
\hline Crust & $\begin{array}{c}\text { Basalt or } \\
\text { "Granite" }\end{array}$ & $\begin{array}{c}\text { Basalt or } \\
\text { "Granite" }\end{array}$ & Anorthosite \\
\hline $\mathrm{Al}_{2} \mathrm{O}_{3} \%$ & 15 & 18 & 30 \\
Mass \% of Mars & 13.0 & 10.7 & 6.3 \\
Volume \% of Mars & 14.1 & 11.7 & 6.8 \\
Thickness $(\mathrm{km})$ & 150 & 120 & 70 \\
\hline
\end{tabular}

lier than $4539 \mathrm{Ga}$ [6-8]. Ages near $4.5 \mathrm{Ga}$ also appear in $\mathrm{Pb}-\mathrm{U}-\mathrm{Th}$ isotope systematics, and in the Rb-Sr whole-rock age for the shergottites $[9,10]$. These ages imply that at least part of Mars' mantle, the source of the SNCs, was not processed or mixed with other reservoirs until $1.3 \mathrm{Ga}[6,7]$.

Primordial Differentiation Effects: Formation of the martian core has been dealt with elsewhere [2-5]. For understanding early silicate/silicate differentiation, the most useful clue is Al. During early differentiation, the SNC source mantle lost approximately three-fifths of its original $\mathrm{Al}$ allotment [2]; this depletion is apparent in $\mathrm{Al} / \mathrm{Ti}, \mathrm{Al} / \mathrm{Yb}$, and $\mathrm{Al} / \mathrm{Ca}$ (and other ratios) for the SNC meteorites $[2,3]$; the simplest interpretation of the data is that $\mathrm{Al}$ was depleted and not that the other elements were enriched $[2,3,11]$.

Where could the Al have gone? Possibilities include a basaltic crust, a "granitic" crust, an anorthositic crust, spinel/gamet restites in the mantle, and basaltic material sunk deep into the mantle. The last possibility reflects the fact that some magmas become denser than their equilibrium olivine at high pressure [12]. The fate of the lost $\mathrm{Al}$ remains unclear. It is not possible, using $\mathrm{Al}$ alone, to distinguish between basaltic and granitic crusts, as both contain $\sim 15-18 \%$ $\mathrm{Al}_{2} \mathrm{O}_{3}$. Garnet, spinel, or basalt magma sunk deep into the mantle are effectively unconstrained, as there are no martian basalts from Al-enriched sources. The SNC meteorites are depleted in V relative to $\mathrm{Ti}$, just as $\mathrm{Al}$ is depleted, which was taken to suggest spinel or garnet fractionation from their source mantle [2]. Fractionation of garnet has long been invoked to explain REE patterns [3,11], and could equally well explain $\mathrm{Al}$ depletion. In all this, however, an anorthositic crust seems highly unlikely. Formation of an anorthosite would cause strong depletions in Eu and $\mathrm{Sr}$ in residual mantle [13,14]. However, there is no sign, isotopic or chemical, that the source mantles for the SNC meteorites magmas were fractionated in Eu or Sr [9].

Complete differentiation of an original martian mantle with $3.0 \% \mathrm{Al}_{2} \mathrm{O}_{3}[3]$ yields possible primitive crusts as in Table 1 . These crusts seem quite thick (except anorthosite crust, which is unlikely) in most but not all $[2,15,16]$. If the model crusts (Table 1) are too thick, it may be that the whole mantle differentiated and part of the differentiates were "buried" in the deep mantle, or that only a part of the whole mantle differentiated.

Assumes Mars' core is $22 \%$ of planet mass [3], Mars mantle + crust averages $3.0 \% \mathrm{Al}_{2} \mathrm{O}_{3}$, and differentiation yielded whole mantle of $1.2 \% \mathrm{Al}_{2} \mathrm{O}_{3}[2]$.

Subsequent History: After primordial differentiation and the Al loss described above, the source mantles for the SNC meteorites were chemically and isotopically isolated through most of martian history. No events are recorded in isotope chronometry from $4.5 \mathrm{Ga}$ to $1.3 \mathrm{Ga}$, when the SNC parent mantle began its current active era.

Conclusions: Mars apparently differentiated early to form a core and silicate portions enriched and depleted in alumina. It seems quite unlikely that anorthosites were produced in any abundance, and quite likely (by analogy with other planets) that at least part of the enriched portion of Mars was a basaltic crust. It seems likely to me that the early differentiation affected only part of the Martian mantle, and that the SNC meteorites do not come from the undepleted and/or Al-enriched parts of the mantle.

Acknowledgments: I am grateful to M. J. Drake and to his other postdocs and students J. H. Jones, H. W. Newsom, and J. L. Berkeley. Supported by NASA grant NAGW-5098.

References: [1] Drake M. J. (1980) Rev. Geophys. Space Phys., 18, 11. [2] Treiman A. H. et al. (1986) GCA, 50, 1071. [3] Longhi et al. (1992) in Mars, Univ. of Arizona. [4] Treiman A. H. et al. (1987) Proc. LPSC 17th, in JGR, 92, E627. [5] Righter and Drake (1996) Icarus, 124, 513. [6] Harper et al. (1995) Science, 267, 213. [7] Lee and Halliday (1997) LPS XXVIII, in press. [8] Musselwhite et al. (1991) Nature, 352, 697. [9] Jagoutz (1991) Space. Sci. Rev., 56, 13. [10] Shih et al. (1982) GCA. [11] Gleason et al. (1996) LPS XXVII, 425. [12] Agee and Walker (1993) EPSL, 114, 315. [13] BVSP (1981) Basaltic Volcanism. [14] Hess (1989) Origins of Igneous Rocks, Harvard. [18] Sohl and Spohn (1997) $J G R, 102,1613$. [19] Kiefer et al. (1996) JGR, 101, 9239.

\section{RADIOCARBON IN SOIL ORGANIC MATTER AND SOIL RESPIRATION: A COMPARISON OF BOREAL, TEMP-} ERATE, AND TROPICALFORESTS. S.E. Trumbore, Department of Earth System Science, University of California, Irvine CA 92697-3100, USA (setrumbo@uci.edu).

I will summarize results of radiocarbon measurements in soil organic matter and soil respired $\mathrm{CO}_{2}$ from temperate, boreal, and tropical forests. An estimated $20-40 \%$ of the $\sim 1500 \mathrm{Pg}$ of $\mathrm{C}$ stored as organic matter in the upper $1 \mathrm{~m}$ of soils has tumover times of centuries or less. This fast-cycling organic matter is largely comprised of undecomposed plant material (low density fraction) and hydrolyzable components associated with mineral surfaces. Tumover times of fast-cycling $C$ vary with climate and vegetation, and range from $<20 \mathrm{yr}$ at low latitudes to $>60 \mathrm{yr}$ at high latitudes. Tumover times derived from ${ }^{14} \mathrm{C}$ must take into account the fact that some of the organic matter entering the soil has resided in living vegetation before entering soil organic matter pools.

Transient sources or sinks in terrestrial $C$ pools result from the time lag between photosynthetic uptake of $\mathrm{CO}_{2}$ by plants and the subsequent release of plant $\mathrm{C}$ to the atmosphere through decomposition in soils. Changes in plant net primary production resulting from fertilization or climate change that do not also affect decomposition rates to the same degree may result in significant interannual to decadal imbalances in terrestrial $\mathrm{C}$ storage and release. Radiocarbon measurements in incubations or soil-respired $\mathrm{CO}_{2}$ may be used to estimate this time lag directly. Where we have measured the radiocarbon content of $\mathrm{CO}_{2}$ efflux from soils, the data indicate that at least $50 \%$ of the $\mathrm{C}$ being respired was fixed more than $10 \mathrm{yr}$ ago. The lag between photosynthesis and respiration is greatest at high latitudes, which also show the largest seasonal variation in soil ${ }^{14} \mathrm{CO}_{2}$. Boreal regions must therefore be involved if soils are acting as sources or sinks of $\mathrm{C}$ on timescales of centuries or longer. The larger land area and overall greater $C$ fluxes into and out of soils at low latitudes suggest that the tropics will dominate interannual to decadal fluctuations in the terrestrial $\mathrm{C}$ cycle. 
URANIUM-238/THORIUM-230 DISEQUILIBRIA, MAGMA PETROGENESIS, AND FLUX RATES BENEATH THE DEPLETED TONGA-KERMADEC ISLAND ARC. S. P. Turner ${ }^{1}$, C. J. Hawkesworth' ${ }^{1}$ N. W. Rogers' , J. Bartlett ', l. Smith', and $\mathrm{T}$. Worthington ${ }^{2}$, 'Department of Earth Sciences, The Open University, Milton Keynes, MK76AA, UK (s.p.tumer@open.ac.uk), ${ }^{2}$ Department of Geology, University of Auckland, New Zealand.

The highly depleted intra-oceanic Tonga-Kermadec island arc forms an end member of arc systems and a unique location in which to isolate the effects of the slab flux. High-precision TIMS U, Th, $\mathrm{Sr}, \mathrm{Nd}$, and $\mathrm{Pb}$ isotopes, along with complete major- and traceelement data, have been obtained on an extensive sample set comprising 58 lavas along the arc. The data provide information on both the petrogenesis of the lavas and material transport rates. Calcium titanium and $\mathrm{A} V \mathrm{Ti}$ ratios extend from values appropriate to a $\mathrm{N}$ MORB source in the southem Kermadecs to very high ratios in Tonga, interpreted to reflect increasing degrees of depletion of the mantle wedge due to backarc basalt extraction. The isotope data emphasize the need for at least three components in the petrogenesis of the lavas: (1) the mantle wedge similar to the source of the Lau BABB, (2) a component with elevated ${ }^{207 \mathrm{~Pb} / 204} \mathrm{~Pb}$ toward which the Kermadec and southern Tongan lavas extend, and (3) a component characterized by high ${ }^{206 \mathrm{~Pb}} / 204 \mathrm{~Pb}$, Ta/Nd, and low ${ }^{143} \mathrm{Nd} / 144 \mathrm{Nd}$ observed only in the northemmost Tongan islands of Tafahi and Niuatoputapu. Additionally, the strong enrichments of $\mathrm{Rb}, \mathrm{Ba}, \mathrm{U}, \mathrm{K}$, $\mathrm{Pb}$, and $\mathrm{Sr}$, relative to $\mathrm{Th}, \mathrm{Zr}$, and the REE in conjunction with large ${ }^{238} \mathrm{U}$ excesses $\left[\left({ }^{230} \mathrm{Th} /{ }^{238} \mathrm{U}\right)=0.8-0.5\right]$ in the more depleted lavas, implicate a fluid component. Component (2) is average pelagic sediment on the downgoing Pacific plate, and mass balance calculations indicate that less than $0.5 \%$ is recycled into the arc lavas; essentially all the subducted sediment is retumed to the upper mantle $\left(\sim 0.03 \mathrm{~km}^{3} \mathrm{yr}^{-1}\right)$. The sediment component is added to the wedge as a partial melt, and exceptionally low concentrations of $\mathrm{Ta}$ and $\mathrm{Nb}$ in the lavas may require that these sediment partial melts were in equilibrium with residual rutile or ilmenite. Component (3) is identified as ocean island basalt volcaniclastics. These could be derived from either Samoa or from the Louisville Ridge; however, ${ }^{206} \mathrm{~Pa} / 204 \mathrm{~Pb}, \mathrm{Ba} / \mathrm{Th}$, and Ti/Nd ratios favor the latter. The Louisville Ridge presently intersects the arc $1100 \mathrm{~km}$ south of Tafahi and Niuatoputapu; however, the angle between the Louisville Ridge and the arc causes the locus of intersection to migrate southward with time such that the Louisville Ridge and volcaniclastic sediments would have been in the process of being subducted beneath Tafahi and Niuatoputapu some $4 \mathrm{~m}$.y. ago. If component (3) is derived from the Louisville Ridge, these observations imply that $\sim 4$ m.y. elapses between the time of subduction of the sediments and their signature being observed in the arc lavas, yet the rate of subduction beneath Tonga is $150-240 \mathrm{~km} \mathrm{~m} \cdot \mathrm{y}^{-1}$ and so the sediments would arrive beneath the arc volcanos in $\leq 1 \mathrm{~m}$.y. if they were transported on the subducting plate. This dichotomy is resolved in that the mantle wedge is only partially coupled to the descending slab, so that convection and down-dip movement in the wedge are much slower than the rate of slab descent. The fluid contribution to the lava source is $\sim 1 \mathrm{ppm} \mathrm{Rb}, 10 \mathrm{ppm} \mathrm{Ba}, 0.02 \mathrm{ppm} \mathrm{U}, 600 \mathrm{ppm} \mathrm{K}, 0.2 \mathrm{ppm}$ $\mathrm{Pb}$, and $30 \mathrm{ppm} \mathrm{Sr}$. It has ${ }^{87} \mathrm{Sr} /{ }^{85} \mathrm{Sr}=0.7035$ and ${ }^{206 \mathrm{~Pb} / 204} \mathrm{~Pb}=18.5$ and thus is inferred to be derived from dehydration of the subducting altered oceanic crust. Uranium-thorium isotope disequilibria reflect the time since fluid release from the subducting slab, and a pseudoisochron through the lowest $\left({ }^{230} \mathrm{Th} /{ }^{232} \mathrm{Th}\right)$ lavas constrains this to be $\sim 50,000 \mathrm{yr}$. Thus fluid-induced melting would appear to occur after the addition of sediment partial melts to the mantle wedge. Published ${ }^{226} \mathrm{Ra}$ data indicate that the lavas also have ${ }^{226} \mathrm{Ra}$ excesses, thus the U.Th and Th-Ra isotope systematics are decoupled and it is suggested that $\mathrm{Th}-\mathrm{Ra}$ isotope disequilibria record the time since partial melting and thus indicate rapid channeled magma ascent. Olivine gabbro xenoliths from Raoul are interpreted as cumulates to their host lavas, with which they form zero-age U-Th isochrons, indicating that minimal time was spent in magma chambers. A plagiogranite xenolith is in U-Th secular equilibrium and inferred to represent a piece of older, accreted suprasubduction zone crust. The subduction signature is not observed in lavas from the backarc island of Niuafo'ou. These were derived from parial melting of fertile peridotite at $130-160 \mathrm{~km}$ depth with melt rates around $2 \times$ $10^{-4} \mathrm{~kg} \mathrm{~m}^{-3} \mathrm{yr}^{-1}$. Fluid-induced melting rates beneath the arc are inferred to be greater than this. The results from the Tonga-Kermadec island arc provide important constraints for island arc geodynamic models, particularly the degree of coupling between the slab and the mantle wedge and the thermal structure in the wedge.

MICROBIALLY MEDIATED, PROTON-PROMOTED FELDSPAR DISSOLUTION BY ORGANIC ACID EXCRETION UNDER UNBUFFERED AND NUTRIENT-LIMITED CONDITIONS IN OXIC AQUIFERS. W. J. Ullman', S. A. Welch', and P.C. Bennett ${ }^{3}$ ' 'College of Marine Studies, University of Delaware, Lewes DE 19958, USA (ullman@udel.edu), 2Department of Geology and Geophysics, University of Wisconsin, Madison WI 53706, USA, '3epartment of Geological Sciences, University of Texas, Austin TX 78712, USA.

The excretion of organic acids by microorganisms potentially impacts of the rates of feldspar dissolution in two ways: (1) the organic moiety can attack the mineral surface and enhance mineral dissolution rates by a ligand-promoted mechanism, and (2) the proton moiety can enhance dissolution rates by a proton-promoted mechanism. In neutral solutions, where the impact of the protonpromoted mechanism is at a minimum and the ligand-promoted mechanism predominates, the rates are linearly dependent on ligand concentration. In more acid environments $(\mathrm{pH}<6)$, the rates of feldspar dissolution remain dependent on ligand concentration, but the proton-promoted dissolution mechanism predominates over the ligand-promoted mechanism. The proton-promoted mechanism will also dominate at elevated temperatures due to differences in activation energy and the changing stability of ligand-metal complexes.

The rates of feldspar dissolution can be regarded as controlled by a balance between proton production by bacteria, the buffering capacity of the environment, and proton consumption by feldspar mineral hydrolysis/dissolution. The rates of microbial acid production in oxic aquifers depend on the partitioning of $C$ between new biomass and the products of complete $\left(\mathrm{CO}_{2}\right.$ /carbonic acid) and partial (organic acids) oxidation of the substrate. The partitioning, in turn, is dependent on the nature and availability of $C$ substrates and electron acceptors. Under nutrient-replete conditions in oxic environments, the products of complete oxidation are the principal metabolites released to solution and biomass increases. Under nutrient-limited but $\mathrm{C}$-rich conditions, such as those found in many aquifer environments, growth is limited and metabolic overproduction of intermediate oxidation products within the microbial cell leads to excretion of organic acids. 
Acids produced in oxic environments by these mechanisms will be consumed initially by the buffering capacity of the solution and subsequently, when the soluble buffers are exhausted, by reactions with mineral buffers, such as carbonate minerals. If the buffering capacity is sufficiently high or the rates of mineral buffering are sufficiently extensive and rapid, the ecosystem will remain near neutral $\mathrm{pH}$ and ligand-promoted dissolution of feldspars will be important. If the soluble buffering capacity is exceeded and/or the most reactive buffering minerals are exhausted, the solution will become increasingly acid and Al silicates will increasingly dissolve by the proton-promoted mechanism. With increasing acidity, feldspar dissolution rates increase and therefore a kinetically controlled buffering system will eventually stabilize ecosystem $\mathrm{pH}$.

An increase in reactive $C$ availability in oxic aquifers as a result of natural processes or contamination can therefore lead to enhanced proton-promoted rates of mineral dissolution due to the exhaustion of groundwater/aquifer buffering capacity and a decrease in $\mathrm{pH}$ in the bulk aquifer. In addition, the rates of both ligand- and protonpromoted dissolution may increase in aquifer microenvironments due to local modification of the biogeochemistry around individual bacterial colonies that lead to the excretion of both ligands and acids. Under some conditions, bases may also be produced in microenvironments and these can also influence dissolution rates. Processes at both spatial scales lead to an increase in the dissolution rates of minerals, such as feldspars, that would otherwise be kinetically stable in the aquifer environment. Evidence of this effect is available from our laboratory studies and field observations.

Acknowledgments: Work by W.J.U. and S.A.W. is supported by the Subsurface Science Program of the Department of Energy. Work by P.C.B. is supported by the National Science Foundation.

\section{EXPERIMENTALSTUDY OF ANORTHITE DISSOLUTION} AND ITS SECONDARY MINERALS UNDER HIGH PARTIAL PRESSURE OF CARBON DIOXIDE: WEATHERING IN THE ARCHEAN. S. Utsunomiya ${ }^{1}$, T. Murakami ${ }^{1}$, H. Kadohara' ${ }^{1}$, and K. Tsukimura ${ }^{2}$, 'Mineralogical Institute, Graduate School of Science, University of Tokyo, Hongo, Tokyo 113, Japan, ${ }^{2}$ Geological Survey of Japan, Tsukuba, Ibaraki, 305, Japan."

Carbon dioxide is considered to be a main component of the primitive atmosphere after the formation of an ocean on the Earth. A 10- to 20-atm $\mathrm{CO}_{2}$ atmosphere, which existed during the first several hundred million years of the Earth's history, kept the surface temperatures at $\sim 85^{\circ}-110^{\circ} \mathrm{C}[1]$. Weathering of silicates containing $\mathrm{Ca}$ and $\mathrm{Mg}$ played an important role for removing $\mathrm{CO}_{2}$ from the primitive atmosphere during the Archean. We made a hydrothermal apparatus with which $\mathrm{CO}_{2}$ could be compressed directly into reaction vessels and be kept its partial pressure during reactions. We did hydrothermal experiments of anorthite under a high partial pressure of $\mathrm{CO}_{2}\left(\mathrm{P}_{\mathrm{CO}_{2}}=1.2 \mathrm{~atm}\right)$ at $150^{\circ} \mathrm{C}$. The $\mathrm{pHs}$ of solutions were maintained by buffer (sodium acetate $0.03 \mathrm{M}$-acetic acid); $\mathrm{pH}=$ 4.56. From the results of the solution analyses, there was less $\mathrm{Ca}$ than expected with anorthite stoichiometry after 10 days of reaction, and little $\mathrm{Ca}$ was found to exist in the solution reacting for 89 days. The TEM (+EDS) and SEM (+EDS) observations and XRD analysis show that prosopite, $\mathrm{CaAl}_{2}(\mathrm{~F}, \mathrm{OH})_{8}$, was formed as a secondary mineral after 89 days of reaction. In general, prosopite is a hydrothermal product formed with volatile gas $\left(\mathrm{H}_{2} \mathrm{O}, \mathrm{CO}_{2}\right.$, etc.) from magma. Another hydrothermal experiment under present-time partial pressure of $\mathrm{CO}_{2}\left(\mathrm{P}_{\mathrm{CO}_{2}}=10-3.5 \mathrm{~atm}\right)$ revealed stoichiometric dissolution of $\mathrm{Ca}$ and $\mathrm{Si}$ and no formation of $\mathrm{Ca}$-bearing phases. These results suggest that the weathering processes under high $\mathrm{P}_{\mathrm{CO}}$ and specific $\mathrm{pH}$ conditions in Archean should be possibly different from those occurring in Phanerozoic as far as Ca mobility is concemed.

References: [1] Kasting (1986).

ASSESSMENT OF WEATHERING RATES INSAND, LOESS, AND CLAY SOILS FOR REGIONAL APPLICATIONS. C. Van der Salm, DLO Winand Staring Centre for Integrated Land, Soil and Water Research, P.O. Box 125, 6700 AC Wageningen, Netherlands (salm@sc.dlo.nl).

Element concentrations in natural ecosystems are strongly governed by the release of cations by mineral weathering. To predict element concentrations in the soil solution by means of simulation models, information on weathering rates is essential. The strong acidification of soils over the past decade and the declining forest vitality in the Netherlands has led to several studies in which weathering rates in dutch soils were measured. These studies have provided information on the average release of base cations by weathering in sand (100-500 $\left.\mathrm{mol}_{c} \mathrm{ha}^{-1} \mathrm{a}^{-1}\right)$, loess $\left(100-700 \mathrm{~mol}_{c}\right.$ $\left.\mathrm{ha}^{-1} \mathrm{a}^{-1}\right)$, and clay soils $\left(500-3500 \mathrm{~mol}_{\mathrm{c}} \mathrm{ha}^{-1} \mathrm{a}^{-1}\right)$. However, up to now, no system has been available to estimate weathering rates as a function of soil properties, which are available on a regional basis.

To obtain weathering rates on a regional scale for the Netherlands the model PROFILE has been used. This model has been developed to calculate weathering rates in soils formed on igneous and metamorphic rocks. To test if the model was applicable to Dutch soils, which are developed in eolian, fluvial, or glacial deposits, the model was calibrated on laboratory experiments. Next, the model was validated on field weathering rates calculated with the historical method and on input-output budgets.

The validated model was applied to predict weathering rates for the Netherlands on a $1 \times 1-\mathrm{km}$ grid scale. The data necessary to run the model were largely based on information of the 1:50,000 soil map together with data from regional inventories of soil chemical properties for forest soils. Mineralogical data necessary to run PROFILE were not available from the above sources and have been calculated from total analyses by means of petrochemical norm calculations.

\section{GEOCHEMICAL FLUXES AT CONVERGENT MARGINS} AND THE COMPOSITION OF WEST SUNDA MAGMATISM. R. Varne' ${ }^{1}$ and M. Gasparon', 'Geology Department, University of Tasmania, GPO Box 252-79, Hobart, Tasmania 7001, Australia (rick.varne@geol.utas.edu.au), 2Department of Earth Sciences, University of Queensland, St. Lucia, Queensland 4072, Australia.

The compositions of Sunda arc volcanics do not provide a simple guide to geochemical fluxes at this convergent margin. Sediment inputs calculated for the individual sections of the west Sunda arc show that the segment of the arc that receives the highest sediment input is the "Bali" sector, where $\mathrm{Sr}, \mathrm{Nd}$, and $\mathrm{Pb}$ isotopic ratios are 
least sediment-like. This is contrary to what might be expected if the extent of sediment recycling in arc magmatism were directly proportional to the amount of sediment subducted along the Sunda trench.

Primitive arc basalts of the "Bali" sector of the west Sunda arc are isotopically similar to Indian Ocean OIB, to primitive, OIB-like basalts of south and central Sumatra (Sukadana and Bukit Telor basalt), and to rare, relatively primitive, olivine-bearing andesitic basalts found in the Sumatra sector. It appears therefore that arc magmas that are isotopically similar to Indian Ocean OIB, and little affected by lithospheric contamination, exist in at least two sectors of the arc, and we argue that such magmas may be more common in the "Bali" sector simply because the lack of a thick continental crust in this sector of the arc minimizes the chances for crustal contamination of the ascending melts, a conclusion also supported by $\mathrm{He}$ and U-Th data. These OIB-like basalts are also strong evidence that OIB mantle occurs within the Sunda mantle wedge, another factor to be taken into account if the composition of Sunda arc magmatism is being used to help quantify geochemical fluxes at this margin.

There is also a clear correlation between degree of magmatic evolution and isotopic values, suggesting that assimilation of arc crust takes place. For example, for the sector of the Sunda arc between $95^{\circ} \mathrm{E}$ and $97^{\circ} \mathrm{E}, \mathrm{Mg} \#$ values range from 65 for the least radiogenic sample to $\sim 50$ for the most radiogenic. In Sumatra, samples isotopically similar to Sumatran OIB-type basalts are among the most primitive $(\mathrm{Mg} \#=65-66)$, whereas the most radiogenic values have been measured in some samples from volcanic centers associated with large caldera explosions and substantial crustal assimilation (Ranau, Maninjau, and Toba complex).

Along-arc variations in the isotopic composition of Sunda arc rocks are readily matched by variations in composition and thickness of the arc crust: continental, and relatively old and thick in Sumatra and west Java, and quasi-oceanic, young, and thin in the Bali sector. In keeping with this interpretation, rocks in the Bali sector have overall higher $\mathrm{Nd}$ and lower $\mathrm{S} r$ and $\mathrm{Pb}$ isotopic ratios than those of the western part of the west Sunda arc where mantlederived melts do not usually survive the transit of the relatively thick and old crust.

COULD FERRAR MAGMATISM HAVE BEEN PRODUCED BY FLUXING OF MID-OCEAN RIDGE BASALT ASTHENOSPHERE BY CRUSTAL MELTS? R. Vame ${ }^{1}$ and R. Sweeney ${ }^{2}$, 'Geology Department, University of Tasmania, GPO Box 252-79, Hobart, Tasmania 7001, Australia (rick.varne@geol.utas.edu.au), ${ }^{2}$ AARL, P.O. Box 106, Crown Mines, South Australia.

Jurassic Ferrar continental flood-basalt magmatism is unlike most large igneous provinces in its distribution along a $4000-\mathrm{km}$ long "hot-line" zone through Gondwanan continental lithosphere. Ferrar magmatism is also remarkably uniform in composition, and has unusual isotopic and compositional characteristics that resemble those of continental crustal rocks more than those of typical mantlederived mafic magmatism of oceanic basins. Two alternative explanations have been proposed. The crustlike characteristics might have been acquired by the Ferrar magmas by crustal assimilation. We note that there is a marked similarity between the isotopic composition of Tasmanian dolerite and Tasmanian Palaeozoic crustal rocks. However, up to $10^{6} \mathrm{~km}^{3}$ of Ferrar magma were erupted or emplaced, so the assimilation process must have been very effec- tive, yet fusion and assimilation of country rock cannot significantly increase the volume of the melt phase and is not likely to produce a uniform melt composition. We have also shown that the Darwin Glacier olivine-bearing chilled margin, which is one of the most primitive Ferrar compositions known, with $\mathrm{Mg} \# 67$, approaching a value likely to be in equilibrium with mantle mineralogy, are $q$ - and hy-normative, with typically high ${ }^{87} \mathrm{Sr} /{ }^{86} \mathrm{Sr}$ at $175 \mathrm{Ma}$ of 0.7090 and low ${ }^{143} \mathrm{Nd} /{ }^{144} \mathrm{Nd}$ of 0.51221 , suggesting that any crustal assimilation occurred very early.

Altematively, Ferrar magmatism might have been derived from a previously depleted mantle source enriched by PATS-like shale during subduction. However, this mechanism requires that Ferrar source mantle and magmatism were generated uniformly along a $4000-\mathrm{km}$-long subduction zone, quite unlike Cenozoic subductionrelated basaltic magmatism.

We propose a new mechanism that involves fluxing of MORBtype asthenosphere by crustal melt. We note that in Antarctica and Australia, the Ferrar rocks are almost entirely located within PermoTriassic sedimentary rocks along the eastward transition from Precambrian craton to Phanerozoic foldbelts and basins. In Tasmania, the magmatism followed the PermoTriassic crustal thinning and basin formation.

Ferrar magmatism might therefore have been triggered by lithospheric pull-apart during aborted rifting along the Gondwanan cratonic margin, leading to upwelling of convecting asthenosphere and massive magmatism as envisaged by Anderson [1]. Adiabatic melting of a rising mantle dyke of depleted MORB-type asthenosphere emplaced in the lower crust could have been accompanied by crustal melting. Fluxing of convecting mantle by crustal melt might increase the amount of mantle melting by lowering fusion temperatures, and the resulting melt compositions would be buffered by the olivine and orthopyroxene of the mantle. At about $1 \mathrm{Gpa}$, the melts would be similar in composition to the Darwin Glacier composition, and there would be plenty of heat to drive the process. This type of mantle-fluxing process would explain the relatively uniform yet unusual composition and large volume of the mafic Ferrar magmatism, as well as its linear distribution.

References: [1] Anderson D. L. (1995) Rev. Geophys., 33, 125-149.

RARE-EARTH-ELEMENT GEOCHEMISTRY OF NATURAL AND MINING-RELATED ACID WATERS, UPPER ANIMAS RIVER BASIN, COLORADO. P. L. Verplanck', D. K. Nordstrom', M. J. Gimeno', and W. G. Wright ${ }^{3}$, 'U.S. Geological Survey, 3215 Marine Street, Boulder CO 80303, USA, 2Instituto de Medioambiente, CIEMAT, Avd. Cumplutense 22, 28040 Madrid, Spain, ${ }^{3}$ U.S. Geological Survey, 701 Camino Del Rio, Durango CO 81302, USA.

The objective of this study is to determine the major processes goveming the fractionation of rare earth elements (REEs) during the weathering of mined and unmined mineralized rock. Within the Upper Animas River basin, naturally occurring acid springs ( $\mathrm{pH}$ 3.1-6.8) and acid mine drainage ( $\mathrm{pH} 3.1-6.4$ ) have high concentrations of REEs $(1-200 \mu \mathrm{g} / \mathrm{L})$ as well as high concentrations of $\mathrm{Cu}(1-$ $150 \mu \mathrm{g} / \mathrm{L}), \mathrm{Zn}(1-5000 \mu \mathrm{g} / \mathrm{L})$, and Fe $(30-67,000 \mu \mathrm{g} / \mathrm{L})$, which generally increase with decreasing $\mathrm{pH}$. Acidic waters produced by pyrite oxidation weather the country rock (weakly and pervasively 
altered rhyodacitic tuffs) to release the REEs. Within the tuffs the REEs are predominantly contained in accessory phases: apatite, allanite, monazite, and zircon. Although allanite, monazite, and zircon tend to have the highest concentrations of REEs, their weathering rates under acidic conditions are much slower than that for apatite. Other studies have shown that during acid leaching, more REEs are released from apatite than any other mineral phase.

When normalized to the North American Shale Composite, the REE patterns of the acid waters from the Upper Animas are convexupward with enrichment in the middle REEs (MREEs) relative to the light and heavy REEs. Similar pattems have been observed in other acid waters, the origin of which is the subject of continued controversy. We suggest that two major processes lead to this convex-upward pattem: (1) weathering of primary REE-bearing mineral phases that are MREE enriched (of which apatites are the most susceptible to acid weathering), and (2) selective enrichment of light REEs (LREEs) and heavy REEs (HREEs) in secondary phases. Aluminous precipitates tend to be enriched in HREEs and secondary phosphates tend to be enriched in LREEs, while Fe oxyhydroxides tend to be enriched in both LREEs and HREEs. Field and laboratory experiments are being designed to test these hypotheses.

HAFNIUM-NEODYMIUM ISOTOPIC COMPOSITION OF THE CRUST AND MANTLE THROUGH TIME: NEW DIRECTIONS WITH HAFNIUM WHOLE-ROCK STUDIES. J. D. Vervoort ${ }^{1}$, J. Blichert-Toft ${ }^{2}$, P. J. Patchett ${ }^{1}$, and F. Albarède ${ }^{2}$, Department of Geosciences, University of Arizona, Tucson AZ 85721,USA (vervoort@geo.arizona.edu), 2Laboratoire de Sciences de la Terre, Ecole Normale Superieure de Lyon, 46 Allee d'Italie, 69364 Lyon Cedex 7, France.

The Lu-Hf isotopic system is an ideal complement to the Sm-Nd system, but its use in crust-mantle studies has not been realized because of the difficulties in analyzing $\mathrm{Hf}$ accurately with conventional thermal ionization mass spectrometry (TIMS). For this reason, much of the Hf work to date using TIMS has been either on zircon samples (which have $\sim 1 \%$ Hf) or on whole-rock samples with higher Hf concentrations. In either case, Hf isotopic work has been tedious and of rather limited scope.

Recent developments with the magnetic sector-multiple collector ICP-MS (also known as the Plasma 54) has allowed the analysis of smaller samples with better precision (about $\pm 0.3 \varepsilon_{\mathrm{Hf}}$ ) and will now enable analysis of a wide range of geologic materials.

Previous work on Hf-Nd isotopic evolution have been in part based on the assumption that the $\mathrm{Hf}$ and $\mathrm{Nd}$ isotopic systems behave similarly in most magmatic environments and that they will be broadly correlated in most crustal rocks. However, this assumption has not been demonstrated. We are currently attempting to resolve the relationship between $\mathrm{Hf}$ and $\mathrm{Nd}$ in a range of crustal compositions, which we will report on here.

We have analyzed several whole-rock samples from early Archean (3.69-3.81 Ga) gneisses from Greenland. Previous work on these rocks have shown large variability in initial $\mathrm{Nd}$ isotopic composition $\left(\varepsilon_{\mathrm{Nd}}\right.$ of -4.5 to +4.5 ) of whole-rock samples. In contrast, the $\mathrm{Hf}$ isotopic composition of zircons from these samples have much less variability (a total range of less than $3 \varepsilon_{\mathrm{Hf}}$; average $\varepsilon_{\mathrm{Hf}}=2$ ). The uniform $\mathrm{Hf}$ isotopic signature in the zircons has demonstrated that the Sm-Nd isotopic system in the whole rocks has been disturbed in these early Archean polymetamorphic gneisses and that the wide range in initial Nd compositions reported for early Archean polymetamorphic gneisses are artifacts of this process. However, the behavior of the Lu-Hf system in the whole rocks has not been demonstrated. We have now analyzed the Hf isotopic compositions of eight of these same early Archean samples (range of more than $9 \varepsilon_{\mathrm{Nd}} ;-4.5$ to +4.5 ). These samples have a narrow range in initial Hf compositions that is similar to that of the zircons (about $3 \varepsilon_{\mathrm{H}}$; -0.2 to +2.2 with one outlier at -1.0 ). The consistency of the wholerock Hf compositions is quite remarkable considering the large range in ${ }^{176} \mathrm{Lu} /{ }^{177} \mathrm{Hf}(0.0009-0.014)$, which requires age corrections that vary from 2 to more than $37 \varepsilon_{\mathrm{Hf}}$.

Whether the Lu-Hf isotopic system is more robust during the rigors of high-grade metamorphism than the Sm-Nd system has not yet been demonstrated. However, based on our initial results, this indeed appears to be the case.

The consistency of the initial $\mathrm{Hf}$ isotopic compositions in ancient samples that have great potential to be disturbed, coupled with the ability of the MC-ICP-MS to analyze Hf in a wide variety of rocks quickly, routinely, and with high precision, should enable the Lu-Hf system to soon realize its potential in crust-mantle studies.

ARGON-XENON FRACTIONATION AND THE MECHANISMS OF RARE GAS DIFFUSION IN POTASSIUM FELDSPAR. I. M. Villa, Isotopengeologie, Erlachstrasse 9a, 3012 Bern, Switzerland (igor@mpi.unibe.ch).

Most diffusion experiments to date have exploited a single rare gas, Ar. Fitting experimental data on Ar loss from feldspars is usually interpreted to prove beyond a doubt that more than one diffusion mechanism is operating, and that a simplification in terms of Fick's Law is invalid [1-7]. Nevertheless, a single-mechanism, Fick's Law diffusion treatment of data is still used by one group [8].

A simple test that could shed additional light on the issue is the relative behavior of rare gases of different mass. In a Fickian system, rare gases must follow Rayleigh fractionation. While such a test is easily performed for zircon, where uranogenic $\mathrm{Kr}$ and $\mathrm{Xe}$ are not released in a way compatible with Fick's Law (in order to model the complexities of the release using the discrete domain theory one would need "domains" of the order of $0.1 \mu \mathrm{m}$; the problem is that spontaneous fission as recorded by fission tracks homogenizes $\mathrm{Kr}$ and Xe on a scale of $10 \mu \mathrm{m}$ !), K-feldspars had so far escaped this sort of ground-truth test because most only contain Ar.

A hydrothermal K-Ba feldspar (an adularia with a high celsian component) was irradiated by fast neutrons, producing ${ }^{39} \mathrm{Ar}$ and ${ }^{131} \mathrm{Xe}$. Visually, crystals are clear and show none of the turbidity that mineralogists consider a telltale sign of alteration in plutonic feldspars. The results fully reflect the mainstream theory and substantially deviate from Rayleigh behavior. In an Arrhenius diagram, the diffusivities calculated from ${ }^{39} \mathrm{Ar}$ release define a single straight line, as had already been reported for common adularia [9]. However, Xe deviates from a straight line. Why is Ar the only gas to follow Fick's Law? Does it at all?

One isotope that is usually overlooked as a mineralogical indicator is ${ }^{38} \mathrm{Ar}$ from $\mathrm{Cl}$. In the present feldspar, the ${ }^{38} \mathrm{Ar} / 131 \mathrm{Xe}$ ratio is smoother than ${ }^{39} \mathrm{Ar} /{ }^{131} \mathrm{Xe}$. A correlated $\mathrm{Cl}+\mathrm{Ba}$ zonation was detected by electron microprobe, i.e., the clear and visually uniform crystals were really compositionally variable. Diagnosing chemical variations by simultaneous use of isotope correlation plots and 
electron microprobe in tum implies that the ${ }^{39} \mathrm{Ar}$ Arrhenius trajectory is an artifact.

In summary, if a sufficient number of experimental parameters are monitored, it is possible to ascertain that the physical basis of Ar release during stepwise degassing of $\mathrm{K}$-feldspars is not a single process and therefore not amenable to Fick's Law.

References: [1] Girard and Onstott (1991) GCA, 55, 3777. [2] Tumer and Wang (1992) EPSL, 110, 193. [3] Burgess et al. (1992) EPSL, 109, 147. [4] Foland (1994) NATO-ASI C421, 415. [5] Villa (1994) EPSL, 122, 393. [6] Amaud and Kelley (1997) $G C A$, in press. [7] Wartho et al. (1997) Terra Nova, in press. [8] Lovera et al. (1989) JGR. [9] Mertz et al. (1989) Terra Abstracts, 1, 353.

STABLE CHLORINE ISOTOPE COMPOSITION OF VOLCANICGASCONDENSATES. C. Wahrenberger ${ }^{l}$, C. J. Eastoe ${ }^{2}$, T.M. Seward ${ }^{1}$, and V. Dietrich ${ }^{1},{ }^{1}$ Institute for Mineralogy and Petrology, ETH Zurich, Zurich, Switzerland, 2 Department of Geosciences, University of Arizona, Tucson AZ, USA.

This study presents $8^{37} \mathrm{Cl}$ values measured in condensates of volcanic gases from Kudriavy (Iturup Island, Kuriles, Russian Federation) and from Vulcano (Sicily, Italy). Condensates were used to circumvent the possible problem of fractionation during sampling with Giggenbach bottles [1]. Samples were made alkaline and later processed and analyzed by procedures described elsewhere [2] Results are given in Table 1.

Both volcanic systems show a linear correlation between $8^{37} \mathrm{Cl}$ and sampling temperature. In the case of Kudriavy, this is interpreted in terms of mixing between two endmember components: a high $\delta^{37} \mathrm{Cl}$ (i.e., positive) component at high temperatures and a low $\delta^{37} \mathrm{Cl}$ (i.e., negative) component at lower temperatures. The former tends to have higher total $\mathrm{Cl}$ concentrations in the gas phase than the latter. The high $\delta^{37} \mathrm{Cl}$ end member is attributed to a magmatic source on the basis of temperature, stable isotope composition, and general gas chemistry (our unpublished results and [3]). The latter is attributed to meteoric water. Two processes could explain the shift of this end member to negative $8^{37} \mathrm{Cl}$ values: water/rock interaction at elevated temperatures, in accordance with a corresponding shift in the $\delta^{18} \mathrm{O} / \delta \mathrm{D}$ system [3], and/or the dissolution of $\delta^{37} \mathrm{Cl}$ depleted

TABLE 1. Stable Cl isotopic composition of gas condensates and salt sublimate from Kudriavy and Vulcano.

\begin{tabular}{lcccc}
\hline Origin & Sample Type & $\begin{array}{c}\text { Gas } \\
\text { Temperature }\left({ }^{\circ} \mathrm{C}\right)\end{array}$ & $\delta^{37} \mathrm{Cl}(\% \mathrm{c})$ & $\begin{array}{c}\mathrm{Cl}_{\text {iodal }} \\
(\mathrm{mol} \%)\end{array}$ \\
\hline Kudriavy 1995 & condensate & 920 & 1.9 & 0.17 \\
Kudriavy 1995 & condensate & 710 & 0.6 .0 .7 & 0.18 \\
Kudriavy 1995 & condensate & 300 & 2.7 & 0.22 \\
Kudriavy 1995 & condensate & 160 & -0.8 & 0.02 \\
Kudriavy 1995 & sublimate $(\mathrm{NaCl})$ & & $-0.8,-1.0$ & \\
Vulcano 1996 & condensate & 504 & 3.9 & 0.01 \\
Vulcano 1996 & condensate & 435 & 0.4 & 0.01 \\
Vulcano 1996 & condensate & 320 & $-1.1 .-1.2$ & 0.10 \\
\hline
\end{tabular}

Values for $\delta^{37} \mathrm{C}$ are given relative to $\mathrm{SMOC}$. Total $\mathrm{Cl}$ composition as $\mathrm{HCl}$ measured on the corresponding total gas. Double determinations were carried out on separate batches of the same sample. Analytical precision is determined to be $\pm 0.075 \%$. chloride minerals by meteoric water. This is in accordance with the matching $\delta^{37} \mathrm{Cl}$ for halite and the low $\delta^{37} \mathrm{Cl}$ end member. The maximum value of $\delta^{37} \mathrm{Cl}=1.9 \%$ brackets the values determined for porphyry $\mathrm{Cu}$ deposits [4].

The interpretation of the data from Vulcano may be more complex. $8^{37} \mathrm{Cl}$ values are higher compared to those of Kudriavy in spite of the much more hydrothermally influenced gas composition and lower temperature. Even though the maximum value is still within the range expected for a potential gas source [5], secondary processes are likely to influence the measured fractionation. A possible process leading to elevated $\delta^{37} \mathrm{Cl}$ values is the sublimation of chloride minerals such as halite. Preliminary $a b$ initio calculations indicate a positive fractionation factor for $\delta^{37} \mathrm{Cl}$ for the gaseous $\mathrm{HCl}-\mathrm{NaCl}$ system. The low $8^{37} \mathrm{Cl}$ end member is interpreted to be an isotopically shifted sea- or meteoric water in accordance with the total gas chemistry and the $\delta^{18} \mathrm{O} / \delta \mathrm{D}$ values of [6].

References: [1] Eggenkamp H. G. M. and Kreulen R. (1994) Geol. Ultraiect., 93-102. [2] Long A. et al. (1993) GCA, 57, 29072912. [3] Taran Y. A. et al. (1995) GCA, 59, 1749-1761. [4] Eastoe C. J. and Guilbert J. M. (1992) GCA, 56, 4247-4255. [5] Magenheim A. J. et al. (1995) EPSL, 131, 427-432. [6] Chiodini G. et al. (1995) Bull. Volcanol., 57, 99-110.

THE IMPACT OF LAND USE CHANGE ON SOIL CARBON DYNAMICS. Y. Wang' ${ }^{1}$ R. Amundson ${ }^{2}$, and S. Trumbore ${ }^{3},{ }^{\prime}$ Department of Geology, Florida State University and NHMFL, Tallahassee FL 32306-3026, USA (ywang@magnet.fsu.edu),2 Division of Ecosystem Sciences, University of Califomia, Berkeley CA 94720 , USA, ${ }^{3}$ Department of Earth System Science, University of California, Irvine CA 92717, USA.

Land-use change impacts soil by altering the soil environment, which may well affect $C$ storage and tumover in soils. In this study, we analyzed the $C$ and ${ }^{14} C$ content of organic matter of two paired natural and disturbed soils in central California. Our $C$ and ${ }^{14} \mathrm{C}$ data indicate that conversion of grassland to agriculture land or logging have resulted in a significant decrease in total soil $\mathrm{C}$ and ${ }^{14} \mathrm{C}$ content as a result of changes in $C$ input rates and tumover times in soils. Most of the $\mathrm{C}$ loss is from the upper horizons. In both natural and disturbed soils, over $70 \%$ of the $\mathrm{C}$ in the upper soil horizons $(\sim 30 \mathrm{~cm})$ resides in fast-cycling $C$ pools with turnover times less than $25 \mathrm{yr}$. At deeper depths, the organic $\mathrm{C}$ is dominated by slowcycling pools with tumover times of thousands of years. Model projection of $\mathrm{C}$ evolution in disturbed soils suggests that after the initial rapid loss of $\mathrm{C}$ following land use change, disturbed soils will eventually become a sink for atmospheric $\mathrm{CO}_{2}$ as they evolve toward a new steady state. This non-steady-state behavior of organic $\mathrm{C}$ in disturbed soils could slow the rise of atmospheric $\mathrm{CO}_{2}$ and provide a negative feedback to global warming.

\section{SILICON IN THE EARTH'S CORE, SULFUR IN THE CORE} OF MARS. H. Wänke and G. Dreibus, Max-Planck-Institut für Chemie, Postfach 3060,D-55020 Mainz, Germany (waenke@mpchmainz.mpg.de).

Figure 1 allows two important conclusions to be drawn: (1) the Viking data point fits nicely to the fractionation line of the SNC meteorites, proving once more their martian origin; and (2) relative 


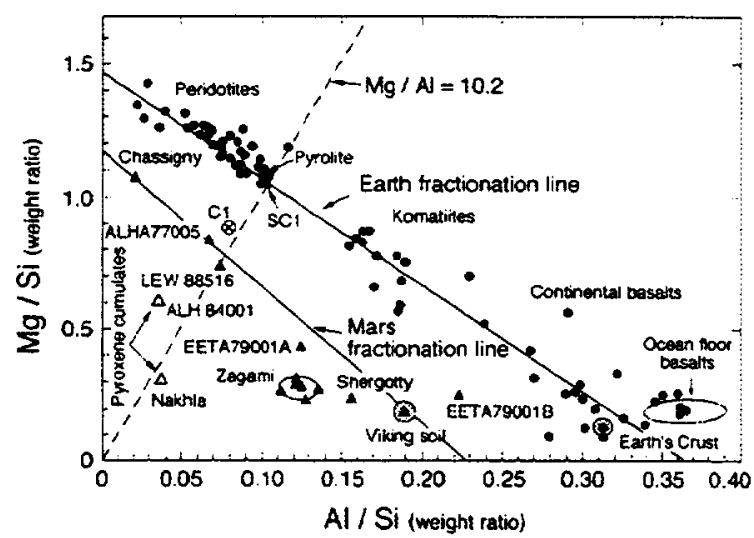

Fig. 1.

TABLE 1. Core compositions.

\begin{tabular}{lccc}
\hline Element & Mars [7] & Earth (this work) & Earth [8] \\
\hline $\mathrm{Fe} \%$ & 78.1 & 77.6 & 79.4 \\
$\mathrm{Ni}$ & 7.8 & 4.8 & 4.9 \\
$\mathrm{Co}$ & 0.38 & 0.25 & \\
$\mathrm{~S}$ & 13.7 & 1.5 & 2.3 \\
$\mathrm{Si}$ & & 14.4 & 7.4 \\
$\mathrm{Cr}$ & & 0.7 & \\
$\mathrm{Mn}$ & & 0.68 & 4.1 \\
$\mathrm{O}$ & & & 32.8 \\
Core mass\% & 21.0 & 32.8 & \\
\hline
\end{tabular}

to the Mars fractionation line the terrestrial line is shifted to higher $\mathrm{Mg} / \mathrm{Si}$ and higher $\mathrm{Al} / \mathrm{Si}$ ratios, indicating depletion of $\mathrm{Si}$ in the Earth's mantle relative to the martian mantle.

A depletion of Si in the Earth's mantle relative to CI chondrites was recognized by various authors. The $\mathrm{CI}$ chondrites formed at solar distances of about 2.5 AU or more. Furthermore, like all other primitive meteorites, they never grew to planet size. This presents an even stronger argument for a comparison to the Earth's close neighbor Mars.

It has been shown that it is possible to form the Earth with strictly $\mathrm{CI}$ abundances if one puts $12.5 \% \mathrm{Si}$ into the core [1]. Metallic $\mathrm{Si}$ in the Earth's core in order to reduce both melting point and density was proposed by Ringwood [2,3] and MacDonald and Knopoff [4]. Later, Ringwood [5] abandoned this model and proposed $O$ as the light element in the core. Recent experiments by Boehler [6] made the presence of $O$ in the Earth's core unlikely. In our new model we assume that Earth and Mars formed from material having the same $\mathrm{Mg} / \mathrm{Al}$ ratio (dashed line Fig. 1) as well as an identical $\mathrm{Mg} / \mathrm{Si}$ ratio. The only difference is the higher abundance of moderately volatile and volatile elements in the building blocks for Mars and its homogeneous accretion, which is opposite to the inhomogeneous accretion favored for the Earth.

References: [1] Wänke H. (1981) Phil. Trans. R. Soc. London, A303, 287. [2] Ringwood A. E. (1958) GCA, 15, 195. [3] Ringwood A. E. (1959) GCA, 15, 257. [4] MacDonald and Knopoff (1958) Geophys. J., 1, 284, 8. [5] Ringwood A. E. (1977) Geoch. J., 11, 111. [6] Boehler R. (1996) Annu. Rev. Earth Planet.
Sci., 24, 15. [7] Wänke and Dreibus (1994) Phil. Trans. R. Soc. London, A349, 285. [8] Allègre et al. (1995) EPSL, 134, 515.

PREDICTION OF THERMODYNAMIC PROPERTIES IN SALT-CO $-\mathrm{CH}_{4}-\mathrm{H}_{2} \mathrm{O}$ : FIRST PRINCIPLE SIMULATIONS AND EQUATION-OF-STATE APPROACHES. J. H. Weare, Department of Chemistry, University of California-San Diego, La Jolla CA 92093-0340, USA.

Accurate thermodynamic models of the properties of natural fluids are necessary for the quantitative interpretation of Earth processes. Our group has been developing models that pay special attention not only to the accurate description of properties as a function of composition, but also to behavior changes as a function of temperature and pressure. Our interest has focused primarily on the system salt $-\mathrm{CO}_{2}-\mathrm{CH}_{4}-\mathrm{H}_{2} \mathrm{O}$, although we have worked with other gases such as $\mathrm{H}_{2} \mathrm{~S}$ and $\mathrm{NH}_{3}$. In order to be applied to the range of conditions encountered in the field we need modeling approaches that can extend from the liquid/solid region all the way to predominantly gas conditions. To achieve this, our group has developed models based on equation-of-state (EOS) approaches and molecular dynamic simulation. The EOS that we have developed can predict free-energy, enthalpy, and liquid-vapor equilibria roughly within the accuracy of experimental data from $0^{\circ} \mathrm{C}$ and 0 bar to temperatures and pressures well above the critical conditions of $\mathrm{H}_{2} \mathrm{O}$. In order to achieve this generality it is necessary to develop phenomenological expressions of the PVT behavior that accurately reflect the behavior of the system at the molecular level. This is best done using molecular-dynamic (MD) simulations. Indeed, for some systems we have shown that MD simulations are more accurate with fewer parameters than EOS representations. In addition, MD provides insight into the molecular processes that lead to the observed thermodynamic behavior. For example, simulations predict ion association constants that agree well with measured values as a function of temperature and pressure. The increase in association in supercritical fluids is clearly represented in simulated data. Similarly, our simulated predictions of diffusion constants are near the observed values. This suggests that simulation can be used to study nonequilibrium as well as equilibrium processes of interest to Earth science.

\section{MAGMATIC AND METAMORPHIC EVOLUTION OF THE GRENVILLE-AGE GUICHICOVI COMPLEX IN SOUTH-} ERN MEXICO. B. Weber ${ }^{1}$, D. J. Morán-Zenteno², F. Söllner ${ }^{3}$, and $\mathrm{H}$. Köhler', 'Mineralogisch-Petrographisches Institut, Theresienstrasse 41, D-80333 München, Germany (bodo@petrol. min.uni-muenchen.de), ${ }^{2}$ Instituto de Geología, Ciudad Universitaria, A. P. 70-296, 04510 México, D.F., Mexico, ${ }^{3}$ Institut für Allgemeine und Angewandte Geologie, Luisenstrasse 37, D-80333 München, Germany.

The Guichicovi complex, which is part of the metamorphic basement of the Maya block in southern Mexico, is located on the western margin of the Tehuantepec isthmus near Matias Romero and covers an area of about $400 \mathrm{~km}^{2}$. Together with a Permotriassic intrusion (Mixtequita batholith) it forms the Mixtequita massif. The Guichicovi complex consists of granulite facies igneous rocks 


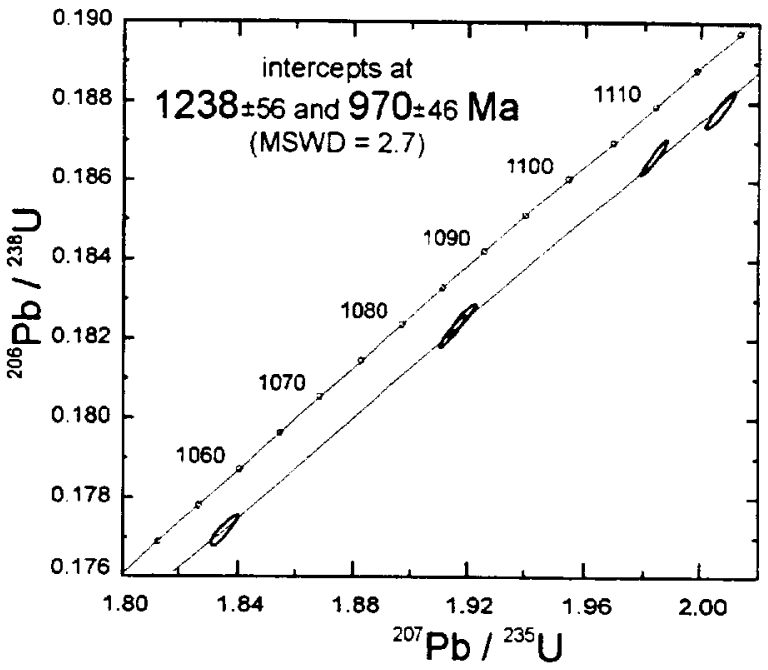

Fig. 1. Concordia diagram of five zircon fractions from a granitic gneiss of the Guichicovi complex.

(former basalts, gabbros, anorthosites, chamockites, and granites) and mostly graphite-rich metasediments with intercalated marbles and calcsilicates. In this work we present results of $\mathrm{Sm}-\mathrm{Nd}, \mathrm{U}-\mathrm{Pb}$, and $\mathrm{Rb}-\mathrm{Sr}$ isotope studies.

Neodymium model ages ( $\mathrm{T}_{\mathrm{DM}}$, calculated after [1]) of the metamagmatites range from 1.4 to $1.7 \mathrm{Ga}$. Some paragneisses have model ages up to $2.0 \mathrm{Ga}$, and indicate an influence of still older crustal component. The Sm-Nd data of 12 metamagmatites define a regression line that corresponds to an age of $1469 \pm 100 \mathrm{Ma}(95 \%$ confidence limit) and an initial $\varepsilon_{\mathrm{Nd}}$ of 3.8. We interpret this age as the time of separation of the magmas from a depleted mantle source.

Uranium-lead data from five zircon fractions from a granitic gneiss plot on a well-defined discordia (Fig. 1) with an upper concordia intercept at $1238 \pm 56 \mathrm{Ma}$. The upper intercept age is interpreted as the time of zircon crystallization, hence the age of intrusion of the protolith magma. This is to date the oldest igneous event identified in a Mexican granulite terrane. The lower intercept age at $970 \pm 46 \mathrm{Ma}$ reflects the time of peak metamorphism. This value is more precisely defined from a concordant zircon fraction from a massif chamockite that gives an age of $990 \pm 2 \mathrm{Ma}$. These age values indicate that magmatism took place approximately $250 \mathrm{Ma}$ before high-grade metamorphism.

Five Sm-Nd garnet/whole-rock ages between $907 \pm 9$ and $932 \pm$ $6 \mathrm{Ma}$ give either the age of gamet crystallization or cooling. The apparent age difference between zircons and garnets of $\approx 60 \mathrm{Ma}$ is suggestive of very slow cooling at deep crustal level. Uplift and subsequent cooling of the granulites is documented by four $\mathrm{Rb}-\mathrm{Sr}$ biotite/whole-rock ages ranging from $866 \pm 21$ to $883 \pm 22 \mathrm{Ma}$.

Most of these results correlate with isotopic data from other granulite outcrops in Mexico (Oaxaca Complex, Novillo Gneiss, and Huiznopala Gneiss [e.g., 2,3]). From both isotopic data and petrographic observations we conclude that the Guichicovi complex is the southeastern extension of the Proterozoic Oaxaquia microcontinent [4], which belongs to the Grenville orogenic belt. The existence of an igneous event around $1240 \mathrm{Ma}$ in the Guichicovi complex [3] and reported ages of magmatism between 1040 and $1130 \mathrm{Ma}$ for the Oaxaca Complex point to an igneous history of the Oaxaquia mi- crocontinent with various episodes of magmatic activity. The similarity of Oaxaquia to the Grenville Province of Canada, where magmatism from 1.2 to $1.3 \mathrm{Ga}$ was reported [e.g., 5], is consistent with the results presented here.

References: [1] De Paolo D. J. (1981)JGR, 86, 10470-10488. [2] Patchett J. and Ruiz J. (1987) Contrib. Mineral. Petrol., 96, 523528. [3] Silver L. et al. (1994) Geol. Soc. Am. , Prog. Abstr., A-48. [4] Ortega-Gutierrez F. et al. (1995) Geology, 23, 1127-1130. [5] Ashwal L. D. and Wooden J. L. (1983) GCA, 47, 1875-1885.

KERGUELEN PLATEAU-BROKEN RIDGE: A MAJOR LARGE IGNEOUS PROVINCE RELATED TO THE KERGUELENPLUME. D. Weis' and F. A. Frey ${ }^{2}$, 'Département Sciences de la Terre et de l'Environnement, CP.160/02, Université Libre de Bruxelles, Av.F. D. Roosevelt 50, 1050 Brussels, Belgium (dweis@resulb.ulb.ac.be), 2Department of Earth and Planetary Sciences, Massachusetts Institute of Technology. Cambridge MA 02139, USA (fafrey@mit.edu).

The formation of large igneous provinces (LIP) on the ocean floor may reflect fundamental changes in convective processes within the Earth's interior. In turn, the eruption of large magma volumes during a brief time interval has major effects on the terrestrial atmosphere and hydrosphere. The Cretaceous period is characterized by the formation of two giant LIP: the Kerguelen PlateauBroken Ridge (KP-BR) and the Ontong-Java Plateau (OJP). The submarine surface exposure of the KP-BR is $2.3 \times 10^{6} \mathrm{~km}^{2}$ with a crustal thickness of about $25 \mathrm{~km}$. A hypothesis for the formation of LIP such as the once-contiguous KP-BR in the southeastern Indian Ocean (Fig. 1) is that they result from the initial "impact" of a mantle plume at the base of the lithosphere. At $\sim 115 \mathrm{Ma}$, the

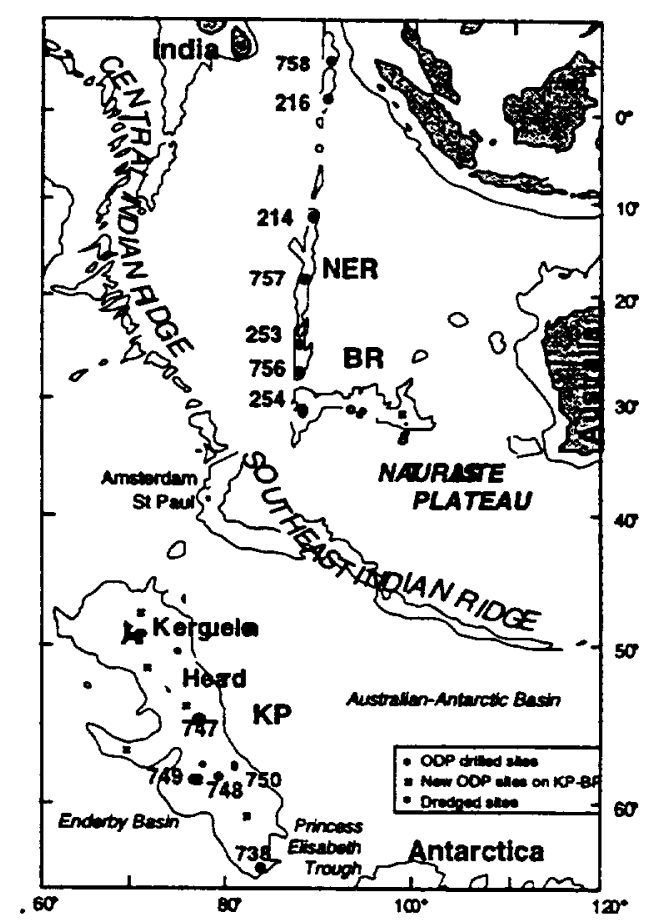

Fig. 1. 
Kerguelen Plume initiated formation of the KP-BR LIP as a subaerial plateau in a young oceanic basin after continental breakup. This is a very different tectonic setting than that of the IcelandicNorth Atlantic LIP or that of the OJP. From $\sim 82$ to $38 \mathrm{Ma}$, the plume generated a 5000-km-long hotspot track (Ninetyeast Ridge, NER) followed by ocean island volcanism on the Kerguelen Archipelago and Heard Island from $\sim 40$ to $0 \mathrm{Ma}$, which are superimposed on the northern part of the KP (Fig. 1). This 115-m.y. volcanic record of the Kerguelen Plume is one of the best long-lived records of plume volcanism; at Hawai' $i$, a hotspot track is present but the LIP is absent, and at the OJP, the LIP is evident but the hotspot track and the present plume location are not obvious. The Kerguelen Plume has a very distinct geochemical signature and carries the Dupal anomaly. The isotopic ratios of lavas erupted over $\sim 115 \mathrm{~m}$.y. are consistent with a common yet isotopically heterogeneous source related to the Kerguelen Plume and the interaction of this enriched plume with various spreading centers in the Indian Ocean. We have recently found significant isotopic heterogeneity in $\sim 30-\mathrm{Ma}$ lavas forming the Kerguelen Archipelago. Sampling of KP basement at three sites in the central KP shows that each site $(747,749$, and 750$)$ is isotopically distinct, but the range of $\mathrm{Sr}$ and $\mathrm{Nd}$ isotopic heterogeneity is similar to that found in $\sim 30-\mathrm{Ma}$ lavas of the Kerguelen Archipelago. In contrast, lavas from the Kerguelen Plateau and Kerguelen Archipelago have very different $\mathrm{Pb}$ isotopic ratios. Like Indian Ocean MORB, KP lavas range to low ${ }^{206} \mathrm{~Pb} / 204 \mathrm{~Pb}(\leq 17.5)$. Another important difference between $<82 \mathrm{Ma}$ and $>85 \mathrm{Ma}$ lavas associated with the Kerguelen Plume is that the $>85 \mathrm{Ma}$ basalts from the southem Kerguelen Plateau (Site 738) and eastern Broken Ridge (Dr 8 ) have distinctive $\mathrm{Sr}, \mathrm{Nd}$, and $\mathrm{Pb}$ isotopic compositions and trace-element abundances indicating the presence of a continental component. At present, interpretations for the origin and changing proportions of source components for KP-BR lavas is hampered because the sampling density over this LIP is too meager to determine the spatial and temporal variations of these geochemical characteristics. The age range, $\sim 115-85 \mathrm{Ma}$, for lavas from the Kerguelen Plateau has major implications for addressing the question of the flux of magma: it is clear that KP-BR did not form during a single magmatic "burst." The age of the northemmost part of the plateau surrounding the Kerguelen Archipelago is a critical issue for determining the magma production rate vs. time, as this large $425,000 \mathrm{~km}^{2}$ area may be coeval with volcanism on the Archipelago. An ODP drilling program consisting of a series of drill sites (Fig. 1) with $200-\mathrm{m}$ basement penetration in the KP-BR will define spatial variations in age and geochemistry of the volcanic basement.

A COMPLETE POSTGLACIAL RECORD OF ATMOSPHERIC LEAD DEPOSITION IN A PEAT BOG PROFILE, JURA MOUNTAINS, SWITZERLAND. D. Weis' ${ }^{1}, W$. Shotyk ${ }^{1}$, R. Frei ${ }^{2}$, and J. D. Kramers ${ }^{2},{ }^{1}$ Geologisches Institut, Universität Bem, Baltzerstrasse 1, CH-3012 Bem, Switzerland, ${ }^{2}$ Mineralogisches-Petrographisches Institut, Gruppe für Isotopengeologie, Universität Bern, Erlachstrasse 9a, CH-3012 Bern, Switzerland.

The surface layers in ombrotrophic bogs are hydrologically isolated from the influence of local groundwaters and surface waters, and receive their inorganic solids exclusively by atmospheric deposition. A core from a peat bog at Etang de la Gruère in the Jura Mountains of Switzerland provides a first complete and detailed record of atmospheric $\mathrm{Pb}$ deposition for Europe extending back $12,370 \mathrm{yr}$.

Constant low background fluxes for $\mathrm{Pb}\left(0.07 \mathrm{mg} \mathrm{Pb} / \mathrm{m}^{2} / \mathrm{yr}\right)$ were only found in the profile during the period $\sim 8000-5500$ yr before present (BP). The greatest natural rates of $\mathrm{Pb}$ deposition were found during the Younger Dryas cold event (YD), peaking at 10,590 BP. This $\mathrm{Pb}$ flux was elevated again at $8230 \mathrm{BP}$ because of volcanic emissions from the Massif Central, France.

Starting at $5320 \mathrm{BP}$ the rate of $\mathrm{Pb}$ deposition increased, but as in the periods before, this was proportional to the dust flux and reflects enhanced soil erosion probably due to soil tillage for agriculture. Starting at $3000 \mathrm{BP}$ the concentrations of $\mathrm{Pb}$ increase out of proportion with $\mathrm{Sc}$, suggesting a nonsilicate source of $\mathrm{Pb}$ : Isotopic analyses show a distinct and pronounced shift toward ore $\mathrm{Pb}$ values at this

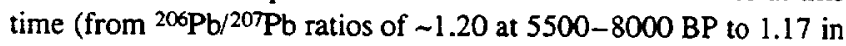
Roman times). This shift is explained by the emergence of mining and smelting activities of Mediterranean civilizations, and marks the beginning of European $\mathrm{Pb}$ pollution. During the Roman period the $\mathrm{Pb}$ fluxes exceeded the Holocene background flux by up to $60 \mathrm{x}$. Lead fluxes increased further with the introduction of leaded gasoline, but have since declined as leaded gasoline is phased out.

\section{FACTORS CONTROLLING ARSENIC AND URANIUM IN SHALLOW GROUNDWATER, SOUTHERN CARSON DESERT, NEVADA. A. H. Welch and M. S. Lico, U.S. Geologi- cal Survey, 333 West Nye Lane, Carson City NV 89706, USA.}

Unusually high As and U concentrations are widespread, but not ubiquitous, in shallow groundwater beneath the southern Carson Desert. The high concentrations are of concern from a human health standpoint because the shallow groundwater is used for domestic supply. Possible effects on wildlife are also a concem, because the groundwater flows into shallow lakes and marshes within wildlife refuges.

Arsenic and $U$ concentrations in groundwater of the southem Carson Desert appear to be affected by evaporative concentration, redox reactions, and adsorption. The relation of these elements with $\mathrm{Cl}$ suggest that most of the high concentrations can be attributed to evaporative concentration of Carson River water, the primary source of recharge.

Beneath areas of less intense evaporation some groundwater contains higher As and $U$ concentrations than can be explained by evaporative concentration alone. Oxidation-reduction reactions involving metal oxides and sedimentary-organic matter appear to occur, contributing $A s$ and $U$ to the groundwater. High concentrations of inorganic $\mathrm{C}, \mathrm{Fe}$, and $\mathrm{Mn}$ in the ground water and the presence of metal oxides and sedimentary-organic $C$ in the aquifer sediments are consistent with this conclusion. The $\mathrm{Fe}$ and $\mathrm{Mn}$ in some sedimentary carbonate and the saturation indexes for their respective carbonates indicate that the oxidation-reduction reactions in some groundwater has proceeded to a greater degree than would be predicted on the basis of the $\mathrm{Fe}$ and $\mathrm{Mn}$ concentrations alone. The presence of As in Fe oxide is strongly suggested by laboratory extractions and is consistent with laboratory adsorption studies. Uranium in both sedimentary-organic $\mathrm{C}$ and metal-oxide coatings has been confirmed by fission tracks and petrographic examination. Together these data are consistent with the presence of $A s$ and $U$ in the reactants involved in the oxidation-reduction reactions. 
A comparison of As concentrations in the groundwater and laboratory extracts of aquifer sediments are broadly consistent with adsorption as a control on dissolved As concentrations. An apparent loss of As from some groundwater as evaporative concentration proceeds is consistent with adsorption as a control on As. The evidence for adsorption should be viewed with caution, as the adsorption model used values for the adsorbent that have not been shown to be valid for the aquifer sediments throughout the southern Carson Desert.

Hydrologic and geochemical conditions in the Carson Desert are similar to other areas known for groundwater with high As and U concentrations. Evaporative concentration of $A s$ and $U$ in the Salton Sea basin and southern San Joaquin Valley have generally led to similar concentrations. Hydrologic and geochemical conditions that produced some sandstone-type U ore deposits, including those in the nonmarine, closed-basin sediments of the Morrison Formation near Grants, New Mexico, suggest that the Carson Desert may be a modern analog for those systems. Reaction of sedimentary-organic matter with metal oxides containing $U$ may be an important role in the development of groundwater that formed the $\mathrm{U}$ ore deposits.

EXPERIMENTAL OBSERVATIONS OF THE EFFECT OF MICROORGANISMSONSILICATE WEATHERING. S. A. Welch ${ }^{1}$, W. W. Barker ${ }^{1}$, and J. F. Banfield 1.2 , 'Department of Geology and Geophysics, University of Wisconsin, 1215 West Dayton Street, Madison WI 53706, USA (swelch@geology.wisc.edu; barker@geology.wisc.edu; jill@geology.wisc.edu),2Mineralogical Institute, University of Tokyo, Hongo, Bunkyo-ku, Tokyo 135, Japan.

Mineral dissolution experiments using batch cultures of several strains of soil and groundwater microorganisms (bacteria and fungi) were monitored with solution chemistry and a variety of microscopic techniques to determine the effects of these organisms on mineral weathering reactions. Several strains of microorganisms that produced both organic and inorganic acids in culture increased $\mathrm{Si}, \mathrm{Fe}$, and $\mathrm{Al}$ release from biotite and plagioclase feldspar by up to 2 orders of magnitude compared to abiotic controls. Nitrogen limited conditions enhanced acid production and mineral dissolution.

Microbially colonized mineral grains were examined by cryoSEM, TEM, confocal scanning laser microscopy (CSLM), and epifluorescence microscopy. Microorganisms colonized all mineral surfaces, often preferentially along cleavage steps and edges of the mineral grains. Low-voltage high-resolution cryo-SEM of high pressure cryofixed and partially freeze-dried colonized minerals showed large numbers of bacteria attached by extracellular polymers of unknown composition. This biofilm covered a much larger area of the mineral surface than bacterial cells alone. Mineral surfaces where bacteria and extracellular polysaccharides occurred appeared more extensively etched than surrounding surfaces without attached bacteria.

CSLM was used to observe microbial colonization of biotite and measure $\mathrm{pH}$ in microenvironments surrounding living microcolonies using a ratiometric $\mathrm{pH}$ sensitive fluorescent dye set. A strain of bacteria (B0693 from the DOE SMCC) formed large attached microcolonies, both on the outer $(001)$ surface and within interlamellar spaces as narrow as $1 \mu \mathrm{m}$. $\mathrm{pH}$ decreased from near neutral at the mineral surface to $3-4$ around microcolonies living within confined spaces of interior-colonized cleavage planes. However, no evidence of $\mathrm{pH}$ microgradients surrounding exterior micro-colonies was noted.

In addition to biogeochemical weathering processes, physical dissagregation of biotite by fungal hyphae was observed using a light microscope. Fungal hyphae split biotite along (001) cleavage planes as the hyphae grew. Our laboratory results indicate that biophysical microbial interactions increase the amount of mineral surfaces available for interaction. Microbial production of acids in these microenvironments may partially explain a significant fraction of increased mineral weathering seen over controls.

EXPERIMENTAL WEATHERING OF GRANITOIDS: IMPORTANCE OF RELATIVE MINERAL REACTION RATES. A. F. White T. D. Bullen, D. V. Vivit, and M. S. Schulz, U.S. Geological Survey, Menlo Park CA 94025, USA.

Leaching experiments of fresh and exfoliated granitoids were conducted in flow-through columns to ascertain the relative importance of specific minerals on solute chemistry and ${ }^{87} \mathrm{Sr} /{ }^{86} \mathrm{Sr}$ isotopic ratios during initial phases of natural weathering. Rocks were obtained from well-characterized research watersheds at Loch Vale, Colorado (Rocky Mountain National Park), Rio Icacos, Puerto Rico, Panola Mountain, Georgia, and the Merced River (Yosemite National Park), Califomia. The experiments consisted of running distilled, deionized water, saturated at $5 \%$ atm $\mathrm{CO}_{2}$ and atmospheric $\mathrm{O}_{2}$ through columns containing $750 \mathrm{~g}$ of $0.25-0.85-\mathrm{mm}$ sized crushed rock at an average flow rate of about $10 \mathrm{ml} / \mathrm{hr}$ for approximately $1 \mathrm{yr}$.

Initial effluents $(<2000 \mathrm{hr})$ from fresh granitoids were dominated by high $\mathrm{Ca} / \mathrm{Si}$ ratios indicative of calcite rather than silicate dissolution (Fig. 1). Calculations indicated that effluents initially approached calcite saturation, then with time became undersaturated. Carbonate $\mathrm{C}$ analyses indicated that calcite in the fresh granitoids varied between 0.02 and $0.24 \mathrm{wt} \%$, but was $<0.01 \mathrm{wt} \%$ in the exfoliated granites, indicating almost total loss during initial weathering. Except for the Merced granite, $\mathrm{Ca}$ solute fluxes indicated that calcite was also completely removed during the leaching experiments of the fresh granitoids. After $2000 \mathrm{hr}$, effluent chemistries of both fresh and exfoliated granitoids were dominated by

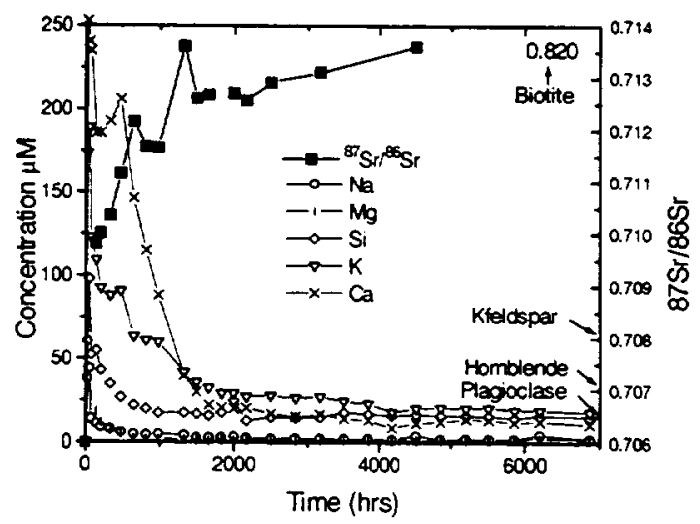

Fig. 1. Effluent chemistry produced from leaching of the Merced River (Yosemite) granite. 
higher $\mathrm{K}$ concentrations relative to $\mathrm{Na}$ and $\mathrm{Ca}$ (Fig. 1). Mass balance calculations indicated that biotite weathering, as defined by $K$ release, was $10-100 \times$ faster than plagioclase weathering.

The transition from calcite-dominated to silicate-dominated weathering in the experiments was also reflected in the effluent ${ }^{87} \mathrm{Sr} /{ }^{86} \mathrm{~S}$ r ratios, which were initially low due to calcite dissolution, and increased with time corresponding to silicate dissolution (Fig. 1). The later ${ }^{87} \mathrm{Sr} /{ }^{86} \mathrm{Sr}$ ratios were significantly higher than found in plagioclase, indicating a major solute input from biotite even though elemental $\mathrm{Sr}$ in plagioclase $(500-1000 \mathrm{ppm})$ is more abundant than in biotite (10-20 ppm). The exfoliated granites approached lower ${ }^{87} \mathrm{Sr} /{ }^{86} \mathrm{Sr}$ ratios than fresh granitoids, suggesting that the weathering rate of biotite, relative to plagioclase, was less in these samples.

The above results imply that initial weathering of granitoids, such as on recently glaciated or tectonically active landscapes, is highly incongruent relative to the dominant mineralogy. Such differences have important ramifications in terms of applications of ${ }^{87} \mathrm{Sr} /{ }^{86} \mathrm{Sr}$ ratios to the geologic record and estimates of weathering fluxes and global elemental balances.

THE DEEP MANTLE SUBDUCTION: FLUX IN THE LESSER ANTILLES. W.M. White ${ }^{\text {, }}$ D. R. Gravatt ${ }^{2}$, and J. D. Devine ${ }^{3}$, 'Department of Geological Sciences, Cornell University, Ithaca NY 14853,USA (white@geology.cornell.edu),2Department of Geology, University of Kansas, Lawrence KS 66045, USA, '3 Department of Geological Sciences, Brown University, Providence RI02912, USA.

Subduction introduces a chemical flux from the crust to the mantle and therefore has profound implications for the chemical evolution of both. Some of the subduction flux is diverted to islandarc magmas and some to the deeper mantle. In this study, we attempt to assess the flux into the deep $(>150 \mathrm{~km})$ mantle. We chose to assess the subduction flux beneath Grenada, Lesser Antilles, because (1) the composition of the sediment is known, (2) sediment subduction is constrained by geophysical studies and drilling, and (3) the unusual presence of primitive basalts allows the composition of primary magmas to be estimated.

We make the following assumptions: (1) deep mantle and arc magmas are the only sinks for subducted material; (2) all sediment beneath the decollement observed in the fore-arc is subducted (i.e., the lower $250 \mathrm{~m}$ of sediment are subducted); (3) a weighted mean of sediment analyses is representative of subducted sediment (weighted mean recalculated from Plank [1]); (4) the oceanic crust has the composition of average (fresh) MORB; (5) "excess" (over MORB) incompatible-element concentrations in arc volcanics are slab-derived (equivalent to assuming that the wedge has composition of depleted mantle); (6) arc magmas are generated by the same percent of melting as MORB; (7) assimilation does not significantly affect primitive magma concentrations; and (8) recent estimates of the convergence rate $(1.5 \mathrm{~cm} / \mathrm{yr} ;[2])$ and magma production rates $(4.5 \mathrm{~km} / \mathrm{m} . \mathrm{y} / \mathrm{km}$ arc; [1]) are correct.

We estimate the composition of primitive magmas by regressing concentrations against $\mathrm{MgO}$. We then calculate an "excess concentration" in primitive arc magmas as the difference between the calculated parental magma composition and MORB. This excess concentration represents the slab contribution to the magmas. We then multiply this excess concentration by estimates of magma production rate to obtain the flux from the slab to the arc magmas.
This is subtracted from the subduction flux to give the "residual flux" to the deep mantle.

The largest uncertainty in these calculations is the arc magma production rate, which is poorly constrained. Despite uncertainties, certain observations are reasonably robust. These are as follows: (1) After passing through the arc magma genesis zone, the subducting slab remains substantially enriched in incompatible elements compared to depleted mantle. (2) For most elements, concentrations in the residual slab (oceanic crust + sediment) are approximately MORB-like. This is particularly true of the rare earths. (3) There is a significant increase in $\mathrm{Th} / \mathrm{U}$ and decrease in $\mathrm{U} / \mathrm{Pb}$. However, the $U$ concentration in the oceanic crust is strongly affected by hyrothermal processes. When hydrothermal effects are considered, $\mathrm{Th} / \mathrm{U}$ in the slab is similar to depleted mantle, but the $\mathrm{U} / \mathrm{Pb}$ ratio remains lower. (4) The $\mathrm{Rb} / \mathrm{Sr}$ ratio is significantly higher than in MORB or depleted mantle. (5) Lead/cerium decreases, but remains about twice as great as in the depleted mantle. (6) There are small increases in the relative $\mathrm{Nb}$ and $\mathrm{Ta}$ abundances. (7) There is a small but significant (4\%) increase in $\mathrm{Sm} / \mathrm{Nd}$ over depleted mantle.

References: [1] Plank T. (1993), Ph.D. Dissertation, Columbia Univ. [2] Gripp A. E. and Gordon R. G. (1990) GRL, 17, $1109-$ 1112.

IN SITU DETERMINATION OF THE HEAT OF SOLUTION OF $\mathrm{LA}_{2} \mathrm{O}_{3}$ IN SILICATE MELTS AT 1760 K. M. C. Wilding and A. Navrotsky, Department of Geosciences, Princeton University, Princeton NJ 08544, USA.

Recent developments in high-temperature-reaction calorimetry enable direct measurement of the heats of solution of component oxides in silicate solvents to be made at temperatures of up to $1500^{\circ} \mathrm{C}$. This provides a direct determination of the partial molar heats of mixing of individual melt components, independent of solubility and spectroscopic studies. These in siru measurements are particularly suited to minor and rare earth elements, which are easily dissolved, have large heat effects, and have a strong influence on the properties of silicate liquids.

The heat of solution of $\mathrm{TiO}_{2}$ in simple silicate solvents has been used to model the anomalous heat capacity of Ti-bearing alkali silicate liquids [1], and the same experimental strategy has been used to investigate the solution of $\mathrm{La}_{2} \mathrm{O}_{3}$ in silicate melts of similar composition.

At $1485^{\circ} \mathrm{C}$, the heat of solution of $\mathrm{La}_{2} \mathrm{O}_{3}$ in $\mathrm{K}$ silicate solvents $\left(\mathrm{K}_{2} \mathrm{O}: 3 \mathrm{SiO}_{2}\right)$ is $-119.1 \pm 9.9 \mathrm{~kJ} / \mathrm{mol}$, comparable with the heat of solution of $\mathrm{La}_{2} \mathrm{O}_{3}$ in $2 \mathrm{PbO}: \mathrm{B}_{2} \mathrm{O}_{3}(-126 \mathrm{~kJ} / \mathrm{mol})$. This suggests limited interaction between $\mathrm{La}^{3+}$ and the silicate framework. The addition of small amounts of $\mathrm{P}_{2} \mathrm{O}_{5}$ to the $\mathrm{K}$ silicate solvent results in a more exothermic heat of solution, $-175 \pm 13.1 \mathrm{~kJ} / \mathrm{mol}$, although it is apparent that this does not represent the formation of La-O-P clusters. The heat of solution of $\mathrm{La}_{2} \mathrm{O}_{3}$ in mixed alkali solvents is $-121 \pm 15 \mathrm{~kJ} / \mathrm{mol}$ and indicates a similar solution mechanism to that of the $\mathrm{K}$ endmember solvents.

The heat of solution of $\mathrm{La}_{2} \mathrm{O}_{3}$ in $\mathrm{Na}$ silicate solvents $\left(\mathrm{Na}_{2} \mathrm{O}\right.$ : $3 \mathrm{SiO}_{2}$ ) is $-93.3 \pm 15.7 \mathrm{~kJ} / \mathrm{mol}$, some $25 \mathrm{~kJ} / \mathrm{mol}$ more endothermic than that in the $\mathrm{K}$ solvent. The heat of solution in this case reflects the interaction between $\mathrm{La}-\mathrm{O}$-La species and the silicate framework and we suggest that $\mathrm{La}-\mathrm{O}-\mathrm{Si}$ melt species are formed, since $\mathrm{La}^{3+}$ has a network-modifying role in silicate melts [2]. The addition of $\mathrm{P}_{2} \mathrm{O}_{5}$ 
does not affect the heat of solution.

These high-temperature calorimetric experiments constrain the interaction between individual melt components and the silicate framework. It is clear from the studies of $\mathrm{La}_{2} \mathrm{O}_{3}$ that the melt composition, in particular the identity of network-modifying cations, has important implications for REE partitioning. $\mathrm{La}_{2} \mathrm{O}_{3}$ dissolution may be favored where La-O-La species are dominant over $\mathrm{La}$ $\mathrm{O}-\mathrm{Si}$ species. Preliminary studies of $\mathrm{La}_{2} \mathrm{O}_{3}$ dissolution in anorthitediopside eutectic solvents indicate that $\mathrm{La}-\mathrm{O}-\mathrm{La}$ species are also favored over La-O-Si and further investigation will constrain the activities of lanthanide species in these haplobasaltic melts.

References: [1] Gan H. et al. (1996) GCA, 60, 4123-4131. [2] Ellison A. J. G. and Hess P. C. (1990) JGR, 95, 15717-15726.

\section{TEMPERATURE-AND FREE-ENERGY-DEPENDENCE OF} ZEOLITE PRECIPITATION AND DISSOLUTION RATES. R. T. Wilkin and H. L. Bames, Ore Deposits Research Section, Pennsylvania State University, University Park PA 16802, USA (rwilkin@geosc.psu.edu).

The kinetics of zeolite- $\mathrm{H}_{2} \mathrm{O}$ reactions are fundamental to the chemical and physical evolution of volcanic and sedimentary rocks in shallow crustal environments. For example, precipitation of zeolites in vugs and veins results in decreased porosity, permeability, fluid flow, metasomatism, and heat transport during aqueous interactions. With increasing temperature and pressure, metastable zeolite assemblages breakdown to form progressively more stable assemblages. Such zeolite transformations characteristically release $\mathrm{H}_{2} \mathrm{O}$ and silica with large, negative changes in molar volumes [1]. Quantification of these processes requires kinetic and solubility data for zeolite- $\mathrm{H}_{2} \mathrm{O}$ systems.

Here we report precipitation and dissolution rates measured in dilute aqueous solutions of the zeolites analcime $\left(\mathrm{NaAlSi}_{2} \mathrm{O}_{6} \times\right.$ $\left.\mathrm{H}_{2} \mathrm{O}\right)$ and $\mathrm{Na}$-exchanged clinoptilolite $\left(\mathrm{NaAlSi}_{5} \mathrm{O}_{12} \times 4 \mathrm{H}_{2} \mathrm{O}\right)$ at $125^{\circ}-250^{\circ} \mathrm{C}$ and slightly alkaline $\mathrm{pH}$. At each temperature, reaction rates were determined over a wide range of saturation states from supersaturated, to near-equilibrium, to far-from-equilibrium conditions. Dissolution rates of analcime, at constant terfperature and $\Delta_{\mathrm{T}} \mathrm{G}$, slightly depend on the ratio of dissolved $\mathrm{Si}$ to Al. Analcime precipitation rates, however, depend not on this ratio but linearly on the solution saturation state for $\Delta_{\mathrm{r}} \mathrm{G}=0-1.2 \mathrm{kcal} \mathrm{mol}^{-1}$. Our data show that the $\Delta_{\mathrm{r}} \mathrm{G}$ functions for precipitation and dissolution are consistent over the temperature range from $125^{\circ} \mathrm{C}$ to $250^{\circ} \mathrm{C}$. Based on rate constants determined at $125^{\circ} \mathrm{C}$ and $175^{\circ} \mathrm{C}$, the activation energy of the analcime precipitation reaction is $8.7 \pm 1.1 \mathrm{kcal}$ $\mathrm{mol}^{-1}$. The activation energy of the analcime dissolution reaction apparently is temperature dependent. Between $125^{\circ}$ and $175^{\circ} \mathrm{C}$ the $\mathrm{Ea}$ is $10.9 \pm 1.7 \mathrm{kcal} \mathrm{mol}^{-1}$; however, between $175^{\circ}$ and $250^{\circ}$, Ea is $6.3 \pm 0.9 \mathrm{kcal} \mathrm{mol}^{-1}$. That the $\Delta_{\mathrm{r}} \mathrm{G}$ function holds over this temperature range suggests that the principal reaction mechanism remains constant. We propose that the decrease in $\mathrm{Ea}$ at higher temperatures is caused by the decrease in the dielectric constant of $\mathrm{H}_{2} \mathrm{O}$ from 49.4 at $125^{\circ} \mathrm{C}$ to 26.9 at $250^{\circ} \mathrm{C}$. It is also possible that the decrease in the $\mathrm{Ea}$ is in part caused by a decrease in the hydration state of analcime with increased temperature.

The results of these kinetic experiments can be used to evaluate the clinoptilolite-to-analcime replacement reaction. The alteration, during low-P and $-\mathrm{T}$ diagenesis, of clinoptilolite + cristobalite \pm glass assemblages to analcime + quartz + calcite assemblages is common in many volcanic and sedimentary sequences [e.g., 2-4]. The stability of high-Si zeolites such as clinoptilolite over low-Si zeolites such as analcime principally is governed by temperature, silica activity, and $\mathrm{Na}$ activity [e.g., 5]. The reaction path might be sequential from clinoptilolite dissolution

$$
\mathrm{NaAlSi}_{5} \mathrm{O}_{12} \times 4 \mathrm{H}_{2} \mathrm{O}+8 \mathrm{H}_{2} \mathrm{O} \Rightarrow \mathrm{Na}^{+}+\mathrm{Al}(\mathrm{OH})_{4}{ }^{-}+5 \mathrm{H}_{4} \mathrm{SiO}_{4}
$$

followed by analcime precipitation

$\mathrm{Na}^{+}+\mathrm{Al}(\mathrm{OH})_{4}{ }^{-}+2 \mathrm{H}_{4} \mathrm{SiO}_{4} \Rightarrow \mathrm{NaAlSi}_{2} \mathrm{O}_{6} \times \mathrm{H}_{2} \mathrm{O}+5 \mathrm{H}_{2} \mathrm{O}$

The rate-controlling step of the replacement process can be identified by comparing, at the same conditions, the rate of clinoptilolite dissolution (1) with that of analcime precipitation (2). The $175^{\circ} \mathrm{C}$ rate data indicate that, at silica concentrations between quartz and cristobalite saturation and when the activity product $\left\{\mathrm{Na}^{+}\right\}\left\{\mathrm{Al}(\mathrm{OH})_{4}^{-}\right\}$is greater than about $10^{-7}$, clinoptilolite dissolution rates should limit the overall rate of replacement. High-silica activities approaching silica glass saturation stabilize silica-rich zeolites, such as clinoptilolite, over analcime + quartz.

Acknowledgments: We gratefully acknowledge the funding provided for this research by the U.S. Department of Energy, Office of Basic Energy Sciences.

References: [1] Coombs D. et al. (1959) GCA, 17, 53-107. [2] Iijima A. and Utada M. (1966) Sedimentology, 7, 327-357. [3] Moncure G. et al. (1981) Clays Clay Min., 29, 385-396. [4] Bish D. and Aronson J. (1993) Clays Clay Min., 41, 148-161. [5] Bowers T. and Burns R. (1990) Am. Min., 75, 601-619.

\section{A PREDICTIVE MODEL FOR RARE-EARTH-ELEMENT PARTITIONING BETWEEN CLINOPYROXENE AND} ANHYDROUS SILICATE MELT. B. J. Wood and J. D. Blundy, CETSEI, Department of Geology, University of Bristol, Bristol BS8 IRJ, UK.

We present a quantitative model to describe the partitioning of rare earth elements (REE) between clinopyroxene and anhydrous silicate melt as a function of pressure, temperature, and bulk composition. The model is based on the Brice (1975) equation relating the partition coefficient of element $i\left(D_{i}\right)$ to that of element $o\left(D_{o}\right)$, where the latter has the same ionic radius $r_{0}$ as the crystallographic site of interest, in this case the clinopyroxene M2 site. The equation is parabolic with the form of the parabola depending on $E_{M 2}$, the Young's Modulus of the site. Values of $E_{M_{2}}$ obtained by fitting to experimental REE partition coefficient pattems are in good agreement with those obtained from the correlation between bulk modulus, metal-O distance, and cation charge. Using this relationship to constrain $E_{M 2}$ for $3+$ cations and then fitting the Brice equation to those experimental data where 3 or more REE partition coefficients had been simultaneously measured yields 82 values of $D_{0}$ and $r_{0}$. The latter was found to be a simple and crystallochemically reasonable function of clinopyroxene composition. We show that for any clinopyroxene-melt pair, if D for one middle REE (e.g., Sm or Gd) is known, then the Brice equation can be used to predict $D$ for all the other REE, with uncertainties similar to those involved in the actual measurements. 
The model was generalized using thermodynamic descriptions of REE components in crystal and melt phases to estimate the free energy of fusion of the fictive REE components REE MgAISiO ${ }_{5}$ and $\mathrm{Na}_{0.5} \mathrm{REE}_{0.5} \mathrm{MgSi}_{2} \mathrm{O}_{6}$. For the melt we find that 6-O melt components ( $\mathrm{CaMgSi}_{2} \mathrm{O}_{6}, \mathrm{NaAlSi}_{2} \mathrm{O}_{6}$, etc.) mix with the constant activity coefficient over a wide range of natural compositions. Propagating $\Delta G_{f}$ into the Brice model we obtain an expression for $D^{3+}$ in terms of the atomic fraction of $\mathrm{Mg}$ on the clinopyroxene $\mathrm{Ml}$ site, the $\mathrm{mg}$ number of the melt, $P$, and $T$. The partition coefficient for any REE can be calculated from $\mathrm{D}^{3+} \mathrm{O}$ using the Brice equation. Over $92 \%$ of $D_{\text {REE }}$ calculated in this way lie within a factor $0.63-1.59$ of the experimental value. The approach can be extended to calculate $D$ for any $R E E$ at a given $P(\leq 6 \mathrm{GPa})$ and $T(1200-2038 \mathrm{~K})$ to within 0.60 $1.66 \times$ the true value given only the crystal and/or melt composition.

The P-T-X dependence of $D_{R E E}$ means that the assumption of constant partition coefficients during magmatic processes can lead to substantial enors in interpretation. We show, for example, that during adiabatic ascent, clinopyroxene-melt partition coefficients change by a factor of 2 along the mantle solidus. Interpretation of REE concentrations of MORB using constant $D_{\text {REE }}$ can lead to substantial overestimates of the extent of melting in their source regions.

References: [1] Brice (1975).

CALCULATION OF THE DISTRIBUTION OF COBALT CHLORIDE COMPLEXES AND THE SOLUBILITY OF COBALT SULFIDES IN HYDROTHERMAL SOLUTIONS TO $350^{\circ} \mathrm{C}$. S. A. Wood, Department of Geology and Geological Engineering, University of Idaho, Moscow ID 83844-3022, USA (swood@uidaho.edu).

Cobalt occurs in significant amounts in a number of hydrothermal ore deposits including the Ag-As-Co vein deposits in the Cobalt district of Ontario, the Blackbird-type, black shale-hosted Au-Co deposits in Idaho, the Cu-Au-Co deposits of the Cloncurry district, Australia, and some Mississippi Valley-type deposits. In many of these deposits, fluid inclusion evidence suggests the involvement of relatively high-temperature $\left(>100^{\circ} \mathrm{C}\right)$, highly saline, chloride-rich brines. However, there are no thermodynamic data available for Co(II)-chloride complexes in hydrothermal solutions above $100^{\circ} \mathrm{C}$. There are also very few data on the solubility of common Co minerals in aqueous solutions at elevated temperatures. Pan and Susak [1] have measured stability constants for the following reactions up to $90^{\circ} \mathrm{C}$ : (1) $\mathrm{Co}^{2+}+\mathrm{Cl}^{-}-\mathrm{CoCl}^{+}$, (2) $\mathrm{Co}^{2+}+2 \mathrm{Cl}^{-}=\mathrm{CoCl}_{2}{ }^{\circ}$, (3) $\mathrm{Co}^{2+}+3 \mathrm{Cl}^{-}=\mathrm{CoCl}_{3}{ }^{-}$, (4) $\mathrm{Co}^{2+}+4 \mathrm{Cl}^{-}=\mathrm{CoCl}_{4}{ }^{2-}$. These data have been extrapolated to $350^{\circ} \mathrm{C}$ using the isocoulombic method [2], employing $\mathrm{Pb}$ (II) chloride complexation reactions (stability constants from [3]) to render the above reactions isocoulombic. The resultant stability constants are presented in the following table.

\section{TABLE 1 .}

\begin{tabular}{llllllllll}
\hline$t\left({ }^{\circ} \mathrm{C}\right)$ & $\log \beta_{1}$ & $\log \beta_{2}$ & $\log \beta_{3}$ & $\log \beta_{4}$ & $t\left({ }^{\circ} \mathrm{C}\right)$ & $\log \beta_{1}$ & $\log \beta_{2}$ & $\log \beta_{3}$ & $\log \beta_{4}$ \\
\hline 25 & 0.6 & 0.02 & -1.71 & -2.09 & 200 & 1.65 & 1.60 & 0.18 & 1.83 \\
50 & 0.66 & 0.10 & -1.62 & -1.70 & 250 & 2.18 & 2.46 & 1.20 & 3.35 \\
100 & 0.89 & 0.43 & -1.21 & -0.69 & 300 & 2.90 & 3.65 & 2.60 & 5.19 \\
150 & 1.22 & 0.94 & -0.61 & 0.50 & 350 & 3.97 & 5.56 & 4.82 & 7.74 \\
\hline
\end{tabular}

These data show that $\mathrm{CoCl}+$ and $\mathrm{CoCl}_{2}{ }^{\circ}$ will be predominant in most brines at $25^{\circ} \mathrm{C}$, with increasing contributions from $\mathrm{CoCl}_{4}{ }^{2-}$ with increasing temperature. The species $\mathrm{CoCl}_{3}{ }^{-}$never attains predominance at any temperature. The equilibrium constants for dissolution reactions for various Co sulfide and oxide phases were calculated using thermodynamic data for the Co phases from [4] and data for aqueous species and water from SUPCRT92 [5]. Log $f_{\mathrm{O}_{2}}-\mathrm{pH}$ diagrams have been produced involving the solid phases $\mathrm{Co}$, $\mathrm{CoS}_{2}$ (cattierite), $\mathrm{Co}_{3} \mathrm{~S}_{4}$ (linnaeite), $\mathrm{CoO}$, and $\mathrm{Co}_{3} \mathrm{O}_{4}$ onto which $\mathrm{Co}$ solubility contours have been plotted. The calculations suggest that significant solubilities of $\mathrm{Co}(>10 \mathrm{ppm})$ can be attained over a relatively wide range of $\mathrm{pH}$ and $\mathrm{f}_{\mathrm{O}_{2}}$, but the concentrations of $\mathrm{Co}$ in a solution in equilibrium with pyrite containing $\mathrm{CoS}_{2}$ in solid solution will be several orders of magnitude less than those of $\mathrm{Fe}$. These calculations are being extended to include other common $\mathrm{Co}$ minerals such as cobaltite, skutterudite, etc.

References: [1] Pan P. and Susak N. J. (1989) GCA, 53, 327. [2] Ruaya J. R. (1988) GCA, 52, 1983. [3] Seward T. M. (1984) GCA, 48, 121. [4] Pankratz L. B. et al. (1987) U.S. Bur. Mines Bull., 689. [5] Johnson J. W. et al. (1992) Comp. Geosci., 18, 899.

\section{CALCULATION OF THE VOLATILITY OF COPPER CHLORIDES AT ELEVATED TEMPERATURES AND PRESSURES: WHY IS COPPER ENRICHED IN THE VAPOR PHASES OF FLUID INCLUSIONS? S. A. Wood, Department of Geology and Geological Engineering, University of Idaho, Moscow ID 83844-3022, USA (swood@uidaho.edu).}

Heinrich et al. [1] reported that a significant quantity of $\mathrm{Cu}$ was found, via PIXE analysis, to be partitioned into the vapor phase relative to the liquid phase in fluid inclusions from Mount Isa. Since that time, $\mathrm{Cu}$ has been found, via SXRF, to partition strongly into the vapor phases of fluid inclusions from porphyry $\mathrm{Cu}$ deposits [2]. The phenomenon has also been observed in fluid inclusions from the $\mathrm{Cu}-\mathrm{Au}-\mathrm{Co}$ deposits of the Cloncurry district [3]. Curiously, $\mathrm{Fe}, \mathrm{Zn}$, and $\mathrm{Pb}$ have not been noted to exhibit similar behavior. The obvious questions that arise are (1) What is the mechanism by which significant concentrations of $\mathrm{Cu}$ can enter the vapor phase? and (2) Why does $\mathrm{Cu}$ appear to behave differently from other base metals?

It has been proposed [1] that $\mathrm{Cu}$ sulfide species are preferentially partitioned into the vapor phase, which may explain the observed behavior of $\mathrm{Cu}$. Thermodynamic data by which to assess this hypothesis are currently not available. However, it is possible to assess the potential role of $\mathrm{Cu}$ chloride species using thermodynamic data from [4] and the approach of Krauskopf [5,6] and Wood [7]. This approach involves calculating the fugacities of various gaseous species of $\mathrm{Cu}$ and $\mathrm{Fe}$ in equilibrium with the most stable $\mathrm{Cu}$ and $\mathrm{Fe}$ minerals as a function of $\mathrm{fO}_{2}, \mathrm{HCl}$ fugacity, temperature, and pressure. Thermodynamic data are available for the following gaseous $\mathrm{Cu}$ and Fe species: $\mathrm{Cu}(\mathrm{g}), \mathrm{CuO}(\mathrm{g}), \mathrm{CuCl}(\mathrm{g}),(\mathrm{CuCl})_{3}(\mathrm{~g}), \mathrm{Fe}(\mathrm{g}), \mathrm{FeS}(\mathrm{g})$, $\mathrm{FeCl}(\mathrm{g}), \mathrm{FeCl}_{2}(\mathrm{~g}),\left(\mathrm{FeCl}_{2}\right)_{2}(\mathrm{~g}), \mathrm{FeCl}_{3}(\mathrm{~g})$, and $\left(\mathrm{FeCl}_{3}\right)_{2}(\mathrm{~g})$. The fugacity of each of these species was calculated assuming equilibrium with two different $\mathrm{O}_{2}$-and $\mathrm{S}_{2}$-buffering assemblages: chalcopyrite + pyrite + pyrrhotite + magnetite and chalcopyrite + pyrite + hematite + magnetite, at temperatures from 600 to $1200 \mathrm{~K}$ and at $1000 \mathrm{bar}$ pressure. In all cases the fugacities of the Fe chlorides were several orders of magnitude higher than those of the corresponding $\mathrm{Cu}$ chloride species. The calculated fugacities cannot be converted into 
vapor-phase concentrations without some additional assumptions. However, the calculations indicate that $\mathrm{Cu}$ chlorides should not partition more strongly into the vapor phase than Fe chlorides. Indeed, the opposite is predicted. Thus, these calculations suggest that the observed strong partitioning of $\mathrm{Cu}$ into the vapor phase is probably not a result of volatilization as chloride complexes. This indirectly supports the hypothesis that $\mathrm{Cu}$ sulfides may be involved. The fact that FeS(g) fugacities are low in equilibrium with either sulfide assemblage is consistent with this hypothesis in that $\mathrm{Fe}$ is not observed to partition into the vapor phase like $\mathrm{Cu}$ does. Altematively, as has been suggested for Pt-group elements [8,9], both sulfide and chloride may be involved in facilitating vapor-phase partitioning of $\mathrm{Cu}$. Perhaps of significance is the fact that, whatever mechanism accounts for the preferential partitioning of $\mathrm{Cu}$ into the vapor, the $\mathrm{Cu}$ remains partitioned into the vapor on cooling the fluid inclusions to the temperature at which PIXE or SXRF analysis is conducted. Thus, either this state is preserved metastably, or the $\mathrm{Cu}$ species involved are also volatile at room temperature.

References: [1] Heinrich C. A. et al. (1992) Econ. Geol., 87, 1566. [2] Bodnar R. J. (1996) Geol. Soc. Am., Progr. Abstr., 28, A402. [3] Williams P. (1996) personal communication. [4] Pankratz L. B. et al. (1984) U.S. Bur. Mines Bull., 677, 355. [5] Krauskopf K. B. (1957) Econ. Geol., 52, 786. [6] Krauskopf K. B. (1964) Econ. Geol., 59, 22. [7] Wood S. A. (1987) GCA, 51, 3041. [8] Fleet M. E. and Wu T.-W. (1993) GCA, 57, 3519. [9] Fleet M. E. and Wu T.-W. (1995) GCA, 59, 487.

CRUSTAL HISTORY AND PROCESSES AS REFLECTED IN LEAD ISOTOPIC SIGNATURES: SOME EXAMPLES FROM NORTH AMERICA. J. L. Wooden, Mail Stop 937, U.S. Geological Survey, 345 Middlefield Road, Menlo Park CA 94025, USA (jwooden@mojave.wr.usgs.gov).

The nature and timing of, and processes involved with, crust formation and the extraction of the crust from the Earth's mantle remain subjects of much debate. The $\mathrm{Pb}$ isotopic system is one of several isotopic systems that have been used to help understand the processes of crust formation and has the advantage of being based on three parent-daughter systems with very different decay rates and two elemental pairs ( $\mathrm{U} / \mathrm{Pb}$ and $\mathrm{Th} / \mathrm{Pb}$ ) with different geochemical properties. Early studies of crustal $\mathrm{Pb}$ isotopic systematics [e.g., 1] established that by the late Archean, crustal provinces existed with distinct $\mathrm{Pb}$ isotopic signatures. Additional work has confirmed these distinctions and emphasized the wide range in characteristics for different crustal regions. For example, a region such as the Wyoming Province requires an early stage with high U/Pb but a second stage with low $\mathrm{U} / \mathrm{Pb}$ and high $\mathrm{Th} / \mathrm{Pb}$ and $\mathrm{Th} / \mathrm{U}$. In contrast, regions such as the southem Superior Province or Greenland and Labrador require primary and secondary stages with low $\mathrm{U} / \mathrm{Pb}$ and $\mathrm{Th} / \mathrm{Pb}$. These variations in $\mathrm{Pb}$ isotopic signatures indicate a significant range in $\mathrm{U} / \mathrm{Pb}, \mathrm{Th} / \mathrm{Pb}$, and $\mathrm{Th} / \mathrm{U}$ in the sources of the crust and or significant variation, including elemental fractionation, in the processes by which crust was formed. Since the extremes of these variations exist in some of the oldest surviving crustal regions (3.9$4.0 \mathrm{Ga}$ ), the implication is that processes operating in the first $0.5 \mathrm{Ga}$ of Earth history must have created heterogeneities in $U / \mathrm{Pb}$, $\mathrm{Th} / \mathrm{Pb}$, and $\mathrm{Th} / \mathrm{U}$ in significant volumes of the upper mantle.

Crust of all ages can have distinctive $\mathrm{Pb}$ isotopic signatures that are very useful in the definition of crustal provinces and for understanding the tectonics of crustal amalgamation. Such a situation exists in the southwestem U.S. where $\mathrm{Pb}$ isotopic data define three Proterozoic crustal provinces, Mojave, Yavapai, and Mazatzal, and a probable tectonically generated transition zone between the Mojave and Yavapai provinces. The initial $\mathrm{Pb}$ isotopic composition of the Yavapai crustal province indicates an oceanic mantle-like source, but Yavapai crustal rocks have higher $\mathrm{U} / \mathrm{Pb}$ and lower $\mathrm{Th} / \mathrm{Pb}$ and $T h / U$ than average crustal values (Stacey-Kramers model). Mazatzal crust has the same initial $\mathrm{Pb}$ isotopic composition as Yavapai crust, implying a common ultimate source, but $\mathrm{U} / \mathrm{Pb}, \mathrm{Th} / \mathrm{Pb}$, and $\mathrm{Th} / \mathrm{U}$ equal to average crustal values, perhaps implying a fundamental difference in the overall processes of crust formation. Mojave crust has a more radiogenic initial $\mathrm{Pb}$ isotopic composition than Yavapai and Mazatzal crust, and lower $\mathrm{U} / \mathrm{Pb}$ and much higher $\mathrm{Th} / \mathrm{Pb}$ and $\mathrm{Th}$ $U$ than average crustal values. Although most of the exposed Mojave Precambrian rocks are the same age as those in Yavapai and Mazatzal crustal provinces, the Mojave province may involve a significant amount of late-Archean and earliest-Proterozoic crustal materials. The distinction in elemental ratios may imply some fundamental processes differed from those involved in crust formation in either the Yavapai or Mazatzal province.

Lead isotopic data are also valuable in analyzing crust formation in modern magmatic arc environments. The largely marginal continental magmatic arcs of Mesozoic age in the western U.S. from Washington to southern California share a surprising number of $\mathrm{Pb}$ isotopic features in spite of their development in association with cratonic regions of widely varying age and isotopic character. All three $\mathrm{Pb}$ isotopic ratios increase systematically from west to east with the least-radiogenic values approaching ocean island-like values and showing a strong positive correlation with ISr. Lead-lead isotopic plots appear to represent two-component mixing at the gross scale. Clearly the processes and volume of magma involved in these arc magmatic environments are capable of minimizing the differences in the continental input to these systems.

References: [1] Oversby (1978).

INTRA-ANNUAL MEASUREMENTS OF $\delta^{18} 0$ COMPARED WITH $8^{13} \mathrm{C}$ IN TREE CELLULOSE: A UNIQUE RECORD REFLECTING EITHER PHYSIOLOGICAL RESPONSES OR CHALLENGING FUNDAMENTAL ASSUMPTIONS. W. E. Wright', S. W. Leavitt', and A. Long' ${ }^{2}$, 'Laboratory of TreeRing Research, The University of Arizona, Tucson, AZ 85721, USA, 2Department of Geosciences, The University of Arizona, Tucson, AZ 85721, USA.

The relationship between the stable isotopic composition of precipitation and that of corresponding wood has not been established. Do the stable isotopic ratios in wood result from constant biochemical isotopic fractionation and proportionally reflect the precipitation source water, or is an additional signal from other fractionation pathways superimposed on the signal from the source water?

Our study has considered this question in a unique setting that provides discrete intra-annual control of precipitation and tree growth. Annual precipitation in southeastern Arizona is equally distributed between two precipitation maxima occurring in the winter and the summer. A drought regularly develops in the spring, causing certain 
species of trees in the proper setting to initiate dormancy as a response to moisture stress. The shutdown manifests itself in these trees as a band of small highly lignified cells known as a "false ring" or "false latewood band." This "false ring" provides a clear intraannual marker within each annual ring.

We have subdivided annual rings of Pinus ponderosa from the Santa Catalina mountains (elevation $2300 \mathrm{~m}$ ) near Tucson, Arizona, into three parts. The rings are subdivided at the false ring, and the portion prior to the false ring is equally subdivided. The stable isotopes of $\mathrm{C}$ and $\mathrm{O}$ were determined for each of these three subdivisions.

Expectations for the stable $\mathrm{C}$ isotopes were that the earliest portion of the ring would be isotopically light, the center portion would be heaviest, and the later portion would be lighter, based on the moisture availability during the time represented by each portion of the ring. The $C$ isotope results were consistent with our expectations.

The $O$ isotopes were expected to follow a pattern similar to the $C$ if additional fractionations caused by soil and leaf evaporation were dominant. However, a gradient from isotopically light to heavy through the year was expected if the cellulose stable $O$ was reflecting primarily the moisture source (isotopically light winter precipitation and heavy summer precipitation).

Neither expectation was met as the stable $O$ isotopes in the cellulose were extremely enriched in the heavier isotope early in the growing season. At this time the soil moisture is highest, the diumal heat load is fairly low, and stable $C$ isotopes were comparatively light, showing little moisture stress. The portion formed during the fore-summer drought revealed much lighter stable $O$ isotope values at a time when soil $\mathrm{H}_{2} \mathrm{O}$ availability is decreasing, the diumal heat load is high, and stable $\mathrm{C}$ isotopes are showing considerable moisture stress. The stable $O$ isotopes fixed in cellulose after the false ring are the least enriched in the heavier isotope at a time when the soil moisture availability is increasing, the heat load is high, and the stable $\mathrm{C}$ isotopes show decreasing stress. Two hypotheses may be posited to explain the seeming contradiction between the $O$ isotopes and the other factors. Either $O$ isotopes in the cellulose are reflecting very high transpiration early in the growing season, lower transpiration due to stomatal closure during the fore-summer drought, and continued lower transpiration through the summer, or $O$ isotopes in the cellulose are reflecting the timing of the secondary cell wall deposition and the transpiration occurring at that time, while the $\mathrm{C}$ in the secondary cell wall reflects a period earlier in the growing season. The final tree-ring isotopic composition may also be affected by the depth(s) at which the roots extract $\mathrm{H}_{2} \mathrm{O}$ during the course of the growing season.

CARBONATE-RICH LIQUIDS AND CRITICAL FLUIDS IN MANTLE PLUMES. P. J. Wyllie' ${ }^{1}$ and I. D. Ryabchikov ${ }^{2}$, 'Division of Geological and Planetary Sciences, California Institute of Technology, Pasadena CA 91 125, USA, ${ }^{2}$ Institute for Geology of Ore Deposits, Russian Academy of Sciences, 35 Staromonetny, Moscow 109017, Russia.

A trace of carbonatite melt must form within a mantle plume with some $\mathrm{CO}_{2}$ and more $\mathrm{H}_{2} \mathrm{O}$ than that stored in solid phases. The independent upward movement of this low-viscosity, buoyant sink for incompatible elements would contribute to the decoupling of trace from major elements in silicate magmas. Schrauder and Navon [1] interpreted the trapped fluid compositions in a suite of Botswana diamonds in terms of fluids from which the diamonds grew. Inclusions in a single diamond define a single composition. The range of inclusion compositions among diamonds shows linear correlation between a carbonatite end member (calcic dolomite), and a hydrous end member, compositions corresponding to those expected in upper-mantle peridotite. The near-solidus liquid for peridotite$\mathrm{CO}_{2}-\mathrm{H}_{2} \mathrm{O}$ deeper than $\sim 65 \mathrm{~km}$, at least to $200 \mathrm{~km}$, is dolomitic (calcic) carbonatite; subsolidus or coexisting vapor phase is hydrous.

Ryabchikov and Wyllie [2] and Wyllie and Ryabchikov [3] considered a critical end point on the solidus for peridotite- $\mathrm{CO}_{2}$ $\mathrm{H}_{2} \mathrm{O}$. Shallower than the critical point, the compositions of liquid and vapor remain separated. Deeper than this, homogeneous fluids with compositions intermediate between the end member's carbonatite liquid (higher temperature) and aqueous vapor (lower temperature) coexist with peridotite; there is no solidus where melting begins. These critical fluid compositions probably show a linear relationship between the two end members. The diamond observations are consistent with the occurrence of a critical end point on the mantle solidus.

The static equilibrium phase assemblages in a simple plume form a cylinder with outer shell containing high-pressure aqueous vapor, enclosing a steep inverted cone (surface $=$ the solidus) where vapor is replaced by a trace of dolomitic carbonatite magma, which changes (with increasing temperature) through kimberlitic to the picrite magma that occurs within a shallow kernel in the central volume high in the plume. Given a critical end point, the solidus surface forming the inverted cone terminates at an isothermal, isobaric near-circle. At greater depths an annulus containing critical fluid extends downward between the central carbonate liquid-bearing mantle (inverted cone) and the outer shell containing hydrous vapor. Phase equilibrium evidence $[4,5]$ indicates that silicate-carbonate liquid immiscibility does not occur within the upper mantle, only within the crust.

Rising volatile components follow different paths depending on position within a plume: (1) central: carbonatite melt is incorporated into picrite magma, (2) outer. hydrous vapor crosses solidus, is converted to carbonatite melt, which enters lithosphere; (3) intermediate: critical fluid may be similar to (1) or (2). The partition of trace elements among peridotite, hydrous vapor, and carbonatite melt occurs at different depths (pressures) within the plume, according to radial distance; partition is pressure sensitive (coefficients not known). If the carbonatite liquids rise through the asthenosphere faster than plume speed (probable) in disequilibrium with peridotite host (possible), then trace-element compositions in magmas reaching the lithosphere should vary radially from the center of the plume, according to the depth of the solidus. This scenario reenriches moving lithosphere with carbonatite melt after the depleting hotspot eruptions.

References: [1] Schrauder and Navon (1994). [2] Ryabchikov and Wyllie (1991). [3] Wyllie and Ryabchikov (1992). [4] Lee and Wyllie (1996). [5] Lee and Wyllie (1997).

AN OCEANIC CRUSTAL ORIGIN FOR YOUNG CONTINENTAL CRUST ALONG THE WEST ANTARCTICAAUSTRALIA SECTOR OF THE PALEOZOIC GONDWANA 
SEABOARD. R. J. Wysoczanski ${ }^{1}$, T. R. Ireland ${ }^{1}$, J. H. Berg ${ }^{2}$, and J. A. Gamble ${ }^{3}$, 'Research School of Earth Sciences, Australian National University, Canberra, ACT 0200, Australia, ${ }^{2}$ Department of Geology, Northern Illinois University, De Kalb IL 60115, USA, ${ }^{3}$ Department of Geology, Victoria University of Wellington, P.O. Box 600, Wellington, New Zealand.

West Antarctica is composed of a number of allochthonous terranes (including Marie Byrd Land (MBL), the Ross Embayment (RE), Thurston Island, the Ellsworth Mountains, and the Antarctic Peninsula) that were sutured to the stable east Antarctic craton in Paleozoic times. At this time, the terranes of New Zealand, the Campbell Plateau, and southeastem Australia were, together with West Antarctica, a part of the paleo-Pacific Gondwana margin. While such a reconstruction is consistent with the known distribution of the terranes, the early history and tectonic environment of the crustal blocks is not well constrained.

Granulite xenoliths entrained in late Cenozoic alkaline magmas from MBL (MBL Volcanic Province) and the RE (McMurdo Volcanic Province) provide constraints on the composition of the lower crust in these areas. These suites show remarkable petrologic and geochemical similarities, given the vast distances between the regions. All are subalkaline meta-igneous cumulate gabbros and norites, consisting of plagioclase, two pyroxenes, olivine, and spinel. Chemically they are low in silica ( $<2 \mathrm{wt} \%$ ), with high $\mathrm{Mg}: \mathrm{Fe}$ ( $\mathrm{Mg \# s}$ of 50-85), low incompatible-trace-element contents (e.g. $<2 \mathrm{ppm} \mathrm{Rb}$, $<190 \mathrm{ppm} \mathrm{Ba},<2 \mathrm{ppm} \mathrm{Nb}$, and $<60 \mathrm{ppm} \mathrm{Zr}$ ), high compatible elements (e.g., up to $2500 \mathrm{ppm} \mathrm{Ni}$ and $\mathrm{Cr}$ ), and depleted mantle-like isotopic ratios that show no evidence of crustal contamination (e.g., ${ }^{87} \mathrm{Sr} /{ }^{86} \mathrm{Sr} 0.70298-0.70424$ and ${ }^{143} \mathrm{Nd}^{144} \mathrm{Nd} 0.51218-0.51298$ ). The similarity of the lower crust in these regions indicates a single, continuous crustal block along the northern Antarctic margin, from MBL to the RE, and possibly northern Victoria Land (NVL). The texture and composition of the xenoliths are closest to layered gabbros formed at a mid-ocean ridge, indicating an origin as oceanic crust or oceanic plateau. Similar xenolith suites occur in New Zealand and in southeastem Australia, suggesting that this crustal block may extend into these regions.

In each of these regions, basement rock consists of turbidite greywackes that were sourced directly from the Gondwana continent. These lower Paleozoic Gondwana greywackes (LPGG) include the Swanson Formation of MBL, the Robertson Bay, and Bowers terranes of NVL, the Greenland Group of New Zealand, the

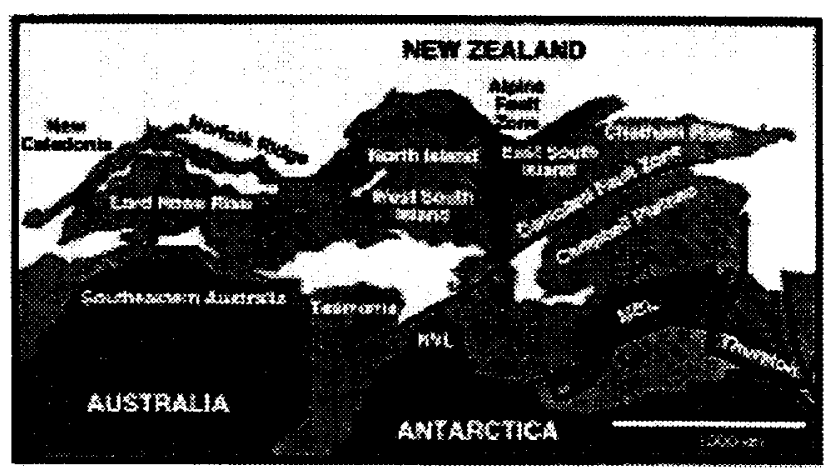

Fig. 1.
Campbell Island Schist of the Campbell Plateau, and Kanmantoo and Lachlan Fold Beit sediments from southeastern Australia. Uranium-lead dating of detrital zircon by SHRIMP reveals a similar age pattem for all these LPGG, indicating the same provenance area(s).

A model for the formation of the West Antarctica-Australia sector of the Paleozoic Gondwana margin is envisaged whereby oceanic crust or oceanic plateau is overlain by turbidite sediments sourced from the Gondwana continent that, with subsequent sedimentation, metamorphism, and magmatism, has evolved into young continental crust.

SURFACE MICROTOPOGRAPH OF AN ALKALI FELDSPAR: TRANSMISSION ELECTRON MICROSCOPY AND SCANNING FORCE MICROSCOPY STUDIES. $H$. $\mathrm{Xu}^{1}$, P. R. Buseck', D. R. Veblen ${ }^{2}$, and B. L. Ramakrishna ${ }^{3}$, 'Department of Geology, Arizona State University, Tempe AZ 85287-1404, USA, 'Deparment of Earth and Planetary Sciences, Johns Hopkins University, Baltimore MD 21218 , USA, ${ }^{3}$ Deparment of Chemistry and Biochemistry, Arizona State University, Tempe AZ 85287-1604, USA.

Exsolution, twinning, and structural modulation are common phenomena in alkali feldspars and ternary feldspars and can provide information regarding the thermal history of the feldspar crystals and their host rocks. The boundaries between neighboring domains may bring strain energy. Because of the complex domain structures in feldspar, the surface microtopography of the feldspars may be highly heterogeneous. Local structure and defects in perthitic feldspars affect their weathering rates; the textures of exsolution and twinning on cleavage surfaces can provide structural information about local reactions during feldspar-water interaction. Also the domain structures in feldspar minerals cause discrepancies in feldspar-water interactions among different laboratory studies. For instance, exsolution lamellae in feldspar cause nonstoichiometrics dissolution, twins cause different dissolution rates for different grain-size fractions. Defect structures at the twin boundaries and between exsolution domains are preferential sites for dissolution.

Transmission electron microscopy (TEM) reveals exsolution lamellae in a cryptoperthite; their spacing results in a greenish yellow iridescent color. High-resolution TEM images show that the boundaries between $\mathrm{Ab}$-rich and Or-rich lamellae are coherent along the $b$ axis. Scanning force microscopy (SFM) of a (001) cleavage surface reveals exsolution lamellae, wavelike $(001)$ surfaces of the Ab-rich lamellae, and surface steps with heights about $\sim 6.6 \AA$ and $\sim 3 \AA$. The wavelike (001) albite surfaces twin lamellae result from surface relaxation. Surface height differences between $\mathrm{Ab}$ - and $\mathrm{Or}$-rich lamellae indicate the boundaries are semi-coherent along the $c$ axis.

BIOGENIC EVAPORITES FROM SECRETION OF POPULUS DIVERSIFOLIA AROUND DESERT AREA, XINJIANG, NORTHWESTERN CHINA. S. Yabuki' ${ }^{1}$ A. Okada', Z. Fan' ${ }^{2}$, and Q. Chang', 'The Institute of Physical and Chemical Research, Riken, Japan, ${ }^{2 X i n j i a n g ~ I n s t i t u t e ~ o f ~ B i o l o g y, ~ P e d o l o g y ~}$ and Desert Research, Chinese Academy of Sciences, China.

Populus diversifolia is a predominant vegetation on the flood- 
TABLE 1. Salt content of Populus diversifolia (meq/kg).

\begin{tabular}{|c|c|c|c|c|c|c|c|}
\hline $\begin{array}{l}\text { Sample } \\
\text { Leaf }\end{array}$ & $\begin{array}{l}\mathrm{CO}_{3}{ }^{2-} \\
2947\end{array}$ & $\begin{array}{c}\mathrm{HCO}_{3}^{-} \\
175 !\end{array}$ & $\mathrm{SO}_{4}^{2-}$ & $\begin{array}{l}\mathrm{Cl}^{-} \\
459\end{array}$ & $\begin{array}{l}\mathrm{Ca}^{2+} \\
-\end{array}$ & $\mathrm{Mg}^{2+}$ & $\begin{array}{c}\mathrm{Na}^{+}+\mathrm{K}^{+} \\
-\end{array}$ \\
\hline Stem & & 1941 & 4 & 273 & 20 & 99 & 2096 \\
\hline Secretion & 4883 & 2897 & 15 & 3192 & 30 & 1299 & 10770 \\
\hline Poplar salt & 3400 & 6820 & 13 & 2571 & 11 & 210 & $8330 \quad 3551$ \\
\hline
\end{tabular}

plain of the Tarim River, the largest river in the Tarim Basin, Xinjiang, northwestem China. Halophytic plants in the saline, arid, and semi-arid areas sometimes have very peculiar physiological features. Populus diversifolia is one such plant, known because it concentrates carbonate and bicarbonate ions in its stems, leaves, and secretion. Therefore, the soil under old Populus diversifolia forest commonly shows an obvious characteristic of soda salinization.

The secretion from a mechanically damaged portion or the cut ends of Populus diversifolia solidify to make an edible salt called poplar salt. As it contains considerable amount of $\mathrm{NaHCO}_{3}$, local people use it for soap production, medicine, or for baking powder.

The authors used a chemical and mineralogical approach to study the poplar salt and found it is made of various kinds of alkaline and alkaline earth carbonates and bicarbonates as well as $\mathrm{KCl}$.

Natural occurrences of $\mathrm{K}$ and $\mathrm{Mg}$ carbonates have been reported very rarely. Because of its peculiar biological features and arid climate, such unusual evaporites seem to be formed.

Chemical Composition: The chemical composition of poplar salt is shown in Table 1 together with referential data. Dominant cations are $\mathrm{Na}$ and $\mathrm{K}$, while $\mathrm{Mg}$ content is low, and only a small amount of $\mathrm{Ca}$ is found. Carbonate and bicarbonate are the main anions and a considerable amount of $\mathrm{Cl}$ is also found.

Mineralogical Study: $\mathrm{X}$-ray diffraction analysis and elemental analysis by EPMA suggest the existence of the following evaporite minerals:

Trona, $\mathrm{NaHCO}_{3} \times \mathrm{Na}_{2} \mathrm{CO}_{3} \times 2 \mathrm{H}_{2} \mathrm{O}$. Trona is the dominant component of poplar salt. It consists of well-developed euhedral crystals. These results suggest that trona crystallized first.

Baylissite, $\mathrm{K}_{2} \mathrm{CO}_{3} \times \mathrm{MgCO}_{3} \times 4 \mathrm{H}_{2} \mathrm{O}$. Colorless fine-grained aggregates, usually adjacent to trona and sometimes enclosed by sylvite.

Sylvite, $\mathrm{KCl}$. Sylvite crystals fill the space between trona aggregates and sometimes euhedral crystals are observed. Chlorine only distributes together with $K$.

$\mathrm{K}: \mathrm{CO}_{3}=2: 1$ phase. Adjacent to sylvite, we often found $\mathrm{K}_{2} \mathrm{CO}_{3}$ phase. Quantitative analysis by EPMA suggests this phase to be $\mathrm{K}_{2} \mathrm{CO}_{3} \times 3 / 2 \mathrm{H}_{2} \mathrm{O}$ phase, but we have not yet recognized this mineral by $\mathrm{X}$-ray diffraction.

$\mathrm{Na}: \mathrm{Ca}: \mathrm{CO}_{3}=1: 1: 2$ phase. From the element distribution map and quantitative analysis by EPMA, this phase seems to be $\mathrm{NaHCO}_{3} \times$ $\mathrm{CaCO}_{3}$.

( $\mathrm{Ca}, \mathrm{Mg}) \mathrm{CO}_{3}$ phase. This phase microscopically looks similar to baylissite and $\mathrm{CaCO}_{3}$ phase. Analytical results show some of the $\mathrm{Ca}$ of $\mathrm{CaCO}_{3}$ is replaced by $\mathrm{Mg}$.

FERRIC AND FERROUS CONTENTS OF MARINE SEDIMENTS: INDICATOR OF THE ATMOSPHERIC $P_{\mathrm{O}_{2}}$
LEVEL AND OF PALEOTECTONIC SETTING. K. Yamaguchi and H. Ohmoto, Department of Geosciences, Pennsylvania State University, University Park PA 16802, USA.

The terrigenous components of modem oceanic sediments (and ancient sedimentary rocks) have provided important information about paleoenvironmental conditions, as demonstrated in the use of some cation ratios in constraining the source-rock composition, provenance, and weathering intensity on land. However, the potential use of ferric and ferrous contents of marine sediments as an indicator of the atmospheric $\mathrm{P}_{\mathrm{O}_{2}}$ level has not been fully examined by previous investigators.

We have examined the ferric and ferrous contents of the deepsea sediments of mainly terrigenous origin (mostly silts) in Deep Sea Drilling Project publications and some other sources. Our research yields 761 datasets from 39 drilling sites in 15 Legs out of the total 624 sites in 96 Legs. The data are from various areas of the world oceans: Red Sea Atlantis II Deep, Japan Sea, North Atlantic, Mid Atlantic Ridges, Rockall Plateau, East Pacific Rise, Galapagos Rift, Japan Trench, Shikoku Basin, Parece Vela Basin, Mariana Trough, Mariana Trench, Baja Califomia, Gulf of California, Middle America Trench, and Galapagos Spreading Center. The majority of these sediments falls in relatively narrow ranges in the atomic $\mathrm{Fe} / \mathrm{Ti}$ ratios: $\mathrm{Fe}^{3+/ \mathrm{Ti}}=5.4 \pm 1.2(\mathrm{l \sigma}), \mathrm{Fe}^{2+} / \mathrm{Ti}=3.5 \pm 0.7, \mathrm{Fe}^{3+} / \mathrm{Fe}^{2+}=1.6$ \pm 3.4 , and $\mathrm{Fe} / \mathrm{Ti}=8.9 \pm 1.4$. In comparison, normal igneous rocks of Phanerozoic ages have corresponding ratios of $3 \pm 2,6 \pm 2,0.5 \pm 0.2$, and $8 \pm 4$ respectively [e.g., 1,2]. The higher $\mathrm{Fe}^{3+} / \mathrm{Ti}$ and $\mathrm{Fe}^{3+} / \mathrm{Fe}^{2+}$ ratios, lower $\mathrm{Fe}^{2+} / \mathrm{Ti}$ ratios, and similar $\mathrm{Fe} / \mathrm{Ti}$ ratios of the marine sediments compared to normal igneous rocks are common to the typical soils formed under an O-rich atmosphere. The ferric and ferrous contents of normal deep-sea sediments represent those of the average soil on land. Therefore, the magnitude of increase in the $\mathrm{Fe}^{3+} / \mathrm{Ti}$ ratios of shales from normal igneous rocks may be used as a measure of the atmospheric $\mathrm{P}_{\mathrm{O}_{2}}$ level during weathering of sourcerocks on land, provided the Fe/Ti ratios of shales are within $9 \pm 2$ and the diagenetic, hydrothermal, and metamorphic effects were minor.

Exceptionally high values of $\mathrm{Fe}^{3+} / \mathrm{Ti}(>10)$ and $\mathrm{Fe} / \mathrm{Ti}(>15)$ with occasionally low $\mathrm{Fe}^{2+} / \mathrm{Ti}$ ratios $(<0.5)$ are found in some DSDP sediments from submarine hydrothermal fields along mid-oceanic ridge systems, such as the Mid-Atlantic Ridges, the East Pacific Rise, and the Galapagos Spreading Center. Such chemical characteristics were probably caused by the addition of ferric hydroxides precipitated from hydrothermal plumes and also by leaching of $\mathrm{Fe}^{2+}$ from rocks by high-temperature fluids. Therefore, such abnormal Fe chemistry, if found in ancient sediments, can be used to measure the proximity of the depositional site to a mid-oceanic ridge system.

References: [1] Kump and Holland (1992). [2] Ohmoto (1996).

EXPERIMENTAL STUDY OF THE EFFECT ON INTRAPLATE MAGMATISM OF ECLOGITE ENTRAINED IN MANTLE PLUMES. G. M. Yaxley and D. H. Green, Research School of Earth Sciences, The Australian National University, Canberra, ACT 0200, Australia (Greg.Yaxley@anu.edu.au).

Trace-element and isotopic data from basalts erupted at intraplate "hotspots" are often interpreted as evidence for multiple components in the basalts' mantle source regions. Some of these postu- 
lated source components have been related to entrainment into mantle plumes of eclogitic material derived from recycling of oceanic crust at convergent margins. However, petrological aspects of entraining discrete bodies of eclogitic, former oceanic crust in an ascending mantle plume, have not yet been investigated. For example, how is mixing of isotopic and trace-element signatures from recycled $\propto$ eanic crust and mantle peridotite actually achieved? What happens when siliceous partial melts of eclogite percolate into peridotite?

We have conducted nominally anhydrous experiments at $3.5 \mathrm{GPa}$ aimed at investigating this problem. Initially, we established the phase relations of average altered ocean-floor basalt (composition GA 1). The solidus lies below $1250^{\circ} \mathrm{C}$ and the liquidus between $1475^{\circ}$ and $1500^{\circ} \mathrm{C}$. The sequence of phase-out boundaries from low to high temperatures is coesite, cpx, and garnet. Low-degree partialmelt compositions of GA1, determined using the "sandwich" technique, were dacitic in composition (63 wt $\% \mathrm{SiO}_{2}, 8 \mathrm{wt} \% \mathrm{\Sigma}$ alkalis at $13 \%$ melting at $1300^{\circ} \mathrm{C}$ ).

Interactions between dacitic partial melts of eclogite and "normal" peridotite were investigated by sandwiching a layer of GAl (10 wt\%) against a layer with fertile mantle composition ( $90 \mathrm{wt} \%$ MORB-pyrolite, MPY90). GA //MPY90 layered experiments were conducted at temperatures from $1200^{\circ}$ to $1500^{\circ} \mathrm{C}$. At $1500^{\circ} \mathrm{C}$, a picritic melt layer $\left(\mathrm{Mg} \# \approx 80\right.$ ) coexisted with aluminous opx $>\mathrm{Fo}_{92}$ ol. At $1425^{\circ} \mathrm{C}$ a picritic melt layer was in contact with a layer of aluminous opx $>\mathrm{Fo}_{90.5} \mathrm{ol}+$ melt. This layer graded into a subsolidus gamet lherzolite assemblage of $\mathrm{Fo}_{90} \mathrm{Ol}+$ sub-Ca cpx + ga + opx. At $1400^{\circ}$ and $1250^{\circ} \mathrm{C}$, a layer of ga $+\mathrm{cpx}$ (formerly the GA1 layer) was in contact with a layer with opx $>\mathrm{cpx}>$ minor ol \pm minor ga. This layer graded into gamet lherzolite. No quenched melt was detected; the charge had solidified, eliminating the melt product from the altered crust by rapid reaction, principally with olivine.

The implications of these results are complex. Siliceous partial melts (e.g., dacites, rhyodacites) of bodies of recycled former oceanic crust (now eclogitic) will react strongly with surrounding mantle, increasing orthopyroxene at the expense of olivine and gamet. Residual refractory eclogitic bodies will remain, retaining particular trace-element and isotopic signatures. Melt migration and reaction will transfer the isotopic and trace element characteristics of recycled oceanic crust to surrounding peridotitic mantle. Subsequent partial melting of this modified peridotite could generate liquids that exhibit trace-element and isotopic evidence of mixed source components. However, unless entrained eclogite is a volumetrically very significant component in plumes, so that the selective mixing process, followed by melting, eliminates olivine as a residual phase, then the major-element geochemistry of primary melts of the mixed source will reflect a peridotitic source. Such melts are picritic at $2.0-3.5 \mathrm{GPa}$. Highly siliceous partial melts of eclogite will not percolate through a volumetrically dominant peridotitic matrix without substantial modification by multiple saturation in peridotitic phases, including opx and ol. Incorporation of isotopic and trace-element characteristics of recycled oceanic crust into intra-plate volcanics should not be interpreted in terms of simple mixing of partial melts of eclogite and peridotite at upper mantle pressures.

LEAD-LEAD AGE AND SOURCE OF SEDIMENTS OF THE PROTEROZOIC INTRACRATONIC CUDDAPAH BASIN,
INDIA. J. K. Zachariah, K. Gopalan, and R. Srinivasan, National Geophysical Research Institute, Hyderabad, 500007 , India (jzachariah@ccmail.sunysb.edu; postmast@csngri.ren.nic.in).

The Cuddapah Basin of southem India serves as a type area for the middle Proterozoic Cuddapah supergroup. A radiogenic isotope and geochemical study of the chemogenic sedimentary rocks of the basin has been initiated to find out the time of sedimentation. Constraints on the time of sedimentation will provide a framework to study the provenance of the sediments, which will help in paleotectonic and paleogeographic reconstruction, and will help us to understand the origin of this intracratonic basin.

The Cuddapah supergroup has been divided into the Papaghni, Chitravati, and Nallamalai groups [1], each of which comprises a cyclic sequence of conglomerate, shale, and limestone. One sample each of stromatolitic dolomite of the Vempalli Formation of the lowermost Papaghni group (sample \#28) and the overlying Tadapatri Formation of the Chitravati group (sample \#14) was used in this study. Sample \#28, collected about $5 \mathrm{~m}$ from a mafic sill, is an impure carbonate rock with small amounts of zoisite and tremolite. Sample \#14 is a micritic dolomite with sand-sized grains of detrital feldspar and quartz, $\sim 10-15$ vol\% in thin section. Lead isotopic composition was determined on $2 \mathrm{~N} \mathrm{HCl}$ leaches of multiple aliquots of each sample. Five analyses of sample $\# 28$ have a limited range in $\mathrm{Pb}$ isotopic composition and give a $\mathrm{Pb}-\mathrm{Pb}$ date of $2274 \pm 380 \mathrm{Ma}$. Thirteen analyses of sample \#14 give a $\mathrm{Pb}$ - $\mathrm{Pb}$ age of $1791 \pm 79 \mathrm{Ma}$. All 18 analyses conform closely to a straight line corresponding to an age of $1793 \pm 37 \mathrm{Ma}$ with $m_{1}=8.9$, indicating that both samples had similar initial uranogenic $\mathrm{Pb}$. However, they differ in traceelement abundance and $\mathrm{Nd}$ and $\mathrm{Sr}$ isotopic compositions as shown in Table 1.

Sample \#28 could have been chemically altered by the nearby mafic intrusion. Thus the $\mathrm{Pb}-\mathrm{Pb}$ date given by this sample may not have any age significance. Sample \#14 appears to have undergone only diagenesis in view of its texture and geochemistry. Hence the $\mathrm{Pb}-\mathrm{Pb}$ age given by the Tadapatri dolomite is a strict younger age limit for its sedimentation. This age agrees well with a whole-rockmineral $\mathrm{Rb}$-Sr date on a mafic sill in the Tadapatri Formation reported by Rao et al. [2].

Sample \#14 has a dolomite-like REE pattern with moderate LREE enrichment $\left(\mathrm{Ce}_{\mathrm{N}} / \mathrm{Yb}_{\mathrm{N}} \sim 5\right)$ and relatively flat HREE $\left(\mathrm{Gd}_{\mathrm{N}^{\prime}}\right.$ $\left.\mathrm{Yb}_{\mathrm{N}} \sim 1\right)$. This sample does not have a $\mathrm{Ce}$ anomaly, but has a pronounced negative Eu anomaly (Eu/Eu* 0.5 ), indicating a crustal

TABLE 1 .

\begin{tabular}{|c|c|c|c|c|c|}
\hline Sample\# & $\mathbf{K}$ & ${ }^{206} \mathrm{~Pb} /{ }^{204} \mathrm{~Pb}$ & EREE & Sm ppm & Nd ppm \\
\hline 28 & 3.4 & $26.5-29.8$ & 215 & $10.92^{*}$ & $56.91^{*}$ \\
\hline 14 & 0.16 & $49-119$ & 25 & $1.2628^{\prime}$ & $6.3132^{+}$ \\
\hline Sample\# & ${ }^{147} \mathrm{Sm} / 144 \mathrm{Nd}$ & ${ }^{143} \mathrm{Nd} d^{144} \mathrm{Nd}$ & $\varepsilon_{\mathrm{Nd}(1790)}$ & ${ }^{87} \mathrm{Sr}^{880} \mathrm{Sr}_{(0)}$ & \\
\hline 28 & 0.11604 & 0.511108 & -11.4 & 0.7057 & \\
\hline 14 & 0.12097 & 0.511437 & -6.1 & 0.7080 & \\
\hline
\end{tabular}

$\kappa=$ calculated ${ }^{232} \mathrm{Th} /{ }^{238} \mathrm{U}$; $\Sigma$ REE = total of $10 \mathrm{REE}$, La to $\mathrm{Lu}$, in ppm;

${ }^{87} \mathrm{Sr}^{86} \mathrm{Sr}_{(0)}=$ uncorrected for in situ decay.

* ICP-MS analyses.

+ ID analyses. 
source for the REE. This sample has $\varepsilon_{\mathrm{Nd(1790)}}$ of -6 , which indicates that the provenance consisted dominantly of rocks at least $600 \mathrm{~m} . \mathrm{y}$. old at $1790 \mathrm{Ma}$. The $\mathrm{Nd}$ in sample \#28 requires addition from an even older source.

References: [1] Rao N. et al. (1987) Geol. Soc. India Mem. No. 6, pp. 33-86. [2] Rao B. et al. (1993) Geol. Soc. India Mem. No. 33 , pp. 329-338.

FIRST LASER ABLATION MICROPROBE MEASUREMENTS OF TRACE-ELEMENT PARTITIONING BETWEEN HYDROUS PHASES IN HIGH-PRESSURE METAMORPHIC ROCKS. T. Zack ${ }^{1.2}$ and S. F. Foley ${ }^{1},{ }^{1}$ Minerologie-Petrologie Institut, Universität Göttingen, Goldschmidtstrasse 1, 37077 Göttingen, Germany (tzack@gwdg.de), 2Department of Earth Sciences, Memorial University of New Foundland, St. John's A IB $3 \times 5$, Canada.

A key question in understanding subduction zone processes is how $\mathrm{H}_{2} \mathrm{O}$ is transported via the subducted slab to the source region of arc magmas. A number of hydrous mineral phases that release water through dehydration reactions upon $\mathrm{P}$ and/or $\mathrm{T}$ increase have been proposed as the main carrier.

Trace-element systematics are a powerful tool in reconstructing geological processes, but have found little application to the traceelement distribution of important high-pressure hydrous phases like amphibole (AMP), phengite (PHE), lawsonite (LAW), and epidote (EPI) in metamorphic rocks. Notable exceptions are detailed geochemical studies of the Catalina Schist including SIMS and PIXE analyses of the mentioned hydrous phases [1-3].

Here, we present the first results for a large number of trace elements (HFSE, LILE, REE, and transition elements) in these hydrous phases analyzed by laser ablation microprobe (LAM). Samples are subduction-related hydrous mineral-bearing eclogites in the Adula nappe, Switzerland, and gamet-bearing blueschists from Jenner, Califomia.

The most interesting feature is the varied degree of incorporation of each LILE in different hydrous phases spanning a range of 3 orders of magnitude. A succession of element enrichment between different hydrous phases can be observed as follows:

$$
\begin{aligned}
& \text { Cs: } \operatorname{PHE}(100)>\operatorname{EPI}(50)>\operatorname{AMP}(5)>\text { LAW }(<3) \\
& \text { Rb: PHE }(100)>\operatorname{EPI}(20)>\operatorname{AMP}(10)>\text { LAW }(<0.1) \\
& \text { Ba: } \text { PHE }(100)>\operatorname{AMP}(15)>\operatorname{EPI}(5)>\text { LAW }(0.2) \\
& \text { Sr. EPI }(4000)>\text { PHE }(100)>\operatorname{AMP}(15)>\text { LAW }(4)
\end{aligned}
$$

Numbers in parentheses are estimated from concentration ratios between coexisting mineral phases and are normalized to phengite. It can be seen that $\mathrm{Cs}, \mathrm{Rb}$, and $\mathrm{Ba}$ are strongly enriched in phengite relative to epidote and amphibole by a factor of 2-20. Epidote accommodates $\mathrm{Cs}$ easier than $\mathrm{Ba}$, but is most easily distinguished by its high $\mathrm{Sr}$ content. Amphibole is only distinguished from phengite by its overall lower abundance of LILE but shows otherwise very similar element/element ratios. Lawsonite in the analyzed sample has very low overall abundances of all LILE (e.g., $0.3 \mathrm{ppm} \mathrm{Sr}$ ), which is in contrast to findings of Domanik et al. [3] , where $\mathrm{Sr}$ is highly enriched in lawsonite (average $230 \mathrm{ppm}$ ). The low values in the Jenner sample might be explained by disequilibrium since lawsonite clearly is a breakdown product of garnet with very low concentrations of Sr. Equilibrium between LAW and the other hydrous minerals was not reached despite direct grain contact. Nevertheless, the low abundances of $\mathrm{Rb}(<0.2 \mathrm{ppm})$ and $\mathrm{Ba}(0.4$ $0.7 \mathrm{ppm}$ ) in lawsonite are in accordance with Domanik et al. [3].

Since LILE are easily mobilized by hydrous fluids it is expected that each dehydration reaction of these phases passes a specific trace-element pattern to the released $\mathrm{H}_{2} \mathrm{O}$, especially if this $\mathrm{H}_{2} \mathrm{O}$ leaves the system without reequilibrating with the surrounding minerals.

Partition coefficients between hydrous mineral phases and a hydrous fluid ( $D^{\operatorname{Min} 1 / F}$ ) can be estimated with $D^{\text {Min2/Min] }}$ measured between hydrous phases and a known mineral phase if it is combined with experimentally determined $D^{\mathrm{Min} 2 \mathrm{~F}}$ for clinopyroxene or gamet $[4,5]$. With this approach, quantitative modeling of the traceelement budget of subduction-relevant dehydration reactions should become possible.

References: [1] Hickmott D. D. et al. (1992) Geology, 20, 347-350. [2] Bebout G. E. et al. (1993) GCA, 57, 2227-2237. [3] Domanik K. J. et al. (1993) GCA, 57, 4997-5010. [4] Brenan J. M. et al. (1995) GCA, 59, 3331-3350. [5] Stalder R. et al. (1997) this volume.

RARE-EARTH-ELEMENT CONCENTRATION OF THE GIANT CLAM FROM OFF HATSUSHIMA COLD SEEP. AGE, SAGAMI TROUGH. J. Zhang and T. Ishii, National Institute for Radiological Sciences, 3609 Isozaki, Hitachinaka, Ibaraki 311-12, Japan.

Activities of biological communities in association with cold seepage have largely and increasingly concentrated interests of biologists and geochemists. The related studies show that such activities are due to the support of microbial chemosynthesis, which oxidizes dissolved compounds in a manner similar to that occuring in deep-sea hydrothermal communities. Recently, several studies investigated the chemistry of seep flow to understand the sources of the fluids and their contribution to the oceanic chemistry. In order to understand the control of the activities of biological communities over the seepage flow chemistry and the effect of biological and biogeochemical processes on oceanic chemistry, we collected the clam samples from the Hatsushima Seepage, Sagami Trough, and measured concentrations of the rare-earth and other elements in their organs, gills, and feet. The results permit us to discuss the concentration distributions and compositional variations in different organs of the clam, and the fractionation between seepage fluids and the creature.

The giant clam Calytogena soyoae was collected from Off Hatsushima in the Sagami Trough. After collection, the clams were immediately stored in a freezer under $-80^{\circ} \mathrm{C}$ and transported to the laboratory on land. Before dissection the frozen clams were unfrozen and washed with Milli-Q water. The dissected feet and gills were washed again with pure water and freeze-dried under $-30^{\circ} \mathrm{C}$. The dried gills and feet were digested with nitric and perchloric acids. The dissolved materials were dried up and then made into sample solution by adding $1 \mathrm{~N}$ nitric acid. The sample solution was filtered with Toyo No. 3C filter paper and introduced to ICP-MS for determination. Zinc, $\mathrm{Mg}$, and $\mathrm{Cd}$ showed very high concentration, compared with other trace elements such as $\mathrm{Mn}, \mathrm{Co}$, and $\mathrm{Ni}$, etc.

The light rare earth elements (REE), especially La, show high concentrations relative to the heavy REE. The REE concentrations of different organs of the clam show no significant differences. 
Although concentrations are variable within different samples and organs, the compositions are very similar. The shale-normalized REE abundances of the foot and gills of the clam show clear enrichment of middle REE and negative Ce anomalies. As compared with the bulk seawater, the organs of the clam show depletion in heavy REE, indicating that the biological processes may fractionate the light and heavy REE in seawater to some extent. Alternatively, the REE compositions of the organs of the clam simply reflect the composition of the seepage water. Yttrium/holmium ratios are relatively constant and comparable with the bulk seawater, which argues against the consideration that biological process fractionates $\mathrm{Y} / \mathrm{Ho}$ ratio in seawater and enriches $\mathrm{Y}$ in seawater. The speciation of the REE in the organs of the clam and the mechanisms to extract the REE from seawater into the organs are not known, and will be the main objective of studies in future.

XENOLOGY AND YOUNG AGE OF EARTH. Y.Zhang, Department of Geological Sciences, University of Michigan, Ann Arbor MI 48109-1063, USA (youxue@umich.edu).

Radiogenic ${ }^{129} \mathrm{Xe}^{*}$ (parent ${ }^{129}$ I with a half-life of 15.7 m.y.) and nucleogenic ${ }^{136} \mathrm{Xe}^{*}$ (parent ${ }^{244} \mathrm{Pu}$ with a half-life of $80 \mathrm{~m}$.y., ignoring the contribution of ${ }^{238} \mathrm{U}$ to air ${ }^{136} \mathrm{Xe}$ ) can be used to estimate the closure age of noble gases on Earth [e.g., 1,2]. Using nonradiogenic air Xe composition of Pepin [3], ${ }^{129} \mathrm{Xe}^{*}$ in air is $2.77 \times 10^{11} \mathrm{~mol}$ and ${ }^{136} \mathrm{Xe}^{*}$ in air is $6.32 \times 10^{10} \mathrm{~mol}$. Assuming that the radiogenic gases were provided by degassing 40-100\% of Earth's mantle [4], the amount of ${ }^{129} \mathrm{I}$ contributing to air Xe at the closure age of Earth was $2.77 \times 10^{11}$ to $6.92 \times 10^{11} \mathrm{~mol}$ and that of ${ }^{244} \mathrm{Pu}$ was $0.90 \times 10^{15}$ to $2.26 \times 10^{15} \mathrm{~mol}$. Using the ${ }^{129} \mathrm{U}^{127} \mathrm{I}$ ratio at $4.56 \mathrm{Ga}$ of $1.1 \times 10^{-4}[5]$ and $I$ concentration in the primitive mantle of $5-20 \mathrm{ppb}[6]$, the above ${ }^{129} \mathrm{I}$ amount in the initial Earth means that the closure age of $\mathrm{I}-\mathrm{Xe}$ was $4.434-4.48 \mathrm{Ga}$. Using a ${ }^{244} \mathrm{Pu} /{ }^{238} \mathrm{U}$ ratio at $4.56 \mathrm{Ga}$ of 0.0068 [5] and $U$ concentration in the primitive mantle of $21 \mathrm{ppb}$ [7], the required $244 \mathrm{Pu}$ concentration means that the closure age of $\mathrm{Xe}$ was $4.364-4.47 \mathrm{Ga}$. One can also find the time when $\mathrm{y}^{244} \mathrm{Pu} / 129 \mathrm{I}$ is the same as ${ }^{136} \mathrm{Xe}^{*} / 129 \mathrm{Xe}^{*}$ in air. This means a closure age of $4.49-$ $4.451 \mathrm{Ga}$. Combining these results, the closure age of Earth for $\mathrm{Xe}$ is $\sim 4.46 \mathrm{Ga}$, about $100 \mathrm{~m}$.y. younger than $4.56 \mathrm{Ga}$. This closure age probably dates the last Mars-sized giant impact that stripped Earth's proto-atmosphere and melted and rehomogenized Earth's mantle. The young age of Earth inferred from $\mathrm{Xe}$ isotopes explains the $\mathrm{Pb}$ paradox [e.g., 8-10] and is consistent with the recent inference of late core formation from $\mathrm{Hf}-\mathrm{W}$ systems [11] and consistent with the age of the Moon [12].

Xenon isotopic ratios in MORB mantle should also provide strong constraints. However, there are many complexities, including (1) Even though nucleogenic ${ }^{131} \mathrm{Xe},{ }^{132} \mathrm{Xe},{ }^{134} \mathrm{Xe}$, and ${ }^{136} \mathrm{Xe}$ in air are plutogenic [3], those in well gases are uranogenic [13], and those in MORB may also be uranogenic [14,15]. (2) Even though ${ }^{129} \mathrm{Xe}^{130} \mathrm{Xe}$ and ${ }^{136} \mathrm{Xe} / 130 \mathrm{Xe}$ ratios in MORB are much greater than those in air, ${ }^{136} \mathrm{Xe}^{*} / 129 \mathrm{Xe}^{*}$ in MORB $(-0.3)$ is only slightly greater than that in air (0.23). (3) Some authors argue that nonradiogenic mantle $\mathrm{Xe}$ is $\mathrm{U}-\mathrm{Xe}$, instead of nonradiogenic air $\mathrm{Xe}$. Among these, the small difference between $\left({ }^{136} \mathrm{Xe}^{*} /{ }^{129} \mathrm{Xe}^{*}\right)$ air and $\left({ }^{136} \mathrm{Xe}^{*} /\right.$ $\left.{ }^{129} \mathrm{Xe}^{*}\right)_{\text {MORB }}$ is especially paradoxical, since significant growth of ${ }^{129} \mathrm{Xe}^{130} \mathrm{Xe}$ ratio in MORB mantle after main degassing should be accompanied by a large ${ }^{136} \mathrm{Xe}^{*} / 129 \mathrm{Xe}^{*}$ increase in MORB mantle due to the much longer half-life of ${ }^{244} \mathrm{Pu}$ and especially of ${ }^{238} \mathrm{U}$.
References: [1] Staudacher and Allègre (1982). [2] Porcelli and Wasserburg (1995). [3] Pepin (1991). [4] Zhang and Zindler (1989). [5] Hohenberg and Kennedy (1981). [6] McDonough and Sun (1995). [7] Hudson et al. (1989). [8] Zindler and Hart (1986). [9] Allègre et al. (1996). [10] Galer and Goldstein (1996). [11] Lee and Halliday (1995). [12] Carlson and Lugmair (1988). [13] Phinney et al. (1978). [14] Allègre et al. (1986). [15] Allègre et al. (1987).

CALCIUM ISOTOPES IN SEAWATER AND THE CALCIUM CYCLE. P. Zhu and J. D. Macdougall, Geosciences Research Division, Scripps Institution of Oceanography, University of California-San Diego, La Jolla CA 92093, USA.

Calcium- 40 is produced by beta decay of ${ }^{40} \mathrm{~K}$, but because of the high abundance of $\mathrm{Ca}$ in most materials and the high natural abundance of ${ }^{40} \mathrm{Ca}$, isotopic variability of $\mathrm{Ca}$ caused by radioactive decay of $\mathbf{K}$ is small in most geochemical reservoirs. Furthermore, because of the relatively low mass of $\mathrm{Ca}$, isotopic fractionation among $\mathrm{Ca}$ isotopes can also occur. Here we present some preliminary data for $\mathrm{Ca}$ isotopes in the weathering-seawater cycle, and discuss their significance. Data are given in terms of the ratio ${ }^{44} \mathrm{Ca} /{ }^{40} \mathrm{Ca}$, expressed as $\delta^{44} \mathrm{Ca}$, which is the deviation of the measured ${ }^{44} \mathrm{Ca}^{100} \mathrm{Ca}$ ratio from an assumed "normal" value of 0.0217 . Measurement precision is typically $\pm 0.1-0.2 \%$. All data were obtained using a ${ }^{42} \mathrm{Ca}-48 \mathrm{Ca}$ double spike and are typically the average of several measurements. Seawater samples from various depths at stations in the Atlantic, North and South Pacific, and Indian Oceans have the same isotopic composition within our measurement capabilities, as would be expected from the long oceanic residence time of $\mathrm{Ca}$. The average measured value is $\delta^{44} \mathrm{Ca}=2.17 \pm 0.06 \%$. A variety of pelagic and benthic foraminifera have $\delta^{44} \mathrm{Ca}$ ranging from $0.71 \%$ to $1.61 \% 0$ and within individual species appear to exhibit temperaturedependent fractionation behavior, although this is an observation that will require considerably more work to be confirmed. Thus, all the $\mathrm{CaCO}_{3}$ precipitating organisms we have examined so far have significantly lighter $\mathrm{Ca}$ than seawater (i.e., lower $\delta^{44} \mathrm{Ca}$ ). Although it is possible that carbonate-secreting organisms thus maintain the high $\delta^{44} \mathrm{Ca}$ of seawater, a quantitative assessment of this possibility requires knowledge of the isotopic composition of all $\mathrm{Ca}$ inputs to (and additional outputs from) the oceans. A single sample from the Ganges-Brahmaputra river system, with very high ${ }^{87} \mathrm{Sr} /{ }^{86} \mathrm{Sr}$, gives $8^{44} \mathrm{Ca}=0.71 \%$. This is the same as the lightest of the forams we have measured. Therefore most of the $\mathrm{Ca}$ input to the oceans, i.e., other rivers and hydrothermal fluids, must have greater $\delta^{44} \mathrm{Ca}$ than this in order to maintain dissolved oceanic $\mathrm{Ca}$ at a value of $2.17 \%$. This is consistent with the expectation that the Ganges-Brahmaputra system is likely to have a larger radiogenic ${ }^{40} \mathrm{Ca}$ component than other inputs.

EFFECT OF MELTING TIME ON THE URANIUM-SERIES DISEQUILIBRIA IN YOUNG LAVAS. H. Zou ${ }^{1}$ and A. Zindler' ${ }^{1}$ ' Division of Isotope Geochemistry, National High Magnetic Field Laboratory and Department of Geology, Florida State University, Tallahassee FL 32306, USA (zouh@magnet.fsu.edu; zindler@magnet.fsu.edu).

Radioactive disequilibria between the nuclides of the $U$ series in recent lavas provide important information on magmatic processes. 
Previous modeling of U-decay-series isotopes during partial melting have addressed the effects of porosity (f) and melting rate ( $\left.\mathrm{M}^{\prime}\right)$ on the variations of $\left({ }^{230} \mathrm{Th} /{ }^{238} \mathrm{U}\right)$ and $\left({ }^{226} \mathrm{Ra} /{ }^{230} \mathrm{Th}\right)$ in young magmas by assuming that the melting time, $T$, approaches infinity. The values of $\left({ }^{230} \mathrm{Th} /{ }^{238} \mathrm{U}\right)_{\infty}$ and $\left({ }^{226} \mathrm{Ra} /{ }^{230} \mathrm{Th}\right)_{\infty}$ have been used to estimate the porosity and melting rate in the mantle source. This estimate is, however, a limiting case, because of the assumption conceming melting time.

We have quantitatively investigated the effect of melting time on $\mathrm{U}$-series disequilibria in young lavas. Three general, non-linear simultaneous equations, describing the variations of $\left({ }^{230} \mathrm{Th} /{ }^{238} \mathrm{U}\right)$, $\left({ }^{226} \mathrm{Ra} /{ }^{230} \mathrm{Th}\right)$, and $\left.{ }^{231} \mathrm{~Pa} /{ }^{235} \mathrm{U}\right)$ in magmas, as a function $\mathrm{f}, \mathrm{M}^{\prime}$, and $T$, have been deduced and shown to yield a unique set of solutions when solved using Broyden's method. We conclude that short melting times, slow melting rates, and low porosity in upwelling garnet peridotite mantle $\left(D_{U}>D_{T h}, D_{T h}>D_{R a}, D_{U}>D_{P_{a}}\right)$ favor the generation of lavas with large $\left({ }^{230} \mathrm{Th} /{ }^{238} \mathrm{U}\right),\left({ }^{226} \mathrm{Ra} /{ }^{230} \mathrm{Th}\right)$, and $\left({ }^{231} \mathrm{~Pa}\right.$ ${ }^{235} \mathrm{U}$ ) ratios (much larger than predicted by previous models. If melting takes place in the spinel peridotite field $\left(D_{T h}>D_{U}, D_{T h}>\right.$ $\left.D_{R a}, D_{U}>D_{P_{a}}\right)$, the same is true for $\left({ }^{226} \mathrm{Ra} /{ }^{230} \mathrm{Th}\right)$ and $\left({ }^{231} \mathrm{~Pa} / 235 \mathrm{U}\right)$, but the reverse is true for $\left.{ }^{230} \mathrm{Th}^{238} \mathrm{U}\right)$.

Spiegelman and Elliott [1] have proposed that the observed ${ }^{230} \mathrm{Th} /{ }^{238} \mathrm{U}$ ) ratios of MORB may be produced during magma transport between the source region and the surface by equilibrium melt percolation. If the whole melting column is in the gamet peridotite stability field, and the maximum porosity at the top of the column is small, large ${ }^{230} \mathrm{Th} /{ }^{238} \mathrm{U}$ ) ratios can be produced at the top of the melting column. However, for the MORB mantle, this may not be the case. Slow melt percolation and continuous chemical reaction with spinel peridotite en route to the surface will buffer the $\left({ }^{230} \mathrm{Th} /\right.$ ${ }^{238} \mathrm{U}$ ) of the percolating melt close to unity [2]. In addition, equilibrium melt percolation is difficult to reconcile with the extreme depletion of incompatible elements observed in abyssal clinopyroxene [3] or major-element (FeO) constraints [4]. Since rapid melt transport through chemically isolated channels probably dominates through much of the regime beneath mid-ocean ridges, $\left({ }^{230} \mathrm{Th} /{ }^{238} \mathrm{U}\right)$, $\left({ }^{226} \mathrm{Ra}^{230} \mathrm{Th}\right)$, and $\left({ }^{231} \mathrm{~Pa}^{235} \mathrm{U}\right)$ ratios in MORB will tend to be controlled by partial melting rather than by melt percolation under equilibrium conditions.

References: [1] Spiegelman M. and Elliott T. (1993) EPSL, 118, 1-20. [2] Iwamori H. (1994) EPSL, I2S, 1-16. [3] Johnson K. T. M. et al. (1990) JGR, 100, 475-496. [4] Lungmuir C. H. et al. (1992) in Mantle Flow and Melt Generation at Mid-Ocean Ridge, 183-280.

INFRACAMBRIAN-SOURCED CRUDE OILS: OCCURRENCE AND CHEMISTRY. J. E. Zumberge, C. F. Schiefelbein, and S. W. Brown, GeoMark Research, Inc., 9748 Whithorn Drive, Houston TX 77095, USA (biomarkers@aol.com).

Crude oils generated from Infracambrian-aged Huqf marlstones from southem Oman are well known. Negative stable $C$ isotope values and abundant $\mathrm{C} 29$ sterane biomarkers characterize these unusual oils. The corresponding petroleum source rocks accumulated in major half grabens during extensional rifting of eastem Pangea between -600 and $540 \mathrm{~m}$.y. Thermally low to moderately mature southern Oman oils are reservoired in Paleozoic clastics. However, more mature Infracambrian-sourced oils are also present in northern Oman, trapped in Cretaceous carbonate reservoirs. Using multivariate statistical techniques, it can also be demonstrated that Cretaceous reservoirs contain mixed oils from two sources (Infracambrian and Mesozoic) in northem Oman.

The East Siberian Platform (e.g., Baykit region) contains oil reservoired in Protozoic and younger reservoirs that chemically closely resemble the oils from Oman. These types of oil are also known from the Indian Rajasthan Basin (Baghewals oil sourced from the Infracambrian bilara marls) and nearby Pakistan. A previously unreported occurrence of this oil type has recently been encountered in the East Caspian Basin of Kazakhstan. 


\section{Author Index}

\begin{tabular}{|c|c|c|c|c|c|}
\hline Abratis $\mathrm{M}$. & 1 & Banks K. A. & 39 & Bottrell S. H. & 34 \\
\hline Adair B. I. & 134 & Banner J. L. & 8 & Bourdon B. & 51 \\
\hline Agee C. B. & 1,126 & Bard E. & 16 & Bourguignon A. & 45 \\
\hline Aghamiri R. & 189 & Barfod D. N. & 17 & Boyd F. R. & 34 \\
\hline Alard $O$ & 2 & Barker W. W. & 217 & Boynton W. V. & 81 \\
\hline Albarède F. & $29,131,212$ & Barling J. & 17 & Brandon A. D. & $35,69,101$ \\
\hline Alexander C. & 70 & Bames H. L. & 25,219 & Brandstätter F. & 114 \\
\hline Alexander J. L. & 2,3 & Barth M. G. & 18 & Brantley S. L. & 35,152 \\
\hline Alfano M. J. & 57,120 & Barth S. & 18 & Brenan J. M. & 36 \\
\hline Aliber C. & 135 & Bartlett J. & 209 & Brevard $\mathrm{O}$. & 4 \\
\hline \multirow[t]{3}{*}{ Allègre C. J. } & $4,51,61,77$ & Bastrakov E. N. & 19 & Brey G.P. & 196 \\
\hline & $109,119,131$ & Basu A. R. & 20 & Bridgwater D. & 29 \\
\hline & 144,193 & Bau M. & 110 & Brodie J. A. & 30 \\
\hline Aller R. C. & 141 & Baumgartner L. P. & 20,80 & Broecker W. S. & 91,92 \\
\hline Alves S. & 4 & Bea F. & 21 & Brooks T. & 123,162 \\
\hline Amakawa $\mathrm{H}$. & 201 & Beard J. S. & 150 & Brown K. & 38 \\
\hline Amelin Yu. V. & 4 & Beck J. W. & 21 & Bruckschen P. & 36 \\
\hline Amundson $\mathrm{R}$. & 14,213 & Becker H. & 21,22 & Buerkert T. P. & 37 \\
\hline Amy $P$. & 194 & Becker U. & 22 & Bulanova G. P. & 160 \\
\hline Anbar A. D. & 5 & Bell D. R. & 43 & Bullen T. D. & 217 \\
\hline Anderson D. L. & 6 & Belyatsky B. V. & 23,118 & Burgess R. & 37 \\
\hline Anderson M. A. & 169 & Bennett P. C. & 23,209 & Burkins D. L. & 38 \\
\hline Andreoli M. A. G. & 114 & Bennett V.C. & $24,25,86$ & Bumard P. G. & 38 \\
\hline Ansari A. A. & 6 & Benning L. G. & 25 & Bur G. S. & $21,39,121$ \\
\hline Antonini P. & 7 & Berg J. H. & 26,222 & Buseck P. R. & 223 \\
\hline Aranyossy J. F. & 45,149 & Berry A. J. & 27,74 & & \\
\hline Araújo M. F. & 7 & Bertka C. M. & 147 & Cabioch G. & 39 \\
\hline Arculus R. J. & 7 & Beukes N. J. & 110 & Calderwood A. R. & 39,40 \\
\hline Arens N. C. & 105 & Bickmore B. R. & 27 & Calsoyas L. & 21 \\
\hline Arima M. & 192 & Biino G. G. & 28 & Cameron B. I. & 26,41 \\
\hline Arthenius $\mathrm{G}$. & 143 & Bintrim S. B. & 28 & Campbell I. H. & 137 \\
\hline Arthur M. A. & 156 & Biscaye P. E. & 92 & Canale B. S. & 157 \\
\hline Arvidson R. S. & 8 & Blais S. & 48 & Canil D. & 34 \\
\hline Arzamastzev A. & 23 & Blank J. G. & 53,91 & Capo R. C. & 41 \\
\hline Asimow P. D. & 76 & Blasztajn J. & 89 & Capobianco C. J. & 42,104 \\
\hline Asmerom Y. & 8 & Blichert-Toft J. & 29,212 & Caprarelli G. & 43 \\
\hline Ayers J. C. & 9,82 & Blum A. E. & 29 & Cardona $\mathbf{M}$ & 86 \\
\hline Ayliffe L. K. & 10 & Blum J. D. & $30,38,87$ & Carlson R. W. & $21,22,43,160$ \\
\hline \multirow[t]{2}{*}{ Azimov P. } & 11 & Blundy J. D. & $30,31,219$ & Carr M. J. & 41,158 \\
\hline & & Blusztajn J. & 32,156 & Cartigny $\mathrm{P}$. & 44 \\
\hline Bacon D. H. & 12 & Bodinier J. L. & 78 & Casanova J. & 45,149 \\
\hline Bagdassarov N. S. & 12 & Bodinier J.-L. & 2 & Castillo P. R. & 46 \\
\hline Bailey A. M. & 13 & Bodnar R. J. & 32 & Castro P. & 194 \\
\hline Bailey E. H. & $2,3,14,84$ & Boehler R. & 94 & Cathelineau M. & 45 \\
\hline Bailey S. C. & 189 & Boghossian N. D. & 157 & Catlos E. J. & 89 \\
\hline Bain D. C. & 95 & Bond G. C. & 92 & Chacko T. & 46 \\
\hline Bajo S. & 64 & Borg L. E. & 108 & Chadwick O. A. & $41,57,111$ \\
\hline Ballentine C. J. & 15,17 & Borisov A. & 33 & & $120,169,205$ \\
\hline Ballhaus C. & 15 & Borton C. J. & 173 & Chan L. H. & 37,47 \\
\hline Banfield J. & 86 & Bosbach D. & 33 & Chang Q. & 223 \\
\hline \multirow[t]{2}{*}{ Banfield J. F. } & $16,63,187$ & Bose $\mathrm{K}$ & 148 & Chang S. & 53,91 \\
\hline & 217 & Bottinga $\mathrm{Y}$. & 185 & Chamock J. M. & 190 \\
\hline
\end{tabular}




\begin{tabular}{|c|c|c|c|c|c|}
\hline Chauvel $\mathrm{C}$. & 48 & Drake M. J. & $104,174,176$ & France-Lanord C. & 101 \\
\hline Chen D. & 48 & Dreibus G. & 213 & Francis D. & 74 \\
\hline Chesley J. & 35 & Driesner $\mathrm{T}$. & 190 & Frank M. & 153 \\
\hline Chesley J. T. & 49 & Dril' S. I. & 162 & Franz L. & 87 \\
\hline Chiarello R. P. & 200 & Dudás F. Ö. & 62 & Fraser D. G. & 27,74 \\
\hline Choi W. J. & 23 & Dunai $T$. & 129,201 & Freeman K. H. & 156 \\
\hline Christensen J. N. & 50,85 & Dunbar N. W. & 54 & Frei R. & $55,147,216$ \\
\hline Church S. E. & 51 & Dupré B. & 4,77 & Frey F. & 182 \\
\hline Civetta L. & 7 & Dziewonski A. M. & 1 & Frey F. A. & 215 \\
\hline Claude-Ivanaj C. & 51 & & & Freydier C. & 75 \\
\hline Cliff R. A. & 52,139 & Eastoe C. J. & 62,213 & Frisia $\mathbf{S}$ & 136 \\
\hline Clynne M. A. & 205 & Edmond $\mathrm{J} . \mathrm{M}$. & $47,63,100$ & Frogner $P$. & 76 \\
\hline Coath C. D. & 172 & Edwards K. J. & 63,187 & Futa $\mathrm{K}$. & 132 \\
\hline Cocherie A. & 52 & Edwards R. L. & $8,39,173$ & & \\
\hline Cockbum H. A. P. & 201 & Eggenkamp H. G. M. & 64 & Gaetani G. A. & 76 \\
\hline Cody G. D. & 53,91 & Eggins S. M. & 137 & Gaillardet J. & 4,77 \\
\hline Cole D. & 46 & Eggleston C. M. & 182,198 & Gallagher K. & 90 \\
\hline Coleman M. L. & 53,64 & Ehlers K. & 60 & Gamble J. A. & 222 \\
\hline Cooper K. M. & 54 & Eikenberg J. & 64 & Gamo T. & 151,184 \\
\hline Copeland P. & 55 & Eiler J. M. & 65 & Ganguly J. & 77 \\
\hline Corfield R. M. & 110 & Eisenhauer A. & 66 & Garcia M. O. & 151 \\
\hline Coulibaly Y. & 45 & Elderfield $\mathrm{H}$. & 66 & Gariepy C. & 4 \\
\hline Crossey L. J. & 83 & Elliott T. & 67 & Garrido C. J. & 78 \\
\hline Cuney $\mathrm{M}$. & 45 & Elthon D. & 139 & Garzione C. N. & 157 \\
\hline \multirow[t]{2}{*}{ Cygan R. T. } & 71 & Engel M. H. & 67 & Gasparon $\mathrm{M}$. & 210 \\
\hline & & Erel Y. & 87,205 & Gaul O. & 82 \\
\hline Dahl P.S. & 55 & Emestova L. S. & 67 & Gauthier-Lafaye F. & 198 \\
\hline Dalton J. A. & 31,166 & Erofeeva E. A. & 82 & Gee M. A. M & 79 \\
\hline D'Antonio $\mathrm{M}$. & 7 & Ertel W. & 68 & Gerdes M. L. & 20,80 \\
\hline Daughney C. J. & 56 & Esat T. M. & $25,86,199$ & Gibb F. G. F. & 73 \\
\hline Dautria J.-M. & 2 & Esin S. V. & 163 & Gibson G. M. & 60 \\
\hline Davidson J. P. & 113,205 & Essene E. J. & 110 & Gibson P. E. & 80 \\
\hline Davies G. F. & 56 & & & Gilmour I. & 114 \\
\hline de Haas G. J. L. M. & 57 & Fairchild I. J. & 136 & Gimeno M. & 211 \\
\hline De Loos Th. W. & 186 & Fallick A. E. & 140 & Gislason S. R. & 81 \\
\hline Demarchi G. & 7 & Fan Z. & 223 & Gleason J. D. & 81,157 \\
\hline Denton G. $\mathrm{H}$. & 201 & Farley K. A. & 68,158 & Godfrey L. V. & 50 \\
\hline DePaolo D. J. & 59 & Farquhar J. & 69,70 & Goldstein S. J. & 194 \\
\hline Derry L. A. & $57,111,120$ & Fein J. B. & 56,70 & Goldstein S. L. & 138 \\
\hline Devine J. D. & 218 & Ferderer D. A. & 51 & Goles G. G. & 35 \\
\hline DeYoreo J. J. & 204 & Fernández-Diáz L. & 168 & Golubev S. V. & 82 \\
\hline Dick H. J. B. & 32,101 & Fernández-González A. & 168 & Goodman R. M. & $28,63,187$ \\
\hline Dietrich V. & 213 & Ferrara G. & 206 & Gopalan K. & 225 \\
\hline Ding R. & 58 & Fessenden J. & 143 & Göpel C. & 4,131 \\
\hline Dingwell D. B. & 68 & Fey D. L. & 51 & Gorisch E. B. & 82 \\
\hline D'Lemos R. & 183 & Filippelli G. M. & 71 & Gorokhov I. M. & 141 \\
\hline Dodson A. & 59 & Fisler D. K. & 71 & Gottschalk M. & 88 \\
\hline Dodson M. H. & 52,52 & Fitton J. G. & 17,171 & Gouveia A. & 7 \\
\hline Doe B. R. & 59 & Fletcher R. C. & 72 & Gouveia M. A. & 167 \\
\hline Donaghy A. G. & 60 & Foden J. & 185 & Graham C. M. & 65 \\
\hline Donahoe R. J. & 60 & Foland K. A. & 73 & Graham D. W. & 38 \\
\hline Donahue D. J. & 21 & Foley S. F. & $18,146,196$ & Graham R. C. & 169 \\
\hline Donald R. & 194 & & 226 & Gravatt D. R. & 218 \\
\hline Doucelance R. & 4,61 & Fornari D. J. & 194 & Gray S. C. & 39 \\
\hline Dove P. M. & 61,204 & Förster H.-J. & 73 & Green D. H. & 224 \\
\hline
\end{tabular}




\begin{tabular}{|c|c|c|c|c|c|}
\hline Griffin W. L. & $82,102,154$ & Hiyagon $\mathrm{H}$. & 151 & Jull A. J. T. & 121 \\
\hline Grimalt J. 0. & 161 & Hoatson D. M. & 195 & & \\
\hline Grime G. W. & 27 & Hoch $\mathrm{M}$ & 95 & Kadohara H. & 210 \\
\hline Groffman A. R. & 83 & Hochella M. F. & 27 & Kagi $H$. & 202 \\
\hline Grove $\mathrm{M}$ & 89 & Hodson M. E. & 95,125 & Kalinowski B. E. & 109 \\
\hline Gruszczynski M. & 53 & Hoff J. A. & 8 & Kamber B. S. & 110,147 \\
\hline Gu Y. & 1 & Hollander D. J. & 128 & Kassens $\mathrm{H}$. & 66 \\
\hline Gudfinnsson $\mathrm{G}$. H. & 84 & Hollings $P$. & $95,96,165$ & Kastner $\mathbf{M}$. & 159 \\
\hline Guille G. & 48 & Holloway J. R. & 96 & Katzir Y. & 167 \\
\hline \multirow{2}{*}{ Guo C. } & 107 & Holmqvist J. & 97 & Keane S. D. & 110 \\
\hline & & Holzheid A. & 97 & Keller C. K. & 12 \\
\hline Haas J. R. & 84 & Honda $\mathrm{M}$ & 98 & Kennedy B. M. & 59 \\
\hline Hadeler A. & 85,114 & Horita J. & 46 & Kennedy F. M. & 95 \\
\hline Halicz L. & 205 & Horn I. & 18,196 & Kennedy M. J. & 111 \\
\hline Hall C. M. & 92 & Hsieh Y.-P. & 99 & Kent A. J. R. & 111 \\
\hline \multirow[t]{2}{*}{ Halliday A. N. } & $17,50,85$ & $\mathrm{Hu} \mathrm{B}$. & 86 & Keppens E. & 136 \\
\hline & $124,163,171$ & Huang Y. & 136 & Kerrich R. & 96,165 \\
\hline Hamelin B. & 4 & Hudson J. D. & 53 & Kerschner $\mathbf{H}$. & 103 \\
\hline Hamers R. J. & 86 & Huh Y. & $47,63,100$ & Kimball B. & 123,162 \\
\hline Hammerschmidt $\mathrm{K}$. & 94 & Hulbert L. & 201 & Kimball B. A. & 51 \\
\hline Hanan B. B. & 130 & Humayun $\mathrm{M}$. & 101 & Kinsley L. & 135 \\
\hline Handelsman J. & 28 & Humbert F. & 101 & Kirby J. G. & 112 \\
\hline Handler $\mathbf{M}$. & 86 & Hutcheon I. D. & 111 & Kirstein L. & 90 \\
\hline Harlavan $Y$. & 87 & Hutchison M. T. & 90 & Klemme S. & 113 \\
\hline Harlov D. E. & 87,88 & & & Knesel K. M. & 113 \\
\hline Harper C. L. & 104 & Ionov D. A. & $82,102,154$ & Koeberl C. & 114 \\
\hline Harris J. W. & $37,44,45,90$ & Ireland J. S. & 28 & Kofod M. & 85,114 \\
\hline Harrison T. M. & 89,172 & Ireland T. R. & 222 & Köhler H. & 214 \\
\hline Hart S. & 156,182 & Isaacs $\mathrm{M} . \mathrm{C}$ & 53 & Konhauser K. $\mathrm{O}$. & 115 \\
\hline Hart S. R. & $32,89,194$ & Isenbeck-Schröter $\mathbf{M}$. & 85,114 & Koretsky C. M. & 116 \\
\hline Harte B. & 90 & Ishii T. & 226 & Korotev R. L. & 116 \\
\hline Haskin L. A. & 116 & Ispolatov V. $O$. & 62 & Korte C. & 117 \\
\hline Hauri E. & 70 & Ito $\mathrm{E}$ & 8 & Kouamelan A. & 52 \\
\hline Hauri E. H. & 175 & Ivanov K. S. & 178 & Kramers J. D. & 147,216 \\
\hline Hawkesworth C. J. & $90,136,209$ & Ivy-Ochs S. & 103 & Krassivskay I. S. & 191 \\
\hline Hazen R. & 53 & & & Kring D. A. & 81,117 \\
\hline Hazen R. M. & 91 & Jacob D. & 105 & Krylov D. P. & 118 \\
\hline Hein J. R. & 50 & Jacobsen S. B. & 103,104 & Krymsky R. S. & 118 \\
\hline Heinrich C. A. & 19 & Jaeger W. L. & 104 & Kubik P. W. & 103 \\
\hline Heinrich W. & 88 & Jagoutz E. & 105 & Kulicki C. & 53 \\
\hline Hellmann R. & 91 & Jahren A. H. & 105 & Kunimaru T. & 119 \\
\hline Hellstrom J. C. & 10 & Jambon A. & 184 & Kunz J. & 119,144 \\
\hline Hemley R. J. & 91 & Jana D. & 106,106 & Kurtz A. C. & 57,120 \\
\hline Hemming N. G. & 91 & Janney P. E. & 46 & Kurz D. & 97 \\
\hline Hemming S. R. & 92 & Javoy $\mathbf{M}$ & $44,45,106$ & Kurz M. D. & 17 \\
\hline Henderson C. M. B. & 73,190 & Jendrzejewski N. & 106 & Kutolin V. A. & 163 \\
\hline Henderson G. M. & 93 & Johannesson K. H. & 107 & Kuzmin Y. V. & 121 \\
\hline Henkel $\mathrm{H}$ & 86 & Johnson $\mathrm{H}$ & 123 & Kyle P. & 156 \\
\hline Hervig R. & 77 & Johnson M. & 164 & & \\
\hline Hervig R. L. & 93,176 & Johnstone $\mathbf{R}$. & 74 & Lal D. & 121 \\
\hline Hiebert F. K. & 23 & Jolliff B. L. & 116 & Lambeck K. & 199 \\
\hline Higgins S. R. & 86 & Jones J. H. & 108 & Lambert D. D. & 17,195 \\
\hline Hillgren V. J. & 94 & Joron J. L. & 109 & Lang L. & 80 \\
\hline Hilton D. R. & 94,129 & Joseph D. & 28 & Langan S. J. & 95 \\
\hline Hilyard M. L. & 150 & Jouanneau J.-M. & 7 & Larson P. B. & 122,179 \\
\hline
\end{tabular}




\begin{tabular}{|c|c|c|c|c|c|}
\hline Larson R. L. & 46 & Malkovets V. G. & 130 & Morgan G. B. & 93 \\
\hline Lasaga A. C. & 122,127 & Manhés G. & 4,131 & Morgan J. W. & 35 \\
\hline Layne G. & 191 & Manning C.E. & 110 & Morgan P. & 154 \\
\hline Layne G. D. & 123 & Mantovani M. S. M. & 90 & Moriarty K. C. & 10 \\
\hline Le Fort $\mathrm{P}$. & 55 & Mao H. K. & 91 & Morowitz H. J. & 91 \\
\hline \multirow[t]{2}{*}{ Leavitt S. W. } & $123,161,162$ & Maréchal C. & 131 & Morris J. D. & 144 \\
\hline & 221 & Marianelli P. C. & 10 & Morrison J. & 145 \\
\hline Lee D.-C. & 85,124 & Marshall B. D. & 132 & Morse S. A. & 123 \\
\hline Lee $M . R$. & 125,157 & Marty B. & 101,184 & Mortimer G. & 135 \\
\hline Leeman W. P. & 206 & Marzoli A. & 132 & Mortimer G. E. & 10 \\
\hline Legendre 0. & 52 & Mathez E. A. & 133 & Mosselmans J. F. W. & 14 \\
\hline Leinen M. & 159 & Mattauer M. & 193 & Mottl M. J. & 66 \\
\hline Leitch E. C. & 43 & Matthews A. & 167 & Mountain B. W. & 145 \\
\hline Lengauer C. & 114 & Maurice P. & 152 & Munizaga $\mathrm{F}$. & 75 \\
\hline Lennie A. R. & 22 & Maury R. & 48 & Munz A. W. & 22 \\
\hline Lepikhina O. P. & 178,179 & McBay E. H. & 202 & Murakami T. & 16,210 \\
\hline Lepland A. & 143 & McBride J. S. & 17 & Murray R. W. & 128,159 \\
\hline Levasseur S. & 4 & McCaig A. M. & 112 & Murrell M. T. & 194 \\
\hline Levsky L. K. & 23 & McCandless T. E. & 134 & Murton B. J. & 79 \\
\hline Lewin E. & 61,109 & McCollom T. & 135 & Musselwhite D. S. & 146 \\
\hline Li B. & 48 & McCulloch M. T. & $10,135,199$ & Mysen B. O. & 147 \\
\hline Li J. & 126 & McDaniel D. K. & 136 & & \\
\hline Libourel G. & 101 & McDermott F. & 136 & Nagler Th. F. & 147 \\
\hline Lico M. S. & 216 & McDonough W. F. & 104,137 & Nagy K. L. & 148 \\
\hline Likhanov I. I. & 126 & McDougall I. & 98 & Nara M. & 202 \\
\hline Lindemann $F$. & 66 & McInnes B. I. A. & 65 & Navrotsky A. & 148,218 \\
\hline Lindstrom M. M. & 142 & McIntosh W. C. & 26,54 & Négrel P. & 45,149 \\
\hline Ling H. F. & 153 & McKeegan K. D. & 172 & Negrey E. V. & 150 \\
\hline Litasov K. D. & 130 & McKnight D. M. & 29 & Nicholls I. A. & 17 \\
\hline Litasov Yu. D. & 130 & McLennan S. M. & 136,138 & Nicolas E. & 131 \\
\hline Liu Jiajun & 126 & Medvedev P. V. & 140 & Nielsen R. L. & 150 \\
\hline Liu Jianming & 126 & Meen J. K. & 139 & Nishio Y. & 151,184 \\
\hline Liu T. & 91 & Meffan-Main S. & 139 & Nordstrom D. K. & 211 \\
\hline Lloyd J. W. & 34 & Mejias J. A. & 74 & Norman M. D. & $111,151,154$ \\
\hline London D. & 93 & Melezhik V. A. & 140,141 & Nozaki Y. & 201,202 \\
\hline Long A. & 221 & Merino E. & 72 & Nugent M. A. & 152 \\
\hline Longinelli A. & 136 & Mertz D. F. & 129 & Nutman A. P. & $24,25,60$ \\
\hline Louvat P. & 4,77 & Meyer $\mathrm{H}$. & 66 & Nyquist L. E. & 108 \\
\hline Lovera O. M. & 89 & Meynadier L. & 4 & & \\
\hline Lowry D. & 79 & Meza-Figueroa D. & 141 & ODP Leg 165 Sci. Party & 128 \\
\hline Luo X. & 85 & Michalopoulos P. & 141 & ODP Leg 168 Sci. Party & 66 \\
\hline Lüttge A. & 127 & Milledge H. J. & 160 & Ohmoto $\mathrm{H}$ & 143,224 \\
\hline Lyons T. W. & 128 & Miller B. V. & 183 & Okada A. & 223 \\
\hline Lyons W. B. & 29 & Mittlefehldt D. W. & 142 & O'Malley J. M. & 39,121 \\
\hline & & Miyata Y. & 201 & O'Neill H. St. C. & $68,97,113$ \\
\hline Macdougall J. D. & 227 & Mock R. L. & 143 & & 134,153 \\
\hline MacInnis I. N. & 127,128 & Mogk D. & 133 & O'Nions R. K. & 110,153 \\
\hline Mackenzie F. T. & 8 & Mojzsis S. J. & 143 & Onuma K. & 128 \\
\hline Macko S. A. & 67 & Moncaster S. J. & 34 & O'Reilly S. Y. & $82,102,154$ \\
\hline Macpherson C. G. & 94,129 & Montanari A. & 68 & Orme C. & 204 \\
\hline Magenheim A. J. & 130 & Montero P. G. & 21 & Orsi G. & 7 \\
\hline Maidment D. W. & 60 & Morán-Zenteno D. J. & 214 & Ottonello G. & 144 \\
\hline Maier-Reimer E. & 93 & Moreira M. & 119,144 & Ovchinnikova G. V. & 141 \\
\hline Makarikhin V. V. & 140 & Moretti R. & 144 & Oxburgh R. & 154,155 \\
\hline
\end{tabular}




\begin{tabular}{|c|c|c|c|c|c|}
\hline Ozima M. & 155 & Putlitz B. & 167 & Saal A. & 182 \\
\hline & & Putnis A. & 33,168 & Samson S. D. & $182,183,198$ \\
\hline Pagani M. & 156 & & & Sandiford M. & 185 \\
\hline Pakhol'chenko Yu. A. & 165 & Quideau S. A. & 169 & Sandimirova G. P. & 165 \\
\hline Palme $\mathrm{H}$. & 33,97 & & & Sano $Y$. & 151,184 \\
\hline Pantano C. & 152 & Rachold V. & 66 & Sarnthein $\mathrm{M}$. & 161 \\
\hline Panter K. & 156 & Raï S. & 55 & Sasaki S. & 151 \\
\hline Paquette J. & 204 & Raiswell R. & 166 & Savenko A. V. & 82,184 \\
\hline Parsons I. & 125,157 & Ramakrishna B. L. & 223 & Savenko V.S. & 82 \\
\hline Patchett P. J. & 157,212 & Rao A. S.P. & 169 & Saxena D. P. & 184 \\
\hline Patino L. C. & 41,158 & Rapp R. P. & 170 & Schaefer B. F. & 185 \\
\hline Patterson D. B. & 68,158 & Ravizza G. & 32 & Schiano P. & 185 \\
\hline Patzelt G. & 103 & Rea D. K. & 50,163 & Schidlowski M. & 186 \\
\hline Paul E. A. & 123 & Reagan M. K. & 170 & Schields P. J. & 148 \\
\hline Paytan A. & 159,159 & Récy J. & 39 & Schlüchter C. & 103 \\
\hline Pearson D. G. & 128,160 & Reeder R. J. & 171 & Schmidt A. P. & 186 \\
\hline Peate D. W. & 90 & Refson K. & 74 & Schmidt G. & 186 \\
\hline Pelejero C. & 161 & Rehkämper M. & 85,171 & Schofield P. F. & 14 \\
\hline Pendall E. & $123,161,162$ & Reid M. R. & 54,172 & Schrauder M. & 114 \\
\hline Pennisi M. & 206 & Renne P. & 132 & Schrenk M. O. & 63,187 \\
\hline Perepelov A. B. & 162 & Reverdatto V. V. & 126 & Schulte M. & 188 \\
\hline Perfit M. R. & 130,194 & Reynolds R. C. & 38 & Schulz M. S. & 188,217 \\
\hline Person $\mathrm{M}$. & 20 & Richards D. A. & 173 & Schwartzman D. W. & 189 \\
\hline Peryt T. & 62 & Richards P. L. & 173 & Schweda P. & 76 \\
\hline Peterman Z. E. & 132 & Riciputi L. & 46 & Senaratne A. & 190 \\
\hline Peterson L. C. & 99,128 & Righter K. & $174,175,176$ & Sequeira Braga M. A. & 167 \\
\hline Petrini R. & 7 & Rimstidt J. D. & 176,180 & Seward T. M. & $145,190,213$ \\
\hline Petrova T. V. & 163 & Ripperdan R. & 46 & Sharkov E. V. & 190,191 \\
\hline Pettersson L. G. M. & 199 & Ritter F. & 12 & Shatagin K. N. & 150,191 \\
\hline Pettke T. & 163 & Ritter G. & 135 & Shaw H. F. & 36 \\
\hline Peucat J. J. & 52 & Roberts D. & 141 & Shimizu $H$. & 119 \\
\hline Phillips F. M. & 54 & Roberts H. H. & 13 & Shimizu N. & $123,170,182$ \\
\hline Piccirillo E. M. & 7,132 & Roberts J. A. & 23 & & 191 \\
\hline Pickering K. T. & 2,3 & Roberts M. S. & 173 & Shirasaka M. & 192 \\
\hline Pierazzo E. & 117 & Robu I. N. & 177,178 & Shirey S. B. & $101,160,193$ \\
\hline Pineau $\mathrm{F}$. & 106 & Robu L. & 177,178 & Shmelev V. R. & 178 \\
\hline Pitonzo B. & 194 & Rodgers K. & 86 & Shock E. & 188 \\
\hline Plank T. & 67,164 & Rogers N. W. & 209 & Shoemaker E. M. & 68 \\
\hline Plank T. A. & 170 & Ronkin Y. L. & 178,179 & Shotyk W. & 216 \\
\hline Pokrovskii V. A. & 19 & Roselle G. T. & 20 & Shtukenberg A. & 11 \\
\hline Pokrovsky B. G. & 141,191 & Rosing M. T. & 29 & Simien F. & 193 \\
\hline Polat A. & 96,165 & Rosso J. J. & 176,180 & Simoneit B. & 135 \\
\hline Polozov A. G. & 165 & Roth M. A. & 157 & Simonetti A. & 138 \\
\hline Poltavets Y. A. & 179 & Rub M. G. & 118 & Sims K. W. W. & 194 \\
\hline Poltavets Z. I. & 179 & Rubie D. C. & 97 & Sinclair D. & 135 \\
\hline Popp R. K. & 147 & Rüde T. R. & 180 & Singh I. B. & 6 \\
\hline Poulton S. W. & 166 & Rudnick R. L. & 181 & Sletten V. W. & 122 \\
\hline Prendergast M. D. A. & 147 & Ruiz J. & $75,134,141$ & Smart P. L. & 173 \\
\hline Presnall D. C. & 166 & Ruiz J. R. & 49 & Smith D. H. & 202 \\
\hline Prieto M. & 168 & Rumble D. III & 69 & Smith I. & 209 \\
\hline Prikhodko V. S. & 102 & Ryabchikov I. D. & 222 & Smith M. C. & 194 \\
\hline Prokofiev V. Yu. & 162 & Ryan C. G. & 82 & Smol'kin V. F. & 191 \\
\hline Prudêncio M. I. & 167 & Ryan J. G. & 181 & Snow J. E. & 186 \\
\hline Purvis O. W. & 84 & Ryerson F. J. & 36,89 & Snyder G. A. & 124 \\
\hline
\end{tabular}




\begin{tabular}{|c|c|c|c|c|c|}
\hline Söllner F. & 214 & Tirone $\mathbf{M}$. & 77 & Weiss D. & 216 \\
\hline Southam G. & 194 & Tobschall H. J. & 6,95 & Weissbart E. J. & 176 \\
\hline Spetsius Z. V. & 195 & Tonarini S. & 206 & Welch A. H. & 216 \\
\hline Spielhagen R. F. & 66 & Traexler K. A. & 207 & Welch S. A. & $207,209,217$ \\
\hline Spiro B. & 136 & Travin A. V. & 130 & Wells R. T. & 10 \\
\hline Sproule R. A. & 195 & Treiman A. H. & 207 & Weng Y.-H. & 166 \\
\hline Srinivas K. & 169,169 & Treuil M. & 109 & Werne J. P. & 128 \\
\hline Srinivasan R. & 225 & Trumbore S. & 213 & Wheat G. & 66 \\
\hline Stalder R. & 196 & Trumbore S. E. & 208 & White A. F. & 188,217 \\
\hline Staudacher Th. & 119 & Tsukamoto K. & 128 & White W. M. & 218 \\
\hline Stewart B. W. & 41 & Tsukimura $\mathrm{K}$. & 210 & Wiegand $\mathrm{B}$. & 66 \\
\hline Stewart K. P. & 197 & Tumer G. & 37,38 & Wilding M. C. & 218 \\
\hline Stille P. & 198 & Tumer S. P. & 90,209 & Wilkin R. T. & 25,219 \\
\hline Stillings L. L. & 35,198 & Turtle E. P. & 117 & Wills J. & 103 \\
\hline Stirling C. H. & 199 & & & Wogelius R. A. & 27,74 \\
\hline Stoian M. & 177 & Ullman W. J. & $23,207,209$ & Wohnlich S. & 180 \\
\hline Stolper E. M. & $65,76,111$ & Upreti B. N. & 55 & Wolf M. B. & 93 \\
\hline Strandh H. & 199 & Utsunomiya S. & 210 & Wood B. J. & 84,219 \\
\hline Stuart F. M. & 200,201 & & & Wood S. A. & $58,80,220$ \\
\hline Sturchio N. C. & 200 & Vali $\mathrm{H}$ & 204 & Wooden J. L. & 221 \\
\hline Suarez D. L. & 202 & Valley J. W. & $20,65,80,167$ & Wömer G. & 1 \\
\hline Subramanian V. & 184 & van der Borg $\mathrm{K}$. & 136 & Worthington $T$. & 209 \\
\hline Suess E. & 66 & Van der Salm C & 210 & Wright W. E. & 221 \\
\hline Sugden D. E. & 201 & van Keken P. & 15 & Wright W. G. & 211 \\
\hline Summerfield M. A. & 201 & Varne R. & 210,211 & Wyllie P. J. & 222 \\
\hline Sun S. S. & 137 & Vaughan D.J. & 22 & Wyman D. & $95,96,165$ \\
\hline Suzuki K. & 201,202 & Vaughn R. B. & 51 & Wysoczanski R. J. & 222 \\
\hline Sverdrup H. & 97 & Veblen D. R. & 223 & & \\
\hline Sverjensky D. A. & 116 & Veizer J. & 36,117 & Xiao Y. & 202 \\
\hline Sweeney R. & 211 & Venn C. J. & 60 & Xu H. & 223 \\
\hline Swihart G. H. & 202 & Verplanck P. L. & 211 & & \\
\hline Swindle T. D. & 203 & Vervoort J. D. & 212 & Yabuki S. & 119,223 \\
\hline Sylvester P. & 15,97 & Villa I. M. & 212 & Yager T. J. & 51 \\
\hline Sylvester P. J. & 68 & Virgo D. & 147 & Yamaguchi K. & 224 \\
\hline \multirow[t]{2}{*}{ Synal H.-A. } & 103 & Vitousek P. & 111 & Yanev Y. & 12 \\
\hline & & Vivit D. V. & 188,217 & Yaxley G. M. & 224 \\
\hline Takahashi K. & 119 & Vogelgsang A. & 180 & Yi W. & 85 \\
\hline Takano B. & 202 & Volkov V. N. & 191 & Yin $A$. & 89 \\
\hline Takazawa E. & 182 & von Blanckenburg $\mathrm{F}$. & 153 & Yin $\mathrm{Q}$. & 103,104 \\
\hline Tatsumoto $\mathbf{M}$. & 155 & & & Yoder H. & 53 \\
\hline Taylor F. W. & 39 & Wahrenberger $\mathrm{C}$. & 213 & Yoder H. S. Jr. & 91 \\
\hline Taylor L. A. & 124 & Walker D. & 106 & & \\
\hline Taylor R. N. & 79 & Walker J. A. & 41 & Zachariah J. K. & 225 \\
\hline Tellam J. H. & 34 & Walker R. J. & 35 & Zack T. & 226 \\
\hline Temmam $\mathbf{M}$. & 204 & Walter M. & 191 & Zhang J. & 226 \\
\hline Ten A. A. & 126 & Wang J. & 70 & Zhang Y. & 227 \\
\hline Teng $\mathrm{H}$. $\mathrm{H}$. & 61,204 & Wang $\mathrm{L}$. & 161 & Zhao Y.J. & 61 \\
\hline Tepley F. J. III & 205 & Wang $Y$. & 148,213 & Zhi X. & 48 \\
\hline Tera F. & 144 & Wänke $\mathrm{H}$. & 213 & Zhou X. & 107 \\
\hline Teutsch N. & 205 & Wasserburg G. J. & 5 & Zhu P. & 227 \\
\hline Thirlwall M. F. & 79 & Weare J. H. & 214 & Zindler A. & 227 \\
\hline Thornton G. & 22 & Weber B. & 214 & Zinner E. & 105 \\
\hline Tiepac I. & 178 & Weidner D. J. & 148 & Zou H. & 227 \\
\hline Tilton G. R. & 206 & Weis D. & 26,215 & Zumsteg I. & 64 \\
\hline
\end{tabular}

